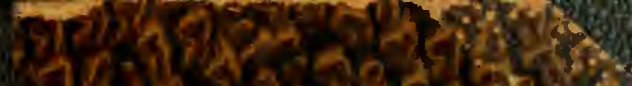

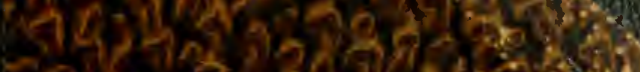

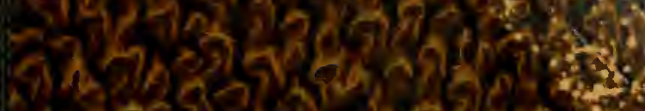

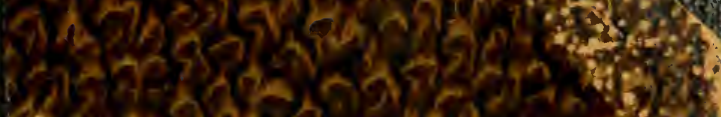

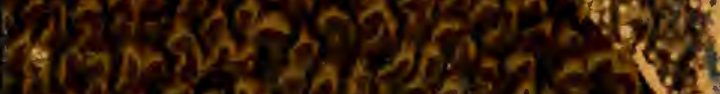

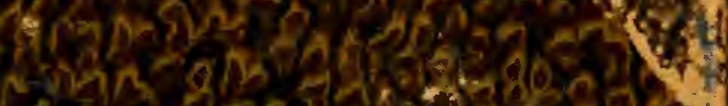
Whathe

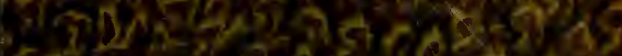
2.

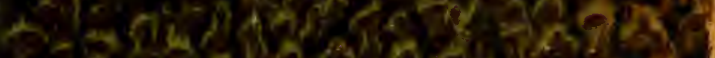

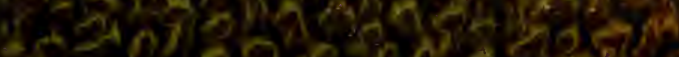

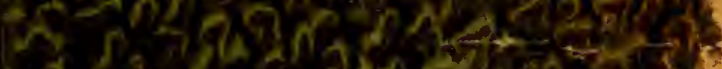

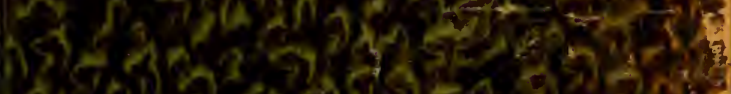

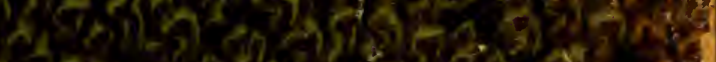

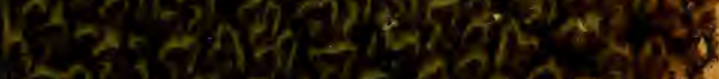

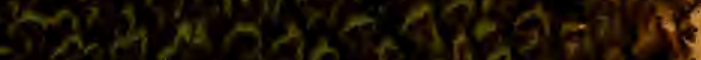

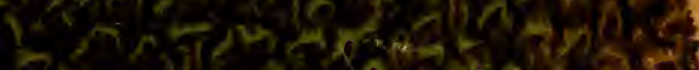
2.

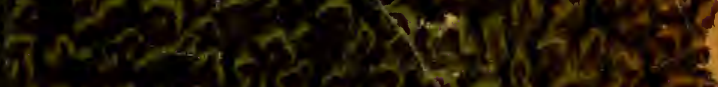
(1)

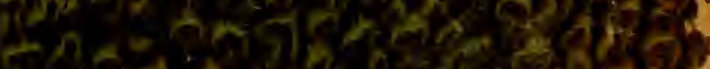

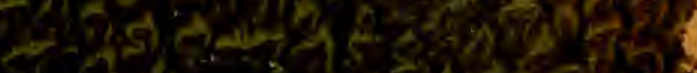

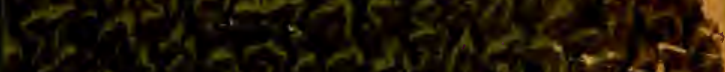

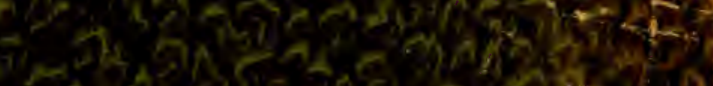

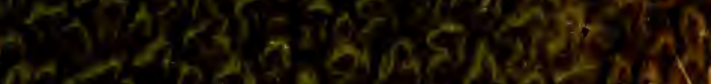

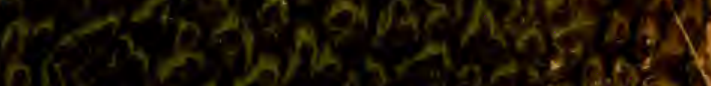

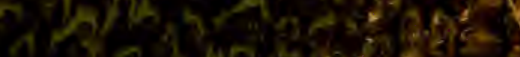
If

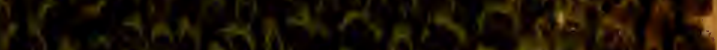

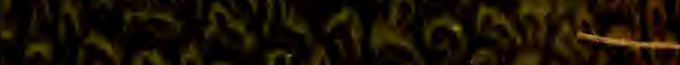

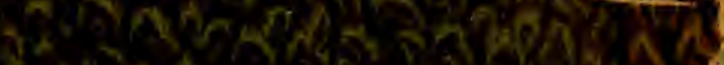
(A)

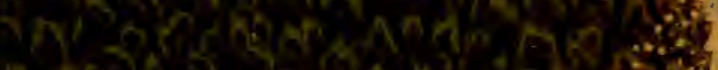

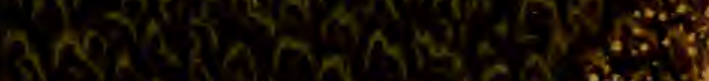

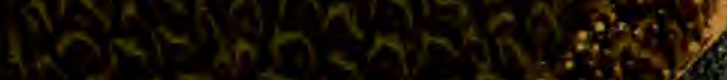

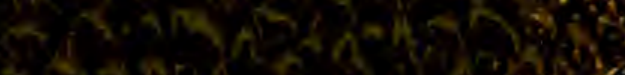




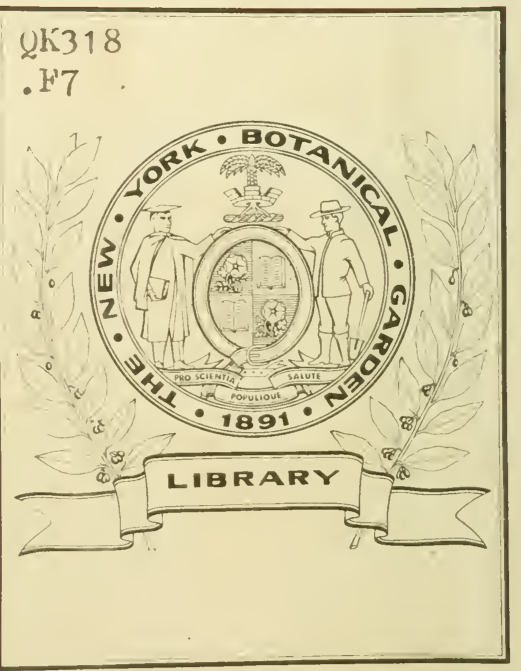



* Soine names herein firot publishel ant vlich appoar in Srays hanual, $7^{\text {Bed }}$

p. 477 Satoreja Vulaario 


\section{Excursionsflora}

\section{für 0esterreich,}

(mit Ausschluss von Galizien, Bukowina und Dalmatien).

Mit theilweiser Benützung

des

„Botanischen Excursionsbuches“ von G. Lorinser

$$
\text { verfasst }
$$

von

\section{Dr. Karl Fritsch,}

k. k. a. 0. Protessor der systematischen Botanik an der k. k. Universität in Wien.

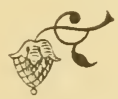

W i e n.

Druck und Verlag von Carl Gerold's Sohn. 1897.

ILIBRARY.

NFW YORK 


$$
\begin{aligned}
& Q K 318 \\
& \text { F }
\end{aligned}
$$




\section{Inhalts - Uebersicht.}

Seite

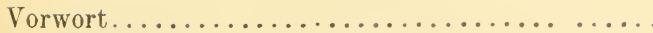

Die wichtigsten Grundbegriffe der botanischen Morphologie ......................

Die wichtigsten Florenwerke für die einzelnen Kronländer ......................

Verzeichniss der Abkürzungen:

$a)$ in den Bestimmungsschlüsseln und Beschreibungen...................

$b)$ bei den Verbreitungsangaben ...........

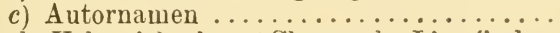

Analytische Uebersicht der 24 Classen des Linné'schen Pflanzensystems ......................

Die Ordnungen der 24 Classen des Linnéschen

Pflanzensystems ................... XXVIII

Analytischer Schlüssel zur Bestimmung der Pflanzengattungen nach dem Linné'schen System .... Uebersicht des natürlichen Pflanzensystems ....... Specieller Theil: Pteridophyta ................. Gymnospermae ............... Monocotyledoneae.............

Dicotyledoneae ...............

Verzeichniss der gebräuchlichsten Synonyme..... Register der deutschen Pflanzennamen........... Register der lateinischen Familien- und Gattungsnamen $\ldots \ldots \ldots \ldots \ldots \ldots \ldots \ldots$. . . . . . . Einige Verbesserungen und Nachträge............

$\mathrm{XXX}$ LXXII

18 23

134

627

645

655

663 



\section{VORWORT.}

Dem Antrage des Verlegers, das in Oesterreich allgemein beliebte "botanische Excursionsbuch" ron G. Lorinser, dessen fünfte Auflage im Jahre 1883 erschienen war, neu zu bearbeiten, folgte ich nicht ohne Zögern und Bedenken, da mir die Schwierigkeiten einer solchen Neubearbeitung mit Rücksicht auf den gegenwärtigen zerfahrenen Zustand der Floristik wohl bewusst waren. Die classische Synopsis von $\mathrm{Koch}$, welche von Lorinser in erster linie benützt wurde, ist heute längst veraltet; die Auffassung des Artbegriffes, die Principien der Nomenclatur, die Methoden der floristischen Forschung haben sich seitiem wesentlich verändert - von diesen Veränderungen gibt eine sehr umfangreiche Literatur Zeugniss - aber kein zusammenfassendes Werk macht die Ergebnisse der neueren Forschungen dem Einzelnen zugänglich, es sei denn Acherson's „Synopsis der mitteleuropäischen Flora", von der wir aber heute erst zwei Lieferungen besitzen. Ferner ist die floristische Durchforschung der einzelnen Kronländer Oesterreichs eine sehr ungleichmäßige : Böhmen, Mähren, Schlesien und Niederösterreich besitzen beispielsweise vortrefflich $\theta$ neuere Floren, während über Tirol und Steiermark nur eine sehr zerstrente Literatur Aufschluss gibt, über Krain aber in neverer Zeit überhaupt nur sehr wenig bekannt wurde. Unter diesen Umständen war es ohne jahrelange Vorstudien von Vornherein unmöglich, eine Excursionsflora, welche auf Vollständigkeit Anspruch erhebt, zu schreiben. Die Zeit, die mir zur Verfügung stand, war eine sehr beschränkte, so dass

Fritsch, Excursionsflora. 
ich nicht daran denken konnte, eine Excerpirung der ungeheueren einschlägigen Literatur vorzunehmen oder nicht genügend aufgeklärte Artengruppen selbst zu untersuchen. Es wird daher sowohl in Bezug auf die Umgrenzung und Diagnostik der Arten, als auch in den Verbreitungsangaben manches zu verbessern sein. Alle, welche das Buch benützen und auf Irrthïmer stoben, bitte ich, mich auf dieselben aufmerksam zu machen, damit ich in die Lage komme, sie in einel etwaigen zweiten Auflage zu verbessern.

Der Verleger wünschte eine Neubearbeitung von Lorinser's "Excursionsbuch", das Resultat meiner" Arbeit ist abel ein ganz neues Buch, welches zwar die äucere Form der Lorinser'schen Tabellen beibehält, aber dem Inhalte nach nur wenig beibehalten konnte. Es stellte sich die unbedingte Nothwendigkeit einer rollständigen Umarbeitung heraus; nur dadurch komnte das Buch dem heutigen Standpunkte der Wissenschaft angepasst werden. Die Principien, welche mich bei der Ausarbeitung des Buches leiteten, möchte ich nun der Hauptsache nach darlegen.

Die Gesammtanor'nung des Lorinser'schen Buches habe ich im Allgemeinen beibehalten, abgesehen von dem Aufgeben des veralteten $\mathrm{De}$ Cand olle'schen Pflanrensystems. Den Bestimmungsschlüssel nach dem Linnéschen System habe ich vollständig umgearbeitet, abel nicht weggelassen, weil die Bestimmung solcher Pflanzen, deren Familie dem Bestimmenden nicht bekannt ist, doch mit Hilfe des Linnéschen Systems am raschesten und leichtesten vor sich geht. Dagegen habe ich den von Lorinser verfassten "Versuch einer Eintheilung der Gefäßpflanzen nach den Fruchtknoten und Eichen" als überflüssig beseitigt. Den Schlüssel zur Bestimmung der natürlichen Familien habe ich bei den einzelnen Hauptabtheilungen des Systems, also namentlich bei den Monocotyledonen und Dicotytedonen, untergebracht.

In Bezug auf die Anordnung und Umgrenzung der Familien bin ich genau den "natürlichen 
Ptlanzenfamilien " von Engler und Prantl gefolgt, auch dort, wo meine persönliche Ansicht von der der betreffenden Bearbeiter abweicht. Auch die Anordnung der Gattungen folgt genau demselben Werke; jedoch erlaubte ich mir in Bezug auf die Umgrenzung einiger weniger Gattungen der Gramineen, Cruciferen u. a. kleine Aenderungen auf Grund eigener Untersuchungen oder Erwägungen. Da die Bearbeitung der Umbelliferen in den "natürlichen Pflanzenfamilien" bis heute nicht erschienen ist, so konnte ich die Anordnung ihrer Gattungen nur beiläufig nach der mir von dem Bearbeiter dieser Familie, Herrn Prof. Dru de, in liebenswürdigster Weișe mitgetheilten Tribus-Eintheilung vornehmen. Die Farnpflanzen, welche in den „natürlichen Pflanzenfamilien" ebenfalls noch nicht bearbeitet sind, habe ich nach Luersen (in Rabenhorst's Kryptogamenflora) angeordnet.

Eine schwierige Frage war die nach del Auffassung des Artbegriffes, nach der für die vorliegende Excursionsflora zweckmässigsten Auswahl und Umgrenzung del aufzunehmenden Arten. Auf dem KochNeilreich'schen Standpunkte der alten "guten "Arten stehen zu bleiben, war mit Rücksicht auf den gegenwärtigen Standpunkt der Wissenschaft unmöglich; andererseits wäre die Aufnahme aller in neuerer Zeit unterschiedenen Formen nicht nur mit Rücksicht auf den Umfang des Buches unmöglich, sondern auch wegen der in diesem Falle unvermeidlichen Verwirrung der Anfänger sehr unzweckmäßig gewesen. Ich habe nun versucht, einen Nittelweg einzuschlagen. Ich habe im Allgemeinen nur jene Formen, deren Artrecht heute kaum mehr zweifelhaft ist, in die Tabellen aufgegenommen, auf beachtenswerthe verwandte Formen jedoch, die noch genauerer Feststellung bedürfon, in Fußnoten aufmerksam gemacht. Eine Ausnahme von dieser Regel habe ich jedoch bei solchen Gattungen und Artengruppen gemacht, die in neuerer Zeit Gegenstand monographischer Arbeiten gewesen sind. So sind z. B. die Orobanche-Arten nach Beck, die EuphrasiaArten und die endotrichen Gentiana-Arten nach 
Wettstein, die Rubus-Arten nach Halácsy, die Alectorolophus-Arten nach Sterneck bearbeitet. Schwierig war die Sachlage bei solchen „kritischen" Gattungen, welche (wenigstens in Bezug auf die österreichischen Arten) noch nicht zusammenfassend und übersichtlich bearbeitet wurden. wie z. B. Rosa, Potentilla, Thymus und Hieracium. Bei diesen Gattungen musste ich mich auf die Aufnahme der Hauptarten beschränken und auf den Formenreichthum derselben in Anmerkungen hinweisen. Die durch diese Umstände bedingte Ungleichmäßigkeit in der Bearbeitung der einzelnen Gattungen war nicht zu vermeiden, da die Zusammenziehung der von Monographen getrennten Arten ebenso wenig zu billigen wäre, wie die getrennte Anführung aller in neuerer Zeit beschriebenen Formen in solchen Gattungen, deren monographische Bearbeitung noch aussteht. - In einzelnen Fällen habe ich übrigens auch zweifelhafte Arten in die Tabellen aufgenommen, um auf dieselben aufmerksam zu machen und vielleicht dadurch $7 u$ deren Klärung anzuregen; dies gilt z. B. von Cerastium filifolinm Vest, Laserpitium Aruncus (Rchb.), Soldanella pirolaefolia Schott, Platanthera Carducciana Goiran u. a. m.

In Bezug auf $\mathrm{Nomenclatur}$ war ich bestrebt, die den hente giltigen Prioritätsgesetzen entsprechenden Namen der Gattungen und Arten anzuwenden. Leider mussten dadurch viele allgemein übliche Namen geändert werden, was aber nicht zu vermeiden war. Um denjenigen, welche an diese Namen der Koch'schen Zeit gewöhnt sind, Fingerzeige zu geben, habe ich ein Register der gebräuchlichsten Synonyme zusammengestellt und außerdem im lateinischen Register diejenigen gebräuchlichen Gattungsnamen, welche geändert wurden, wie Capsella, Falcaria u. a., aufgeführt und mit * bezeichnet. In solchen Fällen, wo Zweifel über die Berechtigung gewisser älterer Namen bestehen, habe ich mich im Allgemeinen möglichst conservativ verhalten, also nicht zweifellose jüngere Namen durch zweifelhafte ältere ersetzt. Doppelnamen, wio Linaria 
Linaria, Alectorolophus Alectorolophus u. a., habe ich nicht angewendet. - Aus Raumrücksichten habe ich in den Text gar keine Synonyme aufgenommen, aber die wichtigsten derselben, wie erwähnt, am Ende des Buches registrirt.

Die Citirung der Autornamen erfolgte in folgender Weise: Wurde eine Art von ihrem ersten Autor gleich in die richtige Gattung gestellt und auch als Art behandelt, so ist nur dieser erste Autor (und zwar ohne Klammer) citirt, z. B. Festuca rubra L. Wurde cine Art von "ihrem ersten Autor zwar in die richtige Gattung gestellt, aber als Varietät betrachtet, so ist ebenfalls nur dieser Autor, aber zwischen Klammern, citirt, z. B. Primula acaulis (L.) = Primula veris var. acaulis I. Wurde dagegen eine Art ron ihrem ersten Autor in eine andere Gattung gestellt, bezw. mit einem anderen Gattungsnamen bezeichnet, so wird dieser erste Autor zwischen Klammern, und hinter der Klammer jener Autor citirt, welcher den Artnamen mit dem heute giltigen Gattungsnamen verbunden hat, z. B. Diplotaxis tenuifolia (L.) D C. = Sisymbrium tenuifolium L. = Diplotaxis tenuifolia D C. Bei Erythraea uliginosa (W. K.) (Wittr.) (= Chironia uliginosa W. K.) steht auch der zweite Autorname zwischen Klammern, weil dieser Autor die Pflanze als Varietät zu Erythraea vulgaris gestellt hat.

In Bezug auf die deutschen Namen war Lorinser bestrebt, alte Namen, namentlich solche nythischen Ursprungs, in den Text seines Excursionsbuches aufzunehmen. In dem Vorworte zur vierten Auflage dieses Buches hat Lorinser dieses Vorgehen eingehend begründet und interessante Aufschlüsse über alte Volksnamen gegeben. Ich bedauere, aus Raumrücksichten auf die Aufnahme dieser Namen zum größten Theile verzichten zu müssen. Ich habe an dem Principe festgehalten, jeder Gattung und Art nur einen deutschen Namen beizufügen. Wo mir ein allgemein verbreiteter Volksname bekannt war, habe ich diesen den gekünstelten, vielfach durch Uebersetzung des lateinischen Namens gewonnenen Bezeich- 
nungen vorgezogen. Viele Arten haben aber zahlreiche Volksnamen, Alpeupflanzen z. B. oft in jedem Gebirgsthal einen anderen, während mit demselben Namen in verschiedenen Gegenden oft ganz verschiedene Pflanzen bezeichnet werden. So ließen sich für Anemone alpina wohl gegen 20 Volksnamen anführen, während z. B. mit dem Namen "Speik" Arten von Valeriana, Primula, Androsace, Achillea, Senecio etc. bezeichnet werden. Solche Volksnamen könuen wohl in Landes- und Localfloren, nicht aber in Excursionsfloren, welche ein großes Gebiet umfassen und an Umfang beschränkt sind, Aufnahme finden.

Eine meiner wichtigsten Aufgaben sah ich in der Einfügung der Verbreitungsangabèn, welche Lorinser bei den meisten Arten ganz wegließ. Wenn ein Anfänger eine Coronilla bestimmen will, die er in Böhmen gesammelt hat, so wird ihm die Bestimmung gewiss sehr erleichtert, wenn er sofort dio Angabe findet, dass von den sieben Arten des Gebietes nur zwei in Böhmen rorkommen. Der weiter vorgeschrittene Florist dagegen wird, wenn er eine für ein Kronland neue Art findet, dadurch veranlasst werden, diesem Funde mehr Aufmerksamkeit zuzuwenden. Die in allen Kronländern vorkommenden Arten sind mit der Angabe .Verbr." (verbreitet), die gemeineren unter ihnen mit „Verbr. $u$. $h f g$. " (verbreitet und häufig) bezeichnet. Gebirgspflanzen, welche nicht nur in den Alpen, sondern auch in den Sudeten vorkommen, sind mit "Geb." (Gebirge) bezeichnet, Alpenpflanzen dagegen, welche in den Sudetenländern fehlen, mit "A." (Alpen), wonn sie auch in tiefere Regionen herabsteigen, mit ${ }_{n} A$. $\iota$. Vora." (Alpen und Voralpen), Voralpenpflanzen mit "Vora." bezeichnet. Ich schöpfte die Verbreitungsangaben zumeist aus den Florenwerken der einzelnen Kronländer; eine Excerpirung der sonstigen Literatur war, wie erwähnt, in der mir zur Verfügung stehenden Zeit nicht möglich, so dass manche wichtige Angabe unbeachtet geblieben sein dürfte. - Von den Culturpflanzen habe ich nur die allerwichtigsten und Läufigsten, sowie diejenigen, welche öfters verwilder't vor- 
kommen, aufgenommen; sie sind mit "Cult.", bezw. "Cult. u. verw." (cultivirt und verwildert) bezeichnet. Sind Pflanzen in einigen Kronländern einheimisch, während sie in anderen nur eingeschleppt oder verwildert vorkommen, so sind die Namen dieser letzteren Kronländer zwischen Klammern gesetzt; so z. B. Polygonum Bellardi: ( $N$. .) $K r . J ., d$. h. in Krain und Istrien einheimisch, in Niederöster'reich nur eingeschleppt beobachtet.

Das Gebiet habe ich im Allgemeinen ebenso umgrenzt wie Lorinser; jedoch labe ich die Grenzen dieses Gebietes strenge eingehalten und daher einige nur im angrenzenden Deutschland oder in Ungarn vorkommende Arten, welche Lorinser aufgenommen hatte, weggelassen. Meine Excursionsflora umfasst Böhmen, Mähren, das ïsterreichische Schlesien, Niederund Oberösterreich, Salzburg, Tirol und Vorarlberg, Kärnten, Steiermark, Krain und das gesammte österreichische Küstenland (d. i. Görz-Gradisca, Triest und Istrien sammt den Inseln Veglia, Cherso und Lussin). Die von den niederösterreichischen Botanikern mit Vorliebe annectirten Pflanzen aus del Umgebung des Neusiedlersees, welche in Niederösterreich selbst fehlen (z. B. Lepidium crassifolium und Ranunculus lateriflorus) habe ich, ebenso wie die Pflanzen des zur ungarischen Reichshälfte gehörigen Gebietes von Fiume, nicht aufgenommen.

Die in den meisten Excursionsfloren bei den einzelnen Arten angegebene Blïtezeit habe ich nach einiger Ueberlegung ganz weggelassen. Mit Rücksicht auf die bedeutenden Differenzen, welche in Bezug auf das Klima innerhalb unseres Gebietes vorkommen, hielt ich dies für geboten. Arten, welche über das ganze Gebiet verbreitet sind, können in Istrien im April, in der Ebene Niederösterreichs im Mai, in den höher gelegenen Alpenthälern im Juni und auf den Alpen selbst im Juli blühen. Viele Arten blühen zweimal oder nicht selten abnormerweise im Spätherbst statt im Frühling. In Localfloren, welche ein pflanzengeographisch einheitliches, kleineres Gebiet umfassen, halte ich die 
Angaben über Blütezeit für sehr wichtig - in einer Excursionsflora aber, welche Theile des baltischen, des pontischen, alpinen und mediterranen Florengebietes umfasst, für entbehrlich, für den Anfänger eventuell sogar schädlich, wenn er wegen der nicht stimmenden Angaben der Blütezeit an der Richtigkeit einer Bestimmung zweifelt. In solchen Fällen jedoch, wo die Blütezeit für einzelne Arten oder zur Unterscheidung melrerer Arten von einander charakteristisch ist, habo ich Bemerkungen, wie: „blüht im Frühling vor der Entwicklung der Blätter": (bei Cornus mas im Gegensatze zu C. sanguinea) oder: „im Sommer (im Herbste) blühende Arten" (bei den endotrichen Gentianen) eingefügt.

Auch durch Weglassung der Zeichen $\odot, \odot, ~ 4$ und t., die in den meisten Floren gebrancht werden, bin ich ron dem Torgange Lorinser's abgewichen. Es schien mir zrecklos, bei allen Arten von Rosa, Prunus oder Pirus das Zeichen t? zu wiederholen, wenn ohnedies schon in der Gattungstabelle die in diese Gattungen gehörigen Pflanzen als Holzgewächse bezeichnet welden. In den Bestimmungstabellen, namentlich dor't, wo diesbezügliche Unterschiede zwischen verwandten Arten bestehen, habe ich diese Zeichen durch die Worte "Kräuter", "Stauden", Halbsträucher" u. s. W. ersetzt. Die Einführung des hier zu Lande in anderem Sinne gebräuchlichen Wertes "Staude " für ausdauernde krautartige Pflanzen wird vielleicht befremden, aber' ich halte den Gebrauch dieses morphologisch unerlässlichen Ausdruckes für sehr zweckmäßig, weil dadurch der Begriff "Kräuter" auf die nur einmal blühenden (1 jährigen oder 2 jährigen) Pflanzen eingeschränkt wird. Tielleicht gelingt es mir, das Wort "Stande" durch diese Excursionsflora einigermaßen einzubürgern.

Ueberhaupt war ich bestrebt, die in dem Buche gebrauchten terminologischen Ausdrücke dem houtigen Standpunkte der wissenschaftlichen Morphologie auzupassen, andererseits aber auch dem Laien so verständlich als möglich zu bleiben; deshalb habe ich auch meist deutsche Ausdrücke (wie Wurzelstock, Blüten- 
hülle u. a.) den fremdsprachigen (Rhizom, Perianth) vorgezogen.

Noch muss ich über die Behandlung der $\mathrm{Ba}$ starte einige Worte sagen. Ich halte die Aufnahme von Bastarten in die Bestimmungsschlüssel, wie dies in manchen Floren geschehen ist, für direct schädlich. weil dadurch die oft ganz klaren Unterscheidungsmerkmale der Arten verwischt werden und der Anfänger nur verwirrt wird. Zudem sind die allermeisten Bastarte im Vergleich zu ihren Stammarten so selten, dass die Wahrscheinlichkeit, dass ein Anfänger, der die Arten einer Gattung noch nicht kennt, einen Bastart findet, überhaupt nicht groß ist. In schwierigeren Gattungen wird überhaupt nur derjenige im Stande sein, Bastarte zu erkennen, der die betreffenden Stammarten gut kennt; ist aber dies der Fall, so genügt ein Hinweis, dass dieser Bastart existirt, vollkommen. Ich habe daher am Ende jeder Gattung, von welcher Bastarte im Gebiete beobachtet wurden, diese aufgezählt, wie dies auch Garcke, Gremli u. A. in ihren Excursionsfloren gethan haben. Auf die binären Namen der Bastarte habe ich hierbei verzichtet; ich hätte sonst oft bei einem und demselben Bastart drei oder noch mehr Namen anführen müssen, da die Benennung einzelner hybrider Individuen immer mehr Mode wird. Die Reihenfolge der aufgeführten Bastarte richtet sich stets nach der Reihenfolge der Arten in den Bestimmungsschlüsseln: zuerst werden alle Bastarte der ersten Art, dann alle der zweiten u. s. w. angeführt.

Bei der Umarbeitúng (oder in sehr vielen Fällen Neubearbeitung) der Bestimmungsschlüssel war mein Bestreben hauptsächlich darauf gerichtet, das Bestimmen thunlichst zu erleichtern. Ich habe daher die von Lorinser in den Vordergrund gestellten Frucht- und Samenmerkmale in den Gattungstabellen der Cruciferen und Umbelliferen so weit als möglich vermieden, und andere an der frischen, blühenden Pflanze auffallende Merkmale, wie Blütenfarbe, Blattgestalt, Behaarung u. s. w. in den Vordergrund 
gestellt. Die Gattungstabellen haben meiner Ansicht nach nicht den Zweck, die wissenschaftlichen Gattungsunterschiede in erster Linie zu bringen, sondern die Bestimmung der Gattung zu erleichtern. Dasselbe Bestreben leitete mich bei der Verfassung der Bestimmungsschlüssel für die Arten; die systematische Reihenfolge opferte ich gerne, wenn ich durch Hervorhebung irgend eines auffälligen Merkmales die Bestimmung erleichtern konnte. - Aehnliche praktische Erwägungen veranlassten mich, bei der Charakteristik der einzelnen Familien nur die im Gebiete vorkommenden Arten zu berücksichtigen. Die Rubiaceen sind beispielsweise als "Stauden oder Kräuter" angeführt, weil bei uns keine holzigen Formen vorkommen.

Fine Einleitung, welche die Grundbegriffe der Morphologie darlegt, soweit sie zum Verständnisse der in den Familiendiagnosen und Bestimmungsschlüsseln vorkommenden Ausdrücke nothwendig erscheinen, hielt ich für unerlässlich. Dieser von mir vollständig nen verfasste Abschnitt folgt unmittelbar diesem Vorworte.

Ob mein Versucb, eine dem heutigen Standpunkte der Wissenschaft so weit als möglich entsprechende, und dennoch auch für den Laien und Anfänger brauchbare Excursionsflora der österreichischen Sudeten- und Alpenländer zu schaffen, gelungen ist, wird sich erst bei der praktischen Benützung des Buches zeigen. An alle Fachgenossen stelle ich die Bitte, bei der Beurtheilung des Buches auch die Eingangs erwähnten Schwierigkeiten in Betracht zu ziehen.

Wien, am 2. März 1897.

Der Yerfasser. 


\section{Die wichtigsten Grundbegriffe der botanischen Morphologie,}

soweit sie zum Verständnisse der in den Bestim. mungstabellen und Beschreibungen vorkommenden Fachausdriicke nothwendig sind.

Die wichtigsten Bestandtheile des Pflanzenkürper's sind die Wurzeln, die Stengel und die Blätter. Auch die Theile der Blüten und Früchte lassen sich auf diese Grundorgane zurückführen.

Die Wurzeln wachsen in der Regel nach abwärts, befestigen die Pflanze im Erdboden und entnehmen die Nahrung aus demselben. Sie unterscheiden sich von den Stengelorganen insbesondere auch dadurch, dass sie niemals Blattorgane tragen - ein Unterschied, der namentlich gegenüber den unterirdischen, oft wurzelähnlichen Stengelorganen (Wurzelstöcken) von Wichtigkeit ist. Verzweigt sich eine Wurzel, so haben ihre Verzweigungen stets wieder die Eigenschaften von Wurzeln, niemals solche von Stengeln oder Blättern. Die Wurzeln bieten der beschreibenden Botanik nur wenig Anhaltspunkte und werden auch nur selten zur Unterscheidung von Pflanzenarten herangezogen.

Die schon am Keimling vorhandene, direct nach abwärts wachsende Hauptwurzel (Pfahlwurzel), welche eine Fortsetzung des Hauptstengels nach unten bildet, und deren Verzweigungen Nebenwurzeln genannt werden, bleibt manchmal, namentlich bei Kräutern, zeitlebens erhalten, in anderen Fällen (namentlich bei Monocotyledonen) stirbt sie bald $a b$ und an ihre Stelle treten zahlreiche Adventivwurzeln, welche in größerer Zahl aus den Stengelorganen der Pflanze entspringen.

Charakteristisch sind für manche Pflanzen rübenförmig verdickte Wurzeln (gelbe Rübe), bei anderen 
sind Theile der Wurzeln oder ganze Wurzeln knollig' verdickt (Wurzelknollen, z. B. bei Ranunculus Ficaria). Wurzeln von Kletterpflanzen, welche nicht die Befestigung der Pflanze in der Erde, sondern die Befestigung an anderen Unterlagen, z. B. Baumstämmen, besorgen, heißen Haft-oder Kletterw urzeln (Epheu); Wurzeln von Schmarotzerpflanzen, die in dio Nührpflanze eindringen und aus derselben die Nahrung entnehmen, nennt man Saugwurzeln (Schuppenwurz).

Als Stengelorgane (Stammorgane) bezeichnet man alle jene Pflanzentheile, welche in regelmäßiger Anordnung $\mathrm{B}$ I ät $\mathrm{t} \theta \mathrm{r}$ (oder diesen gleichwerthige Schuppen etc.) tragen. Hierher gehören nicht nur die oberirdischen Stengel, die Stämme, Aeste und Zweige der Bäume und Sträucher, die Blütenstiele und Fruchtstiele, sondern auch unterirdische Organe: Wurzelstöcke, Knollen (Stammknollen) und /wiebeln. Die Wurzelstöcke und Stammknollen unterscheiden sich von den echten Wurzeln und Wurzelknollen in er'ster Linie dadurch, dass sie stets Blätter, wenn auch oft nur in Form kleiner, oft bald abfallender Schuppen, tragen. Bei den Zwiebeln sind diese Blattorgane groß und dick-fleischig (Zwiebelschalen), während das Stammorgan nur eine Scheibe am Grunde der Zwiebel bildet (Allium). Beispiele für Stammknollen bieten Crocus, die Kartoffel u. a. m.

An dieser Stelle seien die Kategorien von Pflanzen, welche man nach der Lebensdauer unterscheidet, kmrz besprochen. Die drei wichtigsten Formen sind die Holzgewächse, die Stauden und die Kräuter. Die Holzgewächse besitzen verholzte, oft viele Jahre ansdauernde oberirdische Stammorgane, welche alljährlich neue beblätterte Zweige entwickeln. Die Holzgewächse sind entweder Bäume (mit mächtig entwickeltem Hauptstamm) oder S träu cher (ohne solchen). Es scheint nöthig, darauf aufmerksam zu machen, dass viele Sträucher sehr klein und niedrig sind, aber wegren ihrer ausdauernden, verholzenden Stengelorgane doch zu den Holzgewächsen gerechnet werden müssen (Ericaceen, Alpenweiden). Die Halbsträucher vermitteln 
den Uebergang zu den Stauden; bei ihnen stirbt ein großer Theil der oberirdischen Stengel alljährlich $a b$, während der untere, verholzte Theil der Stengel ausdanert und in jedem Jahre neue beblätterte Zweige entwickelt. Der Ausdruck Staude wird in der Mor'phologie in anderem Sinne gebraucht als im Volksmunde. Die "Hollerstaude" des Volkes ist ein Strauch. Unter Staude verstehen wir eine Pflanze, deren oberirdische Organe alljährlich absterben, während die unterirdischen Organe (Wurzelstöcke, Knollen, Zwiebeln oder echte Wurzeln) ausdauern. In vielen Büchern sind die Stauden als „ausdauernde Kräuter" bezeichnet. Boi kleinen, zarten Pflanzen, wie Adoxa Moschatellina oder Oxalis Acetosella, ist der Ausdruck Staude zwar seh" befremdlich, aber bei consequenter Durchführung der durch die Morphologie festgesetzten Fachausdrücke müssen diese ebenso bezeichnet werden wie eine Valeriana officinalis oder eine Filipendula Ulmaria. "Kräuter" nennen wir daher nur die 1- oder 2 jährigen, in der Regel nur einmal blühenden und nach der Fruchtreife absterbenden Gewächse. In diesem Sinne sind obige Bezeichnungen in allen Bestimmungstabellen dieses Buches angewendet; der Gegensatz "Kräuter" - "Stauden" bedeutet also dasselbe wie "Pflanzen 1- oder 2 jährig " sicht auf die Größe der betreffenden Pflanzen.

Ein Stengelstück $z$ wischen den Ursprungsstellen zweier aufeinanderfolgender Blätter wird Stengelgli ed (Internodium) genannt; dagegen die Ursprungsstelle des Blattes oder mehrerer gleich hoch stehender Blätter Stengelknoten. Diese Knoten sind besonders bei den Halmen der Gräser auffallend entwickelt. Die meisten im vorliegenden Buche bei Beschreibung der Stengelorgane vorkommenden Ausdrücke bedürfen keiner Erklärung; was ein windender Stengel, wals ein Ausläufer ist, kann als bekannt vorausgesetzt werden. Ist ein Blüten- 0. Blütenstände tragender Stengel nur am Grunde oder gar nicht beblättert oder nul beschuppt, so wird er Schaft genannt. Stengelorgane können sich auch in Dornen (Crataegus) oder in Ranken 
(Weinstock) umwandeln. Nehmen Stengelorgane die Gestalt von Blättern an, so nennt man sie Phỵllocladien (Ruscus).

I)ie Blattorgane stehen in gesetzmäßiger Stellung an den Stengeln: stehen zwei in gleicher Höhe einandel gegenüber, so sind sie gegenständig; stehen mehrere in gleicher Höhe, so sind sie quirlig oder wirtelig angeordnet; steht jedes in anderer Höhe, so nennt man sie we chselständig, oder, weil ihre Ursprungsstellen dann stets in einer um den Stengel gewunden zu denkenden Schraubenlinie liegen, schraubig gestellt. Die Seitenzweige eines Stengels entspringen fast ausnahmslos unmittelbar oberlialb der Ursprungsstelle eines Blattes (in der Blattachsel oder im Blattwinkel); die Folge davon ist, dass bei Pflanzen mit gegenständigen Blättern auch die Seitenzweige in der Regel gegenständig sind (Ahorn). Das Blatt, in dessen Achsel ein Zweig (oder ein Blütenstiel) entspringt, nennt man das Tragblatt des betreffenden Zweiges; unter dem Tragblatt einer Blüte (oder eines Blütenstandes) versteht man also jenes Blatt, in dessen Achsel die Blüte (bezw. der Blütenstand) steht.

Im gewöhnlichen Leben pflegt man nur die grünen, flachen Blattorgane als Blätter zll bezeichnen, und auch in diesem Buche ist unter "Blatt" schlechtweg in der Regel ein solches grünes Blatt ("Laubblatt" der Morphologie) gemeint. Die wichtigste Aufgabe der grünen Blätter ist die Bildung von organischen Verbindungen mit Hilfe der aus der Luft aufgenommenen Kohlensäure (Kohlensäure-Assimilation). Diese Laubblätter bestehen sehr oft (aber durchaus nicht immer) aus einer Erweiterung am Grunde (Blattsclieide, sehr schön entwickelt bei vielen Umbelliferen), einem stielartig verlängerten 'Theile (Blattstiel) und der Blattfläche (Blattspreite). Die im Texte des Buches fortwährend vorkommenden Beschreibungen der Gestalt der Blätter beziehen sich selbstver'ständlich stets auf die Blattspreite; eine Erklärung der Ausdrücke „lineal", „eiförmig“", „3 zählig“, „fiøder'schnittig“, „gezähnt" 
ii. s. W. ist wohl überflüssig. Am Grunde des Blattstieles finden sich häufig zwei kleine Blättchen, welche man als Nebenblätter bezeichnet. Bei den Gräsern findet sich dort, wo die Blattspreite in die den Stengel umgebende Blattscheide übergeht, gewöhnlich ein häutiges Organ, das sogenannte "Blatthäutchen". - Diejenigen Laubblätter, welche unmittelbar über dem Erdboden am Grunde des Stengels oder aus einem unterirdischen Stengelorgan entspringen, heißen Gr u n dblätter (der Ausdruck "Wurzelblätter"“ ist zu vermeiden, da eine Wurzel nie Blätter trägt); die höher oben am Stengel entspringenden dagegen Stengelblätter.

Außer den Laubblättern finden wir aber an der Pflanze zahlreiche andere Blattorgane, meist von schuppenförmiger Gestalt. Hierher gehören die Niederblätter, welche besonder's an den Wurzelstöcken, aber auch oft am Grunde oberirdischer Stengel auftreten, bei Schmarotzerpflanzen oft ïberhaupt die Stengel an Stelle von Laubblätter'n bekleiden (Orobanche). Aehnlich verhalten sich die in der Umgebung der Blüten vorkommenden Hochblätter (Deckblätter, Vorblätter etc., wovon weiter unten). Die ersten Blätter des Keimling:s heiøen Keimblätter.

Die Nervatur der Blätter bedarf wohl keiner Erläutelung.

Ebenso wie die Stengel, können sich auch Blätter oder Blattheile in Dornen oder Ranken umwandeln (ersteres bei Berberis, letzteres bei Lathyrus, Vicia etc.). Verbreitert sich ein Blattstiel und nimmt die Gestalt einer Blattspreite an, während letztere nicht zur Entwicklung kommt, so spricht man von einem Phyllodium (Lathyrus Nissolia).

Die Blüten stehen oft einzeln, entweder am Ende des Stengels oder der Zweige, oder in den Blattachseln. Häufiger aber sind mehrere oder zahlreiche Blüten einander genähert und zu Blütenständen zusammengestellt. Man kann zwei Hauptformen von Blütenständen unterscheiden: traubige und trugdoldige Blütenstände. Stehen die Blüten in den 
Achseln schraubig angeordneter Hochblätter am Ende eines Stengels, so bilden sie eine Traube, oder, wenn die einzelnen Blüten nicht gestielt sind, eine A ehre (die Tragblätter können anch fehlen). Die Kätzchen, $\mathrm{Zapfen}$ und Kolben sind im einfachsten Falle Formen dieser einfachen traubigen Blütenstände, können aber auch zusammengesetzte Blütenstände sein (Kätzchen der Birke). Sind die Ursprungsstellen der Blütenstiele (bezw. Blüten) am Ende des Stengels dicht zusammengedrängt, so entsteht aus der Traube eine Dolde, aus der Aehre ein Köpfchen. Anßer diesen einfachen traubigen Blütenständen gibt es auch zusammengesetzte, wie die Rispe der Gräser, die zusammengesetzte Dolde der meisten Umbelliferen u. a. m. Während bei den traubigen Blütenständen eine Endblüte fehlt und in der Regel die untersten (bezw. äußersten) Blüten zuerst aufblühen, zeichnen sich die trugdoldigen Blütenstände durch eine in der Mitte stehende, zuerst aufblühende Endblüte aus (welche allerdings auch feblen kann). Unter dieser Endblüte entspringen im einfachsten Falle ans den Achseln zweier gegenständiger Hochblätter zwei Seitenblüten. Häufig verzweigen sich aber die Blütenstiele der Seitenblüten wieder in derselben Weise, oder es sind nicht zwei, sondern mehrere Seitenblüten vorhanden, deren Stiele aus den Achseln wirteliger Hochblätter entspringen. Hierdurch entstehen oft sehr complicirte Blütenstände (Euphorbia); hierher gehören die Schraubeln, Wickeln, Spirren und Blütenknäuel, auf deren Bau hier nicht näher eingegangen werden soll. In den Bestimmungsschlüsseln des vorliegenden Buches sind die complicirteren Blütenstände meist nach ihrem Aussehen als "doldenähnlich", "rispenartig" u. s. w. bezeichnet, da die specielle Beschreibung derselben unthunlich wäre.

Die in der Umgebung der Blüten vorkommenden Hochblätter werden gewöhnlich als Deckblätter bezeichnet. Streng genommen sollten nur die Tragblätter der einzelnen Blüten, bezw. der Blütenstiele, so bezeichnet werden. Der Blütenstiel selbst trägt oft noch 1-2 Hochblätter unterhalb der Blüte, welche man 
als Vorblätter bezeichnet. (Diese Vorblätter können bei trugdoldigen Blütenständen gleichzeitig die Tragblätter der Seitenblüten sein.) Andere die Blüten oder Blütenstände umgebende Blätter pflegt man Hüllblätter zu nennen (Euphorbia). Bei den Umbelliferen mit zusammengesetzten Dolden nennt man die Tragblätter der Blütenstiele Hüllchenblätter (alle zusammen „Hüllchen“), die Tragblätter der Doldenstrahlen Hüllblätter (zusammen die "Hülle“). Die Köpfchen del Compositen sind von zahlreichen schuppenförmigen Hüllblättern (Hüllschuppen) umgeben.

Die Blüte selbst besteht aus dem oft mannigfach ausgebildeten Ende des Blütenstieles (Blütenboden) und aus Blattorganen, welche an demselben in gesetzmäßiger Weise angeordnet sind. Diese Blattorgane sind die Blütenhüllblätter, die Staubblätter und die Fruchtblätter. Die Blütenhülle besteht oft aus zwei Kreisen von Blättern, von denen die äußeren grün oder unscheinbar gefärbt, die inneren aber meist viel zarter und oft lebhaft gefärbt sind; in diesem Falle wird die äußere Hülle als Kelch, die innere als Blumenkrone bezeichnet. Die Blätter, aus denen der Kelch besteht, heißen Kelchblätter, die der Blumenkrone Kronblätter. Häufig sind die Blätter des Kelches untereinander verwachsen, ebenso die der Blumenkrone, oder die Blätter einer einfachen Blütenhülle. Man spricht dann von einel verwachsenblättrigen Blütenhülle (bezw. Kelch oder Blumenkrone) und nennt die oft freien Spitzen der verwachsenen Blätter Zipfel (Kelchzipfel, Blumenkronzipfel). Es gibt auch Blüten ohne Blütenhülle. - Die Staubblätter ("Staubgefäße") bestehen in der Regel aus einem fadenförmigen Theile (Staubfaden) und aus den von demselben getragenen Pollenbehältern (Antheren, Staubbeutel). Der in den letzteren enthaltene Pollen ("Blütenstaub“) hat die Aufgabe, die Befruchtung der Samenknospen herbeizuführen. Verkümmerte Staubblätter, welche keine Antheren tragen und oft die Gestalt kleiner Schüppchen haben, werden Staminodien genannt. - Die Fruchtblätter sind selten 
frei (Coniferen) und tragen in diesem Falle die Samenknospen (Samenanlagen) an ihrer Oberseite; meist sind sie zu einem Fruchtknoten verwachsen, der in seinem Innern die meist an eigenen ,.S a menträgern" befestigten Samenknospen birgt. Die sogenannte $\mathrm{Narbe}$, welche entweder direct dem Fruchtknoten aufsitzt oder häufiger von einem "Griffel" getragen wird, dient zur Aufnahme des Pollens, welch' letzterer durch den Griffelkanal Schläuche (Pollenschläuche) treibt, die in die Samenknospen eindringen und daselbst die Befruchtung bewirken. Der sogenannte „unterständige Fruchtknoten" entsteht dadurch, dass der Blütenboden sich aushöhlt und am oberen Rande der Aushölllung die Blütenhüllblätter und Staubblätter trägt, während die Fruchtblätter im Innern der Aushöhlung sich ausbilden und mit dem Blütenboden fest verwachsen.

Blüten, welche nur Staubblätter, aber keine Fruchtblätter enthalten, werden männliche, solche dagegen, welche nur Fruchtblätter enthalten, weibliche Blüten genannt. Die Z witter b lüten enthalten sowohl Staubblätter als auch Fruchtblätter. Finden sich männliche und weibliche Blüten auf einer und derselben Pflanze, so nennt man die Blüten einhäusig; trägt jede Pflanze immer nur entweder männliche oder weibliche Blüten, so nennt man sie $\mathrm{z}$ weihäusig. Von vielehigen Blüten spricht man, wenn zwittrige und männliche oder zwittrige und weibliche oder Blüten mit theilweise verkümmerten Staub- oder Fruchtblättern vorkommen. - RegelmäBige Blüten sind solche, welche von ihrem Mittelpunkte aus nach allen Richtungen hin gleichmäßig (strahlig) entwickelt sind. Ist dies nicht der Fall, so heißt die Blüte un regelmäßig. Bei unregelmäßigen Blüten sind in der Regel die Blätter der Blütenhülle untereinander ungleich; häufig sind auch die Staubblätter nach einer Seite hin gebogen (Schmetterlingsblüte unserer einheimischen Leguminosen).

Aus der Samenknospe entwickelt sich nach erfolgter Befruchtung der Same, aus dem Frucht- 
knoten gleichzeitig die Frucht. Der Same besteht aus der Samenschale, dem (oft fehlenden) Nährgewebe und dem Keimling. Die Frucht springt entweder auf, um die Samen auszustreuen (Kapsel, Schote, Hülse, Balgfrucht), oder sie zerfällt in Theilfrüchtchen (Spaltfrucht), oder sie bleibt geschlossen (Schließfrucht, Nüsschen, Grasfrucht, Frucht der Compositen). Fleischige Früchte sind die Steinfrüchte, bei welchen die inneren Schichten der Fruchtwand hart sind, und die Beeren, bei welchen nur die Samenschalen hart sind. Verändern sich nicht nur die Fruchtblätter, sondern auch andere Theile der Blüte oder des Blütenstandes, in Folge der Befruclitung, so entstehen Scheinfrüchte (Hagebutte) oder Sammelfrüchte (Naulbeere).

Ueber den von den hier geschilderten Verhältnissen abweichenden Bau der Fortpflanzungsorgane bei den Farnpflanzen vergleiche man Seite 1 des speciellen Theiles. 


\section{Die wichtigsten Florenwerke für die einzelnen Kronländer.}

Ċelakovský, Prodromus der Flora von Böhmen. Prag 1867-1881.

Oborný, Flora von Mähren und österr. Schlesien. Brünn 1881-1886.

Neilreich, Flora von Nieder-Oesterreich. Wien 18509. Beck v. Mannagetta, Flora von Nieder-Oesterreich.

Wien 1890 - 1893. (Hauptwerk.)

Halácsy, Flora von Nieder-Oesterreich. Wien 1896. (Handbuch.)

Duftschmid, Flora von Ober-Oesterreich. Linz 1870 bis 1885 .

Sauter, Flora der Gefäßpflanzen des Herzogthums Salzburg. 2. Auflàge. Salzburg 1879. (Nur Aufzählung; enthält keine Beschreibungen.)

v. Hausmann, Flora von Tirol. Innsbruck 1851 bis $18 \check{4} 4$.

Pacher und v. Jabornegg, Flora von Kärnten. Klagenfurt 1881-1887.

Malý, Flora von Steiermark. Wien 1868. (Nur Aufzählung.)

Fle is chmann, Uebersicht der Flora Krains. Laibach 1844. (Nur Aufzäblung.)

Pospichal, Flora des österreichischen Küstenlandes. Wien $1897 *$ ).

Freyn, Die Flora von Süd-Istrien. (Verhandlungen der zoolog.-botan. Gesellschaft in Wien, 1877).

Berichte über die floristische Erforschung der einzelnen Kronländer finden sich in der österreichischen botanischen Zeitschrift von 1889 an, ferner in den Berichten der deutschen botanischen Gesellschaft von $188 \tilde{\text { - }} 1892$.

*) Bisher erschien nur der erste Band, und auch dieser erst während des Druckes des vorliegenden Buches, so dass dieses Werk hier nicht die ihm gebührende Berücksichtigung finden konnte. 


\section{Verzeichniss der Abkïrzungen.}

\section{a) In den Bestimmungsschlüsseln und Beschreibungen.}

A. = Anthere (Staubbentel) (auch in Zusammensetzungen, z. B.: Afächer $=$ Antherenfächer).

B. = Blatt (anch in Zusammensetzungen, z. B.: Babschnitt = Blattabschnitt, Bachsel = Blattachsel, Brosette = Blattrosette, Bstiel = Blattstiel, Grandb. = Grundblätter a. s. w.).

Blkr. = Blumenkrone (anch in $\mathrm{Zn}-$ sammensetzungen, z. B.: Blkrzipfel = Blumenkronzipfel, Blkrrölure = Blumenkronröhre).

Bt. = Blüte (auch in Zusammensetzungen, z. B.: Bthūlle = Blūtenhülle, Btstand = Blūtenstand, Btstiel = Blūtenstiel, Zwitterbt. $=\mathrm{Z}$ *itterblūte u. s. w.).

-btg. = -blütig (z. B.: 2 btg. = 2 blütig).

Deckb. = Deckblatt.

-f. =-förmig (z. B.: eif. = eiförmig).

Fr. = Fracht (Scheinfr. $=$ Scheinfrucht, Theilfr. = Theilfrucht, Frwand = Fruchtwand u. s. w.). Frkn. = Frnchtknoten.

Gr. = Griffel (Gräste = Griffeläste). Grundb. = Grundblätter.

Hüllsp. = Hüllspelze.

K. = Kelch (Kröhre = Kelchröhre, Kzipfel $=$ Kelchzipfel, Frk. oder Fruchtk. = Fruchtkelch).

Alle übrigen Abkürzangen dūrften selbstverständlich sein.
Kb. $=$ Kelchblätter.

Krb. = Kronblātter.

-1 . = -lich (z. B.: rundl. = rundlich).

N. = Narbe.

Nebenb. = Nebenblätter.

o. $=$ oder.

Pfl. = Pflanze.

$\mathrm{S}$. = Samen Smantel = Samenmantel, Sschale = Samenschale).

-s. = -seits (z. B.: obers. = oberseits).

Scheinfr. = Scheinfrucht.

-st. = -stāndig (z. B.: unterst. = unterständig).

Stb. = Staubblätter.

Stf. = Staubfäden.

Stg. = Stengel.

Stgb. = Stengelblätter.

Theilfr. = Theilfrucht.

$\mathrm{Tr}$. = Traube.

Tragb. = Tragblatt.

u. $=$ und.

Vorb. = Vorblatt.

- w. $=-$ wärts (z. B.: oberw. = oberwărts).

Wst. = Warzelstock.

$\mathrm{Wz} .=$ Warzel $(\mathrm{Wzfasern}=\mathrm{Wrr}-$ zelfasern).

$\mathrm{Z}_{\text {witterbt. }}=\mathrm{Z}_{\text {witterblüte. }}$

\section{b) Bei den Verbreitungsangaben.}

A. = Alpen.

$B$. $=$ Böhmen.

bes. $=$ besonders

cult. $=$ cultivirt.

Geb. = Gebirge.

$h f g$. = hāufig.

$J .=$ Istrien mit Einschluss des österreichischen Litorales, des Gebietes von Triest nnd der Inseln Veglia, Cherso and Lussin.

$\kappa$. = Kärnten.

Kr. = Krain.

$M_{0}=$ Māhren.

$N$. $=$ Niederösterreich.
0 . = Oberösterreich.

$S$. = Salzburg.

Sch. $=$ Schlesien.

Sud. = Sudeten.

Südst. = Sũdsteiermark.

Sï̈dt. = Sūdtirol.

$T$. = Tirol and Vorarlberg.

$u$. $=$ und.

v. $=$ von (z. B.: A. v. S. = Alpen von Salzburg, Geb. v. B. 'T. $=$ Gebirge von Böhmen und Tirol). verbr. = verbreitet.

verw. = verwildert.

Vora. $=$ Voralpen.

Stehen die Namen einzelner Kronländer in Klammern, so kommt die Pflanze dort nur eingeschleppt oder verwildert vor; z. B.: Polycarpon tetraphyllum ist in Istrien heimisch, wurde aber auch in Böhmen eingeschleppt beobachtet - die Verbreitungsangabe lantet daher: $(B.) \mathrm{J}$. 


\section{c) Autornamen.}

A. $B r .=$ Alexander Braun.

Adans. = Adanson.

Ag. $=$ Agardh.

Ait. $=$ Aiton.

All. = Allioni.

$A m b r .=$ Ambrosi.

Andrz. = Andrzeiowsky.

Ang. = Angelis.

Angstr. = Ångstrōm.

Ard. = Ardnino.

$A r n .=$ Arnold.

Aschers. = Ascherson.

Asso $=$ Asso.

Aré Lall. = Avé Lallemant.

$B a b .=$ Babington.

Backh. = Hackhouse.

Bad. = Badarro.

Balb. = Balbis.

Bak. = Baker.

Barr. = Barrandon.

Bartl. = Bartling.

Bast. = Bastard.

Baumg. = Baumgarten.

Bcauv. = Palisot de Beanrais.

Beck $=$ Beck.

Becker $=$ Becker.

Bechst. = Bechstein.

$B \in e b y=$ Beeby.

Bell. $=$ Bellardi.

Benth. = Bentham.

Bergius = Bergius.

Berml. = Bernhardi.

Bert., Bertol. = Bertoloni.

Bess. $=$ Besser.

Bill. $=$ Billot.

Bigel. = Bigelow.

Biria $=$ Biria.

Bischoff $=$ Bischoff.

$B l . N$. sich $=$ Bluff, Nees und

Schauer.

Bluff et Fing. = Bluff und Fingerhuth.

Bod. = Bodard.

Boiss. = Boissier.

Bolton = Bolton.

Borb. = Borbás.

Bor. = Boreau .

Bork $h$. = Borkhansen.

Bory $\epsilon t$ Chaub. = Bory und

Chaubard.

Bönn. = Bönninghausen.

Brig. = Brignoli.

Briq. = Briquet.

Britt. = Brittinger.

Brot. $=$ Brotero.

Bunge = Bunge.

Burn. = Burnat.

Bus. = Buser.

C. A. Mey. = Carl Anton Meyer.

C. Koch = Carl Koch.

Car. = Caruel.

Cass. = Cassini.
Caran. = Cavanilles.

Čelak. = Ćelakovský.

Cesati $=$ Cesati.

Chaix = Chaix.

Cham. = Chamisso.

Chaub. = Chaubard.

Chodat $=$ Chodat.

Choisy $=$ Choisy.

Christ $=$ Christ.

Christener = Christener.

Clar, = Clarion.

Clem. = Clementi.

Coss. = Cosson.

Cr. $=$ Crantz.

Crép. = Crépin.

Curt. $=$ Curtis.

Cuss. $=$ Cusson.

Cust. $=$ Custer.

Cyr. $=$ Cyrillo.

$D C .=$ De Candolle.

Dalla Torre = Dalla Torre.

Del. $=$ Delile.

Desf. $=$ Desfontaines.

Desp. $=$ Desportes.

Desr. = Desrousseanx.

Desv. = Desvaux.

Doll. $=$ Dolliner.

Don $=$ Don.

Dougl. $=$ Donglas.

Duby = Duby.

Duch. = Duchesne.

Dum. = Dumortier.

Dun. = Dunal.

Dur. $=$ Durieu.

Duval-Jouve = Dnval-Jouve.

E. t $Z$. = Ecklon and Zeyher.

Elliot $=$ Elliot.

Endl. = Endlicher.

Ehrh. = Ehrhart.

F. Braun = Apotheker F. Braun.

F. Schltz, Friedrich Wilhelm Schultz.

F. v. Muell. $\Rightarrow$ Ferdinand von Mueller.

Fucch. = Facchini.

Fée $=$ Fée.

$F e \epsilon r=$ Feer.

Fenzl = Fenzl.

Fisch. Fischer.

Fisch.-Oost. = Fischer-0oster.

Fleischn. = Fleischmann.

Flörke = Flörke.

Forsk. = Forskil.

Foug. = Fougeroux.

$F r$. $=$ Fries.

Fres. = Fresenius.

Freyer $=$ Freyer.

Frey $n=$ Freyn.

Fritsch = Fritsch.

Fröl. = Frölich.

Funk = Funk. 
G. If. Sch. $=$ Günther, Mejer und Scherbius.

Giurcke = Garcke.

Gasp. = Gasparrini.

Gaud. = Gaudin.

Gay $=$ Gay.

Gürtu. = Gärtner.

Gilib. = Gilibert.

Gimel. = Gmelin

Gochnat = Gochnat.

Godet $=$ Godet.

Godr. $=$ Godron.

Goiran = Goiran.

Good. = Goodenough.

Goue. = Gouan.

Grab. = Grabowski.

Gray = Gray.

Gremli $=$ Gremli.

Gren. $=$ Grenier.

Grimm $=$ Grimm.

Gris., Griseb. = Grisebach.

Gronov. = Gronovins.

Guersent $=$ Guersent.

Gurn. = Gunner.

Guss. = Gussone.

H. $\mathrm{Br} .=$ Heinrich Brann.

Hack. = Hackel.

Hacq. = Hacquet.

Hol. = Halácsy.

Hall. $=$ Haller.

Hampe = Hampe.

Haračić = Haračić.

Hartm. = Hartman.

Hausm. = Hausmann.

Hausskn. = Haussknecht.

Haw. = Haworth.

Hayne = Hayne.

$H e \epsilon r=$ Heer.

Heimerl = Heimerl.

Heister $=$ Heister.

$H \epsilon l d r .=$ Heldreich.

Herm. = Hermann.

Heuff. $=$ Heuffel.

Heynh. = Heynhold.

Hgtsch., Hegetschw. = Hegetschweiler.

Hill. $=$ Hiller.

Hitclic. $=$ Hitchcock.

Hladn. = Hladnık.

Hnk. = Hänke.

Hochst. $=$ Hochstetter.

Hoffgg. = Hoffinannsegg.

Hoffm. = Hoffmann.

Holundre $=$ Holandre.

Holuby $=$ Holuby.

Hook. $=$ Hooker.

Hoppe $=$ Hoppe.

Horn., Hornem. = Hornemann.

Hornsch. = Hornschach.

Host $=$ Host.

Hueds. = Hudson.

Hut. = Huter.

Jacq. = Jacquin.

Jan $=$ Jan.

Junl, $\alpha=$ Janka.
$J \epsilon s$. . Jescen.

Jurd. $=$ Jordan.

Jur. = Juratzka.

Juss. = Jussieu.

Kultenb. = Kaltenbach.

Kell. $=$ Ke!ler.

$K \epsilon r=$ Ker.

Kern. = herner.

Kirschl. $=$ Kirschleger .

Kit. = Kitaibel.

Kluk $=$ Kluk.

Knuf $=$ Knaf.

Koch $=$ W. D. J. Koch.

Köhl. = Köbler.

Koel. = Köler.

Koen. = König.

Foєrn. = Körnicke.

Kol, $t s=$ Kohts.

Kustel. = liosteletzky.

Kotscliy $=$ Kotschy.

Krause $=$ Krause.

Krock. = Krocker.

Krok $\epsilon$ t $\Delta l m q$. = hrok und Almquist.

Kth. = Kunth.

Ktze. = Kuntze.

Kulin = Kuhn.

Kütz. = Kūtzing.

L. = Linné.

L. $f$. = Linné, Sohn.

L. C. Rich. = Louis Claude Richard,

L' Hér., L'Herit. $=L^{\prime}$ Héritier.

Lachen. = Lachenal.

Lag. = Lagasca.

Lam. = Lamarck.

Lang = Lang

Lap. = Lapeyrouse.

Ledtb. = Ledebour.

Letrs $=$ Leers.

Lehm. = Lehmann.

Lej. = Lejeune.

Léman = Léman.

Less. = Lessing.

Leyb. = Leyhold.

Leyss. = Leysser.

Lge. = Lange.

Libevt $=$ Libert.

Lightf. = Lightfoot.

Lindl. = Lindley.

$L k$. = Link.

Lloyd $=$ Lloyd.

löfl. = Löfling.

Lois. = Loiseleur-Deslongchamps.

Lor. = Loret.

Lumn. = Lnmnitzer.

$M B$. = Marschall von Bieberstein.

M. $K$. Mertens and Koch.

Maratti $=$ Maratti.

Marches. = Marchesetti.

Marss. = Marsson.

Mart. = Martius.

Muxim. = Maximowicz.

Maz. = Mazzugati.

Mtd., Mtdic. $=$ Medicus.

Menyh. = Menyhárt. 
Mey. $=$ Meyer.

Mich. = Micheli.

Michal. = Michalet.

Mich $x_{0}=$ Michaux.

Miel. = Mielichhofer.

Mik. = Mikan.

Milde $=$ Milde.

Mill. $=$ Miller.

Mrich. = Mönch

Moq. = Moquin-Tandon.

Hor. $=$ Moretti.

Moric. $=$ Moricand.

Müll. = Müller.

Murb. = Murbeck.

Murr. = Murray.

Mut. = Mutel.

Mygind = Mygind.

Näg. = Nägeli.

Neck. $=$ Necker.

$N \epsilon e s=$ Nees von Esenbeck.

Neilr. $=$ Neilreich.

Nestl. = Nestler.

Neum. = Neumann.

Noë $=$ Noë.

Nutt. = Nuttall.

Nym. = Nyman.

Opiz $=0$ piz.

Orph. = Orphanides.

Pach. = Pacher.

Pall. $=$ Pallas.

Palla $=$ Palla.

Pant. $=$ Pantocsek.

Panz. = Panzer.

Parl. = Parlatore.

$P a x=$ Pax.

Pernh. = Pernhoffer.

Perp. = Perpenti.

Perr. et Song.= Perrier u. Songeon.

Pers. = Persoon.

Pet.$=$ Peter.

Piré $=$ Piré.

P. J. Müll. = P. J. Müller.

Planch. = Planchon.

P. M. E. $=$ Patze, Meyer und Elkan.

Poir. $=$ Poiret.

Poll. $=$ Pollich

Pollini $=$ Pollini.

Portschlg. = Portenschlag.

Prantl = Prantl.

Presl $=$ Presl.

Pursh $=$ Pursh.

R. $B r .=$ Robert Brown.

R. $S c h ., H_{\text {. }}$ t $S c h$. $=$ Römer und Schultes.

$R a a b=$ Raab.

Raf. = Rafinesque.

Ram. = Kamond.

Rau $=$ Rau.

Rchb. = Reichenbach.

Rechinger $=$ Rechinger.

Red. = Redouté.

Reich. = Reichard.

Retz. = Retzins.
Reut . = Reuter.

Reyn. = Reynier.

Rich. = Richard.

Richt. = Richter.

Risso $=$ Risso.

Roch. = Rochel.

Rog. = Rogowicz.

Rohde $=$ Rohde.

Rohrb. = Rohrbach.

Roth = Roth.

Rottb. = Rottböll.

Roz. = Rozier.

Röhl. = Röhling.

Röm. et $S^{\prime} c h .=$ Römer und Schultes.

Rupr. = Ruprecht.

Rylands = Rylands.

Sabr. = Sabransky.

Sadl.$=$ Sadler .

Salisb. = Salisbury.

Santi $=$ Santi.

Saut. = Sauter.

Savi $=$ Savi.

Sch. $\bar{N} . K$. = Schott, Nyman und Kotschy.

Schäff. = Schäffer.

Scheele $=$ Scheele.

Schimp. = Schimper.

Schimp. $u$. Sp. $=$ Schimper und Spenner.

Schk. = Schkuhr.

Schl. = Schleicher.

Schld., Schldl. = Schlechtendal.

Schleid. = Schleiden.

Schltz. = Schultz.

Schm. = Schmidt.

Schnizlein = Schnizlein.

Schnittsp. = Schnittspahn.

Scholl. = Scholler.

Schott $=$ Schott.

Sckönh. = Schönheit.

Schönl. = Schönlein.

Schrad. = Schrader.

Schr. = Schrank.

Schreb. = Schreber.

Schult. $=$ Schultes

Schumm. = Schummel.

Schur = Schur.

Schw. $t$ t $K$. = Schweigger und

Körte.

Scop. $=$ Scopoli.

Seb. et $M$. Sebastiani u. Mauri.

Seid. = Seidl.

Sér. = Séringe.

Sibth. = Sibthorp.

Sieb. = Sieber.

Simk. = Simonkai (Simkovics).

Sims $=$ Sims.

Sm. = Smith.

Sol. $=$ Solander.

Somm. = Sommeraner.

Sond. = Sonder.

Soy. Willm. = Soyer-Willemet.

Spach = Spach.

Spenn. = Spenner.

Spr. = Sprengel. 


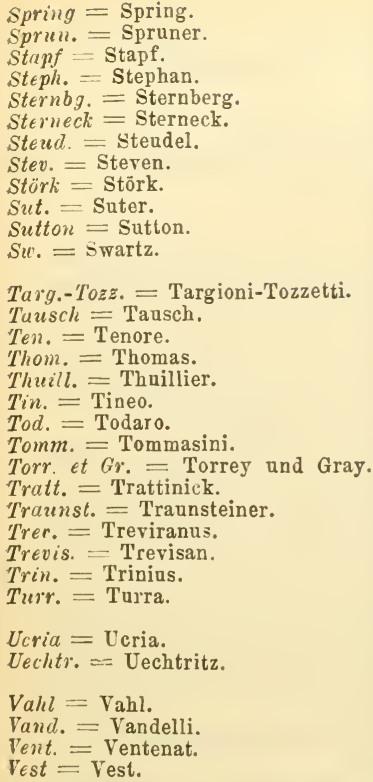

Vill. $=$ Villars.

Fis. $=$ Visiani.

Vitm. = Vitman.

Vic. = Viviani.

Vogler $=$ Vogler.

IV. $K$. $=$ Waldstein und Kitaibel.

Wahlb., Wuhlbq. = Wablenberg.

Wallr. = Wallroth.

Wartm. = Wartmann.

We $b .=$ Weber.

Weig., Wgl. = Weigel.

Weinm. = Weinmann.

Welw. - Welwitsch.

Wender. = Wenderoth.

Wettst. = Wettstein.

Wh. $=$ Weihe.

Wh. t $\boldsymbol{X}$. $=$ Weihe und Nees.

$W_{\iota} b .=$ Wibel.

Wigg. = Wiggers.

Wiesb. = Wiestaur.

Willd. = Willdenow.

Willk. = Willkomm.

Wimm. = Wimmer.

Wirtg. = Wirtgen.

With. = Withering.

Wittr. = Wittrock.

Wohlf. = Wohlfarth.

Woods $=$ Woods.

Wulf. $=$ Wulfen.

Zahlbr. = Zahlbruckner.

Zanted. = Zantedeschi.

Zauschn. = Zauschner.

Zimm. = Zimmeter.

Zucc. = Zuccarini. 


\section{Analytische Uebersicht}

der

\section{Classen des Linné'schen Pflanzensystems.}

In den Blüten der Pflanze finden sich Staubblätter und Fruchtblätter; die letzteren sind meist zu einem Fruchtknoten vereinigt. (Offenblühende 0 . Phanerogamen.) ..............................

Blüten mit Staubblättern und Fruchtblättern fehlen; die Fortpflanzungsorgane sind anders beschaffen. (Verborgenblühende 0 . Kryptogamen.)

XXIV. Cryptogamia. Verborgenblühende.

In jeder einzelnen Blüte finden sich entweder nur Staubblätter (männliche Blüte), o. nur Fruchtblätter (weibliche Blüte), also nur eingeschlechtige

2) Blüten ............................ Staubblätter und Fruchtblätter finden sich in einer und derselben Blüte vereint vor (Zwitterblüten); bisweilen kommen Zwitterblüten mit eingeschlechtigen gemischt vor .....................

Männliche und weibliche Blüten kommen auf einer und derselben Pflanze vor.

XXI. Monoecia. Einhäusige.

Männliche Blüten finden sich auf einer Pflanze, die weiblichen auf einer anderen Pflanze derselben Art. XXII. Dioecia. Zweihäusige.

Es kommen auf der Pflanze nur Zwitterblüten und keine eingeschlechtigen vor................

4 Es kommen auf der Pflanze Zwitterblüten mit eingeschlechtigen gemischt vor.

XXIII. Polygamia. Vielehige.

Die Staubblätter der Zwitterblüte sind frei. (A. und

5 Stf. sind weder untereinander, noch die A. mit der Narbe verwachsen.) .................. 9

A. 0 . Stf. der Zwitterblüte sind verwachsen....... 6

Die Stb. sind an den Griffel angewachsen; die A. stehen in der Nähe der Narben.

XX. Gynandria. Stempelständige. Die Stb. sind nicht an den Griffel angewachsen, sondern untereinander verwachsen.............

Die A. sind zu einer Röhre verwachsen, die Stf. frei. (Die Bt. sind meist zu Köpfchen zusammengestellt).

XIX. Syngenesia. Blütenverein. Die A. sind frei, die Stf. untereinander verwachsen 
( Die Stf. sind in eine Röhre oder in ein Bündel verwachsen ..... XVI. Monadelphia. Einbrüderige Die Stf. sind in 2 Bündel verwachsen, oder 9 sind verwachsen und der zehnte frei.

XVII. Diadelplia. Zweibrüderige. Die Stf. sind in mehr als \& Bündel verwachsen.

XVIII. Polyadelphia. Vielbrüderige.

In der Zwitterblïte befindet sich ein Staubblatt.

I. Monandria. Einmännige. In der Zwitterblüte befinden sich 2 freie Stb.

II. Diandria. Zweimännige. In der Zwitterblüte befinden sich 3 freie Stb.

III. Triandria. Dreimännige. In der Zwitterblüte befinden sich 4 freie Stb., alle

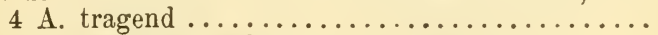
In der Zwitterblüte befinden sich 5 freie Stb., oder 10 , darunter aber 5 ohne A.

V. Pentandria. Fünfmännige.

9 In der Zwitterblüte befinden sich 6 freie Stb...... 11

In der Zwitterblüte befinden sich 7 freie Stb.

VII. Heptandria. Siebenmännige. In der Zwitterblüte befinden sich $S$ freie Stb.

VIII. Octandria. Achtmännige. In der Zwitterblüte befinden sich 9 freie Stb.

IX. Enneandria. Neunmännige. In der Zwitterblüte befinden sich 10 freie Stb.

X. Decandria. Zehnmännige. In der Zwitterblüte befinden sich $12-15$ freie Stb.

XI. Dodecandria. Zwölfmännige.

In der Zwitterblüte befinden sich 20 o. mehr freie Stb. 10

Die Stb. stehen auf dem Rande des ausgehöhiten, scheinbar eine Kelchröhre bildenden Btbodens.

XII. Icosandria. Zwanzigmännige.

Die Stb. stehen auf dem flachen o. kegelig erhöhten Btboden .......XIII. Polyandria. Vielmännige. Die 4 Stb. sind sämmtlich von gleicher Länge.

2 Stb. sind länger, 2 kürzer.

IV. Tetrandria. Viermännige.

XIV. Didynamia. Zweimächtige.

$12\left\{\begin{array}{r}\text { Die } 6 \text { Stb. sind sämmtlich von gleicher Länge. } \\ \text { VI. Hexandria. Sechsmännige. } \\ 4 \text { Stb. sind länger, } 2 \text { kürzer. } \\ \text { XV. Tetradynamia. Viermächtige. }\end{array}\right.$

Anmerkung. Man begnüge sich bei der Bestimmung nach dem Linne'schen System niemals mit der Untersuchung einer einzigen Blüte, da alle Zahlenverhältnisse, auch die Anzahl der Stb., oft an einzelnen Blüten Ausnahmen erleiden. 


\section{Die Ordnungen}

der

\section{Classen des Linné'schen Pflanzensystems.}

Bei den ersten 13 Classen werden die Ordnungen nach der Zahl der Griffel (oder, wenn der Griffel fehlt, der Narben) bestimmt. Die Namen dieser Ordnungen sind daher folgende:

1. Ordnung: 1

2. Ordnung: 2

3. Ordnung: 3

4. Ordnung: 4

5. Ordnung: 5

6. Ordnung: 6 Nehr als 6
Monogymia.

Digynia.

Griffel Trigynia.

(o. Tetragynia.

Narben). Pentagynia.

Hexagynia.

Polygynia.

Die Ordnungen der 14. und 15. Classe werden nach der Beschaffenheit der Frucht gebildet und heißen bei der 14. Classe:

1. Ordnung: Gymnospermia. Nacktsamige. (Mit 4 samigen Spaltfrüchten oder 4 steinigen Steinfrüchten.)

2. Ordnung: Angiospermia. Bedecktsamige. (Mit Kapselfrüchten, seltener Steinfrüchten, Beeren oder Schließfrüchten.)

Bei der 15. Classe:

1. Ordnung: Siliculosa. Mit Schötchen (welche höchstens 4 mal so lang als breit sind).

2. Ordnung: Siliquosa. Mit Schoten (welche mehr als $4 \mathrm{mal}$ so lang als breit sind).

Die Ordnungen der 16., 17. und 18. Classe werden nach der Zahl und der Anheftung der Stb. gebildet, eben so wie die Classen 1-13.

Die Ordnungen der 19. Classe bestimmt man nach dem Geschlechte und der Gestalt der einzelnen Blüten:

1. Ordnung: Polygamia aequalis. Bt. in Köpfchen, alle zwittrig und fruchtbar, dabei röhrig o. zungenförmig.

2. Ordnung: Polygamia superflua. Bt. in Köpfchen, die mittleren zwittrig u. fruchtbar, röhrig, die randständigen weiblich und ebenfalls fruchtbar, zungenförmig o. röhrig. 3. Ordnung: Potygomia frustranea. Bt. in Köpfchen, die mittleren zwittrig u. fruchtbar, die randständigen weiblich, aber unfruchtbar. 
4. Ordnung: Polygamia necessaria. Bt. in Köpfehen, die mittleren zwittrig, aber unfruchtbar, die randständigen weiblich u. fruchtbar.

5. Ordnung: Polygamia segregata. Bt. in Köpfchen, jede mit besonderer Hülle.

6. Ordnung: Monogamia. Bt. mit deutlich entwickeltem Kelch, meist nicht in Köpfehen.

Die Ordnungen der 20.-23. Classe werden nach der Zahl und Anheftung der Stb., so wie deren Verwachsung gebildet, und erhalten dieselben Namen wie die Classen $1-13$ und $16-19$.

Von den Ordnungen der 24. Classe ist nur die 1. Ordnung Filices (Pteridophyten, Farnpflanzen) in diesem Buche enthalten. 


\title{
Analytischer Schliissel
}

\author{
zur \\ Bestimmung der Pflanzengattungen \\ nach dem Liuné'schen System.
}

Anmerkung. Unterscheidende Merkmale der Pflanzen, die ihre Blüte, Blätter, das äußere Ansehen u. s. w. betreffen, sind meist ohne Schwierigkeiten erkennbar. Doch werden bisweilen auch minder augenfällige angeführt, die sich auf die Beschaffenheit der Frucht oder Fruchtanlage beziehen. Finden sich in einem solchen Falle an der zu bestimmenden Pflanze noch keine Früchte vor, so untersuche man mittelst einer guten Lupe einen der Quere, und einen der Länge nach durchschnittenen Fruchtknoten, und man wird die Anzahl der Fächer, die Zahl und Anheftung der Samenknospen u. s. w. selbst bei kleineren Pflanzen recht gut unterscheiden können.

I. Classe. MONANDRIA. In jeder Zwitterblüte nur e in Staubblatt.

1. Ordnung. Monogynia. Griffel (o. Narbe) 1.

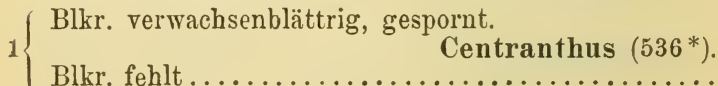

$2\{$ B. quirlständig.............. Hippuris (394).

B. nicht quirlständig, oft fehlend $\ldots \ldots \ldots \ldots \ldots \ldots, 3$

Stg. blattartig verbreitert, klein, gegliedert, im Wasser

3 schwimmend 0 . etwas untergetaucht $\ldots \ldots \ldots \ldots, 4$

Stg. nicht blattartig .................... 5

$4\left\{\begin{array}{l}\text { Stgglieder mit einem Büschel von Wurzeln. } \\ \text { Spirodela (98). }\end{array}\right.$

Jedes Stgglied nur mit einer Wurzel. Lemna (98). $5\left\{\begin{array}{l}\text { Stg. gegliedert, blattlos............................... } 6 \\ \text { Stg. nicht gegliedert; B. handförmig getheilt. }\end{array}\right.$

Alchemilla (297).

*) Die in Klammern stehenden Zahlen hinter den Gattungsnamen verweisen auf jene Seite dieses Buches, auf der man den Schlüssel zur Bestimmung der Arten der betreffenden Gattung findet. 
(Bt. zu 3 verwachsen; S. ohne Nährgewebe.

$6\{$ Salicornia (183).

Bt. frei; S. mit Nährgewebe. Arthrocnemum (183).

2. Ordnung. Digynia. Griffel (o. Narben) 2 .

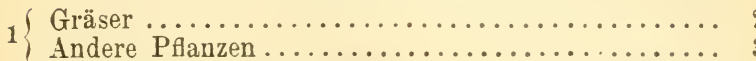

${ }_{2}\{$ Aehrchen $1-2$ blütig .............. Psilurus (72).

$2\{$ Aehrchen mehrblütig ........... Vulpia (68).

$3\{$ Wasserpfl. mit gegenständigen B. Callitriche (364).

$3\{$ Landplanzen ....................... 4

$4\{$ Stg. gegliedert, blattlos $\ldots \ldots \ldots \ldots \ldots \ldots \ldots \ldots \ldots \ldots$

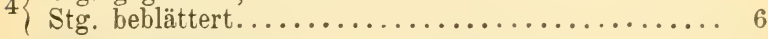

( Bt. zu 3 verwachsen; S. ohne Nährgewebe.

5 Salicornia (183).

Bt. frei; S. mit Nährgewebe. Arthrocnemum (183).

B. 3 eckig, spie§förmig o. länglich-eiförmig, gezähnt;

6 Bt. geknäuelt........... Chenopodium (179).

B. lineal o. pfriemlich, ganzrandig ..............

( Bthülle 5 blättrig...........Polycnemum (179).

7 Bthülle aus wenigen ungleichen Schüppchen gebildet o. fehlend............. Corispermum (183).

II. Classe. DIANDRIA. In jeder Zwitterblüte 2 freie Staubblätter.

1. Ordnung. Monogynia. Griffel (o. Narben) 2.

1 Gras- o. binsenartige Gewächse, o. Wasserpflanzen 1 mit unscheinbaren Bt. ohne deutliche Bthülle ... Pfl. von anderer Beschaffenheit ............. 5

( Kleine Wasserpflanzen mit blattähnlichem, geglie$2\left\{\begin{array}{c}\text { dertem Stg., ohne deutliche B.................. } \\ \text { Wasserpfl. mit borstenförmigen B., gras- } 0 \text {. binsen- }\end{array}\right.$ artige Gewächse ........................ 
$6\left\{\begin{array}{l}\text { Blkr. mit verlängerter Röhre und } 5-8 \text { Zipfeln. } \\ \text { Blkr. bis zum Grunde } 3-4 \text { theilig o. fehlend. } \\ \text { Fraxinus (440). }\end{array}\right.$

${ }_{7}\{$ Blkr. unregelmäßig, gespornt ............ 8

$7\{$ Blkr. nicht gespornt, oft fehlend........... 9

$\int \begin{array}{r}\text { B. ungetheilt, in grundständigen Rosetten; K. } 5 \text { theilig. } \\ \text { Pinguicula (511). }\end{array}$

8 B. im Wasser untergetancht, in haarförmige Zipfel getheilt; K. 2 blättrig ........ Utricularla (512).

$9\{$ Stg. blattlos, gegliedert ............... 10

$9\{$ B. stets deutlich entwickelt............... 11

$10\left\{\begin{array}{l}\text { Bt. zu } 3 \text { verwachsen; S. ohne Nährgewebe. } \\ \text { Salicornia (183). } \\ \text { Bt. frei; S. mit Nährgewebe. Arthrocmemum (183). }\end{array}\right.$

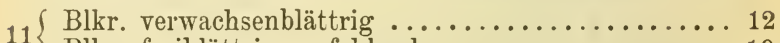

$11\{$ Blkr. freiblättrig 0 . fehlend . . . . . . . . . . 19

$12\{$ Frkn. 1, 1-3- (meist 2-) fächerig .............. 13

$12\{$ Frkn. 4, o. ein 4 fächeriger, 4lappiger Frkn. ..... 17

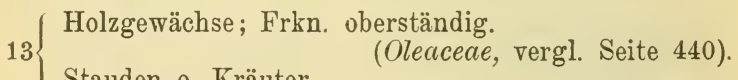

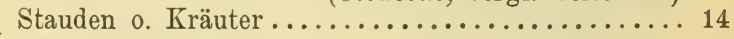

$14\left\{\begin{array}{l}\text { Frkn. oberständig } \ldots \ldots \ldots \ldots \ldots \ldots \ldots \ldots \ldots \ldots \ldots \ldots \\ \text { Frkn. unterständig; } ; \text { jährige Kräuter. } \\ \text { Valerianella (533). }\end{array}\right.$

$15\{2$ fruchtbare u. 2 unfruchtbare Stf. vorhanden; N.

Nur 2 Stb. vorhanden ......................... 16

$16\left\{\begin{array}{l}\text { Stb. über dem Grunde der Blkrröhre eingefügt. } \\ \text { Veronica (495). }\end{array}\right.$

Stb. im obersten Theil der Blkrröhre eingefügt.

Wulfenia (500).

$17\left\{\begin{array}{l}\text { Blkr. trichterförmig, } 4 \text { spaltig, fast regelmäßig. } \\ \text { Lycopus }(480) \text {. }\end{array}\right.$

(Blkr. rachenförmig, unregelmäßig ............ 18

$18\left\{\begin{array}{l}\text { Stf. über dem Grunde mit einem Zahne. } \\ \text { Rosmarinus }(468) . \\ \text { Stf. zahnlos ................ Salvia (475). }\end{array}\right.$

$19\{$ K. u. Blkr. vorhanden .................. 20

Bthülle einfach 0 . fehlend, bezw. die Blkr. fehlend 21

$\int$ Frkn. frei am Grunde des ausgehöhlten Btbodens 20 sitzend; Bt. blattachselständig .. Lythrum (388). Frkn. unterständig; Bt. in Trauben. Circaea (393). 
Bthülle 4 spaltig, aber durch Vorhandensein eines
Außenkelches scheinbar 8 spaltig.

Bthülle 1-5blättrig, ohne Außenk.

Alchemilla (297).

Untere B. fiedertheilig; Bthüllb. (Kb.) 4.

Alle B. ungetheilt, höchstens eingeschnitten-gezähnt

B. 3 eckig o. spießförmig, gezähnt; Bthüllb. meist 5 .

B. Chenopodium (179).

B. lineal, ganzrandig; Bthüllb. 1-3, oft fehlend.

Corispermum (183).

2. Ordnung. Digynia. Griffel (o. Narben) 2 .

Gräser (Arten der Gattungen Coleanthus, Crypsis, Imperata, Anthoxanthum, Hierochloa, Bromus und andere, zu deren Bestimmung die Tabelle auf Seite 34 dient).

Kräuter o. kleine Sträucher mit gegliedertem,

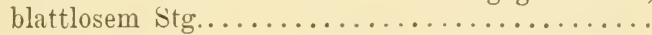

$2\{$ Bt. zu 3 verwachsen; S. ohne Nährgewebe.

Bt. frei; S. mit Nährgewebe. Arthrocnemum (183).

4. Ordnung. Tetragynia. Griffel (o. Narben) 4 . Hieher zuweilen die Gattung Ruppia (29).

III. Classe. TRIANDRIA. In jeder Zwitterblüte 3 freie Staubblätter.

1. Ordnung. Monogynia. Griffel (o. Narbe) 1 .

1) Frkn. unterständig . .................. 2

1 Frkn. oberständig o. die Bthülle fehlt ganz...... 5

Bt. mit unscheinbarem K. u. verwachsenblättriger

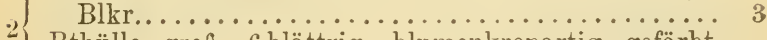

Bthülle groß, 6 blättrig, blumenkronartig gefärbt. (Irideae, vergl. Seite 120).

$3\{$ Blkr. 3 spaltig; die unteren B. wirtelig gestellt.

Blkr. 5 spaltig; Asperula (523).

Stauden; Fr. mit einer Haarkrone. Valeriana (534).

41 jährige, gabelig verzweigte Kräuter; Fr. ohne Haarkrone ............ Valerianella (533).

s! K. 2 blättrig; Blkr. weiळ ........... Montia (186).

5 , Bthülle einfach 0 . fehlend $\ldots \ldots \ldots \ldots \ldots \ldots \ldots \ldots .6$

Fritsch, Excursionsflora. 
( Bthülle deutlich entwickelt, $5-6$ blättrig ........

6 Bthülle fehlend o. nur durch Schüppchen 0. Borsten angedeutet; Bt. von Spelzen umgeben .......... Bthüllb. 5; 1 jährige Kräuter mit spindeliger 7 Hauptwz.; Bt. in den Blattachseln.

Polycnemum (179). Bthüllb. 6; gras- o. binsenartige Pfl. Juncus (99). Bt. in einblütigen Aehrchen, diese in einseitswendiger Achre; B. zweizeilig gestellt, mit gespaltenen Bscheiden .................... Nardus (71). Btstände anders beschaffen; B. dreizeilig gestellt; Bscheiden nicht gespalten.

(Cyperaceae, vergl. Seite 76).

2. Ordnung. Digynia. Griffel (o. Narben) 2 .

Gräser; Bthülle fehlend o. verkümmert; Bt. von Spelzen umgeben, Aehrchen bildend.

(Gramineae, vergl. Seite 34).

Bthülle deutlich entwickelt (wenn fehlend, dann die

Pfl. nicht grasähnlich) .

${ }_{2}\{$ Bthüllb. $1-5$, selten fehlend .............. 3

2 Bthüllb. 6 ; gras- o. binsenartige Pfl. Juncus (99).

$3\{$ B. sehr schmal, lineal o. pfriemlich ........... 4

3 B. mehr o. weniger breit, die unteren niemals lineal 5

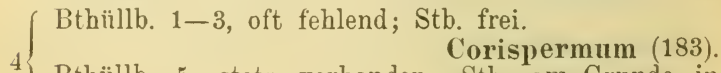

4 Bthüllb. 5, stets vorhanden; Stb. am Grunde in einen Ring verwachsen .....Polycnemum (179).

$5\left\{\begin{array}{l}\text { Bt. von einem Deckb. u. } 2 \text { Vorb. gestützt. } \\ \text { Bt. deckblattlos............ Chenarantus (184). }\end{array}\right.$

3. и. 4. Ordnug. Trigynia und Tetragynia. Griffel (o. Narben) $3-4$.

${ }_{1}$ Aestiger, kahler Strauch mit lederigen B. und gelb-

lichen Bt................... Osyris (170).

Kräuter 0 . Stauden .................... 2

I. 2 theilig 0. 2 blättrig; Blkr. 3 blättrig 0.5 spaltig 3

$2\{$ K. $3-5$ blättrig o. überhaupt nur eine einfache Bthïlle vorhanden ................... 4

$3\left\{\begin{array}{l}\text { Blkr. trichterförmig, auf einer Seite gespalten, ihr } \\ \text { Saum 5spaltig ............... Montia (186). }\end{array}\right.$ Blkr. 3 blättrig ................. Elatine (377).

${ }_{4}$ Bthüllb. 6, die 3 inneren manchmal blumenkron-

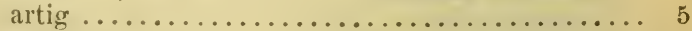

Bthüllb. $3-5$ o. Kb. u. Kıb. je $5 \ldots \ldots \ldots \ldots \ldots$. 6 
(Wasserpfl. mit wirteligen B.; die inneren Bthüllb. Gras- o. binsenartige Pfl.; alle Bthüllb. trockenhäutig.................... Juncus (99).

B. mit trockenhäutigen Nebenb.; kleine, einjährige

6 Kräuter .................. Polycarpon (208).

Nebenb. fehlen .......................... 7

$7\{$ Krb. ausgerandet 0 . fehlend ............... \&

7 Krb. ungetheilt, stets vorhanden..$\ldots \ldots \ldots \ldots$. 9

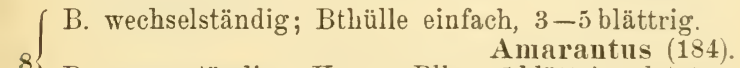

8 B. gegenständig; K. u. Blkr. 5 blättrig, letztere manchmal fehlend ............ Stellaria (199).

Gr. 3 (nur ausnahmsweise $4-5$ ) ............ 10

9 Gr. 4(-5); Kapsel an der Spitze 8(-10)zähnig;

1 jährige, kahle Kräuter.........Moenchia (202).

Kapsel mit 3(-5) ungetheilten Klappen aufspringend.

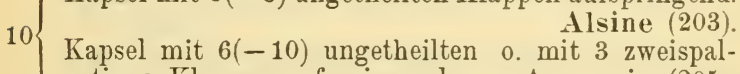
tigen Klappen aufspringend..... Arenaria (205 .

IV. Classe. TETRANDRIA. In jeder Zwitterblüte

4 freie, gleichlange Staubblätter.

1. Ordnung. Monogynia. Griffel (o. Narbe) 1.

$1\{$ Bthülle einfach....................... 2

$1\{$ K. u. Blkr. vorhanden .................... 9

$2\{$ Frkn. unterständig...................... 3

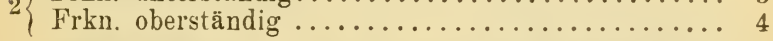

(Bthülle kelchartig; B. gegenständig. Ludwigia (390).

3 Bthülle innen weiß gefärbbt; B. schraubig gestellt.

Thesium (170).

$4\{$ Baum mit schülferigen B........Elaeagnus (387).

Kräuter 0. Stauden ...................... 5

5

Bthüllb., da ein Außenk. vorhanden ist, scheinbar 8.

Bthüllb. Alchemilla (297).

$6\{$ B. gefiedert .............. Sanguisorba (299).

B. ungetheilt........................... 7

B. schmal, pfriemlich; Bt. unscheinbar.

B. breit, nicht pamphorosma (183).

B. breit, nicht pfriemlich..............

B. herzförmig; Bt. weiß, in einer Traube.

Majanthemum (116).

B. nicht herzförmig; Bt. grünlich, in Knäueln.

Parietaria (168). 
Btköpfchen mit reichblättriger Hülle; K. doppelt, der innere zuletzt an die Fr. angewachsen; Blkr. verwachsenblättrig. (Zur Bestimmung der hierher gehörigen Gattungen aus der Familie der Dipsaceen dient der Schlüssel auf Seite 536.)

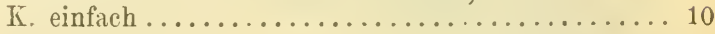

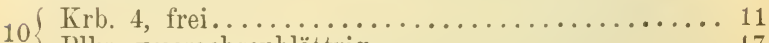

Blkr. verwachsenblättrig $\ldots \ldots \ldots \ldots \ldots \ldots \ldots \ldots 17$

$11\{$ Holzgewächse .................... 12

$11\{$ Kränter 0 . Stauden .................... 14

12 Stb. zwischen den Krb. stehend............. 13

$12\{$ Stb. vor den Krb. stehend .......Rhamnus (370),

13 . Frkn. unterständig; Steinfr. ........ Coruus (424).

13 Frkn. oberständig; Kapselfr..... Evonymus (367).

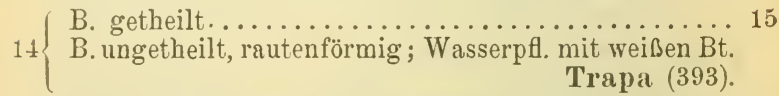

(B. doppelt 3 zählig; Blkr. blutroth, Nebenkrone gelb.

15 B. fiederschnittig o. fiedertheilig Epimedium (227).

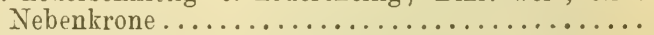

f Fr. lineal, flach, aufspringend .. Cardamine (244).

$16 \mathrm{Fr}$. nierenförmig, nicht aufspringend.

17 Frkn. unterständig .................. 18 Coronopus (237).

Frkn. oberständig . . . . . . . . . . . . . . 19

( B. wirtelig gestellt; Stauden o. Kräuter (Rubiaceae, 18 vergl. Seite 522).

B. gegenständig; kleiner Strauch... Linuaea (531). Frkn. 4, 0. ein 4 fächeriger, 4 lappiger Frkn. (Hieher 19 einige Labiaten, zu deren Bestimmung der Schlüssel auf Seite 463 dient.)

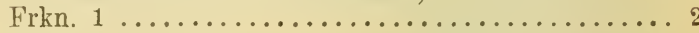

(Bt.gelb; kleines 1 jähriges Kraut mit gegenständigen

20 B. .................... Microcala. (442). Bt. niemals gelb .................... 21

( Blkr. trockenhäutig, mit zurückgebrochenem Saume. 21 Plantago (519).

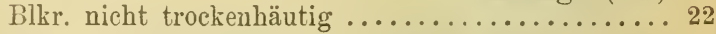

${ }_{22}$ Bt. in Köpfehen, blau o. violett; Blkr. unregel22 mäßig, 3-5 spaltig ......... Globularia. (518). Bt. nicht in Köpfchen ................ 23 ${ }_{23}$ Sehr kleine, 1 jährige Kräuter mit sehr kleinen, 23 weißen 0 . röthlichen Bt. ................ 24 Ansehnlichere Pfl. o. kleine Pfl. mit auffallenden Bt. 26 
$24\left\{\begin{array}{c}\text { B. u. Btstiele grundständig; Blkr. glockig-radförmig. } \\ \text { Limosella (495). }\end{array}\right.$

Stg. beblättert; Bt. blattachselständig ......... 25

25 B. gegenständig; Blkr. 2 lippig... Lindernia (495).

25 B. wechselständig; Blkr. krugförmig, mit 4 spaltigem Saume.............. Centunculus (438).

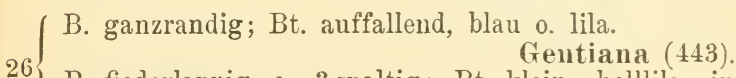
B. fiederlappig o. 3 spaltig; Bt. klein, helllila, in verlängerten Aehren......... Verbena (463).

2. Ordnung. Digynia. Griffel (o. Narben) 2.

( Blattlose, kletternde Schmarotzerpfl. mit wei@en,

1 röthlichen 0 . gelblichen Bt....... Cuscuta (451). Beblätterte Pfl......................

2\{ Holzgewächse; Fr. geflügelt .........Ulmus (166). Stauden 0. Kräuter ..................... 3

$3\{$ K. u. Blkr. vorhanden, letztere verwachsenblättrig . 4

3 Bthülle einfach 0. an Stelle der Blkr. nur Borsten 5

4 Frkn. oberständig (Gentianaceae, vergl. Seite 441).

4 Frkn. unterständig (Rubiaceae, vergl. Seite 522).

$\int_{5}$ Bthülle durch Aushöhlung des Btbodens scheinbar

5 verwachsenblättrig $\ldots \ldots \ldots \ldots \ldots \ldots \ldots \ldots \ldots$ Bthülle deutlich freiblättrig ............... 7

B. gefiedert.............. Sanguisorba (274).

6 B. ungetheilt 0 . fingerförmig getheilt.

Alchemilla (297).

Pfl. am Boden niedergestreckt; B. klein, ganzrandig; an Stelle der Krb. 5 Borsten... Herniaria (208). Meist größsere Pfl; Blkr. ganz fehlend.

Chenopodium (179).

3. Ordnung. Trigynia. Griffel (o. Narben) 3 .

$1\{\mathrm{~K}$. verwachsenblättrig .............. Silene (191).

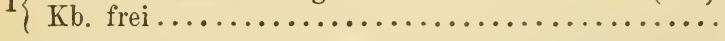

$2\{$ Krb. ausgerandet 0 . fehlend........Stellaria (199).

$2\{$ Krb. ungetheilt, niemals fehlend.. Arenaria (205).

4. Ordnung. Tetragynia. Griffel (o. Narben) 4.

$1\{$ Holzgewächse mit immergrünen B. .... Ilex (366).

Stauden 0. Kräuter .......................

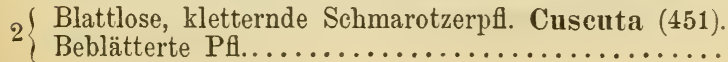


(Wasserpfl. mit unscheinbaren Bt.; Bthülle fehlend

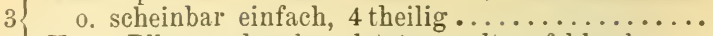

K. u. Blkr. vorhanden, letztere selten fehlend .....

${ }_{4}$ Bthülle scheinbar 4 theilig; Frkn. sitzend.
Potamogeton (27).

Bthülle fehlt; Frkn. gestielt........Ruppia (29).

5 Blkr. verwachsenblättrig . . . . . . . . . . . .

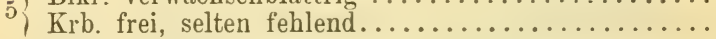

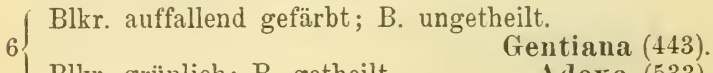

(Blkr. grünlich; B. getheilt ........ Adoxa (533).

$7\left\{\begin{array}{l}\text { Die Zipfel des } 4 \text { spaltigen K. 2-3 spaltig; Frkn. } \\ \text { Sfächerig; sehr kleines Kraut.... Radiola (352). }\end{array}\right.$

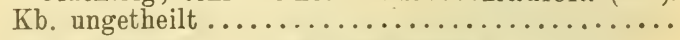

$\int_{8}$ Bt. doldig; Krb. ausgebissen-gezähnt.

Bt nicht doldig.

$9\{$ Kapseln 4 .............. Crassula (263).

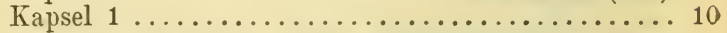

$\int$ Gr. vor den Krb. stehend; Kapsel 4(-5)klappig

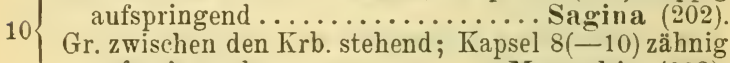

Gr. zwischen den Krb. stehend; Kapsel 8(-10) zähnig aufspringend ............. Moenchia (202).

V. Classe. PENTANDRIA. In jeder Zwitterblüte 5 freie Staubblätter.

1. Ordnung. Monogynia. Griffel (o. Narbe) 1.

1 Bthülle einfach, o. die Krb. faden- o. borstenförmig

$1\{$ K. u. Blkr. vorbanden, letztere normal entwickelt..

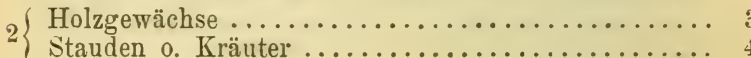

$3\{$ B. gefiedert, lederig........... Ceratonia (314).

$3\{$ B. ungetheilt, schülferig.......... Elaeagnus (387).

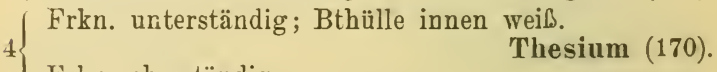

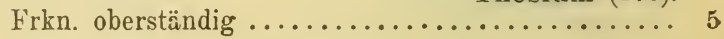

$5\{$ Krb. faden- o. borstenförmig.............. 6

Krb. ganz fehlend .................. 8

Kb. verdickt, von der Seite her zusammengedrückt,

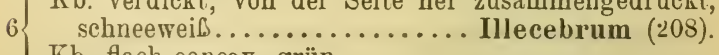

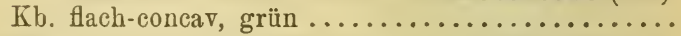

$\int \begin{aligned} & \text { Bt. in endständigen Köpfchen mit großen, trocken- } \\ & \text { häutigen, silberweißen Deckb. Paronychia (208). }\end{aligned}$ Bt. in blattwinkelständigen Knäueln.

Herniaria (208). 
Am Grunde jedes B. eine häutige Nebenbscheide; Bthülle meist blumenkronartig gefärbt. Polygonum (176).
heinbar, grürlich; Nebenb. fehlen; Bthülle unscheinbar,
1jährige Kräuter mit pfriemlichen B.

Polycnemum (179).

Krb. frei 0 . an der Spitze zusammenhängend..... 10

9 Krb. wenigstens am Grunde untereinander ver-

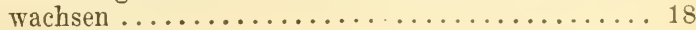

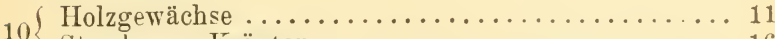

Stauden 0. Kräuter .................. 16

$11\left\{\begin{array}{r}\text { B. gefingert-ə̌ zählig; Klettersträucher. } \\ \text { Parthenocissus (371). }\end{array}\right.$

B. ungetheilt 0 . nur gelappt............... 12

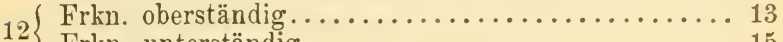

Frkn. unterständig.................... 15

Krb. an der Spitze zusammenhängend; Kletter13 stıäucher mit Panken ............ Vitis (371). Krb. ganz frei; nicht kletternde Holzgewächse ohne Ranken..........................

Stb. mit den Krb. abwechselnd.. Evonymus (367).

14 Stb. vor den Krb. stehend. (Rliamnaceac, vergl. Seite 369).

Mittels Haftwurzeln kletternder Strauch; Bt. in 15 Dolden................. Hedera (394). Aufrechte Sträucher; Bt. in Trauben o. einzeln (selten 2-3 beisammen)......... Ribes (271).

Bt. weiß, regelmäßig; zwischen den Stb. 2 drüsig$16\left\{\begin{array}{l}\text { gewimperte Schuppen ........... Parnassia (271). } \\ \text { Bt. unregelmäßig, gespornt; keine Schuppen zwischen }\end{array}\right.$

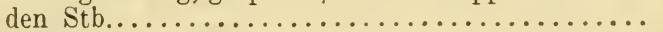

Kb. meist 3, das obere gespornt; Krb. scheinbar 3.

17 Impatiens (369). Kb. 5, mit Anhängseln; Krb. 5, das unterste gespornt ................... Viola (380).

$18\{$ Frkn. halb o. ganz unterständig. ........... 19

Frkn. oberständig.................... 22

(Holzgewächse; Blkr. unregelmäßig. Lonicera (531).

19 Stauden 0. Kräuter; Blkr. regelmäßig o. nur wenig unregelmäßig..................... 20.

$20\{$ B. schraubig gestellt, die untersten oft rosettig.... 21

B. wirtelig angeordnet (Rubiaceae, vergl. Seite 522). 
Außer den 5 fruchtbaren Stb. noch 5 verkümmerte

21 vorhanden; Frkn. halb unterständig.

Nur 5 Stb. vorhanden; Frkn. vollkommelus (437). ständig (Campanulaccae, vergl. Seite 542).

$22\left\{\begin{array}{l}\text { Frkn. } 1 \ldots \ldots \ldots \ldots \ldots \ldots \ldots \ldots \ldots \ldots \ldots \ldots \ldots \ldots \\ \text { Frkn. } 20.4, \text { aber nur } 1 \text { Gr. } 0.13 \ldots \ldots \ldots \ldots \ldots\end{array}\right.$

${ }_{23}\left\{\begin{array}{l}\text { Kletternde Schmarotzerpfl. ohne grüne B. } \\ \text { Cuscuta (451). }\end{array}\right.$

Beblätterte Pfl. ....................... 24

Frkn. 1 fächerig, mit einer Samenknospe.

24 Plumbago (439).

Frkn. 1 fächerig mit 2 o. mehr Samenknospen, o. 2bis mehrfächerig .........................

$25\{$ Frkn. 3 fächerig (Polemoniaceae, vergl. Seite 452).

Frkn. 1-2 fächerig, selten unvollständig 4 fächerig 26

${ }_{26}$ Stb. vor den Zipfeln der Blkr. stehend (Primula-

(Stb. zwischen den Zipfeln der Blkr. stehend.......

$27\left\{\begin{array}{c}\text { Frkn. 1-2 fächerig, mit } 4 \text { Samenknospen; Blkr: } \\ \text { trichterig-glockig, } 5 \text { faltig.................. }\end{array}\right.$ Frkn. mit zahlreichen Samenknospen ........... 29

K. von 2 großen Vorb. eingeschlossen; Narbenlappen

$28\left\{\begin{array}{l}\text { groß, flach .................. Calystegia (451). } \\ \text { K. nicht von Vorb. eingeschlossen; Narbenlappen }\end{array}\right.$ fädlich 0 . keulenförmig..... Convolvulus (451). $29\left\{\begin{array}{l}\text { B. entweder ungetheilt und gegenständig (o. nahezu } \\ \text { gegenständig), o. dreizählig und schraubig gestellt } \\ \text { (Gentianaceae, vergl. Seite 441). }\end{array}\right.$ (Gentianaceae, vergl. Seite 441).

B. schraubig gestellt, niemals 3 zählig ......... 30

A. dem spitzen Ende des Stf. aufliegend, 2 fächerig (Solanaceae, vergl. Seite 484).

30 A. quer 0. schief auf das verbreiterte Ende der Stf. gestellt; große Kräuter 0. Stauden mit radförmiger o. etwas trichteriger Blkr.... Verbascum (490).

B. meist schraubig gestellt; Fr. nicht aufspringend; 31 Pfl. meist rauhhaarig, selten kahl (Borragineae, vergl. Seite 453).

B. gegenständig 0. wirtelig; Fr. aufspringend .... 32

( B. wirtelig (meist zu 3); Holzgewächse mit großen, 32 rosenrothen (selten weißen) Bt... Nerium (449). B. gegenständig; Stauden 0. Halbsträucher....... 33

Bt. einzeln, ansehnlich, meist blau; S. ohne Haar$33\left\{\begin{array}{l}\text { schopf....................... Vinca (449). } \\ \text { Bt. in doldigen, trugdoldigen o. rispenartigen Bt- }\end{array}\right.$ ständen, niemals blau; S. mit Haarschopf ....... 34 
$34\left\{\begin{array}{l}\text { Stf. frei, A. auf der N. liegend; Bt. rosa, in rispen- } \\ \text { artigen Btständen............ Apocynum (449). } \\ \text { Stf. in eine Röhre rerwachsen (Asclepiadeae, vergl. } \\ \text { Seite 450). }\end{array}\right.$

2. Ordnung. Digynia. Griffel (o. Narben) 2.

1 Holzgewächse $\ldots \ldots \ldots \ldots \ldots \ldots \ldots \ldots \ldots \ldots$.

$1\{$ Stauden 0. Kräuter.................... 4

B. ungetheilt $\ldots \ldots \ldots \ldots \ldots \ldots \ldots \ldots \ldots \ldots \ldots$

2 B. gefiedert, gegenständig; Bt. hängend, wei 0. etwas röthlich ............. Staphylea (367).

3) Bthülle einfach (Ulmaceae, vergl. Seite 165).

$3\{$ K. u. Blkr. vorhanden ........... Zizyphus (370).

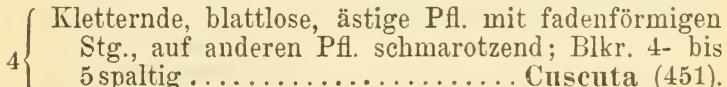

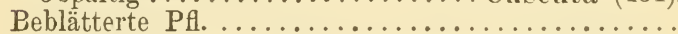

(Zwischen den $5 \mathrm{~Kb}$. stehen 5 sehr kleine pfriemliche

5 Außenkb.; Krb. gelb; Staude mit gefiederten B.

Bthïll Aremonia (298).

Frkn. unterständig; Bt. in zusammengesetzten Dol-

6 den, selteuer in einfachen Dolden 0. Köpfchen

(Umbellifercae, vergl. Seite 395).

Frkn. oberständig ................. 7

7 K. u. Blkr. normal entwickelt ........... 8

7 Bthülle einfach 0 . die Krb. fadenförmig ........ 13

\& Blkr. verwachsenblättrig . .............. 9

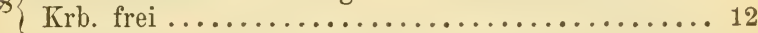

g Frkn. 2, mit gemeinschaftlicher Narbe ......... 10

\{ Frkn. 1, mit 2 gegenständigen Samenträgern ..... 11

( Stf. frei, A. auf der N. liegend; Bt. rosa, in rispen-

10 artigen Btständen ......... Apocynum (449).

Stf. in eine Röhre verwachsen (Asclepiadecie, vergl. Seite 450).

Blkr. radförmig, tief-5 spaltig, mit sehr kurzer Röhre u. 2 gefransten Schuppen 0. Honiggruben am

11 Grunde jedes Zipfels..........Sweertia (448).

Blkr. mit mehr o. wenig verlängerter Röhre (selten radförmig mit kurzer Röhre, dann aber ohne Schuppen u. Honiggruben) .....Gentiana (443).

$12\left\{\begin{array}{l}\text { K. verwachsenblättrig; Nebenb. fehlen. } \\ \text { Gypsophila (195). }\end{array}\right.$

Kb. frei; B. mit häutigen Nebenb.

Polycarpon (208). 
13) Krb. fadenförınig $\ldots \ldots \ldots \ldots \ldots \ldots \ldots \ldots \ldots \ldots$

13) Bthülle einfach .................... 16

( Kb. verdickt, von der Seite her zusammengedrückt, 14 schneeweif............. Illecebrum (208).

Kb. flach-concav, grün ................ 15

(Bt. in endständigen Köpfchen, mit großen, silber15 weißen, häutigen Deckb. ....P.Paronychia (208). Bt. in blattachselständigen Knäueln.

Herniaria (208).

$\int$ Am Grunde der B. befinden sich am Stg. häutige 16 Nebenbscheiden; Bthülle meist blumenkronartig gefärbt...............Polygonum (176). Nebenb. fehlen; Bthülle kelchartig, meist grünlich. 17 Kleine Pfl. mit gegenständigen, halbstielrund-pfriemlichen B.; Bthüllb. grün, weiß berandet.

B. schraubig gestellt, verschieden gestaltet (Chenopodiaceae, vergl. Seite 178).

3. Ordnung. Trigynia. Griffel o. Narben 3.

1) B. fiederschnittig, gefiedert 0.3 zählig ........ 2

$1\{$ B. ungetheilt ...................... 4

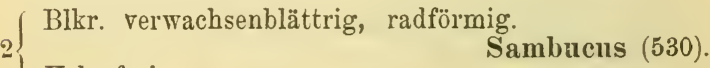

Krb. frei

Bt. ansehnlich, weis o. etwas röthlich, hängend; Fr. 3 groß, aufspringend ........... Staphylea (367).

3 Bt. klein u. unscheinbar, nicht hängend; Fr. klein, nicht aufspringend ............ Rhus (366).

$4\{$ Holzgewächse $\ldots \ldots \ldots \ldots \ldots \ldots \ldots \ldots \ldots \ldots \ldots \ldots$

$4\{$ Kräuter, Stauden o. Halbsträucher ........... 8

B. sehr klein, schuppenförmig; Bt. klein, hellrosa 5 (selten weiß), in Aehren 0. Trauben; S. mit Haal'Bt. normal entwickelt; S. ohne Haarschopf ....... f Blkr. verwachsenblättrig, radförmig; B. gegenständig. Viburnum (531).

Zweige dornig; Fr. groß, geflügelt. Paliurus (370).

7 Zweige wehrlos; Fr. klein, nicht geflügelt.

Cotinus (366).

Alle B. grundständig, rosettig, mit langen rothen

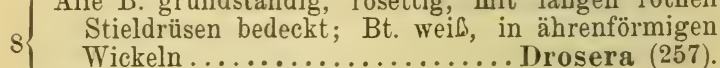

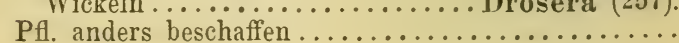


K. röhrig, 5 zähnig; starre Pfl. mit pfriemenförmigen, 9 stechenden B.............. Drypis (195). Alle B. der Bthülle frei.................. 10

Stb. am Grunde in einen Ring verwachsen, zwischen 10 ihnen 5 zahnförmige Staminodien; Blkr. verschieden gefärbt............. Linumı (352).

Stb. frei ; Blkr. weis o. fehlend .............. 11

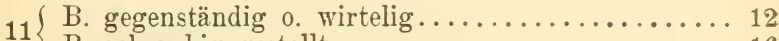

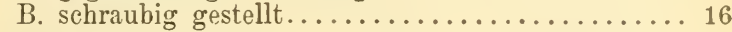

$12\{$ B. mit trockenhäutigen Nebenb. Polycarpon (208).

Krb. vorne ausgebissen-gezähnelt; Bt. in einer

13 Scheindolde............. Holosteum (202).

Krb. ganzrandig o. vorne ausgerandet o. 2 spaltig, manchmal fehlend................. 14

(Kapsel mit 3 Klappen aufspringend; Krb. ganzrandig, selten fehlend........... Alsine (203). Kapsel mit 6 Klappen 0 . Zähnen aufspringend; Krb. 2 spaltig 0 . ausgerandet, selten fehlend ........ $15\left\{\begin{array}{c}\text { Kapsel kugelig o. eiförmig, ihre Klappen bis über } \\ \text { die Hitte reichend............. Stellaria (199). }\end{array}\right.$ Kapsel cylindrisch 0 . kegelig-cylindrisch, mit 6 kurzen Zähnen aufspringend......... Cerastium (200).

16) K. u. Blkr. vorhanden ................ 17

$16\{$ Bthülle einfach ........................ 18

17 springend ............. Telephium (207). N. 3, sitzend; Fr. 1 samig, nicht aufspringend.

Corrigiola (208).

Am Grunde der B. befinden sich häutige Nebenbscheiden; Bthülle meist blumenkronartig gefärbt.

Polygonum (176).

Nebenb. fehlen; Bthülle kelchartig, meist grünlich.

Amarantus (184).

4. Ordnung. Tetragynia. Griffel (o. Narben) 4 .

$1\{$ Holzgewächse; B. gefiedert o. 3 zählig. Rhus (366).

$1\{$ Stauden 0. Kräuter mit ungetheilten B......... 2

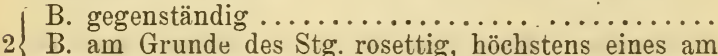

. am Grunde des Stg. rosettig, höchstens eines am

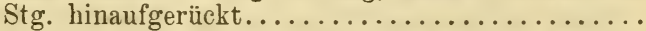

$\left\{\begin{array}{l}\text { Gr. vor den Krb. stehend; Kapsel bis zum Grunde } \\ 4 \text { klappig aufspringend ............. Sagina (202). }\end{array}\right.$ Gr. zwischen den Krb. stehend; Kapsel an der Spitze mit 8 Zähnen aufspringend ... Moenchia (202). 
(B. mit langen rothen Stieldrüsen bedeckt; Bt. klein,

4 in ährenförmigen Wickeln .......Drosera (257). B. kahl; Bt. ansehnlich, einzeln..Parnassia (271).

5. Ordnung. Pentagynia. Griffel (0. Narben) 5. ${ }_{1}$ Bt. unregelmäßig, gespornt; Kb. u. Krb. (scheinbar) 3

(Bt. regelmäßig, nicht gespornt...............

Holzgewächse mit lederigen, in eine dornige Spitze

2 auslaufenden u. meist auch dornig gezähnten B.

Ilex (366).

Kräuter, Stauden 0. Halbsträucher; B. nicht dornig Kleine Alpenpfl. mit 3 zähligen B. u. gelben Bt.

B. nicht 3 zählig

Sibbaldia (296).

(Blkr. verwachsenblättrig; K. 5 zähnig, gefaltet, oft

4 oben trockenhäutig (Plumbagineae, vergl. Seite 438).

$\mathrm{Kr}$ b. frei ........................... 5

$5\{$ Zwischen den 5 Stb. stehen 5 Staminodien....... 6

5 Staminodien fehlen ................. 7

B. fiederförmig getheilt 0 . am Grunde herzförmig u. kurz-gelappt; Fr. in 5 geschnäbelte Theilfr.

6 zerfallend............... Erodium (350). B. ungetheilt, meist schmal, niemals herzförmig; Fr. eine Kapsel .............. Linum (352).

7 B. schraubig gestellt o. am Grunde der Stg. rosettig B. gegenständig 0 . wirtelig ....................

Stg. beblättert; B. fleischig, kahl. . Crassula (263).

8 B. alle grundständig, rosettig, mit langen rothen Stieldrüsen bedeckt ........... Drosera (257).

(Wasserpfl.; B. wirtelig, mit geflügeltem Bstiel, mit

$9\{6$ langen Borsten besetzt.... Aldrovanda (257). Landpfl.; Bstiel nicht geflügelt, oft fehlend ...... 10

$10\left\{\begin{array}{l}\text { B. scheinbar quirlig, mit hinfälligen, häutigen Nebenb. } \\ \text { Spergula (207). }\end{array}\right.$ B. gegenständig, ohne Nebenb.................. 11

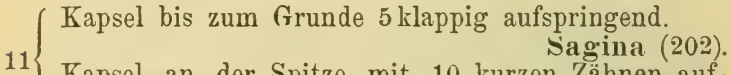

Kapsel an der Spitze mit 10 kurzen Zähnen aufspringend............... Cerastium (200).

6. Ordnung. Polygynia. Griffel (o. Narben) mehr als 5. (Kleine, ausdauernde Alpenpfl. mit 3 zähligen B. u. verkehrt-eiförmigen, 3 zähnigen Blättchen.

Sibbaldia (296).

Kleine, 1 jährige Kräuter mit linealen 0 . in lineale

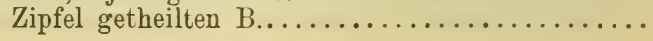


Ǩb. gespornt ; B. lineal, ungetheilt. Myosurus (220).

2 Kb. nicht gespornt; B. 3 theilig o. handförmig zerschlitzt............. Ranuneulus (220).

VI. Classe. HEXANDRIA. In jeder Zwitterblüte 6 freie, gleichlange Staubblätter.

1. Ordnung. Monogynia. Griffel (o. Narbe) 1.

1) Holzgewächse ..................... ?

1 ) Stauden 0. Kräuter .................... 5

Auf Eichen schmarotzender Strauch mit gegenstän2 digen, ungetheilten B. ....... Loranthus (169). Nicht schmarotzende Bäume o. Sträucher .......

Strauch mit dornigen Zweigen; B. gebüschelt; Bt. 3 gelb, in hängenden Trauben.... Berberis (227).

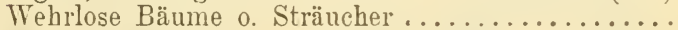

(B. gegenstündig, meist handförmig gelappt; K. и. 4 Blkr. vorhanden............... Acer (368). B. 2 zeilig gestellt, ungetheilt; Bthülle einfach.

Ulmus (166).

Btboden röhrig o. glockig ausgehöhlt, scheinbar eine Kelchröhre bildend, welche am Rande mit 2 Reihen von je 6 Zähnen besetzt ist; Frkn. am Grunde des ausgehöhlten Btbodens sitzend (Lythracecue, vergl. Seite 388).

Btboden nicht ausgehöhlt; K. niemals 12 zähnig...

Bthülle einfach, bald kelchartig, bald blumenkron-

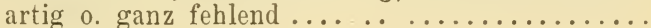
K. u. Blkr. vorhanden .............. 13

7 Bthülle fehlend ..................... s

7 Bthülle vorhanden.................. 9

Sumpfpfl. mit herz-eiförmigen B.; Bt. in Kolben, von einer großen, innen weiß gefärbten Scheide eingeschlossen................ Calla (97).

8 Im Meere lebende Pfl mit breit linealen B.; Bt. zu 5-6 von einer Scheide eingeschlossen.

Posidonia (30).

Frkn. oberständig .................. 10

Frkn. unterständig; ausdauernde Gewächse mit

9 grundständigen, meist linealen B.; Bthülle meist ansehnlich, weiß, gelb o. grünlich gefärbt (Amaryllidecue, vergl. Seite 117).

Btstand kolbenförmig; Bt. sehr klein, dicht an10 einander gedrängt; B. lineal........ Acorus (97). Btstand nicht kolbenförmig. 
Bthüllb. meist 5; B. in der legel mit deutlichem Mittelnerv, an ihrem Grunde eine den Stg. un-

11 grebende häntige Nebenbscheide. Polygonum (176). Bthüllb. 6; B. meist parallelnervig, seltener netznervig; Nebenbscheide fehlt ..............

Bthülle häıtig, meist braun 0 . grünlich, seltener röthlich, gelblich 0 . weiß; N. 3 , fädlich verlängert;

12) Pfl. gras- 0. binsenartig (Juncaceae, vergl. Seite 99).

Bthülle meist blumenkronartig, verschieden gefärbt; N. meist nicht fädlich (Liliacecte, vergl. Seite 104).

13 Stb. vor den Zipfeln der Blkr. stehend ......... 14

Stb. zwischen den Zipfeln der Blkr. stehend ...... 15

Kleine, zarte Staude; B. am Ende des Stg. gehäuft; Bt. weiß, einzeln an verlängerten Stielen in den

14 Blattachseln .............. Trientalis (437). Größere, kräftige Staude; B. gegenständig o. wirtelig; Bt. gelb, in blattachselständigen Trauben. Naumburgia (437).

Einjährige Kräuter mit gelben Bt.; Blkrröhre kurz; $15 \mathrm{Pfl}$. blaugrau bereift....... Blackstonia (443). Kräftige Stauden; Blkrröhre verlängert; Pfl. nicht bereift ................ Gentiana (443).

2. Ordnung. Digynia. Griffel (o. Narben) 2 .

(Holzgewächse mit lanzettlichen, am Grunde schiefen, 2 zeilig gestellten B. ........... Celtis (166). Kleine Alpenpfl. mit nierenförmigen Gruudb.

Oxyria (176).

3. Ordnung. Trigynia. Griffel (o. Narben) 3 .

Bthülle trichterförmig mit verlängerter Röhre u.

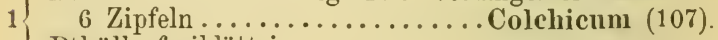
Bthülle freiblättrig $\ldots \ldots \ldots \ldots \ldots \ldots \ldots \ldots \ldots$

${ }_{2}$ B. gegenständig o. wirtelig; K. u. Blkr. 3 blättrig. 2

B. schraubig gestellt, manchmal alle grundständig;

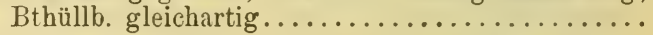

B. gegenständig, ganzrandig; Frkn. oberständig.

Elatine (377). B. zu 3-4 wirtelig, fein gesägt; Frkn. unterständig. Elodea (32).

Frkn. 1; Gr. o. N. 3; am Grunde jedes B. eine den

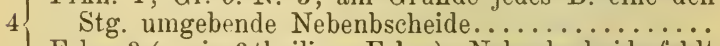
Frkn. 3 (o. ein 3 theiliger Frkn.); Nebenbscheide fehlt 6

j Bthüllb. 6; N. pinselförmig ........ Rumex (173). Bthüllb. meist 5; N. kopfig .... Polygonum (176). 


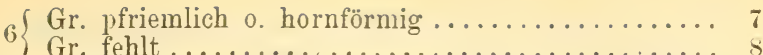

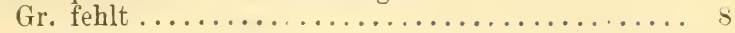

Die 3 Frkn. nur am Grunde verwachsen; B. elliptisch.

Veratrum (107).

7 Die 3 Frkn. bis zur Mitte verwachsen; B. grasartig.

Tofieldia (107).

$\delta\left\{\begin{array}{l}\text { Alle B. grundständig; Bthüllb. frei; A. sitzend. } \\ \text { Triglochin (31). } \\ \text { Stg. beblättert; Bthüllb. am Grunde verwachsen; } \\ \text { Stf. vorhanden............. Scheuchzeria (31). }\end{array}\right.$

4. Ordnung. Hexa-Polygynia. Griffel o. Narben 6 o. mehr.

Die 3 äu@eren Bthüllb. kelchartig, grün, die 3 inneren

blumenblattartig, weiळ; B. nicht grasartig.

Alisma (31)

Alle 6 Bthüllb. grünlich; B. grasartig.

Triglochin (31).

VII. Classe. HEPTANDRIA. In jeder Zwitterblüte 7 Staubblätter.

1. -5. O rd nung. Mono-Pentagynia. Griffel (o. Narben) 1-5.

$1\left\{\begin{array}{l}\text { Bäume mit gefiederten B. u. unregelmäßigen Bt. } \\ \text { A esculus }(369) .\end{array}\right.$

of Bthiille einfach 0. fehlend............... 3

$2\{$ K. u. Blkr. vorhanden ................. 4

(Bthülle fehlend; Bt. in Kiolben, von einer großen, innen weiß gefärbten Scheide eingeschlossen.

3 Calla (97).

Bthülle einfach; am Grunde jedes B. eine den Stg. umfassende häutige Nebenbscheide.

Polygonum (176).

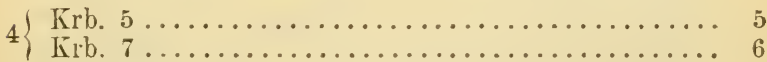

K. verwachsenblättrig, 5.zähnig; B. gegenständig.

Kib. frei; B. scheinbar wirtelig. ...Spergula (207).

Kleine, zarte Staude; B. am Ende des Stg. gehäuft; Bt. weiß, einzeln........... Trientalis (437).

6 Größere, kräftige Staude; B. gegenständig o. wirtelig; Bt. gelb, in blattachselständigen Trauben. 
VIII. Classe. OCTANDRIA. In jeder Zwitterblüte 8 freie Staubblätter.

1. Ordnung. Monogynia. Griffel (o. Narbe) 1.

Blattlose, beschuppte, wachsgelbe Schmarotzerpfl.; K.

1 u. Blkr. 4-5 blättrig ........ Monotropa (426). Pfl. mit grünen B.................. 2

${ }_{2}$ K. u. Blkr. vorhanden $\left.{ }^{*}\right) \ldots \ldots \ldots \ldots \ldots \ldots \ldots \ldots$

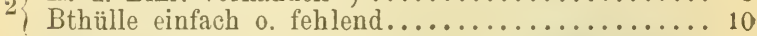

$3\{$ Holzgewächse $\ldots \ldots \ldots \ldots \ldots \ldots \ldots \ldots \ldots \ldots \ldots . \ldots \ldots$

\{ Stauden 0. Kränter................... 7

(Frkn. oberständig; Kapsel 0. Flügelfr.......... 5

4 Frkn. unterständig; niedrige Sträucher mit ungetheilten B.; Fr. eine Beere .... Vaccinium (428).

Bäume o. große Sträucher mit großen, flachen, meist gelappten B.; Krb. frei ; Fr. geflügelt. Acer (368).

5 Niedrige Sträncher mit nadelförmigen o. schuppenförmigen B.; Blkr. verwachsenblättrig; Fr. eine

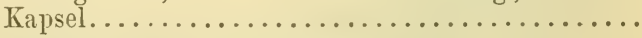

$6\{$ B. gegenständig; Kapseln wandspaltig. Calluna (428).

B. zu 3-4 quirlig; Kapseln fachspaltig. Erica (428).

$\tau\left\{\begin{array}{l}\text { Frkn. oberständig................................. } \\ \text { Frkn. unterständig; } \\ \text { vergl. Seite 389). }\end{array}\right.$

B. gegenständig, ganzrandig; Blkr. verwachsenb lättrig, gelb.............. Blackstonia (443).

8 B. meist schraubig gestellt, niemals ganzrandig; Krb.

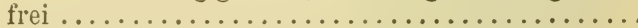

$\int$ Bt. gelb; B. handförnig getheilt o. gelappt.

9 Bt. niemals gelb; B. 3 zählig 0. 2-3 fach gefiedert. Ruta (355).

Bthülle fehlend; Bt. in Kolben, von einer großen, 10 innen weifen Scheide eingeschlossen. Calla (97). Bthülle vorhanden ................... 11

Btboden ausgehöhlt, einer Blkrröhre ähnlich; Stb. in der Aushöhlung des Btbodens, meist hoch über dem Frkn., eingefügt. (Thymelaeaceae, vergl. Seite 385 ).

Btboden nicht ausgehöhlt; Stb. unterhalb des Frkn.

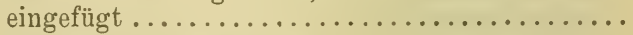

*) Vergl. Paris unter Nr. 13. 
Immergrüne Holzgewächse; A. mit Klappen auf-

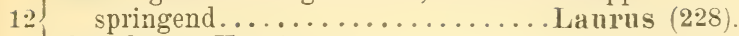

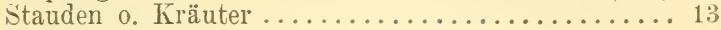

B. schraubig gestellt; Bthüllb. meist $5 \ldots \ldots \ldots \ldots 14$

13 B. am Ende des Stg. zu 4 (o. mehr) wirtelig; Bthüllb. $8 \ldots \ldots \ldots \ldots \ldots \ldots$...........

Fr. nicht länger als die Bthülle, meist mit derselben abfallend; B. nur bei den windenden Arten herzpfeilförmig-dreieckig....... Polygonum (176).

14 Fr. viel länger als die Bthülle, aus derselben herausfallend; B. herz-pfeilförmig-dreieckig; Stg. nicht windend................. Fagopyrum (177.

2. Ordnung. Digynia. Griffel (o. Narben) 2.

Holzgewächse mit 2 zeilig gestellten, ungetheilten B.;

1 Bthülle einfach; Fr. geflügelt......UImus (166).

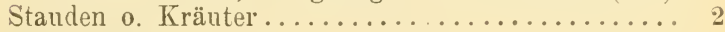

.) K. u. Blkr. vorhanden ................ 3

$\left.{ }^{\prime}\right)$ Bthülle einfach................... 4

(B. ungetheilt; Bt. weis; Fi. aufspringend.

3 Moehringia (206).

B. gefiedert, Bt. gelb; Fr. nicht aufspringend.

Agrimonia (298).

4) Am Grunde der B. eine häutige Nebenbscheide....

Nebenbscheide fehlend ................... 6

Fr. nicht länger als die Bthülle, meist mit derselben abfallend; B. nur bei den windenden Arten herz-

5 pfeilförmig-dreieckig ........Polygonum (176).

Fr. viel länger als die Bthülle, ans derselben herausfallend; B. herz-pfeilförmig-dreieckig; Stg. nicht windend.....................

Bthüllb. grün, mit weißem Rande; B. halbstielrundpfriemlich............. Scleranthus (208). Bthüllb. innen gelb; B. nierenförmig o. halbkreisrund, gekerbt.......... Chrysosplenium (271).

3. Ordnung. Trigynia. Griffel (o. Narben) 3.

Am Grunde der B. eine häutige Nebenbscheide;

1 Bthülle einfach, meist blumenkronartig gefärbt. .

Nebenbscheide fehlend; K. u. Blkr. vorhanden, letz-

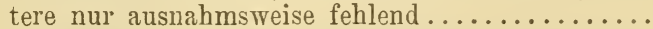

Fr. nicht länger als die Bthülle, meist mit derselben abfallend; B. nur bei den windenden Arten herz-

. pfeilförmig-dreieckig........ Polygonum (176).

2 Fr. viel länger als die Bthülle, aus derselben herausfallend; B. herz-pfeilförmig-dreieckig; Stg. nicht windend ................. Fagopyrum (177). 
$4\left\{\begin{array}{l}\text { Kapsel mit } 3 \text { ungetheilten Klappen aufspringend. } \\ \text { Alsine (203). }\end{array}\right.$ Kapsel mit 6 ungetheilten 0 . mit 3 2spaltigen Klappen aufspringend................ 5 $5\left\{\begin{array}{l}\text { Krb. } 2 \text { spaltig o. doch ausgerandet, selten fehlend. } \\ \text { Stcllaria (199). } \\ \text { Krb. ungetheilt u. ganzrandig, stets vorhanden. }\end{array}\right.$

Yoehringia (206).

4. Ordnung. Tetragynia. Griffel (o. Narben) 4 .

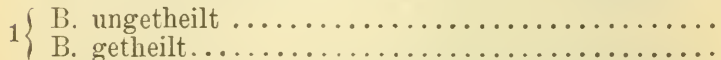

$\int \begin{aligned} & \text { B. gegenständig o. in zahlreichen Wirteln; Blkr. } \\ & \text { weiß o. röthlich, manchmal fehlend ........... }\end{aligned}$

2 B. am Ende der Stg. zu 4 (0. mehr) wirtelig; Bthüllb. 8, grünlich .......... Paris (117).

${ }_{3}$ Bt. sehr klein, in den Blattachseln; Wasser-o.

3 Schlammptl. ................. Elatine (377).

Bt. o. Btstände endständig; Landpfl.......... 4

$\int \begin{array}{r}\text { Gr. vor den Krb. stehend; Kapsel bis zum Grunde } \\ 4 \text { klappig aufspringend .......... Sagina (202). }\end{array}$

4 Gr. zwischen den Krb. stehend; Kapsel an der Spitze mit 8 Zähnen aufspringend.... Moenchia (202).

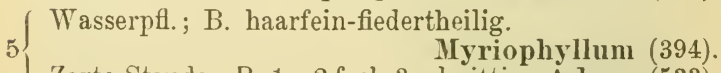

Zarte Staude; B. 1-2 fach 3 schnittig. Adoxa (533).

IX. Classe. ENNEANDRIA. In jeder Zwitterblüte 9 freie Staubblätter.

1. - 3. Or d n ung. Mono-Hexagynia. Griffel(o. Narben) 1-6.

f Holzgewächse mit immergrünen B.; A. mit Klappen

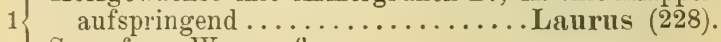
Sumpf- o. Wasserpfl. .................... 2

$2\left\{\begin{array}{l}\text { Bt. grof, rosenroth; B. grundständig, lineal, } 3 \text { kantig. } \\ \text { Butomus (32). }\end{array}\right.$

Bt. klein, weiø; B. klein, lanzettlich, zu $3-4$ wirtelig. Elodea (33).

X. Classe. DECANDRIA. In jeder Zwitterblüte 10 freie Staubblätter.

1. Ordnung. Monogynia. Griffel (o. Narbe) 1.

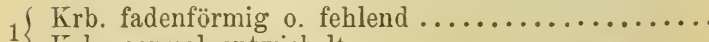

Krb. normal entwickelt................ 4 
B. nierenförmig o. halbkreisrund, gekerbt; Kb. innen gelb; Krb. ganz fehlend. Chrysosplenium (271).

B. ganzrandig; Kb. grün 0 . weiß ; Krb. fadenförmig Kb. weiß, gekielt $u$. zugespitzt; B. fleischig.

Kb. grün, flach-concav; B. kaum fleischig.

Illecebrum (208).

Herniaria (208).

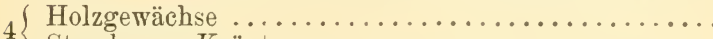

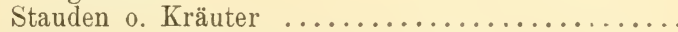

(Blkr. schmetterlingsförmig, rosemroth; B. nierenförmig, ganzrandig .............. Cercis (313).

Blkr. nicht schmetterlingsförmig; B. niemals nieren-

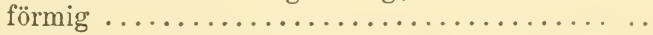

B. klein, schuppenförmig; Krb. frei ; S. mit Haarschopf ................. Myricaria (378).

6 B. verschieden gestaltet (wenn schuppenförmig, dann die Blkr. verwachsenblättrig); S. ohne Haarschopf (Ericaceae, vergl. Seite 426 ).

Wachsgelbe, statt der B. mit Schuppen versehene Pfl.; Blkr. glockig, Krb. am Grunde höckerig.

Monotropa (426).

Pfl. nicht wachsgelb, mit normal entwickelten B...

Frkn. halb unterständig; Blkr. verwachsenblättrig,

8 weiß; Bt. klein, in Trauben; Staude. Samolus (437).

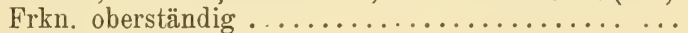

B. ungetheilt, steif, etwas lederig, glänzend, immergrün; Kb. u. Krb. am Grunde meist etwas verwachsen; A. mit Löchern aufspringend....... 10

B. oft getheilt (wenn ungetheilt, dann nie lederig); Kb. u. Krb. frei ..................... 11

( Bt. in einer Dolde o. Doldentraube; Gr. sehr kurz u. dick, mit schildförmiger N. Chimaphila (425). 10 Bt. in Trauben 0. einzeln; Gr. verlängert, N. 5 zähnig. Pirola (425).

11 Stf. am Grunde meist etwas verwachsen; N. $5 \ldots . .1$ Stf. frei; N. 1 ..................... 13

(B. 3zählig; zarte Stauden o. Kräuter; Bt. gelb, weis 0 . lila................ Oxalis (351).

12 B. nicht 3 zählig; Bt. nie gelb (Geraniaceae, vergl. Seite 347).

Bt. regelmäßig, gelb................ 14

13 Bt. groß, unregelmäßig, rosenroth (selten weiß); Stb. abwärts geneigt; B. gefiedert. Dictamnus (355).

B. einfach gefiedert, mit Nebenb.; Fr. dornig, in

14 Theilfr. zerfallend .......... Tribulus (354). B. doppelt 0.3 fach gefiedert 0.3 zählig, ohne Nebenb.; Fr. wehrlos, aufspringend........ Ruta (355). 
2. Ordnung. Digynia. Griffel (o. Narben) 2.

1 Krbb. fadenförmig 0 . fehlend .............

(B. nierenförmig o. halbkreisrund, gekerbt; Kb. innen

2 gelb; Krb. ganz fehlend. Chrysosplenium (271).

B. ganzrandig; Kb. grünlich 0 . weiß; Krb. faden-

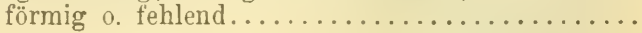

B. mit trockenhäutigen Nebenb., lanzettlich, länglich

3 0. elliptisch; Krb. fadenförmig. Heruiaria (208). Nebenb. fehlen; B. halbstielrund-pfriemlich; Krb. fehlend............... Scleranthus (208).

Fr. mit 2 von den bleibenden Gr. gebildeten Schnäbeln, zwischen denselben mit einem Loch

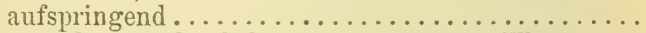

Fr. nicht geschnäbelt, mit mehreren Klappen 0. Zähnen o.gar nicht aufspringend (Caryophyllaceae, vergl. Seite 187).

Krb. gefärbt (oft weiß), nach unten verschmälert, vom Btboden deutlich abgegliedert.

Saxifraga (265).

5 Krb. grünlich, den Kb. ähnlich u. wie diese am Grunde verbreitert $u$. vom Btboden nicht deutlich abgegliedert..........Zahlbrucknera (271).

3. Ordnung. Trigynia. Griffel (o. Narben) 3 .

Hierher gehören nur viele Caryophyllaceae (vergl. Seite 187).

4. u. 5. Ordnung. Tetra-Pentagynia. Griffel (o. Narben) $4-5$.

$1\left\{\begin{array}{l}\text { Kletterstrauch; B. lederig; Bt. in Dolden. } \\ \text { Hedera (394). }\end{array}\right.$

Frkn. u. Fr. an der Spitze offen; Bt. unregelmäßig, 2 unscheinbar; Krb. meist gespalten. Reseda (256). Frkn. vollständig geschlossen; Bt. regelmäßig ..... 3

3) B. getheilt...................... 4

B. ungetheilt................... 5

(B. 3zählig; zarte Stauden o. Kräuter; Krb. frei, 4 gelb, weiø o. lila............ Oxalis (35̌1). B. 1-2fach 3 schnittig; zarte Staude; Blkr. verwachsenblättrig, radförmig, grünlich. Adoxa (533). 
Frkn.4-5, in einen Kreis gestellt, frei o. am Grunde verwachsen; B. mehr oder weniger fleischig, meist 5 schraubig gestelit (Crassulacece, vergl. Seite 258). Frkn. 1; B. gegenständig, selten fleischig (Caryophyllaceae, vergl. Seite 187).

6. Ordnung. Polygynia. Griffel (o. Narben) mehr als 5.

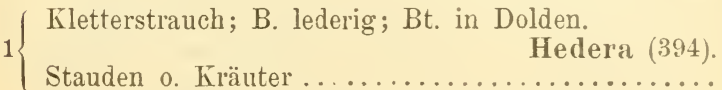

$\int$ Bthülle einfach, 5 blättrig; B. nicht fleischig; Fr.

2 eine Beere.............. Phytolacea (185).

K. u. Blkr. vorhanden; B. mehr oder weniger fleischig; Fr. aufspringend........ Sedum (258).

XI. Classe. DODECANDRIA. In jeder Zwitterblüte 12-15 freie Staubblätter.

1. Ordnung. Monogynia. Griffel (o. Narbe) 1.

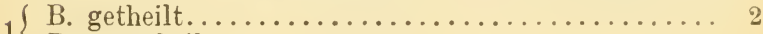

$1\{$ B. ungetheilt...................... 3

$\int$ K. u. Blkr. vorhanden; B. doppelt zusammengesetzt.

2 Bthülle einfach; B. einfach gefiedert. Actaea (215).

Sanguisorba (299).

(K. u. Blkr. vorhanden ................. t

3 Bthülle einfach, 3 spaltig; B. nierenförmig.

Asarum (172).

K. 2 spaltig; Blkr. 5 blättrig, gelb. Portulaca (186).

4 K. meist 6 zähnig, mit 6 dazwischen liegenden Zühnen des Außenk.; Blkr. meist 6 blättrig.

Lythrum (388).

2. Ordnung. Digynia. Griffel (o. Narben) 2 .

( Kb. 4-5, 1 reihig, unter ihnen ein mehrreihiger Kranz hakiger Weichstacheln. Agrimonia (298). Kb. 2 reihig, die äußeren (Außenkb.) sehr klein, zahnförmig ............. Aremonia (298).

3. $0 \mathrm{rdnung}$. Trigynia. Griffel (o. Narben) 3 (ausnahmsweise auch $4-6$ ).

Bt. unregelmäळig; Frkn. u. Fr. an der Spitze offen. Reseda (256).

(Vgl. eventuell Euphorbia [Seite 358], welche aber nur scheinbar Zwitterbt. mit etwa 12 Stb. hat.) 
4. Ordnung. Dodecagynia. Griffel (o. Narben) 12. Krb. frei ....................... Krb. am Grunde unter sich und mit den Stb. mehr 0. weniger verwachsen..... Sempervivum (260).

XII. Classe. ICOSANDRIA. In jeder Zwitterblüte mindestens 20 freie Staubblätter, welche am Rande des scheibenförmigen 0 . ausgelıöhlten Blütenbodens (scheinbar in der Kröhre) eingefügt sind.

1.-3. Ordnung. Mono-Polygynia. Griffel (o. Narben) 1 bis viele.

$1\left\{\begin{array}{c}\text { Stamm fleischig, aus zusammengedrückten Gliedern } \\ \text { bestehend, mit Stachelbüscheln besetzt, ohne deut- } \\ \text { liche B. ................... }\end{array}\right.$

Pfl. mit normal entwickelten B. .............. 2

B. schraubig gestellt, meist mit Nebenb. (Rosaceae, 2 vergl. Seite 272).

B. gegenständig, ohne Nebenb. ............. 3

Krb. meist 6, scharlachroth; Beeren sehr groß, 3 apfelförmig, meist roth...........Punica (389). Krb. $4-5$, weiß...................... 4

$4\left\{\begin{array}{l}\text { Gr. 4(-10)spaltig; Fr. trocken, aufspringend. } \\ \text { Philadelphus (271). } \\ \text { Gr. ungetheilt; Fr. eine blauschwarze Beere. } \\ \text { Myrtus (389). }\end{array}\right.$

(Vergl. eventuell anch Sempervivum [Seite 260].)

XIII. Classe. POLYANDRIA. In jeder Zwitterblüte mindestens 20 freie Staubblätter, welche auf dem mehr o. weniger kegelförmig erhobenen Blütenboden eingefügt sind.

1. -3. Ordnung. Mono-Polygynia. Griffel (o. Narben) 1 bis viele.

${ }_{1}\left\{\begin{array}{c}\text { Kb. 2, meist sehr bald abfallend (Papaveraceae, } \\ \text { vergl. Seite 228). }\end{array}\right.$ Kb. mehr als 2 ....................... 2

Frkn. u. Fr. sehr lang gestielt; Kb. u. Krb. 4; 2 Sträucher mit ungetheilten B...Capparis (256). Frkn. sitzend 0 . nur ganz kurz gestielt.......... 3 
Bäume mit herzförmig-rundlichen, gesägten B.; ein flügelartiges Hochb. an den Stiel jedes Btstandes angewachsen ................. Tilia (372).

Sträucher, Stauden o. Kräuter ohne flügelartige

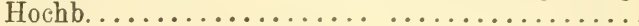

Frkn. 1, 6-20 fächerig, mit grober schildförmiger N.; Krb. zahlreich; große Wasserpfl. mit schwimmenden, herzförmigen B. (Nymphaeaceae, vergl. Seite 209).

Frkn. 1 0. mehrere, $1-5$ fächerig ...........

Stb. in 3-5 Bündel zusammengestellt; Frkn. 1, 1-5 fächerig; Bt. gelb; B. ganzrandig, gegen-

5 ständig 0 . wirtelig........... Hypericum (375). Stb. nicht in Bündel zusammengestellt; Frkn.

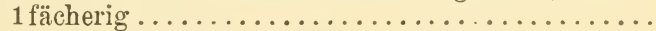

Frkn. in jeder Bt. mehrere (wenn 1, dann die B.

6 getheilt) (Ranunculaceae, vergl. Seite 210).

Frkn. 1; B. ungetheilt (Cistineae, vergì. Seite 378).

XIV. Classe. DIDYNAMIA. In jeder Zwitterblüte 4 freio Staubblätter, von denen 2 länger und 2 kürzer sind.

1. Ordnung. Gymnospermia. Im Grunde des K. 4 unbedeckte Nüsschen o. Steinfr., in deren Mitte der Gr.

Frkn. 4, Nüsse 4; Blkr. meist unregelmäßig, rachig o. 2 lippig, seltener fast regelmäßig 4 spaltig ( $L a-$ biatae, vergl. Seite 463).

Frkn. 1, 4 fächerig, Frucht in 4 Nüsse zerfallend 0. eine 4 steinige Steinfr.; Blkr. stieltellerförmig, mit 5 lappigem Saume (Verbenaceae, vergl. Seite 463).

2. Ordnung. Angiospermia. Fr. eine Kapsel, selten eine Steinfr., Beere 0. Schliebfr.

(Frkn. unterständig; kleiner Strauch mit gegenständigen B.; Blkr. trichterig-glockig, hellrosa 0.

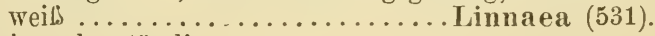

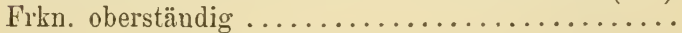

Frkn. mit 1 Samenknospe; K. 5spaltig; Zipfel der

Blkr. 5, ungleich; Bt. meist blau, in Köpfchen.

Globularia (518).

Frkn. mit 2 o. mehr Samenknospen............. Schmarotzerpfl. ohne grüne B.; Btstand ährenartig; Blkr. rachenförmig; Frkn. 1 fächerig, mit wand$3)$ ständigen Samenträgern (Orobanchacece, vergl. Seite 513).

Pf. mit normal entwickelten B............. 
Bt. grof, in steifen, dicken Aehren, von steifen, stachelig-gezähnten Deckb. gestützt; Grundb. groß, 4 buchtig-fiedertheilig; Stf. dick und steif; Frkn. mit 4 Samenknospen .........Acanthus (519). Deckb. niemals stachelig, wenn auch oft gezähnt..

Frkn. (1-)2 fächerig, mit zahlreichen, seltener mit wenigen Samenknospen (Scrophulariaceac, vergl. $5\{$ Seite $48 \pi$ ).

Frkn. 4 fächerig, mit 1 Samenknospe in jedem Fache (Verbenaceae, vergl. Seite 463).

XV. Classe. TETRADYNAMIA. In jeder Zwitterblüte 6 freie Staubblätter, von denen 4 länger und 2 kürzer sind.

In diese Classe gehören nahezu alle Arten der Cruciferen; zur Bestimmung der Gattungen dient der Schlüssel auf Seite 232.

XVI. Classe. MONADELPHIA. Alle Staubfäden jeder Zwitterblüte in ein Bündel 0. in eine Röhre o. doch am Grunde untereinander verwachsen.

1. Ordn ung. Tetrandria. Staubblätter 4 .

Kleines 1 jähriges Kraut mit gegenständigen B. und sehr kleinen, weisen Bt.......... Radiola (352).

2. Ordnung. Pentandria. Staubblätter 5 .

$1\{$ Blkr. verwachsenblättrig .................. 2

$1\{$ Krb. frei .......................... 6

$2\{$ B. gegenständig, ganzrandig 0. fast ganzrandig.... 3

$2\{$ B. nicht gegenständig, meist gelappt o. eckig..... 5

(Bt. ausgesprochen gelb, ohne Nebenkrone; Frkn. 14

3 Bt. weif, gelblich, fleischfarben 0. röthlich, mit Nebenkrone; Frkn. 2 (Asclepiadeae, vergl. Seite 450). Zwischen den Krb. 5 Schuppen (unfruchtbare Stb.); Bt. in blattachselständigen Trauben.

Naumburgia (437).

4 Zwischen den Krb. keine Schuppen; Bt. in den Blattachseln einzeln 0 . trugdoldig angeordnet.

Lysimachia (437).

Stg. beblättert; PA. meist Ranken tragend; Bt. gelb,

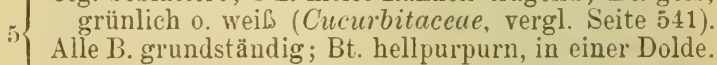
Cortusa (436). 
(Bt. unregelmäßig, gespornt; 1 jährige Kräuter mit

6 ungetheilten B............. Impatiens (369).

Bt. regelmäळig, nicht gespornt........... 7

( B. 3 zählig; zarte Stauden o. Kräuter mit gelben,

7 weisen 0 . lilafarbenen Bt. ........ Oxalis (351).

B. nicht 3 zählig .................. 8

Gr. 5, zu einem Schnabel des Frkn. vereinigt; B. oft getheilt 0 . gelappt; Fr. in geschnäbelte Theilfr. zerfallend (Geraniaceae, vergl. Seite 347 ).

Gr. 3-5, frei 0. nur am Grunde verwachsen; B. ungetheilt, meist schmal; Fr. eine Kapsel.

Linum (352).

3. Ordnung. Octandria. Staubblätter 8 .

Hieher nur Polygalaceae (vergl. Seite 356).

4. Ordnung. Decandria. Staubblätter 10.

$1\left\{\begin{array}{l}\text { Blkr. unregelmäßig, schmetterlingsförmig (Legumi- } \\ \text { uosae, vergl. Seite 308). }\end{array}\right.$

Blkr. regelmäßig . . . . . . . . . . . . . . .

Sträucher mit schuppenförmigen B.; Bt. rosa; S. mit

2 Haarschopf............... Iyricaria (378).

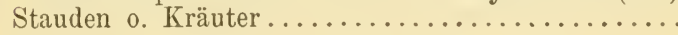

B. 3 zäblig; zarte Pfl. mit gelben, weiben o. liia-

B. nicht 3 zählig; Bt. nie gelb; Fr. in geschnäbelte Theilfr. zerfallend (Geraniaceae, vergl. Seite 347 ).

5. Ordnung. Polyandria. Staubblätter zahlreich.

Diese Ordnung fällt mit der natürlichen Familie der Malvaceen zusammen; zur Bestimmung der Gattungen dient der Schlüssel auf Seite 372.

XVII. Classe. DIADELPHIA. Dio Staubfäden jeder 'Zwitterblüte in zwei Bündel verwachsen oder ein Staubfaden frei, die übrigen in ein Bündel verwachsen.

1. Ordnung. Hexandria. Staubblätter 6 , je 3 verwachsen. (Fr. länglich o. elliptisch, vielsamig, aufspringend; Stauden, selten Kräuter....... Corydalis (229). Fr. kugelig, 1 samig, nicht aufspringend; 1 jährige Kräuter....................

2. Ordnung. Octandria. Staubblätter 8 , je 4 verwachsen. Hieher nur Polygalaceae (vergl. Seite 356). 
3. Ordnung. Decandria. Staubblätter 10, hievon 1 frei, 9 miteinander verwachsen.

Hieher die Mehrzahl der Leguminoscue (vergl. Seite 308).

XVIII. Classe. POLYADELPHIA. Die Staubfäden jeder Zwitterblüte an Grunde in 3-5 Bündel verwachsen.

1. Ordnung. Polyandria. Staubblätter zahlreich.

( Bäume mit schraubig gestellten, schief-herzförmig-

rundlichen B.; Bt. gelblichweib ..... Tilia (372).

Stauden 0. Halbsträucher mit gegenständigen 0 . wirteligen B.; Bt. gelb........ Hypericumı (375).

XIX. Classe. SYNGENESIA. Die Staubbeutel jeder Zwitterblüte mit einander verklebt 0 . zu einer Röhre verwachsen, durch welche meist der Griffel hindurchgeht.

Die ersten 5 Ordnungen dieser Classe werden von der natürlichen Familie der Compositae gebildet; zur Bestimmung ihrer Gattungen dient der Schlüssel auf Seite 551.

6. Ordnung. Monogamia. Jede Blüte mit deutlichem Kelch.

$\int$ Blkr. verwachsenblättrig, regelmäßig; Bt. nicht ge-

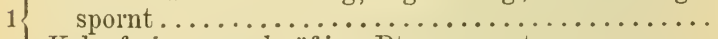

Krb. frei, unregelmäßig; Bt. gespornt .......... 5

Bt. blau, in ein von Hüllb. umgebenes Köpfchen 2 zusammengestellt; Frkn. unterständig.

Bt. Jasione (550).

Bt. nicht in einem Köpfchen ...............

(Frkn. unterständig; meist rankentragende Pfl. (Cu3 curbitaceae, vergl. Seite 541).

Frkn. oberständig; Pfl. olıne Ranken .......... 4

Blkr. walzlich-glockig, kurz うzähnig; Pfl. fast $4\left\{\begin{array}{c}\text { stechend-steifhaarig ........... Onosma }(461) . \\ \text { Blkr. radförmig, 5 spaltig; Pfl. verschieden behaart } \\ \text { o. fast kahl................ Solanm }(485) .\end{array}\right.$

( Kb. meist 3, das obere gespornt; Krrb. scheinbar 3, $5\left\{\begin{array}{l}\text { die seitlichen } 2 \text { spaltig ........ Impatiens (369). } \\ \text { Kb. 5, mit Anhängseln am Grunde; Krb. 5, das }\end{array}\right.$ unterste gespornt............ Viola (380). 
XX. Classe. GYNANDRIA. Die Staubblätter jeder Zwitterblüte mit den Griffeln verwachsen.

1. u. 2. Ordnung. Monandria, Diandra. Staubblätter 1-2.

Diese beiden Ordnungen werden von der natürlichen Familie der Orchideen gebildet; zur Bestimmung der Gattungen dient der Schlüssel auf Seite 124.

3. Ordnung. Hexandria. Staubblätter 6 .

Hieher nur die Gattung Aristolochia. (172).

XXI. Classe. MONOECIA. Blüten einhäusig, d. h. auf einer und derselben Pflanze theils männlich, theils weiblich.

1. Ordnung. Monandria. In jeder männlichen Blüte 1 Staubblatt.

1 ( Holzgewächse $\ldots \ldots \ldots \ldots \ldots \ldots \ldots \ldots \ldots \ldots \ldots \ldots \ldots \ldots \ldots$

Stauden 0. Kräuter ...................... 3

(B. nadelförmig 0. schuppenförmig; Btstände kätzcheno. zapfenförmig, die männlichen von den weiblichen getrennt (Coniferae, vergl. Seite 19).

$B$. breit, herzförmig, meist gelappt; männliche $u$. weibliche Bt. im Innern eines fleischigen Behälters eingeschlossen ................ Ficus (16 7 ). $3\left\{\begin{array}{c}\text { Land- o. Sumpfpflanzen .................... } \\ \text { Schwimmende o. untergetauchte Wasserpfl. mit } \\ \text { kleinen, unscheinbaren Bt................ }\end{array}\right.$

Bt. in einem Kolben, der von einer großen Scheide umgeben ist; B.breit, herz- o. pfeilförmig (Araceae, vergl. Seite 97$)$.

Eine weibliche u. mehrere o. zahlreiche männliche Bt. von einer gemeinsamen, glockigen Hülle umgeben; Pfl. Milchsaft enthaltend. Euphorbia (358).

Stg. blattähnlich, gegliedert, ohne deutliche B., schwimmend o. etwas untergetaucht; Bt. äuferst klein, 2 männliche u. 1 weibliche von einer gemeinsamen Scheide eingeschlossen (Lemnaceae, vergl. Seite 98).

B. stets deutlich entwickelt; Pfl. meist untergetaucht 6

Zahlreiche männliche u. weibliche Bt. von einer Bscheide eingeschlossen, alle ohne Bthülle; A. sitzend; B. grasartig............ Zostera (30). Bt. einzeln 0. 1 männliche u. 1 weibliche neben einander 
(A. sitzend (ohne Stf.); Bthülle becherförmig, bei der männlichen Bt. doppelt, bei der weiblichen ein7 fach 0 . fehlend; B. gegenständig o. wirtelig, lineal, ausgeschweift-gezähnt.......... Najas (30).

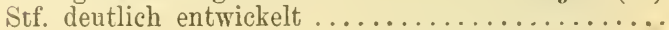

Frkn. meist 4; Gr. 4, mit schildförmiger N.; weibliche Bt. mit glockiger Bthülle; B. schmal-lineal 0 . borstlich ................ Zanichellia (30).

8 Frkn. 1, oft 4 lappig; Gr. 2, fädlich; Bthülle fehlend; Bt. mit 2 sichelförmigen Vorb.; B. lineal 0 . verkehrt-eiförmig........... Callitriche (364).

2. u. 3. Ordnung. Diandria, Triandria. In jeder männlichen Blüte 2 oder 3 freie Staubblätter.

1) Holzgewächse .......................

$1\{$ Stauden 0. Kräuter .................... 5

B. nadelförmig 0. schuppenförmig; Btstände kätzcheno. zapfenförmig; Samenknospen auf der Oberseite 2 der Frb., niemals in einem geschlossenen Frkn. (Coniferac, vergl. Seite 19).

B. breit u. flach, oft gelappt o. getheilt; Samenknospen im Innern eines geschlossenen Frkn. ...

$3\{$ B. gefiedert; Fr. geflügelt ........ Fraxinus $(440)$.

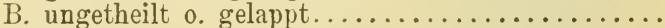

Bt. in Kätzchen; Fr. geflügelt ...... Betula (162).

4 Bt. im Innern eines fleischigen Behälters verborgen; Sammelfr. fleischig ............ Ficus (167).

(Schwimmende o. etwas untergetauchte, sehr kleine 5 Wasserpfl.; Stg. blattähnlich, gegliedert, ohne deutliche B. (Lemnaceae, vergl. Seite 98).

Pfl. mit wohl entwickelten B............... 6

B. lineal 0 . lanzettlich, parallelnervig $\ldots \ldots \ldots \ldots 7$

6 B. verschieden gestaltet, netznervig 0 . nur mit einem Mittelnerv ...................... 11

(Frkn. meist 4, gestielt; Wasserpfl. mit borstlich7 linealen B................ Ruppia (29).

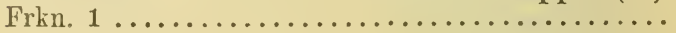

Bt. in Kolben, die weiblichen unter den männlichen, 8 alle lang behaart; Frkn. lang gestielt. Typha (25). Wenigstens die männlichen Bt. nicht in Kolben;

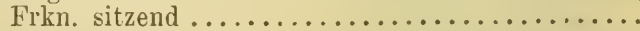
$9\left\{\begin{array}{l}\text { Bt. in kugeligen Köpfchen, mit } \begin{array}{l}3 \text { blättriger Bthülle. } \\ \text { Sparganium (26). }\end{array} \\ \text { Bt. ohne deutliche Bthülle, von Spelzen umgeben.. } 10\end{array}\right.$ 
B. zweizeilig, breit lineal-lanzettlich; männliche Bt. in einer endständigen Rispe, weibliche in blatt10 achselständigen, vou Scheiden umhüllten Kolben; Gr. 1, sehr lang............... Zea (43). B. dreizeilig, schmal, meist lineal; Bt. in Aehrehen; N. 2-3 (Cyperaceae, vgl. Seite 76).

Bt. in einem Kolben, der von einer großen Scheide 11 umgeben ist; B. herz- 0. pfeilförmig. Arum (98). Bt. nicht in Kolben ..................... 12

Bt. von Deckb. und meist auch 2 Vorb. gestützt.

Männliche Bt. deckblattlos........ Atriplex (181).

4. Ordnung. Tetrandria. In jeder männlichen Blüte 4 freie Staubblätter.

$1\left\{\right.$ Holzgewächse $\left.{ }^{*}\right) \ldots \ldots \ldots \ldots \ldots \ldots \ldots \ldots \ldots \ldots$

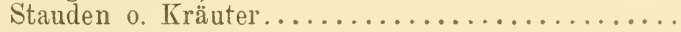

B. nadelförmig o. schuppenförmig; Btstände kätzcheno. zapfenförmig; Samenknospen auf der Oberseite

2 der Frb., niemals in einem geschlossenen Frkn. (Coniferae, vergl. Seite 19).

B. flach; Samenknospen im Innern eines geschlossenen Frkn.

Schmalotzerpfl. mit gegenständigen, ganzrandigen

3 B. u. weißen Beeren ........... Viscum (169). Nicht schmarotzende Sträucher o. Bäume........

B. lederig, ganzrandig, gegenständig; Bt. in blatt4 B. niemals ganzrandig, schraubig gestellt; Bt. in Kätzchen 0. Aehren $\left.{ }^{* *}\right) \ldots \ldots \ldots \ldots \ldots \ldots \ldots \ldots$

Bt. in Kätzchen, die weiblichen ohne Bthülle; Fr.

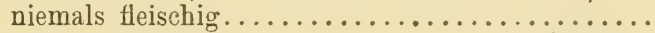

Bt. in Aehren, alle mit 4 blättriger Bthülle; Sammelfrucht fleischig................ Morus (167).

Bthülle der männlichen Bt. 1-2blättrig; Stb. 2, oben 2 theilig (also nur scheinbar 4); Deckschuppen

6) $\begin{gathered}\text { der Frkätzchen abfällig............. Betula (162). } \\ \text { Bthülle der männlichen Bth. 4blättrig; Stb. 4, un- }\end{gathered}$ getheilt; Deckschuppen der Frkätzchen holzig, stehen bleibend............... Alnus (163).

B. gefiedert; Bt. in dichten, fast köpfehenförmigen

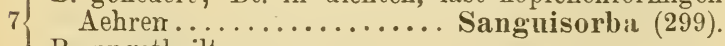

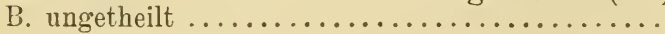

*) Vergl. auch Nr. 13.

**) Sind die Bt. im Innern eines fleischigen Behälters eingeschlossen, so vergl. man Ficus (167). 
( Bt. in einem Kolben, der von einer großen Scheide

8 umgeben ist; B. helz- 0. pfeilförmig.A rum (98).

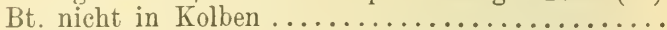

Frkn. unterständig; B. gegenständig, eiförmig; Bt.

9 blattachselständig ........... Ludwigia (390).

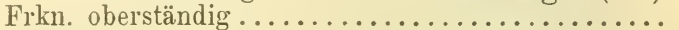

K. u. Blkr. vorhanden, letztere trockenhäutig; kleine

10 Sumpfpfl. mit fleischigen, stielrund-pfriemlichen

10 B.; männliche Bt. einzeln an langen Stielen, weibliche sitzend............... Litorella (522).

Bthülle einfach ................... 11

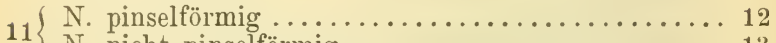

$11\{$ N. nicht pinselförmig................ 13

${ }_{12} \int$ b. gegenständig, gesägt; Pfl. mit $\begin{gathered}\text { Brennhaaren. } \\ \text { Urtica (168). }\end{gathered}$

12 B. wechselständig, ganzrandig; Pfl. ohne Brennhaare.

Parietaria (168).

Sternhaariger, niedriger Strauch mit lanzettlichen

13 B. u. wolligen weiblichen Bt.......Eurotia (183). Kahle, mehlig bestäubte o. schülferige Kräuter, seltener kleine Sträucher........Atriplex (181).

5. Ordnung. Penta-Polyandria. In jeder männlichen Blüte 5 o. mehr freie Staubblätter.

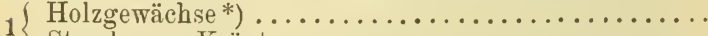

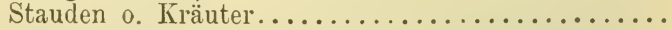

B. nadelförmig 0.schuppenförmig; Btstände kätzcheno. zapfenförmig; Samenknospen auf der Oberseite des Frb., niemals in einem geschlossenen Frkn. (Coniferae, vergl. Seite 19).

B. flach, manchmal getheilt oder gelappt; Samenknospen im Innern eines geschlossenen Frku. ...

B. gefiedert; männliche Bt. in Kätzchen, weibliche einzeln 0. zu 2-3.......... Juglans (154).

B. ungetheilt 0 . gelappt................ 4

Bt. im Innern eines fleischigen Behälters verborgen;

4 Sammelfr. fleischig; B. meist gelappt. Ficus (167).

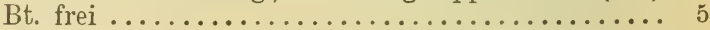

Männliche Bt. in Kätzchen o. in gestielten, fast

5 kugeligen, reichblütigen Büscheln ...........

Bt. einzeln 0. zu wenigen beisammen; $B$. länglich-lanzettlich, zugespitzt, geschärft-gesägt. Celtis (166).

$6\{$ N. 2 (Betulaceae, vergl. Seite 161).

N. 3 o. mehr (Fagaccae, vergl. Seite 163).

*) Vergl. auch Atriplex (Seite 181). 
(Wasserpfl. mit quirligen, in borstliche 0 . haarförmige Zipfel getheilten B.

B. nicht quirlig, niemals in haarförmige Zipfelgetheilt

B. gabelspaltig getheilt; Bthüllb. 9-12, am Grunde verwachsen; Stb. 12-20, mit kurzen, dicken Stf.; Frkn. oberständig....... Ceratophyllum (210).

B. fiederförmig getheilt; Kb. u. Krb. 4, letztere manchmal fehlend; Stb. meist 8; Frkn. unterständig............. Myriophyllum (394).

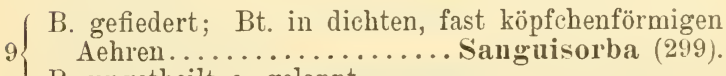

B. ungetheilt 0 . gelappt................ 10

$10\left\{\right.$ Frkn. unterständig* $\left.{ }^{*}\right) \ldots \ldots \ldots \ldots \ldots \ldots \ldots \ldots \ldots \ldots$

Frkn. oberständig, 0. die Bt. ohne Bthülle ....... 13

Einjährige Kräuter mit eiförmigen, ganzrandigen B.;

11 Bt. unscheinbar, zu 2-3 beisammen; Bthülle einfach; Stb. meist $12 \ldots$.... Thelygonum (185).

B. niemals ganzrandig; Stb. 5 (o. scheinbar weniger) 12

Mittels Ranken kletternde o. am Boden liegende Kräuter 0. Stauden; Bt. ansebnlich 0. doch nicht unscheinbal, niemals in Köpfchen; N. 3-5 (Cucurbitaceae, vergl. Seite 541).

Aufrechte, 1 jährige Kräuter ohne Ranken; Bt. unscheinbar, die männlichen in Köpfchen, die weiblichen zu 2 von einer gemeinsamen Hülle eingeschlossen............... Xanthium (568).

Bt. ohne Bthülle, in einem von großer, innen weißer Scheide eingeschlossenen Kolben; B. herzeiförmig.

Calla (97).

Bt. nicht in Kolben; Bthülle stets vorhanden**)... 14

$14\{$ K. u. Blkr. vorhanden; Frkn. 4-viele.......... 15

Bthülle einfach; Frkn. $1 \ldots \ldots \ldots \ldots \ldots \ldots \ldots \ldots$

Kb. u. Krb. 3, letztere weiø; Stb. u. Frkn. zahlreich; B. theils lineal, theils pfeilförmig.

Sagittaria (31).

Kb. u. Krb. 4--6; Stb. 8-12; Frkn. 4-6; B. mehr o. weniger fleischig........... Sedum (258).

*) Bei Thelygonum ist der Frkn. einseitig entwickelt und kann leicht für oberständig gehalten werden.

**) Vergl. auch Andrachne (Seite 358). 
( B. lineal, parallelnervig, 2 zeilig gestellt; Bt. in ku16 geligen Köpfchen; Bthülle 2 blättrig, unscheinbar.

Sparganium (26).
nervig............

Frkn. 2(-3) fächerig, in jedem Fache 1 Samenknospe (selten 2) enthaltend; Stb. 9-12.

Mercurialis (358).

Frkn. 1 fächerig, mit einer einzigen Samenknospe; Stb. 5........................ 18

$\int$ Bt. von Deckb. u. meist auch von 2 Vorb. gestützt. podiaceae, vergl. Seite 178).

6.-8. Ordnung. Monadelphia, Polyadelphia, Syngenesia. Die Staubblätter jeder männlichen Blïte entweder mit ihren Staubfäden oder mit ihren Antheren untereinander mehr oder weniger verwachsen.

Holzgewächse mit nadelförmigen 0 . schuppenförmigen B.; Samenknospen auf der Oberseite der

1 Frb., niemals in einem geschlossenen Frkn. (Coniferae, vergl. Seite 19).

Stauden 0. Kıäuter; Samenknospen stets im Inneru

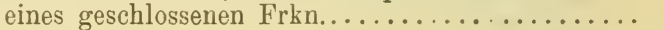

Schmarotzerpf. von rothgelber oder carminrother Farbe; B. schuppenförmig; Stb. 8, an eine Mittelsäule angewachsen; Frkn. unterständig.

Cytinus (172).

Nicht schmarotzende Pfl. mit normalen B.; Stb. stets weniger als $8 \ldots \ldots \ldots \ldots \ldots \ldots \ldots \ldots$

$3\left\{\begin{array}{l}\text { B. lineal, parallelnervig; Bt. in Kolben, lang behaart. } \\ \text { Typha (25). }\end{array}\right.$

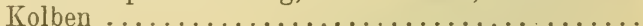

Wenigstens die männlichen Bt. in Köpfchen; Frkn.

4 unterständig (Compositae, vergl. Seite 551).

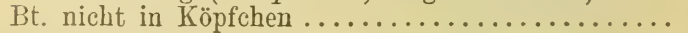

Frkn. unterständig; mittels Ranken kletternde 0. am Boden liegende Kräuter o. Stauden; B. niemals ganzrandig; alle Bt. mit K. u. Blkr., letztere verwachsenblättrig (Cucuvbitaceae, vergl. Seite 541). Frkn. oberständig, 3 fächerig; B. klein, ganzrandig; Bt. klein, wei@lich.......... Andrachne (358). 
XXII. Classe. DIOECIA. Blüten zweihäusig, d. h. auf einer Pflanze entweder nur männliche oder nur weibliche.

1. u. 2. Ordnung. Monandria-Diandria. In jeder männlichen Blüte 1-2 freie Staubblätter.

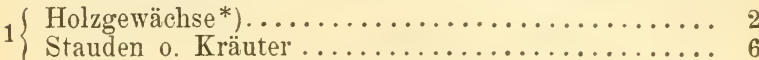

(B. gefiedert; Blkr. tief 3-4 theilig o. fehlend; Fr.

2 geflïgelt................ Fraxinus (440).

B. ungetheilt, manchmal schuppenförmig .........

B. gegenständig, schuppenförmig, paarweise zu stengelumfassenden Scheiden verwachsen; Sträucher von schachtelhalmähnlichem Aussehen; Zweige gegliedert................ Ephedra (22).

B. stets frei, oft nadel- o. schuppenförning; Zweige nicht gegliedert .......................

( B nadel- o. schuppenförmig, gegenständig o. wirtelig, meist dicht gedrängt; Fr. beerenartig.

Juniperus (21).

B. flach (wenn nadelförmig, dann wechselständig)..

B. lineal, den Tannennadeln ähnlich; weibliche Bt. aus einer einzigen von Hüllb. umgebenen Samen-

5 knospe bestehend.............. Taxus (21).

B. flach, nicht nadelförmig; Bt. in Kätzchen; Frkn. mit 2 N.; s. mit Haarschopf....... Salix (155).

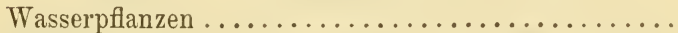

Landpfl.; B. schuppenförmig, in ihren Achseln

6 Büschel nadelförmiger o. fadenförmiger Zweige; Bthülle 6 blättrig; Fr. eine Beere.

Asparagus (116).

Stg. blattähnlich, gegliedert, schwimmend o. etwas

7 untergetaucht, ohne deutliche B. (Lemnaceae, vergl. Seite 98).

B. stets deutlich entwickelt ................ 8

$8\{$ Stb. 2; B. verlängert-lineal, grasartig ............ zähnt, gegenständig o. wirtelig.......Najas (30).

Bt. ohne Bthülle; Frkn. 2, mit fädlichen Gr.; lebt 9 im Meere ................. Cymodocea (30).

K. u. Blkr. 3 blättrig; Frkn. unterständig; lebt im süßen Wasser .............. Vallisneria (33).

*) Vgl. auch Asparagus unter Nr. 6. 
3. Ordnung. Triandria. In jeder männlichen Blüte 3 freie Staubblätter.

1\{ Holzgewächse . ....................

$1\{$ Stauden 0. Kräuter ......................... 6

${ }_{2}\left\{\begin{array}{r}\text { B. gefiedert; Bthülle einfach, } 3(-5) \text { blättrig. } \\ \text { Pistacia (365). }\end{array}\right.$

B. ungetheilt 0 . gelappt $\ldots \ldots \ldots \ldots \ldots \ldots \ldots \ldots$

.

(Männliche und weibliche Bt. im Innern eines flei-

$3\left\{\begin{array}{r}\text { schigen Behälters eingeschlossen; B. meist gelappt. } \\ \text { Ficus (167). }\end{array}\right.$

St. in Kätzchen, ohne Bthülle; S. mit Haarschopf.

4 Salix (155).

Bthülle stets vorhanden; Bt. nicht in Kätzchen ...

Bthülle einfach, 3 spaltig, gelblich; N. 3; Fr. flei5 schig, röthlich .................

5 Kb. u. Krb. 3, letztere rosa ; N. 6-9 strahlig; Steinfr. schwarz .............. Empetrum (364).

$6\{$ Untergetauchte Wasserpfl.; K. u. Blkr. 3 blättrig .. 7

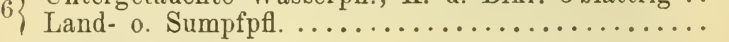

B. klein, lanzettlich, fein gesägt, zu $3-4$ wirtelig.

$\int_{7}$ B. verläugert-lineal, nur Elodea (33). 8 gesägt, am Grunde des schaftes rosettig.

Vallisneria (33).

$8\left\{\begin{array}{l}\text { Riedgräser; Bt. ohne Bthülle, von Spelzen umgeben. } \\ \text { Carex (84). }\end{array}\right.$

Pfl. nicht grasartig; Bthülle stets vorhanden......

Blkr. verwachsenblättrig; Stauden mit gegenstän-

9 digen B. .............. Valeriana (534).

Bthülle einfach, freiblättrig ............ 10

${ }_{10}$ Pfl. mit Brennhaaren; B. gegenständig, gesägt; N. 1,

10 kopfig-pinselförmig ............. Urtica (168).

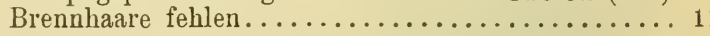

Am Grunde der B. häutige Nebenbscheiden; kleine Alpenpfl. mit nierenförmigen B.; Bthüllb. 4; Gr. :2;

11 Fr. geflügelt ................. Oxyria (176). Nebenbscheiden fehlen; B. niemals nierenförmig; Bthüllb. $3(-5)$.............. Atriplex (181)

4. Ordnung. Tetrandria. In jeder männlichen Blüte 4 freie Staubblätter.

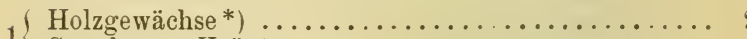

*) Vgl. auch $\mathrm{Nr}$. 8 . 
Auf Holzgewächsen schmarotzende Sträucher mit

2 gegenständigen, manchmal schuppenförmigen B.;

Frkn. unterständig (Loranthaceae, vergl. Seite 169)

Nicht schmarotzende Pfl....................

Bt. in Kätzchen, ohne Bthülle, von schuppenförmigen

3 Tragb. gestützt ................ Salix (155). Bt. nicht in Kätzchen, stets mit Bthülle ........ 4

${ }_{4}$ Bthüllb. 2; dorniger Strauch; B. lineal-lanzettlich, 4 unterseits weißlich-schülferig..Hippophaë (387).

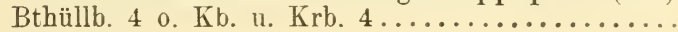

(Kb. u. Krb. 4, letztere selten fehlend; Bt. niemals 5 in Aehren; B. niemals gelappt. Rliamnus (370). Bthülle einfach; Bt. in gestielten, dickblütigen Aehren ; B. meist gelappt..........Morus (167).

( Pfl mit Brennhaaren; B. gegenständig, gesägt.

6 Urtica (168).

Brennhaare fehlen.......................

N. 4; Kräuter mit spießförmig-dreieckigen, ganz7 randigen B................ Spinacia (181).

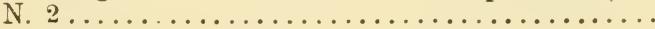

\& $\left\{\begin{array}{l}\text { Sternhaariger, niedriger Strauch mit lanzettlichen } \\ \text { B. und wolligen weiblichen Bt..... Eurotia (179). } \\ \text { Kahle, mehlig bestäubte } 0 . \text { schülferige Kräuter, sel- }\end{array}\right.$ tener kleine Sträucher........... Atriplex (181).

5. Ordnung. Pentandria. In jeder männlichen Blüte 5 freie Stanbblätter.

1) Holzgewächse*) ....................... 2

Stauden 0. Kräuter...................... 10

(Mittels Ranken kletternde Sträucher mit gelappten

2 o. gefingerten B.; K. 5 zähnig 0 . undeutlich; Krb. 5 (Ampelideae, vergl. Seite 371).

Rankenlose Pfl. .......................

$3\{$ B. gefiedert 0. 3 zählig ................... 4

B. ungetheilt 0 . gelappt.................. 6

Bthülle einfach...................... 5

4 K. u. Blkr. 5 blättrig; Frkn. oberständig, mit einer Samenknospe; N. $3 \ldots \ldots \ldots$......Rhus (366).

Frkn. mit einer einzigen Samenknospe; Blättchen

5 am Grunde nicht abgegliedert ...Pistacia (365).

Frkn. mit mehreren Samenknospen; Blättchen am Grunde abgegliedert.......... Ceratonia (314).

*) Vgl. auch Atriplex unter Nr. 14. 
( B. gelappt; Krb. u. Krb. 5; Frkn. unterständig; Fr.

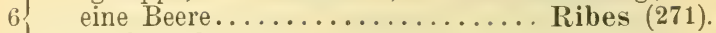

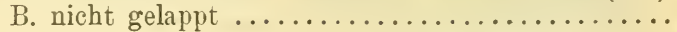

B. nadelförmig-lineal o. schuppenförmig; Samen-

7 knospen auf der Oberseite der Frb. ........... B. flach; Samenknospen im Innern eines geschlossenen Frkn.

B. nadel- o. schuppenförmig, gegenständig 0 . wirtelig,

8 meist dicht gedrängt............ Juniperus (21).

B. lineal, den Tannennadeln ähnlich, 2 zeilig gestellt.

Taxis (21).

( K. u. Blkr. 5 blättrig, letztere selten fehlend; Bt.

9 nicht in Kätzchen........... Rhamnus (370).

Bt. in Kätzchen, ohne Bthülle, von schuppenförmigen Tragb. gestützt . . . . . . . . . . Salix (155).

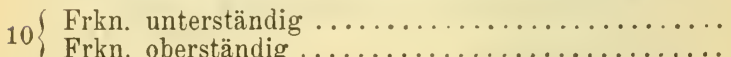

Bt. in Köpfchen gehäuft, welche von Hüllb. umgeben sind; Blkr. verwachsenblättrig (Compositce, 11 vergl. Seite 551).

Bt. in zusammengesetzten Dolden; Krb. frei.

Trinia (412).

Pfl. windend; B. gelappt, seltener ungetheilt; Stg.

12 von Klimmhaaren rauh; männliche Bt. in Rispen,

weibliche in Kätzchen.........Humulus (167).

Pfl. nicht windend..................... 13

Einjähriges Kraut mit handförmig 3-9 schnittigen

13 B.; Btstände beblättert, die männlichen traubenartig, die weiblichen ährenartig. Cannabis (167).

B. ungetheilt 0 . gelappt................. 14

N. 4; Kräuter mit spießförmig-dreieckigen, ganz-

14 randigen $\mathrm{B} . \ldots \ldots \ldots \ldots \ldots$. . . . . . N. 2; Kräuter o. kleine Sträucher; B. meist gezähnt. Atriplex (181).

6. Ordnung. Hexandria. In jeder männlichen Blüte 6 freie Staubblätter.

1) Kletterpflanzen..................... 2

$1\{$ Nicht kletternde Gewächse ............... 3

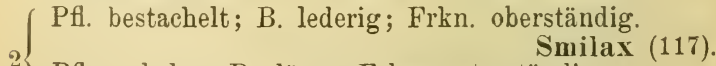

2 Pfl. wehrlos; B. düın; Frkn. unterständig.

Tamus (119).

Auf Holzgewächsen schmarotzende Sträucher mit 3 gegenständigen B............ Lorauthus (169).

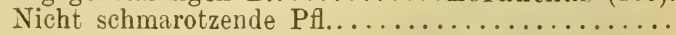


(Untergetauchte Wasserpfl. mit wirteligen B.; K. u.

4 Blkr. 3 blättrig; Frkn. unterständig. Elodea (33). Land- o. Sumpfiptl.; B. nicht wirtelig ...........

B. schuppenförmig, in ihren Achseln Büschel nadel-

5 förmiger 0. fadenförmiger Zweige; Bthüllb. 6; Fr. eine Beere............. Asparagus (116).

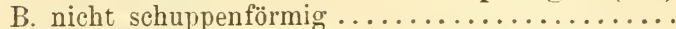

Holzgewächse; Bt. in Kätzchen, ohne Bthülle, von 6 schuppenförmigen Tragb. gestütıt.. Salix (155). Stauden o. Kräuter; Bthüllb. 6 ....Rumex (173).

7. $O r d n u n g$. Octandria. In jeder männlichen Blüte 8 freie Staubblätter.

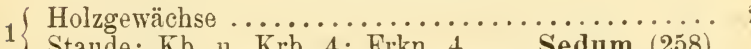

Staude; Kb. u. Krb. 4 ; Frkn. 4 .... Sedum (258) K. u. Blkr. vorhanden; B. gegenständig, meist ge-

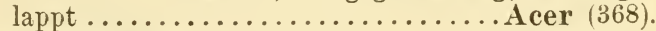
Bt. in Kätzchen, ohne Bthülle, von schuppenförmigen

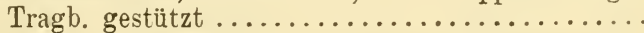

Tragb. der Bt. (Kätzchenschuppen) gespalten o. doch gezähnt; B. lang gestielt, rundlich, dreieckig 0 .

3 rhombisch ............................ Tragb. der Bt. ungetheilt; B. kurz gestielt, elliptisch 0 . eiförmig ..................

8. Ordnung. Enneandria. In jeder männlichen Blüte 9 freie Staubblätter.

( Holzgewächse; Bt. in Kätzchen, ohne Bthülle (Sali-

1 cinecue, vergl. Seite 154).

(Stauden o. Kräuter; Bthïlle stets vorhanden..... 2

(Wasserpfl.; Kb. u. Krb. 3; Frkn. unterständig .... 3

2 Landpfl.; Bthülle einfach, grünlich; Frkn. oberständig; B. gegenständig......Mrercurialis (358).

B. lang gestielt, lundlich-nierenförmig, ganzrandig;

3 Bt. ansehnlich ............ Hydrocharis (33). B. sitzend, lanzettlich, fein gesägt, wirtelig; Bt. klein.

Elodea (33).

9.-12. Ordnung. Decandria, Dodecandria, Icosandria, Polyandria. In jeder männlichen Blüte 10 oder mehr freie Staubblätter.

$1\{$ Holzgewächse $\ldots \ldots \ldots \ldots \ldots \ldots \ldots \ldots \ldots \ldots \ldots \ldots$

$1\{$ Stauden 0. Kräuter .....................

(Bt. ohne Bthülle, in kätzchen- o. zapfenförmigen Btständen, seltener einzeln

Bthüllb. 4; Stb. 12, A. mit Klappen aufspringend;

B. lederig, immergrün ........ Laurus (228). 
(B. nadelförmig-lineal u. schuppenförmig; Samenknospen auf der Oberseite der Frb. ............

B. flach; Samenknospen im Innern eines geschlossenen Frkn.; S. mit Haarschopf (Salicineae, vergl. Seite 154).

B. nadel- o. schuppenförınig, gegenständig o. wirtelig, 4 meist dicht gedrängt..........Juniperus (21). B. lineal, den Tannennadeln ähnlich, 2 zeilig gestellt. Taxus (21).

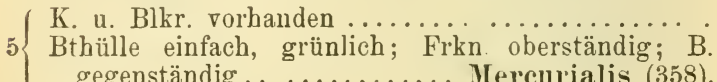
gegenständig........... Mercurialis (358).

$6\left\{\begin{array}{l}\text { Kb. u. Krb. } 3-4 \ldots \ldots \ldots \ldots \ldots \ldots \ldots \ldots \\ \text { Kb. u. Krb. } 5 \text { (nur ausnahmsweise } 4 \ldots \ldots \ldots \ldots \ldots \ldots\end{array}\right.$

Kb. u. Krb. 3, letztere weiß; Wasserpfl. mit schwertförmig-linealen, 3 kantigen, stachelig gezähnten B.

7 Stratiotes (33).

Ko. u. Krb. 4, letztere grünlichgelb o. röthlich; Gebirgspfl. mit länglich-lanzettlichen, dicklichen B. Sedum (258).

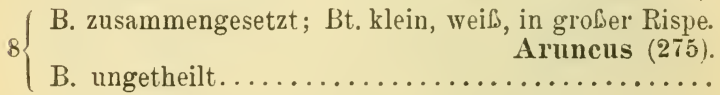

(B. gegenständig; Frkn. 1, Gr. 3-5 (Caryophyllaceae. vergl. Seite 187).

B. schraubig gestellt, herz-nierenförmig, 5 lappig; Frkn. u. Gr. mehrere ..........Rubus (278).

13.-15. Ordnung. Monadelphia, Polyadelphia, Syngenesia. Die Staubblätter jeder männlichen Blüte entweder mit ihren Staubfäden oder mit ihren Antheren unter einander mehr oder weniger verwachsen.

Kleinel Strauch mit gegliederten Zweigen; B. gegenständig, schuppenförmig. paarweise zu stengelumfassenden Scheiden verwachsen. Ephedra (22).

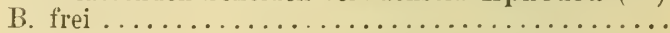

( Holzgewächse mit nadel- o. schuppentörmigen $\mathrm{B}$;

2 Samenknospen auf der Oberseite der Frb.......

Samenknospen im Inneren eines geschlossenen Frkn.

(B. lineal, den Tannennadeln ähnlich, 2 zeilig gestellt.

$3\left\{\begin{array}{l}\text { Taxus (21). } \\ \text { B. nadel- o. schuppenförmig, gegenständig } 0 \text {. wirtelig. }\end{array}\right.$ Juniperus (21).

Mittels Ranken kletternde Gewächse; Blkr. ver-

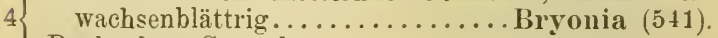

Rankenlose Gewächse .................. 5 
5 Bt. auf der Oberseite blattartig verbreiterter Zweige

5 (Phyllocladien) eingefügt; Stb. 3. Ruscus (116). Zweige nicht blattartig; Stb. $20 .(4-) 5 \ldots \ldots \ldots 6$

( Holzgewächse; Bt. in Kätzchen; Stb. 2. Salix (155).

6 Stauden 0. Kräuter; Bt. in Köpfchen; Stb. (4-)5. (Compositae, vergl. Seite 551).

XXIII. Classe. POLYGAMIA. Blüten vielehig, d. h. neben zwittrigen finden sich auch männliche oder weibliche Blüten.

Die hieher gehörigen Gattungen sind nach der Beschaffenheit ihrer Zwitterblïten in den entsprechenden Classen (I-XX) zu suchen.

XXIV. Classe. CRYPTOGAMIA. Pflanzen ohne Blüten, d. h. ohne Staubblätter und ohne Fruchtblätter.

In diese Classe gehören die Farnpflanzen, Moose, Algen, Pilze und Flechten. Von diesen sind in dem vorliegenden Buche nur die Farnpflanzen behandelt, zu deren Bestimmung die Tabellen auf Seite $1-17$ dienen. 


\section{Uebersicht des natiirlichen Pflanzen- systems.}

Die Pflanzen werden nach ihren Fortpflanzungsrerhältnissen in vier große Hauptstämme eingetheilt, deren wichtigste Merkmale hier folgen.

1. Hauptstamm. Thallophyta. Lagerpflanzen.

Pflanzen ohne deutliche Gliederung in Stengel, Blätter und Wurzeln. Die Fortpflanzungsverhältnisse sind sehr verschieden, jedoch kommt der für die folgenden Hauptstämme charakteristische regelmäßige Wechsel zwischen einer ungeschlechtlichen (Sporen erzeugenden) und einer geschlechtlichen (männliche und weibliche Fortpflanzungsorgane erzeugenden) Generation hier niemals vor. Die Fortpflanzungsorgane der Lagerpflanzen werden gewöhnlich Sporen genannt, sind aber unter einander sehr verschieden.

$\mathrm{Zu}$ diesem Hauptstamme gehören die Pilze, Flechten und Algen, welche in diesem Buche nicht abgehandelt sind.

\section{Hauptstamm. Bryophyta. Moose.}

Pflanzen mit oder ohne Gliederung in Stengel, Blätter und Wurzeln, welche in eigenen Sporenbehältern (Sporogonen) ungeschlechtliche Fortpflanzungsorgane (Sporen) erzeugen. Aus der Spore entwickelt sich zunächst ein kleiner, meist fadenförmiger, oft verzweigter Vorkeim (Protonema), und aus diesem die eigentliche Moospflanze. An letzterer kommen dann männliche und weibliche Fortpflanzungsorgane (Antheridien und Archegonien) zur Entwicklung. In den Antheridien entstehen zahlreiche mikroskopisch kleine Befruchtungszellen (Spermatozoiden), in jedem Archegonium stets nur eine Eizelle. Nach der Vereinigung der Befruchtungszellen mit der Eizelle (Befruchtung) entsteht aus letzterer ein (oft gestielter) Sporenbehälter.

Zu diesem Hauptstamme gehören die Lebermoose und die Laubmoose, welche in diesem Buche nicht abgehandelt sind.

3. Hauptstamm. Pteridophyta. Farnpflanzen.

Vergl, unten Seite 1.

4. Hauptstamm. Anthophyta. Blütenpflanzen.

Vergl. unten Seite 18. 


\section{Fteridophyta. Farnpflanzen.}

Pflanzen mit Stengeln, Blättern und Wurzeln, welche in eigenen Sporenbehältern (Sporangien) ungeschlechtliche Fortpflanzungsorgane (Sporen) erzeugen. Aus der Spore entwickelt sich zunächst ein kleiner, laubartiger oder knollenförmiger, manchmal nur aus wenigen Zellen bestehender Vorkeim (Prothallium), welcher männliche oder weibliche Fortpflanzungsorgane (Antheridien oder Archegonien) oder beiderlei nebeneinander trägt. In den Antheridien entstehen zahlreiche mikroskopisch kleine Befruchtungszellen (Spermatozoiden), in jedem Archegonium stets nur eine Eizelle. Nach der Tereinigung der Befruchtungszellen mit der Eizelle (Befruchtung) entsteht aus letzterer der Keim (Embryo), aus dem sich dann erst die Sporenbehälter tragende Pflanze entwickelt.

\section{Classen.}

Stengel gegliedert, an den Knoten von ringsum geschlossenen, gezähnten Scheiden (wirtelständigen,

1 verwachsenen B.) ungeben.... Equisetinae. II. Stengel nicht gegliedert; B. nicht in Scheiden ver-

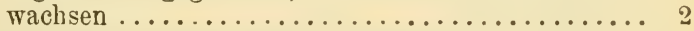

Sporenbehälter am Grunde der Oberseite der B. einzeln sitzend, oft zu Aehren vereinigt.

Lycopodinae. III. Sporenbehälter in Gruppen vereinigt, auf der Unterseite der B. oder an eigenen, umgestalteten Blattabschnitten.................. Filicinae. I.

\section{Classe. Filicinae. Farnartige Gewächse,}

\section{Familien.}

Landpflanzen. Sporenbehälter zahlreiche, untereinander gleiche Sporen enthaltend (Isosporeae).... Sumpf- oder Wasserpflanzen. Sporenbehälter von zweierlei Art [Makrosporangien, welche nur eine einzige Spore (Makrospore), und Mikrosporangien, welche zahlreiche viel kleinere Sporen (Mikrosporen) enthalten], in eigene Gehäuse (Sporenfrüchte, Sporocarpien) eingeschlossen (Heterosporeae)......... 
Jedes fruchtbare $B$. in zwei ganz getrennte Theile gesondert: der eine laubartig, ungetheilt oder fiederig getheilt, ohne Sporenbehälter: der andere nicht laubartig, die Sporenbehälter tragend; $\mathrm{V}_{\mathrm{O}}$ keim sehr klein, unterirdisch, nicht grün gefärbt

Ophioglossaceae. III.

Fruchtbare B. nicht in zwei Theile gesondert oder der obere Theil eines getheilten B. die Sporenbehälter tragend; Vorkeim laubartig, oberirdisch, grün gefärbt

Fruchtbare B. doppelt gefiedert: die Abschnitte der unteren Fiedern laubartig, ohne Sporenbehälter; die der oberen Fiedern in Sporangienähren umgewandelt; Sporangien ohne Ring, mit einem Längsriss aufspringend..... Osmundaceae. II. Sporenbehälter in verschieden gestalteten Gruppen (Sori) auf der Unterseite der fruchtbaren B., init einem Ring verdickter Zellen umgeben, mit einem Querriss aufspringend .......Polypodiaceae. I. Schwimmende Wasserpflanzen mit fast sitzenden, ungetheilten Schwimmb. und wurzelähnlichen, in viele lange Zipfel gespaltenen Wasserb., zwischen deren Zipfeln die Sporenfrüchte sitzen, deren jede entweder nur Makrosporangien oder nur Milirosporangien enthält..........Salviniaceae. IV. Sumpfpflanzen mit echten Wurzeln und entweder binsenartigen oder langgestielten, vierzähligen B.; Sporenfrüchte am Grınde der B., jede Makrnsporangien und Mikrosporangien nebeneinander enthaltend............... Marsiliaceat. V.

\section{Familie. Polypodiaceae. Echte Farnkräuter.}

Stauden mit ausdauerndem Wurzelstock (sehr selten Kräuter). B. gewöhnlich groß, schraubig gestellt, meist einbis mehrfach fiederförmig getheilt, stets deutlich (meist ziemlich lang) gestielt. Sporenbehälter in verschieden gestalteten Gruppen (Sori) auf der Unterseite normal ausgebildeter oder mehr oder weniger umgestalteter B., gestielt, von einem Pinge verdickter Zellen umgeben, mit einem Querriss aufspringend. Vorkeim laubartig, grün gefärbt, oberirdisch, meist Antheridien und Archegonien nebeneinander tragend.

\section{Gattungen.}

Fruchtbare B. von den unfruchtbaren auffallend verschieden; die unreifen Sporenbehälter von den umgerollten Rändel'n der Blattabschnitte oder von einem, eingerollten Schleier (Indusium) bedeckt.. Fruchtbare B. wie die unfruchtbaren normal ausgebildet..$\ldots \ldots \ldots \ldots \ldots \ldots \ldots \ldots \ldots \ldots$ 
Fruchtbare B. einfach gefiedert oder fiederschnittig, mit ganzrandigen oder fiederlappigen, sitzenden

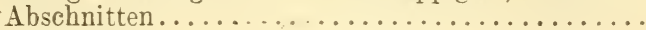

Fruchtbare B. 2-4 fach gefiedert, mit gestielten

2 Fiederchen; Sori bis zur. Sporenreife ron den ungerollten Rändern der Fiederchen bedeckt; unfruchtbare B. kürzer gestielt, $2-4$ fach gefiedert, mit eingeschnitten-gekerbten Abschnitten.

Cryptogramme. IT

Unfruchtbare und fruchtbare B. fiederschnittig, mit ganzrandigen Fiedern; fruchtbare B. länger; Sporenbehälter zu beiden Seiten des Mittelnerven jeder Fieder lange, lineale Streifen bildend, welche von je einem eingerollten, fast die ganze Länge der Fieder einnehmenden Schleier bedeckt sind.

Blechnum. TII.

Unfruchtbare B. gefiedert, mit fiederspaltigen Fiedern; fruchtbare B. viel kürzer; Sporenbehälter in kleinen Gruppen, deren jede anfangs von einem Schleier bedeckt ist, alle von den zurückgerollten Fiederrändern eingeschlossen.......... Onoclea. XY.

B. oberseits dunkelgrün, unterseits von anfangs silbergrauen, später rostbraunen Spreuschuppen dicht bedeckt, also ausgesprochen zweifarbig....

B. nicht zweifarbig, beiderseits heller oder dunkler grün (nur durch die reifen Sporen unterseits oft mehr oder minder braun überzogen)..........

B. fiedertheilig, mit ganzrandigen oder etwas gelappten Fiedern; Sori lineal, ohne deutlichen Schleier, aber von den Spreuschuppen dicht bedeckt.

Ceterach. XI.

B. doppelt fiederschnittig; Sori vor dem Rande der Fiederchen zu einem breiten Bande vereinigt, welches jedoch ron den Spreuschuppen rerdecht ist, ohne Schleier........... Notholaena. III.

B. ungetheilt oder unregelmäßig gelappt oder am Grunde mit einigen ganz abgetrennten Abschnitten; Sori lineal oder länglich, mit Schleier.

Scolopendrinm. TIII.

B. regelmäßig fiederschnittig oder gefiedert (selten dreischnittig) oder mehrfach getheilt ......... Sporenbehälter am Rande der Fiederchen eine ununterbrochene Linie bildend. mit doppeltem Schleier*); B. grol, im Umrisse dreieckig, 3-4fach fiederschnittig .......... Pteridium. VI. Sporenbehälter nicht am Rande der Fiederchen eine Linie bildend.

*) Der äußere Schleier kann leicht als umgerolltel Blattrand angesehen werden. 
Sori von umgeschlagenen, braunen Lappen des Randes der Fiederchen bedeckt; Wst. kriechend;
B. 2-3 fach gefiedert, mit sehr dünnem Bstiel.

Sori frei oder von einem Schleier bedeckt ......

Sori mit einem fast bis zum Grunde in harförmige Zipfel getheilten Schleier (daher scheinbal' von zahl9 reichen Haaren umgeben)....... Woodsia. XVI. Sori mit ungetheiltem, seltener am Rande gezähntem und gewimpertem Schleier oder schleierlos ......

10 Sori vor der Reife von einem Schleier bedeckt ....

Sori ohne Schleier, von Anfang an nackt........ 15

Sori rundlich 0 . eiförmig, oft sehr klein........ 12

11 Sori länglich, lineal oder hakenförmig, manchmal zu größeren Flecken zusammenfließend ..........

Schleier schildförmig oder nierenförmig, den ganzen Sorus bedeckend; meist growe, kräftige Farne mit

12 1-3 fach fiederschnittigen B... Aspidium. XIII. Schleier eiförmig, zugespitzt oder verkïmmert und den Sorus nur theilweise verdeckend .........

Schleier eiförmig, zugespitzt, vergänglich; zarte Farne mit mehrfach fein getheilten B.

Schleier verküınmert, kann 2-3 fach fiederschnittig........ Athyrium. IX'

Spreuschuppen durch Verdickung der Wandzellen gegittert, starr, oft borstenförmig, dunkel gefärbt; meist kleine Farne mit düınem Bstiel; Btheilung

14 verschieden ............... Asplenium. X. Spreuschuppen weich, hellbraun, nicht gegittert; kräftige Farne mit großen, $2-3$ fach fiederschnittigen B............. Athyrium. IX.

B. tief fiedertheilig, mit ganzrandigen oder gesägten Abschnitten; Wstock kriechend, zweizeilig be-

15 blättert; Bstiel am Grunde abgegliedert; Sori kreisrund............... Polypodium. I.

B. mindestens doppelt fiederschnittig ......... 16

Einjähr. *), kleine Pflanze; B. $2-3$ fach fiederschnittig, mit gabelspaltigen oder ausgerandeten Fiederchen;

$16\{$ Sori meist länglich ........Gymnogramme. II. Wst. ausdauernd; Fiederchen weder gabelspaltig noch

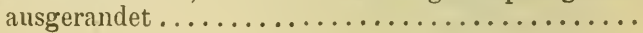

*) Streng genommen ist die Pfl. 2jährig, der Vorkeim sogar ausdauernd. 
Wst. dünn, kriechend; Bstiel dünn, mindestens so lang als die Spreite; ziemlich kleine, zarte Farne.

Phegopteris. XII.

Wst. dick, schief oder aufrecht; Bstiel viel kürzer als die große, 2 --3 fach fiederschnittige Spreite.

Athyrium. IX.

\section{Arten.}

I. POLYPODICM. L. Tüpfelfarn.

Babschnitte lineal-länglich; Sori zu beiden Seiten des Mittelnervs. Tertr.......vulgare. L. Engelsüß.

\section{GYMNOGRAMME. Desv. Nacktfarn.}

Bstiel braun, glänzend; Bspreite zart, hellgrün; Sori auf den Endabschnitten der Fiederchen, oft zuletzt zusammenfließend. Südt.

leptophylla. (L.) Desv. Zartblättriger N.

\section{NOTHOLAENA. $R$. Br. Pelzfarn.}

Fiederchen länglich, die oberen am Grunde verbreitert, ganzrandig, die unteren oft etwas gelappt. MI. N. St. T.

Marantae. (L.) R. Br. Maranta's P.

\section{V. CRYPTOGRAMIE. $R$. $B r$. Rollfarn.}

Fiederchen der fruchtbaren B. meist lineal oder länglich; zwischen den unfruchtbaren und fruchtbaren B. oft solche mit nur theilweise fruchtbaren Fiederchen. Gel, von B. N. St. K. S. T. crispa. (L.) R. Br. Alpen-R.

\section{ADIANTUM. L. Haarfarn.}

Fiederchen verkehrt-eiförmig, am Grunde keilig, vorne meist eingeschnitten-gelappt, die unfruchtbaren fein gekerbt. Sü̈lt. $I i r . J$.

Capillus Veneris. L. Venushaar.

\section{PTERIDIUM. Kuhn. Adlerfarn.}

Wst. kriechend; B. einzeln; Fiederchen meist ganzrandig. Ver.br. $u$. $h \mathrm{fg}$.

aquilinum. (L.) Kulın. Gemeiner A.

\section{BLECHNUM. L. Rippenfarn.}

Wst. dicht beblättert; B. daher gebüschelt, die unfruchtbaren oft am Boden liegend. Verbr.

Spicant. (L.) Sm. Gemeiner R. 


\section{SCOLOPENDRIUM. Sm. Hirschzunge.}

B. groß, lineal-länglich, ganzrandig, selten etwas wellig und gekerbt; Sori lineal. Verbr. (fehlt Sch.) vulgare. Sm. Gemeine $\mathrm{H}$.

B. klein, mindestens gegen den Grund zu gelappt oder daselbst mit einigen ganz getrennten $\mathrm{Ab}$ schnitten; Sori länglich, ziemlich dick. .J. (Lussin). hybridum. Milde. Bastart-H.

\section{ATHYRILM. Roth. Frauenfarn.}

Sori länglich oder hakenförmig, mit gut entwickeltem, am Rande meist gewimpertem Schleier; Fiederchen schmal, spitz, eingeschnitten-gesägt. Verbr. u. $h \mathrm{fg}$.

Filix femina. (L.) Roth. Geineiner F.

Sori rundlich, klein, mit verkümmertem, kaum bemerkbarem Schleier; Fiederchen weniger spitz, mit etwas breiteren Sägezähnen. Geb.

alpestre. (Hoppe.) Rylands. Alpen-F.

\section{ASPLENIUH. L. Streifenfarn.}

B. handförmig oder unregelmänig gabelig- $2-5$ theilig, nicht deutlich gefiedert ...............

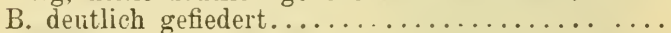
2

Babschnitte 2-5, lineal o. lineal-lanzettl., an der Spitze ungleich eingeschnitten - 2-3zähnig, kahl. I erbr. septentrionale. (L.) Hoffm. Nordischer S.

Babschnitte meist 3, rhombisch-eif., an der Spitze manchmal 2-3spalt., am Grunde keilig, dicht behaart; Pfl. sehr klein. Sï̈t. K. Kr. J. N.

Seelosii. Leyb. Tiroler St.

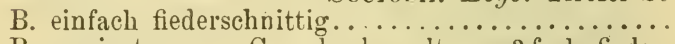

B. wenigstens am Grunde doppelt- 0. 3 fach fieder-

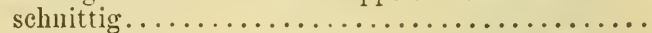

Bstiel nur am Grunde braun, sonst wie die Bspindel griin; Fiedern rundlich-eiförmig, am Grunde keilig, gekerbt. Terbr. ....... viride. Huds. Grüner ș. Bstiel und mindestens der untere Theil der Bspindel

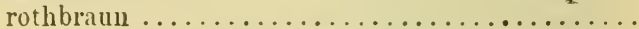

Die ganze Bspindel rothbraun, schmalhäutig geflügelt; Fiedern eiförmig oder länglich, abstehend. Verbr. ı. hfg..... Trichomanes. L. Schwarzstieliger S. Bspindel nicht geflügelt, gegen die Spitze zı grün; Fiedernn rundlich-eiförmig, zurückgeschlagen. B. M. St. . . adulterinum. Milde. Unechter S. B. gegen die Spitze u. gegen den Grund hin verschmälert, im Umrisse lineal-lanzettlich, doppelt fiederschnittig; Fiederchen stachelspitzig-gezähnt oder fiederspaltig. T. K. St.

fontanum. (L.) Bernh. Quellen-S.

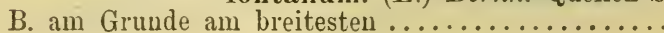


Schleier gewimpert-gezähnt ............. 8

Schleier ganzrandig oder etwas gekerbt........ 9

B. kurz drüsig behaart, Abschnitte zart, breit keilförmig, vorne meist dreilappig, mit gekerbten Lappen. Sü̈lt. J... lepidum. Presl. Drüsiger S.

8 B. kahl (sehr selten behaart); Abschnitte derb, verkehrt eiförmig oder länglich, am Grunde keilig, vorne meist gekerbt oder gezähnt, seltener gelappt. Verbr. u. hfg. .... Ruta muraria. $L$. Mauer-S.

B. zart, sehr fein zertheilt; Fiederchen lineal-keilig, vorne gezähnt oder $2-3$ spaltig. 1 . O. St. Kr.J. K. Sï̈dt. ........fissum. Kit. Feinblättriger s

B. derb, oft lederig; Fiederchen eiförmig oder länglich, selten verkehrt-eiförmig oder am Grunde

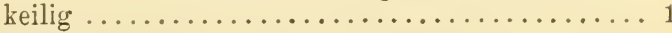

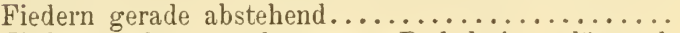

Fiedern aufwärts gekrümmt; B. lederig, glänzend, überwinternd; Fiederchen meist länglich. Sïdt. $J$

Onopteris. L. Spitziger S.

B. lederig, glänzend, überwinternd; Fiederchen eiförmig oder länglich. Verbr. (fehlt $S$. O.)

Adiantum nigrum. $L$. Schwarzer S.

B. nicht glänzend, im Herbste absterbend, feiner getheilt; Fiederchen am Grunde keilig. B. M. N. St. cuneifolium. Viv. Serpentin-S.

Anmerkung. Der Bastart A. septentrionale $X$ Trichomanes kommt in mehreren Formen vor. Auberdem wurden beobachtet $A$. adulterinum $\times$ viride, A. Ruta muraria $\times$ Trichomanes und A. Adiantum nigrum $X$ Trichomanes.

\section{CETERACH. Willd. Milzfarn.}

B. lederig, überwinternd; Fiedern eiförmig oder länglich, stumpf. $B$. T. Südst. $K r$. J.

officinarum. Willd. Europäischer II.

\section{PHEGOPTERIS. Fée. Punktfarn.}

B. im Umrisse eiförmig-dreieckig, lang zugespitzt, beiderseits behaart, fiederschnittig; Fiedern fiederspaltig, die untersten meist herabgeschlagen, die mittleren am Gruude zusammenfließend; Fiederchen länglich, stumpf, ganzrandig, seltener gekerbt. Verbr......... polypodioides. Fée. Buchenfarn.

B. im Umrisse breit-dreieckig, 3 zählig-doppelt-fiederschnittig; Fiedern nicht zusammenfließend ...... 
B. kahl, weich und schlaff; die drei Hauptabschnitte des Blattes nahezu gleich groß. Verbr. B. fein drüsig, derb und steif; der mittlere Hauptabschnitt des Blattes viel gröber als die seitlichen. Verbr. Robertiana. (Hoffm.) A. Br. Kalkfarn.

\section{ASPIDIUM. Sx. Schildfarn.}

B. einfach-gefiedert, Fiedern lanzett.-sichelf, am Grunde vorne spitz-geöhrlt, doppelt-gesägt, Sägezähne dornig-stachelspitzig; Schleier kreisrund, 1 schild förmig. Geb.

Lonchitis. ( $L$ ) Sw. Lanzen-Sch.

B. doppelt- bis 3 fach-gefiedert, oder doch mit fieder-

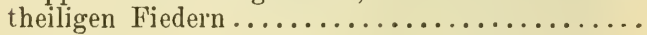

2 Schleier kreisrund, schildförmig, in der Mitte befestigt

2 Schleier nierenförmig, in der Ausrandung befestigt

B. derb, lederig, oberseits glänzend, überwinternd, doppelt-fiederschnittig; Fiederchen länglich-eiförmig oder fast sichelförmig, stachelspitzig gesägt, das erste obere jeder Fieder größer; Schleier derb, lange bleibend. Vertr:

lobatum. (Huds.) Su. Gelappter Sch.

B. nicht lederig, glanzlos, doppelt-fiederschnittig; Fiederchen gesägt, die unteren oft fast fiederspaltig, das erste obere nicht auffallend größer, Sägezähne plötzlich in Grannen auslaufend; Schleier zart, hin-

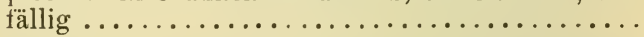

B. am Grunde wenig verschmälert; Fiedern lang zugespitzt, im Umrisse lineal-lanzettlich; Fiederchen (wenigstens die unteren) kurz gestielt. $M$. Sch. aculeatum. (L.) Sw. Stacheliger Sch.

B. am Grunde stark verschmälert; Fiedern kurz zugespitzt, im Umrisse länglich; Fiederchen fast sitzend, die oberen herablaufend. Verlr. (feblt $O$. $K r$.J.) ........ Braunii. Spenn. Braun's Sch.

Fiederchen ganzrandig oder etwas wellig .........

5 Fiederchen wenigstens vorne gesägt oder fieder-

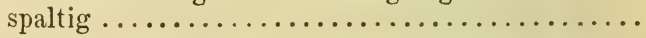

$\mathrm{W}$ st. dünn, kriechend; B. lang gestielt, nach unten wenig oder gar nicht verschmälert, drüsenlos; fruchtbare Fiederchen am Rande eingerollt. Verbr.

Thelypteris. ( $L$ ) Siv. Sumpf-Sch.

Wst. dick, dicht beblättert; B. kurz gestielt, nach unten stark verschmälert, unterseits drüsig; fruchtbare Fiederchen flach. $V(r)$.

montanum. (Vogler.) Aschers. Berg-Sch. 
Fiedern fiederspaltig oder fiedertheilig ......... 8

7 Fiedern gefiedert oder doppelt gefiedert, B. also vollkommen doppelt- oder 3 fach-gefiedert.........

Bstiel kurz, kräftig; Fiedern lineal-lanzettlich, zugespitzt; Fiederchen vorne gesägt, Sägezähne ohne stachelspitze. Verbr. u. hifg.

Filix mas. (L.) Sw. Wurmfarn.

Bstiel lang, dünn; Fiedern dreieckig-eiförmig, nicht zugespitzt; Fiederchen fein gesägt, mit stachelspitzigen Sägezähnen. B. T. S. K.

cristatum. (L.) Su. Gezackter Sch.

B. kurz gestielt, im Umrisse länglich-lanzettlich, beiderseits drüsig; Fiederchen stumpf; eingeschnitten-gesägt oder fiederspaltig. $A$.

rigidum. (Hoffm.) Sw. Starrer Sch.

B. lang gestielt, im Umrisse dreieckig-eiförmig oder

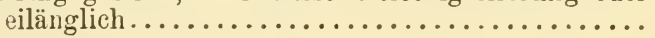

Bstiel so lang oder länger als die Spreite, spärlich mit hellbraunen Spreuschuppen besetzt; B. doppeltfiederschnittig, mit gezähnten oder fiedertheiligen Fiederchen, drüsenlos. Verbr.

spinulosum. (Müll.) Su. Dorniger Sch.

Bstiel kürzer als die Spreite, mit dunkelbraunen

spreuschuppen meist ziemlich dicht besetzt; $B$. 3-4 fach fiederschnittig, oft drüsig. Verbr.

dilatatum. (Hoffin.) Sm. Verbreiterter Sch.

Anmerkung. Von Bastarten wurden im Gebiete $\mathrm{A}$. Lonchitis $\times$ lobatum, A. Braunii $\times$ lobatum, A. Filix mas $X$ spinulosum und $A$. cristatum $X$ spinulosum beobachtet.

\section{CYSTOPTERIS. Bernh. Blasenfarn.}

Wst. dünn, kriechend, entfernt beblättert; Bstiel länger als die Spreite; B. im Unrisse dreieckig oder eiförmig, 3 fach gefiedert, mit gezähnten oder

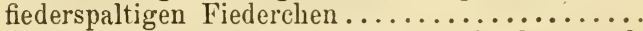

Wst. kurz, dicht beblättert; Bstiel meist kürzer als die Spreite; B. im Umrisse lanzettlich oder läng-

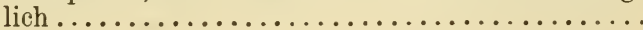

B. im Umrisse dreicckig-eiförmig, fast 3 zählig getheilt (die untersten Fiedern viel größer als die folgenden); Schleier kahl oder fast kahl. $A$. montana. (Lam.) Bernh. Berg-B.

B. im Umrisse breit-eiförmig; die untersten Fiedern nur wenig größer als die folgenden; Schleier dicht mit kleinen Drüsenhärchen besetzt. $M$. Sch.

Sudetica. A. Br. et Milde. Sudeten-B. 
B. 2-3 fach gefiedert; Fiederchen länglich, gezähnt oder fiederspaltig, mit stumpfen oder spitzen, selten ausgerandeten Abschnitten. Verbr. $u$. $h f y$.

fragilis. (I.) Bernh. Gemeiner B.

B. 3 fach oder fast 4 fach gefiedert, kleiner und feiner zertheilt; Fiederchen in lineale, an der Spitze ausgerandete Abschnitte getheilt. $A$. alpina. (Wulf.) Desv. Alpen-B.

\section{V. ONOCLEA. L. Straußfarn.}

Wst. dick, dicht beblättert; die untersten Fiedern sehr kurz; fruchtbare B. starr, braun gefärbt. Verbr. (fehlt $M . K r$. J.)

struthiopteris. (L.) Hoffm. Gemeiner S.

\section{WOODSIA. $R$. Br. Woodsie.}

Bstiel glänzend rothbraun, sowie die Bspindel ziemlich reichlich mit Spreuschuppen und Haaren

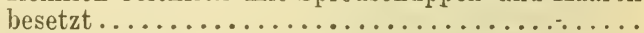

Bstiel gelblich oder grünlich, nur am Grunde schwarzbraun und mit Spreuschuppen besetzt, sonst wie die Bspindel kahl oder nur mit sehr kurzen Härchen besetzt; Pfl. klein und zart. T. $K$.

glabella. $R$. $B r$. Kahle W.

Fiedern im Umrisse eiförmig oder länglich-eiförmig, stumpf gelappt oder fiederspaltig, mit jederseits . höchstens 3-4 verkehrt-eiförmigen, meist ganzrandigen Fiederchen. B. $M . T . S . K$.

alpina. (Bolton.) Gray. Alpen-W.

Fiedern im Umrisse länglich (am Grunde breiter), regelmäßig fiederspaltig, mit jederseits $5-8$ eiförmigen, gekerbten Fiederchen. Pfl. größer und kräftiger. B. $M . T$. S. St.

ilvensis. (L.) $R$. Br. Röthliche W.

\section{Familie. Osmundaceae. Rispenfarne.}

Stauden mit ausdauerndem Wurzelstock. B. grob, schraubig gestellt, fiederig getheilt, gestielt. Sporenbehälter in Haufen gruppirt, kurz gestielt, an einer Seite mit einer Gruppe verdickter Zellen (die aber keinen Ring bilden), mit. einem Längsriss aufspringend. Vorkeim laubartig, grün gefärbt, oberirdisch, Antheridien und Archegonien nebeneinander tragend.

\section{Gattung.}

B. doppelt gefiedert; die Abschnitte der oberen Fiedern in Sporangienähren umgewandelt .. Osmunda. I. 
Art.

\section{OSMUNDA. L. Rispenfarn.}

Fiederchen länglich-lanzettlich, am Grunde gestutzt, meist ganzrandig; fruchtbarer Theil des B. zur Zeit der Sporenreife braun. B. Südt.

regalis. L. Königsfarn.

\section{Familie. Ophioglossaceae. Natterzungen.}

Stauden mit kurzem Wst. Fruchtbare B. in zwei Theile gesondert: der eine laubartig, ungetheilt oder fiederig getheilt, unfruchtbar; der andere in eine gestielte Sporangienähre oder Sporangienrispe umgewandelt. Sporenbehälter ohne Ring, mit einem Querriss aufspringend. Torkeim sehr klein, unterirdisch, nicht grün gefärbt, Antheridien und Archegonien nebeneinander tragend.

\section{Gattungen.}

Sporenbehälter eingesenkt, in zwei Reihen angeordnet und zu einer Aehre verwachsen; unfruchtbarer Babschnitt ungetheilt, ganzrandig

Ophioglossum. I. Sporenbehälter frei, von einander getrennt, rispig (sehr selten ährig) angeordnet; unfruchtbarer Babschnitt verschiedenartig getheilt (selten ungetheilt) ................ Botrychium. II.

\section{Arten.}

\section{OPHIOGLOSSUM. $L$. Natterzunge.}

Unfruchtbarer Babschnitt eiförmig oder länglich, am Grunde kurz verschmälert; Sporenreife im Sommer. Verbr. (fehlt S.).

vulgatum. $L$. Gemeine N.

Unfruchtbarer Babschnitt lanzettlich, nach unten keilig verschmälert; Pfl. klein; Sporenreife im Winter. J. Lusitanicum. L. Portugiesische N.

\section{BOTRYCHIUI. Sw. Mondraute.}

Unfruchtbarer Babschnitt im Umrisse länglich, eiförmig oder dreieckig-eiförmig, länger als breit, stets ganz kahl ...................... 2

Unfruchtbarer Babschnitt in Umrisse breit-dreieckig, breiter als lang, 2-4 fach fiederschnittig, in der Jugend behaart......................... 
Unfruchtbarer Babschnitt und dessen Fiedern stumpf

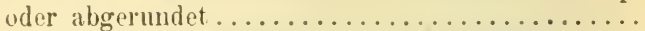

Uufruchtbarer Babschnitt und dessen Fiedern spitz, let \%tere gegen den Grund verschmälert, gesägt oder fiederspaltig; fruchtbarer Babschnitt den unfruchtbaren wenig überragend. Südt.

lanceolatum. Angstr. Ianzettliche M.

Unfruchtbarer Babschnitt fiedertheilig, mit ganzrandigen, gekerbten oder handförmig eingeschnittenen Fiedern, seltener dreitheilig oder ungetheilt;

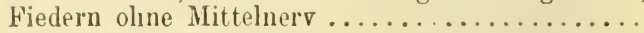

Unfruchtbarer Babschnitt fiedertheilig; Fiedern fiederspaltig (selten nur gekerbt), mil Mittelnerv. I3. M. Sch. T. K. St.

ramosum. (Roth.) Aschers. Aestige M.

Unfruchtbarer Babschnitt sehr kurz gestielt, regelmässig fiedertheilig, mit schief-eiförmigen, unten halbmondförmig ausgeschnittenen Fiedern; fruchtbirer Babschnitt meist doppelt fiederschnittig. lerbr.............unaria. (L.) Sw. Gemeine M. Unfruchtbarer Babschnitt meist ziemlich lang gestielt, unregelmälig fiedertheilig, dreitheilig oder ungetheilt; fruchtbarer Babsclinitt ineist einfach fiederschnittig; Pfl. klein. Sch. T.

simplex. Hitchc. Kleine M.

Unfruchtbarer Babschnitt lang gestielt, fleischig, mit stumpfen, ganzrandigen oder gekerbten Fiederchen. Verbr. (fehlt $O . K r . J$.

Matricariae. (Schrk.) Spr. Kamillen-M. Unfruchtbarer Babschnitt sitzend, nicht fleischig, mit ziemlich spitzen, gezähnten Fiederchen. $N$. St.

Virginianum. (L.) Su. Virginische M.

\section{Familie. Salviniaceae. Schwimmfarne.}

Schwimmende Wasserpflanzen. Sporenbehälter von zweierlei Art: Makrosporangien, welche nur 1 Spore (Makrospore) und kleinere Mikrosporangien, welche zahlreiche kleinere Sporen (Mikrosporen) enthalten. Beiderlei Sporenbehälter in eigene Gehäuse (Sporenfrüchte, Sporocarpien) eingeschlossen, deren jedes entweder nur Makrosporangien oder nur Mikrosporangien enthält. Vorkeime verkümmert und in der spore eingeschlossen, die aus den Mikrosporen sich entwickelnden nur 1 Antheridium, die aus den Makrosporen entstehenden mehrere Archegonien tragend. 


\section{Gattung.}

Echte Wurzeln fehlen. B. zu 3 wirtelständig, 2 davon normal ausgebildet, ungetheilt, an der Ober-täche des Wassers schwimmend (Schwimmblätter), eines untergetaucht, in wurzelähnliche Zipfel gespalten (Wasserblatt). Sporenfrüchte zwischen den Zipfeln des Wasserblattes sitzend.............salvinia.

\section{Art.}

I. SAIVINIA. All. Salvinie.

Schwimmb. fast sitzend, eiförmig, ganzrandig, behart. II. Sch. Südt.J. natans. (L.) All. Schwimmende S.

\section{Familie. Marsiliaceae. Sumpffarne.}

Ausdauernde Sumpfpflanzen. Stämmchen dünn, kriechend, mit Blättern und echten Wurzeln besetzt. Jede Sporenfrucht enthält nebeneinander Makrosporangien und Mikrosporangien. Vorkeime verkïmınert, die aus den Mikrosporen sich entwickelnden 1 Antheridiun, die aus den Makrosporen entstehenden 1 Archegonium tragend.

\section{Gattungen.}

B. langgestielt, vierzählig; Sporenfrüchte gestielt, bohnenförmig, am unteren Theile des Bstieles befestigt, oft $2-3$ beisammen ...... Marsilia. I. B. binsenförmig; Sporenfrüchte kugelig, fast sitzend, am äußersten Grunde des B. befestigt, stets einzeln

\section{Pilularia. If.}

Arten.

I. MARSILIA. L. Marsilie.

Blättchen keilig-verkehrt-eiförmig, ganzrandig. S. (). $K$. St. $K r$. . . quadrifolia. L. Vierblättrige M.

\section{PILULARIA. L. Pillenfarn.}

Stämmchen verzweigt, an den Zweigenden behaart; B. in der Jugend eingerollt. (B. M.?) J. globulifera. L. Kugelfrüchtiger $P$.

II. Classe. Equisetinae. Srhachtelhalmartige Gewächse.

Einzige Familie. Equisetaceae. Schachtellalme.

Stauden mit ausdauerndem Wst. Stengel gegliedert, an den Knoten von ringsum geschlossenen, gezähnten Scheiden umgeben, welche durch Verwachsung wirtelständiger B. ent- 
standell sind. Aeste wirtelständig, oft fehlend. Fruchtbare B. an der Spitze des Stg. (oft auch der Aeste) eine Aehre bildend, wirtelständig, zu schildförmigeu, gestielten Trägern umgestaltet, welche an der Innenseite die Sporenbehälter tragen. Sporen von zwei schraubig gewundenen Bïndern (Elateren) umgeben. Vorkeim laubartig, grün gefärbt, oberirdisch, meist nur Antheridien oder nur Archegonien tragend.

Einzige Gattung:........ Equisetum. I.

\section{Arten.}

\section{EQUISETUI. $L$. Schachtelhalm.}

fruchtbare Stengel weißlich oder röthlich, von den unfruchtbaren verschieden ................. Fruchtbare und unfruchtbare Stengel gleich ausge-

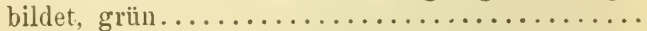

Fruchtbare Stengel unverzweigt, nach der Sporen-

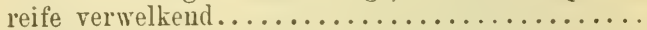

Fruchtbare Stengel nach der Sporenreife grüne Aeste entwickelnd und dann den unfruchtbaren ähnlich

Scheiden des fruchtbaren Stengels 6-12 zähnig; unfruchtbarer Stg. grün, gefurcht. Verbr. u. hfg.

arvense. $L$. Acker-Sch.

Scheiden des fruchtbaren Stengels 20-30zähnig; unfruchtbarer Stg. beinweiß oder grünlich, stielrund. Verbr. .....maximum. Lam. Zinnkraut.

deste wieder quirlig-verästelt, $4-5 \mathrm{kantig}$, Aestchen 3 seitig; Stgscheiden röthlich-braun, lappig-gespalten oder -gezähnt, die an den Aestchen mit 3 pfrieml. Zähnen. Verbr.

silvaticum. $L$. Wald-Seh.

Aeste einfach, 3 seitig; Stgscheiden grün, 10-16zähnig, mit spitzen, trockenhäutigen Zähnen, die an den Aesten mit 3 eif. spitz. Zähnen. Verbr.

pratense. Ehrh. Hain-Sch.

Aehre stumpf; Stg. gegen den Winter hin ab-

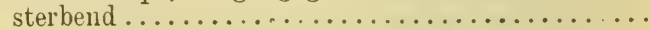

Aehre stachelspitrig; Stg. oft überwinternd, mehr

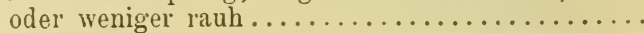

Zähne der fast kreiself. Scheiden am Rücken mit 1 Längsfurche, lanzettl. verschmälert-spitz, breithäutig-berandet; Stg. tief-6-8 furchig. Verl $r$. $u$. $h f g . . \ldots \ldots \ldots \ldots$ palustre. $I$. Sumpf-Sch. Zähne der walzl. Scheiden am Rücken ohne Längsfurche, convex, lanzettlich-pfriemlich, feinzugespitzt, sehr schmal-häutig berandet; Stg. mit 10-20 seichten Rillen, glatt. Verbr.

limosum. $L$. Schlamm-Sch. 
Stg. ästig, graugrün, im Herbste absterbend, mit $8-20$ convexen, nicht gefurchten Riefen; Scheiden glockenförmig erweitert. Verbr (fehlt Sch. O. $K r$.) ramosissimum. Desf. Aestiger Sch.

Stg. unverzweigt oder am Grunde mit einigen stengelähnlichen, verlängerten Aesten, meist überwinternd; Riefen gefurcht ................

PHl. ansehnlich; Stg. meist unverzweigt, mit 8-20 Riefen; Scheiden meist eng anliegend (seltener etwas erweitert und dann nur locker anliegend), mit meist frübzeitig abfallenden Zähnen. Verbr. (fehlt Sch. $K r . J$.$) ... hiemale. L. Winter-Sch.$ Pfl. klein; Stg. dünn, oft am Grunde verzweigt, mit 3-s Riefen; Scheiden glockig erweitert, mit blei-

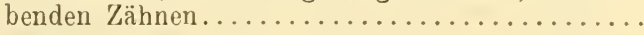

Stg. mit 6-8 schmal- und nicht tiefgefurchten Riefen, welche viel schmäler als die Furchen sind. Verbr. (feblt $M$. Sch.)

variegatum Schl. Bunter Sch.

9 Stg. mit 3-4 breit- und tiefgefurchten Riefen, welche ebenso breit als die Furchen sind, so dass der Stg. regelmäßig $6-8$ kantig erscheint. $K$. (Heiligenblut.)

scirpoides. Michx. Binsenartiger Sch.

Anmerkung. Zwischen E. arvense und E. limosum kommt ein Bastart vor.

III. Classe. Lycopodinae. Bärlappartige

Gewächse.

\section{Familien,}

(Alle B. grundständig, lang, binsenartig; untergetauchte Wasserpflanzen........ Isoëtaceae. II. B. klein, an dünnen, meist verzweigten Stengeln

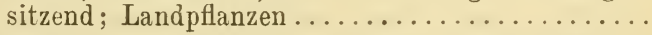

Alle Sporenbehälter enthalten zahlreiche, sehr kleine, untereinander gleiche Sporen. Lycopodiaceae. I. Zweierlei Sporenbehälter: Makrosporangien, welche 4 Sporen enthalten, und Mikrosporangien, welche zalilreiche viel kleinere Sporen enthalten.

Selaginellaceae. III.

\section{Familie. Lycopodiaceae. Bärlappe.}

Stengel verlängert, meist verzweigt, dicht beblättert. B. klein und schmal, ungetheilt. Sporenbehälter einzeln, am Grunde der Oberseite normaler oder etwas umgestalteter B., 
meist zu Aehren vereinigt, mit einem Querriss aufspringend. Vorkeim knollenförmig, nicht grün gefärbt, unterirdisch, Antheridien und Archegonien nebeneinander tragend.

\section{Gattung.}

B. nur von einem Nerven durchzogen, meist lineallanzettlich, seltener breiter, schraubig oder wirtelig angeordnet .................

\section{Arten.}

\section{LYCOPODIUM. L. Bärlapp.}

Keine Aehre vorhanden; Sporenbehälter in den Achseln der oberen B.; Stg. dicht beblättert, vom Grunde an gabelspaltig-ästig; Aeste gleichhoch. Verbr...................... Ta gela. L. Tannen-B.

Aehre vorhanden, wenn auch bisweilen weniger

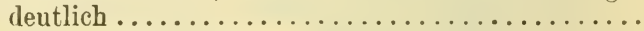

Aehre undeutl.; fruchtbare B. den Stgb. ziemlich ähnlich, meist länger u. am Grunde ein wenig breiter; Stg. kurz, liegend; Aeste aufrecht mit 1 Aehre. Verbr. (fehlt $\boldsymbol{M}$. J.)

inundatum. $L$. Sumpf-B.

Achre deutlich; fruchtbare B. von den Stgb. ganz

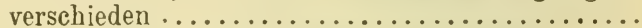

Aehren einzeln an der Spitze der Aeste, nicht ge3

Aehren zu 2-6 (selten einzeln), lang gestielt....

Aeste gabelspaltig; B. lineal-lanzett., zugespitzt, stachelspitzig, vorne gesägt, abstehend 0. zurückgebogen, 5reihig. Verbr.

annotinum. L. Sprossender B.

Aeste gabelspaltig-gebüschelt, die fruchttr.gleichhoch; B. lanzett., spitz, ganzrandig, angedrückt, an den Aesten 4reihig. Geb...... alpinum. L. Alpen-B.

B. mit 1 langen Haare endigend, schraubig gestellt, lineal-lanzett., zugespitzt; Aeste aufstreb.; Aehren meist zu 2-3. Ierbr. clavatum. L. Keuliger B. B. ohne Haarspitze; Aestchen zusammengedrückt, 2 schneidig; B. der Aestchen 4 reihig..........

Aestchen büschelig; B. der Aestchen lanzett., zugespitzt-stachelspitzig, die seitlichen so wie die inneren und äußeren fast gleichgebildet. B. Sch. T.S.K.

6) Aestchen fächerförmig; die seitenst. B. der unfruchtbaren Aestchen eiförmig, zugespitzt-stachelspitzig, die äußeren lanzett., die inneren pfrieml., sehr klein. Verbr. .... complanatum. L. Flacher B. 


\section{Familie. Isoëtaceae. Brachsenkräuter.}

Wst. knollenförmig, dicht mit langen, binsenartigen B. besetzt. B. gauzrandig, am Grunde scheidig erweitert. Sporenbehälter in einer Grube an der Oberseite des Bgrundes, und zwar die Makrosporangien an den äußeren, die Mikrosporangien an den inneren B.; oberhalb der Grube ein kleines Häutchen (Blatthäutchen). Vorkeime verkümmert, die aus den Mikrosporen sich entwickelnden nur 1 Antheridium, die aus den IIakrosporen entstehenden 1 oder mehrere Archegonien tragend.

Einzige Gattung ................ Isoëtes. I.

Arten.

I. ISOËTES. $L$. Brachsenkraut.

B. dunkelgrün, steif, kaum durchscheinend, im Wasser meist aufrecht; Makrosporen warzig oder höckerig, selten fast glatt. $B$. S.

lacustris. $L$. Gemeines B.

B. hellgrün, weich, durchscheinend, im Wasser abstehend oder zurückgekrümınt; Nakrosporen mit langen dünnen, zerbrechlichen Stacheln bedeckt. B.........echinospora. Durieu. Schlaffes B.

\section{Familie. Selaginellaceae. Joosfarne.}

Kleine moosähnliche Pflanzen mit verzweigten, dicht beblätterten Stengeln. B. klein, ungetheilt, nur von einem Nerven durchzogen. Sporenbehälter einzeln am Grunde der Oberseite etwas umgestalteter B., zu Aehren vereinigt, von zweierlei Art: Makrosporangien, welche nur 4 Sporen (IIakrosporen) enthalten, und Mikrosporangien, welche zahlreiche viel kleinere Sporen (Mikrosporen) enthalten. Torkeime verkümmert, die aus den Mikrosporen sich entwickelnden nur 1 Antheridium, die aus den Makrosporen entstehender 1 oder mehrere Archegonien tragend.

Einzige Gattung ........... Selaginella. I.

Arten.

I. SELAGINELLA. Spring. Moosfarn.

B schraubig angeordnet, lanzettlich, zugespitzt, entfernt-gezähnt. Geb.

selaginoides. (L.) $L k$. Alpen-II.

B. der unfruchtbaren Stg. 4 reihig, paarweise ungleich, die größeren eiförmig, die kleineren eilanzettlich, alle ganzrandig. Verbr. (fehlt $B . M$. Sch.)......... helvetica. ( $L$. $L k$. Schweizer M.

Fritsch, Excursionsflora. 


\section{Anthophyta. Blütenpflanzen.}

Pflanzen mit Stengeln, Blättern und Wurzeln, welche in ihren Blüten männliche und weibliche Fortptlanzungsorgane entwickeln. In den Staubblättern entstehen kleine, den Mikrosporen der höheren Farnpflanzen entsprechende Zellen (Pollenzellen); an den Fruchtblättern bilden sich die Samenknospen aus, welche eine große, der Makrospore der höheren Farnpflanzen entsprechende Zelle (Embryosack) enthalten. Der Inhalt der Pollenzellen wächst in Form eines Schlauches (Pollenschlauch) dem Embryosack entgegen und befruchtet die in letzterem enthaltenen Eizellen. In Folge der Befruchtung entsteht aus der Eizelle der Keim (Embryo), der von der zum Samen ausgereiften Samenknospe eingeschlossen ist, und aus dem sich dann nach Durchbrechung der Samenschale (Keimung) wieder eine neue Pflanze entwickelt.

\section{Hauptabtheilungen.}

Frb. frei und ausgebreitet, nicht zu einem Frkn. verwachsen und daher die Samenknospen von aubell sichtbar (oder nur durch Aneinanderdrängung der Frb. verdeckt); Gr. und N. fehlen; Embryosack mehrere Eizellen enthaltend, schon vor der Befruchtung von einem Zellgewebe erfüllt; Bt. niemals zwittrig, meist ohne Bthülle.

Gymnospermae. I.

Frb. zu einem geschlossenen (selten oben offenen) Gehäuse (Frkn.) verwachsen, in dessen Innern sich die Samenknospen befinden; Gr. und N. oder doch die letztere vorhanden; Embryosack meist nur 1 Eizelle und neben dieser vor der Befruchtung nur wenige Zellen enthaltend; Bt. zwittrig, seltener eingeschlechtig, meist mit Bthülle.

Angiospermae. II.

\section{Hauptabtheilung. Gymnospermae. Nackt- samige Bliitenpflanzen.}

\section{Classen.}

Harzführende Holzgewächse mit grünen, ungetheilten, derben, nadelförmigen oder schuppenförmigen $\mathrm{B}$.; Bt. ohne oder mit freiblätteriger Bthülle.

Coniferinae. I.

Harzlose Sträucher mit gegliederten Zweigen und sehr kleinen gegenständigen, zu stengelumfassenden Scheiden verwachsenen, häutigen, schuppenförmigen B.; Bt. mit verwachsenblättriger Bthülle.

Gnetales. II. 
I. Classe. Coniferinae. Nadelholzartige Gewäclıse.

\section{Einzige Familie. Coniferae. Nadelhölzer.}

Harzführende, meist immergrüne Holzgewächse mit ungetheilten, nadelförmigen oder schuppenförmigen B. Bt. tinhäusig oder zweihäusig, meist kätzchenförmig. Männliche Bt. nur aus Stb. bestehend, die an ihrer Unterseite 2-8 Pollensäcke tragen. Weibliche Bt. aus (manchmal verkümmerten) Frb. bestehend, welche an ihrer Oberseite 1. 2 oder mehr Samenknospen tragen. Fr. zapfenförmig oder beerenartig.

\section{Gattungen.}

B. gegenständig oder wirtelig, oft dicht dachig gestellt; Bt. zweihäusig; Frb. mit 1-2 Samenkinospen; Fr. beerenartig. ..... Juniperus. V.*)

B. schraubig gestellt, oft gebüschelt oder in 2 Reihen angenrdnet $\ldots \ldots \ldots \ldots \ldots \ldots \ldots \ldots \ldots \ldots \ldots$.

Alle B. einzeln stehend, schraubig gestellt, oft zwei-

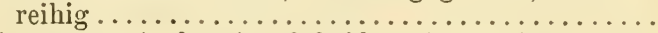

B. zu 2-5 in häutige Scheiden eingeschlossen oder theils gebüschelt, theils schraubig gestellt ......

B. zusammengedrückt-4 kantig, stachelspitzig; Fr. cin hängender Zapfen mit bleibenden Schuppen (Frb.); Bt. einhäusig. .............. Picea. III. B. flach; Fr. ein aufrechter Zapfen oder beerenartig.

Bt. einhäusig; Stb. mit 2 Pollensäcken; weibliche Bt. mit zahlreichen Frb., deren jedes 2 Samenknospen trägt; Fr. ein aufrechter Zapfen mit abfallenden Schuppen (Frb.) .......... Abies. IV. Bt. zweihäusig; Stb. mit 5-8 Pollensäcken; weibliche Bt. aus einer einzigen, von Hüllb. umgebenen Samenknospe bestehend, aus der' sich eine rothe Beerenfrucht entwickelt....... Taxus. VI.

(B. zu 2-5 in häutige Scheiden eingeschlossen, den Winter überdauernd; Fr. erst im zweiten oder dritten Jahre reifend ............. Pinus. I. B. theils in Büscheln, theils schraubig gestellt, im Herbste abfallend; Fr. im ersten Jahre reifend.

Larix. II.

*) Ueber die verwandten Gattungen Cupressus und Thuja vergl. die Anmerkung hinter Juniperus. (S. 21.) 
Arten.

I. PINUS. $L$. Föhre.

B. dreikantig, zu $3-5$ in einer Scheide; junge Zweige filzig; Zapfenschuppên an der Außenseite fast flach, am Ende gebuckelt; S. grol, hartschalig, ungeflügelt. A. Cembra. $L$. Zirbelkiefer.

B. halbstielrund, zu 2 in einer Scheide; junge Zweige kahl; 'Zapfenschuppen an der Außenseite pyramidenförmig gebuckelt; S. klein, geflügelt ......

P. (wenigstens die heurigen) blaugrün, kurz; Zapfen gestielt, hängend, matt graubraun. Verbr.

silvestris. L. Gemeine Föhre.

B. dunkelgrün; Zapfen fast sitzend, wagrecht oder schief-abstehend, mehr oder weniger glänzend braun Zapfen regelmäßig, ringsum gleichmäßig oder nur

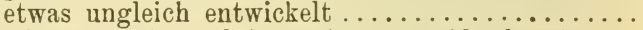

Zapfen an einer Seite mit pyramidenförmig erhobenen, gegen den Grund des Zapfens gekrümmten Schuppen, an der anderen Seite mit mehr abgeflachten Schuppen; Wuchs baumartig, seltener strauchig; B. kurz. Sch. B. N.

uliginosa. Neum. Moorföhre.

Wuchs strauchartig ("Krummholz"), selten baumartig; B. kurz, mit kaun stechender Spitze; Zapfen klein, eiförmig oder fast rundlich (selten eikegelförmig), meist aufrecht abstehend. Verbr. (bes. Geb.)......... montana. Mill. Legföhre. Baum mit langen, starren, stechend stachelspitzigen B.; Zapfen groß, im geschlossenen Zustande eikegelförmig, wagrecht abstehend. $N$. St. K. Kr . .I. (sonst cult.) ..... nigra. Arn. Schwarzföhre.

Anmerkung. Die Bastarte P. silvestris $X$ uliginosa und $P$. nigra $X$ silvestris warden im Gebiete beobachtet. Verschiedene hier nicht einheimische Pinus-Arten werden theils in Parkanlagen, theils auch in Wäldern oder zu Aufforstungszwecken angepflanzt und machen manchmal den Eindruck wildwachsender Bäume. Dieselben wurden in obiger Tabelle nicht berücksichtigt.

\section{LARIX. Mill. Lärche.}

Baum mit hellgrünen B.; weibliche Bt. purpurroth; Zapfen klein, graubraun. Verbr. (in B. nur cult.). decidua. Mill. Europäische L.

\section{PICEA. $L k$. Fichte.}

Hoher Baum; weibliche Bt. purpurroth; der ganze Zapfen nach Ausstreuung des S. abfallend. Verbr. u. $h f g$. ......excelsa. (Poir.) Lk. Gemeine F. 
IV. ABIES. Juss. Tanne.

Hoher Baum; B. flach, meist ausgerandet (selten stachelspitzig), unterseits mit 2 weißen Streifen; weibliche Bt. grünlich - weiß; Zapfenschuppen einzeln mit den S. abfallend. Verbr.

alba. Mill. Weiftanne.

\section{JUNIPERLS. L. Wachholder.}

B. meist schuppenförmig und den Zweigen dicht anliegend, seltener nadelförmig und abstehend, gegenständig oder $\mathrm{zu} 3$ wirtelig, mit einer Harzdrüse am Rücken....................

B. nadelförmig, zu 3 wirtelig, ohne Harzdrüse .... 3

B. in der Regel gegenständig, spitz; Fr. schwarz, bläulich bereift. $T$. S. K. Kr. J. (sonst cult.)

Sabina. $L$. Sadebaum.

B. $\mathrm{zu} 3$ wirtelig, meist schuppenförmig und stumpf (nur ausnahmsweise nadelförmig und spitz); $\mathrm{Fr}^{\circ}$ roth. J. ...... Phoenicia. L. Phönicischer W.

B. obers. 2 furch., unters. scharf gekielt, weit abstehend, lanzett.-lineal .

B. obers. seicht-rinnig, unters. stumpf-gekielt, mit 1 eingedrückten, den Kiel durchziehenden Linie Aeste steif; B. starr, gelblichgrün; Fr. gehäuft. glänzend braunroth. $J$.

Oxycedrus. $L$. Rothfrüchtiger W.

4 Aeste schlank, biegsam; B. blaugrün, biegsam; Fr. größer, anfangs blau bereift, später schwärzlichbraun. $J$.

macrocarpa. Silth. et Sm. Grobfrüchtiger W. Liegend; B. einwärts-gekrümmt, lanzett.-lineal; Fr. fast so lang als die B. Geb.

nana. Willd. Zwerg- $\mathbb{W}$

5 Aufrecht; B. weit abstehend, lineal-pfrieml.; Fr. 2-3 mal kürzer als die B. Verbr.

communis. $L$. Gemeiner W.

A nmerkung. Zwischen J. communis und J. nana kommt ein Bastart vor. - Im südlichen Theile des Gebietes wird die Cypresse (Cupressus sempervirens, $L$.), welche sich von allen Juniperus-Arten durch einhäusige Bt., Frb. mit zahlreichen Samenknospen und holzige, zapfenförmige Fr. unterscheidet, häufig cultivirt. Die noch häufiger cultivirten ThujaArten hahen gleichfalls einhäusige Bt., aber Frb. mit 1-2 Samenknospen.

\section{TAXUS. L. Eibe.}

B. lineal, spitz, in 2 Reihen stehend; Bt. achselständig; Fr. roth. Verbr. baccata. L. Gemeine E. 


\section{Classe. Gnetales. Gnetumartige Gewächse.}

Einzige Familie. Gnetaceae. Gnetaceen.

Harzlose Holzgewächse mit gegenständigen B. und meist 2 häusigen $\mathrm{Bt}$. Männliche $\mathrm{Bt}$. mit 2 blättriger, am Grunde verwachsener Bthülle und 2-8 an einem gemeinsamen säulenförmigen Träger befestigten Stb.; Antheren 2 fächerig. Weibliche Bt. mit schlauchförmiger Bthülle und 1 Samenknospe. S. in rothe Scheinbeeren eingeschlossen.

\section{Gattung.}

Sträucher von schachtelhalmähnlichem Aussehen. Zweige gegliedert; B. sehr klein, schuppenförmig, paarweise zu stengelumfassenden Scheiden rerwachsen .................... Ephedra. I.

\section{Art.}

\section{EPHEDRA. L. Meertränbchen.}

Niedriger Strauch; Träger der A. weit aus der Bthülle herausragend ; weibliche Bt. zu 2 beisammen. Südt............. distachya. $L$. Gemeines M. Höherer Strauch; Träger der A. kaum aus der Bthülle herausragend; weibliche Bt. einzeln.

J. (Lussin). Nebrodensis. Tineo. Sicilianisches M.

\section{Hauptabtheilung. Angiospermae. Bedecktsamige Blütenpflanzen.}

\section{Classen.}

Nur 1 Keimb. vorhanden; Hauptwurzel meist sehr friih absterbend ; Stg. von meist zerstreut stehenden, von einander getrennten Gefäßbündeln durchz.ogen, daher ohne geschlossenen Holzkörper und ohne deutliche Scheidung von Rinde, Holz und Mark; B. sehr selten gegenständig (manchmal wirtelig), sehr oft zweizeilig oder dreizeilig angeordnet, gewöhnlich parallelnervig, selten netznervig; Bthüllb. sehr häufig in 3 gliedrigen (niemals in 5 gliedrigen) Wirteln angeordnet.

Honocotyledoneae. I.

Meist 2 gegenständige Keimb. vorhanden; Hauptwurzel oft lange bleibend; Gefäßbündel des Stg. fast immer in einen Kreis gestellt, sehr oft einen geschlossenen Holzkörper bildend, der das Mark von der Rinde trennt; B. oft gegenständig, noch häufiger schraubig (aber selten zweizeilig) gestellt, 
gewöhnlich netznervig; Bthüllb. sehr häufig in 5 - oder 4 gliedrigen (selten in 3 gliedrigen) Wirteln angeordnet, manchmal schraubig gestellt.

Dicotyledoneae. II.

l. Classe. Monocotyledoneae. Einkeimblätrige. Blütenpflanzen.

Familien.

Schr kleine, schwimmende oder etwas untergetauchte Wasserpflanzen mit blattähnlichem, gegliedertem Stg. und ohne dentliche B.; Wr. einfach, haarförmig; Bt. selten vorhanden, äußerst klein, einhäusig, ohne Bthülle, nur aus 1 Stb. oder 1 Frkn. bestehend, aber 2 männliche und 1 weibliche in eine gemeinsame Scheide eingeschlossen. Lemnaceae. XII. Verschieden gestaltete Pfl. mit stets deutlich ent-

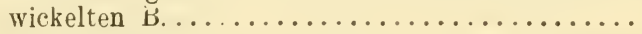

Bt. regelmäßig oder ohne Bthülle, selten etwas unregelmäßig, dann aber die Stb. frei ...........

2 Bt. mit unregelmäßiger, verschieden gefärbter, 6 blättriger Bthülle; Frkn. unterständig; Stb. 1-2, an die Griffelsäule angewachsen.

Orchideae. XVIII.

Bthülle aus mindestens 4 (meist 6) deutlich entwickelten B. bestehend $\left.{ }^{*}\right) \ldots \ldots \ldots \ldots \ldots \ldots \ldots$ Bthülle aus höchstens 3 kleinen Blättchen bestehend, oft schlauchförmig, undeutlich oder ganz fehlend 15

$4\{$ Frkn. oberständig $\ldots \ldots \ldots \ldots \ldots \ldots \ldots \ldots \ldots \ldots \ldots$

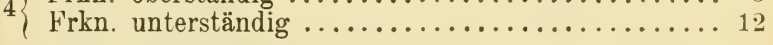

Alle B. der Bthülle ungefähr von gleicher Be-

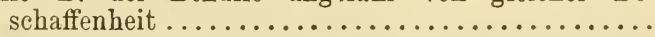
Bthülle 6 blättrig, die 3 äußeren B. grün, kelchartig, die 3 inneren zarter, blumenblattartig gefärbt (weib oder rosa); Stb. und Frkn. mindestens 6 , getreunt; Sumpf- und Wasserpflanzen.

Alismaceae. VI.

Stb. höchstens 8 (meist 6$) \ldots \ldots \ldots \ldots \ldots \ldots$

6 Stb. $9 ;$ B. der Bthülle 6 , rosenroth gefärbt; Frku. 6; hohe Wasserpfl. mit linealen B.

Butomaceae. VII.

*) Bei der Gattung Potamogeton haben die 4 Stb. blattartige Anhängsel, welche leicht für eine 4 blättrige Bthïlle gehalten werden können. 
Btstand kolbenförmig; Bt. sehr klein, in großer Zahl dicht aneinander gedrängt; B. der Bthülle $7\{$ u. Stb. 6 ; Frkn. 1, 2-3 fächerig; B. lineal.

Araceae. XI.

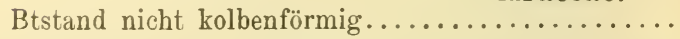

Frkn. 3 (selten mehr, nie weniger), nur am Grunde

8 verwachsen; B. der Bthülle und Stb. 6 ; B. lineal

Frkn. 1, meist 3 fächerig ...................

$\int_{9}$ Gr. kurz; N. klein, kopfig; Fr. vielsamig.

9 Gr. fehlend; N. länglich; Theilfrucht 1-2 samig. Juncagineae. $\mathrm{V}$.

$10\left\{\begin{array}{l}\text { Stf. fehlend; A. 6, am Grunde der Bt. sitzend; } \\ \text { B. der Bthülle } 6 \text {; B. lineal.....Juncagineae. V. }\end{array}\right.$ Stf. stets vorhanden, wenn auch manchmal kurz... 11 Bthülle häutig, meist braun oder grünlich, seltener gelblich oder weiß; 1 Gr. mit 3 verlängerten, fädlichen N.; Pfl. gras- oder binsenartig.

Juncaceae. XIII.

Bthülle meist blumenblattartig, verschieden gefärbt; 1 oder 3 Gr.; N. selten fädlich. Liliaceae. XIV.

${ }_{12}$ Bt. 2 häusig oder vielehig; wenigstens die 3 äußeren 12 B. der Bthülle grünlich, kelchartig.......... 13 Bt. zwittrig; alle B. der Bthülle blumenblattartig. 14 Wasserpflanzen; die 3 inneren B. der Bthülle weiß, blumenblattartig; Stb. meist 6 , 9 oder 12 .

Hydrocharideae. VIII.

Windende Landpfl.; alle $6 \mathrm{~B}$. der Bthülle grünlich, kelchartig; Stb. 6 ....... Dioscoreaceae. XVI.

Stb. 3; Narbenlappen verbreitert, oft groß und 14 blumenblattartig $\ldots \ldots \ldots \ldots \ldots$ Irideae. XVII. Stb. 6; Narben klein, nie mit blumenblattartigen Lappen............... Amaryllideae. XY.

In jeder zwittrigen oder weiblichen Bt. nur 1 Frkn. 16 15 Bt. zwittrig oder einhäusig, mit mehreren (meist 4) Frkn.; Stb. 1 oder 4; ausdauernde Wasserpflanzen............. Potamogetoneae. III.

Untergetauchte Wasserpflanzen mit gegenständigen 16 oder wirteligen B.; Bt. 1-oder 2 häusig, einzeln; Stb. 1, ohne Stf.; Frkn. 1. .... Najadeae. IV. B. schraubig (oft 2- oder 3 zeilig) angeordnet..... 17

B. lineal, seltener lanzettlich, mehr oder weniger grasartig $\ldots \ldots \ldots \ldots \ldots \ldots \ldots \ldots \ldots \ldots \ldots \ldots \ldots \ldots \ldots \ldots \ldots$

B. breit, herzeiförmig oder pfeilförmig; Bt. einhäusig oder vielehig, in Kolben, welche von einer großen Scheide eingeschlossen sind; Fr. eine

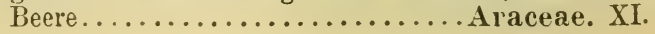


Bt. einhäusig, in Kolben dicht gedrängt stehend, die männlichen an der Spitze des Stengels, die weiblichen tiefer stehend; Stb. meist 3, von langen 18 Haaren umgeben; Frkn. auf langem, dünnem, lang behaartem Stiel; B. zweizeilig.

Typhaceae. I.

Bt. nicht in Kolben; Frkn. sitzend............ 19

Bt. einhäusig, in kugeligen Köpfchen, mit 3 blättriger Bthülle; Stb. meist 3; B. zweizeilig.

Bt. ohne deutliche Bthülle aber von Trab. II Sparganiaceae. II.
aber von Tragb. und oft auch Vorb. (,Spelzen") umgeben..........

B. dreizeilig; Stg. oft dreikantig; jede Bt. von einem Tragb. gestützt, aber ohne Vorb. oder die weibliche Bt. mit schlauchförmigen Vorb.; S. frei.

Cyperaceae. $\mathrm{X}$.

20 B. zweizeilig; Stg. stielrund oder zweischneidigzusammengedrückt; jede Bt. von einem Tragb. und einem niemals schlauchförmigen Vorb. umgeben; S. mit der Fruchtwand verwachsen.

Gramineae. IX.

I. Familie. Typhaceae. Rohrkolbengewächse.

Ausdauernde Sumpf- und Wasserpfl. mit linealen, zweizeilig gestellten B. Bt. einhäusig, in Kolben dicht aneinander gedrängt; die männlichen an der Spitze des Stg., die weiblichen tiefer, ohne Bthülle. Stb. meist 3, von zahlreichen Haaren umgeben. Frkn. 1, lang gestielt, mit langhaarigem Stiel, 1 Samenknospe enthaltend. N. lineal oder spatelförmig, auf verlängertem Gr. Fr. nussartig, 1 samig.

Einzige Gattung ............ Typha. I.

Arten.

J. TYPHA. L. Rohrkolben.

B. des blühenden Stg. scheidenförmig, den Btstand niemals überragend; weiblicher Kolben nach dem Verblühen dick-keulig oder fast kugelig. Verbr. (fehlt $B . M$. Sch. J.)

minima. Funk. Kleinster $\mathrm{P}$.

B. des blühenden Stg. normal entwickelt, verlängert lineal, den Btstand meist überragend; weiblicher

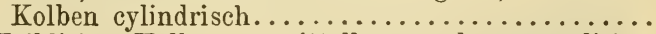

Weiblicher Kolben unmittelbar an den männlichen anstoßend (sehr selten von ihm getrennt); weibliche Bt. ohne Tragb.; N. spatelförmig ........ ӟ

2 Weiblicher Kolben von dem männlichen entfernt (sehr selten anstoßend); weibliche Bt. mit schuppenförmigem Tragb.; $\mathrm{N}$. lineal. Verbr.

angustifolia. $L$. Schmalblättriger $R$. 
Männlicher Kolben nicht erheblich kürzer als der schwarzbraune weibliche: Haare des Fruchtknotenstiels niemals über die N. hinausragend. Verbr.

latifolia. $L$. Breitblättriger R.

3) Männlicher Kolben bedeutend kürzer als der weibliche; Haare des Fruchtknotenstiels noch dem Verblühen die N. überragend, der Kolben daher silbergrau; B. schmäler. St.

Shuttleworthii. Koch et Sond. Mittlerer R.

\section{Familie. Sparganiaceae. Igelkolbengewächse.}

Ausdauernde Sumpf- und Wasserpflanzen mit linealen, zweizeilig gestellten B. Bt. einhäusig, in kugeligen Köpfchen, ınit 3 blättriger, unscheinbarer Bthülle. Männliche $\mathrm{Bt}$. in den oberen Köpfchen, meist mit 3 Stb. Weibliche Bt. in den unteren Köpfchen, mit 1 sitzenden Frkn., welcher $1-$ ? Samenknospen enthält. N. 1-2, zungenförmig, sitzend. Fr steinfruchtartig, $1-2$ samig.

Einzige Gattung ...........Sparganium. I.

\section{Arten.}

\section{SPARGANIUM. $L$. Igelkolben.}

Stg. oben ästig, auch an den Aesten unten weibliche

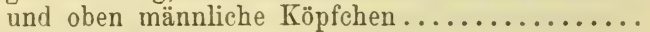

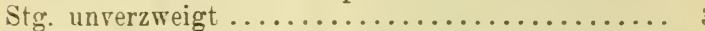

( Fı: verkehrt pyramidenförmig, kurz bespitzt; B. steif

2 aufrecht. Verbr.... erectum. L.* A dufrechter I. Fr. eikegelförmig, zugespitzt; B. schlaffer, abstehend. $B$ Sïdt. J. neglectum. Beeby. Kiegelfrüchtiger I. Fr. (auch schon der Frkn.) lang geschnäbelt; männ-

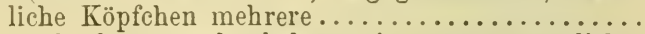
Fr. sehr kurz geschnäbelt; meist nur 1 männliches und $1-3$ weibliche Köpfchen; Stg. schlaff, sammt den B. niederliegend 0 . schwimmend. Terbr.

\section{minimum. $F r$. Kleinster I.}

B. meist steif aufrecht**), am Grunde 3 kantig; A. $6-8 \mathrm{mal}$ länger als breit; $N$. verlängert, linealzungenförmig. Verbr.

simplex. $L$. Unverzweigter I. B. schmal-lineal, schlaff, liegend oder schwimmend, am Grunde rundlich oder flachgedrückt; A. 3 bis 4 mal länger als breit; $\mathrm{N}$. kurz zungenförmig. $B$. affine. Schnizlein. Schwimmender I.

*) S. microcarpum (Neum.) (B. T.) ist niedriger u. hat länger bespitzte $\mathrm{Fr}$.

**) Es gibt auch eine Wasserform mit schwimmenden B. 
III. Familie. Potamogetoneae. Laichkrautgewächse.

Ausdauernde Wasserpflanzen. B. ungetheilt, meist zweizeilig gestellt, seltener gegenständig oder wirtelig. Bt. zwittrig, seltener 1 - oder 2 häusig; die $z$ wittrigen und männlichen ohne Bthülle, die weiblichen manchmal mit glockiger Bthülle. Stb. 1-4, oft mit kelchartigen Anhängseln. Frkn. meist vier, jeder mit 1 Samenknospe. Fr. nussartig oder steinfruchtartig, einsamig.

\section{Gattungen.}

Wenigstens die unteren Bt. zwittrig mit mindestens

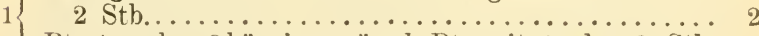
Bt. 1 - oder 2 häusig; männl. Bt. mit 1 oder 2 Stb. 4 Stb. 4, mit kelchartigen Anhängseln, welche scheinbar eine 4 blättrige Bthülle bilden; Frkn. meist 4, sitzend; N. sitzend; Bt. in Aehren.

Potamogeton. I.

Stb. ohne kelchartige Anhängsel................ 3

${ }_{3}$ Frkn. meist 4, gestielt; B. sehr schmal-lineal, borstlich ..................... Ruppia. II. Frkn. 1; B. breit-lineal.......... Posidonia. III.

Bt. 2 häusig, einzeln, lang gestielt; Stb. 2; Frkn. 2, mit fädlichen Gr........... Cymodocea. V. Bt. 1 häusig; Stb. 1; Frkn. 1 oder mehrere (meist 4 , niemals 2$) \ldots \ldots \ldots \ldots \ldots \ldots \ldots \ldots \ldots$.

Zahlreiche männliche und weibliche Bt. in einer Bscheide eingeschlossen : Bthülle fehlt; A. sitzend; Frkn. 1; Gr. fädlich, 2 spaltig..... Zostera. IV.

5 Bt. einzeln oder 1 männliche und 1 weibliche Bt. neben einander; A. gestielt; weibliche Bt. mit glockiger Bthülle; Frkn. meist 4; Gr. mit breiter, schild förmiger N. ...........Zanichellia. VI.

\section{Arten.}

\section{POTAMOGETON. L. Laichkraut.}

Alle B. gegenständig, eilanzettlich oder elliptisch, stengelumfassend. Verbr. (fehlt Sch. St. K. J.)

densus. L. Dichtblättriges L.

B. wechselständig, nur die obersten manchmal gegen-

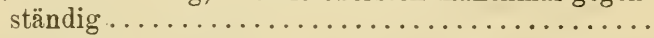

Alle B. gestielt; Bstiel mindestens halb so lang als die Bspreite........................... Alle oder doch die untergetauchten B. sitzend oder höchstens sehr kurz gestielt, manchmal umfassend 
Von den untergetauchten B. ist zur Btzeit die Spreite durch Fäulniss bereits zerstört, daher nur die Bstiele übrig; Schwimmb. am Grunde seicht-herzförmig, oval oder länglich. Verbr

natans. $L$. Schwimmendes $\mathrm{L}$.

Die untergetauchten B. während der Btzeit un-

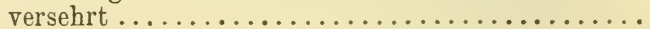

Die untergetauchten B. verlängert-lanzett,, die schwimmenden lederig, länglich-lanzett. oder oval, am Grunde spitz oder abgerundet; Bstiele so lang als die Spreite. Verbr. (fehlt Sch. St. Kr.J.)

fuitans. Roth. Fluthendes L.

B. alle häutig, durchsichtig, am Rande glatt, die untersten lanzett., die schwimmenden fast herzeiförmig; Bstiele halb so lang als die Spreite.

B. $O . N$. T. . . coloratus. Horn. Gefärbtes L.

B lineal-lanzettlich oder breiter bis zur rundlichen Form .......................... 6

B. genau lineal, grasartig oder borstenförmig ..... 11

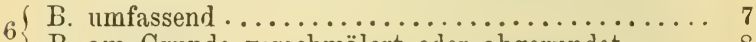

B. am Grunde verschmälert oder abgerundet..... \&

B. aus herzförmigeun Grunde eiförmig oder eilanzettlich, am Rande etwas rauh; Fr. am Rücken stumpf. Verbr.

perfoliatus. L. Durchwachsenes L. B. aus eiförmigem Grunde länglich oder lanzett., am Rande glatt, an der Spitze kappenförmig-zusammengezogen; Fr. am Rücken scharf gekielt. B. O. $K r$. praelongus. Wulf. Langblättriges $\mathrm{L}$.

$8\{$ Aehrenstiele nach oben verdickt, dicker als der Stg. 9 Aehrenstiele nach oben nicht verdickt ......... 10

Alle B. untergetaucht, kurz gestielt, elliptisch oder lanzettlich, fein gesägt. Verbr.

lucens. $L$. Glänzendes L.

9 Untergetauchte B. lineal-lanzettlich, sitzend, am Rande rauh; Schwimmb. lang gestielt, eiförmig oder breit lanzettlich, oft fehlend. T'erbr. (fehlt St. J.) gramineus. L. Grasartiges L.

Alle B. untergetaucht, lineal-länglich, fein gesägt; Aehre armblütig; Fr. geschnäbelt. Verbr.

crispus. $L$. Krauses L.

10 Untergetauchte B. länglich-lanzettlich, ganzrandig; Schwimmb. etwas breiter, oft fehlend; Aehre reichblütig; Fr. kurz bespitzt. Verbr. (fehlt $K r$. J.) alpinus. Balb. Alpen-L. 
B. scheidenlos, sitzend, 3 - vielnervig, oder 1 nel'vig und aderlos ....................... 12

11 B. mit Bscheide, und an deren Spitze mit Bhäutchen versehen, 1 nervig und queraderig; Aehren

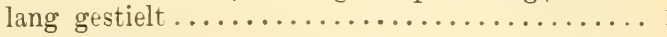

B. borstl.-lineal, zugespitzt, 1 nervig, aderlos; Aehrenstiele $2-3 \mathrm{mal}$ so lang als die $4-8$ btg. Aehre; Fr. halbkreisrund; Stg. stielrundl., sehr ästig.

12 B. M. N. S. T. K. J.

trichoides. Cham. et Schld. Haarartiges L. B. lineal, nicht borstl., 3-5-vielnervig; Stg. zusammengedrückt................... 13

Stg. fast blattartig-flachgedrückt; B. vielnervig mit 3.5 stärkeren Nerven................. 14

Stg. zusammengedrückt mit abgerundeten Kanten; B. $3-5$ nervig..................... 15

B. stumpf, hurz-stachelspitzig; Aehre 10-13 btg., viel kürzer als ihr Stiel. B. M. O. S. St.

compressus. $L$. Zusammengedrücktes $\mathrm{L}$.

B. am Ende haarspitzig; Aehre 4-8btg., nicht oder wenig kürzer als ihr Stiel. Verbr. (fehlt T. St. J.) acutifolius. $L k$. Spitzblättriges L.

Aehrenstiele so lang als die $6-8$ btg. ununterbroch. Aehre; B. stumpf, kurz-stachelspitzig. B. M. $N$. obtusifolius. M. K. Stumpfiblättriges L.

Aehrenstiele 2-3 mal so lang als die $4-8$ btg., oft unterbroch. Aehre; Fr. schief-ellipt.; B. kurz zugespitzt. Verbr........ pusillus. L. Kleines L.

Fr. schief - verkehrt-eiförmig, halbkreisrund, zusammengedrückt, getrocknet auf dem Rücken gekielt, mit kurzem, aufsteigendem Gr.; B. borstlichlineal, spitz. Verbr. (fehlt St.)

pectinatus. $L$. Fadenblättriges $\mathrm{L}$

$\mathrm{Fl}$. verkehrt-eiförmig, fast kugelig, getrocknet runzelig, auf dem Rücken breit-abgerundet, kiellos, mit breiter, sitzender $\mathrm{N}$.

B. schmal-lineal, gleich breit, plötzlich gestutzt. $T$. juncifolius. Kern. Binsenblättriges L. B. borstlich, fast haarförmig, sehr spitz. T. S. O.K. J. (?)
marinus. L. Meer-L.

\section{RUPPIA. L. Meerfaden.}

A-Fächer länglich; Fr. eiförmig, schief-aufrecht, auf langem, gewundenem Stiel. J.

maritima. L. Echter M.

A-Fächer fast kugelig; Fr. fast halbmondförmigeiförmig. auf kurzem stiel. $J$.

rostellata. Koch. Geschnäbelter M. 


\section{POSIDONIA. Koen. Neptunsgras.}

Wst. dick, dicht mit Schuppen und Fasern besetzt; B. steif, dunkelgrïn, an der Spitze abgerundet, anfangs gekrümmt, später gerade; Bt. meist fehlend. J. (im Meere).

oceanica. (L.) Del. Gemeines $\mathrm{N}$.

\section{ZOSTERA. (L.) Seegras.}

B. 3-7 nervig, lineal, grasartig, am Grunde scheidig; Stiel der Btscheide nach oben verbreitert.. . (im Meere)...........marina. $L$. Gemeines S. B. 1 nervig, schmal-lineal; Stiel der Btscheide gleich breit. $J$......... nana. Koth. Kleines S.

V. CYIODOCEA. Koen. Tanggras.

Wst. dünn, gegliedert; B. schlaff, trübgrün, lineal, an der Spitze abgerundet; Bt. meist fehlend. $J$. (im Meere)...nodosa. (Ucria.) Aschers. Gemeines T.

\section{ZANICHELLIA. L. Teichfaden.}

Fr. langgestielt; Gr. schlank, so lang als die Fr. $N$. St. .... pedicellata. $F v$. Stielfrüchtiger 'T' Fr. kurzgestielt; Gr. halb so lang als die Fr. Verbr. palustris. L. Gemeiner $\mathrm{T}$.

\section{Familie. Najadeae. Najadengewächse.}

Einjährige, im Wasser untergetanchte Kräuter mit gegenständigen oder wirteligen, linealen, ausgeschweift-gezähnten B. Bt. 1- oder 2 hä̉usig, einzeln. Bthülle becherförmig, bei der männlichen Bt. doppelt, bei der weiblichen einfach oder fehlend. A. 1, sitzend. Frkn. 1, mit 2-3 Narbeu und 1 Samenknospe. Fr. steinfruchtartig, 1 samig.

Einzige Gattung............. Najas. I.

Arten.

I. NAJAS. $L$. Najade.

B. aufgerichtet, mit ganzrandiger Scheide. B. N. S. T. K. J.........marina. L. Meer-N. B. fast borstlich, zurückgekrümmt, mit wimperiggezähnelter Scheide. B. N. O.T.K. St. Kr. J. minor. All. Kleine N.

\section{Familie. Juncagineae. Dreizackgewächse.}

Kahle Stauden feuchter Orte mit linealen, grasartigen B. Bt. zwittrig, in Trauben. Bthülle 6 blättrig, kelchartig, manchmal am Grunde verwachsen. Stb. 6. Frkn. 1, 
oberständig, 3-6fächerig oder $3-6$ nur am Grunde verwachsene 1 fächerige Frkn.; Samenknospen 3-6. Fr. aufspringend.

\section{Gattungen.}

Alle B. grundständig; B. der Bthülle frei; A. sitzend; 1 Frkn. ................ Triglochin. I. Stg. beblättert; B. der Bthülle am Grunde verwachsen; Stf. vorhanden; $3(-6)$ Frkn.

\section{schenchzeria. II.}

\section{Arten.}

\section{TRIGLOCHIN. L. Dreizack.}

Frkn. 3 fächerig; N. 3, federig; Fr. keulig-lineal. Verbr. ............. palustre. I. Sumpf-D. Frkn. 6 fächerig; N. 6, hakig; Fr. eiförmig. $\Lambda$. J maritimum. L. Meerstrands-D.

II. SCHECCHZERIA. I. Blumensimse.

Tr. armblütig, am Grunde beblättert; Fr. schiefeiförmig. Verbr. (fehlt J.)

palustris. $L$. Sumpf-B.

VI. Familie. Alismaceae. Froschlöffelgewächse.

Ausdauernde Wasser- und Sumpfpflanzen mit verschieden restalteten, ganzrandigen B. Bt. zwittrig oder 1 häusig. Bthülle 6 blättrig; die 3 äußeren $B$. kelchartig, grün; die 3 inneren B. blumenblattartig, weic oder rosa. Stb. 6 oder mehr. Frkn. 6 o. mehr, oberständig, mit 1 Samenknospe. Fr nussartig, 1 samig.

\section{Gattungen.}

Bt. einhäusig, die oberen männlich, zu 3 wirtelig; Stb. zahlreich............... Sagittaria. I. Bt zwittrig; Stb. $6-12 \ldots \ldots \ldots$. Alisma. II.

\section{Arten.}

I. SAgitTaria. L. Pfeilkraut.

B. theils lineal, theils verbreitert, die iberen pfeilförmig; Krb. weiß mit purpurnem Nagel. Verbr. (fehlt $S . K$. J.) . sagittifolia. $L$. Gemeines Pf.

\section{ALISMA. $L$. Froschlöffel.}

Stg. beblättert; Bt. an den Stgknoten einzeln oder zu $3-5$; Stgb. gestielt, oval oder länglich, Grundb. 1 sitzend, lineal. $K$. $K r$.

natans. $L$. Schwimmender $\mathrm{F}$,

Schaft blattlos 
Fr. an der Spitze abgerundet-stumpf, grannenlos, auf dem Rücken 1-3 furchig, in einen stumpf-

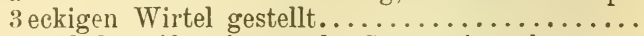
Fr. verkehrt-eiförmig, an der Spitze einw. begrannt, vielrillig; B. tief-herzförmig. Sü dt. $K$. St.

parnassifolium. $L$. Herzblättriger $\mathrm{F}$.

Btschaft aufrecht; Krb. 2-tmal länger als die $\mathrm{Kb}$.; Stb. viel länger als der Frkn., mit länglichen A. Verbr. . $h f g$....Plantago. L. Gemeiner F. Btschaft am Grunde bogig; Krb. $1 \frac{1}{2}$ mal so lang als die $\mathrm{Kb}$; Stb. die Frkn. nicht ïberragend, mit rundlichen A. B. N.

arcuatum. Michal. Gebogener F.

\section{Familie. Butomaceae. Wasserviolen.}

Ausdauernde, kahle Sumpfpfl. mit linealen, 3 kantigen B. Bt. zwittrig, in Dolden. Bthiille 6 blättrig, blumenblattartig gefärbt. Stb. 9. Frkn. 6, oberständig, am Grunde verwachsen, mit zahlreichen Samenknospen. Fr. aufspringend, vielsamig.

\section{Gattung.}

B. der Bthülle bis zur Fruchtreife bleibend.

Butomus. I.

Art.

I. BUTOMUS. $L$. Wasserviole.

Alle B. grundständig; Schaft stielrund, hoch; Bt. rosenroth. Verbr. (fehlt $S$.)

umbellatus. $L$. Gemeine W.

VIII. Familie. Hydrocharideae. Froschbissgewächse.

Wasserpflanzen mit ungetheilten B. Bt. 2 häusig oder vielehig. Bthülle 6 blättrig; die 3 äußeren B. kelchartig, die 3 inneren blumenblattartig, weiß gefärbt. Stb. meist 3, 6, 9 oder 12 . Frkn. unterständig, 1- oder 6 fächerig ; Samenknospen in unbestimmter Zahl. Fr. mehr oder weniger beerenartig, mehrsamig.

\section{Gattungen.}

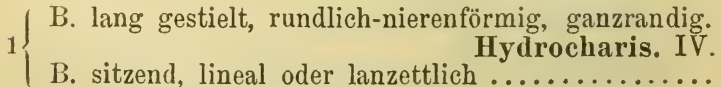

B. klein, lanzettlich, fein gesägt, in 3- oder 4 glied-

2 rigen Wirteln ....................... I.

B. verlängert-lineal, am Grunde des Schaftes rosettig 3 
B. derb und steif, fast schwertförmig, 3 kantig, am Rande und Mittelnerv stachelig-gezähnt; Krb. ansehnlich, viel größer als die Kb. Stratiotes. III.

B. schlaff, flach, nur gegen die Spitze zu fein gesägt; Krb. sehr klein, viel kürzer als die Kb.

$$
\text { Vallisneria. II. }
$$

\section{Arten.}

\section{ELODEA. Rich. Wasserpest.}

Bt. vielehig, einzeln, die männlichen mit 9 Stb., die weiblichen mit 32 spaltigen $\mathrm{N}$., die zwittrigen mit 3-6 Stb. und $3 \mathrm{~N}$. B. Sch. N. K. T. (eingeschleppt)...Canadensis. Rich. Canadische W.

\section{Vallisneria. L. Vallisnerie.}

Bt. 2 häusig; männliche Bt. mit $2-3 \mathrm{Stb}$, in großer Zahl beisammen; weibliche Bt. auf langen, dünnen, gedrehten Stielen. T. (Gardasee).

spiralis. L. Gedrehte $Y$

\section{STRATIOTES. $L$. Wasserscheere.}

Bt. ansehnlich, 2häusig; die männlichen Bt. in armblütigen Dolden, mit meist $12 \mathrm{Stb}$; weibliche Bt. meist einzeln. Sch. M. N. O. Kr.

aloides. $L$. Aloëblättrige $W$.

\section{HYDROCHARIS. L. Froschbiss.}

Bt. ansehnlich, 2 häusig; die männlichen Bt. in armblütigen Dolden, mit meist 6-9 fruchtbaren Stb.; weibliche Bt. einzeln. Verbr.

Morsus rawae. $L$. Gemeiner $\mathrm{F}$.

\section{Familie. Gramineae. Echte Gräser.}

Ausdauernde oder 1-2jährige Gewächse mit knotig gegliedertem, stielrundem oder mehr oder minder zweischneidig zusammengedrückten Stg. B. ungetheilt, lineal oder lanzettlich, parallelnervig, niemals gestielt, aber stets mit verlängerter, den Stg. umfassender Bscheide, an deren oberem Ende das Bhäutchen hervorragt. Bt. meist zwittrig, selten einhäusig, von einem Tragb. (Deckspelze) und einem Vorb. (Vorspelze) umgeben, entweder einzeln oder zı mehreren in einem Aehrchen, welches von (meist 2) Hüllb. (Hüllspelzen) umgeben ist. Aehrchen sehr selten einzeln, meist in grölserer Zahl in Rispen oder Aehren zusammengestellt. Bthülle niemals deutlich entwickelt, nur kleine Schüppchen an ihrer Stelle. Stb. meist 3, selten 1-2. Frkn. 1 , mit 1 Samenknospe und meist 2 (selten 1) gewöhnlich federigen N. S. mit der Fruchtwand verwachsen, manchmal die Frucht auch mit den Spelzen verwachsen, niemals aufspringend, stets trocken (Kornfrucht). 


\section{Gattungen.}

Bt. einhäusig; die männlichen Bt. in einer Rispe am Ende des Stg.; die weiblichen Bt. auf dicken, von Scheiden umhüllten, blattachselständigen Kolben; Gr. 1, sehr lang, fadentörmig ...Zea. I. Bt. zwittrig oder vielehig, niemals rein einge-

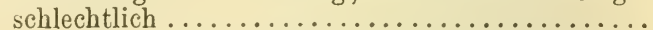

Gr. 1, fädlich, aus der Spitze der Bt. hervortretend, mit 1 nicht federigen N.; Aehrchen einzeln in den Aushöhl. der Spindel sitzend, 1 blütig; Hüllspelzen fehlend; Deckspelzen lederig, pfriemlich3 seitig; Vorspelzen häutig ...Nardus. LXXVII.

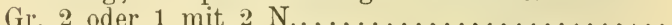
Aehrchen entweder in den Aushöhl. oder auf den Zähnen der Spindel sitzend, keines gestielt*); Gr. sehr kurz oder fehlend; N. federig, am Grunde der Bt. beiderseits hervortretend ............. Aehrchen länger oder kürzer, manchmal auch sehr kurz gestielt, oder die Aehrchen an den Gelenken einer Aehre oder gegliederten Rispe parig, das eine sitzend, das andere gestielt ........... 15

$4\{$ Hüllsp. 1, nur an dem endständigen Aehrchen meist 2 Alle Aehrchen mit 2 Hüllspelzen................ Aehrchen mit dem Rücken gegen die Spindel gestellt, selten in die Aushöhlungen derselben eingesenkt,

5 3- bis vielblütig.......... Lolium. IXXVIII. Aehrchen ganz in die Aushöhlungen der Spindel

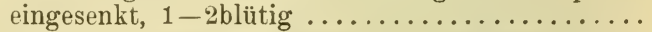
Hüllspelzen lederig, das Aehrchen bedeckend; Deckspelzen wehrlos.......... Monerma. LXXIX. Hüllspelzen sehr klein; Deckspelzen begrannt.

Psilurus. LXXXI.

Aehrchen in die Aushöhlungen der gegliederten Spindel eingesenkt, einzeln; Aehrchen 1-2 blütig; 1 jährige Gräser........................... Aehrchen nicht eingesenkt, auf den Zähnen der aus-

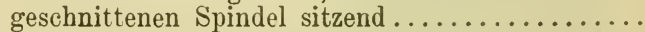
Aehrchen auf den Zähnen der Spindel in der Mitte der Aehre zu 2-6 (meist 3); die Hüllsp. der zu 3 gestellten Aehrchen eine 6 blättrige Hülle dar-

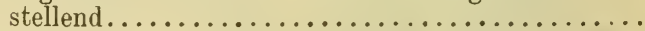

Aehrchen einzeln, mit der breiten Seite gegen die Spindel gerichtet...................... 10

Aehrchen $1 \mathrm{btg}$. oder mit 1 grannenförmigen Ansatze $\mathrm{zu}$ einer 2. Bt.; seitenst. Bt. meist männlich.

Hordeum. LXXXVII.

Aehrchen 2-vielbtg.; die oberste Bt. oft verkümmert.

Elymus. LXXXVIII.

*) Vgl. auch Catapodium u. Nardurus. 
Hüllsp. an del Spitze 2-4 zähnig, Zähne lanzett.pfrieml., oft in Grannen auslaufend; Aehrchen 3-4 blütig; Deckspelze an der Spitze 1-4 grannig.

Hïllsp. An der Spilops. LXXXV.

Hüllsp. an der Spitze nicht gezähnt.......... 11

Deckspelze auf dem Rücken begrannt; Granne am Grunde gewunden; Aehrchen $4-7$ blütig.

Gandinia. XLIV.

Deckspelze aus der Spitze begrannt oder wehrlos; Hüllsp. gekielt .................. 12

Hüllsp. pfriemlich, 1 nervig; Aehrchen 2 btg., mit einem langgestielten Ansatze zı einer 3. Bt.

Secale. LXXXIT.

Hüllsp. länglich oder eiförmig; Aehrchen 3-vielbtg. 13 Ausdauernd, mit Wst.; Hüllsp. lanzettlich oder lineal: Decksp. am Grunde wulstig verdickt.

Agropyrum. LXXXII.

1-2jähıig, ohne Wst.; Hüllsp. eiförmig oder länglich; Decksp. ohne wulstige Verdickung ....... 14

Hüllsp. eiförmig, 3-vielnervig.

Hüllsp. länglich, gestutzt, 2 kielig.

\section{Triticum. LXXYVI.}

Haynaldia. LXXXIII.

Aehrchen an den Gelenken einer bei der Reife meist zerbrechlichen und an den Gelenken sich trennenden Aehre oder geglied. Rispe paarig, das eine sitzend, das andere gestielt, die endst. zu 3, davon nur das mittlere sitzend; alle Aehrchen vom Rücken her zusammengedrückt, 1 btg., mit 3 Hüllsp..... 16

Aehrchen länger oder kürzer, manchmal auch sehr

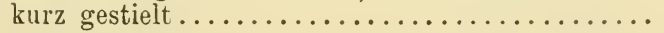

$16\left\{\begin{array}{l}\text { Aehrchen sämmtl. zwittrig; Btstand lang behaart } 17 \\ \text { Die gestielten Aehrchen männlich............ 18 }\end{array}\right.$

Decksp. nicht begrannt; Stb. 2; Rispe ährenförmig.

Decksp. begrannt; Stb. 3; Rispe sehr ästig.

Imperata. II.

Erianthus. III.

Die oberen sitzenden Aehrchen durch Fehlschlagen weibl., knorpelig, die unteren sitzenden krautig, sammt den gestielten männlich.

Heteropogon. VII.

Die sitzenden Aehrchen sämmtlich zwittrig, höchstens das unterste männlich ............. 19

Alle Aehrchen lineal.................. 20

Die sitzenden Aehrchen eiförmig oder eilanzettlich, Hüllsp. derselben an der Spitze 3 zähnig. 
Btstand aus 2 oder mehr fingerförmig nebeneinander stehenden Scheinähren gebildet; Aehrchen paarweise, nur die endständigen $\mathrm{zu} 3$.

Btstand rispig; Aehrchen uur andropogon. IV. Rispenzweige, stets zu 3 (das mittlere sitzend).

Chrysopogon. VI.

Aehrchen 1 blütg., oder 1 btg. sammt eilem Ansatze $\mathrm{zu}$ einer 2 . oberen, oder zu $1-2$ unteren Bt. ... 21 Aehrchen 2-vielbtg., oder zweierlei: 1 blütige und aus zahlreichen leeren Spelzen bestehende Aehrchen

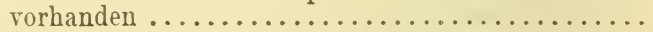

Aehrchen vom Rücken hel zusammengedrückt oder convex und vorne flach, $1 \mathrm{btg}$. oder mit 1 Ansatze

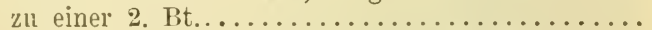

Aehrchen von der Seite her zusammengedrückt oder stielrund

3 Hüllsp. vorhanden; Decksp. knorpelig und lederig; 23 Aehrchen auf dem Rücken convex, vorne flach... 30

Nur 2 Hüllsp. vorhanden .................

Aehrchen von langen, grannenförmigen Borsten (Hüll24 borsten) umgeben; Rispe dicht und schmal, ährenförmig; 1 jährige Gräser......... Setaria. XIII. Aehrchen nicht von Borsten umgeben ...........

Die 2 unteren Hüllsp. begrannt; Aehrchen in Büscheln, welche eine unterbrochene Scheinähre bilden.

Die unterste Hüllsp. folgenden manch-

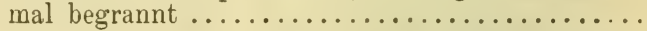

Btstand handförmig verzweigt; Zweige dünn, Schein-

26 ähren bildend ..............

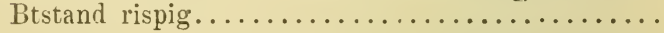

Rispenäste dichtblütig, ährenförmig; Hüllsp. borst-

27 lich, die oberen meist begrannt. Echinochloa. X. Rispe weitschweifig, lockerblütig; Hüllsp. kahl, wehrlos.................... Panicum. XI.

Gr. verlängert; $N$. sprengwedelförmig, unter der spitze der Bt. hervortretend; die untere Hüllsp. häutig, sehr klein, die obere lederig, dornig, die Bt einschließend........... Tragus. VIII. Gr. kurz oder fehlend; N. federig; Fr. von den knorpeligen oder papierartigen Spelzen dicht lim-

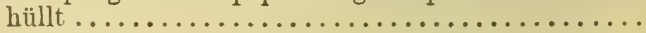

Deckspelzen wehrlos, eiförmig, bauchig.

Deckspelzen an der Spitze begrannt, Granne am Grunde eingelenkt und abfällig. Oryzopsis. XXI. 


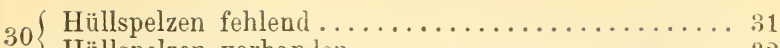

Hüllspelzen vorhanden ............... 32

Sehr kleines, einjähriges Gras; Decksp. begrannt; N. fädlich, kurzhaarig; Spelzen die Fr. nicht ein31 hüllend............. Coleanthus. XXVII. Hochwüchsiges, ausdauerndes Gras; Decksp. wehrlos; $\mathrm{N}$. federig; Spelzen die Fr. einhüllend.

Leersia. XIV.

${ }_{32} \int 3-4$ Hüllsp. vorhanden, die 2 inneren manchmal

Nur 2 Hüllsp vorhanden.................

Stb. 2 ; die 2 oberen Hüllsp. begrannt; Rispe zusammengezogen, ährenähnlich.

Anthoxanthum. XVII.

Stb. 3; Hüllsp. wehrlos................. 34

Aehrchen in einer dichten Scheinähre; die 2 unteren Hüllsp. am Kiele geflügelt, die 1-2 oberen viel kleiner, aber nicht federförmig... Phalaris. XV. Aebrchen in einer reichblütigen Rispe; Hüllsp. nicht geflügelt, die 2 oberen federförmig,

\section{Baldingera. XVI.}

N. aus der Spitze des Aehrchens hervortretend, fädlich, flaumig oder zottig................36

N. unter der Spitze oder am Grunde des Aehrchens vortretend, sprengwedelförmig oder federig ......

Decksp. schlauchförmig, an dem inneren Rande gespalten, auf dem Rücken begrannt; Vorsp. fehlend; Gr. lang............... Alopecurus. XXVI.

Decksp. nicht schlauchförmig; Vorsp. vorhanden ... 37

Hüllsp. fast gleich, viel länger als die Decksp.; Ansatz zu einer obern Bt. stielförmig oder ganź fehlend; Gr. mäßig lang; N. sehr lang

Phleum. XXV.

Hüllsp. ungleich, die untere kürzer, nicht länger als

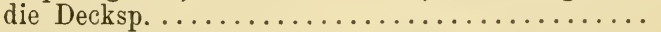

Aehrchen in 1 seitige Aehren geordnet; das Ende der Spindel nackt, fast dornig; Vorsp. nachenförmig, 2nervig, länger als die zusammengedrücktgekielte Decksp............ Spartina. XLVII. Aehrchen in einer (manchmal kopfförmigen) S`heinähre; Vorsp. etwas kürzer als die Decksp....... 39

Scheinähre cylindrisch oder elliposidisch; Vorsp. 2 nervig; Stb. 3 .......... Heleochloa. XXIV. Scheinähre kopfförmig; Vorsp. 1 nervig; Stb. 2.

Crypsis. XXIII. 
N. fast sprengwedelförmig, auf verlängertem $\mathrm{Gr}$. unter der Spitze der Bt. vortretend; Aehren 1 seitig, schmal, 3-7, fingerförmig zusammento gestellt .................... Cynodon. XLV. N. federig, am Grunde der Aehrchen vortretend; Gr. kurz oder fehlend; Aehrchen in Rispen oder

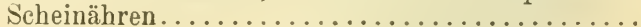

Hüllsp. sehr zusammengedrückt, am Grunde fast 41 kugelig-gedunsen, spitz...... Gastridium. XXX. Hüllsp. am Grunde nicht kugelig-gedunsen........

Decksp. fast lederig, walzl.-zusammengerollt, mit 1 am Grunde abgegliederten, meist gedrehten, oft sehr langen, zottig-federigen oder liahlen Granne;

42 Fr. von den knorpeligen Spelzen eingehüllt; Hüllsp. sehr spitz begrannt............ stipa. XIX.

Decksp. nicht walzl-zusammengerollt, Grannen derselben weder abgegliedert noch gedreht, oder fehlend 43

( Hüllsp. begrannt, länger als die Decksp.; 1 jährige

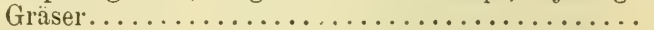

Hüllsp. spitz, aber nicht begrannt .......... 45

Hüllsp. pfrieml., in 1 Granne verschmälert; Decksp. mit 2 endst., geraden, und einer rückenst. geknieten Granne; Scheinähre eiförmig.

Laguius. XXXIV.

Hüllsp. aus der stumpfen oder etwas ausgerandetell Spitze borstig-begrannt; Decksp. begranut; Rispe gedrungen, lappig ........ Polypogon. XXVIII.

Bt. kahl, oder am Grunde mit Haaren umgeben, die kürzer sind als der Querdurchmesser der Decksp. $\left.{ }^{*}\right) \ldots \ldots \ldots \ldots \ldots \ldots \ldots \ldots \ldots \ldots \ldots \ldots \ldots \ldots \ldots$

45 Bt. am Grunde mit Haaren umgeben, die längel sind als der Querdurchmesser der Decksp., oder die letztere auf dem Rïcken lang-behaart; ausdauernde Gräser*) . . . . . . . . . . . . . . .

Ausdauernde Gräser; die untere Hüllsp. länger als die obere; Ansatz zu einer oberen Bt. meist fehlend ...................

46 Einjährige Gräser; die unt. Hüllsp. kürzer als die obere; ein stielförmiger Ansatz zu einer 2. Bt. vorhanden; Decksp. begrannt, Granne 3-4 mal so lang als die Decksp........... Apera. XXXIII.

*) Stimmt keine der unter Nr. 46-47 angeführten Gattungen, so vergl. man noch die Gattung Melica, bei der die Aehrchen oft 1 blütig sind. 
Decksp. auf dem Rücken mit verlängerten Haaren besetzt, unter der Spitze derselben eine starke, ge-

47 kniete Granne; Spelzen zuletzt fast lederig.

Lasiaglostis. XX.

Bt. am Grunde mit verlängerten Haaren umgeben 48

Die unt. Hüllsp. größer; Rispe locker.

48 Die untere Hüllsp. kleiner; Rispe ährenförmig-gedrungen; B. eingerollt .... Ammophila. XXXII.

N. aus der Spitze der Bt. vorgestreckt, fädlich, bis-

49 weilen etwas federig ........................... hervortretend, sprengwedelförnig oder federig...

Gr. lang; N. etwas federig; Aehrchen $3 \mathrm{btg}$., die 2 unt. Bt. männlich, die oberste zwittrig; Rispe

50 ausgesperrt ............ Hierochloa. XVIII. Gr. sehr kurz oder fehlend; N. fädlich; Hüllsp. groß, fast die Bt. bedeckend ................ 51

Decksp. ungetheilt, stachelspitzig oder begrannt, oder an der Spitze 3-5 zähnig; ausdanernde Gräser .. 52

51 Decksp. handförmig-5 spaltig, Zipfel lanzett. -pfrieml., krautig, steif; Vorsp. 2 spaltig; Scheinähre kopfigkugelig; 1 jähriges Gras.... Echinaria. XLVIII.

Aehrchen in einer allseits gleichmäळig entwickelten Scheinähre................. Sesleria. XLIX. Aehrchen in einer zweizeiligen, einseitswendigen, ährenförmigen Traube.......... Oreochloa. L.

N. sprengwedelförmig, unter der Spitze der Bt. vor53 tretend; Gr. verlängert; ausdauernde liohrgräser N. federig, am Grunde der Bt. vortret.; Gr. meist

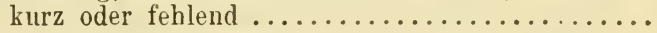

Bt. alle zwittrig; Decksp. auf dem Rücken mit verlängerten Haaren besetzt, an der Spitze 3 spaltig, Zipfel stachelspitzig, der mittlere in eine längere 54 borstige Granne vorgezogen........ Arumdo. LII. Die untere Bt. männlich, die folgenden zwittrig, von verlängerten Haaren umgeben; Decksp. wehrlos, ungetheilt............ Phragmites. LIII.

Zwittrige Aehrchen mit leeren gemischt, oder die

55 Aebrchen enthalten nebst den Zwitterbt. auch noch männliche Bt. oder leere Spelzen ....... 56

Aehrchen nur Zwitterbt. enthaltend ............ 59

Zwittrige Aehrchen mit leeren gemischt oder die Aehrchen enthalten nebst den Zwitterbt. auch

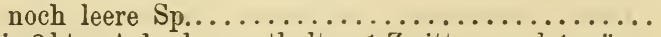

Die 2 btg. Aehrchen enthalten $1 \mathrm{Zwitter}$ - und 1 männ-

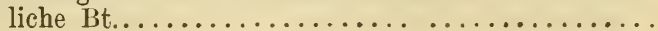


Zwittrige Aehrchen mit leeren gemischt, 2 btg., 1 gestielte Zwitterbt. und 1 langgestielte geschlechtslose Bt. enthaltend; Hüllsp. schmal begrannt-zugespitzt; Decksp. aus 2 spalt. Spitze begrannt; die leeren Aehrchen mit 5-11 Spelzen, viel gröळer . ............. Lamarckia. LXV. Alle Aehrchen 1-2blütig, mit einer gestielten, verkümmerten Bt.; Decksp. wehrlos, zuletzt knorpelig.......................

Die obere Bt. männlich, mit begrannter Decksp., die untere Bt. zwittrig, grannenlos; Gr. sehr kurz.

Holcus. XXXV.

58 Die untere Bt. männlich, mit begrannter Decksp.; obere Bt. zwittrig, mit wehrloser oder seltener begrannter Decksp.; Gr. fehlend.

Arrhenatherum. XLIII.

(Gr. 0. N. oberhalb der Mitte des an der Spitze 59 behaarten Frkn. auf dessen vorderer Seite eingefügt; Aehrchen vielbtg....... Bromus. LXXV. Gr. o. N. auf eine andere Weise eingefügt ......6 60

Decksp. auf der Mitte des Rückeus oder am Grunde begrannt, oder die rückenst. Granne in $1 \mathrm{Knie}$ gebogen und am Grunde gedreht...........6 61

Decksp. an der Spitze oder nahe an der Spitze be-

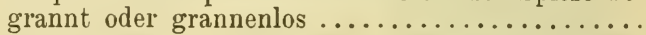

Decksp. (wenigstens die der obersten Bt.) an der Spitze 2 zähnig oder 2 grannig, manchmal 2 spaltig mit unregelmäßig-gezähnelten Zipfeln, auf dem Rü.cken begrannt, Granne am Grunde gedreht und in 1 Knie gebogen; Aehrchen 2-vielblütig; Gr.

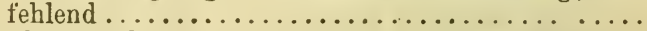

Decksp. an der Spitze ganzrandig, oder abgeschnitten und 4 zähnig; Gr. sehr kurz; Aehrchen 2 blütig, oft mit 1 Ansatze zu einer 3. Bt., seltener 3blütig. 66

Decksp. der untersten Bt. ohne rückenständige Granne ................ Ventenata. XL. Alle Decksp. oder doch die der untersten Bt. be-

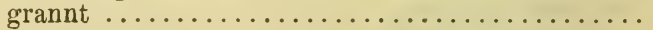

Aehrchen 2 blütig, ohne Ansatz $z u$ einer dritten 63 Bt.; zarte einjährige Gräser.......Aira. XXXVI. Aehrchen mehrblütig, oder 2 blütig mit Ansatz zu

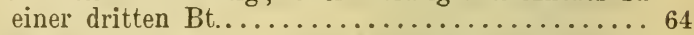

Hüllsp. 1-3 nervig; ausdauernde Gräser ......... Aehrchen .................. Avena. XLI. 
Decksp. an der Spitze fein 2spitzig, undeutlich 5 nervig; Vorsp. häutig...... Trisetum. XXXIX.

65 Decksp. an der Spitze kurz-2zähnig, deutlich 5- bis 7 nervig; Vorsp. am Grunde verdickt.

Avenastrum. XLII.

Decksp. an der Spitze ganzrandig, am Grunde begrannt; Granne gerade, oberw. keulig, in der Nitte mit 1 bärtig. Gelenke.

Weingaertneria. XXXVII.

Decksp. an der Spitze abgeschnitten, 4 zähnig, am Grunde oder auf der Nittę des Rückens begrannt. Deschampsia. XXXVIII.

Vorsp. am Rande mit steifen Börstchen kammförmiggewimpert; Decksp. lanzettlich oder pfrieml., auf dem Rücken stielrund; Frkn. kahl; Gr. kurz uder fehlend; Aehrchen sehr kurz gestielt, in einer einfachen Traube........ Brachypodium. LXXVI.

Die obere Spelze am Rande fein gewimpert, behaart oder ganz kahl, aber nicht kammförmig borstig . 68

Decksp. eiförmig, stumpf, aufgeblasen-bauchig, am Grunde geöhrlt-herzförmig, wehrlos; Aehrchen 2 zeilig, gestielt .................. Briza. LXI.

Decksp, nicht geöhrlt-herzförmig........... 69

Hüllsp. groß, fast das ganze Aehrchen umfassend . 70

69 Hüllsp. meist kürzer als die nächste Decksp., niemals

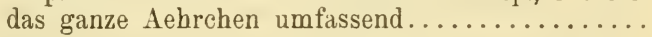

70 Decksp. an der Spitze 2 spaltig, mit langer, gestielter und gedrehter Granne........ Danthonia. XLV.

Decksp. ohne oder mit gerader Granne ..........

Decksp. an der Spitze kurz 2 zähnig, mit einer sebr kurzen, die Zähne kaum überragenden, fast unmerklichen Granne in der Ausrandung.

Sieglingia. LIV.

Decksp. wehrlos oder mit verlängerter Granne.....

Aehrchen groß, hängend; Decksp. an der Spitze 2 spaltig, wehrlos.................. Aehrchen klein, aufrecht oder abstehend, dicht gedrängt in einer zusammengezogenen, meist ährenförmigen Rispe; Decksp. meist ungetheilt, seltener an der Spitze 2 spaltig, dann aber begrannt.

Koeleria. LVIII.

Decksp. auf dem Rücken zusammengedrückt-gekielt 74

73 Decksp. halbwalzlich oder stielrund, nicht oder nur gegen die Spitze zu gekielt............. 80

$74\{$ Decksp. begrannt oder stachelspitzig.......... 75

Decksp. wehrlos ................... 78 
Decksp. eiförmig, an der Spitze etwas nach einwärts 75 (stachelspitzig); Aehrchen in dichten Knäueln oder

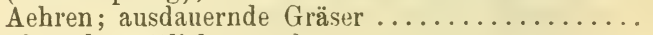

Decksp. lanzettlich, gerade.............. 77

${ }_{76}\left\{\begin{array}{l}\text { Wuchs rasig, ohne Ausläufer; Decksp. } 5 \text { nervig. } \\ \text { Dactylis. LXIII. }\end{array}\right.$

76 Wst. mit kriechenden Ausläufern; Decksp. 9- bis 11 nervig . .............. Aeluropus. LXII.

Decksp. auf dem Rücken unterw. haarig; hohes Rohr77 gras; Rispe einseitswendig. Ampelodesmos. LI. Decksp. auf dem Rücken ohne Haare; Rispe ährenförmig . . ..............Koeleria. LVIII.

Hüllsp. scharf gekielt; Gr. sehr kurz oder fehlend. 79

78 Hüllsp. zusammengedrückt, aber nicht scharf gukielt; Gr. verlängert; einjährige Gräser; Bscheiden an der Mündung gebärtet ........Eragrostis. LVII. Aehrchenstiele sehr kurz und dick, die Rispe daher starr, gedrungen; Decksp. am Grunde knorpelig. siclerochloa. LXVI.

Aehrchenstiele dünn, meist verlängert; Decksp. krautig oder häutig.............Poa. LXVII.

Rispe gedrungen, einseitig, init kammförmigen, leeren Aehrchen neben den fruchtbaren.

Alle Aehrehen fruchtbar ...... Cynosurns. MXIY. Cynosurus. IAXIV.

Decksp. an der Spitze abgerundet, abgestutzt, stumpf

81 oder ausgerandet (oft mit einer Stachelspitze in der Ausrandung), niemals deutlich begrannt.... 82

Decksp: spitz oder zugespitzt, oft begrannt...... 86

Aehrchen in einer einfachen ährenförmigen Traube, sehr kurz gestielt, der Spindel angedrückt

A ehrohen in einer ausgebreteten oher zusammenCatapodium. LXXIII.
eiteten oder zusammen-

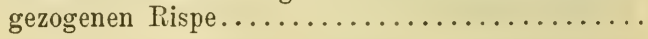

Aehrchen klein, meist 2 blütig, in einer ausge83 breiteten, reichblütigen Rispe; Decksp. 3nervig Catabrosa. LIX.

Aehrchen mindestens 4 blütig; Decksp. 5-7nervig 84 $84\left\{\begin{array}{c}\text { Einjährige Gräser mit sehr steifer Rispe; Aehrchen- } \\ \text { stiele sehr kurz und dick; Aehrchen zusammen- } \\ \text { gedrückt............... Scleropoa. LXXIV. }\end{array}\right.$ Ausdauernde Gräser; Aehrchen fast stielrund..... 85

Gr. kurz, aber deutlich; Decksp. 7 nervig; Aehrchen Gr. fehlend; Decksp. schwach 5nervig; Aehrchen sehr kurz gestielt ........... Atropis. LXIX. 
Aehrchen in einer einfachen, ährenförmigen Traube, auf sehr kurzen, dicken Stielen, der Spindel angedrückt; einjährige Gräser.. Nardurus. LXXII. Aehrchen in einer ausgebreiteten oder zusammen-

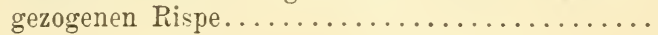

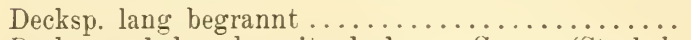

87 Decksp. wehrlos oder mit sehr kurzer Granne (Stachel-

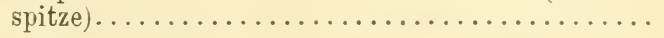

Ausdauernd; Aehrehen nach dem Verblülen gegen die Spitze verschmälert; Stb 3; N. felerig, answärts gebogen................. Festuca. LXX. Einjährig (selten 2 jährig); Aehrchen nach dem Verblühen gegen die Spitze verbreitert; Stb. meist nu* 1; N. klein, aufrecht ..........Vulpia. LXXI.

Decksp. am Grunde bauchig-erweitert, gegen die Spitze zu kegelförmig verschmälert; Fr. frei .... 90

89 Decksp. nicht bauchig erweitert, lanzettlich oder priemlich; Fr. meist der Torsp. angewachsen.

Festuca. LXX.

$90\{$ Decksp. mit sehr kurzer Granne .. Diplachne. LV. Decksp. wehrlos ............. MIolinia. LVI.

Arten.

I. ZEA. L. Mais.

Einjährig; B. breit, behaart; Hüllsp. der männlichen Aehrchen lanzettlich, spitz, gewimpert. Cult.

Mays. L. Gemeiner M.

\section{IMPERATA. Cyr. Silbergras.}

Ausdauernd; Aehrchen in einer dicken, cylindrischen, silberweiß behaarten Scheinähre. $J$.

arundinacea. Cyr. Rohrartiges S.

\section{ERIANTHLS. Rich. Wollrohr.}

Ausdauernd; Hüllsp. am Grunde lang behaart. $J$.

Ravennae. (L.) Beaui. W. von Ravenna.

\section{ANDROPOGON. L. Bartgras.}

Scheinähren zu mehreren; untere Hüllsp. der zwittrigen Aehrchen lang behaart. $V e r b r$.

Ischaemum. L. Gemeines B.

Scheinähren zu 2 ; alle Hüllsp. behaart. $J$. pubescens. Vis. Flaumiges B.

\section{SORGHUM. Pers. Mohrenhirse.}

(Ausdauernd, mit Ausläufern; Rispe abstehend; zwittr.

Aehrch. längl.-lanzett., die männlichen lanzett. Sïdt. J. ......halepense. (L.) Pers. Wilde M.

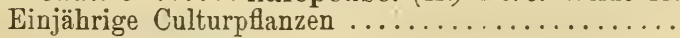


Aeste der Rispe fast bis zur Mitte nackt, die blüh. sehr weit abstehend, die fruchttr. aufrecht; die zwittr. Aehreh. vrkhrt.-eif.-ellipt. Cult.

saccharatum. (Ard.) Pers. Zuckerhirse.

Rispe dicht zsmgezogen, eilängl.; die zwittrigen Aehrch. vrkhrt.-eif. Cult.

vulgare. Pers. Gemeine M.

\section{CHRYSOPOGON. Trin. Goldbart.}

Ausdauernd; Rispenäste quirlig, unterhalb der zwittrigen Aehrchen fuchsroth gebärtet.

N. Kr. J. Sï̈t. Gryllus. (L.) Trin. Gemeiner G.

VII. HETERopogoN. Pers. Schopfgras.

Ausdauernd; Scheinährell einseitswendig, lang begrannt, kahl. Südt. . glaber. Pérs. Kahles Sch.

VIII. TRAGUS. Hull. Klettengras.

Kleines, einjähriges Gras; Rispe zusammengezogen, ährenförmig. M. N. Kr. J. Sültt.

racemosus. (L.) Desf. Gemeines K.

\section{DIGITARIA. Scop. Fingergras.}

B. u. Bscheiden kahl; Scheinähren 2-5 (meist 3); Aehrchen beiderseits flaumig, elliptisch; zweite Hüllsp. die Decksp. ganz verdeckend. Verbr.

linearis. (Krock.) Crép. Kleines F.

B. u. Bscheiden ziemlich behaart; Scheinähren 2-12 (meist 5), Aehrchen außen ziemlich kahl, länglichlanzettlich; Decksp. weit über die zweite Hüllsp.

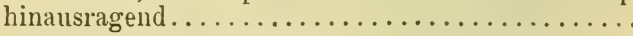

Dritte (oberste) Hüllsp. am Rande borstig gewimpert. Verbr.

ciliaris (Retz.) Koel. Gewimpertes F. Dritte Hüllsp. am Rande fein flaumig, aber nicht borstig gewimpert. Verbr.

sanguinalis. (L.) Scop. Gemeines F.

\section{ECHINOCHLOA. Beauv. Stachelgras.}

Einjährig; Aehrchen bald kurz, bald lang*) begrannt. Verbr.... Crus galli. (L.) Beauv. Gemeines St.

\section{PANICUM. L. Hirse.}

Rispe überhängend; B. lanzettlich, nebst den Bscheiden behaart. Cult. . . miliaceum. L. Echte $H$. Rispe abstehend, mit haardünnen Aesten; B. u. Bscheiden sehr rauhhaarig. Eingeschleppt (selteu). capillare. $L$. Amerikanische $\mathrm{H}$.

*) Die lang begrannte Form ist E. oryzoides (Ard.) Fritsch. 


\section{OPLISMENUS, Beauv. Borstenhirse.}

Einjährig; Stg. u. Bscheiden rauhhaarig; B. breit ei-lanzettlich; Hüllsp. begrannt. Sïdt. .J.

undulatifolius. (Ard.) R. Sch. Europäische B.

\section{SLTARIA. Beauv. Borstengras.}

Aehrenförmige Rispe doppelt zusammengesetzt, lappig; Hüllborsten von aufwärts gerichteten Zähnehen rauh. Cult.

italica. (L.) Beauv. Vogelhirse. Aehrenförmige Rispe cylindrisch, am Grunde oft unterbrochen, aber nicht gelappt, mit kurzen, armblütigen Aesten ....................... Hüllborsten von abwärts gerichteten Zähnchen rauh; Rispe am Grunde oft unterbrochen. Verbr.

verticillata. (L.) Beauv. Quirliges B. Hüllborsten von aufwärts gerichteten Zähnchen rauh. Decksp. querrunzelig, die zweite Hüllsp. überragend; Hüllborsten fuchsroth. Verbr.

Decksp. ziemlich glatt, von der zweiten Hüllsp. verdeckt; Hüllborsten grün oder rothbraun...... Hüllborsten 1-2; Rispe am Grunde meist unterbrochen. J..... ambigua. Guss. Täuschendes B Hüllborsten zahlreich, Rispe gedrungen. Verbr.

viridis. (L.) Beauv. Grünes B.

XIV. LEERSIA. Sw. Reisquecke.

Rispe abstehend, Aeste schlängelig; B. sehr rauh. Verbr........... oryzoides. (L.) Sw. Gemeine R.

\section{PHALARIS. L. Glanzgras.}

Aisdauernd; Stg. am Grunde knollig verdickt; Hüllsp. 3 ; Decksp. kahl. J.

Einjährige Gräser aquatica. L. Ausdauerndes G.

Aeußere Hüllsp. am Rande 3 nervig; Scheinähre

2 cylindrisch; neben den fruchtbaren auch leere

Aehrchen. J...... paradoxa. L. Sonderbares G.

Aeußere Hüllsp. am Kande 1 nervig ............ 3

Flügel der äußeren Hüllsp. ganzrandig; Scheinähre eiförmig oder fast kugelig, seltener kurz cylindrisch.........................

Flügel der inneren Hüllsp. gezähnelt; Scheinähre länglich. J........... minor. Retz. Kleines G. Innere Hüllsp. halb so lang als die Decksp. Eingeschleppt (wicht selten).

Callariensis. L. Canarisches G.

Innere Hüllsp. vielmal kürzer als die Decksp. $J$. bracliystachys. $L k$. Gedrungenblütiges $G$. 
XVI. BALDINGERA. G. Mi. Sch. Bandgras. Ausdauerndes, rohrartiges Gras. Verbr. $\iota$. $h f g$. arundinacea. (L.) G. M. Sch. Gemeines B.

X VII. ANTHOX ANTHUM. $L$. Ruchgras.

Ausdanernd; die dritte Hüllsp. ausgerandet, in der Ausrandung begrannt; die vierte Hüllsp. unter der Mitte ihres Rückens lang begrannt. Verbr. $\iota$. h fg. ............ orloratum. L. Gemeines R.

X VIII. HIEROCHLOA. Gmel. Mariengras.

Aehrchenstiele liahl; Decksp. der männlichen Bt. kaum merklich begrannt. $B$. $M$.

odorata. (L.) Wahlb. Wohlriechendes M.

Aehrchenstiele an der Spitze behaart; Decksp. der oberen männlichen Bt. mit verlängerter, geknieter Granne. Verbr. (fehlt Sch. S.)

australis. (Schrad.) Röm. ét Sch. Südliches M.

XIX. STIPA. L. Pfriemengras.

( Granne der Decksp. sehr lang, federig, gekniet und

1 gedreht. Verbr..... pennata. 1..*) Federiges Pf.

Granne der Decksp. nicht federig, sondern haar-

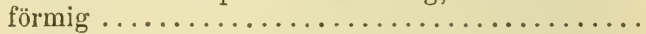

Granne der Decksp. vielmal länger als die Decksp., gekniet und gedreht. B. M. N. O. T.

capillata. $L$. Langgranniges $\mathrm{Pf}$.

Granne der Decksp. gerade, kaum doppelt so lang als die Decksp. $J$.

Aristella. L. Kurzgranniges Pf.

XX. LAsIAGRostis. Lk. Rauhgras.

Rispe abstehend. weiss schimmernd; Granne $3 \mathrm{mal}$ so lang als die Decksp. O. S. T. K. Kr.J.

Calamagrostis. (L.) $L k$. Silberhariges $\mathrm{R}$.

XXI. ORYZOPSIS. Mich. Grannenhirse.

Decksp behaart, viel kürzer als ihre Granne.

$N$. Kr.J. virescens. (Trin.) Beck. Grünliche G.

Decksp. kahl, wenig kürzer als ihre Granne.

Südt. J. (N.) miliacea. (L.) Richt. Gemeine G.

XXII. MLIUM. $L$. Flattergras.

Ansehnliches Gras mit breiten B. und abstehender

Rispe. Verbr. ........effusum. L. Gemeines F.

XXIII. CRYPSIS. L. Dorngras.

Niedriges, starres, einjähriges Gras; Scheinähre von bauchigen Bscheiden eingeschlossen. $M . N$. J.

aculeata. $L$. Starres $D$.

*) Umfasst inehrere Formen! 


\section{HELEOCHLOA. Host. Sumpforas.}

Halme meist unverzweigt; Scheinähre länglich-walzlich; oberste Bscheide nicht bauchig, meist von der Scheinähre entfernt. $M . \Lambda . J$.

alopecuroides. Host. Fuchsschwanzartiges S. Halme oft ästig; Scheinähren ellipsoidisch, am Grunde von $1-2$ bauchigen Bscheiden umgeben. M. N. Kr . J. schoenoides. (L.) Host. Knopfgrasartiges S.

\section{PHLEUM. L. Lieschgras.}

Decksp. 5 nervig, am Ende abgeschnitten; Hüllsp. am Rücken halbmondförmig-gekrümmt, kurzstachelspitzig, fein-knötig-rauh; Pfl. einjährig. $K r$. J......bulbosum. (I.) Richt. Knolliges L.

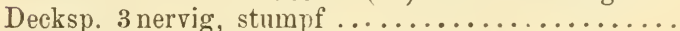
Ein Stielchen am Grunde der Vorsp. (Ansatz zu einer

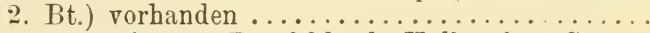
Ansatz zu einer 2. Bt. fehlend; Hüllsp. in 1 Granne plötzl. zugespitzt, am Kiele steifhaarig-gewimpert Hüllsp. lanzett., in 1 kurze Granne zugespitzt, am

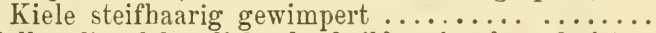
Hüllsp. lineal-länglich oder keilförmig, abgeschnitten,

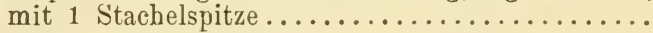

Einjährig; Rispe ährenförmig, länglich, am Grunde ıneist verschmälert $J$. . . a arenarium. $L$. Sand-L. Ausdauernd und rasenbildend; Rispe ährenförmig, walzl. A. u. Tora. . Michelii. All. Micheli's L. Ausdauerıd; Hüllsp. lineal-länglich, schief-abgeschnitten, zugespitzt-stachelspitzig, zusammengedrückt, auf dem Rücken steifhaarig-gewimpert oder rauh. Verbr. (fehlt Sch.)

phalaroides. Koel. Glanzgrasartiges L. Einjährig; Hüllsp. keilförmig, abgeschnitten, an der Spitze aufgeblasen-kantig, stachelspitzig, rauh. Sïdt. J. (B. N.) ..... asperum. Vill. Rauhes L. Einjähriges Gras; Hüllsp. eiförmig-länglich, quer abgeschnitten, kürzer als ihre Granne. $J$.

echinatum. Host. Stachliges I. Ausdauernde Gräser; Hüllsp. länglich, quer-abgeschnitten, so lang oder länger als ihre Grannen . Granne $3 \mathrm{mal}$ kürzer als die Hüllsp ; Bscheiden walzl.; Halm über der $\mathrm{W} z$. oft zwiebelig-verdickt. Verbr. $u$. $h f g . . . . .$. pratense. $I$. Wiesen-I. Granne so lang als die Hüllsp., selten kürzer; die oberste Bscheide aufgeblasen; Scheinähre meist trübviolett. Geb. alpinum. $L *^{*}$ ) Alpen-L.

*) Umfasst mehrere Formen, die sich manchmal sehr dem $\mathbf{P}$. pratense L. nähern. 


\section{XIVI. ALOPECURUS. L. Fuchsschwanz.}

Hüllsp lederig-knorplig, am Rücken stark höckerigconvex; Scheinähren eif. o. längl.; die oberste Bscheide bauchig-aufgeblasen; Pfl. 1 jährig. St. J. utriculatus. Pers. Aufgeblasener F.

Hüllsp. krautig-häutig, am Pücken höckerlos; Scheinähre walzl.

Halme aufrecht; Hüllsy. bis zur Mitte o. nahe bis

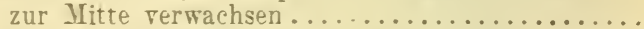

Halme am Grunde liegend, aufstreb.; Hüllsp. stumpf, gewimpert, nur am Grunde verwachsen.......

Ausdauernd; Halm kahl; Hüllsp. zottig-gewimpert; Scheinähre stumpf. Verbr. u. $h f g$.

pratensis. $L$. Wiesen-F.

Einjährig; Halm oben etwas rauh; Hüllsp. sehr kurz gewimpert; Scheinähre beiderseits verschmälert. Verbr.............

Decksp. unter der Mitte begrannt, Granne fast doppelt so lang als die Decksp.; A. blassgelb, dann braun; B. grasgrün. Terbr.

Decksp. ungefähr in der Mitte begrannt, Granne haum länger als die Decksp.; A. rothgelb; B. meist seegrün. Verbr... fulvus. Sm. Pothgelber F.

\section{COLEANTHCS. Seid. Scheidengras.}

Rispe traubenförmig, mit wirtelig gestellten, döldchenförmigen desten. B. M. N. Sïdt.

subtilis. Seid. Feines Sch.

\section{POLYPOGON. Desf. Bürstengras.}

Hüllsp. unter der Spitze begrannt; Decksp. begrannt. .J. .... Monspeliensis. (L.) Desf. Gemeines B. Hüllsp. in der Ausrandung der zweispaltigen Spitze begrannt; Decksp. wehrlos. .J. maritimus. Willd. Meerstrands-B.

\section{AGrostis. L. Windhalm.}

B. alle flach, lineal 0 . höchstens mit eingerollten Rändern; Decksp. fast immer wehrlos. Grundb. zsmgefaltet-borstl.; Decksp. fast immer be-

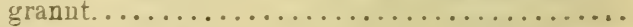

Blatthäutchen länglich, stets länger als die Breite

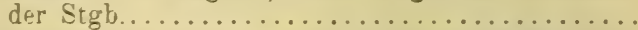
Blatthäutchen kürzer als die Breite der Stgb., meist

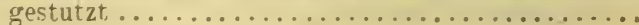


Decksp. höchstens $1^{1}{ }_{2}$ mal so lang als die Torsp., länger als die halbe Hüllsp. Verbr.

Decksp. fast $3 \mathrm{mal}$ so lang als die Vorsp., kaum länger als die halbe Hüllsp. $J$.

olivetorum. Godr. et Gren. Oliren-W.

Decksp. 3nerrig, ungefähr doppelt so lang als die Vorsp.; Rispenäste etwas rauh. Terbr. u. hfg.

valgaris. $L$. Gemeiner IT.

Decksp. 4nervig, fast $4 \mathrm{mal}$ so lang als die Torsp.; Rispenäste sehr rauh. Südt.

tarda. Bartl. Spätblühender W.

Rispenäste glatt; Decksp. unter der Mitte lang berupestris. All. Felsen- $\mathbb{T}$.

Decksp. unter der Mitte begrannt (selten wehrlos). an der Spitze gezähnelt. Terbr.

canina. $L$. Hunds- WT.

Decksp. über dem Grunde lang begrannt, an der Spitze mit 2 längeren Zähnen; Wuchs niedrig. Geb. ................. alpina. Scop. Alpen-W.

Xxx. GASTRIDIUM. Beaur. Nissengras.

Einjährig; Rispe ährenförmig; Decksp. begrannt. J. lendigerum. ( $L$.) Gaud. Südliches N.

Xxi. CALAMAgrostis, Roth. Reitgras.

Ansatz zu einer 2. Bt. fehlend; Decksp. häutig,

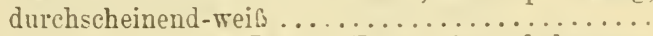

Ansatz zu einer 2. Bt. in Form eines behaarten, aus dem Grunde der ob. Spelze herrortretenden Stielchens vorhanden; Decksp. derber, am Rü̈cken

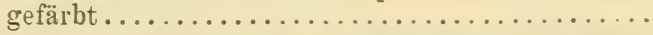

Haare halb so lang als die Decksp., diese mit 1 geraden Granne 0. ohne diese: Hüllsp. lanzett.. spitz. A. (fehlt $N . O . J$.)

tenella. (Schrad.) Host. Zartes R.

Haare länger als die Decksp................. 3

Granne der Decksp. endst.; Hüllsp. schmal-lanzett.

3 Granne aus der Mitte 0. unter der Mitte des Rüickens der Decksp. herrortretend, gerade; Hüllsp. lanzett. Hüllsp. zugespitzt; Granne rielmal kürzer als die Decksp. Verbr. (fehlt T. Kr. St.)

lanceolata. Roth. Lanzettliches $\mathrm{R}$.

4 Hüllsp. in 1 pfrieml., zsmgedrückte Spitze rerschmälert; Granne so lang o. länger als die Hälfte der Decksp. Verbr. (fehlt B. M. Sch.)

pseudophragmites. (Hall.) Baumg. Schilfart. R

Fritsch. Exeursionsflora. 
Stg. glatt; Aehrchen ziemlich gleichmäळig zerstreut; Hüllsp. zugespitzt. Verbr.

villosa. (Chaix.) Mut. Glattes R.

5 Stg. unter der Rispe rauh; Aehrchen zu dichtblütigen Büscheln zusammengestellt; Hüllsp. in eine pfriemliche, zusammengedrückte Spitze verschmälert. Verbr. ......Epigeios. (L.) Roth. Röhriges R.

Hüllsp. kurz zugespitzt; Haare*) ungefähr so lang als die Decksp.; Granne die Hüllsp. kaum überlagend. Verbr. (fehlt Sch. $\boldsymbol{M}$.)

varia. (Schrad.) Baumg. Geschecktes $R$. Hüllsp. lang zugespitzt; Haare*) höchstens halb so

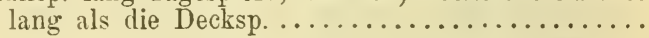

Haare*) reichlich, etwa halb so lang al's die Decksp.; Granne die Hüllsp. wenig überragend. S. O. $N$.

acutiflora. (Schrad.) DC. Spitzblütiges R. Haare*) spärlich, stets kürzer als die halbe Decksp); Granne weit über die Hüllsp. hinausragend. Verbr. arundinacea. (L.) Roth. Wald-P.

\section{AMMOPHILA. Host. Sandrohr.}

Starres, rohrartiges Gras mit eingerollten B. J. arenaria. (L.) $L k$. Gemeines $\mathrm{S}$.

\section{APERA. Adans. Windfahne.}

Rispe lockerblütig, weitschweifig, schlaff. Verbr.

Spica Venti. (L.) Beauv. Gemeine W. Rispe zusammengezogen, schmal, ziemlich dichtblütig; Pfl. kleiner. M. N. $K r$.

interrupta. (L.) Beauv. Dichtblütige W.

\section{LAGURUS. L. Sammtgras.}

Pfl. weichhaarig; Scheinähren weißlich o. röthlichweiß. Südt. J......... ovatus. L. Südliches S.

\section{XXXT. HOLCUS. L. Honiggras.}

Bscheiden dicht weichhaarig; Granne die Hüllsp. kaum überragend. Verbr. $\iota$. $h f g$.

lanatus. $L$. Wolliges $\mathrm{H}$.

Bscheiden spärlich behaart o. kahl; Granne die Hüllsp. weit überragend. Verbr: mollis. $L$. Weiches $\mathrm{H}$.

*) Hier sind stets die Haare am Grunde der Decksp., nicht jene des Ansatzes zur zweiten Blüte gemeint. 
XXXVi. AIRA. L. Nelkenhafer.

Pispe ährenförmig zusammengezogen, länglich 0. oval ; Hülss. wenig länger als die Decksp. B. $K r$.

praecox. $L$. Frühblühender $N$.

Rispe abstehend o. ausgesperrt, sehr lockerblütig; Hüllsp. viel länger als die Decksp.

Aehrchen an der Spitze der Aeste etwas gedrängt, oft zum Theil länger als ihre stiele. Verbr. (fehlt $S . K$.) ... caryophyllea. $I$. Gemeiner $\mathrm{N}$.

Aehrchen gleichförmig zerstrent, die meisten viel kürzer als ihre stiele. Südt. St. J.

capillaris. Host. Haarfeiner $\mathrm{N}$.

XXXVII. WEINGAERTNERIA. Berm.Keulengras.

Einjährig; B. borstlich zusammengerollt, steif, graugrün; Rispe länglich. $B . M . N . J$.

canescens. (L.) Bernhl. Graugrïnes $K$.

XXXVII. DESCHAMPSIA. Beanv. Schmiele.

B. flach, oberseits rauh; Granne der Decksp. über die Hüllsp. wenig o. gar nicht hinausragend. Verbr. u. hfg.

caespitosa. (L.) Beauv. Rasige Schm. B. borstlich-zusammengefaltet; Granne der Decksp. über die Hüllsp. weit hinausragend. Verbr.

flexuosa. (L.) Trin. Schlängelige Schm.

XXXIX. TRISETUII. Pers. Goldhafer.

Rispe fast ährenförmig zusammengezogen, eiförmig

o. cylindrisch, oft etwas lappig. A. v. T. S. K. St.

spicatum. (L.) Richt. Aehriger G.

Rispe ausgebreitet, lockerblütig................

Wuchs dicht rasig, ohne Ausläufer; B. mehr o. weniger behaart.

Wst. kriechend, Ausläufer treibend; B. kahl, nur die unteren Bscheiden oft etwas flaumig...........

Rispenäste rauh; Aehrehen meist gelblichgrün, seltener gescheckt; Frkn. kahl. Verbr. u. $h f g$.

flavescens. (L.) Beauv. Gemeiner G.

Rispenäste glatt; Aehrchen größer, meist gescheckt; Frkn. an der Spitze flaumig; Wuchs niedriger. $A$. alpestre. (Host.) Beauv. Alpen-G.

B. zuletzt flach; längere Rispenäste mit $3-4$ Aehrchen; Decksp, kaum doppelt so lang als die Haare an ihrem Grunde. $A$.

distichophyllum. (Vill.) Beauv. Fächerblättr. G.

B. rinnig, fast borstenförmig; längere Rispenäste mit 4-8 Aehrchen; Decksp. fast 3 mal so lang als die Haare an ihrem Grunde. A. v. T. K. Kr. St. argenteum. (Willd.) R. Sch. Silberhafer. 
XI. VENTExATA. Koel. Schmielenhafer.

Einjährig; B. zusammengerollt o. doch rinnig; Hüllsp. 5-9nervig, zugespitzt. $B . M . N$. J.

dulia. (Leers.) Boiss. Zarter Schm.

XLI. A VENA. I. Hafer.

Aehrchenspindel rauhbaarig, o. unter den Bt., wenigstens an der untersten 0 . obersten Bt. büschelig-

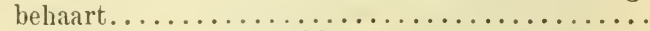

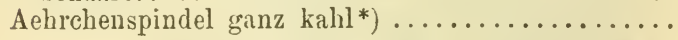

Decksp. vom Grunde bis zur Mitte borstig-behaart, lanzett., auf dem Rücken begrannt; Aehrchen-

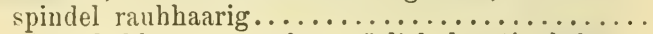

Decksp. kahl o. nur sehr spärlich borstig behaart; Aehrchen meist 2 blütig .

Rispe gleich, abstehend; Aehrchen meist 3 blütig; Decksp. an der Spitze gezähnt-2 spaltig. Verbr.

fatua. $L$. Flughafer.

3. Rispe einseitswendig, etwas abstehend; Aehrohen meist 2 blütig; Decksp. an der Spize 2 spaltig, Zipfel borstl., in je eine gerade Granne auslaufend. J............ barbata. Brot. Gebärteter H.

Aehrchen-Spindel borstig-rauhhaar.; Decksp. kahl, gegen die Spitze verschmälert, an der Spitze 2 spalt. und etwas gezähnelt, sämmtl. begrannt. Terbr. (?)

Aehrchen-Spindel unter den Bt., wenigstens am Grunde der untersten oder der obersten Bt. kurzbüschelig-behaart, sonst kahl ..............

Decksp. an der Spitze 2 spalt. mit gerade-begrannten Zipfeln, auf dem Rücken mit 1 geknieten Granne; Hüllsp. so lang als die Decksp.; Spindel am Grunde der oberen Bt. kurz-büschelig-beliaart. $B . M . N$. $O$.

strigosa. Schreb. Rauhhafer.

Decksp. an der Spitze kurz-2spaltig und gezähnelt, die obere wehrlos; Hüllsp. länger als die Bt.; Spindel am Grunde der unterst. Bt. kurz-büschelig-

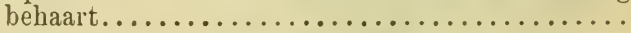

Rispe gleich, abstehend. Cult.

$6\left\{\begin{array}{r}\text { sativa. L. Futterhafer. } \\ \text { Rispe einseitswendig, zusammengezogen. Cult. } \\ \text { orientalis. Schrcb. Fahnenhafer. }\end{array}\right.$

*) Man verwechsle nicht die an der Decksp. stehenden Haare mit jenen der Aehrchenspindel. 
Decksp. kahl, an der Spitze haarspitzig-2 spaltig; Aehrchen meist $3 \mathrm{btg}$. Cult. (selten).

nuda. L. Nackter H.

Decksp. vom Grunde bis fast zur Mitte borstig-behaart, an der Spitze 2 zähnig-2 spaltig; Aehrchen meist 4 btg. J. ...........sterilis. L. Tauber H.

XIII. AVENASTRUM. Koch. Wiesenhafer.

B. beiderseits, sowie die unteren Bscheiden be-

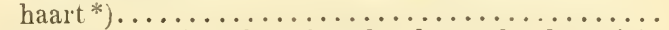

B. an Rande oder oberseits oft sehr rauh, abel nicht behaart.

Hüllsp. 1 nervig, an der Spitze weiss-trockenhäutig, die obere so lang als das Aehrchen oder kürzer. Verbr. $u$. $h f g$.

pubescens. (L.) Jess. Kurzhaar. W. Hüllsp. 3 nervig, das untere Drittel derselben violett gefärbt, die obere länger als das Aehrchen. T. K. sesquitertium. (L.) Fritsch. Violetter W.

Bscheiden 2 schneidig, flachgedrückt; B. flach, am Rande rauh, die halmständigen lanzett.-lineal. Geb. v. B. $\boldsymbol{H}$. St. K. Kr.

planiculme. (Schrad.) Jess. Platthalmiger W. Bscheiden stielrund .................. 4

B. oberseits ziemlich glatt $\ldots \ldots \ldots \ldots \ldots \ldots \ldots \ldots$

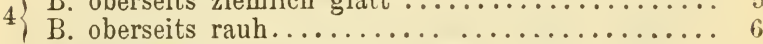

Aehrchen 5 blütig, zu $1-2$ an den Aesten der gedrängten, fast eiförmigen Rispe. A. (fehlt $N . O . J$. versicolor. (Vill.) Fritsch. Bunter W.

Aehrchen 3 blütig, in armblütiger Traube; Stg. fast blattlos. A. v. 'T'

pseudoviolaceum. (Kern.) Fritsch. Armblüt. W. Rispe zusammengezogen, traubig, die unt. oder alle Aeste zu 2, 1-2 Aehrchell tragend .......... Rispe ausgebreitet, die unt. Aeste zu 3-4, die längern 2-5 Aehrchen tragend; Grundb. zusammengefaltet,

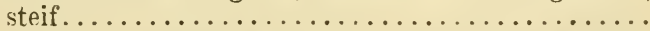

Aehrchen meist 8 btg. ; Decksp. auf dem Rücken oberhalb der Mitte begrannt; alle Aeste der Rispe zı 2. A. v. T. $K . K r$.

alpinum. (Sm.) Fritsch. Alpen-W.

Aehrchen 4-5 btg.; Decksp. auf der Mitte des Rückens begrannt; die unt. Aeste der Rispe zu 2, die obern einzeln. Verbr.

pratense. (L.) Jess. Kahler W.

*) Avenastrum pubescens (I.) Jess. kommt auch in einer fast kahlen Form vor. 
Bhäutchen der Halmb. längl., kahl; Decksp. von sehr kleinen Pünktchen rauh, inatt, vom Grunde an 3-5 nervig. $A$.

Parlatorii. (Woods.) Beck. Parlatore's W. Bhäutchen der Halmb. kurz, dicht-gewimpert; Decksp. glatt, glänzend, undeutl-nervig, aber an der Spitze von kleinen Pünktchen etwas rauh und deutl. 5 nervig. $J$.

filifolium. (Lag.) Fritsch. Fadenblättriger W.

XLIII. ARRHENATHERUM. Beauv. Glatthafer. Ausdauernd; B. flach; Rispe länglich. Verbr. $u$. $h f g$. elatius. (L.) $M . K$. Gemeiner $\dot{G}$.

XliV. GAUDINiA. Beauv. Aehrenhafer. Einjährig; B. flach; Aehre gegliedert, zerbrechlich. $J$. fragilis. (L.) Beauv. Zerbrechlicher A.

XLV. DANTHONIA. $D C$. Kelchgras.

Ausdauernd; Bscheiden oben gebärtet; Aehrchen meist in einfacher 'Traube. $N$. Südt. Südst. Kr . J. provincialis. DC. Europäisches $\mathrm{K}$.

\section{CYNODON. Pers. Hundszahn.}

Ausdauernd, Ausläufer treibend; B. unterseits behaart. Verbr. (fehlt Sch. S.)

Dactylon. (L.) Pers. Gemeiner $\mathrm{H}$.

XLVII. SPARTINA. Schreb. Besengras.

Ausdauernd; B. cingerollt; Aehrchen flaumig, aufrecht. J.........stricta. (Ait.) Roth. Steifes B.

\section{XIVIII. ECHINARIA. Desf. Igelgras.}

Aehrchen meist 2 blütig; untere Hüllsp. mit 3-4 starren Grannen. ..

capitata. (L.) Desf. Kopfiges I.

XLIX. SEsLERIA. Scop. Elfengras.

Decksp. an 'der Spitze ausgerandet und daselbst kurz-begrannt; B. schmal-lineal, stumpflich; Scheinähre kugelig. A. (fehlt $S . O . N$.)

sphaerocephala. $\left.A \cdot d .^{*}\right)$ Rundköpfiges $\mathrm{E}$.

Decksp. an der Spitze mehrborstig oder mit $1-5$

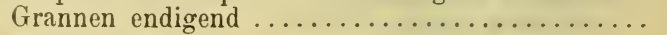

*) S. leucocephala Lam. et DC. unterscheidet sich Wurch weibliche (nicht violette) Aehrchen und kürzere Grannen. 
Decksp. 5 grannig, die mittlere Granne länger als die Spelze; B schmal-lineal, stumpfl.; Scheinähre eiförmig; Aehrchen 2 blütig. $A$. (fehlt $N$.J.)

ovata. (Hoppe.) Kern. Kleinköpfiges E.

Decksp. in 2-4 Borsten und 1 Granne endigend, Granne und Borsten nicht balb so lang als die Spelze

Bscheiden zuletzt in schlängelig-verwebte Fäden aufgelöst; Scheinähre länglich; B. schmal-lineal, rinnig, getrocknet zusammengerollt. $K r . J$.

tenuifolia. Schrad. Schmalblättriges E.

Bscheiden unzertheilt, zuletzt am Rande geschlitzt.

Aehre oval-länglich, meist einseitswendig; B. flach, an der Spitze plötzlich in eine rauhe Stachelspitze zusammengezogen; im Frühling blühende

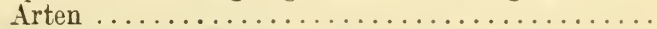

Aehre verlängert-walzl.; B. rinnig, in eine sehr rauhe Spitze verschmälert; meist im Herbst blühend. $K r$.J. autumnalis. (Scop.) Kern. Herbst-E.

Wuchs dicht rasig; B. grün, nicht bereift, mit stark vorragendem, weisslichem Rand und Mittelnerv; Scheinähre länglich-eiförmig; Felsenpflanze. Verbr.

varia. (Jacq.) Wettst. Buntes $\mathrm{E}$.

Rasen meist ringförmig ausgebreitet; B. oberseits bläulichweiß bereift, mit weniger scharf vortretendem Rand und Mittelnerv; Scheinähre kugelig oder eiförmig; Pflanze feuchter Wiesen.

B. O. N. St....coerulea. (L.) Host. Blaues E.

L. OREOCHLOA. $L k$. Alpengras.

B. fadenförmig; Aehrchen $3-6$ blütig. $A$. (fehlt $\Lambda$. O. J.) ... disticha. (Hoffm.) $L k$. Zweizeiliges A.

\section{AMPELODESMOS. $L k$. Rebenrohr.}

Rispe überhängend; B. lineal, rinnig, lang-verschmälert, sehr spitz; Halm ausgefüllt. J.

tenax. $L k$. Zähes $\mathrm{R}$.

\section{ARUNDO. L. Pfahlrohr.}

B. lanzett., lang-verschmälert; Rispe abstehend; Aehrchen meist 3 blütig. Südt $J$. (auch cult.)

Donax. L. Gemeines P.

B. breit-lineal; Rispe schmal; Aehrchen 1-2 blütig. J............Pliniana. Turr. Plinius-P.

LIII. PHRAGMITES. Trin. Schilfrohr.

Rispe ausgebreitet; Aehrchen 4-5blütig. Ver $r$ r. $u$. hfg..........communis. Trin. $\left.{ }^{*}\right)$ Gemeines Sch.

*) Gewöhnlich sind die Rispen violettbraun, bei der var. flavessens Cust. braungelb. 
LIV. SIEGLINGIA. Bernh. Dreizahn.

Ausdauernd; B. schmal-lineal, behaart; Rispe traubenähnlich oder eine einfache, armblütige Traube. Verbr.

lecumbens. (I.) Bernh. Niederliegender D.

\section{DIPLACHNE. Beauv. Steifhalm.}

Ausdauernd; Halme steif, bis nahe zur Rispe mit kurzen, lineal-lanzettlichen $\mathrm{B}$. besetzt; blïht im Spätsommer und Herbst. N. Südt. J.

serotina. (L.) $L k$. Spätblühender St.

\section{MOLINIA. Schrl: Molinie.}

Rispenäste aufrecht oder wenig abstehend, kahl; Aehrchen 3-4blütig; wächst vorzugsweise auf 'Torfmooren. Verbr.

coerulea. (L.) -Mnch. Blaue M. Rispe weitschweifig, stellenweise gewimpert; Aehrchen 1-2 blütig; Pfl. höher und stärker; wächst vorzugsweise auf Bergwiesen und in Auen. Verbr. arundinacea. Schrk. Rohrartige M.

\section{ERAGROSTIS. Host. Liebesgras.}

Die unt. Rispenäste halbquirlig zu 4-5; Aehrchen lineal, 5-12 btg.; Decksp. ziemlich spitz.

1 N. St. K. J... pilosa. (L.) Beauv. Behaartes L. Rispenäste einzeln 0. zu 2; Decksp. stumpf; B. am

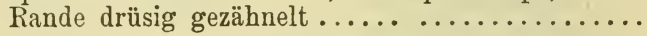

Decksp. an der etwas ausgerand. Spitze kurz-stachelspitzig; Aehrch. lineal - längl., 15-20 btg. N. Sï dt. J.

multiflora. (Forsh.) Aschers. Vielblütiges L. Decksp. ohne Stachelspitze; Aehrch. lanzett.-lineal, $8-16$ btg. Verbr. .... minor. Host. Kleines L.

\section{KOEIARIA. Pers. Schillergras.}

Decksp. grannenlos o. kurz-stachelspitzig ........

1 Decksp. aus ganzer 0. 2 spalt. Spitze begrannt;

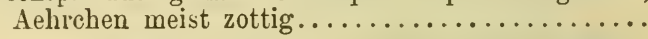

Die vertrockneten Bscheiden zuletzt in schlängeligverwebte Fäden aufgelöst; Rispe dicht-gedrungen; Grundb. zusammengerollt, kahl. $T$.

Valesiaca. Gaud. Walliser Sch. Bscheiden unzertheilt; Rispe am Grunde meist unter-

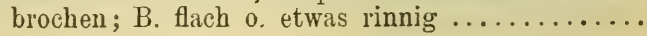


Decksp. spitz o. zugespitzt; B. meist grasgrün*)... 4 Decksp. stumpflich; B. seegrün, borstlich - lineal, gegen den Grund zu flaumig. B. M. Sch. N. Kr. J. glauca. (Schk.) DC. Seegrünes Sch.

B. kahl; Halm oben filzig: Decksp. borstig-rauh. A. v. Sï̈t. K. $K r$.

Carniolica. Kern. Krainer Sch.

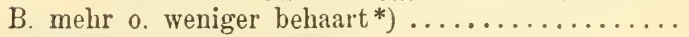

Wst. derb, verholzt, fast knollig; Wuchs niedrig; Aehrehen fast sitzend, oft zottig behart. $J$.

australis. Kern. Südliches Sch.

Kein knolliger Wst. vorhanden; Aehrchen kur', aber deutlich gestielt.

B. flach, lineal, meist lang gewimpert; Halm kräftig, unter der Scheinähre oft filzig. Verbr.

cristata. (L.)*) Kämmiges Sch.

B. schmal, meist zusammengerollt, dicht behart; Halm dünn, kahl; Bt. kleiner. $M . N . K . J . * *)$ gracilis. Pers. Zierliches Sch.

Ausdauernd; Halm oben filzig; Rispe eiförmig o. eilängl.; B. schmal-lineal, kahl. A. v. T. K.

hirsuta. Gaud. Rauhhaariges Sch.

Einjährig; Halm kahl; Rispe walzl.; B. breit-lineal, behaart. Sïdt. J.

phleoides. Pers. Einjähriges Sch.

\section{CATABROSA. Beauv. Quellgras.}

Ausdauerndes Gras mit kriechendem Wst.; Rispenäste sehr dünn. Verbr.

aquatica. (L.) Beauv. Gemeines Qu.

\section{MELICA. L. Perlgras.}

Decksp. gewimpert.....................

1 Decksp. nicht gewimpert; Rispe einseitswendig;

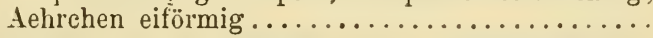

Decksp. am Rande durchaus dicht gewimpert-zottig; verkümmerte Bt. länglich; Rispe ährenförmig ...

Decksp. am Rande nur bis über die Mitte gewimpertbehaart; verkümmerte Bt. kreiselförmig; Rispe locker, fast einseitswendig. .J.

Bauhini. All. Bauhin's P.

*) K. cristata var. montana Hausm. (Südt. K.) hat fast kahle, etwas seegrüne $B$. zustellen.

$\left.{ }^{* *}\right)$ Die Verbreitung dieser Art ist noch genauer fest- 
Rispe dicht-oder lockerblütig, aber weder gelappt

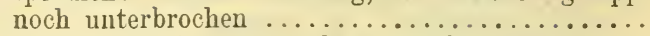

Rispe sehr verlängert, gelappt und unten unterbrochen; Bscheiden kahl. J.

Magnolii. Godr. et Gren. Lappiges P.

Rispe lockerblütig, ihre Aeste an die Spindel angedrückt, die längsten 5-10 Aehrchen tragend; Bscheiden meist kahl. Terbr. (fehlt $S$.)

ciliata. L. Gewimpertes P.

Rispe sehr dichtbiütig, ihre längeren Aeste aufrecht abstehend, 12-20 Aehrchen tragend; wenigstens die unteren Bscheiden behaart. $\Lambda$.

Transsilvanica. Sclurr. Siebenbürgisches P.

Aehrchen aufrecht, mit 1 einzigen vollkomm. Bt.; Bhäutchen dem B. gegenst., zugespitzt. V'erbr.

uniflora. Retz. Einblütiges $\mathrm{P}$.

Aehrchen hängend, meist mit 2 vollkommenen Bt.

Wst. kriechend; Bhäutchen äuœerst kurz, abgestutzt;

Decksp. grün, dünn, deutlich 5 nervig. Verbr.

nutaus. $L$. Nickendes P.

6 Wuchs dicht rasig; Bhäutchen verlängert; Decksp. dick, glänzend, undeutlich 5 nervig. $B$. $M$.

picta. C. Koch. Buntes P.

\section{BRIZA. L. Zittergras.}

Ausdauerndes Gras; Bhäutchen sehr kurz, abgeschnitten; Rispe aufrecht, abstehend; Aehrchen fast her'zförmig-eiförmig, 5-9 blütig. Verlr. $u$. $h f g . \ldots \ldots \ldots \ldots \ldots \ldots$ merlia. L. Gemeines Z. Einjährige Gräser; Bhäutchen lanzettlich, spitz.... Aehrchen eiförmig, $9-17$ blütig; Rispe an der Spitze überhängend. J.. maxima. L. Größtes Z. Aehrchen 3 eckig, $6-7$ blütig; Rispe aufrecht. $J$. minor. L. KIeines Z.

\section{AELUROPUS. Trin. Strandgras.}

Niedriges, starres, sehr ästiges Gras mit dicht 2 zeiligen $B . J$.

littoralis. (Gouan.) Parl. Mittelmeer-Str.

\section{DACTYLIS. L. Knäuelgras.}

Wenigstens die unteren Aehrchenknäuel gestielt und von einander getrennt; Decksp. in die kurze Granne verschmälert. Terbr. $u$. $h f g$.

glomerata. L. Gemeines $\mathrm{K}$.

Alle Aehrchenkuäuel dicht zusammengedrängt; Decksp. ausgerandet, in der Ausrandung kurz begrannt. $J$.

Hispanica. Roth. Spanisches $\mathrm{K}$. 


\section{CYNOSURUS. L. Kammgras.}

Ausdauernd; Scheinähre lineal; Decksp. mit kurzer Stachelspitze. Verbr.. cristatus. L. Gemeines K. Einjährig; Scheinähre eiförmig; Decksp. lang begrannt. (O. N.) St. Kr.J. Südt.

echinatus. L. Begranntes $\mathrm{K}$.

LXV. LAMARCKIA. Mnch. Lamarckie.

Einjährig; Halme niedrig; Rispe länglich, gedrungen, glänzend. $J$.

aurea. (L.) Mnch. Goldglänzende L.

\section{SCLEROCHLOA. Beauv. Hartgras.}

Einjähriges, niedriges, steifes Gras; Bscheiden zusammengedrückt. Verbr. (fehlt Sch. S. K.)

dura. (L.) Beauv. Gemeines H.

\section{POA. L. Rispengras.}

Halme und Bscheiden stielrund oder zusammengedrückt, aber nicht zweischneidig-flach ...... 2

Halme und Bscheiden zweischneidig-flachgedrückt.. 17

Rispenäste einzeln oder $\mathrm{zu} 2$ (sehr selten mehr) ... 3

Die unteren Rispenäste meist zu 5 (oder doch mehr als 2) $\ldots \ldots \ldots \ldots \ldots \ldots \ldots \ldots \ldots \ldots \ldots \ldots \ldots \ldots \ldots \ldots \ldots \ldots \ldots \ldots \ldots$

3) Halme und Bscheiden zusammengedrückt; B. flach. Ausdauernde Gräser mit nahezu stielrunden Halmen 5

Einjähriges (selten 2jähriges) Gras; Aehrchen bleichgrün, seltener etwas violett überlaufen. Verbr. $u$. $h f g . \ldots \ldots \ldots \ldots \ldots$ annua. L. Einjähriges R.

Ausdauerndes Gras; Aehrchen wenige, dicht stehend, violett und gelblich gescheckt. Geb.

supina. Schrad. Niedriges R.

Bhäutchen der unteren B. kurz, abgestutzt, der

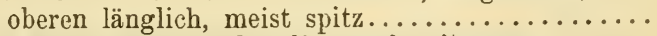
Bhäutchen aller $\mathrm{B}$. länglich und spitz ......... 8

Wst. kriechend, mit zusammengedrückten Ausläufern ; Stg. am Grunde nicht verdickt. $A$.

cenisia. All. ${ }^{*}$ ) Zweizeiliges $\mathrm{R}$. Wuchs dicht rasig, ohne Ausläufer; Stg. am Grunde durch die ihn umgebenden Bscheiden verdickt...

*) Gewöhnlich sind die Aehrchen violett überlaufen, bei P. pallens Gaud. aber blassgrünlich. 
B. grasgrün, nicht deutlich berandet; untere Rispenäste während der Bt. wagrecht abstehend.

Geb. (hfg.) ............. alpina. L. *) Alpen-R.

7 B. kur'z und breit, graugrün, knorpelig berandet; untere Rispenäste aufrecht abstehend; Rasen sehr dicht. $M . N$. O. T. $K r$.

Badensis. Hänlie. Badener R.

Rispe an der Spitze nickend oder überhängend, länglich oder eiförmig, zusammengezogen; Aeste

8 kahl oder ziemlich kahl, haar- oder fadenförmig. Rispe aufrecht, abstehend oder spreizend; Aeste rauh; Decksp. länglich-lanzettlich ............

Rispenäste fädlich, steif; Aehrchen eiförmig, meist 3 blütig; Decksp. eiförmig-lanzettlich, meist frei ; B. verschmälert-spitz. Geb. v. B. S. T. K. Krv. St.

laxa. Huk. Schlaffies R.

Rispenäste haardünn; Aehrchen länglich-eiförmig, $4-6$ blütig; Decksp. lanzettlich, am Grunde durch Wolle zusaminenhängend. $A$.

minor. Gaud. Kleines R.

Rispe spreizend, Aeste fast rechtwinkelig auseinanderfihrend; Aehrchen gleichförmig zerstreut, eiförmig, $4-6$ blütig; Bt. frei. A. v. $K$. $K$ r.

pumila. Host. Niederes $\mathrm{R}$. Rispe abstehend; Aehrchen an der Spitze der Aeste gedrungen; Halm am Grunde oft zwiebelig-verdickt 11

Bt. frei; Aehrchen eiförmig, spitz, 6-10 blütig. $K r$. J.........Carniolica. Hladn. Krainer R. 11 Bt. mit einer sich lang hervorziehenden Wolle zusammenhängend; Aehrchen 4-7 blütig. Verbr. bulbosa. $L{ }^{*}$ ) Knolliges $\mathrm{R}$.

12 Bhäutchen länglich, spitz............... 13

Bhäutchen kurz, abgestutzt..............

Grundb. fast stielrund eingerollt; Stgb. flach oder zusarnmengefaltet; Aehrchen meist 3 blütig, ihre

13 Spindel unter jeder Bt. gebärtet. $A$. v. T. S. K. $K r$. St........ violacea. Bell. $\left.{ }^{* *}\right)$ Violettes $\mathrm{R}$. Alle B. Hach ....................... 14

*) P. alpina L. und P. bulbosa L. kommen bäufig mit vergrünten $B t$. vor.

**) P. Brennia (Facch.) Nym. (A. v. T.) hat 5-sblütige Aehrchen. 
Halme u. Bscheiden glatt; oberstes Stgb. mindestens so lang als dessen Bsıheide; Decksp. unter der Spitze mit gelbem Fleck. Verbr.

palustris. $L$. Sumpf-R. Halme u. Bscheiden rauh; oberstes Stgb. kürzer als dessen Bscheide; Decksp. nicht gelb gefleckt, grün o. violett überlaufen. Verbr. $u$. hf g.

trivialis. L. Gemeines R.

Oberstes Stgb. länger o. doch so lang als dessen Bscheide; Decksp. unter der Spitze mit gelbem Fleck. Verbr. $u$. $h f g . . .$. nemoralis. L. Hain-R. Oberstes Stgb. kürzer als dessen Bscheide....... 16

Halmknoten von den Bscheiden verdeckt; Wuchs rasig, ohne Ausläufer. Geb. (fehlt $N$. O.J.)

caesia. Sm. Hechtblaues $R$.

Halmknoten frei; Wst. mit langen Ausläufern. Verbr. $u$. $h f g \ldots \ldots \ldots \ldots \ldots$ pratensis. $L$. Wiesen-P.

Wrst. mit langen Ausläufern; B. schmal-lineal; Rispenäste meist einzeln 0 . zu 2, seltener bis 5; Aehrchen länglich, 5-9 blütig. Verbr. $u$. hfg. compressa. $L$. Zusammengedrücktes R.

Wst. meist ohne 0. nur mit kurzen Ausläufern; B. meist breit-lineal; untere Rispenäste meist zu 5; Aehrchen eiförmig, 3-jblütig...........

B. lanzett.-lineal, an der Spitze plötzlich zugespitzt u. kapuzenf.-zsmgezogen; die unfruchtb. Bbüschel während der BtZeit grünend. Decksp. kahl. Sud.; N. T. K.* ${ }^{*}$....Chaixii. Vill. Breitblättriges $\mathrm{P}$.

B. aus lanzett.-linealem Grunde nach und nach sehr spitz-verschmälert; unfruchtb. Bbüschel während der BtZeit meist schon vertrocknet; Decksp. am Grunde etwas wollig. $A$.

hybrida. Gaud. Bastart-P.

LXVIII. GLICERIA. $R, B r$. Süßgras.

Hohes, rohrartiges Gras; B. breit lineal; Rispe ausgebreitet, sehr reichblütig; Aehrchen sehr zahlreich, länglich, 5-9 blütig, von den Rispenästen abstehend. Verbr.

aquatica. (L.) Wahlbg. Wasser-S.

Nicht rohrartige Gräser; Aehrchen lineal, wenigstens anfangs an die Rispenäste angedrückt

*) Verbreitung noch genauer festzustellen. 
Rispe ziemlich gleichmäßig ausgebreitet, ihre unteren

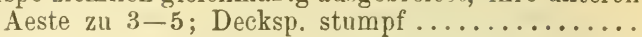
Rispe einseitswendig, ihre Aeste einzeln o. zu 2 (selten mehr); Decksp. schmal-elliptisch, spitzlich. Verbr.*) Huitans. (L.) R. Br. Fluthendes S.

Bhäutchen wenig zerschlitzt; Aehrchen $7-11$ blütig; Decksp. länglich, etwas rauh, mit 7 fast gleichlangen Nerven. Verbr. u. hfo. ${ }^{*}$ )

plicata. Fr. Gefaltetes S. Bhäutchen der oberen B. am Rande in haarförmige Fransen zerschlitzt; Aehrchen meist 7 blütig (die . untersten nur 2-3 blütig); Decksp. eiförmig, glatt, mit 4 stärkeren längeren und 3 schwächeren kürzeren Nerven. B. M. Sclt.

nemoralis. Uechtr. et Körn. Hain-S.

\section{ATROPIS. Rupr. Salzschwaden.}

Pispe einseitswendig, gedrungen, ihre Aeste (mit Ausnahme der längsten) vom Gi'unde an Aehrchen tragend. ..

Borreri. (Bab.) Richt. Gedrungenblütiger S. Rispe gleichmäßig ausgebreitet, ihre Aeste gegen den Grund zu keine Aehrchen tragend.........

Rispenäste ausgesperrt 0 . herabgeschlagen; Decksp. fast viereckig. Verbr.

distans. (L.) Gris. Gemeiner S. Rispenäste aufrecht abstehend; Decksp. länglich. $I$. festucaeformis. (Host.) Beck. Schwingelartiger S

\section{I.XX. FESTUCA. L. Schwingel.}

(Bhäntchen 2 öhrig (sehr kurz und beiders. mit 1 rundl. Oehrchen) ..................... 2 Bhäutchen abgeschnitten, vorgezogen oder länglich, nicht 2 öhrig**)..................

B. sämmtl. zusammengefaltet, borstlich ........ 3 Grundb. zusammengefaltet, borstl., selten flach; Halmb. flach, selten rinnig; Rispe während der Btzeit abstehend; Aehrchen $4-5$ btg.......... 18

*) In den südlichen Provinzen ist die Verbreitung von G. fluitans (L.) R. Br. und G. plicata $F r$. noch genauer festzustellen.

**) Ist die Aehrchenspindel unter den Bt. gebärtet, so vergl. nuan Poa violacea Bell. 
Obere Bscheiden der nicht blühenden Stg. in ihrer' unteren Hälfte geschlossen und daselbst von einer tiefen, engen Längsfurche durchzogen; Aehrchen lineal-länglich; Decksp. wehrlos (selten mit sehr kurzer Granne). B. N. O.S. T.

amethystina. I. Amethyst-Sch.

Bscheiden der nicht blühenden Stg. meist gespalten, seltener geschlossen, aber dann ohne Längsfurche; - Aehrchen elliptisch oder länglich; Decksp. meist

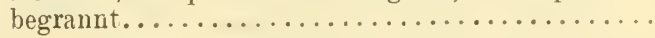

Bscheiden der nicht blühenden Stg. gespalten, höchstens im untersten Theile geschlossen ........ 5 Obere Bscheiden der nicht blühenden Stg. geschlossen 1 t

Obere B. der nicht blühenden Stg. nahezu cylindrisch, im getrockneten Zustande ohne Furchen....... Obere B. der nicht blühenden Stg. zusammengedrückt, im getrockneten Zustande gefurcht.......... 12

B. grün oder grangrün, aber nicht bereift ...... B. glatt, graugrün und namentlich gegen den Grund zu mit bläulichem Reif bedeckt..............

Decksp. wehrlos oder mit äu@erst kurzer Stachelspitze; B. haarfein, hellgrün; Aehrchen klein, elliptisch. ( $N$. ?) $K ?$. J.

capillata. Lam. Haarblättriger S.

Decksp. kürzer oder länger begrannt ..........

Bscheiden bis zum Grunde oder fast bis zum Grunde

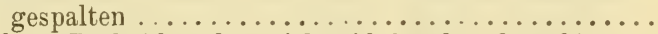

Obere Bscheiden der nicht blühenden Stg. bis nngefähr zu einem Drittel ihrer Länge geschlossen; Halme niedrig, oben rauh oder flaumig; B. feinborstlich, meist glatt, grün; Rispe kurz, arm- aber dichtblütig. Sud.; A. v. T. K. St.

supina. Schur. Niedriger S.

B. düm-borstenförmig oder fast haarförmig, meist rauh; Decksp. 3-4 mal länger als ihre Granne. B. M. N. O. S. T. ...ovina. L. Echter Schaf-S. B. dick-borstenförmig, sowie die Stg. steif; Decksp. oft kaum doppelt so lang als ihre Granne ..... 10

B. 5 nervig, rauh, unit angedrückt flaumigen Bscheiden ; Halme oben rauh. $N$.

stricta. Host. Rauhblättriger S.

B. 7 nervig, meist glatt, mit kahlen (selten flaumigen) Bscheiden; Halme oben meist glatt. ( $N$. ?) Südt. .J. duriuscula. L. Borstenblättriger S. 
Decksp. begrannt; Vorsp. spitz; wächst zumeist auf Felsen.*) Verbr.... glauca. Lam. Blaugrüner S. Decksp. wehrlos oder höchstens mit äulerst kurzer Stachelspitze; Vorsp. stumpf; wächst auf sandigem Boden in der Ebene. $M I$. $N$.

vaginata. $W . K$. Sand-S.

B. grün oder grangrüu, aber nicht bereift ....... 13

B. haarförmig, wenigstens gegen den Grund zu mit

12 bläulichem Reif überzogen; Decksp. kurz begrannt. B. M. N. Südt. J. Valesiaca. Schl. Walliser S. Halm, zart, glatt; B. haardünn; Aehrchen klein. $B$. II. N. J. pseudovina. (Hack.) Falscher Schaf-S. 13 Halm kräftig, oben meist rauh; B. dick-borstenförmig; Achrchen gröber. Verbr.

sulcata. (Hack.) Gefurchtblättriger S.

A. sehr klein, kaum ${ }^{1}{ }_{3}$ so lang als die Vorsp.; Decksp. lanzettlich-pfriemlich; Halm zart, niedrig; B. haardünn; Aehrchen blassgrïn, locker, 3-4blütig. A. v. T. S. K. Kr.

alpina. Sut. Alpen-S.

A. die Mitte der Torsp. erreichend oder überragend ${ }^{* *}$ )

B. 7 nervig......................... 16

B. 5 nervig, borstenförmig; Halm niedrig, oben 15 kantig; Rispe kurz und dichtblütig, traubenförnnig; Decksp. breit-lanzettlich. A. v. T. S. O. N. St........ rupicaprina. (Hack.) Felsen-S. Rispe sehr kurz und dichtblütig, länglich, einfach traubenförmig, höchstens die untersten Aeste mit 2 (sehr selten 3) Aehrchen; Halm sehr niedrig; Decksp. schmal lanzettlich; Aehrehen violettgescheckt (höchst selten gelblich). A. v. Sï̈t.

Halleri. All. Haller's S.

Die untersten Rispenäste 3-6 (selten nur 2) Aehrchen tragend......................... 17

Rispe lineal-länglich; Aehrchen blassgrün oder gelblich; Hüllsp. pfriemlich, sehr spitz; Decksp. lanzettlich-pfriemlich. N. St. $K . K r$.

17 stenantha. (Hack.) Schmalrispiger S. Rispe länglich-eitörmig; Aehrchen violett-gescheckt; Hüllsp. und Decksp. breit lanzettlich. A. v. T. S. K. St............. dura. Host. Harter S.

$18\{$ Wuchs dicht rasig, ohne Ausläufer ........... 19

Wuchs locker rasig; kriechende Ausläufer vorhanden 24

*) F. psammophila Hack. ( $T$.) wächst auf Sandboden und näbert sich durch oft fast wehrlose Decksp. der $F$. varinata $\mathrm{W} . \mathrm{K}$.

**) V'ergl. auch F. Carnica (Hack.) (unter Nr. 23). 
B. der nicht blühenden Stg. borstlich oder haarförmig, kantig; Halmb. viel breiter und stets flach B. der nicht blühenden Stg. von den Halmb. nicht sehr auffallend verschieden, alle zusammengefaltet oder die Halmb. nahezu flach...............

B. der nicht blühenden Stg. haarförmig, 3 kantig; Frkn. an der Spitze sehr fein beborstet. *) Terbr. (?)

heterophylla. Lam. Verschiedenblättriger S. B. der nicht blühenden Stg. borstenförmig, stumpf6 kantig; Frkn. an der Spitze kahl.*) Verbr.

fallax. Thuill. Täuschender S.

B. der nicht blühenden Stg. haarförmig o. dünn borstenförmig, getrocknet kantig; untere Bscheiden bald in (oft spärliche) Fasern aufgelöst........22

B. der nicht blühenden Stg. steif borstenförmig, getrocknet am Rücken ziemlich gerundet; untere Bscheiden lange bleibend, nicht in Fasern aufgelöst. A. v. T. S. O. St. K. $K r$.

Norica. (Hack.) Norischer S.

Decksp. kurz begrannt 0 . nur stachelspitzig; Halm

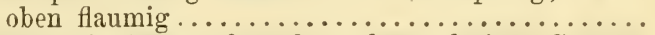

Decksp. höchstens doppelt so lang als ihre Granne; Halm kahl; Aehrchen lebhaft violett-gescheckt. A. v. T......nigricans. Schl. Schwärzlicher S.

Halmb. kaum breiter als die der nicht blühenden Stg., alle fast haarförmig; Wuchs niedrig; Aehlchen wenige; Decksp. nur stachelspitzig.

A. v. $K r$. St. ... Carnica. (Hack.) Karnischer S. Halmb. deutlich breiter u. flacher als die borstlichen B. der nicht blühenden Stg.; Aehrchen zahlreich; Decksp. kurz begrannt. $A$. v. S. $N$. St. $K$. $K r$.

picta. Kit. Bunter S.

Alle B. flach; Aehrchen groß, reichblütig, grün; Decksp. lanzettlich, kurz begrannt. $N$.

planifolia. (Hack.) Flachblättriger S.

Wenigstens die B. der nicht blühenden Stg. zn-

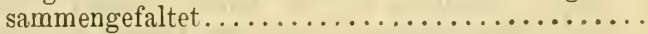

Halmb. flach. Verbr. ....... rubra. L. Rother S.

25 Halmb. mehr 0 . weniger zusammengefaltet. $J$.

uliginosa. (Schur.) Sumpf-s.

Alle B. borstlich zusammengefaltet, ungefähr stiel26 rund; Frkn. an der Spitze behaart.......... 27 Alle B. oder doch die Halmb. flach (seltener rinnig) 33

*) Sind die B. der nicht blülenden Stg. borstenförm ig und stumpfkantig, der Frkn. aber oben fein beborstet, so vergl. man F. nigricans Schl. (unter $\mathrm{Nr} .22$ ).

Fritsch, Excursionsflora. 
Bhäutchen der oberen B. lang vorgezogen, spitz, 3 nervig; B. sehr steif, stcchend; Aehrchen gelblichgrün 0. etwas gescheckt. Südt. $K$.

alpestris. $R$. et Sch. Voralpen-S.

Bhäutchen wenig vorgezogen, stumpf 0 . gestutzt,

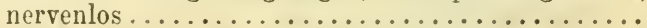

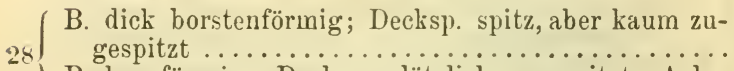

B. haarförmig; Decksp. plötzlich zıgespitzt; Aehrchen meist lebhaft gescheckt ...............

Decksp. begrannt; Rispenäste rauh; Aehrchen meist 29 etwas gescheckt. $A$. v. $K r$.

pungens. Kit. Stechender $\mathrm{S}$.

Decksp. wehrlos o. stachelspitzig............ 30

Obere Hüllsp. 1 nervig (höchstens am Grunde undeutlich 3 nervig); Aehrchenspindel etwas rauh.. 31

30 Obere Hüllsp. bis über die Mitte deutlich 3 nervig; B. sehr lang und spitz; Aehrchenspindel glatt. A. v. $K r . . \ldots \ldots \ldots$ calva. (Hacli.) Glatter S.

Rispe eiförmig, etwas nickend; Aehrchen 4-7blütig; die untersten B. der nicht blïhenden Stg. vielmal kürzer als die obersten. Geb. (fehlt $K r$.J.)

varia. Hnk: Gescheckter S.

Rispe kurz; Aehrchen meist 3 blütig; die untersten B. der nicht blühenden Stg. höchstens 3 mal kürzer als die obersten. $A$. v. $N$.

brachystachys. (Hack.) Kurzrispiger S.

B. grasgrün, weich, getrocknet kantig. $A$.

pumila. Vill. Niedriger S.

B. graugrün, etwas steif, fast stielrund; Aehrchen größer. $A$. v. $T$. $K r$.

rigidior. (Mut.) Steifblättriger S.

B. oberseits sammtig, schmal-lineal, die unt. zsıngefaltet; Frknoten an der Spitze behaart; Rispe 33 schlaff-überhängend; Aehrchen lebhaft gescheckt. $K$. Kr. J.......... laxa. Host. Schlaffer S.

B. obers. nicht sammtig, meist alle flach ....... 34

Bscheiden del nicht blühenden Stg. knorpelig-verdickt; Frknoten an der Spitze behaart; B. schmal-

34 lineal, kahl; Bhäutchen eiförmig.

T. S. K. $K r$....... aurea. Lam. Goldbrauner s. Bscheiden der nicht blühenden Stg. niclıt knorpelig. 35

$35\{$ Frknoten an der Spitze deutlich behaart....... 36

35 Frknoten kahl (o. mit vereinzelten Börstchen)..... 39 
B. breit, lanzettlich-linèn, zu beiden Seitel des Mittelnervs mit mehr als 12 Nerven, welche oberseits kaum hervorragen................... 37

B. verlängert-lineal, zu beiden Seiten des Mittelnervs mit weniger als $10 \mathrm{Ner} v e n$, welche oberseits

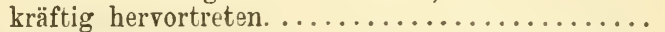

Wuchs dicht rasig, ohne Ausläufer; nicht blühende Stg. unten von $4-5$ breiten, dicken Schuppen umgeben; Mündung der Bscheiden kahl. Terbr. (fehlt J.) ........ silvatica. (Poll.) Vill. Wald-S.

Wst. mit langen Ausläufern; nicht blühende Stg. unten höchstens mit 2-3 dünnen, bald verschwindenden Schuppen umgeben; Mündung der B.scheiden gefranst. $\Lambda$. $O$.

montana. $M$. B. Berg-S.

B. breit lineal; Rispe sehr groo, nickend, ihr längster Ast mit mindestens 20 Aehrchen. Sïdt.

nemorosa. (Poll.) Hain-S.

B. schmal lineal; Rispe fast aufrecht, ihr längster Ast mit weniger als 15 Aehrchen. $K r$.

Carniolica. (Hack.) Krainer S.

Bhäutch. längl., stumpf; Rispe abstehend, an der Spitze überhängend; Decksp. spitz, rauh, 5̌nervig; $\mathrm{B}$ lineal, kahl. $A$.

pulchella. Schrad. Schöner S.

Bhäutch. sehr kurz .................. 40

Decksp. mit langer, schlängeliger Granne; Rispenäste schlaff-überhängend. Verbr. u. $h \mathrm{fg}$.

gigantea. (L.) Vill. Riesen-S.

Decksp. ohne 0. (selten) mit sehr kurzer Granne... 41

Rispe ausgebreitet, überhängend, ihr längster Ast mindestens 10 Aehrehen tragend; Aehrchen eilanzettlich, meist $4-5$ blütig; hochwiichsige Art. Verbr.......arundinacea. Schreb. Rohrartiger S. Rispe zusammengezogen, oft einseitswendig, ihr längster Ast höchstens 7 Aehrchen tragend; Aehrchen meist 5-8blütig. A..................

Bscheiden glatt; Aehrchen lineal-lanzettlich; Decksp. undeutlich nervig. Verbr. $u$. hfg.

elatior. $L$. Wiesen-S.

Bscheiden u. Rispenäste rauh; Aehrchen elliptisch, in steifer Rispe; Decksp. mit 5 erhabenen, seh. rauhen Nerven; hochwüchsige Art. $N$.

Uechtritziana. Wiesb. Steifrispiger S.

Anmerkung. In $N$. wurde ein Bastart F. pseudovina $\times$ vaginata, in $B$. ein Bastart $F$. elatior $X$ gigantea beobachtet. Ferner kommt ein Bastart zwischen $\mathrm{F}$. elatior und Lolium perenne vor. 
- Mehrere Arten von Festuca, besonders solche mit zusammengerollten B., sind durch Zwischenformen verbunden, die vielleicht. zum. Theil hybriden Ursprungs sind.

\section{VULPIA. Gmel. Fuchsschwingel.}

Rispe abstehend, steif; die untersten Aeste halb so lang als die Rispe; untere Hüllsp. 2- bis mehrmal kürzer als die obere; Decksp. rauh. B. Südt. K. J...bromoides. (L.) Dum. Trespenartiger F. Rispe zusammengezogen, fast ährig............

Decksp. zottig u. dicht bewimpert; obere Hüllsp. 2 spitz, untere sehr kurz o. fehlend. Südt. J. ciliata. (Pers.) Lk. Gewimperter F.

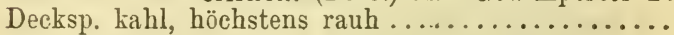

Rispe bogig überhängend; obere Hüllsp. spitz, ohne Granne; Decksp. rauh. Verbr. (fehlt M. O.S.K.)

Myurus. (L.) Gmel. Gemeiner F. Rispe aufrecht; obere Hüllsp. begrannt; Decksp. nur an der Spitze etwas rauh. $J$.

uniglumis. (Sol.) Dum. Vielgranniger F.

LXXII. NARDURUS. Rchb. Aehrenschwingel. Decksp. behaart o. kahl, begrannt o. wehrlos. $J$. unilateralis. (L.) Boiss. Einseitswendiger Ae.

LXXII. CATAPODIUM. $L k$. Lolchschwingel. Ausdauernd; B. flach; Aehrchen lineal-länglich. $J$. loliaceum. (Huds.) Lk. Gemeiner I,

\section{SCLEROPOA. Gris. Starrgras.}

Rispe einseitswendig, mit 3 kantigen Aesten; Aehrchen lineal. Südt. $K r$. J. rigida. (I.) Gris. Gemeines St.

\section{LXXY. BROMUS. L. Trespe.}

Aehrchen gegen die Spitze verschmälert.........

1 Aehrchen gegen die Spitze verbreitert; Vorsp. kamm-

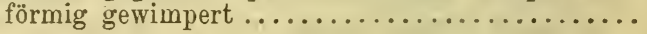

Untere Hüllsp. 3-5 nerv., obere 5-vielnerv.; Vorsp. mit ziemlich steifen Borsten entfernt-kammf.-gewimpert, untere 7 nervig; $1-2$ jährige Gräser...

Unt. Hüllsp. 1-, obere 3 nervig ; Vorsp. am Rande kurzflaumig; Aehrchen lineal-lanzettlich; ausdauernde Gräser.......................... 
Decksp. breit-ellipt., so lang als die Vorsp., die fruchttr. stielrundlich eingerollt, die nächstobere nicht dachig-deckend; Rispe zuletzt überhängend. Verbr. ............... secalinus. L. Roggen-T.

Decksp. bei der FrReife mit den Rändern sich gegenseitig dachziegelig-deckend, 0. nur etwas entfernt.

Decksp. ziemlich so lang als die Vorsp., ellipt.-lanzett.; Granne fast so lang als die Decksp.; Aehrchen lineal-lanzett., meist gescheckt. Verbrr. (fehlt S.)............... arvensis. $L$. Acker-T.

Decksp. merklich länger als die Vorsp..........

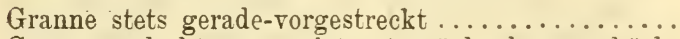

5 Granne gedreht, gespreizt o. zurückgebogen, höchstens anfangs $и$. bei feuchter Witterung gerade..

Aehrch. längl.-lanzett,, kahl; Decksp. ellipt.-längl. ; Rispe abstehend, zuletzt überbängend. Verbr.

Aehrch. eif.-längl.; Decksp. breit-ellipt.; Rispe nach dem Verblühen zusammengezogen ...........

Decksp. am Rande abgerundet; Aehrchen kahl. Verbr. (?)........ racemosus. $L$. Traubige T. Decksp. am Rande oberhalb der Mitte in eine stumpfe Ecke hervortretend; Aehrch. weich-behaart, seltener kahl. Verbr. $u$. $h f g$.

mollis. $L$. Weichharige $\mathrm{T}$.

8 Rispe gedrungen, aufrecht, nach dem Verblühen zusammengezogen.................. 9

Rispe abstehend, überhängend; Granne spreizend... 11

Die unteren Rispenäste mehrere Aehrchen tragend; außerdem büschelig angeordnete Aehrchen an der Rispenspindel fast sitzend ............... 10

9 Rispe fast einfach traubenförmig, ohne büschelig angeordnete Aehrchen; Bscheiden zottig; Aehrchen sehr groß. $J$.

macrostachys. Desf. Gro@ährige T.

Aehrchen locker aneinanderliegend; Granne der Decksp. erst nach dem Verblühen gedreht u. zurückgébogen. $J$.

molliformis. Lloyd. Spanische T.

10 Aehrchen sehr dicht aneinander gedrängt; Granne der Decksp. schon zur Blütezeit (iin trockenen Zustande) gedreht u. zurückgebogen; Aehrchen kleiner, weniger deutlich weiß gescheckt. J.

scoparius. $L$. Gedrungene $T$. 
Aehrchen länglich-lanzettlich; Decksp. elliptisch-lanzettlich, zur Fruchtzeit etwas von einander entfernt. B. M. N. St. K. Kr.J. T.

patulus. $\boldsymbol{M} . K$. Ueberhängende T.

Aehrchen eilanzettlich; Decksp. breit elliptisch (fast rhombisch), zur Fruchtzeit sich gegenseitig vollständig deckend. $M . N$. $(K$.$) Südt. J.$

squarrosus. $L$. Sparrige T.

${ }_{12}$ Rispe groß, überhängend; B. breit, lanzettlich-lineal,

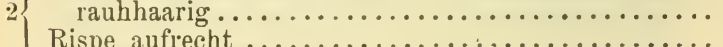

Rispe aufrecht ........................ 14

Oberste Bscheide kahl 0. kurz flaumig; unterste Rispenäste zu 3-5, der kürzeste derselben nur 1 Aehrchen tragend; Hüllsp. meist etwas violett überlaufen. Verbr.

asper. Murr. Rauhhaarige T.

Oberste Bscheide langhaarig; unterste Rispenäste zu 2, jeder mehrere Aehrchen tragend; Hüllsp. meist grün, mit weißlichem Hautrande. B. $M . N .^{*}$ )

ramosus. Huds. Aestige T.

B. kahl (sehr selten behaart); Decksp. sehr kurz begrannt 0 . stachelspitzig. Verbr.

14 inermis. Leyss. Wehrlose T. Grundb. am Rande gewimpert, schmäler; Decksp. begrannt, länger als die Granne. Verbr.

erectus. Huds. Aufrechte T.

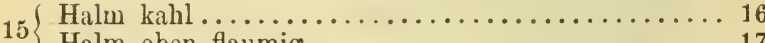

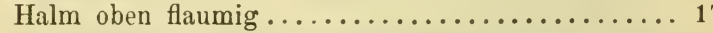

Rispe überhängend; Aeste verlängert, an der Spitze hängend; Granne länger als die Decksp. Verbr.

Rispe aufrecht; Granne so lang.

Sïdt. J......... Madritensis. L. Mittelmeer-'T.

Rispe hängend; Aehrch. lineal; Granne so lang als die Decksp. Verbr.......tectorum. L. Dach-'T'.

17 Rispe aufrecht; Aehrch. längl., sehr groß; Granne länger als die Decksp. $J$.

maximus. Desf. Größte T.

\section{BRACHYPODIUM. Beauv. Zwenke.}

Aehrch. zahlreich, 2 zeilig angeordnet; B. flach, lineal

o. lanzett.-lineal; ausdauernde Gräser.......... 2

Aehrch. 1-j an der Spitze des Halmes ........ 3

*) Die Verbreitung dieser Art ist noch näher festzustellen, da sie von der vorhergehenden meist nicht unterschieden wurde. 
Wst. faserig; Granne an der oberen Bt. länger als die Decksp.; B. schlaff. V'erbr. $u$. $h f g$.

silvaticum. (Huds.) R. et Sch. Wald-Z.

Wst. kriechend; Granne kürzer als die Decksp.; B. ziemlich steif. Verbr. $u$. $h f g$.

pinnatum. (L.) Beauv. *) Gemeine Z.

Ausdauernd; Aehrch. 2-5; B. abstehend, zsmgerollt, sehr schmal, bläul.-grün; Halm ain Grunde sehr ästig. J. . ramosum. (I.) R. et Sch. Aestige Y.

Einjährig; Aehrch. 1-3 an der Spitze des Halmes; B. Hach. J.

distachyon. (L.) R. et Sch. Zweiährige Z.

\section{NARIUUS. $I$. Hirschhaar.}

Niedriges, ausdauerndes, kahles Gras vou dicht rasigem Wuchs; Wst. holzig; B. borstenförmig, starr, seegrün; Aehrchen schmutzig-violett. Verbr.

stricta. $I$. Steifes $H$.

\section{I.XXVIII. LOLIUI. L. LoIch.}

( Ausdanernde Gräser von dicht rasigem Wuchs, mit unfruchtbaren Bbüscheln $\mathrm{z}$ wischen den blühenden Halmen.......................

1-2jährige Gräser ohne unfruchtbare Bbüschel ... 3

Decksp. wehrlos o. höchstens stachelspitzig; Hüllsp. länger als das halbe Aehrchen; B. in der Jugend zusammengefaltet. Verbr. $u$. hfg.

2 Decksp. begrannt (sehr selten fast wehrlos); Hüllsp. ungefähr so lang o. kürzer als das halbe Aehrchen; B. in der Jugend eingerollt. B. M. N.S. T. K. St. J.... Italicum. A. Br. Italienischer L.

$3\{$ Hüllsp. kürzer als das Aehrehen ........... 4

Hüllsp. so lang o. länger als das Aehrchen ...... 6

Decksp. lanzettlich, krautig 0 . häutig, wehrlos ... 5 Decksp. elliptisch, am Grunde knorpelig, schmäler

4 als die Vorsp., wehrlos 0. kurz begrannt; Aehrchen klein, $3-8$ blütig. Verbr.

remotum. Schrk. Lockerblütiger L.

Aehrchen 3-9 blütig, aufrecht, in schmaler, steifer Aehre, wenig länger als die Hüllsp. $J$.

5 rigidum. Gaud. Steifer L.

Aehrchen 7-15blütig, schief abstehend, doppelt so lang als die Hüllsp. J.

Siculum. Parl. Sicilianischer Is.

*) Bei der typischen Form des B. pinnatum sind die Aehrchen dicht behaart, bei B. rupestre (Host) R. et Sch. $(T . K r . J.) \mathrm{kahl}$; bei B. caespitosum (Host) R. et Sch. (J.) sind die B. schmallineal und die Aehrchen kleiner u. kahl. 
Aehrchen entfernt, keilförmig, 3-4blütig, vor und nach der Blütezeit ganz in die Aushöhlungen der Spindel versenkt; Decksp. weif-häutig, wehrlos. J..... subulatum. Vis. Pfriemenförmiger L. Aehrchen ziemlich genähert, länglich, meist 5-8 (selten 3-4) blïtig, stets aus der Spindel helvortretend; Decksp. am Grunde knorpelig, meist begrannt. Verbr.......temulentum. L. Taumel-L.

LXXIX. MONERMA. Beauv. Pfriemenschwanz. Einjährig; Aehre aufrecht, stielrund. $J$.

cylindrica. (Willd.) Coss, et Dur. Europäischer Pf.

\section{LEPTURUS. $R$. Br. Schuppenschwanz.}

Aehre stielrund, im trockenen Zustande einwärts-gekrümmt; Hüllsp. angedrückt, das Aehrchen weit überragend. $J$.

incurvatus. (L.) Trin. Gekrümmter Sch.

Aehre etwas zusammengedrückt, aufrecht 0 . kaum gekrümmt; Hüllsp. abstehend, das Aehrchen kaum überragend. $J$.

filiformis. (Roth.) Trin. Dünner Sch.

LXXXI. PSILURUS. Trin. Borstenschwanz.

Einjähriges Gras; Aehre sehr lang, gekrümmt. J.

aristatus. (L.) Lor. et Barr. Begrannter B.

LXXXII. AGROPYRUM. Gärtn. Quecke.

Aehre oval o. länglich, kammförmig-2 zeilig; Aehrchen abstehend, begrannt; Hüllsp. 3 nervig, gekielt. N.... cristatum. (L.) Bess. Kämmige Qu. Aehre lineal; Aehrchen an die Spindel angelehnt .. Die Nerven der B. oberseits mit zahlreichen Reihen sehr kurzer, sammtiger Haare o. spitziger Pünktch. dicht-besetzt; Wst. weit-kriechend.............

Die Nerven der B. oberseits mit 1 einfachen Reihe sehr kleiner Börstchen 0. Pünktchen besetzt $u$. dadurch

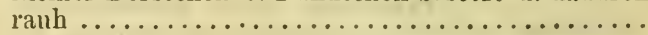

B. oberseits mit spitzen Pünktchen dicht besetzt; Hüllsp. 7 nervig; Aehrchen genähert. $J$.

acutum. $(D C$.) $R$. et Sch. Spitzige Qu.

B. oberseits weichsammtig; Hüllsp. 9-11 nervig; Aehrchen entfernt. $K r$. J.

junceum. (L.) Beauv. Binsen-Qu.

Hüllsp. u. Decksp. (o. doch erstere) spitz o. zuge-

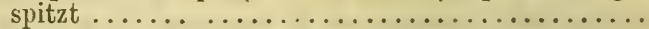
HuIlsp. u. Decksp. oder doch letztere stumpf 0 . abgestutzi (wenn auch stachelspitzig 0 . begrannt).. 
Wst. mit kriechenden Ausläufern; Aehrchen wehr-

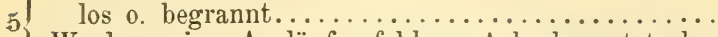

Wuchs rasig; Ausläufer fehlen; Aehrchen stets be-

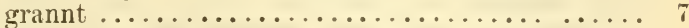

Hüllsp. 3-5 nervig, länger als das halbe Aehrchen; B. meist flach; Aehrchen 4-5 blütig. Verbr. $u$. hfg........ repens. (L.) Beauv.*) Gemeine Qu. Hüllsp. 7 nervig, kaum so lang als das halbe Aehrchen; B. seegrün, zuletzt eingerollt, etwas stechend; Aehre sehr dicht; Aehrchen 7-9 blütig. $J$.

pungens (Pers.) R. et Sch. Stechende Qu.

B. beiderseits rauh; Granne länger als die zugespitzte Decksp. Verbr.

caninum. Schreb. Hunds-Qu.**)

B. kahl, am Rande etwas rauh; Granne fast $3 \mathrm{mal}$ kürzer als die Decksp. J.

biflorum. (Brig.) R. et Sch. Zweiblütige Qu.

Aehre sehr gedrungen, starr, 4 kantig; B. seegrïn, zusammengerollt, fast stechend. $J$.

litorale. (Host.) Dum. Küsten-Qu.

Aehre wenigstens im unteren Theile locker, nicht

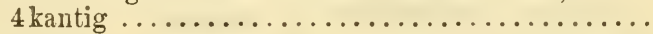

Wuchs rasig, ohne Ausläufer; Hüllsp. 9 nervig; Aehrchen wehrlos. Südt. J.

elongatum. (Host.) Beauv. Langährige Qu.

9 Wst. mit kriechenden Ausläufern; Hüllsp. 5-7 nervig; Aehrchen wehrlos, selten begrannt.

B. M. N. O. Südt. J.

glaucum. (Desf.) $R$. et Sch. Seegrüne Qu.***)

LXXXIII. HAYNALDIA. Schur. Haynaldie.

B. knötig-behaart; Aehrchenspindel u. Hüllsp. büschelig-behaart: Aehrchen lang begrannt. $J$.

villosa. (L.) Schur. Zottige $H$.

\section{SECALE. L. Roggen.}

1-2jährig; Halm oben flaumig; B. seegrün; Aehrchen lang begrannt. Cult. u. verv.

cereale. $L$. Gemeiner $R$.

*) Gewöhnlich sind die B. grün und die Achrchen wehrlos; bei A. caesium Presl sind die B. bläulich bereift, bei A. dumetorum (Hoffm.) Richt. sind die Aehrchen begrannt.

**) A. pseudocaninum Schur $(N$.) unterscheidet sich durch armblütige, nicht violett überlaufene Aehrchen und aufrechte Aehren. chen behaart.

***) Bei A. trichophorum (Lk.) Richt. sind die Aehr- 
IXXYV. AEGILOPS. $L$. Walch.

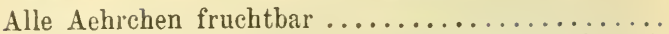

Die obersten 1-2 Aehrchen unfruchtbar; Aehre eilanzettlich, nach oben verschmälert; Hüllsp. der fruchtbaren Aehrchen mit einer neben der Spitze entspringenden langen Granne. J.

uniaristata. Vis. Eingranniger W.

Aehre lineal-verlängert; Hüllsp. 2-3 grannig, Grannen der obersten Aehrchen noch 1 mal so lang; Decksp. 3 zähnig, Zähne kürzer als die Spelze. J.

triuncialis. L. Langgranniger W. Aehre eiförmig; Grannen aller Aehrchen gleich, die der Decksp. viel länger als diese.............

Grannen der Aehrchen vom Grunde an am Rande rauh : Hüllsp. meist 4 grannig. Sïdt. $J$.

ovata. L. Gemeiner W.

Grannen der Aehrchen unterw. am Rande kahl; Hüllsp. $2-3$ grannig. $J$.

triaristata. Willd. Dreigranniger W.

\section{IXXXVI. TRITICUM. $L$. Weizen.}

Spindel zerbrechlich; Fr. von den Spelzen dicht um-

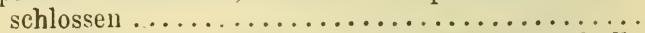
Spindel zähe; Fr. von den Spelzen locker-umhüllt.

Aehre der breiten Seite der Spindel parallel zsmgedrückt, locker; Hüllsp. breit-eif., abgeschnitten, 2 zähnig, der Zahn am Kielende gerade, der vordere schwach; Aehrch. meist 4 btg. Cult.

Spelta. L. Spelz.

Aehre dem Rande der Spindel parallel zsmgedrückt, dicht dachig.

Hüllsp. gezähnt-stachelspitzig, schief-abgeschnitten; Kiel zsmgedrückt, sehr hervortretend, oberw. mit dem Zahne der Spitze einwärts gebogen; Aehrch. meist $4 \mathrm{btg}$. Cult.

dicoccum. Schrk. Zweikörniger W.

Hüllsp. an der Spitze 2 zähnig, Zähne spitz, nebst der Kielspitze gerade; Aehrch. meist 3 btg. Cult.

monococcum. L. Einkörniger W.

Aehre unregelmäb.-4 seitig o. zsmgedrückt, meist blaugrün; Aehrch. meist 3 btg.; Hüllsp. längl.-lanzett., papierart.-krautig, vielnervig, gekielt, an der Spitze kurz-2 zähnig. Cult.

Polonicum. L. Polnischer W.

Aehre regelm.-4seitig; Aehrch. meist 4 btg.; Hüllsp.

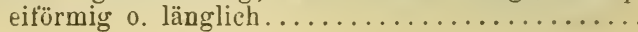


Hüllsp. auf dem Rücken abgerundet-convex, mit 1 stumpf-hervortreteuden Nerven. Cult.

vulgare. Vill. Gemeiner W.*)

Hüllsp. gekielt, Kiel der ganzen Länge nach hervortret., fast flügelförmig . . . . . . . . . . . .

Hüllsp. eiförmig, abgeschnitten, stachelspitzig. Cult.

Hüllsp. längl., 3 mal so lang als breit, breit-stachelspitzig C'ult........... durum. Desf. Hart-W.

\section{HORDEUM. I. Gerste.}

Bt. alle zwittrig, o. die seitenst. männlich, u. diese

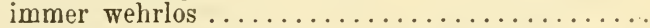

Die seitenst. Bt. männlich o. verkümmert, aber alle begrannt; wildwachsende Arten ............6 6

Aehrch. alle zwittrig; 1-2jährige Getreidearten ... 3

2 Die seitenst. Aehrchen männl. u. wehrlos, nur das mitt-

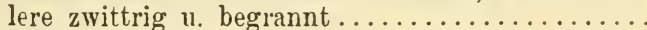

FrAehrch. ungleich-6 reihig geordnet, 2 Reihen auf beiden Seiten mehr hervorspringend. Cult.

3 vulgare. L. Gemeine G. Die Aehrch. gleichf.-6reihig geordnet, eiförmig. Cult. hexastichon. L. Sechszeilige G.

Ausdauernd; Aehrch. sämmtl. lanzettlich; Halm über dem Grunde knollig-verdickt. $J$.

1-2 jährige Getreidearten; zwittrige Aehrch. eif., die männl. lineal; Aehre z zeilig ............

Grannen der mittl. Aehrch. aufrecht, mit der Aehre 5 parallel. Cult...... distichum. I. Zweizeilige G. Grannen der mittl. Aehi'ch. fächerf.-abstehend. Cult. zeocriton. I. Pfauen-G.

Hïllsp. der mittl. Aehrch. an beiden Seiten gewimpert, lineal-lanzett. : untere Hüllsp. der seitenst.

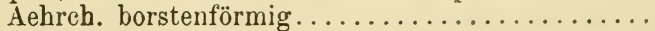

Hüllsp. des mittl. Aehrchens beborstet 0 . rauh, nicht

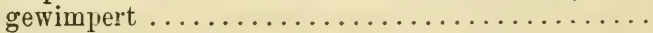

Obere Hüllsp. der seitenst. Aehrchen jener des mittleren Aehrchens gleich gestaltet; Decksp. undeut-

7 lich 5 nervig. Südt. J..leporinum. $L k$. Hasen-G.

Obere Hüllsp. der seitenst. Aehrchen viel schmäler als die des mittleren Aehrchers; Decksp. erhaben 3 nervig. Verbr.........murinum. L. Mauer-G.

*) Aehrchen bald begrannt ("Bartweizen“), bald wehrlos. T. compactum Host unterscheidet sich durch kurze u. dicke, vierkantige, steife Aehren. 
A usdanernd; Hüllsp. aller Aehrchen borstlich. O. J. secalinum. Schreb. Roggenartige G.

Einjährig; die oberen Hüllsp. der seitenständigen Aehrchen fast geflügelt-lıalblanzettlich, die übrigen borstlich. $(M . N$. $) J$.

maritimum. With. Neerstrands-G.

\section{IXXXVIII. ELYMUS. L. Haargras.}

Aehrchen lang begrannt; Hüllsp. auf dem Kiele nicht

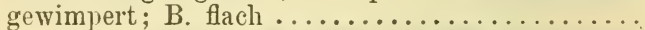

1 Aehrchen wehrlos; Hüllsp. anf dem Kiele gewimpert; B. zuletzt starr zusammengerollt; ausdauerndes Gras. B.......... arenarius. $L$. Sand-H.

Ausdauernd; B. kahl, mit behaarten Bscheiden. $V c r b r$. (fehlt St. $K r$. J.)

europaeus. $L$. Europäisches S.

Einjährig; B. oberseits zottig, mit kahlen Bscheiden. J............... crinitus. Schreb. Mähnen-H.

\section{Familie. Cyperaceae. Riedgräser.}

Ausdauernde, seltener einjährige Gewächse von grasartigem oder binsenartigem Aussehen. Stg. nicht knotig gegliedert, dreikantig 0 . stielrund, niemals zweischneidig. B. ungetheilt, schmäler 0 . breitur lineal, parallelnervig, niemals gestielt, aber meist mit umfassender Bscheide; manchmal nur letztere vorhanden. Bt. zwittrig 0.1 häusig, selten 2 häusig, stets mit Tragb. (Deckspelze), aber ohne Vorb. 0. nur die weiblichen Bt. mit einem schlauchförmigen, den Frkn. umbüllenden Vorb., in einzelnen o. zu verschiedenen Blütenständen vereinigten Aehren (Aehrchen), welche oft von den Decksp. ähnlichen Hüllb. (Hüllspelzen) umgeben sind. Bthülle niemals deutlich entwickelt, jedoch öfters Borsten 0. Haare (Bthüllborsten) an ihrer Stelle. Stb. meist 3, seltener 2. Frkn. 1, mit 1 Samenknospe u. 2-3 fädlichen, meist verlängerten $\mathrm{N}$. Fr. mit freiem S., nussartig, niemals aufspringend, die aus zwittrigen Bt. sich entwickelnden frei, die aus weiblichen Bt. entstehenden meist von einem Vorblattschlauch gänzlich verhïllt (Schlauchfrucht).

\section{Gattungen.}

1 Bt. zwittrig..................... 2

$1\{$ Bt. 1- 0. 2 häusig; ausdauernde Pfl. .......... 16

Spelzen zweizeilig-dachig, am Rücken gekielt..... 3

2 Spelzen von allen Seiten her ziegeldachig-aufeinandergelegt . . . . . . . . . . . . . . . . 
Spelzen meist zahlreich, alle bttragend 0. 2-3 der untersten kleiner u. leer; Aehrchen deutlich2reihig in Köpfchen, Büscheln 0. Spirren.

Cyperus. I.

Spelzen 6-9, nur die oberste 0 . die $2-3$ obersten fruchtbar, die 3-6 untersten kleiner u. leer; Aehrch. weniger deutl.-2 reihig, in 1 Köpfeh. vereinigt; ausdauernde Pfl........ Schoenus. XII.

Die 3-4 untern Spelzen kleiner u. leer, $6-7$ in einem Aehrchen; ausdauernde Pfl............

Nur 1-2 (selten keine) der unteren Spelzen unfruchtbar u. gröЊer ......................

Bthüllborsten fehlen; Fr. mit einer krustigen, zerbrechlichen Schale; Gr. fädlich, abfallend.

Cladium. XIII.

Bthüllborsten eingeschlossen; Gr. bleibend, zsmgedrückt-kegelförmig, mit der Fr. durch ein Gelenk verbunden ............ Rhynchospora. XIT.

Bthüllborsten zahlreich, zur Zeit der Fruchtreife sehr verlängert, so dass das Aehrchen dann mit langen Wollhaaren bedeckt ist; ausdauernde Pfl.

Eriophorum. III. Bthïllborsten fehlend 0 . höchstens 6, zur Zeit der Fruchtreife selten verlängert............... 7

Ein einziges endständiges Aehrchen vorhanden.... 8 8

7 Mehrere bis zahlreiche endständige Aehrchen in verschiedenen Blütenständen, oder 1 -mehrere scheinbar seitenständige Aehrchen vorhanden ....... 10

Blühende Stg. nur mit spreitenlosen Bscheiden am Grunde................... Heleocharis. X.

8 Wenigstens die oberste der am blühenden Stg. vorhandenen Bscheiden trägt eine kleine Blattspreite..............................

Bthüllborsten 6, manchmal zur Zeit der Fruchtreife sehr verlängert; niedrige, ausdauernde, rasenbildende Pfl..............Trichophorum. II. Bthüllborsten fehlen ............... Isolepis. IV.

Aehrchen in eine zweizeilige Aehre gestellt.

Aehrchen zu Büscheln, Köpfchen 0. Spirren zusammengestellt, selten einzeln.............. 11

Gr. zusammengedrückt, oben gewimpert, unten verbreitert und durch ein Gelenk mit dem Frkn. ver-

11 bunden; kleine, einjährige $\mathrm{PA}$. mit beblättertem Stg...................... Fimbristylis. XI.

Gr. weder gewimpert noch unten verbreitert...... 12 
Btstand deutlich endständig............. 13

12 Btstand scheinbar seitenständig, da unter demselben ein langes, einer Fortsetzung des Stengels gleichendes $B$. entspringt. ............... 14

Aehrchen in ein Köpfchen zusammengedrängt; Bthüll13 borsten fehlen; N. 2........ Dichostylis. VI. Aehrchen in der Spirre, seltener in einem Köpfchen; Bthïllborsten vorhanden; N. 3. ... Scirpus. IX. Aehrchen zu einem oder häufiger zu mehreren ungleich lang gestielten Köpfchen dicht zusammen14 geballt..................... Holoschoenus. V. Aehrchen einzeln oder häufiger zu $3-5$ gebüschelt, die Büschel oft zu Spirren zusammengestellt.....

Stg. fadenförmig; Aehrchen 1-3; Fr. erhabenlängsstreifig. ............... Isolepis. IV.

15 Stg. binsenartig, stielrund o. dreikantig; Aehrchen meist mehr als 3 ; Fr. glatt o. querrunzlig.

Schoenoplectus. VII.

Aehrchen meist mehrbtg.; Frkn. von einer besonderen, flaschenförmigen Vorb.-Hülle eingeschlossen, welche zuletzt eine falsche Schlauchfr. darstellt; N. 2-3.

Aehrch. 1-2btg., alle o. wenigstens die weiblichen von Deckb. bedeckt; Vorb.-Hülle fehlt; Fr. daher frei ; N. $3 . \ldots \ldots \ldots \ldots \ldots \ldots \ldots \ldots \ldots \ldots \ldots$

Aehrch. 2 btg., in 1 endständigen, linealen, stielrunden Aehre; jedes am Grunde von 1 großen, schuppenf. Deckb. umgeben .......................

17 Aehrch. 1btg., in 4-5 kurzen, linealen Aehren, die all der Spitze des Halmes eine doppelt-zsmgesetzte, ziemlich schmale Aehre bilden; untere Aehrch. meist weiblich, die ob. männlich u. deckblattlos.

Kobresia. XVI.

Arten.

\section{CYPERUS. $L$. Cypergras.}

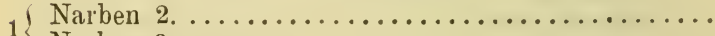

Narben 3

Btstand deutlich endständig.

Btstand durch Verlängerung eines Hüllb. scheinbar seitenständig; Spelzen weißlichgrün mit 2 rothbraunen Flecken. $N$.

Pannonicus. Jacq. Ungarisches C. Kleines, einjähriges Pflänzchen; Spelzen gelblich. Verbr............ flavescens. L. Gelbliches C. Hochwüchsige Pfl.; Wst. kriechend, ausdauernd; Hüllb. sehr lang; Btstand groß; Spelzen rothbraun. Sïdt. $K r$. J.

serotinus. Rottb. Spätblühendes C. 
Spelzeu lineal, hellbraun; Aehrchen zu kugeligen 0. eiförmigen Köpfchen dicht zusammengeballt. Südt. $J$. $\bar{r}$. Südst....glomeratus. L. Geknäueltes C.

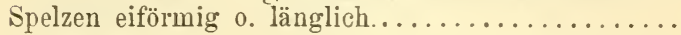

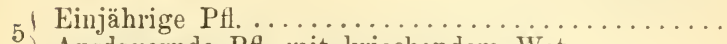
6

Ausdauernde Pfl. mit kriechendem Wst.........

Spelzen schwarzbraun mit grünlichem Kiel, seltener grünlichbraun, nicht deutlich nervig; Wuchs niedrig. Verbr........ fuscus. $L$. Schwärzliches C.

6 Spelzen rothbraun mit grünen Rändern u. grünem Kiel, vielnervig: Stg. höher. $K r$. J.

glaber. $L$. Kahles C.

Aehrehen eilanzettlich, dicht zu Köpfchen zusammengeballt, armblütig: Spelzen am Grunde lebhaft rothbraun, nach oben zu gelbgrün. $J$.

capitatus. Vand. Kopfiges C.

Aehrehen lineal, in lockeren, meist zahlreichen Büscheln, reichblütig; Spelzen rothbraur.

N. Südt. J. ......longus. L. Langblättriges C.

Anmerkung. C. esculentus L. (Erdmandel) wird in den südlichen Provinzen wegen der essbaren Wzknollen cultivirt; die Art ist durch strohgelbe Aehrchen ausgezeichnet.

\section{TRICHOPHORUM. Pers. Haarbinse.}

Stg. stielrund, etwas gefurcht, grasgrün; Bthüllborsten stets kürzer als die Spelzen. Verbr. (fehlt $M$. Sch.). . caespitosum. (L.) Hartm. Rasige H. Stg. oben dreikantig, mit rauhen Kanten, etwas seegrün: Bthüllborsten zur Zeit der Fruchtreife sehr verlängert u. schlängelig-gewunden. Verbr. (fehlt J.) ....... alpinum. (L.) Pers. Alpen-H.

\section{ERIOPHORUM. L. Wollgras.}

1 A Ahrch. einzeln $\ldots \ldots \ldots \ldots \ldots \ldots \ldots \ldots \ldots \ldots \ldots$

1 ) Aehrch. mehrere .................... 3

Stg. oben 3seitig: B. am Rande rauh; Wst. dicht rasig, ohne Ausläufer, Verbr. (fehlt J.)

2 Stg. stielrund; B. glatt; Wst. ausläufertreibend. A. (fehlt $N . K r$.)

Scheuchzeri. Hoppe. Scheuchzer's W. 
B. durchaus 3 kantig; Halm undeutlich-3 seitig; Aehrchenstiele filzig-rauh. ${ }^{*}$ )

3 Verbr. (fehlt M. Sch. J.)

gracile. Koch. Schlankes W.

B. flach 0. rinnig, nur an der Spitze 3 kantig.... \&

B. flach; Aehrchenstiele rauh. Verbr.

latifolium. Hoppe. Breitblättriges $\mathrm{W}$.

B. rinnig, lineal; Aehrchenstiele glatt.

Verbr. (fehlt J.)

polystachyum. $L$. Schmalblättriges W.

\section{ISOLEPIS. $R$. $B r$. Zartriet.}

Ausdauernd: Stg. fadendünn, niederliegend 0 . fluthend, beblättert; Aehrchen am Ende langer, in den Blattachseln entspringenden Stiele; N. 2. Kr. .T. fluitans. (L.) R. Br. Fluthendes Z.

Einjährig; Stg. niedrig, meist aufrecht, mit Bscheiden, deren oberste $(1-2)$ öfters Spreiten tragen; Aehrchen zu 1-3, scheinbar seitenständig: N. 3 .

Verbr.......setrcea. (L.) R. Br. Borstliches Z.

$r$. HOLOSCHOENUS. $L k$ : Glanzbinse.

Ausdauernd; Stg. stielrundlich, mit Bscheiden, deren oberste $(1-2)$ eine fädliche Spreite tragen.

Verbr. (fehlt Sch. O. S. K.)

vulgaris. $L k^{* *}$ ) Gemeine $\mathrm{G}$.

\section{DICHOSTYLIS. Beauv. Doppelgriffel.}

Einjähriges, niedriges Pflänzchen; Stg. 3 kantig, unten beblättert; Aehrchen klein, grünlich.

B. MI. N. St. K.

Micheliana. (L.) Nees. Europäischer D.

\section{SCHOENOPLECTUS. Rchb. Teichbinse.}

$1\left\{\begin{array}{c}\text { Stg. stielrund (wenigstens unterwärts); Aehrchen } \\ \text { büschelig-gehäuft } \ldots \ldots \ldots \ldots \ldots \ldots \ldots \ldots \ldots \ldots \ldots \ldots \ldots \ldots \ldots \ldots \ldots \ldots \ldots \ldots \ldots \ldots\end{array}\right.$

Halm unterw. stielrund; oben 3 seitig; Spelzen glatt;

2 N. 2. N. O. T..... carinatus. Sm. Gekielte T.

Halm durchaus stielrund ................ 3

*) Sind die Aehrchenstiele glatt, so liegt E. polystachyum L. var. alpinum Gaud. vor, bei dem die B. ebenfalls fast bis zum Grunde 3 kantig sind.

**) H. australis (L.) Fritsch u. H. Romanus (L.) Fritsch haben dünneren, niedrigeren Stg., ersterer kaum erbsengroße, letzterer haselnussgroße, meist einzelne Köpfchen. 
Niedrige, einjährige Pfl.; das die Fortsetzung des Stg. bildende Hüllb. ist fast so lang als dieser; Bthüllborsten fehlen; Fr. querrunzelig.

N. $K r$. J. ...supiuus. (L.) Palla. Einjährige T. Hochwüchsige, ausdauernde Pfl.; das die Fortsetzung des Stg. bildende Hüllb. ist viel kürzer als dieser; Bthüllborsten 6 ; Fr. glatt . ..............

Stg. dick u. sehr hoch, grasgrün; Spelzen glatt; N. 3;

Fr. 3 kantig; wächst meist im Wasser. Verbr. lacustris. (L.) Palla. Gemeine T.

4 Stg. seegrün, niedriger; Spelzen punktirt rauh; N. 2 ; Fr. 2 seitig; wächst meist in Sümpfen u. am Rande der Gewässer. Verbr. (fehlt $K$. $K r$.)

Tabernaemontani. (Gmel.) Palla. Seegrüne T.

Spelzen stumpf, stachelspitzig, nicht ausgerandet; Fr. querrunzelig: Aehrchen in 1 Büschel gehäuft. T. K. St. Kr. J.

mucronatus. $(L)$. Palla. Stachelspitzige T. Spelzen ausgerandet, niit einer Stachelspitze in der Ausrandung: Fr. glatt ...............

Spelzen am Rande gefranst; Bthüllborsten rück-

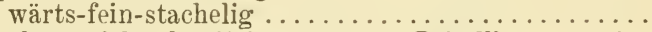

6 Spelzen nicht deutlich gefranst; Bthüllborsten pinselig-federig; Aehrchen zahlreich, nicht gebüschelt. J. litoralis. (Schrad.) Palla. Meerstrandsbinse.

Aehrchen gebüschelt, in meist lockerer Spirre; A. kahl. Verbr. (fehlt $K$. J.) Aehrchen alle sitzend, in dichten Knäulen; A. an der Spitze wimperig-gezähnelt. T. (Bregenz.)

pungens. (Vahl.) Palla. Stechende T.

\section{BLISMUS. Panz. Quellriet.}

Ausdauernd; Wst. kriechend; Stg. niedrig, stumpfkantig, beblättert; Aehrchen rothbraun. Verbr.

compressus. (L.) Panz. Gemeines Qu.

\section{SCIRPUS. L. Grabenbinse.}

Spelzen an der Spitze 2 spaltig, in der Ausrandung stachelspitzig; Aehrchen groß, braun.

Verbr. (fehlt $S$. K.). maritimus. L. Braune G. Spelzen stumpf, mit o. ohne Stachelspitze; Aehrchen klein, schmutziggrün 0 . schwärzlich 
Aehrchen zahlreich, theils einzeln, theils gebüschelt; Spelzen fein stachelspitzig; Bthüllborsten gerade, rauh. Verbr. $u$. hfg. silvaticus. L. Gemeine G. 2 Aehrchen alle einzeln, die meisten lang gestielt; Spelzen ohne Stachelspitze; Bthüllborsten gewunden, glatt. Verbr. (fehlt $K$.)

radicaus. Schr. Wurzelnde G.

Anmerkung. S. radicans $X$ silvaticus wurde in $B$. beobachtet.

X. HeleoChaRIS. $R$. $B r$. Sumpfriet.

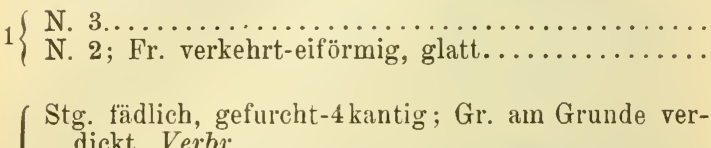
$2\left\{\begin{array}{c}\text { dickt. Verbr. } \\ \text { acicularis. (L.) R. Br. Nadelförmiges S. } \\ \text { Stg. stielrund; Gr. am Grunde nicht verdickt..... }\end{array}\right.$

Stg. am Grunde braun bescheidet; Aehrchen braun, eiförmig. Verbr. (fehlt J.)

$3\left\{\begin{array}{l}\text { pauciflora. (Lightf.) } L k \text {. Armblütiges S. } \\ \text { Stg. am Grunde mit sehr dünnen, häutigen Bschei- }\end{array}\right.$ den; Aehrchen gelblich-grün, länglich. $J$.

parvula. (R. et Sch.) Palla. Kleines S.

Ausdauernde Arten mit kriechendem Wst.; wenigstens die oberen Spelzen ziemlich spitz; Fr. mit abge-

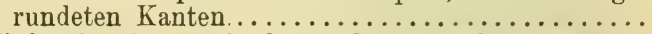

Einjährige Arten; Spelzen sehr stumpf; Fr. mit ge-

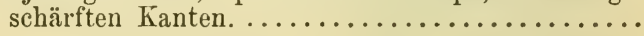

Die unterste Spelze (Hüllsp.) umfasst das lineallängliche Aehrchen zur Hälfte; Stg. blaugrün. Verbr. u. $h f g$. 5 Die unterste Spelze (Hüllsp.) umfasst das eilängliche Aehrchen ganz; Aehrchen dunkler braun; Stg. grasgrün. Verbr.

uniglumis. (Lk.) Schult. Grasgrünes S.

Die unterste Spelze (Hüllsp.) umfasst das eiförmige Aehrehen zur Hälfte; Fr. grünlichbraun. Verbr.

$6\left\{\begin{array}{c}\text { ovata. (Roth.) } R . B r \text { Eiförmiges S. } \\ \text { Die unterste Spelze (Hüllsp.) umfasst das längliche }\end{array}\right.$ Aehrchen ganz; Fr. strohgelb. $K$. Kr. Südst.

Carniolica. Koch. Krainer S. 
XI. FIMBRISTYLIS. Vahl. Fransenbinse.

B. etwa so lang als der Stg.; Aehrchen zahlreich, länglich-eiförmig, in einer zusammengesetzten Spirre. Süidt. J.

dichotoma. (L.) Vahl. Gabelige F.

B. viel kürzer als der Stg.; Aehrchen $2-6$, in einer einfachen Scheindolde. S. Südt. $K r$.

annua. (All.) R. et Sch. Doldige F.

\section{SCHOENUS. L. Knopfgras.}

Aehrchen 5-10, in einem eiförmigen, deutlich endständigen Köpfehen; B. etwa halb so lang als der Stg. Verbr. (fehlt Sch. St.)

nigricans. $L$. Schwärzliches $\mathrm{K}$.

Aehrchen $2-3$, in einem länglichen, scheinbar unter der Stgspitze seitenständigen Köpfchen; B. viel kürzer als der Stg.

Verbr. (fehlt Sch. M. J.)

ferrugineus. L. Rostfarbenes $\mathrm{K}$.

Anmerkung. Der Bastart Sch. ferrugineus $X$ nigricans ist selten.

\section{CLADIUM. $R$. $B r$. Schneide.}

Stg. hochwüchsig, fast stielrund, beblättert; B. gekielt, am Kiel u. Pand sehr rauh; Aehrehen zahlreich, in zusammengesetzten Spirren.

N. O. S. T. K. J.

Mariscus. (L.) R. Br. Gemeine S.

\section{RHY NCHOSPORA. Vahl. Schnabelbinse.} Aehrchen weißlich, später bräunlich, fast ebensträuß.-geknäult, Büschel etwa so lang als die Hüllb.; Wz. faserig. Verbr. (fehlt J.)

alba. $(L)$ Vahl. Weiße Sch.

Aehrch. braun, kopfig-geknäult, Büschel viel kürzer als die Hüllb.; Wst kriechend.

B. O. S. T. K. Kr.

fusca. (L.) R. et Sch. Braune Sch.

XV. ELYNA. Schrad. Nacktriet.

Niedrige, ausdauernde Pfl.; B. borstlich.

A. (fehlt $N$.)... Bellardi. (All.) Simk. Alpen-N.

XVI. KOBRESIA. Willd. Schuppenriet.

Niedrige, ausdauernde Pfl.; B. flach.

A. (fehlt $N . K r$. J.)

bipartita. (All.) Dalla Torre. Alpen-Sch. 
XVII. CAREX. L. Segge.

Eine einzige, endständige, einfache Aehre an der

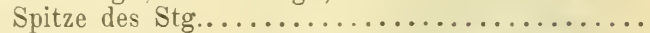
Aehren mehrere, o. eine einzige, aus mehreren Aehrchen zusammengesetzte Aehre, bezw. Köpfchen 0.

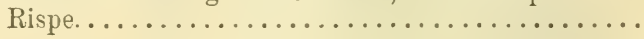

Bt. 2 häusig; N. 2................... 3

2 Bt. 1 häusig; jede Aehre oben männliche, unten weibliche Bt. enthaltend.

Wst. kriechend; Stg. u. B. glatt: Fr.*) eiförmig.

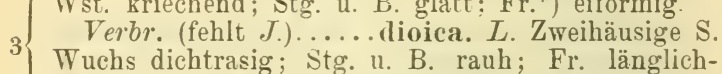
lanzettlich. Verbr.... Davalliana. Sm. Rauhe S.

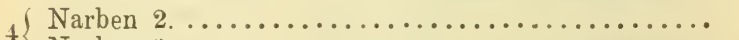

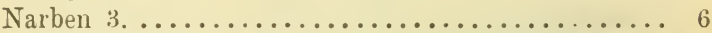

Aehre längl.; Fr. nach beiden Seiten verschmälert, zurückgebogen; weibliche Spelzen abfällig; B.

5 borstlich. Verbr.......... pulicaris. L. Floh-S. Aehre rundl.-zif.; Fr. eif., zugespitzt, flach-zsmgedrückt, länger als die bleibenden Spelzen. $T$.

capitata. L. Kopfige S.

Fr. an der vorderen Seite mit 1 grünen Granne, 6 lanzettlich, zurückgebogen. $T$.

microglochin. Wahlbg. Gehörnte S.

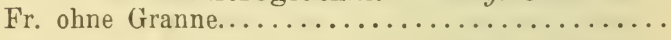

Aehre 3-4 btg., strohgelb; Fr. lanzett.-pfrieml., zurückgebogen; weibl. Spelzen hinfällig.

7 Verbr. (fehlt J.)

Aehre vielbtg., lineal, an der Spitze männl., braun; Fr. kürzer als die Spelze, zsmgedrückt - 3 kantig; B. lineal, flach. Geb. v. Sch. MI. N. St. K. S. T. rupestris. All. Felsen-S.

Alle 0 . doch die meisten Aehrchen enthalten männ-

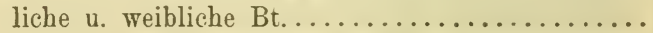

8 Jedes Aehrchen enthält entweder nur männliche 0. nur weibliche Bt. 0 . höchstens das endständige männl. u. weibl.**) ${ }^{* *} \ldots \ldots \ldots \ldots \ldots \ldots \ldots \ldots . \ldots \ldots$

$9\{$ N. 3; Aehrch. oberw. männlich........... 10

*) Unter „Fr.“ ist bei Carex immer die ganze Schlauchfr. $\mathrm{zu}$ verstehen.

**) Bei einzelnen Exemplaren vieler Arten kommt es vor, dass die sonst rein männlichen Aehrchen auch einige weibl. Bt. enthalten 0. umgekehrt; man untersuche deshalb mehrere Exemplare. 
Aehrehen strohgelb o. grünlich, entfernt, 2-4; Fr. entfernt, elliptisch, 2 nervig. $J$.

Linkii. schk. Lockerblütige S.

o. braun, sehr genähert......... 11

(Aehrchen weis, in ein lappiges Köpfehen geballt, an dessen Grunde 2-3 lange Hüllb.; Fr. kaum geschnäbelt. Südt..... Baldensis. $L$. Baldische S.

11 Aehrchen braun, in ein längliches Köpfchen gehäuft, ohne blattartige Hüllb.: Fr. länglich, 3 kantig. lang geschnäbelt. $A$. (fehlt $\Lambda$. $K r$. J.)

currula. All. Dreinarbige S.

$12\{$ Aehrch. oberw. männlich ................ 13

Aehrch. am Grunde männlich; Fr. geschnäbelt .... 25

Wst. unterirdische verlängerte Ausläufer treibend. . 14

13 Wuchs dichtrasig; Ausläufer ganz fehlend 0 . sehr kurz ........................... 18

Fr, aufgeblasen, höckerig-convex, zugespitzt-geschnäbelt, Schnabel glatt, an der Spitze schief-ab14 geschnitten; Stg. glatt, einwärts gebogen, so lang als die B. A. $\imath . T$.

incurva. Lightf. Eingekrümmte S.

Fr. nicht aufgeblasen, eiförmig............... 15

Frschnabel am Rande glatt, an der Spitze trockenhäutig, kurz-2lappig; Fr. nervig-rillig; Stg. glatt, viel länger als d. B.; A ehrch. in ein rundl. Köpfch. gehäuft. O. S. K. T.

chordorrhiza. Ehrh. Fadenwurzlige S.

Frschnabel am Rande feingesägt-rauh........... 16

Die oberen Aehrch. männl., die unt. weibl., die mittl. an der Spitze männl.; Fr. 7-9 nervig. J.

arenaria. L. Sand-S.

Alle Aehrch. enthalten männliche u. weibliche Bt. 17

B. etwa so breit als der Stg.; Aehrchen in einem Köpfchen; Fr. 9 11 nervig, in einen an der Spitze wei@l.-häutigen, am Rücken ausgerandeten Schnabel zugespitzt. B. M. N. St. T.

stenophylla. Wahlbg. Schmalblättrige S.

17 B. bedeutend breiter als der Stg.; A Aehrchen in einer länglichen Aehre; Fr. breit-eif., längsnervig, in einen tief- u. spitzig-2 spalt. Schnabel zugespitzt; Spelzen so lang als die Fr. N. St. Kr. J.

divisa. Huds. Getheilte S.

Aehrch. in ein rundl.-eif. Köpfchen gehäuft; Fr. eif., in einen an der Spitze 2 theil., am Rande feingesägten Schnabel zugespitzt; Stg. an den Kanten rauh; Wst. kurze Ausläuf. treibend. A. v. T.

foetida. Vill. Stinkende S.

Aehrch. in eine Aehre 0. Rispe zsmgestellt ....... 19 
(Aehrchen rothbraun 0. graubraun; Fr. meist aufrecht.

Aehrchen weißlichgrün o. bräunlichgrün; Fr. meist sparrig abstehend.

Fr. beiderseits gerillt; Aehrchen rothbraun; Seiten des Stg. oberw. etwas convex. Verbr. (fehlt J.)

paradoxa. Willd. Seltsame S.

Fr. nervenlos 0. am Grunde etwas gerillt. ........

Fr. eiförmig, zusammengedrückt, nervenlos, geschnäbelt, so lang als die Spelze; Frschnabel an der Spitze innen ganz, auf dem Rücken gespalten;

21 W st. mit sehr kurzen Ausläufern. A. v. S.

microstyla. Gay. Kleingrifflige S.

Fr. beiderseits o. doch hinten höckerig-convex, mit zweizähnigem, am Rande gesägtem Schnabel.....

Wst. etwas kriechend; Stg. nur oben 3 kantig; B. schmal lineal; Frähre wenig ästig; Fr. beiderseits höckerig-convex. I'erbr. (fehlt Sch.)

teretiuscula. Good. Stielrundliche S.

Wuchs dicht rasig; Stg. überall 3 kantig; B. breit lineal; Frähre rispig ästig; Fr. vorne ziemlich flach, hinten höckerig-convex. Verbr.

paniculata. $L$. Rispige $\mathrm{S}$.

(Fr. eiförmig, 5-7nervig; Seiten des Stg. concav. 2:) Verbr.............. vulpina. L. Fuchs-S. Die unteren Fr. lanzettlich-eiförmig, nervenlos 0. undeutlich-nervig; Seiten des Stg. flach.........

Bscheiden an der Mündung quer abgeschnitten, ganz; Aehrchen meist entfernt; Stg. meist schwach, oft überhängend. Verbr. virens. Lam. Grüne S. Bscheiden an der Mündung mit vorgezogenem, zuletzt zerreißendem Bhäutchen; Aehrchen meist genähert. Verbr.........muricata. L. Sparrige S.

Wst. lange unterirdische Ausläufer treibend; Fr.-

25 Schnabel 2 spaltig, am Rande feingesägt ........

Wuchs dicht rasig; Ausläufer fehlend 0. nur sehr

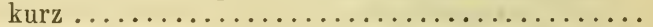

Aehrchen blassgelblich, gekrümmt, länglich-lanzettlich; Fr. lanzettlich; B. breiter als der Stg. Verbr.

brizoides. $L . *$ ) Zittergrasartige $\mathrm{S}$.

26 Aehrchen braun, gerade, eiförmig-länglich; Fr. länglich-eiförmig; B. kaum breiter als der Stg. Verbr. (fehlt $S . K$.)

praecox. Schreb. *) Frühblühende S.

*) C. curvata Knaf hat gekrümmte, aber hellbraune Aehrchen und steht auch sonst $\mathrm{zwischen} \mathrm{C}$. brizoides und C. praecox in der Mitte. 
Die Tragb. der unteren Aehrchen blattartig, sehr

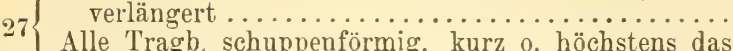

Alle Tragb. schuppenförmig, kurz o. höchstens das unterste blattartig. . .

Aehrchen in ein kugeliges Köpfchen zusammengeballt. Verbr. (fehlt S. K. Kr. J.)

cyperoides. $L$. Cypergras-S.

Aehrchen sehr entfernt, die unteren blattachselständig. Verbr. u. hfg... remota. L. Schlaffe S.

Fr. lanzettlich, abstehend, nervig-vielstreifig, auf dem Rücken convex, Schnabel am Rande rauh;

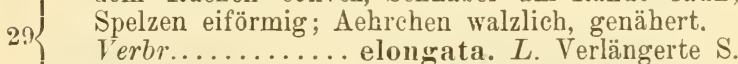
Fr. eiförmig; Aehrchen rundlich, elliptisch o. eiförmig ........................... 30

Fr. aufrecht $\ldots \ldots \ldots \ldots \ldots \ldots \ldots \ldots \ldots \ldots \ldots \ldots \ldots \ldots$

30 Fr. sparrig abstehend; Stg. stumpfkantig, glatt.

Verbr............ echinata. Murr. Stachlige S.

Frschnabel am Rande glatt; Fr. flach-convex, glatt; Aehrchen zu 3 in einer Aehre, rundlich-elliptisch, 31 gedrungen; Stg glatt. A. v. T. S. K. St.

lagopina. Wahllog. Schneehuhn-S.

Frschnabel am Rande rauh..................

Fr. glatt; Aehrehen meist $3-4 \ldots \ldots \ldots \ldots \ldots . \ldots 33$

32 Fr. mehr o. weniger deutlich gerillt; Aehrchen meist

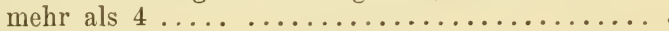

$\mathrm{Fr}$. zusammengedrückt-3 kantig, mit kurzem, ungetheiltem Schnabel. S. O. N.

Heleonastes. Ehrh. Torf-S.

33 Fr. zusammengedrückt, auf dem Rücken gewölbt, in der Mitte mit einer Längsfurche, vorne concav; Schnabel etwas gespalten, die Spelze überragend. $T$. tetrastachya. Traunst, Vierährige S.

Aehrchen genähert, meist hellbraun; Fr. flach-convex, am Rande geflïgelt, mit langem, 2 zähnigem

34 Schnabel. Verbr........... leporina. I. Hasen-S. Die unteren Aehrchen meist entfernt; Fr. nicht geflügelt, mit kurzem Schnabel ................

Aehrchen bleichgrün, eilänglich; Fr. zusammengedrückt, auf dem Rücken gewölbt; Schnabel abgestutzt 0 . etwas ausgerandet. Verbr. (fehlt $K r$. J.)

canescens. L. Grauliche S.

Aehrchen bräunlichgrün, eiförmig; Fr. am Rücken etwas convex; Schnabel hinten der ganzen Länge nach gespalten. A. v. T. S. K. St. Kr.

brunnescens. (Pers.) Bräunliche S. 
Die obersten und untersten Aehrchen weiblich, die mittleren männlich; Fr. eiförmig, 9-11 nervig, mit einem schmalen feingesägten Rande; Wst. ausläufertreibend. Verbr. (fehlt $K$. J.)

disticha. Huds. Zweizeilige S.

Die oberste Achre männlich, einzeln, die seitenständigen weiblich, seltener die oberste Aehre zweigeschlechtig 0 . mehrere männlich; die unterste

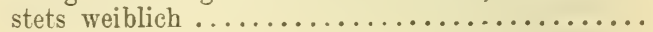

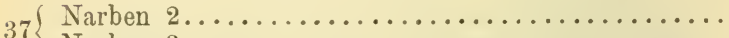

Narben $3 \ldots \ldots \ldots \ldots \ldots \ldots \ldots \ldots \ldots \ldots$

Fr. schnabellos, kahl, verkehrt-eiförmig, stumpf ; Aehren gestielt, die oberste nur am Grunde männ38 liche Bt. enthaltend. A. v. T. S. K. $K r$.

bicolor. All. Zweifarbige $\mathrm{S}$.

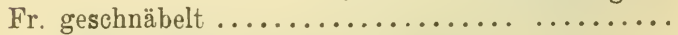

Fr. mit einem berandeten, an der Spitze 2 spaltigen o. 2 zähnigen, vorne flachen Schnabel endigend ..

39 Fr. mit einem sehr kurzen, stielrunden, ungespaltenen, gestutzten 0 . schief abgeschnittenen Schnabel

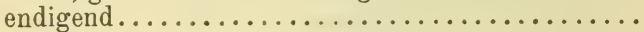

Fr. flaumig, länglich, Schnabel 2 spaltig; B. borstlich-rinnig; die männliche Aehre lanzettlich, weibliche 1-4, halb so lang, elliptisch-rundlich, sitzend. A.........mucronata. All. Stachelspitzige S.

Fr. kahl, Schnabel 2 zähnig; B. schmal-lineal, tiefrinnig, am Rande rauh; endständige Aehre männlich 0. an der Spitze weiblich. O. T.

microstachya. $E h r \cdot h$. Kleinährige S.

(Grundständige Bscheiden (wenigstens die untersten)

41 in ein Fasernnetz aufgelöst............. 42

Grundständige Bscheiden nicht zerfasert........ 44

Wst. kriechend, mit Ausläufern; grundständige B.$42\left\{\begin{array}{l}\text { scheiden rothbraun; Fr. eiförmig, grasgrün, nerven- } \\ \text { los. B. M. St...... Buekii. Wimm. Banater S. }\end{array}\right.$ Wst. dichte Rasen bildend, ohne Ausläufer........

Stg. kräftig, starr; grundständige Bscheiden bellbraun; Fr. ellipsoidisch, seegrün, längsnervig. Verbr................ stricta. Good. Steife S. 43 Stg. dünn und schlank; grundständige Bscheiden purpurbraun; Fr. kugelig-eiförmig, hellgrün 0 . schmutziggrün, nervenlos. B. MI. T. O. K.

caespitosa. L. Rasige $\mathrm{S}$. 
(B. lineal-lanzettlich, stark zurückgekrümmt; nur 1 männliche Aehre; Fr. zusammengedrückt, nervenlos, am Grunde von den Spelzen eingehüllt.

44 Sud.; A. v. T. K.

rigida. Good. Starrblättrige S.

B. lineal, flach; männliche Aehren 1-4; Fr. mehr 0 . weniger deutlich längsnervig .............

Hochwüchsige Art; B. breit lineal; die Tragb. der untersten (1-2) Aehren überragen die Spitze der obersten Aehre; männliche Aehren 2-4, weibliche $3-5$, die untersten gestielt und oft überhängend; Fr. beiderseits gewölbt. Verbr.

rufa. $\left.(L .)^{*}\right)$ Rothe $\mathrm{S}$.

Stg. nieuriger; B. ziemlich schmal lineal; die Tragb. überragen selten die Spitze der obersten Aehre; männliche Aehren 1-2, weibliche 2-4, alle fast sitzend und aufrecht; Fr. vorne flach, hinten gewölbt. Verbr.........nigra. $\left.(L .)^{*}\right)$ Schwarze S.

Fr. schnabellos o. in einen stielrunden, gestutzten, schief-abgeschnittenen 0 . kurz-2 zähnigen Schnabel endigend

Fr. geschnäbelt, der Schnabel am Rücken gewölbt, vorne flach, an der Spitze 2 zähnig 0. 2 spaltig, 0 . der Schnabel stielrund mit 2 langen Haarspitzen 80

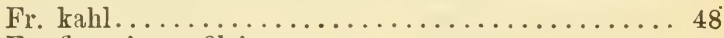

Fr. flaumig 0 filzig $\ldots \ldots \ldots \ldots \ldots \ldots \ldots \ldots \ldots \ldots$

48 Tragb. der Aehren gar nicht o. undeutlich scheidig 49 Tragb. der Aehren (wenigstens der unteren) scheidig 58 Die endst. Aehre nur am Grunde männlich; Fr.Schnabel klein-2 zähnig................ 50

49 Die endst Aehre männlich, die weiblichen genähert; Frschnabel abgeschnitten, 0 . 2 lappig und trockenhäutig; Wst. ausläufertreibend ..............

Grundständige Bscheiden netzig - gespalten; endst. Aehre verkehrt-eiförmig; weibliche Aehren meist 50 3; Fr. elliptisch, stumpf, 3 kantig; Spelzen braun, haarspitzig. Verbr. (fehlt $K r$.J.)

Buxbaumii. Wahlbg. Buxbaum's S.

Grundständige Bscheiden ungetheilt .......... 51

Stg. rauh; Aehren 3-5, schwarzviolett, länglichwalzlich, aufrecht, die weiblichen gestielt; Fr. rundlich-eiförmig, zusammengedrückt, am Rücken stumpf-gekielt. Geb. (fehlt $N$. $K r$. J.)

aterrima. Hoppe. Kohlschwarze S.

Stg. glatt........................ 52

*) C. rufa (L.) und nigra (L.) sind sehr veränderlich; es gibt auch Mittelformen zwischen beiden. 
Aehren zu einem endständigen Büschel dicht zusammengedrängt, ihre Tragb. sehr klein ........

52 Aehren zwar genähert, aber locker gestellt; das Tragb. der untersten Aehre meist verlängert und

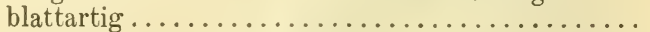

Aehren 3, rundlich, kurz gestielt; Spelzen schwarzbraun, hell gerandet; Fr. 3 seitig, grün.

A. v. T. K. St........ alpina. Sw. Alpen-S.

53 Aehren 3-4, kaum gestielt; Spelzen schwarz-violett; Fr. zusammengedrückt, schwarzviolett, nur am Rande grün. $A$.

parviflora. Host. Kleinblütige $\mathrm{S}$.

Spelzen schwarzviolett; Aehren eiförmig, 3-5, die $54\left\{\begin{array}{l}\text { weiblichen gestielt, zuletzt hängend; Fr. rundlich- } \\ \text { eiförmig, zusammengedrückt, am Rücken stumpf }\end{array}\right.$ gekielt. Geb........ atrata. L. Geschwärzte S. Spelzen dunkelbraun; Aehren $2-3 \ldots \ldots \ldots \ldots \ldots$.

Stg. dünn; Aehren rundlich, kurz gestielt; Spelzen u. Fr. fast schwarzbraun. $A$. v. $S$.

55 bina. Schk. Zweiährige S. Stg. kräftig; Aehren gestielt; Spelzen kastanienbraun; Fr. eiförmig, blass gelblichbraun. $A$. v. $S$. castanea. Miel. Kastanienbraune s'.

Fr. kugelig-elliptisch, 3 kantig, glänzend, Schnabel 2 lappig, trockenhäutig; weibliche Aehren 1-2, rundlich, sitzend, halb so lang als die länglichlanzettliche männliche Aehre. $\mathcal{B} . M . N . \quad$ O. T.

supina. Wahlbg. Kleine S.

Fr. rundlich-oval, stumpf, linsenförmig-zusammengedrückt, Schnabel algeschnitten; weibliche Aehren lang- und dünn-gestielt, nickend 0 . hängend ....

Fr. nervenlos 0. schwach-nervig; weibliche Aehren 2-3, eiförmig; B. lineal, flach, glatt, am Rande nach der Spitze hin rauh.

Geb. v. B. S. T. K. St. Kr.

57 irrigua. Sm.*) Berieselte S.

Fr. längsnervig; weibliche Aehren 1-2, länglich; B. schmal-lineal, faltig-rinnig, am Rande vom Grunde an rauh. Verbr. (fehlt J.)

limosa. L. Schlamin-S.

¡s $\{$ Grundb. behaart 0. doch am Rande gewimpert**). . 59

Alle B. kahl .......................6 60

*) C. planifolia Kohts (T.) unterscheidet sich u. a. durch rothbraune Spelzen u. graugrüne B.

**) Eine Alpenform der C. pallescens L. (var. alpestris Kohts) hat ganz kahle B. 
Wst. kriechend; B. breit lineal o. lineal-lanzettlich, am Rande (wenigstens die grundständigen) gewimpert, sonst kahl; weibliche Aehren lineal, lockerblütig, entfernt, Verbr. (fehlt $S$.)

pilosa. Scop. Gewimperte S.

Wuchs dicht rasig; B. ziemlich schmal lineal, behaart*); weibliche Aehren eilänglich, gedrungenblütig, genähert. Verbr .

pallescens. L. Bleiche S.

${ }_{60}$ B. schmal lineal, rinnig o. zusammengelegt; Wuchs

B. lineal, flach

Tragb. der Aehren blattartig, wenn auch oft fast borstenförmig; die Stiele der weiblichen Aehren heraustretend, sehr dünn; männliche Aehre klein, 61 gelblich; Spelzen der weiblichen Aehren mit breitem weißen Hautrande. Geb.

capillaris. $L$. Haarstielige $\mathrm{S}$.

Tragb. der Aehren häutig ..................... 62

Fr. keulig-verkehrteiförmig; Spelzen braun.

A. v. T. S. K. St. N.

62 ornithopodioides. Hausm. Vogelfußartige S. Fr. kugelig-eiförmig; Spelzen weißlich.

Verbr. (fehlt B. M. Sch.) alba. Scop. Weiße S.

$63\left\{\begin{array}{l}\text { Männliche Aehren } 2-4 \ldots \ldots \ldots \ldots \ldots \ldots \ldots \ldots \ldots \\ \text { Nur eine männliche Aehre } \ldots \ldots \ldots \ldots \ldots \ldots\end{array}\right.$

Weibliche Aehren walzenförmig (ziemlich gleich dick), ihre Spelzen mit grünem Mittelnerv.

Verbr. u. hfg.......flacea. Schreb. Seegrüne S.

64 Weibliche Aehren keulenförmig (gegen das Ende verdickt), ihre Spelzen mit gelblichem Mittelnerv und grannenartiger Spitze. A. v. T. S. K. Kr .

clavaeformis. Hoppe. Keulenährige S.

Tragb. der Aehren ausgesprochen blattartig ......66 66 65 $\begin{gathered}\text { Tragb. der Aehren häntig, nur das unterste meist } \\ \text { mit blattartiger Spitze; Fr. mit zweilappigem }\end{gathered}$ Schnabel............................ 69

Weibliche Aehren 4-7, gedrungenblütig, übergebogen, zuletzt hängend; hochwüchsige $\mathrm{Pfl}$. mit breiten B. und sehr langen Aehren.

66 Verbr. (fehlt J.)

pendula. Huds. Ueberhängende S.

Weibliche Aehren 2-5, lockerblütig, aufrecht oder nickend........................... 6 
B. grasgrün

B. seegrün; Spelzen purpurbraun mit hellem Rande und grünem Rückenstreifen. Verbr.

panicea. $L$. Hirse-S.

Spelzen weißlichgrün ; Fr. länglich-lanzettlich, 3 seitig, längsnervig, gegen die Spitze verschmälert. $N$. St.

strigosa. Huds. Schlankährige S.

68 Spelzen rostbraun; Fr. 3 seitig-eiförmig, nervenlos, mit deutlich abgesetztem Schnabel.

Sud.; A. v. $K$.

vaginata. Tausch. Bescheidete S.

Fr. flachgedrückt, oval; weibliche Aehren nickend o. hängend; Spelzen schwarzbraun mit rostgelbem Rande. A. v. T. K. St.

ustulata. Wahlbg. Brandige S.

Fr. kugelig-eiförnig; weibliche Aehren aufrecht; Spelzen hellrostbraun mit weißlichem Rande.

N. O. Südt. K. St. Kr. J.

nitida. Host. Glänzende S.

Die oberste weibliche Aehre steht dicht unter der männlichen Aehre und überragt dieselbe o. er-

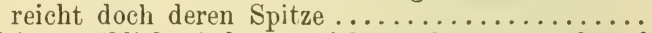

Keine weibliche A ehre erreicht auch nur annähernd die Spitze der männlichen Aehre .......... 72

Weibliche Aehren etwas entfernt; Fr. so lang als 71 die Decksp. Verbr. digitata. L. Fingerförmige S.

71 Weibliche Aehren dicht-zusammengestellt; Fr. länger als die Decksp. S. O. N. St. K. T.

ornithopoda. Willd. Vogelfuß-S.

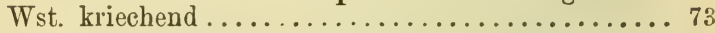

Tragb. der Aehren häutig, das unterste manchmal mit blattartiger Spitze, aber stets aufgerichtet... 74

Tragb. der Aehren blattartig, das unterste zuletzt

73 wagrecht abstehend; grundständige Bscheiden röthlich; Aehren rostbraun; Fr. filzig, fast kugelig. Verbr. (fehlt $K . K r . J$.

tomentosa. $\left.L *^{*}\right)$ Filzfrüchtige S.

Decksp. der weiblichen Aehren spitz o. zugespitzt, nicht randhäutig. Verbr.

verna. Vill. Frühlings-S.

Decksp. der weiblichen Aehren abgerundet, am Rande häutig u. fransig-gewimpert.**) Verbr.

(fehlt $K r$. J.) ...... ericetorum. Poll. Heide-S.

*) C. Nordmanni Kern. (N.) unterscheidet sich dure längliche, deutlich gestielte weibliche Aehren. Decksp.

**) C. membranacea Hoppe ( $A$.) hat fast wirnperlose 
(Weibliche Aehren sitzend; Tragb. der Aehren scheidenlos ..................... 76

Mindestens die unterste weibliche Aehre gestielt; das unterste Tragb. stets scheidig.............

Männliche Aehre lineal, mit hellbraunen, weißlich berandeten Spelzen; grundständige Bscheiden braun. Verbr. (fehlt .J.) pilulifera. $L$. Pillentragende S.

Männliche Aehre länglich, mit schwarzbraunen, nicht randhäutigen Spelzen; grundständige Bscheiden blutroth. Verbr..........montana. I. Berg-S.

Die unterste weibliche Aehre steht weit von den oberen entfernt am Grunde des Stg. auf sehr langem Stiel; Fr. erhaben längsnervig. N. O. St. .J. Südt. Halleriana. Asso. Haller's S. Alle weiblichen Aehren kurz gestielt 0. die oberen

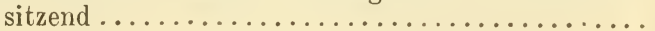

Weibliche Aehren $2-5$ blütig, längs des ganzen Stg. vertheilt; B. schmal lineal, zuletzt länger als der niedrige Stg.; Spelzen mit breitem silberweißem Rande. Verbr. (fehlt Sch.)

humilis. Leyss. Niedrige $\mathrm{S}$.

Weibliche Aehren mindestens 10 blütig ..........

Weibliche Aehren lineal, entfernt; Spelzen mit weißlichem Hautrande; Fr. fast schnabellos; Stg oben fast zottig-rauh. $B$.

pediformis. C. A. Mey. Fußförmige S.

Weibliche Aehren länglich, genähert; Spelzen ohne Hautrand; Fr, mit deutlichem Schnabel. Verbr. (fehlt Sch. J.) umbrosa. Host. Schattenliebende S.

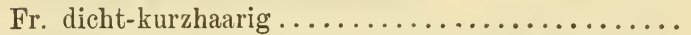

80 Fr. kahl, höchstens nach oben zu etwas rauh 0.

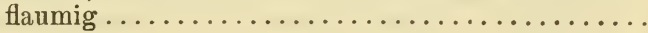

B. schmal lineal, eingerollt 0 . doch rinnig, stets kahl; Tragb. der Aehren scheidenlos o. das unterste mit kurzer Scheide. Verbr. filiformis. I. Fädliche S.

B. lineal, flach, meist behaart*); Tragb. der Aehren mit langen Scheiden. Verbr. hirta. L. Behaarte S.

Endst. Aehre oben weiblich, nur am Grunde männlich; weibliche Aehren 2-3, alle gestielt, ziemlich genähert; Spelzen dunkelbraun; Fr. lanzettlich, am Rande feingesägt-wimperig; Wuchs rasig. $A . . . \ldots \ldots$ fuliginosa. Schk. Russfarbige S. Endst. Aehre männlich..................

*) Bei C. hirtiformis Pers. sind die B. kahl o. fast kahl 
Rand des Frschnabels glatt .............. 84

83 Rand des Frschnabels feingesägt-wimperig 0 . doch

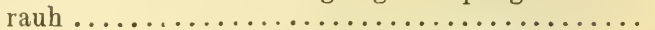

$84\left\{\begin{array}{c}\text { Tragb. der Aehren mit deutlichen Scheiden ...... } 85 \\ \text { Tragb. der Aehren scheidenlos } 0 . \text { höchstens das } \\ \text { unterste mit kurzer Scheide } \ldots \ldots \ldots \ldots \ldots \ldots .88\end{array}\right.$

Fr. lanzettlich-länglich, 3 seitig; weibliche Aehren lineal, hervortretend-gestielt, die fruchttragenden überhängend; B. borstlich-lineal. Vora.

brachystachys. Schrle. Dünne S.

Fr. eiförmig o. elliptisch; B. lineal, aber nicht

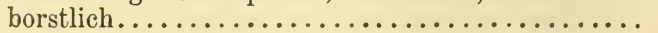

Fr. elliptisch, 3 seitig, nervenlos, in einen linealen, 2 spaltigen Schnabel zugespitzt; weibliche Aehren lineal, lockerblütig, langgestielt, entfernt, hängend; Spelzen bleichgrünlich; B. breit-lineal. Verbr. u. $h \mathrm{fg}$. silvatica. Huds. Wald-s.

Fr. eiförmig, beiderseits convex, nervig, Schnabel kurz-2zähnig; weibliche Aehren länglich-oval 0. rundlich, dichtblütig, die oberen sitzend ........

Spelzen stumpf, fein-stachelspitzig; weibliche Aehren 2-4, ziemlich gedrängt, die unterste entfernt, eingeschlossen - gestielt; Tragb. der Aehren sehr lang, zuletzt zurückgekrümmt; B. rinnig. $J$.

extensa. Good. Ausgedehnte S.

Spelzen zugespitzt, mit einer rauhen Stachelspitze; weibliche Aehren 3, entfernt, die unterste hervortretend-gestielt; das Tragb. der untersten Aehre so lang als der Halm o. länger; B. flach. $T$.

punctata. Gaud. Punktirte S.

Weibliche Aehren hängend, lang-gestielt, walzlich, 4-6; Fr. eiförmig-lanzettlich; Spelzen linealpfriemlich, rauh. Verbr.

Pseudo-Cyperus. L. Cypergrasähnliche S. Weibliche Aehren aufrecht 0 . die unteren zuletzt

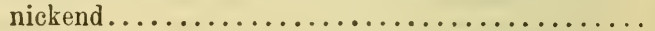

Fr. eiförmig o. länglich-eiförmig, zusammengedrückt, etwas 3 seitig, längsnervig; weibliche Aehren $2-3$, walzlich, sitzend 0 . gestielt; Spelzen zugespitzt 0 . haarspitzig. Verbr. acutiformis. Ehrh. Sumpf-S. Fr. eiförmig-kegelförmig 0 . fast kugelig, nicht zusammengedrückt, sondern aufgeblasen, längsnervig

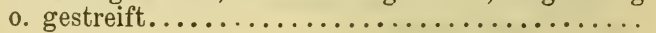

$90\{$ Stg. scharf dreikantig, mit rauhen Kanten ....... 91

Stg. stumpfkantig, nur oben rauh.......... 92 
B. sehr breit, starr, seegrün; männliche Aehren dunkelbraun; Fr. mit kurzem, 2 zähnigem Schnabel. Verbr............... riparia. Curt. Ufer-S.

B. lineal, grasgrün; Aehren hellbraun; Frschnabel fast so lang als die halbe Fr., mit 2 haarspitzigen Zähnen. Verbr....vesicaria. L. Aufgeblasene S.

B. seegrün; Aehren gelblichbraun; Fr. fast wagrecht abstehend, kugelig - eiförmig, längsnervig, plötzlich in einen Schnabel zugespitzt, der fast halb so lang als die Fr. ist und 2 haarspitzige Zähne trägt. Verbr.

rostrata. With. Geschnäbelte S.

B. grasgrün; männliche Aehren rothbraun; Fr. eikegelförmig, eingedrückt-längsstreifig, mit kurzem 2 zähnigem Schnabel. B. N. St. T.

nutans. Host. Nickende S.

Fr. sparrig abstehend; weibliche Aehren rundlich-eiförmig, 2-3, genähert; ihre Tragb. blattartig, zuletzt abstehend 0 . herabgeschlagen; Wuchs dicht

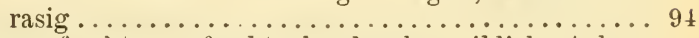

Fr. aufrecht 0 . aufrecht abstehend; weibliche Aehren eilänglich bis lineal.....................

Frschnabel lineal, meist herabgekrümmt, so lang als die Fr. Verbr. $u$. hfg..... flava. L. Gelbe S.

94 Frschnabel pfriemlich, gerade, bedeutend kürzer als die Fr.; Pfl. in allen Theilen meist kleiner als vorige. Terbr............... Oederi. Ehrh. Oeder's S.

Tragb. der Aehren häutig, höchstens das unterste mit kurzer, blattartiger Spitze; B. lineal-lanzettlich, kurz und starr, 3 reihig-abstehend; Fr. ellip-

95 soidisch-lanzettlich, in den Schnabel allmälig verschmälert. A..... firma. Host. Steifblättrige S. Tragb. der Aehren blattartig, höchstens die obersten häutig................................

$96\{$ Männliche Aehren 1-2, bleichgelblich o. grünlich 97

Männliche Aehre 1, heller o. dunkler braun...... 99

Wst. kriechend; Tragb. der Aehren kurz; weibliche Aehren 1-2, lockerblütig; nur eine männliche Aehre. Verbr. (fehlt Sch. S.)

97 Michelii. Host. Micheli's S. Wuchs dicht rasig; Tragb. der Aehren weit über die (meist 2) männlichen Aehren hinausragend; weibliche Aehren meist mehr als 2, gedrungenblütıg............................. 
Weibliche Aehren 2-4, jede in der Achsel eines Tragb. einzeln; Spelzen der männlichen Aehren stumpf. $M . N$. K.J.

hordeistichos. Vill. Gersten-S.

98 Die unteren weiblichen Aehren meist am Grunde verzweigt, so dass 2-4 Aehren in der Achsel desselben Tragb. stehen; Spelzen der männlichen Aehren zugespitzt. $B . M$. $N$.

secalina. Wahlbg. Roggen-S.

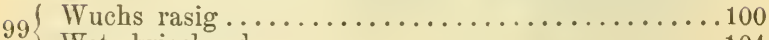

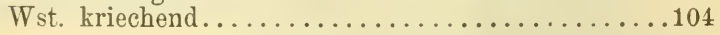

Die unterste weibliche Aehre so lang o. länger als

$100\left\{\begin{array}{c}\text { ihr Tragb.................................. } \ldots 101 \\ \text { Die unterste weibliche Aehre viel kürzer als } \mathrm{ihr}\end{array}\right.$ Tragb. .............................

Grundb. breit lineal, steif, graugrün; Stgb. sehr kurz; Fr. deutlich längsnervig. $B$.

101 brevicollis. DC. Kurzblättrige S. Grundb. schmal-lineal, schlaff, grasgrün; Fr. fast nervenlos. $A$.

sempervirens. Vill. Immergrüne S.

Weibliche Aehren 3-6 blütig; Fr. grün, längsnervig, mit linealem, 2 lappigem Schnabel. J.

102\{

Ventricosa. Curt. Armblütige S.

Weibliche Aehren gedrungenblütig .............103

Spelzen der weiblichen Aehren mit kurzer Stachelspitze; Fr. aufrecht; Zähne des Frschnabels außen und innen feinstachelig-gewimpert. Verbr.

103 Sistans. L. Entferntährige S.

Fr. etwas abstehend; Zähne'des Frschnabels außen feinstachelig-gewimpert, innen glatt. Verbr.

Hornschuchiana. Hoppe. Hornschuch's S.

$104\{$ Die unteren weiblichen Aehren zuletzt überhängend 105 Alle weiblichen Aehren aufrecht ..............106

B. rinnig, grasgrün; weibliche Aehren länglich, gedrungenblïtig, schwarzbraun. $A$. (fehlt $N$.)

B flach, grasgrün; foibliche All. Kalteliebende S.

frigida. All. Kälteliebende S.
weibliche Aehren lineal, lockerblütig, rothbraun. $A$.

ferruginea. Scop. Rostbraune S.

Stg. scharfkantig, rauh; weibliche Aehre gedrungenblütig. A. v. T..... fimbriata. Schk. Kantige s'. 106 Stg. stumpfkantig, glatt; weibliche Aehren lockerblütig; B. breit und starr. A. v. T.

Kerneri. Kohts. Kerner's S. 
Anmerkung. Ton Bastarten wurden im Gebiete beobachtet: C. dioica $\times$ echinata, paniculata $\times$ remota, brizoides $\times$ remota, echinata $\times$ remota, ferruginea $X$ flacea, flara $\times$ Hornschuchiana, ferruginea $X$ sempervirens.

\section{Familie. Araceae. Arongewächse.}

Ausdauernde, kahle Gewächse mit herz- oder pfeilförmigen, seltener linealen, stets ganzrandigen B. Bt. in Kolben, einhäusig, vielehig 0 . zwittrig. Bthülle 6 blättrig, unscheinbar, meist jedoch ganz fehlend. Stb. 1-6, seltener mehr. Frkn. 1, 1-3 fächerig, niemals unterständig; Samenknospen in jedem Fache mehrere. Gr. meist fehlend; N. 1, meist klein. Fr. eine armsamige Beere.

\section{Gattungen.}

B. lineal; Bt. zwittrig, mit 6 blättriger Bthülle; Kolben ohne Scheide, scheinbar seitenständig.

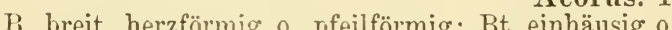
Acorus. I.
einhäusig 0. vielehig (nur theilweise $\mathrm{zwittrig}$ ), ohne Bthülle; Kolben deutlich endständig, mit großer Scheide..

Kolben bis zur Spitze mit Bt. bedeckt; Scheide innen weiø; Bt. theilweise zwittrig ......... Calla. II.

2 Kolben oben nackt; Scheide verschieden gefärbt, aber niemals weiß; Bt. einhäusig, die oberen jedes Kolbens männlich, die unteren weiblich.........

Zwischen den männlichen $u$. weiblichen $\mathrm{Bt}$. des Kolbens finden sich stets verkümmerte Bt.; das nackte Ende des Kolbens keulenförmig, ziemlich gerade; Stb. $3-4 \ldots \ldots \ldots \ldots \ldots \ldots$ Arum. III. Auf die 3-5 weiblichen Bt. am Grunde des Kolbens folgen gleich die männlichen Bt.; das nackte Ende des Kolbens einwärts gekrümmt; Stb. 1.

Arisarum. IV.

\section{Arten.}

\section{ACORLS. L. Kalmus.}

Wst. dick, kriechend; B. 2 zeilig; Kolben gelblichgrün. Verbr..............Calamus. $L$. Gemeiner $\mathrm{K}$.

\section{CALLA. L. Drachenwurz.}

Wst. dick, hohl; B. herzeiförmig, glänzend; Beeren scharlachroth. Verbr. (fehlt J.)

palustris. $L$. Sumpf-D. 


\section{ARUM. L. Aronsstab.}

B. oberseits gleichförmig grün 0 . bräunlich gefleckt; nacktes Kolbenende braunroth. Verbr. (fehl; $K$.) maculatum. L. Gemeiner A.

B. oberseits weißlich geadert; nacktes Kolbenende gelb. Sïdt. $K r$. J. Italicum. Nill. Italienischer A.

\section{ARISARUM. Targ. Tozz. Krummstab.}

B. herzförmig; Scheide braunroth, weißlich geadert, oben kapuzenförmig. $J$.

$$
\text { vulgare. Targ. Tozz. Gemeiner K. }
$$

XII. Familie. Lemnaceae. Wasserlinsengewächse.

Sehr kleine, einjährige, schwimmende o. etwas untergetauchte Wasserpfl. mit blattähnlichem, gegliedertem Stg. u. ohne deutliche B. Wz. haarförmig, im Wasser frei herabhängend, niemals einwurzelnd. Bt. selten vorhandell, schwer bemerkbar, einhäusig, ohne Bthülle. 2 männliche, nur aus 1 Stb. bestehende Bt. mit einer weiblichen Bt. von einer gemeinsamen Scheide eingeschlossen. Frkn. 1, flaschenförmig, mit 1-6 grundständigen Samenknospen. N. klein, etwas trichterförınig. Fr. nicht regelmäßig aufspringend, armsamig. S. bei der Keimung mittels eines Deckels sich öffnend.

\section{Gattungen.}

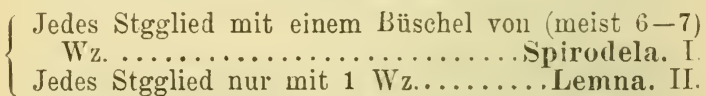

\section{SPIRODELA. Schleid. Teichlinse.}

Stgglieder rundlich-verkehrteiförmig, oberseits dunkelgriin, unterseits oft rothviolett. Verbr.

polyrrhiza. (L.) Schleid. Vielwurzlige T.

\section{LEMNA. L. IVasserlinse.}

Alle Stgglieder schwimmend, verkehrt eirundlich, aneinander sitzend, niemals gestielt............

1 Stgglieder meist untergetaucht, elliptisch 0 . lanzettlich, gestielt und kreuzweise zusammenhängend. Verbr.........trisulca. L. Untergetauchte W. $2\left\{\begin{array}{r}\text { minor. L. Gemeine W. } \\ \text { Stgglieder unterseits bauchig-aufgetrieben; Samen- }\end{array}\right.$ 
XIII. Familie. Juncaceae. Simsengewächse.

Ausdauernde, seltener einjährige Gewächse von binsenartigem o. grasartigem Aussehen. Stg. nicht knotig gegliedert, stielrund 0 . zusammengedrückt, nie scharf kantig. B. ungetheilt u. ganzrandig, parallelnervig, lineal o. lanzettlich, oft auch cylindrisch 0 . borstenförmig; manchmal nur häutige Bscheiden vorhanden. Bt. zwittrig, mit 6 blättriger, häntiger Bthülle. Stb. 6, seltener 3. Frkn. 1, oberständig. 1-3 fächerig, mit 3-vielen Samenknospen. Gr. 1; N. 3, fädlich verlängert. Fr. eine fachspaltig-3 klappige Kapsel.

\section{Gattungen.}

(Frkn. meist mehr o. weniger vollkommen 3 fächerig, mit zahlreichen Samenknospen; Kapsel vielsamig; 13. stets kahl; einige Arten 1 jährig...Juncus. I. Frkn. 1 fächerig, mit 3 Samenknospen; Kapsel mit (1-)3 Samen; B. stets flach, meist am Pande o. doch am Grunde gewimpert, seltener ganz kahl; alle Arten ausdauernd............. Luzula. II.

\section{Arten.}

\section{JUNCUS. $L$. Sinise.}

(Btstand scheinbar seitenständig, da ein Hüllb. den

1 Stg. scheinbar fortsetzt; ausdauernde Arten .....

Btstand dentlich endständig, manchmal nur aus $1 \mathrm{Bt}$. bestehend............................

Btstand vielblütig $\ldots \ldots \ldots \ldots \ldots \ldots \ldots \ldots \ldots$

2 Btstand armblütig (Bt. 3-10); Fr. unvollkommen 3 fächerig ........................ 8

${ }_{3}\left\{\right.$ Grundb.* ${ }^{*}$ stielrund, stechend $\ldots \ldots \ldots \ldots \ldots \ldots \ldots, 4$

3 Grundb.*) nicht stechend................... 5

(Fr. ungefähr so lang als die Bthülle, deren änßere

4 B. lanzettlich. .. maritimus. $L$. Meerstrands-S. Fr. fast doppelt so lang als die Bthülle, deren äußere B. eiförmig. $J$. acutus. $L$. Stechende S.

5 Stb. 6; Mark des Stg. fächerig unterbrochen ..... 6

5 Stb. 3; Mark des Stg. nicht unterbrochen........ 7

Spirre locker, mit verlängerten äußeren Aesten, strohgelb; Fr. gelbbraun, seltener dunkler. J.

6 paniculatus. Hoppe. Rispige S. Spirre ziemlich gedrungen, braun; Fr. glänzend schwarzbraun. Verbr. u. hfg.

glaucus. Eh»h. Seegrüne S.

*) Die Grundb. können leicht für nicht blühende Stg. gehalten werden. 
stg. graugrïn, glanzlos; Griffelrest auf einem Buckel der Fr. sitzend. Verbr.(?)

Leersii. Marss. Geknäuelte S.

7 Stg. grasgrün, glänzend; Griffelrest in einem Grübchen der Fr. sitzend. Terbr. u. hfy. effusus. L. Gemeine S.

Das die Fortsetzung des blühenden Stg. bildende Hüllb. ist mindestens so lang als dieser, so dass der Btstand ungefähr in der Mitte des Stg. zu stehen scheint; Bthülle hellbraun o. grünlich; Fr. fast kugelig, glänzend olivembraun. Verbr.

filiformis. $I$. Fädliche $\mathrm{S}$.

Das die Fortsetzung des blühenden Stg. bildende Hüllb. ist viel kürzer als dieser; Bthülle u. Fr. schwarzbraun, letztere 3 kantig. A. v. $T$.

arcticus. $I$. Nordische $\mathrm{S}$.

$9\{$ Stb. 3; B. borstlich . . . . . . . . . . . . 10

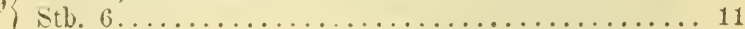

Ausdauernd; Stg. beblättert; B. der Bthülle gleichlang, spitz, gerade, kürzer als die Fr. Verbr. (fehlt S.).......... bulbosus. L. Knollige S.

10 Einjährig; B. nur grundständig; B. der Bthülle ungleich, auswärts gekrïmmt, länger als die Fr. B. M. Sch. N. K. J. capitatus. Weig. Kopfige S.

B. gegliedert, inwendig fächerig-röhrig; Bt. zu meh-

11 reren in Köpfchen, diese zu endständigen Spirren B. ungegliedert, inwendig nicht fächerig-röhrig..... 16 $12\left\{\begin{array}{l}\text { B. der Bthülle gleichlang, stumpf (oft mit kurzer } \\ \text { Stachelspitze) } \ldots \ldots \ldots \ldots \ldots \ldots \ldots \ldots \ldots \ldots \ldots \ldots \ldots \ldots \ldots \ldots\end{array}\right.$ Wenigstens die äuferen Bthüllb. spitz o. zugespitzt 14

Spirrenäste aufrecht; Bthülle dunkelbraun, kürzer als die schwarzbraune Fr. Verbr.

alpinus. Vill. Alpen-s.

13 Spirrenäste sparrig abstehend; Bthülle gelbbräunlich, so lang als die hellbraune Fr.

Verbr. (fehlt Sch. M. Kr.)

obtusiflorus. Ehrh. Stumpfblütige S.

Bthüllb. gleich lang, die äußeren spitz, die inneren stumpf, kürzer als die Fr. Terbr. $u$. $h \mathrm{fg}$.

articulatus. $L$. Glieder-S.

Die inneren Bthüllb. lïnger, an der Spitze umgebogen, alle zugespitzt-begrannt; Fr. eiförmig, zu-

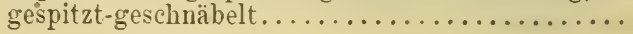


Bthüllb. braun, kürzer als die Fr.; Bglieder glatt. Verbr.........silvaticus. Reich. Spitzblütige S. Bthüllb. fast schwarz, glänzend, etwa so lang als die Fr.; Bglieder kantig-gestreift.

B. M. Sch. N. S. K. T.

atratus. Krol: Schwarzblühende S.

16 Bt. in Köpfchen zusammengestellt 0. nur $1-3$; ausdauernde Gebirgspt................ 17

Bt. in Spirren zusammengestellt........... 22

B. borstlich-lineal, an der Mündung der Bscheide mit zerschlitzt-bewimpertem Bhäutchen ........ 18

Mündung der Bscheiden nicht zerschlitzt-bewimpert 19 Die Bscheiden am Grunde des Stg. tragen keine 0. nur sehr kurze Spreiten; aufer den Tragb. der Bt. ist höchstens 1 langes B. am oberen Theile des Stg. vorhanden; Fr. so lang als die Bthülle. Geb................trifidus. L. Bürsten-S. Stg. mit 2-3 langen, von einander entfernten B. (außer den 'Tragb. der Bt.); Fr. länger als die Bthülle. A.... monanthus. Jacq. Einblütige S. Bt. mit Vorb.; Bthüllb. zugespitzt, glänzend schwarzbraun; N. fleischfarben; Köpfchen 2-10blütig; nur 1 langes Stgb. vorhanden. $A$. (fehlt $O$.)

Jacpuini. L. Gemsen-S.

Bt. ohne Vorb.; Bthüllb. braun 0. grünlich ...... 20

Stg. nur am Grunde beblättert, dünn; Bt. 2-4, dicht beisammen; Bthüllb. stumpflich, bräunlich.

20 A. (fehlt $N$. J.)...triglumis. $L$. Dreiblütige S. Stg. mit $1-3$ entfernten B.; Bt. in $1-3$ armbliitigen Köpfchen; Bthüllb. spitz ...............

Wst. ohne Ausläufer; Stg. dünn; Bthüllb. grünlich. A. . T............stygius. L. Stygische S.

21 Wst. mit Ausläufern; Stg. derb; Bthüllb. kastanienbraun. A. v. T' S. K. St.

castaneus. Sm. Kastanienbraune s.

Ausdauernde Arten; Aeste der Spirre trugdoldig 0.

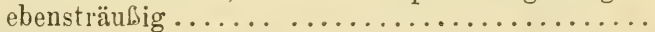

Einjährige Arten; Aeste der Spirre verlängert, 2 spaltig; Bthüllb. zugespitzt ..............

Wst. kriechend; Stg. beblättert; Bthüllb. sehr stumpf 24

23 Wst. nicht kriechend; B. nur grundständig; Bthüllb. spitz 0 . stumpflich .....................

Stg. zusammengedrückt; Bthüllb. und Gr. halb so lang als die fast kugelige Fr. Verbr. $u$. h f $y$. 24 Stg. fast stielrund; Bthüllib. und Gr. ungefähr so lang als die länglich-eiförmige $\mathrm{Fr}$.

B. M. N. T. J. Gerardi. Lois. Stielrundliche S. 
B. starr, abstehend; Hüllb. kurz, die spirre niemals überragend: Stf. viel kïrzer als die $A$.

$25 \quad B . M . S c h . N$. O... squarrosus. L. Sparrige S. B. aufrecht; Hüllb. meist länger als die Spirre; Stf. länger als die A. B....tenuis. Willd. Zarte S. Aeste der Spirre abstehend; Bthïlle braun, so lang als die rundl. Fr. B. 1 . N. St. Kr.

Tenageia. Ehrh. Schlamm-S.

Aeste der spirre aufrecht; Bthüllb. meist grünlich, länger als die $\mathrm{Fr} . \ldots \ldots \ldots \ldots \ldots \ldots \ldots \ldots \ldots . . \ldots \ldots$

Fr. fast kugelig, stumpf; Stg. $1-2$ blättrig. B. N. O. Sphaerocarpus. Nees. Kugelfrüchtige S.

Fr. länglich; Stg. mehrblättrig.............. 28 Bt. längs der Spirrenäste gleichmäßig vertheilt; blïht im Sommer u. Herbst. Verbr. u. hfg.

bufonius. $L$. Kröten-S.

Bt. zu 2-3 gegen das Ende der Spirrenäste genähert; blüht im Frühling. $J$. insulanus. Viv. Mittelmeer-S.

Anmerkung. Zwischen J. effusus und J. glaucus kommt ein Bastart vor.

\section{LUZULA. $D C$. Hainsimse.}

Bt. einzeln o. gebüschelt in einer Spirre; Same an der Spitze mit 1 Anhängsel, 0. das Anhängsel

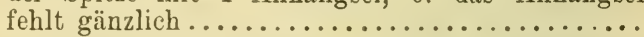

Bt. zu kopfförmigen Aehrchen dicht zusammengestellt, die Aehrchen oft zu doldenähnlichen Spirren vereinigt; Same meist am Grunde mit einem kegelförmigen Anhängsel (Nabelwalze) ........... 1

Bt. einzeln; Same an der Spitze mit einem groben Anhängsel; B. am Rande langhaarig ..........

Die meisten Bt. gebüschelt, andere oft einzeln; Same an der Spitze ohne Anhängsel, o. dieses klein u. unscheinbar...........................

Bt. strohgelb; Spirre doldig; Aeste meist 1 blütig; Grundb. lineal; Wst. kriechend. Verbr. (fehlt B. M. J.) Havescens. (Host.) Gaud. Gelbliche H. Bt. braun 0. röthlich; Spirre ebensträußig; Wst. nicht

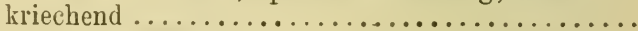

Anhängsel des Samens gerade, stumpf; Grundb. lineal; fruchttragende Spirrenäste meist aufrecht.

N. O. Siidt. J. Forsteri. (Pers.) DC. Forster's H.

4 Anhängsel des Samens sichelförmig; Grundb. breit, lineal-lanzettlich; fruchttragende Spirrenäste meist herabgeschlagen. Terbr.

pilosa. (L.) Willd. Haarige H. 
(Bt. hellgelb; B. ganz kahl o. am Grunde etwas bärtig, lanzettlich-lineal. $A$. v. T.

lutea. (All.) $D C$. Gelbe $\mathrm{H}$.

Bt. weißlich, röthlich 0 . braun.............. 6

6

B. am Rande mit langen Haaren dichter o. spärlich bewimpert ..................... 7

B. kahl o. nur am Grunde gebärtet.......... 10

$7\{$ Hüllb. so lang 0 . länger als die Spirre.......... 8

Hüllb. viel kürzer als die Spirre ............ 9

Btbüschel 2-4 blütig; Bthüllb. wei@lich o. röthlich (sehr selten schwarzbraun); A. fast sitzend. Verbr. u. $h f g$.

angustifolia. (Wulf.) Garcke. Weißliche $\mathrm{H}$. Btbüschel mehrblütig; Bthüllb. glänzend weiø; Stf. so lang als die A. T. K.J.

nivea. (L.) $D C$. Schneeweibe $\mathrm{H}$.

Grundb. breit, lineal-lanzettlich, zerstreut langhaarig ; Spirre reichblütig. Verbr. (fehlt $K r$. J.)

9 silvatica. (Huds.) Gaud. Grobe H. Grundb. lineal, ziemlich schmal, reichlicher langhaarig; Spirre armblütig. $B . T$. $K$.

Sieberi. Tausch. Sieber's H.

B. breit, lanzettlich, ganz $\mathrm{kahl}$ (o. die obersten am Grunde etwas gebärtet); Bt. locker gestellt, viele einzeln. $A$. (fehlt J.)

glabrata. (Hoppe.) Desv. Kahle $\mathrm{H}$.

B. schmäler, lineal-lanzettlich, am Grunde lang gebärtet; Bt. dichter gestellt, die meisten gebüschelt. A. v. T. S. K. St.

spadicea. (All.) DC. Braune $\mathrm{H}$.

B. lineal, rinnig, am Grunde behaart; Aehrchen zu einer gelappten, überhängenden Aehre zusammengestellt; Bthüllb. fein haarspitzig; S. ohne Anhängsel. Geb. v. B.S. T. K. St.

spicata. (L.) $D C$. Aehrige $\mathrm{H}$.

B. lineal o. lineal-lanzettlich, flach, am Rande behaart, zuletzt kahl; Aehrchen in einer doldenähnlichen Spirre, seltener in einem lappigen Köpfchen; Bthüllb. stachelspitzig; S. am Grunde mit kegelförmigem Anhängsel .............. 12

Alle Btbüllb. ziemlich gleichlang, die Fr. meist deutlich überragend................. 13 Die 3 inneren Bthüllb. dentlich kürzer als die 3 äußeren 
Wuchs locker rasig; Stg. niedrig; Aehrchen 2-5, einige zuletzt herabgebogen; Stf. viel kürzer als die A. Verbr. campestris. ( $L$.) $D C$. Gemeine H.

Wuchs dicht rasig; Aehrchen 5-10, meist aufrecht; Stf. ungefähr so lang als die A. Verbr.

multiflora. (Hoffm.) Lej. Vielblütige $\mathrm{H}$.

Wst. etwas kriechend; Stg. steif; Aehrehen 5-10, schwarzbraun. Geb.

Sudetica. (Willd.) $D C$. Sudeten-H.

Wuchs dicht rasig; Stg. schlaff; Aehrehen zahlreich, gelblich 0 . hellbraun. $B . M$. Sch.

pallescens. (Wahlog.) Bess. Blasse H.

\section{Familie. Liliaceae. Liliengewächse.}

Ausdauernde, aber selten verholzte (sehr selten einjährige) Gewächse, sehr oft mit Zwiebeln, seltener mit Wst. B. ungetheilt und (fast ausnahmslos) ganzrandig, manchmal häutig und schuppenförmig. Bt. meist $\mathrm{z}$ wittrig, seltener vielehig 0 . 2 häusig. Bthüllb. meist 6 (selten 4 o. 8), nicht selten verwachsen, meist blumenkronartig gefärbt. Stb. meist 6 (selten 3,4 0.8). Frkn. 1, oberständig, meist 3 fächerig (sehr selten 4 fächerig $0.1-2$ fächerig), meist mit unbestimmter Zahl der Samenknospen. Gr. meist 1 (seltener 3, sehr selten 4); N. 3 o. 1 (selten 4), selten fädlich. Fr. eine Kapsel 0. Beere, meist mehrsamig.

\section{Gattungen.}

1) Bthüllb. 6, oft verwachsen ............. 2

1 Bthüllt. 4 0. 8, am Grunde verwachsen ............. 26

Bt. vielehig-2häusig, anf der Oberseite blattartig verbreiteter Zweige (Phyllocladien) eingefügt; Stb.

2 3, ihre Stf. zu einer Pöhre verwachsen; Fr. eine meist 1-2 samige Beere......... Ruscus. XX.

Bt. nicht auf Phyllocladien stehend; Stb. 6 ......

Bestachelte Kletterpfl. mit immergrünen, gestielten, herz- o. spiebförmigen B.; Bt. vielehig-2 häusig; $\mathrm{Fl}$ eine meist 1-2 samige Beere.

smilax. XXVI.

Stachellose*) Pfl.; B. sehr selten herzförmig, dann

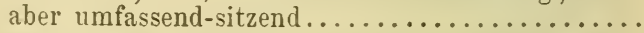

*) Die Phyllocladien von Asparagus acutifolius L. sind steif und stechend. 
B. schuppenförmig, häutig o. fleischig; in der'en Achseln stehen Büschel nadel- o. fadenförmiger Zweige (Phyllocladien); Bt. vielehig-2 häusig; Fr. eine armsamige Beere....... Asparagus. XIX:

B. normal entwickelt, nie schuppentörmig; Phyllo-

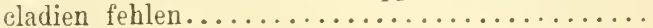

Bthüllb. getrennt 0 . höchstens am Grunde etwas

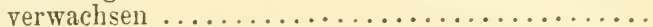

Bthüllb. verwachsen, nur im oberen Thrile frei:

Bthülle daher 6 zähnig 0. 6 spaltig .......... 22

Stg. 1 blütig, selten 2 blütig; Zwiebelgewächse.... 7

6) Stg. mehrblütig, nur bei kümmerlichen Exemplaren manchmal $1-2$ blütig .................. 11

( Bthüllb. am Grunde mit Honiggrube .............

7) Bthüllb. ohne Honiggrube; Stg. armblättrig; Bt. ansehnlich, gelb.............Tulipa. IIII.

8) Gr. an der Spitze 3 spaltig, d. b. mit 3 getrennten N.

5 Gr. ungetheilt, mit 3 kantiger N..............

Nur 2 B. am Grunde des Stg. rorhanden; Bthüllb. zuletzt zurïckgebogen, heller oder dunkler rosenroth (selten wei(s)......... Elythroniım. XIV. Stg. reichlich beblättert; Bthülle glockig, meist schachbrettartig gezeichnet .... Fritillaria. III. Zarte Alpenpfl. mit weiblichen Bt....Iloydia. IV. 10 Kräftige Pfl. mit ansehnlichen, lebhaft gefärbten Bt. Liliun. XI.

Btstand endständig; Fr. eine Kapsel .......... 12

11 Bt. einzeln o. zu 2 den 2 zeilig angeordneten Stgb. gegenüber entspringend; Fr. eine Beere.

Streptopus. IXII.

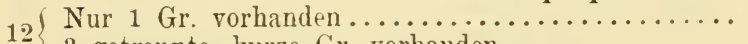

3 getrennte, kurze Gr. vorhauden ............ 21

13 Btstiele oben abgegliedert; Zwiebel fehlt ......... 14 Btstiele nicht abgegliedert; Zwiebel meist vorhanden 16

Bt. weiß; alle B. grundständig ............ 15

14 Bt. gelb, in einfacher 'Traube; Stb. herabgebogen; Stg. beblättert...................... Bthüllb. am Grunde verwachsen; Stf. am Grunde verbreitert und den Frkn. ïberdeckend.

Bthüllb. ganz frei; Stf. nicht verbreitert.

Asphodelns. If.

Anthericum. VII.

Stf. am Grunde der A. eingefügt; Bthüllb. innen gelb, auden meist grünlich; Bt. ungleich lang ge16 stielt, fast doldig, die untersten mit blattartigen

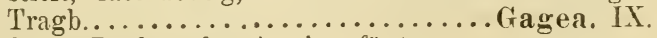
Stf. am Rücken der $A$. eingefügt ............ 
Bthüllb. am Grunde mit einer honigabsondernden Furche; Bt. ansehnlich, verschieden gefärbt.

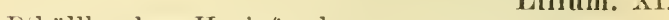

Bthüllb. ohne Honigfurche .............. 18

Btstand doldig, vor dem Aufblühen in eine Scheide 18 eingeschlossen ................... Allium. X. Btstand eine Traube o. Doldentraube, ohne Scheide 19

Frkn kurz gestielt; Stf. an der Spitze dieses Stieles eingefügt; 'Traube einseitswendig, armblütig; Bt.

19 grob, glockig-trichterig, weiळ.... Paradisia. VI. Frlin. sitzend; Stf. am Btboden 0. am Grunde der Bthüllb. eingefügt; Zwiebelpfl..............

Bthülle weif, grünlich o. gelb, bleibend; Stf. am Btboden eingefügt, manchmal den Bthüllb. etwas

2. anhängend.............. Ornithogalum. XVII. abfällig; Stf. am Grunde der Bthüllb. eingefügt.

\section{Scilla. XVI.}

Kahle Pfl.; B. schwertförmig-lineal; Bt. in einfacher (nur ausnahmsweise ästiger) Traube. Tofieldia. I.

21 Große Pfl. mit breiten, ovalen, elliptischen o. lanzettlichen B.; Bt. in einer flaumig behaarten Rispe. Veratrum. II.

Bt. ansehnlich, trüb-gelbroth o. gelb; Stf. lang, gebogen; B. breit lineal, gekielt.

Hemerocallis. VIII.

Bt. blau, violett, lila, weiß o. grünlich ......... 23

( Stg. beblättert; Wst. kriechend; Bt. einzeln o. ge23 büschelt in den Blattachseln, weiß 0 . grïnlich. Alle B. grundständig ......................

Bthülle mit langer Röhre, meist rosa-lila; Gr. 3, sehr verlängert; Bt. grundständig. Colchicum. III.

24 Bthülle mit kurzer, glockiger o. walzlicher Röhre, blau, violett 0 . weis; nur $1 \mathrm{Gr}$. vorhanden; Bt. in

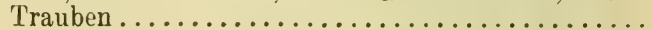

Zwiebelpflanzen; B. mehrere (selten nur 2), schmäler o. breiter lineal; Bt. meist blau 0. violett (nur ausnahmsweise weib), die obersten unfruchtbar.

Muscari. XVIII.

Wst. kriechend; B. meist 2, elliptisch, lang gestielt; Bt. weiß, alle fruchtbar....Convallaria. XXIV. Stg. oben mit 4 (selten mehr) quirlständigen B.; Bt. einzeln, endständig; Bthülle grünlich, 8 theilig; Stb. 8 ; Gr. 4 ; Beere blauschwarz ..Paris. XXV. Stg. mit 2 wechselständigen B.; Bt. in einer Traube; Bthülle weiß, klein, 4 theilig; Stb. 4 ; Gr. 1 ; Beere roth.............. Majanthemum. XXI. 


\section{Arten.}

\section{TOFIELDIA. Huds. Graslilie.}

Tragb. der Bt. lanzettlich; Vorł. 3lappig; Bthülle gelblich; Traube meist verlängert.*) Verbr.

calyculata. (L.) Wahlbg. Gemeine G. Tragb. der Bt. dreilappig; Vorb. fehlt; Bthülle weiblich; Traube kurz, fast kopfig.

A. v. T. S. O. St. K. palustris. Huds. Sumpf-G.

\section{VERATRUM. L. Germer.}

Bt. schwarzpurpurn; Rispenäste filzig; B. breit-

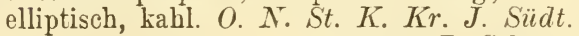

nigrum. $L$. Schwarzer G.

Bt. innen weiß, außen grünlich**); Rispenäste Hlaumig; B. elliptisch o. lanzettlich, unterseits flaumig. Verbr. (besonders $A$.)

album. $L$. Weiber G.

\section{COLCHICUM. $L$. Zeitlose.}

B. breit, aufrecht, flach, stumpf; Zipfel der Bthülle mit wellig verlaufenden Nerven.**) Verbr. $u$. $h f g$.

autumnale. $L$. Herbst-\%.

B. hin- u. hergebogen, lanzettlich, zugespitzt; Zipfel der Bthülle schmal, mit meist geradlinigen Nerven. J.............. Kochii. Parl. Istrianische Z.

\section{ASPHODELCS. $L$. Affodill.}

(Einjährige Art; B. pfriemlich, halbstielrund, röhrig;

1 Bthüllb. mit grünlichem o. purpurnem Rückenstreifen. J......... fistulosus. L. Röhriger A. Ausdauernde Arten; B. breit-lineal, flach......... 2

$2 \begin{gathered}\text { Btstand ästig; Kapsel kugelig. Kr.J. } \\ \text { microcarpus. Viv. Kleinfrüchtiger A. }\end{gathered}$ Bt. in einfacher Traube $\dagger$ ); Kapsel eiförmig, 3seitig. J. $K r$. Sïdt............ albus. Mill. Weißer A.

*) Bei der Hochalpenform ('T. glacialis Gaud.) ist die Traube sehr kurz und fast kopfig. grünlich.

**) Bei V. Lobelianum Bernh. sind die Bt. beiderseits

***) Gewöhnlich erscheinen die Bt. im Herbst und die B. im Frühjahr; manchmal erscheinen aber auch im Frühjahr Bt., die dann meist verkümmert und oft grünlich gefärbt sind. Schult.

$\dagger$ ) Eine Form mit ästigem Btstand ist A. neglectus 
V. ASPHODELINE. Rch $b$. Junkerlilie.

B. glatt; Tragb. mindestens so lang als die Btstiele. J............... Intea. (I.) Rchb. Gelbe J.

B. auf den Rillen gezähnelt-rauh; Tragb. viel kürzer als die Btstiele. $J$.

Liburnica. (Scop.) Rchb. Liburnische J.

VI. PARADISIA. Maz. Trichterlilie.

Stg. einfach; B. lanzettlich-lineal, flach. Südt. $K$. $K r$.

Liliastrum. (L.) Bert. Schneeweibe T.

VII. ANTHERICLI. L. Zaunlilie.

Btst. eine einfache Traube; Gr. abwärts-geneigt. N. O. St. K. T..........Liliago. L. Astlose Z. Btstand meist ästig; Gr. gerade. Verbr.

ramosum. $L$. Aestige $Z$.

VIII. HEMEROCALLIS. I. Taglilie.

Zipfel der Bthülle rein gelb, flach, nur mit Längsnerven. T. K. St. Kr. J., sonst cult. (B. verw.)

flava. $L$. Gelbe T'.

Zipfel der Bthülle trüb gelbroth, die inneren am Rande wellig, nit Längsnerven und Queradern. B. I. S. T. K. Kr. (z. Th. nur rerw.)

fulva. $L$. Gelbrothe T.

\section{IX. (*AGEA. Salisb. Gelbstern.}

Neben der den blülienden Stg. entsendenden Zwiebel finden sich noch 2 freie Zwiebeln; meist nur 1 grundständiges, schmal lineales, dickliches, seegrünes B. vorhanden; Btstiele kahl.

B. M. Sch. N. O. St. Sü̈t.

pratensis. (Pers.) Rchb. Wiesen-G.

Neben der den blühenden Stg. entsendenden Zwiebel findet sich höchstens noch eine Zwiebel, die aber mit der ersteren gemeinsam durch Häute ein-

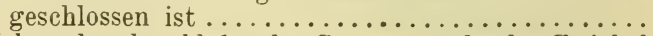

Neben der den blühenden Stg. entsendenden Zwiebel findet man stets noch eine zweite Zwiebel, die mit ersterer gemeinsam durch Häute eingeschlossen ist. An der blïhenden $\mathrm{Pfl}$. findet man stets nur $1 \mathrm{Z}$ wiebel. Grundb. 1-2, röhrig-hohl; Btstiele meist behaart;

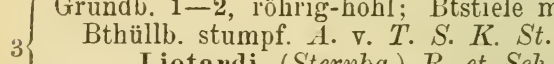

$3\left\{\begin{array}{c}\text { Bthüllb. stumpf. A. v. T. S. K. St. } \\ \text { Liotardi. (Sternbg.) R. et Sch. Liotard's G. }\end{array}\right.$ Grundb. flach o. rinnig, manchmal fast fadenförmig. 4 Nur 1 Grundb. vorhanden; Btstiele meist kahl; Bthüllb. lineal-lanzettlich, zugespitzt.

4 B. M. Sch. N.S. T. K. St.

minima. (L.) R. et Sch. Kleinster G.

2 Grundb. vorhanden; Btstiele behaart ........... 
Grundb. grasgrün, schmal lineal, rinnig, aber nicht fadenförmig; Bt. mehrere; Bthüllb. nach oben verschmälert, spitz. Verbr. (fehlt $S$.)

arvensis. (Pers.) R. et Sch. Acker-G. Grundb. bläulichgrün, fast fadenförmig; Bt. 1-2; Bthüllb. nach oben verbreitert, stumpf. $B . M$. N. Bohemica. (Zauschn.) R. et Sch. Böhmischer G. Grundb. breit, lineal-lanzettlich, flach; Bthüllb. läng6 lich. Terbr........lutea. (L.) Ker. Gemeiner G. Grundb. schmal-lineal, rinnig; Bthüllb. lanzettlich. II. N. St. J. pusilla. (Schm.) R. et Sch. Zwerg-G.

Anmerkung. Zwischen $G$. arvensis u. $G$. pusilla wurde in $\boldsymbol{\Lambda}_{\text {. }}$. ein Bastart gefunden.

X. ALLIUI. L. Lauch.

B. dentlich gestielt; Dolde ohne Brutzwiebeln; Stf. zahnlos.

B. ohne Bstiel

B. mehrere, kurz gestielt, lanzettlich o. elliptisch; Dolde kugelig; Stf. länger als die grünlichweibe Bthülle; blüht im Sommer. Geb.

Victorialis. L. Allermannsharnisch.

B. 2, langgestielt, elliptisch-lanzettlich; Dolde flach; Stb. kürzer als die rein weiße Bthülle; blüht im Frühling. Verbr........ursinum. L. Bären-L.

B. wenigstens am Grunde hohl, stielrund o. halbstielrund, bisweilen an der Spitze rinnig .......... B. flach 0. rinnig, lineal, bisweilen hohl, aber in diesem Falle grasartig ................. 10

B. oberwärts rinnig; Stg. bis zur Mitte beblättert; Stb. länger als d' Bthülle, die 3 inneren 3 fach-

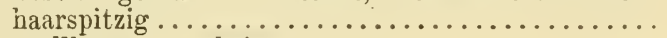

B. vollkommen röhrig................ 6

B. stielrund; die mittlere Haarspitze der inneren Stf. länger als der Stf.; Dolde mit Brutzwiebeln; Bt. rosenroth. Verbr. (fehlt $T$. S.)

vineale. $L$. Weinlauch.

B. halbstielrund; die mittlere Haarspitze der inneren Stf. halb so lang als der Stf.; Dolde ohne Brutzwiebeln; Bt. dunkelpurpurn. B. M. N. O. T. J. sphaerocephalum. $L$. Rundköpfiger $L$.

( B. gleichförmig-stielrund, lineal, pfriemlich.......

6 B. sammt dem Stg. bauchig-aufgeblasen; Dolde

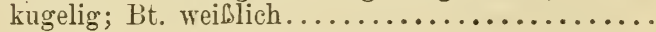

Scheide so lang als die fast kugelige Dolde; Stf. zahnlos

7 Scheide kürzer als die Dolde; die 3 inneren Stf. am Grunde beiderseits mit einem Zahne; Bthüllb. weiß; blüht selten. Cult. Ascalonicum. L. Schalotte. 
Stg. niedrig, nur am Grunde beblättert; B. vollkommen stielrund; Bthüllb. hellrosa, eilanzettlich. B. O.T., sonst cult. Schoenoprasum. L. Schnitt-L. St. höher, etwa bis zu einem Drittel seiner Länge beblättert; B. theilweise halbstielrund; Bthüllb. hellpurpurn, lineal-lanzettlich. Geb.

foliosum. Clar. Alpen-Schnitt-I.

Stg. unter der Mitte bauchig; die 3 inneren Stf. am Grunde beiderseits mit einem Zahne. Cult.

Cepa. L. Zwiebel.

Stg. in der Mitte bauchig; Stf. zahnlos. Cult.

fistulosum. $L$. Winterzwiebel.

Die 3 inneren Stf. breiter, 3 fach-haarspitzig, die mittlere Haarspitze die A. tragend, die seitlichen fädlich, meist zusammengedrückt; B. flach ......

Stbf. einfach 0 . abwechselnd breiter, aber nicht 3 fach. haarspitzig, höchstens am Grunde mit einem kurzen,

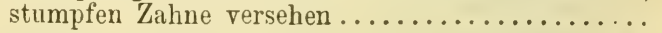

B. am Rande rauh; Dolde mit Brutzwiebeln; Bt. purpurröthlich. Verbr. (fehlt S. St. $K r$. J.)

Scorodoprasum. L. Schlangen-L.
B. am Rande glatt; Dolde ohne Brutzwiebeln.....

B. dunkelgrün; Stb. in der Bthülle eingeschlossen; die mittlere Haarspitze 3 mal kürzer als der Stf.; Bt. purpurn. B. M. N. O. Sï̈lst. J.

rotundum. $L$. Runder L.

B. seegrün; Stb. länger als die Bthülle; Bt. rosa 0 . weißlich

Die mittlere Haarspitze halb so lang als der gemein-

13 same Stf. Cult........... Porrum. L. Porre.

Die mittlere Haarspitze so lang als der gemeinsame Stf. J........Ampeloprasum. L.*) Schwert-L.

Stg. unter der Erde, sehr kurz; Grundb. lineal, am Rande kulz-gewimpert; fruchttragende Strahlen

14 der Dolde zurückgekrümmt; Bt. weiß; blüht in Winter. J......... Chamaemoly. $L$. Dünen-L. Ein deutlicher oberirdischer Stg. vorhanden ...... 15

15 Stg. scharfkantig; B. flach, lineal, etwa so breit wie

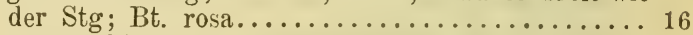

Stg. ungefähr stielrund .................. 17

B. unterseits kiellos; Dolde rundlich; Stb. länger als die Bthülle. Verbr....... senescens. L. Berg-L.

16 B. unterseits scharf-gekielt; Dolde flach; Stb. so lang als die Bthülle. B. M. N. O. T. K. St.

angulosum. $L$. Kantiger L.

*) Bei der var. Lussinense Haračić sind alle 6 Stf. 3 fach-haarspitzig. 
Stg. blattlos; Stf. zahnios; Grundb. flach, breit-

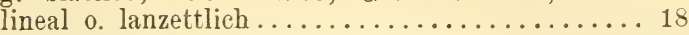

Stg. unten 0. bis zur Mitte beblättert ......... 20

Bt. rosenroth; *) Grundb. am Rande gezähnelt-rauh. 18 J............... rosenm. I. Posenrother L. Bt. weiß o. wei@lich mit grünem Rückenstreifen... 19

Frknoten schwarzgrün; Bthüllb. weißlich, mit grünem Kiele; B. breit-lanzettlich, kahl. (N. O.) Sïdt.

nigrum. L. Schwarzer L.

Frknoten gelblich-grün; Bthïllb. weiø; B. breitlineal, am Rande zottig-gewimpert. $J$.

subhirsutum. L. Bewimperter L.

Stb. tief am Grunde der Bthülle eingefügt, abwechselnd breiter, 0 . abwechselnd am Grunde beider-

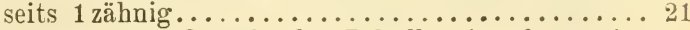

Stb. über dem Grunde der Bthülle eingefügt, einfach; Btscheide 2 blättrig, das eine B. sehr lang

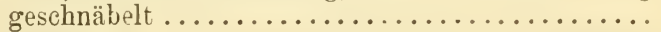

B. pfriemlich, stielrund, gefurcht, schmal- u. tiefrinnig; Bthüllb. weis o. röthlich, mit dunklerem

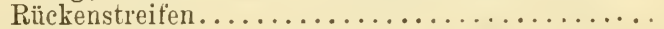

B. lineal, flach $\ldots \ldots \ldots \ldots \ldots \ldots \ldots \ldots \ldots \ldots$

B. am Rande fein-wimperig-rauh; Stb. $u^{1}{ }^{1}{ }_{3}$ kürzer als die Bthülle. Südst. J.

moschatum. $L$. Bisam-L.

B. am Rande kahl; Stb. doppelt so lang als die Bthülle. $K r$. J....... saxatile. $M B$. Stein-L.

Die Stb. abwechselnd breiter, aber ohne Zahn am Grunde; B. unterseits scharf-gekielt......... 24

Die Stb. am Grunde beiderseits mit einem kurzen, stumpfen Zahne versehen.................

Bt. gelblich-weiß o. weißlich; Bscheiden an der Spitze quer-abgeschnitten. Sü dt. K. Südst. Kr. J.

ochroleucum. WK. Gelblichweißer L.

Bt. hellpurpurn; Bscheiden an der Spitze schief-abgeschnitten. $N . T . K r . J$.

suaveolens. Jacq. Wohlriechender L.

Bt. hellpurpurn; B. unterseits fast halbstielrund; Dolde ohne Brutzwiebeln; Zwiebel netzig-faserig. 25 B. T. Kr...strictum. Schrad. Steifblättriger L. Bt. schmutzig-weiß; B. flach, breit-lineal; Dolde mit Brutzwiebeln; Zwiebeln gehäuft............

*) Allium atropurpureum W. K., welches in $N$. beobachtet wurde, hat dunkelpurpurne Bt. 
( B. oberseits rinnig; Zwiebelchen länglich. Cult.

26 sativum. L. Knoblauch. B. durchaus flach; Zwiebelchen rundlich-eiförmig. Cult... Ophioscorodon. Don. Natternknoblauch. $27\left\{\begin{array}{c}\text { Bt. hellgelb; Stb. doppelt so lang als die Bthülle. } \\ T . . T \text {. (S.) T..........flarum. L. Gelber L. }\end{array}\right.$ Bt. weiblich 0. grünlich, bräunlich 0. rosenroth; B.

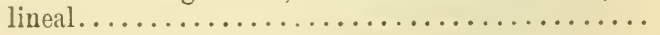

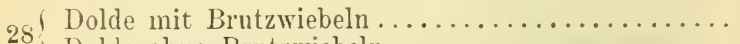

Bthüllb. wei@lich-grün, o. hell-schmutzig-röthlich, mit griinem o. purpurnem Rückenstreifen; Stb. so lang

29 als die Bthülle. Verbr. oleraceun. L. Gemüse-L. Bthüllb. rosenroth; Stb. fast doppelt so lang als die Bthülle. N. U. S. T. K. St. Kr. J. carinatum. $\dot{L}$. Gekielter L.

Bthüllb. spitz, meist hell karminroth; B. halbstielrund, schmal, rinnig. $J$.

Bthüllb. stumpf 0 . abgestutzt, manchmal mit kurzer, plötzlich aufgesetzter Spitze ..............

Bthüllb. milchweiß, mit grünlichem o. röthlichem Uittelnerv; B. am Grunde stielrund und hohl; Btstiele kurz; Stb. etwas aus der Bthülle herausragend. J. ......... Coppoleri. Tin. Bleicher L.

Bthüllb. grïnlich, bräunlich o. lebhaft rosenroth...

Bthüllb. lebhaft rosenroth; Stb. länger als die Bthülle. Sïdt. $K r$. J.

Bthüllb. grünlich o. bräunlich; Stb. so lang oder etwas

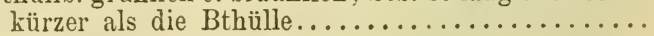

Grundb. flach, ziemlich breit; Stgb. seegrün. J.

fuscum. ITK. Bräunlicher L.

33 Grundb. nur gegen die Spitze zu flach, unten halbstielrund; Stgb. dunkelgrün. J.

longispathum. Red. Langscheidiger L.

\section{LILIUM. L. Lilie.}

Die mittleren B. quirlig; Bt. überhängend; Bthüllb. zurïckgerollt, hell-violett-fleischroth mit purpurbraunen Flecken. Verbr.

Martagon. L. Türkenbund-L.

B. schraubig angeordnet. 
(Bt. aufrecht, glockig-trichterig; Bthüllb. feurig orange, mit braunrothen Strichen und Punkten. Verbr.............bulbiferum. L. Feuer-L. Bt. überhängend; Bthüllb. zurückgerollt, mennigroth o. gelb, mit braunpurpurnen Warzen.

K. Südst. Kr. J. Carniolicum. Bernh. Krainor L.

\section{FRITILLARIA. L. Schachblume.}

B. 4-6, lanzettlich, alle der Bt. genähert; Gr. verkehrt-kegelförmig; N. 3 lappig. Südt.

Velphinensis. Gren. et Godr. Französische S. B. von einander entfernt, vur die obersten oft der

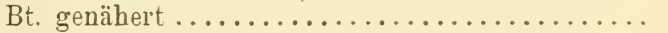

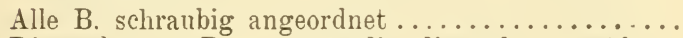

2 Die 2 obersten $B$. gegenständig, die anderen entfernt. Südt. J............tenella. M. B. Zarte S.

Bthüllb. fleischfarben 0 . gelblich, mit schachbrettartiger Zeichnung (selten einfärbig weiß).

3 B. O. St. $K \%$. T. ....Meleagris. L. Gemeine S. Bthüllb. fleischfarben, in der Nitte gelblich-griin, ohne oder mit undeutlicher Zeichnung. $J$.

neglecta. Parl. Einfärbige S.

XIII. TLLIPA. L. Tulpe.

B. lineal-lanzettlich, graıgrün; Bthüllb. zugespitzt, am Grunde gebärtet.

B. MI. Sch. N. O. T. Kr. (meist verw.)

silvestris. $L$. Wilde $\mathrm{T}$.

XIV. ERITHRONICM. L. Schoßwurz.

B. länglich-elliptisch, so wie die Bthüllb. spitz.

B. Südt. K. St. Kr. J.

Dens canis. L. Gemeine S.

\section{LLOYDIA. Salisb. Faltenlilie.}

Grundb. lineal; Stgb. lineal-lanzettlich, viel kürzer; Bt. aufrecht. A. จ. T. S. K. St. $K r$.

serotina. (L.) Salisb. Spätblühende F.

\section{SCILLA. L. Blaustern.}

B. röthlich-violett, im Spätsommer u. Herbst erscheinend; B. mehrere, schmal-lineal, nach der Bt. erscheinend; Btstiele ohne Tragb. J. Südt.

autumnalis. $L$. Herbst-B.

Bt. blau, im Frühling erscheinend; B. zur Btzeit

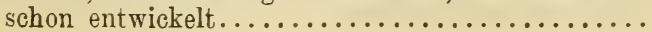


B. 2, selten 3 ; Stg. stielrund; Btstiele meist ohne Tragb., die unteren länger als die Bt. Verbr.

bifolia. L. Gemeiner B.

B. 2-4; Stg. kantig; Btstiele mit kleinen schuppenförmigen Tragb., kürzer als die Bt. Verv.

amoena. $\left.L *^{*}\right)$ Schöner B.

IVII. ORNITHOGALUM. L. Milchstern.

Stf. lanzettlich, einfach $\ldots \ldots \ldots \ldots \ldots \ldots \ldots$.

Sti. blumenblattartig verbreitert, oben 3 zähnig, der mittlere Zahn die A. tragend ............. 10

Btstand eine verlängerte, reichblütige Traube ; Frstiele

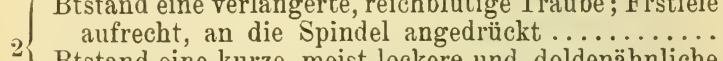

2 Btstand eine kurze, meist lockere und doldenähnliche Traube; Frstiele abstehend o. herabgeschlagen...

Bthüllb. schwefelgelb mit gelbgrünem Rückenstreifen; Frkn. eiförmig, spitz; B. grasgrün, lanzettlichlineal, ziemlich flach. (O.) Sï̈dt. K. Kr.J.

Pyrenaicum. $L$. Schwefelgelber M. Bthüllb. weiß o. grünlich; B. seegrün, lineal-lanzett-

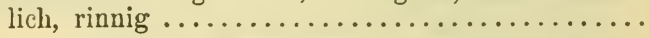

Bthüllb. lineal-länglich, grünlich-weiß; Frkn. kugelig. M. N. O. St. K. Kr. J. Südt.

$4\left\{\begin{array}{l}\text { sphaerocarpum. Kern. Kugelfrüchtiger M. } \\ \text { Bthüllb. keilig-länglich, milchweiß, außen mit grünem }\end{array}\right.$ Rückenstreifen; Frkn. ellipsoidisch ...........

Bttraube oben kegelförmig zugespitzt; Tragb. viel kürzer als die Btstiele. $N$. J.

pyramidale. $L$. Pyramidenförmiger $M$.

5 Bttrambe nach oben allmählig verschmälert; Tragb. kaum kürzer als die Btstiele. J.

Narbonense. L. Dalmatiner M.

B. ohne weißen Mittelstreifen, am Rande gewimpert, zur Btzeit oft schon verwelkt; Bthüllb. länglich, stumpf; Frstand traubig. N. J.

comosum. $L$. Schopfiger M.

B. mit weißem Mittelstreifen, kahl, zur Btzeit noch

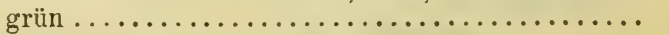

B. aufrecht 0 . nur ihr oberer Theil zurückgekrümmt 8

7 B. abstehend 0. zurückgebogen; Frstiele fast rechtwinklig abstehend; Fr. verkehrt-eiförmig. $J$.

divergens. Bor. Ausgespreizter M.

*) Auch S. Italica L., mit kantigem Stg. und ziemlich langen Tragb. der Btstiele, welche (letztere) länger als die Bt. sind, kommt verw. vor. 
Die unteren Frstiele herabgeschlagen, mit aufgerichteter Fr.; Kanten der Fr. paarweise genähert, fast geflügelt; Zwiebel von zahlreichen kleinen Brutzwiebeln umgeben. $J$.

refractum. Kit. Zurückgebrochener M.

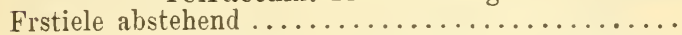

Zwiebel von zahlreichen, beblätterten Brutzwiebeln umgeben; B. dicklich, ziemlich breit lineal; Frstiele fast wagrecht abstehend; Fr. keulenförmig, mit fast gleichweit $\nabla$ on einander entfernten Kanten. Verbr..............umbellatum. L. Garten-M. Zwiebel ohne Brutzwiebeln; B. schmal-lineal; Frstiele aufrecht abstehend ; Fr. verkehrt-eiförmig, mit paarweise genäherten Kanten. B. M. N. O. Kr.J.

Kochii. Parl. Berg-M.

Frkn. eiförmig, an der Spitze tief genabelt, kürzer als der Gr.; Bthüllb. weiß, außen mit breitem, grünem Streifen. B. M. Sch. N. O. K. Sï̈t.

nutans. L. Nickender M.

Frkn. kegelförmig; nicht genabelt, so lang als der Gr.; Bthüllb, auch innen mit grünlichem Streifen. N. O. T.

Boucheanum. (Kth.) Aschers. Bouché's M.

\section{MUSCARI. L. Traubenhyacinthe.}

( Traube dichtblütig, kurz, im Umriss eiförmig o. länglich, oben mit nicht zahlreichen unfruchtbaren Bt.

Traube verlängert, oben an der spitze meist mit einem Schopf zahlreicher, unfruchtbarer Bt.....

Fruchtbare Bt. violettbraun, ohne weißen Rand; Traube eiförmig o. fast kugelig; Bthülle verkehrteiförmig, oben plötzlich verschmälert. $J$.

commutatum. (Ten.) Guss. Verwechselte T. Fruchtbare Bt. heller o. dunkler violettblau (ausnahmsweise weiß), mit weißlichem Rande.......

B. schmal-lineal, dicklich, fast stielrund, oberseits rinnig-gefurcht, zurückgekrümmt; Traube gedrungen, eiförmig. Verbr. (fehlt S.)

racemosum. L. Gemeine T.

B. verbreitert lineal, breit rinnig 0 . fast flach, aufrecht 0 . etwas zurückgekrümmt; Traube zuletzt

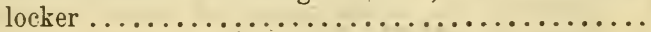

B. ziemlich zahlreich, breit-lineal, schlaff; Bt. fast schwarzblau. N. J.

neglectum. Guss. Uebersehene T.

B. 2-3, nach oben verbreitert, ziemlich steif; Bt. violettblau. Verbr. (oft nur verw.; fehlt Sch.)

botryoides. L. (Mill.) Steifblättrige T. 
Bthülle der fruchtbaren Bt. kurz-glockig, mit citronengelbem Rande; unfruchtbare Bt. manchmal fehlend, meist keinen Schopf bildend. $J$.

5 Calaudrinianum. ( Parl.) Ǩern. Calandrinische T. Bthüllb. der fruchtbaren Bt. walzlich, mit weiblichem 0. schwärzlichem Rande; unfruchtbare Bt.

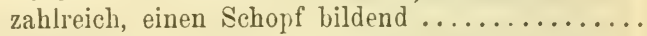

Unfruchtbare Bt. viel kürzer als ibre Stiele; Bthülle del fruchtbaren Bt. mit grünlich-weißem Rande; B. sehr breit. Verbr. (fehlt $S$.)

comosum. (L.) Mill. Schopfige T.

Unfruchtbare Bt. nicht oder, nur etwas kürzer als

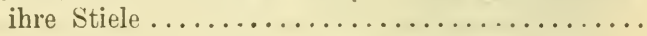

B. ziemlich steif, länger als der ziemlich hohe Stg.; Traube verlängert walzlich. $B . M . N$.

tenuiflorum. Tausch. Schmalblütige T.

B. schlaff, lang zugespitzt, kürzer als der niedrige Stg.; T'raube kegelförmig. $J$.

Holzmanni. (Heldrr.) Boiss. Holzmann's T.

\section{ASPARAGUS. L. Spargel.}

Stg. strauchig, kantig; Zweige flaumig; Phyllocladien lineal-stielrundlich, steif. J. Südt.

acutifolius. L. Strauchiger $\mathrm{Sp}$.

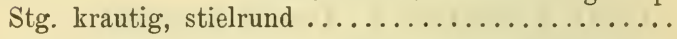

Stf. der männlichen Bt. viel länger als die rundliche A.; Phyllocladien haardünn, sammit den Zweigen ganz kahl. Südt. K. Südst. $K r$. J.

tenuifolius. Lam. Feinblättriger Sp. Stf. der männlichen Bt. so lang als die länglichen A.; Phyllocladien borstenförmig.............

Zweige fein-kantig-gerieft; Phyllocladien gezähnelt$3\left\{\begin{array}{c}\text { rauh. J................ maritimus. (L.) Küsten-Sp. } \\ \text { Zweige u. Phyllocladien kahl u. glatt. Verbr. (auch }\end{array}\right.$ cult.) ...................

\section{RUSCUS. L. Mäusedorn.}

Phyllocladien eiförmig, stachelspitzig, stechend; Bt. 1-2, mit kleinem, häutigem Tragb.

Südt. Südst. $K r$. J. aculeatus. $L$. Stechender MI.

Phyllocladien länglich-lanzettlich, zugespitzt, nicht stechend; Bt. zu mehreren, mit einem krautigen Tragb. $N$. St. $K r$. J.

Hypoglossum. I. Zungen-M.

XXI. MAJANTHEMUM. Wigg. Schattenblume.

B. herzförmig, gestielt. Verbr.

bifolium. (L.) $D C$. Zweiblättrige Sch. 


\section{STREPTOPUS. Michx. Knotenfuß.}

B. herzförmig, umfassend; Bt. weib) Beeren roth. Verbr. amplexifolius. (L.) DC. Europäischer K.

XXIII. POLYGONATUM. Adans. Weißwurz.

B. quirlig; Stg. aufrecht, kantig. Verbr.

1 verticillatum. (L.) All. Quirligblättrige W.

B. wechselständig ..................... 2

B. kurz gestielt, eiförmig, zugespitzt; Stg. kantig;

2 Btstiele flammig. B. N. O. St. $K r$.

2 latifolium. (Jacq.) Desf. Breitblättrige W.

B. umfassend, sitzend; Btstiele kahl........... 3

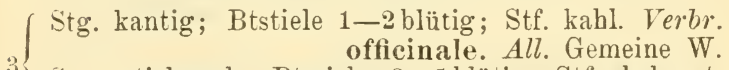

3 Stg. stielrund; Btstiele 3-5 blütig; Stf. behaart. Verbr. ...multiflorum. (L.) All. Vielblütige W.

XXIV. CONVALLARIA. L. Maiglöckchen.

Bt. glockig, überhängend; Beere roth. Verbr: majalis. L. Gemeines M.

XXV. PARIS. L. Einbeere.

B. breit, elliptisch, spitz. Verbr.

quadrifolia. L. Vierblättrige E.

\section{SMILAX. L. Stechwinde.}

Stg. stachelig, kantig; B. stachelig-gezähnt, lederig;

Bt. grünlich. J. $K r$.... aspera. $L$. Gemeine St.

XV. Familie. Amaryllideae. Narcissengewächse.

Ausdauernde Gewächse, meist mit Zwiebeln, selten mit Wst. B. nur grundständig, ungetheilt, lineal und ganzrandig, selten lanzettlich und stachlig gezähnt. Bt, zwittrig. Bthüllb. 6 , frei oder häufiger im unteren Theile verwachsen, ${ }^{*}$ meist blumenkronartig (weiß, gelb oder grünlich) gefärbt. Stb. 6. Frkn. 1, unterständig, 3 fächerig, mit zahlreichen Samenknospen in jedem Fache. Gr. 1, mit ungetheilter o. 3lappiger N. Fr. eine 3 klappige, mehrsamige Kapsel, meist mit etwas fleischiger Außenwand.

\section{Gattungen.}

(Große Pfl. mit dickem Wst.; B. starr u. dickfleischig, blangrün, am Rande stachlig gezähnt; blühender Stg. sehr hoch, verzweigt, mit sehr zahlreichen großen Bt. ............... Agave. V. Zwiebelpflanzen mit ganzrandigen B. ; Stg. 1-3 blütig 0 . am Ende eine Scheindolde tragend ......... 
Bthüllb. im unteren Theile in eine Röhre verwachsen, die 6 Zipfel ausgebreitet; am oberen Ende der

2 Röhre eine glockige oder schüsselförmige Nebenkrone.................. Narcissus. IT.

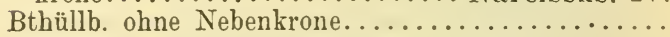

${ }_{3}$ Bthüllb. gelb, am Grund verwachsen, aufrecht.

Bthüllb, frei, weis o theilweise grünlich. Sternbergia. III. Bthüllb. nahezu gleichlang, weiß mit grünlichem 0 .

$4\left\{\begin{array}{l}\text { gelbem Fleck vor der Spitze ..... Leucojum. II. } \\ \text { Die } 3 \text { äußeren Blhüllb. ganz weiß, die } 3 \text { inneren viel }\end{array}\right.$ kürzer, ausgerandet, mit grünem Fleck.

Galanthus. I.

\section{Arten.}

\section{GALANTHUS. L. Schneeglöckchen.}

B. 2 ; Stg. 1 blütig; Bt. überhängend. Verbr. nivalis. $L$. Gemeines $\mathrm{S}$.

\section{LEUCOJUM. L. Knotenblume.}

Stg. 1- (selten 2-) blütig; Gr. keulenförmig; S. blass ; blüht im ersten Frühjahr. Verbr.

vernum. L. Frühlings-K.

Bt. in einer armblütigen Scheindolde; Gr. oben wenig verdickt; S. schwarz; blüht im April u. Mai.

M. N. St. $K r$. J. ....aestivum. L. Sommer-K.

\section{STERNBERGIA. W. $K$. Gewitterblume.}

B. schmal-lineal; Stg. 2 schneidig, 1 blütig; blüht im Herbst. J.......... lutea. (I.) Ker. Gelbe G.

\section{NARCISSUS. L. Narcisse.}

$1\{$ Stg. 1-2-(selten 3-) blütig; Bt. ansehnlich ..... 2

1 Bt. ziemlich klein, in 3-12 blütigen Scheindolden . 6

(Bt. weiß o. schmutzig weiß; Nebenkrone gelb, kurz,

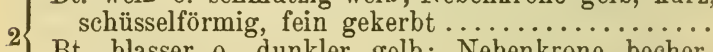

Bt. blasser o. dunkler gelb; Nebenkrone becher-

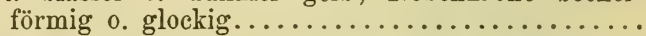

Nebenkrone mit weißlichem Rande; Stg. meist 2 blütig.

3 Südt. Südst......biflorus. Curt. Zweiblütige N. Nebenkrone mit scharlachrothem Rande; Stg. 1 btg. 4 Frkn. während der Btzeit zusammengedrückt-2 schneidig; Nebenkrone in eine flache Schüssel ausgebreitet; Zipfel der Bthülle schneeweiß. Verbr. (doch meist verw.)..... poëticus. $L$. Dichter-N. Frkn. während der Btzeit fast stielrund; Nebenkrone aufrecht, napfförmig; Zipfel der Bthïlle schmutzigweiß. N. O. S. K. St. Kr. J.

radiiflorus. Salisb. Strahlblütige $N$. 
Nebenkrone halb so lang als die blassgelben Zipfel der Bthülle, am Rande kraus; B. ziemlich flach. Südt. $K r$. (sonst cult. und veru.)

incomparabilis. Curt. Unvergleichliche $\mathrm{N}$.

Nebenkrone so lang als die lebhaft gelben Zipfel der Bthiille, am Rande wellig; B. etwas rinnig. Terbr. (doch meist verv.)

Pseudo-Narcissus. L. Gelbe N.

Zipfel der Bthülle weif; Nebenkrone sattgelb; B. etwas rinnig, blaugrün. $J$.

$6\left\{\begin{aligned} & \text { Tazetta. L. } * \text { Z) Zweifarbige } N \text {. } \\ & \text { Zipfel der Bthülle u. Nebenkrone weiß o. fast weiß; }\end{aligned}\right.$ B. flach, ziemlich grasgrün. J.

polyanthus. Lois. Vielblütige $\mathrm{N}$.

V. AGAVE. L. Agave.

B. mit kräftigem Enddorn; Bt. groß, grünlich, sehr selten erscheinend. Cult. u. in Südt. u. J. ver $u$.

Americana. L. Amerikanische A.

XVI. Familie. Dioscoreaceae. Yamswurzgewächse.

Windende, durch Knollen ausdauernde Gewächse. B. schraubig gestellt, ungetheilt und ganzrandig, netznervig. Bt. 2 häusig. Bthüllb. 6, am Grunde verwachsen, kelchartig. Stb. 6. Frkn. 1, unterständig, 3fächerig; in jedem Fache 2 Samenknospen. Gr. 3 spaltig; N. 3, 2 spaltig. Fr. eine armsamige Beere.

\section{Gattung.}

Bthülle der männlichen Bt. radförmig-glockig, größer als die der weiblichen; Beere kugelig, roth.

Tamus. I.

Art.

I. TAMUS $L$. Sclimeerwurz.

B. herzförmig, zugespitzt; Btstäude in den Blattachseln, die männlichen viel länger und reichblütiger. Südt. Südst. Kr.J.

communis. L. Gemeine S.

\section{Familie. Irideae. Schwertelgewächse.}

Ausdauernde Gewächse mit Wst. oder zwiebelähnlichen hnollen. B. lineal oder lanzettlich, oft schwert- oder sichelförmig, stets ungetheilt und ganzrandig, parallelnervig. Bt. zwittrig. Bthüllb. 6, am Grunde verwachsen, stets blumen-

*) N. neglectus Ten. (J.) unterscheidet sich durch den nicht aus der Röhre der Bthülle herausragenden Gr. 
kronartig gefärbt. Stb. 3. Frkn. 1, unterständig, 3 fächerig, selten 1 fächerig, mit zahlreichen Samenknospen. Gr. 3 theilig, oft mit getheilten oder mit blumenblattartigen, großen N. Fr. eine fachspaltig-3 klappige, mehrsamige Kapsel.

\section{Gattungen.}

Bt. unregelmäßig, fast 2 lippig, in einseitswendigen, äbrenförmigen Btständen, heller oder dunkler

1 purpurroth; Knollengewächse.... Gladiolus. VI. Bt. regelmäळig, niemals rein purpurroth; Btstände nicht ährenförmig . . . . . . . . . . . . .

N. blumenblattartig gefärbt, sehr breit und flach; die 3 äußeren Bthüllb. zurückgebogen, die 3 inneren anders gestaltet, aufrecht; Gewächse mit (manchmal

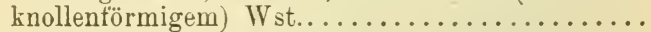

$\mathrm{N}$. nicht blumenblattartig . . . . . . . . . . . .

Grundb. vierkantig, stachelspitzig; Frin. 1 fächerig Hermodactylus. III.

3 Grundb. flach. schwert- oder sichelförmig; Frkn. 3 fächerig.................. Iris. IV.

Bthüllb. am Grunde zu einer sehr verlängerten Röhre verwachsen, ihre Zipfel glockig zusammenschließend; Knollengewächse ohne oberirdischen Stg.

Crocus. I.

4 Bthüllb. am Grunde zu einer kurzen, manchmal fast unmerklichen Röhre verwachsen, ihre Zipfel mehr oder weniger ausgebreitet; oberirdischer Stg. stets vorhanden, wenn auch oft kurz ..............

Stg. verlängert, zweischneidig; Stf. zu einer Röhre verwachsen............. Sisyrinchium. V. Stg. kurz, nicht zweischneidig; Stf. frei. Romulea.II.

Arten.

\section{CROCUS. $L$. Safran.}

N. ungefähr so lang als die Zipfel der Bthülle, herabgebogen; Bt. violett, im Herbst erscheinend. Cult.............. officinalis. (L.) Echter S.

N. viel kürzer als die Zipfel der Bthülle, aufrecht; Bt. im ersten Frühjahr erscheinend ...........

Zipfel der Bthülle helllila o. weiß, die 3 äußeren außen mit 3-5 dunkelvioletten Streifen; Schlund der Bthülle innen mehr oder weniger lebhaft gelb;

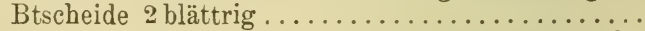

Zipfel der Bthülle heller oder dunkler violett oder weiß, selten und dann nur verschwommen gestreift; Schlund der Bthülle nicht gelb; Btscheide 1 blättrig 
Aeu§ere Häute des Knollens papierartig, glatt, unten quer abgeschnitten; Grundfarbe der Bthülle fast weiß. J.........biflorus. Mill. Zweifärbiger S. Aeußsere Häute des Knollens in netzige Fasern aufgelöst; Grundfarbe der Bthülle blassbläulich-lila. J. variegatus. Hoppe et Hornsch. Gestreifter S. Zipfel der Bthïlle grofs und breit, heller o. dunkler violett (selten weiß); $\mathrm{N}$. über die $\mathrm{A}$. hinausragend. Sch. $M$. . N. T. $K r$. J. vernus. (L.) Frühlings-S. Zipfel der Bthülle ziemlich schmal, weib o. violett, selten gestreift; $N$. die A. nicht überragend. Verbr. (fehlt Sch. $M$. B.) . . albiflorus. Kit. Weißer S.

\section{ROMULEA. Maratti. Fadennarbe.}

B. pfriemlich, gefurcht, zuletzt zurückgekrümmt; Bt. violett o. weißlich, mit gelbem Schlund, im ersten Frühjahr erscheinend. J.

Buibocodium. (L.) Seb. et $M$. Gemeine F.

III. HERMODACTILUS. Adans. Ḱnollenlilie.

Stg. 1 blütig, von den Grundb. weit überragt; Bt. gelblichgrün, die Platte der äußeren Bthüllb. violettbraun. J...tuberosus. (L.) Salisb. Gemeine K.

\section{IRIS. $L$. Schwertlilie.}

Die 3 äußeren Bthüllb. innen mit einem Längs-

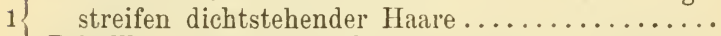

Bthüllb. ohne Haarstreifen................... 12

Btscheiden schon zur Zeit der Blüte ganz häutig.. 3

2 Alle 0. doch die untersten Btscheiden zur Zeit der Blüte wenigstens am Grunde krautig......... 6

Stg. niedrig, kürzer als die Grundb., 1 blütig; Bt. violett oder hellgelb. $M . N$. (sonst verw.)

pumila. L. Niedrige $\mathrm{S}$. Stg. verlängert, länger oder doch so lang als die Grundb., 2 -mehrblütig (selten 1 blütig) ....... 4

Bt. hellblauviolett ................. 5

4 Bt. gelb; Stg. 2 blütig; Grundb. schmal schwertförmig, oft so lang als der Stg. $M$.

arenaria. $W . K$. Sand-S.

Stg. meist 2 blütig, die beiden Bt. meist in fast gleicher Höhe; A. viel kürzer als die Stf. Südt. Cengialti. Ambr. Südtiroler S.

Bt. 2-5, traubig angeordnet; A. so lang als die Stf.; Pfl. höher und kräftiger. Südt. $J$.

Illyrica. Tomm. ${ }^{*}$ ) Illyrische $\mathrm{S}$.

*) Die oft cultivirte I. pallida Lam. ist noch höher und reichblütiger. 


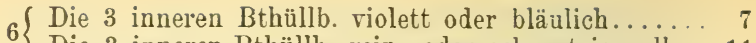

Die 3 inneren Bthüllb. rein- oder schmutzig-gelb .. 11

(Grundb. länger als der Stg.; Btscheiden nur am Rande und an der Spitze trockenhäutig; Bt. violett; Bart der äuœeren Bthüllb. hellviolett. $B$. $\boldsymbol{M}$.

aphylla. L. Armblättrige S. Grundb. kürzer und höchstens so lang als der Stg.; Bart der äußeren Bthüllb. gelb ............ 8

$8\{$ A. so lang als die Stf................ 9

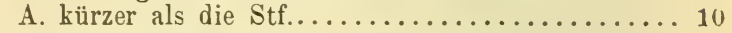

(Stg. die Grundb. weit überragend; Btscheiden am Grunde krautig; innere Bthüllb. hellviolett. Verbr. (doch meist veru.) Germanica. L. Deutsche S.

9 Stg. die Grundb. wenig oder gar nicht überragend; Btscheiden zur Zeit der Blüte mit Ausnahme der untersten ganz häutig; innere Bthüllb. lebhaft purpurviolett. J......Kochii. Kern. Istrianer S.

Innere Bthüllb. lebhaft violett; N. weißlich. Südt.

Benacensis. Kern. Gardasee-S.

Innere Bthüllb. schmutzig-graublau; N. schmutziggelb. B. $\Lambda$. O. Südt. J. (oft nur verw.)

sambucina. $L$. Hollunder-S.

Btscheiden ganz krautig; äußere Bthüllb. gelblichweiß mit violetten Adern, innere rein gelb.:

$11\left\{\begin{array}{l}M . N . O . K . \ldots . \ldots . . . \text { variegata. L. Bunte S. } \\ \text { Btscheiden an der Spitze häutig; äußere Bthüllb. }\end{array}\right.$ violett, innere schmutzig-gelblich. Südt. J.

squalens. L. Schmutzig-gelbe S.

(Stg. 2 schneidig, meist 2 blütig; B lineal; Bt. violett.

12 Verbr. (fehlt $S$.) graminea. I. Grasblättrige S.

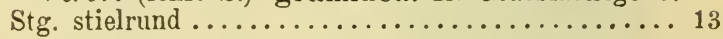

( B. so lang als der mehrblütige Stg., lanzettlichlineal; Bt. gelb. Verbr.

Pseud-Acorus. L. Wasser-S.

B. kürzer als der Stg; Bt. blassviolett......... 14

Stg. röhrig; äußere Bthüllb. mit kurzem, nicht scharf abgesetztem Nagel; Frkn. 3 seitig. Verbr.

Sibirica. L. Sibirische Sch.

Stg. nicht röhrig; äußere Bthüllb. mit langem Nagel und kurzer, rundlicher Platte; Frkn. 6 seitig. N. J................. spuria. L. Bastart-Sch

\section{SISIRINCHIUM. L. Grasschwertel.}

B. grasartig; Bt. 1-4, purpurviolett mit gelben Flecken am Grunde der Bthüllb. $B$. $N$. (eingeschleppt.)

angustifolium. Mill. Schmalblättriges G. 


\section{GLADIOLUS. L. Siegwurz.}

A. länger als die Stf.; seitliche Bthüllb. lineal-keilförmig; Kapsel kugelig, 3 furchig. .J. Südt.

segetum. Ker. Saat-S.

A kürzer als die Stf.; die oberen seitlichen Bthüllb.

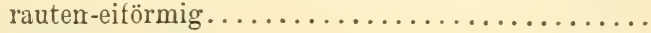

Fasern der Knollenhäute netzig mit rundlichen Maschen; Kapsel länglich-verkehrt-eiförmig, an der Spitze abgerundet. $M . \Lambda . O . S . T . K . K r$.

palustris. Gaud. Sumpf-S.

Fasern der Knollenhäute gleichlaufend mit sehr schmalen Maschen; Kapsel fast 3seitig, an der

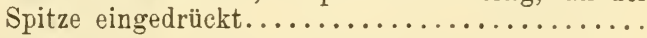

Nzipfel vom Gr. bis zur Mitte lineal u. am Rande kahl, über der Mitte plötzlich in eine rundlicheiförmige, am Rande warzig-gewimperte Platte verbreitert. $K$. $K r$. J.

Illyricus. Koch. Illyrische S. Nzipfel aufwärts allmälig breiter werdend, u. fast

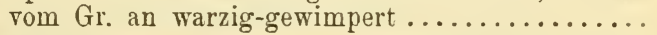

Kanten der Kapsel oberwärts stumpf-gekielt; Nägel der Bthüllb. fast rostbraun. O. St. K. Kr.J. (meist verw.)......communis. L. Siegmarswurz.

4 Kanten der Kapsel überall abgerundet; Bt. genähert, klein, getrocknet bläulich; das unterste Bthüllb. meist stumpf. B. M. Sch.

imbricatus. $L$. Dachige $\mathrm{S}$.

\section{Familie. Orchideae. Knabenkrautgewächse.}

Ausdauernde Gewächse mit Wzknollen oder Wst. B. zweizeilig gestellt, stets ungetheilt und ganzrandig, manchmal nur als häutige Schuppen entwickelt. Bt. zwittrig, unregelmäßig, in verlängerten oder seltener zu Köpfchen verkürzten Aehren oder Trauben, selten einzeln, Bthüllb. 6, meist blumenkronartig gefärbt; eines der 3 inneren von den andern in Gestalt und oft auch Färbung abweichend (Honiglippe), meist nach unten, selten nach oben gewendet. Stb. 1, selten 2, ohne Stf., an die Grsäule angewachsen. Frkn. 1, unterständig, meist gedreht, 1 fächerig, mit zahlreichen Samenknospen, über die Ansatzstelle der Btbülle hinaus zu einer Griffelsäule verlängert, an deren Ende oft ein Nlappen das sogenannte Schnäbelchen bildet. Fr. eine vielsamige, mit Längsspalten aufspringende Kapsel. S. sehr klein, mit unvollkommen entwickeltem Keimling. 


\section{Gattungen.}

(Bt. mit 2 Stb.; Honiglippe bauchig, aufgeblasen; 1 Grsäule 3 spaltig, die seitlichen Lappen die Stb. tragend ................. Cypripedilum. I.

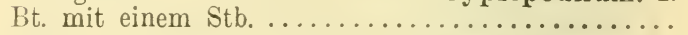

$2\{$ Honiglippe gespornt. (Sporn bisweilen bentelförmig) 2

$3\{$ Honiglippe nach oben gewendet $\ldots \ldots \ldots \ldots \ldots \ldots$

3 Honiglippe nach unten gewendet ............... 5

B. grïn, grasartig; Bt. klein, in eine köptchenartige Aehre dicht zusammengedrängt, karminroth 0 . schwarzpurpurn............. Nigritella. X. An Stelle der B. häutige Schuppen; Bt. groß, wenige, in einer lockeren Traube, bleich weißlich-violett. Epipogon. XVI.

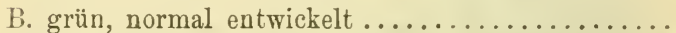

An Stelle der B. violette Schuppen; Bt. grob, violett, in lockerer Traube........... Centrosis. XV.

Afächer gleichlaufend, unterwärts aneinanderliegend mit einem dazwischen geschobenen Fortsatze des

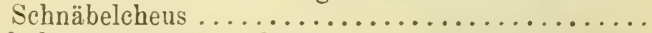

Afächel unterwärts durch eine Bucht der ausgeschnittenen N. von einander getrennt; Schnäbelchen fehlend; Honiglippe lineal, ungetheilt 0 . an

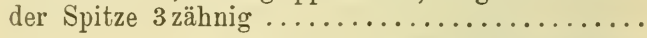

Afächer am Grunde durch ein gemeinschaftliches

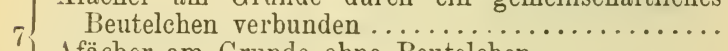
Afächer am Grunde ohne Beutelchen.

Gymnadenia. XI.

( Honiglippe gewunden, 3 theilig, Zipfel lineal, der 8 mittlere sehr lang ....... Himantoglossum. V. Honiglippe nicht gewunden, abstehend.

Honiglippe ohne Leisten; Afächer auf 2 getrennten Klebdrüsen eingefügt............ Orchis. III.

9. Honiglippe am Grunde mit 2 Leisten; Afä.cher auf einer gemeinschaftlichen Klebdrüse eingefügt; Honiglippe am Grunde mit 2 Plättchen.

Anacamptis. VI.

Sporn kurz, beutelförmig; Honiglippe an der Spitze Sporn lang, fädlich; Honiglippe ungetheilt.

Platanthera. XII.

$11\left\{\begin{array}{l}\text { B. normal entwickelt, grün, seltener violett über- } \\ \text { laufen } \ldots \ldots \ldots \ldots \ldots \ldots \ldots \ldots \ldots \ldots \ldots \ldots \ldots \ldots \ldots \ldots \ldots \ldots \ldots\end{array}\right.$

B. sehr kleirl, häutig, schuppenförmig. 
$12\{$ Honiglippe nach unten gewendet (wenn auch oft auf-

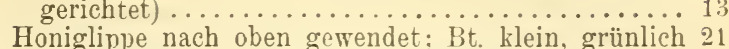

$13\{$ Afächer gestielt; Wzknollen vorhanden......... 14 Afächer nicht gestielt; Wrknollen selten vorhanden 17

( Honiglippe 2 gliederig, an der Spitze 3 lappig, der

14 mittlere Lappen verlängert, knieförmig zurückgebrochen u. herabhängend.......... Serapias. IV. Honiglippe ungegliedert ................

Alle oder doch 5 Bthüllb. helmartig o. glockig zu15 sammenschliefiend .......................... 16

Ophrys. II.

B. schmal-lineal, grasartig; Honiglippe herabhängend, ungetheilt, meist mit 2 Zähnen (daher schwach 3 lappig) ............. Chamaeorchis. VII.

16 B. länglich; Honiglippe 3 spaltig, am Grunde sackartig-vertieft; alle 6 Bthiillb. glockig zusammenschliebend............ Herminium. VIII.

Stg. nur mit 2 gegenständigen (sehr selten 3) B.;

17 Bt. grünlich; Honiglippe herabhängend, 2- 0. mehispaltig............................. IVtera.

B. meist mehr als 2, niemals gegenständig...... 18

Honiglippe ungegliedert, vorn zurückgekrümmt; Bt. klein, weiß

Honiglippe 2 gliedrig, das untere Glied sackartig-

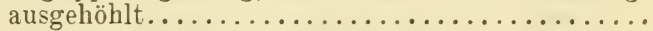

Wzknollen vorhanden; B. parallelnervig; Honiglippe aufrecht, am Grunde rinnig, stumpf.

Spiranthes. XVII.

Wzknollen fehlen; B. netznervig; Honiglippe vorgestreckt, am Grunde sackartig-ausgehöhlt, zugespitzt........................

Frkn. gedreht, sitzend; Honiglippe vorgestreckt, von den anderen zusammenschließenden Bthüllb. verdeckt. .............. Cephalanthera. XIII.

Frkn. nicht gedreht, gestielt, mit gedrehtem Stiel; Honiglippe nicht verdeckt, sowie die anderen Bthüllb. etwas abstehend....... Epipactis. XIV.

Honiglippe zugespitzt; Grsäule kurz, gerade...... 22

21 Honiglippe stumpf; Grsäule nach vorne gekrümmt. Sturmia. XXI.

Meist nur ein B. vorhanden; alle Bthüllb. nahezu $22\left\{\begin{array}{l}\text { von gleicher Länge, } 2 \text { der inneren fast fädlich- } \\ \text { lineal....................... }\end{array}\right.$ B. $2-4$; die 3 inweren Bthüllb. kürzer als die äuseren, 2 der inneren länglich. Malaxis. XXII. 
Wst. korallenartig verzweigt, ohne Wzfasern; Honiglippe weiß mit purpurnen Punkten, seicht 3lappig oder ungetheilt......... Coralliorrhiza. XXIV.

Wzfasern zahlreich, nestartig verflochten; Honiglippe bräunlich, 2 lappig ............ Neottia. XIX.

\section{Arten.}

I. CYPRIPEDILLM. L. Franenschuh.

Wst. stielrund, knotig; B. groß, elliptisch o. eilänglich; Bt. 1-2, groß; Honiglippe schuhförmig, gelb, die übrigen Bthüllb. purpurbraun.

Verbr. (fehlt $J$.).... Calceolus. $L$. Gemeiner F.

\section{OPHRYS. L. Ragwurz.}

(Honiglippe an der Spitze ohne Anhängsel ....... Honiglippe an der Spitze mit einem kahlen Anhängsel, länglich oder rundlich-verkehrt-eiförmig,

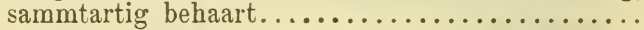

Honiglippe länglich, flach, 3 spaltig, purpurbraun, in der Mitte mit einem graublauen, fast 4 eckigem kahlen Flecke, der mittlere Lappen an der Spitze tief-2spaltig; die 2 anderen inneren Bthüllb. fädlich-zottig und zusammengerollt. Verbr.

(fehlt Sch. M. J.)

myodes. (L.) Fliegentragende R.

Honiglippe verkehrt-eiförmig 0 . fast kreisrund; die

2 anderen inneren Bthüllb. länglich..........

Honiglippe convex, gedunsen, in der Mitte mit 2 bis 4 kablen Linien; die 2 anderen inneren Bthüllb.

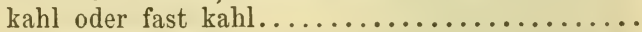
Honiglippe schwarzpurpurn, ziemlich flach, behaart. vor der kurz-3 lappigen, ein wenig aufstrebenden Spitze mit einem fast 4 eckigen bleicheren kahlen Flecke; die 2 anderen inneren Bthüllb, am Rande flaumig. Südt. J. Bertolonii. Mor. Bertoloni's R. Honiglippe länglich-verkehrt-eiförmig, am Grunde höckerig; Honiglippe purpurbraun, später mehr gelblich. N. O. St. Kr. J. T.

aranifera. Huds. ${ }^{*}$ ) Spinnentragende $\mathrm{R}$.

Honiglippe fast kreisrund, seltener elliptisch, am Grunde flach; Honiglippe violettbraun, mit gelblicher Behaarung. $J$.

Tommasinii. Vis. Tommasini's R.

*) O. atrata Lindl (J.) unterscheidet sich durch dunklere, mehr zottige Honiglippe und größere Buckel an deren Grunde. 
(Honiglippe länglich-verkehrt-eiförmig, am Gruude mit 2 langen hornartigen Buckeln, braun, zottig behaart, in der Mitte mit kahlen, gelblichen Linien; die 2 anderen inneren Bthüllb. zottig. $J$.

cornuta. Stev. Gehörnte R.

Honiglippe rundlich-verkehrt-eiförmig, am Grunde mit 2 kleinen Höckern, seltener ohne solche....

Honiglippe ungetheilt, an der Spitze seicht-ausgerandet, purpurbraun mit gelblicher Zeichnung und grünlichgelbem Anhängsel. N. O. St. K. Kr.J. T.

arachnites. (I.) Hummeltragende $\mathrm{R}$.

Honiglippe 3-5lappig, braun mit gelblicher Zeichnung, die 2 seitlichen Lappen kurz, eilänglich, der mittlere zurückgekrümmt. $N$. St. $K . K r$. J. T.

apifera. Huds. Bienentragende $\mathrm{R}$.

Anmerkung. In $N$. wurde 0 . aranifera $X$ myodes und (etwas zweifelhaft) 0 . arachnites $X$ aranifera beobachtet.

\section{ORCHIS. L. Knabenkraut.}

5 Bthüllb. in einen Helm zusammenschließend, frei 0 . verwachsen; Knollen ungespalten ...........

1 Die 2 seitlichen der 3 äußeren Bthüllb. abstehend 0. zurü.ckgebogen, nur das 3. sammt 2 innern in einen

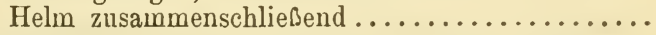

Honiglippe rundlich-eiförmig, gezähnt, ungetheilt; Sporn pfriemlich, hinabsteigend; Deckb. $3-5$ nervig;

2 B. lanzettlich; Bt. purpurn. J. $K r$.

papilionacea. $L$. Schmetterlings-K.

Honiglippe 3 theilig, 3 spaltig 0.3 lappig .........

Honiglippe 3 lappig, Lappen breit, kurz, der mittlere abgestutzt-ausgerandet; Sporn walzlich 0 . fast keulig; Bt. purpurn, oft grün-geadert, auch weiß,

3 violett 0. rosa. Verbr. Morio. L.* ) Gemeines K.

Honiglippe 3 spaltig 0.3 theilig, mit verlängertem 0 . an der Spitze verbreitertem u. 2 spaltigem Mittel-

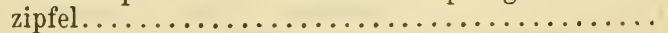

Honiglippe bis zur Hälfte 3 spaltig, der Mittelzipfel länglich, ganz 0 . abgestutzt-ausgerandet; Deckb.

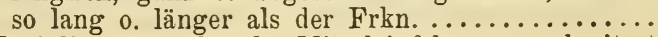

Honiglippe 3 theilig, der Mittelzipfel vorn verbreitert u. 2 spaltig, in der Bucht meist mit einem Zähnchen; Deckb. kürzer als der Frkn...........

*) O. picta Lois. $(J$.$) unterscheidet sich durch kleinere,$ locker stehende Bt. u. dem Frkn. gleichlangen Sporn. 
Honiglippe herabhängend, Zipfel fast gleich, der mittlere länglich, ungetheilt; die anderen Bthüllb. zugespitzt; Sporn kegelförmig; Bt. schmutzig-rothbraun, Honiglippe hellröthlich, purpurn-punktirt, Zipfel grïn mit röthlichem Rande. Terbr.

coriophora. $\left.I .{ }^{*}\right)$ Stinkendes $K$.

Honiglippe gerade vorgestreckt, Zipfel länglich, der mittlere breiter, ausgerandet; die anderen Bthiillb. eiförmig, spatelig-haarspitzig; Sporn fast walzlich : Bt. purpurn, Honiglippe punktirt. Vertr).

globosa. L. Kugelähriges $K$.

(Deckb. halb so lang als der Frkn. o. länger.......

6 Deckb. vielmal kürzer als der Frkn.; 5 Bthüllb. in einen eiförnigen Helm zusammenschließend, am Grunde verwachsen .....................

Aehre fast kugelig; Honiglippe kahl, punktirt; Sporn halb so lang als der Frkn.; Bt. hellpurpurn, Honiglippe purpurn-punktirt. Terbr.

tridentata. Scop.**) Buntes K.

Aehre walzlich-länglich; Honiglippesammtig-punktirt; Sporn 3 mal kürzer als der Frkn.; Bt. schwarzpurpurn, Honiglippe weiß mit satt-purpurnen Flecken. Verbr. ustulata. 1. Brandblïtiges K.

Honiglippe sammtig-punktirt, die seitlichen Zipfel schmal-lineal, einwärts gekrümmt, der mittlere 2 spaltig; Bt. graulich-purpurn, Honiglippe blasspurpurn o. weiblich, dunkler punktirt.

J. Südst. Südt.......... Simia. Lam. Affen-Ǩ. Honiglippe pinselig-punktirt, die seitlichen Zipfel

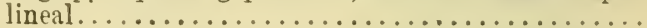

Der mittlere Zipfel der Honiglippe verkehrt-herzförmig; Bt. braun-purpurn, dunkler-punktirt 0 . grünlich und schwarz-purpurn-punktirt, Honiglippe weiß o. blass-rosa, purpurn-punktirt. Terbr. (fehlt Sch. S. K.)

purpurea. Huds. Braumrothes K.

Der mittlere Zipfel der Honiglippe lineal, an der Spitze verbreitert, 2 spaltig; Bt. graulich-rosi, Honiglippe blasspurpurn, in der Mitte weißlich, purpurn-punktirt. Verbr. militaris. L. Helm-K.

*) O. fragrans Poll. (J.) hat hellere, wohlriechende Bt., während 0 . coriophora nach Wanzen riecht.

**) 0. commutata Tod. (Südt. J.) unterscheidet sich durch lockeren Btstand und sehr lang zugespitzte äußere Bthüllb. 
(Deckb. 1nervig, so lang als der Frkn.; Knollen un-

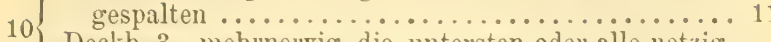

Deckb. 3-mehrnervig, die untersten oder alle netzigaderig ......................... 14

Sporn kegelförmig-walzlich, senkrecht-hinabsteigend, kürzer als der Frkn.; Honiglippe etwas sammtig, Lappen breit, gekerbt, der mittlere ausgerandet; B. länglich-verkehrt-eiförmig, stumpf; Bt. purpurn. A. v. T. S. N......spitzelii. Saut. spitzel's K. Sporn walzlich 0 . fast keulig, wagrecht 0 . aufstrebend, fast so lang als der Frkn.............. 12

Bt. purpurn (sehr selten weiß); Lappen der Honiglippe breit, gezïhnt, am Grunde kurzharig; die anderen Bthüllb. eiförmig-länglich; Aehre locker;

12 B. länglich o. lanzettlich; Bt. purpurn. Terbr. mascula. L. ${ }^{*}$ ) Stattliches K.

Bt. hellgelb; Lappen der Honiglippe gekerbt o. ganzrandig, am Grunde sammtig ..............

B. verkehrt-eiförmig-länglich, stumpf; Aehre eiförmig, dichtblütig; mittlerer Zipfel der Honiglippe größer als die seitlichen. Terbr. (fehlt B.)

pallens. L. Bleiches K.

B. lanzettlich, feill-stachelspitzig; Sporn gekrümmt; Aehre schlaff, armblütig; mittlerer Zipfel der Honiglippe klein. $J$.

pauciflora. Ten. Armblütiges K.

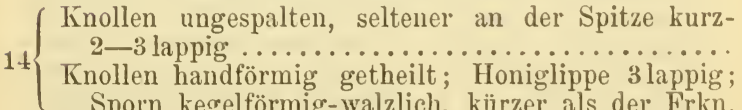
Sporn kegelförmig-walzlich, kürzer als der Frkn. 16

Sporn walzlich, wagrecht 0 . aufstrebend, kürzer als der Frkn.; die 2 seitlichen äußeren Bthüllb. zurückgeschlagen; B. lanzettlich-lineal; Bt. purpurn.

15 Verbr..... laxiflora. Lam. $\left.{ }^{* *}\right)$ Lockerblütiges $\mathrm{K}$. Sporn kegel-walzenförmig, hinabsteigend, so lang als der Frkn.; Bt. blassgelb o. purpurn. Verbr. (fehlt $O$.) sambucina. $L$. Hollunder-K.

*) O. speciosa Host unterscheidet sich durch lang zugespitzte äußere Bthüllb.

**) Bei 0. palustris Jacq. ist der mittlere Zipfel der Honiglippe so lang oder länger als die seitlichen, bei der typischen 0 . laxiflora Lam. kürzer.

Fritsch, Excursionsflora. 
Stg. nicht hohl, meist 10 blättrig, die oberen B. deckblattartig, die mittleren lanzettlich, die untersten länglich; seitliche Bthüllb. abstehend; Bt. hell-lila mit purpurnen Flecken und Strichen; B. oft braun gefleckt. Verbr.

maculata. L. Geflecktes K. Stg. röhrig, 4-6 blättrig; die seitlichen Bthüllb. zuletzt aufwärts-zurückgeschlagen; Bt. purpurn, seltener gelblichwei $\ldots . . \ldots \ldots \ldots \ldots \ldots \ldots \ldots$.

B. abstehend, die unteren oval o. länglich, stumpf, die oberen kleiner, lanzettlich, zugespitzt; untere u. mittlere Deckb. länger als die Bt.; B. meist gefleckt. Verbr..... latifolia. L. Breitblättriges K. B. ziemlich aufrecht, verlängert-lanzettlich 0 . lanzettlich-lineal, meist ungefleckt ............

B. dem Stg. fast parallel, verlängert-lanzettlich, verschmälert, an der Spitze kapuzenförmig zusammengezogen, das oberste über den Grund der Aehre hinaufreichend; Honiglippe ungetheilt. Verbr.

incarnata. $L$. Fleischfarbiges $K$.

Die unteren B. lineal-lanzettlich, etwas abstehend, die oberen lineal, aufrecht, an der Spitze flach, etwas rinnig; Honiglippe 3 lappig. T. S.

angustifolia. Rchb. Schmalblättriges K.

Anmerkung. Von Bastarten wurden im Gebiete beobachtet: 0 . Morio (picta) $\times$ papilionacea, tridentata $X$ ustulata, militaris $X$ Simia, militaris $\times$ purpurea, mascula $X$ pallens, mascula $X$ sambucina, maculata $X$ mascula, incarnata $X$ laxiflora, maculata $X$ sambucina und latifolia $X$ maculata; ferner $(z$. Th. etwas unsicher): Orchis papilionacea $\times$ Serapias Lingua, Orchis papilionacea $\times$ Serapias longipetala, Orchis coriophora (fragrans) $\times$ Serapias longipetala, Coeloglossum viride $X$ Orchis sambucina, Gymnadenia conopea $X$ Orchis maculata und Gymnadenia odoratissima $\times$ Orchis maculata.

\section{SERAPIAS. $L$. Schwertwurz.}

Hinteres Glied der Honiglippe nach innen mit einer einfachen Schwiele, das vordere am Grunde sparsam behaart, länglich-lanzettlich; Bt. blass-röthlich, dunkler gestreift; Schwiele schwarzroth, mit weißem Saume. J. ........ Lingua. L. Zungentragende S. Hinteres Glied der Honiglippe nach innen mit zwei länglichen Plättchen besetzt, das vordere am

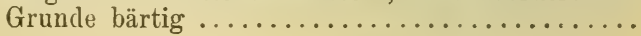


Vorderes Glied der Honiglippe breit-eiförmig oder herzförmig; Bt. ziegelroth mit dunkleren Streifen. $J . . . \ldots \ldots \ldots$ cordigera. L. Herztragende S.

2 Vorderes Glied der Honiglippe lanzettlich 0. länglichlanzettlich; Honiglippe ziegelroth mit dunkleren Seitenlappen. Sü̈t. $K r . J$. longipetala. (Ten.) Poll. Langblütige S.

Anmerkung. Ueber Bastarte zwischen Serapias- und Orchis-Arten vgl. die Anmerkung unter Orchis.

V. HIMANTOGLOSSUM. Spr. Riemenzunge.

Wzknollen rundlich; $B$. länglich-lanzettlich; Bt. weiblich-purpurn und grünlich.

II. N. St. Kr. J. Südt.

hircinum. (L.) Spr. Bocks-R.

VI. ANACAMPTIS. Rich. Hundswurz.

Wzknollen rundlich; B. lineal-lanzettlich; Bt. purpurn. Verbr.

pyramidalis. (L.) Rich. Pyramidenförmige $\mathrm{H}$.

VII. CHAMAEORCHIS. Pich. Zwergstendel. Knollen ungetheilt, länglich; Aehre locker, armblütig; Bt. gelblichgrün. A.

alpina. Rich. Alpen-Z.

VIII. HERMINIUM. $R$. Br. Herminie.

Knollen rundlich; B. 2, länglich; Bt. klein, gelblichgrün. Verbr. (fehlt Sch. M. J.)

Monorchis. $(L)$.$R . Br. Einknollige H.$

IX. Coeloglosum. Hartm. Hohlzunge.

Knollen länglich, ungetheilt 0 . handförmig gespalten;

B. elliptisch, die oberen lanzettlich; Bt. gelblichgrün. Verbr......viride. (L.) Hartm. Grüne H.

Anmerkung. In $N$. wurde ein Bastart zwischen $C$. viride und Orchis sambucina gefunden.

X. NIGRITELLA. Rich. Kohlröschen.

Btstand während des Blühens annähernd kugelig; Bt. schwarzpurpurn; Honiglippe dreieckig mit fast geraden Rändern. A... nigra. (L.) Schwarzes K. Btstand walzlich; Bt. rosenroth; Honiglippe eiförmig mit geschweiften Rändern. $A$.

rubra. (Wettst.) Richt. Rothes $\mathrm{K}$.

Anmerkung. Nigritella nigra bildet mit allen 3 Gymnadenia-Arten Bastarte. 


\section{GYMNADENIA. $R$. Br. Friggagras.}

Knollen bis zum Grunde in spindlige Abschnitte gespalten; Bt. weißlich; 5 Bthüllb. in einen Helm zusammenschließend; Sporn keulig-walzlich, viel kürzer als der Frkn. Geb.

albida. (L.) Rich. Weißliches F.

Knollen handförmig gespalten; nur 3 Bthüllb. zusammenschließend; Sporn fädlich.............

Sporn bedeutend länger als der Frkn.; B. lanzettlich; Bt. hellpurpurn, selten weiß. Verbr. conopea. (L.) R. Br. Gemeines F.

2 Sporn so lang 0. etwas kürzer als der Frkn.; B. lineal-lanzettlich; Bt. hellpurpurn, rosa o. weiß. Verbr. (fehlt B. M. Sch.)

odoratissima. (L.) Rich. Wohlriechendes F.

Anmerkung. G. conopea bildet mit den beiden anderen Arten Bastarte. Vgl. außerdem die Anmerkungen unter Orchis und unter Nigritella.

\section{PLATANTHERA. Rich. Stendelwurz.}

Deckb. so lang o. kürzer als der Frkn........... Deckb. doppelt so lang als der Frkn.; Btstand lang, dicht- und reichblütig; Bt. weiß. Südt.

Carducciana. Goiran. Südtiroler St.

Afächer parallel, genähert; Sporn fädlich; Bt. meist weiß, selten etwas grünlich. Verbbr.

bifolia. (L.) Rchb. Zweiblättrige St.

Afächer ziemlich weit auseinanderstehend; Sporn fädlich, am Ende etwas keulig; Bt. bleich-grünlich. Verbr.... montana. (Schm.) Rchb. Berg-St. XIII. CEPHALANTHERA. Rich. Kopfstendel.

Frkn. flaumig; Bthüllb. zugespitzt; Bt. rosa. Verbr.

Frkn. kahl; Bt. wei Deckb. länger als der Frkn.; B. lanzettlich o. eiförmig; Bt. gelblich-weiß. Verbr.

alba. (Cr.) Simk. Bleicher K.

Deckb. viel kürzer als der Frkn.; B. lanzettlich 0 . lineal-lanzettlich; Bt. schneeweiß mit einem gelblichen Flecke auf der Honiglippe. Verbr.

longifolia. (L.) Fritsch. Langblättriger K. XIV. EPIPACTIS. Rich. Sumpfstendel.

Das vordere Glied der Honiglippe rundlich, stump f; B. lanzettlich; äußere Bthüllb. grall-grünlich, purpurn ïberlaufen; Honiglippe weiß, roth-gestreift. Verbr.......... palustris. (L.) Cr. Gemeiner S. Das vordere Glied der Honiglippe zugespitzt, an der Spitze zurückgekrümmt ................ 
(B. eilanzettlich o. lanzettlich mit kahlen Nerven, kürzer als die Stgglieder; Höcker der Honiglippe faltig-kraus; Bthüllb. grünlich, am Rande röthlich,

2 Honiglippe am Rande weiß. N. O. St. K. Kr.J. microphylla. (Ehrh.) Sw. Kleinblättriger S.

B. eiförmig, seltener lanzettlich, mit flaumig-rauhen

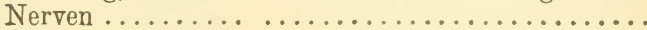

Höcker der Honiglippe glatt; alle Bthüllb. kahl, grünlich, oft purpurn überlaufen, vorderes Glied der Honiglippe lila. Verbr.

latifolia. (L.) $\left.A l l .^{*}\right)$ Breitblättriger S.

Höcker der Honiglippe faltig-kraus; die 3 äußeren Bthüllb. flaumig, schmutzig-violett, o. grün, rostfarben-überlaufen. Terbr.

rubigiuosa. $(C r$.$) Gaud. Braunrother S.$

Anmerkung. Zwischen Cephalanthera alba und Epipactis rubiginosa wurde in $N$. ein Bastart beobachtet.

XV. CENTROSIS. $S w$. Dingel.

Honiglippe eiförmig, wellig; Sporn pfriemlich; die ganze $\mathrm{Pfl}$, violett überlaufen.

S. O. N. St. Kr. J. Südt.

abortiva. (L.) Sw. Violetter D.

XVI. EPIPOGON. Gmel. Widerbart.

Pfl. bleich; Bt. hängend; Sporn fleischroth.

Verbr. (fehlt $K r$.)

aphyllus. (Schm.) Sw. Blattloser W.

XVII. SPIRANTHES. Rich. Drehähre.

Stg. beblättert; B. lanzettlich-lineal; Honiglippe länglich-eiförmig, an der Spitze abgerundet.

N. O. S. T. K. Kr. J.

aestivalis. (Lam.) Rich. Sommer-D.

Stg. blattlos, bescheidet; Grundb. eiförmig 0. eiförmig-länglich; Honiglippe verkehrt-eiförmig, ausgerandet. $V e r \cdot b r$.

spiralis. (L.) C. Koch. Herbst-D.

XVIII. LISTERA. $R$. $B r$. Zweiblatt.

Pfl. kräftig; B. eiförmig; Honiglippe lineal, 2 spaltig. Verbr...ovata. (L.) $R$. Br. Eirundblättriges Z.

Pfl. zart; B. herzförmig; Honiglippe 3 spaltig, der mittlere Zipfel 2 spaltig. Verbr.

cordata. (L.) R. Br. Herzblättriges $\mathrm{Z}$.

*) Bei E. purpurata Sm. sind die B. lanzettlich und oft kürzer als die Stgglieder. 
XIX. NEOTTIA. L. Nestwurz.

Die ganze Pfl. blass braungelb. Verbr.

Nidus avis. (L.) Rich. Blattlose N.

XX. GOODYERA. $R$. Br. Drehling.

Grundb. eiförmig, gestielt; Stg. oberwärts nebst den Bt. behaart. Verbr.

repens. (L.) $R$. $\mathrm{Br}$. Kriechender D.

XXI. STURIIA. Rchb. Zwiebelstendel.

Stg. 3 kantig, am Grunde meist 2 blättrig; B. elliptisch-lanzettlich; Bt. sehr klein, gelbgrün. Verbr. Loeselii. (L.) Richb. Sumpf-Z.

XXII. MALAXIS. Sw. Weichstendel.

B. eilänglich; Stg. 5́seitig; Bt. klein, hellgrün. T. S. O. B. N. St. Kr.

paludosa. (L.) Su. Sumpf-W.

XXIII. MICROSTYLIS. Nutt. Kleingriffel.

B. eilanzettlich; Stg. oben stumpfkantig; Bt. klein, gelbgrün. Verbr. (fehlt J.)

monophylla. (L.) Lindl. Einblättriger K.

XXIV. CORALLIORRHIZA. Hall. Korallenwurz.

Bthüllb. spitz, die unteren herabgebogen; Honiglippe länglich, stumpf, im Mittelfelde mit zwei Schwielen; Bt. grünlich-weiß. Verbr.

innata. $R$. Br. Europäische K.

II. Classe. Dicotyledoneae. Zweikeimblättrige Blütenpflanzen.

Familien.

Bthülle doppelt, d. h. aus $K$. und Blkr. bestehend (der K. besteht manchmal, namentlich bei unterständigem Frkn, nur aus einem kaum merklichen

Rand 0 . kleinen Zähnchen o. Haaren)......... 2 Bthülle einfach 0 . fehlend ......................

Krb. frei (manchmal an der Spitze zusammenhängend

2 o. am Grunde mit den Stf. verwachsen)........ 3 Krb. wenigstens am Grunde miteinander verwachsen 82

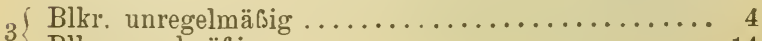

Blkr. regelmäßig ................... 14 
Blkr. schmetterlingsförmig; Stb. 10, 1- o. 2 brüdrig; Griffel 1; K. 5 zähnig 0. 2 lippig; Frkn. 1, frei, mit einem seitenständigen Samenträger; Fr. eine Hülse; B. wechselständig, meist mit Nebenb.

Leguminosae. XXXII.

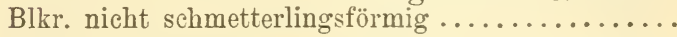

Bäume; K. 5 zähnig; Blkr. 4-5blättrig, unter einer Btscheibe eingefügt; Stb. 7-8, auf der Scheibe eingefügt; Frkn. 3 fächerig; Samen mit einem breiten Nabel am Grunde.

Hippocastaneae. XLVIII.

Kräuter, Stauden 0. Halbstrắucher .............

$6\left\{\begin{array}{l}\text { Stb. } 10 \text { o. } \operatorname{mehr} \ldots \ldots \ldots \ldots \ldots \ldots \ldots \ldots \ldots \ldots \ldots \ldots \ldots \ldots \ldots \\ \text { Stb. } 5-8 \ldots \ldots \ldots \ldots \ldots \ldots \ldots \ldots\end{array}\right.$

In jeder Bt. mehrere o. ein nicht gelappter Frkn.; Stb. zahlreich; K. 5 blättrig, blumenblattartig, die Krb. überragend........ Ranunculaceae. XXI. In jeder Bt. ein 3-6lappiger Frku.; Stb. 10-40; Kb. 4-6, nicht blumenblattartig...........

K. bleibend; Frkn. 1 fächerig, an der Spitze offen, 3-6lappig, mit 3-6 Griffeln; die Samenträger wandständig, mit den Griffeln abwechselnd; Stb. $10-40 \ldots \ldots \ldots \ldots$. . . Resedaceae. XXVII. K. abfällig, 5 theilig; Frkn. 5 fächerig; Samenträger central; Griffel 1; Stb. 10, abwärts-geneigt; Kb. 5; B. mit durchscheinenden Punkten bestreut.

Rutaceae. XXXVII.

Frkn. 5 fächerig; K. $3-5$ blättrig, das oberste Kb. viel gröber und gespornt; Blkr. 3 blättrig (jedes der seitenständigen $\mathrm{Krb}$. eigentlich aus $2 \mathrm{zu}-$ sammengewachsenen Krb. bestehend); Stb. 5, mit verklebten A.; Kapsel 5 klappig, elastisch aufspringend.............. Balsamineae. XLIX.

Frkn. 1-2 fächerig .................. 10

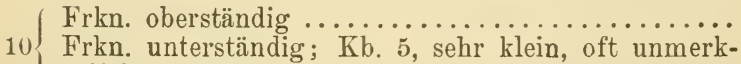
lich; Krb. 5; Gr. 2...... Umbelliferae. LXIX.

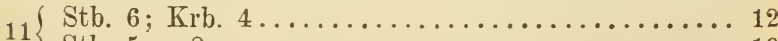

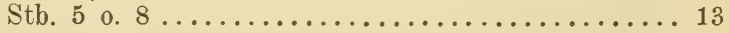

Kb. 2 ; Stb. in 2 Bündel verwachsen; das obere Krb. 12 gespornt; Frkn. 1 fächerig. Papaveraceae. XXIV. Kb. 4; Stb. frei, ungleich lang; Krb. nicht 'gespornt; Frkn. $1-2$ fächerig .......... Cruciferac. XXV. 
Stb. 5 ; A. 2 fächerig, mit 2 Längsspalten aufspringend, an der inneren Seite der Stf., welche an der Spitze in ein häutiges Anhängsel endigen, angewachsen; Kelchblätter am Grunde in ein Anhängsel vorgezogen; Blkr. 5 blättrig, das untere Krb. gespornt; Frkn. 1 fächerig, mit 3 wandständigen Samenträgern ...... Violaceae. LVIII. Stb. 8, am Grunde 1 brüdrig, oberwärts frei 0 . in 2 Bündel verwachsen; A. 1 fächerig, mit einem Loche aufspringend; die 2 inneren $K b$. größer, blumenblattartig; Blkr. 3-5blättrig, an die Stf. angewachsen, das untere Krb. kielförmig; Frkn. 2 fächerig.........P. Polygalaceae. XXXVIII.

Frkn. oberständig, frei o. untereinander, aber nicht $14\left\{\begin{array}{l}\text { seitlich mit dem Btboden verwachsen........... } 15 \\ \text { Frkn. unterständig, d. h. in den ausgehöhlten Bt- } \\ \text { boden eingesenkt und mit demselben verwachsen. } 68\end{array}\right.$

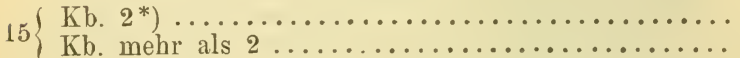

K. 2 blättrig, abfällig; Krb. 4; Stb. zahlreich ; Kapsel schotenförmig 0 . unvollkommen-4-20 fächerig; Kräuter 0. Stauden mit weißem o. gelbem Milchsaft................Papaveraceae. XXIV.

16 K. 2 spaltig, bis zur Fruchtreife bleibend; Krb. 4-6; Frkn. 1 fächerig, mit centralem, freiem Samenträger; Gr. 1, in 3-6 Narben getheilt.

Portulacaceae. XVII.

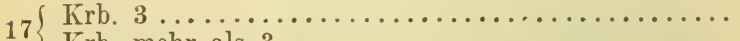

Immergrüner Strauch mit 2 häusigen Bt.; Stb. 3; N. 6-9 strahlig; Steinfrucht 1 fächerig.

Empetraceae. XLI.

$18\{$ Kleine, einjährige Sumpf- und Teichpfl, mit gegenständigen B.; K. 2-3 theilig; Stb. 3 o. 6; Kapsel 3 fächerig, vielsamig.......... Elatineae. LV.

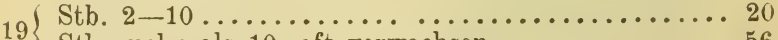

Stb. mehr als 10 , oft verwachsen .......... 56

(Holzgewächse (Sträucher o. Bäume) ............21

20 Kräuter o. Stauden (öfters niedrige Halbsträucher mit verholzten Stämmchen)............. 29

*) Sind die B. gegenständig und der Frkn. 2-3fächerig, so vergl. man die Gattung Elatine. 
Mit Ranken kletternde Sträucher; Bt. klein, grünlich; K. 5 zähnig o. fast ganzrandig; Stb. 5; 21 Frkn. 2 fächerig, mit 2 Samenknospen in jedem Fache; Fr. eine Beere.........Ampelideae. LI. Ranken fehlen; nicht kletternde Holzgewächse.....

B. sehr klein, schuppenförmig; Bt. in kätzchenförmigen Aehren o. Trauben; K. 5 theilig; Krb. 5; Stb. 5 0. 10, oft am Grunde verwachsen; N. 3 lappig, mit o. ohne Gr.; Frkn. 1 fächerig; S. mit Haarschopf............. Tamariscineae. LVI. B. nicht schuppenförmig; S. ohne Haarschopf ..... 23

Krb. 4-5; B. nicht stachlig gezähnt.......... 24 Krb. 6, am Grunde mit 2 Drüsen, gelb; Kb. 6;
Frkn. 1; Gr. 1; Fr. eine längliche, rothe Beere; dorniger Strauch mit stachlig gezähnten B.

Berberideae. XXII.

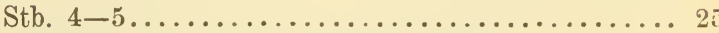

Stb. 8-10, nur ausnahmsweise weniger........ 28

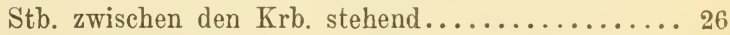

Stb. vor den Krb. stehend; K. 4-5 spaitig, in der Knospenlage klappig, die Zipfel abfällig; B. gegenständig o. schraubig gestellt, ungetheilt.

Rhamnaceae. L.

Frkn. 1 fächerig, mit einer grundständigen Samenknospe; Gr. 3, oft am Grunde verwachsen; Fr. nicht aufspringend, 1 samig.

Anacardiaceae. XLIII.

Frkn. 2-5 fächerig, mit 20 . mehr Samenknospen in jedem Fache; Gr. 1-3; Fr. eine mehrsamige

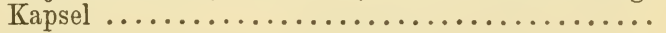

B. ungetheilt; Btstand trugdoldig, blattachselständig; Bt. grünlich 0. röthlich; Gr. 1, kurz, mit 3- bis 5 lappiger N.; S. mit fleischigem Smantel.

B. gefiedert: Btstand traubio endständig; Bt. o. etwas röthlich; Gr. 2-3, verlängert; S. ohne Mantel...................... Xtaphyleaceae. XLVI.

Bäume o. hohe Sträucher mit gegenständigen, meist handförmig gelappten B.; Stb. meist 8; Fr. in 2 geflügelte Theilfrüchtchen zerfallend.

Acerineae. XLVII.

Niedriger Strauch mit schraubig gestellten, ganzrandigen B.; Bt. weiß; Stb. 10 ; Fr. eine 5 fächerige Kapsel ..............Ericaceae. LXXII.

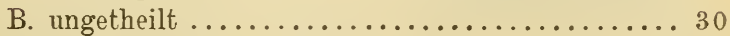

B. verschiedenartig getheilt............. 48 


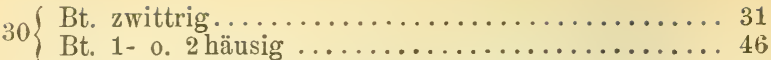

$31\{$ Gr. 1, manchmal mit mehreren N.......... 32

Gr. $2-6$ o. mehrere sitzende N............ 35

( K. röhrig, an der Spitze 8-12 zähnig*); Krb. 4-6;

32 Stb. $6 \ldots \ldots \ldots \ldots \ldots \ldots$. Lythraceae. LXII. K. $4-5$ blättrig $0.4-5$ theilig...............

Stb. 6, ungleich lang, selten weniger, niemals mehr; Kb. u. Krb. 4; Fr. 2 klappig, seltener nicht auf33 springend o.in Glieder zerfallend. Cruciferae. XXV. Stb. 8-10, manchmal nur 5 mit A., 5 ohne A.; Fr. 4-5 klappig aufspringend oder in 5 Theilfrüchtchen zerfallend...................

Kb. 5, stets frei; Krb. 5, meist rosa, purpurn, lila, violett, blau o. braun (nur ausnahmsweise weiß); Stb. 10, am Grunde etwas verwachsen, manchmal 5 ohne A.; Frkn. 5 fächerig, mit 2 Samenknospen in jedem Fach; Fr. in 5 langgeschnäbelte, meist

1 samige Theilfr. zerfallend. Geraniaceae. XXXIII.
Kb. 4-5, oft am Grunde verwachsen; Krb. 4-5, weiß, rosa, grünlich o. bleichgelblich; Stb. 8-10, frei, alle mit A.; Frkn. vollständig o. unvollständig 4-5fächerig, mit zahlreichen Samenknospen in jedem Fache; Fr. 4-5klappig aufspringend................ Pirolaceae. LXXI.

$35\{$ Krb. 4; kleine Pfl. mit gegenständigen B. ...... 36

Krb. 5 ......................... 39

Kb. am Grunde verwachsen ............... 37

36 Kb. 4, ganz frei; Stb. 4 0. 8; Gr. 2-4; Fr. eine vielsamige Kapsel....... Caryophyllaceae. XVIII.

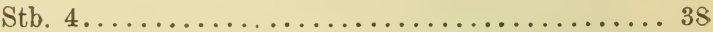

37 Stb. 8 ; K. 4 theilig; Kapsel 4 fächerig, vielsamig; Sumpf- o. Teichpfl. .......... Elatineae. LV.

Stb. am Grunde verwachsen; Frkn. 1; Kb. an der $38\left\{\begin{array}{l}\text { Spitze } 2-3 \text { zähnig ................ Lineae. XXXV. } \\ \text { Stb. frei ; Frkn. 4; Kb. ungetheilt. }\end{array}\right.$

Crassulaceae. XXIX.

K. trichterig-röhrig, 5 zähnig, wenigstens theilweise 39 trockenhäutig, gefaltet; Stb. 5; Gr. 5; alle B. grundständig..........Plumbagineae. LXXIV. K. nicht gefaltet

*) Vergl. die Fußnote auf Seitc 141. 
Stb. 5, am Grunde verwachsen, zwischen ihnen 5 kleine Zähnchen; Gr. 5; Frkn. scheinbar zehnfächerig, mit einer Samenknospe in jedem Fache. Lineae. XXXV.

Stb. frei.

Frkn. 1 .

Frkn. mehrere, in einen Kreis gestellt, frei 0 . am Grund etwas verwachsen; K. 5 theilig 0.5 spaltig; Sth. 5 0. 10; B. meist dick, fleischig.

Crassulaceae. XXIX.

Fr. mit 2 von den bleibenden Gr. gebildeten Schnäbeln, zwischen denselben mit einem Loch aufspringend; Stb. 10 .... Saxifragaceae. XXX. Fr. nicht geschnäbelt, mit mehreren Klappen oder Zähnen oder gar nicht aufspringend.

Caryophyllaceae. XVIII.

Gr. 4 (ausnahmsweise 3 o. 5); Kb. 5; zwischen den 5 Stb. stehen 5 mit langen Drüsenhaaren bewimperte Schuppen; Bt. einzeln, weiø; B. herzförmig.............. Saxifragaceae. XXX. Gr. 3 o. 5 (nul ausnahmsweise 4); keine Schuppen zwischen den Stb.

Samenknospen wandständig; Stb. stets こ; Sumpfpfl. mit nur grundständigen, mit langen röthlichen Drüsenhaaren bekleideten B. o. Wasserpfl. mit wirtelständigen, $\nabla$ on geflügelten Bstielen getragenen B.......... Droseraceae. XXVIII. Samenknospen mittelständig; Stb. 3-10; Kräuter o. Stauden von anderer Beschaffenheit.

Caryophyllaceae. XVIII.

Bt. 1 häusig, nur die männlichen mit Blkr.; Stb. 5 .

B. gegenständig; Stb. meist 10 ; Kb. 5, verwachsen; Krb. 5, stets vorhanden; Frkn. 1.

Caryophyllaceae. XVIII.

B. schraubig gestellt; Stb. meist 8 ; Kb. und Krb. meist 4, letztere manchmal fehlend; Frkn. meist 4.

Crassulaceae. XXIX.

Stb. 6 0. 4, selten 2 (nur ganz ausnahmsweise 5);

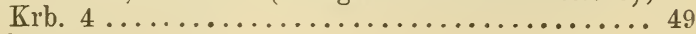

Stb. 8-10, seltener 5; Krb. meist 5, selten $4 \ldots$. 50 
Innerhalb der Blkr. liegen 4 grofe, kapuzenförmige Nectarien; Stb. 4; B. doppelt dreizählig, mit herzförmigen Blättchen ........ Berberideae. XXII. Nectarien sehr klein und unscheinbar o. fehlend; Stb. 6, selten weniger ...... Cruciferae. XXV.

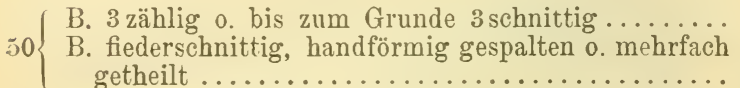

Frkn. 1; kein Außenkelch vorhanden; Fr. auf-

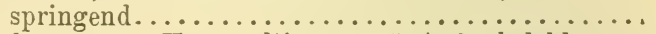

51 Frkn. 5-10; K. 5 spaltig, von 5 Außenkelchb. umgeben; Krb. 5; Fr. nicht aufspringend; Alpenpfl. Rosaceae. XXXI.

Stb. am Grunde etwas verwachsen; Gr. 5; Kb. u. Krb. stets 5; B. denen des Klees ähnlich.

Stb. frei; Gr. 1; Kb. u. Krb. meist 4.

Oxalideae. XXXIV.

Rutaceae. XXXVII.

(Gr. 2; Stb. 10; Fr. mit 2 Schnäbeln, zwischen 53 diesen mit einem Loch aufspringend; Kb. u. Krb. 5.

Saxifragaceae. XXX.

Gr. 1, manchmal sehr kurz; Kb. u. Krb. 3-5 ... 54

Krb. gelb; Stb. frei ................ 55

Krb. 5, verschieden gefärbt, aber nie gelb; Kb. 5;

54 Stb. 10, manchmal 5 ohne A.; Fr. in 5 langgeschnäbelte, meist 1 samige Theilfr. zerfallend.

\section{Geraniaceae. XXXIII.}

B. 2-3 fach fiederschnittig, schraubig gestellt; Bt. in trugdoldigen Btständen; Kb. u. Krb. meist 4; Stb. meist 8; Fr. aufspringend.

Rutaceae. XXXVII.

B. gefiedert, oft gegenständig; Bt. einzeln; Kb. u. Krb. 5; Stb. 10; Fr. nicht aufspringend, in 5 Theilfr. zerfallend....Zygophylleae. XXXVI.

Stf. in eine Röhre 0 . in mehrere Bündel verwachsen

B. ungetheilt u. ganzrandig, gegenständig, seltener wirtelig; A ußenkelch fehlt; Krb. gelb; Stf. am Grunde in $3-5$ Bündel verwachsen... Guttiferae. LIV.

B. schraubig gestellt, oft handförmig gelappt oder gespalten; Außenkelch meist vorhanden; Krb. meist rosa, selten gelb; Stf. in eine Röhre verwachsen. Malvaceae. LIII. 
K. röhrig-verlängert, oben 8-12 zähnig*); Krb. 4-6; Stb. meist 12; Stauden mit gegenständigen oder wirteligen B............. Ly thraceae. LXII. K. nicht röhrig verlängert 0 . nicht $8-12$ zähnig... 59

$59\{$ Krb. 5 o. weniger .................. 60 Krb. 6 o. mehr................... 65

$60\{$ Frkn. 1; Gr. $1 \ldots \ldots \ldots \ldots \ldots \ldots \ldots \ldots \ldots \ldots \ldots \ldots \ldots \ldots \ldots \ldots \ldots$ Frkn. mehrere (nur ganz ausnahmsweise 1) .....6 64

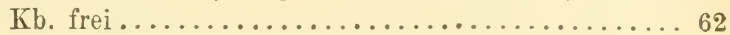

61 Kb. am Grunde verwachsen; Krb. 5; Holzgewächse mit ungetheilten B. und Steinfr.

Rosaceae. XXXI.

( Kb. u. Krb. 4; Frkn. auf verlängertem Träger; Fr. eine Beere; B. ungetheilt, ganzrandig.

Capparideae. XXVI.

Bäume mit gro@en, herzförmig-rundlichen, gesägten, schraubig gestellten B.; Kb. ungefähr gleich; Fr.

63 nicht aufspringend......... Tiliaceae. LII.

Sträucher, Halbsträucher, Stauden o. Kräuter; B. meist gegenständig; die 2 äuberen $K b$. oft kleiner; Fr. eine Kapsel ............ Cistineae. LVII.

$\mathrm{Kb}$. frei; Stb. auf dem kegelförmig erhobenen Btboden eingefügt...... Ranunculaceae. XXI. Kb. am Grunde verwachsen; Stb. am Rande des ausgehöhlten oder scheibenförmig verbreiterten Btbodens (scheinbar am Rande der Kelchröhre) eingefügt. ............... Rosaceae. XXXI.

Frkn. 1, vielfächerig, mit schildförmiger N.; Kb. $4-5$; Krb. zahlreich; Wasserpfl. mit großen,

65 schwimmenden, herzförmigen, ganzrandigen B.

Nymphaeaceae. XIX.

Frkn. mehrere (nur ganz ausnahmsweise 1 einfächeriger) 66

Stb. genau doppelt so viele als Krb., 12-40; Kb.

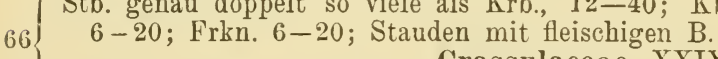

Crassulaceae. XXIX.

Stb. zahlreich, in unbestimmter Zahl............

$\mathrm{Kb}$. frei; Stb. auf den kegelförmig erhobenen Btboden eingefügt....... Ranunculaceae. XXI. Kb. am Grunde verwachsen; Stb. scheinbar am Rande der Kröhre (thatsächlich am Rande des ausgehöhlten 0. scheibenförmig verbreiterten Btbodens) eingefügt ............... Rosaceae. XXXI.

*) Eigentlich ist der Btboden ausgehöhlt und röhrig verlängert; $\mathrm{Kb}$. sind $4-6$ vorhanden, zwischen ihnen ebenso viele Außenkb. 
Stamm fleischig, aus verkehrt-eiförmigen, zusammengedrückten Gliedern bestehend, mit Stachelbü68 scheln besetzt; Bt. schwefelgelb; Stb. zahlreich. Cacteae. LIX.

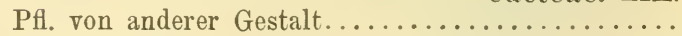

$69\{$ Holzgewächse $\ldots \ldots \ldots \ldots \ldots \ldots \ldots \ldots \ldots \ldots$

(Auf den Aesten der Eichen schmarotzender Strauch; 70 Blkr. 6 blättrig*); Frucht eine einsamige Beere; Blüten 2 häusig.......... Loranthaceae. VIII. Bäume 0 . nicht schmarotzende Sträucher........ 71

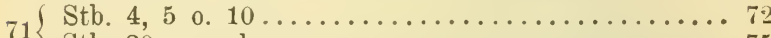

Stb. 20 o. mehr....................... 75

$\int$ B. handförmig gelappt; Kb., Krb. u. Stb. 4-5;

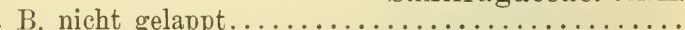
Saxifragaceae. $\mathrm{XXX}$.

Mittels Haftwurzeln kletternder Strauch ; K. 5 zähnig;

73 Krb. 5; Stb. 5 ; Gr. 1, kurz; Beere 5 fächerig.

Nicht letternde Sträucher Araliaceae. LXVIII.

Nicht kletternde Sträucher mit Steinfr......... 7t

Stb. vor den Krb. stehend, 4-5; Kb. u. Krb. 4-5; 74 Gr. $1-4$, am Grunde verwachsen; B. nicht immer Stb. zwischen den Krb. stehend, 4 ; Kb. und Krb. 4 ; Gr. 1; B. stets gegenständig. Cornaceae. LXX.

B. schraubig gestellt, mit Nebenb.; Stb. in der Knospenlage einwärts-gekrümmt, sammt den Krb. 75 einem den Schlund des $K$. umgebenden Ringe eingefügt; Ksaum 5 zähnig o. 5 spaltig; Krb. 5; Frkn. 2-5 fächerig......... Rosaceae. XXXI. B. meist gegenständig, ohne Nebenb. .......... 76

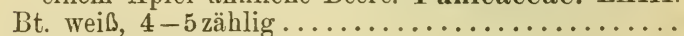

(B. drüsig-punktirt, die Queradern in eine einzige, dem Rande gleichlaufende zusammenfließend; "Kröhre" fast kugelig, Saum 5 theilig; Krb. 5; Beere $2-3$ fächerig..........Myrtaceae. LXIV.

B. ohne Punkte und ohne eine Randader; K. 4- bis 5 spaltig; Krb. 4-5; Gr. meist 4 spaltig; Kapsel meist 4-5 klappig; Bt. weiß. Saxifragaceae. XXX.

*) Eigentlich ist die Bthülle einfach, aber eine Wucherung des Blütenbodens (Scheinkelch) ahmt so täuschend einen K. nach, dass man beim Bestimmen die Pfl. an dieser Stelle suchen wird. 
Gr. fehlt; Narben 4, zottig; Bt. meist 1 häusig; Ksaum 4 theilig; Krb. 4; Stb. $8(0.4)$; Wasserpfl. mit quirligen, haarfein o. borstlich fiedertheiligen B.

Halorrhageae. LXVII.

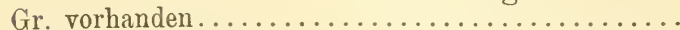

1 Griffel vorhanden, mit kopfiger o. gespaltener Narbe; Stb. 2, 4 0. 8; Ksaum 2-4theilig 0. -spaltig; Krb. 2-4, in der Knospenlage gedreht o. dachig; Frkn. 2-4fächerig, mit centralen

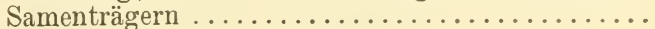

2 Griffel vorhanden; Stb. $5-10 \ldots \ldots \ldots \ldots \ldots .8$ 80

Zwei- o. mehrjährige Landpfl. (selten Wasserpfl.); B. oft gegenständig 0 . quirlig; Stb. 8 o. 2 ; Fr. aufspringend $u$. vielsamig 0 . nicht aufspringend und dann sehr klein, birnförmig, 1-2 fächerig, mit 1 samigen Fächern.... Oenothereae. LXV.

Einjährige Wasserpfl. mit schraubig gestellten, ungetheilten B.; Stb. 4; Fr. groß, gehörnt, nicht aufspringend, 1 fächerig, 1 samig.

\section{Hydrocaryaceae. LXVI.}

Stb. 5; Ksaum unmerklich 0. 5 zähnig; Kronblätter 5 ; Frkn. 2 fächerig, Fächer mit einer Samenknospe; Fr. aus zwei Theilfr. zusammengesetzt, an der Spitze einer 2 spaltigen 0. 2 theiligen Achse

81 hängend; Btstand eine zusammengesetzte o. einfache Dolde............. Umbelliferae. LXIX. Stb. 10 ; K. 5 spaltig 0. 5 theilig; Krb. 5; Kapsel 2 fächerig, 2 schnäbelig, vielsamig.

\section{Saxifragaceae. $\mathrm{XXX}$.}

Frkn. unterständig, d. h. in den ausgehöhlten Bt82 boden eingesenkt und mit demselben verwachsen

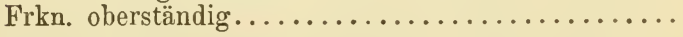
83 92

Bt. in Köpfchen dicht gehäuft, welche von einer mehrblättrigen Hülle umgeben sind; Bt. entweder zungenförmig 0 . mehr 0 . weniger röhrig 0 . trichterförmig; Stb. der Blkrröhre eingefügt ......... 84 Bt. nicht in ein solches von einer gemeinschaftlichen Hülle umgebenes Köpfchen gehäuft ......

Stb. 4, frei; Stf. nicht gegliedert; Narbe einfach; K. zuletzt an den Frkn. angewachsen, von einem Außenk. umgeben; Blkr. 4-5spaltig mit ungleichen Zipfeln............ Dipsaceae. XCV. Stb. 5; Stf. in der Mitte mit einem Gelenke; A. in eine Röhre verwachsen; Griffel mit $2 \mathrm{~N}$.; K. an den Frkn. angewachsen, sein Saum trockenhäutig, haarig (Pappus) o. verschieden gestaltet, o. kurz und kaum bemerkbar. 
$85\left\{\begin{array}{l}\text { Stb. 5, dem Btboden (o. scheinbar dem Kelche) ein- } \\ \text { gefügt. }\end{array}\right.$

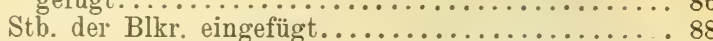

Stb. 8 o. 10; A.gehörnt, an der Spitze mit Löchern aufspringend; kleine Sträucher; Fr. eine Beere.

Ericaceae. LXXII.

Stb. 5 (oft verwachsen); A. der Länge nach aufspringend; Stauden 0. Kräuter.............

Bt. eingeschlechtig; Stb. 5, paarweise o. alle verwachsen; Fr. fleischig; Frkn. 3fächerig, Fächer bisweilen 2 theilig; Samenträger wandständig; Stauden o. Kräuter, meist mit schraubenförmigen Wickelranken.......... Cucurbitaceae. XCVI.

87 Bt. zwitterig; Blkr. regelmäßig, entweder mit linealen Zipfeln, die beim Aufblühen verwachsen sind und sich dann vom Grunde gegen die Spitze zu lösen, 0. glockenförmig 0. radförmig; Griffel 1, mit 2 bis 5 Narben; Kapsel mit Löchern 0. Klappen aufspringend... ..... Campanulaceae. XCVII.

5 fruchtbare und 5 verkümmerte Stb.; Frkn. 1 fächerig, mit centralen Samenträgern und zahlreichen Samenknospen; Kapsel 5 klappig; B. wechselständig.

Primulaceae. LXXIII.

Stb. alle fruchtbar, o. weniger als 10.

B. (scheinbar) zu 4-12 wirtelig; Krand unmerklich o. gezähnt; Blkr. meist 4 spaltig; Stb. meist 4, selten 3 o. 5 ; Frkn. 2 fächerig; Fr. 2 knotig 0 . 3 hörnig............... Rubiaceae. XCI.

B. (manchmal mit Ausnahme der grundständigen) gegenständig (nur ausnahmsweise zu 3 wirtelig) 90

Holzgewächse 0. Stauden; Frucht beeren- o. steinfruchtartig; Frkn. 3-5 fächerig; Stb. 5, 8 o. 10, o. auch 4 zweimächtige; Ksaum 2-3 spaltig 0 .

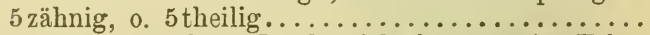

Kräuter 0. Stauden; Frucht nicht beerenartig; Frkn. 1 fächerig 0 . auch $2-3$ fächerig, mit einem einzigen fruchtbaren Fache; Stb. meist 3 o. weniger; Ksaum eingerollt und zuletzt in eine Haarkrone ausgebreitet, o. gezähnt o. unmerklich; Saum der Blkr. 5spaltig, meist ungleich, Röhre am Grunde oft höckerig 0 . gespornt. Valerianaceae. XCIV.

(Zarte Staude mit 3 schnittigen 0 . doppelt 3 schnittigen B.; Bt. grünlich, zu 5-7 am Ende des Stg. gehäuft; K. $2-3$ spaltig; Stb. 8 o. 10.

Adoxaceae. XCIII.

Holzgewächse, selten große Stauden (im letzteren Falle die B. gefiedert); K. 5 zähnig 0.5 theilig; Stb. $4-5$........... Caprifoliaceae. XCII. 


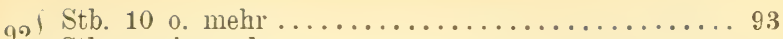

Stb. weniger als $10 \ldots \ldots \ldots \ldots \ldots \ldots \ldots \ldots$.

Frkn. 1, selten $3 \ldots \ldots \ldots \ldots \ldots \ldots \ldots \ldots \ldots . . \ldots$

93 Frkn. 5 0. mehr, in einen Kreis gestellt, frei 0 . am Grunde etwas verwachsen; B. meist dick, fleischig. Crassulaceae. XXIX.

K. 5 blättrig, blumenblattartig gefärbt, gespornt; 94 Blkr. kleiner als der K., gespornt; Fr. eine Balg. kapsel .............. Ranunculaceae. XXI. Weder K. noch Blkr. gespornt............ 95

Stb. 10, alle 0. 9 derselben in eine Röhre verwachsen; Blkr. schmetterlingsförmig; K. 5 zähnig o. 2 lippig; Fr. eine Hülse............eguminosae. XXXII. Stb. frei 0. mit der Blkr. verwachsen......... 96

K. 2 spaltig; Krb. 4-6; Frkn. 1 fächerig; Fr. eine 96 Kapsel..............Portulacaceae. XVII. Kzipfel 0. Kzähne $4-5 \ldots \ldots \ldots \ldots \ldots \ldots \ldots . . .67$

Stb. dem Btboden eingefügt, höchstens ganz unten an die Blkr. angewachsen; Frkn. 2-5 fächerig.

Stb. der Blkrröhre eingefügt; Frkn. 1 fächerig. Ericaceae. LXXII. Primulaceae. LXXIII.

Stb. 6 o. 8, in 2 Bündel 0 . wenigstens am Grunde 98 alle mit einander verwachsen; Bt. unregelmäßig. 99 Stb. frei, selten 8 , noch seltener $6 \ldots \ldots \ldots \ldots \ldots 100$ Kb. 5 , die 2 inneren größer, meist blumenblattartig ("Flügel"); das untere Krb. kahnförmig, an der Spitze mit einem Anhängsel; Stb. 8, in 2 99 Bündel 0. am Grunde alle verwachsen.

Polygalaceae. XXXVIII.

Kb. 2; Blkr. gespornt; Stb. 6, in 2 Bündel verwachsen..............Papaveraceae. XXIV

Frkn. 4, 0. ein Frkn. mit 4 Nähten, der bei der Reife in 4 Nüsse zerfällt; Nüsse vom Kelche eingeschlossen; Griffel 1, in der Mitte der Frkn. ...101 Frkn. 1, bei der Reife nicht in 4 Nüsse zerfallend,

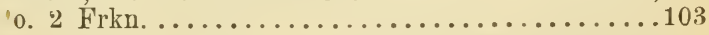

Stb. 4 o. 2 ; B. gegenständig ................... 102

101 Stb. 5, mit den Zipfeln der Blkr. abwechselnd; B. meist schraubig gestellt. Borragineae. LXXXI. Frkn. 4, Nüsse 4; Stb. 4, zweimächtig, o. 2; K. röhrig; Blkr. meist unregelmäßig, rachig 0.2 lippig. Labiatae. LXXXIII.

102 Frkn. 1, 4 fächerig, Frucht in 4 Nüsse zerfallend; Stb. 4, zweimächtig; Blkr. stieltellerförmig, mit 5 lappigem Saume...... Verbenaceae. LXXXII. 


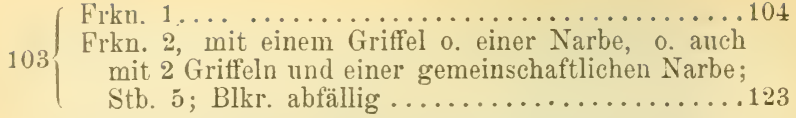

Frkn. 1 fächerig, mit einer Samenknospe........105

104 Frkn. 1 fächerig mit 20 . mehr Samenkwospen, 0. 2 -mehrfächerig ................... 106

K. 5 zähnig, gefaltet, oft oben trockenhäutig; Stb. 5; Blkr. regelmäßig; Griffel 5, 0. 1 mit 5 Narben. Plumbagineae. LXXIT. 105 K. 5spaltig; Stb. 4, zweimächtig; Zipfel der Blkr. ungleich; Gr. 1; Narbe 2 spaltig.

Globulariaceae. LXXXVIII.

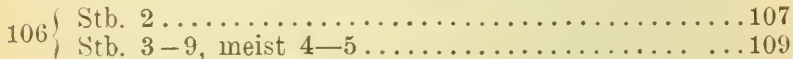

Holzgewächse; K. mit 3-8 Zipfeln o. Zähnen; Blkr. 3-8-theilig 0. -spaltig, regelmäßig; Frkn. 2fächerig, in jedem Fache mit 1-3 Samenknospen.

Kräuter o. Stauden; Blkr. mehr o. weniger unregelmäßig; Frkn. 1-2 fächerig, mit zahlreichen Samen-

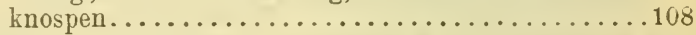

Blkr. gespornt; Frkn. 1 fächerig, mit centralem Samenträger ........... Utriculariaceae. LXXXVI.

108 Blkr. nicht gespornt; Frkn. 2 fächerig, mit an der Scheidewand befestigten Samenträgern.

Scrophulariaceae. LXXXV.

109 S'chmarotzerpfl. ohne grüne B. ..............110

Pflanzen mit normal entwickeltem B...........111

Stg. aufrecht, nicht windend; Btstand ährenartig; Blkr. rachenförmig; Stb. 4, 2 mächtig; Frkn. 1 fächerig, mit wandständigen Samenträgern u. zahlreichen Samenknospen; Gr. 1; Fr. eine unvollständig 2 klappige Kapsel.

Orobanchaceae. LXXXVII.

Stg. dünn, windend; Bt. in Knäulen; Blkr. glockig

o. krugförmig; Stb. 4-5, gleichlang; Frkn. 1-2fächerig, mit wenigen Samenknospen; Gr. 1-2; Fr. eine rundum aufspringende Kapsel.

Convolvulaceae. LXXIX.

K. 2 blättrig 0. 2 spaltig; Blkr. entweder unregelmäßig trichterförmig, auf einer Seite gespalten, 0 .

111 aus 4-6 Krb. bestehend; Stb. 3-5 0. 8-9; Gr. 1; N. $3-8 \ldots \ldots \ldots \ldots$. Portulacaceae. XVII.

Kblätter, Kzipfel 0 . Kzähne 3-9, meist 4-5 ....112 
Blkr. trockenhäutig. meist 4 spaltig, bleibend; Stb. 4; Fr. eine rundum aufspringende Kapsel o. eine Nuss. Plantagineae. XC.

Blkr. nicht trockenhäutig..................... 113

113 Holzgewächse .......................114

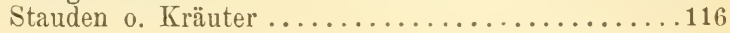

B. 5-7 zählig gefingert, gegenständig; K. 5 zähnig;

114 Blkr. etwas unregelmäbig; Frlin. 4 fächerig; Steinfr. mit 4 Steinen ........ Verbenaceae. LXXXII.

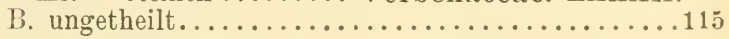

B. breit, lederig, immergrün, dornig gezähnt 0 . doch mit Enddorn; K. krugförmig, 4-6 zähnig; Blkr. radförmig, 4-6 theilig; Stb. u. N. 4-6; Frkn.

$1154-6$ fächerig; Steinfr..... Aquifoliaceae. XLIT. B. nicht dornig gezähnt; Kzipfel o. Kzähne 4-5; Blkr. 4-5-spaltig 0. -zähnig; Stb. 5 o. 8; Kapsel, Steinfr. o. Beere........... Ericaceae. LXXII.

Frkn. 3 fächerig; K. 5 spaltig; Blkr. glockig-radförmig o. stieltellerförmig, 5 spaltig; Stb. 5 ; Gr. 1, N. 3. Polemoniaceae. LXXX.

Frkn. 1-2 fächerig, selten unvollständig 4 fächerig 117

Stb. so viele als Zipfel der Blkr. (4-7) und vor diesen stehend; Frkn. 1 fächerig mit centralem Samenträger ......... Primulaceae. LXXIII. Stb. zwischeu den Zipfeln der Blkr. stehend, so viele o. weniger als diese....................118

Stb. 4, mehr o. weniger deutlich zweimächtig; Blkr. meist unregelmäßig; Frkn. 2fächerig; Fr. eine

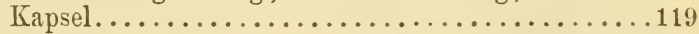

Stb. meist 5, selten $6-90.4$, in letzterem Falle alle gleichlang...............................

Bt. gros, in steifen, dicken Aehren, von großen, steifen, stachelig gezähnten Deckb. gestützt; Grundb. groß, buchtig-fiedertheilig; Stf. dick u. steif; Frkn. mit 4 Samenknospen.

Acanthaceae. LXXXIX.

Deckb. niemals stachelig, wenn auch oft gezähnt; Frkn. neist mit zahlreichen, seltener mit wenigen Samenknospen..... Scrophulariaceae. LXXXY.

Frkn. 1-2 fächerig, mit 4 Samenknospen; Kb. 5; Blkr. trichterig-glockig, 5 faltig; Stb. 5 ; N. 2; Fr. 120 eine Kapsel; Stg. oft windend.

Convolvulaceae. LXXIX.

Frkn. mit zahlreichen Samenknospen ..........121 
B. ungetheilt u. vollkommen o. nahezu gegenständig, seltener dreizählig u. schraubig gestellt; Blkr. meist bleibend, 4-9 spaltig; Stb. 4-9; Frkn. 1-2fächerig; Gr. 2, oft verwachsen; Fr. eine Kapsel. Gentianaceae. LXXVI.

B. schraubig gestellt, niemals dreizählig; Blkr. abfällig, mit 5 Zipfeln; Stb. 5 .................

A. auf das verbreiterte Ende des Stf. quer o. schief angewachsen, 1 fächerig; Blkr. ungleich-radförmig.

Scrophulariaceae. LXXXV.

122 A. an dem spitzigen Ende des Stf. aufliegend, 2 fächerig; Blkr. mit 5 lappigem Saume, in der Knospenlage faltig o. dachig.

Solanaceae. LXXXIV.

123 B. meist schraubig gestellt; Fr. aus 2 zweifächerigen 23 Nüssen bestehend........ Borragineae. LXXXI. B. gegenständig; Fr. aus 2 Balgkapseln bestehend.124

Pollen staubartig o. körnig; Blkr. glockig o. stieltellerförmig, in der Knospenlage schief zusammengedreht; Stf. frei; A. auf der Narbe liegend.

A pocyneae. LXXVII.

124 Pollen in Massen zusammengetlossen, welche den 5 Fortsätzen der Narbe anhängen; Blkr. fast radförmig, in der Knospenlage gedreht o. klappig; Stf. in eine Röhre verwachsen.

Asclepiadeae. LXXVIII.

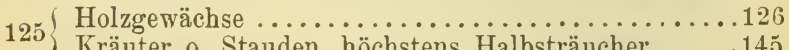

Kräuter o. Stauden, höchstens Halbsträucher .......145

$126\{$ B. ungetheilt 0 . gelappt $\ldots \ldots \ldots \ldots \ldots \ldots \ldots \ldots \ldots \ldots \ldots \ldots \ldots \ldots \ldots \ldots \ldots \ldots \ldots$

B. gefiedert ...............................

Auf Holzgewächsen schmarotzende Sträucher mit gegenständigen, ganzrandigen, manchmal schuppenförmigen B. und gabelspaltigen Zweigen; Bt. 2 häusig; Bthüllb. 2-6, am Grunde oft verwachsen ; Stb. 2-6; Fr. eine Beere. Loranthaceae. VIII. Nicht schmarotzende (selten auf Wurzeln unterirdisch schmarotzende) Sträucher o. Bäume; B.

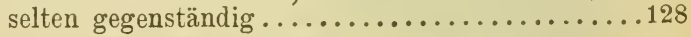

$128\{$ B. ganzrandig, höchstens am Rande wellig ........129

B. gesägt, gezähnt, gekerbt 0 . gelappt...........137

${ }_{129}$ B. halbstielrund, fleischig, o. scheinbar ganz fehlend; Zweige oft gegliedert... Chenopodiaceae. XIII.

B. nicht fleischig, normal entwickelt...........130 
Stb. 2 ; Bt. 2 häusig, in Kätzchen, jede von einem schuppenförmigen Tragb. gestützt, ohne Bthülle, aber mit 1-2 Honigdrüsen am Grunde; Frkn. 1, mit 2 N.; Fr. eine 2 klappige Kapsel; S. mit Haarschopf............... Salicineae. II. Mindestens $3 \mathrm{Stb}$. vorhanden ...................131

Stb. 3; Bt. vielehig-2 häusig; Bthülle 3 spaltig; 131 Frkn. 1, unterständig, mit einem Gr. und 3 N. Santalaceae. IX

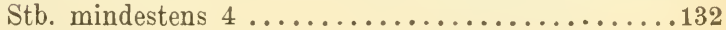

Bt. 1 häusig............................ 133

132 Bt. zwittrig o. 2 häusig; Frkn. 1 fächerig, mit einer Samenknospe............................

Stb. 4-5; Frkn. oberständig ............... 134 Stb. $6-15$, selten weniger; männliche Bt. in verlängerten Kätzchen 0 . in fast kugeligen Büscheln, 133 die weiblichen von einer becherförmigen Hülle umgeben; Bthülle unscheinbar; Frkn. unterständig, 3 fächerig, mit 2 Samenknospen in jedem Fache; N. 3 ................. Fagaceae. IV.

B. wollig behaart o. schülferig; Frkn. 1 fächerig, mit einer Samenknospe. Chenopodiaceae. XIII.

134 B. kahl, glänzend, lederig, immergrün; Frkn. 3 fächerig, mit 2 Samenknospen in jedem Fach.

Buxaceae. XLII.

Bt. zwittrig o. vielehig, mit 8 Stb.; Bthüllb. 4, meist blumenblattartig gefärbt... Thymelaeaceae. LX.

Bt. 2 häusig o. zwittrig, in letzterem Falle mit 4

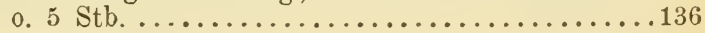

Bt. zwittrig 0. 2 häusig, mit $4-5$ Stb.; B. schülferig; Fr. beeren- 0. steinfruchtartig.

Elaeagnaceae. LXI.

136 Bt. 2 häusig, die männlichen mit 12 Stb., die weiblichen mit 4 verkümmerten Stb.; B. immergrün, lederig, oberseits glänzend, nicht schülferig; Fr. eine Beere...............Lauraceae. XXIII.

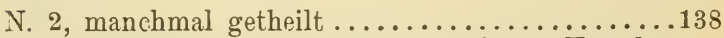

N. 3 o. mehr; Bt. 1 häusig, die männlichen in Kätzchen o. Büscheln, mit $5-8$ theiliger, unscheinbarer Bthülle u. 4-15 Stb., die weiblichen einzeln 0 . zu mehreren von einer becherförmigen Hülle umgeben, mit unterständigem, mehrfächerigem Frkn.; Fr. nicht aufspringend, aber in einem manchmal aufspringenden Becher eingeschlossen. Fagaceae. IV. 
Alle Bt. zwittrig o, neben zwittrigen auch eingeschlechtige vorhanden; Bthülle $4-8$ theilig; Stb.

$13 \varepsilon \quad 4-8$; Frkn. meist 1 fächerig, mit einer Samenknospe; Fr. geflügelt 0 . eine Steinfr.

Ulmaceae. V.

Bt. 1- 0. 2 häusig............................. 139

Frkn. 1-2 fächerig, mit 1-2 Samenknospen ......140

Frkn. 1 fächerig, mit zahlreichen Samenknospen; Bt.

139 2 häusig (nur ausnahmsweise 1 häusig 0. zwittrig), in Kätzchen, jede von einem schuppenförmigen Tragb. gestützt; Fr. eine 2 klappige Kapsel; S. mit Haarschopf ...............Salicineae. II.

Männliche $u$. weibliche Btstände verschieden gestaltet, die ersteren bedeutend größer, meist verlängerte, hängende Kätzchen, die weiblichen Bt. in kleinen Kätzchen 0. zu wenigen beisammen; Fr. niemals fleischig . .............. Betulaceae. III. Alle Btstände untereinander ähnlich, niemals hängend; Bthülle 3-5theilig; Stb. 1-6; Sammelfrucht fleischig ................ Moraceae. VI.

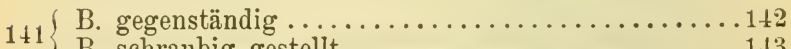

B. schraubig gestellt................. 143

Bäume; Stb. 2; Frkn. 1, 2 fächerig; Fr. geflügelț.

142 Klettersträucher; Stb. zahlreich; Frkn. mehrere, 1 fächerig; Fr. meist vom bleibenden Gr. gesch wänzt. Ranunculaceae. XXI.

Männliche Bt. in hängenden Kätzchen, weibliche einzeln 0. zu 2-3; Stb. zahlreich; N. 2.

Juglandaceae. I.

Bt. in Trauben 0. Rispen; Stb. meist 5; N. 10.3144

Gr. ungetheilt, mit $1 \mathrm{~N}$.; Frkn. mit zahlreichen Samenknospen; Fr. eine Hülse. Leguminosae. XXXII.

144 Gr. 3 theilig, mit 3 N.; Frkn. mit 1 grundständigen Samenknospe; Fr. eine Steinfr.

Anacardiaceae. XLIII.

Auf den Wurzeln der Cistrosen schmarotzende Pfl. von rothgelber Farbe mit schraubig gestellten, schuppenförmigen B.; Bt. 1 häusig; Bthüllb. 4, am Grunde verwachsen; Stb. 8, an eine Mittelsäule angewachsen; Fr. eine vielsamige Beere.

Rafflesiaceae. $X I$.

Nicht schmarotzende, seltener schmarotzende, aber daun grüne Pflanzen ..................... 146 
Wasserpfl. mit wirteligen B. $\left.{ }^{*}\right)$............... 147

146 B. schraubig gestellt 0 . gegenständig*), manchmal scheinbar fehlend ........................ 148

B. gabelspaltig getheilt; Bt. 1 häusig; Bthülle 10- bis 12 spaltig; Stb. 12-16; Frkn. mit 1 Samenknospe.

Ceratophylleae. XX.

147 B. ungetheilt 0 . fiedertheilig; Bt. zwittrig 0.1 häusig; Bthülle 4 spaltig o. röhrig ohne deutliche Zipfel; Stb. 1 o. 8 (selten 4 0.6); Frkn. mit 1-4 Samenknospen ............ Halorrhageae. LXVII.

Frkn. ganz o. doch halb unterständig, d. h. in den ausgehöhlten Btboden eingesenkt und mit demselben verwachsen, höchstens der oberste Theil frei;

148 Bthülle stets vorhanden ................. 149 Frkn. oberständig, zwar manchmal in den ausgehöhlten Btboden eingesenkt, aber nicht mit demselben verwachsen; Bthülle manchmal fehlend ...155

$149\left\{\begin{array}{c}\text { Griffel } 2 ; \text { Fr. entweder } 2 \text { schnäbelig } 0 . \text { aus } 2 \text { Frücht- } \\ \text { chen bestehend } \ldots \ldots \ldots \ldots \ldots \ldots \ldots \ldots \ldots \ldots \ldots \ldots \ldots \ldots \ldots \ldots\end{array}\right.$

Griffel 1, bisweilen 2spaltig, o. mehrere Narben ...151

Kapsel durch die bleibenden Gr. 2schnäbelig, 1 fächerig; K. 4(-5) spaltig mit ungleichen Zipfeln;

150 Stb. 8 (selten 10)....... Saxifragaceae. XXX. Fr. aus 2 Theilfrüchtchen bestehend; Krb. 5; Stb. 5 ; jeder Griffel am Grunde in eine Scheibe verbreitert.............. Umbelliferae. LXIX.

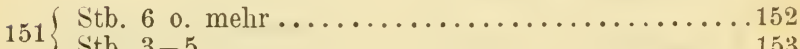

Stb. $3-5 \ldots \ldots \ldots \ldots \ldots \ldots \ldots \ldots \ldots \ldots \ldots \ldots \ldots \ldots \ldots \ldots \ldots \ldots$

Stauden mit herz- o. nierenförmigen B. u. ziemlich großen, zwittrigen Bt.; Bthülle glockig o. röhrig; Stb. 6 o. 12 ; Frkn. u. Kapsel 6 fächerig.

A ristolochiaceae. $\mathrm{X}$.

Einjähriges Kraut mit eiförmigen B. u. unscheinbaren, 1 häusigen Bt.; Frkn. 1 fächerig; Steinfr.

\section{Thelygoneae. XV.}

Stb. frei ..............................

Stb. 5, ihre A. in eine Röhre verwachsen; Griffel

153 mit 2 Narben; Bt. röhrig o. zungenförmig, in ein von einer gemeinschaftlichen Hülle umgebenes Köpfchen gehäuft........Compositae. XCVIII.

*) Hat man eine Landpfl. mit wirteligen B. vor sich so vergl. man die Familie der Rubiaceae. 
B. wechselständig; Stb. 3-5, am Grunde der Bthüllb. eingefügt $u$. vor diesen stehend; Bthülle 3- bis 5 spaltig, teller- o. trichterförmig; Frkn. 1 fächerig; Fr. eine trockene 0 . saftige, von der bleibenden Bthülle bekrönte Steinfr...... Santalaceae. IX. B. gegenständig; Stb. 4; Bthülle 4 theilig; Gr. fädlich; N. kopfig; Kapsel 4 fächerig, 4 klappig, vielsamig. Oenothereae. LXV.

155 Frkn. mehrere 0. 1 Frkn. mit 7 o. mehr Gr.......156 Frkn. 1; Gr. höchstens 5......................

Bt. in verlängerten, reichblütigen Trauben; Bthüllb. 5; Stb. 10-20; Frkn. mit 7-10 Gr.; Beere 7- bis 10 fächerig; hohe Staude mit schraubig gestellten, ganzrandigen B........ Phytolaccaceae. XVI.

Bt. nicht in Trauben...................... 157

Bthüllb. frei; Stb. u. Frkn. auf dem kegelförmig erhobenen Btboden eingefügt.

Ranunculaceae. XXI.

Bthüllb. am Grunde verwachsen, bezw. so wie die Stb. am Rande des ausgehöhlten Btbodens eingefügt; Frkn. in der Aushöhlung des Btbodens eingeschlossen............. Rosaceae. XXXI.

Bthülle glockig, 12 zähnig; Stb. 6 ; Kapsel 2 fächerig, vielsamig; einjähriges Kraut mit gegenständigen, ganzrandigen B........... Lythraceae. LXII. Zipfel o. Zähne der Bthülle, wenn vorhanden, höchstens $6 \ldots \ldots \ldots \ldots \ldots \ldots \ldots \ldots \ldots \ldots$. . . . . . . . .

Zarte Wasserpfl mit 1 (ausnahmsweise 2) Stb.; Gr. 2, pfriemlich; Frkn. 2(-4) fächerig, mit einer Samenknospe in jedem Fach; B. gegenständig.

Callitrichineae. XL.

Landpfl., selten Wasserpfl., dann aber mit mehreren Stb. ............................... 160

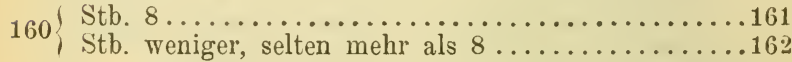
Bthülle röhrig, mit 4 spaltigem Saume; Gr. u. N. 1; B. ohne Nebenbscheide.... Thymelaeaceae. LX. 161 Bthülle tief 5 theilig (seltener $3-4$ theilig); N. $2-3$; B. mit häutigen Nebenbscheiden.

Polygoneae. XII. N. pinselförmig o. wenn kopfig, mit kurzen Fransen besetzt

N. nicht pinselförmig, oft kopfig, aber nicht gefranst ........................

B. gefiedert; Bthülle 4 spaltig; Stb. $4-30$; Fr. 1631 samig, in der Aushöhlung des erhärteten Btbodens eingeschlossen........... Rosaceae. XXXI. B. ungetheilt, höchstens eingeschnitten gezähnt...164 
$164\left\{\begin{array}{l}\text { B. mit häutigen Nebenbscheiden; Stb. 6; N. } 2-3 . \\ \text { Polygoneae. XII. } \\ \text { B. ohne o. mit freien Nebenb.; Stb. } 4-5 ; \text { N. } 1 \text {. } \\ \text { Urticaceae. VIr. }\end{array}\right.$

$165\{$ Frkn. 1 fächerig, mit einer Samenknospe .........166 Frkn. 1-3 fächerig, mit 2 o. mehr Samenknospen..172

B. mit häutigen Nebenbscheiden; Bthülle 5 theilig 166 (seltener $3-4$ theilig); N. 2-3; Fr. nicht aufspringend.................. Polygoneae. XII. B. mit freien Nebenb. 0 . ohne Nebenb...........167

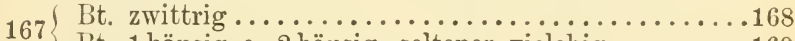
Bt. 1 häusig 0. 2 häusig, seltener vielehig..........169 B. meist mit häutigen Nebenb., wenn nicht, dann gegenständig und pfriemlich-halbstielrund.

Caryophyllaceae. XVIII.

B. ohne Nebenb., meist schraubig gestellt, wenn gegen ständig, dann verkümmert.

Chemopodiaceae. XIII.

Weibliche Bt. einzeln o. häufiger zu 2 von einer mit zahlreichen Hakenborsten bekleideten Hülle eingeschlossen; männliche Bt. in kugeligen Köpfchen, jede mit Tragb.; einjährige Kräuter.

Compositae. XCVIII.

Weibliche Bt. ohne eine solche Hülle............170

Windende Pfl. mit meist gelappten B. o. aufrechtes Kraut mit handförmig getheilten B.; Bt. 2 häusig; Stb. 5; N. 2; Fr. 1 samig....... Moraceae. VI. Pfl. weder windend, noch mit handförmig getheilten B.

Einjährige Kräuter; Bt. 1 häusig 0 . vielehig, in Knäueln, welche oft zu ährenartigen Btständen vereinigt sind; Bthülle 2-5 theilig; Stb. 3 o. 5; N. $2-3 \ldots \ldots \ldots \ldots$ Amarantaceae. XIV.

Kräuter 0 . Stauden mit 1 häusigen, selten 2 häusigen Bt.; die hieher gehörigen einjährigen Kräuter haben entweder 2 häusige Bt., 0. alle 0 . einen Theil der weiblichen Bt. ohne Bthülle.

Chenopodiaceae. XIII.

Bt. 1- o. 2häusig, im ersteren Falle meist eine weibliche Bt. zusammen mit zahlreichen männlichen Bt. von einer gemeinschaftlichen Hülle umgeben; Frkn. 2-3 fächerig, mit 2-3 (selten mehr) Samenknospen..Euphorbiaceae. XXXIX.

Bt. zwittrig........................... 173

B. gegenständig; Bthüllb. $5 \ldots \ldots \ldots \ldots \ldots \ldots \ldots 174$

B. schraubig gestellt; Kb. 4, frei; Stb. $4-6$; Gr. 1.

Cruciferae. XYV. 


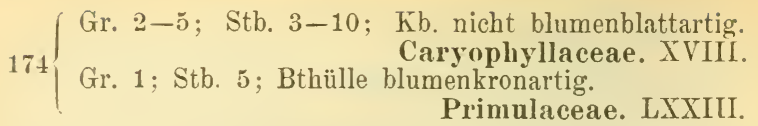

I. Familie. Juglandaceae. Wallnussgewächse.

Bäume mit gefiederten, schraubig gestellten B., ohne Nebenb. Bt. 1 häusig. Männliche Bt. in hängenden Kätzchen, von schuppenförmigen Tragb. gestützt, an welche die 5 bis 6 unscheinbaren Bthüllb. angewachsen sind; Stb. zahlreich. Weibliche Bt. einzeln 0 . $\mathrm{zu} 2-3$, mit 4 theiliger unscheinbarer Bthülle; Frkn. unterständig, mit einer Samenknospe; N. 2. Steinfr. mit hartem, holzigem Stein; S. mit sehr großen, runzelig gefalteten Keimb.

\section{Gattung.}

Männliche Kätzchen an den Seiten, weibliche Bt. an den Spitzen der Zweige .........Juglans. I.

\section{Art.}

I. JUGLANS. I. Nussbaum.

Blättchen meist 9, oval, kahl, etwas gesägt; Fr. kugelig. Cult.......... regia. L. Gemeiner N.

\section{Familie. Salicineae. Weidengewächse.}

Sträucher o. Bäume mit ungetheilten, schraubig gestellten (sehr selten gegenständigen) B., mit (oft abfälligen) Nebenb. Bt. 2 häusig (ausnahmsweise auch 1 häusig), in Kätzchen, von schuppenförmigen Tragb. (Deckschuppen) gestützt. An Stelle der Bthülle ist entweder ein schief abgeschnittener Becher 0 . es sind $1-2$ zahnartige Schuppen (Discusdrüsen) vorhanden. Stb. sehr oft 2 (diese manchmal miteinander verwachsen), häufig aber auch $3-10$ o. zahlreich. Frkn. 1, 1 fächerig, mit zahlreichen Samenknospen. Gr. 1, oft sehr verkürzt; N. 2, oft gespalten. Fr. eine 2klappige Kapsel. S. klein, mit Haarschopf, ohne Nährgewebe.

\section{Gattungen.}

Deckschuppen gespalten 0 . doch gezähnt; Discus becherförmig; Stb. $8-30$ (nur ausnahmsweise 4 bis 7); B. lang gestielt, meist von rundlichem, 0 . breit dreieckigem, 0. rhombischem Umriss.

Populus. I.

Deckschuppen ungetheilt; 1-2 Discusdrüsen, selten ein gelappter Discusring vorhanden; Stb. meist 2, seltener $3-10$; B. meist kurz gestielt, gewöhnlich viel länger als breit............. Salix. II. 


\section{Arten.}

\section{POPULUS. L. Pappel.}

1) Deckschuppen zottig gewimpert; Stb. meist $8 \ldots \ldots$ 2

1 , Deckschuppen kahl 0. fast kahl; Stb. $12-30 \ldots . .3$

B. fast kreisrund, grob gezähnt, kahl, nur die der Stocktriebe behaart; Blattknospen kahl, klebrig; Deckschuppen handförmig gespalten. Verbr.

tremula. L. Zitter-P.

B. rundlich-eiförmig, oft gelappt, unterseits weißfilzig (später nur grau); Blattknospen filzig, nicht klebrig; Deckschuppen ungleich gezähnt 0 . fast ganzrandig. Verbr............. alba. L. Silber-P

${ }_{3}\{$ Junge B. am Rande flaumig.............. 4

B. am Rande stets kahl................. 5

Bstiel von der Seite zusammengedrückt; Aeste schlank, gelblich. Cult.

monilifera. Ait. Rosenkranz-P.

Bstiel stielrund, oberseits rinnig; Aeste kurz und dick. Cult. u. verw. balsamifera. L. Balsam-P.

Baum mit abstehenden Aesten und daher ausgebreiteter Krone; B. 3eckig-eiförmig, am Grunde abgeschnitten. Verbr...... nigra. L. Schwarz-P.

Schlanker Baum mit aufgerichteten Aesten; B. rautenförmig-3 eckig. Cult. (Alleebaum).

pyramidalis. Roz. Pyramiden-P.

Anmerkung. Zwischen P. alba und P. tremula kommt ein Bastart vor.

\section{SALIX. $L$. Weide.}

Kätzchen endständig; kleine Alpensträucher mit am Boden niedergestrecktem Stamme und aufstrebenden

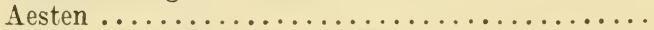

Kätzchen seitenständig . . . . . . . . . . . . . .

Kapsel eiförmig, filzig; B. lang gestielt, elliptischkreisrund, am Rande zurückgerollt, oberseits runzelig, unterseits seegrün, netzaderig, zuletzt kahl. A.........reticulata. L. Netzaderige W. Kapsel eiförmig-kegelförmig, kahl; B. kurz gestielt 0 . fast sitzend, beiderseits grasgrün ..........

B. verkehrt-eiförmig 0 . länglich-keilig, gleichlaufendaderig, ganzrandig 0 . am Grunde drüsig-gezähnelt. A......... retusa. $\left.L .^{*}\right)$ Gestutztblättrige $W$.

B. kreisrund o. oval, netzaderig, gesägt, beiderseits glänzend. Geb........herbacea. L. Krautige W.

*) S. serpyllifolia Scop. hat sehr kleine, verkehrteiförmige $B$. und sehr armblütige Kätzchen. 
Deckschuppen gleichfarbig, gelblich o. grün; Kätzchen am Ende kurzer beblätterter Seitenzweige; Stb. am Grunde ein wenig zusammenhängend und

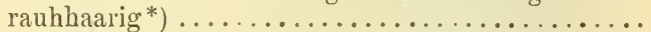

Deckschuppen an der Spitze anders gefärbt als am

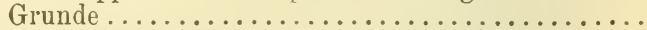

B. beiderseits 0 . doch unterseits seidenhaarig**), lanzettlich, zugespitzt; Nebenb. lanzettlich; Stb. 2; männliche Bt. mit 2 Discusdrüsen, weibliche nur mit 1; Frkn. fast sitzend; Gr. fast fehlend.

Verbr. $\iota . h f g \ldots \ldots \ldots \ldots \ldots$ alba. $L$. Silber-W.

B. beiderseits kahl o. nur in der Jugend seidenhaarig**), Frkn. ziemlich lang gestielt........

Stb. 3; Gr. fast fellend, N. wagrecht abstehend; Discusdrüsen in der männlichen Bt. 2, in der weiblichen 1; Deckschuppen der weiblichen Bt. nicht abfällig; B. lanzettlich 0 . länglich. Terbr.

triandra. L. Mandel- $\Pi$.

Stb. 2 0. 5-10 (nur ganz ausnahmsweise $3-4$ ); Gr. deutlich entwickelt, wenn auch oft kurz....

Discusdrüsen 2 (in beiderlei Bt.); Gr. kurz; Deckschuppen der weiblichen Bt. vor der Frreife ab-

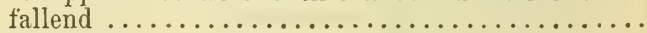

In beiderlei Bt. nur eine Discusdrüse; Stb. 2; Gr. verlängert; Deckschuppen der weiblichen Bt. bieibend; B. elliptisch 0 . verkehrt-eiförmig, oberseits glänzend grün, unterseits hechtgrau bereift; niedriger Strauch. A. u. Vora.

glabra. Scop. Glänzende W.

Stb. 2 (ausnahmsweise 3-5); B. lanzettlich 0 . länglich-lanzettlich, ohne o. mit 2 Drüsen am Blattstiel; Aeste sehr brüchig. Verbr. $8\left\{\begin{array}{l}\text { fragilis. } L \text {. Bruch-W. } \\ \text { Stb. } 5-10 \text {; B. eiförmig o. elliptisch, mit mehreren }\end{array}\right.$ Drüsen am Blattstiel; Aeste wenig brüchig. Verbr. (fehlt St. $K r \cdot J$.

pentandra. L. Lorbeer-W.

*) Bei S. incana Schrk., deren Deckschuppen auch oft gleichfarbig sind, sind die B. unterseits graufilzig.

**) In diese Artengruppe gehört anch die durch aünne hängende Zweige ausgezeichnete, namentlich auf Gräbern oft cultivirte Trauerueide (S. Babylonica L.). 
Die beiden Stb. sind vollständig miteinander verwachsen, so dass scheinbar nur 1 Stb. vorhanden ist; A. anfangs purpurn; Frkn. oval, stumpf, filzig, sitzend; N. kopfförmig, fast sitzend; B. verkehrtlanzettlich, kahl, unterseits bläulich bereift, nicht selten gegenständig. Verbr. $\iota$. $h f g$.

purpurea. L. Purpur-IV.

Die beiden Stb. sind wenigstens an der Spitze vollständig von einander getrennt; Frkn. entweder kahl o. gestielt, o. nach oben kegelig verschmälert; B. höchst selten u. nur ausnahmsweise gegen-

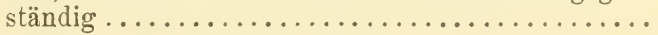

Kätzchen schlank u. dünn, mehr o. minder bogenförmig gekrümmt, vor dem Aufblühen nicht weißlich-zottig; Stb. am Grunde verbunden; Frkn. kahl, gestielt; Gr. verlängert, mit abstehenden N.; B. lineal-lanzettlich, unterseits graufilzig.

Verbr. (fehlt B.)...... incana. Schrl. Ufer-W. Kätzchen nicht sehr dünn, vor dem Aufblühen oft weißlich-zottig; Stb. frei; Frkn. bei den Arten mit unterseits dauernd filzigen B. stets filzig....

B. schon zur Blütezeit fast kahl o. doch nur spärlich

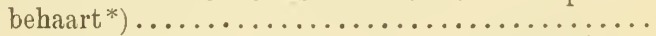

11 B. zur Blütezeit unterseits dicht seidenhaarig 0. filzig, später bei manchen Arten nur wenig be-

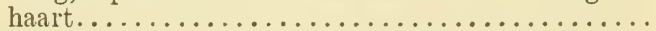

Kleiner Baum, seltener Strauch mit meist hechtgrau bereiften Zweigen; B. länglich-lanzettlich, zugespitzt, glänzend, zur Blütezeit noch ganz unentwickelt; Kätzchen sehr grof, dick walzlich, sitzend, vor dem Aufblühen dicht weif-zottig; Frkn. kahl, sitzend; Gr. verlängert, mit abstehenden N. Verbr.......daphnoides. Vill. Seidelbast-W. Sträucher, meist von niedrigem Wuchse; Zweige nicht bereift; B. zur Blütezeit meist schon sichtbar; Kätzchen nicht auffallend groß, oft gestielt 13

Deckschuppen sehr zottig, Zotten lang, gekräuselt, glänzend weil; Frkn. u. Stf. kahl; B. eiförmigelliptisch o. lanzettlich, klein gesägt; Nebenb. 13 halbherzförmig mit gerader Spitze. M. S. T. K. hastata. $L$. Spießblättrige W. Deckschuppen kahl o. zottig-haarig, die Haare jedoch nicht gekräuselt ....................

*) Man untersuche, wenn die B. noch nicht entfaltet sind, die Blattknospen. 
(B. beiderseits glänzend grün; Kätzchen auf langen,

B. entweder beiderseits oder doch unterseits matt, oft seegrün 0 . bläulich .................

$\int_{15} \begin{array}{r}\text { B. am Rande fein-drüsig gesägt. } A . \text { v. T. } S . K . \\ \text { Myrsinites. } L . \text { Myrsinen-W. }\end{array}$

$15)$ B. ganzrandig. $A$.

Jacquiniana. Willd. Jacquin's W.

B. beiderseits glanzlos, blaugrün, ganzrandig; Stf. meist theilweise verwachsen; A. purpurn, später gelb, zuletzt schwärzlich; Frkn. filzig; Kätzchen klein, auf kurzen beblätterten Stielen. $A$. v. T.

caesia. Vill. Hechtblaue W.

B. oberseits heller oder dunkler grün, meist glänzend, unterseits blasser, bläulich o. seegrün .....

A. zuerst purpurn, dann gelb, zuletzt schwärzlich; Frkn. kahl, gestielt; Gr. sehr kurz; die männlichen Kätzchen sitzend, eiförmig, die weiblichen auf ziemlich langen, beblätterten Stielen, locker, armblütig; niedriger Strauch mit elliptischen 0 . ovalen, ganzrandigen B. B. T. $K$.

myrtilloides. $L$. Heidelbeer- W.

A. immer gelb, höchstens vor dem Aufblühen röthlich; Frkn. ineist filzig (wenn kahl, dann der Gr.

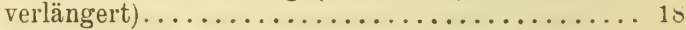

Niedrige Gebirgssträucher mit filzigem Frkn.*) .... 19

Ziemlich hohe Sträucher mit kahlem Frkn.*); B. in der Gestalt veränderlich, in der Jugend meist unterseits flaumig; Kätzchen klein, die männlichen hellgelb, die weiblichen trübgrün; Gr. verlängert. Verbr. (fehlt B. M. J.)

nigricans. Sm. Schwärzliche IT.

Kätzchen an der Spitze kurzer beblätterter Seitenzweige, nicht vor Juni blühend; Frkn. fast sitzend. $A . \ldots \ldots \ldots \ldots$ arbuscula. L. Bäumchen-W. Kätzchen auf kurzen, klein beblätterten Stielen, im Mai blühend; Frkn. ziemlich lang gestielt. $B$.

phylicifolia. $L$. Zweifarbige $\mathrm{W}$.

Selır niedrige Sträucher, theils auf den Gebirgen,

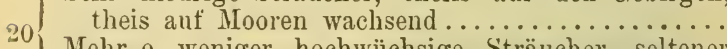

Mehr o. weniger hochwüchsige sträucher, seltener

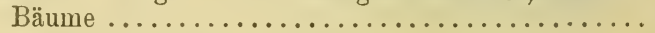

*) Ein niedriger Gebirgsstrauch mit kahlem Frkn. ist s. Daphneola Tausch (Sud.), welche sich von der nahe rerwandten S. Lapponum L. durch kahle B. und Frkn. unterscheidet. - Von s. nigricans Sm. kommt selten eine Form init behaartem Frkn. vor. 
A. purpurn, dann gelb, zuletzt schwärzlich; Stiel des Frkn. mindestens doppelt so lang als die Discusdrüse; B. unterseits seidenharig, zuletzt manchmal kahl, in der Gestalt veränderlich, doch meist schmal; Kätzchen sehr klein, eiförmig 0 . fast kugelig. Verbr. rosmarinifolia. L. Moor-W.

A. gelb, höchstens vor dem Aufblühen röthlich; Stiel des Frkn. kürzer als die Discusdrüse ......

B. drüsig gezähnt, elliptisch, unterseits weißfilzig; Kätzchen fast sitzend; Gr. verlängert. A. v. T. S. K. St. Helvetica. Vill. Schweizer W. B. ganzrandig, höchstens am Rande wellig.......

Die jüngeren B. seidig-zottig, die älteren oberseits runzlig, unterseits filzig, glanzlos, alle kurz zugespitzt; Nebenb. halbherzförmig, an der Spitze zurückgekrümmt; Kätzchen fast sitzend. Sud.

Lapponum. L. Lappländische IV.

Die jüngeren B. unterseits grau, beiderseits seidigzottig, die älteren zuletzt kahl werdend, spitz, die untersten ganz stumpf; Nebenb. eiförmig, spitz, gerade; Kätzchen lang gestielt. $A$. v. T. $K$.

glauca. $L$. Seegrüne IV.

B. 'lineal-lanzettlich, nahezu ganzrandig, unterseits seidenharig und dadurch silbern schimmernd; Frkn. filzig, sitzend; Gr. verlängert, mit zurückgebogenen N. Verbr. . . . viminalis. $L$. Korb-W. B. breit, elliptisch, eiförmig, verkehrteiförmig 0 . fast kreisrund; Frkn. lang gestielt; Gr. kurz o. fast

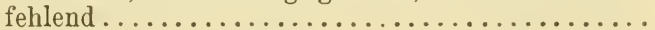

Die jungen Zweige und die Blattknospen sind dicht sammtig-filzig; B. elliptisch o. verkehrteiförmig, meist gegen den Grund lang verschmälert, oberseits dünnflaumig, unterseits filzig; Frkn. filzig; N. fast sitzend. Verbr. ... cinerea. L. Graue W. Die jüngeren Zweige und die Blattknospen sind kahl

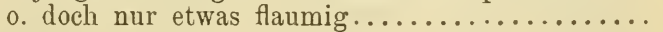

Kätzchen ansehnlich, sitzend, die männlichen dick, eiförmig 0 . fast cylindrisch, die weiblichen cylindrisch ; B. eirundlich 0 . breit elliptisch, oberseits zuletzt kahl, unterseits filzig; Nebenb. kürzer als der Bstiel; Wuchs oft baumartig. Verbr. $u$. $h f^{\prime} g$.

Caprea. L. Sahl-W. Kätzchen ziemlich klein, öfters kurz gestielt; Nebenb. grof, meist länger als der Bstiel; Wuchs nie baum-

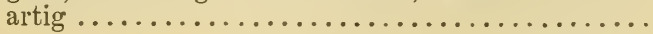


(B. klein, runzelig, unterseits filzig; Frkn. filzig; N. 27 fast sitzend. Verbr. ........ aurita. L. Ohr-W. B. im ausgebildeten Zustande unterseits dünn-flaumig o. fast kahl; Gr. kurz, aber dentlich entwickelt..

B. länglich-verkehrteiförmig, undeutlich gesägt, zuletzt unterseits bläulich, dünn flaumig; Frkn. filzig, sein Stiel meist 5-6 mal so lang als die Discusdrüse. Verbr. (fehlt $B$. MI. Sch.)

grandifolia. Sér. Großblättrige W.

B. verkehrteiförmig, wellig gesägt, zuletzt fast kahl, beiderseits fast gleichfarbig; Frkn. kahl o. seidenhaarig, sein Stiel meist 3-4mal länger als die Discusdrüse. B. M. Sch.

Silesiaca. Willd. Schlesische W.

A n m e r k ung. Die Weidell neigen auferordentlich zur Bastartirung; es gibt daher zwischen den meisten Arten Bastarte. In der Regel kommen aber die Bastarte nur vereinzelt und selten vor, so dass der Anfänger, welchem die häufig vorkommenden Arten noch nicht bekannt sind, schwerlich einen Bastart finden wird. Im Gebiete wurden beobachtet: S. arbuscula $X$ reticulata, glabra $X$ retusa, hastata $X$ retusa, Jacquiniana $X$ retusa, Helvetica $\times$ retusa, glauca $X$ retusa, alba $\times$ triandra, alba $X$ fragilis, alba $X$ pentandra, fragilis $X$ triandra, triandra $X$ viminalis, glabra $X$ hastata, glabra $X$ nigricans, fragilis $X$ pentandra, incana $X$ purpurea, daphnoides $X$ purpurea, nigricans $X$ purpurea, purpurea $X$ rosmarinifolia, purpurea $X$ viminalis, cinerea $X$ purpurea, Caprea $X$ purpurea, aurita $X$ purpurea, grandifolia $\times$ purpurea, purpurea $\times$ Silesiaca, daphnoides $X$ incana, incana $X$ viminalis, cinerea $X$ incana, Caprea $X$ incana, aurita $X$ incana, grandifolia $X$ incana, daphnoides $X$ viminalis, Caprea $X$ daphnoides, hastata $X$ nigricans, hastata $X$ Helvetica, hastata $X$ Silesiaca, arbuscula $\times$ caesia, aurita $\times$ myrtilloides, cinerea $\times$ nigricans, arbuscula $\times$ Helvetica, arbusculi $X$ grandifolia, rosmarinifolia $X$ viminalis, aurita $X$ rosmarinifolia, Lapponum $X$ Silesiaca, cinerea $X$ viminalis, Caprea $X$ viminalis, Caprea $X$ cinerea, aurita $X$ cinerea, cinerea $X$ grandifolia, aurita $X$ Caprea, Caprea $\times$ grandifolia, Caprea $\times$ Silesiaca, aurita $\times$ Silesiaca. - Höchst wahrscheinlich kommen auch Tripel-Bastarte vor; wenigstens S. Caprea $X$ cinerea $X$ viminalis und $S$. aurita $X$ Caprea $X$ Silesiaca sind kaum zweifelhaft. 


\section{Familie. Betulaceae. Birkengewächse.}

Bäume o. Sträucher mit ungetheilten (nur bei abnormen Formen zerschlitzten o.gelappten), aber niemals ganzrandigen, schraubig gestellten B., mit abfälligen Nebenb. Bt. einhäusig. Männliche Bt. in meist hängenden Kätzchen, einzeln o. zu 3 von Deckschuppen gestützt, ohne o. mit unscheinbarer 1-5 blättriger Bthülle; Stb. 2-12, oft 2 theilig. Weibliche Bt. entweder in kleinen Kätzchen o. zu wenigen einen knospenförmigen Btstand bildend, zu 2-3 von Deckschuppen gestützt, ohne 0. mit unscheinbarer Bthülle; Frkn. 1, bei Vorhandensein einer Bthülle unterständig, am Grunde 2 fächerig, mit 2 Samenknospen u. 2 Gr. Fr. 1 samig, nicht aufspringend, manchmal geflügelt, oft von Hüllen o. flügelartigen Organell umgeben. S. ohne Nährgewebe.

\section{Gattungen.}

Männliche Bt. einzeln in der Achsel der Deckschuppen, ohne Bthülle; Stb. 2-12, 2 theilig; A. mit Haarschopf; weibliche Bt. mit Bthülle; Fr. von einer Hülle o. von flügelartigen Organen um-

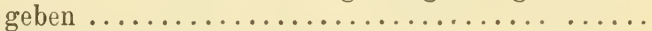

Männliche Bt. zu 3 in der Achsel der Deckschuppen, mit Bthülle; Stb. meist 2 o. 4, im ersteren Falle 2 theilig; A. ohne Haarschopf; weibliche Bt. ohne Bthülle; Fr. oft geflügelt, aber ohne Hülle......

B. zur Zeit der Bt. noch ganz unentwickelt; Stb. meist 4, mit $8 \mathrm{~A}$.; weibliche Bt. zu wenigen in kleinen, knospenartigen Btständen; Fr. groß, mit zerschlitzter Hülle............ Corylus. III.

2 B. zur Zeit der Bt. mindestens schon in der Entfaltung begriffen; Stb. 6-12 (A. 12-24); weibliche Bt. in lockeren Kätzchen; Fr. klein, von flügelartigen Organen umgeben 0 . mit sackartiger Hülle..............................

Männliche Kätzchen lockerblütig; Frhülle flügelartig,

Männliche Kätzchen dichtblütig; Frhülle sackartig geschlossen .................. Ostrya. II.

Bthülle der männlichen Bt. 1-2 blättrig; Stb. 2, oben 2 theilig; Deckschuppen der Fruchtkätzchen 3 theilig, mit der geflügelten Fr. abfallend.

Betula. IV.

Bthülle der männlichen Bt. 3-5- (meist 4-) blättrig; Stb. 3-5 (meist 4), ungetheilt; Deckschuppen der Fruchtkätzchen 5 lappig, holzig, stehen bleibend. Alnus. V. 


\section{Arten.}

I. CARPINUS. L. Hainbuche.

(Deckschuppen der Fruchtkätzchen 3 theilig, die Zipfel lanzettlich, der mittlere verlängert; männliche Kätzchen verlängert. Verbr.

Betulus, L. Gemeine H.

Deckschuppen der Frkätzchen eiförmig, ungleich-gesägt; männliche Kätzchen kurz; B. kleiner. J.

Duinensis. Scop. Kleinblättrige $\mathrm{H}$.

II. OSTRYA. Mich. Hopfenbuche.

Frkätzchen eiförmig, hängend; B. eiförmig, zugespitzt, am Grunde fast herzförmig.

T. K. Südst. $K r$. J.

carpinifolia. Scop. Gemeine H.

\section{CORYLUS. L. Haselstrauch.}

Frhüllen glockig, an der Spitze etwas abstelıend; Fr. eiförmig. Verbr. $u$. hfg.

Avellana. $L$. Gemeiner $\mathrm{H}$. Frhüllen röhrig-walzlich, an der Spitze verengert; Fr. fast walziich. J., sonst cult.

tubulosa. Willd. Lamberts-H.

Anmerkung. Die durch baumförmigen Wuchs ausgezeichnete C. Colurna L. (Baumhasel) kommt cult. u. halb verw. vor. Diese Art hat eine doppelte Frhülle.

\section{BETULA. L. Birke.}

B. ästig-aderig, nicht augenfällig netzaderig, 'zugespitzt, doppelt-gesägt, lang gestielt; männliche und Fruchtkätzchen hängend; Bäume o. größere

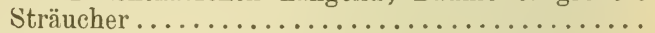

B. unterseits dicht-netzaderig, kurz gestielt; alle Kätzchen aufiecht; niedrige Sträucher .........

B. rautenförmig-3 eckig, fast kahl, doppelt-gesägt; junge Zweige fast kahl; Frflügel doppelt so breit als die Fr. Verbr. $u$. hfg.

verrucosa. Ehrh. Gemeine B.

B. eiförmig o. rautenförmig, flaumig, zuletzt kahl o. unterseits an den Winkeln der Adern bärtig; Frflügel ungefähr so breit als die Fr. Verbr.

alba. $\left.L *^{*}\right)$ Moor-B.

B. klein, fast kreisrund, gekerbt, Kerben abgerundetstumpf; weibliche Kätzchen sitzend. B. N. O. S. T. K. St. $K r$.. nana. L. Zwerg-B.

B. rundlich-eiförmig o. eiförmig, ungleich-gekerbtgesägt, Sägezähne spitz; weibliche Kätzchen gestielt. M. S. T. K. . humilis. Schrk. Strauch-B.

*) B. Carpatica W. K. ist schwächer behaart als B. alba. 


\section{ALNUS. L. Erle.}

Kätzchen im ersten Frühjahre vor Beginn der Belaubung blühend; Bthülle der männlichen $\mathrm{Bt}$. deutlich entwickelt, 4 spaltig; Fr. ohne 0 . mit undurchsichtigem Flügelrande................

Kätzchen während der Entfaltung der B. blühend;

1 Bthülle der männlichen Bt. 3-5blättrig, schwach entwickelt; Fr. mit häutigem, durchscheinendem Flügelrande; B. eiförmig, spitz, geschärft doppelt gesägt, kahl, beiderseits grün, unterseits auf den Nerven kurzhaarig. Verbr. (fehlt Sch.)

viridis. (Vill.) DC. Grün-E.

Die seitlichen weiblichen Kätzchen sitzend o. kaum merklich gestielt; B. unterseits bläulich, fein flaumig behaart, eiförmig, spitz, scharf doppeltgesägt; Rinde glatt. Verbr. u. hfg.

Die seitlichen weiblichen Kätzchen ziemlich lang gestielt; B. unterseits blässer grün, aber nicht bläulich, selten doppelt gesägt ................

Baum, seltener Strauch mit rissiger Rinde; B. rundlich, sehr stumpf o. ausgerandet, am Grunde keilig, ungleich-gesägt, unterseits in den Nervenwinkeln gebärtet, sonst kahl. Verbr. u. h fg .

3 glutinosa. (L.) Gärtn. Schwarz-E. Strauch mit glatter Rinde; B. eiförmig-länglich, spitz o. stumpf, am Grunde abgerundet, klein gesägt, unterseits auf den Nerven rauhhaarig, auch auf der Fläche mehr o. minder behaart. B. (verw.) rugosa. (Ehrh.) Spr. Hasel-E.

Anmerkung. Zwischen A. glutinosa und A. incana kommt ein Bastart vor.

\section{Familie. Fagaceae. Buchengewächse.}

Bäume, selten Sträucher mit ungetheilten o. fiederlappigen, schraubig gestellten B. Nebenb. früher 0 . später abfällig. Bt. 1 häusig. Männliche Bt. in verlängerten Kätzchen, seltener in fast kugeligen Büscheln, mit o. ohne Deckschuppen, mit 5-8 theiliger, unscheinbarer Bthülle; Stb. 4-15. Weibliche Bt. einzeln 0. zu $2-3$ (selten mehr) von einer becherartigen Hülle umgeben, im ersteren Falle meist mehrere einander genähert, mit unscheinbarer, meist 6 blättriger Bthülle; Frkn. unterständig, unten 3 fächerig, seltener $(4-) 6(-9)$ fächerig, mit 2 Samenknospen in jedem Fache; N. so viele als Frknfächer. Fr. meist 1 samig, nicht aufspringend, einzeln 0 . zu 2-3 (selten mehr) von der vergrößerten, lederigen 0 . verholzten, oft klappig aufspringenden Hülle der weiblichen Bt. (Frhülle) umgeben. S. ohne Nährgewebe. 
Gattungen.

Männliche Bt. in verlängerten Kätzchen ......... Männliche Bt. in fast kugeligen, lang gestielten Büscheln; weibliche Bt. zu 2 in gemeinschaftlicher Hülle; N. 3; Frhülle 4 klappig aufspringend, außen mit Weichstacheln besetzt; B. ganzrandig o. am Rande wellig, nur selten etwas gezähnt.

Fagus. I.

Männliche Bt. zu mehreren in Knäueln, die Knäuel in verlängerten, schmalen Kätzchen; weibliche Bt. meist zu $2-3$, seltener einzeln 0 . zu mehreren in gemeinschaftlicher Hülle, am Grunde der männlichen Kätzchen stehend; N. meist 6; Frhülle stachelig, 4 klappig aufspringend; B. ungetheilt, stachelspitzig gezähnt .......... Castanea. II. Männliche Bt. nicht geknäuelt, wenn auch oft $\mathrm{zu}$ mehreren genähert; weibliche Bt. meist zu mehreren, jede mit besonderer Hülle, von den männlichen Kätzchen entfernt; N. 3; Frhülle becherförmig, nicht stachelig, nicht aufspringend, stets nur eine Fr. umschließend; B. fiederlappig 0 . ungetheilt.

Quercus. III.

\section{Arten.}

\section{FAGUS. $L$. Buche.}

Baum; B. eiförmig, am Rande gewimpert, sonst kahl. Verbr................silvatica. $L$. Rothbuche.

\section{CASTANEA. Adans. Kastanienbaum.}

Baum; B. länglich-lanzettlich, zugespitzt, stachelspitzig-gesägt, zuletzt kahl.

Verbr., doch meist cult. u. verw. (fehlt Sch. S.) sativa. Mill. Echter K.

\section{QUERCUS. $L$. Eiche.}

B. abfällig, fiederlappig ...................

B. immergrün, ungetheilt, dabei ganzrandig o. gezähnt 0 . gesägt........................

B. mit stachelspitzigen Lappen, unterseits flaumig o. graufilzig; Schuppen der Frhülle lineal-pfriemlich, abstehend, gewunden. M. N. St. Kr. J.

Cerris. L. Zerr-E.

Blappen stumpf, wehrlos; Schuppen der Frhülle angedrückt............................

Junge $\mathrm{Z}$ weige flaumig; B. im Frühlinge filzig, die älteren unterseits flaumig, zuletzt oft kahl, gestielt; Blappen stumpf, ganzrandig 0. eckig-gezähnt. Verbr. (fehlt Sch. O. S.) lanuginosa. (Lam.) Flaumige E. B. kahl, nur anfangs unterseits flaumig, mit abgerundetstumpfen Lappen ...................... 
Junge Zweige kahl o. fast kahl; Frstiele so lang als die Bstiele o. kürzer; B. ziemlich lang gestielt, am Grunde ausgerandet 0 . in den Bstiel vorgegezogen. Verbr. (feblt $S$.)

sessiliflora. Salisb. Winter-E.

Frstiele viel länger als der Bstiel; B. kurz-gestielt o. fast sitzend, am Grunde meist tief-ausgerandet. Verbr......................... Stiel-E.

B. eiförmig, dornig-gezähnt, kahl. J.

coccifera. L. Kermes-E.

B. ganzrandig 0 . stachelspitzig-gesägt, unterseits

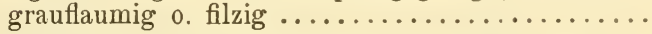

Rinde rissig-schwammig, korkig; vorjährige B. kurz vor der Blütezeit abfallend. J.

Pseudosuber. Santi. Falsche Kork-E. Rinde glatt; B. 2 Jahre bleibend, in der Form veränderlich. J. Südt. .........Ilex. I. Stein-E.

A n m e rk ung. Im Osten und Süden des Gebietes kommen verschiedene Eichenformen vor, welche in ihren Merkmalen $\mathrm{zwischen} \mathrm{Qu}$. lanuginosa (Lam.), Robur L. und sessiliflora Salisb. schwanken; unter diesen sind sicher Bastarte, die aber oft schwer $\mathrm{zu}$ erkennen sind, weil die beiden erstgenannten Arten in ihren Merkmalen sehr veränderlich sind. In $N$. wurden alle drei Bastarte $z$ wischen den genannten Arten gefunden; in $J$. wachsen Qu. aurea Wierzb., laciniosa Bor., Virgiliana Ten. u. Tommasinii Kotschy, die zum Theil auch Formen oder Bastarte der oben genannten 3 Arten sein dürften.

\section{Familie. Ulmaceae. Ulmengewächse.}

Bäume, selten Sträucher mit ungetheilten, gesägten zweizeilig angeordneten B., mit abfälligen Nebenb. Bt. zwittrig 0. vielehig, in Büscheln o. einzeln. Bthüllb. unscheinbar, 4-6 (-8), oft am Grunde verwachsen. Stb. so viele als Bthüllb. Frkn. 1, oberständig, 1(-2) fächerig, mit 1(-2) Samenknospen. N. 2, verlängert, ohne oder mit kurzem gemeinsamem Gr. Fr. nicht aufspringend, entweder breit geflügelt 0 . eine Steinfr. S. ohne Nährgewebe.

\section{Gattungen.}

Bthüllb. am Grunde breit verwachsen; A. purpurn, nach außen gewendet; Fr. breit geflügelt; B. zur Btzeit noch ganz unentwickelt ....... Ulmus. 1. Bthüllb. fast ganz frei; A. gelb, nach innen gewendet; Steinfr.; B. zur Btzeit in Entfaltung begriffen.

Celtis. II. 
Arten.

\section{ULMUS. $L$. Ulme.}

(Bt. fast sitzend, in rundlichen, aufrechten Büschelı;

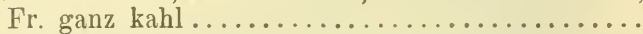
Bt. gestielt, in länglichen, herabhängenden Büscheln; 1 Fr. am Rande zottig-gewimpert; B. oberseits kahl o. etwas rauh, unterseits weichhaarig.

Verbr. (fehlt J.)

perlunculata. Foug. Flatter-U.

Zipfel der Bthülle mit weißen Wimpern; Same im oberen Theile der Flügelfr. liegend; B. ziemlich kahl, oberseits wenig rauh 0 . glatt und glänzend.

2 Verbr. ................... Mill. Feld-U. Zipfel der Bthülle mit rostfarbenen Wimpern; Same nahezu in der Mitte der Flügelfr. liegend; B. namentlich oberseits sehr rauh, groß und breit. Verbr............. montana. With. Berg-U.

\section{CELTIS. L. Ziirgelbaum.}

B. länglich-lanzettlich, zugespitzt, geschärft-gesägt; unterseits-weichhaarig. Sïdt. Südst. $K r$. J.

australis. L. Europäischer Z.

\section{Familie. Moraceae. Maulbeergewächse.}

Holzgewächse, Kletterpfl. o. Kräuter mit ungetheilten, gelappten 0 . handförmig getheilten, niemals ganzrandigen, schraubig gestellten oder gegenständigen B., mit (oft abfälligen) Nebenb. Bt. 1 - 0. 2 häusig, in verschiedenen Bt.ständen. Bthülle unscheinbar, aus $3-5$ oft am Grunde verwachsenen $B$. bestehend 0 . becherförmig. Stb. 1-6, meist 4-5. Frkn. 1, ober- o. unterständig, 1-2 fächerig, mit einer samenknospe u. 2 N. mit 0 . ohne Gr. Fr. nicht aufspringend, oft zu fleischigen Sammelfrüchten vereinigt. S. mit o. ohne Nährgewebe.

\section{Gattungen.}

Holzgewächse mit schraubig gestellten B. und fleischiger Sammelfr.; Bt. 1 häusig, nur ausnahms-

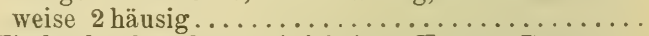
Windende Staude o. einjähriges Kraut; B. gegenständig; Bt. 2 häusig; Fr. nicht fleischig, frei.... 
( Männliche und weibliche Bt. im Innern eines fleischigen, birnförmigen Behälters eingeschlossen; Bthüllb. der männlichen Bt. 3, der weiblichen 5; Stb. 1-6; Sammelfr. birnförmig, die Einzelfr. im Innern bergend (Feige) ........... Ficus. II. Männliche und weibliche Btstände von einander getrennt, gestielte, dichtblütige Aehren bildend; Bthüllb. 4 ; Stb. 4 ; Sammelfr. traubenartig (Maulbeere)..................... IIorus. I.

Windende Staude mit gelappten 0 . ganz ungetheilten B................... Humulus. III. Einjähriges Kraut mit handförmig getheilten B.

Canuabis. IV.

\section{Arten.}

\section{MORUS. $L$. Maulbeerbaum.}

B. beiderseits ziemlich kahl; weibliche Aehren ungefähr so lang als ihr Stiel; Bthülle u. N. kahl; Sammelfr. gestielt, meist weiß, seltener purpurn o. fast schwarz. Cult.........alba. $L$. Weißer M. B. unterseits weichhaarig; weibliche Aehren länger als ihr Stiel; Bthülle am Rande behaart; N. rauhhaarig; Sammelfr. schwarzpurpurn, fast sitzend. Cult............... nigra. L. Schwarzer M.

A n m e r k n g. Der Papiermaulbeerbaum (Broussonetia papyrifera (L.) Vent), ausgezeichnet durch filzig behaarte Zweige und B., sowie durch zweihäusige Bt., von denen die weiblichen in kugeligen Köpfchen stehen, wird oft cultivirt.

\section{FICUS, $L$. Feigenbaum.}

B. herzförmig, meist gelappt, oberseits rauh unterseits flaumhaarig. Siidt. J. (auch cult.)

Carica. L. Echter F.

\section{HUMULUS. L. Hopfen.}

Stg. von Klimmhaaren rauh; männliche Btstände rispenähnlich, weibliche kätzchenförmig.

Verbr. (auch cult.) ...Lupulus. L. Gemeiner H.

\section{CANNABIS. $L$. Hanf.}

B. 3-9 schnittig (nur die obersten ungetheilt), mit verlängert - lanzettlichen, gesägten Abschnitten; männliche Btstände traubenähnlich, weibliche ährenförmig, beblättert. Cult. u. verw.

sativa. $L$. Gemeiner $H$. 
VII. Familie. Urticaceae. Nesselgewächse.

Stauden o. Kräuter mit ungetheilten, gesägten oder ganzrandigen, gegenständigen 0 . wechselständigen B., mit o. ohne Nebenb. Bt. 1- 0. 2 häusig o. vielehig, in Knäueln, welche oft zu rispenähnlichen Btständen vereinigt sind. Bthüllb. 4-5, oft am Grunde verwachsen. Stb. 4-5. Frkn. 1, oberständig, 1 fächerig, mit einer Samenknospe. N. 1, kopfig-pinselförmig, mit 0 . ohne Gr. Fr. nicht aufspringend, von der Bthülle eingeschlossen. S. mit Nährgewebe.

\section{Gattungen.}

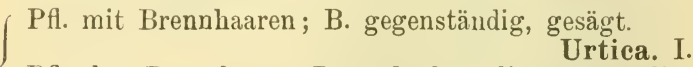
Pfl. ohne Brennhaare; B. wechselständig, ganzrandig. Parietaria. II.

\section{Arten.}

\section{URTICA. L. Brennessel.}

Einjähriges Kraut mit spindliger W.; B. oval; Bt. einhäusig, in kurzen, nicht hängenden Btständen. Verbr.................. Kurens. $L$. Kleine B. Stauden mit kriechendem Wst.; B. am Grunde herzförmig; Bt. in verlängerten, hängenden Btstäuden.

Stg. aufrecht, reichlich borstig; B. trübgrün; Bt. meist 2 häusig; Bthülle der weiblichen Bt. borstig. Terbr. u. $h f g . . . \ldots \ldots \ldots$ dioica. L. Gemeine B. Stg. aufsteigend, am Grunde wurzelnd, nahezu kahl; B. hellgrün; Bt. meist 1 häusig; Bthülle der weiblichen Bt. fast kahl. $N$.

Kioviensis. Rogov. Sumpf-B.

Anmerkung. U. pilulifera L., ausgezeichnet durch die in kugeligen Knäueln stehenden weiblichen Bt., wurde in B. u. O. eingeschleppt gefunden. - U. oblongata Koch $(S t$.) ist vielleicht U. dioica $X$ urens.

\section{PARIETARIA. $L$. Glaskraut.}

Stg. aufrecht, einfach; B. länglich-eiförmig; Deckb. sitzend. Vertr. (fehlt J.)

officinalis. $L$. Aufrechtes G. Stg. gestreckt, ausgebreitet, ästig; B. eiförmig; Deckb. herablaufend. St. $K r$. J. Südt. ramiflora. Mnch. Ausgebreitetes G. 
VIII. Familie. Loranthaceae. Mistelgewächse.

Auf Bäumen schmarotzende Sträucher mit gegenständigen, ganzrandigen, manchmal schuppenförmigen B. und gabelspaltigen Zweigen. Nebenb. fehlen. Bt. 2 häusig. Bthüllb. 2-6, oft am Grunde verwachsen; außerhalb derselben bildet der Btboden oft einen kelchartigen, gezähnten 0 . abgeschnittenen Rand (Scheinkelch). Stb. 2-6. Frkn. unterständig, ohne deutlich entwickelte Samenknospen. N. 1, mit 0. ohne Gr. Fr. eine Beere.

\section{Gattungen.}

B. normal entwickelt; Bt. in endständigen Knäueln, Aehren 0. Trauben; A. durch zahlreiche Löcher o. durch einen Längsspalt anfspringend ........ 2 An Stelle der B. kleine Schuppen; Bt einzeln, achselständig; A. durch einen Querspalt aufspringend; kleiner, sehr ästiger Strauch, welcher auf Wachholder-Arten schmarotzt.

Arceuthobium. II.

(B. dunkelgrün, abfällig; Bt. in lockeren Trauben 0. Aehren; Bthüllb. meist 6 ; A. mit Längsspalt aufspringend; Gr. fädlich, mit kopfförmiger N.; Beeren gelb; auf Eichen schmarotzend ...Loranthus. I.

2 B. gelbgrün, im Herbste nicht abfallend; Bt. zil 3 bis 5 in Knäueln; Bthüllb. meist 4; A. mit zahlreichen Löchern aufspringend; N. sitzend; Beeren meist weißlich; auf verschiedenen Bäumen schma. rotzend.................... Viscum. III.

\section{Arten.}

\section{LORANTHUS. L. Riemenmistel.}

B. verkehrt-eiförmig o. länglich-oval, lederig; Bt. gelblich. B. M. N. St. Kr. J.

Europaeus. Jacq. Europäisehe R

\section{ARCEUTHOBIUM. M. B. Wachholdermistel.}

Beeren länglich, bläulich. $J$.

Oxycedri. $(D C$.) $M B$. Europäische W.

\section{VISCUM. L. Mistel.}

B. keilig-länglich 0. lanzettlich; Bt. grünlichgelb. Verbr... .......... album. $\left.L .^{*}\right)$ Gemeine M.

*) V. Austriacum Wiesb. ist eine schmalblättrige Form, die auf Nadelhölzern (besonders auf der Schwarzföhre in $N$.) wächst. 
IX. Familie. Santalaceae. Sandelgewächse.

Auf Wurzeln schmarotzende, aber grüne Stauden, seltener Kräuter o. Sträucher. B. schraubig gestellt, lineal o. lanzettlich, ganzrandig. Nebenb. fehlen. Bt zwittrig, seltener vielehig-2häusig. Bthüllb. 3-5, am Grunde verwachsen. Stb. 3-5. Frkn. unterständig, 1 fächerig, mit 2 bis 4 hautlosen Samenknospen. Gr. 1, mit 1 o. 3 N. Fr. nicht aufspringend, manchmal fleischig. S. ohne Schale, mit Nährgewebe.

\section{Gattungen.}

Strauch mit vielehig-2 häusigen Bt.; Bthülle 3 spaltig, gelblich; Stb. 3 ; N 3; Fr. fleischig. Osyris. I. Stauden 0. Kräuter mit zwittrigen Bt.; Bthülle 4bis 5 spaltig, außen grün, innen weiß; Stb. 4-5; N. 1, kopfig; Fr. trocken, seltener fleischig.

Thesium. II.

Arten.

\section{OSYRIS. L. Harnstrauch.}

Zweige ruthenförmig, ziemlich dicht beblättert; männliche $\mathrm{Bt}$. in kurzen, lockeren Trauben, weibliche meist einzeln; Fr. röthlich. $J$.

alba. L. Weißer $\mathrm{H}$.

\section{THESIUM. L. Bergflachs.}

( 3 Hochb. (1 Deckb. u. 2 Vorb.) unter jeder Bt.; Stg. oberwärts traubig 0. rispig, bis zur Spitze mit Bt.

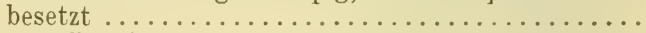

Nur 1 Deckb. (kein Vorb.) unter jeder Bt.; fruchttragender Stg. an der Spitze durch unfruchtbare

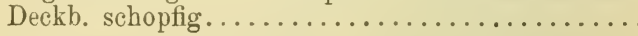

Saum der Bthülle nach dem Verblühen bis auf den Grund eingerollt und einen kurzen Knopf auf der Fr. bildend

Saum der Bthülle nach dem Verblühen röhrig, nur

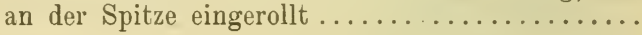

Fr. deutlich gestielt; Stg. oberwärts rispig verzweigt 4

3 Fr. fast sitzend, eiförmig; Stg. oberwärts traubig 0.

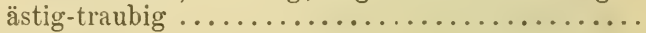

B. 1 nervig 0 . schwach-3 nervig, lineal o. lineal-lanzettlich; Fr. oval o. länglich-walzlich..........

B. stark-3 nervig o. 5 nervig, breit, lanzettlich, lang5 zugespitzt; Fr. rundlich-eiförmig; Wst. ohne Ausläufer. B. N. O. Südst. $K r$. K. Sü̈dt.

montanum. Ehrh. Großer B. 
Wst. ohne Ausläufer; B. lineal, spitz; Fr. länglichwalzlich. J. .... divaricatum. Jan. Sparriger B.

5 Wst. mit dünnen Ausläufern; B. lineal-lanzettlich, zugespitzt; Fr. oval. Verbr. (fehlt Sch.)

intermedium. Ehrh. Mittlerer B.

Frstiel 3-4mal länger als die Fr., abstehend; B. lanzettlich 0 . lineal, undeutlich 3 nervig.

M. N. St....... ramosum. Hayne. Aestiger B. Erstiel viel kürzer als die Fr., aufrecht; Fr. dem Stg. anliegend; B. limeal, 1 nervig. M. $N$.

humile. Valıl. Niedriger B.

Bthülle meist 4 spaltig; Btstand einseitswendig; Fr.stiele aufgerichtet; B. lineal, 1 nervig.

Verbr. (bes. Geb.).....alpinum. L. ${ }^{*}$ ) Alpen-B.

7 Bthülle meist 5 spaltig; Btstand allseitswendig; Fr.stiele abstehend; B. lineal-lanzettlich, schwach3 nervig. Verbr. (fehlt .J.)

pratense. Ehrh. Wiesen-B.

Wst. mit Ausläufern; Fr. gestielt, oval, lederig, mindestens so lang als die eingerollte Bthülle.

B. N. ... ebracteatum. Hayne. Vorblattloser B.

8 W st. ohne Ausläufer; Fr. sitzend, fast kugelig, saftig, citronengelb gefärbt, halb so lang als die röhrige, nur an der Spitze eingerollte Bthïlle. B. S.T.K.

rostratum. $M$. et $K$. Schnabelfrüchtiger B.

Anmerkung. In $\boldsymbol{N}$. wurde Th. intermedium $\times$ ramosum beobachtet.

\section{Familie. Aristolochiaceae. Osterluzeigewächse.}

Stauden mit wechselständigen, ungetheilten, herz- 0 . nierenförmigen, ganzrandigen B., ohne Nebenb. Bt. zwittrig. Bthülle röhrig o glockig, entweder regelmäßig u. 3 spaltig o. unregelmäßig u. mit lippenförmigem Saume. Stb. 60 . 12 , oft an die Grsäule angewachsen. Frkn. unterständig, meist 6 fächerig, mit zahlreichen Samenknospen. Gr. 6, zu einer Säule verwachsen; N. 6 strahlig. Fr. eine 6 fächerige, 6 klappig 0. unregelmäßig aufspringende Kapsel. S. mit Nährgewebe.

\section{Gattungen.}

Bthülle glockig, regelmäßig, 3(-4) spaltig; Stb. 12, frei...................... Asarum. I. Bthülle bauchig-röhrig, unregelmäßig, mit einlippigem Saume; Stb. 6, an die Grsäule angewachsen. Aristolochia. II.

*) Th. tenuifolium Saut. (N. O.) hat rispig-ästige Stg. u. allseitswendigen Btstand, sonst die Merkmale von Th. alpinum L. 


\section{Arten.}

\section{ASARUM. L. Haselwurz.}

Wst. kriechend; Bt. dicht über dem Boden, einzeln, außen grünlichbraun, innen schmutzig-blutroth. Verbr......... Europaeum. L. Europäische H.

\section{ARIsTOLOCHIA. L. Osterluzei.}

(Bt. einzeln in den Bachseln; Wst. knollig ........

1 Bt. in den Bachseln gebüschelt, blassgelb; Wst. kriechend. Verbr.....Clematitis. $L$. Gemeine 0 .

B. fast sitzend, herzeiförmig; Lippe der Bthülle stumpf u. ausgerandet, so lang als die Röhre, von röthlicher Giundfarbe. $K r$. J.

rotunda. $L$. Rundblättrige 0 .

B. gestielt, dreieckig-nierenförmig; Lippe der Bthülle zugespitzt, halb so lang als die Röhre, von gelbl. Grundfarbe. Südst. $K r$. J.

pallida. Willd. Bleiche 0 .

\section{Familie. Rafflesiaceae. Rafflesiengewächse.}

Auf den Wurzeln der Cistrosen schmarotzende Pf. mit schraubig-gestellten, schuppenförmigen, gelb bis blutroth gefärbten B. Bt. an der Spitze des Stg. dicht aneinander gedrängt, 1 häusig. Bthülle etwas fleischig, röhrig, regelmäßig, 4 spaltig. Stb. 8 , an eine Mittelsäule angewachsen. Frkn. unterständig, 1 fächerig, mit zahlreichen Samenknospen. Gr. 8, zu einer Säule verwachsen; N. kopfig. Fr. eine vielsamige Beere. S. sehr klein, mit spärlichem Nährgewebe u. ungegliedertem Keim.

\section{Gattung.}

Saum der Bthülle tellerförmig ausgebreitet, Röhre gefächert.................

\section{Art.}

\section{CYTINUS. L. Hypocist.}

Pfl. gelbroth bis carminroth; Bt. gelblichweiß. $J$.

Hypocistis. L. Europäischer $\mathrm{H}$.

\section{Familie. Polygoneae. Knöterichgewächs $\theta$.}

Stauden o. Kräuter mit schraubig gestellten, ungetheilten B. u. häutigen Nebenbscheiden. Bt. zwittrig, seltener 2 häusig o. vielehig. Bthüllb. 4-6, am Grunde verwachsen, kelchartig 0 . auch blumenblattartig gefärbt (in letzterem Falle meist rosa 0. weiß). Stb. 5-8. Frkn. 1, oberständig, 1 fächerig, mit einer Samenknospe. Gr. 2-3, oft verwachsen; 
N. kopfig o. pinselförmig. Fr. nicht aufspringend, oft von den inneren B. der Bthülle (Frhülle) verhüllt. S. groß, mit reichlichem mehligem Nährgewebe.

\section{Gattungen.}

N. pinselförmig; Stb. 6; Bthüllb. 6, seltener 4.... 2

1 N. kopfig, 2-3, oft verwachsen; Stb. 5-8; Bthüllb.

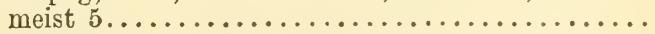

(Bthüllb. 6; Gr. 3; Fr. 3 kantig, von den inneren 2 Bthüllb. (Frhüllb.) verhüllt ..........Rumex. I. Bthüllb. 4; Gr. 2; Fr. flach, breit geflügelt.

Oxyria. II.

Fr. nicht länger als die Bthülle, meist mit derselben abfallend; S. mit schmalen, nicht gefalteten Keimb.; B. nur bei den windenden Arten herz-pfeilförmigdreieckig.................. Polygonum. III.

3 Fr. viel länger als die Bthülle, aus derselben herausfallend; S. mit breiten, zusammengefalteten Keimb.; B. herz-pfeilförmig-dreieckig; Stg. nicht windend. Fagopyrum. IV.

Arten.

\section{RÜMEX. $L$. Ampfer.}

B. am Grunde verschmälert, abgerundet 0 . herzförmig ;

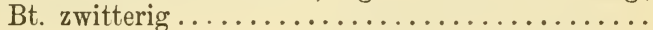

B. am Grunde spieß- o pfeilförmig; Bt. vielehig 0. 2 häusig ..............................

Alle oder doch die meisten Btquirle von B. gestützt; die 3 inneren Frhüllb. mit einer Schwiele....... Btquirle blattlos, traubig angeordnet, höchstens die untersten von B. gestuitzt ...................

Die 3 inneren Frhüllb. beiderseits borstlich-2 zähnig,

3 an der vorgezogenen Spitze ganzrandig; B. lan3 zettlich-lineal, in den Bstiel verschmälert ....... Die 3 inneren Frhüllb. ganzrandig o. fast dornigvielspaltig $\ldots \ldots \ldots \ldots \ldots \ldots \ldots \ldots \ldots \ldots$.

Die inneren Frhüllb. fast rautenförmig, die Zähne von der Länge des Längendurchmessers der Fr.hüllb.; die oberen Btquirle zusammenfließend. B. M. Sch. N. O. St. J.

maritimus. $L$. Goldgelber A.

Die inneren Frhüllb. eiförmig o. eiförmig-länglich, die Zähne kürzer als die Frhüllb; Btquirle locker gestellt. B. M. N. O. T.

limosus. Thuill. Grüngelber A. 
Die inneren Frhüllb. grubig-netzig, fast dornig-vielzähnig, eiförmig-länglich; die unteren B. herzförmig o. herzförmig-länglich, oft fast geigenförmig, stumpf; Aeste weit abstehend. Südt. J.

pulcher. $L$. Schöner A

Die inneren Frhüllb. ganzrandig, lineal-länglich; alle o. doch die oberen B. spitz. Terbr. $u$. hfg.

conglomeratus. Murr. Geknäuelter A.

$\int$ Die inneren Frhüllb. gezähnt, Zähne dreieckig, pfriem-

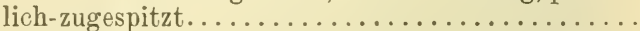

Die inneren Frhüllb. ganzrandig 0 . sehr klein-ge-

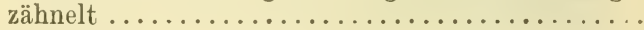

Innere Frhüllb. eiförmig-3eckig, in eine stumpfe Spitze vorgezogen, alle schwielig; unteren B. herzeiförmig, stumpf o. spitzlich. Verbr. u. hfg.

obtusifolius. $L{ }^{*}$ ) Wiesen-A.

7 Innere Frhüllb. eiförmig, fast herzförmig, stumpf, alle oder nur eines schwielig; Grundb. und untere Stgb. herzförmig-länglich, spitz. $M . N$.

biformis. Menyh. Ungarischer A.

Die inneren Frhüllb. lineal-länglich, stumpf, ganzrandig, nur eines schwielentragend; untere $\mathrm{B}$. herzförmig-länglich 0 . fast geigenförmig. Verbr.

sanguineus. $L$. Hain-A.

Die inneren Frhüllb. eiförmig 0. herzförmig-rundlich

Die 3 inneren Frhüllb. alle 0 . eines derselben eine

9 Schwiele tragend .................... 10

Alle Frhüllb. schwielenlos ............... 12

Bstiele oberseits flach; B. lanzettlich o. die unteren elliptisch, zugespitzt; die 3 inneren Frhüllb. dreieckig-eiförmig, alle eine Schwiele tragend; hohe, 10 kräftige Sumpfpf. Verbr. (fehlt J.)

Hydrolapathum. Huds. Teich-A. Bstiele oberseits rinnig; die 3 inneren Frhüllb. herzförmig 0 . rundlich ............... 11

B. lanzettlich, die unteren länglich, alle wellig gekraust; alle 3 inneren Frhüllb. eine Schwiele tragend, selten 1-2 Schwielen undeutlich.

11 Verbr. $u . h f g . \ldots \ldots \ldots . .$. crispus. L. Krauser A. B. eilänglich 0 . eilanzettlich, die obersten lanzettlich, wellig, aber nicht gekraust; nur eines der inneren Frhïllb. eine Schwiele tragend; Pfl. größer und kräftiger. N. (sonst verw.) Patientia. L. Garten-A.

*) R. silvester Wallr. unterscheidet sich durch kleinere, in eine längere Spitze vorgezogene, nicht deutlich gezähnte innere Frhüllb.; R. subulatus (Rechinger) $(K$.) dagegen durch lange, fein haarspitzige Zähne der innern Frhüllb. 
Grundb. herz-eiförmig, spitz, am Grunde verbreitert; Bstiele oberseits schmal- und seicht-, unter dem B. aber deutlich-rinnig; Sumpfpfl. Terbr.

Grundb. rundlich-herzförmig, abgerundet-stumpf, 0. an der stumpfen Spitze kurz-zugespitzt; Gebirgspfl. Geb.................. alpinus. L. Alpen-A.

Bt. vielehig (theils zwittrig, theils männlich); die inneren Frhüllb. rundlich-herzförmig, ohne Schwiele ; B. eiförmig, oft fast geigenförmig, am Grunde spießo. pfeilförmig, seegrün o. grasgrün.

Verbr. (fehlt Sch.; B. M. nur verw.)

scutatus. $L$. Schildblättriger A.

Bt. 2 häusig........................... 14

Die inneren Frhüllb. netzaderig, ohne Schwiele, die äuœeren aufrecht, angedrückt; B. spießförmig, lanzettlich 0 . lineal, alle gestielt. Verbr.

Acetosella. L.*) Gauch-A.

Die inneren Frhüllb. mit Schwielen 0. Schuppen, die äußeren zurückgeschlagen ...................

B. dicklich, fast nervenlos; die äuœeren Grundb. rundlich-eiförmig, fast herzförmig, ganz stumpf; 15 Stg. einfach, blattlos $0.1-2$ blätterig. A. v. T. S. O. Kr.J. nivalis. Hgtsch. Schnee-A. B. aderig 0 . 5-7nervig, spieß- 0 . pfeilförmig $\ldots \ldots 16$

Nebenb. ganzrandig; B. fast dreieckig, am Grunde abgestutzt 0 . spießförmig, strahlig-5-7 nervig; Stg. oberwärts ästig. Geb.

arifolius. All. Aronblättriger A.

Nebenb. geschlitzt-gezähnt; B. eilänglich, am Grunde pfeilförmig, aderig. Verbr. $u$. $h f g$.

Acetosa. L. Sauer-A.

A n merkung. Bastarte $\mathrm{z}$ wischen den $\mathrm{z}$ wittrigen Arten der Gattung Rumex sind nicht sehr selten, aber leicht zu übersehen und meist nur an den Früchten mit Sicherheit zu erkennen. Im Gebiete wurden beobachtet: $R$. conglomeratus $X$ maritimus, maritimus $X$ obtusifolius, biformis $X$ maritimus, conglomeratus $X$ obtusifolius, conglomeratus $X$ crispus, obtusifolius $X$ sanguineus, crispus $X$ obtusifolius, obtusifolius $\times$ Patientia, biformis $\times$ Patientia, aquaticus $\times$ Hydrolapathum, crispus $X$ Patientia.

*) Bei R. angiocarpus Murbeck sind die inneren Fr.hüllb. mit der Fr. verwachsen. 


\section{OXYRIA. Hill. Sänerling.}

Grundb. lang gestielt, nierenförmig, ausgeschweift, kahl. A. v. T. S. K. St.

digyna. (L.) Hill. Nierenblättriger S.

\section{POLTGONUM. L. Knöterich.}

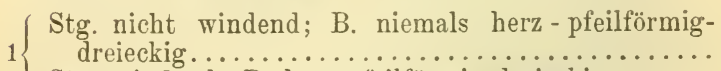

Stg. windend; B. herz-pfeilförmig-dreieckig ......

Bt. in endständigen Aehren, nie blattwinkelständig; Stb. $5-8 \ldots \ldots \ldots \ldots \ldots \ldots \ldots \ldots \ldots \ldots \ldots$

2 Bt. in rispig angeordneten Trauben o. blattwinkelständig, gebüschelt 0 . unterbrochene Aehren bildend; Stb. $8 \ldots \ldots \ldots \ldots \ldots \ldots \ldots \ldots \ldots$

Die Aehre enthält im unteren Theile Brutknospen; Staude mit ovalen 0 . lanzettlichen, am Rande umgerollten B.; Bt. weiß o. blassrosa. $A$.

viviparum. $L$. Otterwurz.

Die Aehre enthält keine Brutknospen.............

(Aehren walzlich, länglich 0. oval, gedrungen, auf-

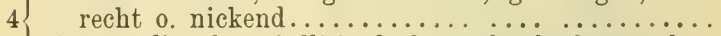
Aehren lineal 0. fädlich, locker, oft überhängend .. 8

$5\{$ Ausdauernde Arten; Stb. 5 0. $8 \ldots \ldots \ldots \ldots \ldots \ldots 6$

5 Einjährige Arten; Stb. meist $6 \ldots \ldots \ldots \ldots \ldots \ldots . \ldots$

Wst. dickwalzlich, fast knollenförmig, nicht kriechend; Bstiel oben geflügelt; Sth. 8 ; N. rundlich, sehr klein. Verbr...... Bistorta. L. Natterwurz.

6 Wst. stielrund, ästig, kriechend; Bstiel nicht geflügelt; Stb. $5 ;$ N. groß, kopfig. Verbr.

amphibium. $L{ }^{*}$ ) Wasser-K.

Nebenbscheiden kahl o. etwas wollig, am Rande kurz und sehr fein gewimpert; Btstiele und Bthülle drüsig-rauh. Verbr. $u$. $h \mathrm{fg}$.

7 lapathifolium. L. ${ }^{* *}$ ) Ampferblättriger K.

Nebenbscheiden meist steifhaarig, am oberen Rande stets lang gewimpert; Btstiele und Bthülle drüsenlos. Verbr.............Persicaria. L. Floh-K.

*) Die Wasserform hat lang gestielte kahle B., die Landform kurz gestielte, steifhaarige B.

**) P. tomentosum Schrk. hat unterseits graufilzige B.; P. Danubiale Kern. (M. N.) hat kurze, rundlich-eiförmige $B$. 
Bthülle grünlich, seltener röthlich, drüsig-punktirt; S. glanzlos; B. von pfefferartigem, brennendem Geschmack. Verbr.

Hydropiper. L. Wasserpfeffer. Bthülle rosa 0 . weiß, drüsenlos; $\mathrm{S}$. glänzend; $\mathrm{B}$. ohne brennenden Geschmack .................

B. länglich-lanzettlich 0 . lanzettlich, nach beiden Enden gleichmäßig verschmälert, mit deutlichen Seitennerven. Verbr......mite. Schrk. Milder K.

B. lineal o. lineal-lanzettlich, mit nahezu parallel laufenden Rändern; Seitennerven undeutlich; Bt. kleiner. Verbr.........minus. Huds, Kleiner K.

Bt. blattwinkelständig, oft unterbrochene Aehren bildend; am Grunde der Stb. keine Drüsen ..... 11

Bt. in rispig angeordneten Trauben; am Grunde der Bthülle zwischen den Stb. Drüsen; B länglichlanzettlich, wellig, unterseits flaumig; Bt. gelblichweib o. blassrosa. A. v. Südt.

alpinum. All. Alpen K.

Staude; B. am Rande umgerollt, elliptisch; Stg. ästig; Fr. glatt, glänzend. $J$.

maritimum. L. Meerstrands-K. Einjährige Kräuter; B. flach; Fr. fein-runzelig-gestreift ..............................

Aeste bis zur Spitze beblättert; alle Btbüschel daher deutlich blattwinkelständig. Verbr. $u$. hfg .

aviculare. $L$. Vogel-K.

12 B. an der Spitze der ruthenförmigen Aeste sehr verkleinert, so dass die obersten Btbüschel scheinbar blattlose, unterbrochene Aehren bilden. ( $N$.) $K r$. J.

Bellardi. All. Bellardi's K.

Die 3 inneren Frhüllb. häutig-geflügelt; Fr. glänzend; Stg. auf Gebüsche kletternd. Verbr.

dumetorum. $L$. Hecken-K.

Die 3 inneren Frhüllb. stumpf-gekielt; Fr. glanzlos; Pfl. kleiner, meist am Boden liegend. Verbr. u. hfg.

Convolvulus. $L$. Windender $\mathrm{K}$.

\section{FAGOPYRUM. Gärtn. Buchweizen.}

Bt. rosa 0 . weißlich, in blattwinkelständigen, dichtblütigen Doldentrauben; Kanten der Fr. ganzrandig. Cult. u. verw. (hfg.)

sagittatum. Gilib. Gemeiner B.

Bt. grünlich, in blattwinkelständigen Büscheln, zu unterbrochenen Aehren zusammengestellt; Kanten der Fr. ausgeschweift-gezähnt. Cult. u. verw.

Tataricum. (L.) Gärtn. Tatarischer B. 


\section{Familie. Chenopodiaceae. Gänsefußgewächse.}

Kräuter, Stauden, Halbsträucher o. kleine Sträucher. B. meist ungetheilt, manchmal verkümmert, schraubig gestellt, seltener gegenständig, ohne Nebenb. Bt. zwittrig 0. eingeschlechtig, stets unscheinbar und meist grünlich. Bt.hüllb. meist kelchartig, 5 o. weniger, oft am Grunde miteinander verwachsen, nicht abfällig, selten fehlend. Stb. 5 o. weniger. Frkn. 1, oberständig, 1 fächerig, mit einer Samenknospe. Gr. 1, mit 1-4 N. Fr. meist nicht aufspringend, seltener mit einem Deckel sich öffnend, manchmal zu Scheinbeeren verwachsen. S. meist mit Nährgewebe.

\section{Gattungen.}

( Stg. gegliedert, scheinbar blattlos, kahl; Bt. in end1 ständigen, fleischigen Scheinähren, zu 3 beisammenstehend; Stb. $1-2 \ldots \ldots \ldots \ldots \ldots \ldots \ldots \ldots$. Stg. nicht gegliedert...................

Kräuter o. kleine Sträucher; Scheinähren deutlich gestielt, am Ende unfruchtbar und daher ziemlich spitz; die 3 beisammenstehenden Bt. mehr 0. minder verwachsen; S. ohne Nährgewebe, mit zu-

2 sammengefaltetem Keim........ Salicornia. XI.

Kleiner Strauch mit fast sitzenden, dick keulenförmigen, stumpfen Scheinähren; Bt. frei; S. mit Nährgewebe und gekrümmtem, ruthenförmigem Keim................. Arthrocnemum. X.

$3\{$ Bt. zwittrig, seltener mit eingeschlechtigen gemischt

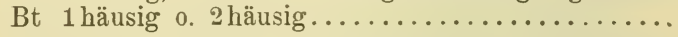

B. lineal 0 . pfriemlich, stachelspitzig 0 . in einen Dorn auslaufend; Bt. einzeln in den Bachseln, oft zu Aehren zusammengestellt; 1 jährige Kräuter..

B. nicht stachelspitzig o. dornig; Bt. in blattachselständigen 0 . zu verschiedenen Btständen zusammengestellten Kräueln, selten einzeln .......... 7

Bthüllb. 5 . . . . . . . . . . . . . . . . .

5 Bthüllb. 1-3, ungleich, durchscheinend, oft ganz fehlend; B. 1 nervig......... Corispermum. IX.

(Bthüllb. am Rücken mit Querkiel; Stb. 5, frei. $6\left\{\begin{array}{l}\text { Salsola. XIII. } \\ \text { Bthüllb. ohne Querkiel; Stb. meist 3, am Grunde } \\ \text { in einen Ring verwachsen...... Polycnemun. I. }\end{array}\right.$

B. halbstielrund, pfriemlich 0 . lanzettlich-lineal, stets

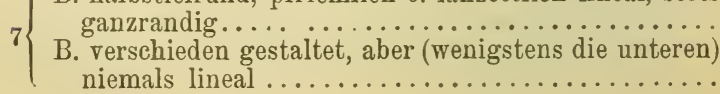


8 Bthülle behaart, glockig, mit 4 Zipfeln; Stb. 4.

Bthüllb. und Stb. $5 \ldots \ldots \ldots \ldots \ldots \ldots \ldots \ldots \ldots$

$\left\{\begin{array}{l}\text { Pfl. kahl; Zipfel der Frhülle ohne Anhängsel. } \\ \text { Snaeda. XII. }\end{array}\right.$

Pfl. mehr o. weniger behaart; Zipfel der Frhülle mit Anhängseln .............. Kochia. VIII.

Bt. am Grunde verwachsen; N. eiförmig o. lanzettlich; Fr. eingesenkt, mit der erhärteten Bthülle verwachsen, zuletzt mit einem Deckel sich öffnend.

Beta. II.

Bt. frei; N. fädlich o. pfriemlich, von Papillen flaumig; Fr. frei, von der unveränderten Bthülle umgeben, nicht aufspringend: Chenopodium. III.

$11\{$ Bt. 2 häusig; N. 4; Kräuter .........Spinacia. IV.

11 Bt. 1 häusig; N. 2 ................... 1

S Sternhaariger, niedriger Strauch mit lanzettlichen B.

12 u. wolligen weiblichen Bt.; Stb. 4. Eurotia. VI.

Kahle, mehlig bestreute o. schülferige Kräuter, seltener kleine Sträucher; Stb. 3-5. Atriplex. V.

\section{Arten.}

\section{POLYCNEMUM. L. Knorpelkraut.}

('I'ragb. rneist grasgrïn, mindestens $3 \mathrm{mal}$ so lang als die Bthülle. Verbr. (fehlt $S . K$. $K r$.)

arvense. $L *$ ) Acker-K.

Tragb. graugrün, höchstens 2 mal so lang als die Bthülle; Fr. sehr klein. $M$. N.

verrucosum. Lang. Warziges K.

\section{BETA. L. Runkelribe.}

(Staude mit mehreren, niederliegenden Stg.; N. lanzettlich; Wz. dünn. J... maritima. $L$. Wilde R. Kraut mit aufrechtem Stg.; N. eiförmig; Wz. oft rïbenartig verdickt. Cult. u. verv.

\section{vulgaris. L. Gebaute R.}

Anmerkung. Die rothe Rübe, die Zuckerrübe, die Burgunderrübe und der Mangold sind Culturvarietäten der Beta vulgaris L.

\section{CHENOPODIUM. L. Gäusefuß.}

(Stg. u. B. mehr o. weniger drüsig-flaumig; B ge-

1 zähnt 0 . fiederspaltig; 1 jährige Kräuter........ 2 Stg. u. B. mehlig o. kahl, nicht drüsig-flaumig.... 4

*) Die Vorb. sind bei der typischen Pfl. höchstens so lang, bei P. majus A. Br. deutlich länger als die Bthülle. 
B. buchtig-fiederspaltig; drüsige Behaarung reichlich; Btstand fast blattlos; Stb. meist 5 .

${ }_{2}$ Verbr. (oft nur eingeschleppt; fehlt $S$. J.)

Botrys. I. Flaumiger G.

Die unteren o. alle B. buchtig-gezähnt, nicht fiederspaltig; Behaarung spärlich; Btstand durchblättert

Die oberen B. lanzettlich 0 . nahezu lineal, oft ganzrandig; Stb. meist 5. Cult. u. rerw.

ambrosioides. L. Wohlriechender G.

Alle B. länglich eiförmig, beiderseits buchtig-3 zähnig; Stb. 1. M. (eingeschleppt.)

carinatum. $R$. Br. Einmänniger G.

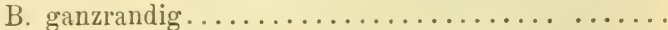

B. buchtig gezähnt, nur die obersten oft ganzrandig; einjährige, selten 2 jährige Kräuter ..... Staude; B. spie@förmig-dreieckig; Frkn. der meisten Bt. von der Seite flachgedrückt, $\mathrm{S}$. daher meist aufrecht. Terbr. $\iota . h f g$.

bonus Henricus. L. Guter Heinrich.

Einjährige Kräuter; B. rautenförmig o. eilänglich; Frkn. der meisten Bt. voll oben zusammenge-

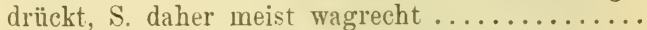

B. eilänglich, kahl; Frhülle abstehend. Verbr.

B rautenförmig, mehlig bestäubt; Frhülle aufrecht. Verbr............Vulvaria. I. Stinkender G.

Die meisten B. am Grunde herzförmig, eckig-gezähnt, die Zähne groß, zugespitzt, der mittlere verlängert; S. grubig-punktirt. Verbr.

hybridum. $L$. Bastart-G.

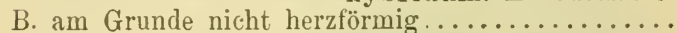

B. kahl und glatt, meist glänzend, nur anfangs nft mehlig bestäubt, im Umrisse dreieckig 0 . rautenförmig

B. matt, beiderseits 0 häufiger nur unterseits mehlig bestäubt, im Umrisse nicht dreieckig ......... 
Btknäuel in beblätterten, seltener blattlosen Aehren; Frhïlle nicht fleischig. Verbr. (fehlt $S$. St.)

rubrum. $L$. Rother $G$.

Wenigstens die unteren Btknäuel blattachselständig; Frhülle fleischig, roth gefärbt, so dass die Fr.knäule den Eindruck rother Beeren machen.....

B. eingeschnitten-gezähnt; alle Btknäuel blattachselständig, von einander entfernt.

Verbr. (meist nur verw.)

foliosum. (Much.) Aschers. Ruthenförmiger Erdbeerspinat.

B. schwach gezähnt; nur die unteren Btknäuel blattachselständig, die oberen zu einer Aehre vereinigt. Verbr. (meist nur verw.)

capitatum. (L.) Aschers. Aehriger Erdbeerspinat.

Die unteren B. 3 lappig-spießförmig, gezähnt, der mittlere Lappen verlängert, länglich-lanzettlich, stumpf; die oberen B. lineal-lanzettlich; S. eingedrückt-punktirt. Sch. $M . \Lambda . O . T . J$.

ficifolium. Sm. Feigenblättriger G.

B. rundlich-rautenförmig, ei - rautenförmig 0 . länglich ........................ 1

\section{4}

B. rundlich-rautenförmig, fast 3 lappig, sehr stumpf. ausgebissen-gezähnt, die oberen elliptisch-lanzettlich; Same glatt, glänzend. Verbr. (fehlt Sch. S.)

opulifolium. Schrad. Schneeballblättriger G.

B. ei-rautenförmig 0 . länglich............. 1

B. länglich, ausgesprochen zweifarbig, oberseits dunkelgrün, unterseits bläulichgrau; Bthüllb. 2-5. Ver.br.

glaucum. $L$. Seegrüner $G$.

B. rautenförmig o. länglich, beiderseits ziemlich gleichfarbig, wenn auch unterseits mehr graulich; Bthüllb. 5. Verbr. $u$. $h f g$. album. L. Gemeiner G.

Anmerkung. In Bezug auf den Btstand sind die Chenopodium-Arten, insbesondere Ch. polyspermum L. und Ch. album L., sehr veränderlich.

\section{SPINACIA. $L$. Spinat.}

(B. länglich-eiförmig; $\mathrm{Fr}$. wehılos. Cult.

glabra. Mill. Sommer-S.

B. am Grunde beiderseits spielsförmig-2 zähnig; Fr. gehörnt. Cult.......... oleracea. L. Winter-S.

\section{ATRIPLEX. L. Melde.}

Kleiner Strauch mit gegenständigen, verkehrt-eilänglichen, ganzrandigen, schülferigen B. J.

portulacoides. $L$. Keil-M.

Einjährige Kräuter mit wechselständigen, seltener gegenständigen, meist gezähnten B.......... 
B. lineal-lanzettlich, gezähnt o. ganzrandig, ohne Seitemnerven; Vorb. der weiblichen Bt. zur Zeit 2 der Frreife gezähnt. J... .litoralis. L. Ufer-M. B. verschieden gestaltet, mit deutlichen seiten-

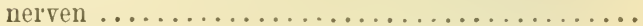

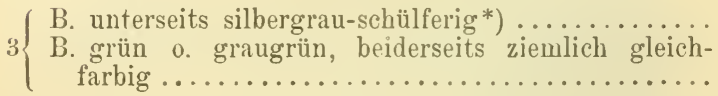
3

B. herzförmig-dreieckig, meist buchtig-gezähnt, oberseits glänzend dunkelgrün; Vorb. der Fr. frei,

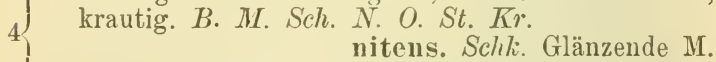

B. oberseits mattgrün; Vorb. der Fr. bis zur Mitte

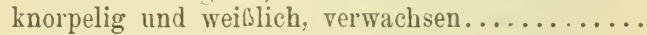

B. tief-buchtig-gezähnt, fast spießförmig, die unteren 3 eckig-rautenförmig, die oberen spießförmig-länglich; Aehren nur am Grunde beblättert.

5 B. M. N. J....... Tataricum. L. Gelappte M. B. buchtig-gezähnt, die unteren rautenförmig, die oberen eiförmig; Aehren bis hinauf beblättert.

B. M. N. J..........roseum. L. Rosen-M.

Die unteren B. 3 eckig-spießförmig, die oberen spießförmig-lanzettlich, die obersten ganzrandig ....... Die unteren B. lanzettlich-spiebförmig o. eiförmig.

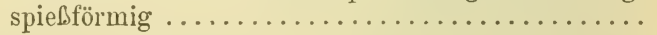

B. am Grunde herzförmig; Vorb. der Fr. rundlich, ganzrandig; S. theils aufrecht, theils wagrecht.

Cult. u. verw.......... hortense. L. Garten-M.

7 B. am Grunde querabgeschnitten; Vorb. der Fr. 3 eckig, oft gezähnt; alle S. aufrecht.

B. M. Sch. N. O. St. J.

hastatum. L. Spießblättrige M.

Aeste aufrecht; untere B. eilanzettlich, fast spießförmig; Frähren an der Spitze überhängend, locker ; Vorb. der Fr. rautenförmig oder eiförmig, ganzrandig. B. M. N. O.

oblongifolium. $W . K$. Länglichblättrige M.

Untere Aeste spreizend; untere B. lanzettlich-spießförmig, gezähnt; Frähren steif; Vorb. der Fr. spieß-rautenförmig. Verbr. $u$. $h f g$.

patulum. L. Gemeine M.

*) In $N$. kommt eine grauschülferige Form von A. hastatum L. vor. 


\section{EUROTIA. Adans. Hornmelde.}

B. ganzrandig, spitz; männliche Btknäuel in beblätterten endständigen Aehren, weibliche blattachselständig. $N$. (eingeschleppt).

ceratoides. (L.) C. A. Mey. Graufilzige H.

\section{CAMPHOROSMA. L. Kampherkraut.}

Rauhhaarige Staude mit blattachselständigen Bt.knäueln. J......... Monspeliaca. L. Haariges K.

\section{KOCHIA. Roth. Strandkraut.}

Einjährige Kräuter .....................

1 Stg. ausdauernd, halbstrauchig; B. lineal, flaumig; Anhängsel der Frhülle rundlich. M. N.

prostrata. (L.) Schrad. Halbstrauchiges S.

B. fädlich-pfriemlich, etwas fleischig, unterseits gefurcht; Anhängsel der Frhülle trockenhäutig, fast rautenförmig. $M . N$.

2 arenaria. (M. B.) Roth. Schmalblättriges S. B. lineal-lanzettlich, flach; Anhängsel der Frhülle krautig, sehr kurz, 3 eckig. Cult. u. verw. scoparia. (L.) Schrad. Ruthenförmiges S.

\section{CORISPERMUII. L. Wanzensame.}

Stg. hin- u. hergebogen, glänzend, sehr ästig, reichblütig. N........ nitidum. Kit. Glänzender W.

\section{ATHROCNEMUM Moq. Gliedermelde.}

Glieder der 'Lweige becherförmig ausgehöhlt, breithäutig-berandet. $J$.

macrostachyum. (Moric.) Bunge. Dickährige G.

\section{SALICORNIA. L. Glasschmalz.}

Einjähriges Kraut; die 3 beisammenstehenden Bt. in ein Dreieck gestellt. $M . N$. J.

herbacea. $L$. Krautiges G.

Kleiner Strauch; die 3 Bt. neben einander stehend. $J . \ldots \ldots \ldots \ldots \ldots$ fruticosa. L. Strauchiges G.

XII. SUAEDA. Forsk. Salzmelde.

Einjährige Kräuter; B. ziemlich spitz; N. 2.....

1 Kleiner Strauch; B. stumpf; N. 3. J. (?) fruticosa. (L.) Del. Strauchige S.

S. schwarz, netzig gefurcht. $M$. N. Südst. J. und dicker. N.....salsa. (L.) Pall. Russische S. 
XIII. SAISOIA. L. Salzkrant.

Stg. kurzhaarig; Aeste ausgebreitet; B. pfriemlich, mit dorniger Spitze; Frhülle knorpelig.

B. MI. N. St. Kr. J. .......Kali. L. Kali-S. Stg. kahl; Aeste aufgerichtet; B. lineal, halbstielrund, mit kurzer Stachelspitze; Frhülle häutig. J. Soda. $L$. Soda-S.

XIV. Familie. Amarantaceae. Fuchsschwanzgewächse.

Einjährige Kräuter mit ungetheilten, eiförmigen 0 . rautenförmigen, ganzrandigen o. doch nicht scharf gezähnten, schraubig gestellten B., ohne Nebenb. Bt. vielehig 0. 1häusig, meist mit Deckb. u. 2 Vorb., in Knäueln, welche meist zu ährenartigen Btständen vereinigt sind. Bthüllb. kelchartig, 3 o. 5 (ausnahmsweise 2 0. 4). Stb. so viele als Bthüllb. Frkn. 1, oberständig, 1 fächerig, mit einer Samenknospe. N. 2-3 (ausnahmsweise 4), mit kurzem 0. ohne Gr. Fr. mit einem Deckel aufspringend 0 . nicht aufspringend. S. mit Nährgewebe.

\section{Gattung.}

Stb. frei ; S. linsenförmig..........Amarantus. I.

\section{Arten.}

\section{AMARANTUS. L. Fuchsschwanz.}

$\int_{1} \begin{gathered}\text { Vorb. länger als die Bthülle, fast dornig-stachel- } \\ \text { spitzig; Stb. 5; Stg. kurzhaarig................ }\end{gathered}$

Vorb. nicht länger als die Bthülle; Stb. 3; Stg. kahl 0 , oben behaart ....................

Btstand gedrungen; Vorb. doppelt so lang als die Bthülle; Bthüllb. lineal-länglich.

Verbr. (fehlt Sch.)

retroflexus. $L$. Rauhhaariger $\mathrm{F}$.

Btstand ziemlich locker; Vorb wenig länger als die Bthülle; Bthüllb. eiförmig. J. Südt.

Stg. oben so wie die Bstiele fein behaart, nieder-

3 gestreckt; Vorb. ungefähr so lang als die Bthülle; Fr. länglich-eiförmig, nicht aufspringend. $J$.

deflexus. I. Niedergestreckter F.

Btknäuel blattachselständig*); Vorb. ungefähr so lang als die Bthülle; Fr. aufspringend.

4 Verbr. (fehlt Sch. O. S.) silvester. Desf. Wald-F. Die oberen Btknäuel zu Aehren vereinigt; Vorb. kürzer als die Bthülle; Fr. nicht aufspringend. Verbr................ viridlis. $L$. Grüner F.

*) Bei A. commutatus Kern. sind die obersten Knäuel zu kurzen Aehren vereinigt. 
XV. THELYGONEAE. - XVI. PHYTOLACCACEAE. 185

A nmerkung. Einige andere Arten, besonders der durch rothe Btstände ausgezeichnete A. caudatus L., werden oft cultivirt und verwildern bisweilen.

XV. Familie. Thelygoneae. Hundskohlgewächse.

Einjährige Kräuter mit eiförmigen, ganzrandigen, theils gegenständigen, theils wechselständigel) B., mit häutigen Nebenb. Bt. 1 häusig, unscheinbar, zu $2-3$ beisammen. Männliche Bt. mit 2-3 theiliger Bthülle und 100 . mehr (meist 12) Stb. Weibliche Bt. mit kleiner, keulig-röhriger, 2-4 lappiger Bthülle. Frkn. 1 fächerig, mit einer Samenknospe, unterständig, aber ganz einseitig entwickelt, so dass der ungetheilte Gr. und die Bthülle grundständig erscheinen. Fr. eine kugelige, dünnfleischige Steinfr. S. mit Nährgewebe.

Einzige Gattung...........Thelygonum. I.

\section{Art.}

\section{THELYGONUM. L. Hundskohl.}

Stg. niederliegend, streifenweise fein behaart; B. gestielt, etwas fleischig. $J$.

Cynocrambe. L. Europäischer H.

\section{Familie. Phytolaccaceae. Kermesgewächse.}

Hohe Stauden mit ungetheilten, wechselständigen B., ohne Nebenb. Bt. zwitterig, in reichblütigen Trauben. Bt.hüllb. 5. Stb. 10-20. Frkn. 1, oberständig, 7-10 fächerig, mit einer Samenknospe in jedem Fache; Gr. 7-10. Fr. eine mehrsamige Beere. S. schwarz, mit Nährgewebe.

\section{Gattung.}

Frkn. 7-10 riefig, die Riefen den Fächern entsprechend ....................... Phytolacea. I.

\section{Art.}

\section{PHYTOLACCA. L. Kermesbeere.}

Pfl. kahl; B. eilanzettlich, ganzrandig; Bt. röthlich; Beeren schwarz. Südt. J. (cult. u. verw.)

decandra. $I$. Gemeine $\mathrm{K}$. 


\section{Familie. Portulacaceae. Burzelkohlgewächse.}

Kleine Kräuter o. Stauden mit ungetheilten, ganzrandigen, wenigstens zum Theil gegenständigen B., ohne 0 . mit häutigen Nebenb. Bt. zwittrig. Bthülle doppelt: Kb. 2, oft am Grunde verwachsen; Krb. meist 5, oft am Grunde verwachsen. Stb. 3-5 0. 8-15. Frkn. 1, oberständig 0 . halb unterständig, 1 fächerig. mit mehreren Samenknospen. Gr. kurz, mit $3-8 \mathrm{~N}$. Fr. eine mehrsamige Kapsel. S. mit Nährgewebe.

\section{Gattungen.}

Kb. frei, bleibend; Blkr. weiß, trichterförmig, auf einer Seite gespalten, mit 5 theiligem, etwas ungleichem Saume; Stb. 3-5; Kapsel 3 klappig aufspringend, $2-3$ samig............. Montia. I.

Kb. verwachsen, ihr freier Theil zur Zeit der Frreife abfallend; Blkr. gelb, regelmäßig 5 blättrig; Stb. 8-15; Kapsel mit einem Deckel aufspringend, vielsamig.............. Portulaca. II.

\section{Arten.}

\section{MONTIA. $L$. Quellkraut.}

Einjähriges Kraut mit niedrigem, aufrechtem Stg.; Kapsel wenig länger als der K.; S. knötig-rauh, fast glanzlos. Verbr. (fehlt J.)

minor. Gmel. Aufrechtes Qu.

Staude mit fluthendem, verlängertem Stg.; Kapsel fast doppelt so lang als der K.; S. glänzend, fein punktirt. Verbr. (fehlt $J_{\text {.) }}$

rivularis. Gmel. Fluthendes $\mathrm{Qu}$.

\section{PORTULACA. L. Burzelkohl.}

B. länglich-keilig, fleischig, unter den Bt. zusammengedrängt. Verbr. (fehlt Sch.)

oleracea. L. Wilder B.

\section{Familie. Caryophyllaceae. Nelkengewächse.}

Kräuter o. Stauden, seltener Halbsträucher mit ungetheilten und meist auch ganzrandigen, gegenständigen, seltener wechselständigen B., ohne 0 . mit häutigen Nebenb. Bt. meist zwittrig, seltener vielehig 0. 2 häusig. Bthülle meist doppelt: Kb. 5, seltener 4, bald frei, bald verwachsen, in letzterem Falle gewöhnlich eine verlängerte Röhre (Kröhre) bildend und nur an der Spitze frei, so dass die Kröhre am Rande 4-5 zähnig ist; Krb. 5, seltener 4, manchmal fadenförmig o. ganz fehlend. Stb. 10 o. weniger. Frkn. 1, oberständig, meist 1 fächerig, mit zahlreichen, seltener mit wenigen 0. nur mit einer Samenknospe. Gr. 2-5 (selten 
mehr). Fr. meist eine mit Klappen 0 . Zähnen aufspringende Kapsel, selten nicht aufspringend und dann manchmal beerenartig. S. mit Nährgewebe.

Anmerkung. Bei einigen Gattungen ist die Btachse zwischen der Einfügung des K. u. der Blkr. verlängert ( „Frträger“).

\section{Gattungen.}

(Kb. zu einer Röhre verwachsen, nur an der Spitze

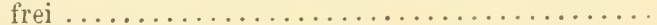
Kb. frei 0. nur am Grunde verwachsen ........ 17

Gr. 2; Stb. 10; Kapsel 1fächerig, an der Spitze

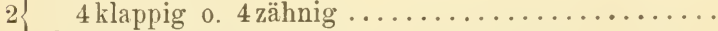
Gr. 3 o. $5 \ldots \ldots \ldots \ldots \ldots \ldots \ldots \ldots \ldots \ldots \ldots$

K. am Grunde von 2 o. mehreren schuppenförmigen

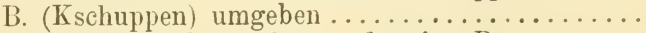
K. am Grunde ohne schuppenförmige B....... 6

Kb. zwar verwachsen, aber durch 5 trockenhäutige Streifen deutlich von einander geschieden, 3 nervig Kb. 7-11 nervig, ohne trockenhäutige Zwischenstreifen; Krb. mit verlängertem, linealem Nagel.

Dianthus. XIII.

Kleine, zarte Staude; Bt. einzeln in rispenähnlichen Btständen; K. glockig, am Grunde von 4 Schuppen umgeben; Krb. weiß o. rosa, nach unten keiligverschmälert ................. Tunica. XI. Einjährige Kräuter; Bt. zu hopfförmigen Büscheln vereinigt, welche von $6-8$ trockenhäntigen Schuppen ungeben sind; K. cylindrisch, am Grunde mit 2 Schuppen; Krb. rosa, mit verlängertem, linealem Nagel................. Kohlrauschia. X.

Kb. zwar verwachsen, aber durch 5 trockenhäutige Streifen deutlich von einander geschieden, 1- bis 3 nervig; Krb. nach unten keilig verschmälert.

Gypsophila. IX.

Kb. ohne trockenhäutige Zwischenstreifen, schwach 3 - 5 nervig; Krb. mit verlängertem, linealem

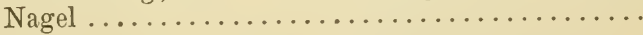

Stauden; K. mehr o. weniger cylindrisch; Krb. am Grunde der Platte mit Anhängsel (Nebenkrone).

Kahle 1 jährige Kräuter mit fleischrothen (selten weißen) Bt.; K. bauchig-5kantig; Krb. ohne Anhängsel............... Vaccaria. XII. 
Stb. 5; K. 5spaltig; Fr. eine rundum aufspringende 8 Kapsel; B. stechend; Bt. röthlich.. Drypis. VII. Stb. 10; Fr. eine mit 3-5 Zähnen aufspringende Kapsel, selten eine Beere; B. nicht stechend ....

N. ringsum behaart; Nagel der Krb. mit Flügel9 leisten; Kzipfel lang, blattartig; Gr. 5.

N. kahl (nur innen mit Papillen besetzt); Nagel der

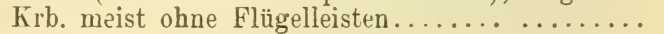

$10\left\{\begin{array}{l}\text { Gr. } 3 \text { (nur ausnahmsweise } 4-5 \text { ) } \ldots \ldots \ldots \ldots \ldots \\ \text { Gr. } 5 \text { (ausnahmsweise mehr } 0 \text {. weniger) } \ldots \ldots \ldots\end{array}\right.$

$\int \begin{aligned} & \text { Fr. eine } 1 \text { fächerige Beere; Krb. } 2 \text { spaltig; Stg. lie- } \\ & \text { gend } 0 \text {. kletternd; Bt. grünlich-weiß. }\end{aligned}$

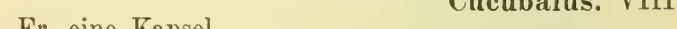

Fr. eine Kapsel ...................... 12

( Nagel der Krb. mit Flügelleisten; niedrige Alpenpfl.

12 mit großen, lebhaft rosenrothen Bt.

Nagel der Krb ohne Flïgelleisten. Saponaria. XIV. $13\left\{\begin{array}{c}\text { Kapsel } 1 \text { fächerig .................................... } 14 \\ \text { Kapsel am Grunde unvollständig } 3(-5) \text { fächerig, mit } \\ 6(-10) \text { Zähnen aufspringend........ Silene. III. }\end{array}\right.$

Zarte Stauden mit kleinen Bt; K. schwach 10 nervig; Krb. meist 4-5zähnig; S. am Rande mit strah-

14 lendem Kamm ............Heliosperma. V. Kräuter oder Stauden mit ansehnlichen Bt.; K. 10rippig; Krb. 2 spaltig; S. oft höckerig, aber ohne strablenden Kamm..........Melandryum. VI.

$15\left\{\begin{array}{l}\text { Bt. zwittrig; Kapsel mit } 5 \text { (selten } 3,4,6) \text { Zähnen } \\ \text { aufspringend } \ldots \ldots \ldots \ldots \ldots \ldots \ldots \ldots \ldots \ldots \ldots \ldots \ldots \ldots \ldots \ldots \ldots \ldots \ldots\end{array}\right.$ Bt. 2 häusig; Kapsel mit 10 (o. mehr) Zähnen aufspringend.............. Melandryum. VI.

$16\{$ Kapsel 1 fächerig. ................ Lychnis. IV.

Kapsel am Grunde mehrfächerig..... Viscaria. II.

$\int \begin{gathered}\text { Krb. } 2 \text { spaltig } 0 \text {. mit einer spitzigen Kerbe ausge- } \\ \text { randet; Bt. wei } \ldots \ldots \ldots \ldots \ldots \ldots \ldots \ldots \ldots \ldots \ldots \ldots \ldots \ldots \ldots\end{gathered}$

Krb. ungetheilt 0 . seicht ausgerandet 0 . ausgebissengezähnt, bisweilen fadenförmig 0 . ganz fehlend.. 20

Nebenb. fehlen; Gr. $3-5 \ldots \ldots \ldots \ldots \ldots \ldots \ldots$

18 Trnckenhäutige Nebenb. vorhanden; Gr. 1, 3 theilig.

Polycarpon. XXVI 
Gr. meist 3, seltener 2, 4 0. 5, im letzten Falle vor den Krb. stehend; Kapsel kugelig o. eiförmig, mit 4 bis 10 (meist 6 ) bis über die Mitte reichenden, ungetheilten, seltener mit 4-6 an der Spitze 2 spaltigen Klappen aufspringend...... Stellaria. XV. Gr. meist 5, zwischen den Krb. stehend, seltener 3 bis 4 ; Kapsel cylindrisch 0 . kegelig-cylindrisch, mit 6-10 (meist 10) kurzen Zähnen aufspringend.

Cerastium. XVI.

20 Kib. normal entwickelt, wenn auch oft sehr klein . 21

$20\{$ Krb. fadenförmig (Stf. ähnlich) 0. ganz fehlend ... 31

$21\{$ B. mit trockenhäutigen Nebenb............. 22

$21\{$ Nebenb. fehlen ..................... 26

22 B. gegenständig (oft scheinbar büschelig o. quirlig) 23

B. wechselständig ...................... 25

Gr. 1, 3 theilig; einjährige Kräuter.

Gr. Polycarpon. XXVI.

B. scheinbar gebüschelt o. quirlig; Gr. 5 ; S. kreisrund; 1 jährige Kräuter mit weiðen Bt.

Spergula. XXIII.

24 B. gegenständig; Gr. meist 3 (seltener 4-5); S. 3 eckig 0. verkehrt-eiförmig; Kräuter o. kleine Stauden mit blass rosenrothen, seltener weißen Bt.

Spergularia. XXIV.

Gr. 3, fädlich, abstehend-zurückgekrümmt; Fr. 3klappig aufspringend, vielsamig.

Telephium. XXV.

3 sitzende N. vorhanden; Fr. 1 samig, nicht aufspringend ............. Corrigiola. XXVII.

$26\{$ Gr. $2-3$ (nur ausnahmsweise mehr) .........

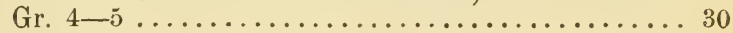

Kapsel mit 3 (ausnahmsweise 4-5) ungetheilten

27 Klappen aufspringend .............. Alsine. XX. Kapsel mit 4 0.6 (ausnahmsweise 8 o. 10) ungetheilten o. mit $2-3$ zweispaltigen Klappen aufspringend . 28

$\mathrm{Krb}$. vorne ausgebissen-gezähnelt; Stb. $3-5$; Bt. in 28 einer Scheindolde; Pfl. mehr o. weniger drüsig behaart. .............. Holosteum. XVII. Krb. ganzrandig o. etwas ausgerandet .......... 29 Krb. stets 5 ; Kapselklappen wenigstens anfangs kurz, zahnförmig; S. ohne Anhängsel.

Arenaria. XXI.

Krb. 4-5; Kapselklappen ziemlich tief reichend; S. mit schuppenförmigem Anhängsel.

Moehringia. XXII. 
Gr. vor den Krb. stehend; Kapsel bis zum Grunde 4-5 klappig aufspringend; S. glatt. Sagina. XIX. Gr. zwischen den Krb. stehend: Kapsel an der Spitze mit 8-10 Zähnen aufspringend; S. bekn̈rnelt; 1 jährige, kahle Kräuter....... Moenchia. XVIII.

B. mit trockenhäutigen Nebenb.; Krb. faden- 0. 31 borstenförmig, selten fehlend; Stb. 5.........

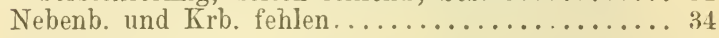

$\mathrm{Kb}$. weiß, knorpelig-verdickt, gekielt und fein zu32 borstenförmig; Stb. 5........Illecebrum. XXX. Kb. grün, etwas concav; kleine Stauden 0. Halbstr. 33 Bt. dicht gedrängt, von großen, silberweißen Deckb. umhüllt; Gr. 2 theilig .....Parony chia. XXVIII. 33 Bt. in blattwinkelständigen Knäueln, ohne auffallende Deckb.; Gr. äußerst kurz, mit $2 \mathrm{~N}$.

Herniaria. XXIX.

$34\{$ Gr. $2-3$ (nur ausnahmsweise mehr) ......... 35

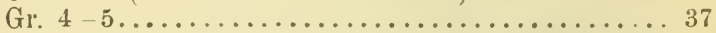

(Fr. nicht anfspringend, 1 samig; Gr. 2; Kb. knorpelig, erhärtend und mit der Fr. abfallend.

Scleranthus. XXXI.

Fr. eine vielsamige Kapsel; Gr. meist 3; Kb. krautig 36

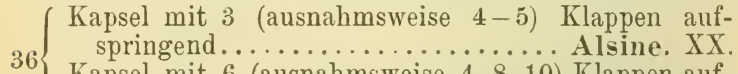
Kapsel mit 6 (ausnahmsweise 4, 8, 10) Klappen aufspringend................. Stellaria. XV. 37 Kapsel bis zum Grunde 4-5 klappig aufspringend. Kapsel an der Spitze mit 6-10 (meist 111) kurzen Zähnen aufspringend........ Cerastium. XVI.

Arten.

\section{AgRostemin. $L$. Kornade.}

Einjähriges, hochwüchsiges Kraut; Stg. anliegend behaart; B. lineal-lanzettlich; Blkr. trübpurpurn. Verbr.............. Githago. I. Gemeine K.

\section{VISCARIA. Röhl. Pechnelke.}

Stg. unter den oberen Knoten Klebrig; Btstand unterbrochen; Krb. ungetheilt, earminroth (selten weiß). Verbr.

viscosa. (Gilib.) Aschers. Klebrige P. Stg. nicht klebrig; Btstand dicht, kopfig; Krb. 2 spaltig, hellpurpurn. A. v. T. S. $K$.

alpina. (L.) Don. Alpen-P 


\section{SILENE. L. Leimkraut.}

Dichtrasige Alpenpfl. mit sehr kurzem o. fast feh$1\left\{\begin{array}{l}\text { lendem Stg.; B. lineal-pfriemlich; Bt. rosenroth } \\ \text { (selten weiß). A.... acaulis. L.*) Stengelloses L. }\end{array}\right.$ Stg. stets gut entwickelt................ 2

K. eiförmig, stark aufgeblasen, 20-30 rippig u. netzaderig; Krb. in der Knospe dachig, weißlich. Verbr. u. hfg.

2 venosa. (Gilib.) Aschers.**) Aufgeblasenes L.

K. nicht netzaderig, nur manchmal mit Quernerveu zwischen den Rippen (dann aber nur 10 rippig);

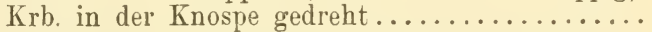

K. 30 rippig, klebrig-flaumig, zuletzt eiförmig; Stg. 3 grauflaumig; Krb. rosenroth. (N. Sïdt.) Kr. J.

conica. L. Kegelfrüchtiges L.

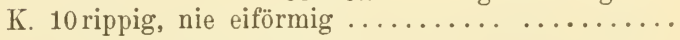

Bt. in einseitswendigen o. 2 zeiligen, oft gepaarten

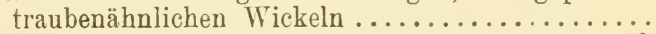

4 Bt. in einfachen 0 . häufiger zusammengesetzten, oft traubig 0. rispig angeordneten Trugdolden, seltener einzeln ........................ 10

Krippen durch Quernerven verbunden; Kzipfel schmal u. spitz; Krb. rosenroth; Stf. kahl; Stg. u. B. von

5 kurzen Haaren rauh. $K$. $K r$. (?)

cerastioides. L. Hornkrautähnliches L.

K. ohne Quernerven .................. 6

(Bt. in gepaarten Wickeln, sehr kurz gestielt; Krb. 2 spaltig

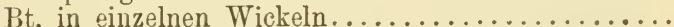

Bt. weiऽ; Frträger kahl, viel kürzer als die Fr.; S. an den Seiten flach. ( $M . N$.) $J$.

dichotoma. Ehrh. Gabelspaltiges L

Bt. rosenroth; Frträger flaumig, kaum kürzer als die Fr.; S. an den Seiten ausgehöhlt. J.

vespertina. Retz. Abend-L.

Kzipfel spitz; Krb. ungetheilt (selten ausgerandet), fleischroth 0 . weißlich ${ }^{* * *}$ ); Btstand drüsig-behaart. B. M. Sch. N. St. Kr. J. T.

Gallica. L. Französisches L.

Kzipfel stumpf; Krb. 2 lappig o. 2spaltig, rosen-

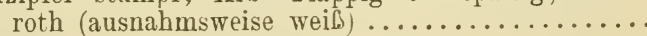

*) Die Kapsel ist gewöhnlich viel länger als der K., während sie bei S. exscapa All. den K. kaum überragt.

**) In Bezug auf die Wuchsform u. die Gestalt der B. lassen sich mehrere Formen unterscheiden.

***) S. quinquevulnera L. (J.) hat große blutrothe Flecken auf dem Krb. 
K. ziemlich schmal cylindrisch, nach oben etwas keulig verdickt; Krb. bis über die Mitte 2 spaltig; Frträger kaum kürzer als die Fr.; S. am Rücken tief-spitzrinnig. J...colorata. Poir. Gefärbtes L. K. nach dem Verblühen stark aufgeblasen; Krb. 2 lappig; Frträger viel kürzer als die Fr.; S. am Rücken stumpfrinnig. $N$. J. (verv.)

pendula. $L$. Hängendes $\mathrm{L}_{\text {s }}$.

Bt. einzeln, endständig, nur ausnahmsweise mehrere an einem Stg., weißlich .............. 11

Stg. mehrblütig ................... 1

Alle Kzipfel stumpf; Nägel der Blkr. nur etwas aus dem K. herausragend; wenigstens der untere Theil der Kapsel im K. eingeschlossen. T. K. St. Kr. J.

Saxifraga. L. Steinbrech-L.

2-3 Kzipfel spitz, die anderen stumpf; Nägel der Blkr. weit aus dem K. herausragend; Kapsel über den Kelch emporgehoben. $K$. St. J.

fruticulosa. Sieb. Halbstrauchiges L.

Stg. u. K kahl (ersterer manchmal unten mit vereinzelten Härchen), jedoch oft klebrig*)....... 13

Stg. (u. meist auch der K.) mehr o. weniger dicht, wenigstens stellenweise flaumhaarig 0 . doch rauh 16

Btstand durchaus trugdoldig; Krb. ausgerandet 0 . höchstens bis zu einem Drittel ihrer Länge 2spaltig . . . . . . . . . . . . . . . . . .

Btstand traubenartig; Krb. bis über die Mitte 2spaltig, weißlich; Btstiele viel kïrzer als der verlängerte, keulig-walzliche K.; B. grau; Stg. oben klebrig; Staude. $B$.

longiflora. Ehrh. Langblütiges L.

Btstiele viel kürzer als der verlängerte, keulig-walzliche K.; Krb. lebhaft rosa, selten weiß; Btstand dicht, fast ebensträußig; B. eiförmig, wie der klebrig beringelte Stg. bläulich bereift; einjähriges Kraut. Sïdt. Kr. J., sonst cult. u. verw.

Armeria. L. Garten-L. Btstiele länger als der kurze K.; Krb. weiß 0 rosa;

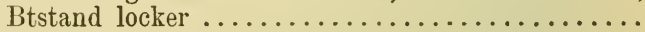

Einjähriges Kraut; Stg. oben klebrig beringelt; Bt. mittelgroß, nicht viele, von einander sehr entfernt. Sïdst. J.......... Cretica. L. Beringeltes L.

15 Niedrige, zarte Staude; Stg. meist sehr verzweigt, nicht klebrig, wie die B. bläulichgrün; Bt. klein, zahlreich, auf dünnen Stielen. $A$. (fehlt $N$. O. J.) rupestris. $L$. Felsen-L.

*) In $B$. u. $M$. kommt eine kahle Form der S. nutans L. vor. 
$16\{$ Einjährige Arten; Btstand trugdoldig ........ 17

Stauden; Btstand trauben- 0 . rispenartig ....... 18

Pfl. niedrig, drüsig-weichhaarig; die unteren B. verkehrteiförmig, die oberen länglich-lanzettlich; Bt.

17 rosa. J..........sedoides. Poir. Fetthennen-L. Pfl. hochwüchsig, äußerst kurz flaumig, nicht drüsig behaart; B. lineal-lanzettlich; Bt. Heischroth.

(N. O.) T. K. Sïdst. J. linicola. Gmel. Flachs-L.

Krb. ungetheilt, grünlich; K. röhrig-glockig, kahl; B. grauflaumig, die unteren fast spatelig.

18 B. II. N. O. St. Südt.

Otites. (L.) Sm. Ohrlöffel-L.

Krb. 2 spaltig . ................... 19

Stg. oben klebrig.................... 20

Stg. nicht klebrig, sehr kurz flaumhaarig; B. läng-

19 lich-keilig, die oberen lineal; Bt. fast quirlig stehend; Krb. ohne Krönchen, grünlich-weiß. N. multiflora. (Ehrh.) Pers. Vielblütiges L.

K. am Grunde abgestutzt und genabelt........21

K. am Grunde allmälig verschmälert, walzlich, drüsig-weichhaarig wie die ganze Pfl, zur Frzeit aufgeblasen; Krb. grünlichweiß, meist bekrönt. Südst. $K r$. J. viridiflora. $L$. Grünblühendes L.

${ }_{21}$ Bt. nickend, meist weißlich ${ }^{*}$ ); die unteren B. ellip21 tisch-lanzettlich. Verbr. nutans. $L$. Nickendes $L$. Bt. aufrecht 0 . abstehend, nicht nickend.........

Krb. mit 2 spaltigem Kr rönchen und kahlen Nägeln; untere B. spatelig-lanzettlich; Bt. kurz gestielt, grof; Kapsel lang verschmälert. $J$.

paradoxa. L. Seltsames L.

22 Krb. meist ohne oder mit undeutlichem Krönchen $\mathrm{u}$. etwas bewimperten Nägeln; untere Zweige des Btstandes verlängert, abstehend; Frträger behaart. Verbr. (fehlt Sch. MI. O. S.)

Italica. Pers.**) Italienisches L.

\section{LYCHNIS. L. Lichtnelke.} $1\left\{\begin{array}{l}\text { Krb. ungetheilt o. ausgerandet, purpurn o. weiß; } \\ \text { Stg. ll. B. dicht filzig; Btstiele länger als der K. }\end{array}\right.$ Sïdt. Kr. J. coronaria. (L.) Desr. Bekrönte L. Krb. 2- 0. 4 spaltig, fleischroth (selten weiß) ..... 2

*) Silene livida Willd. (im Süden des Gebietes) hat trübröthliche $\mathrm{Bt}$.

$\left.{ }^{* *}\right)$ S. nemoralis W. K. hat breitere Grundb. und einen dichteren Btstand; in B. u. $N$. wächst nur diese. 
Krb. 2 spaltig, mit breiten, abgerundeten Lappen; Stg. u. B. dicht filzig. Sü̈t.

Flos Jovis. (L.) Desr. Jupiter's L. 2 Krb. tief 4 spaltig, mit schmalen, linealen Zipfeln; Stg. kurzhaarig; B. fast kahl. Verbr.

Flos Cuculi. L. Kukuks-L.

\section{HELIOSPERMA. Rchb. Strahlensame.}

Pfl. weißlich - wollig; B. lanzettlich, die unteren spatelig; Kapsel fast kugelig, im K. eingeschlossen; Krb. weib. St. $K r$. J.

eriophorum. Juratzka. Wollhaariger St.

Pfl. kahl o. fast kahl, nur oben klebrig beringelt

B. schmal-lineal; K. kahl; Kapsel ungefähr so lang als der K.; Krb. weiß, seltener rosa.

A. u. Vora. (hfg.)

quadrifidum. (L.) A. Br. Vierzähniger St.

B. lineal-lanzettlich; K. feinflaumig; Bth. größer; Kapsel doppelt so lang als der K.; Ḱrb. weiß o. rosa. A. u. Vora. (fehlt J.)

alpestre. (Jacq.) A. Br. Alpen-St.

\section{MELANDRYUM. Röhl. Marienröschen.}

$1\{$ Bt. zwittrig; Gr. $3 \ldots \ldots \ldots \ldots \ldots \ldots \ldots \ldots \ldots$

Bt. 2 häusig; Gr. 5 (manchmal mehr) ...........

Niedrige Staude, deren blühende Stg. seitlich aus der Brosette entspringen; B. lanzettlich; Bt. groß, rosenroth, mit aufgeblasenem, drüsig bebaartem K. Sïdt. Elisabethae (Jan.) Rohrb. Großblütiges M.

Kräuter mit endständigem Btstand............. Krb. ohne Krönchen, milchweiß; Btstand reichblütig, die Bt. in Scheinquirlen angeordnet; $\mathrm{Pfl}$. 2jährig. $B . M . \Lambda$.

viscosum. (L.) Čelak. Klebriges M.

$3 \mathrm{Krb}$. mit 2 theiligem Krönchen, bleichrosa 0 . weiß; Btstand armblütig, die Bt. von einander mehr 0 . weniger entfernt; Pfl. 1 jährig.

$V e r b r$. (fehlt $K . K r$.J.)

noctiflorum. ( $L$.) $F$ r. Nachtblühendes M.

Btstiele u. K. drüsig behaart; Bt. weiß, selten hellrosa; Kapsel eikegelförmig, mit gerade vorgestreckten Zähnen aufspringend. Verbr.

album. (Mill.) Garcke. Weißes M.

4 Btstiele u. K. zottig, ${ }^{*}$ ) aber nicht drüsig; Bt. gesättigt rosenroth, selten blaßrosa 0 . weiß; Kapsel rundlich-eiförmig, mit zurückgerollten Zähnen aufspringend. Verbr.

rubrum. (Wgl.) Garcke. Rothes M.

*) In $B$. wurde eine vollständig kahle Form beobachtet. 
A n merk u ng. Zwischen M. album u. M. rubrum kommt ein Bastart vor.

\section{DRYPIS. L. Kronenkraut.}

Stämmchen dicht u. steif; äußere Deckb. lanzettlich, mit langem Enddorn, viel länger als die Bt.; $\mathrm{K}$. nach unten verschmälert, am Grunde häutig; Krb. bis zum Grunde der Platte 2 spaltig, ihr Nagel deutlich aus dem $\mathrm{K}$. herausragend. .J.

spinosa. L. Dorniges $K$.

Stämmchen lockel und schlaff; äußere Deckb. eiförmig, mit kurzem Enddorn, nicht länger als die Bt.; K. gleich breit, bis zum Grunde lederig; Krb. nicht ganz bis zum Grunde der Platte 2 spaltig, ihr Nagel kaum aus dem $\mathrm{K}$. herausragend. $K r$. J.

Jacquiniana. Murb. et Wettst. Krainer K.

\section{CLCUBALUS. L. Taubenkropf.}

Staude; Stg. 4 kantig, etwas raul, oben fein behaart; B. eiförmig, wimperig-gesägt; Bt. grünlich-wei $\mathrm{B}$. Verbr. (fehlt $S$. J.) ...baccifer. $L$. Gemeiner 'T.

\section{GYPSOPHILA. L. Gypskraut.}

(Einjähriges Kraut; Bt. rosa, über die ganze Pf. zerstreut; Stg. vom Grunde an gabelig-verzweigt; K. kreiselförmig, 5zähnig; B. lineal, nach beiden Enden verschmälert. Verbr. (fehlt J.)

muralis. L. Mauer-G.

Stauden; Bt. rispig oder doldentraubig ...........

B. lineal, nach beiden Enden verschmälert; Bt. fast ebensträußig, weiß 0 . rosa $\ldots \ldots \ldots \ldots \ldots \ldots$

B. lanzettlich, sehr spitz, meist 3 nervig; Bt. in

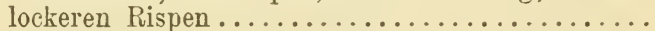

Stg. oberw. nebst den Aesten kahl; Stb. u. Gr. kürzer als die Blkr. A. u. Vora.

repens. $L$. Kriechendes $G$.

Stg. oberw. nebst den Aesten klebrig-flaumig; Stb. u. Gr. länger als die Blkr. B. $M$. Sch.

fastigiata. $L$. Doldiges $G$.

Stg. kahl; Rispenäste u. Btstiele klebrig-flaumig . 5

4 Stg. unterw. kurzhaarig; Kzipfel rundlich-eiförmig; Bt. weiß, selten rosa. $M$. $N$.

paniculata. $L$. Rispiges G.

Kzipfel zugespitzt, zurückgekrümmt; Krb. weib. $N$. (eingeschleppt).

acutifolia. Fisch. Spitzblättriges G.

Kzipfel fast stumpf; Krb. lila. $N$. (eingeschleppt.)

perfoliata. L. Durchwachsenblättriges G. 
Anmerkung. Bei Triest wurde G. porrigens (L.) Boiss., durch 3 nervige Kzipfel ausgezeichnet, eingeschleppt gefunden.

\section{KOHLRAUSCHIA. Kth. Knopfuelke.}

Stg. kahl; Bscheiden sehr kurz; S. fast glatt.

Verbr. (fehlt Sch. O. S.)

prolifera. (L.) Kth. Sprossende K. Stg. an den mittleren Gliedern behaart; B scheiden etwa $3 \mathrm{mal}$ so lang als die Breite der B.; S. mit Dörnchen besetzt. $J$.

velutina. (Guss.) Rchb. Sammtige K.

\section{TUNICA. Scop. Felsennelke.}

Stg. liegend oder aufsteigend; B. lineal, spitz, an den Stg. angedrückt. Verbr:

saxifraga. (L.) Scop. Gemeine F.

\section{VACCARIA. Medic. Kulikant.}

Krbnägel nicht aus dem $K$. herausragend, Platte keilig-verkehrt-eiförmig, blassrosa. Verbr.

parviflora. Mnch. Kleinblütiges $\mathrm{K}$.

Krbnägel deutlich aus dem $\mathbf{K}$. herausragend, Platte größer, verkehrt-eiförmig, lebhaft rosa.

B. N. Kr. J. grandiflora. (Fisch.) Großblütiges K.

\section{DIANTHUS. $L$. Nelke.}

$1\left\{\begin{array}{c}\text { Krb. gezähnt, seltener ganzrandig, fleischfarben } 0 . \\ \text { purpurn } \ldots \ldots \ldots \ldots \ldots \ldots \ldots \ldots \ldots \ldots \ldots \ldots \ldots \ldots \ldots \ldots \ldots \ldots \ldots\end{array}\right.$

$\mathrm{Krb}$. tief-fingerig 0 . fiederspaltig-eingeschnitten .... 17

${ }_{2}$ Bt. in Büscheln o. in Köpfchen............ 3

$2\{$ Bt. rispig o. einzeln .................. 10

Hüllb. u. Kschuppen rauhhaarig, gefurcht, lanzettlich-pfriemlich, so lang als die Kröhre; Stg. flaum-

3 haarig. Verbr..........Armeria. L. Rauhe N. Hüllb. u. Kschuppen kahl, o. nur am Rande behaart,

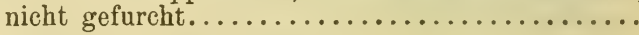

B. kurz gestielt, darunter scheidig, lanzettlich; äußere Hüllb. lineal-lanzettlich, sehr spitz, zurückgebogenabstehend. T. K. St. Kr. J. (sonst cult. u. verw.) barbatus. $L$. Bart-N.

B. nicht gestielt, lineal o. lineal-lanzettlich....... 
Bscheiden so lang als die Breite des B.; Kschuppen eiförmig, begrannt; B. lineal-lanzettlich, verschmälert-zugespitzt, meist 5 nervig; Krb. verkehrteiförmig, gezähnt. B. N. St. Kr. J. Südt.

Seguierii. Vill. Seguier's N.*,

Bscheiden doppelt 0. 4 mal so lang als die Breite des B.; Kschuppen lederig..................

Bcheiden 2 mal länger als die Breite des B.; Stg. 4 kantig; Bt. in einem endständigen, meist 6 blütigen Köpfchen; Kschuppen bleichgrün, pfriemlich-bespitzt, Spitze so lang als die Kröhre. $J$.

Liburnicus. Bartl. Illyrische N.

Bscheiden 4 mal länger als die Breite des B.; Kschuppen braun, sehr stumpf, begrannt ......... 7

Platte der Krb. ungefähr so lang als ihr Nagel... 8

7 Platte der Krb. höchstens halb so lang als ihr Nagel; Btköpfchen $6-20$ blütig ....................

Stg. 4 kantig: Btköpfchen meist reichblütig; $K$ schuppen lederig-häntig. $T . S$. ( $K r$ ? ?)

vaginatus. Chaix. Langscheidige $\mathrm{N}$.

Stg. fast stielrund; Btköpfehen armbliitig; Kschuppen krautig. Verbr.

Carthusianorum. L. Karthäuser-N.

Platte der Krb. halb so lang als der Nagel, hellpurpurn, verkehrt-eiförmig, vorn scharf gezähnelt, nicht gebärtet. $M . \quad N$.

Pontederae. Kern. Vielblütige N.

9 Platte der Krrb. mehrmals kürzer als der Nagel, dunkelblutroth, spatelförmig, vorn wenig gezähnelt, am Grunde etwas gebärtet. $J$.

sanguineus. Vis. Blutrothe $\mathrm{N}$.

Stg. flaumig-rauh; Bt. einzeln; Kschuppen elliptisch, samint der Granne halb so lang als der K.; Krb. verkehrt-eiförmig, gezähnt, rosa mit einem purpurnen Ringe, selten weiß. Verbr.

deltoides. $L$. Deltafleckige N.

Stg. $k a h l \ldots \ldots \ldots \ldots \ldots \ldots \ldots \ldots \ldots \ldots \ldots \ldots \ldots \ldots \ldots$

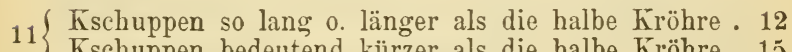
Kschuppen bedeutend kürzer als die halbe Kröhre. 15

*) Der typische D. Seguierii Vill. hat kahle, am Rande rauhe B.; bei D. silvaticus Hoppe (B.) sind die B. ganz kahl und weniger zugespitzt; bei D. collinus W. K. (N. St. Südt.) sind die B. auch auf den Flächen von kurzen Härchen rauh. 
Alpenpfl. mit meist 1 blütigem Stg.; Krb. mit breit abgerundeter, vorne gezähnelter Platte........ 13

Stg. mehrblütig; Platte der Krb. nach der Spitze verschmälert, meist ganzrandig; Kschuppen fast dornig-stachelspitzig, am Rande trockenhäutig. $J$. ciliatus. Guss. Gewimperte N.

B. lineal-lanzettlich, verhältnismäßig breit u. kurz; Krb. doppelt so lang als der K., am Schlunde dunkler gesprenkelt. $A$. (fehlt $\left.K r^{\circ} . J.\right)$

alpinus. $L$. Alpen-N.

B. lineal......................... 14

B. spitz u. starr; Kschuppen mit spitzer, steifer Granne. A. v. T.

neglectus. Lois. Vernachlässigte $\mathrm{N}$.

B. stumpf, dicklich; Kschuppen mit langer, krautiger Spitze. A. v. T. S. K. S't.

glacialis. Hke. Gletscher-N.

4 Kschuppen an den K. angedrückt; Krb. vorne gezähnt

Nur 2 Kschuppen an den $K$. angedrückt, die übrigen Schuppenpaare vom $K$. entfernt; Krb. fast ganzrandig. J.... Tergestimus. Rchb. Triestiner N.

B. grasgrün, spitz; Krb. nicht gebärtet; Bt. geruchlos. S. T. K. St. Kr.J.

inodorus. (L.) Geruchlose N.

B. seegrün*), stumpflich; Krb. gegen den Schlund hin gebärtet; Bt. wohlriechend. M. B. O. T.

caesius. Sm. Blaugraue N.

Kschuppen mindestens halb so lang als die Kröhre, pfriemlich-begrannt; B. lineal; Bt. fleischfarben

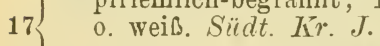

monspessulanus. $L$. Vorgebirgs-N.

Kischuppen 3-4mal kürzer als die Kröhre....... 18

B. lineal-lanzettlich, grasgrün; Platte der Krb. fast bis zum Grunde zerschlitzt; Bt. rosa o. lila, wohl18 riechend. Verbr....... superbus. I. Hochmuth. B. lineal-pfriemlich; Platte der Kirb. höchstens bis

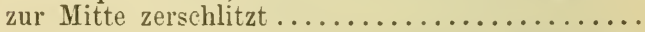

Pfl. grasgrün; Stg. oben nicht kantig; Kschuppen verkehrt-eirundlich; Platte der Krb. kürzer als die Kröhre, weiß. $N$.

serotinus. W' $K$. Spätblühende N.

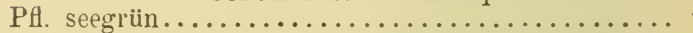

*) Hierher gehört auch die oft cultivirte Gartennelke (D. Caryophyllus L.), welche sich u. a. durch bartlose Blkr. von D. caesius Sm., durch seegrüne B. u. wohlriechende Bt. von D. inodorus (L.) unterscheidet. 
Kschuppen eiförmig o. länglich-eiförmig, geschweift

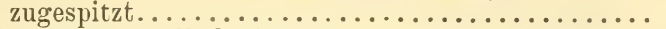

Kschuppen rundlich-eiförmig, mit aufgesetzter kurzer Stachelspitze; Platte der Krb. fast so lang als die Kröhre; Bt. bleichrosa, selten weiß, wohlriechend. M. $\boldsymbol{N}$. O. St. K. Kr. J.

plumarius. L. Feder-N.

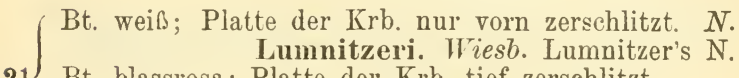

21 Bt. blassrosa; Platte der Krb. tief zerschlitzt.

A. u. Vora. v. O. St. K. Kr. J. Südt.

Sternbergii. Sieb. Sternberg's N.

Anmerkung. Dianthus - Bastarte sind sehr selten; im Gebiete wurden wildwachsend beobachtet: D. Armeria $X$ deltoides $(B),$.$D . barbatus \times$ monspessulanus $(J$.$) und D$. barbatus $X$ superbus $(S$.$) .$

\section{SAPONARIA. L. Seifenkrant.}

Dichtrasige Alpenpfl. mit sehr kurzem, 1 blütigem Stg. und großen, lebhaft rosenrothen (selten weißen) Bt.; B. lineal; K. aufgeblasen, kurz-zottig.

A. v. T. S. K. St. Pumilio. (L.) Fzl. Alpen-S.

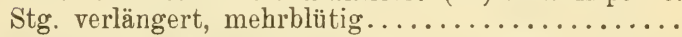

Bt. groß, blass-rosa 0 . weiß, in ziemlich dichten Büscheln; alle B. spitz; Btstand kahl o. behaart. Verbr........... officinalis. L. Gemeines S.

2 Bt. klein, lebhaft rosenroth (selten weiß), in lockeren Trugdolden; B. klein, die unteren stumpf; Btstand klebrig-zottig. $T$. $K$. $K r$.

ocymoides. $L$. Kleinblütiges $\mathrm{S}$.

\section{STELLARIA. $L$. Sternmiere.}

$1\{$ Stg. stielrund.....................

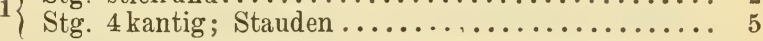

Kraut; Krb. höchstens so lang als der K., manch2 mal fehlend; Stg. 1 reihig behaart; B. eiförmig. Verbr. u. $h f g . . . \ldots \ldots$ media. $\left.L{ }^{*}\right)$ Hühnerdarm.

Stauden; Krb. länger als del K............ 3

Gr. 3 ; Kapsel 6 klappig ............... 4

Gr. 5; Kapsel 5 kantig, mit 5 an der Spitze 2 zähnigen Klappen aufspringend; B. herz-eiförmig. Verbr......... aquatica. (L.) Scop. Wasserdarm.

*) Die typische Art hat meist 3-5 Stb.; St. Cerastium Pers. ist in allen Theilen größer und hat 10 Stb.; St. pallida (Dum.) Piré ist eine zarte Folm ohne Krb. und mit 2-3 Stb. 
Wst. Knöllchen tragend; B. fast sitzend; Krb. wenig länger als der K. Südst. Kr.K.

bulbosa. Wulf. Knollige St.

4 Wst. ohne Knöllchen; untere B. lang gestielt; Krb. doppelt so lang als der K. Verbr.

nemorum. $L_{0}^{*}$ ) Wald-St.

Krb. bedentend kürzer als der K.; Stg. kahl; B. elliptisch-lanzettlich, am Grunde gewimpert; DeckB. am Rande kahl. Verbr.

uliginosa. Murr. Schlamm-St.

$\mathrm{Krb}$. so lang 0 . länger als der K.; B. lanzettlich 0 .

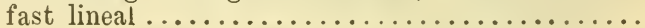

Deckb. krautig; B. lanzettlich, lang zugespitzt, am Rande $u$. auf dem Kiele rauh; Krb. doppelt so lang als die $\mathrm{Kb}$. Verbr.

Deckb. trockenh

Holostea. L. Großblumige St.

Stg. u. B. vollkommen kahl; B. lineal-lanzettlich, spitz; Deckb. am Rande kahl; Krb. meist bedeutend länger als der K. B. $M$. Sch. $N$.

palustris. Ehrh. Sumpf-St.

B. am Grunde meist gewimpert, ebenso die Deckb. am Rande; Krb. ungefähr so lang als der K....

Stg. kahl; B. u. Deckb. am Grunde etwas bewimpert; Krb. 3 nervig. Verbr. graminea. L. Grasartige St.

8 Stg. oberwärts rauh; B. am Rande u. auf dem Kiele rauh; Krb. (im frischen Zustande) nervenlos. B. Sch. S. T. Frieseana. Sér. Raubblättrige St.

\section{CERASTIUM. $L$. Hornkraut.}

Krb. kaum länger als der K., oft kürzer, manchmal

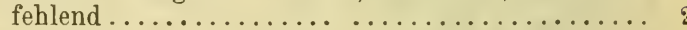

Krb. doppelt so lang 0 . doch beträchtlich länger als

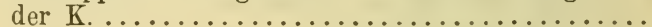

Kb. und die krautigen Deckb. an der Spitze bärtig; einjährige Kräuter................... 3

$\mathrm{Kb}$. und die oberen Deckb. an der Spitze kahl .... 4

*) St. glochidisperma Murbeck (S̈̈̈st. J.) ist meist fast kahl; ihre Kapsel ist fast doppelt so lang als der K. und die S. sind am Rande feinstachelig. 
(Stf. kahl; Frstiele so lang o. kïrzer als der $\mathrm{K}$.; B. rundlich o. oval; Stg. oben drüsig. Verbr.

viscosum. L. Klebriges $\mathrm{H}$.

3 Stf. gewimpert; Frstiele 2-3 inal so lang als der K.; B. länglich o. oval; Stg. langhaarig, seltener oben drüsig.*) Verbr. (fehlt Sch.)

brachypetalum. Desp. Kleinblütiges $H$.

Stg. selten drüsig, die seitenständigen am Grunde wurzelnd; Pfl. 2-mehrjährig; Deckb. und Kb. am Rande trockenhäutig. Terbr.

vulgatum. L.**) Gemeines $\mathrm{H}$.

Stg. aufrecht o. aufstrebend, nicht wurzelnd, meist drüsig; einjähriges Kraut. Verbr. (fehlt $S$.)

semidecandrum. $L$ ***) Kleines $H$.

$5\{\operatorname{Gr}$ (in der Regel) $5 \ldots \ldots \ldots \ldots \ldots \ldots \ldots$

Gr. (in der Regel) $3 \ldots \ldots \ldots \ldots \ldots . \ldots \ldots$

B. etwas fleischig, lineal, 3 kantig; Stg. melirblütig. A. v. St. (Hochsehwab).

B. nicht fleischig

Wenigstens die unteren Deckb. krautig o. höchstens an der Spitze schmal-trockenhäutig; B. elliptisch o. lanzettlich....................... s

Deckb. breit-trockenbäutig-berandet; Btstiele flaumig

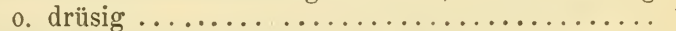

Btstand reichblütig; untere B. eiförmig, spitz, ziemlich lang gestielt, obere lanzettlich, fast sitzend; Pfl. schlaff, kurz behaart. $N$. O. St. Kr. J. Südt. silvaticum. W. $K$. Wald-H.

Btstand armblütig, oft 1 blütig; Alpenpfl. mit sitzen-

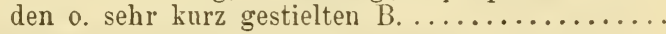

Deckb. ganz krautig; Stg. 1-3 blütig; Frstiele ein$9\left\{\begin{array}{l}\text { geknickt. A. Iatifolium. L. } \uparrow \text { ) Breitblättriges } H \text {. } \\ \text { Deckb. an der Spitze schmal-trockenhäutig; Frstiele }\end{array}\right.$ schief-abstehend. A. (fehlt N.)

$$
\text { alpinum. L. } \dagger \text { †) Alpen-H. }
$$

*) Die Form mit oben drüsigem Stg. ist C. Tauricum Spr.

**) Die Alpenform mit größeren S. und längeren Kapseln ist C. fontanum Baumg.

***) C. glutinosum Fr. hat krautige Deckb., während dieselben bei dem typischen C. semidecandrum L. einen breiten Hautrand haben.

†) Auf den Urgebirgen wachsen C. uniflorum Murr. und C. filiforme Schl., beide mit kleineren Bt. u. längeren Frstielen, letzteres mit zurïckgerollten Zähnen der Kapsel. $\dagger$ †) Eine lang zottig behaarte Form ist C. lanatum Lam. 
Die oberen B. eiförmig, zugespitzt; Frstiele schiefabstehend. A. Carinthiacum. Vest. Kärntner H. 10 Die oberen B. lineal o. lanzettlich; Frstiele aufrecht, mit nickendem $\mathrm{K}$. Verbr.

arvense. $\left.L .^{*}\right)$ Acker-H

A usdauernde Alpenpfl.; B. sitzend, länglich-lanzettlich, kahl; Stg. oben einzeilig behaart; Deckb. u. K. kahl o. fast kahl; Btstiele nach dem Verblühen herabgebogen. $A$.

trigynum. Till. Dreigriffliges $\mathrm{H}$.

Einjähriges Kraut; untere B. kurz gestielt, obere sitzend, drüsig-flaumig, wie auch Stg., Deckb. u. K.; Btstiele aufgerichtet. B. MI. N. anomalum. $W^{5}$. $K$. Abweichendes $H$.

\section{HOLOSTEUM. L. Spure.}

Einjähriges, kleines Krraut; B. elliptisch o. länglichlanzettlich, ganzrandig; Krb. weiß, seltener röthlich. Verbr....... umbellatum. $L$. Gemeine Sp.

\section{VII. MOENCHIA. Ehr. IVeißmiere.}

䒘b. Krb. u. Stb. 4; Gr. zurückgekrümmt; Krb. kürzer als der K. B. $K r$. J.

erecta. (L.) G. M. Sch. Vierzählige W.

Kb. u. Krb. 5; Stb. 10; Gr. fast gerade; Krb. länger als der K. Südt. Südst. $K r$. J.

mantica. (L.) Bartl. Fünfzählige W.

\section{SAGINA. L. Mastkraut.}

(Gr. 4; Kapsel 4 klappig; Stb. 4; Krb. 4, kürzer als der K. o. fehlend; Kb. $4 \ldots \ldots \ldots \ldots \ldots \ldots \ldots$

Gr. 5; Kapsel 5klappig; Stb. 10; Kirb. u. Kb. 5;

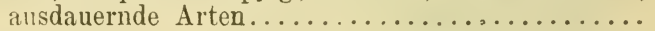

Die 2 äußeren Kb. sehr kurz-stachelspitzig; B. am 2 Grunde gewimpert; 1 jährige Kräuter mit sehr kleinen, oft fehlenden Krb...............

Alle Kb. stumpf..................... 4

Btstiele immer aufrecht; K. abstehend.

Sch. B. O. $K$. $K r$. apetala. $L$. Kleinblütiges M. 3 Btstiele nach dem Verblühen herabgekrümmt, später wieder aufrecht; K. anliegend. N. J. ciliata. $F r$. Gewimpertes $\mathrm{M}$.

*) C. strictum Ilke. ist die fast kahle Alpenform. Uebrigens ist $C$. arvense $\mathbf{I}$. eine veränderliche Pflanze. 
Pfl.einjährig; Stg. aufrecht; B. etwas fleischig; Btstiele stets aufrecht. $J$.

maritima. Don. Meerstrands-M.

4 Pfl. ausdauernd; Stg. niederliegend, am Grunde oft wurzelnd; B. fast fädlich; Btstiele nach dem Verblühen herabgekrümmt. Verbr. $u$. $h f g$.

procumbens. $L{ }^{*}$ ) Gemeines $M$.

$5\{$ Krb. höchstens so lang als der K. ..........

$\mathrm{K} \cdot \mathrm{b}$. länger als der $\mathrm{K} . \ldots \ldots \ldots \ldots \ldots \ldots \ldots \ldots$

B. mit kurzer Stachelspitze; Btstiele kahl; Krb. kürzer als der K.; Fr. fast doppelt so lang als der K. Geb...........Linnaei. Presl. Felsen-II.

6 B. mit langer Stachelspitze; Btstiele flaumig; Krb. so lang als der K.; Fr. wenig länger als der $\mathrm{K}$. Sch. B. Südt. Südst. Kr.

subulata. (Sw.) Torr. et Gr. Pfriemliches MI.

Obere B. viel kürzer als die unteren; Btstiele stets aufrecht. Verbr. nodosa. (L.) Fenzl. Knotiges M.

7 Obere B. nicht auffallend kürzer als die unteren; Btstiele vor dem Aufblühen überhängend. A. v. T. S....glabra. (Willd.) Koch. Kahles M.

XX. ALSINE. Wahlbg. Miere.

1) B. lanzettlich o. eiförmig, dicklich o. fleischig ....

B. schmal-lineal o. pfriemlich............. 4

Kb. u. Krb. 4 ; Stb. 8 ; B. länglich-lanzettlich, fleischig, oberseits tief rinnig, unterseits convex, sich gegen-

2 seitig deckend; Bt. einzeln, endständig, sehr kurz gestielt. $A$. (fehlt $N$. J.)

aretioides. (Somm.) M. et $K$. Speik-M.

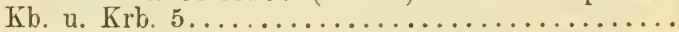

Alpenpfl.; B. aus abgerundetem Grunde verschmälert, lanzettlich; Bt. zwittrig; Krb. ungefähr so lang als der K.; Kapsel eiförmig. A. v. T. $S . K$. $K r$.

3 Janceolata. (All.) $M$. et $K$. Felsen-M.

Meerstrandspfl.; B. eiförmig; Bt. vielehig, die männlichen mit längeren Krb.; Kapsel kugelig, fleischig. J. ........ peploides. (L.) Wahlbg. Strand-M.

$4\{$ Niedrige Stauden................... 5

$4\{$ Kräuter mit Pfahlwuizel; Krb. viel kürzer als der K. 16

Kb. weiø, mit $1-2$ grünen Rückenstreifen...... 6

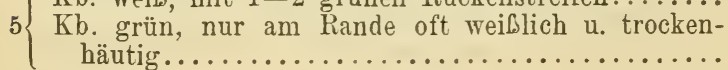

*) S. bryoides Fröhl. hat breitere und kürzere, am Rande fein gezähnelte $B$. 
Krb. kürzer als der K.; Btstiele kaum länger, meist kürzer als der K. T.

mucronata. L. Spitzblättrige M.

Krb. etwas länger als der K.; Btstiele 2-3 mal so lang als der K. B. M. N. O. St. K.

setacea. (Thuill.) $M$. et $K$. Borstenblättrige M.

${ }_{7}\left\{\begin{array}{l}\text { B. nervenlos } 0.1 \text { nervig; } \mathrm{Kb} \text {. mehr o. weniger } \\ \text { stumpf } \ldots \ldots \ldots \ldots \ldots \ldots \ldots \ldots \ldots \ldots \ldots \ldots \ldots \ldots \ldots \ldots \ldots \ldots \ldots \ldots \ldots \ldots\end{array}\right.$

B. (wenigstens getrocknet) deutlich 3 nervig; Kb. meist spitz 0. zugespitzt ............... 10

Bt. klein; Krb. um die Hälfte länger als der K.; Stg. $1-2$ blütig; B. 1 nervig. A. v. T. $K$.

8 biflora. (L.) Wahlbg. Zweiblütige M. Bt. ansehnlich; Krb. nahezu doppelt so lang als der K. ; Stg. meist mehrblütig ; B. nervenlos.......

Btstiele u. K. drüsig behaart; K. nach unten verschmälert; Kapsel länger als $\operatorname{der}$ K. $A$. v. $T$. liniflora. (L. $f$.) Hgtsch. Leinblütige M. 9 Btstiele u. K. flaumig, aber nicht drüsig; K. unten abgestutzt; Kapsel so lang als der K.

A. u. Vora. (fehlt S.)

laricifolia. (L.) Wahlbg. Lärchenblättrige M.

Krb. fast doppelt so lang als der K., am Grunde

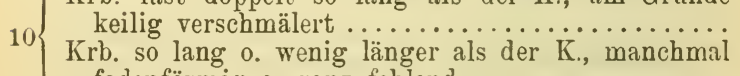
fadenförmig 0 . ganz fehlend................

Stg. meist 2 blütig; B. kahl, mit 3 etwas undeutlichen Nerven, ohne Queradern; Gr. keulenförmig; Kapsel länger als der K. $A$. (fehlt $S$.) Austriaca. $M$. et $K$. Oesterreichische $\mathrm{M}$. Stg. 2-7- (meist 3-) blütig; B. etwas flaumig, zwischen den 3 Nerven mit Queradern; Gr. fadenförmig; Kapsel höchstens so lang als der K. $A$. v. $K$.

Villarsii. $M$. et $K$. Villars' M.

Stg. kurz, 1-3 blütig, nur ausnahmsweise mehrblütig. ......................... 13

Stg. trugdoldig verzweigt und in der Regel mehr 12 als 3 Bt. tragend; B. lineal-pfriemlich; Btstiele drüsenhaarig; Kapsel etwas länger als der $K$.

Verbr. (fehlt Sch. M. S.)

verna. (L.) Bartl.*) Frühlings-M.

*) A. Facchinii Rchb. (Südt.) hat weit abstehende, in den Achseln mit Bbüscheln versehene $B$. 
Kb. stumpf; Krb. fadenförmig o. fehlend, selten normal entwickelt; Stg. 1 blütig; Wuchs dicht13 rasig. A.... sedoides. (L.) $F$. Schltz. Zwerg-M. $\mathrm{Kb}$. spitz 0. zugespitzt; Krb. stets normal ent-

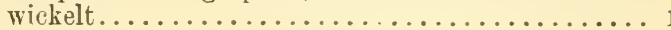
14

B. zurückgekrümmt, dicht stehend, sehr schmal; Kb. lang zugespitzt; Krb. oval, so lang als der K. A. v. T. K.

recurva. (All.) Wahlbg. Krummblättrige M.

B. nicht zurückgekrümmt, kurz; Kb. spitz....... 15

B. pfriemlich-lineal, stumpf; Btstiele länger als der K. Geb. Gerardi. (Willd.) Wahlbg. Gerard's M.

15 B. spitz, breit, pfriemlich-lineal; Btstiele ungefähr so lang als der K. A. v. T. $K$.

decandra. (Rchb.) Dalla Torre. Gletscher-M.

$\mathrm{Kb}$. weif, mit 2 grünen Rückenstreifen, fein zugespitzt; Stg. starr, mit aufgerichteten Aesten; 16 Bt. gebüschelt. $M . N$. O. Südt.

fasciculata. (L.) $M$. et $K$. Gebüschelte M.

Kb. grün, randhäutig .................. 17

Bt. gebüschelt; K. drüsenhaarig. J.

densiflora. (Vis.) Dichtblütige M.

Btstände locker, trugdoldig............... 18

Stg. kahl, nur die Btstiele u. K. oft klebrig.

Südt. Südst. Krr. J.

18 tenuifolia. $(L$.) $C r$. Feinblättrige M.

Stg. wenigstens im oberen Theile dicht drüsenhaarig; Bt. kleiner. B. M. N.

viscosa. Schreb. Klebrige M.

\section{ARENARIA. $L$. Sandkraut.}

I Einjährige Kräuter; Krb. kürzer als der K.; B. ei-

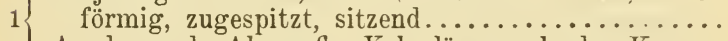
Ausdauernde Alpenpfl.; Krb. länger als der K.... 3

Krb. oval; Kb. lanzettlich, zugespitzt, die inneren mit trockenhäutigem Rande von der Breite des krautigen Mittelstreifens; Pfl. kurzhaarig, seltener drüsig. Verbr. $u$. $h \mathrm{fg}$.

$2\left\{\begin{array}{l}\text { serpyllifolia. } L_{*}^{*} \text { ) Gemeines S. } \\ \text { Krb. eiförmig; Kb. eilanzettlich, haarspitzig, die }\end{array}\right.$ inneren mit trockenhäutigem Rande von höchstens halber Breite des krautigen Mittelstreifens; $\mathrm{PA}$. etwas länger borstenhaarig. A. v. T. S. K.

Marschlinsii. Koch. Alpen-S.

*) A. leptoclada Guss. (J.) unterscheidet sich durch die längliche (nicht fast kugelige) Kapsel u. zarteren Bau. 
B. am Rande rerdickt, lanzettlich-pfriemlich, begrannt; Kb. steif begrannt. A. v. N. St. K. J. T. grandiflora. All. Großblütiges $\mathrm{S}$.

B. rundlich, eiförmig 0 . breit lanzettlich, stumpf 0 .

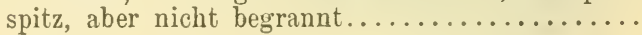

B. rundlich, stumpf; Krb. oval.

4 A. v. T. S. O. St. K. biflora. L. Zweiblütiges S. B. eiförmig 0. lanzettlich, spitz; Krb. eiförmig ....

B. am Grunde keilig verschmälert, undeutlich nervig; Stg. 1-2 blütig, seltener mehrblütig; Kb. 1 - bis 3 nervig. A........ ciliata. L. Gewimpertes S.

B. nahe am Grunde am breitesten, deutlich nervig; Stg. trugdoldig mehrblütig; Kb. mehrnervig. A. จ. T. .....multicaulis. $L$. Vielstengliges $\mathrm{S}$.

\section{MOEHRIYGIA. L. Nabelmiere.}

$1\{$ Kb. u. Krb. 4 (nur ausnahmsweise 5); Stb. $8 \ldots \ldots$

Kb. u. Krb. 5 ; Stb. $10 \ldots \ldots \ldots \ldots \ldots \ldots \ldots$

B. fast fadenförmig, halbstielrund, spitz, grasgrün ; Stg. oben haardünn. Verbr. (fehlt B. M. Sch.)

muscosa. L. Moosmiere.

B. verlängert-spatelförmig, dicklich, aber flach, seegrün; Stg. dicklich. J.

Tommasinii. Marches. Triestiner N.

Alle B. eiförmig 0. eilänglich, 3-5 nervig, die unteren lang gestielt; Btstiele so lang als die B.; Krb. kürzer als der K. Verbr.

trinervia. (I.) Clairv. Dreinervige N.

B. lineal o. lineal-lanzettlich, nur die untersten manchmal elliptisch o. eiförmig; Krb. so lang 0. länger als $\left.\operatorname{der} \mathrm{K} .^{*}\right) \ldots \ldots \ldots \ldots \ldots \ldots \ldots \ldots$

B. lineal-lanzettlich, die untersten elliptisch o. ei-

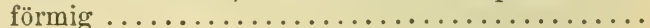
B. lineal

Pfl. kahl; Kb. eiförmig, 1 nervig; Krb. so lang als der K. St. K. $K r$.

diversifolia. Doll. Verschiedenblättrige N.

5 Pfl. dicht kurzhaarig; Kb. lanzettlich, nervenlos; Krb. länger als der K. $K$. $K r$.

villosa. (Wulf.) Fzl. Kurzhaarige N.

*) M. ciliata (Scop.) Dalla Torre kommt ausnahmsweise init schmalen Krb. vor welche kürzer als der K. sind. 
Pfl. grasgrün; B. kurz lineal, etwas fleischig, meist gedrängt stehend; Bt. kurz gestielt; Krb. etwas länger als der K. $A$.

ciliata. (Scop.) Dalla Torre.*) Alpen-N.

Pfl. blaugrün; Bt. lang gestielt ................

B. fleischig, stielrund; Kb. stumpf, 3 nervig; Krb. länger als der K. Südt. St.

Bavarica. (L.) Kern. Fleischige N.

B. halbstielrund, fast fadenförmig; $\mathrm{Kb}$. ziemlich spitz, gekielt-1 nervig; Krrb. so lang als der K. Sïdt......... glaucovirens. Bert. Blaugrüne N.

A nmerkung. In $T$. wurde M. ciliata $X$ muscosa beobachtet.

\section{SPERGULA. L. Spark.}

B. grasgrün, oberseits gewölbt, unterseits gefurcht; S. mit sehr schmalem Hautrande; blüht im Sommer. Verbr................ arvensis. L. Acker-Sp.

B. bläulichgrün, fast stielrund, unterseits ohne Furche; S. breit geflügelt; blüht im Frühling.

B. II. Sch. T. K. J.

pentandra. $L .^{* *}$ Fünfmänniger $S p$.

\section{SPERGULARIA. Presl. Salzmiere.}

B. beiderseits flach, lineal-fädlich, etwas fleischig, stachelspitzig; Kapsel so lang als der K.; S. nicht geflügelt. Verbr.

campestris. (L.) Aschers.***) Feld-S.

$B$ halbstielrund, fleischig, stumpflich; Kapsel wenigstens etwas länger als der $K \ldots \ldots \ldots \ldots \ldots \ldots$. Stb. meist 5; Kapsel wenig länger als der K. alle o. die meisten $\mathrm{S}$. ungeflügelt; Pfl. 1-2 jährig. B. M. N. S. J.

22 marina. (L.) Bess. Meerstrands-S. Stb. meist 10; Kapsel fast doppelt so lang als der K.; alle S. geflügelt; Pfl. ausdanernd. B.M. N. J. media. (L.) Gris. Flügelsamige S.

\section{TELEPHIUM. L. Zierspark.}

Kahle Staude; B. verkehrt-eiförmig, ganzrandig. dicklich, seegrün; Btstand ziemlich dichtblütig; Krb. weiß. T...... Imperati. L. Europäischer Z.

*) M. sphagnoides Fröl. ist eine Zwergform mit fast sitzenden Bt.

**) Die typische Pflanze hat 5 Stb.; S. Morisonii Bor. hat meist $10 \mathrm{Stb}$. u. breitere Krb.

${ }^{* * *}$ ) S. echinosperma Celak. (B.) ist viel zarter, hat breit dreieckige Nebenb. u. stachelige S. 
XXYI. POLYCARPON. L. Nagelkraut.

B. länglich-verkehrt-eiförınig; Btstand locker; Stb. 3. (B.) J. . . . tetraphyllum. L. Vierblättriges N.

B. rundlich-verkehrt-eiförmig; Btstand dichtblütig; Stb. 5. J. alsinefolium. $D C$. Mierenblättriges N.

XXVII. CORRIGIOLA. L. Hirschsprung.

Einjähriges, kahles Kraut; Stgb lineal-keilig ; Btstand reichblütig, beblättert. $B$. Südst.

litoralis. $L$. Gemeiner $\mathrm{H}$.

XXVIII. PARON YCHIA. Juss. Mauerraute.

Kleine Staude: B. länglich-lanzettlich, gewimpert; Btstand kopfförmig; K. steifhaarig. $K r . J$.

Kapela. (Hacq.) Kern. Illyrische M.

\section{XYIX. HERYIARIA. L. Bruchkraut.}

B. u. K. kahl; $\left.{ }^{*}\right)$ Btknäuel meist 10 blütig. Terbr.

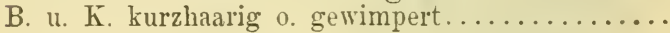
glabra. $L$. Kahles B.

Kzipfel von einer längern Borste stachelspitzig; B. elliptisch 0. länglich; Btknäuel meist 10 blütig. B. M. N. O. St. T....liirsuta. L. Behaartes B. Kzipfel gleich-behaart; Btknäuel meist 3 blütig .... Stg. u. B. borstig-behaart; Kzipfel spitz, länger als die Fr. N. J. .......... incana. Lam. Graues B.

3 Stg. kahl; B. nur am Rande gewimpert; Kzipfel stumpf, etwas kürzer als die Fr. $A$. $\nabla . T$. St. alpina. Vill. Alpen-B.

\section{ILLECEBRUM. L. Knorpelblume.}

Stg. dünn, niederliegend, kahl; B. verkehrt-eirund, ganzrandig, stumpf. $B$. $N$.

verticillatum. $L$. Quirlblütige $\mathrm{K}$.

XXX1. SCLERANTHUS. L. Knäuel.

Kraut; Kzipfel spitz, sehr schmal, häutig berandet, zur Frzeit etwas abstehend. Verbr. $\iota$. $h f g$.

annuus. $L$. Einjähriger K.

Staude; Kzipfel abgerundet-stumpf, breit, milchweißberandet, zur Frzeit zusammenschließend.

Verbr. (fehlt $S . J$.) perennis. $L$. Ausdauernder K.

Anmerkung. S. annuus L. ist eine sehr veränderliche Pflanze, so dass man mehrere Unterarten unterscheiden kann. Auberdem kommt ein Bastart $\mathrm{zwischen} \mathrm{S}$. annuus und S. perennis vor.

*) Die selten vorkommenden behaarten Formen der $\mathbf{H}$. glabra L. unterscheiden sich von H. hirsuta L. durch den Mangel der Stachelspitze der Kzipfel, die außerdem kürzer sind als die Fr. 
XIX. NYMPHAEACEAE. - XX. CERATOPHYLLEAE. 209

XIX. Familie. Nymphaeaceae. Seerosengewächse.

Ausdauernde Wasserpfl. mit schraubig gestellten, sehr lang gestielten, an der Wasseroberfläche schwimmenden B. u. Bt. Schwimmb. lederig, rundlich 0. oval, tief herzförmig ausgeschnitten. Bt. ansehnlich, weiß o. gelb, zwittrig. Kb. $4-5$ (ausnahmsweise $6-7$ ), innen blumenblattartig gefärbt. Krb. zahlreich, schraubig angeordnet. Stb. zahlreich. Frkn. 1, oberständig, mehrfächerig, mit zahlreichen Samenknospen. N. sitzend, schildförmig, mit so vielen Strahlen, als Fächer des Frkn. vorhanden sind. Fr. beerenartig, vielfächerig, vielsamig. S. mit Nährgewebe.

\section{Gattungen.}

(Bt. weib; Kb. 4; Krb. mindestens so lang als die $\mathrm{Kb}$., ohne Honiggrübchen, sammt den Stb. an den Frkn. angewachsen ........... Nymphaea. I. Bt. gelb; Kb. 5; Krb. viel kürzer als die Ǩb., mit Honiggrübchen auf dem Pücken, sammt den Stb. frei.........................

\section{Arten.}

\section{NYMPHAEA. $L$. Seerose.}

( Narbe 12-20 strahlig, hellgelb; Frkn. bis zur N. hin mit Stb. besetzt. Verbr. alba. $L$. Gemeine S. Narbe 6-12strahlig; Frkn. an der Spitze von Stb. entblöbt

Bt. weit geöffnet; Nstrahlen gelb o. roth.

B. M. Sch. N........ candida. Presl. Kleine S. Bt. nur halb geöffnet; Nstrahlen hochroth.

B. MI. Sch. St. S. T.

biradiata. Somm. Rothnarbige S.

\section{NCPHAR. Sm. Nixenblume.}

Stb. lineal-länglich; Narbe ganzrandig, flach, 10bis 20 strahlig. Strahlen noch vor dem Rande verschwindend. Verbr. Inteum. (L.) Sm. Gelbe N. Stb. rechteckig; Narbe sternförmig, spitz-gezähnt, zuletzt halbkugelig, meist 10 strahlig, Strahlen bis zum Rande auslaufend. B. MI. N.S. T. K.

pumilum. Sm. Kleine N.

\section{Familie. Ceratophylleae. Hornblattgewächse.}

Ausdauernde Wasserpflanzen mit wirtelständigen, gabelspaltig getheilten B. Bt. 1 häusig, einzeln in den Blattachseln stehend. Bthüllb. 9-12, am Grunde verwachsen, die der männlichen Bt. weißlich, die der weiblichen grünlich. Stb. 12-20, mit sehr kurzen und dicken Stf. Frkn. 1, ober- 
ständig, 1 fächerig, mit 1 Samenknospe. Gr. 1, ungetheilt, pfriemlich zugespitzt, nicht abfällig. Fr. nicht aufspringend. S. mit Nährgewebe.

Einzige Gattung ......... Ceratophyllum. I.

Arten.

I. CERATOPHYLLUM. $L$. Hornblatt.

B. weich, in 4-8 haardünne Zipfel getheilt; Gr. viel kürzer als die dornlose Fr. Verbr. (fehlt St. J.) submersum. L. Glattes $H$.

B. starr, zerbrechlich, in $2-4$ borstliche Zipfel getheilt; Gr. so lang o. länger als die am Grunde mit 2 kurzen Dornen o. Höckern besetzte Fr.

Verbr..............lemersum. L. Rauhes H.

\section{Familie. Ranunculaceae. Hahnenfußgewächse.}

Kräuter, Stauden oder seltener Klettersträucher mit ungetheilten 0 . verschiedenartig getheilten, meist schraubig gestellten, seltener gegenständigen B., meist mit deutlich entwickelten Bscheiden, aber nur selten mit deutlichen, häutigen Nebenb. Bt. fast immer zwittrig, mit einfacher o. doppelter Bthülle, deren B. häufig nicht in Wirteln, sondern schraubig angeordnet sind. Bthüllb. oft 50.10 , jedoch nicht selten mehr 0. weniger, entweder alle 0 . nur die inneren blumenkronartig gefärbt.*) stb. zahlreich. Frkn. oberständig, 1 fächerig, in unbestimmter Zahl, selten nur 1 (dann auch oft mehrfächerig), mit 1 oder mehreren Samenknospen. Gr. meist mehrere, ungetheilt. Fr. bald aufspringend, bald nicht aufspringend, aber nur selten beerenartig. S. mit Nährgewebe.

\section{Gattungen.}

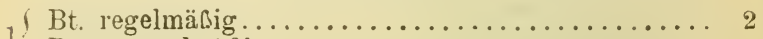

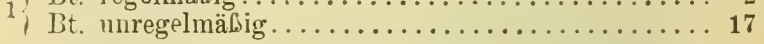

( B. gegenständig; Bt. meist 4 zählig, mit weiß oder

2 blauviolett gefärbtem K.; Fr. einsamig, nicht aufspringend............... Clematis. XIV. B. nicht gegenständig................. 3 $3\left\{\begin{array}{r}\text { Krb. gespornt; Stauden mit zusammengesetzten B.; } \\ \text { K. u. Blkr. gefärbt; Fr. mehrsamig, aufspringend. } \\ \text { Aquilegia. X. }\end{array}\right.$ Krb. nicht gespornt ................ 4

*) Die ${ }_{n}$ Honigb." mehrerer Gattungen (durch Honiggruben an ihrem Grunde ausgezeichnet) sind hier als Kr.b. bezeichnet. 
(Stg. nur mit 3 (selten 4) quirlständigen B. ;*) Stauden

4 mit gefärbtem K., ohne Blkr.; Fr. einsamig, nicht aufspringend............. Anemone. XIII. Stgb. nicht quirlständig, manchmal fehlend.......

Kb. gespornt; einjähriges Kraut mit linealen, grundständigen B.; Krb. schmal, mit langem Nagel;

5 Fruchtboden sehr verlängert; Fr. einsamig, nicht aufspringend............... Myosurus. XV.

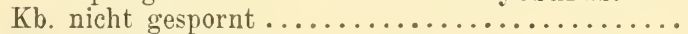

(Bt. meist 4 zählig, in Trauben o. Rispen; Stauden

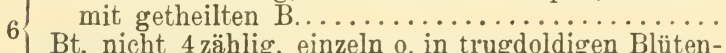
ständen ..............................

Krb. vorhanden; B. doppelt zusammengesetzt; K. 7 gasch abfallend, weißlich; Frkn. 1-5; Fr. mehrKrb. fehlen; Fr. mehrere, einsamig, nicht aufspringend.............. Thalictrum. XVII.

K. u. Blkr. normal entwickelt ................

8 Krb. kürzer und schmäler als die meist gefärbten Kb. o. ganz fehlend; Fr. mehrsamig, aufspringend

Krb. am Grunde mit einer Honiggrube, letztere oft

9 mit einer Schuppe bedeckt; Fr. einsamig, nicht aufspringend........................ 10

Krb. ohne Honiggrube ................... 11

Samenknospe am Grunde der Bauchnaht des Frkn. entspringend, aufrecht, mit 1 Haut und nach unten gekehrter Mündung; Kräuter o. Stauden mit weißen o. gelben, selten rosenrothen Bt.

$10\left\{\begin{array}{l}\text { Ranunculus. XVI. } \\ \text { Samenknospe seitlich von der Bauchnaht des Frkn. ent- }\end{array}\right.$ springend, hängend, mit 2 Häıten und nach oben gekehrter Mündung; Stauden der Alpen und Voralpen mit mehrfach getheilten B. und wei@en 0 . röthlichen Bt. ...........Callianthemum. IV.

Kräuter 0. Stauden mit in schmallineale Zipfel zertheilten B.; Frkn. zahlreich; Fr. einsamig, nicht aufspringend ................ Adonis. XVIII. Stauden mit großen, zusammengesetzten B.; Bt. groß, purpurn; Frkn. 2-5; Fr. mehrsamig, aufspringend...................... Paeonia. I.

*) Bei Anemone Hepatica stehen die 3 quirlständigen B. unmittelbar unter der Blüte und können daher leicht für $\mathrm{Kb}$. gehalten werden. 
Blkr. fehlt; kahle Stauden mit ungetheilten, herz-

12 förmig-rundlichen $\mathrm{B}$. und dottergelben $\mathrm{Bt}$.

Caltha. II.

Blkr. vorhanden; B. getheilt oder doch eingeschnitten 13

(B. in schmal lineale Zipfel zertheilt; einjährige 13 Kräuter; Bt. hellbau o. weiß..... Nigella. VII. Bzipfel nicht schmal lineal; Stauden .......... 14

B. doppelt zusammengesetzt; Bt. weiß, klein.

Isopyrum. VIII.

B. handförmig o. fußförmig getheilt 0 . nur einge-

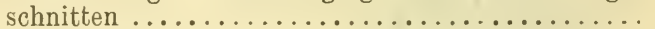

15 Krb. flach; Kb. zahlreich; B. handförmig getheilt;

15 Bt. hellgelb o. grünlich..........Trollius. III.

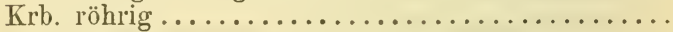

Kb. weiø, grün o. röthlich, derb, nicht abfällig; Frkn. nicht gestielt, am Grunde verwacissen.

Kb. gelb, zart, abfällig; Frkn. frei, gestielt.

Helleborus. $V$.

Oberes Kb. helmförmig, zwei lang benagelte, kapuzenförmige, gespornte Krb. einschließend; Stauden mit handförmig 0 . fußförmig getheilten 0 . doch gelappten B.; Bt. in einfachen o. zusammenge-

17 setzten Trauben........... Aconitum. XII.

Oberes Kb. gespornt; $1-2 \mathrm{Krb}$. ebenfalls gespornt, sitzend; Kräuter 0. Stauden mit getheilten 0 . doch gelappten B. und traubigen Btständen.

lelphinium. XI.

Arten.

I. PAEONIA. $L$. Pfingstrose.

Bchen elliptisch o. länglich, ungetheilt, das endständige am Grunde keilig. St. $K r$.

corallina. Retz. Großblättrige Pf.

Bchen 2-3 spaltig, mit ganzrandigen 0 . wieder 2bis 3 spaltigen Zipfeln. T. $K r$. J.

peregrina. Mill. Gemeine $\mathrm{Pf}$.

\section{CALTHA. L. Dotterblume.}

(Fr. allmälig in einen kurzen Schnabel verschmälert, gekrümmt, abstehend; B. gekerbt, am Grunde oft scharf gezähnt, vorne oft fast ganzrandig. $M$. $N$. cornuta. Sch. N. K. Geschnäbelte D.

Fr, rasch in den Schnabel zusammengezogen, auf-

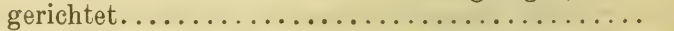

${ }_{2}\{$ Rücken der Fr. gerade o. wenig gebogen........ 3

$2\{$ Rücken der Fr. gekrümmt............... 4 
Schnabel der Fr. gerade; B. meist scharf gezähnt. Verbr......laeta. Sch. N. K. Geradfrüchtige D. Fr. klein, mit sehr kurzem, etwas gekrümmtem Schnabel; Bt. klein; B. klein, gekerbt, böchstens am Grunde etwas gezähnt. $A$.

$$
\text { alpestris. Sch. N. K. Alpen-D. }
$$

Stg. aufsteigend, nicht wurzelnd; B. rundlich 0. nierenförmig; Bt ansehnlich. Verbr. u. hfg.

Stg. liegend, schlaff, an den Knoten wurzelnd; Grundb. fast dreieckig; Bt. klein. $M$.

procumbens. (Beck.) Niederliegende D.

\section{TROLLIUS. L. Trollblume.}

B. handförmig-5 theilig, Zipfel rautenförmig, eingeschnitten-gesägt; Bt. einzeln. Verbr.

Europaeus. L. Europäische T.

IV. CALLIANTHE.IUM. C. A. Mey. Jägerkraut.

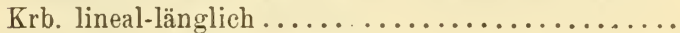
Krb. verkehrt-eiförmig, weiß o. etwas röthlich, am Grunde mit gelbem Fleck; B. 3 fach fiederschnittig, mit linealen Abschnitten. $A$. (fehlt $N$.)

rutaefolium. (L.) C. A. Mey. Rautenblättriges J.

Bt. ansehnlich; Krb. weiß o. etwas röthlich, am Grunde gelb; Pfl. kräftig, mit (nach dem Blühen) verlängerten Blattstielen und 3 fach 3 theiligen B.; Fr. netznervig. $O . N$. St.

anemonoides. (Zahlbr.) Schott. Oesterreich. J. Bt. kleiner, meist stark röthlich; Pfl. niedrig, gedrungen; Fr. glatt. Sü dt.

Kernerianum. Freyn. Südtiroler J.

V. HELLEBORUS. $L$. Nießwurz.

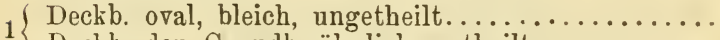

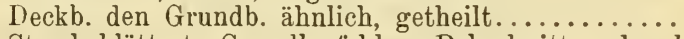

Stg. beblättert; Grundb. fehlen; Babschnitte schmal lanzettlich, fein gesägt; Bt. klein, grün.

$S$. T. St. $K r \ldots \ldots \ldots \ldots$ foetidus. $L$. Bärenfuß. Schaft blattlos; Grundb. lederig, nur vorne gezähnt; Kb. groß, weiß oder röthlich (nach dem Verblühen

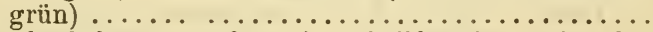

B dunkelgrün; Babschnitte keilförmig, weit über der Mitte am breitesten, vorne mit vorwärts gerichteten Zähnen. Vora.

niger. $L$. Gemeine Schneerose.

B. bläulichgrün; Abschnitte breit lanzettlich, nahe der Mitte am breitesten, vorne mit stechenden, etwas abstehenden Zähnen. Süidt. $K$. $K r$. J.

macranthus. Freyn. Großblütige Schneerose. 
4 Bt. grün o. gelblichgrün $\ldots \ldots \ldots \ldots \ldots \ldots \ldots \ldots$. 5

4 Bt. mehr o. weniger trüb violett überlaufen..... 8

Alle Babschnitte in mehrere, schmale, fein und scharf gesägte Zipfel gespalten, unterseits behaart;

5 Kb. schmal. $K r . J$. multifidus. Vis. Vielspaltige N. Babschnitte ungetheilt oder nur einige derselben 2bis 3 theilig....................... 6

Adern der B. unterseits sämmtlich hervorragend .. Die Hauptadern unterseits wenig hervorragend, die 6 Nebenadern eingesenkt; Babschnitte lanzettlich, ziemlich gleichmäßig klein-gesägt, kahl. N. St. $K r$. dumetorum. WK. Hecken-N.

B. im Herbste absterbend; Abschnitte zurückgekrümmt, rinnig gebogen, verlängert - lanzettlich, ungleich-tief-gesägt, fast kahl; N. aufrecht. Verbr. viridis. $L$. Grüne N.

B. überwinternd: Abschnitte flach, breit-lanzettlich, fast gleichmäßig klein-gesägt, unterseits behaart; N. wagrecht-zurückgekrümmt. St. $K . K r$. J.

odorus. WK. Duftende N.

B. fußförmig getheilt; Abschnitte ungetheilt, kahl o. fast kahl; Kb. klein und schmal; N. auswärts gebogen. St. $K r$. atrorubens. WK. Violette $\mathrm{N}$. B. fast handförmig getheilt; Abschnitte meist 2bis 5 theilig, unterseits behaart; $K \mathrm{~b}$. breit; N. fast aufrecht. $K r$.

purpurascens. WK. Röthliche N.

A nmerkung. In $K r$. wurden $H$. atrorubens $X$ dumetorum und $H$. atrorubens $X$ odorus beobachtet.

\section{ERANTHIS. Salisb. Winterling.}

Grundb. schildförmig-vieltheilig; Bt. einzeln, mit sternförmiger Hülle. Cult. u. verw.

hiemalis. (L.) Salisb. Sternblütiger W.

\section{NIGELLA. L. Schwarzkïmmel.}

Stb. stachelspitzig; Fr. halb verwachsen; Kb. weil, gegen die Spitze bläulich.

1 Verbr. (fehlt S. T. K.) arvensis. I. Wilder S. Stb. nicht stachelspitzig; Fr. von unten bis oben

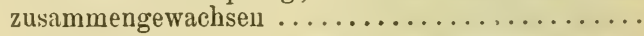

Bt. von getheilten B. umhüllt; Fr. glatt; Kb. hellblan. $J$. (sonst cult.)

Damascena. $I$. Jungfer im Grïnen.

Bt. nicht umhüllt; Fr. drüsig-scharf, am Rücken 1 nervig; Kb. bläulich-weiß. Cult. u. verw. sativa. $L$. Gebauter S. 


\section{IsOPYRUM. L. Muschelblimchen.}

Wst. kriechend; Wz. büschelig; untere B. doppelt3 zällig; Pfl. kahl, vielblütig. Verbr. (fehlt $S$.) thalictroides. I. Europäisches 11.

\section{AC'TAEA. L. Christophskraut.}

Nur ein Frkn. vorhanden; Fr. eine schwarze Beere;

Traube kurz. Terbr.

nigra. (L.) Schwarzfrüchtiges Chr. Mehrere Frkn. vorhanden; Fr. Balgkapseln; Trauben verlängert, rispig zusammengestellt. $M . N$.

Cimicifuga. L. Wanzenkraut.

\section{AQLiLEgIA. $L$. Akelei.}

sporne an der Spitze gerade, ziemlich so lang als die Platte der Krb.; Kb. lanzettlich, zugespitzt, fein gewimpert; Stg. oberwärts klebrig-haarig; Bt. blau-

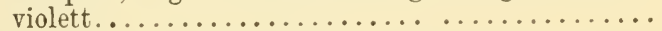

Sporne an der Spitze hakig ..............

B. beiderseits lilebrig-haarig, Abschnitte lineal-lannglich. Sïdt.

thalictrifolia. Schott. Wiesenrautenblättriger A.

B. unterseits etwas behaart, oberseits kahl; Abschnitte eiförmig 0 . verkehrteiförmig.

\section{T. S. K. St. Kr, J.}

Finseleana. Schltz. Einsele's A.

Bt. schwarz-violett (ausuahmsweise blau-violett); Stb. $1^{1}$ mal so lang als die Platte der Krb.

T. S. O. N. St. K. Kr.

atroviolacea. (Avé Lall.) Schwarzvioletter A. Bt. blauviolett, selten fleischfarben 0. weib; Stb. uur wenig länger als die Platte der Krb. ......... Blättchen 2-3lappig, gekerbt; Platte der Krb. ausgerandet. B. II. Sch. N. O. St. Kr.

vulgaris.*) $I$. Gemeiner A.

4 Blättchen bis über die Mitte 3 spaltig, eingeschnitten-gekerbt; Platte der Krb. gestutzt, kürzer als der Sporn; Bt. groß. K. Kr. st.

nigricans. Baumg. Dunkler A.

\section{DELPHIXILA. L. Rittersporn.}

Blkr. in ein gesporntes Krb. verwachsen; Frkn. 1; einjährige K̂́räuter mit fein zertheilten B...... Blkr. aus 2 gespornten und 2 spornlosen Krb. be-

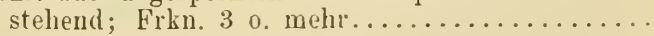

*) Eine Form mit lileineren Bt. und kleinen, unterseits stärker behaarten Blättchen ist $\mathrm{A}$. Ebneri Zimm. ( $\mathrm{N}$. St.) 
Frkn. u. Fr. kahl; Bt. azurblau (ausnahmsweise rosa 2 o. weiß). Terbr......... Consolida. L. Feld-R.

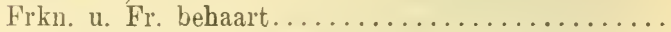

Bt. rothviolett; Vorb. verlängert, mindestens die unteren weit über den Grund der Kb. hinausreichend; Gr. sehr kurz; S. bräunlich.

N. (eingeschleppt).

orientale. Gay. Orientalischer R.

Bt. azurblau (ausnahmsweise rosa 0. weiß); Vorb. klein, kaum den Grund der Kb. erreichend; Gr. verlängert; S. schwärzlich. Cult. u. rerw.

Ajacis. I. Garten-R.

Die 2 unteren Krb. in der Mitte bärtig; Stauden..

Die 2 unteren Krb. bartlos, die 2 oberen nur kurz gespornt; zweijähriges Kraut; B. handförmig getheilt, Abschnitte breit, behaart; Bt. azurblau. J. Staphisagria. L. Scharfer R.

B. bis zum Grunde in schmale Zipfel gespalten; Kb. azurblau; Krb. weiß, die oberen an der Spitze blau. J. . hybridum. Steph. Schlitzblättriger R. B. handförmig gespalten, mit breiten, am Grunde zusammenhängenden Abschnitten; Kb. heller oder dunkler-blau; Krb. schwarz-violett ...........

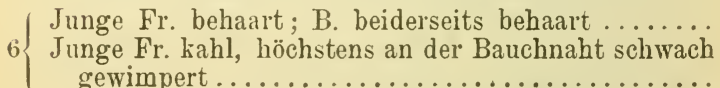
6 7

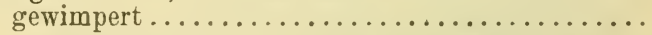

Kb. und halbreife Frucht zerstreut behaart.

7 T. (Volderthal.)....Tiroliense. Kern. Tiroler K. Kb. dicht (fast zottig) behaart; halbreife Fr. dicht flaumig. Südt........montanmm. DC. Berg-R.

Tragb. ungetheilt, lineal (selten die untersten getheilt); Btstiele kahl. Sucl. elatum. L. Hoher R.

8 Die unteren Tragb. getheilt, oft den Laubb. ähnlich; Btstiele meist behaart. (Gel. (fehlt $O . N . K r . J$. alpinum. WK. Alpen-R.

\section{X11. ACONITUM. L. Eisenhut.}

Sporn der 2 oberen Krb. kreisförmig zusammen-

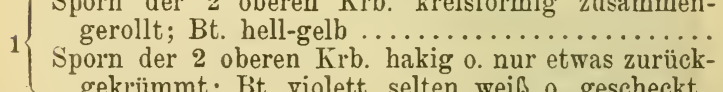
gekrümmt; Bt. violett, selten weiß o. gescheckt. 4

Wz. rübenförmig; K. bleibend; Bzipfel schmal-lineal; Helm ungefähr so hoch als breit.

2 M. N. St. Kr. J. T. .....Anthora. I. Giftheil. Wz. faserig; $K$. abfallend; Helm viel höher als

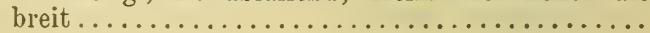


B. handförmig 5-7 spaltig, Abschnitte in breite Zipfel gespalten; Btstand locker, meist ästig, mit abstehenden Aesten. Terbr.

Vulparia. Rchb. Wolfs-E.

B. bis nahe zum Grunde gespalten, Abschnitte meist bis in die Mitte oder noch tiefer wiederholt getheilt, mit schmalen Zipfeln; Btstand dicht, unverzweigt oder am Grunde mit kurzen, aufgerichteten Aesten. Vora. v. Südt. $K r$.

ranunculifolium. Rchb. Hahnenfuङblättriger E.

Stg. oberw. sammt Btstielen u. K. von drüsentrag. Haaren klebrig-flaumig; Btstand verzweigt; Helm schief- o. regelmäßig-halbkreisrund; Nagel der 2 oberen Krb. fast halbkreisrund-vorgebogen, Kapuze wagrecht oder abwärts geneigt. $A$. (fehlt $\Lambda$. O.) paniculatum. Lam. Rispiger $\mathrm{E}$. Stg. oberw. kahl o. mit drüsenlosen Haaren besetzt

Nagel der 2 oberen Krb. gerade o. etwas geneigt; Helm länger als breit. Verbr.

rostratum. Bermh. Geschnäbelter E. Nagel der 2 oberen Krb. bogig; Helm wenig länger,

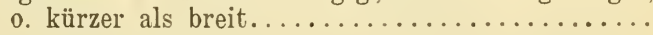

6 Traubenspindel u. Btstiele behaart. Verbr. (bes. Geb.)

T'raubenspindel

Napellus. L. Venuswaǵen.

Bzipfel kurz, seltener verlängert, vorgestreckt; Bt.stand dicht, meist unverzweigt; Bt. dunkelviolett. $A$. (fehlt $\Lambda^{\tau}$.) Tauricum. Wulf. Tauern-E. Bzipfel schmal u. lang, oft abstehend; Btstand locker, oft verzweigt; Bt. hell-violett 0 . weislich. A. $\nabla . K r$. . . . . albicans. Host. Weiblicher E.

Anmerkung. Mehrere Arten, namentlich A. Vulparia u. A. Napellus, sind sehr veränderlich. Zwischen A. Vulparia u. A. ranunculifolium, ferner zwischen A. Napellus, Tauricum u. albicans kommen noch genauer festzustellende Mittelformen vor. Von Bastarten ist nur A. Napellus $X$ rostratum mit Sicherheit aus dem Gebiete bekannt.

\section{ANEMONE. L. Windröschen.}

Hüllb. ungetheilt 0 . an der Spitze 3 spaltig; Fr.

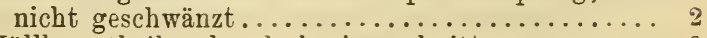
Hüllb. getheilt oder doch eingeschnitten ........ 3 
Hüllb. dicht unter der Bt. stehend und daher einem Kelch ähnlich; B. dreilappig; Bt. blau-violett, seltener rosa o. wein. Verbr. u. $h f g$.

Hepatica. L. Leberblümchen.

Hüllb. von der Bt. entfernt; B. theils 3 spaltig, theils wiederholt getheilt; Bt. rosa, seltener weif 0. hell-gelb. J........hortensis. L. Garten-W.

$3\{$ Fr. vom langen behaarten Gr. geschwänzt ....... 4

Hüllb. den Grundb. ähnlich, doppelt 3 schnittig, mit flachen, eingeschnittenen Zipfeln; Bt. weiß (außen oft hellviolett überlaufen, seltener gelb.*) Geb.

alpina. $L$. Alpen $-\mathrm{IV}$.

Hüllb. den Grundb. unähnlich, handförmig getheilt, mit schmal-linealen Zipfeln...............

f Grundb. handförmig getheilt; Bt. meist blauviolett.

5 B..... patens. $L$. Ausgebreitete Küchenschelle.

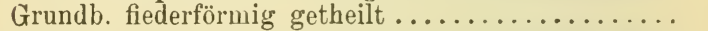

Grundb. überwinternd, fiederschnittig, Zipfel meist 3 spaltig; K. glockig, nickend, weil, aulien violett. Sch. B. N.; A. v. T. S. K. 'St.

vernalis. $L$. Frühlings-Küchenschelle.

Grundb. im Herbste absterbend, meist doppelt fiederschnittig; Bt. violett (ausnahmsweise rosa 0. weiß)

Bt. übergebogen 0 . überhängend $\ldots \ldots \ldots \ldots \ldots \ldots$

Bt. aufrecht; Grundb. 2-3 fach-fiederspaltig; Kb. doppelt so lang als die Stb., am Grunde glockig, von der Mitte an zurückgebogen-abstehend.

Verbr. Pulsatilla. L. ${ }^{* *}$ ) Gemeine Küchenschelle.

Kb. gerade-zusammenschließend, mit auswärts gebogener Spitze, dann sternförmig ausgebreitet, doppelt so lang als die Stb. T. $K r$. J.

montana. Hoppe. Berg-Küchenschelle.

8 Kb.glockig-zusammenschlielend, an der Spitze zurückgerollt, wenig länger als die Stb.

B. M. N. St. K. Kr .

nigricans. (Störk.) Fritsch. Osterblume.

Bt. weiß, selten rosa ................ 10

Bt. gelb, meist 2; Wst. kriechend; Hüllb. den Grundb. ähnlich, letztere einzeln am Wst. entspringend. Verbr. u. hfg. ... ranunculoides. $L$. Gelbes W.

*) Die gelb blühende Forın ist A. sulfurea L. - Die stets weiß blühende Form der $S u d$. ist A. alba (Rchb.) Kern. **) Eine Form mit weniger getheilten B. und breiten Bzipfeln ist A. grandis (Wender.) Kern. ( $N$. St.) 
Bt. in einer armblütigen Dolde, weiळ; Grundb. u. Hüllb. handförmig getheilt 0 . eingeschnitten. Geb.

narcissiflora. L. Berghähnlein.

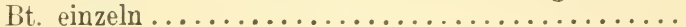

Mehrere Grundb. vorhanden; Wst. kurz; K. aufen behaart....................... 12

Grundb. einzeln aus dem verlängerten, kriechenden

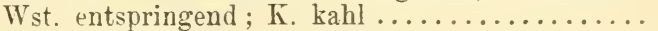

Grundb. doppelt-3 zälllig, Blättchen 3 theilig, Zipfel 3 zähnig; $\mathrm{Kb}$. meist 9 ; Fr. wollig. A. (fehlt $N$. O.)

Baldensis. L. Baldisches W.

Grundb. 5 theilig, Zipfel rautenförmig, 2-3 spaltig, ungleich-gesägt; Kó meist 5; Fr. filzig.

B. M. N. O. St........silvestris. L. Wald-W.

Blattabschnitte ungetheilt, breit-lanzettlich, zugespitzt, gesägt, am Grunde ganzrandig.

Verbr. (fehlt B. M. Sch. O.)

trifolia. L. Dreiblättriges W.

Blattabschnitte eingeschnitten-gesägt, der mittlere 3 spaltig, die seitlichen 2 spaltig. Verbr. $u . h f g$.

nemorosa. $L$. Busch-lV.

Anmerkung. Bastarte zwischen AnemoneArten sind sehr selten. Im Gebiete wurden beobachtet: A. nigricans $X$ patens, $A$. nigricans $\times$ Pulsatilla. $A$. nemorosa $X$ ranunculoides und $A$. nemorosa $X$ trifolia.

\section{CLEMATIS. L. Waldrebe.}

B. ungetheilt, eiförmig, ganzrandig; Bt. violett; Staude. M. N. St. Kr. J.

B. getheilt ..............................

Bt. einzeln, ansehnlich, violett $\mathrm{c}$. blau (ausnahmsweise

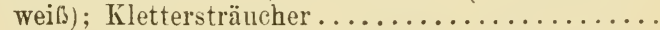

Bt. in trugdoldigen Blütenständen, klein, weißlich; Fr. von dem langen, behaarten Griffel geschwänzt

Die äusseren Stb. in Krb. umgewandelt; Fr. von dem langen, behaarten Griffel geschwänzt; B. doppeltdreizählig. A...... alpina. (L.) Mill. Alpenrebe.

Alle Stb. fruchtbar; Fr. mit kurzem, kahlem Schnabel ;

B. gefiedert, Fiedern 3 zählig. J., sonst cult.

Viticella. L. Italienische W.

Kletternde Sträucher...................

Staude mit gefiederten B.; Fiedern ganzrandig; Kb. 5 am Rande flaumig. Ierbr. (fehlt Sch. S.) 
B. einfach gefiedert; Fiedern oft gesägt o. gelappt; $\mathrm{Kb}$. beiderseits filzig; Fr. eiförmig. Verbr. $u$. lıfg. Vitalba. $L$. Gemeine W.

5 B. doppelt gefiedert; Kb. nur am Rande filzig; Fr. scheibenförmig. Südst. J.

Flammula.*) $L$. Blatterzug

IV. MYOSURUS. $L$. Mäuseschwanz.

Pf. sehr klein, kahl; Bt. gelblich.

Tertr. (fehlt $S . T . K$.) minimus. $I$. Kleinster M.

\section{IVI. RANUYCULUS. L. Hahnenfuß.}

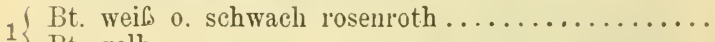

Wasserpflanzen mit untergetauchten 0 . theilweise

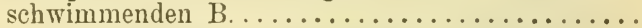

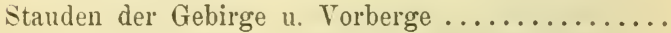

Schwimmb. nierenförmig, 3-5 lappig; untergetauchte B. in viele borstliche Zipfel gespalten; Stb. zahlreich, über die Frkn. hinausragend. Verbr.

aquatilis. $\mathrm{L}$. Wasser-H.

Schwimmb. tief $3-5$ theilig 0 . fehlend ........ 4

B. steif, 3 theilig: die drei Abschnitte wiederholt gabelig getheilt: Zipfel auberhalb des Wassers ausgebreitet bleibend; Stb. über die Frkn. hinausragend. Verbr.

divaricatus. Schrk. Ausgespreizter $\mathrm{H}$.

B. schlaffer, außerhalb des Wassers gewöhnlich pinselförmig zusammenfallend; Stb. über die Frkn. nicht

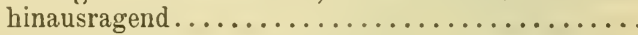

B. im Umrisse länglich, 3 theilig; die drei Abschnitte wiederholt gabelig getheilt; Zipfel sehr verlängert, auch im Wasser parallel vorgestreckt; Fr. kahl. Verbr........... Huitans. Lam. Fluthender $H$. B. im Umrisse rundlich, wiederholt 3 theilig; Zipfel

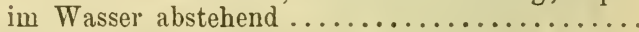

B. gestielt; der mittlere Abschnitt viel kürzer als die beiden seitlichen Abschnitte; Nebenb. u. Fr. behaart. Verbr.

pancistamineus. Tausch. ${ }^{* *}$ ) Haarblättriger $\mathrm{H}$. Obere B. sitzend; die drei Abschnitte nahezu gleich groß; Nebeub. u. Fr. kahl. Verbr.

Petiveri. Koch. Petiver's H.

*) Die Form mit linealen Blättchen ist C. maritima L.

**) Mehrere mit $\mathrm{R}$. paucistamineus Tausch verwandte Formen, welche nicht genau genug bekannt sind, fanden hier keine Aufnahme. 
$7\{$ Grundb. ungetheilt, ganzrandig ........... 8

7 Grundb. getheilt 0 . mindestens gekerbt......... 9 Grundb. lanzettlich, kahl. A. จ. T. $K$.

Pyrenaeus. L. Pyrenäischer $\mathrm{H}$.

8\{ Grundb. herz-eiförnig, am Rande zottig. A. v. T. K.

parnassifolius. L. Paruassienblättriger $H$.

g) Grundb. nierenförmig, gekerbt............ 10

Grundb. getheilt 0 . doch gelappt........... 11

Grundb. undeutlich 5 nervig, mit theilweise spitzen

Kerben; Krb. rundlich-eiförmig. A. v. St.

crenatus. $W . K$. Gekerbter $H$.

Grundb. deutlich 5 nervig, doppelt-stumpf-gekerbt; Krb. länglich-eiförmig. $A$. v. Sü̈tt.

bilobus. Bert. Zweilappiger $\mathrm{H}$.

K. dicht rauhhaarig, meist rothbraun gefärbt; B. mehrfach getheilt; Bt. grof, weiß o. rosenroth:

11 K. u. Blkr. nicht abfällig. A. v. T. S. K. St.

glacialis. $L$. Gletscher-H.

K. kahl o. spärlich behaart, abfällig, ebenso die Blkr, 12

Niedrige Stauden der Alpen mit $1-3$ blättrigem Stengel......................... 13

12 Höhere, mehrblütige Stauden der Gebirge und Vorberge, zuweilen auch in der Ebene.......... 15

Pfl. wenigstens anfangs zottig behaart; Grundb. u. Stgb. mehrfach getheilt.

13 A. จ. T.K. Kr.....Seguieri. Vill. Seguier's H. Pfl. kahl; Stgb. 1 - 2, ungetheilt 0. 2-3 theilig ... 14 Grundb. 3-5 spaltig, im Umrisse herzförmig-rundlich, Zipfel verkehrt-eiförmig, vorne eingeschnitten-gekerbt; Stgb. meist 3 spaltig. A. ( $h f g$.)

14 Grundb. 3 theilig, im Umrisse nierenförmig, der mittlere:Zipfel 3 spaltig, die seitlichen tief- 2 spaltig; Stgb. meist lineal. A. (selten.)

Traunfellneri. Hoppe. Traunfellner's H. Btstiele behaart; B. 3 theilig, mittlerer Abschnitt gestielt. Terbr. (fehlt $M$. Sch. Kr.J.)

15) aconitifolius. L. Eisenhutblättriger $\mathrm{H}$ Btstiele kahl, verlängert; B. tief 3 spaltig, die drei Abschnitte zusammenhängend. Verbr.

platanifolius. $L$. Platanenblättriger $\mathrm{H}$.

$16\{$ Knollig verdickte Wurzeln vorhanden .................

Knollig verdickte Wurzeln fehlen ............ 24

${ }_{17}\{\mathrm{~Kb}$. meist 3 ; Krb. 8-12, schmal; niedrige Stauden 7 mit herzförmigen $B . \ldots \ldots \ldots \ldots \ldots \ldots \ldots \ldots 18$ Kb. u. Krb. meist 5, letztere breit .......... 19 
Stg. wurzelnd, gleichmäळig beblättert; in den Blattachseln oft Brutknospen; Lappen des Blattgrundes auseinanderfahrend; Fr. meist fehlsehlagend.

Verbr. u. hfg. .. Ficaria. I Gemeine Feigwurz.

18 Stg. nicht wurzelnd, meist oberwärts blattlos; Brutlinospen fehlen; Lappen des Blattgrundes einander deckend; Fr. meist gut entwickelt. $J$.

calthaefolius. (Rehb.) Bl. N. Sch. Dotterblumenblättrige Feigwurz.

Kahle Standen der Alpen; B. ungetheilt oder nur gelappt....................... 20 Stauden wärmerer Gebiete; Stg. behaart; B. getheilt 21

Grundb. fehlen; unteres Stgb. rundlich-nierenförmig, gekerbt. A. v. T. K. Kr. St.

Thora. $L$. Giftiger $\mathrm{H}$. Grundb. einzeln, lang gestielt, quer-breiter, vorn eingeschnitten-gelappt; Stgb. ebenso. $A$.

hybridus. Biria. Bastart-H.

K. zurückgeschlagen $\ldots \ldots \ldots \ldots \ldots \ldots \ldots \ldots$

K. an die Blkr. angedrückt; Wurzelknollen dünn; Stg. am Grunde mit Faserschopf; Bzipfel spitz. J.

flabellatus. Desf. Fächerblättriger $\mathrm{H}$.

Fr. mit gut entwickeltem, hakigem oder fast geradem Schnabel .....................

Fr. mit sehr kurzem Schmabel; B. 3 spaltig, mit eingeschnittenen Abschnitten; Frboden abstehend behaart. $J$.

Neapolitanus. Ten. Neapolitanischer $\mathrm{H}$.

Die ersten B. ungetheilt, schmal lanzettlich, die folgenden 3 theilig, mit ungetheilten $0.2-3$ theiligen Abschnitten; Pfl. dicht seidenhaarig; Frschnabel fast gerade. B. MI. N. J.

Die ersten B. dreilappig, die folgenden dreischnittigfiedertheilig, mit linealen stumpfen Zipfeln; Frschnabel hakig. $J$.

chaerophyllus. L. Peloponnesischer H.

24 Sumpf- und Wasserpflanzen mit ungetheilten B...2 25

B. getheilt 0 . doch gelappt ............... 27

B. lineal o. lanzettlich, seltener elliptisch; Fr. glatt (unter der Lupe fein punktirt)............ 26

25 Untere B. herzeiförmig, die oberen länglich-elliptisch; Fr. körnig-rauh, berandet, geschnäbelt. $J$. ophioglossifolius. Vill. Natterzungenblättriger H. 
Hohe Staude mit dickem, hohlem Wst.; Bt. grow; Fr. berandet, mit kurzem, breitern Schnabel. Verbr.

Lingua. L. Großer $\mathrm{H}$. Zartere Staude mit kleinen Bt. und aufgeblasenen, kaum berandeten, kurz-bespitzten Fr. Verbr.

Flammula. L. Brennender $\mathrm{H}$.

Sehr kleine, wollig behaarte, einjährige Kräuter; B. nur grundständig; Bt. klein, hellgelb; Fr. mit langem Schnabel und 2 hohlen Höckern an den Seiten .......................... 28

Stauden o. Kräuter mit beblättertem (mindestens 1 blättrigem) St.; Fr. ohne hohle Höcker........

Fr. oberseits mit schmaler Furche, unterseits mit einem fast 4 eckigen Kamme, mit fast geradem Schnabel. B. M. I. T.

testiculatus. $\mathrm{Cr}$. Geradfrüchtiges Hornköpfchen.

Fr. oberseits mit breiter Grube, unterseits gekielt, ohne Kamm, mit sichelförmig einwärts gebogenem Schnabel. B. MI. N.

falcatus. $L$. Sichelfrüchtiges Hornkỏpfehen.

Sehr kleine, kahle Alpenpflanze mit 1 blütigem, die Grundb. nicht überragendem Stg.; Grundb. 1-2, handförmig gelappt; Stgb. $1-2$, tief $3-5$ spaltig; Krb. klein, kürzer als die Ǩb. A. v. T. $S . K$.

pygmaeus. Wahlbg. Zwerg-H. Stg. die Grundb. überragend, meist mehrblütig....

Frboden walzlich verlängert; Honiggrube der Krb. ohne Schuppe; Krb. blassgelb, kaum länger als die Kb.; einjähriges, kahles Kraut mit hohlem Stg. Verbr.......... sceleratus. L. Giftiger H. Frboden halbkugelig gewölbt; Honiggrube meist mit

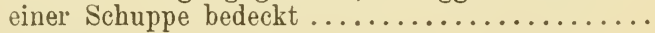

Btstiele hohl, nach oben aufgeblasen verdickt, unter der Bt. aber wieder eingeschnürt; untere B. 5lappig, obere dreitheilig; Bt. achselständig, klein, hellgelb; Fr. knotig-rauh. $K r$. $J$.

Chius. $D C$. Aufgeblasener $\mathrm{H}$.

Btstiele nicht aufgeblasen verdickt ........... 32

${ }_{32}\left\{\begin{array}{c}\text { Fr. linsenförmig zusammengedrückt, berandet, glatt } \\ \text { (nur bei R. Sardous oft etwas knotig) ........ }\end{array}\right.$ 33

Fr. flachgedrückt, geschnäbelt, bestachelt o. knotigrauh; einjährige Kräuter mit kleinen hellgelben Bt. 46

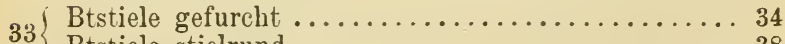

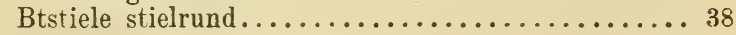

$34\{$ K. zurückgeschlagen ................... 35

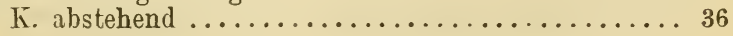


Staude; Stg. am Grunde zwiebelig verdickt; Fr. glatt, mit hakigem Schnabel. Verbr.

bulbosus. $\left.L .^{*}\right)$ Knolliger $\mathrm{H}$. Kraut; Stg. am Grunde nicht verdickt; Fr. glatt 0 . vor dem Rande feinknotig, mit geradem Schnabel. Verbr.

Sardous. $\mathrm{Cr}$. Rauhhaariger $\mathrm{H}$.

Wst. Ausläufer treibend; Grundb. 3 zählig o. doppelt 3 zählig; Fr. fein punktirt. Verbr. $u$. $h f g$.

repens. $L$. Kriechender $H$.

Wst. ohne Ausläufer; Grundb. handförmig getheilt 37

Abschnitte der Grundb. breit verkehrteiförmig; Krb. orange; Fr. mit eingerolltem Schnabel. Verbr.

nemorosus. JC. Wald-H.

37 Abschnitte der Grundb. schmal, in lineale Zipfel zertheilt; Krb. goldgelb; Fr. mit etwas hakigem Schnabel. Verbr.

polyanthemus. $L$. Vielblütiger $H$.

K. zurückgeschlagen; Stg. u. B. meist zottig behaart; Frboden kahl; Fr. berandet. $J$.

velutinus. Ten. Sammtiger $H$

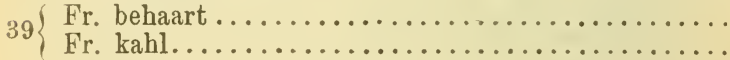

Stg. am Grunde mit Schuppen und 1-2 ungetheilten, rundlichen, etwas weichhaarigen $\mathrm{B}$. bekleidet; Stg. mit länglichen, grob gesägten Abschnitten. B. M. Sch. N...Cassubicus. L. Wendischer H.

40 Stg. am Grunde ohne Schuppen; Grundb. mehrere, kahl, die oberen meist gelappt o. gespalten; Stgb. mit linealen, ganzrandigen 0. keilförmigen, grob gezähnten Abschnitten. Verbr.

auricomus. $L$. Goldgelber $\mathrm{H}$.

Grundb. u. Stgb. gleich gestaltet, nur die oberen

41 kleiner $u$. weniger getheilt; Frboden kahl......4 41

Grundb. u. Stgb. verschieden gestaltet.......... 44

B. 3-5 theilig; Stg. anliegend behaart.........43

42 B. 3-5 lappig; Stg. abstehend zottig; B. orange. Verbr.......... lauuginosus. $L$. Wolliger $H$.

Wst. kurz; Bzipfel schmal, tief eingeschnitten; Schnabel der Fr. fast gerade. Terbr. $\iota . h f g$.

43 Wst. verlängert, kriechend; Bzipfel breit, grob gezähnt; Schnabel der Fr. breit, hakig. M. $N$.

Steveni. Andr\%. Steren's H.

*) R. Aleae Willk. (Sü̈lt.) hat spindelig verdickte Wz. 
Wst. kurz, aufrecht; Abschnitte der Grundb. spitz gezähnt. $A$. (selten.)

Hornschuchii. Hoppe. Hornschuch's H. Wst. verlängert, dick, wagrecht; Abschnitte der Grundb. stumpflich gezähnt ............... t5

Pfl derb; Abschnitte der Grundb. breit; Stgb. 1-3, meist vieltheilig; Schnabel der Fr. gekrümmt.

A. u. Vora. (lifg.) ..montanus. Willd. Berg-H. 45 Pfl. zart; Abschnitte der Grundb. schmal, auseinander fahrend; Schnabel der Fr. kurz, hakig. A. (seltener.)

Carinthiacus. Hoppe. Kärntnerischer $\mathrm{H}$. Grundb. 3 spaltig, gezähnt; Stgb. 3 zählig, Blättchen 3-vielspaltig, Zipfel keiltörmig; die obersten B. lineal; Fr. wenige, grob.*) Verbr.

Die unteren B. rundlich o. nierenförmig, 3-5lappig, ungleich grob gekerbt ................. 4

Frboden behaart; Fr. bestachelt. $K r . J$.

muricatus. $L$. Stachelfrüchtiger $\mathrm{H}$. Frboden kahl; Fr. knotig-rauh. J.

parriflorus. $L$. Kleinblütiger $\mathrm{H}$.

\section{THALICTRUII. $L$. Wiesenrante.}

Fr. 3 kantig, geflügelt; Stf. nach oben rerbreitert; Btstand ebensträußig, gedrungen; B. denen des Akelei ähnlich, mit häutigen Nebenblättchen; Bt. lila 0 . weib. Terbr.

aquilegifolium. L. Akeleiblättrige W. Fr. der Länge nach gefurcht-gerieft; Stf. nicht ver-

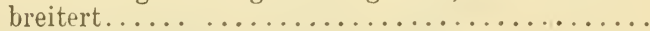

Fr. an der Spitze mit der Narbe hakig-gebogen;

2 , Bttraube einfach, endständig; Frstiele herabgekrümmt; Bt. grünlich, röthlich überlaufen.

A. (fehlt $O$. N.) ........ alpinum. $L$. Alpen-W.

Fr. an der Spitze gerade; Frstiele aufrecht....... 3

3 ( Bt. sammt den Stb. niederhängend; A. bespitzt ... 4

3 Bt. sammit den Stb. aufrecht; A. vorherrschend stumpf 9

(Narbe am Rande fransig-gezähnelt, ınit ihren Rändern sich nach hinten zusammenlegend; Btstiele fast stielrund; Stg. u. B. meist drüsenhaarig.**)

4 B.T. St. Kr. ..... foetidum. L. Stinkende W. Narbe am Rande nicht gezähnelt, die Ränder zuletzt zurückgekrümmt......................

*) Bei der gewöhnlichen Form dieser Art sind die Fr. bestachelt, bei der var. tuberculatus Koch jedoch nur warzig.

**) Die kahle Form ist Th. alpestre Gaud. (T.)

Fritseh, Excursionsflora. 
(Stg. fein gerillt, seltener kantig; B. 3 zählig-zu-

5 sammengesetzt, etwa so lang als breit.........

Stg. kantig-gefurcht; B. fiederig zusammengesetzt, länger als breit; Wst. kriechend ... . . . . . . .

Aeste des Bstiels zusammengedrückt-stielrund, undeutlich-kantig; Wst. kriechend. A. v. T. S. K.

6

saxatile. Schl. Berg-W.

Aeste des Bstiels durch erhabene Linien kantig;

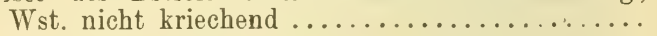

Stg. an den Gelenken hin- und hergebogen, sammt den $B$. bereift; mittlere Aeste der Rispe fast

7 wagrecht. Verbr........ minus. L. Graumändl. Stg. gerade, nicht bereift; Aeste der Rispe aufrecht abstehend. Verbr. flexuosum. Beruh. Hügel-W.

Blättchen breit keilig, die meisten vorne 3 spaltig. B. T. S. K. St. Kr......simplex. L. Steife W.

$8\{$ Blättchen lineal 0 . länglich, meist ungetheilt. Verbr. (fehlt B. Sch. O.)

galioides. Nestl. Labkrantartige W.

Wst. kriechend; Nebenblättchen vorhanden; Blättchen breit, vorne 3 spaltig. B. M. Sch. N.

flavum. $L$. Gelbe W.

Wst. nicht kriechend; Nebenblättchen fehlen; Blättchen breit 0 . schmal, häufiger ungetheilt.

Verbr. $u$. $h f g$......lucidum.*) L. Amstelkraut.

\section{ADONIS. L. Feuerröschen.}

( Staude mit großen, gelben, im Frühling erscheinenden Bt.; K. behaart; Kronb. 10-20; Fr. behaart, mit hakigem Schnabel. B. M. N.

vernalis. $L$. Teufelsauge.

Einjährige, im Sommer blühende Kräuter; Kronb. $6-10$; Fr. kahl, mit geradem 0 . etwas gebogenem Schnabel

Kronb. halbkugelig zusammenneigend, blutroth, am Grunde schwarz; Schnabel der Fr. gerade.

Kr. J. Sïdt. (sonst cult.)

atrorubens. (L.) Blutströpfehen.

Kronb. ausgebreitet; Schnabel der Fr. etwas aufgebogen .

*) Die Form mit schmallinealen Blättchen ist Th. angustissimum Cr, jene mit breiteren Blättchen und drüsiger Behaarung Th. nigricans Scop. 
K. behaart; Kronb. scharlachroth, selten gelb; Schnabel der Fr. an der Spitze schwarz. Verbr. (fehlt S. T. Kr.)

flammea. Jacq. Scharlachrothes F.

K. kahl ; Kronb. mennigroth, selten gelb....... 4

Fr. außen mit einem spitzen, abstehenden Zahne und mit langem, grünem Schnabel.

Verbr. (fehlt $S$.) phoenicea. ( $L$.) Mennigrothes F. Fr. außen mit einem stumpfen Zahne, an den der dunkel gefärbte Schnabel angedrückt ist. $J$.

microcarpa. $D C$. Kleinfrüchtiges $\mathrm{F}$.

XXII. Familie. Berberideae. Sauerdorngewächse.

Sträucher 0. Stauden mit ungetheilten o. zusammengesetzten, schraubig gestellten B. u. sehr kleinen Nebenb. Bt. zwittrig, in Trauben o. Rispen. Bthülle doppelt: Kb. 4 $0.6 ; \mathrm{Krb} .4$ o. 6. Zwischen Krb. u. Stb. oft noch Honigb. eingeschaltet. Stb. 4 0. 6. Frkn. 1, oberständig, 1 fächerig, mit wenigen 0. zahlreichen Samenknospen. Gr. ı. N. 1. Fr. aufspringend 0 . beerenartig. S. mit Nährgewebe.

\section{Gattungen.}

Staude mit zusammengesetzten B.; Kb., Krb., Honigb. u. Stb. 4; Fr. aufspringend ......Epimedium. I. Dorniger Strauch mit ungetheilten B.; Kb., Krb. u. Stb. 6 ; Fr. eine rothe Beere..... Berberis. II.

\section{Arten.}

\section{EPIMEDIUI. L. Sockenblume.}

B. doppelt 3 zählig; Blkr. blutroth; Honigb. kapuzenförmig, gelb. $T$. $K r$. J. . alpinum. $L$. Alpen-S.

\section{BERBERIS. $L$. Sauerdorn.}

B. länglich-verkehrt-eiförmig, feinstachelig-gesägt, gebüschelt; Traube hängend. Terbr. u. lifg.

vulgaris. L. Gemeiner S

\section{Familie. Lauraceae. Lorbeergewächse.}

Holzgewächse mit immergrünen, wechselständigen, ganzrandigen 0 . etwas welligen B., ohne Nebenb. Bt. 2 häusig, mit einfacher, 4 blättriger Bthülle, deren B am Grunde etwas verwachsen sind. Männliche Bt. mit $12 \mathrm{Stb}$, deren A. mit 2 Klappen aufspringen. Weibliche Bt. mit 4 verkümmerten Stb.; Frkn. 1, oberständig, 1 fächerig, mit 1 Samenknospe u. 1 Gr. Fr. eine Beere. S. ohne Nährgewebe, mit fleischigen Keimb. 


\section{Gattung.}

Bthülle grünlich- o. gelblichweiß; Fr. schwarzblau, eiförmig ......................

Art.

\section{LAURUS. L. Lorbeerbaum.}

B. länglich-lanzettlich, oberseits glänzend, unterseits matt, durchscheinend punktirt.

Sïdt. J. (Cult. u. veru.) . nobilis. L. Echter L.

\section{Familie. Papaveraceae. Mohngewächse.}

Kräuter o. Stauden mit wechselständigen (selten fast gegenständigen), meist getheilten, seltener nur gelappten 0 . gezähnten, niemals ganzrandigen B., ohne Nebenb. Bt. zwittrig, oft unregelmäbig, mit doppelter Bthülle. Kb. 2, oft sehr klein, meist hinfällig. Krrb. 4, manchmal an Grunde verwachsen. Stb. entweder zahlreich und frei 0. 6 und dann in 2 Bündel verwachsen. Frkn. 1, oberständig, 1 fächerig 0 . unvollständig gefächert. Gr. kurz o. fehlend; $\mathrm{N}$. oft 2 lappig o. mehrstrahlig. Fr. eine mehrsamige Kapsel o. eine 1 samige Schließfrucht S. mit Nährgewebe.

\section{Gattungen.}

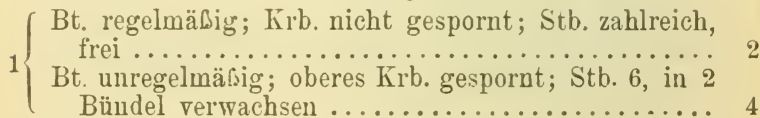

(Kapsel mehr o. wenigel kugelig, unvollkommen 2 4-20 fächerig, mit Löchern unter der N. aufspringend; N. 4-20 strahlig ..... Papaver. III. Kapsel schotenförmig verlängert, 2 klappig; N. 2 lappig Kapsel 1 fächerig, vom Grunde gegen die Spitze aufspringend; Staude; Bt. in Dolden.

Chelidonium. I.

3 Kapsel unecht 2 fächerig, von der Spitze gegen den Grund aufspringend; Kräuter; Bt. einzeln, blattwinkelständig .............. Glaucium. II.

Fr. länglich o. elliptisch, vielsamig, aufspringend; 4 Stauden, seltener Kräuter ....... Corydalis. IV. Fr. kugelig, einsamig, nicht aufspringend ; einjährige Kräuter ................... Fumaria. V.

\section{Arten.}

\section{CHELIJONIUM. L. Schöllkraut.}

Stg. mehr 0. weniger wollig-behaart; B. fiederschuittig, nahezu kahl, unterseits seegrün; Bt. gelb. Verbr. u. hfg....majus. L. Gemeines Sch. 


\section{GLAUCIUM. Adans. Hornmohn.}

Btstiele kahl; Schoten knötig-rauh; obere B. mit tief-herzförmigem Grunde umfassend; B. gelb.

II. N. O. St. J.......flavum. Cr. Gelber H. Btstiele steifhaarig; Scboten borstig-steifhaarig; obere B. mit abgestutztem Grunde sitzend; Bt. roth o. orange. B. $M . N$. St.

corniculatum. (L.) Curt. Rother $\mathrm{H}$.

\section{PAPA VER. L. Moln.}

1 Niedrige Stauden der Alpen; B. nur grundständig.

Einjährige Kräuter mit beblättertem Stg.........

B. fiedertheilig, mit breit-lanzettlichen, behaarten, manchmal 2-3 spaltigen Zipfeln; Bt. weiß oder gelb. A. v. S. T. K. Kr .

2 Pyrenaicum. Willd. Pyrenäischer MI. B. 2-3 fach fiedertheilig, mit schmal-lineal-lanzettlichen, oft fast kahlen Zipfeln; Bt. weifo, seltener gelb. A. ............. alpinum. L. Alpen-M.

Stg. u. B. kahl, bläulich bereift; obere B. ungetheilt, umfassend; Stf. nach oben verbreitert; Fr. kahl; Bt. roth, lila o. weib. Cult. u. verw.

Stg. u. B. steifhaarig; B. fiederspaltig oder doch ge-

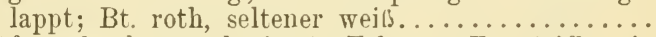

4 Stf. nach oben verbreitert, Frkn. 11. Fr. steifhaarig 4 5

Stf. nicht verbreitert; Frkn. u. Fr. kahl ......... Fr. kugelig, mit steifen, stark gekrümmten Borsten 5 reichlich bekleidet. J...hyloridum. L. Bastart-M. Fr. ellipsoidisch 0 . keulenförmig, mit geraden 0 . fast

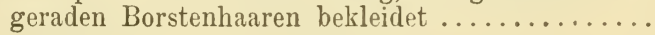

$\int_{6} \begin{aligned} & \text { Fr. ellipsoidisch, klein, reichlich steifhaarig. J. } \\ & \text { Apulum. Ten. Apulischer M. }\end{aligned}$ Fr. keulenförmig, spärlich steifhaarig.

Verbr. (fehlt $S$.)......Argemone. L. Sand-MI. Läppchen der N. mit ihren Rändern sich deckend; Fr. verkehrt-eiförmig. Verbr.

Rhoeas. L. Klatsch-M.

Läppchen der N. von einander entfernt; Fr. keulenförmig. Verbr. (fehlt St. K. Kr. J.) dubium. $L$. Zweifelhafter M.

A nm erkung. Zwischen P. dubium u. P. Rhoeas wurde ein Bastart beobachtet.

\section{CORYDALIS. DC. Lerchensporn.}

Stg. aus einem unterirdischen Knollen entspringend,

1 1-2 blättrig; Stauden mit endständiger Bttraube

Stg. ästig, beblättert; kein Knollen vorhanden; Tr.

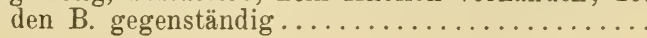


Knollen hohl; Stg. 2 blättrig, ohne Schuppe; Bt. purpurn 0. weib, wohlriechend. Verbr.

cava. (L.) Schw. et $K$. Hohlwurz.

Knollen nicht hohl; eine häutige Schuppe unter dem unteren Stgb.

Deckb. ganzrandig; fruchttragende Traube nickend; Frstiele 3 mal kürzer als die Fr.; Bt. hellpurpurn.

3 Verbr. (fehlt O. St. J.)

intermedia. (L.) $P . M . E$. Taubenkropf.

Deckb. fingerig-getheilt 0 . eingeschnitten.........

Frtragende Traube aufrecht, verlängert; Frstiele so lang als die Fr.*) Verbr. (fehlt $S$.)

solida. (L.) Sm. Grimwurz.

Frtragende Traube nickend, gedrungen; Frstiele 3 mal kürzer als die Fr.; Bt. hellpurpurn.

B. II. N. St. pumila. (Host.) Rchb. Niedriger L. Stauden; Deckb. länglich, gezähnelt, haarspitzig; Sporn kurz, sackartig.................

5 Kraut; das unterste Deckb. den Stgb. ähulich; B. 6 3 zählig, Blättchen 3 theilig 0.3 spaltig; Sporn fast so lang als die gelblich-weißen Krb. T.

capnoides. (Sm.) Wahlbg. Weicer L.

Bstiele mit beiderseits hervortretendem Rande; Fr. länger als die Frstiele; Same fast glanzlos; Krb.

6 weiflich-gelb, an der Spitze gelb.

T. K. $K r$. J. ochroleuca. Koch. Blassgelber L.

Bstiele unberandet, oberseits flach..............

Fr. 2-3 mal kürzer als die Frstiele; Same fast glanzlos; B. weiblich-graugrün; Krb. schneeweiß, an der Spitze gelblich-grün. $J$.

acaulis. Pers. Stengelloser L.

Fr. meist länger als die Frstiele; Same glänzend; B. lauchgrün; Blkr. gelb. T. J.

Iutea. (L.) DC. Gelber L.

\section{FUMARIA. L. Erdrauch.}

$\int$ Frstiele aufrecht abstehend oder nur einige etwas

1 zurückgekrümmt; Fr. fein runzelig............ Frstiele herabgekrümmt (manchmal einige gerade). 8 Bt. ansehnlich, rosenroth 0 . weislich; Kb. eilanzettlich, ringsum gezähnt; Fr. groß, stumpf, fast aus-

2 gerandet, dicht runzelig. $J$.

Major. Bad. Grober L.

6


Deckb. ebenso lang o. etwas kürzer als der Frstiel; Kb. breiter als die Blkr.; Bzipfel schmal. B. $M$. N. rostellata. Knaf. Geschnäbelter E.

Deckb. viel kürzer als der Frstiel; Kb. so breit als die Blkr.; Bzipfel relatio kurz u. breit. .J.

Gussonii. Boiss. Gussone's E.

$\mathrm{Kb}$ eilanzettlich, etwa 3 mal kürzer als die Blkr. (ohne Sporn), ziemlich lange bleibend; B. rosenroth: Fr. etwas breiter als lang, ausgerandet. Verler. $u$. lefg..... officinalis, L. Gemeiner E. $\mathrm{Kb}$. sehr klein u. hinfällig; Fr. kugelig o. eiförmig,

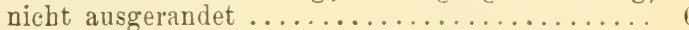

Deckb. so lang 0 . wenig kürzer als der Frstiel .... 7 Deckb. viel kürzer als der Frstiel; Fr. kugelig, kurz bespitzt; Bt. rosenroth (selten weiळ). B. M. N.

Schleicheri. Soy. Willm. Schleicher's E.

Fr. kugelig, stumpf; Bt. blassrosa; Pfl. stark blaugrau bereift. Vertur. (fehlt S.)

Vaillantii. Lois. Vaillant's E. Fr. eiförmig, kurz zugespitzt; Bt. weiß; Pfl. bereift. $J$. (sonst eingeschleppt).

parviflora. Lam. Kleinblïtiger E.

Bt. ansehnlich, weißlich o. etwas rosa ïberlaufen; Deckb. kürzer als der Frstiel; Bzipfel breit .....

8 Bt. klein, rosenroth; Deckb. länger als der Frstiel; Fr. rundlich, fast glatt; Bzipfel schmal. $J$.

Kraliki. Jord. Kralik's E.

Fr. runzelig, abgerundet; Tr. armblütig. $J$.

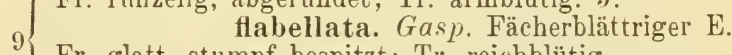

Fr. glatt, stumpf bespitzt; Tr. reichblütig. Südt. St. J. ..... capreolata. L. Rankender E.

\section{Familie. Cruciferae. Kreuzblütler.}

Kräuter o. Stauden, selten Halbsträucher mit wechselständigen, bald ungetheilten, bald mehr 0 . weniger getheilten B., ohne Nebenb. Bt. zwittrig, zumeist in Trauben, die beim Aufblühen oft doldenförmig sind, regelmäßig, seltener, namentlich die unteren (äußeren) des Btstandes unregelmäßig. Bthülle doppelt: Kb. u. Krb. 4, letztere manchmal fehlend Stb. meist 6, wovon 2 kürzer sind als die übrigen, seltener weniger; an ihrem Grunde Honigdrüsen. Frkn. 1, oberständig, 2- 0 . 1 fächerig, meist mit zahlreichen, seltener mit 10 . wenigen Samenknospen Gr. 1, manchmal 2 spaltig; N. oft 2lappig. Fr. am häufigsten eine 2 klappig aufspringende Kapsel ( Schote" 0. "Schötchen"), seltener eine Schlieifr., manchmal auch in Glieder zerfallend. S. ohne deutliches Nährgewebe. 


\section{Gattungen.}

${ }_{1}$ Fr. 4- o. mehrmal länger als breit $\left({ }_{n}\right.$ Schote $\left.{ }^{*}\right) \ldots .2$

1 Fr. höchstens 3 mal länger als breit ("Schötchen") 24

N. aus 2 aufrechten, nebeneinander liegenden Plättchen gebildet ..................

N. kopfig, stumpf 0 . ausgerandet, selten 2 lappig... 5

$3\left\{\begin{array}{l}\text { N. kegelförmig; Fr. stielrund; Bt. purpurn. } \\ \text { IVilckia. XLVII. }\end{array}\right.$

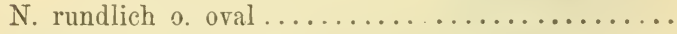

Plättchen der N. auf dem Rücken höckerig, zuletzt

4 etwas umgebogen ................ Matthiola. L. Plättchen der N. auf dem Rücken flach, oval, nicht zurückgebogen.............Hesperis. XLIX.

$\int$ Klappen der Fr. nervenlos 0. am Grunde mit 1

Ansatze zu einem Mittelnerv ... der Fr. 1-3-5nervig, 0. mit mehreren

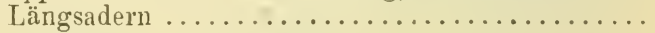

(Wst. wagrecht, fleischig, schuppig-zackig o. gezähnt;

6 Keimb. im S. gewölbt....... Dentaria. XXX. Wst. nicht gezähnt, 0. fehlend; Keimb. im S. flach $7\{$ Bt. weiळ o. lila........... Cardamine. XXIX. $7\{$ Bt. gelb ................ Roripa. XXVII.

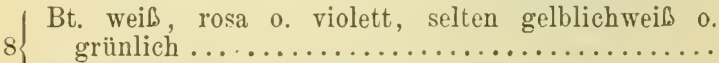

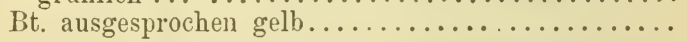

Fr. lang geschnäbelt; Keimb. im S. rinnig; Kräuter mit borstiger (manchmal spärlicher) Behaarung; untere B. leierförmig; Krb. mit violetten Adern 0 . ganz violett................... 10 Fr. nicht lang geschnäbelt; Keimb im S. Hach;

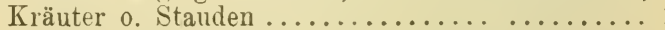

(Fr. aufspringend, mit zweischneidigem, flachem 10 Schnabel ................. Eruca. XVIII. Fr. nicht aufspringend, oft in Glieder zerfallend, nit kegelförmigem Schnabel..... Raphanus. XXIII. ${ }_{11} \int$ Klappen der Fr. (vom Rücken her) flachgedrückt.

11 Arabis. XXXVIII.

Klappen der Fr. gekielt 0 . gewölbt............ 12

( Niedrige Staude der Alpen; B. ungetheilt; Dolden12 trauben dicht; $\mathrm{S}$. in jedem Frfach 2 reihig.

Stgb. ganzrandig, kahl (o. nur die untersten behaart),

$13\left\{\begin{array}{r}\text { umfassend } \ldots \ldots \ldots \ldots \ldots \ldots \ldots \ldots \ldots \ldots \ldots \ldots \ldots \ldots \\ \text { Stgb. nicht umfassend } \ldots \ldots \ldots \ldots\end{array}\right.$ 
S. in jedem Frfache 1 reihig; alle B. ganzrandig

14 und kahl................ Conringia. LII. S. in jedem Fache 2 reihig; Grundb. gezähnt, behaart.................. Arabis. XXXVIII.

B. herzförmig-rundlich o. fast dreieckig; Klappen

15 der Fr. dreinervig................ Alliaria. XII.

B. elliptisch o. lanzettlich; Klappen der Fr. einnervig.

Stenophragma. XXXVII.

${ }_{16}$ Fr. achtkantig; alle B. ganzrandig, kahl, umfassend.

Fr. vierkantig, stielrund 0 . flachgedrückt......... 17

${ }_{17}$ Klappen der Fr. 1 nervig (höchstens mit 2 schwachen,

17 gebogenen Seitennerven)................ 18

Klappen der Fr. $3-5$ nervig ................. 22

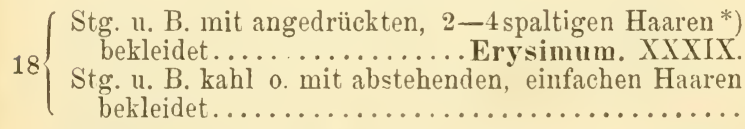

Klappen der Fr. flachgedrückt; S. in jedem Fache

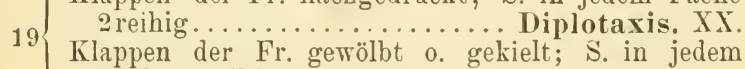
Fache 1 reihig............................

Fr. lang geschnäbelt; obere B. bläulich bereift.

$20\{$ Brassica. XXII.

Fr. kurz o. gar nicht geschnäbelt; B. nicht bereift. 21

Stg. wenigstens unten behaart; B. fiederspaltig; Fr. fast stielrund; Keimb. im S. rinnig.

21

Erucastrum. XXI.

Pfl. ganz kahl; untere B. leierförmig - fiederspaltig, obere ungetheilt; Fr. fast 4 kantig; Keimb. im S. flach.................... Barbarea. XXVI.

${ }_{22}\left\{\begin{array}{l}\text { Fr. lang geschnäbelt; Keimb. im S. rinnig......... } \\ \text { Fr. nicht geschnäbelt; Keimb. im S. flach. } \\ \text { Sisymbriun. XIII. }\end{array}\right.$

$\int$ Fr. aufspringend, mit mehr o. weniger flachgedrück23 tem Schnabel............... Sinapis. XIX. Fr. nicht aufspringend, in Glieder zerfallend, mit kegelförmigem Schnabel .....Raphanus. XXIII.

$24\{$ Krb. weiß, rosa 0. violett, manchmal fehlend..... 25 Krb. gelb.......................... 45

$25\left\{\begin{array}{c}\text { Fr. quer in } 2 \text { Glieder sich trennend, Glieder nicht } \\ \text { aufspringend } \ldots \ldots \ldots \ldots \ldots \ldots \ldots \ldots \ldots \ldots \ldots \ldots \ldots \ldots\end{array}\right.$

Fr. nicht in Glieder zerfallend ............... 27

*) Die 2 spaltigen, in der Mitte befestigten Haare können leicht für einfache gehalten werden! 
Staude; unteres Frglied stielförmig, unfruchtbar,

26 oberes kugelig, 1 samig.......... Crambe. XXV. Einjähriges Kraut; unteres Frglied kreiselförmig, oberes schwertförmig. ......... Cakile. XIV.

(Wenigstens 2 Stf. gezähnt, geflügelt 0 . mit einem

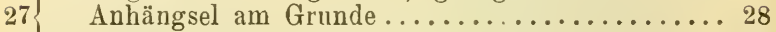

Alle Stf. einfach, gerade 0 . gebogen........... 31

Stg. u. B. mit Sternhaaren bekleidet; Krb. 2 spaltig; die 2 kürzeren Stf. am Grunde gezähnt; Fr. zu-

28 sammengedrückt, aufspringend. Berteroa. XLIII.

Stg. u. B. kahl o. etwas einfach behaărt; Krb. un-

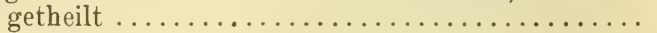

Fr. geflügelt, aufspringend $\ldots \ldots \ldots \ldots \ldots \ldots \ldots$

Fr. nicht geflügelt, eiförmig, kurz bespitzt, 1 samig,

29 nicht aufspringend; die 4 längeren Stf. am Grunde geflügelt; einjähriges, kahles Kraut.

Calepina. XVI.

Staude; die 4 längeren Stf. geflügelt (oft auch ge$30\{$ zähnt) ................. Aethionema. VI. 1 jähriges Kraut; alle Stf. am Grunde mit einem den Frkn. bedeckenden Anhängsel Teesdalia. I.

Scheidewand fast so breit als der größte Durchmesser der Fr., diese vorn Rücken her zusammengedrückt, rundlich o. länglich, o. aufgedunsen, und dann kugelig, oval, birnförmig o. stielrund.

Scheidewand schmal, lineal o. lanzettlich; Fr. von der Seite (den Klappenrändern her) zusammengedrückt, Klappen kahnförmig ............. 40

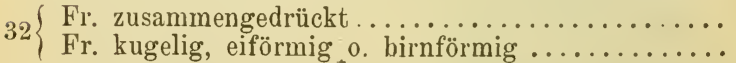
33 37

Fr. an einem stielförmig verlängerten Frträger be33 festigt, flach; S. zweireihig; Bt. grob, rothviolett.

Fr. auf dem Frboden sitzend ................. 34

$34\left\{\begin{array}{c}\text { Fr. } 2 \text { fächerig, aufspringend......................... } \\ \text { Fr. } 1 \text { fächerig, nicht aufspringend; kahle Staude mit } \\ \text { kleinen, weißen Bt. } \\ \text { Peltaria. XI. }\end{array}\right.$

Frfächer 1 samig; S. berandet; anliegend behaarter 35 Halbstrauch ............... Lobularia. XLII. Frfächer 2- oder mehrsamig; S. nicht berandet.... 36

Bt. rosa (ausnahmsweise weiß); rasenbildende Alpen$36\left\{\begin{array}{l}\text { pfl. mit } 3-5 \text { spaltigen B...... Petrocallis. VII. } \\ \text { Bt. weiß; B. ungetheilt, oft gezähnt. }\end{array}\right.$

Draba. XXXVI. 
1 jähriges Kraut; Fr. kugelig o. eiförmig, kurz geschnäbelt, nicht aufspringend, mit 1 samigen

37 Fächern................... Soria. XLVIIII. Stauden; Fr. aufspringend, mit 2- 0 . mehrsamigen Fächern .......................... 38

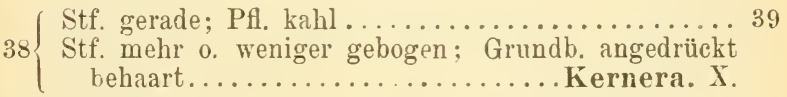

${ }_{39}$ Frklappen bis zur Spitze mit schwachem Mittelnerv.

Frklappen nervenlos....... Armoracia. XXVIII.

Aeußere Bt. der Doldentraube unregelmäळig, mit viel größeren Krb.; Fr. geflïgelt, aufspringend,

40 mit 1 samigen Fächern; einjährige Kräuter.

Alle

Alle Bt. regelmäळig, mit gleich großen Krb. . ... 41

$41\{$ Frfächer 1 samig ....................... 42

Frfächer 2-mehrsamig, aufspringend......... 43

Fr. aufspringend, mit lanzettlicher o. elliptischer 42 Scheidewand; Keimb. im S. flach. Lepidium. II. Fr. nicht aufspringend, mit linealer Scheidewand; Keimb. in S. eingeknickt...... Coronopus. III.

$43\{$ Fr. geflügelt ................ Thlaspi. VIII.

Fr. gekielt, aber nicht geflügelt............. 44

Fr. vorne abgerundet o. spitz. Hut chinsia. XXXII. 44 Fr. vorne verbreitert, abgestutzt 0 . ausgerandet.

Bursa. XXXIII.

Fr. gedunsen 0 . vom Rücken her zusammengedrückt, mit breiter Scheidewand ................. 46

Fr. von der Seite (den Klappenrändern her) zusammengedrückt, mit schmaler Scheidewand.... 56

Fr. unten nahezu stielrund, obeu abgesetzt erweitert,

$46\left\{\begin{array}{l}\text { nicht aufspringend........................................ } \\ \text { Fr. kugelig, ellipsoidisch, birnformig, vierkantig } 0 .\end{array}\right.$ zusammengedrückt................... 48

Fr. 2 gliedrig, unteres Glied fast stielrund, 1- bis 2 samig 0. leer, oberes Glied kugelig 0. eiförmig,

47 1 samig; Stg. unten behaart. Rapistrum. XXIV. Fr. 1 samig, der erweiterte obere Theil leer; kahles Kraut.................... Myagrum. XV.

$48\{$ Fr. zusammengedrückt $\ldots \ldots \ldots \ldots \ldots \ldots \ldots \ldots 49$

Fr. kugelig, ellipsoidisch, birnförmig o. vierkantig. 52

Fr. 2 fächerig, aufspringend............... 50

49 Fr. 1 fächerig, 1 samig, nicht aufspringend, kreisrund, flach; Stf. gezähnt; 1 jähriges, sternhaariges Kraut.

Clypeola. XLI. 
Stf. meist gezähnt; Frklappen nur am Grunde mit Mittelnerv; S. berandet ................ 51

50 Stf. nie gezähnt; Frklappen mit sehr zartem, bis zur Spitze laufendem Mittelnerv; S. unberandet. Draba. XXXVI.

$51\left\{\begin{array}{l}\text { Kelch offen, nicht gesackt; Fr. klein, mit mehr } 0 . \\ \text { weniger gewölbten Klappen...... Alyssum. XL. }\end{array}\right.$ Kelch geschlossen, am Grunde gesackt; Fr. groß, breit elliptisch, flach ...........Fibigia. XLIV'

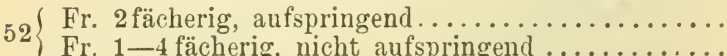

Fr. 1-4 fächerig, nicht aufspringend

S. geflügelt; K. gesackt*); Stauden.

S. nicht geflügelt. Vesicaria. XLV.

Frklappen bis zur Spitze 1 nervig; nach dem Aufspringen trägt eine der Klappen den Gr.; 1 jährige

54 Kräuter............. Camelina. XXXIV. Frklappen nervenlos; nach dem Aufspringen trägt die Scheidewand den Gr.; Kräuter o. Standen.

Roripa. XXVII.

Fr. kugelig, 1 fächerig 0 . unvollständig 2 fächerig, meist 1 samig; Keimb. im S. flach; B. ungetheilt, die oberen pfeilförmig-umfassend; 1 jähriges Kraut.

Neslia. XXXV.

Fr. vierkantig o. eiförmig, 2-4 fächerig, mit 1 samigen Fächern; Keimb. im S. eingerollt; wenigstens die unteren B. fiederig gelappt 0 . getheilt. Bunias. LI.

$\left\{\begin{array}{c}\text { Fr. } 2 \text { fächerig, mit } 1 \text { samigen Fächern, nicht } \\ \text { hängend } \ldots \ldots \ldots \ldots \ldots \ldots \ldots \ldots \ldots \ldots \ldots \ldots \ldots \ldots \ldots \ldots \ldots \ldots \ldots\end{array}\right.$

Fr. 1 fächerig, 1-2 samig, geflügelt, hängend; hohe Staude................... Isatis. XVII.

Fr. brillenförmig, mit sich ablösenden (aber nicht 57 aufspringenden) Fächern....... Biscutella. IV. Fr. eiförmig 0 . rundlich, aufspringend.

Lepidium. II.

\section{Arten.}

I. TLESDALIA. $R$. Br. Teesdalie.

Grundb. rosettig, leierförmig-fiederspaltig, seltener ungetheilt; Krb. ungleich, weiß, sehr klein. B. N. nudicaulis. (L.) $h$. B $r$. Gemeine T.

\section{LEPIDIUM. $L$. Kresse.}

Krb. citronengelb; untere B. 2-3 fach fiedertheilig, 1 obere herzeiförmig, ganzrandig, umfassend; 1 jähriges Kraut. $B . M . N . K$. perfoliatum. L. Gelbe K.

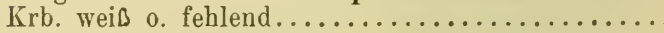

*) Ist der K. nicht gesackt, so vgl. Alyssum. 
${ }_{2}\{$ Obere Stgb. am Grunde pfeilförmig-umfassend .... 3

$2\{$ Stgb. nicht umfassend .................... 4

Kraut; Aeste am Grunde beblättert; Fr. vorne breit geflügelt. Verbr. (fehlt $O . K$.)

campestre. (L.) R. Br. Feld-K.

Staude; Aeste des Btstandes blattlos; Fr. ungeflügelt.

Verbr. .............. Draba. L. Graue K.

Kräuter; obere B. lineal, die unteren oft fiedertheilig

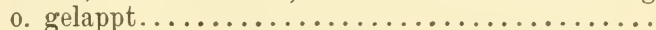
Kräftige Staude; B. ungetheilt, die untersten eiförmig, die obersten lanzettlich; Fr. zerstreut langhaarig. $M . N$. $(K r . T$.)

latifolium. L. Breitblättrige $\mathrm{K}$.

Fr. an die Spindel angedrückt, vorne breit geflügelt; Keimb. 3 theilig. Cult. u. verw.

sativum. I. Garten-K.

Frstiele abstehend; Fr. schmal o. gar nicht geflügelt;

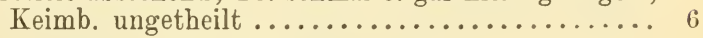

$\int \begin{aligned} & \text { Fr. stumpf, fast griffellos } \ldots \ldots \ldots \ldots \ldots \ldots \ldots \ldots \\ & \text { Fr. spitz, mit deutlichem } \mathrm{Gr} \text {; die meisten B. un- }\end{aligned}$ getheilt. Süldt. J.

graminifolium. L. Grasblättrige K.

Obere B. meist ganzrandig; Krb. fast immer fehlend; Stb. 2; Fr. kaum merklich geflügelt. Verbr.

ruderale. $L$. Stinkende $K$.

Obere B. meist gezähnt; Krb. stets vorhanden; Stb. 6 ; Fr. deutlich geflügelt. $S$. (eingeschleppt).

Virginicum. $L$. Virginische $\mathrm{K}$.

\section{CORONOPUS. Hall. Krähenfuß.}

Einjähriges, kahles Kraut; B. fiedertheilig; Bt. weiß, sehr klein. $B . M$. $N$. Kr.J.

procumbens. Gilib. Gemeiner K.

\section{BISCUTELLA. L. Brillenschötchen.}

(Einjährige Arten; Kb. aufrecht, die 2 äußeren ge-

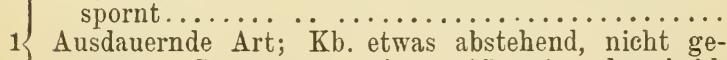
spornt; Stg. unten meist steifhaarig, oben kahl. I erbr.............laevigata. L.*) Gemeines B.

$\left\{\begin{array}{l}\text { Fr. vorne ausgerandet; Stg. dicht steifhaarig. } J . \\ \text { hispida. } D C \text {. Steifhaariges } B .\end{array}\right.$ 2 Fr. vorne in den Gr. zulaufend; Stg. oben kahl. J. auriculata. L. Geöhrltes B.

*) Die Art ist in der Behaarung u. auch in der Gestalt der Fr. veränderlich. 


\section{IBERIS. L. Bauerusenf.}

Fliigel der Fr. gerade vorgestreckt, spitz o. zugespitzt Flügel der Fr. auseinanderfahrend, stumpf-dreieckig; B. lineal, vorme $2-3$ theilig 0 . fiederspaltig, die oberen manchmal ungetheilt; $\mathrm{Kb}$. violett, $\mathrm{Krb}$. weiß. J., sonst cult. u. verw.

pinnata. $L$. Gefiederter B.

B. spitz, die oberen stets ganzrandig .......... B. stumpf, vorne $1-3$ zähnig (sehr selten ganzrandig); $\mathrm{Fr}$. fast kreisrund, mit 3 eckigen Flügeln; Krb. meist weiß. $K r$. J., sonst cult. u. verw.

amara. $L$. Bitterer $B$.

Frstiele aufgerichtet; Fr. sehr dicht gestellt; Flügel so lang als die Frfächer; Bt. meist fleischfarben. $K r$. J., sonst cult. u. verw.

umbellata. $L$. Doldiger B.

Frstiele abstehend; Flügel viel kürzer als die Frfächer; Bt. weiß o. blassrosa. $J$.

intermedia. Guersent. Mittlerer B.

VI. AETHIONEMA. $R$. $B r$. Steintäschel.

B. lineal-länglich, die untersten oval; die ganze Pfl. bläulich-bereift; Bt. fleischroth 0 . weiblich. Verbr. (fehlt B. M. Sch.)

saxatile. (L.) $R$. Br. Gemeines St.

VII. PETROCALLIS. $R$. $B r$. Steinschmïckel.

B. keilförmig, 3 spaltig, die unteren 5 spaltig. $A$.

Pyrenaica. (L.) R. Br. Alpen-st.

\section{THLASPI. L. Täschelkraut.}

Frtraube verlängert; Bt. weiß, selten etwas röthlich;

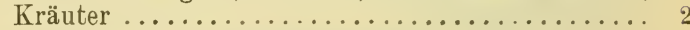

Frtraube kurz, doldenförmig; Bt. violett 0. rosa,

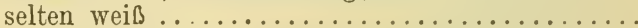

Stgb. am Grunde verschmälert u. pfeilförmig; Same

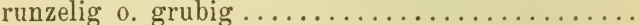

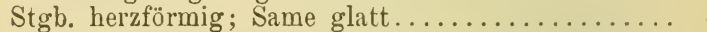

Fr. flach, breit geflügelt; Same bogig-runzelig. Verbr.................. arvense. $L$. Feld-T.

3 Fr. bauchig, sehr schmal geflügelt; Same grubignetzig; die unteren B. leierförmig-buchtig. $S$. $O . J \ldots \ldots \ldots \ldots \ldots$ alliaceum. $L$. Lauch-T.

Stauden mit ästigem Wst.; Gr. deutlich........ 5

4 Einjähriges Kraut; Narbe fast sitzend. Verbr.

perfoliatum. L. Durchwachsenes T.

$5\{$ Stämmchen kurz, rasenartig zusammengedrängt ... 
A. nur anfangs gelb, dann purpurn, zuletzt schwärzlich; Gr. ungefähr von der Länge der Ausrandung der Fr. Verbr. (fehlt Sch. O.J.)

A. stets gelb; Gr. die Ausrandung der Fr. stets

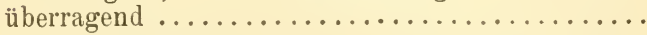

K. mehr 0 . weniger purpurn gefärbt; Krb. schmal; Flügel vorne mindestens so breit als die Frfächer. Südt. K. Sü̈st. $K r$. J.

K. grünlich o. weißlich; Krb. breit, ansehnlich; Flügel schmäler als die Frfächer. $N$.

Goesingense. Hal. Gösing-T.

Fr. rundlich-verkehrt-herzförmig, am Grunde abgerundet, vorne breit geflügelt. $B . N . O . S . K$. St. montanum. L. Berg-T.

Fr. länglich-verkehrt-herzförmig, gegen den Grund verschmälert, vorne schmal geflügelt. $A$.

alpinum. $\mathrm{Cr} \cdot{ }^{* *}$ ) Alpen-T.

Obere Stgb. am Grunde umfassend-geöhrlt; Grundb. meist ganzrandig. $A$.

rotundifolium. (L.) Gaud. Rundblättriges T. Obere Stgb. ohne Oehrchen; Grundb. stumpfzähnig. A. v. Sï̈t. $K$. $K r$.

cepeaefolium. Koch. Dickblättriges T.

\section{COCHLEARIA. L. Löffelkraut.}

Grundb. gestielt, etwas fleischig, glänzend, rundlich 0. nierenförmig***). Bt. weiß. $N$. St. $K$. officinalis. L. Gemeines L.

\section{KERNERA. Medic. Kugelschötchen.}

Stg. verlängert, mit sehr lockerer, meist blattloser Frtraube; die 2 längeren Stf. knieförmig gebogen. A. $u$. Vora. saxatilis. (L.) Rchb. Gemeines K. Stg. sehr kurz, mit gedrungener, beblätterter, die Grundb. wenig 0. gar nicht überragender Frtraube; Sif. nur etwas gebogen. $A$. v. Südt.

alpina. (Tausch.) Prantl Kleines K.

*) T. coerulescens Presl (B. $M$.) hat röthliche Bt. u. tiefer ausgerandete Fr.; T. Huteri Pernh. ( $T^{\prime}$.) hat anffallend gezähnte Stgb. u. häufig verzweigten Stg.

**) T. Kerneri Hut. ( $K r$.) hat dichter rasigen Wuchs und kleinere Bt.

***) C. Pyrenaica DC. hat Grundb. mit tief herzförmigem Grunde. 


\section{PELTARIA. L. Scheibenkraut.}

Stgb. mit tief-herzförmigem Grunde umfassend; Fr. fast kreisrund, flachgedrückt, netzig-geadert.

N. O. St. J......... alliacea. L. Gemeines Sch.

\section{ALLIARIA. Adans. Lauchkrant.}

Untere B. nierenförmig, grob-geschweift-gekerbt, obere herz-eiförmig, spitz gezähnt; zweijähriges Kraut. Verbr. . officinalis. Audrz. Gemeines L.

\section{SISYMBRIUM. $L$. Rauke.}

(B. verschiedenartig getheilt, höchstens die obersten

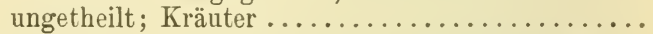

B. ungetheilt, länglich-lanzettlich, ungleich gezähnt, behaart; Stg. hoch, starr, ästig, reichblütig; Staude. Verbr. (fehlt Sch.) strictissimum. L. Steife R.

B. 2-3 fach-fiederschnittig; Abschnitte der unteren B. schmal-lanzettlich, der oberen lineal; Frstiele dünner als die Fr. Verbr.

Sophia. L. Feinblättrige R.

B. schrotsägeförmig-fiedertheilig, die obersten bisweilen einfach-fiedertheilig 0 . spießförmig.......

Fr. pfriemenförmig, flaumig, an die Spindel ange3 drückt; Endlappen der B. 3 eckig o. spießförmig.

3 Verbr. u. hfg. officinale. Scop. Gebräuchliche R. Fr. stielrund, abstehend ............... 4

$4\{$ Frstiele kurz, ziemlich so dick als die Fr. ...... 5

$4\{$ Frstiele schlank u. dünn; Stg. u. B. grasgrün.... 6

$\mathrm{Kb}$. wagrecht-abstehend; obere B. einfach-fiederschnittig, Abschnitte schmal-lineal.

B. M. N. Südt. $K r$.

Sinapistrum. $\mathrm{Cr}$. Ungarische $\mathrm{R}$.

Kb. aufrecht; B. sämmtlich schrotsägeförmig-fiederspaltig, die oberen oft ungetheilt; $\mathrm{Pfl}$. graugrün. Verbr. (fehlt B. Sch.)

Orientale. $L$. Orientalische $R$.

Die jüngeren Fr. über die Bt. weit hinausragend; Krb. sehr klein, citrongelb. B. N. S. J.

Irio. $L$. Schlaffe R.

Die jüngeren Fr. die Bt. nicht überragend; Krb.

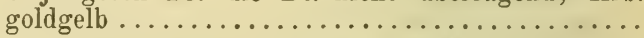

Stg. und untere B. steifhaarig. B. M. N. O. T.

7 Stg. und B. kahl o. sparsam borstig.

Loeselii. $L$. Lösel's R. M. N. St. $K r$. T.

Austriacum. Jacq. Oesterreichische R. 
XIV. CAKILE. Adans. Meersenf.

B. fleischig, meist fiederspaltig; B. lila. $J$. maritima. Scop. Echter II.

\section{MYAGRUM. L. Hohldotter.}

Grundb. buchtig-fiederspaltig; Stgb. tief-pfeilförmigumfassend. II. N. O. K. J.

perfoliatum. $L$. Pfeilblättriger $\mathrm{H}$.

\section{CALEPINA. Desv. Calepine.}

Grundb. buchtig-fiederspaltig; Stgb. länglich, am Grunde pfeilförmig. $J$.

Corvini. (All.) Desv. Europäische C.

XVII. ISATIS. $L$. Waid.

Bläulich-bereift; B. kahl, die oberen mit tief-pfeilförmigem Grunde sitzend. B.MT. N. St.K. Kr. Südt. tinctoria. L. Färber-W.

XVIII. ERUCA. Adans. Ruke.

Bt. weißlichgelb, violett geadert.

Sïdt. J. (auch cult.) sativa. Lam. Gebaute $\mathbf{R}$.

XIX. SINAPIS. $L$. Senf.

Frklappen 5 nerrig; B. fiedertheilig o. leierförmigfiederlappig. Verbr. (auch cult.)

Frklappen 3 nervig; B. eiförmig o. länglich $\mathrm{S}$. unteren oft fast leierförmig. Verbr. u. hfg.

arvensis. $L$. Acker-S.

XX. DIPLOTAXIS. $D C$. Doppelrauke.

Krb. länglich-keilig, allmälig in den Nagel verschmälert; Btstiele kürzer als die eben geöffneten Bt.; 1 jähriges Kraut. $J$. viminea. $(L$.) $D C$. Ruthenförmige $\mathrm{D}$. Krb.rundlich-verkehrt-eiförmig, in einen kurzen Nagel zusammengezogen........................

Btstiele viel länger als die Bt.; Stg. am Grunde holzig;

2 Staude. Verbr. tenuifolia. (L.) D C. Aestige D. Btstiele so lang als die Bt.; Stg. nicht holzig; Kraut. Verbr.............muralis. (L.) $D C$. Mauer-D. 


\section{xxi. ERUCASTRUM. Presl. Rempe.}

Trauben blattlos; Kb. wagrecht-abstehend; die längeren Stb. oberwärts vom Frkn. abgebogen; Bt. citronengelb. $M . N$. N. S. T. Kr.

obtusangulum. (Hall.) Rchb. Stumpfkantige R. Trauben unterwärts beblättert; $\mathrm{Kb}$. aufrecht-abstehend; die längeren Stb. an den Frkn. angepresst; Bt. grünlich-gelb. B. M. N. O.S.T. St. Pollichii. Schimp. $u$.'Sp. Pollich's R.

\section{BRASSICA. L. Kohl.}

Alle B. gestielt, die oberen lanzettlich, ganzrandig;

Fr. an die Spindel angedrückt; $K$. wagrecht-abstehend. Cult. u. verw.

nigra. (L.) Koch. Schwarzer Senf.

Die oberen B. sitzend 0 . stengelumfassend .........

Bttraube während des Aufblühens flach, gedrungen; die geöffneten Bt. höher als die Knospen; obere B. eiförmig, zugespitzt, mit tiefherzförmigem Grunde umfassend. Verbr. u. hfg. (auch cult.)

Rapa. L. Rübenkohl.

Bttraube vor $u$. während des Aufblühens verlängert, locker, die geöffneten Bt. tiefer als die Knospen; obere B. sitzend 0 . halbstengelumfassend........

$\mathrm{Kb}, u$. Stb. aufrecht; obere B. mit verschmälertem Grunde sitzend. Cult. u. verw.

oleracea. L. Gemüsekohl. $\mathrm{Kb}$. und die kürzeren Stb. abstehend; obere B. mit breitem herzförmigem Grunde halbstengelumfassend. Cult. u. verw. Napus. L. Repskohl.

Anmerkung. Kohlrübe u. Karfiol sind Culturvarietäten von B. oleracea; die Steckrübe stamint von B. Napus, die weiße Rübe von B. Rapa.

\section{Xxil. RAPHANUS, $L$. Rettig.}

Fr. länglich-walzlich, gar nicht 0 . nur etwas eingeschnürt; Krb. violett mit dunkleren Adern.

1 Cult. u. verw. ............ sativus. L. Garten-R. Fr. perlschnurförmig, bei der Reife in Glieder zerfallend............................

Fr. cylindrisch, 3-8'gliedrig, getrocknet kantig; Bt. weiß 0 . hellgelb, meist violett geadert.

Verbr. u. hf g. ..... Raphanistrum. L. Acker-R.

2 Fr. kegelförmig, $1-5$ gliedrig, getrocknet nur etwas gestreift; untere $\mathrm{B}$. meist unterbrochen leierförmigfiederspaltig; Bt. helllila, violett geadert. $K r$. J. Landra. Moretti. Kurzfrüchtiger $\mathrm{R}$. 


\section{RAPISTRUM. Cr. Rapsdotter.}

Ausdauernd; B. fiederspaltig; Gr. kurz-kegelförmig. B. M. N. O. St. J.

perenne. (L.) All. Gemeiner R. Einjährig; B. leierförmig mit groœem, eiförmigem Endlappen; Gr. fädlich. Südt. Südst. J. (N.)

rugosum. (L.) All. Runzliger R.

\section{XXY. CRAMBE. L. Meerkohl.}

Grundb. doppelt o. mehrfach fiedertheilig-zerschlitzt, zuerst steifhaarig, später sammt dem Stg. kahl. II. (J.)........ Tataria. Jacq. Tatarischer M.

\section{BARBAREA. R. Br. Barbarakrant.}

Die Seitenlappen der unteren B. 2-3 paarig, sehr klein, der Endlappen sehr groß, länglich-eiförmig; Krb. um ${ }^{1 / 3}$ länger als der K. Verbr.

stricta. Andrz. Steifes B.

Die Seitenlappen der unteren B. 4 paarig, das obere Paar so breit als der Endlappen; Krb. doppelt so

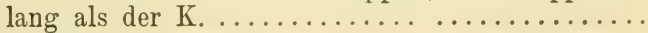

Aufblühende Traube gedrungen, die jüngeren Fr. schräg-aufrecht. Verbr.

vulgaris. $R . B r$. Gemeines B.

Aufblühende Tr. locker; die jüngeren $\mathrm{Fr}$. bogenförmig-aufwärts gekrümmt. Verbr.

arcuata. Rchb. Gebogenfrüchtiges B.

\section{RORIPA. Scop. Sumpfkresse.}

Obere Stgb. fiederig getheilt..................

1 Obere Stgb. ungetheilt, höchstens eingeschnitten gezähnt .............................. 5

Fr. ungefähr so lang als der Frstiel........... 3

2 Fr. kurz ellipsoidisch, 2-3 mal kürzer als der Frstiel; Bzipfel schmal lineal. $K r$.

Pyrenaica. (L.) Rchb. Pyrenäische S.

(Fr. eiförmig-länglich, gedunsen; Krb. so lang als die

$3 \mathrm{~Kb}$.; untere B. leierförmig, obere tief-fiederspaltig. Verbr........palustris. (Poll.) Bess. Gemeine S. Fr. lineal; Krb. länger als die Kb............

Alle B. tief-fiederspaltig o. fiederschnittig, Fiedern gezähnt 0 . fiederspaltig. Verbr.

4 Die untersten B. ungetheilt, oval, lang gestielt, die folgenden leierförmig, die oberen tief-fiederspaltig. K. Kr.J. Lippicensis. (Wulf.) Rchb. Lippizer S. 
Fr. kugelig, vielmal kürzer als der Frstiel; B. lanzettlich 0 . spatelig, mit tief-herzförmig-geöhrltem Grunde sitzend, die unteren in den Bstiel verschmälert. B. MI. Sch. N. O. St.

Austriaca. (Jacq.) Bess. Oesterreichische S. 5 Fr. länglich-eiförmig o. elliptisch; B. kamm- o. leierförmig-fiederspaltig, die oberen länglich-lanzettlich, sitzend, ungleich-sägezähnig; Stg. am Grunde wurzelnd. Verbr.

amphibia. (L.) Bess. Wasserkresse.

Anmerkung. R. silvestris bildet mit R. palustris, Austriaca u. amphibia Bastarte.

\section{ARMORACIA. G. $M$. Sch. Kren.}

Grundb. groß, gestielt, länglich-eiförmig o. länglichherzförmig, gekerbt. Cult. u. verw.

rusticana. G. M. Sch. Gebauter K.

\section{CARDAMINE. L. Schaumkraut.}

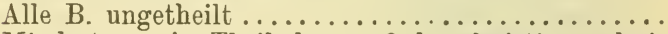

1 Mindestens ein Theil der B. fiederschnittig o. dreischnittig

Hochwüchsige Pfl; B. herzförmig-rundlich, geschweift-gezähnt. Sïdt.

2 asarifolia. L. Haselwurzblättriges Sch. Kleine Alpenpfl.; Grundb. rauten-eiförmig, lang-gestielt; Stgb. ganzrandig o. etwas gelappt. $A$.

alpina. Willd. Alpen-Sch.

Grundständige B. fiederschnittig, o. theilweise drei-

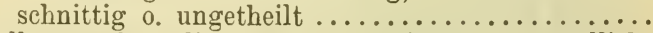
Alle grundständigen $B$. dreischnittig, mit rundlichrautenförmigen, geschweift-gekerbten Abschnitten. Verbr.......... trifolia. L. Kleeblättriges Sch.

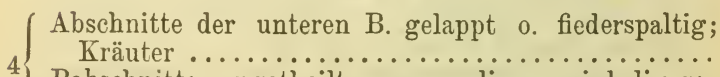

Babschnitte ungetheilt, ganzrandig 0 . winkelig-gezähnt (höchstens der Endabschnitt gelappt) .....

Stgb. am Grunde pfeilförmig-geöhrlt; Krb. sehr klein, hinfällig, manchmal ganz fehlend. Verbr.

impatiens. $L$. Spring-Sch.

5 Stgb. nicht geöhrlt; Krb. ansehnlich; Stg. meist vom Grunde an ästig. $J$.

maritima. Portschlg. Meerstrands-Sch.

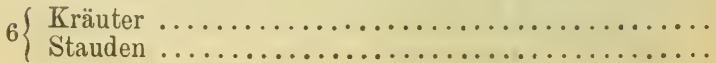


Krb. klein, höchstens doppelt so lang als die $\mathrm{Kb}$; alle $\mathrm{B}$. fiederschnittig .................... Krb. ansehnlich, vorn ausgerandet; Pfl. niedrig, meist vom Grunde an ästig; Grundb. oft ungetheilt. J.......... glauca. Spr. Blaugrünes Sch.

Stg. fast kahl; Stb. meist 4; Fr. aufrecht, die Bt. weit überragend. Verbr.

hirsuta. $L$. Vielstengliges Sch.

Stg. mehr o. weniger steifhaarig; Stb. 6 ; Fr. aufrecht, aber auf abstehenden Stielen, die Bt. wenig überragend. Verbr. .... silvatica. $L k$. Wald-Sch. $\left\{\begin{array}{c}\text { Kleine Alpenpflanze; die untersten Grundb. unge- } \\ \text { theilt, rundlich o. eiforrmig, lang gestielt. Geb. }\end{array}\right.$

resedifolia. $L$. Resedablättriges Sch

Alle B. fiederschnittig................... 10

A. purpurviolett, zuletzt schwärzlich; Babschnitte eckig gezähnt; Stg. gefurcht. Verbr. amara. $\left.L{ }^{*}\right)$ Bitteres Sch.

A. gelb............................ 11

Fr. flachgedrückt, mit 1 reihigen S.; Grundb. rosettig 12

Fr. stielrundlich, gekrümmt, mit unregelmäßig

112 reihigen S.; Stg. am Grunde kriechend; Krb. weib. Verbr.

Nasturtium. (L.) Ktze. Brunnenkresse. Krb. lila (selten weiß); Abschnitte der oberen Stgb. spitzwinklig-abstehend. Verbr.

pratensis. $L *^{* *}$ ) Wiesen-Sch.

Krb. weiß; Abschnitte der oberen Stgb. rechtwinkligabstehend 0 . zurückgekrümmt. MI. N.

Hayneana. Welw. Hayne's Sch.

\section{DENTARIA. L. Zahnwurz.}

$1\{$ B. gefingert $3-5$ zählig $\ldots \ldots \ldots \ldots \ldots \ldots \ldots \ldots \ldots \ldots \ldots \ldots$

1\{ B. gefiedert, die oberen oft ungetheilt ........ 5

$2\{$ B. 3 zählig, am Stg. zu 3 quirlständig ***) ...... 3

B. wechselständig, gestielt................. 4

$3\left\{\begin{array}{l}\text { Stb. so lang als die gelblich-weiße Blkr. Verbr. } \\ \text { enneaphylla. L. Neunblättrige Z. } \\ \text { Stb. halb so lang als die purpurne Blkr. Mr. Sch. }\end{array}\right.$ glandulosa. $W K$. Drüsige $\mathrm{Z}$.

*) Bei C. Opicii Presl sind die B. behaart und 5- bis 8 paarig fiederschnittig.

$\left.{ }_{* *}^{*}\right)$ C. dentata Schult. hat gezähnte Babschnitte u. meist weiße Bt.

${ }^{* * *}$ ) Bei D. enneaphylla L. sind die B. manchmal wechselständig. 
Alle B. 3 zählig; Blättchen stumpf-gesägt, stumpfzugespitzt; Krb. weiß. St. $K r$.

trifolia. $W K$. Dreiblättrige $\mathrm{Z}$.

B. 5 zählig, die oberen 3 zählig; Blättchen ungleichgesägt, fein zugespitzt; Krb. rosa. T. K. St. Kr.J. ligitata. Lam. Fingerblättrige Z.

Alle B. gefiedert.

5 Obere B. ungetheilt; Stg. in den Bachseln zwiebeltragend; Krb. rosa 0. weißlich. Verbr.

bulbifera. L. Zwiebeltragende Z.

B. oft quirlständig; Blättchen lang zugespitzt; Krb. gelblichweiß. Kr. J.

polyphylla. W $K$. Vielblättrige $\mathrm{Z}$.

B. stets wechselständig; Blättchen spitz; Krb. wei@

o. helllila. Südt. St. pinnata. Lam. Gefiederte Z.

XXXI. LUNARIA. L. Mondviole.

Staude; B. gestielt, tiefherzförmig, zugespitzt, ungleich-gezähnt; Fr. elliptisch-lanzettlich, an den beiden Enden spitz. Verbr.

rediviva. L.*) Ausdauernde M.

XXXII. HUTCHINsIA. $R$. $B r$. Gemskresse.

(Ausdauernde Alpenpfl. mit grundständiger Brosette;

1 Krb. ungefähr doppelt so lang als der K....... Einjährige Kräuter mit beblättertem Stg.; Krb. wenig

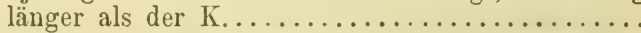


XXXIII. BURSA. Wigg. Hirtentäschel.

Fr. mit convexen 0 . fast geraden Seitenrändern; Krb. deutlich länger als die $\left.\mathrm{Kb}{ }^{*}\right)$, nicht selten fehlend. Verbr. u. hfg.

pastoris. Wigg. Gemeines $H$.

Fr. mit concaven Seitenrändern; Krb. kaum länger als die meist röthlichen $\mathrm{Kb} . J$.

rubella. (Reut.) Ktze. Röthliches $\mathrm{H}$.

\section{CAMELINA. Cr. Leindotter.}

Stg. u. B. von einfachen u. ästigen Haaren rauhhaarig; Fr. birnförmig, hartschalig, 2-3 mal so lang als der Gr., mit breitem zusammengedrücktem Rande. Vertr.

microcarpa. Audrz. Kleinfrüchtiger $\mathrm{L}$.

Stg. u. B. von kurzen, meist sternförmigen Haaren etwas rauh o. fast kahl; Fr. 3-5 mal so lang als der Gr., mit schmalem zusammengedrücktem Rande

Fr. hartschalig, birnförmig, vorn abgerundet, auf aufrecht-abstehenden Stielen; B. ganzrandig 0. gezähnelt. B. M. N.J.

glabrata. ( $D C$.) Kurzhaariger L.

2 Fr. weichschalig, oft fast kugelig, vorn gestutzt 0 . ausgerandet, auf wagrecht-abstehenden 0 . herabgebogenen Stielen; untere B. meist buchtig gezähnt, seltener ganzrandig. Verbr. (fehlt $K$. Kr. J.)

dentata. (Willd.) Pers. Gezähnter L.

\section{XXXY. NESLIA. Desv. Ackemüsschen.}

Stgb. pfeilförmig-lanzettlich, sammt dem Stg. gabeligbehaart. Verbr. paniculata. (L.) Desv. Rispiges A.

\section{DRABA. L. Hungerblïmchen.}

(Krb. gelb; ausdauernde Pfl. mit starren, borstig-gewimperten Grundb. u. blattlosem Schaft....... 2 Krb. weib, selten gelblich (in letzterem Falle der Stg. beblättert)................... 4

Stb. viel kürzer als die Krb.; B. lanzettlich, stumpflich, nach unten verschmälert. $A$. v. T. S. St.

2 Santeri. Hoppe.**) Sauter's H. Stb. so lang als die Krb.; B. lineal o. lineal-länglich, spitzlich ...

*) In $J$. wurde B. grandiflora (Bory et Chaub.) Ktze. eingeschleppt gefunden; die Krb. dieser Art sind doppelt so lang als die $\mathrm{Kb}$. bebaarten Schaft.

**) D. Spitzelii Hoppe (S.) unterscheidet sich durch 
Gr. viel kürzer als die Breite der Fr.; sehr kleine Alpenpfl. A. v. T. S. K. St.

33 Hoppeana. Rchb. Hoppe's H. Gr. fast so lang o. länger als die Breite der Fr. A. u. Vora...... aizoides. $L$. ${ }^{*}$ ) Immergrünes $H$.

Krb. 2 spaltig; Schaft blattlos; Grundb. lanzettlich, 4 spitz, nach unten verschmälert; kleines, 1 jähriges Kraut. Verbr. ........ verna. L. Frühlings-H. Krb. ungetheilt, höchstens ausgerandet ....... 5

Btstiele kahl...................... 6

5 Btstiele von Steruhaaren flaumig, nur nach dem Verblühen manchmal kahl werdend.......... 11

Einjährige Kräuter mit beblättertem Stg. u. ver-

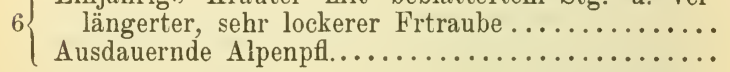

Krb. weiß; Fr. kahl. B. J...muralis. L. Mauer-H.

7 Krb. gelblich; Fr. meist flaumig. $M . N$.

nemorosa. $L$. Busch-H.

$8\left\{\begin{array}{l}\text { Stg. unten behaart, oben meist kahl; B. sternhaarig } \\ \text { Stg. ganz kahl ......................... } 10\end{array}\right.$

Gr. stets deutlich entwickelt; Bt. ziemlich gros.

A. v. O. St. N. stellata. Jacq. Sternhaariges H. 9 Gr. sehr kurz, oft fast fehlend; Bt. klein. A. v. T. S. K. St.

Carinthiaca. Hoppe. Kärntner $\mathrm{H}$.

B. am Rande gewimpert, sonst kahl o. etwas stern$10\{$ haarig. A. v. T. S. K. St. Kr. B. ganz kahl; Fr. sehr klein, oval. $A . \nabla . T S . K$. laevigata. Hoppe. Kahles $\mathrm{H}$. Stg. verlängert, reichlich beblättert; $\mathrm{Fr}$. meist

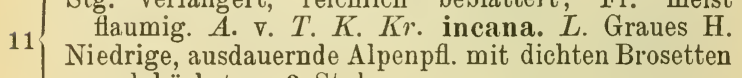
und höchstens $3 \mathrm{Stgb} . . \ldots \ldots \ldots \ldots \ldots \ldots \ldots$

$\int \begin{aligned} & \text { Fr. flaumig o. doch gewimpert; Pfl. dicht stern- } \\ & \text { haarig. A. v. T. S. O. K. Kr: }\end{aligned}$ $12\left\{\begin{array}{r}\text { haarig. } A . \vee . T . S . O . K . K r \\ \text { tomentosa. Wahlbg. Filziges H. }\end{array}\right.$

Fr. kahl.................................. oft fast kahl..................... 14

13 Stg. dicht sternhaarig, sehr niedrig, kaum die Brosette ïberragend. $A$. $\nabla$. $S$.

pumila. Miel. Kleinstes $\mathrm{H}$.

*) D. affinis Host hat schmal-lanzettliche Fr., D. Aizoon Wahlbg. (N.) behaarte Fr. 
Fr. dicht zusammengedrängt und der Spindel angedrückt; B. oberseits zerstreut sternhaarig, gelblichgrün. A. v. T. K....Pacheri. Stur. Pacher's H. 14 Fr. locker gestellt, aufrecht abstehend; B. beiderseits von dicht stehenden Sternhaaren graugrün. A. v. T. S. K. Kr. St.

dubia. Sut. Kahlfrüchtiges $\mathrm{H}$.

Anmerkung. Zwischen den auf den Alpen wachsenden Draba-Arten kommen verschiedene, noch nicht genügend bekannte Bastarte vor, so $\mathrm{D}$. aizoides $\times$ Sauteri, D. Carinthiaca $\times$ Fladnitzensis, D. Carinthiaca $\times$ dubia, $D$. dubia $\times$ Fladnitzensis $u$. a.

XXXYII. STENOPHRAGMA. Čelali, Ackerkresse.

Einjährig; Grundb. rosettig, meist gezähnt; Stgb. meist ganzrandig; Pfl. bläulich bereift. Verbr.

Thalianum. (L.) Celak. Gemeine A.

\section{ARABIS. L. Gänsekresse.}

Wenigstens die oberen Stgb. mit herz- o. pfeilförmigem Grunde umfassend.................

Stgb. nicht umfassend, seltener halbumfassend, am

Grunde verschmälert 0 . abgerundet ........... 12

Alle oder doch die oberen Stgb. kahl, höchstens am

Rande gewimpert ....................... Alle $\mathrm{Stgb}$. behaart .........................

Krb. gelblich-weiळ; Fr. 4 kantig, aufrecht; S 2 reihig; Stengelgrund u. Grundb. behaart. Verbr.

glabra. (L.) Weinm. Thurmkraut.

Krb. weiß; Fr. flachgedrückt; S. 1 reihig.........

Grundb. zerstreut behaart; Fr. aufrecht; S. vorne geflügelt. Sud..... Sudetica. Tausch. Sudeten-G:

4 Pfl. ganz kahl; Fr. schief-abstehend; S. ungeflügelt. B. M. N. O. St. T. J.

pauciflora. (Grimm.) Garcke. Armblütige G.

$5\left\{\begin{array}{l}\text { Bt. violett; Fr. abstehend; } 1 \text { jähriges Kraut. } J . \\ \text { verna. }(L .) R . B r \text {. Frühlings-G. }\end{array}\right.$

Bt. weiß o. grünlichweiß

Fr. abwärts gebogen; S. breit geflügelt; Bt. grünlichweiß. Verbr. (fehlt B. Sch.)

Turrita. L. Gebogenfrüchtige G.

Fr. aufrecht 0 . abstehend; S. nicht 0 . sehr schmal geflügelt . 
Ausläufer treibende Staude; Krb. grob, verkehrteiförmig, abstehend; Fr. abstehend. $B$. (Riesengeb.); A. u. Vora.

alpina. $L{ }^{*}$ ) Alpen-G.

Kräuter ohne Ausläufer; Krb. klein, keilig, fast auf-

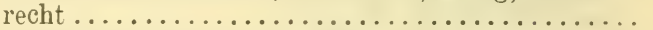

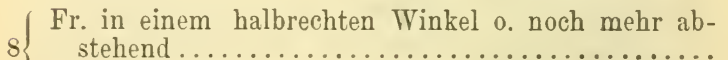

Fr. aufrecht.

$\left\{\begin{array}{l}\text { Fr. so breit als der Frstiel. B. M. N. } \\ \text { auriculata. Lam. Oehrchentragende G. }\end{array}\right.$

9 Fr. 3 mal breiter als der Frstiel. Südt.

saxatilis. All. Felsen-G.

(Die untere Hälfte der Stgb. sammt den Oehrchen

10 dem Stg. anliegend; Same netzig-punktirt.

B. $N$. O..........Gerardi. Bess. Gerard's G.

Stgb. u. die Oehrehen vom Stg. abstehend ....... 11

Stgb. mit gestutzt-geöhrltem o. seicht-herzförmigem Grunde sitzend. Verbr.

11 hirsuta. (L.) Scop. Rauhhaarige G. Stgb. mit tief-herz-pfeilförmigem Grunde sitzend; Pfl. höher u. ästiger. Verbr.

sagittata. $D C$. Pfeilblättrige $\mathrm{G}$.

Grundb. in den Bstiel verschmälert, ungetheilt, höchstens gezähnt .................... 13

12 Grundb.leierförmig o. fiederspaltig, seltener ungetheilt, aber dann plötzlich in den Bstiel zusammen-

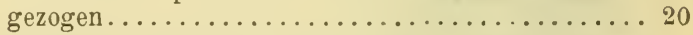

Krb. schmal, blänlich-violett; Grundb. vorne gezähnt; S. geflügelt; kleine Alpenpfl. $A$.

coerulea. (All.) Hänke. Blaue G.

Krb. weiß; Grundb. undeutlich 0. gar nicht gezähnt 14

( Pfl. ganz kahl; S. geflügelt. A. u. Vora. (fehlt J.)

14 Jacquinii. Beck. Jacquin's G.

B. behaart o. doch am Rande gewimpert......... 15

Krb. klein u. schmal, aufrecht; Fr. schmal, kurz 15 gestielt; S. ungeflügelt. $A$.

ciliata. (Reyn.) R. Br.**) Gewimperte G.

Krb. ansehnlich, mehr o. weniger abstehend...... 16

$16\left\{\begin{array}{l}\text { S. breit geflügelt; B. glänzend. A. } \\ \text { pumila. Jacq. Niedrige G. }\end{array}\right.$

16 S. ungeflügelt o. nur mit einem sehr schmalen (nur an der Spitze manchmal breiteren) Hautrande... 17

*) In $J$. kommt auch die durch graufilzige B. ausgezeichnete A. Caucasica Willd. vor.

**) Die dicht sternharige Form ist A. alpestris Schl. 
B. am Rande von einfachen, abstehenden Borstenhaaren gewimpert; Krb. rundlich-verkehrt-eiförmig; Fr. kurz u. breit. $A$. $\nabla . K r$. $J$.

Scopoliana. Boiss. Scopoli's G.

B. am Rande mit angedrückten, gegabelten Haaren besetzt 0 . überall sternhaarig ..............

B. dicht sternhaarig u. daher graulich; Fr. aufrecht;

S. mit schmalem Hautrande. Sïdt.

muralis. Bert. Mauer-G.

B. nur am Rande u. oft am Mittelnerven behaart,

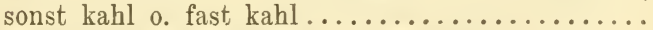

Gr. sehr kurz; Pfl. lange Ausläufer treibend; B. kurz bespitzt. $K r$.

procurrens. $W K$. Ausläufertreibende G.

Gr. verlängert; Pfl. kleiner; Fr. kürzer u. breiter; B. abgerundet-stumpf. St. K. Kr. J. Südt.

Tochinensis. Spr. Wocheiner G.

Stgb. länglich-lineal, ganzrandig; Stg. meist kahl; Krb. weiळ. Terbr. (fehlt Sch. S. K. J.)

hispida. Mygind. Borstige G.

Wenigstens die unteren Stgb. gezähnt, leierförmig

0. fiederspaltig ....................... 21

Ohne Ausläufer; Grundb. leierförmig-schrotsägeförmig, sammt dem Stg. gabelig-bebaart; Krb. rosa o. weib. Verbr. ......... arenosa. Scop. Sand-G. Ausläufertreibend; Grundb. herzförmig-rundlich 0 . eiförmig, öfters leierförmig, die mittleren Stgb. eiförmig, die oberen lanzettlich; Bt. weiß, selten rosa. ${ }^{*}$ ) Verbr. (fehlt $S$.) Halleri. L. Haller's G.

Anmerkung. Zwischen A. ciliata und A. hirsuta kommt ein Bastart vor.

\section{ERYSINIUM. L. Hederich.}

Halbstrauch mit lanzettlichen, ganzrandigen B.; Bt. gelb 0 . braungelb; N. tief 2 lappig. J. (sonst cult. u. verw.) Cheiri. (L.) Cr. Goldlack. Stauden 0 . Kräuter; N. stumpf 0 . ausgerandet..... Btstiele 2-3 mal länger als der $K$., fast so lang als die halbe Fr.; B. länglich-lanzettlich, mit 3 spaltigen Haaren. Verbr.

cheiranthoides. $L$. Goldlackartiger $\mathrm{H}$. Btstiele so lang 0 . kürzer als der K............. 3

$3\{$ Btstiele ungefähr so lang als der K.......... 4

*) A. Ovirensis Wulf. (Karawanken) hat stets ungetheilte Grundb. u. rosenrothe Bt. 
Haare der B. fast alle 2spaltig*); Fr. grauhaarig mit grünen Kanten; B. lineal-lanzettlich, an der Spitze zurückgebogen; unfruchtbare Aestchen in den Bachseln. M. N. O. St. Kr .

canescens. Roth. Graublättriger $\mathrm{H}$.

Haare der B. 3 spaltig; Fr. flaumig-rauh..........

B. dicht grauhaarig, die oberen ganzrandig; Krb. schwefelgelb; Gr. kurz. B. M. N. J.

Iurum. Presl. Harter $\mathrm{H}$.

B. mattgrün, zerstreut bebaart, meist gezähnelt; Krb. goldgelb; Gr. verlängert. B. MI. Sch. N. O. St.

hieracifolium. $L$. Habichtskrautblättriger $\mathrm{H}$.

B. mit 3 spaltigen, o. mit 2- u. 3 spaltigen Haaren, lanzettlich 0 . länglich-lanzettlich; Kräuter ......

6 B. mit 2 spaltigen Haaren**), lineal-lanzettlich, ganzrandig 0. entfernt gezähnt; Fr. flaumig o. grau-

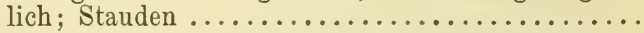

Einjährig; B. zugespitzt; Fr. kaum dicker als die wagrecht abstehenden, verdickten Btstiele, oberwärts in die gestutzte $\mathrm{N}$. verschmälert.

7 B. M. N. O.S.St.J.

repandium. $L$. Ausgeschweifter $H$.

Untere B. stumpf, kurz-stachelspitzig, in den Bstiel verschmälert; zweijährige Kräuter...........

Fr. graufilzig, an den Kanten kahler und grün, scharf-4kantig; Bt. wohlriechend; Haare der B. 3 spaltig. Verbr. (fehlt Sch. S. K.)

Pannonicum. $\mathrm{Cr}^{* *}$ ) Wohlriechender $\mathrm{H}$.

Fr. gleichfarbig, stumpf-4 kantig; Bt. geruchlos; Haare der B. vorherrschend 2 spaltig. B. St.

crepidifolium. Rchb. Pippaublättriger $\mathrm{H}$.

Die Bachseln mit Bbüscheln o. unfruchtbaren Aestchen versehen; Fr. sehr lang. $T$.

Rhaeticum. $D C$. Rhätischer $\mathrm{H}$.

9 Die Bachseln nackt; Griffel so lang, als die Fr. breit ist; Bt. wohlriechend. Verbr.

(fehlt $B . M$. Sch.)..... silvestre. $\mathrm{Cr}$. Wald-H.

\section{ALISSCM. L. Steinkraut.}

Fr. kahl o. nur am Rande bewimpert........... 2

1 Fr. (wenigstens die jüngeren) von dicht angedrückten Sternhärchen grau 0 . flaumig-kurzhaarig .......

*) Die 2 spaltigen Haare sind in der Mitte befestigt und sehen einfachen, anliegenden Haaren täuschend ähnlich !

**) Bei E. Carniolicum Doll. sind die B. buchtig gezähnt 0 . fast fiederspaltig u. die Bt. größer. 
Einjähriges, niedriges Kraut; Bt. bleichgelb, zuletzt

weiß; Fr. kreisrund; B. grauhaarig. N. $J$.

desertorum. Stapf. Steppen-St.

Halbsträucher, Stauden 0. 2 jährige, ziemlich hohe

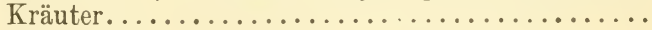

Fr. aufgeblasen, höchstens am Rande zusammen-

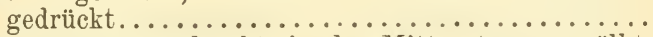

3 Fr. zusammengedrückt, in der Nitte etwas gewölbt, aber nicht aufgeblasen. $B . M . N$. $O . K r$.

Arduini. Fritsch. Felsen-St.

Fr. fast kugelig-aufgeblasen; Grundb. meist buchtig

4 gezähnt. Kr.J. sinuatum. L. Blasenfrüchtiges St.

Fr. am Rande zusammengedrückt, in der Mitte aufgeblasen...$\ldots \ldots \ldots \ldots \ldots \ldots \ldots \ldots \ldots$.

Zweijähriges, ziemlich hohes Kraut; B. graugrün; Frfächer 2 samig. $K$. $K r$. J.

5 petraeum. Ard. Venetianisches St.

Niedrige, fast halbstrauchige Staude; B. graufilzig; Frfächer meist 4 samig. $J$.

medium. Host. Dalmatiner St.

${ }_{6}$ Pfl. einjährig; Bt. bleichgelb, zuletzt weiß; Fr. kreis-

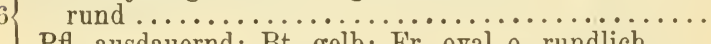

Pfl. ausdauernd; Bt. gelb; Fr. oval 0. rundlich .... 8

Die längeren Stf. nicht geflügelt; K. bleibend; Fr.

7 grau. Verbr. calycinum. L. Kelchfrüchtiges St. Die längeren Stf. schmal-geflügelt; K. abfällig; Fr. flaumig-kurzhaarig. J.....campestre. L. Feld-St.

Btstand rispig verzweigt, fast ebensträußig; Stg. ziemlich hochwüchsig, mit kleinen destchen in den Bachseln; B. unterseits graufilzig. $J$.

argenteum. (All.) Vitm. Graues St. Btstand unverzweigt; Stg. meist ohne Aestchen in den Bachseln...........................

Fr. dicht sternhaarig, anfangs grau, später graugrün; B. graugrün $\ldots \ldots \ldots \ldots \ldots \ldots \ldots \ldots \ldots \ldots \ldots \ldots \ldots \ldots \ldots \ldots$

Fr. zerstreut sternhaarig, zuletzt fast kahl, größer;

B. grün, beiderseits zerstreut sternhaarig ....... 11

Stg. u. Btstiele angedrückt fein-sternhaarig; Pfl. niedrig, gedrungen. Verbr. (fehlt Sch. S.)

montanum. L. Berg-St.

10 Stg. u. Btstiele von unregelmäßigen, zum Theile abstehenden Stern- u. Gabelhaaren rauh; Pfl. in allen Theilen größer; B. u. Fr. weniger dicht behaart. St.

Transsilvanicum. Schur. Siebenbürgisches St. 
Die unteren B. elliptisch, allmälig in den Bstiel verschmälert; Frstiele 2 mal so lang als die Fr.

St. $K$. $K r .$. Wulfenianum. Bernh. Kärntner St. Die unteren B. rundlich, plötzlich in den Bstiel zusammengezogen; Frstiele kaum länger als die Fr. A. v. T. K....... Ovirense. Kern. Alpen-St.

XLI. CLYPEOLA. L. Schildkraut.

Stg. liegend 0. aufstrebend; B. lineal-länglich, ganzrandig; Bt. sehr klein, gelb, zuletzt weib. J. Jonthlaspi. L. Liegendes Sch.

\section{LOBUlaria. Desv. Lappenblume.}

B. lineal-lanzettlich, spitz; Fr. flachgedrückt, oval, kahl, 1-2 samig. $J$.

maritima. (L.) Desv. Meerstrands-L.

XLIII. BERTEROA. DC. Graukresse.

(Zweijähriges Kraut; B. lanzettlich; Krb. weiß; Fr. oval, sternhaarig. Verbr. (fehlt $S$.)

incana. (L.) $D C$. Gemeine G.

Halbstrauchige Staude; B. länglich-lanzettlich; Krb. weiß o. blassrosa; Fr. flachgedrückt, elliptisch, kahl. J. mutabilis. (Vent.) $D C$. Veränderliche G.

XLIV. FIBIGIA. Med. Fibigie.

Zweijähriges Kraut; B. lanzettlich. Südt. J.

clypeata. (L.) Med. Schildfrüchtige F.

XLV. VESICARIA. Lam. Blasenschötchen.

B. kahl, länglich, ganzrandig, die unteren bewimpert, spatelförmig. $J$.

utriculata. (L.) Lam. Gemeines B.

XLVI. BRAYA. Sternbg. et Hoppe. Breitschötchen.

B. lineal-lanzettlich, ungetheilt, die grundständigen lang gestielt; Frtraube gedrängt, eiförmig.

A. v. T. $K$. alpina. Sterubg. et Hoppe. Alpen-B.

XLVII. WILCKIA. Scop. Meerviole.

B. länglich-lanzettlich, spitz, die unteren gesägtgezähnt; Fr. rauhhaarig. $N$.

Africana. (L.) Hal. Afrikanische M.

\section{XIVIII. SORIA. Adans. Schnabelschötchen.}

Fr. gabelig-behaart; Gr. kegelförmig; B. länglichlanzettlich; Bt. weiß. $M . N$ St. J.

Syriaca. (L.) Desv. Syrisches Sch. 
XLIX. HESPERIS. L. Nachtviole.

Krb. verkehrt-eiförmig o. länglich-verkehrt-eiförmig;

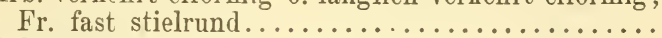

1 Krb. lineal-lanzettlich, schmutzig gelbgrün mit violetten Adern; Fr. flachgedrückt, abstehend. $M . N$. tristis. $L$. Traurige N.

Btstiel kürzer als der Kelch; Krb. bleichgelb oder schmutzig purpurn; Fr. wie die ganze Pfl. drüsig

${ }_{2}$ behaart; untere B. leierförmig-fiederspaltig. $J$.

glutinosa. Vis. Klebrige N. Btstiel mindestens so lang als der Kelch; Krb. lila

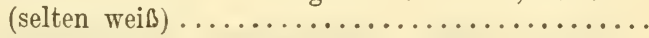

Stg. kahl o. von einfachen und ästigen, nicht drü3 sigen Haaren flaumig. Verbr. (oft cult. u. verw.)

Stg. namentlich oben von drüsentragenden Haaren flaumig. $M . N$. ....... silvestris. $C r$. Wald $-\mathrm{N}$.

\section{MATTHIOLA. $R$. $B r$. Lambertveilchen.}

Staude; B. lineal, ganzrandig; Bt. fast sitzend. Sïdt.

Zweijähriges Kraut; B. lanzettlich, filzig, die unteren buchtig-gezähnt; Bt. gestielt. $J$. sinuata. (L.) R. Br. Buchtiges L.

\section{BUNIAS. $L$. Zackenschötchen.}

Fr. mit geflügelten Kanten; B. meist schrotsägeförmig; Stg. drüsig-punktirt.

S. O. N. St. J. Sïdt.

Erucago. L. Senfblättriges S.

\section{CONRINGIA. Heister. Ackerkohl.}

Krb. grünlichweiß; Fr. 4 kantig, mit 1 nervigen Klappen. B. M. Sch. N. O. St. J.

Orientalis. (L.) Andrz. Orientalischer A. Krb. citronengelb; Fr. 8 kantig, mit 3 nervigen Klappen. $N$.

Austriaca. (Jacq.) Reichb. Oesterreichischer A.

XXVI. Familie. Capparideae. Kapperngewächse.

Kahle Sträucher mit wechselständigen, ungetheilten, ganzrandigen $\mathrm{B}$. und zu hakigen Dornen umgebildeten (oft fehlenden) Nebenb. Bt. einzeln, blattachselständig, lang gestielt, zwittrig. $\mathrm{Kb}$. und Krb. 4. Stb. zahlreich. Frkn. oberständig, lang gestielt, 1 fächerig, mit zahlreichen Samenknospen. Gr. sehr kurz. Fr. eine lang gestielte, vielsamige Beere. S. ohne Nährgewebe, mit gekrümmtem Keim. 


\section{Gattung.}

Bt. ansehnlich; Beeren oval, dickschalig; S. nierenförmig................. Capparis. I.

\section{Art.}

I. CAPPARIS. L. Kappernstrauch.

B. rundlich 0 . eiförmig, stumpf 0 . ausgerandet; Bt. weiß o. rosa. Sült. J. spinosa. L. Dorniger K.

XXVII. Familie. Resedaceae. Waugewächse.

Kräuter mit wechselständigen, ungetheilten o. fiedertheiligen 0 . theilweise $\mathbf{3}$ spaltigen $\mathrm{B}$., mit Nebenb. Bt. zwittrig, unregelmäßig, in reichblütigen, oft ährenförmigen Trauben. Kr. 4-7 theilig. Krb. 4-7. Stb. $10-40$. Frkn. 1, oberständig, oben offen, 1 fächerig, mit zahlreichen Samenknospen. Gr. 3-6, kurz. Fr. häutig, oben offen, nicht aufspringend. S. nierenförmig, ohne Nährgewebe, mit gekrümmtem Keim.

\section{Gattung.}

Bt. unscheinbar, weißlich o. gelblich; Krb. ungleich, meist gespalten ............... Reseda. I.

\section{Arten.}

\section{RESEDA. $L$. W au.}

Kb. u. Krb. $6 \ldots \ldots \ldots \ldots \ldots \ldots \ldots \ldots \ldots \ldots$ Kb. u. Krb. 4; B. ungetheilt, länglich-lanzettlich; Trauben verlängert, ährenförmig; Bt. gelblich. Verbr. (fehlt Sch. S.).... Iuteola. L. Färber-W.

Alle B. fiedertheilig, nur die untersten öfters unge-

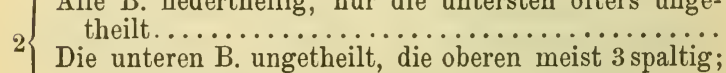
Krb. weißlich.......................

$3\{$ Krb. gelblich; N. 3. Verbr.... lutea. L. Gelber W.

3 Krb. weiß; N. 4. J. (Sïdt.?).. alba. L. Weißer W.

Kzipfel ungefähr von der Länge des Btstiels, länglich, zur Zeit der Frreife vergrößert. N. Kr. J. Südt.

Phyteuma. L. Stumpfblättriger W. Kzipfel kürzer als der Btstiel, lineal-keilig, zur Zeit der Frreife kaum vergrößert. $K r$. J. 
XXVIII. Familie. Droseraceae. Sonnenthangewächse.

Ausdauernde Sumpf- o. Wasserpflanzen mit rosettig angeordneten 0 . wirtelständigen, ungetheilten B., ohne dentliche Nebenb. Bt. zwittrig, regelmäbig. Kb., Krb. u. Stb. 5. Frkn. 1, oberständig, 1 fächerig, mit zahlreichen 0. doch mehreren Samenknospen. Gr. 3̈-5 Fr. eine mehrsamige Kapsel. S. mit Nährgewebe.

\section{Gattungen.}

Wasserpfl. mit wirtelständigen B., welche drüsenlose Borsten tragen; Bt. grünlich, einzeln in den Bachseln ................. Aldrovanda. I. Sumpf- o. Moorpflanzen mit grundständiger Brosette; B. mit langen rothen Stieldrüsen bedeckt; Bt. weiß, in ährenförmigen Wickeln ...Drosera. II.

\section{Arten.}

I. ALDROVANDA. L. Wasserhade.

Bstiel geflügelt, am Ende mit 6 Borsten; Bspreite zusammengeklappt einen Hohlraum bildend.

Sch. T. ........... vesiculosa. L. Blasige W.

\section{DRoserA. L. Sonnenthat.}

(B. kreisrund; Schaft aufrecht, ungefähr 3 mal so lang

1 als die B. Verbr. rotundifolia. L. Rundblättriger S.

B. verkehrt-eiförmig 0. keilig................. 2

(Schaft aufrecht, ungefähr doppelt so lang als die B.; Bstiele spärlich behaart. Verbr. (fehlt J.)

2) Anglica. Huds. Langblättriger S. Schaft am Grunde bogig 0 . darniederliegend, aufstrebend, wenig länger als die B.; Bstiele kahl.

S. K. $K r$. J...intermedia. Hayne. Mittlerer S.

Anmerkung. Zwischen D. rotundifolia u. D. Anglica kommt ein Bastart vor.

\section{Familie. Crassulaceae. Dickblattgewächse.}

Stauden 0. Kräuter mit wechselständigen, seltener gegenständigen, ungetheilten, meist mehr 0 . weniger dicken u. fleischigen B., ohne Nebenb. Bt. zwittrig, selten 2 häusig. Bthülle doppelt: Kb. $4-20$, oft am Grunde verwachsen; Krb. so viele als Kb., inanchmal verwachsen, selten fehlend. Stb. 4-40, meist doppelt so viele, seltener ebensoviele als Krb. Frkn. 4-20, in einen Kreis gestellt, oft am Grunde verwachsen und daselbst gewöhnlich mit je einer Honigdrüse. Samenknospen in jedem Frkn. meist zahlreich. Gr. soviele als Frkn., mit oft undeutlich abgesetzter N. Fr. stets aufspringend, meist vielsamig. S mit spärlichem Nährgewebe.

Fritsch, Excursionsflora. 


\section{Gattungen.}

Untere B. fast kreisrund, schildförmig; Krb. 5, glockig verwachsen; Stb. 10 .... Cotyledon. III. B. nicht schildförmig; Krb. frei o. nur am Grunde verwachsen

$\int \mathrm{Kb}$., Krb. u. Stb. 4-5; 1 jährige Kräuter. Kb. u. Krb. 4-20; Stb. 8-40, stets doppelt so viel

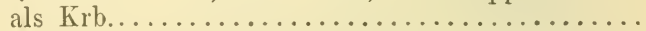

Kb. meist 5, seltener 4 o. 6; Krb. ebensoviele als Kb., frei; Stb. 10, seltener 8 0. 12; Frkn. meist 5 , seltener $t 0.6 \ldots \ldots \ldots \ldots \ldots$ Sedum. I. Kb. 6-20; Krb. ebensoviele als Kb., meist am Grunde unter sich und mit den Stb. verwachsen; Stb. 12-40; Frkn. 6-20; Grundb. rosettig.

Sempervivum. II.

Arten.

\section{SEDUM. $L$. Fetthenne.}

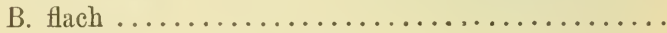

B. mehr 0 . weniger walzlich.............. 10

B. ganzrandig.

B. wenigstens rorne gezähnt-gesägt, selten nahezu ganzrandig; Stauden...........

Staude; B. rundlich o. verkehrt-eiförmig; Btstand gedrungen, ebenstränßig; Krb. purpurn, selten weiß, nit grünem Kiel. Südt.

Auacampseros. $L$. Rundblättrige F.

3 Kraut; die unteren B. verkehrteiförmig, die oberen lineal-keilig; Btstand locker, rispig; Krb. hellrosa mit purpurnem, seltener grünem Kiel. Südt.

Cepaea. L. Rispige F.

Bt. zwittrig, in der Pegel 5 zählig, seltener 6 zählig Bt. 2 häusig. 4 zählig; B. flach, länglich-lanzettlich, vorne gesägt, mit verdickter Spitze; Krb. grünlich-gelb, oft röthlich überlaufen. Geb.

roseum. (L.) Scop. Rosenwurz.

$5\{$ Bt. gelb 0. blassgelblich ................ 6

Bt. rosa 0. purpurn, selten weiß ........... 8

Wz. rübenförmig verdickt; die oberen $B$. mit seichtherzförmigem Grunde fast umfassend; Krb. an der Spitze kappenförmig vertieft $u$. mit einem Hörnchen endigend, blassgelblich. Verbr.

maximum. (L.) Große F.

Wz. faserig; alle B. nach unten keilig verschmälert;

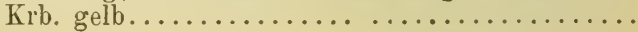


Btstand gedrungen, mit laubartigen Deckb.; B. breit-

7 lanzettlich. B. (verw.) Aizoon. L. Deckblättrige F.

Btstand locker; Deckb. nicht laubartig; B. verkehrteilänglich. N. (iervo.). hybridum. L. Bastart-F

Wz. rübenförmig verdickt; B. nicht knorpelig ge-

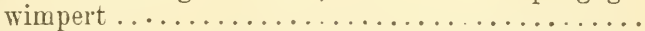

$\mathrm{W}_{\mathrm{z}}$. faserig; B. breit verkehrt-eiförmig, gegen den Grund keilig verschmälert, am Rande gewimpert; A. roth, daun schiefergrau. Cult. u. verw. (B. N.) spurium. $M ., B$. Kaukasische F.

B. oft gegenständig o. quirlig, die oberen am Grunde abgerundet, seltener verschmälert; Krb. auswärts gebogen; Frkn. am Rücken gefurcht. B. M. N. O.S. K...purpureum. (L.) Rothe F. B. wechselständig, alle gegen den Grund keilig-verschmälert; Krb. abstehend; Frkn. ohne Furche. Sch. M........ Fabaria. Koch. Gebirgs-F.

Kräuter ohne kriechende Stämmchen, nicht rasen-

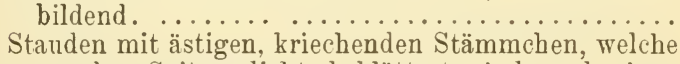
11 an der Spitze dicht beblättert sind und einen Rasen bilden, aus dem die blühenden Stg. hervortreten .......................... 14

Krb. meist 6, fast 4 mal so lang als der K., weiß, mit röthlichem Rückenstreifen; Stb. meist 12 ; Btstand fast kahl. Sü̈t. K. Südst. Kr.J.

Hispanicum. L. Spanische F.

Krb. ungefähr doppelt so lang als der K., meist 5;

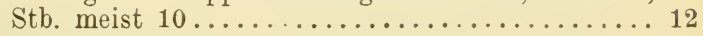

Btstand sammt den linealen, fast stielrunden $B$. drüsig-flaumig; Krb. eiförmig, spitz, r'osa, mit

12 purpurnem Rückenstreifen. Verbr. (fehlt J.)

villosum. $L$. Drüsenharige $\mathrm{F}$.

Btstand u. überhaupt die ganze Pfl. kahl .........

(1)


Btstand kahl; Krb. lanzettlich o. länglich-lanzettlich 16 Btstand drüsig-flaumig; Krb. eiförmig, doppelt so lang

15 als der K., mit purpurnem Rückenstreifen; B. dick, elliptisch, am Rücken höckerig. T. S. K. Kr. St. dasyphyllum. L. Dickblättrige F.

B. lineal-walzlich; Kb. oval, sehr stumpf; Krb. länglich-lanzettlich, kurz zugespitzt, 3 mal so lang als die $\mathrm{Kb}$. Verbr. $\iota$. hfg...... album. L. Weiße F.

16 B. verkehrt-eiförmig 0 . fast kugelig, sehr stumpf; $\mathrm{Kb}$. lanzettlich, stumpflich; Krb. lanzettlich, stumpflich, kleiner. $N$.

micranthum. Bast. Kleinblütige $\mathrm{F}$.

B. am Grunde abgerundet-gestutzt .......... 18

17 B. am Grunde vorgezogen, etwas gespornt 0 . nach

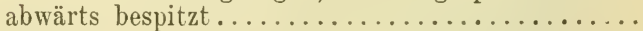

B. eiförmig, am Rücken höckerig; Krb. lanzettlich, spitz; die unfruchtbaren Stg. 6 zeilig-beblättert.

18 Verbr............. acre. L. Scharfer Mauerpfeffer. B. lineal, beiderseits fast flach; Krb. eiförmig-länglich, stumpf. Geb. (fehlt N.)

alpestre. Vill. Alpen-F.

B. stumpf, stielrund, am Grunde abwärts bespitzt; Krb. lanzettlich; die unfruchtbaren Stg. 6 zeiligbeblättert. Verbr.

Boloniense. Lois. Milder Mauerpfeffer.

B. kurz stachelspitzig, am Grunde etwas gespornt, an den unfruchtbaren Stg. dachig .............

Krb. weißlichgelb, aufrecht, zugespitzt; B. seegrün, oberwärts fast flach. $J$.

ochroleucum. Chaix. Blassgelbe F.

Krb. lebhaft gelb, abstehend; B. beiderseits gewölbt, an den unfruchtbaren Stg. abstehend u. zurück-

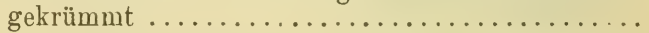

${ }_{21}\left(\begin{array}{rl}\text { B. lebhaft grasgrün. } B . T . & S . K . \\ \text { reflexum. } & \text { L. Zurückgekrümmte F. }\end{array}\right.$

B. seegrün o. blangrau. B. M. Sch. N. St. Kr. T. rupestre. $L$. Felsen-F.

\section{SEMPERVIVUM. L. HaUSWUY.}

(Krb. 12 o. mehr, selten weniger, samint den Kzipfeln

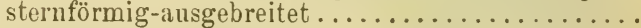
Krb. 6, sammt den Kzipfeln aufrecht, glockig zusammenschließend, gelblich-weiß .............

(Rosettenb. am Rande gewimpert, sonst kahl, höch-

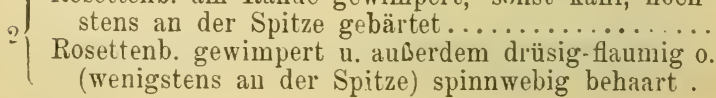


${ }_{3}\{\mathrm{Krb}$. hellgelb o. grünlich, selten röthlich ...... 4

$3\{$ Krb. rosenroth 0 purpurn............. . 5

Rosettenb. länglich-verkehrt-eiförmig, unten u. oben mit einzelnen Wimpern; Stgb. eilanzettlich; Krb. 3 mal so lang als die Kzipfel. A. v. T. S. K. St.

Wulfeni. Hoppe. Wulfen's H.
Rosettenb. lineal-spatelig, sehr fein gewimpert; Stgb. lineal-lanzettlich; Krb. doppelt so lang als die Kzipfel. A. v. T.

Widderi. Lehm. u. Schnittsp. Widder's H.

Wimpern der Rosettenb. drüsenlos ........... 6

5 Rosettenb. mit drüsenlosen Haaren u. (oft viel kürzeren) Drüsenhaaren gewimpert, an der Spitze

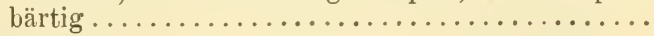

$\left\{\begin{array}{l}\text { Krb. } 3 \text { mal so lang als die Kzipfel, am Rande drüsig } \\ \text { gewimpert; Rosettenb. grangrün, kurz zugespitzt. }\end{array}\right.$ 11

6 A. v. T....... alpinum. Gris. et Sch. Alpen-H.

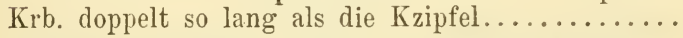
Rosettenb. grasgrün, plötzlich in eine Stachelspitze $\int_{7}$ zusammengezogen; Krb. eilanzettlich, drüsenhaarig.

7 A. v. T. (sonst cult. u. verw.)

tectorum. L. Dach-H.

Rosettenb. graugrün o. grasgrün, allmälig zugespitzt 8

Rosetten flach u. offen, mehr 0 . weniger graugrün . 9

8 Rosetten kugelig geschlossen, sehr klein, grasgrün; Krb. breit-lanzettlich. A. v. Südt.

dolomiticum. Facch. Dolomiten-H.

Rosetten groß, mit länglich-verkehrt-eiförmigen B. 10 Rosetten klein, viele aneinander gedrängt, mit ei-

9 lanzettlichen B.; Krb. lineal-lanzettlich, kurz rauhhaarig. Südt.

Mettenianum. Schnittsp. et Lehm. Mettenius' H. Rosettenb. in eine langgezogene Spitze verschmälert; Krb. lanzettlich, lang zugespitzt. Sïdt. $K$. $J$.

10 acumiuatum. Schott. ${ }^{*}$ ) Zugespitzte H. Rosettenb. in eine kurze Spitze zugeschweift; Krb. lineal-lanzettlich. Südt. J. glaıcum. Ten.*) Blaugrüne $\mathrm{H}$. Krb. 3 mal so lang als der K.; Rosettenb. lineal 0. länglich-lineal, am Rande von weißen Haaren $\mathrm{u}$. dazwischen stehenden viel kürzeren, spärlichen

11 Drüsenhaaren gewimpert. $T$.

angustifolium. Kern. Schmalblättrige $\mathrm{H}$. Krb. doppelt so lang als der K.; Rosettenb. eiförmig

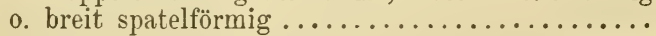

*) S. acuminatum Schott u. S. glaucum Ten. sind vielleicht von einander nicht specifisch verschieden. 
Rosettenb. breit spatelförmig; Kzipfel u. Krb. lineallanzettlich. A. จ. T. S. K.

fimbriatum. Schnittsp. et Lehm. Gefranste H. Rosettenb. eiförmig, zugespitzt; Kzipfel eilanzettlich; Krb. breit lineal-lanzettlich. $T$.

Hausmanni. Lehm. et Schnittsp. Hausmann's H.

${ }_{13}\{$ Rosettenb. an der Spitze durch spinnwebige Haare 13 verbunden 0 . doch daselbst flockig gebärtet .... 14 Rosettenb. ohne Bart u. spinnwebige Haare...... 16

Spinnwebige Haare an den Spitzen der Rosettenb. zur Zeit der Bt. reichlich vorhanden ......... 15 Spinnwebige Haare an den Spitzen der verkehrt14 eilanzettlichen, kurz zugespitzten Rosettenb. zur Zeit der Bt. sehr spärlich 0. ganz fehlend; Krb. eilanzettlich, doppelt so lang als die Kzipfel. T. S. K. ......Doelliamum. Lehm.*) Döll's H.

Rosettenb. länglich - verkehrt-eiförmig, beiderseits drüsenhaarig; Krb. länglich-lanzettlich, $3 \mathrm{mal}$ so lang als die Kzipfel. A. v. T. S. K. St.

arachnoideum. $L$. Uebersponnene $H$. lanzettlich, lang zugespitzt, an der Spitze gebärtet. S. St.

heterotrichum. Schott. Verschiedenhaarige H.

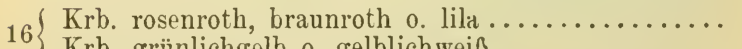

Krb. grünlichgelb 0 . gelblichweiß .......... 19

B. am Rande mit längeren drüsenlosen Wimpern versehen ....................... 18

B. am Rande kurz drüsig gewimpert, eilänglich 0 .

17 keilig-länglich, kurz bespitzt, beiderseits dicht drüsenhaarig; Krb. fast $4 \mathrm{mal}$ so lang als die Kzipfel, lila mit dunklerem Rückenstreifen. $A$.

montanum. $L$. Berg-H.

Rosettenb. länglich 0 . eilanzettlich, kämmig gewimpert; Krb. rosenroth, $2-3 \mathrm{mal}$ so lang als die Kzipfel. A. v. T. S. K. St.

Funkii. F. Braun. ${ }^{* *}$ ) Funk's H.

Rosettenb. lineal-spatelig, lang gewimpert; Krb. braunioth, auffallend schmal. $T$. debile. Schott. ${ }^{* *}$ ) Schwache $\mathrm{H}$.

*) Ob S. oligotrichum Bak. (A. v. Sï̈lt.) von S. Doellianum Lehm. verschieden ist, scheint $\mathrm{zweifelhaft.}$

**) In $T$. soll auch das durch graugrüne, spatelig-verkehrt-eiförmige Rosettenb. ausgezeichnete S. assimile Schott rorkommen. 
Krb. 3 mal so lang als die Kzipfel, grünlichgelb, roth gestrichelt; Rosettenb. grasgrün, länglichverkehrt-eiförmig. $A$. v. $T$.

rupicolum. Kern. Felsen-H. Krb. doppelt so lang als die Kzipfel, nicht roth ge-

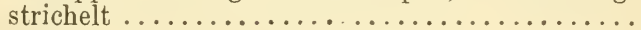

Rosettenb. blassgrün, roth gefleckt; Krb. einfärbig gelblichweiß. St. Pittonii. Sch. N. K. Pittoni's H. 20 Rosettenb. ganz grasgrün; Krb. gelblich, mit grünem Rï̈ckenstreifen. A. จ. T. S. K.

Brannii. Funk. Braun's H.

Stgb. beiderseits kurz drüsenhaarig, länglich 0 . ei21 lanzettlich. $N . O . S . T . K . K r$. St.

Stgb. beiderseits kahl, nur am Rande gewimpert..

( Rosettenb. länglich - verkehrteiförmig o. länglich22 keilig, ziemlich breit. B. M. Sch. N. U. (K.?)

soboliferum. Sims. Sprossende $\mathrm{H}$.

Rosettenb. schmal, lanzettlich o. länglich-lanzettlich 23

(Stgb. aus breiterem Grunde eilänglich; Krb. Jan-

23 zettlich. T. S. K. St. arenarimm. Koch. Sand-H. Rosettenb. u. Stgb. lanzettlich, namentlich erstere

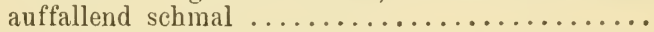

Stg. überall behaart; Krb. mit schmal-geflügeltem, gesägtem Längskiel. $N$.

Neilreichii. Schott. Neilreich's H.

Stg. nur oben behaart; Krb. mit haarig-zerissenem Längskiel. $K$. st.

Hillebrandtii. Schott. Hillebrandt's H.

Anmerkung. Die Sempervivum-Arten, namentlich jene der Alpen, bilden leicht Bastarte, die jedoch vielfach noch nicht mit genügender Sicherheit erkannt sind, weil die Artengrenzen selbst heute noch unklar sind. Nit Sicherheit sind im Gebiete S. arachnoideum $\times$ Wulfeni, montanum $\times$ Wulfeni $u$. arachnoideum $X$ montanum nachgewiesen. Wahrscheinlich sind auch einige der oben angeführten Arten nichts anderes als Bastarte.

\section{COTYLEDON. $L$. Nabelkrant.}

Staude mit knolligem Wst.; obere B. keilförmig; Bt. in verlängerten Trauben, gelb 0 . röthlich. $J$.

horizontalis. Guss. Dalmatinisches N.

\section{CRASSULA. L. Dickblatt.}

B. gegenständig, lineal, ganzrandig; Bt. 4 zählig, 1 weil. B.M. N.

aquatica. (L.) Schöıl. Wasser-D.

B. schraubig gestellt, dick; Bt. 5 zählig......... 
Aeste u. K. drüsig-haarig; B. zerstreut, halbwalzlich; $\mathrm{K}$ !b. weis, mit fleischrothem Kiel. $J$.

rubens. $L$. Röthliches D.

2 Aeste u. K. kahl; B. dachig, eiförmig, stumpf ; Krb. fleischroth, mit purpurnem Kiel. $J$. caespitosa. Cavan. Kahles D.

XXX. Familie. Saxifragaceae. Steinbrechgewächse.

Stauden 0. Hallusträucher, seltener Kräuter o. Sträucher mit ungetheilten, gelappten 0 . getheilten, schraubig gestellten, seltener gegenständigen B., meist ohne Nebenb. Bt. zwittrig, selten 2 häusig, mit doppelter, seltener einfacher Bthülle. $\mathrm{Kb} .4-5$, am Grunde mehr 0 . weniger verwachsen. Krb. 4-5, manchmal fehlend. Stb. 5, 8 0. 10 (selten 4) 0. zahlreich; manchmal außerdem 5 mit langen Drüsenhaaren bewimperte Schuppen (Staminodien) vorhanden. Frkn. 1, oberständig 0 . halb- 0 ganz unterständig, 1-2 fächerig, seltener mebrfächerig, mit zahlreichen Samenknospen. Gr. 2-5, seltener mehr, manchmal am Grunde verwachsen. Fr. mehrsamig, meist aufspringend, seltener beerenartig. S. mit Nährgewebe.

\section{Gattungen.}

Sträucher mit gegenständigen B.; Stb. zahlreich; N. 4-10; Kapsel 4-10 klappig. Philadelphus. V.

1 Sträucher mit gelappten, wechselständigen B., 0. Halbsträucher, Stauden o. Kräuter; Stb. 100. weniger; Gr. $2-5 \ldots \ldots \ldots \ldots \ldots \ldots \ldots \ldots$.

Sträucher mit gelappten B.; Frkn. unterständig; Fr. eine Beere ................Ribes. VI.

2 Halbsträucher, Stauden 0. Kräuter ; Frkn. bald oberständig, bald mehr o. weniger unterständig; Fr.

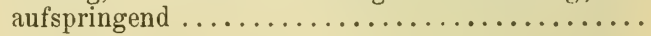

Blkr. vorhanden; Kb. 5 ; Stb. 5 o. $10 \ldots \ldots \ldots \ldots 4$

3 Blkr. fehlend; Kb. 4 (selten 5); Stb. 8 (selten 10) Chrysosplenium. III.

5 Stb. u. zwischen ihnen 5 mit langen Drüsenhaaren bewimperte Schuppen vorhanden; Kapsel 1 fächerig.

Parnassia. IV.

10 Stb. vorhanden, aber keine bewimperten Schuppen zwischen ihnen; Kapsel 2 fächerig. .

Krb. gefärbt (meist weiß, purpurn o. gelb), nach unten verschmälert, vom Btboden deutlich abge-

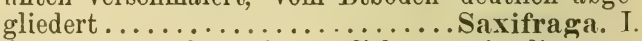

Krb. grünlich, den Kb. ähnlich u. wie diese am Grunde verbreitert $u$. vom Btboden nicht deutlich abgegliedert ........... Kahlbrucknera. II. 


\section{Arten.}

\section{SAXIFRAGA. L. Steinbrech.}

B. am Rande o. an der Spitze mit eingestochenen Punkten 0. Grübchen versehen, die mit weißen,

$1\{$ später ausfallenden Kalkschüppchen bedeckt sind B. entweder ohne eingestochene Punkte 0 . Grübchen, o. doch ohne weiße Kalkschüppchen............

Bt. weiß o. gelb, seltener rothbraun; B. schraubig gestellt, längs des Randes mit einer Reihe zahlreicher o. doch mehrerer, mit Kalkschüppchen bedeckter, eingestochener Punkte; B. der Stämmchen dicht gedrängt, oft Rosetten bildend...............

Bt. purpurn, violett 0 . rosa, sehr selten weiß; an der dicken Spitze der gegenständigen B. befinden sich nur 1-3, mit Kalkschüppchen bedeckte, eingestochene Punkte...................... 14

B. der Rosetten längs des Randes vielpunktig... . 4

3 B. der Stämmchen oberwärts längs des Randes 5bis 7 punktig; Bt. weiß o. gelblich-weiß ........

Krb. orangegelb, seltener rothbraun, lineal-lanzettlich, spitz; B. der Rosetten zungenförmig, vorn ganzrandig 0 . schwach gesägt.

4 A. u. Vora. (fehlt J.)......mutata. L. Kies-St. Krb. weiß o. gelblich-weiß, zuweilen am Grunde purpurn o. purpurn geadert o. punktirt, abge-

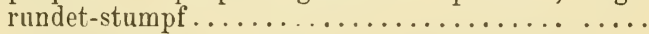

B. der Rosetten ganzrandig (durch die Kalkschuppen scheinbar gelierbt), lineal, stumpf; Krb. verkehrteiförmig. A. (fehlt $N$. O.)

incrustata. Vest. Krustiger St.

B. der Rosetten gekerbt 0 . gesägt...............

B. der Rosetten durch abgestutzte Kerbzähne gekerbt; Stg. traubig-rispig; Aeste an der Spitze ebensträuœig $6-12$ blütig.

6 (B.) Südt. K. St. Kr. J.

Hostii. Tausch.*) Hochstengliger St.

B. der Rosetten durch zugespitzte, vorwärts gerichtete Sägezähne gesägt.....................

Rosettenb. mit der Spitze herabogebogen; Aeste des Btstandes 6-12 blütig, dicht drüsenhaarig; Krb.

7 weiß, mit zahlreichen rothen Punkten. $K$. St.

altissima. Kern. Höchster St.

Rosettenb. gerade o. einwärts gebogen............

$\left.{ }^{*}\right)$ S. Rhaetica Kern. (A. v. Südt.) hat sehr große B und zahlreiche rothe Punkte auf den Krb. 
Rispe pyramidal, gleich über der Brosette beginnend; Aeste von der Mitte an 5-15 blütig; Krb. keilig. (K. ?).... Cotyledon. $L$. Pyramidenförmiger St. Stg. oberwärts traubig-rispig; Aeste 1 blütig 0 . an der Spitze 2-5blütig; Krb. rundlich.

Verbr. (bes. A.).... Aizoon. Jacq. Traubiger St.

$\int$ B. der Stämmchen eilanzettlich 0 . lineal-pfriemlich,

B. der Stämmchen lineal-lanzettlich 0 . lineal-länglich, über der Mitte am breitesten ...........

B. der Stämmchen pfriemlich, zugespitzt, oberseits mit 7 Punkten; Stg. 1 blütig; Krb. rundlich, gekerbt. A. u. Vora..... . Burseriana. L. Burser's St. B. der Stämmchen eilanzettlich, spitz o. stumpflich; Stg. wenigblütig, dicht-drüsig-zottig; Krb. keiligverkehrt-eiförmig . . . . . . . . . . . . . .

Btstand rispig, 3-7- (selten mehr-) blütig; B. der Stämmchen spitz und stachelspitzig; Stgb. mit langer Stachelspitze. A. v. Südt. (St. ?)

11 Vandellii. Sternbg. Vandelli's A.

Btstand traubig, 1 - 3 blütig; B. der Stämmachen sehr klein, stumpflich, weichstachelig; Stgb. spitz. A. v. Südt. Tombeanensis. Boiss. Tombeaner St.

Stg. überall dicht drüsenhaarig*); B. der Stämmchen gerade; Btstand 2-3 blütig; Krb. schneeweiß. A. v. Südt.

12 diapensioides. Bell. Diapensienartiger St. Stg. oben zerstreut-drüsenhaarig $\left.0 . \mathrm{kahl}^{*}\right)$; B. der Stämmchen wenigstens an der Spitze zurückge-

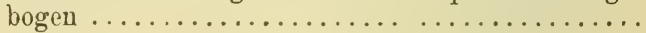

B. der Stämmchen vom Grunde an bogig-zurückgekrümmt; Seitennerven der Krb. meist gebogen. A.. ........... caesia. L. Blaugrüner St.

B. der Stämmchen nur an der Spitze zurückgebogen; alle Nerven der Krb. gerade.

A. v. T. K. St. Kr. J. squarrosa. $L$. Sparriger St.

Kzipfel am Rande kahl; B. 3 punktig, 4 reihig-dachig; $14\left\{\begin{array}{l}\text { Krb. hellpurpurn. A. v. S. St. } \\ \text { retusa. Gouan. Gestutzter St. }\end{array}\right.$ Kzipfel gewimpert; B. an der Spitze 1 punktig .... 15

*) S. caesia L. kommt auch in einer stark drüsenhaarigen Form vor, ist aber an den zurïckgekrümmten B. der Stämmchen leicht zu erkennen. 
Bt. einzeln; Stämmchen sehr ästig, Aeste aufrecht, gedrungen-rasig; B. 4 reihig-dachig; Bt. zuerst rosa, dann violett.

Bt. zu 2-9, kopfig; B. etwas entfernt 0. lockerdachig, die oberen sammt den Kzipfeln drüsiggewimpert

Wuchs locker rasig; Kzipfel drüsenlos gewimpert. Geb. (fehlt Sch. M. N.)

oppositifolia. L. Gegenblättriger St.

16 Wuchs dicht rasig; Kzipfel sammt den oberen $B$. meist drüsig gewimpert; Bt. fast sitzend. A. v. T. S. K. St.

Rudolphiana. Hornsch. Rudolph's St.

Krb. von einander abstehend, lanzettlich, etwa so lang als die Stb.; Bt. violett, selten rosa 0 . weiß. A. v. T. S. K. St. biflora. All. Zweiblütiger St. Krb. einander berührend, länglich, $2-3 \mathrm{mal}$ so lang als die Stb.; Bt. hellviolett. A. v. T. S. K. St.

macropetala. Kernn. Großblütiger St.

B. vor der Spitze mit einem Knötchen versehen, in welchem sich ein oft mit einer Drüse versehenes Grübchen befindet, am Rande steif gewimpert,

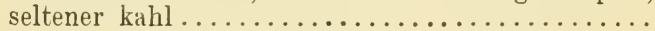

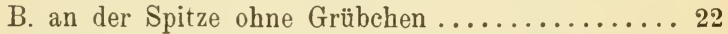

Grundfarbe der Krb. gelblichweiß ........... 20

Krb. lebhaft gelb, orange 0. braunroth; B. fleischig, nahezu lineal, stachelspitzig. A. u. Vora.

aizoides. $L$. Immergrüner St.

B. lineal-lanzettlich, stachelig-begrannt u. bewimpert; Kzipfel schwach-stachelspitzig ..............21

20 B. lineal-pfriemlich, haarspitzig begrannt, borstig gewimpert 0 . kahl; Kzipfel begrannt.

A. v. T. K. St. J.....tenella. Wulf. Zarter St.

Stg. mehrblütig; Stgb. abstehend; Bknospen halb so lang als das sie stützende B.

A. v. T. S. K. St. Kr. aspera. L.*) Rauher St. 21 Stg. 1 blütig; Stgb. fast angedrückt; Bknospen mindestens so lang als das sie stützende $\mathrm{B}$. A. v. T. S. K. St. Kr.

bryoides. $\left.L *^{*}\right)$ Moosartiger St.

Neben dem blühenden Stg. sind ausdauernde, beblätterte Stämmchen vorhanden............. 23 Ausdauernde Stämmchen fehlen; der Stg. stirbt jährlich bis zum Grunde $a b \ldots \ldots \ldots \ldots \ldots \ldots$

*) Zwischen S. aspera L. und S. bryoides L. kommt eine Mittelform vor: S. intermedia Hegetschw. (ob Bastart?). 
23 Stf. nach oben verbreitert; alle B. grundständig... 24 Stf. pfriemlich, nach oben verschmälert........ 25

B. verkehrt-eiförmig-keilförmig, abgerundet-stumpf, ausgeschweift-gekerbt; Bstiel keilförmig, kahl. A. v. T. K. Sü̈lst. $K r$. J.

cuneifolia. L.*) Keilblättriger St.

B. verkehrt-eiförmig, etwas gestutzt, gekerbt; Bstiel lineal, am Rande zottig-gewimpert.

Cult. u. verv. (O. S. St.)

Imbrosa. $L .^{*}$ ) Schatten-St.

( K. ganz o. fast ganz frei, seine Zipfel zuletzt zurück-

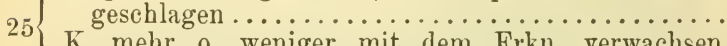

K. mehr o. weniger mit dem Frkn. verwachsen, seine Zipfel aufrecht 0 . abstehend............

Bt. gelb; Stg. reichlich beblättert; B. lanzettlich, ganzrandig. Sch. S. .....Hirculus. L. Moor-St.

26 Grundfarbe der Bt. weiß ; B. alle grundständig, verkehrt-eiförmig-keilförmig, meist vorne gezähnt. A. stellaris. L. $\left.{ }^{* *}\right)$ Sternblütiger St.

Krb. lineal, zugespitzt, 3 mal schmäler, aber etwas

länger als die Kzipfel, citronengelb; B. keilig, 327 bis 5 spaltig; Stg. oben blattlos, 1 blütig.

(fehlt $K r$. J.)... aphylla. Sternbg. Blattloser St.

Krb. nicht lineal 0 . nicht zugespitzt ......... 28

Krb. mindestens doppelt so lang als die Kzipfel,

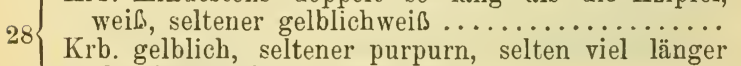
als die Kzipfel ............................. 34

$29\{$ B. $3-5(-9)$ spaltig .................. 30

B. ungetheilt 0 . vorn $3-5$ zähnig ............ 33

Zipfel der Rosettenb. zugespitzt, stachelspitzig; Bstiel flach, glatt 0.1 furchig. $B$.

quinquefida. Haw. Fünfspaltiger St.

Zipfel der Rosettenb. grannenlos 0. stumpf mit

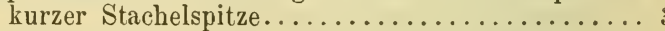

Zipfel der B. 3-5, lineal o. länglich, abgerundetstumpf, tief gefurcht, Furchen am Bstiele in eine einzige zusammenfliefend; Bt. weib o. gelblich-weiß. A. v. T. S. K. Kr. St.

exarata. Vill. Gefurchter St.

'Zipfel der B. 3-9, gar nicht 0 . schwach-gefurcht, Furchen mit der schwachen Furche des Bstiels nicht zusammenhängend; Bt. weiß ...........

*) In $O$. ist auch die durch herzförmig-rundliche B. ausgezeichnete S. Geum L. verw. beobachtet worden. **) Sehr veränderliche Art! 
Wuchs dichtrasig; B. meist 3 spaltig; Krb. doppelt so lang als die Kzipfel. $N$.

caespitosa. L. Rasiger St.

32 Wuchs lockerrasig; Stg. höher; B. 3-9 spaltig; Krb. fast 3 mal so lang als die Kzipfel.

B. M. N. (sonst. cult.)

decipiens. Fhrh. Trügerischer St.

Stg. blattlos 0. 1 blättrig; Rosettenb. spatelig o. verkehrt-eiförmig, oft an der Spitze 3 zähnig. $A$.

androsacea. $L$. Mannsschildartiger St.

Stg. 2-5 blättrig; Rosettenb. lineal-länglich, abgelundet-stumpf. A. v. T. K. S O.

planifolia. Lap. Flachblättriger St.

B. ungetheilt, lanzettlich, spitz u. stachelspitzig; $\mathrm{Krb}$. eiförmig, spitz, so lang o. kürzer als der K. A....... serloides. $\left.L .^{*}\right)$ Fetthennenähnlicher St.

B. nicht stachelspitzig, lineal, verkehrt-eiförmig 0 . spatelig-lanzettlich, bisweilen auch lanzettlich, aber abgerundet-stumpf $0.3-5$ spaltig .............

B. lineal 0 . lineal-länglich 0 . keilig $u .3(-5)$ spaltig mit linealen Zipfeln; Bt. gelblich, seltener purpurı 36

B. spatelig-lanzettlich, stumpflich; Stg. blattlos 0 . 1-(selten 2-3-) blättrig; Krb. länglich-lineal, ungefähr so lang u. so breit als die Kzipfel.

A v. T. S. ........Seguieri. S S r. Seguier's St.

B. stets ungetheilt, abgerundet-stumpf; Stg. 1- bis 4 blättrig; Krb. verkehrt-eiförmig-keilig, so breit u. etwas länger als die Kzipfel. $A$. v. Südt. $S$.

Facchinii. Koch. Facchini's St.

B. theils $3(-5)$ spaltig, theils ungetheilt, selten alle ungetheilt (dann die Krb. länglich); Stg. blattlos o. 1-3 blättrig; Krb. meist länger als die Kb. in der Gestalt veränderlich. $A$.

moschata. Wulf.**) Moschusduftender St.

Stg. beblättert ................................

37 entfernt gezähnt 0 . fast ganzrandig; Krb. blassgrïn, am Rande oft purpurn, eiförmig, spitz, so lang als die Kzipfel. A. v. St. $K$.

hieracifolia. W. $K$. Habichtskrautblättriger St.

Stg. aufrecht; Bt. weiß ............... 39

38 Stg. niederliegend; Wz. einfach o. spindelförmig-

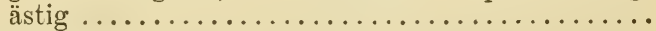

*) Gewöhnlich ist der Stg. blattlos; bei S. Hohenwartii Sternbg. ist derselbe bis hinauf beblättert und die Krb. sind größer.

**) Eine sehr veränderliche Art! 
1 jährige Arten; Grundb. keilig 0. spatelig, ungetheilt,

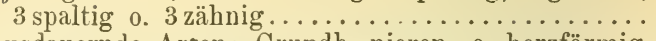
Ausdauernde Arten; Grundb. nieren- 0. herzförmig,

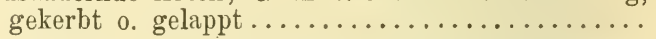

Frstiele viel länger als der Frkelch; Stgb. handförmig3 spaltig 0. ungetheilt; Bt. sehr klein. Verbr.

40 tridactylites. $L$. Dreifingeriger St. Frstiele kaum so lang als der Frkelch; B. keilig, vorne 3-5 zähnig; Bt. größer; Pfl. kräftiger. $A$. adscendens. $L$. Aufsteigender St.

Bt. einzeln, selten $\mathrm{zu} \mathbf{2 - 5}$ traubig angeordnet; Grundb. nierenförmig, handförmig 5-7lappig; Krb. länglich, gestutzt. A. v. Südt. K. St.

cernua. $L$. Nickender St.

Bt. in doldenförmig o. rispenförmig zusammen-

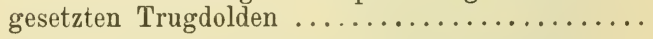

Staude mit walzlichem Wst., ohne Knöllchen; K. fast ganz frei, mit abstehenden Zipfeln; Krb. länglich-lanzettlich, sternförmig ausgebreitet, weiß, meist gelb- u. purpurn-punktirt. A. u. Vora.

rotundifolia. L. Rundblättriger St.

Pfl. ohne Wst., mit kleinen Knöllchen zwischen den Wz. ; K. verwachsen, mit aufrechten Zipfeln; Krb. länglich-verkehrteiförmig, glockig-abstehend, nicht

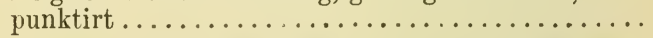

Stg. ästig, armblättrig; Stgb. keilförmig, 3-5 spaltig, ohne Zwiebeln; Btstand trugdoldig-rispig.

Verbr. (fehlt $K . T$.) granulata. L. Körniger St. Stg. unverzweigt, vielblättrig; Grundb. nierenförmig, lappig-gekerbt; Stgb. in den Bwinkeln $\mathrm{zwiebel-}$ tragend; Btstand fast doldenförmig.

M. N. Südst. J. Südt.

bulbifera. $L$. Zwiebeltragender St.

Bt. weiß; B. handförmig-3 spaltig, eingeschnittengezähnt, Zipfel zugespitzt. Sïdt. $K r$. J.

petraea. $L$. Felsen-St. Bt citronengelb, zuletzt locker-traubig; B. rundlichverkehrt-eiförmig, vorne sehr stumpf, 3 - 5 lappig. Sïdt... arachnoidea. Sterubg. Spinnwebiger St.

Anmerkung. Von Bastarten wurden im Gebiete beobachtet: $S$. caesia $X$ mutata, aizoides $X$ mutata, Hostii $X$ incrustata, Aizoon $X$ cuneifolia, caesia $X$ squarrosa, caesia $X$ aizoides, aizoides $X$ squarrosa, biflora $X$ oppositifolia, macropetala $X$ oppositifolia, sedoides $X$ tenella. 


\section{ZAHLBRUCKNERA. Rehb. Glimmer- steinbrech.}

Stg. liegend; untere B. herz-nierenförmig, 5- bis 7 lappig, die oberen 3 lappig. Vora. v. St. K.

paradoxa. (Sternbg.) Rchb. Merkwürdiger G.

\section{CHR Y SOSPLENIUM. L. Milzkraut.}

B. wechselständig, nierenförmig, tief-gekerbt, Kerben ausgerandet. Verbr.

alternifolium. $L$. Wechselblättriges $\mathrm{M}$.

B. gegenständig, halbkreisförmig, ausgeschweiftgekerbt. B. M. Südst. (T.?)

oppositifolium. L. Gegenblättriges M.

\section{PARNASSIA. L. Studentenröschen.}

Grundb. herzförmig; Stgb. umfassend; Bt. weiß. Verbr. u. hfg. ......... palustris. L. Sumpf-St.

\section{T. PHILADELPHUS. L. Pfeifenstranch.}

B. elliptisch, zugespitzt, oberseits kahl, unterseits kurzhaarig; Bt. wei $\Omega$, wohlriechend.

B. O. St. Südt. (theilweise verw.; sonst cult.)

coronarius. $L$. Wohlriechender Pf.

\section{RIBES. $L$. Johamnisbeere.}

(Btstiele 1(-3)blütig; Zweige mit (meist 3 theiligen) Stacheln. Verbr. (auch cult.)

Grossularia. L.*) Stachelbeere.

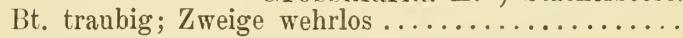

Btstiele kürzer als ihre Tragb.; Tr. aufrecht, drüsigflaumig; K. kahl. Verbr. (bes. Geb.)

Btstiele länger als ihre Tragb.; Trauben zuletzt

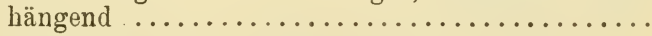

K. drüsig-punktirt; Krb. länglich; B. unterseits 3 drüsig-getïpfelt; Fr. schwärzlich.

3 Verbr. (meist nur verw.) nigrum. L. Schwarze J.

K. kahl; Kzipfel u. Krb. spatelig; Fr. roth ...... 4

K. beckenförmig, Zipfel am Rande kahl; Tr. kahl o. fast kahl; Bt. gelblich-grün.

4 Verbr. (oft nur verw.) ....rubrum. L. Rothe J. K. glockig, Zipfel am Rande gewimpert; Tr. flaumig; Bt röthlich. Geb....petraeum. ITulf. Felsen-J.

A nmerk ung. Aus der Familie der Platanaceae werden einige Arten der Gattung Platanus L.(Platane) oft cultivirt, namentlich als Alleebäume. Dieselben

*) Bei der typischen Form sind die Frkn. drüsig-behaart, bei $R$. Uva crispa L. drüsenlos behaart. 
sind an der sich in Blättern ablösenden Rinde, den ahornähnlichen B. und den kugeligen Btköpfchen, welche zu mehreren an langen Stielen herabhängen, leicht $\mathrm{zu}$ erkennen.

\section{Familie. Rosaceae. Rosengewächse.}

Holzgewächse o. Stauden, selten Kräuter mit schraubig gestellten, oft getheilten B., meist mit Nebenb. Bt. meist zwittrig, mit doppelter (seltener einfacher), stets regelmäbiger Bthülle. $\mathrm{Kb}$. 5, seltener weniger 0 . mehr, nicht selten mit ebenso vielen Außenkb. zwischen ihnen, ebenso wie die Krb. u Stb. ain Rande des scheibenförmigen 0. mehr o. weniger ausgehöhlten Btbodens eingefügt. Krb. so viele als $\mathrm{Kb}$., manchmal fehlend. Stb. in verschiedener Zahl vorhanden, am häufigsten zahlreich, aber manchmal auch nur 1-4. Frkn. zahlreich, wenige o. nur 1, bald frei, bald untereinander u. mit dem Btboden verwachsen, oberständig o. unterständig. Sind mehrere freie 0.1 oberständiger Frkn. vorhanden, so sind dieselben 1 fächerig u. enthalten 1 bis zahlreiche Samenknospen; ist der Frkn. unterständig, so ist er gewöhnlich 2-5 fächerig $u$. enthält in jedeın Fache 1 bis zahlreiche (am häufigsten 2) Samenknospen. Gr. meist so viele als Frkn. o. Frknfächer, manchmal verwachsen; N. meist klein, oft kopfig, seltener pinselförmig. Fr. sehr verschieden ansgebildet, manchmal mit dem fleischig werdenden Frboden eine Scheinfrucht darstellend. S. meist ohne 0. mit spärlichem Nährgewebe.

\section{Gattungen.}

1\{ Blkr. vorhanden ....................... 2

$1\{$ Blkr. fehlend......................... 24

Kb. einreihig, gleichgebildet $\ldots \ldots \ldots \ldots \ldots \ldots \ldots$

2 Kb. 2 reihig, die äußeren (Anßenkelchb.) kleiner u. mehr abstehend ...................... 18

Kb. 8-9; Krb. 8-9; Früchtchen von dem blei3 benden, federartigen Gr. geschwänzt. Dryas. XVI. Kb. $4-5$; Krb. $4-5 \ldots \ldots \ldots \ldots \ldots \ldots \ldots \ldots . . \ldots$

Wehrlose Stauden mit unterbrochen gefiederten $B$. u. gelben Bt.; außerhalb des $\mathrm{K}$. ein mehrreihiger

4 Kranz hakiger Weichstacheln. Agrimonia. XIX. Stauden mit weißen o gelblichweißen Bt. 0. häufiger Holzgewächse ........................

Holzgewächse mit ungetheilten B.; Frkn. 1, ober$5\left\{\begin{array}{l}\text { ständig; Fr. eine Steinfr........ Prunus. XXIII. } \\ \text { Hnlzgewächse o. Stauden; Frkn. unterständig } 0 .\end{array}\right.$ mehrere bis viele oberständige...$\ldots \ldots \ldots \ldots$. 
(Frkn. frei, wenn auch oft tief in den ausgehöhlten

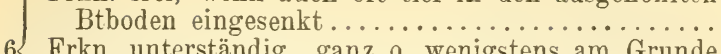

6 Frkn. unterständig, ganz o. wenigstens am Grunde mit dem ausgehöhlten Btboden verwachsen; Holzgewächse; Fr. mehr o. weniger fleischig (Apfelfr.) 12

$7\left\{\begin{array}{l}\text { Sträucher mit ungetheilten B.; Fr. aufspringend. } \\ \text { Spiraea. I. }\end{array}\right.$

Sträucher mit getheilten B. 0. Stauden..........

B. mehrfach-zusammengesetzt, ohne Nebenb.; grole

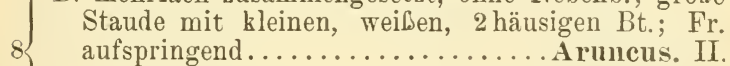

B. 3 zählig, (einfach o. doppelt) gefiedert 0 . gefingert, mit Nebenb.; Fr. nicht aufspringend ..........

Mehr o. wenige bestachelte, selten fast wehrlose

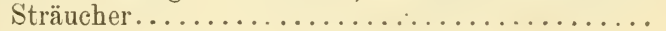

Wehrlose 0. schwach bestachelte Stauden ....... 1

Btboden ziemlich flach; Frkn. in der Mitte der Bt.

10 ein erhöhtes Köpfchen bildend; B. 3 zählig, ge-

Btboden tief ausgehöhlt, in seinem Innern die Frkn. verbergend; B. gefiedert..........Rosa. XXII.

B. unterbrochen gefiedert; Bt. klein, sehr zahlreich;

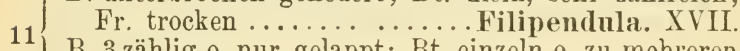
B. 3 zählig o. nur gelappt; Bt. einzeln o. zu mehreren fast doldig genähert; Fr. fleischig.... Rubus. X.

$12\{$ Bt. einzeln an der Spitze der Zweige........... 13

Bt. in Büscheln, Trauben o. Doldentrauben ....... 14

Kzipfel länger als die Krb., ganzrandig; Steinapfel oben mit einer erweiterten Scheibe.

Mespilus. VIII.

Kzipfel viel kürzer als die Krb., gezähnelt; Apfelfr. mit vielsamigen Fächern.......... Cydonia. IV.

Steinapfel mit 35 zusammenhängenden, an der Spitze freien, nicht in das Frfleisch eingesenkten Steinen; Krb. fast so lang als der der K.: B. ganzrandig ................. Cotoneaster. UI. Steinapfel mit eingesenkten Steinen, 0. Apfelfr. 0. Beere; Krb. viel länger als der K.......... 15

$15\{$ Bt. in kurzen, oft doldenähnlichen Trauben .......

Bt. in Ebensträußen ................. 17

Trauben doldenförmig (Doldentrauben); Krb. rundlich o. länglich, kurz benagelt; Frfächer nicht gespalten.......................... Pirus. $T$.

16 Trauben nicht doldenförmig (d. h. die Bt. stehen nicht in gleicher Höhe); Krb. lanzettlich, nach unten keilig verschmälert; Frfächer unvollkommen 2 spaltig. 
$17\left\{\begin{array}{l}\text { Fr. ein Steinapfel (die Frfächer knöchern erhärtet); } \\ \text { Zweige dornig .................. Crataegus. IX. } \\ \text { Fr. eine Beere (Frrfächer dünnhäutig); Z Zeige wehrlos. } \\ \text { Sorbus. VI. }\end{array}\right.$

(Frkn. u. Gr. 2; Außenkb. sehr klein, pfriemlich; 18 Stb. 5-10; Staude mit unterbrochen gefiederten Grundb. und gelben Bt.........Aremonia. XX.

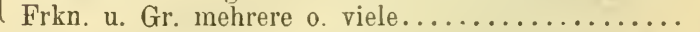
$19\left\{\begin{array}{c}\text { Stb. und Gr. 5, selten 10; Krb. lanzettlich; kleine } \\ \text { Alpenpfl mit } 3 \text { zähligen B..... Sibbaldia. XIII. }\end{array}\right.$

Grundb. 3 zählig.................... 21

20 Grundb. gefingert 0 . gefiedert, manchmal mit sehr großem Endblättchen ..................

Frkn. 3-5, lang seidig-behaart, mit langen, endständigen Gr.; Fr. lederig, mit 1 aufsteigenden $\mathrm{S}$.

Waldsteinia. XIV.
Frkn. zahlreich, mit oft seitenständigen Gr.; Fr. hart, mit 1 hängenden $\mathrm{S} . \ldots \ldots \ldots \ldots \ldots \ldots$.

Frboden bei der Reife fleischig-saftig, eine Scheinfrucht (Erdbeere) darstellend; Bt. weiß.

Frboden bei der Reife unverändert, trocken; Bt. gelb o. weib, seltener rosa 0 . purpurbraun

Potentilla. XII.

Gr. lang, stehen bleibend; Fr. lederig, mit 1 auf-

steigenden S.; Grundb. unterbrochen gefiedert, oft

23 mit sehr großem Endblättchen......Geum. XV.

Gr. kurz, abfällig; Fr. hart, mit 1 hängenden S.; Grundb. gefingert o. gefiedert...Potentilla. XII.

B. 3 spaltig, gefingert o. häufiger nur handförmig gelappt; Außenk. vorhanden; Gr. grundständig.

B. gefiedert; Außenk, fehlend; Gr. endständig. Alchimilla. XVIII. Sanguisorba. XXI.

\section{Arten.}

\section{SPIRAEA. L. Spierstraucl.}

Bt. blassrosa 0 . weiß, in endständigen, pyramidalen Rispen; B. länglich-lanzettlich, ungleich- fast doppelt-gesägt, kahl.

B. M. N. O. St. K. Kr. (sonst cult.) 
Btstand an beblätterten Zweigen endständig...... Btstand seitenständig, fast sitzend; B. verkehrt-eiförmig, stumpf, an der Spitze ungleich-gekerbt; Kzipfel an die Blkr. angedrückt. $K r$.

obovata. WK. Kleinblättriger Sp.

Btstand zusammengesetzt, ebensträußig; B. ganz kahl, verkehrt-eiförmig o. länglich, stumpf, ungleich- fast doppelt-gesägt, am Grunde ganzrandig. $K$. decumbens. Koch. Niederliegender Sp. Doldentr einfach, fast halbkugelig; die jüngeren $\mathrm{B}$.

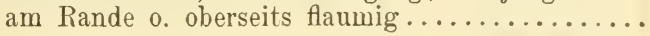

Zweige kantig-gerieft; B. eiförmig, spitz, ungleichfast doppelt gesägt, ain Grunde abgerundet.

Sïdst. $K r$.J. ulmifolia. Scop. Ulmenblättriger Sp.

4 Zweige stielrund; B. länglich, ganzrandig o. vorne mit wenigen Sägezähnen, nach unten verschmälert. St. $K r . J$.

oblongifolia. $W K$. Länglichblättriger Sp.

Anmerkung. Die nur cultivirt und gelegentlich in Hecken und Anlagen halb verwildert vorkommenden Arten der Gattung sind hier nicht berücksichtigt. So verhält sich auch der Knackbusch (Physocarpus opulifolia (L) Maxim.), der sich durch gelappte B. und aufgeblasene Fr. auszeichnet.

\section{ARUNCUS. Adans. Geißbart.}

Blättchen eiförmig, fein zugespitzt, ungleich-doppeltgesägt; Btstand umfangreich, rispig-zusammengesetzt. Verbr. ....... silvester. Kostel. Wald-G.

\section{COTONEASTER. Med. Steinmispel.}

(Btachse außen kahl; Btstiele etwas flaumig; B. rundlich-eiförmig, spitz 0 . ausgerandet. Terbr.

integerrima. Med. Gemeine St.

Btachse u. Btstiele filzig; B. oval, abgerundet-stumpf. N. O. S. T. K. St. Kr.

tomentosa. (Ait.) Lindl. Filzige St.

\section{CYDONIA. Juss. Quitte.}

B. eiförmig, ganzrandig, unterseits filzig; Bt. grof, blassrosa. C'ult. u. verw.

vulgaris. Pers. Gemeine Q.

\section{PIRUS. L. Birnbaum.}

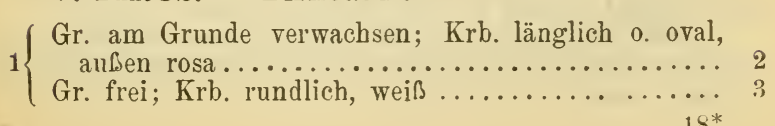


B. elliptisch, unterseits filzig; Btstiele u. Btachse außen dünnfilzig. Cult. u. verw.

B. fast rundlich, kahl, Bttiele fast rundlich, kahl; Btstiele u. Btachse kahl.
Verbr............silvestris. Mitl.*) Holzapfel.

B. ungefähr so làng als der Bstiel, eiförmig 0 . rundlich, gesägt, die ausgebildeten kahl; Fr. rundlich. Terbr.......Piraster. ( $\left.L^{* *}\right)$ Holzbirne.

B. länger als der Bstiel, wenigstens anfangs unterseits filzig, an der Spitze schwach-kleingesägt 0 .

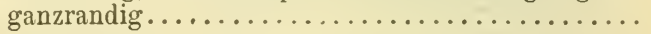

B. wenig länger als der Bstiel, eiförmig o. elliptisch, anfangs unterseits filzig, später fast kahl; Fr. in den Frstiel verschmälert. Verbr. (?)

Achras. Wallr. Schmalbirne.

B. 3-4 mal so lang als der Bstiel, unterseits dicht filzig; Fr. am Grunde abgestutzt............

B. länglich-lanzettlich, ihre Mittelrippe nicht drüsig; Fr. schmutziggrün, fast kugelig. $J$.

amygdaliformis. Vill. Mandelblättriger B.

5 B. verkehrt-eiförmig, nach unten keilig verschmälert, ihre Mittelrippe drüsig; Fr. gelblich, niedergedrücktkugelig, sehr spät reifend. $M . N$. K. (ob wild?) nivalis. Jacq.***) Schneebirne.

\section{SORBUS. L. Eberesche.}

$1\{$ B. gefiedert . . . . . . . . . . . . . . . .

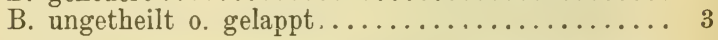

(Fr. meist birnförmig, gelb; Gr. 5; Bknospen kahl, klebrig. Verbr. (meist nur cult.)

domestica. $L$. Speierling. Fr. kugelig, roth; Gr. 3-5; Bknospen filzig. Verbr. aucuparia. L. Vogelbeerbaum.

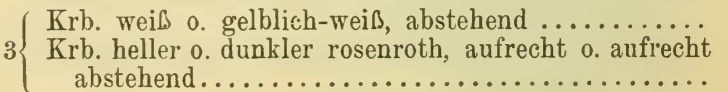

*) P. dasyphylla Borkh. ist ein wildwachsender Apfelbaum mit nahezu rundlichen, aber unterseits dünnfilzigen B.; er kommt in $M$., $N$. u. $K$. vor u. ist, sicher weiter verbreitet.

**) P. brachypoda Kern. hat schmälere u. längere, in der Jugend wollige $B$. und auffallend kurze Btstiele.

***) P. Austriaca Kern. (N.) hat breit elliptische, am Grunde nicht keilige B. u. in den Frstiel verschmälerte Fr. (Lederbirnen). 
B. zuletzt kahl, spitz gelappt, Lappen ungleicb gesägt, die unteren größer; Beeren lederbraun.

4 Verbr. (oft nur cult.)

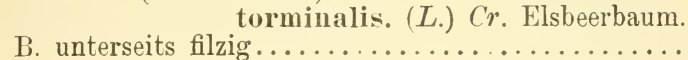

B. eingeschnitten-gelappt, unterseits dünn-grau- 0 . fast weiøfilzig ........................

B. eiförmig o. eiförmig-länglich, doppelt-gesägt, aber nicht deutlich gelappt, unterseits dicht weisfilzig. Verbr. (fehlt Sch.)

Aria. (L.) Cr. Gemeiner Mehlbeerbaum.

B. länglich-eiförmig, am Grunde abgerundet, meist mit 8 Seitennerven beiderseits, Lappen parallel, vorne abgerundet, durch den mittleren Zahn weichstachelspitzig; Kzipfel bei der Frreife abstehend. B. (Riesengeb.), sonst cult.

Suecica. (L.) Krok et Almq. Schwedischer Mehlbeerbaum.

B. oval o. eiförmig, gegen den Grund keilig-verschmälert, meist mit 10-11 Seitennerven beiderseits, Lappen weniger tief; Kzipfel bei der Frreife aufrecht o. einwärtsgebogen; Fr. kleiner. A. u. Vora. v. N. St.

Mougeoti. Soy Will. et Godr. AlpenMehlbeerbaum.

B. beiderseits kahl u. glänzend; Krbb. aufrecht, dunkelrosenroth. A. (fehlt $J$.)

Chamaemespilus. (L.) $\mathrm{Cr}$. Alpen-Zwergmispel. B. unterseits graufilzig; $K r b$. aufrecht abstehend, hellrosenroth. B. (Riesengeb.)

Sudetica. (Tausch.) Nym. Sudeten-Zwergmispel.

An merkung. Von Bastarten kommen im Gebiete wildwachsend vor: S. Aria $\times$ aucuparia, Aria $X$ torminalis, Aria $\times$ Chamaemespilus u. Chamaemespilus $X$ Mougeoti; cultivirt wird S. aucuparia $X$ Suecica.

\section{AMELANCHIER. Medic. Felsenbirne.}

B. oval, stumpf, anfangs unterseits filzig; Bt. weils, vor Entwicklung der B. erscheinend.

Verbr. (fehlt B. MI. Sch.)

ovalis. Medic. Gemeine F.

Anmerkung. In $B$. wurde A. Botryapium (Pers.) D C., durch länglich-elliptische, zugespitzte B. ausgezeichnet, verwildert gefunden. 


\section{MESPILCS. L. Mispel.}

B. lanzettlich, unterseits filzig; Bt. groß, weiß; Fr. braun. Südt. J. (sonst cult. u. verv.)

Germanica. L. Echte M.

\section{CRATAEGLS. L. Weißdorn.}

Junge Zweige filzig; B. 3-5spaltig; Btstiele u.

1 Btachsen außen filzig-zottig; Kzipfel 3 eckig.

Südt. $K r$.J. (verw.).....Azarolus. L. Azarole. Zweige kahl; Ḱzipfel lanzettlich u. eiförmig.......

B. 3-5 lappig; Btstiele kahl; Kzipfel eiförmig; Gr. $1-3$; Fr. meist oval, mit $1-3$ Steinkernen.

${ }_{2}$ Verbr......... Oxyacantha. $L$. Gemeiner W.

2 B. 3-5 spaltig; Btstiele meist behaart; Kzipfel lanzettlich; Gr. 1; Fr. meist fast kugelig, mit 1 Steinkern. Terbr. . monogyna. Jacq. Einsamige W.

Anmerkung. Der Bastart C. monogyna $X$ Oxyacantha ist nicht selten.

\section{RUBUS. L. Brombeere.}

Wehrlose Staude mit ungetheilten, herz-nierenförmigen, 5 lappigen B.; Bt. 2 häusig, einzeln; Krb. groß, weiß; Fr. orange. B. (Riesengeb.)

Cliamaemorus. $L$. Moltebeere.

B. getheilt, höchstens die obersten ungetheilt; Pfl. mehr 0 . weniger bestachelt; Bt. zwittrig, niemals (außer bei verkümmerten Pfl.) einzeln .........

Wenigstens einige Schösslingsb. unpaarig gefiedert; B. unterseits weiळfilzig (sehr selten grün); Krb., klein, aufrecht; Fr. roth. Tcrbr. u. hifg.

Ilaeus. $L$. Himbeere.

B. 3 zählig 0 . gefingert-5 zählig, selten 7 zählig, dann aber die 4 unteren Blättchen aus einem Punkte

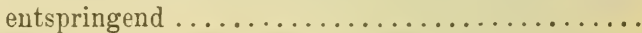

Staude mit peitschenförmigen, liegenden Schösslingen, welche im Herbste bis zum Grunde absterben; Btzweige daher grundständig; B. 3 zählig; Blättchen verkehrt-eiförmig, eingeschnitten gesägt, fein behaart, beiderseits grün; Fr roth. Verbr. (bes. A.) saxatilis. L. Felsenbeere.

Sträucher mit überwinternden Schösslingen, aus denen im zweiten Jahre die Btzweige entspringen; Fr. schwarz, manchmal blau bereift, im reifen $\mathrm{Zu}-$

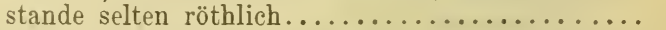

$4\{$ Die ganze Pfl. ohne Drüsenhaare........... 5

Drüsenhaare wenigstens im Btstande vorhanden ... 18 
Schösslinge aufrecht, kahl; B. beiderseits grün; Krb. grün, weib berandet; Stb. nach dem Verblühen in

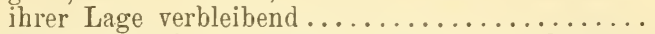

5 Schösslinge mehr 0 . weniger bogig, kahl o. behaart; B. unterseits meist mehr o. weniger filzig; $\mathrm{Kb}$. filzig; Stb. nach dem Verblühen zusammenneigend

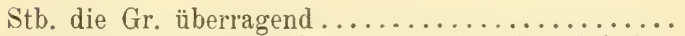
Stb. die Gr. nicht überragend; Bt. in einfachen

6 Trauben 0. Rispen; Blättchen oft gefaltet; Stacheln kräftig, herabgekrümmt. Verbr. (fehlt $K r$. J.)

plicatus. Wh. et $\lambda$. Gefaltete B.

Schösslinge mit kurzen, kegelförmigen, meist schwarzpurpurnen Stacheln bewehrt, ihre B. 5-7zählig, die untersten Bättchen sitzend; Fr. schwarzpurpurn. Verbr. (fehlt J.)

Nessensis. Hall. Aufrechte B. Schösslinge mit kräftigen Stacheln bewehrt, ihre B. 5 zählig, die untersten Blättchen deutlich gestielt; Fr. schwarz. Verbr. (fehlt J.) sulcatus. Vest. Gefurchte B.

$8\{$ Schösslinge dicht bereift $\ldots \ldots \ldots \ldots \ldots \ldots \ldots \ldots$

Schösslinge nicht bereift ................ 10

(Schösslingsb. unterseits angedrückt weißfilzig; Krb. lebhaft rosenroth; Stb. die Gr. nicht überragend. Siidt. Kr.J.

ulmifolius. Schott. Ulmenblättrige B. Schösslingsb. unterseits graufilzig; Krb. weiß; Stb. die Gr. überragend. (II.?) $N$.

rorulentus. Hal. Bereifte B.

Stb. die Gr. überragend............... 11

Stb. die Gr. nicht überragend; Bt. lebhaft rosen10 roth; Btstand dicht zottig; Schösslingsb. unterseits weinfilzig, auferdem beiderseits seidig schimmernd, mit fast kreisrundem Endblättchen. $J$. carpinetorum. Freyn. Buchenhain-B.

Stacheln des Btstandes zahlreich, lang, gerade o. nur etwas gebogen; Btstand abstehend behaart...... 12 Stacheln des Btstandes spärlich, seltener zahlreich, dann aber sichelig gekrümmt 0 , hakenförmig ... 13 
B unterseits wei@filzig, 3 zählig 0 . fußförmig-5 zählig; Btstand abstehend behaart; Bt. rosa. Verbr.

bifrons. Vest. Zweifarbige B.

12 Ausgebildete B. beiderseits grün 0 . unterseits höchstens dünn graufilzig, 3 zählig 0 . gefingert-5 zählig; Bt. blassrosa o. weiß. B. M. Sch. N.

villicanlis. Köhl.*) Zottige $\mathrm{B}$.

( Schösslingsb. unterseits dicht grau- o. weißfilzig...

13 Schösslingsb. unterseits grïn 0 . höchstens durch dünnen

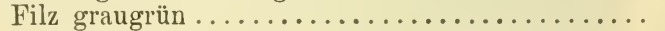

Schösslinge kahl o. zerstreut behaart......... 15

Schösslinge dicht abstehend behaart, ihre B. ge-

14 fingert-5 zählig; Btstand sehr reichblütig, mit zerstreut stehenden, hakigen Stacheln bewehrt; Bt. weiß. J. ...myrianthus. Freyn. Reichblütige B.

Endblättchen der Schösslingsb. breit elliptisch 0 . rundlich; Btstand mit kräftigen, sichelig gekrümmten Stacheln bewehrt, mit an der Spitze der Aeste gehäuften, meist hellrosa gefärbten Bt. Ver.br. (fehlt Sch.)

macrostemon. Focke. Derbstachelige B. Endblättchen der Schösslingsb. elliptisch o. eiförmig; Btstand mit wenigen, schwachen Stacheln, schmal u. locker; Bt. nicht gedrängt stehend, weiß 0. hellrosa. Verbr... montanns. Libert. $\left.{ }^{* *}\right)$ Berg-B.

Frkn. wenigstens an der Spitze behaart.........

Frkn. kahl; Btstand locker, mit wenigen schwachen Stacheln; Schösslingsb. 5 zählig, mit großen, beiderseits grünen Blättchen, deren endständiges eiförmig u. lang zugespitzt ist. Sch. M. N. O. St. macrophyllus. IVh. et $N$.***) Großblättrige B.

Endblättchen der Schösslingsb. breit herz-eiförmig o. rundlich; Bt. weiß o. hellrosa, mit grünlichen Stf. u. Gr. M. N. O. S. St. K. $K r$.

Vestii. Focke. Vest's B.

Endblättchen der Schösslingsb. verkehrt-eiförmig; Bt. rosenroth, mit hellpurpurnen Stf. u. Gr. T. S. persicinus. Kern. Pfirsichblütige $B$.

*) R. Kelleri Hal. (N.) zeichnet sich durch das am Grunde herzförmige Endblättchen der Schösslingsb., sowie durch den bis zur Spitze durchblätterten Btstand aus.

**) Eine sehr veränderliche Art!

***) R. Schlechtendalii Wh. ( $N$.) hat verkelırt-eiförmige, kurz bespitzte $B$. 
Nebenb. schmal, lineal o. fast fadenförmig ; Schösslinge bei den meisten Arten nicht bereift........... Nebenb. lineal-lanzettlich o. lanzettlich; B. 3 zählig 19 0 5 zählig, in letzterem Falle die 2 untersten Blättchen sitzend; Schösslinge meist mehro. weniger

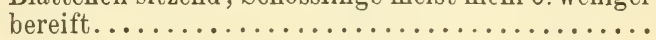

Bstiel oberseits deutlich rinnig; Schösslingsb. 3zählig o. fußförmig 5 zählig, oberseits sternhaarig-graufilzig o. auch fast kahl, unterseits weibfilzig, ihr Endblättchen rautenförmig, am Grunde keilig,

19 vorne ungleich eingeschnitten-gesägt; Bt. klein, gelblich-weiß, selten rosa überlaufen. Verbr.

tomentosus. Borlih. Filzige B. Bstiel oberseits flach 0 . nur am Grunde etwas rinnig; B. oberseits nicht sternhaarig; Bt. weiß o. rosa.

Schösslinge mehr o. weniger kantig, seltener rundlich, mit ziemlich gleichartigen größeren Stacheln, zwischen welchen auch kleine Stachelchen, Borsten und Drüsenhaare vorkommen können; Drüsenhaare des Btstandes zerstreut o. reichlich, aber nicht wesentlich länger als die Haare 0. als der Querdurchmesser der Btstiele .................

Schösslinge rundlich, seltener kantig, reichlich mit größeren und kleineren Stacheln, Borsten und Drüsenhaaren bekleidet; Drüsenhaare des Btstandes reichlich, die meisten länger als die Haare und als der Querdurchmesser der Btstiele..........

Schösslinge dicht rauhhaarig, außerdem bestachelt und mehr o. weniger reichlich drüsenhaarig; $B$. unterseits filzig i. außerdem durch längere Haare sammtig schimmernd und weich anzufühlen.... 22 Schösslinge mehr 0 . weniger behaart, selten ganz kahl, stets bestachelt, mit 0 . obne Drüsenhaare; B. unterseits bald grün, bald grau- 0. selbst weibfilzig, aber nicht sammtig weich ............

${ }_{22}\{$ Frkn. dicht behaart o. filzig-zottig .......... 23

Frkn. kahl o. nur spärlich behaart.......... 25

Stb. die Griffel überragend; Bt. weis; Btstand durchblättert, dicht bestachelt; Schösslinge stumpfkantig, 23 nicht bereift, ihre B. 3 zählig, mit rundlich-eiförmigem Endblättchen. $N$.

vestitifolius. Fritsch. Sammtigblättrige B. Stb. die Griffel nicht überragend............ 24 
( Schösslinge etwas bereift, mit gleichartigen, rückwärts geneigten Stacheln und wenigen Drüsenhaaren; Btstand spärlich mit geraden Stacheln bewehrt; Bt. weiß; Gr. grünlich. T.

Gremblichii. Hal. Gremblich's B.

Schösslinge nicht bereift, mit ungleichen geraden Stacheln und zahlreichen Drüsenhaaren; Btstand reichlich bestachelt; Bt. weiß o. röthlich; Gr. röthlich. N.....fuscidulus. Hal. Röthliche B.

Schösslinge bereift, mit sicheligen Stacheln bewehrt, das Endblättchen ihrer B. herzeiförmig, lang zugespitzt; Btstand umfangreich, mit gelben, hakigen 25 Stacheln bewehrt; Bt. weiß; Stb. die Griffel nicht überragend. N... Halácsyi. Borb.*) Halácsy's B. Schösslinge nicht bereift; Stb. die Griffel mehr 0. weniger deutlich überragend.

Kräftigere Arten, deren Kb. nach dem Verblühen

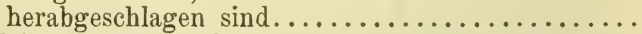
Kleine Art mit niederliegenden, schwach bestachelten

26 Schösslingen, deren B. ein verkehrteiförmiges 0. fast rundliches Endblättchen haben; $K \mathrm{~b}$. nach dem Verblühen abștehend; Bt. weiß. T. S.

teretiusculus. Kaltenb. Rundstenglige B.

Endblättchen der Schösslingsb. fast kreisrund; Schöss${ }_{27} \begin{aligned} & \text { linge mit geraden Stacheln bewehrt; Btstand } \\ & \text { zottig; Bt. Weil o. röthlich. N. O. St. K. T. }\end{aligned}$

leucostachys. Schleich. Weichblättrige B. Endblättchen der Schösslingsb, elliptisch o. eiförmig 28

Schösslinge spärlich drüsig, ihre B. oberseits etwas behaart, mit kurz bespitztem Endblättchen; Btstand mit kräftigen Stacheln und wenigen Drüsenhaaren. $N$.

28 pyramidalis. Kalteub. Pyramidenförmige B. Schösslinge reichlich drüsig, ihre B. oberseits kahl, lang zugespitzt; Btstand reichlich mit feinen Stacheln und kurzen Drüsenhaaren besetzt. $T$. dasyclados. Ker $n$. Behaartstenglige $B$.

$29\left\{\begin{array}{l}\text { Stb. die Griffel überragend o. doch erreichend...... } \\ \text { Stb. deutlich kürzer als das Frknköpfehen sammt }\end{array}\right.$ 30 den Griffeln; Bt. weiß ................ 52

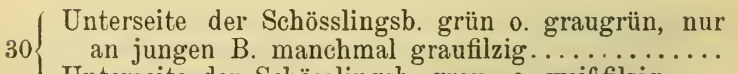
27 
Schösslinge mit ziemlich gleichförmigen größeren Stacheln besetzt, zwischen welchen keine o. nur zerstrente Drüsenhaare und Borsten vorkommen 32

Schösslinge mit ziemlich gleichförmigen größeren Stacheln bewehrt und außerdem von zahlreichen kleinen Borsten und Drüsenhaaren rauh ....... 38

$32\left\{\begin{array}{l}\text { Stb. die Griffel überragend ..................... } \\ \text { Stb. die Griffel erreichend, aber nicht deutlich über- }\end{array}\right.$ 33

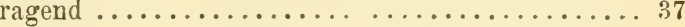

(Endblättchen der Schösslingsb. breit herzeiförmig 0. fast rundlich. .

Endblättchen der Schösslingsb. elliptisch o. eilänglich 36 Blättchen oberseits fast kahl, unterseits durch dichte Behaarung graugrün; Btstand locker, nach unten verbreitert und daselbst durchblättert; Frkn. behaart. N........ quadicus. Sabr. Quaden-B. Blättchen oberseits striegelhaarig 0 . fast kahl, unterseits an den Nerven behaart, beiderseits grün; Frkn. kahl o. spärlich behaart............ 35

Schösslingsb. fußförmig-5̌ zählig; Blättchen oberseits fast kahl, unterseits an den Nerven spärlich behaart; Btstand verlängert, unten durchblättert, nur oben gedrungen. Verbr. (fehlt $T$. K $r$. J.)

Gremlii. Focke. Gremli's B.

Schösslingsb. gefingert-5 zählig; Blättchen oberseits striegelhaarig, unterseits auf den Nerven weichhaarig; Btstand schmal, gedrungen. B. $M$.

Silesiacus. Wh. Schlesische B.

Schösslinge fast kahl; Btstand kul'z, armblütig, oft einfach traubig, mit kleinen, hakigen Stacheln bewehrt; Frkn. kahl N. St. $K$.

Styriacus. Hal. Steierische B.

Schösslinge behaart; Btstand umfangreich, locker, durchblättert, mit kurzen, geraden Stacheln bewehrt; Frkn. etwas behaart. $N$.

Beckii. Hal. Beck's B.

Schösslinge abstehend behaart, nicht bereift, ihre B. oberseits etwas striegelhaarig, unterseits nur auf den Nerven behaart, mit elliptischem Endblättchen; Btstand bis zur Spitze durchblättert; Krb. länglich, grünlich-weiß; Frkn. kahl. $B$.

chlorothyrsos. Focke. Durchblätterte B. Schösslinge kahl o. etwas behaart, schwach bereift, ihre B. oberseits kahl, unterseits dicht weichhaarig, mit breit eiförmigem Endblättchen; Btstand nur unten durchblättert; Krb. rundlich-elliptisch, weiß; Frkn. meist behaart. $O . N$.

epipsilos. Focke. Kahlblättrige B. 
Endblättchen der Schösslingsb. am Grunde herzförmig

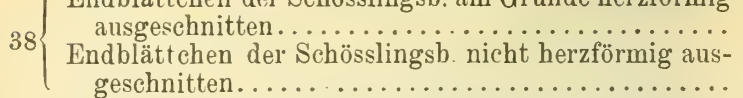

Kb. nach dem Verblühen abstehend 0 . aufgerichtet 40

Kb. nach dem Verblühen zurückgeschlagen; Btstand

39 verlängert, unten durchblättert; Schösslingsb. fußförmig 5 zählig, mit fast kahlen Blättchen.

B. M. N. O. St. K... Clusii. Borb. Clusius' B.

Schösslinge fast kahl, etwas bereift; Btstand mit feinen Stacheln u. ungleich langen Drüsenhaaren

40 reichlich besetzt; Krb. weiß; Stb. die Gr. etwas überragend; Frkn. behaart. B. $M$.

thyrsiflorus. Wh. et $N$. Straußblütige B.

Schösslinge reichlich behaart ...............

Schösslinge bereift, mit gefingert- 5 zähligen $B$, deren Endblättchen kurz bespitzt ist; Btstand breit, reichblütig; Krb. u. Stb. meist hellrosa, letztere die Gr. überragend. $N$.

Joannis. Beck. Johannes-B.

Schösslinge nicht bereift, mit fußförmig-5 zähligen B., deren Endblättchen lang zugespitzt ist; Btstand schmal; Krb. weiß; Stb. die Gr. nicht überragend. M............ Moravicus. Sabr. Mährische B.

Schösslinge kahl o. fast kahl; Btstand sparrig ausgebreitet, angedrückt-filzig; Krb. schmal u. klein, blassrosa; Frkn. kahl. S. O. N.

rudis. Wh. et $N$. Rauhe B.

Schösslinge behaart; Btstand verlängert, rauhhaarigfilzig; Krb. elliptisch, weiß; Frkn. etwas behaart. B. U. N. Südt.

foliosus. Wh. et $N$. Reichblättrige B.

$43\{$ Stb. die Gr. überragend.

Stb. die Gr. erreichend, aber nicht überragend ....

Schösslinge ohne Drüsenhaare, nur mit gleichartigen kräftigen Stacheln besetzt, ihre B. 5zählig, mit gefalteten Blättchen; Btstand reichlich bestachelt, aber sehr arm an Drüsenhaaren; Bt. weiß.

B. M. N...senticosus. Köhl. Dichtstachelige B.

Schösslinge außer den großen Stacheln wenigstens mit zerstreuten Drüsenhaaren, oft auch mit Borsten

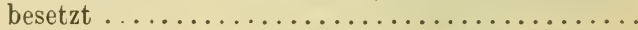

Endblättchen der Schösslingsb. breit-eiförmig 0 . fast kreisrund, kurz bespitzt; Drüsenhaare am Schöss-

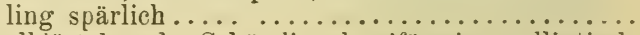

Endblättchen der Schösslingsb. eiförmig o. elliptisch, lang zugespitzt; Drüsenhaare u. Borsten am Schössling mehr 0 . minder reichlich vorhallden ...... 
Schösslinge etwas bereift, das Endblättchen ihrer B. breit-eiförmig o. rundlich; Btstand umfangreich, sparrig; Krb. klein, elliptisch, lebhaft rosenroth; Stb. purpurn; Frkn. behaart. N.

Ceticus. Hal. Cetische B. Schösslinge nicht bereift, das Endblättchen ihrer B. herzförmig; Btstand schmal, mit sparrig abstehenden Aesten; Krb. ziemlich groß, blassrosa; Stb. grünlich; Frkn. wenig behaart. T. S. N. $M$. Caflischii. Focke.*) Caflisch'B.

Endblättchen der Schösslingsb. am Grunde herzförmig; Kb. nach dem Verblühen abstehend; Stb. nach dem Verblühen purpurn. $K$.

Carinthiacus. Hal. Kärntner B.

Endblättchen der Schösslingsb. am Grunde abgestutzt; Kb. nach dem Verblühen zurückgeschlagen; Stb. grünlich. B. M. N. O. S. T.

Radula. W' $h$. Feilen-B.

Schösslinge bereift, mit fußförmig- 5 zähligen B., deren Endblättchen herzeiförmig $u$. lang zugespitzt ist; 48 Btstand schmal; Bt. rosenroth; Stb. grünlich; Frkn. behaart. $N$. inaequalis. Hal. Ungleiche B.

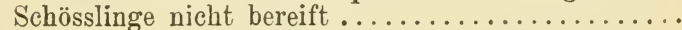

Frkn. kahl o. wenig behaart............. 50

Frkn. zottig behaart; Stb. grünlich; Schösslinge kriechend, etwas behaart, mit zahlreichen zurückgebogenen Stacheln bewehrt, das Endblättchen ihrer B. elliptisch 0 . eiförmig, kurz bespitzt, am Grunde abgerundet. $N$.

Grossbaueri. Beck. Grossbauer's B.

Krb. weiß; Btstand schmal, verlängert ........ 51

Krb. rosenroth, klein; Btstand nach unten pyramidal verbreitert; Schösslinge niederliegend, fast rundlich, mit 3 zähligen 0 . fußförmig-5 zähligen B., deren Endblättchen breit elliptisch 0 . rundlich ist. $S$. $O$. Salisburgensis. Focke. Salzburger B.

*) Die in $N$. wachsende Pflanze ist durch schwache Bestachelung ausgezeichnet (R. Breyninus Beck). In $S$. wächst der durch Kleinheit aller Theile und röthliche Stb. u. Gr. ausgezeichnete R. thelybatos Focke. 
Schösslinge niederliegend, an Drüsenhaaren arm; Kb. nach dem Verblühen herabgeschlagen; Stb. grünlich; Frkn. kahl. N. (O.?)

pseudomelanoxylon. Hal. Rothbraune B.

51 Schösslinge ziemlich reichlich mit Drüsenhaaren u.

Borsten besetzt; Kb. nach dem Verblühen abstehend, zuletzt aufgerichtet; Stb. rötblich; Frkn. etwas behaart. $T$. N.

denticulatus. Kern. Gezähnelte B.

$52\{$ Schösslinge bereift.

Schösslinge nicht ber.

Schösslinge mit kräftigen Stacheln und zerstreuten Drüsenhaaren besetzt, das Endblättchen ihrer B. breit herzeiförmig 0 . rundlich-eiförmig; Btstand schmal; Krb. klein, verkehrt-eiförmig. $N$.

orthosepalus. Hal Semmering-B.

53 Schösslinge reichlich mit Stacheln, Borsten $u$. Drüsenhaaren besetzt, das Endblättchen ihrer B. breitelliptisch; Btstand nach unten verbreitert; Krb. groß, elliptisch. $N$.

macrocalyx. Hal. Großkelchige B

Btstand umfangreich, mit langen, vielblütigen Aesten; $\mathrm{Kb}$. nach dem Verblühen abstehend; Frkn. filzig behaart. $N$...amplus. Fritsch. Umfangreiche B. Btstand schmal, mit sehr kurzen Aesten; Kb. nach dem Verblühen herabgeschlagen; Frkn. kahl. N.St. brachystemon. Heimerl. Kurzfädige B.

Stb. die Griffel überragend o. doch erreichend..... 56

55 Stb. bedeutend kürzer als das Frknköpfchen sammt den Griffeln; Bt. weiß ..................

Schösslinge mit sehr ungleichen Stacheln bewehrt, deren größere kräftig und am Grunde verbreitert sind.

Schösslinge mit ungleichen, aber durchwegs schwachen, pfriemlichen 0 . nadelförmigen Stacheln bekleidet;

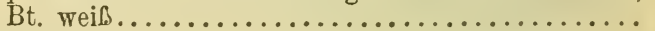

$57\{$ Stb. die Griffel deutlich überragend; Bt. weiß.....58 Stb. die Griffel erreichend, aber nicht überragend . 63

$\mathrm{Kb}$. stets zurückgeschlagen, graufilzig u. drüsenborstig; Btstand locker, meist durchblättert; Schösslinge nicht bereift, spärlich behaart, mit fußförmig-5 zähligen B. Sch. M. B. N. O. T.

Koehleri. Wh. et $N$. Köhler's $B$.

$\mathrm{Kb}$. nach dem Verblühen abstehend 0 . aufgerichtet, zuletzt manchınal wieder zurückgeschlagen ...... 
Btstand locker, kurz, fast anliegend behaart, mit wenigen langen Drüsenhaaren und feinen Nadelstacheln an den sehr verlängerten Btstielen; Schöss-

59 linge spärlich behaart, mit 3 zähligen, glänzenden, wenig behaarten B. $N$.

Richteri. Hal. Richter's B. Btstand abstehend behaart o. filzig, mit zahlreichen Drüsenhaaren und Stachelborsten besetzt ...... 60

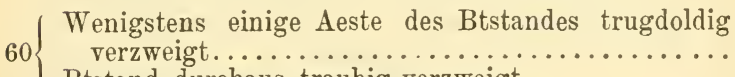
61

Btstand durchaus traubig-verzweigt ............ 62

Schösslinge abstehend behaart, das Endblättchen ihrer B. breit-elliptisch, am Grunde abgerundet; Btstand kurz, oben dicht gedrängt. $M . N$. O.

apricus. Wimm. Holzschlag-B.

Schösslinge sehr spärlich behaart, das Endblättchen ihrer B. herzeiförmig; Btstand locker, verlängert, bis zur Spitze durchblättert. $N$.

foliolatus. Hal. Payerbacher B.

Schösslinge etwas bereift, mit beiderseits behaarten B., deren Endblättchen verkehrt-eiförmig und an dem verschmälerten Grunde abgestutzt ist; Btstiele mit wenigen langen und zahlreichen kurzen Drüsenhaaren bekleidet. Sch. M. B. N. O. K. T.

Schleicheri. Wh. Schleicher's B.

Schösslinge nicht bereift, mit derben, wenig behaarten B., deren Endblättchen elliptisch o. eiförmig und am Grunde seicht herzförmig ist; Btstiele dicht mit langen Drüsenhaaren bekleidet. M. N. St. O. S. T.

subacnleatus. Beck. Kleinstachelige B.

Kb. nach dem Verblühen aufgerichtet .........6 64

$\mathrm{Kb}$. stets zurückgeschlagen, zottig-filzig $\mathrm{u}$. mit rothen

63 Drüsenhaaren besetzt; Btstand oben dichtblütig, abstehend zottig u. rothdrüsig; Schösslinge abstehend behaart, mit 3 zähligen B. $N$.

Caroli. Beck. Carl's B.

Schösslinge etwas bereift, an Drüsenhaaren arm, ihre B. unterseits meist etwas graufilzig; $\mathrm{Kb}$. nach dem Verblühen nicht auffallend verlängert; $K r b$. verkehrt-eiförmig, rosa. $N$.

pilocarpus. Gremli. Behaartfrüchtige B.

Schösslinge nicht bereift, reichlich drüsenhaarig, ihre B. beiderseits grün; Kb. nach dem Verblühen sehr verlängert; Krb. elliptisch, weiß. $N$. glottocalyx. Beck. Langzipfelige B 
(Endblättchen der Schösslingsb. mit schmaler, plötz-

65 lich aufgesetzter Spitze..............66 66

Endblättchen der Schösslingsb. allmälig zugespitzt. 68

Schösslinge bereift................. 67

Schösslinge nicht bereift, spärlich behaart, aber dicht rothdrüsig, ihre B. 3 zählig, beiderseits grün, mit rundlich-herzförmigem Endblättchen; Btstiele durch dicht stehende Borsten u. Drüsenhaare violettroth; Krb. eiförmig, weiß; Stb. die am Grunde röthlichen Gr. nicht überragend. $K$.

Wittingii. Hal. Witting's B.

Schösslinge etwas behaart, mit meist 3 zähligen B., deren Endblättchen elliptisch und am Grunde abgerundet o. seicht ausgerandet ist; Btstand kurz, locker, mit 1-3 blütigen Aesten.

Verbr. (fehlt St. $K r$. J.)

Bellardii. Wh. et $N$. Drüsige $\mathrm{B}$.

Schösslinge kahl, mit fußförmig-5 zähligen B., deren Endblättchen breit elliptisch 0 . fast rundlich und am Grunde herzförmig ausgeschnitten ist; Btstand umfangreich, durchblättert, mit vielblütigen Aesten. N. ........Vindobonensis. Sabr. Wiener B.

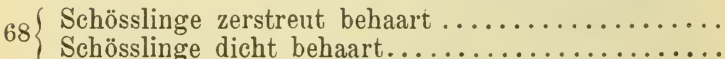

Frkn. filzig-kurzhaarig; Btstand verlängert, locker 0. oben gedrungen .................. 70

Frkn. kahl; Btstand kurz, einfach traubig o. rispig; Schösslinge bereift, mit beiderseits grünen $\mathrm{B}$. $M$. N. O. K. T...serpens. Wh. Kriechende B.

Schösslinge etwas bereift; Kzipfel nach dem Verblühen abstehend o. aufgerichtet; Stb. die Gr. wenig überragend. M. N. O.T.

rivularis. $P$. J. Müll. Ufer-B.

Schösslinge nicht bereift; Kzipfel stets zurïckgeschlagen; Stb. die Gr. weit überragend. St.

Preissmanni. Hal. Preissmann's B.

Schösslinge dicht mit Drüsenhaaren besetzt......

Schösslinge an Drüsenhaaren arm, mit meist 3 zähligen, beiderseits grünen B.; Btstand mit 2-4 von einander entfernten, aus der Achsel großer 3 zähliger B. entspringenden, armblütigen Aesten; Stb. die Gr. weit überragend. $B$.

tectiflorus. Hal. Bedecktblütige B. 
Aeste des Btstandes dicht mit langen, violettrothen Drüsenhaaren und Borsten besetzt; Schösslingsb. oberseits dunkelgrün, unterseits blassgrün. Verbr.

hirtus. WK. Rauhstenglige $B$.

72 Aeste des Btstandes mit gelblichen Nadelstacheln und röthlichen Drüsenhaaren bekleidet; Schösslingsb. graugrün, unterseits durch dichte Behaarung grauschimmernd 0 . fast graufilzig. N. $K$.

lamprophyllus. Gremli. Glänzendblättrige B.

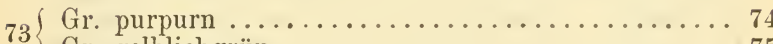

Gr. gelblichgrün................... 75

Frkn. kahl o. spärlich behaart; Schösslingsb. beiderseits anliegend behaart. Verbr. (fehlt $K r$. J.)

Guentheri. Wh. et $\Lambda$. Günther's B.

Frkn. filzig; Schösslingsb. beiderseits behaart, unterseits seidig schimmernd. B. N. St. K. S.

polyacanthus. Gremli. Reichstachelige B.

Schösslinge dicht behaart.............. 76

Schösslinge wenig behaart; Btstand kurz behaart $u$. mit kurzen Nadelstacheln u. zahlreichen hellen, seltener dunkelrothen Drüsenhaaren bekleidet; Kb. mit grünlichen o. rothen Drüsenhaaren.

Verbr. (fehlt $K r$.J.) Bayeri. Focke. Bayer's B.

Frkn. spärlich behaart 0 . kahl; Kb. wegen dichter Bekleidung mit Drüsenhaaren $u$. Borsten violettroth; Btstand dünnfilzig u. dicht mit langen violettrothen Borsten und Drüsenhaaren bekleidet.

B. $M . N$.

erythrostachys. Sabr.*) Rothrispige B. Frkn. filzig; Kb. grangrün, filzig und mit hellen Drüsenhaaren bekleidet; Btstand filzig, mit kurzen Nadelstacheln $u$. zahlreichen hellen Drüsenhaaren besetzt. $M$. N. K. S.

brachyandrus. Gremli. Kleine B.

Nebenb. breit lanzettlich, fast blattartig; Fr. blau bereift, nicht glänzend; Schösslinge stielrund, bereift, schwach bestachelt und mehr 0 weniger drüsig; alle B. 3 zäblig. Verbr. $u$. $h \mathrm{fg}$.

caesius. I,. Bereifte B.

Nebenb. lineal-lanzettlich; Fr. zwar oft glanzlos, aber nicht bereift; B. 3-5 zählig ...........

*) R. tardiflorus Focke $\left(\Lambda^{\top}\right.$.) ist durch lang zugespitzte, unterseits in der Jugend filzige B. und kurze, armblütigc Btstände ausgezeichnet. 
Schösslinge u. Btstand reich an Drüsenhaaren, erstere meist schwach u. rundlich, seltener stumpfkantig, mit geraden, pfriemlichen Stacheln; Bt. weiß....

Schösslinge stumpfkantig o. rundlich, meist kräftig, mit ziemlich großen, am Grunde oft verbreiterten Stacheln bewehrt, an Drüsenhaaren arm o. ganz drüsenlos; Btstand meist nur spärlich drüsig; Bt. weib o. rosa; Frkn. kahl. Verbr.

dumetorum. Wh. Hain-B.

Kb. an der Fr. abstehend, graufilzig u. dicht drüsenhaarig; Schösslinge kräftig bestachelt, stumpfkantig, mit 3-5 zähligen, unterseits weichhaarigen

79 B., deren Endblättchen fast rundlich u. kurz bespitzt ist. $B . M$. (K.?)

orthacanthus. Wimm. Geradstachelige B.

Kb. an der Fr. aufgerichtet ................

80 Schösslingsb. wenigstens anfangs unterseits graufilzig

Schösslingsb. beiderseits grün..............

Frkn. filzig; Stb. die Gr. nicht überragend; Schösslinge dicht ranhhaarig, nicht bereift, mit 3 zähligen 0 . doch nicht vollkommen 5 zähligen B. $N$. subsessilis. Hal. Kahlenberg-B.

Frkn. kahl; Stb. die Gr. etwas überragend; Schösslinge wenig behaart $\ldots \ldots \ldots \ldots \ldots \ldots \ldots \ldots$

Schösslinge ziemlich kräftig, bereift, mit $3-5$ zähligen B., deren Endblättchen rundlich und kmrz bespitzt ist. $M I$. . . fossicola. Holuby. Graben-B. Schösslinge dünn, nicht bereift, mit 3 zähligen $B$., deren Endblättchen eirautenförmig und spitz ist. N...........Heimerlii. Hal. Heimerl's B.

Stb. die Gr. entschieden überragend; Schösslinge mit zahlreichen langen Borsten und Drüsenhaaren bekleidet, mit 3-5 zähligen B., deren Endblättchen rundlich 0 . breit eiförmig ist. Sch. M. B. N. O.

oreogeton. Focke. Vorgebirgs-B.

Stb. die Gr. nicht 0. kaum merklich überragend; Schösslinge mit kurzen, nicht sehr zahlreichen Drüsenhaaren besetzt ................ 84

Endblättchen der 3-5zähligen Schösslingsb. eiherzförmig 0. eirautenförmig; Btstand rispig, kurz, eiförmig, ziemlich gedrungen. T. $K$. St.

Ebneri. Kern. Ebner's B.

Endblättchen der 3 zähligen Schösslingsb. elliptisch o. eiförmig, am Grunde abgerundet; Btstand fast einfach traubig, klein, armblütig. $N$.

pseudopsis. Gremli. Kleinste B.

A n m erkung. Mit den vorstehend angeführten zahlreichen Rubus-Arten ist der Formenreichthum 
der Gattung im Gebiete noch lange nicht erschöpft. Aus manchen Kronländern (z. B. Krain) ist über die dort vorkommenden Rubus-Arten sehr wenig bekannt und die genauere Erforschung solcher Gegenden wird gewiss noch viele neue Formen zu Tage fördern, sowie die Kenntniss von der Verbreitung der bereits bekannten erweitern. Einige Arten, deren Vorkommen im Gebiete noch nicht ganz sichergestellt ist, wurden nicht berücksichtigt. - Bastarte sind nicht selten, jedoch oft schwer zu erkennen, da viele Arten auch durch nicht hybride Zwischenformen miteinander verbunden sind. Es ist sehr wahrscheinlich, dass mehrere der oben angeführten Arten selbst nur Bastarte sind. Mit Sicherheit oder großer Wahrscheinlichkeit wurde das Vorkommen folgender Bastarte im Gebiete nachgewiesen: $R$. caesius $X$ Idaeus, sulcatus $X$ ulmifolius, montanus $X$ sulcatus, tomentosus $\times$ ulmifolius, caesius $X$ ulmifolius, caesius $X$ rorulentus, carpinetorum $X$ tomentosus, bifrons $X$ montanus, bifrons $X$ tomentosus, bifrons $X$ leucostachys, bifrons $X$ Clusii, macrostemon $\times$ tomentosus, Gremlii $X$ macrostemon, caesius $X$ macrostemon, montanus $X$ tomentosus, lencostachys $X$ montanus, Gremlii $\times$ montanus, Clusii $\times$ montanus, hirtus $X$ montanus, caesius $X$ montanus, caesius $X$ Vestii, hirtus $X$ tomentosus, lamprophyllus $X$ tomentosus, oreogeton $X$ tomentosus, caesius $X$ tomentosus, caesius $\chi$ Halácsyi, hirtus $X$ leucostachys, Gremiii $X$ hirtus. In $N$. wurde auch ein Bastart zwischen 3 Arten ('Tripelbastart), nämlich R. caesius $\times$ leucostachys $X$ tomentosus, gefunden.

\section{FRAGARIA. L. Erdbeere.}

Frkelch angedrückt; Blättchen sehr kurz gestielt, beiderseits flaumig; Bt. vielehig. Verbr.

collina. Ehr $h$. Hügel-E.

Frkelch wagrecht-abstehend 0 . zurückgeschlagen ...

Haare der seitenständigen Btstiele aufrecht 0 . angedrückt; Bt. zwittrig. Verbr. u. hfg.

2 vesca. $L$. Wald-E.

Haare aller Btstiele wagrecht-abstehend; Bt. vielehig; Pfl. kräftiger. Vurbr.

elatior. Ehrh: Garten-E.

Anmerkung. Alle 3 Arten bilden untereinander Bastarte.

XII. Potentilla. L. Fingerkrant.

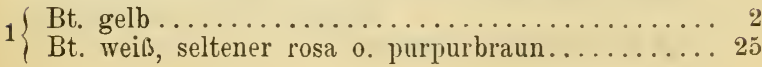


Kräuter; Wz. einfach, einen o. mehrere Stg. treibend Wst. holzig, vielköpfig, blühende Stg. u. unfruchtbare, erst im folgenden Jahre blühende Stämmchen treibend

B gefiedert, Blättchen länglich, die oberen herablaufend; Bt. einzeln; Stg. u. B. flaumig.

B. M. Sch. N. O. S. T. supina. L. Niedriges F.

3 Stgb. 3 zählig; Grundb. oft $2-3$ paarig - gefiedert; die oberen Bt. zuletzt fast traubig; Haare des Stg. u. der B. abstehend. B. MI. Sclı. N. St. S. S'̈̈̈dt. Norvegica. L. Norwegisches F.

B. vielpaarig unterbrochen gefiedert; Blättchen länglich, scharf gesägt, unterseits (manchmal auch 4 oberseits) weiß)-seidenhaarig; Stg. kriechend; Bt. einzeln. Verbr. u. lıfg.... anserina. L. Gänse-F.

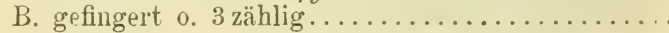

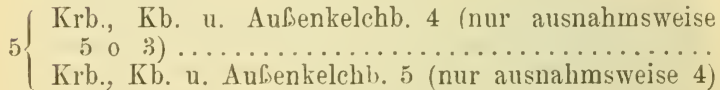

Stg. an den Gelenken wurzelnd; Stgb. gestielt; Blättchen verkehrt-eiförmig; Nebenb. ganzrandig o. 2bis 3 zähnig. B. II. Sch.

procumbens. Sibth. Niederliegendes F. Stg. nicht wurzelnd; Stgb. sitzend o. kurz gestielt; Blättchen länglich-lanzettlich, die der unteren B. verkehrt-eiförmig; Nebenb. 3-vielspaltig.

Terbr. u. hfg....erecta. (L.) Hampe. Blutwurz.

7 B. 3 zählig ; Stg. armblütig, oft 1 blütig.........

B. 5-7(-9) zählig, oft mit 3 zähligen gemischt.... 12

Blättchen unterseits matt-schneeweif-filzig, glanzlos, 8 eingeschnitten-gesägt; Stg. aufrecht, armblïtig.

A. v. T. S. K...... nivea. L. Schneeweißes F. Blättchen graufilzig 0 . ganz ohne Filz..........

Blättchen, Bstiele u. Stg graufilzig; Stämmchen gestreckt, oft wurzelnd. (B. $N$. ?) $K r$. J.

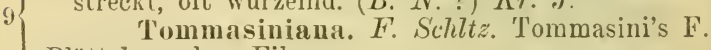

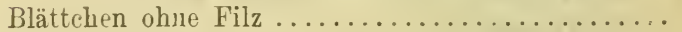

Sehr zottig; Blättchen stumpf gezähnt, verkehrteiförmig, die Zähne am Rande sich deckend; Stg. $10\{$ meist 1 blütig. A. v. T. S. K. St.

frigida. Till. Gletscher-F. 
Stg. aufrecht, 3-7blütig, kurzhaarig, Haare wagrecht-abstehend; Blättchen oberseits flaumig, unterseits zottig. A. v. T. S. St. $K r$. grandiflora. L. Großblütiges F. Stg. aufstrebend, flaumig, meist 1 blütig; Blättchen am Rande und unterseits auf den Adern behaart, sonst kahl. A. .....minima. Hall. Kleinstes F.

Stg. hingestreckt, rankenförmig, kriechend; B. 5zählig, hie und da mit 3 zähligen untermischt; Blättchen stumpflich-gesägt; Bt. einzeln.

Verbr. $u$. hfg...... reptans. $L$. Kriechendes F. Stg. aufrecht 0 . aufstrebend, nicht kriechend ...... 13

13 Stg. filzig, bisweilen zugleich zottig o. haarig ..... 14 Stg. haarig 0. flaumig (nicht filzig).......... 17

Blättchen der oberen $B$. länglich-lanzettlich, unterseits langhaarig-graufilzig; Stg. nebst dem Filze weichzottig, an der Spitze ebenstränßig verzweigt;

14 Fr. schwach berandet. Verbr.

canescens. Bess. Grauliches F. Blättchen verkehrt-eiförmig 0 . keilförmig; Fr. nicht

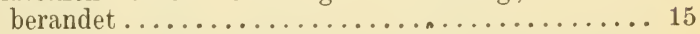

Stämmchen niedergestreckt; Stg. sehr kurz, armblütig, sammt Bstielen und B. grau-filzig und haarig; Blättchen gestutzt, beiderseits meist 4 zähnig. B. M. N. O. St. K. Kr .

arenaria. Borlih. Sand-F.

Stg. verlängert, reichblütig . ............ 16

Stg. aufstrebend; Blättchen am Rande umgerollt, unterseits (seltener beiderseits) filzig, bisweilen fiederspaltig-zerschlitzt; Btstiele nach dem Verblühen aufrecht. Verlur.

argentea. $L$. Silberweiøes F.

Stg. nach allen Seiten niederliegend; Blättchen flach, unterseits an den Adern rauhhaarig und außerdem flaumig o. filzig; Btstiele nach dem Verblühen abstehend o. zurückgebogen.

B. M. N. O. S. K. T. collina. Wib. Hügel-E.*)

Stg. aufrecht, kräftig, reichblättrig, durch abstehende, lange, auf Knötchen sitzende Haare rauhhaarig; Blättchen unterseits ohne Filz; B. 5-7zählig;

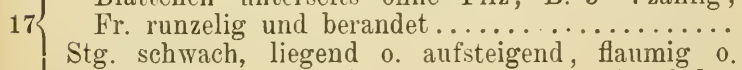
rauhhaarig; Fr. unberandet 0 . sehr schmal beberandet

*) Umfasst mehrere Formen! 
Stg. u. Bränder mit Drüsenhaaren; Blättchen unterseits rauhhaarig, länglich, am Grunde keilig.

Verbr. (fehlt S.)..... recta. $L$. Aufrechtes $\mathrm{F}^{*}$ )

18 Stg. u. B. ohne Drüsenhaare; Blättchen eingeschnitten-gesägt, die der Grundb. verkehrt-eiförmig-keilig; Stgb. lineal-keilig. $K$. $K r$. J. pedata. Nestl. Fußblättriges $\mathrm{F}^{* *}$ )

Grundb. 5-9 zählig, ihre Blättchen ringsum 0. duch bis gegen den Grund gesägt; Stg. lang (oft abstehend) zottig und auberdem kurzhaarig ...... 20 Grundb. 5 zählig, selten 7 zählig, ihre Blättchen meist nur vorne mit einigen Sägezähnen; Behaarung des Stg. anliegend 0 . etwas abstehend.............

Stg. aufstrebend, oben rispig verzweigt, die meist 7 zähligen Grundb. weit überragend; Btstiele auch nach dem Verblühen anfrecht, höchstens an der Spitze nickend. B. T.

Thuringiaca. Bernh. Thüringer $\mathrm{F}^{* * *}$ ) Stg. niederliegend, die Grundb. wenig o. gar nicht überragend; Btstiele zuerst aufgerichtet, nach dem Verblühen oft herabgekrümmt..........

Zottenhaare des Stg. wagrecht abstehend; Blättchen der Grundb. länglich-keilig, gestutzt; Außenkb. länglich; Kb. schmal-dreieckig-eiförmig. Verbr. rubens. $(\mathrm{Cr}$.) Zimm. Röthliches F.

Zottenhaare des Stg. aufrecht-abstehend; Blättchen der Grundb. lineal-keilig; Außenkb. lineal-länglich; Kb. breit dreieckig-eiförmig. $M$.

patula. WK. Ausgebreitetes F.

Unfruchtbare Stämmchen verlängert, unten ohne trockene Nebenb.; Nebenb. der Grundb. lineal 0. schmal lineal-lanzettlich...................

Unfruchtbare Stämmchen kurz, dicht mit trockenen (alten) Nebenb. bedeckt; Nebenb. der Grundb.

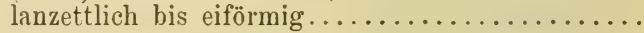

*) Die Bt. der typischen Form sind sehr grow und schwefelgelb, die von P. obscura Willd. kleiner und goldgelb.

**) Die B. sind bei der typischen Form fußförmig getheilt, bei P. laeta Rchb. handförmig getheilt.

***) Umfasst mehrere Formen. 
Grundb. ohne Sternhaare, grasgrün; Stg. u. Btstiele mit aufrecht abstehenden längeren Haaren bekleidet $u$. außerdem flaumig u. manchmal drüsig. Verbr. ....... viridis. (Neilr.) Frühlings-F.*) Grundb. mehr o. weniger reichlich sternhaarig und daher wenigstens unterseits graugrün; Stg. und Btstiele flaumig und langhaarig. T. K. S. O. N. Gaudini. Gremli. ${ }^{* *}$ ) Sternhaariges F.

Stg. angedı̈̈ckt behaart; Blättchen länglich, am Rande und an den Adern unterseits silberweißseidenhaarig, ihr Endzahn kleiner als die übrigen; Nebenb. der Grundb. lanzettlich. Geb.

aurea. $L$. Goldgelbes F.

Stg. flaumig; Blättchen verkehrt-eiförmig, am Rande und an den Adern unterseits abstehend-behaart, ihr Endzahn kaum kleiner als die übrigen; Nebenb. alle eiförmig. $A$. (fehlt $O$. J.)

Crantzii. (Cr.) Beck: Geflecktes F.

Bt. rosa 0 purpurbraun $\ldots \ldots \ldots \ldots \ldots \ldots \ldots \ldots 26$

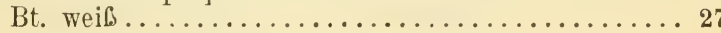

Kleine Alpenpfl. mit 3 zähligen, seidenhaarig-filzigen B ; Bt. meist einzeln; Krb. rosa, viel läuger als die Kb. A. v. Südt. K. Kr.J.

nitida. $L$. Glänzendes F.

Hochwüchsige Sumpfpfl. mit gefiederten B.; Btstand trugdoldig verzweigt; Krb. braunpurpurn, viel kürzer als die Kb. Verbr. (fehlt J.)

palustris. (L.) Scop. Sumpf-F.

B. gefiedert, nur die oberen 3 zählig; Blättchen eirundlich, eingeschnitten gesägt, flaumig; hochwüchsige Staude. Verbr. (fehlt S. J.)

rupestris. $L$. Felsen-F.

B. 3 zählig 0 . gefingert (die oberen manchmal un-

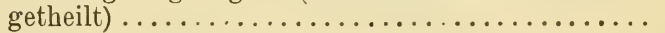

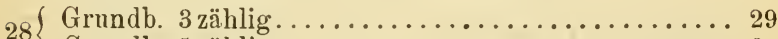

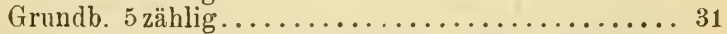

Das Stgb. 3 zählig; Blättchen rundlich-eiförmig; Stämmchen kriechend. B. N. O. St. S. T.

29 sterilis. (L.) Garcke. Erdbeerartiges F.

Das Stgb. einfach; Blättchen oval; kriechende

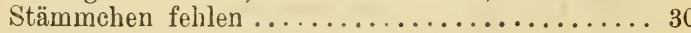

*) Eine sehr formenreiche Art!

**) Die typische Pfl. wächst nur in $T$.; in den anderen angegebenen Kronländern wachsen verwandte Formคn. 
Krb. länger als die Kb.; Btboden gelblich. Südst. $K r$.

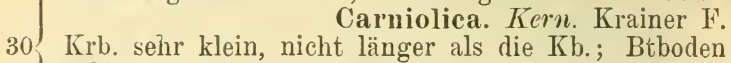
blutroth. N. O. St. T.

micrantha. Ram. Kleinblütiges $\mathrm{F}$.

Blättchen 2 farbig, oberseits dunkelgrün, kahl, unterseits durch dichte seidige Behaarung silbergrau; Bt. lang gestielt, von einander entfernt; Fr. nur am Nabel langhaarig. Verbr. (fehlt $S . K$.)

alba. $I$. Weißes F.

Blättchen beiderseits ziemlich gleichfarbig, wenn auch unterseits seidenhaarig; Bt. einander genähert, selten einzeln; Fr. überall zottig.......

Stf. kahl; Stg. 1-3 blütig; Blättchen länglich-lanzettlich, oberseits ziemlich kahl, unterseits zottig. A............. Clusiana. Jacq. Alpen-F. Stf. rauhhaarig; Stg. vielblütig; Blättchen fast sitzend, länglich-lanzettlich, etwas zottig. Vora. canlescens. L. Stengeltreibendes F.

Anmerkung. In obiger Tabelle wurden in der Regel nur die Hauptarten der sehr formenreichen Gattung berücksichtigt. - Von Bastarten wurden im Gebiete gefunden: $P$. procumbens $X$ reptans, erecta $X$ reptans, Crantzii $X$ nivea, aurea $X$ grandiflora, arenaria $\times$ rubens, arenaria $X$ viridis, argentea $X$ recta, argentea $X$ Gaudini, rubens $X$ viridis, Fragariastrum $X$ micrantha, alba $X$ Fragariastrum.

\section{SIBBALDIA. L. Gelbling.}

Blättchen verkehrt-eiförmig-keilförmig, 3 zälnnig, behaart; Bt. sehr klein, gelb. A. (fehlt $O$. J.)

procumbens. L. Niedergestreckter $G$.

\section{WALDSTEINIA. Willd. Waldsteinie.}

Blättchen ungleich-gelappt und gekerbt; Stg. 3- bis 7 blütig; Bt. gelb. K. (Koralpe.)

teruata. (Steph.) Fritsch Dreizählige W.

\section{GEUM. $L$. Nelkenwurz.}

Stg. mehrblütig; Gr. in der Mitte hakig-gegliedert, $1\left\{\begin{array}{l}\text { las obere Glied abfällig .............................. } \\ \text { Stg. } 1 \text { blütig; Gr. nicht gegliedert; Alpenpfit. mit } \\ \text { unterbrochen-gefiederten B. u. grofen, gelben Bt. }\end{array}\right.$ 
Kb. zurückgeschlagen; Bt. aufrecht, gelb; das untere Glied der Frgranne 4 mal so lang als das obere. Verbr....................... Echte N. Kb. aufrecht; Bt. nickend, röthlich; die beiden Glieder der Frgranne nahezu gleich lang. Verbr. rivale. $L$. Bach-N.

Pfl. ohne Ausläufer; Endblättchen der Grundb. sehr groß, fast herzförmig, ungleich gekerbt; Nebenb. der Stgb. fast handförmig eingeschnitten.

Geb. (fehlt M. Sch.)....montanum. L. Berg-N.

Pfl. mit Ausläufern; Blättchen der Grundb. eingeschnitten gesägt, das endständige 3-5 spaltig; Nebenb. der Stgb. ganzrandig. A. v. T. S. K. St. reptans. $L$. Kriechende $\mathrm{N}$.

Anmerkung. Von Bastarten wurden im Gebiete $G$. rivale $X$ urbanum und $G$. montanum $X$ rivale gefunden.

\section{DRYAS. $L$. Silberwurz.}

Niedriger Halbstrauch; B. lederig, länglich, gekerbtgesägt, unterseits weißfilzig; Bt. groß, weiß; Fr. lang geschwänzt. $A$.

octopetala. L. Europäische S.

\section{HILIPENIUULA. Adans. Mädesiiß.}

(Blättchen eiförmig, ungetheilt, beiderseits grün o unterseits filzig, das endständige grölser, handförmig-3-5 spaltig; Wzfasern nicht verdickt; Fr. kahl, gewunden. Verbr. u. $h f g$.

Ulmaria. (L.) Maxim. Echtes M.

Blättchen länglich, fiederspaltig-eingeschnitten, mit gesägten Abschnitten, beiderseits grüı; Wzfasern nach unten verdickt; Fr. flaumig, nicht gew unden. Verbr........hexapetala. Gilib. Knolliges M.

\section{ALCHEMILLA. L. Franenmantel.}

(Einjähriges Kraut; Bt. blattwinkelständig, geknäuelt; 1 B. handförmig-3 paltig, Zipfel vorne eingeschnitten3-5 zähnig. Verbr. arvensis. (L.) Scop. Feld-F. Stauden; Bt. in endständigen Ebensträußen ... ...

${ }_{2}$ Grundb. nierenförmig, mehr 0 . weniger tief 7 - bis

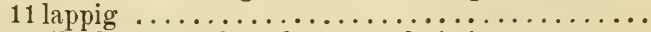
Grundb. bis zum Grunde 5-9 schnittig.........

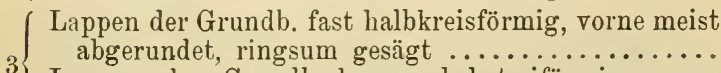
Lappen der Grundb. kurz-verkehrt-eiförmig, vorne gestutzt u. gesägt, an den Seiten ganzrandig.... 
Bt. kahl, ziemlich locker gestellt; B. behaart 0. kahl,

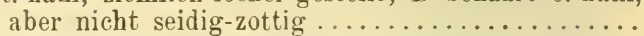

4 Bt. dicht behaart, geknäuelt; B. unterseits seidigzottig u. dadurch schimmernd. Verbr.

hybrida. (L.) Berg-F.

(Die ganze Pfl. kahl o. fast kahl. Verbr. (bes. Geb.) 5 alpestris. Schmidt. Voralpen-F.

Bstiele abstehend behaart; $B$. wenigstens unterseits behaart. Verbr......vulgaris. L.*) Gemeiner F.

Bt. kahl, ziemlich locker gestellt; Grundb. spärlich behaart, bis zur Mitte gespalten.

Geb. v. B. O. St. K. S. T.

$6\left\{\begin{array}{l}\text { fissa. Schummel. Schlitzblättriger F. } \\ \text { Bt. dicht behaart, geknäuelt; Grundb. beiderseits }\end{array}\right.$ reichlich behaart, nicht bis zur Mitte gespalten. A. (fehlt $N . J$.)

flabellata. Bus. Fächerblättriger F.

Grundb. 5 schnittig, beiderseits kahl 0 . fast kahl, die mittleren Abschnitte verkehrt-eiförmig-keilig, eingeschnitten-gezähnt. $A$. v. $T$.

pentaphyllea. $L$. Fünfblättriger $\mathrm{F}$.

Grundb. 5-9 schnittig, unterseits dicht seidenhaarig, Abschnitte keilig-länglich, nur vorne gesägt. $A$. alpina. $L *^{* *}$ ) Alpen-F.

\section{Agrimonia. $L$. Odermennig.}

Frboden verkehrt-kegelförmig, bis zum Grunde tief gefurcht, die äußeren Weichstacheln abstehend; B. unterseits dicht grauhaarig; Bt. klein. Verbr.

Eupatoria. L. Echter 0 .

Frboden halbkugelig-glockig, bis zur Mitte seicht gefurcht, die äußeren Weichstacheln zurückgeschlagen; B. unterseits wenig behaart, aber drüsig; Bt. größer. B. M. Sch. N. T. Kr .

odorata. Mill. Wohlriechender 0 .

\section{AREMONIA. Neck. Aremonie.}

Stg. rauhhaarig; B. beiderseits grün; jede Bt. von einer kelchartigen, 6-10 spaltigen Hochbhülle umgeben. Südt. K. Südst. Kr. J.

agrimonioides. (L.) Neck. Odermennigartige A.

*) A. pastoralis Bus. hat kleinere, beiderseits behaarte B. und nähert sich der A. hybrida (L.). Außerdem sind zahlreiche Formen unterschieden worden.

**) Umfasst mehrere Formen! 


\section{SANGUISORBA. $L$. Wiesenknopf.}

Bt. dunkelpurpurn; Stb. 4; Frkn. 1; N. kopfig,

1 warzig. Verbr. ..... officinalis. $L$. Gemeiner W. Bt. grünlich o. etwas röthlich; Stb. 20-30; Frkn. 1-3 (meist 2); N. pinselig................

Frboden schmal-geflügelt-4 kantig, netzig-runzelig; Blättchen der Grundb. kurz gestielt. Verbr.

minor. Scop. Grüner W.

2 Frboden breit-geflügelt-4 kantig, tief-grubig-runzelig; Blättchen der' Grundb. wenig länger als ihre Stiele. (T. ?) K. Südst. Kr.J. polygama. (WK.) Garclie. Stachelfrüchtiger W.

\section{ROSA. L. Rose.}

( Bt. dottergelb; A. am Grunde spießförmig; Scheinfr.

1 gelbroth. (ult. u. verw. . lutea. Nill. Gelbe R.*) Bt. wei $§$, rosa 0 p purpurm $\ldots \ldots \ldots \ldots \ldots \ldots \ldots .2$

Kb. ungetheilt, nicht fiederspaltig, oder nur 1 o. 2 am Grunde etwas fiederspaltig.............. 3

Kb. alle, o. doch 3-4 derselben fiederspaltig..... 14

Gr. zu einer weit aus dem Btboden herausragenden Säule verwachsen, ungefähr so lang als die Stb.; Bt. weiß; Stacheln derb, sichelförmig, am Grunde zusammengedrückt.................... 4

Gr. frei, viel kürzer als die Stb............. 5

Blättchen verschiedenfarbig, unterseits glanzlos, abfällig; Gr. kahl. Verbr. (fehlt Sch. B.)

4 Blättchen gleichfarbig, beiderseits spiegelnd, im Winter nicht abfallend; Gr. zottig. $K r$. J.

sempervirens. $L$. Immergrüne $R$.

Kb. kürzer als die Blkr.; Stacheln pfriemlich 0.

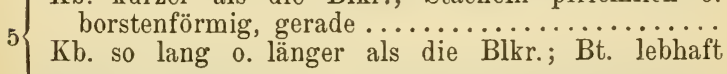
rosa 0 purpurn ........................ 9

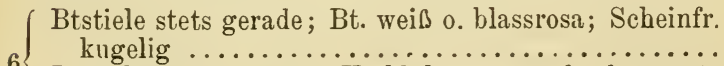

6 Btstiele nach dem Verblühen zurückgekrümmt; Scheinfr. eiförmig, roth .

*) R. punicea Mill. hat Krb., welche außen gelb, innen scharlachroth sind; sie wird selten cultivirt und verwildert sehr selten. 
(Blättchen klein, meist rundlich; Scheinfr. schwarz o. schwarzpurpurn. Verbr. (fehlt Sch. S.)

spinosissima. L. Dornigste $R$. Blättchen groß, eilänglich 0 . fast rautenförmig; Scheinfr. orangeroth. ('ult. u. verw. (N.)

blanda. Ait. Eschenblättrige R.

Krb. lebhaft rosa; Blättchen 5-7, eiförmig, mit drüsigen Zähnen. Südst. $K r$. J.

reversa. II $K$. Flatter-R. Krb. weiß o. blassrosa; Blättchen $7-11$, rundlich o. oval, mit fast drüsenlosen Zähnen. K. Südt. J. rubella. $S m$. Blassrothe R.

Btstiele nach dem Verblühen zurückgekrümmt; Btzweige $u$. erwachsene Stämme meist wehrlos; Blättchen 7-11. Verbr. (bes. Geb.)

peurlulina. I. Hängefrüchtige $\mathrm{R}$.

Btstiele stets gerade; Btzweige u. erwachsene Stämme meist bestachelt; Blättchen $5-7 \ldots \ldots \ldots \ldots$.

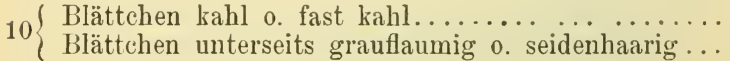

Zweige hechtblau bereift; die jüngeren B. purpurn gefärbt; Nebenb. der an den Btzweigen stehenden B elliptisch-verbreitert; Schösslinge mit zerstreuten

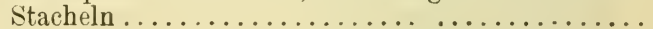

Zweige nicht bereift; B. grün, oberseits glänzend; Nebenb. drüsig gesägt, die an den Btzweigen wenig verbreitert; Schösslinge dicht mit pfriemlichen Stacheln besetzt; Bt. rosa; Scheinfr. plattkugelig. Cult. u. verw. (B.). lucida. Ehrh. Spiegelnde R.

Blättchen einfach gesägt, länglich-eiförmig o. elliptisch; Scheinfr. klein, meist nahezu kugelig. Voru. ferruginea. Vill. Rothblättrige R. Blättchen doppelt gesägt, rundlich-eiförmig; Scheinfr. groß, eilänglich. K...Pacheri. Kell. Pacher's R.

Drïsenborsten fehlen; Nebenb. der nicht blühenden Aestchen lineal-länglich, mit röhrig-zusammenschließenden Rändern; Fr. kugelig, von dem bleibenden zusammenschließenden $K$. bekrönt; $B$ t. lebhaft rosenröth. Verbr. (meist nur verw.)

cinnamomea. $L$. Zimmt-R.

Stacheln mit drüsentragenden Borsten gemischt; Nebenb. elliptisch o. länglich, ziemlich flach; Fr. elliptisch 0 . länglich, von dem weit-abstehenden K. bekrönt; Bt. bläulich-purpurn. Cult. u. verw. turbinata. Ait. Kreiselfrüchtige $\mathrm{R}$. 
Gr. eine kurze, über den Btboden herausragende Säule bildend, kahl, von ungleicher Länge, so dass das von den $\mathrm{N}$. gebildete Köpfchen länglich ist; $\mathrm{Kb}$. fast so lang als die weißen o. blassiosa gefärbten Krb. N. St. J.

stylosa. Desv. Langgrifflige $\mathrm{R}$.

Gr. über den Btboden kaum hervorragend; das von den N. gebildete Köpfchen daher flach-rundlich .

Nebenb. lineal-länglich, an sämmtlichen B. ziemlich gleich gestaltet; Blättchen elliptisch o. rundlich, etwas lederartig; niedriger, ungleich bestachelter u. drüsiger Strauch mit purpurnen Bt. Verbr.

Gallica. L. Französische R.

Nebenb. an den B. der Btzweige größer, elliptischkeilig, an den übrigen $B$. länglich ............

Blättchen mehr o. weniger lederig, kahl o. behaart, oft drüsig, aber nicht weichfilzig o. sammtig; die größeren Stacheln in der Regel derb, zusammengedrückt, am Grunde verbreitert, gewöhnlich gekı ümmt; Kb. nach dem Verblühen zurückgeschlagen, abstehend 0 . aufgerichtet, früh 0 . spät abfallend. 17

Blättchen dicht weichfilzig 0 . sammtig behaart, meist außerdem drüsig, kaum lederig; Stacheln gerade o. etwas gebogen, meist schmal u. pfriemlich 0 . kegelförmig; $\mathrm{Kb}$. nach dem Verblühen $\mathrm{ab}$ stehend 0 . aufgerichtet, meist lange bleibend.... 36

Blättchen unterseits kahl o. behaart, aber ohne

Drüsen 0. höchstens am Mittelnerv drüsig ..... 18

Blättchen unterseits auf der ganzen Fläche 0 . wenigstens am Rande o. auf den Seitennerven drüsig . 26 ${ }_{18} \begin{aligned} & \text { Blättchen beiderseits kahl (nur im Jugendzustande } \\ & \text { manchmal etwas behaart) } \ldots \ldots \ldots \ldots \ldots \ldots \ldots \ldots\end{aligned}$

Blättchen wenigstens unterseits (mindestens am Mittelnerven) behaart ...................

Btstiele und der Rücken der Kb. drüsenlos o. höchstens vereinzelte Drüsen führend ........... 20

Btstiele o. der Rücken der Kb. o. beide drüsen-

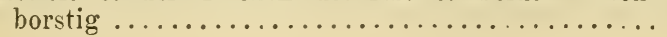


Kb. nach dem Verblühen zurückgeschlagen, früh abfallend; Bestachelung derb; Btstiele in der Regel die Deckb. überragend. Verbr. $u$. $h f g$.

caniua. L.*) Hunds-R.

$20 \mathrm{~Kb}$. nach dem Verblühen abstehend 0 . aufgerichtet, verhältnissmäßig lange bleibend; Bestachelung etwas schwächer; Btstiele kurz, meist von großen Deckb. verdeckt. Verbr.

glauca. Vill. Blaugrüne $\mathrm{R}$.

Kb. nach dem Verblühen zurückgeschlagen, früh abfallend; Bestachelung derb; Btstiele in der Regel die Deckb. überragend. $B$. $N$.

Andegavensis. Bast. Andegavische R.

$21 \mathrm{~Kb}$. nach dem Verblühen abstehend 0 . aufgerichtet, verhältnissmäßig lange bleibend; Bestachelung etwas schwächer; Btstiele kurz, meist von großen Deckb. verdeckt. Vora. v. N. St. Kr. K. Südt.

montana. Chaix. Berg-R.

${ }_{22}$ Btstiele drüsenlos 0. höchstens mit vereinzelten

22 Drüsen bekleidet .................. 23

Btstiele mehr 0 . minder reichlich drüsig........ 24

Kb. so lang o. länger als die Krb., nach dem Verblühen aufgerichtet, lange bleibend; Bt. lebhaft rosenroth. Verbr.

coriifolia. $F r$. Lederigblättrige R.

$\mathrm{Kb}$. kürzer als die Krb., nach dem Verblühen zurückgeschlagen, ziemlich bald abfallend; Bt. blassrosa. Verbr.... dumetorum. Thuill.**) Busch-R.

Kb. nach dem Verblühen aufgerichtet, lange bleibend; Bt. Jebhaft rosa; Gr. dicht weißwollig, ein sehr breites Nköpfchen bildend. $M$. $N$.

Kerneri. H. Br. Kerner's R.

$\mathrm{Kb}$. nach dem Verblühen herabgeschlagen, verhältnissmäßig bald abfallend; Bt. rosa 0. weiß; Gr. wollig, zerstreut behaart 0 . kahl ............

*) Die zahlreichen Formen dieser Art lassen sich in 2 durch Uebergänge verbundene Hauptgruppen bringen: R. canina L. (im engeren Sinne) mit einfach gesägten Blättchen und fast ganz ohne Drüsen, R. dumalis Bechst. mit doppelt gesägten Blättchen und Drüsen am Bstiel, den Nebenb. und dem Rande der Kb.

**) R. dumetorum Thuill. ist nahezu ebenso formenreich als $R$. canina $L$. $-R$. platyplyylla Rau ist eine Form mit sehr schwacher Behaarung der Blättchen und nähert sich der R. canina L. 
Bt. weiø; Blättchen rundlich-elliptisch o. nahezu kreisrund, beiderseits 0 . doch unterseits dicht behaart und dadurch graugrün. Cult. u. verw.

alba. $L$. Weiße $R$.

25 Bt. heller o. dunkler rosa; Blättchen elliptisch 0. verkehrt-eiförmig, seltener fast kreisrund, bald dichter, bald lockerer, beiderseits 0 . nur unterseits behaart. B. II. N. St. S. T.

collina. Jacq. Hügel-R.

Blättchen unterseits nur am Rande o. an den Nerven, seltener $z$ wischen den Nerven mit Drüsen besetzt, niemals dicht mit Drüsen bedeckt u. nicht wohl-

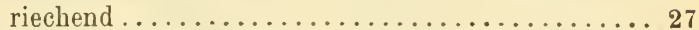

Blättchen unterseits dicht mit wohlriechenden Drüsen bedeckt, daher namentlich gerieben stark duftend 31

Niedrige sträucher mit großen, lebhaft rosenrothen Bt.; Blättchen grob, starl, doppelt bis vierfach tief und scharf drïsig-gesägt, unterseits kahl 0 . wenig (selten dicht) behaart, mit auffallend vortretendem blassgrünen Adernetze............

Höhere Sträucher mit mittelgroßen o. kleinen Bt. Blättchen klein, fein doppelt gesägt, unter'seits ohne auffallend vortretendes Adernetz ..........

Btstiele und Rücken der Kb. mit Drüsenborsten besetzt. B. M. N. O.K. T.

trachyphylla. Rau. Kurzblättrige R.

Btstiele und Rücken der Kb. drüsenlos. $N$.

decora. Kern. Schöne R.

Blättchen unterseits mehr 0 . weniger behaart .... 30 $29 \begin{gathered}\text { Blättchen beiderseits kahl (höchstens am Mittel- } \\ \text { nerven etwas flaumig); Bt. blassrosa; Gr. behaart. }\end{gathered}$ $M . N$. K.......nitidula. Ress. $\left.{ }^{*}\right)$ Glänzende R.

Kb. nach dem Verblühen abstehend o. aufgerichtet, lange bleibend; Blättchen blaugrün; Bt blassrosa; Gr. kahl o. etwas behaart $K$. $30\left\{\begin{array}{l}\text { abietina. Gren. Tannen-R. } \\ \mathrm{Kb} \text {. nach dem Verblühen zurückgeschlagen; Blätt- }\end{array}\right.$ chen grün; Bt. fast weiß; Gr. wollig o. kahl. Sch. M. N. K. J.

tomentella. Léman. Flaumige R.

(Btstiele und Rücken der Kb. ohne Drüsenborsten**) 32 31 Btstiele und meist auch der Rücken der Kb. mit Drüsenborsten besetzt $\left.{ }^{* *}\right) \ldots \ldots \ldots \ldots \ldots \ldots \ldots$

*) P. scabrata (Crép.) unterscheidet sich durch den Mangel der Drüsen an den Btstielen.

${ }_{* *}^{*}$ ) In $K$. wurden mehrere Formen beobachtet, welche theils drüsenlose, theils drüsige Btstiele haben; die auffallendste derselben ist. R. Gussenbaueri Kell. et Pach. 
Kb. nach dem Verblühen abstehend, zuletzt aufgerichtet, bis zur Frreife bleibend; Gr. kurz, wollig behaart. Verbr.......... agrestis. Savi. Feld-R.

$32 \mathrm{~Kb}$. nach dem Verblühen zurückgeschlagen, bald abfallend; Gr. meist kahl o. wenig behaart.

B. M. N. K. Südt.

graveolens. Gren. et Godr. Wohlriechende R. $33\left\{\begin{array}{c}\text { Gr. wollig } 0 . \text { doch behart; Krb. meist lebhaft } \\ \left.\text { rosa }{ }^{*}\right) \ldots \ldots \ldots \ldots \ldots \ldots \ldots \ldots \ldots \ldots \ldots \ldots \ldots \ldots \ldots \ldots \ldots \ldots \ldots \ldots \ldots \ldots \ldots \ldots\end{array}\right.$

Gr. kahl; Krb. meist blassrosa 0. weiß*) ....... 35

Blättchen am Grunde abgerundet, seicht gesägt; Bt. meist auffallend klein, kurz gestielt.

Verbr. (fehlt Sch.)....rubiginosa. L. Wein-R.

34 Blättchen nach dem Grunde zu keilig verschmälert, tief gesägt; Bt. ziemlich groß, lang (jedoch ungleich) gestielt. $M . \Lambda$.

anisopoda. Christ. Ungleichstielige $\mathrm{R}$.

Blättchen breit eiförmig 0 . fast rundlich, am Grunde etwas verschmälert, seicht gesägt; Bt. blassrosa o. weiß. Verbr. (fehlt Sch.)

micrantha. Sm. Kleinblütige $\mathrm{R}$.

Blättchen verkehrt-eiförmig o. elliptisch, nach dem Grunde keilig verschmälert, tief und scharf gesägt; Bt. meist reinweiß. M. N. K.

Gizellae. Borb. Gizella's R.

Stacheln schwach gebogen 0 . fast gerade; Blättchen weichfilzig 0 . wenigstens unterseits sammtig behaart, drüsenlos o. drüsig; Btstiele die Deckb. überragend, drüsenborstig ; ${ }^{* *}$ ) Bt. klein, blassrosa; Kb. vor der Frreife abfallend; Scheinfr. aufrecht, scharlachroth, knorpelig. Verbr. (fehlt J.)

tomentosa. Sm. Filzige R.

Stacheln kegelig-pfriemlich, meist ganz gerade (die an den Btzweigen wohl auch gebogen); Blättchen unterseits meist reichdrüsig; Btstiele gewöhnlich kurz; Bt. lebhaft rosenroth, nicht auffallend klein; $\mathrm{Kb}$. nicht abfällig; Scheinfr. aufrecht 0 . nickend.

Blättchen unterseits rauhhaarig-zottig und dicht drüsig, verkehrt-eiförmig; Aeste weinroth; Btstiele sehr kurz, von den Deckb. verhüllt, mit langen

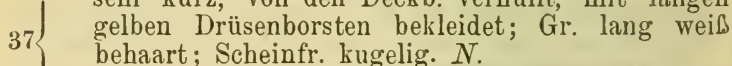

Mauternensis. Kell. R. v. Mautern.

Blättchen unterseits filzig 0 . seidig behaart, aber nicht rauhhaarig-zottig..................

*) R. Gremlii Christ (MI. N.) hat weiße Bt. und behaarte Gr., sonst aber die Merkmale der R. micrantha Sm. **) Die seltene R. farinosa Bechst. ( $T$. $K r$.) hat drüsenlose Btstiele. 
Blättchen dicklich, durch dichten Filz wenigstens

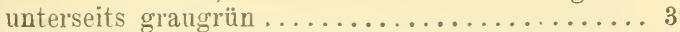

Blättchen dünn, beiderseits grün, unterseits anliegend seidig behaart, elliptisch; Kb. am Rücken dicht mit Drüsenborsten bekleidet; Gr. weifwollig; Scheinfr. kugelig, bestachelt, zuletzt nickend, höchstens halb so lang als ihr Stiel. Vora. (fehlt J.) resinosa. Sternby. Harzige R.

Zweige reichlich, oft ungleich, bestachelt; Scheinfr. kugelig, eiförmig 0 . birnförmig .......... 40 Zweige an Stacheln arm, manchmal fast wehrlos; Blättchen verlänger't-oval, oberseits anliegend seidig behaart, unterseits dicht graufilzig; Btstiele drüsenborstig, die Deckb. oft überragend; Gr. weißwollig; Scheinfr. eilänglich, oben in einen Hals zusammengezogen. $B$. $M I$.

vestita. Godet. Sammtige R.

Großer, locker ästiger Strauch mit bogig verlängerten Schösslingen; Blättchen lanzettlich, spitz, nach dem Grunde verschmälert; Scheinfr. eiförmig, aufrecht, scharlachroth. $M . N$.

nmbelliflora. Sw. Doldenblütige R. Niedriger, gedrungener Strauch mit steifen, geraden Schösslingen; Blättchen länglich-elliptisch, stumpf o. zugespitzt, am Grunde abgerundet 0 . etwas ausgerandet; Scheinfr. grob, kugelig o. birnförmig, nickend, blutroth und etwas blau bereift.

Vora. v. T. S. K. St. O. (sonst verw.)

pomifera. Herm. Apfelfrüchtige $\mathrm{R}$.

A n m e r ung. Von der außerordentlich formenreichen Gattung Rosa konnten hier nur die Hauptarten Berücksichtigung finden. Die meisten dieser Hauptarten sind sehr veränderlich und außerdem noch durch Zwischenformen mit anderen Hauptarten verbuuden. Die Verbreitung mancher Arten ist noch mangelhaft bekannt. Bastarte sind nicht sehr selten, aber oft von anderen Zwischenformen schwer zu unterscheiden. Im Gebiete wurden mit Sicherheit oder Wahrscheinlichkeit beobachtet: R. arvensis $\times$ Gallica, pendulina $X$ spinosissima, dumetorum $X$ pendulina, pendulina $X$ tomentosa, pendulina $X$ pomifera, canina $\times$ Gallica, Gallica $\times$ glauca, Gallica $X$ trachyphylla, glauca $\times$ pomifera, micrantha $X$ rubiginosa, rubiginosa $X$ tomentosa. 


\section{PRUNUS. L. Pflaume.}

Narbe kopfig-nierenförmig, ausgerandet; Gr. mit einer herablaufenden Furche; Bt. einzeln, zu 2-3 o. in doldenförmigen Büscheln ........... 2 Narbe kopfig, nicht ausgerandet; Gr. ohne Furche; Bt. in Trauben o. Doldentrauben..

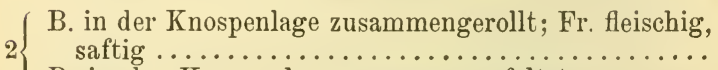

B. in der Knospenlage zusammengefaltet........

(Fr. sammtig; B. eiförmig, fast herzförmig, zugespitzt, doppelt-gesägt, kahl; Bstiel drüsig; Bt.

3 vor den B. hervorbrechend, weiß, außen röthlich. Cult. u. verw. . Armeniaca. L. Aprikosenbaum. Fr. kahl, bereift; B. elliptisch 0 . breit-lanzettlich..

(Btstiele kahl, meist einzeln entspringend, wenn auch 4 oft einander genähert; Fr. kugelig, schwarz, blau bereift. Verbr..........spinosa. L.*) Schlehdorn.

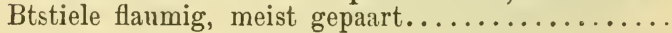

Aestchen sammtig; Krb. rundlich; Fr. kugelig, 5 hängend. Verbr. (meist nur cult. u. verw.)

$5\left\{\right.$ insititia. $L{ }^{* *}$ ) Kriechenbaum. Aestchen kahl; Krb. länglich-eiförmig; Fr. länglich. Cult. u. verw...domestica. L. Zwetschkenbaum.

$\int$ Bt. sehr kurz gestielt, einzeln o. gepaart; Fr. meist

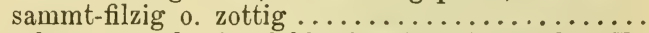
Bt. lang gestielt, in doldenförmigen Büscheln; Fr.

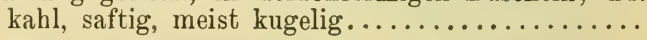

B. drüsig gesägt, länglich-lanzettlich; Bstiel so lang o. länger als die Breite des B.; Btboden glockig ausgehöhlt; Fr. lederig, trocken, bei der Reife aufreißend; Steinkern glatt, löcherig; Bt. weiß 0 .

7 blassrosa, im ersten Frühjahre vor den B. erscheinend. Cult.

communis. (L.) Fritsch. Mandelbaum.

B. drüsenlos gesägt, sehr kurz gestielt; Bt. rosa; Steinkern mehr 0 . weniger gefurcht ..........

*) Umfasst mehrere Formen!

**) P. Italica Borkh. (Reineclaude) ist schwächer behaart u. hat größere, süßere Fr. 
Baum mit großen, lanzettlichen, zugespitzten, spitz gesägten B.; Btboden glockig ausgehöhlt; Fr. grob, fleischig, sammtig-filzig (selten kahl); Steinkern tief gefurcht u. löcherig. Cult.

Persica. (L.) Zucc. Pfirsichbaum.

8 Strauch mit kleinen, keilig-lanzettlichen, spitzen, gesägten B. ; Btboden röhrig verlängert; Fr. klein, lederig, trocken, seidig-zottig; Steinkern schwach gefurcht, nicht löcherig. N. (sonst cult.)

nana. (L.) Zucc. Zwergmandel.

B. flach, kahl, fast lederig; Bstiel oft drüsenlos; Btbüschel am Grunde mit kleinen B. besetzt.... $10^{-}$

B. etwas runzelig, unterseits flaumig; Bstiel 2 drüsig; Btbüschel blattlos. Verbr. avium. L. Kirschbaum.

Kleiner Baum o. Strauch; B. elliptisch, alle zugespitzt; Dolden gehäuft u. zerstreut; Krbb. rundlich. Verbr. (meist nur cult. u. verw.)

Cerasus. L. Weichselbaum.

10 Niedriger Strauch; die oberen B. länglich 0 . lanzettlich, zugespitzt, die seitenständigen verkehrteiförmig, abgerundet-stumpf; Dolden einzeln; Krb. länglich. B. M. N. Südst.

pumila. (L.) Zwergweichsel.

Bt. in verlängerten, überhängenden Trauben; B. elliptisch, fast doppelt gesägt; Bstiel 2 drüsig.

Verbr. Padus. L. Traubenkirsche

11 Bt. in gewölbten, kurzen Doldentrauben; B. rundlich-eiförmig, fast herzförmig, stumpf gesägt.

Verbr. (fehlt Sch. B. K.)

Mahaleb. L. Steinweichsel.

Anmerkung. Von Bastarten sind aus dem Gebiete bekannt: $P$. insititia $X$ spinosa, avium $X$ Cerasus und Cerasus $X$ pumila.

XXXII. Familie. Leguminosae. Hülsenfrüchtler.

Kräuter, Stauden o. Holzgewächse mit schraubig gestellten, meist gefiederten 0.3 zähligen, seltener gefingerten o. ungetheilten B., meist mit Nebenb. Bt zwittrig, fast immer mit doppelter, unregelmäßiger Bthülle. K. stets mehr o. weniger röhrig u. 5 spaltig, 5 zähnig o. 2 lippig, seltener 1 lippig 0. abgestutzt. Blkr. 5 blättrig, schmetterlingsförmig: das oberste B. am größten, ausgebreitet ("Fahne“), die 2 seitlichen vorgestreckt, schmäler ( Flügel $\left.^{*}\right)$, die 2 untersten am unteren Rande gewöhnlich mehr 0. weniger verwachsen, zusammen das ,Schiffchen" bildend; sehr selten die Blkr. ganz fehlend. Stb. 10, alle 0 . häufiger nur $9 \mathrm{mehr} 0$. weniger lang $\mathrm{zu}$ einer den Gr. einschließenden Röhre verwachsen, sehr selten 10 o. nur 5 ganz freie Stb. vorhanden. Frkn. 1, 
oberständig, 1 fächerig, selten unvollständig 2 fächerig, meist mit zahlreichen, seltener nur wenigen 0. 1-2 Samenknospen. Gr. 1, meist verlängert, mit unscheinbarer N. Fr. in der Regel 2 klappig aufspringend (Hülse), seltener in Glieder zerfallend 0 . überhaupt geschlossen bleibend. S. mit spärlichem, selten reichlichem Nährgewebe 0 . ohne solches.

\section{Gattungen.}

(Blkr. vorhanden, schmetterlingsförmig; Stb. 10,

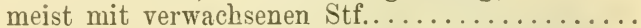

Blkr. fehlend; Stb. 5; Holzgewächs mit gefiederten, lederigen B..................

B. ungetheilt, nierenförmig; Stf. frei; Holzgewächs mit rosenrothen Bt. ..................

2 B. 3 zählig, gefiedert, gefingert o. ungetheilt, im letzteren Falle aber nicht nierenförmig; alle 100. doch 9 Stf. in eine Röhre verwachsen .........

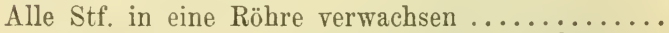

9 Stf. in eine (oft oben gespaltene) Röhre verwachsen, der zehnte ganz 0. größtentheils frei...

B. ungetheilt, 3 zählig 0 . unpaarig gefiedert...... B. 5-9 zählig gefingert; einjährige Kräuter mit 5 weißen o. blauen Bt.; K. 2 lippig; Schiffchen in einen Schnabel zugespitzt; Hülse lederig, schwammig-querwandig .............. Lupinus. III.

B. ungetheilt 0.3 zählig; K. abgestutzt 0 . mehr 0 . weniger tief gespalten, 2 lippig, 5 spaltig 0 . nur

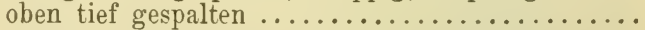

5 B. unpaarig gefiedert, seltener 3 zählig (mit sehr 6 großem Endblättchen) 0 . einige ungetheilt; $K$. röhrig, dabei oft bauchig, an der Spitze 5 zähnig, die Hülse einschließend; Stauden . Anthyllis. XV.

K. nur oberseits tief gespalten, daher 1 lippig, an der Spitze trockenhäntig u. kurz 5zähnig; Gr. pfriemlich, kahl; Strauch mit ruthenförmigen Zweigen u. ungetheilten B.........Spartium. V.

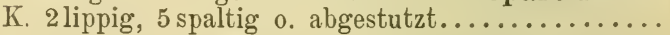

K. 2 lippig, oft mit 2 theiliger Oberlippe, o. abgestutzt; Flügel der Blkr. am oberen Rande über dem Nagel runzelig gefaltet; Holzgewächse 0. Halbsträucher .........................

K. 5 spaltig; Flügel der Blkr. nicht gefaltet; die meisten B. 3 zählig; Fr. aufgedunsen; Halbsträucher, Stauden 0. Kräuter.............. Ononis. X. 
K. mit tief 2 theiliger Oberlippe (so dass derselbe tief 3 theilig erscheint) und 3 zähniger 0.3 spaltiger Unterlippe; Bt. gelb .................

K. mit ungetheilter 0 . kurz 2 zähniger, manchmal schwach ausgeprägter Oberlippe und 3 zähniger 0 . ungetheilter Unterlippe; Bt. gelb, seltener purpurn 10

B. 3 zählig, wechselständig, mit krautigen Nebenb.; N. schief, nach außen abschüssig.

Argyrolobium. IV.

B. ungetheilt, seltener 3 zählig, dann aber gegenständig und ohne Nebenb.; N. schief, nach innen abschüssig ....................... VI.

$10\{$ Bt. in überhängenden Trauben, gelb; S. ohne Nabel-

10 wulst . . . . . . . . . . . Laburnum. VII.

Bt. in aufrechten Trauben o. in anderen Btständen 11

Dorniger Strauch mit gebüschelten, gelben Bt.; S. ohne Nabelwulst.......... Calycotome. VIII.

11 Sträucher 0. Halbsträucher (wenn dornig, dann mit einzelnen Bt.); Bt. gelb o. purpurn; S. mit Nabelwulst.......................

B. 3 zählig o. unpaarig gefiedert, seltener 5 zählig-

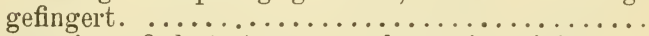

B. paarig gefiedert (nur ausnahmsweise einige unpaarig gefiedert), mit einer Borste o. Panke endigend, seltener ganz ungetheilt 0 . durch eine Ranke

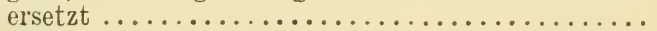

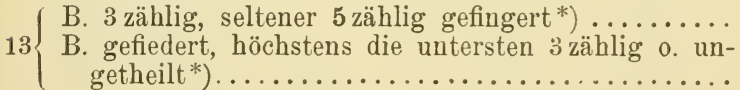

Blättchen mit kleinen Nebenblättchen; Gr. ołelwärts behaart und schraubig gedreht, in der Mitte knorpelig-verbreitert; Bt. in lockeren Trauben 0. einzeln............... Phaseolus. XXXVIII.

Blättchen ohne Nebenblättchen; Gr. kahl o. nur am Grunde behaart, nicht gedreht; B. meist in Dolden 0. Köpfchen, selten einzeln ............. 15

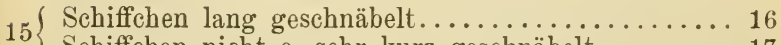

Schiffchen nicht 0 . sehr kurz geschnäbelt ....... 17

*) Diejenigen Gattungen, bei welchen Zweifel über diese Merkmale entstehen könnten, sind bei beiden Gegensätzen berücksichtigt. 
Blättchen 5, die 2 untersten dem Stg. sehr genähert und daher wie Nebenb. aussehend; Fr. 2 klappig aufspringend, mit zuletzt gedrehten Klappen.

Lotus. XIX.

Blättchen 3, das endständige viel größer, die seitenständigen wie Nebenb. aussehend; Fr. gegliedert, nicht aufspringend ......... Coronilla. XXIX.

B. 5 zäblig, die 2 untersten Blättchen wie Nebenb. gestellt; die eigentlichen Nebenb. verkümmert, frei; Bt. weißlich 0. rosa, Schiffchen an der Spitze schwarzviolett............ Dorycnium. XVIII. B. 3 zählig; Nebenb. dem Btstiel angewachsen ....

Krb. mit der Stbröhre verwachsen, verwelkend und die Fr. einschlie@end, nicht abfallend; Bt. in Köpfchen 0 . Aehren ............ Trifolium. XIV.

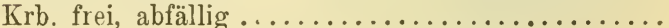

$19\{$ Bt. blau 0. violett..................... 20

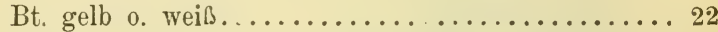

Blättchen stumpf 0 . ausgerandet, meist wenigstens vorne fein gesägt 0 . gezähnelt; Bt. in dichten, länglichen 0. rundlichen Trauben; Frkn. mit mehreren Samenknospen ..................

Blättchen ganzrandig, die oberen spitz; Bt. in lang gestielten, dichtblütigen Köpfchen; Frkn. kurz, eiförmig, mit einer Samenknospe; Fr. geschnäbelt.

Psoralea. XX.

Blättchen nur vorne gezähnelt; Trauben länglich; Frkn. aufwärts gekrümmt; Fr. schneckenförmig gedreht; Stauden............ Medicago. XII.

21 Blättchen ringsum gesägt, selten fast ganzrandig; Trauben rundlich 0. oval; Frkn. gerade; Fr. eilänglich, geschnäbelt; 1 jährige Kräuter.

Trigonella. XI.

Bt. klein, hängend, in verlängerten, lockeren Trauben; Fr. kurz, gedunsen, meist nicht geschnäbelt.

Melilotus. XIII.

Bt. in kurzen Trauben, in Dolden, gepaart o. einzeln

Frkn. aufwärts gekrümmt; Fr. sichelförmig 0 . schneckenförmig gedreht, seltener nierenförmig; Kräuter o. Stauden........... Medicago. XII.

Frkn. gerade (nur der Gr. gekrümmt); Fr. lineal, geschnäbelt, oft gebogen; 1 jährige Kräuter.

Trigonella. XI. 
( Dorniger Baum; Bt. weiß, in hängenden, reichblü25 tigen Trauben; Fr. lineal-länglich, holperig.

Wehrlose Sträucher mit gelben Bt. Robinia. XXII. 26

Bt. in armblïtigen aufrechten Trauben; Fahne kurz benagelt; Fr. aufrecht......... Colutea. XXIII.

26 Bt. in armblütigen Dolden; alle Krb. sehr lang benagelt; Gr. kahl; Fr. stielrund, gegliedert.

Coronilla. XXIX.

Blättchen 5, die 2 untersten dicht an den Stengel

27 gerückt und daher wie Nebenb. aussehend ....... 28

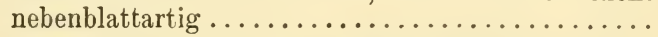

Bt. meist gelb; Schiffchen lang geschnäbelt; Fr. lineal. Lotus. XIX.

28 Bt. weißlich 0. rosa; Schiffchen an der Spitze schwarzviolett, sehr kurz geschnäbelt; Fr. eilänglich 0 . fast kugelig ............. Doryenium. XVIII.

$29\{$ Bt. heller o. dunkler gelb ............... 30

Bt. verschieden gefärbt, aber nicht gelb ....... 36

Das Endblättchen viel größer als die Seitenblättchen; Fr. flachgedrückt, nierenförmig, fast kreisrund, am Au@enrande dornig gezähnelt; einjähriges Kraut ....................... Xircinus. XVI. Das Endblättchen nicht auffallend größer als die Seitenblättchen; Fr. nicht nierenförmig ........ 31

Schiffchen zugespitzt-geschnäbelt........... 32

31 Schiffchen stumpf, manchmal mit aufgesetzter

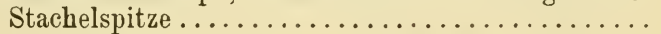

Fr. gegliedert, bei der Reife meist in Glieder zer-

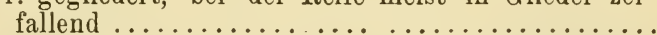

Fr. nicht gegliedert, verlängert, zusammengedrückt, lang hakig geschnäbelt.......Bonaveria. XVII.

Fr. am oberen Rande buchtig-ausgeschweift 0 . mit tiefen kreisrunden Ausschnitten, mit halbmondförmigen 0 . hufeisenförmigen Gliedern.

Hippocrepis. XXX.

Fr. ziemlich stielrund 0. 4-6 kantig, ohne Ausschnitte................ Coronilla. XXIX.

Schiffchen ganz stumpf, ohne Stachelspitze....... 35

Schiffchen unterhalb des stumpfen Endes mit einer

34 Stachelspitze; Fr. gedunsen 0. cylindrisch, durch eine von der Bauchnaht hineinragende Scheidewand unvollständig 2 fächerig. Oxytropis. XXV. 
$35\left\{\begin{array}{c}\text { Stf. abwechselnd oben verbreitert; Fr. gegliedert, } \\ \text { zusammengedriickt ....... Ornithopus. XXVIII. } \\ \text { Alle Stf. pfriemlich; Fr. nicht gegliedert. } \\ \text { Astragalus. XXIV. }\end{array}\right.$

$36\{$ Bt. in Dolden, Köpfchen o. einzeln*)......... 37

$36\{$ Bt. in Trauben 0. Aehren*) .............. 41

(Schiffchen zugespitzt geschnäbelt; Fr. gegliedert, 374 kantig ............... Coronilla. XXIX. Schiffchen nicht geschnäbelt, jedoch manchmal mit aufgesetzter Stachelspitze; Fr. nicht 4 kantig....

38 Alle 0. einige Stf. oben verbreitert; Bt. einzeln 0. Alle Stf. pfriemlich; Bt. in Dolden 0. Köpfchen ...

Bt. einzeln; Fr. nicht gegliedert, aufgeblasen, 2 samig; S. runzelig, spitz................. Xicer. XXXIII.

39 Bt. zu $2-5$ beisammen; Fr. gegliedert, zusammengedrückt, mehrsamig; S. nierenförmig.

Ornithopus. XXVIII.

$40\left\{\begin{array}{l}\text { Schiffehen stumpf, ohne Stachelspitze. } \\ \text { Astragalus. XXIV. } \\ \text { Schiffchen unterhalb des stumpfen Endes mit einer } \\ \text { Stachelspitze............. Oxytropis. XXV. }\end{array}\right.$

Alle $5 \mathrm{~K}$ rb. frei; K. etwas 2 lippig; Afächer oben zusammenfließend; Bt. blassviolett, in lockeren,

$41\left\{\begin{array}{l}\text { verlängerten Trauben ..... Glycyrrhiza. XXVI. } \\ \text { Die } 2 \text { Krb., welche das Schiffchen bilden, mehr } 0 .\end{array}\right.$ weniger mit einander verwachsen; K. 5 zähnig; Afächer getrennt ....................

Schiffchen stumpf, bisweilen kurz (und stumpf) ge-

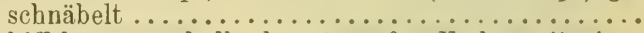

42 Schiffchen unterhalb des stumpfen Endes mit einer Stachelspitze; Fr. gedunsen o. cylindrisch, durch eine von der Bauchnaht hineinragende Scheidewand unvollkommen 2 fächerig. Oxytropis. XXV.

Fr. gegliedert, lineal, zusammengedrückt, bei der 43 Reife in Glieder zerfallend; Alpenpfl. mit großen, purpurnen Bt............Hedysarum. XXXI.

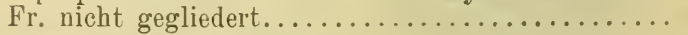

*) Arten, deren Btstand Zweifel erregen könnte, sind bei beirlen Gegensätzen berïcksichtigt. 
Fr. nicht aufspringend, zusammengedrückt, halbkreisförmig 0 . verkehrt-eiförmig, dornig, 1 fächerig, meist 1 samig; Frkn. mit 1-3 Samenknospen.

Onobrychis. XXXII.

Fr. 2klappig aufspringend, seltener nicht aufspringend, nicht dornig, oft 2 fächerig, meist mehr-

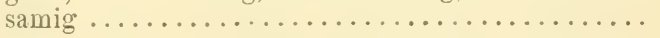

Das oberste Stb. ganz frei; Fr. 2 klappig aufsprin45 gend, oft 2 fächerig......... Astragalus. XXIV. Das oberste Stb. unten mit den übrigen verwachsen; Fr. nicht aufspringend, 1 fächerig. Galega. XXI.

( B. ungetheilt o. durch eine Wickelranke ersetzt;

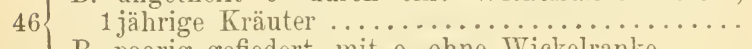
B. paarig gefiedert, mit o. ohne Wickelranke..... 48

B. gestielt, länglich-lanzettlich; Bt. gelb, meist zu mehreren beisammen; Fr. gegliedert, dornig, zusammengerollt............ Scorpiurus. XXVII.

47 B. lineal-lanzettlich, sitzend o. durch eine Wickelranke ersetzt (in letzterem Falle die Nebenb. groß, blattartig); Bt. einzeln, blattachselständig, karminroth 0 . gelb; Fr. nicht gegliedert, nicht dornig. Lathyrus. XXXVI.

Stbröhre schief abgeschnitten; Gr. fädlich, seltener oben etwas verbreitert ......................

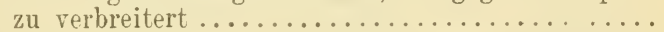

Gr. ganz fädlich; Fr. meist mehrsamig, mit rundlichen o. etwas zusammengedrückten S.; Kräuter o. Stauden ................ Vicia. XXXIV.

$49 \mathrm{Gr}$. nach oben etwas verbreitert; Fr. 1-2 samig, mit flachgedrückten, im Umrisse kreisrunden S. („Linsen"); 1 jährige Kräuter mit bläulichweißen

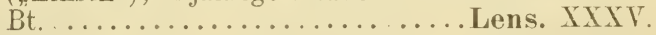

Gr. 3 kantig, unterseits von einer Rinne durchzogen, oberseits gekielt und gegen die Spitze zu bärtig; 50 Bt. $1-3 \ldots \ldots \ldots \ldots \ldots \ldots \ldots$. . . . . . . . Gr. nicht 3 kantig, unterseits ohne Rinne, oberseits gebärtet ....................

\section{Arten.}

\section{CERCIS. L. Judasbaum.}

B. ganzrandig, kahl; Bt. aus den vorjährigen Zweigen hervorbrechend. Sü̈t. J.

Siliquastrum. L. Europäischer J. 


\section{CERATONIA. L. Johannisbrotbaum.}

Blättchen oval, glänzend, immergrün; Fr. hängend, flachgedrückt, braun gefärbt. $J$.

Siliqua. L. Echter J.

\section{LUPINUS. $L$. Wolfsbohne.}

Bt. blau; Vorb. lineal; Oberlippe des K. 2 spaltig; Pfl. abstehend rauhhaarig. $J$.

Bt. weiß, nur an der Spitze blau; Oberlippe des K. ungetheilt o. kurz 2zähnig; Pfl. anliegend seidenhaarig $\ldots \ldots \ldots \ldots \ldots \ldots \ldots \ldots \ldots \ldots \ldots$

Vorb. lanzettlich; das längste Blättchen fast so lang als der Bstiel. J. (eingeschleppt.)

Termis. Forsk. Deckblättrige W. Vorb. fehlen; das längste Blättchen kaum so lang als der halbe Bstiel. J. (eingeschleppt.)

\section{albus. $L$. Weiße W.}

\section{ARGYROLOBIUM. $E$. et $Z$. Silberklee.}

Dicht seidenhaariger Halbstrauch; Bt. zu 2-4 beisammen; K. u. Fahne außen seidenhaarig. Sï̈t. Kr.J.

argenteum. (L.) Willk. Gemeiner S.

\section{SPARTIUM. L. Pfriemen.}

B. lanzettlich, ganzrandig; Bt. gelb, in lockeren Trauben. Südt. Südst. Kr. J. junceum. $L$. Binsenartiger Pf.

\section{GENISTA. L. Ginster.}

$1\{$ B. gegenständig, 3 zählig; Blättchen lineal ...... 2

B. schraubig gestellt, ungetheilt, selten einige 3 zählig 3 Tragb. der Bt. eiförmig; Fahne ausgerandet, nur am Kiele behaart. Südt. K. Südst. Kr. J. $2\left\{\begin{array}{l}\text { radiata. ( } L \text {.) Scop. Strabliger G. } \\ \text { Tragb. der Bt. lineal-pfriemlich; Fahne abgerundet, }\end{array}\right.$ außen dicht seidenhaarig. $K r . J$.

holopetala. (Fleischm.) Rchb. Ganzfahniger G $3\left\{\begin{array}{l}\text { Stg. } 2 \text { schneidig-geflügelt, gegliedert; ; Bt. in kurzen, } \\ \text { endständigen Trauben. N. O. St. K. }\end{array}\right.$ sagittalis. L. Geflügelter G. Stg. nicht geflügelt...................

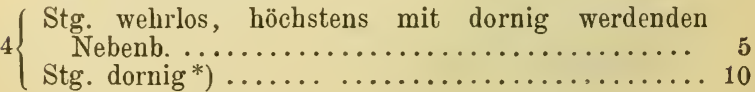

*) In Südt kommt eine wehrlose Form der G. Germanica $\mathrm{L}$. vor. 
(Fahne u. Schiffchen seidenhaarig, ebenso die Blätt-

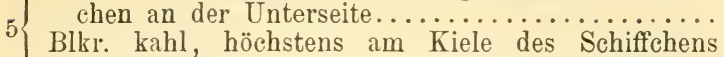
Blkl: kahl, hochstens am Kiele des Schiffchens flaumig.

Bt. zu 2-4 an den Enden der Zweige; Btstiele halb so lang als der $\mathbf{K}$., wie dieser seidig-zottig.

6 Südt. Kr. J. . sericea. Wulf. Seidenhaariger G. Bt. an den Zweigen seitenständig, oft zu lockeren beblätterten Trauben zusammengestellt ........

Alle B. ungetheilt, verkehrt-eilänglich, stumpf 0 . kurz bespitzt; Fahne wenig länger als die übrigen Krb. Verbr. (fehlt S. T.) pilosa. L. Behaarter G.

7. Die B. der Btregion öfters 3 zählig, ihre Blättchen wie die ungetheilten B. lanzettlich, spitz; Fahne viel länger als die übrigen Krb. J. (Cherso.)

pulchella. Vis. Schöner G.

B. u. Stg. kahl; Nebenb. bleibend, pfriemlich, zuletzt dornig; Aeste geflügelt-3 kantig.

8 Sïdst. Kr.J. triangularis. Kit. Dreikantiger G. B. rauhhaarig 0 . wenigstens am Rande flaumig; Nebenb. sehr klein, pfriemlich ............

B. nebst dem Stg. rauhhaarig, eiförmig, lanzettlich o. elliptisch; Hülsen dicht rauhhaarig.

(N.?) St. Kr. J. S̈̈̈dt.

lasiocarpa. Spach. Behaartfrüchtiger G.

B. am Rande flaumig, elliptisch o. lanzettlich; Hülsen kahl; Stg. stielrund, gerieft, oberwärts flaumig. Verbr.......tinctoria. L.*) Färber-G.

$10\{$ Zweige abstehend behaart . . . . . . . . . . . 11

Die blühenden Zweige wehrlos; B. länglich-lanzettlich. Verbr.......Germanica. L. Deutscher G.

11 Alle Zweige mit steifen, 4 kantigen Dornen besetzt; B. lineal-lanzettlich. $J$.

Dalmatica. Bartl. Dalmatinischer G.

Dornen aufrecht, fein gerieft; B. lanzettlich; Stg. angedrückt-haarig; K. u. Schiffchen flaumharig.

12 Sïdst. $K r \cdot J \ldots \ldots \ldots$ silvestris. Scop. Wald-G. Dornen bogig, 4 kantig; Stg. oberwärts seidenhaariggrau; B. lineal; K. und Schiffchen seidenhaarig. J. .............. arcuata. Koch. Bogiger G.

*) G. elatior Koch ist eine sehr hohe, stark ästige Form wärmerer Lagen. 


\section{V11. LABURNUM. Griseb. Goldregen.}

Junge Zweige $u$. Unterseite der Blättchen angedrückt behaart; K. u. Fr. seidenhaarig.

N. St. K. Kr. J. Sï̈lt. (sonst cult. u. verv.)

vulgare. Griseb.*) Gemeiner G.

Zweige u. Blättchen nahezu kahl o. letztere am Rande u. unterseits abstehend behaart; K. u. Fr. kahl o. erstere zerstreut behaart.

Südt. K. Südst. $K r$. J.

alpinum. (Mill.) Griseb. Alpen-G.

V'III. CALYCOTOME. Lk. Dornklee.

Blättchen keilig-verkehrteiförmig, unterseits wie die Fr. angedrückt seidenhaarig. 'J.

infesta. (Presl.) Guss. Seidenhaariger D.

\section{CYTISUS. L. Geißklee.}

( Bt. purpurn, seitenständig; Pfl. kahl o. fast kahl;

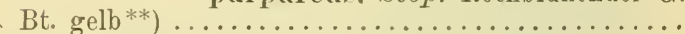

${ }_{2}\{$ B. ungetheilt $\ldots \ldots \ldots \ldots \ldots \ldots \ldots \ldots \ldots \ldots \ldots \ldots \ldots \ldots \ldots$

B. 3 zählig, nur die obersten manchmal ungetheilt. 4

Zweige, B. u. K. kahl o. fast kahl. Südst. $K r$. J.

3 Zweige, Bunterseite, Btstiele u. K. angedrücktbehaart. Mr. N. Sü̈lst. Kr $r$.

Kitaibelii. Vis. Niederliegender G.

Gr. sehr lang, zirkelförmig eingerollt; $N$. end4 ständig, klein, kopfig; Kelchlippen trockenhäutig.

scoparius. (L.) Lk. Besenstrauch.

Gr. pfriemlich, aufstrebend, mit schiefer N...... 5

Kröhre kurzglockig; Bt. in blattlosen Trauben..... 6

Kröhre verlängert, Lippen kürzer als die Röhre; Bt. in endständigen Köpfchen 0 . beblätterten Trauben

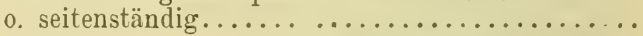

Trauben reichblütig, so wie die Zweige u. K. angedrückt behaart; Bt. ohne Vorb. Verbr.

nigricans. L. Schwärzlicher G.

Trauben armblütig, wie die ganze Pfl kahl; Bt. mit Vorb. Südt. J.......sessilifolius. L. Kahler G.

*) Bei L. Alschingeri (Vis.) C. Koch (Südt. J.) ist die Unterlippe des $K$. viel länger als die Oberlippe $u$. die Nägel der Krb. ragen aus der Kröhre heraus.

**) Von C. hirsutus L. wurde in Sïdt. auch eine purpurn blühende Form gefunden (vielleicht $\mathrm{C}$. hirsutus $\mathrm{X}$ purpureus?). 
(Aeste dornig, pfriemlich; Bt. einzeln; Pfl. oberwärts

7 silberweib-seidig. $J$.

Apinescens. Sieb. Dorniger G.

${ }_{8}$ Bt. endständig, doldig o. kopfig (wenigstens die an

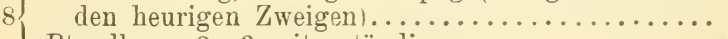

Bt. alle zu 2-3 seitenständig .............. 11

Bt. heller o. dunkler gelb .................. 10

9 Bt. weißlich; Zweige filzig; Blättchen anliegend behaart; K. zottig. $I I$.

leucanthus. WK. Weisblühender G.

B. von anliegenden Haaren grau; K. u. Zweige rauhhaarig; Aeste aufrecht. $B . M T . N$. O. St. $K r$.

10 Austriacus. L. Oesterreichischer G. B., K. u. Zweige von abstehenden Haaren rauhhaarig; Aeste steif, aufrecht-abstehend, gleichhoch. Verbr............... supinus. $L$. Niedriger $G$.

K., Zweige u. B. rauhhaarig, Haare abstehend; Aeste aufstrebend. M. N. O. St. K. Kr. J. Südt.

11 hirsutus. L. Rauhhaariger G.

K., Zweige u. B. seidenhaarig, Haare angedrückt; Aeste niedergestreckt. Yerbr.

Ratisbonensis. Schaeff. Regensburger G.

Anmerkung. Zwischen C. Austriacus L. und

C. supinus L., ferner zwischen C. hirsutus L. und

C. Ratisbonensis Schaeff. kommen Bastarte vor.

\section{ONONIs. $L$. Hauhechel.}

1\{

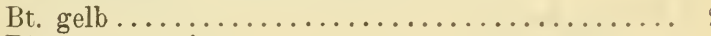

Drüsig-flaumig; Blkr. kürzer als der $\mathrm{K}^{*}{ }^{*}$ ); Hülse aufrecht, eiförmig. $N$. J. Süidt.

subocculta. Vill. Berg-H.

2 Drüsig und zottig; Blkr. länger als der K.; Hülse hängend, lineal. Südt. Südst. Kr. J.

Natrix. L. Gelbe $\mathrm{H}$.

Einjähriges Kraut; Stg. u. B. drüsig und zottig; Nebenb. gezähnelt; Bt. einzeln in den Bachseln; Hülse hängend, lineal, gedunsen, zottig. $J$.

reclinata. $L$. Nickende $H$.

Stauden 0. Halbsträucher.................... 4

$\int$ Hülse hängend, lineal; Blättchen fast kreisrund, ge-

$4\left\{\begin{array}{r}\text { zähnt; Nebenb. ganzrandig. } T \cdot K \text {. } \\ \text { rotundifolia. } L \text {. Rundblättrige } H .\end{array}\right.$

Hülse aufrecht, eiförmig; Blättchen nicht rundlich.

*) Manchmal findet man auch Bt., deren Blkr. länger als der $\mathrm{K}$. ist. 
(Bt. zu 2 o. die obersten einzeln, an der Spitze der

5 Aeste dicht ährig; Stg. wehrlos, zottig. Verbr.

hircina. Jacq. Bocks-H.

Bt. meist einzeln; Aeste oft dornig .......... 6

Aeste reichlich dornig.................. 7

Aeste wehrlos, seltener mit einzelnen, meist weichen

6 Dornen; Zweige zottig; K. so lang o. länger als die Hülse. Verbr. (?)

foetens. $\left.A l l .^{*}\right)$ Stinkende $\mathrm{H}$.

Blättchen länglich-lanzettlich 0 . oval, fein-drüsig, fast kahl erscheinend; Hülse so lang o. länger

$7\left\{\begin{array}{r}\text { als der K. Verbr........ spinosa. } L \text {. Dornige H. } \\ \text { Blättchen klein, elliptisch, die oberen schmäler, }\end{array}\right.$ drüsig-schmierig; Hülse kürzer als der K. J.

antiquorum. $L$. Kleinblättrige $\mathrm{K}$.

\section{TRIGONELLA. L. Hornklee.}

Bt. gelblich o. weißlich ................

Bt. hellviolett, in kurzen, köpfchenartigen Trauben; Flügel kürzer als die Fahne, länger als das Schiffchen; Hülsen eilänglich, kahl, längsaderig.

Cult. u. verw.....coerulea. (L.) Sér. Blauer H.

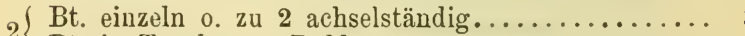

$2\{$ Bt. in Trauben 0. Dolden .................

Hülsen kahl, meist mit 10-12 Samen; Blättchen länglich-keilförmig, vorne gezähnelt.

Cult. u. verw. (bes. M.)

3 Foenum graecum. L. Griechischer $\mathrm{H}$.

Hülsen flaumig, meist mit 4-6 Samen; Blättchen verkehrt-eiförmig, geschärft klein gesägt. $J$.

gladiata. Stev. Säbelfrüchtiger $\mathrm{H}$.

Bt. in fast sitzenden, achselständigen Dolden; Bt. hellgelb; die ganze Pfl. nebst den Hülsen flaumhaarig. $B . M . N . T . J$.

44 Monspeliaca. L. Französischer H. Bt. in lang gestielten, kurzen Trauben; Bt. dottergelb; Stg. oben zerstreut behaart; Hülsen kahl. J. corniculata. $L$. Traubiger $\mathrm{H}$.

\section{MEDICAGO. $L$. Schneckenklee.}

( Hülsen nierenförmig, sichelförmig 0. schneckenförmiggewunden, aber im Mittelpunkte der Windung

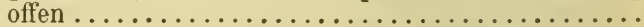

Hülsen schneckenförmig - gewunden, mit einer 0 . mehreren Windungen, im Mittelpunkte geschlossen;

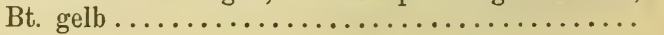

*) 0. Austriaca Beck (T. N.) ist eine Wiesenpfl. mit ruthenförmigen, fast einfachen Zweigen. 
Hülsen sichelförmig 0 . schneckenförmig gewunden, zusammengedrückt; Stauden ................

2 Hülsen nierenförmig, blattartig-flach, mit sich be3 rührenden Enden, am vorderen Rande dornig, am hinteren gefranst; Bt. gelb ; einjähriges Kraut. (J.?) radiata. $L$. Strahliger Sch.

Hülsen, Stg., Bstiele und B. dicht-wollig-filzig; Blättchen verkehrt-eiförmig, vorne gezähnelt; Bt.

3 gelb. J............. marina. $L$. Meer-Sch. Hülsen flaumhaarig o. kahl; Blättchen ausgerandet, stachelspitzig..........................

Btstiele doppelt so lang als der K., nach dem Verblühen zurückgeschlagen; Traube $5-10$ blütiz; Bt.

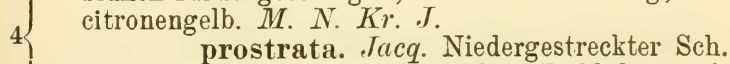
Btstiele kürzer als der K., nach dem Verblühen aufrecht; Trauben vielblütig..................

Trauben länglich; Hülse fast $3 \mathrm{mal}$ gewunden, angedrückt-flaumig; Bt. meist violett o. bläulich

5 Cult. u. verw...........sativa. L. Luzernerklee. Trauben kurz, oft kopfig; Hülse sichelförmig $0.1 \mathrm{mal}$ gewunden, flaumig 0 . abstehend-drüsig-haarig; Bt. gelb. Verbr............. falcata. $L$. Sichel-Sch.

Hülsen wehrlos o. mit kurzen Knötchen besetzt;

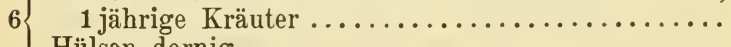

Hülsen dornig.......................... 11

Nebenb. eiförmig, fast ganzrandig; Aehren reichblütig, gedrungen; Hülsen nierenförmig. gedunsen,

7 an der Spitze gewunden. Verbr. u. hfg.

lupulina. $L$. Hopfenklee.

Nebenb. gezähnt 0 . fiederspaltig; Bt. zu $1-3 \ldots$.

Stg. kahl; Hülsen schneckenförmig-krejsrund; Windungen meist 6 ; Nebenb. tief-borstlich-fieder-

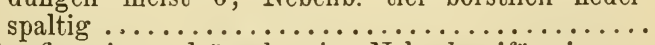
Stg. flaumig 0 . drüsenhaarig; Nebenb. eiförmig, gezähnt .

(Hülsen beiderseits etwas convex, die Windungen mit dem eingebogenen Rande dicht-aufeinanderliegend. Sïdt. Kr.J.

orbicularis. (L.) Kreisfrüchtiger Sch.

Hülsen beiderseits flach, die Windungen am Rande von einander entfernt. $J$. (?)

marginata. Willd. Berandeter Sch. 
Hülsen aderlos, Windungen dicht-aufeinanderliegend, mit Knötchen 0 . stumpfen Zitzen besetzt. J.

tuberculata. Willd. Knötiger Sch.

Hülsen schief-netzig-aderig, Windungen beckenförmig, concentrisch-zusammengerollt, glatt. $J$.

scutellata. (L.) Schildfrüchtiger Sch.

Dornen der Hülsen am Grunde fast stielrund, ohne deutliche Furche, auf dem Rande der Windungen selbst stehend, Windungen aufeinanderliegend... 12

11 Dornen der Hülsen am Grunde zusammengedrückt, beiderseits mit einer deutlichen Furche, daher fast 2 schenkelig, Windungen locker-aufeinanderliegend 0 . abstehend

12 Hülsen filzig-flaumig 0 . drüsenhaarig . . . . . . 13

Ḧ̈lsen kahl o. zerstreut-haarig; 1 jährige Kräuter. 14

Hülsen filzig-flaumig, mit 4-7 Windungen; Nebenb. eilanzettlich; 1 jähriges Kraut. Südt. J.

rigidula. (L.) Steifer Sch.

Hülsen drüsenhaarig, mit $3-4$ Windungen; Nebenb. pfeilförmig-lanzettlich; Staude. J.

Pironae. Vis. Pirona's Sch.

Fahne fast doppelt so lang als das Schiffchen; Hülse zerstreut-haarig; Blättchen verkehrt-eiförmig. $J$.

14 tribuloides. Desr. Burzeldornähnlicher Sch. Fahne kaum länger als das Schiffchen; Hülse kahl; Blättchen 3 eckig-verkehrt-herzförmig. J.

litoralis. Rohde. Strand-Sch.

Der hintere Schenkel der Dornen aus dem Rande der Hülse selbst entspringend; 1 jährige Kräuter . 16

15 Der hintere Schenkel der Dornen aus einer erhöhten, mit dem Rande gleichlaufenden, vom Rande entfernten Linie, oder aus einer starken Ader des netzigen Mittelfeldes entspringend...........

Oberfläche der Windungen glatt, die oberste wehrlos, die übrigen 2 zeilig-dornig; Stg. zottig-flaumig. $J$. .....disciformis. $D C$. Scheibenförmiger Sch. Oberfläche der Windungen aderig, der Rand breit, 4 kielig, 2 zeilig-dornig, Dornen bogig-gekrümmt. $J . . . \ldots \ldots$......Arabica. (L.) Arabischer Sch.

Oberfläche der Windungen aderlos, 0. mit einfachen, bogigen Adern, spärlich haarig o. grau-weich-

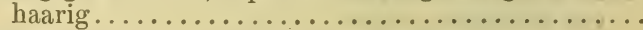
Oberfläche der Windungen netzig-aderig ........ 19 
Trauben 1-2 blütig, ihre Stiele länger o. kürzer als ihre Tragb.; Windungen der Hülsen $3-5$, aderlos, die 2 zeiligen Dornen des schmalen Randes pfriemlich, gerade, an der Spitze hakig; Blättchen verkehrt-eiförmig. Verbr. (fehlt Sch. S.)

minima. $\left.(L .)^{*}\right)$ Kleinster Sch.

Trauben vielblütig, ihre Stiele 2-3 mal so lang als ihre Tragb.; Windungen der Hülsen 2, die 2 zeiligen Dornen des breiten Randes nach auf- und abwärts senkrecht kronenförmig zusammengestellt, einwärtsgebogen. J. (?)... coronata. (L.) Gekrönter Sch.

Staude; Blättchen verkehrt-eiförmig: Nebenb. spitzgezähnt; der hintere Schenkel der Dornen aus einer starken Ader des Mittelfeldes entspringend.

19 Sï̈t. K. Südst. Kr . .J.

Carstiensis. Wulf. Karst-Sch.

1 jährige Kräuter; Nebenb. eingeschnitten-gezäbnt

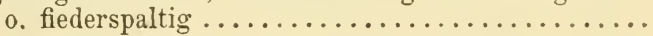

Nebenb. eingeschnitten-gezähnt; Hülsen zottig, fast kugelig; der hintere Schenkel der Dornen aus einer starken Ader des Mittelfeldes entspringend. $J$............. ciliaris. (L.) Gewimperter Sch.

Nebenb. fiederspaltig; Hülsen kahl, beiderseits flach; der hintere Schenkel der Dornen aus einer mit dem Rande gleichlaufenden erhabenen Linie entspringend. J. hispida. Gärtu. ${ }^{* *}$ ) Borstiger Sch.

Anmerkung. Zwischən M. falcata L. und M. sativa L. kommt nicht selten ein Bastart vor, der meist schmutzig-grünliche Bt. hat. In $N$. wurde auberdem M. falcata $\times$ prostrata beobachtet.

\section{IIELILOTUS. Adans. Steinklee.}

Bt. weib; Flügel ungefähr so lang als das Schiffchen,

1 kürzer áls die Fahne; Hülse kahl, stumpf, stachelspitzig. Verbr...........albus. Desr. Weißer St.

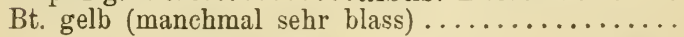

Hülsen gleichlaufend-bogig-quer-gerieft, rundlich . ganz stumpf; Fahne so lang als das Schiftchen, länger als die Flügel; Nebenb. am Grunde pfriemlich-gezähnt. $J$.

sulcatus. Desf. Gefurchtfrüchtiger st.

Hülsen netzig-runzelig

*) In Bezug auf Behaarung, sowie auf Bedornung der Hülsen lassen sich mehrere Unterarten unterscheiden.

**) Die Länge der Dornen der Hülsen ist bei dieser Art sehr veränderlich.

Fritsch, Excursionsflora. 
( Nebenb. am Grunde eingeschnitten-gezähnt; Hülsen

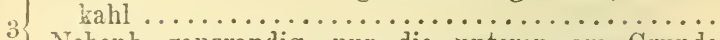
Nebenb. ganzrandig, nur die unteren am Grunde manchmal beiderseits $1-2$ zähnig ...........

Blättchen länglich 0 . lanzettlich; K. 5 nervig; Bt. hellgelb; Hülsen spitzlich. B. MI. N. Südt.

dentatus. (WK.) Pers. Gezähnter St.

Blättchen breit verkehrt-eiförmig, mit keiligem Grunde; K. 10 nervig; Bt. goldgelb; Hülsen stumpf. J..Italicus. (I.) Desr. Italienischer St.

Hülsen aufrecht, zugespitzt-geschnäbelt, kugelig; Nebenb. fast borstlich. $J$.

Neapolitanus. Ten. Neapolitanischer St. Hülsen hängend, nicht geschnäbelt............

Flügel so lang als das Schiffchen, deutlich kürzer als die Fahne; Bt. sehr klein; Hülsen bräunlich, fast kugelig, stumpf, mit sehr kurzer Stachelspitze, kahl. $J$.

parviflorus. Desf. Kleinblütiger St.

Flügel so lang als die Fahne 0 . kaum merklich kürzer; Hülsen stachelspitzig ..............

Flügel so lang 0 . kaum länger als das Schiffchen; Hülsen angedrückt flaumig, auf dem Rücken scharf gekielt, zuletzt schwarz. Verbr. (fehlt St. K. $K r$.)

altissimus. Thuill. Hoher St.

Flügel länger als das Schiffchen; Hülsen kahl, auf dem Rücken abgerundet, stumpf gekielt, bräunlich. Verbr............. officinalis. (L.) Gelber St.

\section{TRIFOLIUM. L. Klee.}

K. innen am Schlunde mit einer erhabenen, schwieligen, oft behaarten Linie, o. mit einem Haarkranze besetzt; Bt. sitzend 0 . sehr kurz gestielt, in rundlichen 0. länglichen Aehren; Hülsen 1 samig (nur ausnahmsweise 2 samig); Gr. an der Spitze

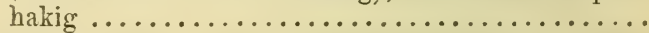

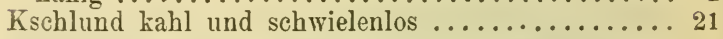

Kröhre (wenigstens zur Frzeit) kahl, die Kzähne behaart 0. gewimpert ...................

Kröhre behaart

Aehren länglich-walzenförmig, meist zu 2, am Grunde oft umhüllt; Kzähne pfriemlich, gewimpert; Blättchen länglich-lanzettlich, fein gesägt, sammt dem aufrechten Stg. ganz kahl; Bt. purpurn; Staude. $V$ erbr. (fehlt S.)...... rubens. $L$. Röthlicher $\mathrm{K}$.

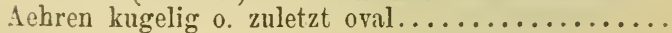


K. 20 nervig; Kzähne fast so lang als die Blkr., borstig-haarig; Blättchen verkelirt-eiförmig, gezähnelt; 1 jähriges Kraut mit ästigem, ausgebreitetem Stg.; Bt. röthlich-weiß. J.

lappaceum. $L$. Kletten-K.

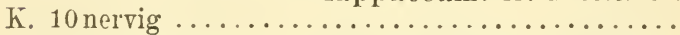

Staude mit purpurnen (sehr selten wei@en) Bt.; Blättchen elliptisch, fein gezähnelt; Kzähne fädlich, gewimpert, aufrecht. Verbr.

medium. $L$. Mittlerer $\mathbf{h}$.

Einjährige Kräuter mit weiळlichen 0 . rosenrothen Bt. Kzähne lanzettlich, 3 nervig, behaart, der unterste auswärts gebogen; Blättchen länglich o. lanzettlich, fast ganzrandig; Bt. weiß o. blassröthlich. J.

6 maritimum. Huds. Meerstrands-K.

Kzähne lineal-pfriemlich, 1 nervig, gewimpert, abstehend; Bt. rosenroth. J.

supinum. Savi. Niedriger K.

K. so lang als die halbe Blkr. o. kürzer; Stauden

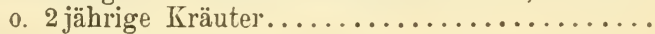

7 K. so lang als die ganze Blkr. 0. länger, seltener etwas kürzer als dieselbe; 1 jährige Kräuter, selten Stauden .......................... 1

Der freie Theil der Nebenb. 3 eckig-eiförmig, allmälig zugespitzt; Aehre kugelig, nickend; Kzähne lineal-pfriemlich, fast gleich; B. u. Stg. weichzottig; Blättchen länglich-lanzettlich; Bt. weiß. A. v. Südt. K. St. Kr.J.

Noricum. Wulf. Norischer $\mathrm{K}$.

Der freie Theil der Nebenb. eiförmig, plötzlich abgebrochen-begrannt 0 . lanzettlich-pfriemlich.....

Der freie Theil der Nebenb. eiförmig, plötzlich in eine, an der Spitze mit einigen Haaren besetzte

9 Granne zusammengezogen; K. 10 nervig, flaumig, Zähne fädlich, gewimpert ................. 10

Der freie Theil der Nebenb. lanzettlich o. pfriemlich 11

$\mathrm{K}$. so lang als die halbe Blkr., die 4 oberen Kzähne erheblich länger als die Kröhre; Aehren einzeln; Blättchen eiförmig, nebst den Bstielen u. Stg. durch abstehende Haare zottig; Bt. weiß o. röthlich. J.

10 pallidum. $W K$. Blasser $K$.

K. kürzer als die halbe Blkr., die 4 oberen Kzähne so lang als die Kröhre; Aehren meist zu 2 ; Blättchen oval, durch anliegende Haare flaumig; Bt. meist hellpurpurn. ${ }^{*}$ ) Verbr. $u$. $h f g$.

pratense. $L$. Wiesen- $K$.

*) T. nivale Sieb. ist eine Alpenform mit weißlichen o. nur etwas röthlichen Bt. Das gewöhnliche T. pratense L. blüht selten weis. 
K. 20 nervig, zottig, Zähne fädlich, gewimpert, die 4 oberen fast so lang o. kürzer als ihre Röhre; Blättchen länglich-lanzettlich; Stg. flaumig; Bt. purpurn (selten weiß). Verbr. (fehlt Sch.)

alpestre. $L$. Wald-K.

K. 10 nervig, Kzähne lanzettlich-pfriemlich; Aehren einzeln; Bt. gelblich-weiß ................

Aehren kugelig o. breit oval, oft behüllt; K. abstehend rauhhaarig, der unterste Zahn bei der Frreife herabgebogen, so lang als die Röhre, die anderen kürzer. Verbr. (fehlt $S$.)

ochroleucum. L. Gelblichweißer K.

Aehren sehr grof, länglich-oval, gestielt, nicht behiillt; K. zottig, die 4 oberen Kzähne so lang als die Röhre, der unterste doppelt so lang, bei der Frreife alle aufrecht. $K r$.

Pannonicum. Jacq. Ungarischer K.

Aehren am Grunde behüllt............... 14

13 Aehren am Grunde hüllenlos, einzeln; K. 10 nervig 0. 10 streifig; zottig behaarte Kräuter .........

K. 20 nervig, rauhhaarig, Zähne fädlich, fast gleichlang, so lang o. länger als die Blkr.; Stg., B. u. Nebenb. zottig; Aehre kugelig; Blättchen verkehrtherzförmig; Bt. weißlich. J.

Cherleri. $L$. Cherler's K. K. 10 nervig; Aehren end- und seitenständig.....

Weichhaarige Staude; Kzipfel biegsam, borstlich, fast so lang als die Kröhre, zur Zeit der Frreife aufrecht; Blkr. weißlich. A. v. T.

saxatile. All. Felsen-K.

Kräuter; Kzipfel starr, lanzettlich o. pfriemlich ...

Blättchen mit sehr deutlichen, gegen den Rand hin verdickten und in einem Bogen abwärts gekrümmten Seitennerven durchzogen, verkehrt-eitörmig oder länglich keilförmig; $K$. flaumig, länger als die Blkr.; Kzänne zuletzt in einem Bogen abstehend; Bt. weiß 0. röthlich. Südt. J.

scabrum. L. Rauher K. Blättchen mit sehr deutlichen, gleich dicken, gegen den Rand hin ziemlich geraden Seitennerven; K. so lang als die Blkr. o. kürzer; Kzähne gerade, wenn auch abstehend; Bt. rosa, selten weiß.... 
( K. flaumig; Kzähne an die Blkr. angedrückt; Kröhre zur Frzeit nicht bauchig; der freie Theil der Nebenb. lanzettlich-pfriemlich. $J$.

Bocconii. Savi. Boccune's K.

17 K. zottig; Kzähne abstehend; Kröhre zur Frzeit bauchig-gedunsen; der freie Theil der Nebenb. eirund, plötzlich in eine pfriemliche Spitze verschmälert. B. $M . N . K r$. J. Sü dt.

striatum. $L$. Gestreifter $\mathrm{K}$.

18 Blättchen lineal o. lineal-länglich; Bt. hellrosa .... 19

18 Blättchen verkehrt-herzförmig o. verkehrt-eiförmig. 20

K. borstig-rauhhaarig, der untere Kzahn länger als die Blkr., die übrigen etwas kürzer; Aehren kegelförmig-länglich; Blättchen der oberen B. lineal. $J$. angustifolium. $L$. Schmalblättriger K.

K. weichzottig; Kzähne länger als die Blkr.; Aehren eiförmig, zuletzt walzlich; Blättchen länglich-keilig o. fast lineal. Verbr. ...... arvense. L. Acker-K.

Frkn. am Schlunde durch einen schwieligen Ring u. filzige Haare geschlossen, borstlich rauhhanrig; Kzähne länger als die Blkr., an den fruchttragenden K. sternförmig ausgebreitet, netzig-aderig; Blättchen verkehrt-herzförmig; Bt. weiblich-fleischroth.

$20 \quad J . \ldots \ldots \ldots \ldots \ldots \ldots$ stellatum. L. Stern-K. Frkn. am Schlunde offen, haarig; Kzähne kürzer als die Blkr.; Blättchen verkehrt-eiförmig, gestutzt; Bt. purpurn, fleischroth o. weiblich.*)

J. Südt., sonst cult. u. verw.

incarnatum. $I$. Fleischrother $K$.

21 K. nach dem Verblühen bauchig-aufgeblasen ......

K. nicht aufgeblasen..................... 25

Bt. weiß; K. 2tnervig, kahl, zur Frzeit eirund; Aehre oval ; Deckb. eiförmig, so lang als die
Kröhre; Krb. zugespitzt, trockenhäutig, vielstreifig. $J . . . . . m$ multistriatum. Koch. Vielstreifiger $\hat{\mathrm{K}}$. Bt. fleischroth o. rosenroth; Frkn. kugelig-aufgeblasen; Köpfchen zuletzt kugelig ...........

Frkn. wei§filzig-haarig, die 2 oberen Zähne kurz, fast ganz mit Filz bedeckt; Köpfchenstiel kürzer als sein Tragb.; Blkr. rosa, 2 mal länger als der K. $J$..............tomentosum. L. Filziger K. Frkn. zottig, die 2 oberen Zähne gerade vorgestreckt 24. Balb. (J.)

*) Die letztere Farbe haben die Bt. des T. Molineri 
Hülle vieltheilig, so lang als der $\mathrm{K}$.; Köpfchenstiel länger als sein Tragb.; Bt. fleischfarben. Verbr.

fragiferum. $L$. Erdbeer-K.

24 Hülle 10-12 lappig, sehr kurz, so lang als die Btstiele; Köptchenstiel so lang als sein Tragb.; Blkr. rosa, 3 mal länger als der $\mathrm{K}$. J.

resupinatum. L. Verkehrtblumiger $K$.

( Gr. an der Spitze hakig-umgebogen; 1 jährige 25 Kräuter mit weißlichen o. etwas röthlichen Bt...

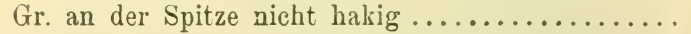

Fruchtbare Bt. doldig, 2-5; K. kahl, Zähnє fädlich, kürzer als die Blkr.; unfruchtbare Bt. nach dem Verblühen der fruchtbaren erscheinend, ohne Blkr., ein rundliches Köpfchen bildend; Stg. niedergestreckt, rankenartig; Blättchen verkehrt-herzförmig. J. . subterraneum. L. Unterirdischer K. Fruchtbare Bt. in reichblütigen Aehren o. Köpfchen

K. kürzer als die Blkr., der untere Kzahn länger, herabgekrümmt; Blättchen verkehrt-eiförmig, stumpf, die oberen lanzettlich, geschärft-drïsiggezähnelt. J. .....laevigatum. Poir. Kahler $\mathrm{K}$. $K$. etwas länger als die Blkr.; die 2 oberen Kzähne länger, alle in einem Bogen aufwärts-gekrümmt; Blättchen verkehrt-eiförmig, geschärft-gesägt, mit verdickten Adern; Bt. weißlich. B. $M$.. . J.

strictum. L. Steifer K.

Staude ohne oberirdischen Stg.; alle B. u. Köpfehenstiele grundständig; Bt. grol;, purpurn o. rosa, selten weiß, gestielt, locker gestellt; Blättchen lineallanzettlich, schwach klein-gesägt. A. $\nabla$. $T$ '.

alpinum. L. Alpen-K.

Oberirdischer Stg. vorhanden ............... 29

99 Blkr. weiß, gelblich-weiß 0. rosenroth ......... 30

Blkr. gelb, beim Verblühen braun werdend ...... 39

Bt. sitzend, o. mit Btstielen, die viel kürzer sind als der $K . . . \ldots \ldots \ldots \ldots \ldots \ldots \ldots \ldots \ldots . \ldots \ldots$

30 Die inneren Btstiele so lang o. länger als die Kröhre; Köpfchenstiele blattwinkelständig, länger als ihre Tragb.; K. kahl, die 2 oberen Kzähne länger.... 34

Bt. sitzend, aufrecht; Aehren blattwinkelständig, sitzend, genähert, sammt den sehr kurzen Stg. an die Erde angedrückt; K. kahl, doppelt so lang als die Blkr.; Kzähne abwärts-gekrümmt, die 2 oberen länger; Nebenb. die Aehre umhüllend. $J$. suffocatum. $I$. Sand-K.

Bt. kurz gestielt ...................... 32 
K. etwas zottig; Btstiele nach dem Verblühen herabgebogen; Blättchen elliptisch, geschärft-klein-gesägt, unterseits nebst dem Stg. haarig, a: Rande dichtaderig, Aderchen verdickt; Bt. weib. Terbr.

montanum. L. Berg- h.

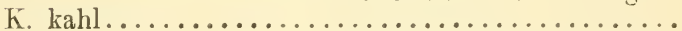

Aehren end- und seitenständig, sitzend; Btstiele kürzer als die sehr kleinen Deckblätter; Kzähne gleich, eiförmig, zugespitzt, am Grunde herzförmig. . . .......... glomeratum. $L$. Geknäuelter $\bar{h}$.

33 A Aehrenstiele blattwinkelständig, länger als ihre Tragb.; Blättchen feingesägt, sammt dem Stg. kahl; Stg. rasig, aufstrebend; K. länger als die halbe Blkr.; Kzähne lanzettlich, zugespitzt, die 2 oberen länglich. A. v. T. K. St. Kr..... Thalii. Vill. Pasiger K.

Die oberen Frstiele so lang als die Kröhre...... 35

34 Frstiele (wenigstens die oberen) $2-3$ mal länger als

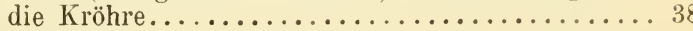

Stg. niedergestreckt, wurzelnd; Kzähne lanzettlich o. pfriemlich; Blättchen verkehrt-herzförmig $c$. verkehrt-eiförmig, klein-gesägt ............

Stg. aufstrebend 0. rasig-darniederliegend ....... 37

Bt. weio, zuletzt etwas röthlich; Stg. nur am Grunde wurzelnd. Verbr. $u$. hfg.

repens. $L$. Kriechender $\mathrm{K}$.

Bt. rosenroth; Stg. sammt den Aesten überall wurzelnd und dem Boden angedriickt. J.

Biasolettii. Steud. et Hochst. Niederliegender K. K. 3 mal kïrzer als die Blkr.; Stg. rasig-niederliegend; Blättchen klein-gesägt, sammt dem Stg: kahl; Bt. weiß 0. gelblich. A. (fehlt $\Lambda$. 0. )

pallescens. Schreb. Verbleichender K.

K. so lang als die halbe Blkr.; Stg. aufstrebend; Blättchen vorne klein-gesägt, von der Mitte bis zum Grunde ganzrandig; Bt. weiß. J. Südt.

nigrescens. Viv. Schwärzlicher K.

Stg. aufrecht o. aufstrebend, ganz kahl, röhrig, weich; Blättchen rautenförmig-elliptisch, mit beilänfig 20 Adern am Rande; Bt. weiß, dann rosa. Verbr. ............hybridum. L. Bastart-K.

38 Stg. in einen Kreis niedergestreckt, an der Spitze aufstrebend, oberwärts flaumig, nicht hohl, hart; Blättchen verkehrt-eiförmig, mit fast 40 Adern am Rande; Bt. röthlich. .J.

elegans. Savi.*) Zierlicher K.

*) In $B$. u. $M$. findet sich das dem T. elegaris Savi verwandte T. prostratum (Sond.), weiches aber kahle Stg. $u$. die Nervatur des $\mathrm{T}$ hybridum L. hat. 
Ubere Stgb. fast gegenständig; Köpfchen scheinbar endständig, einzeln o. zu 2-3; Fahne vom Grunde an eiförmig-gewölbt, gefurcht; Flügel gerade vorgestreckt; Gr. 4 mal kürzer als die Hülse; Hülse

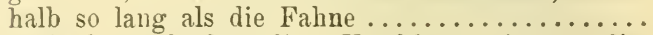
Alle Stgb. wechselständig; Köpfchen seitenständig, meist mehrere......................

Köpfehen zuletzt walzlich; Btstiele nach dem Verblühen herabgebogen; Kzähne haarig; Nebenb. alle länglich-lanzettlich. Verbr. (fehlt $K r$. J.)

spadiceum. L. Kastanienbrauner $\mathrm{K}$. Köpfchen kugelig, zuletzt oval-rundlich; die unteren Btstiele herabgebogen; Nebenb. länglich-lanzettlich, die oberen fast eiförmig. $A$. (fehlt $K r$. J.)

badium. Schreb. Lederbrauner K.

Flügel seitlich-abstehend; Fahne löffelförmig, gefurcht; Hülse halb so lang als die Fahne....... 42

Flügel gerade vorgestreckt: Fahne zusammengefaltet, fast glatt, kaum gefurcht; Hülse wenig kürzer als lie Fahne; Köpfchen locker, 2-10blütig; 1 jährige

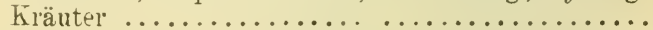

Gr. 4 mal kürzer als die Hülse; das mittlere Blättchen viel länger gestielt als die seitlichen; Nebenb. eiförmig; Köpfchen fast 40 blütig; Kzähne an der spitze etwas haarig. Verbr.

campestre. Schreb. Feld-K. Gr. fast so lang als die Hülse, das mittlere Blättchen nicht 0 . nur wenig länger gestielt als die

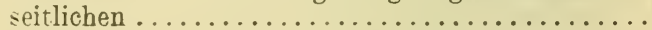

Köpfehen dicht, rundlich 0. oval; Nebenb. länglichlanzettlich, am Grunde gleich breit. Verbr.

aureum. Poll. Goldfarbener K.

Köpfchen locker, während des Blühens halbkugelig; Nebenb. eiförmig, am Grunde breiter und deutlicher herzförmig; Kzähne an der Spitze etwas haarig. (S.?) Südt. Südst. Kr.J.

patens. Schreb. Abstehender K.

Nebenb. am Grunde abgerundet-verbreitert, eiförmig; Köpfchen meist 6-12 blütig. Verbr.

minus. Sm. Kleiner K. Nebenb. länglich, am Grunde so breit wie in der

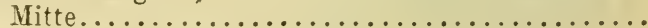

Köpfehen S-20blütig; Kzähne viel länger als die Kröhre. J. ....Sebastiani. Savi. Sebastiani's K. $45\{$ Köpfchen $2-6$ blütig; die 2 oberen Krähne kaum länger als die Kröhre. $J$.

filiforme. $L$. Fadenförmiger $\mathrm{K}$. 
Anmerkung. Verschiedene, namentlich 1 jährige Trifolium-Arten, welche nur gelegentlich eingeschleppt gefunden wurden (namentlich bei Triest), fanden hier keine Aufnahme.

\section{ANTHYLLIS. L. Wundklee.}

Kröhre bauchig erweitert, mit schiefer Mündung, viel länger als die Kzähne; Platte der Fahne kürzer als ihr Nagel; Grundb. ungetheilt 0. gefiedert mit gröЊerem Endblättchen ........... Kröhre cylindrisch, nicht länger als die Kzähne; Platte der Fahne doppelt so lang als ihr Nagel; alle B. gefiedert mit zahlreichen seidenhaarigen Blättchen, deren endständiges nicht größer ist als die übrigen; Bt. blass-fleischfarben.

N. Südst. Kr. J. K. Sü dt.

Jacquini. Kern. Oesterreichischer W.

Stg. ziemlich hoch, nahezu gleichmäßig beblättert;

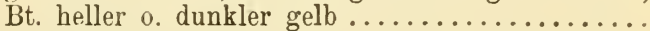

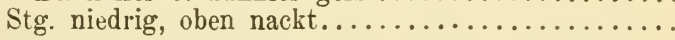

Stg. unten von abstehenden Haaren zottig; Deckb. so lang als die Btköpfchen; K. abstehend zottig.

B. M. N. J. polyphylla. Kit. Vielblättriger W. Stg. anliegend seidig behaart; Deckb. etwas külzer als die Btköpfchen; K. seidig-zottig, mit aufrecht abstehenden Haaren. Verbr. (?)

Vulneraria. I. Echter W.

K. weißlich o. graugrünlich, nicht purpurn über-

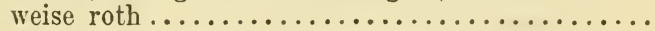

$\mathrm{K}$. vorne trübpurpurn überlaufen; Bt. meist blutroth, seltener nur theilweise roth 0 . ganz gelb...

$\mathrm{K}$. weißlich, von kurzen anliegenden Haaren schimmernd; Platte der Fahne etwas kürzer als ihr Nagel; Bt. meist goldgelb. Verbr.

vulgaris (Koch.) Gemeiner W.

K. lang seidig- o. zottig-behaart; Platte der Fahne

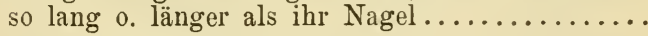

B. meist mehrpaarig gefiedert; K. weißlich, abstehendzottig; Blkr. meist weißlichgelb, ziemlich klein. Vora. v. S. St. O. N.

affinis. Britt. Blassgelber W.

6 B. ungetheilt 0 . armpaarig gefiedert mit sehr grofem Endblättchen; K. graugrünlich, mit langen aufrechten seidigen Haaren bekleidet; Blkr. ziemlich groß, meist goldgelb*). $A$.

\section{alpestris. Kit. Alpen-W.}

*) A. pallidiflora Jord. (A. v. südt.) blüht weißlichgetb, hat aber sonst die Merkmale der A. alpestris Kit. 
(Stg. kurz anliegend behaart o. fast kahl; B. mehrpaarig gefiedert; K. anliegend behaart. $N$. J.

Dillenii. Schult. Rother IV. Stg. unten abstehend, oben anliegend behaart .....

Endblättchen viel größer als die Seitenblättchen; $\mathrm{K}$. verhältnissmäßig groß. Sïdt. .J.

$8^{\prime}$ Illyrica. Beck. Illyrischer W. Endblättchen kaum größer als die Seitenblättehen; K. klein. J....Adriatica. Beck. Adriatischer W. A umerkung. Die Abgrenzung der Arten ist nicht endgiltig: festgestellt, ebenso auch nicht die Verbreitung der einzelnen Arten.

XVI. CIRCINUS. Med. Pfennigklee.

Die untersten B. ungetheilt, die oberen gefiedert, mit ganzrandigen Blättchen. $J$. circinatus. (L.) Ktze. Gemeiner Pf.

XVII. BONA VERIA. Scop. Beilwicke.

Einjähriges, kahles Kraut; Blättchen 7-17, verkehrt-eiförmig, gestutzt 0 . ausgerandet; Bt. zu 3 bis 9 in lang gestielten Dolden. $J$.

Securidaca. (L.) Scop. Gemeine B.

XVIII. DORYCNIUM. Adans. Backenklee.

Bt. klein, weißlich; K. fast 2lippig; Flügel vorne zusammenhängend, in der Mitte aufgeblasen; Fr.

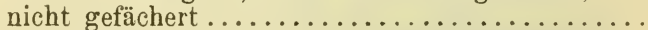

1 Bt. ziemlich groh, rosa; K. gleichmäßig 5̃ähnig; Flügel nicht zusammenhängend, am oberen Rande mit einem Längseindrucke; Fr. querfächerig; Stg. II. B. dicht abstehend-zottig. Südt. J.

hirsutum. (L.) Sér. Rauhhaariger B.

Blättchen lineal-keilig, fast seidenartig-zottig, Haare anliegend; Köpfchen meist 12 blütig. M. N. O. St. K. Kr. J. T.

suffruticosum. Vill. Halbstranchiger B. Blättchen länglich - keilig, zelstreut-haarig, Haare abstehend; Köpfchen meist 20 blütig.

N. St. K. Kr. J. Sü̈lt.

herbacemm. Vill. Krautiger B.

\section{LOTUS. L. Schotenklee.}

Hülse zusammengedrückt, lineal, gekrümmt, innen gefächert, kahl ; Stg. flaumig, ausgebreitet; einjähriges Kraut mit $3-5$ blütigen Dolden. $J$.

ornithopodioides. $L$. Vogelfußartiger Sch.

Hülsen stielrund 0.4 kantig .................

$2\left\{\begin{array}{l}\text { Bt. einzeln o. zu } 2-3 \ldots \ldots \ldots \ldots \ldots \ldots \ldots \ldots \ldots \ldots \\ \text { Bt. in } 4-12 \text { blütigen Dolden } \ldots \ldots \ldots \ldots \ldots \ldots\end{array}\right.$ 
Hülsen 4 kantig, mit geflügelten Kanten; Gr. oben verdickt; Staude mit großen, hellgelben, manchmal rosa überlaufenen Bt. Verbr.

siliquosus. $L$. Vierkantiger Sch. Hülsen stielrund; Gr. pfriemlich-fädlich; 1 jährige

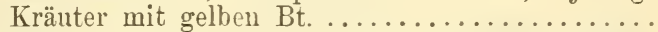

Kzähne gewimpert, aus breiterem Grunde fädlich; Hülsen schlank. gerade, 5-6 mal länger als der K. J. augustissimus. $L$. Schmalfrüchtiger Sch. Kzähne rauhhaarig, lanzettlich, 3 mal länger als die Kröhre; Hülsen gedunsen, gebogen, 2-3mal länger als der K. J.....edulis. L. Essbarer Sch. Pfl. von angedriickten Haaren grau; Kzähne längl.lanzettlich, die 2 seitlichen kürzer; Hülsen etwas gekrümmt; Köpfchen meist 5 blütig. J.

cytisoides. $I$. Geibkleeartiger Sch. Pfl. kahl o. abstehend-behaart; Hülsen gerade, lineal

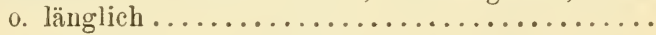

Kzähne länger als die Kröhre, lineal, von der klein॰n Blkr. nur wenig überragt; Hülsen länglich, den K. kaum überragend; PH. abstehend zottig. J.

parviflorus. Desf. Kleinblütiger Sch.

Kzähne aus 3 eckigem Grunde pfriemlich, von der Blkr. weit ïberragt; Hülsen lineal, vielmal länger

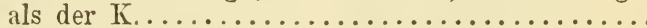

Stg. aufrecht, hohl, kah]; Dolden 6-12 blütig; Kzähne vor dem Aufblühen zurückgebogen. B. $M$. Sch. N. S. T. Kr.

uliginosus. Schk. Sumpf-Sch.

Stg. liegend 0. aufsteigend; Dolden meist 4 - bis 6 blütig; Kzähne vor dem Aufblühen zusammenschließend ...

Flügel breit-verkehrt-eiförmig; Blättchen u. Nebenb. verkehrt-eiförmig. Terbr. $u$. $h \mathrm{fg}$.

corniculatus. L.*) Gemeiner Sch.

S Flügel länglich-verkehrt-eiförmig, schmal; Blättchen und Nebenb. lineal o. lineal-verkehrt-eiförmig. Verbr. (fehlt Sch. S.)

tenuifolius. L. Schmalblättriger Sch.

\section{PSORALEA. L. Herzklee.}

Große Staude; Stg. gerillt, etwas anliegend behaart;**) Endblättchen lang gestielt. $J$.

bituminosa. L. Duftender $\mathrm{H}$.

*) Die typische Pfl. ist kahl 0. zerstreut behaart; L. villosus Thuill. ist zottig behaart. haart.

**) Bei P. plumosa Rchb. ist der Stg. abstehend be- 
XXI. GALEGA. L. Geißraute.

Staude; Blättchen lanzettlich, stachelspitzig, kahl; Nebenb. breit-lanzettlich; Trauben länger als ihre Tragb.; Bt. lila o. weiß. Verbr. (fehlt $S$.) officinalis. L. Gebräuchliche G.

\section{ROBINIA. L. Robinie.}

Blättchen oval o. länglich, stachelspitzig; Trauben hängend, reichblütig; Bt. weiß, wohlriechend.

Cult. u. veru. ...P.Pseudacacia. L. Gemeine R.

XXIII. COLCTEA. L. Blasenstrauch.

Blättchen elliptisch, etwas ausgerandet; Bt. gelb.

N. T. J. (sonst cult. u. rerw.)

arborescens. L. Gemeiner B.

XXIV. ASTRAGALUS. L. Tragant.

(Nebenb. frei o. nul unter sich verwachsen, höchstens dem Grunde des Bstieles anhängend..........

Nebenb. fast bis zu ihrer Mitte an den Bstiel angewachsen; B. 12-20 paarig; Stg. sehr verkürzt...

Die oberen Nebenb. sind unter sich zu einem dem B. gegenüberstehenden Blättchen verwachsen.......

Nebenb. frei 0 . nur die untersten verwachsen ..... 10

B. 3-4 paarig gefiedert; Blättchen lineal, stumpí; $\mathrm{Tl}$ 4-8 blütig; Hülsen lineal-länglich, so wie die ganze Pfl. seidig-grau; Bt. fleischroth. $B$.

arenarius. L. Sand-T.

B. 6-13 paarig gefiedert: Blättchen lanzettlich 0 . eiförmig (selten lineal); Aehren kopfig.........

Bt. gelblich-weiø; Hülsen fast kugelig, aufgeblasen, rauhhaarig; Stg. u. B. angedrückt behaart. Verbr.

Bt violett, blau, purpurn 0. weiclich L. Kicher-T.

Cicer. L. Kicher-T.

Fahne $3 \mathrm{mal}$ so lang als die Flügel; Aehre länglich o. eiförmig; Hülsen aufrecht, eiförmig, zugespitzt, rauhhaarig; Blättchen lanzettlich 0 . lineal, die der unteren B. eiförmig, ausgerandet; Bt. bläulichpurpurn. Verbr. (fehlt Sch.J.)

Onobrychis. .L. Langfahniger T. Fahne höchstens doppelt so lang als die Flügel ...

Frkn. sitzend; Aehren eiförmig; Hülsen oval-länglich, rauhhaarig; B. 6-9 paarig; Blättchen länglicheiförmig; Bt. hellblau. T. K. Kr. St.

Leontinus. Wulf:*) Tiroler T.

Frkn. oft sehr kurz gestielt ...............

*) A Murrii Huter (T.) hält die Mitte zwischen A. Leontinus Wulf. und A. Onobrychis L. 
$\int$ Frkn. etwa 6 mal so lang als sein Stiel; Bt. purpurn 0 . vinlett ............................................

Frkn. $23 \mathrm{mal}$ so lang als sein Stiel; Bt. violett $u$. meist weis gescheckt ...................

Blättchen 21-25, eilanzettlich, an der Spitze 2 zähnig-ausgerandet; Hülsen kugelig-eiförmig, am Grunde ausgebuchtet. Siidt.

purpureus. Lam. Purpurrother T.

Blättchen $13-17$, an der Spitze nicht ausgerandet; Hülsen kugelig-eiförmig. A. v. T. S. K. St.

oroboides. Hornem. Walderbsen-T.

Schiffchen fast so lang als die Fahne; Hülsen hängend, rauhhaarig. A. . T. S. K. St.

alpinus. L. Alpen-T.

9 Schiffchen viel kürzer als die Fahne; Hülsen aufrecht, zottig. B. II. Südst.

Danicus. Retz. Dänischer T.

$10\{$ Flügel tief ausgerandet 0.2 spaltig............. 11

Flügel stumpf, nicht ausgerandet ............. 13

Blättchen 21-31, lanzettlich o. lineal ; Bt. blassgelb; Hülsen aufrecht, angedrückt behaart. MI. NV.

Blättchen $7-21$; Bt. lila 0 . weid, selten gelblich; Hülsen zuletzt hängend................ 12

Blättchen 7-15, oval 0. länglick-lanzettlich; Bt. 'meist weiß; Hülsen kahl. A. v. T. S. K. St. J. australis. (L.) Lam. Südlicher T.

Blättchen 15-21, lineal; Bt. lila, selten weiß; Hülsen angedrückt behaart. $B . M . N . K r$.

Austriacus. Jacq. Oesterreichischer T.

Nebenblätter lineal-lanzettlich; Blättchen 19-25, lineal-länglich, unterseits flaumig, das endständige länger gestielt; Bt. hängend, ziemlich lang gestielt, 13 sattgelb. A. v. T. S. K. Kr.

penduliflorus. Lam. Hängeblütiger T. Nebenblätter eiförmig, eilanzettlich 0. lanzettlich; Bt. violett, lila, weiß o. geblichweiß, nie sattgelb 14

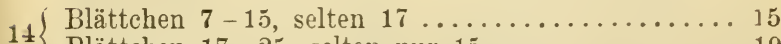

Blättchen $17-25$, selten nur $15 \ldots \ldots \ldots \ldots \ldots . \ldots$

Stg. u. B. angedrückt behaart, grün, graugrün 0. silbergrau............................ 16 Stg. kahl 0. fast kahl; B. kahl o. unterseits u. am Rande langhaarig; Bt. gelblich-weiß.......... 18 
Nebenblätter klein, eiförmig, spitz; Blättchen lineallanzettlich; Kröhre schmal, verlängert; Bt. violett; Hülsen doppelt so lang als der K., fast 3 kantig, grau-seidenhaarig. $J$.

Muelleri. Steud. et Hochst. Silberbaariger T. Nebenblätter lanzettlich, lang zugespitzt; Blättchen länglich o. elliptisch; Kröhre glockig; Bt. violett,

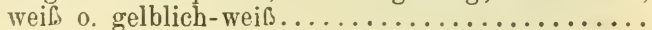

Stg. u. B. durch dichte Behaarung graugrün; Fahne ausgerandet; Hülsen länglich, wenig länger als der K., weißzottig. $N$. Sïdt.

vesicarius. $L$. Aufgeblasener T.

Stg. u. B. grün, zerstreut anliegend behaart; Fahne nicht ausgerandet; Hülsen lineal, doppelt so lang als der K., kurz weißhaarig. $K r$. J.

Carniolicus. Kern. Krainer 'T'.

Trauben lang gestielt, ihre Tragb. überragend; K. zerstreut schwarzhaarig, mit kurzen, 3 eckigeiförmigen Zähnen; Hülsen abstehend. A. (fehlt $K r . J$.)

frigidus. ( $I$.) $D C$. Kälteliebender T. Trauben kurz gestielt, ihre Tragb. niemals überragend; K. kahl, mit pfriemlichen Zähnen; Hülsen aufgerichtet. Verbr. glycyphyllos. L. Süßer T.

Bt. hellviolett; Blättchen schmal lanzettlich 0 . lineal; Btstand angedrückt behaart; Hülsen lìneal19 länglich, kurz gestielt. $N$.

sulcatus. I. Gefurchter T.

Bt. gelblich o. weißlich; Hülsen sitzend ..........

Stg. sehr kurz o. fast fehlend; Endblättchen nicht länger gestielt als die Seitenblättchen; Hülsen gerade. Südt...depressus. $L$. Niederliegender T. 20 Stg. entwickelt, beblättert; Endblättchen länger gestielt als die Seitenblättchen; Hülsen halbkreisförmig hinaufgebogen. $J$.

hamosus. $L$. Hakenfrüchtiger T.

Bt. gelb; Pfl. zottig; Hülsen eiförmig, zugespitzt, zottig. B. M. N. Sïdt.

exscapus. $L$. Stengelloser T.

Bt. purpurn; Pfl. flaumig 0. fast kahl......... 22 Traubenstiele ihre Tragb. überragend: Hülsen lineal, aufwärts gekrïmmt, zuletzt fast kahl, 10 bis 20 Samen enthaltend. Südt.

monspessulanus. $L$. Französischer T. Traubenstiele ihre Tragb. kaum an Länge erreichend; Hülsen lineal-länglich, abwärts gekrünmt, angedrückt grauhaarig, $24-30$ Samen enthaltend. J. 


\section{OXYTROPIS. JC. Spitzkiel.}

Von beiden Nähten der Hülse gehen Scheidewände aus, die im Innern der Hülse sich berühren, die Hülse deshalb 2 fächerig; Stg. sehr verkürzt, zottigseidig: Hülsen aufrecht im $K$. sitzend, eiförmig, aufgeblasen; Bt. lila. A. v. T. S. $K$.

Halleri. Bunge. Haller's sp.

Nur von der oberen Naht der Hülse geht eine Scheidewand nach innen, die Hülse deshalb halb2 fächerig o. die Scheidewand fehlt ganz.......

$\int_{2} \begin{gathered}\text { Hülsen halb-2 fächerig, im K. sitzend; Aehren ei- } \\ \text { förmig }\end{gathered}$ Hülsen einfächerig, deutlich gestielt; Trauben abge-

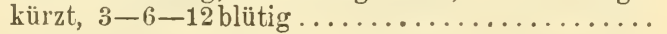

Stg. sehr verkürzt; Hülsen aufgeblasen, eiförmig; B. meist 12 paarig; Blättchen lanzettlich; Aehrenstiel sammt den $\mathbf{K}$. haarig, Haare aufrecht ......... Stg. verlängert, aufrecht, zottig; Hülsen lineal, fast stielrund; Blättchen der unteren B. länglich, der oberen lanzettlich; Aehrenstiele länger als die B.; Bt. blassgelb. B. M. N. K. T.

$$
\text { pilosa. (L.) } D C \text {. Zottiger Sp. }
$$

Schiffchen an der Spitze ungefleckt, nicht kürzer als die Flügel; Platte der Fahne doppelt so lang als breit; Bt. gelblich, selten weis o. blauviolett. A. v. T. S. K. St.

campestris. (L.) DC. Feld-Sp.

Schiffchen an der Spitze mit dunklen Augenflecken, kürzer als die Flügel; Platte der Fahne $3-4$ mal so lang als breit; Bt. heller 0 . dunkler violett, seltener gelblich 0 .'weiß. A. v. T. S. K.

Tiroliensis. (Sicb.) Fritsch. Tiroler Sp.

Trauben 3 blütig; Stg. sehr verkürzt; Traubenstiele so lang als die B.; Fahne doppelt so lang als das Schiffchen. A. v. T. S. K. St. $K r$.

triflora. Hoppe. Dreiblütiger $\mathrm{Sp}$. Trauben $6-12$ blütig, seltener mehrblütig........

Hïlsen hängend, lineal. stielrund; Traubenstiele zuletzt doppelt so lang als die B.; Bt. hellviolett. A. v. T. S. K.

Lapponica. (Wahlbg.) Gay. Lappländischer Sp. Hülsen zuletzt aufrecht 0 . abstehend, länglich 0 . eiförmig; Traubenstiele ungefähr so lang als die $B$. 
Pfl. dicht grauhaarig; Kzähne fast so lang als die Kröhre; Stiel der reifen Hülse halb so lang als die Kröhre; Bt. blauviolett. A. v. T. $K$. neglecta. Gay. Blauer Sp.
Pfl. behaart 0. fast kahl; Kzähne kürzer als die 11. behaar't 0 . fast kahl; Kzähne kürzer als die halbe Kröhre; Stiel der reifen Hülse ungefähr so

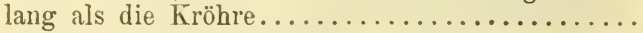

Hülsen zuletzt abstehend, eiförmig; Stg. entwickelt; Bt. blauviolett. $A$. v. $K$.

8) Carinthiaca. Fisch. Oost. Kärntner Sp. Hülsen zuletzt aufrecht, länglich-oval; Stg. sehr verkürzt; Bt. rothviolett. $A$.

montana. (I.) DC. Berg-Sp.

\section{GLYCYRRHIZA. L. Süßholz.}

Große Staude; Blättchen eilänglich; Schiffchen spitz; Hülse länglich, zusammengedrückt, holperig.

Cult. u. veru. (M.).....glabra. I. Gemeines S.

\section{SCORPIURUS. I. Scorpionswicke.}

Einjähriges Kıaut; die äußeren Rippen der Hülse 6-8 steifliche, an der Spitze fast hakige Dörnchen tragend. J. ... subvillosus. L. Feinstachelige S.

\section{ORNITHOPUS. L. Serradella.}

Einjähriges Krraut; Blättchen 15-25, klein, elliptisch; Bt. rosa. Cult. u. veru.

sativus. Brot. Echte S.

\section{CORONILLA. $L$. Kronwicke.}

Nagel der Krb. 3 mal so lang als der K.; Nebenb. frei, lanzettlich; Blättchen verkehrt-eiförmig; Strauch. Verbr. (fehlt B. M. Sch.)

Emerus. $L .{ }^{*}$ ) Strauchige K.

Nagel der Kirb. ungefähr so lang als der K.; Hïlse 4 kantig 0.4 flïgelig

${ }_{2}\{$ Bt. gelb ........................

(Einjähriges Kraut; B. 3 zählig, das Endblättchen sehr grob; Hülse gebogen, gestreift. J. Südt.

scorpioides. (L.) Koch. Krautige K.

Ausdauernde Arten; B. 3-6 paarig-gefiedert. .

*) C. emeroides Boiss. et Sprun. (J.) hat kleinere, zu 4-7 beisammenstehende $\mathrm{Bt}$. 
Strauch: Nebenb. frei, grob, nierenfürmigr. abfällir: Hülsen zusammengedrütkt-4 kantiø. .I.

Valentiua. L. Valentinische $k$.

Stauden o. kleine Halbstrïucher: Nebenb. eiförmis, länglich o. fädlich-lineal. oft zusammengewachsent

Nebenb. eiförmig. zusammengrawachen, ron dex Gröde der Blättchen; Blïttchen rerkehrt-eitörmin: Hülsen 4 thïgelig. Jerbr. (fehlt sch..$I$.)

vaginalis. Lam. Seheidenblätrige K. Nebenb. kleiner als die Blättchen: Mülsen 4 kantig

Btstiele so lang o. wenig länger als die kröhre: Dolden 5-sblitig. Südt. minima. T. Kleinste $\mathrm{k}$.

(6) Btstiele 3 mal so lang als die Kröhre: Dolden $15-$ bis a oblïtig. N. (I. st. K. Kr. I. Süldt. coronati. I. Berg-K

Einjähriges krant: Dollen 3 -6blütigr: Btstiele so lang als der K.: Blättehen 1:3-17: Bt. weidlich. Fahne purpurn gestreifr, Schifichen sehwarz-purpurn. d.......... (retica. I. Kretensisehe K. Staude: Dolden etwa 20 blïtig: Btstiel 3 mal so lang als die Kröhre: Blittchen meist 21; Fahne rosa, Flïgel und sehittchen weib, letzteres an der spitze schwarz-purpurn. Verbr. u. hig.

Varia. I. Bunte li

\section{HIPPOCREPLS. L. IInteisenklee.}

Kleine Staude: Dolden 4-sblütigr. lingr gestielt: Glieder der Hülse halbmondförmig. aneinander schliebend. Verbr. (fehlt B. .II. sih.)

comosa, I. Gemeinel $H$

Einjähriges Krant: Bt. einzeln, blattwinkelstäntig. sehr kurz gestielt: Glieder der Hülse fast krejsförmig, durch breite Zwischenlappen getrennt. d. unisiliquosa. L. Einfrichtiger H.

\section{HEDYSARUM. L. Siißklee.}

Nebenb, in ein einziges. aspaltiges rerwachen: Bt. und Hülsen hängend. (ieb. obscurum. I. Alpen-s.

Xxxil, ONObR ICHIs. Adans, Esparsette.

Einjähriges hraut; Blkr. rosenroth, den k. kamm; überriggent. $J$.

1 Caput enalli. (1.) Iam. Hahnenkopf-l:

Stauden: Blkr. den $\mathrm{K}$. Weit überragend........... 
Die Zähne des unteren gekielten Randes der Hülse halb so lang als die Breite des Kieles; Bt. rosa o. purpurn, dunkler linirt. Verbr. (oft nur verw.) viciaefolia. Scop. ${ }^{*}$ ) Gemeine E.
Die mittleren Zähne des unteren gekielten Randes der Hülse so lang als die Breite des Kieles; Bt. rosa 0 . weißlich. $J$.

Tommasinii. Jord.*) 'Tommasini's E.

\section{CICER. L. Kichererbse.}

Einjähriges Kraut; Blättchen oval; Bt. röthlich, bläulich o. weiß. Cult. u. rerw.

arietinum. L. Gemeine $\mathrm{K}$.

\section{VICIA. L. Wicke.}

$\left\{\begin{array}{l}\text { Bt. in lang gestielten, 2- bis vielblütigen Trauben } \\ \text { o. einzeln an langen Stielen in den Blattachseln. }\end{array}\right.$

1 Bt. einzeln 0. zu 2-6 in den Blattachseln, stets sehr kurz gestielt 0 . fast sitzend........... 17

Alle o. doch einige Nebenb. gezähnt 0 . zerschlitzt.

2 Alle Nebenb. ganzrandig, wenigstens die unteren

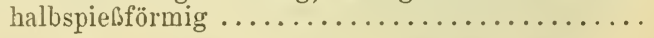

Bt. einzeln, bläulich; Nebenb. paarweise ungleich, das eine lineal und ganzrandig, das andere halbmondförmig u. zerschlitzt; Hülsen breit, länglich. (B. II. N. O.)

monantha. (L.) Dest. Einblütige W. Bt. in Trauben; Nebenb. paarweise gleich ........

( Bt. violett o. azurblau; Gr. unter der N. bärtig ... 4

4 Bt. gelblich-weib o. weib mit violetten Adern; Gr. unter der $N$. ringsum gleichmäßig flaumhaarig..

Nebenb. halbmondförmig, in 5-7 haarspitzige Zähne gespalten; Trauben meist 6 blütig; B. meist 5 paarig; Blättchen eiförmig; Bt. rothviolett mit dunkleren Adern. Verbr.

dumetorum. $L$. Hecken-W.

5 Nebenb. halbspießförmig, in der Mitte $2-3$ zähnig; Trauben 6-12 blütig; Bt. entfernt; B. 5-8paarig; Blättchen lineal u. lanzettlich; Bt. blau, am Grunde weißlich. J.

onobrychioides. L. Esparsetteartige $W$.

*) In $N$. wurde auch die durch lang zugespitzte, lockere Trauben ausgezeichnete 0 . areuaria (Kit.) Sér. (SandE.) gefunden. 
Bt. gelblich-weib; Trauben ihr Tragb. nicht überragend; B. meist 5 paarig; Nebenb. halbpfeilförmig. Terbr. (fehlt S. K. J.)

pisiformis. $L$. Erbsenartige W.

Bt. weis mit violetten Adern; Trauben ihr Tragb. überragend; B. meist 8 paarig; Nebenb. halbmondförmig. Verbr........... silvatica. $L$. Wald-W.

7 Bt. in 2-6 blütigen Trauben o. einzeln........ 8

' Bt. in reichblütigen Trauben ............. 11

Staude; Bt. in $3-6$ blütigen Trauben, ziemlich ansehnlich; Fahne blau, Flügel $u$. Schiffchen nur vorne bläulich, sonst weiß; Hülsen zuletzt 1 samig. J. ........Adriatica. (Freyn.) Adriatische W. Einjährige Kräuter; Bt. klein; Hülsen 2-6 samig.. Kzähne so lang als die Kiröhre; Hülsen flaumig, länglich, 2 samig; Trauben 2-6 blütig, ihr 'Tragb. kaum überragend; die oberen B. meist 6 paarig; Blättchen lineal; Bt. bläulich-wei£. Verbr.

hirsata. (L.) Koch. Rauhhaarige W. Kzähne kürzer als die Kröhre; Hülsen kahl, lineal, $4-6$ samig; obere B. $3-4$ paarig ........... 10

Bt. einzeln, ihr Stiel so lang als das Tragb.; Blättchen lineal, stumpf; Hülsen 4 samig; Fahne lila, Flügel und Schiffchen weis. Verbr.

tetrasperma. (L.) Wnch. Viersamige W.

Bt. zu $2-4$, selten einzeln, ihr gemeinsamer Stiel sein Tragb. zuletzt weit überragend; Blättchen lineal, spitzig; Hülsen 6 samig. $J$.

gracilis. Lois. Schlanke W.

11 Platte der Fahne deutlich kürzer als ihr Nagel ... 12 Platte der Fahne so lang o. länger als ihr Nagel.. 14 Stg. u. B. abstehend zottig; B. meist 8 paarig; Bt. violett; Hülsen elliptisch-rautenförmig.

Verbr. (fehlt T.).... villosa. Roth. Zottige W. Stg. u. B. kahl o. zerstreut behaart; B. rothviolett 13

Trauben 6-12 blütig, locker; Platte der Fahne wenig kürzer als ihr Nagel; wächst in Gebüschen und Hecken. J............ varia. Host. Bunte W.

13 Trauben vielblütig, ziemlich gedrungen; Platte der Fahne viel kürzer als ihr Nagel; wächst in Getreidefeldern. Verbr.

glabrescens. (Koch.) Kahle W.

Platte der Fahne doppelt so lang o. doch länger als ihr Nagel; B. meist 10 paarig, mit lineal-länglichen, starren Blättchen; Hülsen lineal-länglich. Verbr: (fehlt S.)

tenuifolia. Roth. Feinblättrige W.

Platte der Fahne ungefähr so lang als ihr Nagel.. 15 
Trauben sammt ihrem Stiele stets kürzer als ihr Tragb.; Blättchen länglich-lanzettlich, mit zahlreichen Seitennerven; Fahne rothviolett; Flügel und Schiffchen bläulich-weiß.

15 Verbr. (fehlt O.S.K.)

Cassubica. L. Cassubische W. Trauben in der Regel ihr Tragb. überragend; Blättchen länglich 0 . fast lineal, mit wenigen Seiten-

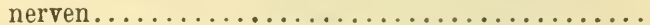

Stiel der Hülse kürzer als die Kröhre; Blättchen angedrückt-flaumig; B. meist 10 paarig.

Verbr. u. hfg...........Cracea. L. Vogel-W. Stiel der Hülse länger als die Kröhre; Blättchen abstehend-behaart; die oberen B. meist 15 paarig. $T$. K. J........Gerardi. $D C$. Gerard's W.

Blkr. weiß, Flügel mit einem großen schwarzen Flecke; Tr. 2-4blütig, sehr kurz; Bspindel mit einer Stachelspitze endigend; Blättchen elliptisch. Cult. u. verw. ...........Faba. I. Saubohne.

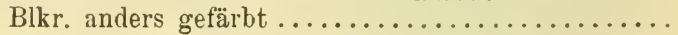

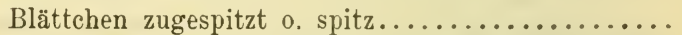
Blättchen stumpf, abgestutzt, eingedrückt 0 . ausgerandet; Bspindel (wenigstens die der oberen B.)

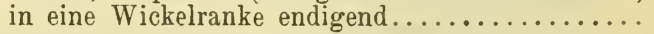

Staude; Blättchen eiförmig, zugespitzt; B. 2 paarig; Bspindel in eine Stachelspitze endigend; Tr. 3bis 6 blütig; Bt. hellgelb. $N$. St. $K$. $K r$. J. Südt. oroboides. Wulf. Breitblättrige W.

Einjähriges Kraut; Blättchen elliptisch o. lanzettlich; nur die oberen B. 2 paarig; Bspindel in eine Wickelranke endigend; Bt. zu 1-2; Hülsen zottig; Bt. purpurn. J... Bithynica. $L$. Bithynische W.

$20\{$ Fahne behaart; einjährige Kräuter .............

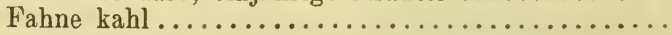

Tr. 2-4blütig; Kzähne so lang als die Kröhre; Hülsen rauhhaarig, Haare ohne Knötchen ...... 22

21 Bt. einzeln; Hülsen elliptisch-länglich, rauhhaarig, Haare auf kleinen Knötchen sitzend; Bt. gelblichweiß. J. ...........hybrida. L. Bastart-W.

Bt. weißlich o. bleich-gelbgrün; Hülsen länglich; S. sammtschwarz. M. N. St. (B. S.)

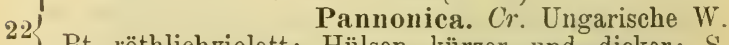
Bt. röthlichviolett; Hülsen kürzer und dicker; S. braun, dunkler marmorirt. (M. N.) J.

striata. $M I$. B. Gestreifte W.

$23\{$ B. 2 -3- (höchstens 4-) paarig gefiedert; Kräuter .. 24

B. $4-12$ paarig gefiedert ................. 26 
Bt. groß, schwärzlich-purpurn, in 2-6 blütigen, sehr kurzen Trauben, seltener einzeln; Blättchen sehr

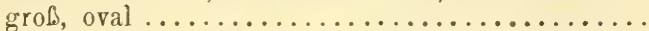

Bt. klein, rothviolett, meist einzeln in aen Bachseln fast sitzend; Blättchen klein, lanzettlich o. lineal, die der untersten B. verkehrt eiförmig; kleines Pflänzchen. Verbr. (fehlt $S$.)

lathyroides. $L$. Platterbsenartige W.

Blättchen ganzrandig; Bt. zu 1-2; S. groא, schwarz, mit weißem Nabel. J. (B. cult.)

Narbouensis. L. Französische W. Blättchen der oberen 0. aller B. scharf gezähnt; Bt. zu 2-6; S. kleiner, dunkelbraun. $N$.

serratifolia. Jacq. Gezähntblättrige W.

Staude; Bt. in kurzen, 2 - 5 blïtigen Trauben, hellviolett; Blättchen oval o. länglich; die 2 oberen Kzähne zusammenneigend; Hülsen lineal-länglich, kahl. Verbr. $u$. $h f g . . . . .$. sepium. L. Zaun-W.

Kräuter; B. einzeln 0. zu 2 in den Blattachseln ...

B. ohne Wickelranke, 8-12 paarig; Nebenb. halbspießförmig, borstlich gezähnt; Bt. weißlich-rosa; Hülsen fast perlschnurförmig.

27 Südt. (sonst eingeschleppt).

Erviiia. (L.) Willd. Linsenartige W. Wenigstens die oberen B. mit einer Wickelranke

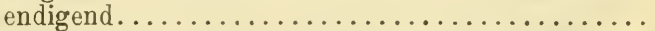

Die 2 obersten o. die 4 oberen und seitlichen Kzähne 28 aufwärts gekrümmt 0 . zusammenneigend........

Alle Kzähne gerade vorgestreckt .................. 30

4 Kzähne aufwärts gekrïmmt, nur der unterste gerade vorgestreckt; Bt. rothviolett; Hülsen länglich, flaumig; Blättchen lineal. Südt. Südst. J.

pęregrina. $L$. Fremde W.

Nur die 2 oberen Kzähne etwas aufgerichtet u. zusammenneigend, die 3 anderen gerade vorgestreckt; Bt. schwefelgelb, oft grünlich o. röthlich überlaufen, o. fast weiß; Hülsen rauhhaarig; Blättchen länglich 0. lineal. (N.) Südt. J.

lutea. L*) Gelbe W.

Bt. von weißlich-gelber Grundfarbe, mit rauchgrau überlaufener Fahne; Hülsen lineal-länglich, flaumig,

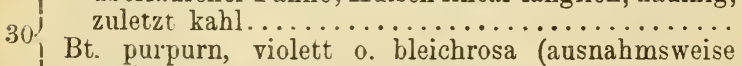
auch weis o. gelblich, aber nicht rauchgrau überlaufen $\ldots \ldots \ldots \ldots \ldots \ldots \ldots \ldots \ldots \ldots . \ldots \ldots$

*) V. hirta Ball. (J.) ist mehr behaart, hat 8- bis 12 parige obere $B$. u. bleichere $\mathrm{Bt}$. 
Blättchen verkehrt-herzförmig, wenig länger als breit, in der Ausrandung stachelspitzig; Hülsen lineallänglich. St. $K r$. J.

grandiflora. Scop. Großblütige W. Blättchen keilig-länglich 0 . nahezu lineal, viel länger als breit, gestutzt o. stumpf, meist mit Stachelspitze; Hülsen lineal. $M . \Lambda$. J.

sordida. $W^{r} K$. Schmutziggelbe W.

Alle Krb. ziemlich gleichfarbig purpurviolett ...... 33

Krb. auffallend verschieden gefärbt, die Flügel purpurn, die Fahne mehr bläulich, das Schiffehen weißlich (ausnahmsweise alle Krb. weib o. gelblich)

B. 3-5 paarig gefiedert, die unteren mit verkehrteiförmigen, die oberen mit länglich-elliptischen, ausgerandeten Blättchen; Bt. ansehnlich; Hülsen breit-lineal, dicht kurzhaarig, nicht holperig, zuletzt schwarz. $J$.

macrocarpa. Bert. Großfrüchtige W.

B. 4-7 paarig gefiedert, die unteren mit verkehrteiförmigen, ausgerandeten, die oberen mit länglichen 0. linealen, gestutzten Blättchen; Bt. ziemlich klein; Hülsen zuletzt kahl o. fast kahl .....

Reife Hülsen sehwarzbraun, holperig, den K. zerreißend; B. 5-7 paarig gefiedert, mit meist länglichen Blättchen. Verbr.

segetalis. Thuill. Saat-W.

Reife Hülsen kohlschwarz, nicht holperig, den $\mathbf{K}$. nicht zerreißend; B. meist 5 paarig gefiedert, die oberen meist mit linealen Blättchen. Verbr.

nigra. (L.) Schmalblättrige W.

Hülsen kurzhaarig, zuletzt lederbraun $u$. dann fast kahl; B. mit 3 theiliger Wickelranke u. verkehrteiförmig-keiligen, ausgerandeten 0 .gestutzten Blättchen. Verbr. (meist cult. u. verw.)

sativa. $L$. Futter-W.

Hülsen kahl .......................

Reife Hülsen sehr holperig, lederbraun o. schwärzlich; B. mit langer, getheilter Wickelranke u. länglich-keiligen Blättchen. .J.

Cosentini. Guss. Cosentini's W.

36 Reife Hülsen kaum hoḷperig, grünlich-schwarz; B. mit kurzer, oft einfacher (die unteren ohne) Wickelranke u. rundlichen bis länglichen Blättchen. Südt. K. $K r$. J.

cordata. Koch. Herzblättrige W. 
XXXY. LENS, Adans. Iinse.

Alle B. olne Wickelranke, mit einer Stachelspitz. endigend: Nebenb. halbpfeilförmig, gezälnt; B zu $1-2$ an langem gemeinsamem Stiel; Hülsen kahl. $K r \cdot J$.

nigricans. (M. B.) Godr. Schwärzliche L.

Die oberen B. in eine Wickelranke endigend ......

Die oberen B. meist 6 paarig gefiedert; Bt. zu 1-3. ihr gemeinsamer Stiel in eine Granne auslaufend; K. so lang als die Blkr.; Hülsen kahl.

2 Cult. u. verw.....esculenta. Nuch. Gemeine $L_{\text {. }}$ Stiel nicht begrannt; hí. kürzer als die Blkr.; Hülsen flaumig. $K$. $K r$. J.

Lenticula. (Schreb.) Godr. Kileine I.

\section{XXXYi. LATHYRUS. $L$. Platterbse.}

B. ungetheilt 0 . durch eine Wickelranke ersetzt... 2

1 Alle 0 . doch die oberen B. ein-bis rielparig gefiedert.............................

An Stelle der B. eine Wickelranke; Nebenb. seb? groß, eiförmig, am Grunde pfeilförmig geöhrlt; Bt. gelb. st. Kr. J. Südt. Aphaca. L. Ranken-P.

2 B. ungetheilt, lineal-lanzettlich (eigentlich nur ein verbreiterter Bstiel vorhanden), ohne Wickelranke; Nebenb. pfriemlich; Bt. purpurn.

Sch. M. N. (S.) St. Kr. J.

Nissolia. $L_{.} *^{*}$ ) Einfachblättrige $\mathrm{P}$.

Bstiele geflügelt, die unteren ohne Blättchen u. ohne Wickelranke .........................

Alle B. ein- bis vielpaarig gefiedert, mit o. ohne Wickelranke .........................

Bt. gelblich-weiß, einzeln, kurz gestielt; Hülsen am oberen Rande 2 flügelig; Blättchen elliptisch. $J$. Ochrus. (L.) DC. Bleichgelbe P.

4 Bt. in $1-5$ blütigen, lang gestielten Trauben; Fahne purpurn, Flügel bläulich, Schiffchen weislich; Hülsen am oberen Rande stumpf 2 kielig; Blättchen lineal. J. ..... Clymenum. L. Purpurne P.

Kräuter; Bt. einzeln o. in 2-3- (selten 4-) blütigen Trauben .......................... 6 Stauden; Bt. in mehrblütigen (mindestens 3 blütigen)

Trauben ............................. 14

*) Die Hülsen sind flaumig, bei L. gramineus Kern. dagegen kahl 0 . fast kahl. 
Kizipfel blattartig, viel länger als die kurzglockige Kröhre; Hülsen meist 4 samig, netzig-aderig, zusanmengedrückt, am oberen Rande 2 flügelig 0 .

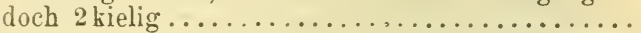

Kzipfel kürzer o. so lang als die Kröhre; Hülsen am oberen Rande stumpf ...................

Der obere Rand der Hülse gerade; Kzipfel aufrecht; S röthlich, nicht gefleckt; Bt. roth. $K r . J$.

Cicera. $L$. Rothe $\mathrm{P}$.

7 Der obere Rand der Hülse gekrümmt; Kzipfel abstehend; S. ledergelb, braun gefleckt; Bt. lila, blau, rosa o. weib. Cult. u. verv.

sativus. $L$. Angebaute $P$.

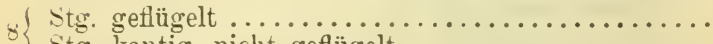

Bt. gelb o. orange, das Tragb. des (gemeinsamen) Stieles nicht überragend: Hülsen kahl. $J$.

annuus. $L$. Einjährige $P$.

9. Bt. violett, das Tragb. des (gemeinsamen) Stieles überragend; Hülsen raubhaarig.

Sch. II. I. J. Südt.

hirsutus. $L$. Rauhhaarige $\mathrm{P}$.

Frkn. seidig-zottig; Hülsen flaumig; S. oval; Bt.

10) violett. J.....inconspicuus. $L$. Kleinblütige P.

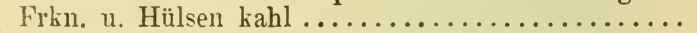
Btstiel kürzer als sein Tragb............... 12

11 Btstiel länger als sein Tragb.; Bt. purpurn; Hülsen schmal-lineal, meist 10 samig. $J$.

angulatus. $L$. Würfelsamige $P$.

Btstiel am Grunde gegliedert, ohne Granne; Bt. violett; Frkn. fein-drüsig-punktirt; Hülsen lineal.

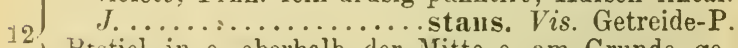
Btstiel in 0 oberhalb der Mitte 0 . am Grunde gegliedert, in letzterem Falle stets an der Gliede-

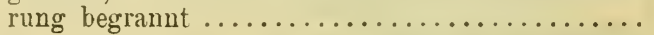

Bt: rosenroth; Hülsen schief-elliptisch, flachgedrückt, 2-3 samig; S. knötig-rauh. Südt. J. setifolius. $L$. Borstenblättrige $\mathrm{P}$. Bt. ziegelroth; Hülsen lineal, 8-10 samig; S. glatt. Südt. J......sphaericus. Retz. Kugelsamige P.

B. mit einer Wickelranke endigend ........... 15

14 B. mit einer Stachelspitze endigend, ohne Wickelranke .............................. 23

$15\{$ Stg. kantig, nicht geflügelt $\ldots \ldots \ldots \ldots \ldots \ldots \ldots \ldots 16$

Sitg. gefliggelt ....................... 18 
B. 1 paarig gefiedert .................... 17

16 B. $2-5$ paarig gefiedert; Blättchen elliptisch; Nebenb. spießförmig; Bt. purpurn. J. (?)

maritimus. (L.) Bigel. Meerstrands-P.

Bt. purpurn; Wst. mit Knollen besetzt; Blättchen

17 oval. Verbr. (fehlt $S$.) tuberosus. $L$. Knollige P. Bt. gelb; Wst. ohne Knollen; Blättchen lanzettlich. Verbr. $u$. $h f g . . . . .$. pratensis. $L$. Wiesen-P. Alla B. 1 paarig gefiedert*)............... 19

18 Alle 0. doch die oberen B. $2-5$ paarig gefiedert*). 21

Nebenb. vielmal schmäler als der Stg. sammt den Flügeln; Blättchen lanzettlich o. lineal-lanzettlich, vielmal länger als breit; Bstiele schmal geflügelt; Bt. rosenroth und gelblich-grün gemischtfärbig. Verbr.................. silvester. $L$. Wald-P.

Nebenb. mindestens halb so breit als der Stg. sammt den Flügeln; Bstiele breit geflügelt; Bt. gesättigt

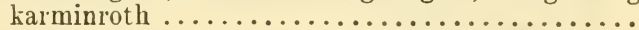

Blättchen elliptisch 0 . länglich, höchstens $5 \mathrm{mal}$ länger als breit; Traubenstiele mehr als doppelt so lang als ihr Tragb. M. N. Süidst. Kr. J. Südt. megalanthus. Steudel. Großblütige P.

Blättchen lineal-lanzettlich o lineal, vielmal länger als breit; Traubenstiele höchstens doppelt so lang als ihr Tragb. $J$.

membranaceus. Presl. Schwertblättrige P.

Bstiele ebenso breit 0 . noch breiter geflügelt als der Stg.; untere B. 1 paarig, obere $2-3$ paarig gefiedert;*) Blättchen oval 0. lanzettlich; Bt. sattrosenroth. B. T.

heterophyllus. $L$. Verschiedenblättrige $\mathrm{P}$. Bstiele viel schmäler als der Stg. o. gar nicht geflügelt; alle B. 2-5 paarig gefiedert ............

Bstiele schmal geflügelt; Blättchen eilänglich o. elliptisch; Gr. nicht gedreht; Hülsen feindrüsig. $B$.

pisiformis. L. Erbsenartige P.

22 Bstiele nicht geflügelt, nur berandet; Blättchen lineal-lanzettlich o. länglich; Gr. gedreht; Hülsen kahl. B. M. Sch. N. O. S. Südt.

paluster. L. Sumpf-P.

Stg. geflügelt; B. 2-3 paarig; Blättchen unterseits seegrün, glanzlos; Wzstock kriechend, an den Gliedern knollig. $B$. Südt. K. Südst. Kr. J. montanus. Bernh. Berg-P.

Stg. kantig, höchstens oberwärts schmal-geflügelt.. 24

*) L. heterophyllus L. kommt ausnahmsweise auch mit nur 1 paarigen $B$. vor. 
B. meist 2-3 paarig; Blättchen eiförmig, zugespitzt,

B. meist 4-6 paarig; Blättchen elliptisch o. eiförmiglänglich, unterseits seegrün, glanzlos ..........

Blättchen kahl, lineal-lanzettlich o. lineal; Wz. büschelig, Fasern keulig o. walzig verdickt; Bt. weib o. gelblich, Fahne auf dem Rücken oft rosa. B. M. Sch. N. Kr. J.

Pannonicus. (Jacq.) Garcke.*) Ungarische P. Blättchen flaumig-gewimpert, unterseits glänzend,

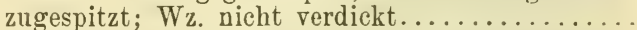

Traubenstiele gerade, meist 4 blütig; Blättchen länglich-eiförmig oder lanzettlich, lang-zugespitzt; Bt. purpurn, daun blau, endlich grünlich. Verbr.

vernus. (L.) Bernh. Frühlings-P.

26 Traubenstiele gekrümmt, vielblütig; Blättchen breiteiförmig, am Grunde schief-abgerundet; Fahne purpurn, Flügel und Schiffchen rosa.

N. Südt. $K r$. J.

variegatus. (Ten.) Godr. et Gren. Bunte P.

Bt. purpurn; B. meist 6 paarig; Blättchen eilänglich, klein; Stg. ästig, 4 kantig. Verbr.

niger. (L.) Bernh. Schwarze P.

Bt. ockergelb, zuletzt bräunlich; B. meist 4 paarig; Blättchen groß, elliptisch o. eiförmig; Stg. wenig o. gar nicht ästig, stumpfkantig .............

Pfl. mehr o. weniger behaart; Blättchen spitzlich, elliptisch; Kzähne gut entwickelt, der unterste in der Regel verlängert.

Vora. v. T. S. U. St. K. Kr.J. occidentalis. (Fisch. et Mey.**) Fritsch. Westeuropäische P.

Pfl. fast ganz kahl; Blättchen kurz zugespitzt, eiförmig; Kzähne sehr kurz, die obersten oft kaum bemerkbar; Bt. kleiner. St. $K r$.

laevigatus. (W. K.) Fritsch.**) Kahle P.

XXXVII. PISUM. L. Erbse.

Nebenb. 2-3 mal kürzer als der (gemeinsame) Btstiel;

1 B. 3 paarig; Blättchen elliptisch 0 . länglich .....

Nebenb. so lang 0 . wenig kürzer als der (gemeinsame) Btstiel; Blättchen eiförmig ............

*) L. versicolor (Gmel.), welcher auf trockenem Boden wächst, hat lange walzliche Wzfasern. Der typische L. Pannonicus wächst auf feuchten Wiesen und hat kurze keulige Wzknollen.

**) L. Scopolii Fritsch (= Orobus montanus Scop.) bält die Mitte $\mathrm{zwischen} \mathrm{L.} \mathrm{occidentalis} \mathrm{und} \mathrm{L.} \mathrm{laevigatus.}$ 
$2\left\{\begin{array}{l}\text { Same kohlschwarz, fein gekörnelt. } J . \\ \text { elatius. } I I . \text { B. Große E. } \\ \text { S. grünlich, braun gefleckt und schwarz gestrichelt, } \\ \text { glatt. J........ biflorum. Raf. Zweiblütige E. }\end{array}\right.$

Same kugelig, gleichfarbig; B. 3 paarig; Bt. weiß. Cult. .............. sativum. L. Garten-E.

3 Same kantig-eingedrückt, braun punktirt; B. 2- bis 3 paarig; Bt. hellviolett, Flügel purpurn.

Cult. u. veru........... arvense. L. Zucker-E.

\section{PHASEOLES. L. Bohne.}

Traubenstiele armblütig, kürzer als ihr Tragb.; Bt. weiß, seltener gelblich, lila o. röthlich. Cult.

vulgaris. L.*) Gemeine B.

Traubenstiele mehrblütig, länger als ihr Tragb.; Bt. scharlachroth, seltener weif 0 . gescheckt. Cult. coccineus. L. Feuer-B.

XXXIII. Familie. Geraniaceae. Storchschnabelgewächse.

Kräuter o. Stauden mit ungetheilten, gelappten o. getheilten, theils gegenständigen, 1heils wechselständigen B., meist mit Nebenb. B. zwittrig, regelmäßig o. fast regelmäßig. Kb. 5, frei. Krb. 5, frei. Stb. 10, am Grunde etwas verwachsen, manchmal j ohne A. Frkn. 1, oberständig, 5 fächerig, mit 2 Samenknospen in jedem Fache; Gr. 5, zu einem langen Schnabel des Frkn. vereinigt. Fr. in 5 lang geschnäbelte, meist 1 samige Theilfr. zerfallend. S. ohne Nährgewebe.

\section{Gattungen.}

B. handnervig, bandförmig-gelappt o. - getheilt; Schnabel der Theilfr. innen kahl, zuletzt elastisch abspringend $u$. sich zirkelförmig zurückrollend; Stb. abwechselnd gröler, alle mit $A$.

Geranium. I.

B. fiedernervig, dabei ungetheilt 0 . fiederförmig getheilt; Schnabel der Theilfr. innen bärtig, zuletzt schraubenförmig gewunden; 5 Stb. mit, 5 obne A., letztere breiter............. Erodium. II.

*) Der Stg. windet; bei Ph. nanus L. (Zwergbohne) ist er aufrecht und viel kürzer. 
Arten.

\section{GERANILM. L. Storchschnabel.}

(Bt. schwarz-violett; Blkr. Hach, etwas zurückge1 bogen, etwas länger als die stachelspitzigen Kíb.

Verbr......... phaeum. L. Braunblühender St.

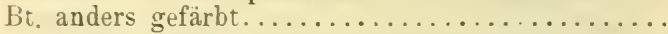

I Krb. spatelig u. lang-benagelt, o. länglich-keilig u.

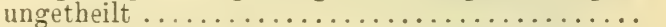

Krbb. verkehrt-eiförmig 0 , verkehrt-herzförmig..... 4

Staude; Krb. spatelig, Nagel so lang als der K.; Stb. abwärtsgeneigt; Bt. grob, blutroth o. dunkelrosa. Südt $K$. Südst. $K r$. J.

macror rhizum. L. Grobwurzeliger St.

3 Einjähriges Krraut; Krb. länglich-keilig, ungetheilt, etwas länger als die kurzbegraunten Kb.; B. im Umrisse nierenförmig, die unteren 7 spaltig; Bt. klein, fleischrotb. Verbr. (fehlt Sch. MI.)

rotundifolium. L. Rundblättriger St.

Krb. am Grunde u. am vorderen Rande gewimpert; Stg. u. Btstiele drüsig-haarig u. zottig; Bt. blau, mit 5 violetten Adern. B. $T$.

Bohemicum. L. Böhmischer St. Krb. am vorderen Rande nichıt gewimpert ...... 5

$5\{$ Krb. verkehrt-herzförmig o. 2spaltig .......... 6

Krb. verkehrt-eiförmig ............... 13

Krb. ungefähr so lang als die Kb.; einjährige Kräuter ........................

Krb. länger als die Kb................ 10

7 B. höchstens bis zur Mitte $5-9$ spaltig ....... 8

B. fast bis zum Grunde $5-i$ theilig.......... 9

Stg. kurz-flaumig; Krb. länglich-verkehrt-herzförmig, rosa 0. lila; Frklappen flaumig, ohne Querrunzeln. Verbr...pusillum. L. Kleiner St. Stg. langzottig u. drüsig; Krbb. verkehrt-herzförmig, hellrosa, dunkler geadert; Frklappen kurzhaarig, querrunzelig. B. II. N. T.

divaricatum. Ehrh. Ausgespreizter St.

Stg. abstehend kurzhaarig; Bt. purpurn, das Tragb. des gemeinsamen Btstieles nicht überragend; Frklappen drüsenhaarig. Verbr.

dissectum. L. Schlitzblättriger St.

9 Stg. angedrückt-flaumig; Bt. größer, hellpurpurn, weit über das Tragb. des gemeinsamen Btstieles hinausragend; Frklappen fast kahl. Verbr.

columbinum. $L$. Tauben-St. 
Stg. angedrückt behaart 0. fast kahl; B. 5spaltig, mit breiten, gesägten Abschnitten; Kb. lang begrannt; Bt. hellrosa; Staude. Südt. $K r$. J.

nodosum. $L$. Knotiger St.

Stg. abstehend zottig; B. 5-9 spaltig, mit 3 spaltigen Abschnitten; Kb. kurz bespitzt ............ 11

Krb. doppelt so lang als der $\mathrm{h}$............. 12

$11 \mathrm{Krb}$. nur etwas länger als der $K$, purpurn; Fr. querrunzelig; Kraut. Verbr. (fehlt sch.)

molle. $L$. Weicher St.

Staude; Krb. violett (sehr selten weiß); Fr. glatt. angedrückt behaart. $B . M . \Lambda . D S . S t . K . '$ '.

Pyrenaicum. L. Pyrenäischer St.

Kraut; Krb. purpurn; Fr. querrunzelig, kahl. J.

villosum. Teu. Zottiger St.

Krb. so lang als die begrannten Kb.; Stg. rauhhaarig; B. handförmig-5 theilig mit rautenförmiglänglichen, eingeschnitten-gesägten Zipfeln; Frklappen glatt, flaumig; Bt. blassrosa mit purpurnen Adern. Sch. M. $N$. Sibiricum. L. Sibirischer St.

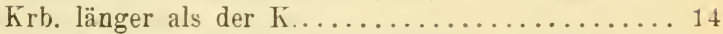

Kräuter mit kleinen Bt.; Kb. zur Zeit der Bt. aufrecht, zusammenschließend; Bt. rosa (selten weib) 15 Stauden mit ansehnlichen Bt.; Kb. zur Zeit der Bt.

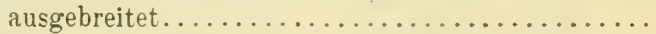

Stg. u. B. kahl o. ersterer flaumig; B. glänzend, 5-7 spaltig, mit 3 spaltigen Abschnitten; Kb. querrunzelig. N. Südst. $K r$.J. Südt.

lucidım. L. Glänzender St.

Stg. u. B. drüsig-rauhhaarig; B. 3-5theilig, mit fiederspaltigen Abschnitten; $\mathrm{K} b$. ohne Querrunzeln 16

Pfl. stinkend; Krb. doppelt so lang als der K.; A. meist purpurbraun, dann gelb. Verbr.

Robertianum. L. Stinkender St. Pfl. fast geruchlos; Krb. schmal, wenig länger als der h.; A. schwefelgelb. .J.

purpureum. Vill. Purpurner St.

Die ganze Pfl. von dichter seidiger Behaarung gran; B. 5-7theilig, mit 3 spaltigen Abschnitten; Bt. hellrosa. A. v. Südt. $K r$.

Pf. nicht grau-seidig

argenteum. I. Silbergraner St.

$18\left\{\begin{array}{l}\text { Stg. oberwärts drüsig, aufrecht; B. } 5-7 \text { spaltig.... } \\ \text { Stg. oberwärts rauhhaarig, aber drüsenlos, ausge- }\end{array}\right.$ 19

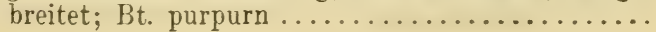


Bt. violett o. lila (selten weiß); Btstiele nach dem Verblühen aufrecht; Stf. lanzettlich ..........20 20

Bt. blau; Btstiele nach dem Verblühen herabgeschlagen; Stf. aus breitem Grunde plötzlich verschmälert, fädlich. Verbr.

pratense. $L$. Wiesen-St.

Krb. schmutzig-lila, wagrecht ausgebreitet o. etwas zurückgeschlagen; Frklappen querfaltig; Stg. oben zottig und dazwischen drüsig. $O . K . K r$. T.

lividum. L'Hérit. Lilablütiger St. Krb. violett, aufrecht-abstehend; Frklappen ohne Querfalten; Stg. oben drüsig-flaumig. Verbr.

silvaticum. $L$. Wald-St.

Btstiele nach dem Verblühen herabgeschlagen 0. doch seitlich abgebogen; Bt. purpurn (ausnahmsweise

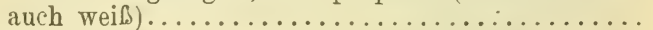

Btstiele nach dem Verblühen aufrecht; Bt. weiø, roth geadert; Frklappen glatt; B. fast bis zum Grunde 5-7 theilig, mit eingeschnitten-fiederspaltigen Abschnitten. A. v. Südt.

rivulare. Vill. Bach-St.

Bt. einzeln; B. bis zum Grunde getheilt, mit gespaltenen Abschnitten und schmalen Zipfeln.

Verbr. .......... sanguineum. $L$. Blutrother St. Bt. zu 2; B. tief (aber nicht bis zum Grunde) gespalten, mit breiten Abschnitten und grob gezähnten Zipfeln. Terbr. . palustre. L. Sumpf-St.

Anmerkung. In $T$. wurde G. molle $\times$ pusillum beobachtet.

\section{ERODIUM. L'Hér. Reiherschnabel.}

B. herzförmig o. herzförmig-länglich, stumpf- und kurz-gelappt; die ganze Pfl. drüsig-flaumig. $J .(K$.$) malacoides. (L.) Willd. Herzblättriger R.$

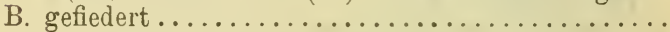

Die 5 fruchtbaren Stb. vom Grunde bis zur Mitte lanzettlich und bewimpert, oben fadenförmig und

2 kahl; B. herablaufend-gefiedert; Bt. hellblau. J. (N.)...ciconium. Willd. Langschnäbeliger R. Stb. kahl; Bt. hellpurpurn ................ Blättchen sitzend, fast bis zum Mittelnerven fiederspaltig; die fruchtbaren Stb. ohne Zähnchen.

Terbr.

cicutarium. (L.) L'Hér. Schierlingsblättriger R. Blättchen gestielt, ungleich-doppelt-gesägt, fast kleingelappt; die fruchtbaren Stb. am Grunde 2 zähnig. T. S. K. St. Kr. J.

moschatnm. (L.) L'Hér. Bisamduftender R. 


\section{Familie. 0xalideae. Sauerkleegewächse.}

Kräuter 0. Stauden mit dreizähligen (Kleeblättern ähnlichen), lang gestielten, schraubig gestellten B., mit 0 . ohne Nebenb. Bt. zwittrig, regelmäßig o. fast regelmäßig. Kb. u. $\mathrm{Krb}$. je 5, frei o. am Grunde etwas verwachsen. Stb. 10, am Grunde etwas verwachsen. Frkn. 1, oberständig, 5 fächerig, mit mehreren Samenknospen in jedem Fache. Gr. 5. Fr. eine 5̌klappige, mehrsamige Kapsel. S. mit Nährgewebe.

\section{Gattung.}

Kleine, zarte Pfl.; die 5 äu@eren Stb. kürzer; Kapsel fachspaltig aufspringend ............ Oxalis. I.

\section{Arten.}

\section{OXALIS. $L$. Sauerklee.}

(Kleine, zarte Staude mit weiben o. lilafarbenen Bt.;

B. alle grundständig; Wst. kriechend, gezähnt.

1 Verbr. $u$. hfg......Acetosella. L. Gemeiner S. Bt. gelb; Stg. beblättert...................

Unterirdische Ausläufer vorhanden; Pfl. zerstreut behaart, hellgrün; Nebenb. fehlen; Frstiele aufrecht abstehend. Verbr..... stricta. $L$. Steifer S. Einjähriges Kraut ohne Ausläufer; Pfl. dicht behaart, trübgrün 0 . violett ïberlaufen; Nebenb. sehr klein, an dem Bstiel angewachsen; Frstiele herabgeschlagen. Verbr. (bes. im Süden.)

corniculata. L. Gehörnter S.

\section{Familie. Lineae. Leingewächse.}

Kräuter o. Stauden mit ungetheilten, meist schmalen, schraubig gestellten o. gegenständigen B., ohne Nebenb. 0 . mit Drüsen an Stelle der Nebenb. Bt. zwittrig, regelmäळig. Kb. 4-5. Krb. 4-5. Stb. 4-5, am Grunde verwachsen. Frkn. 1, oberständig, (3-) 4-, 5-, 8- 0. 10 fächerig, mit 80. 10 Samenknospen. Gr. 3-5. Fr. eine 4-5- 0. 8-10 fächerige, 8- o. 10 samige Kapsel. S. mit Nährgewebe.

\section{Gattungen.}

(Kib. 4, an der Spitze 2- o. 3 zähnig; Krb. u. Stb. 4; Kapsel 4 fächerig (unvollständig 8 fächerig).

Radiola. I.

Ǩb. 5, ungetheilt; Krb. u. Stb. 5; Kapsel meist 5c. 10 fächerig................... Linum. II. 


\section{Arten.}

I. RADIOLA. Gmel. Zwergflachs.

Kleines, sehr zartes, einjähriges Krant; Stg. kahl, gabelspaltig; B. gegenstäudig, eiförmig 0 . länglich; Bt. weib, sehr klein. Sch. MI. B. Südst.

linoides. Gmel. Kleiner Z.

\section{IINUM. $L$. Lein.}

B. sämmtlich gegenständig, die unteren verkehrteiförmig, die oberen lanzettlich; Stg. fädlich; Bt. weiß, sehr klein. Terbr.

catharticum. I. Purgier-L.

B. sämmtlich 0 . doch die meisten wechselständig.. 2

$2\{\mathrm{~Kb}$. am Rande drüsig gewimpert........... 3

Kb. am Rande drüsenlos ................. 10

$\left.{ }_{3}\right)$ Bt. gelb ....................... 4

Bt. blau, rosenroth o. weiß .............. 8

B. am Rande schärflich, lineal-lanzettlich; $\mathrm{Kb}$. in

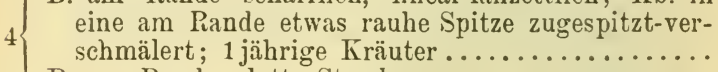

B. am Rande glatt; Stauden .................. 7

. Frstiele riel kürzer als der K.; B. am Rande sehr

5 scharf. J............ strictum. $L{ }^{*}$ ) Steifer L.

Frstiele so lang 0 . länger als der K........... 6

Aestchen der Rispe ganz kahl; Kb. 11/2 mal so lang als die Kapsel. $K r$. J.

Gallicum. L. Französischer L.

$6\{$ Aestchen der Rispe einwärts ain Grunde flaumig; $\mathrm{Kb}$. doppelt so lang als die Kapsel. $J$.

corymbulosum. Richb. Ebensträußiger L.

$\mathrm{Kb}$. eiförmig, kurz zugespitzt, fast so lang als die Kapsel; B. ohne Drüsen, die unteren gegenständig, elliptisch. J.... maritimum. L. Meerstrands-L.

$7 \mathrm{~Kb}$. lanzettlich, zugespitzt, länger als die Kapsel; B. am Grunde beiderseits mit einer Drüse, die oberen manchmal gegenständig.

B. $M . N . O . S t$. K. $K r$. J. flavum. L. Gelber L.

Stg. kahl; B. lineal, am Rande wimperig-rauh, sonst kahl; Kb. elliptisch, an der Spitze ptriemlich; N. kopfig; Bt. rosa, lila o. weis.

Verbr. (fehlt Sch. S.)

tenuifolium. L. Feinblättriger L.

Stg. zottig; B. nicht lineal; Kb. lanzettlich, zuge-

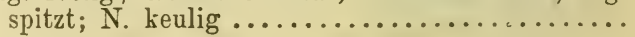

*) L. spicatum Pers. hat sehr kurze Btstandäste, so dass der Gesammtbtstand einer Aehre ähnelt. 
Stg. filzig-zottig; B. zottig, nur die obersten drüsig gewimpert; K. zottig-rauhhaarig; Blkr. azurblau, am Grunde gelblich.

$M$. N. O. St. $K$. hirsutum. L. Rauhbaariger L. Stg. klebrig-langzottig; B. am Rande drüsig-gewimpert, sonst wenig behaart; $K$. wenig behaart; Blkr. rosa. O. S. K. Südst. Kr. J. Südt.

viscosum. $L$. Klebriger $L$.

Bt. gelb; Kb. verlängert-lineal, stachelspitzig, am Rande feingesägt-scharf; B. am Grunde beiderseits mit einer Drüse, am Rande scharf, die unteren verkehrt-eiförmig-lanzettlich, die oberen lanzettlich. J........nodiflor'um. $L$. Knotenblütiger L. Bt. blau; B. am Grunde ohne Drüsen ........... 11

Einjähriges Kraut; Stg. einzeln, aufrecht; B. lanzettlich; Kb. eiförmig, zugespitzt, fein-gewimpert, fast so lang als die Kapsel. Cult. u. verw.

usitatissimum. $L$. Echter L.

Stauden; Stg. zahlreich; B. lineal-lanzettlich..... 12

$12\{\mathrm{~Kb}$. zugespitzt, lanzettlich 0 . eiförmig .......... 13

$\mathrm{Kb}$. eiförmig, die inneren stumpf ............. 14

$\mathrm{Kb}$. lanzettlich, doppelt so lang als die Kapsel; B. am Rande schärflich. Südt. Südst. Kr. J.

Narbonense. L. Französischer L

$\mathrm{Kb}$. eiförmig, fast so lang als die Kapsel, die inneren schwach-gewimpert; B. kahl. $K r$. J.

angustifolium. Huds. Schmalblättriger $\mathrm{L}$.

$14\{$ Frstiele einseitswen dig-hinabgebogen.$\ldots \ldots \ldots \ldots 15$

Frstiele aufrecht .................... 17

Bt. wässerig hellblau; Krb. von der Mitte an am Rande von einander entfernt; Stg. niedrig, armblütig; Kapsel länger als der K. A. v. N. O. St.

Bt. hellazurblau; Krb. an den Rändern der ganzen Länge nach sich deckend; Kapsel so lang o. etwas

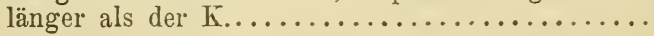

Kb. eiförmig, breit randhäutig, kurz zugespitzt; B. lineal-lanzettlich. $M . \Lambda$. St. $K$. $K r$. J. Austriacum. L. Oesterreichisclerer L.
16 Kb. eilanzettlich, schmal randhäutig, länger zuge spitzt; Bt. kleiner; B. sehr schmal. $J$.

Tommasinii. Rehb. Tommasini's L. 
Bbüschel in den Bachseln fehlen; Kb. eiförmig, die inneren rundlich, viel kürzer als die Kapsel.

N. O......... peremne. $L$. Ausdamernder L.

17 Stg. niedriger: in einer o. mehreren der oberen Bachseln ein Bbüschel o. ein kurzer, beblätterter Ast; die äußeren Kb. breitlanzettlich, kurz zugespitzt, nur etwas kürzer als die Kapsel.

A. v. T. S. K. $K r$. J... laeve. Scop. Glatter L.

XXXVI. Familie. Zygophylleae. Doppelblattgewächse.

Einjährige Kräuter mit paarig gefiederten, gegenständigen 0. wechselständigen B., mit Nebenb. Bt. zwittrig, regelmäßig. Kb. u. Kurb. 5. Stb. 10, frei. Frkn. 1, oberständig, 5fächerig, mit mehreren Samenknospen in jeden Fache. Gr. 1. Fr. in 5 Theilfr. zerfallend, mit gefächerten, meist 2 samigen Theilfr. S. ohne Nährgewebe.

\section{Gattung.}

Bt. gelb; Gr. sehr kurz; N. halbkugelig, 5 strahlig; Fr. 5eckig............... Tribulus. I.

\section{Arten.}

\section{TRIBULUS. L. Burzeldorn.}

Krb. länger als die Stb.; Fr. kalıl, mit kahlen Dornen besetzt, welche fast doppelt so lang sind als der Querdurchmesser der Theilfr. $N$.

orientalis. Kcru. Oestlicher B.

Krb. so lang als die Stb.; Fr. flaumig-filzig, mit am Grunde flaumigen Dornen besetzt, welche nicht länger sind als der Querdurchmesser der Theilfr. $K r$. J.........terrestris. $L$. Südlicher B.

\section{Familie. Rutaceae. Rautengewächse}

Stauden o. Halbsträucher mit getheilten, durchscheinend punktirten, schraubig gestellten B., ohne Nebenb. Bt. zwittrig, regelmäßig o. unregelmäßig. Ǩb. u. Krb. 4-5. Stb. 8 o. 10, frei. Btboden zwischen den Stb. u. Frb. zu einer polsterförmigen s'cheibe erweitert. Frkn. 1, oberständig, 4-5 lappig und 4-5 fächerig, ${ }^{*}$ ) mit mehreren Samenknospen in jedem Fache. Gr. 1, mit kleiner N. Fr. aufspringend, mehrsamig. S. mit Nährgewebe.

*) Man kann auch sagen: Frkn. 1-5, 1 fächerig, am Grunde verwachsen. 


\section{Gattungen.}

B. 3 zählig 0. 2-3 fach gefiedert; Bt. regelmäßig, gelb, die meisten 4 zählig; Stb. meist 8 , gerade, abstehend.......................... Inta.

B. gefiedert; Bt. unregelınäßig, rosenroth (selten weiß), 5zählig; Stb. 10, abwärts geneigt.

\section{I)ictamnus. II.}

Arten.

I. RU'A. L. Raute.

B. 3 zählig, sitzend; Blättchen lineal o. lanzettlich; Lappen der Kapsel stumpf, außen mit einem Hörnchen; Stg., K. u. Btstiele zottig. J.

Patavina. L. Gilbraute.

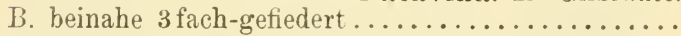

Krb. lang gefranst; Lappen der Kapsel zugespitıt; B.

2 fast sitzend. $J$..bracteosa. DC. Deckblättrige $\mathrm{R}$. Kirb ganzrandig o. gezähnelt; Lappen der Kapsel

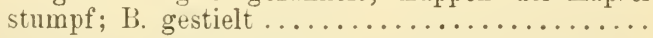

Blättchen stark riechend, bläulich-grün, oval-länglich, die endständigen verkehrt-eiförmig.

Sïld. (sonst ver $x$.)...graveolens. $L$. Garten-R. 3 Blättchen fast geruchlos, gelblich-grün, länglichlineal, die endständigen der unteren $B$. verlängertverkehrt-eiförmig. o. $K r$. Sï̈dst.

divaricata. Ten. Spreizende R.

\section{IICTAMNUS. L. spechtwurz.}

Pfl. drüsenreich; Blättchen elliptisch o. länglich, klein-gekerbt-gesägt; Bt. ansehnlich, stark duftend. B. II. Sch. N. Sü̈st. Kr. J. Sü̈t.

albus. L. Gemeine Sp.

\section{Familie. Polygalaceae. Kreuzblumen- gewächse.}

Stauden o. Halbsträucher mit ungetheilten, ganzrandigen, schraubig gestellten $B$, ohne Nebenb. Bt. zwittrig, unregelmäळig. Kb. 5, zwei derselben (Flügel) sehr groß, blumenblattartig. Krb. $3-5$, das unterste derselben am größten u. kahnförmig gestaltet (Kiel), unter der Spitze mit einem gefransten Anhängsel. Stb. 8, unten alle verwachsen, oben in 2 Bündel verwachsen 0 . frei. Frkn. 1, oberständig, zusammengedrückt, 2 fächerig, mit 1 Samenknospe in jedem Fache. Fr. 1; N. 2 lappig. Fr. 2 klappig aufspringend, 2 samig. S. mit o. ohne Niihrgewebe. 


\section{Gattungen.}

Halbstrauch mit immergrünen B.; Kflügel aufgerichtet 0 . zurückgeschlagen, vor der Frreife abfallend; Anhängsel der Blkr. 4lappig; Stf. nur am frunde verwachsen.......... Chamaebuxus. I. Stauden; Kflügel gerade vorgestreckt, bleibend; Anhängsel der Blkr. kämmig-vielspaltig; Stf. in 2 Bündel verwachsen...........Polygala. II.

\section{Arten.}

\section{CHAMAEBUXUS. $D C$. Zwergbuchsbaum.}

Pfl. kahl; B. lanzettlich o. elliptisch, ganzrandig; Bt. einzeln o. zu 2; Kflügel meist weiß̉lich, selten rosenroth; Blkr. gelb, seltener ganz o. theilweise braumroth. Verbr. (fehlt Sclı. MI.)

alpestris. Spach. Gemeiner Z.

\section{POLTGALA. L. Kreuzblume.}

Stiel des Frkn. 3-4 mal länger als der Frkn.; Bt. sehr groß, meist rosenroth. M. N. Südst.

major. Jacq. Großblütige $\mathrm{K}$.

Stiel des Frkn. eben so lang 0. kürzer als dieser;

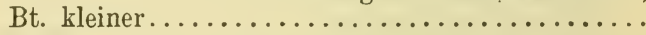

Flügel 3 nervig, Seitennerven nach außen schwachaderig, Adern nicht netzig verbunden .......... Flügel 3 nervig, Seitennerven nach außen aderig, Adern ästig und netzig verbunden .......... 6

. Grundb. viel größer als die Stgb., rosettig ........

3 Grundb. nicht 0. wenig größer als die Stgb., nicht deutlich rosettig; Bt. meist azurblau ..........

Bt. ziemlich groß, meist azurblau, seltener violett 0 . rosa, sehr selten weiß; Deckb. ziemlich lange bleibend; Flügel länger als die Fr. Verbr. (?)

amara. $L$. Bittere $\mathrm{K}$.

Bt. klein, weißlich o. blau u. weiß gescheckt, seltener ganz blau; Deckb. sehr hinfällig; Flügel ungefähr so lang als die Fr. Verbr.

amarella. $C r$. Sumpf-K.

Bt. groß; Flügel breit elliptisch, kürzer als die Blkr., länger als die Fr. $K r$. $J$.

Carniolica. Keru. Krainer K.

5 Bt. ziemlich klein; Flügel verkehrt-eiförmig, länger als die Blkr., ungefähr so lang als die Fr. A. v. T. S. K. Kr.

microcarpa. Gaud. Kleinfrüchtige K. 
Trauben meist 5 blütig, zuletzt seitenständig; B. lanzettlich, die mittleren fast gegenständig; Stg. dünn, niedergestreckt; Bt. blau 0. weiß. B. T.

serpyllacea. Wh. Quendelblättrige $\mathrm{K}$.

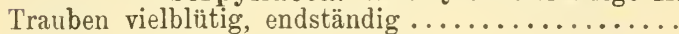

Deckb. kaum länger als die Btstiele; die Traube daher vor dem Aufblühen nicht schopfig........ Deckb. bedeutend länger als die Btstiele; die Traube daher vor dem Aufblühen schopfig...........

Zahlreiche ausläuferartige Stämmchen vorhanden; Stg. sehr zahlreich, dünn, liegend o. aufsteigend; Flügel fast doppelt so lang als die Fr.; Bt. meist azurblau. $K r$. J. Croatica. Chodat. Croatische K. Stämmchen u. Stg. wenige; Flügel wenig länger als die Fr.; Bt. blau, seltener rosa 0. weib. Verbr.

vulgaris. $L$. Gemeine $K$.

Flügel groß, breit elliptisch o. fast kreisrund, am Grunde plötzlich zusammengezogen ......... 10

9 Flügel elliptisch-verkehrt-eiförmig, gegen den Grund 10 verschmälert; Bt. rosenroth, blau 0. violett, selten weiß. Verbr......... comosa. Schk. Schopfige K.

Traube verlängert, locker; Btstiele nicht auffallend kurz; Bt. meist rosenroth, seltener blau. Südt. J.

Nicaeensis. Risso. Nicaeische K. Tranbe kurz, dichtblütig; Btstiele äußerst kurz; Bt. meist rosenroth, seltener blau. $K$. $K r$.

Forojulensis. Kern. Friauler K.

XXXIX. Familie. Euphorbiaceae. Wolfsmilchgewächse.

Stauden 0. Kräuter mit ungetheilten, schraubig gestellten 0 . gegenständigen, in der Btregion oft auch wirtelständigen B., mit 0 . ohne Nebenb. Bt. 1 häusig 0. 2 häusig,*) unscheinbar. Bthülle selten doppelt, häufiger einfach, noch häufiger verkümmert 0 , ganz fehlend. Stb. 1, 5 0. 9-12. Frkn. 1, bei Vorhandensein einer Bthülle oberständig, 2-3fächerig, mit 1, seltener 2 Samenknospen in jedem Fache. Gr. 2-3, oft am Grunde verwachsen. Fr. eine 2- bis 3 klappig aufspringende, sich oft in $\mathbf{2}-\mathbf{3}$ Theilfr. spaltende, 2-6 samige Kapsel. S. mit reichlichem Nährgewebe.

*) Die Btgruppen der Euphorbia-Arten können leicht für Zwitterbt. gehalten werden. 


\section{Gattungen.}

Bt. 1 häusig; 10 bis viele männliche u. 1 weibliche Bt. in ihrer Mitte von einer gemeinschaftlichen Hülle umgeben, eine falsche Zwitterb. (Btgruppe) darstellend; die gemeinschaftliche Hülle glockig, 9-10zähnig, 5 Zähne aufrecht o. einwärts-gekrümmt, dazwischen $4-5$ auswärts - gekehrt u. oben eine fleischige Scheibe (Drüse) tragend; männliche Bt. ein einzelnes auf dem Btstielchen stehendes Stb., gestützt von einem gewimperten 0. gespaltenen Schüppchen; weibliche Bt. einzeln im Mittelpunkte der gemeinschaftlichen Hülle; die eigentliche Bthülle sehr klein o. ganz fehlend; Gr. 3 spaltig 0 . 3 theilig; Kapsel 3 knotig ....... Euphorbia. III. Bt. einzeln, gesondert, 1-2 häusig, ohne gemeinsame drüsentragende Hülle; die eigentliche Bthülle stets deutlich entwickelt, $3-5$ theilig, manchmal doppelt . . . . . . . . . . . . . . . . .

B. groß, gesägt 0. gekerbt, gegenständig ; Bt. 2 häusig (nur ansnahmsweise 1 häusig); Bthülle einfach, 3 theilig; Stb. 9-12; Gr. 2-3 theilig; Kapsel 2(selten 3-) knotig, meist 2 samig. Iercurialis. II. B. klein, ganzrandig, wechselständig; Bt. 1 häusig; Bthülle 5 theilig, bei den männlichen Bt. doppelt; Stb. 5 ; Gr. 3 theilig; Kapsel 3 fächerig, 6 samig. Andrachne. I.

\section{Arten.}

\section{ANDRACHNE. L. Myrtenkraut.}

B. eiförmig, kurz-zugespitzt, kahl; Bt. klein, wei jlich. J.......telephioides. L. Europäisches M.

\section{MERCURIALIS. $L$. Bingelkraut.}

Einjähriges, im Sommer u. Herbst blühendes Kraut mit vierkantigem, meist ästigem Stg.; B. eiförmig o. eilänglich; weibliche Bt. zu 1- :) fast sitzend. Verbr. (fehlt S.).....annua. L. Einjähriges B. Im Frühling blühende Stauden mit kriechendem Wst. u. stielrundem, nicht verzweigtem Stg. .... B. gestielt, eilänglich 0 . länglich-lanzettlich. Verbr. peremnis. $L$. Ausdanerndes $\mathrm{B}$.

B. fast sitzend, eiförmig o. fast rundlich. M. N. St. K. Kr. J. Sï̈dt. ovata. Sternb. et Hoppe. Rundblättriges B.

\section{EUPHORBIA. $L$. Wolfsmilch.}

( B mit Nebenb., gegenständig; einjährige Kräuter . 2

1 B. ohne Nebenb.; Btgruppen in trugdoldigen Bt-

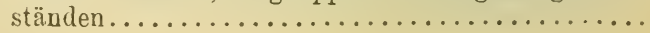


Stg. aufrecht o. aufsteigend; B. länglich, am Grunde schief-pfeilförmig ; Btgruppen in endständigen Trugdolden. (Sïdt.) ..nutans. Lagasca. Nickende W. Stg. niederliegend; Btgruppen einzeln, blattachsel-

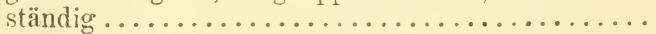

B. rundlich, an Grunde schief, rorne seicht-gekerbt ; Stg. u. B. kahl o. ranhhaarig; S. querrunzelig. .I.

Chamaesyce. L. Niedrige W.

3 B. länglich, stumpf, ausgerandet, hinten klein-gekerbt 0 . ganzrandig, am Grunde halb-herzförnig; Stg. u. B. kahl; S. glatt. .J.

Peplis. L. Meerstrands-W

Drüsen der gemeinschaftlichen Hülle rundlich 0 . quer-oval, nicht ausgeschnitten $\left.{ }^{*}\right) \ldots \ldots \ldots \ldots \ldots$ Drüsen der gemeinschaftlichen Hülle halbınondförmig-ausgeschnitten 0.2 hörnig *..........

Kapsel mit halbkugeligen, kurzwalzlichen 0 . faden-

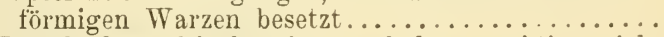
Kapsel glatt, fein-knötig o. erhaben punktirt, nicht warzig

Btstand vielstrahlig; Aeste 3 spaltig und weiter 2 spaltig; Warzen der Kapsel länglich-walzlich; B. sitzend, lanzettlich, kahl: die gegenständigen Deckb. des Btstandes elliptisch, stumpf, am Grunde verschmälert; kräftige Staude.

B. II. N. O. St. K. Kr.J.

Btstand $3-5$ strahlig

palustris. L. Sumpf-W.

Warzen der Kapsel fadenförmig verlängert; B. sitzend; Stauden ....................... 8

Warzen der Kapsel halbkugelig o. kurz-walzlich... 9

Zipfel der Hülle 4 mal kürzer als die Hülle selbst; Deckb. rundlich-eiförmig; Kapsel kugelig.

Sïdst. $K r$. .J.

epithymoides. L. Erdbeertragende W. 8 Zipfel der Hiille so lang als diese selbst; Deckb. elliptisch, ausgerandet; Kapsel länglich. B. M. N. Südst. K. Kr.

polychroma. Kern. Vielfärbige W.

*) Bei E. Gerardiana und E. Pannonica sind bisweilen halbmondförmige, bei E. Nicaeensis bisweilen quer-ovale Drüsen eingemengt. 
Deckb. stachelspitzig, fast 3 eckig-eiförmig, kleingesägt; B. spitz, von der Mitte an ungleich-kleingesägt, lanzettlich, mit herzförmigem Grunde sitzend, die untersten verkehrt-eiförmig, ganz stumpf, in den Bstiel verschmälert; Kräuter .... 10

Deckb. stumpf; B. kurz-gestielt o. fast sitzend;

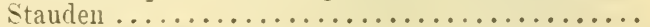

Warzen der Kapsel fast halbkugelig; S. rundlich. Verbr...... platyphylla. $\left.L .{ }^{*}\right)$ Breitblättrige W.

10 Warzen der Kapsel kurz-walzlich; S. oval; Stg. höher u. ästiger. Sch. II. N. O. S. T. K. Südst. stricta. L. Steife W.

Deckb. am Grunde abgestutzt, 3 eckig-eiförmig, fein-

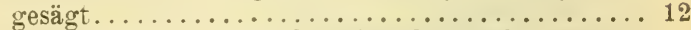

Deckb. elliptisch, am Grunde abgerundet o. verschmälert, kurz-gestielt; Drüsen gelb.........

Stg. stielrund; B. lanzettlich-länglich, stumpf, nach dem Grunde verschmälert; Deckb. lanzettlich; Kapsel ungleich-warzig, meist behaart **); Drüsen zuletzt schwarz-purpurn. Verbr.

dulcis. Jacq. Süße W.

Stg. scharf-kantig-gestreift; B. länglich-oval o. länglich, vorne kleingesägt; Deckb. eiförmig, sitzend; Drüsen gelb, dann rostbraun. Verbr. (fehlt Sch. S.)

angulata. Jacq. Kantige W.

B. lanzettlich-länglich, stumpf, ganzrandig, nach dem Grunde verschmälert; Aeste des Btstandes überhängend; Deckb. ganzrandig.

Südt. K. Sïdst. Kr. J.

Carniolica. Jacq. Ḱrainer W.

B. länglich - eiförmig, fein - gesägt; Aeste des Btstandes aufrecht; Deckb. fein-gesägt.

Verbr. (fehlt B. II. Sch.)

verrucosa. Lam. Warzige W.

Einjähriges Kraut; B. verkehrt-eiförmig, vorne gesägt; Btstand $\mathbf{5}$ strahlig, Aeste 3 spaltig u. weiter

14 gegabelt; Kapseln glatt; S. wabig-netzig. Verbr. helioscopia. $L$. Sonnenwendige W. Stauden; B. länglich, lanzettlich o. lineal; S. glatt 15 B. fein-gesägt 0 . ganzrandig, wenigstens unterseits zottig, seltener fast kahl; Deckb. oval, stumpf,

15. hinten abgerundet 0 . verschmälert.......... 16

B. ganzlandig o. vorne schwach-klein-gekerbt, seegrün, stets kahl; Deckb. stachelspitzig.........

*) Die B. sind meist kahl, bei E. literata Jacq. unterseits zottig.

**) E. purpurata Thuill. hat kahle Kapseln. 
B. länglich o. länglich-lanzettlich, am Grunde abgerundet 0 . fast herzförmig, sitzend; Deckb. rundlich-oval; Kapsel glatt (selten etwas warzig), kahl o. zerstrent behaart. Verbr. (fehlt $S$.)

villosa. $W K$. Zottige $W$.

B. länglich-spatelig, am Grunde verschmälert und oft etwas gestielt; Deckb. elliptisch; Kapsel fein warzig und langhaarig. Vora. v. N. O. St.

Austriaca. Kern. Oesterreichische W.

B. lanzettlich-lineal o. lineal, zugespitzt-stachelspitzig, ganzrandig; Deckb. 3 eckig-eiförmig, quer-breiter, begrannt, stachelspitzig; Strahlen des Btstandes wiederholt 2 spaltig. B. MI. N. O. Südst. Südt.

Gerardiana. Jacq. Gerard's W.

B. breit, länglich-lanzettlich, kurz-stachelspitzig, vorne schwach-klein-gekerbt, die oberen breiter; Deckb. breit - eiförmig, stumpf, stachelspitzig; Strahlen des Btstandes 2 spaltig. $N$.

Pannonica. Host. Ungarische W.

18 Deckb. paarweise zusammengewachsen; Stauden.... 19

Deckb. frei ........................ 20

Kapsel kahl; B. flaumig, verkehrt-eiförmig-länglich o. lanzettlich; Deckbpaare in ein flaches Scheibchen zusammengewachsen. Verbr.

amygdaloides. $L$. Mandelblättrige W.

Kapsel dicht-zottig; B. beiderseits sammtig-filzig, lanzettlich-lineal, sitzend; Deckbpaare kreiselförmigzusammengewachsen; Stg. sehr hoch, unten nackt. J........... Wulfenii. Hoppe. Wulfen's W.

Stgb. gekreuzt gegenständig. länglich-lineal; Deckb. länglich-eiförmig, spitz; Drüsen blassgelb; hochwüchsiges Kraut.

20 Südt. K. Sï̈st. Kr. J. (sonst verw.)

Lathyris. L. Springwurz.

Stgb. schraubig gestellt (nur die Deckb. oft gegenständig) $\ldots \ldots \ldots \ldots \ldots \ldots \ldots \ldots \ldots \ldots \ldots$

$21\left\{\begin{array}{l}\text { Stauden } \ldots \ldots \ldots \ldots \ldots \ldots \ldots \ldots \ldots \ldots \ldots \ldots \ldots \ldots \ldots \ldots \ldots \ldots \ldots \ldots \ldots \ldots \ldots \ldots \ldots \ldots \ldots \ldots \ldots \\ \text { Einjährige Kräuter } \ldots \ldots \ldots \ldots \ldots \ldots\end{array}\right.$ 33

B. dicht-flaumig, lanzettlich, ganzrandig, nach beiden Enden verschmälert. $M$. N.

salicifolia. Host. Weidenblättrige W.

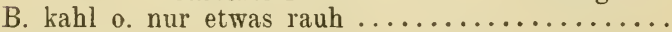

S. glatt; B. lineal, lanzettlich, länglich 0 . elliptisch,

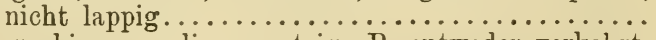

S. grubig, runzelig o. netzig; B. entweder verkehrteiförmig 0 . die unteren lineal, die oberen breiter

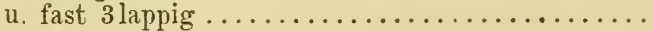


24 Btstand vielstrahlig................. 25

24 Btstand 3-5strahlig, mit 2 spaltigen Strahlen..... 29 Strahlen des Btstandes einmal 2 spaltig; B. seegrün, länglich-lanzettlich, fast fächerförmig-längsnervig; Deckb. herzeiförmig. Südt. $K r$. J.

25 Nicaeensis. All. Glatte W. Strahlen des Btstandes wiederholt 2 spaltig; B. fiedernervig, lanzettlich 0 . lineal ............. 26

B. genau lineal o. nach dem Grunde verschmälert;

26 Drüsen wachsgelb...................... 27

B. von der Mitte gegen die Spitze hin verschmälert 28

B. lineal, ganz kahl, die der Aeste viel schmäler. Verbr. ............ Cyparissias. I. Cypressen-W.

27 B. lineal-lanzettlich, gegen die Spitze hin am Rande rauh, die unteren kurz-gestielt, die der Aeste wenig schmäler. Verbr. (fehlt S.)

Esula. L. Gemeine IV.

B. glanzlos; Drüsen wachsgelb. Verbr. (fehlt S. K.)

28 B. steif, glänzend, unten sehr breit; Drüsen zuletzt rothgelb. B. $M T$. N. $K r$.

Iucida. $W$. $K$. Glänzende $W$.

B. spitz, seltener stumpflich ............. 30

B. sehr stumpf, abgestutzt 0 . ausgerandet, oft mit

29 einer Stachelspitze in der Ausrandung, in der Mitte der blïhenden Stg. rosettenartig zusammen-

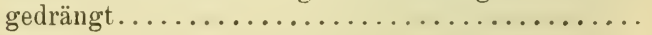

Meerstrandspflanze; B. seegrün, dicklich, länglichlineal o. lineal; Deckb. queroval, concav; Drüsen rothgelb, halbmondförmig, am äußeren Rande eingeschnitten-gezähnt. $J$.

Paralias. L. Dickblättrige W.

Felsenpflanze; B. grasgrïn, die unteren elliptisch, die oberen größer, länglich-lanzettlich; Deckb. dreieckig-herzförmig; Drüsen kurz 2 hörnig. Sü̈t.

variabilis. Cesati. Veränderliche W.

Stg. niedrig; B. abgestutzt 0 . ausgerandet, lineallänglich, die oberen oval; Drüsen wachsgelb, 2 hörnig, die Hörnchen stumpf, kürzer als die Breite der Drüse. $N$. Sï̈lst. $K r$.

saxatilis. Jacq. Felsen-II.

Stg. höher; B. sehr stumpf, länglich, die oberen eiförmig; Drüsen purpurbraun, 2 hörnig, die Hörnchen verdickt, fast so lang als die Breite der Drüse. Sïdt. K........ Kerneri. Huter. Kerner's W.

*) E. Tommasiniana Bert. $(J$.$) ist niedriger und hat$ kleinere, am Grunde herzförmige B. 
B. verkehrt-eiförmig o. länglich-verkehrt-eiförmigr, zugespitzt; Deckb. stachelspitzig; Drüsen 2 hörnig. J.............. Mrrsinites. $I$. Südliche W.

B. stumpf, die unteren lineal-lanzettlich, die oberen breiter, fast 3 lappig; Drüsen halbmondförmig. $J$.

Pinea. L. Fichtenblättrige W.

Drüsen roth oder bräunlich: B. verkehrt-eiförmig, die unteren fast kreisrund; die unteren Aeste liegend 0 . aufsteigend. $J$.

peploides. Gouan. Schutt-W.

Drüsen gelblich . .

Deckb. aus fast herzförmigem Grunde lineal, spitz; B. lineal o. lineal-keilig; S. knötig-runzelig. Verbr. exigua. $L$. Kleine W.

Deckb. eiförmig, rautenförmig 0 . nierenförmig ... 35

B. eiförmig, gestielt, in den Bstiel vorgezogen, die unteren fast kreisrund; Kapseln mit 6 flügelförmigen Längsleisten. Terbr.

Peplus. I. Garten-W.

B. lanzettlich, keilig o. lineal; Kapseln ohne Längsleisten. ..................... $30^{\circ}$

B. lineal o. lineal-lanzettlich; Btstand meist 5 strahlig; Deckb. nieren- o. rautenförmig, stachelspitzig; S. grubig-netzig. Südst. J.

segetalis. L. Saat-W.

36 B. keilig-lanzettlich; Btstand meist 3-4 strahlig; Deckb. schief-eiförmig, stachelspitzig: S. mit 4 Reihen ausgestochener Querstriche besetzt.

B. M. N. O. Südst. K. Südt. J.

falcata. $L$. Sichelförmige W.

A nmerkung. Bastarte sind in der Gattung Euphorbia sehr selten. Mit Sicherheit wurde im Gebiete nur E. Esula $X$ salicifolia $(N$.) beobachtet.

XI. Familie. Callitrichineae. Wassersterngewächse.

Zarte, meist ausdauerude Wasserpfl. mit ungetheilten, gegenständigen, am Ende des Stg. oft rosettenartig gehäuften B., ohne Nebenb. Bt. sehr klein und unscheinbar, in den Bachseln stehend, 1 häusig, ohne Bthülle, aber meist mit 2 sichelförmigen, hinfälligen Vorb. Die männliche Bt. besteht aus einem einzigen Stb. mit verlängertem Stf. Die weibliche Bt. besteht aus einem 2 fächerigen (unvollständig 4 fächerigen), 4 Samenknospen enthaltenden Frkn., der 2 verlängerte, fädliche Gr. trägt. Fr. 4lappig und 4 fächerig, nicht aufspringend, sondern in 4 Theilfr. zerfallend. S. mit fl eischigem Nährgewebe. 
Einzige Gattung .......... Callitriche. I.

Arten.

\section{CALLITRICHE. L. Wasserstern.}

B. alle verkehrt-eiförmig; Vorb. sichelförmig, mit den Spitzen zusammenneigend; Gr. bleibend, zuletzt zurückgekrümmt. Verbbr

stagnalis. Scop. Breitblättriger W.

B. alle 0 , häufiger nur die unteren lineal ........

(Vorb. an der Spitze hakig; Gr. sehr lang, spreizend. B. M. S. K. St.

2 hamulata. Kütz. Hakenblütiger W.

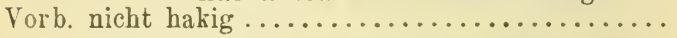

Gr. bleibend, zuletzt zurückgekrümmt; Vorb. sichelförmig, mit den ziemlich geraden Spitzen sich kreuzend. B. MI. O. St. J.

platycarpa. Kütz. Breitfrüchtiger W. Gr. bald abfallend, aufrecht; Vorb. etwas gekrümmt, mit den Spitzen kaum zusammenneigend. Verbr. verna. $\left.L{ }^{*}\right)$ Frühlings-W.

XLI. Familie. Empetraceae. Rauschbeergewächse.

Kileine, immergrüne Sträucher mit ungetheilten, schraubig gestellten B., ohne Nebenb. Bt. klein, in den Bachseln stehend, 2 häusig-vielehig, mit doppelter Bthülle. Kb. u. Kirb. 3. Stb. 3. Frkn. 1, oberständig, 6-9 fächerig, mit 1 Samenknospe in jedem Fache. Gr. kurz, mit 6-9 strahliger N. Steinfrucht beerenartig, mit 6-9 Steinen. S. mit fleischigem Nährgewebe.

\section{Gattung.}

Zweige dicht beblättert, drüsig-flaumig; B. unterseits mit tiefer Furche .......... Empetrum. I.

\section{Art.}

\section{EMPETRUM. L. Rauschbeere.}

B. länglich o. lineal, stumpf; Bt. rosa; Steinfr. schwarz. Geb.........nigrum. I. Schwarze R.

*) C. angustifolia Hoppe ist eine Wasserform mit durchaus linealen B.; C. minima Hoppe ist eine kleine Land form. 


\section{Familie. Buxaceae. Buchsbaumgewächse.}

Immergrüne Holzgewächse mit ungetheilten, ganzraudigen, lederigen, gegenständigen B., ohne Nebenb. Bt. 1 häusig, in blattachselständigen Knäueln, deren Endbt. meist weiblich ist. Bthülle einfach, von unscheinbarer Farbe, 1 --6 blättrig. Stb. meist 4. Frkn. 1, oberständig, 3 fächerig, mit 2 Samenknospen in jedem Fache. Gr. 3, kurz. Fr. eine Kapsel. S. mit Nährgewebe.

\section{Gattung.}

Stf. am Grunde gekrümmt: A. am Grunde pfeilförmig...................... Buxus. 1.

\section{Art.}

\section{BUXUS. L. Buchsbaum.}

Strauch o. kleiner Baum; B. eiförmig; Bstiele am

Rande etwas behaart.

O. S. Sïdt. .J. (oft nur rerw.)

sempervirens. $L$. Immergrüner $B$.

\section{Familie. Anacardiaceae. Pistaziengewächse.}

Holzgewächse mit gefiederten 0 . ungetheilten, schraubig gestellten B., ohne Nebenb. Bt. zwittrig, vielehig 0. 2 häusig, klein, in rispenartigen Btständen. Bthülle einfach o. doppelt, 3-5 zählig. Stb. 3-5. Frkn. 1, oberständig, 1 fächerig, mit einer grundständigen, umgewendeten Samenknospe. Gr. 3 o. 1, in letzterem Falle 3 spaltig. Steinfr. trocken. S. ohne Nährgewebe.

\section{Gattungen.}

(B. ungetheilt, ganzrandig; Bt. vielehig; Stiele der 1 fehlschlagenden Bt. nach dem Verblühen verlängert und abstehend langhaarig ........ Cotinus. II. B. gefiedert 0.3 zählig .................... 2

(Bthülle doppelt, 5 zählig; Bt. vielehig-2 häusig; N. 2 kopfig .................... Rhus. III Bthülle einfach, aus 1-5 B. bestehend; Bt. 2 häusig; N. an der Innenseite der Gr.......P. Pistacia. 1.

\section{Arten.}

\section{PISTACIA. L. Pistazie.}

B. sommergrün, unpaarig-gefiedert; Blättchen meist 7, spitz; Bstiel nicht geflügelt. Sü̈dt. $K r$. J.

Terebinthus. $L$. Terpentinbaum.

P. immergrün, paarig-gefiedert; Blättchen meist 8 , lederig, stumpf; Bstiel geflügelt. J.

Lentiscus. L. Mastixbaum. 


\section{I1. COTINUs. Adans. Perickenbaum.}

B. verkehrt-eiförmig o. oval, kahl; Bt. grünlichweiß. N. Südst. Kr.J. Sï̈t. (sonst cult.)

Coggyeria. Scop. Gemeiner P.

\section{RHUS. I. Sumach.}

B. gefiedert, Blättchen eiförmig-lanzettlich, scharfgesägt, unterseits graulich-behaart; Frrispe purpurbraun. Cult. u. verw. ...typhina. L. Essigbaum. 13. 3 zählig; Blättchen breit-eiförmig, ganzrandig 0 . geschweift, wenig behaart; Pfl. sehr giftig! B. $(v c r w.) \ldots \ldots$. . Toxicodendron. L. Gift-S.

XIIV. Familie. Aquifoliaceae. Stechpalmengewächse.

Immergrüne Holzgewächse wit ungetheilten, meist dornig gezähnten, lederigen, schraubig gestellten B., mit rerkümmerten Nebenb. Bt. vielehig, in den Bachseln gebüschelt, mit doppelter Bthïlle. K. lirugförmig, 4(-6) zähnig, bleibend. Blkr. radförmig, $4(-6)$ theilig, abfällig. Stb. $4(-6)$. Frlin. 1, oberständig, 4(-6) fächerig, mit 1-2 Samenknospen in jedem Fache. N. $4(-6)$, untereinander verwachsen, sitzend. Fr. eine beerenartige, meist 4 steinige Steinfr. S. mit fleischigem Nährgewebe.

\section{Gattung.}

Bt. weis o. etwas röthlich; Fr. scharlachroth, kugelig.

\section{Art.}

llex. I.

\section{ILEX. L. Stechpalme.}

B. glänzend, kahl, eiförmig o. elliptisch, mindestens an der Spitze mit einem Dorn.

T. S. O. N. St. Kr. Aquifolium. L. Gemeine St.

\section{XI,V. Familie. Celastraceae. Spindelbaumgewächse.}

Sommergrüne Holzgewächse mit ungetheilten, gegenständigen B. u. kleinen, hinfälligen Nebenb. Btstände trugdoldig, blattachselständig. Bt. zwittrig, regelmäßig, mit doppelter Bthülle. K. 4-5 spaltig. Krb. 4-5. St.b. 4-5. Frkn. 1, oberständig, 3-5fächerig, mit meist 2 Samenknospen in jedem Fache. Gr. kurz, mit 3-5lappiger $N$. Fr. eine $3-5$ klappige Kapsel. S. mit fleischigem, lebhaft gefïrbtem Smantel u. fleischigem Nährgewebe.

\section{Gattung.}

Kapsel 3-5 kantig, karminroth; Samemmantel orange o. scharlachroth............... Evonymus. I. 
Arten.

\section{EVONYMUS. $L$. Spindelbaum.}

Zweige stielrund, mit dunklen Warzen besetzt; Bt. meist 4 zählig; Krb. rundlich, rothpunktirt; Kapseln stumpfkantig; S. schwarz, vom Mantel nur halb bedeckt. Verbr.

verrucosa. Scop. Warziger Sp.

Zweige ohne Wrarzen; Krb. grünlich; S. weißlich,

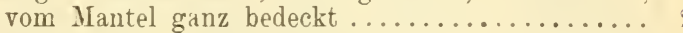

Zweige etwas zusammengedrïckt; Bt. meist 5 zählig; Krb. rundlich; Kapseln an den Kanten geflügelt. Verbr. (fehlt B. M. Sch.)

latifolia. Scop. Breitblättriger Sp.

Zweige 4 kantig, später rundlich; Bt. meist 4 zählig; Krb. länglich; Kapseln stumpfkantig. Verbr.

vulgaris. Scop. Gemeiner sp.

XLVI. Familie. Staphyleaceae. Pimpernussgewächse.

Sommergrüne Holzgewächse mit gefiederten, gegenständigen B., mit Nebenb. Bt. zwittrig, regelmäßig, in endständigen, hängenden Trauben 0 . Rispen. Bthülle doppelt. K. 5 theilig. Krb. u. Stb. 5. Frkn. 1, oberständig, tief 2-bis 3 lappig, 2-3 fächerig, mit zahlreichen Samenknospen. Gr. $2-3$, verlängert. Fr. eine aufgeblasene, 2-3lappige $u$. 2-3 fächerige Kapsel; Fächer armsamig. S. ohne Mantel; Nährgewebe spärlich.

\section{Gattung.}

Krb. wei@ o. etwas röthlich, glockig-zusammenschließend; S. braun, knochenhart, glänzend, mit großem Nabel................ Staphylea. I.

\section{Art.}

\section{STAPHYLEA. L. Pimpernuss.}

Blättchen eiförmig o. elliptisch, gesägt, kahl; Fr. blassgrün, sehr groß. Verbr. (fehlt Sch. K.)

piunata. L. Gemeine $\mathrm{P}$.

\section{Familie. Acerineae. Ahorngewächse.}

Sommergrüne Holzgewächse mit gegenständigen, meist bandtörmig gelappten B., ohne Nebenb. Btstände traubig o. häufiger ebensträußig. Bt. vielehig, regelmäßig, mit doppelter Bthülle. Kb. u. Krb. meist 5. Stb. meist 8. Frkn. 1, oberständig, 2 lappig, 2 fächerig, mit 2 Samenknospen in jedem Fache. Gr. 0. N. 2. Fr. in 2 geflügelte Theilfr. zerfallend. S. ohne Nährgewebe. 


\section{Gattung.}

Btboden zu einer ringförmigen Scheibe (Discus)

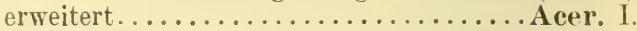

\section{Arten.}

I. ACER. L. Ahorn.

(B. herzförmig-oval, etwas eingeschnitten, ungleichgesägt; Bt. weißlich. $K r$. (sonst cult.)

Tataricum. L. Tatarischer A.

B. handförmig-lappig $\ldots \ldots \ldots \ldots \ldots \ldots \ldots \ldots \ldots \ldots \ldots$

(B. handförmig-3 lappig, Lappen stumpf, ganzrandig ;

2 Ebensträufe hängend; Bt. gelbgrün. J. Sïdt.

monspessulanum. L. Dreilappiger A.

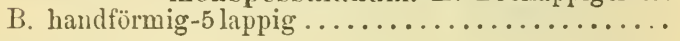

Trauben hängend; B. unterseits matt u. seegrün, 3 Lappen zugespitzt, ungleich-grobgesägt; Bt. grünlich. Verbr.... Pseudoplatauns. L. Trauben-A.

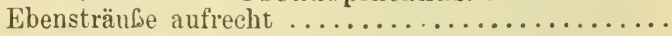

Btstiele drüsig, umbehaart; Lappen der B. buchtig3-5 zähnig, sammt den Zähnen fein-zugespitzt; Bt. lebhaft grünlich-gelb. Verbr.

platanoides. $L$. Spitz-A. Btstiele drüsenlos, kurzhaarig; Lappen der B. ganzrandig, länglich, der mittlere stumpf-2-3lappig; Bt. grünlich. Terbr....campestre. L.*) Feld-A.

XLVIII. Familie. Hippocastaneae. Rosskastaniengewächse.

Sommergrüne Holzgewächse mit gegenständigen, handförmig getheilten B., olne Nebenb. Btstände pyramidenförmig, ansehnlich. Bt. zwittrig o. vielehig, unregelmäßig, mit doppelter Bthülle. K. 5 zähnig. Krb. 4-5, ungleich. Stb. 7-8. Frkn. 1, oberständig, 3 fächerig, mit 2 Samenknospen in jedem Fache. Gr. 1, verlängert. Fr. eine 3 klappige, etwas fleischige Kapsel. S. sehr groß, mit breitem Nabel, ohne Nährgewebe, mit sehr dicken, großen Kei mb.

\section{Gattung.}

K. glockig; Stb. abwärts geneigt, aufstrebend; Kapsel kugelig, stachelig; B. 5-7 zählig...A Aesculus. I.

*) Nach der Lappung der B. u. nach der Bohaarung der Fr. werden mehrere Unterarten unterschieden. 
XLIX. BALSAMINEAE, - L. RHAMNACEAE, 369

\section{Art.}

I. AESCULUS. $L$. Rosskastanie. Blättchen unterseits röthlich-zottig, zuletzt kahl; Krb. weiß, gelb- o. roth-gefleckt; S. braun. Cult. u. veru. Hippocastanum. I. Gemeine R. Anmerkung. Die fleischroth blïhende A. rubicunda Lois, wird oft cultivirt.

XLIX. Familie. Balsamineae. Springkrautgewächse.

Einjährige Kräuter mit ungetheilten, schraubig gestellten B., ohne Nebenb. Bt. zwittrig, unregelmäßig. líb. $3-5$, das zur Blütezeit oben stehende gröser und gespornt. Krb. eigentlich 5, aber je 2 seitlich in ein 2 spaltiges verwachsen, also scheinbar 3. Stb. 5. Frkn. 1, oberständig, 5 fächerig, mit melıreren Samenknospen in jedem Fache. Gr. 1, kurz. Fr. eine mehrsamige, elastisch 5klappig aufspringende Kapsel. S. ohne Nährgewebe.

\section{Gattung.}

Stg. saftreich, zerbrechlich; B. gesägt; Btstände locker, blattachselständig......... Impatiens. I.

\section{Arten.}

\section{IMPATIENS. L. Springkraut.}

Bt. ansehnlich, gelb, hängend; Sporn zurückgebogen; S. 4 kantig, runzelig. Verbr. $u$. $h f g$.

noli tangere. L. Gemeines $S$.

Bt. klein, weislichgelb, aufrecht; Sporn gerade; $\mathrm{S}$. fein gestreift, an einer Seite rinnig. B. S. (veru.) parviflorя. $D C$. Kleinblütiges \&.

\section{Familie. Rhamnaceae. Kreuzdorngewächse.}

Holzgewächse von meist strauchigem Wuchse. B. ungetheilt, gegenständig 0 . schraubig gestellt, mit hinfälligen 0 . in Dornen umgewandelten Nebenb. Bt. zwittrig o. vielehig-2 häusig, regelmäßig, unscheinbar. K. $4-5$ spaltig. Krb. 4-5. Stb. 4-5, vor den Krb. stehend. Frkn. 1, 2-4 fächerig, mit 1 grundständigen Samenknospe in jedem Fache, bald oberständig, bald halb 0 . ganz unterständig. Gr. 0. N. 1-4. Fr. eine saftige 0 . trockene, manchmal geflügelte Steinfr. S. mit spärlichem Nährgewebe.

\section{Gattungen.}

Gr. 1, ungetheilt 0. 2-4 spaltig; Krb. schuppenförmig; Frsteine meist der Länge nach aufspringend ;

1 Nebenb. hinfällig............ Rhamnus. III. Gr. 2-3, kegelförmig; Krb. verkehrt-eiförmigspatelig, genagelt; Frsteine nicht anfspringend;

Nebenb. meist in Dornen umgewandelt .......... 
Steinfr. saftig, flügellos; Zweige kahl. Zizyphus. II.

2 Steinfr. trocken, von einem kreisförmigen Flügel umzogen; Zweige flaumig ........... Paliurus. I.

\section{Arten.}

\section{PALILRUS. Juss. Stechdorn.}

B. eiförmig, kurz zugespitzt, 3 nervig; Nebenb. in Dornen umgewandelt; Bt. grünlichgelb; Frflügel meist roth. Südt. $K r$. J.

anstralis. Gürtn. Gemeiner St.

\section{ZIZYPHUS. Juss. Judendorn.}

B. eiförmig, ausgerandet, gezähnelt, kahl; Nebeǹ. meist in Dornen umgewandelt; Fr. roth.

Südt. Kr. J. (cult. u. verw.)

vulgaris. Lam. Gemeiner J.

\section{RHAMNUS. L. Krrenzdorn.}

Zweige gegenständig; Dornen an den heurigen Zweigen

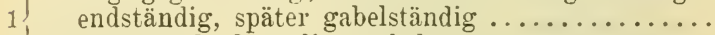

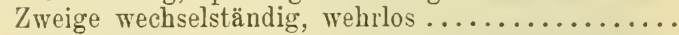

Pstiele 2-3 mal so lang als die hinfälligen pfriemlichen Nebenb, ; B. eiförmig o. elliptisch, am Grunde fast herzförmig; Furche der Samen geschlossen; Bt. grünlich-gelb; Fr. schwarz. Verbr: cathartica. L. Gemeiner K.

Bstiele ungefähr so lang als die Nebenb.; Furche

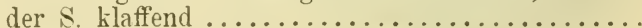

Steinfrüchte auf dem flachen Frboden sitzend; B. rundlich-verkehrt-eiförmig. $J$.

intermedia. Steud. et Hochst. Mittlerer K.

Steinfrüchte auf dem convexen o. halbkugeligen

Frboden sitzend; B. elliptisch, lanzettlich o. verkehrt-eiförmig.

Niedergestreckter, knorriger Strauch mit sparrig abstehenden Aesten; junge Zweige u. B. wenig behaart o. kahl. Verbr. (fehlt B. M. Sch.) Aurechter Strauch mit schlanken verlängerten Aesten; junge Zweige u. Bunterseite flaumig. $\Lambda$. tinctoria. WK. Fächer-K. Bt. in Trauben; B. lederig, ausdauernd, kahl, entfernt-gezähnelt-gesägt. $J$.

Alaternus. $L$. Immergrüner W.

Bt. in Büscheln; B. abfällig............... 6

Gr. 3 spaltig; Bt. 2 häusig; Krb. u. Stb. meist 4,.. 7

6 Gr. ungetheilt; N. kopfig; Bt. zwittrig; Krb. und

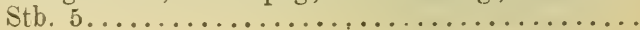


Strauch aufrecht; B. groß, länglich - lanzettlich, beiderseits mit $14-20$ geraden Seitennerven.

K. Sïdt. $K r$. J....Carniolica. Kern. Krainer K.

7 Strauch niedergestreckt, knorrig; B. elliptisch 0. rundlich, beiderseits mit $4-6$ etwas bogigen Seitennerven. A. (fehlt $\boldsymbol{N}$. O.)

pumila. L. Niedriger W.

B. oval o. rundlich, stumpf-gekerbt-gesägt; Krb. breit-verkehrtherzeiförmig. $K r$. J.

rupestris. Scop. Felsen-Faulbaum.

8 B. breit elliptisch 0. verkehrteiförmig, stumpflich zugespitzt, ganzrandig o. nur etwas geschweift; Krb. eiförmig. Verbr.

Frangula. L. Gemeiner Faulbaum.

A nmerkung. In $K r$. whirde ein muthmaßlicher Bastart zwischen Pin. Carniolica und Rh. pumila beobachtet.

LI. Familie. Ampelideae. Rebengewächse.

Mittels Ranken kletternde Sträucher mit handförmig gelappten o. getheilten, wechselständigen B., mit Nebenb. Bt. unscheinbar, zwittrig 0 . vielehig-2 häusig, regelmäßig. K. うzähnig o. fast gerade abgesohnitten. Krb. 5. Stb. 5, vor den Krb. stehend. Frkn. 1. oberständig, 2 fächerig, mit 2 Samenknospen in jedem Fache. Gr. 1. Fr. eine 1-2 fächerige, 1-4 samige Beere. S. mit hart-fleischigem Nährgewebe.

\section{Gattungen.}

B. gelappt; K. ว̌zähnig; Krb. an der Spitze zusammenhängend, am Grunde sich ablösend und wie eine Mütze zusammen abfallend.... Vitis. I.

B. 5 zählig; $K$. fast ganzrandig; Krb. an der Spitze frei............... Parthenocissus. II.

\section{Arten.}

\section{VITIS. $L$. Weinstock.}

(Bt. zwittrig o. vielehig; Beeren saftig-fleischig, wohlschmeckend, blassgrün, purpurn o. blauviolett. Cult.

vinifera. $L$. Edler W.

Bt. 2 häusig; Beeren klein, an Fleisch und Saft arm, sehr sauer, blauviolett. $M . N$. Sü̈dst. $K r$. J. Sü dt. silvestris. Gmel. Wald-W.

\section{PARTHENOCISSUS. Planch. Zaunrebe.}

Blättchen kahl, eilänglich, zugespitzt, gesägt; Bt. grünlich; Beeren schwarzblau. Cult. u. verw.

quinquefolia. (L.) Planch. Wilder Wein. 


\section{Familie. Tiliaceae. Lindengewächse.}

Bäume mit ungetheilten, wechselständigen B., mit Nebenb. Bt. zwittrig, regelmäßig. Kb. u. Krb. 5. Stb. zahlreich, frei. Frkn. 1, oberständig, meist 5 fächerig, mit 2 Samenknospen in jedem Fache. Gr. 1. Fr. nicht aufspringend, trocken, 1 fächerig, 1-2 samig. S. mit fleischigem Nährgewebe.

\section{Gattung.}

B. schief-herzförmig-rundlich, zugespitzt, gesägt; Bt. gelblich-wei $\oint$, wohlriechend, in trugdoldigen Btständen, an deren Stiel ein grobes, bis zur Frreife bleibendes, flügelartiges Hochb. angewachsen ist...........................

\section{Arten.}

I. Tilia. L. Linde.

B. unterseits kurzhaarig, blassgrün, in den Aderwinkeln weißlich gebärtet; Btstand 2-5 blütig; Fr. gerippt. Verbr.

platyphylla. Scop. Sommer-L. B. unterseits seegrün, in den Aderwinkeln rothgelb gebärtet, sonst kahl; Btstand 3-9 blütig; Fr. schwachgerippt. Verbr. cordata. Mill. Winter-L.

Anmerkung. Beide Arten sind ziemlich veränderlich. Der Bastart T. cordata $X$ platyphylla ist selten und meist nur cultivirt zu finden. Verschiedene andere Arten werden in Parkanlagen und Alleen cultivirt; auch diese bilden untereinander und mit den einheimischen Arten Bastarte.

\section{Familie. Malvaceae. Malvengewächse.}

Stauden 0. Kräuter mit schraubig gestellten, handnervigen, meist gelappten 0 . getheilten B., mit Nebenb. Bt. zwittrig, regelmäßig. $\mathrm{Kb}$. 5, am Grunde meist verwachsen, in der Regel von einem 3-9 spaltigen 0 , aus 3 freien $B$. bestehenden Außenk. umgeben. Krb. 5, in der Knospe gedreht. Stb. zahlreich, in eine Röhre verwachsen, welche den Frkn. verdeckt. Frkn. 1, oberständig, aus 5 o. mehr in Kreise angeordneten und an eine Mittelsäule angewachsenen Frb. bestehend. Jedes Frb. enthält 10 . mehrere Samenknospen. Gr. 1, oben in so viele Aeste, als Frb. vorhanden sind, getheilt. Fr. entweder in Theilfr. zerfallend o. seltener eine Kapsel. S. mit Nährgewebe.

\section{Gattungen.}

Außenk. vorhanden .................... 2

1 Außenk. fehlend; hochwüchsiges einjähriges Kraut mit gelben Bt. ............... Abutilon. I. 
(Griffeläste 5; Außenk. vieltheilig; Fr. eine 5 fächerige 2 Kapsel ......................... Griffeläste viele; Fr. in Theilfr. zerfallend .......

$3\{$ Außenkb. 3, frei ................. Malva. IV Außenkb. am Grunde verwachsen ...........

$\int$ Außenkb. 3 ; Mittelsäule die Theilfr. überragend. Außenkb. 6-9; Mittelsäule die Theilfr. nicht überragend ...................

Arten.

I. ABUTILON. Gärtn. Sammtpappel.

B. rundlich-herzförmig, zugespitzt, gekerbt, filzig; Bt. blattachselständig. $J$.

Avicennae. Gärtn. Europäische S.

\section{LAVATERA. L. Stranchpappel.}

Sternhaarig-filzige Staude; B. 5 lappig; Bt. groß, hellrosa, blattachselständig. Sch. M. B. N. O. J.

Thuringiaca. L. Thüringer Str.

Anmerkung. L. trimestris L. ist eine einjährige, hie und da verwildert vorkommende Gartenptlanze. Auf Lussin wurde die strauchige L. arborea L. gefunden.

\section{AL'THAEA. L. Eibisch.}

Btstände mehrblütig; filzig-behaarte Stauden; Bt.

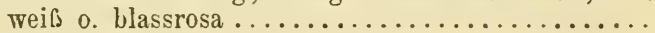
Bt. einzeln o. $\mathrm{zu} 2$

B. 3-5 lappig; Btstände die Spitze ihres Tragb. niemals erreichend. Verbr. (oft nur cult. u. verw.)

officinalis. L. Gebräuchlicher E.

B. tief 3-5 spaltig, mit lanzettlichen Abschnitten; Btstände die Spitze ihres Tragb. oft erreichend. $J$. (Veglia.). . Taurinensis. $D C$. Italienischer E.

Einjähriges Kraut; die ganze Pfl. von wagrecht-abstehenden Haaren steifhaarig; B. gekerbt, die unteren nierenförmig-5 lappig, die mittleren handförmig, die oberen tief-3 spaltig; Bt. lila o. rosa. N. Südt. $K r$. J...hirsuta. I. Rauhhaariger E. Pfl. 2- o. mehrjährig, filzig-rauhbaarig .......... 
Zweijähriges Kraut; B. rundlich o. eiförmig, meist mit herzförmigem Grunde, schwach 5-7 lappig 0 . fast ungetheilt; Lappen ungleich-gekerbt; Krb. lila, am Grunde schwefelgelb. $M . N . J$.

pallida. W. $K$. Blasser E.

Staude; die unteren B. handförmig, die oberen fingerig- 5 spaltig, die obersten tief- 3 theilig, alle gesägt-gezähnt; Krb. rosa mit purpurnem Nagel. J. ............cannabina. I. Hanfblättriger E.

Anmerkung. A. rosea (L.) Car. ist die „Pappelrose" der Gärten.

\section{MALVA. L. Käsepappel.}

Stgb. handförmig-5 - 7 theilig; Bt. blattwinkelständig

1 einzeln, o. endständig gehäuft; Stauden .........

B. gelappt; Bt. blattwinkelständig, büschelig ......

Btstiele u. K. filzig-rauh; B. des Außenk. eiförmig; Fr. kahl; Bt. rosa, geruchlos. Verbr.

Alcea. $L^{*}$ ) Spitzblättrige $\mathrm{K}$.

2 Btstiele u. K. von meist einfachen Haaren steifhaarig; B. des Außenk. lineal-lanzettlich; Fr. rauhhaarig; Bt. rosa, wohlriechend.

Verbr. (oft nur verw.) ..moschata. L. Bisam-K.

Außenkb. eiförmig o. elliptisch; Krb. länger als der

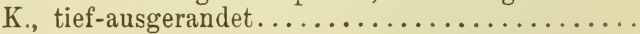

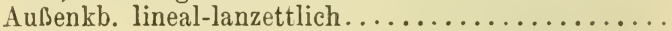

Stg. aufrecht o. aufstrebend; Krb. 3-4 mal so lang als del K., rosa mit Purpurstreifen; Außenkb. elliptisch-länglich. Verbr. silvestris. L. Wald-K. Stg. niedergestreckt, aufstrebend; Krb. doppelt so lang als der K., rosa; Außenkb. eiförmig. J.

Nicaeensis. All. Nizzäische $\mathrm{K}$.

Krb. 2-3 mal so lang als der K., tief ausgerandet; Fr. am Rande abgerundet, glatt 0 . schwach-runzelig; Bt. hellrosa. Verbr.

neglecta. Wallr. Gemeine K.

Krb. so lang als der K., seicht-ausgerandet; Fr. berandet, grubig-runzelig; Bt. hellrosa.

B. M. Sch. N. O. S....pusilla. Sim. Kleine K.

Anmerkung. Zwischen M. neglecta u. M. pusilla kommt ein Bastart vor. - M. crispa L. u. M. Mauritiana L. sind zuweilen verwildernde Gartenpflanzen.

*) Umfasst mehrere Formen! 


\section{HIBISCUS, I. Ibisch.}

Einjähriges Kraut; obere B. 3-5theilig, mit verlängertem Mittelzipfel; K. aufgeblasen; Krb. blass schwefelgelb, am Grunde schwarzpurpurn.

Verbr. (oft nur ver $w$.). Trionum. L. Stunden-I.

Anmerkung. Der strauchige H. Syriacus L. (mit großen, purpurnen o. weißen Bt.) wird in Süidt. u. J. häufig in Hecken etc. cultivirt u. verwildert manchmal.

LIV. Familie. Guttiferae. Harthougewächse.

Stauden o. Halbsträucher mit ungetheilten, ganzrandigen, gegenständigen, selten wirteligen B., ohne Nebenb. Bt. zwittrig, regelmäßig, in trugdoldigen Btständen. Kb. u. Krb. 5. Stb. zahlreich, am Grunde in 3-5 Bündel verwachsen. Frkn. 1, oberständig, vollständig, seltener unvollständig 3-5 fächerig 0. 1 fächerig, mit zahlreichen Samenknospen. Gr. 3-5, frei o. am Grunde verwachsen. Fr. eine mehrsamige Kapsel, seltener eine Beere. S. ohne Nährgewebe.

\section{Gattung.}

B. meist deutlich durchscheinend punktirt; Bt. gelb. Hypericum. I.

Arten.

\section{HYPERICLM. I. Johamiskraut.}

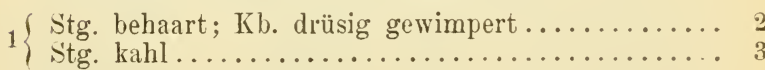

Zwischen den 3 Stbbündeln 3 Honigdrüsen; Stb. $9-15$, bis über die Mitte in 3 Bündel verwachsen;

2 Kapsel 1 fächerig. O..... Elodes. L. Sumpf- J. Honigdrüsen fehlen; Stb. zahlreich, nur am Grunde in 3 Bündel verwachsen; Kapsel 3 fächerig. Verbr. hirsutum. $I$. Rauhhaariges $J$.

(Kb. ganzrandig, nicht gefranst, selten mit einzelnen

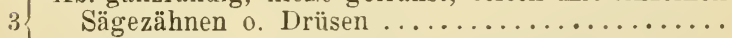
Kb. gefranst 0 . drüsig-gesägt $\ldots \ldots \ldots \ldots \ldots \ldots \ldots 9$

4 Stg. 2 schneidig 0 . fast stielrund $\ldots \ldots \ldots \ldots \ldots \ldots \ldots$

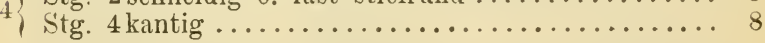

Khb. breit-eiförmig, sich deckend, nach dem Verblühen zurückgeschlagen; Stb. in 5 Bündel ge5 stellt; Fr. eine schwarze Beere. Südt. Südst. Kr $r$. Androsaemum. $L$. Blutheil. $\mathrm{Kb}$. länglich, lanzettlich o. lineal-lanzettlich; Stb. in 3 Bündel gestellt; Fr. eine Kapsel......... 
Stg. fädlich, niederliegend; K̉b. länglich, stumpf, stachelspitzig; Stb. 15-20. Verbr.

humifusum. L. Niedergestrecktes J.

Stg. aufrecht 0 . aufstrebend, 2 schueidig; Kb. lanzettlich, spitz; Stb. $50-60 \ldots \ldots \ldots \ldots \ldots \ldots$

Ḱb. 2mal so lang als der Frknoten, sehr spitz; B. oval-länglich; Btstand ebensträußig, reichblütig.

Verbr. $u$. lifg......perforatum. $L$. Gemeines J.

7 Kb. so lang als der Frknoten, spitz; B. lineal-länglich; Btstand oval, nicht umfangreich.

1I. N. Südst. $K r$. J. Sïdt

Veronense. Schrk. Veronesisches J.

Kb. elliptisch, stumpf; Stg. ungeflügelt; B. nur hin und wieder o. gar nicht punktirt. Verbr.

quadrangulum. L. Vierkantiges J.

Kb. lanzettlich, spitz; Stg. an den Kanten schmal geflügelt; B. dicht punktirt. Verbr.

acutım. Mnch. Vierflügeliges J.

B. wirtelig, zu 3-4, lineal, stumpf; Stg. halbstrauchig.

9 Vora. v. Südt.......Coris. L. Quirlblättriges J.

B. gegenständig ................... 10

Kb. am Rande drüsig-gesägt.............. 11

$10 \mathrm{~Kb}$. am Rande drüisenlos, gefranst, höchstens an der

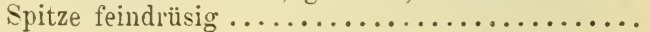

Kíb. verkehrt-eiförmig, stumpf; Stgb. herzförmig-

113 eckig, stumpf; Deckb. nicht gefranst.

B. MI. Südst. Kr. ...pulchrum. L. Schönes J.

Kb. lanzettlich o. eilanzettlich, spitz.......... 12

stg. bis zum Btstande gleichmälig und ziemlich dicht beblättert, meist mit kurzen Aesten in den Blattachseln; Krb. zerstreut o. am Rande schwarz punktirt....................... 13

Stg. entfernt beblättert, meist ganz unverzweigt, oben nackt; Btstand gedrängt; Krb. ohne schwarze Punkte. Verbr. ........montanum. L. Berg-J.

Stg. stielrund; Krb. doppelt so lang als der K.; PA. hochwüchsig. $J$.

13 perfoliatum. I. Durchwachsenblättriges J. Stg. oben 2 kantig; Krb. $3 \mathrm{mal}$ so lang als der K. B. M. N.......elegans. Steph. Zierliches J.

Fransen der $\mathrm{K} b$. viel länger als die Breite der $\mathrm{Kb}$.; B. länglich-lanzettlich, unter'seits längsaderig.

N. Südst.......barbatum. Jacq. Gebärtetes J Fransen der $\mathrm{K} b$. nicht länger als die Breite der $\mathrm{Kb}$.; B. elliptisch, unterseits netzaderig. A. v. $K r$. J. Richeri. Vill. Gefranstes J. 
Anmerkung. Von Bastarten wurde im Gebiete nur $H$. perforatum $\times$ quadrangulum mit Sicherheit nachgewiesen.

LV. Familie. Elatineae. Tännelgewächse.

Kleine, zarte, kahle, einjährige Kräuter, welche im Schlamm 0. im Wasser leben. B. gegenständig o. quirlig, ungetheilt, mit Nebenb. Bt. zwittrig, regelmäßig, einzeln in den Blattachseln. K. 2-4 theilig. Krb. 3-4. Stb. 3, 6 o. 8. Frkn. 1, oberständig, 3-4 fächerig, mit zahlreichen Samenknospen. Gr. 3-4. N. kopfig. Fr. eine vielsamige, 3- bis 4 klappige Kapsel. S. ohne Nährgewebe.

Gattung.

Bt. klein, weiø o. rosa.............. Elatine. I.

\section{Arten.}

I. ELATINE. $L$. Tännel.

B. quirlig; Bt. 4 zählig; Stb. 8. B. MI. N.

Alsinastrum. L. Wirtelblättriger T.

Wenigstens die unteren B. kürzer als der Bstiel;

2 K. 4 theilig; Krb. 4; Stb. 8. B. MI. (N.? O.?) K.

Hydropiper. L. Pfefferfrüchtiger T.

B. länger als der Bstiel; Krb. $3 \ldots \ldots \ldots \ldots \ldots . . .3$

$3\left\{\begin{array}{l}\text { Bt. sitzend; K. } 2 \text { theilig; Stb. 3. B. MI. N. O. S. St. } \\ \text { triundra. Schli. Dreimänniger T. } \\ \text { Bt. gestielt; K. } 3 \text { theilig; Stb. 6. B. } M . N . \text { (O.?) T. }\end{array}\right.$ hexandra. $D C$. Sechsmänniger T.

LVI. Familie. Tamariscineae. Tamariskengewächse.

Sträucher mit sehr kleinen, schuppenförmigen, schraubig gestellten B., ohne Nebenb. Bt. in Aehren o. Trauben, klein, zwittrig, regelmäßig, hellrosa (selten weiß). Kb. u. Krb. 5 . Stb. 5 o. 10. Frkn. 1, oberständig, 1 fächerig, mit zahlreichen Samenknospen. Gr. 0. N. 3. Kapsel 3 klappig aufspringend, vielsamig. S. mit Haarschopf, ohne Nährgewebe.

\section{Gattungen.}

Stb. 5, frei o. fast frei; Gr. keulig; S. mit sitzendem Haarschopf; Btstände seitenständig.. Tamarix. I. Stb. 10, unten verwachsen; N. sitzend; S. mit gestieltem Haarschopf; Btstände endständig.

Myricaria. II. 
Arten.

\section{TAMARIX. L. Birtze.}

B. eiförmig, angedrückt-dachig; Deckb. zugeschweifthaarspitzig; Gr. kurz. J. (sonst cult.)

Gallica. L. Französische B.

B. eilanzettlich, abstehend-dachig; Deckb. stumpf; Bt. größer; Gr. verlängert. J. (sonst cult.)

Africana. Poir. Afrikanische B.

\section{IIRICARIA. Desv. Porstbirtze.}

Deckb. länger als die Btstiele; B. lineal-lanzettlich, sitzend. Verbr.

Germanica. (L.) Desv. Deutsche P.

\section{Familie. Cistineae. Cistrosengewächse.}

Sträucher, Halbsträucher, Stauden o. Kräuter mit ungetheilten, meist gegenständigen, seltener schraubig gestellten B., mit 0 . ohne Nebenb. Bt. zwittrig, regelmäßig. Kb. 5, ungleich. Krb. 5. Stb. zahlireich. Frkn. 1, oberständig, 1 fächerig, mit zalllreichen Samenknospen. Gr. 1. Fr. eine 3-, 5- 0. 10 klappige, vielsamige Kapsel. S. mit Nährgewebe.

\section{Gattungen.}

Die 2 äußeren Kb. fast so groß o. größer als die inneren; Bt. purpurn, rosa 0. weiß; N. 5lappig;

$1\left\{\begin{array}{r}\text { Kapsel 5klappig } \ldots \ldots \ldots \ldots \ldots \ldots \ldots \ldots \text { Cistus. I. } \\ \text { Die } 2 \text { äußeren Kb. kleiner als die inneren; Bt. meist }\end{array}\right.$ gelb, selten weiß o. rosa; N. 3lappig; Kapsel

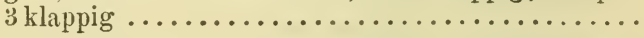

Bt. in endständigen Scheintrauben; alle Stb. fruchtbal; B. selten rein lineal, flach o. am Rande zurückgerollt ................ Helianthemum. II.

2 Bt. einzeln o. in Scheintrauben; die äußeren Stb. ohne A., perlschnurförmig; B. lineal o. lineal-lanzettlich, zusammengerollt......... Fumana. III.

\section{Arten.}

\section{Cistus. $L$. Cistrose.}

$1\{$ Bt. purpurn; B. filzig-kurzhaarig .............

B. sitzend, halb umfassend; Kb. filzig, ohne längere

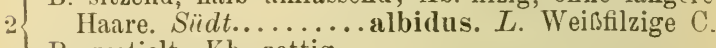

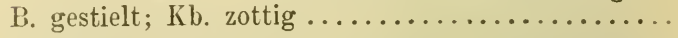

Zweige kurzharig; B. unterseits fast weißfilzig; $3\left\{\begin{array}{l}\text { Btstiele zottig. J...... incanus. L. Graufilzige C. } \\ \text { Zweige u. Btstiele abstehend langzottig; Pfl. höher" }\end{array}\right.$ und kräftiger. J........ villosus. $L$. Zottige C. 
B. lineal-lanzettlich, beiderseits klebrig-flaumig; Btstand einseitswendig. $J$.

Monspeliensis. L. Französische C.

B. eiförmig, stumpf, kurzhaarig rauh, unterseits etwas filzig; Btstiele an der Spitze der Zweige fast doldig. $J$. salvifolius. $L$. Salbeiblättrige C.

II. HELIANTHEдUM. Adans. Sonnenröschen.

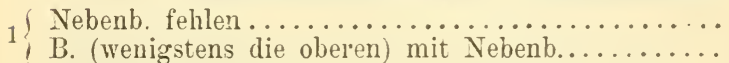

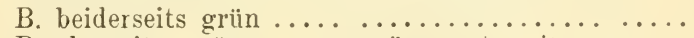

B. oberseits grün 0 . graugrün, unterseits grau- 0 . weißfilzig. B. O. N. St. J. Südt.

canum. (L.) Dun. Graufilziges S.

B. oval o. länglich, stumpf; Kapsel kahl o. nur am Rande der Klappen behaart. $A$.

alpestre. (Jacq.) Dun. Alpen-s.

B. lineal-länglich, spitz; Kapsel büschelhaarig. $I I$. rupifragum. Keru. Felsenbewohnendes s.

Gr. lang, unten knieförmig gebogen, nach oben verdickt.

Gr. kurz und gerade, 0. fehlend

Bt. gelb (höchst selten weiß); B. elliptisch, länglich o. lineal-länglich, ain Rande nicht 0 . wenig um-

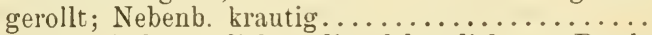
Pt. weiß; B. lanzettlich o. lineal-länglich, am Rande zurückgerollt, filzig; Nebenb. nicht krautig, lineal o. pfriemlich. Süidt. (S'iidst. ?)

velutinum. Jord. Sammtiges S'.

B. unterseits grau- o. weibfilzig; innere Kb. grauflaumig 0 . büschelhaarig.

B. unterseits zerstrent behaart 0 . fast kahl, nicht filzig; innere $\mathrm{Kb}$. flaumhaarig 0 . fast kahl .....

B. oval o. länglich, ziemlich stumpf; Kb. grauflaumig. N. Südt........ vulgare. Gürtu. Gemeines S.

B. eilanzettlich 0 . länglich, ziemlich spitz; Kb. büschelhaarig; Bt. grölser. $A$. v. (Sü dt.?) $K r$.

tomentosum. (Scop.) Willk. Filziges S.

B. unterseits zerstreut behaart, meist trübgrün;

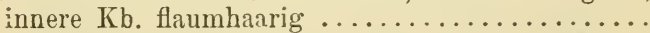

B. unterseits mit Ausnahme des Randes und Mittelnerven kahl, hellgrün; Kb. fast kahl; Bt. groß. A. v. N. O. St. ....glabrum. (Koch.) Kahles S. Btstand ziemlich reichblütig; Kb. flaumbaarig. Verbr. obscurum. Pers. Trübgrünes S.

Btstand armblütig; Bt. größer; Kb. abstehend büschelhaarig. Geb. v. M. O. S. T. K. Kr.J.

grandiflorum. (Scop.) $D C$. Grofblütiges S. 
B. kurz gestielt, fiedernervig; Btstiele mit Tragb.; $\mathrm{Kb}$. deutlich 3 nervig. $J$.

salicifolium. (L.) Perss. Weidenblättriges S.

B. sitzend, 3 nervig; Btstiele ohne Tragb.; Kb. undeutlich nervig. $J$.

guttatum. (L.) Mill. Geflecktes S.

\section{FUMANA. Spach. Haideröschen.}

Stg. drüsig behaart u. dadurch klebrig; B. gegenständig, mit Nebenb.; Bt. in endständigen Scheintrauben; Frstiele gerade. $J$.

glutinosa. (L.) Boiss. Klebriges $\mathrm{H}$. Stg. nicht klebrig, flaumig o. fast kahl; B. schraubig gestellt, ohne Nebenb.; Bt. einzeln in den Bachseln; Frstiele herabgekrümmt.

M. N. O. St. K. Kr. J. Südt.

procumbens. (Duu.) Gren. et Godr. Gemeines H.

LVIII. Familie. Violaceae. Veilchengewächse.

Stauden o. Kräuter mit ungetheilten o. getheilten, scbraubig gestellten B., mit Nebenb. Bt. zwittrig, unregelmäßig. Kb. 5. Krb. 5, ungleich, das unterste nach rückwärts in einen hohlen Sporn verlängert. Stb. 5, zusammenneigend. Frkn. 1, oberständig, 1 fächerig, mit zahlreichen Samenknospen. Gr. 1. Fr. eine 3 klappige, vielsamige Kapsel. S. mit Nährgewebe.

\section{Gattung.}

Jedes Kb. am Grunde mit einem Anhängsel.

Viola. I.

Arten.

\section{VIOLA. L. Veilchen.}

$4 \mathrm{Krb}$. nach aufwärts gerichtet, oft dachig-übereinanderliegend: Gr. oberwärts keulig .........

$12 \mathrm{Krb}$. nach aufwärts, 3 nach abwärts gerichtet, anliegend o. abstehend; Gr. am Grunde einge-

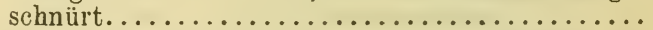

Gr. winkelig-gebogen; N. flach, fast 2lappig; B. nierenförmig; Stg. meist 2 blütig; Bt. gelb.

2 Geb.............biflora. L. Zweiblütiges V. Gr. ziemlich gerade; N. krugförmig, beiderseits mit

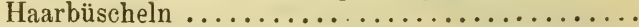

Nur Grundb. vorhanden, diese gekerbt, rundlich 0. eiförmig; Nebenb. an den Bstiel angewachsen; Bt. groB, blauviolett. $A$. v. N. O. St. alpina. $L$. Alpen- $V$.

Stg. beblättert; Nebenb. frei ................ 
B. ganzrandig, die unteren eiförmig, die oberen 4 länglich; die oberen Nebenb. spatelförmig; Bt. blauviolett. A. v. T. cenisia. $L$. Ganzblättriges V.

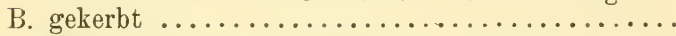

Sporn so lang als die Krb.; B. eiförmig, die oberen länglich 0. lanzettlich; Nebenb. oft 3 spaltig; Bt. violett 0. gelb. $\left.^{*}\right) A$. v. $T . K . K r$.

calcarata. $L$. Langgesporntes V.

Sporn halb so lang als die Ḱrb............. 6

$6\{$ Stg. ästig, aufstrebend; Stämmchen fehlen ....... 7

Sta. einfach; Stämmchen fädlich, kriechend ...... 11

Krb. so lang o. kürzer als die Kb., gelblich 0 . wei $\Omega$, öfters violett gestreift 0 . bläulich überlaufen; Pfl. einjährig. Verbr. $u$. hfg.

arvensis. Mnch. Acker-V.

Kirb. stets deutlich länger, oft doppelt so lang als die $\mathrm{Kb}$.

Stg. u. B. dicht mit kurzen, abstehenden Haaren bekleidet; Krb. hellviolett 0.2 farbig. $T$.

hispida. Lam. Kurzhaariges V.

Stg. u. B. zerstreut kurzhaarig o. kahl ..........

Alle B. stumpf o. die oberen etwas spitz; Bt. meist

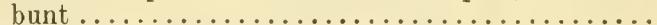

9 Die oberen B. zugespitzt o. doch spitz; Bt. gelb, groß; Pfl. ausdauernd. Verbr. (?)

saxatilis. Schm. Felsen-V.

Kraut; meist nur die 2 oberen Krb. ganz 0 . theilweise violett, die anderen gelb o. weiß̉lich (seltener alle gelblich); obere B. länglich 0 . lanzettlich, stumpf. Verbr. $u$. hf g.

tricolor. $L$. Dreifarbiges V.

Staude; Bt. bunt, in der Farbe sehr veränderlich; B. breit, die oberen eilanzettlich, etwas spitz.

T. S. St. K.polychroma. Kern. Vielfarbiges V.

Obere Stgb. lanzettlich-lineal, untere dicht übereinanderstehend; Krb. violett. Südt.

heterophylla. Bert. Verschiedenblättriges V.

11 Obere Stgb. elliptisch-lanzettlich, alle von einander entfernt; Krb. gelb (selten theilweise o. ganz violett). Sud.; A. v. Südt. K. St.

lutea. Huds. Gelbes V.

$12\{$ Alle B. grundständig; Kb. stumpf........... 13

Stg. beblättert**); Kb. spitz 0 . zugespitzt ...... 27

*) Die gelbblühende Form ist V. Zoysii Wulf.

**) V. mirabilis L. hat zu Beginn der Btzeit nur grundständige B.; sie ist von den Arten der ersten Abtheilung durch spitze $\mathrm{Kb}$. verschieden. 
1 $\mathrm{N}$. beckenförmig-ausgehöhlt 0 . in ein schiefes

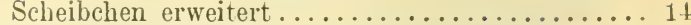

$N$. in ein dünnes Schnäbelchen umgebogen...... 17

B. vieltheilig; N. fast 3 seitig; Bt. blass-violett.

$14 T$. $K . K r . J$. ...pinnata. L. Fiederblättriges $V$.

B. ungetheilt..................... 15

Nebenb. bis über die Mitte dem geflügelten Bstiele angewachsen, lanzettlich, drüsig-gezähnelt; Bt.

15 hellviolett. ( $S$. ?) $K \cdot K r$.

uliginosa. Bess. Moor-T.

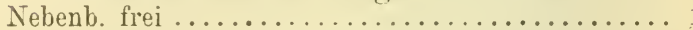

Das unpaarige Krb. geadert; B. nierenherzförmig, kahl; Bt. klein, blasslila. Verbr. (fehlt J.)

palustris. $L$. Sumpf-V.

Das unpaarige $\mathrm{Krb}$. nicht geadert; das zweite B. eiherzförmig, unterseits zerstreut behaart; Bt. größer, blau. Sch. M. S. (K. ?) epipsila. Ledeb. Torf-V.

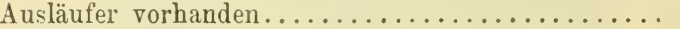

Ausläufer fehlend...................... 23

$18\{$ Frkn. u. Fr. flaumhaarig . . . . . . . . . . . 19

Frkn. u. Fr. kahl; B. glänzend, ganz o. fast kahl.. 22

B. rundlich-herzförmig, breit-abgerundet; Nebenb. sehr kurz gefranst; Bt. violett (selten weib), wohl-

19 riechend. Verbr. odorata. L. Wohlriechendes V.

B. herzeiförmig 0 . herzförmig-länglich, mehr 0 . minder spitz (seltener stumpt) ..............

Fransen der Nebenb. ungefähr von der Länge der Nebenbbreite 0 . nur etwas kürzer .............

Fransen der an den Btstiel angewachsenen Nebenb. ungefähr so lang als die halbe Nebenbbreite; Bt. violett, wohlriechend; Krb. ansgerandet. St.

Szilyana. Borb. Szily's V.

Bt. blau, mit weißem Schlund; Vorb. unter der Mitte des Btstiels eingefügt. T.S. K. St. N. J.

Anstriaca. Kern. Oesterreichisches V.

21 Bt. weis, seltener theilweise o. fast ganz violett; Vorb. in o. über der Mitte des Btstieles eingefügt; B. überwinternd. Verbr. (fehlt $B$. Sch.)

alba. Bess. Weißes V.

B. ganz kahl; Sporn etwas hakig; B. violett, am Schlunde weiblich. .J.

Adriatica. Freyn. Adriatisches V.

B. an den Nerven etwas behaart; Sporn stumpf; Bt. blau, am Schlunde weiß. B. $M$. $N$. 
Frkn. u. Kapsel mehr o. weniger (oft nur spärlich) behaart*) ........................ 24

Frkn. u. Kapsel länglich-eiförmig, kahl; B. glänzend, 23 fast kahl, breit eiförmig; Nebenb. dicht gefranst; Bt. violett, am Schlunde weis, wohlriechend. T. K. S. O.

sciaphila. Koch. Schattenliebendes V.

Nebenb. lang gefranst und außerdem am Rande fein gewimpert; B. weichhaarig, unterseits oft graugrün; Bt. blauviolett, mit weislichem Sporn, wohlriechend. Verbr. (fehlt Sch. J.)

collina. Bess. Hügel-V.

Nebenb. gefranst, am Rande kahl 0 . nur oben etwas

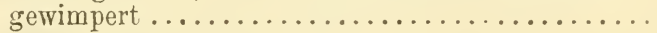

B. am Grunde deutlich herzförmig, mehr o. minder dicht behaart; Bt. meist blassviolatt (selten weiß) 26

B. am Grunde gestutzt o. gegen den Bstiel zuge25 schweift, eilänglich, dicklich, wenig behaart; Bt. gesättigt violett, wohlriechend, die B. nicht überragend. $B . M . N$. $(K$. ? $)$

ambigua. $W . K$. Puszten- $V$.

B. am Grunde mit ziemlich tiefem und schmalem Herzausschnitt; Nebenb. eilanzettlich, spitz 0. stumpflich; Bt. geruchlos. Verbr. u. $h f g$.

hirta. $L$. Rauhhaariges $V$.

B. am Grunde mit seichtem, weit offenen Ausschnitt; Nebenb. lineal-lanzettlich, fein haarspitzig; Bt. wohlriechend. $T$.

Thomasiana. Perr. et Song. Schweizer V.

Stg. einseitig-behaart, zu Beginn der Blütezeit noch unentwickelt (Btstiele daher grundständig); Bt. bleichviolett. Verbr.

mirabilis. L. Nerkwürdiges V. Stg. kahl o. flaumig, aber nicht einreihig behaart, zu Beginn der Blütezeit stets entwickelt.......

Die Nebenb. der mittleren Stgb. so lang 0. länger

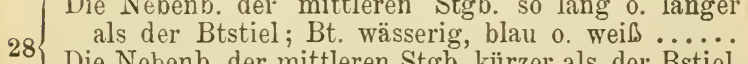
29 Die Nebenb. der mittleren Stgb. kürzer als der Bstiel, nur die der obersten B. manchmal länger...... 30

*) V. ambigua W. K. kommt auch mit kahlen Fr. (var. gymnocarpa Janka) vor. 
Stg. ziemlich niedrig, kahl; B. glänzend, fast kahl. schmal lanzettlich mit meist keiligem Grunde.

B. M. N. (O. K. ?) pumila. Chaix. Wiesen-T. 29 Stg. sehr hoch, oben flaumig; B. matt, wenigstens an den Nerven kurzhaarig, aus gestutztem 0 . seicht herzförmigem Grunde breit-lanzettlich.

B. M. N. (O. T. K. St. Kr. ?) J.

elatior. $\mathrm{Fr}$. Hochwiichsiges $\mathrm{V}$.

Die Nebenb. der mittleren Stgb. ungefähr so lang 30 als der halbe Btstiel, die der obersten so lang als der ganze Bstiel; Bt. wässerig blan 0. weiß.. 31

Nebenb. kürzer als der halbe Bstiel .......... 32

Sporn 2-3 mal so lang als die Kelchanhängsel, zugespitzt, anfwärts gekrïmmt; Bt. wässerig blau o. weib. B. N. St. (Kr.K.T. ?)

stagnina. Kit. Graben-V.

Sporn ungefähr so lang als die Kelchanhängsel. stumpf; Bt. weib, anfangs gelblich.

B. S. T. St. Kr. J. Schultzii. Bill.*) Schultze's V.

Stg. kurz; B. klein, herzförmig-rundlich; Frkn. und die eiförmige Fr. meist flaumig, seltener kahl.

${ }_{32}$ Verbr. (fehlt Sch.) rupestris. Schmidt. Felsen-V. Stg. mehr o. weniger verlängert; $B$. herzförmig 0 . eilänglich, seltener herzförmig-rundlich; Frkn. u.

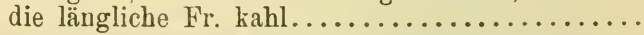

Bt. sammt dem Sporn hellviolett (sehr selten weiß), ziemlich klein; Anhängsel der Kb. sehr klein.

33 Verbr.............. silvestris. Lam. Wald- $\mathrm{V}$. Bt. blassblau-lila, mit gelblich-wei@em Sporn, groß ; Anhängsel der $\mathrm{Kb}$. verhältnissmäßig groß...... 34

Die Stg. entspringen aus einem Büschel grundständiger B.; B. ungefähr so breit als lang, weich, kurz zugespitzt; Kapseln spitz. Verbr.

Riviniana. Rchb. Groblütiges $Y$. Kein gruudständiger Bbüschel vorhanden; B. meist länger als breit, etwas lederig, stumpf o. spitz; Kapseln stumpf, mit aufgesetzter Spitze. Verbr. canina. $I$. Hunds- $T$.

Anmerkung. In der Gattung Viola sind $\mathrm{Ba}-$ starte verhältnissmäßig häufig. Im Gebiete wurden (nehr 0 . weniger sicher) beobachtet: V. lutea $X$ saxatilis; $V$. Austriaca $X$ odorata, alba $X$ odorata, odorata $X$ sciaphila, collina $\times$ odorata, ambigua $\times$ odorata, hirta $X$ odorata, odorata $X$ Thomasiana, alba $X$

*) In J. soll auch die durch milchweiße Bt. und am Grunde zum Theil keilig in den Bstiel verlaufende B. ausgezeichnete $\mathrm{V}$. lactea Sm. vorkommen. 
Austriaca, Austriaca $\times$ collina, ambigua $\times$ Austriaca, Austriaca $X$ hirta, Adriatica $X$ alba, alba $X$ cranea, alba $X$ collina, alba $X$ hirta, collina $X$ cranea, ambigua $X$ cranea, cyanea $X$ hirta, collina $\times$ sciaphila. hirta $X$ sciaphila, a mbigua $X$ collina, collina $X$ hirta, ambigua $X$ hirta; $V$. mirabilis $X$ silvestris, mirabilis $X$ Riviniana, elatior $X$ pumila, canina $X$ Schultzii, rupestris $X$ silvestris, Riviniana $X$ rupestris, canina $X$ rupestris, Riviniana $X$ silvestris, canina $X$ silrestris, canina $X$ Ririniana.

LIX. Familie. Cacteae. Fackeldistelgewächse.

Stamm fleischig, aus verkehrt-eiförmigen. dicken, zusammengedrückten Gliedern bestehend, mit Stachelbüscheln besetzt. B. verkümmert, stielrund, hinfällig, ohne Nebenb. Bt. ansehnlich, zwittrig, regelmäøig. Ǩb. n. Kirb. zahlreich, schraubig gestellt. Stb. zahlreich, frei. Frkn. unterständig, 1 fächerig, mit zahlreichen Samenknospen. Gr. 1, mit zahlreichen N. Fr. eine mit Stachelbüscheln besetzte, saftige Beere. S. mit harter Schale u. spärlichem Nährgewebe.

\section{Gattung.}

Kb. blattartig, die obersten flach, kurz; Blkr. radförmig ausgebreitet; Gr. am Grunde eingeschnürt.

Opuntia. I.

Art.

\section{OPUNTIA. Mill. Feigendistel.}

Bt. schwefelgelb; Beeren roth, feigenähnlich.

Südt. (verw.)...... vulgaris. Nill. Gemeine F.

\section{Familie. Thymelaeaceae. Seidelbastgewächse.}

Kleine Sträucher o. Halbsträucher, selten Kräuter mit ungetheilten, ganzrandigen, schraubig gestellten B., ohne Nebenb. Bt. zwittrig o. rielehig, regelmä Lig. Btboden ausgehöhlt u. krugförmig o. häufiger röhrig verlängert, oft blumenblattartig gefärbt $n$. daher scheinbar eine Blkrröhre (o. Kröhre) darstellend. Kb. 4, blumenblattähnlich, am oberen Rande des ausgehöhlten Btbodens eingefügt Krb. fehlend. Stb. 8, mit sehr kurzen Stf., 4 am oberen Rande, 4 etwas tiefer am Btboden eingefügt. Frkn. 1, frei am Grunde des ausgehöhlten Btbodens sitzend o. etwas gestielt, 1 fächerig, mit einer hängenden Samenknospe. Gr. 1, sehr kurz; N. 1. Fr. trocken 0. häufiger fleischig-beerenartig, niemals aufspringend. S. ohne 0 . mit spärlichem Nährgewebe. 


\section{Gattungen.}

Bt unscheinbar, gelblich-grün; Btboden kurz, krugförmig 0. röhrig, bleibend; $A$. herz-eiförmig; $\mathbf{N}$. kopfig; Fr. trocken ............Thymelaea. I. Bt. oft lebhaft gefärbt; Btboden röhrig verlängert, mit Ausnahme des Grundes nach dem Verblühen meist abfallend; A. oval; N. niedergedrückt, in der Mitte vertieft-genabelt; $\mathrm{Fr}$. mehr o. weniger fleischig, beerenartig........... Daphne. II.

\section{Arten.}

\section{THYMELAEA. Lam. Togelkopf.}

Einjähriges, kahles Kraut; B. lineal-lanzettlich, spitz. Verbr. (fehlt $S$.)

Passerina. (L.) Coss. Einjähriger V. Strauch mit filzigen Zweigen; B. eiförmig, fleischig, oberseits filzig, unterseits kahl. $J$.

hirsuta. (L.) Endl. Rauhhaariger V.

\section{DAPHNE. I. Seidelbast.}

Bt. an den Seiten der Aeste, o. in blattwinkelständigen, kurzen Trauben; B. lanzettlich, am Grunde keilförmig-verschmälert, kahl ..............

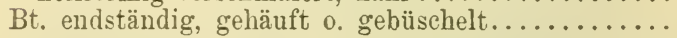

Bt. seitenständig, sitzend, meist zu 3, flaumig, rosa, selten weiß; B. sommergrün. Verbr.

Mezereum. L. Gemeiner S.

2 Trauben blattwinkelständig, kurz, meist 5 blütig, nickend; Bt. kahl, gelblich-grün; B. immergrün, lederig. N. O. Südst. $K r$. J. Südt.

Laureola. $L$. Immergrüner $\mathrm{S}$.

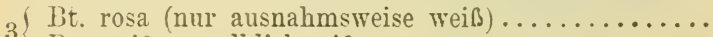

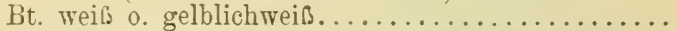

B. ohne Stachelspitze, lineal-keilig, am Rande mulstig-verdickt; Bt. flaumig. Südt.

petraea. Leyb. Felsen-S.

B. kurz-stachelspitzig, am Rande ohne Wulst .....

Bt. sitzend, kahl; Deckb. eiförmig, kulz-stachelspitzig; Zweige kahl. A. v. T. K. Kr. Südst. striata. Tratt. Kahles Steinröslein. Bt. kurzgestielt, flaumig; Deckb. sehr kurz, abgestutzt; Zweige flaumig. Verbr. (fehlt Sch. S. J.)

Cneorum. L. Flaumiges Steinröslein.

B. sommergrün, anfangs flaumig; Bt. sitzend; $\mathrm{Kb}$. zugespitzt. Südt. K. Südst. Kr.J.

alpina. L. Alpen-S.

B. immergrün, lederig, kahl; Bt. kurz gestielt; Kb. abgerundet. $K r^{\circ}$. Blagayana. Freyer. Krainer S. 
LXI. Familie. Elaeagnaceae. Oelweidengewächse.

Holzgewächse mit ungetheilten, ganzrandigen, schraubig gestellten, schülferigen B., ohne Nebenb. Bt. zwittrig, vielehig 0. 2 häusig, regelmä@ig. Btboden bald röhrig ausgehöhlt, bald nahezu flach. Kb. 2 0.4. Krb. fehlend. Stb. 4, mit sehr kurzen Stf. Frkn. 1, frei, am Grunde des ausgehöhlten Btbodens sitzend u. von demselben enge umschlossen, 1 fächerig, mit einer grundständigen Samenknospe. Gr. 1, verlängert; N. 1. Fr. scheinbar eine Steinfr., an deren Bildung sich der Btboden betheiligt. S. mit harter Schale $u$. sehr spärlichem 0 . fehlendem Nährgewebe.

Gattungen.

$\{$ Bt. 2 häusig; Kib. 2 ............Hippophaë. I. Bt. zwittrig 0. vielehig; Kb. 4 .... Elaeagnus. II.

\section{Arten.}

\section{I. НіРРОРНАЁ. $L$. Sanddorn.}

Aeste dornig; B. lineal-lanzettlich, oberseits kahl, unterseits weißlich-schülferig; Bt. klein, gelblichrostfarbig. N. O. S. T. K. St.

rhamnoides. $L$. Gemeiner $\mathrm{S}$.

\section{ELAEAGNUS. L. Oelweide.}

B. lanzettlich, spitz, beiderseits schülferig-silberweiø; Bt. außen silberweiø, innen gelb.

J. (verw., sonst cult.)

angustifolia. $L$. Schmalblättrige $\mathrm{Oe}$.

\section{Familie. Lythraceae. Weiderichgewächse.}

Stauden o. Kräuter mit ungetheilten u. ganzrandigen, oft gegenständigen B., ohne deutlich entwickelte Nebenb. Bt. zwittrig, regelmäळig o. fast regelmäßig. Btboden ausgehöblt, röhrig o. glockig, scheinbar eine Kröhre darstellend. Kb. 4-6, von ebensovielen Außenkb. umgeben, alle klein, so dass die "Kröhre" 8-12zähnig erscheint. Krb. 4-6, manchmal fehlend. Stb. 6 o. 12, selten weniger als 6. Frkn. 1, frei am Grunde des ausgehöhlten Btbodens sitzend 0 . kurz gestielt, vollständig 0 . unvollständig 2 fächerig, mit zahlreichen samenknospen. Gr. 1. Fr. 2 klappig aufspringend 0 . unregelmäßig zerreißend, vielsamig. S. ohne Nährgewebe. 


\section{Gattungen.}

Btboden kurz, glockig, etwas zusammengedrückt; Krb. 6, oft fehlend; Gr. sehr kurz, mit kreis-

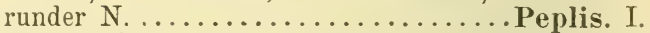
Btboden röhrig verlängert; $\mathrm{Krb}$. 4-6, niemals fehlend; Gr. fädlich, mit kopfiger N. .Lythrum. II.

\section{Arten.}

\section{PEPLIS. L. Sumpfquendel.}

Zartes, einjähriges Kraut; B. gegenständig, verkehrteiförmig, gestielt; Bt. einzeln, blattwinkelständig, fast sitzend, blassröthlich. Verbr.

Portula. L. Gemeiner S.

\section{LITHRUM. L. Weiderich.}

Einjähriges Kraut; Bt. klein, lila, blattachselständig; Stb. meist 6 ; B. länglich 0 . lanzettlich, meist schraubig gestellt. B. M. Sch. N. St. J.

1 hyssopifolium. L. Ysopblättriger W.

Stauden; Bt. ansehnlich, purpurn, in ährenartigen Btständen; Stb. meist 12; wenigstens die unteren

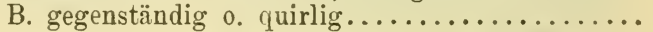

B. lanzettlich, am Grunde herzförmig; Btstände ziemlich dicht; Außenkb. viel kürzer als die $\mathrm{Kb}$. $V e r b r$. u. $h f g . . . .$. Salicaria. L. Gemeiner W. B. lanzettlich, am Grunde verschmälert (die unteren oft abgerundet); Btstände locker, schlank; Außenkb. wenig kürzer als die $\mathrm{Kb}$.

B. II. Sch. N. O. St. Kr.

virgatum. $L$. Ruthenförmiger $\mathrm{W}$.

LXIII. Familie. Punicaceae. Granatapfelgewächse.

Holzgewächse mit ungetheilten, ganzrandigen, meist gegenständigen B., ohne Nebenb. Bt. ansehnlich, zwittrig, l'egelmäßig. Btboden ausgehöhlt und seitlich mit dem Frkn. verwachsen, über letzteren hinaus verlängert, eine falsche Kröhre darstellend. Kb. u. Krb. 5-8 (meist 6). Stb. zahlreich. Frkn. unterständig, mehrfach gefächert, mit zahlreichen Samenknospen. Gr. 1, mit kopfiger N. Fr. eine große, vielsamige, einem Apfel ähnliche Beere. S. ohne Nährgewebe. 


\section{Art.}

\section{PUNICA. I. Granatapfelbaum.}

B. länglich-lanzettlich o. verkehrt-eiförmig; Bt. scharlachroth; Fr. mit lederiger Schale, im Innern fleischig. Südt. J. (cult. u. verw.)

Granatum. L. Gemeiner G.

LXIV. Familie. Myrtaceae. Myrtengewächse.

Sträucher mit ungetheilten, ganzrandigen, gegenständigen B., ohne Nebenb. Bt. zwittrig, regelmäLig, blattachselständig. Kb. u. Krb. 5. Stb. zahlreich. Frkn. unterständig. 2-3 fäccherig, mit zahlreichen Samenknospen. Gr. 1, verlängert. Fr. eine 2-3 fächerige, vielsamige Beere. S. ohne Nährgewebe.

\section{Gattung.}

Bt. weif; Beeren schwarzblau, schwammig-fleischig. Myrtus. I.

\section{Art.}

\section{MYRTUS. L. Myrte.}

B. eilanzettlich 0 . lanzettlich, lederig, immergrün. $J$. Italica. Mill. Italienische M.

\section{Familie. Oenothereae. Nachtkerzengewächse.}

Stauden, seltener Kräuter mit ungetheilten, schraubig gestellten, gegenständigen 0 . wirteligen B., ohne 0 . mit unscheinbaren Nebenb. Bt. zwittrig, regelmäßig o. etwas unregelmäßig. Btboden ausgehöhlt, mit dem Frkn. seitlich rerwachsen und oft über denselben hinaus verlängert. $K b .2$ 0 . häufiger 4. Krb. 4, seltener 2, machmal fehlend. Stb. 2, 4 o. 8. Frkn. unterständig, oft sehr verlängert, $2-4$ fächerig, selten $1 \mathrm{fächerig,} \mathrm{meist} \mathrm{mit} \mathrm{zahlreichen,} \mathrm{seltener} \mathrm{mit} 1$ bis 2 Samenknospen. Gr. 1, mit kopfiger 0. 2-4 theiliger $\mathrm{N}$. Fr. eine 4 klappige, vielsamige Kapsel, seltener eine 1- bis 2 samige Schliebfrucht. S. oft mit Haarschopf, stets ohne Nährgewebe.

\section{Gattungen.}

( Stb. 8; N. 4, kreuzförmig-abstehend o. in eine Keule 1 verwachsen; Krb. 4; Kb. 4, abfällig; Kapsel $\left\{\begin{array}{r}4 \text { fächerig, } 4 \text { klappig, mehrsamig } \ldots \ldots \ldots \ldots \ldots \ldots \ldots \\ \text { Stb. } 2-4 ; \text { Krb. } 2 \ldots \ldots \ldots \ldots \ldots \ldots \ldots \ldots\end{array}\right.$

(Btboden ( Kröhre“) so lang o. etwas länger als der Frkn.; Bt. purpurn, rosa 0. weiळ; Stauden...... Btboden ( Kröhre“) viel länger als der Frkn.; Bt. gelb; 2 jährige Kräuter......... Oenothera. IV. 
Bt. regelmäßig; Stb. 2 reihig, aufrecht; Btljoden über den Frkn. hinaus etwas verlängert; B. meist gegenständig ............... Epilobium. II.

3 Bt. etwas unregelmäßig; Stb. 1 reihig, herabgebogen; Btboden über den Frkn. hinaus kaum verlängert; B. schraubig gestellt....... Chamaenerium. III.

Stb. 2; Krb. 2, verkehrt-herzförmig; Kb. 2; SchlieЦfr. $1-2$ samig..................... Stb. 4; Krb. fehlend; Kb. 4; Kapsel 4 fächerig, $4 \mathrm{klappig,} \mathrm{mehrsamig} \mathrm{...........Ludwigia.} \mathrm{I.}$

\section{Arten.}

\section{IUUDIVIGIA. L. Heusenkraut.}

Staude; Stg. kahl; B. gegenständig, eiförmig, spitz; Bt. blattachselständig. T. K. Sïdst. Kr$r . J$. palustris. (L.) Elliot. Sumpf-H.

\section{EPILOBIUI. $L$. Weidenröschen.}

Stg. stielrund, ohne erhabene Linien ...........

1 Stg. zwar stielrund, aber mit 4 o. 2 erhabenen $u$. herablaufenden Linien bezeichnet; N. keulig ....

N. 4 theilig . . . . . . . . . . . . . . . . . N. keulig; B. lanzettlich, ganzrandig o. gezähnelt, mit keilförmigem Grunde sitzend; Stg. etwas flaumig; Ausläufer fädlich. Verbr.

palustre. $L$. Sumpf-W.

B. ganzrandig, eiförmig, zugespitzt; Bt. weiß, später blassrosa. B. ( $K$.? $)$

3 hypericifolium. Tausch. Hartheublättriges W. B. gezähnelt 0 . gesägt, höchstens die untersten ganzrandig. . .

B. stgumfassend, etwas herablaufend, spitz o. feinzugespitzt, gesägt; Stg. sehr ästig, mit einfachen, wagrecht-abstehenden u. drüsigen, kürzeren Haaren; Bt. groß, purpurn (selten weiß). Verbr.

hirsutum. L. Zottiges W.

B. kurz gestielt o. sitzend; Bt. klein, hellpurpurn,

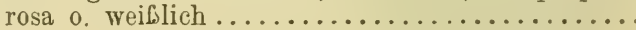

Stg. von abstehenden Haaren zottig o. Haumig; B. lanzettlich 0 . lineal-lanzettlich, gezähnelt, spitz, die unteren kur'z gestielt. Verbr. u. $h f g$. 
B. eiförmig 0. eilanzettlich, ungleich-gesägt-gezähnt 7

B. lanzettlich, in den Bstiel allmälig ver'schmälert, entfernt gesägt-gezähnt, am Grunde ganzrandig; Bt. weib, dann rosa. ML. ( $\Lambda$. Südt.?)

lanceolatum. Seb. et $M$. Lanzettblättriges W.

Stg. wenig 0. gar nicht rerästelt; B. ziemlich grob. die meisten in der Regel gegenständig.

Verbr. u. hfg..........montanum. L. Berg-W.

Stg. niedrig, meist reichlich verästelt; B. klein, nur die unteren gegenständig. V'erbr.

collinum. Gmel. Hügel-IV.

B. ziemlich lang gestielt, länglich, an beiden Enden spitz, dicht-ungleich-gezähnelt-gesägt, am Rande und an den Adern flaumig; Stg. sehr ästig, rielblütig; Bt. weiblich o. bleichrosa. Terbr.

roseum. Schreb. Rosenrothes II.

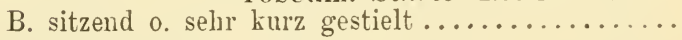

Die mittleren B. kurz herablaufend, lanzettlich, scharf gezähnelt; Stg. ästig, fast kahl; wächst an feuchten Orten. Terbr.

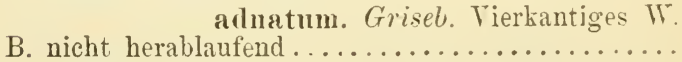

B. groß, glänzend, länglich-eiförmig, zugespitzt, am Rande u. an den Nerven flaumig, meist zu 3 (selten 4) quirlig, seltener gegenständig, die oberen oft schraubig gestellt, sitzend 0 . kaum gestielt.

Verbr. (bes. Geb.; fehlt J.)

alpestre. (Jacq.) Voralpen-W.

B. niemals quirlig, die meisten gegenständig ..... 11

Frkn. u. junge Fr. grauflaumig ............ 12

11 Frkn. u. junge Fr. zerstrent-drïsenharig, bald kibl werdend ......................... 14

Stg. meist reichlich verästelt ; $B$. entfernt gezähnelt;

S. verkehrt-eiförmig . . . . . . . . . . . . 13

12 Stg. niedrig, unverzweigt; $B$. eilänglich, ganzrandig, nur die oberen entfernt gezähnelt; Bt. nickend; S. länglich. Geb. v. B. IT. Sch. N. O. S. K. T. nutans. Schmidt. Nickendes W.

Oberirdische Ausläufer fehlen; Stg. meist mit 4 herablaufenden Linien; mittlere B. lineal-länglich. etwas graugrïn; Bt. hellpurpurn. B. $M I . N$. O.S.

Lamyi. Schltz. Graugrünes WV.

Oberirdische Ausläufer vorhanden; Stg. meist mit 2 herablaufenden Linien; mittlere $B$. länglichlanzettlich, dunkelgrün; Bt. rosa. B. MI. Sch. N. obscurum. Schreb. Dunkelgrünes IT. 
Ausläufer unterirdisch; B. eiförmig, entfernt gezähnelt, kahl, die oberen zugespitzt, die unteren stumpf. Geb.

alsinefolium. Till. Nierenblättriges W. Ansläufer oberirdisch, beblättert; B. länglich 0 . länglich-lanzettlich (die untersten eiförmig), stumpt, meist ganzrandig. Geb.

anagallidifolium. Lam. Gauchheilblättriges W.

Anmerkung. Von Bastarten wurden im Gebiete die folgenden beobachtet: E. palustre $X$ parviflorum, montanum $\times$ palustre, roseum $\times$ palustre, adnatum $X$ palustre, nutans $X$ palustre, obscurum $X$ palustre, alsinefolium $\times$ palustre, hirsutum $X$ parviflorum, montanum $X$ parviflorum, parviflorum $X$ roseum, adnatum $X$ parviflorum, collinum $\times$ montanum, montanum $X$ roseum, alpestre $>$ montanum, Lamyi $\times$ montanum, montanum $\times$ obscurum, alsinefolium $X$ montan $ı$, collinum $X$ obscurum, adnatum $\times$ roseum, obscurum $\times$ roseum, alsinefolium $\times$ roseum, adnatum $\times$ Lamyi, alsinefolium $\times$ nutans, Lamyi $X$ obscurum, anagallidifolium $X$ alsinefolium.

\section{CHAMAENERIUM. Scop. Unholdenkraut.}

B. unterseits netzaderig, lanzettlich; Krb. verkehrteiförmig, benagelt, purpurn (selten weiß).

Verbr. u. $h f g$.

angustifolium. (L.) Scop. Gemeines U. B. nicht netzaderig, lineal o. lineal-lanzettlich; Krb. ohne Nagel, elliptisch-länglich .............

Gr. am Grunde flaumig, so lang als die lüngsten Stb.; Krb. lila-purpurn. Verbr. (fehlt B.)

palustre. Scop. Sumpf-U.

Gr. bis zur Vitte flaumig, halb so lang als die längsten Stb.; Krb. lebhaft purpurn. T. J.

Fleischeri. (Hochst.) Fritsch. Alpen-U.

\section{OENOTHERA. $L$. Nachtkerze.}

Krb. kürzer als die Kb., aber länger als die Stb.; $\mathrm{Kb}$. au@en behaart, aber glatt; Rosettenb. länglichverkehrteiförmig 0 . elliptisch, stumpf bespitzt.

Verbr............... biennis. L. Gemeine N. Kb., Krb. u. Stb. ungefähr gleich lang; Kb. außen lauhhaarig, Haare auf Knötchen sitzend; Rosettenb. verlängert lanzettlich, zugespitzt. $B . N$.

muricata. L. Kleinblïtige $\mathrm{N}$.

Anmerkung. Der Bastart 0 . biennis $X m u-$ ricata wurde in $B$. u. $N$. beobachtet. 


\section{CIRCAEA. L. Hexenkraut.}

(Tragb. d. Btstiele fehlend; B. eiförmig, am Grunde

1 abgerundet 0 . fast herzförmig, ausgeschweift-gezähnelt. Verbr......... lutetiana, L. Großes H.

Tragb. d. Btstiele borstlich, hinfällig ............

Krb. so lang als die $\mathrm{Kb}$.; Fr. fast kugelig-verkehrteiförmig; B. eiförmig, am Grunde herzförmig. Verbr.......... intermedia. Ehrh. Mittleres H.

B. breit-eiförmig, am Grunde tief-herzförmig.

Verbr.................lpina. I. Alpen-H.

LXVI. Familie. Hydrocaryaceae. Wassernussgewächse.

Einjährige Wasserpflanzen mit ungetheilten, schraubig gestellten B. u. kleinen Nebenb. Bt. zwittrig, regelmäßig. Kb., Krb. u. Stb. 4. Frkn. 1, halb unterständig, 2 fächerig, mit einer Samenknospe in jedem Fache. Gr. 1, mit kopfiger N. Fr. groß, gehörnt, holzig, nicht aufspringend, aus dem Frkn. sammt Btboden u. Kb. gebildet, 1 fächerig, 1 samig. $\mathrm{S}$. groß, ohne Nährgewebe, mit einem großen und einem kleinen Keimb.

Einzige Gattung .............. Trapa. I.

Art.

\section{TRAPA. L. Wassernuss.}

B. lang gestielt, rautenförmig, grob gezähnt; Bt. weiß, blattachselständig; Fr. 4 hörnig; S. essbar. B. M. Sch. N. O. Südst. K.

natans. $L$. Schwimmende W.

LXVII. Familie. Halorrhageae. Tausendblattgewächse.

Ausdauernde Wasserpflanzen mit quirlständigen, theilweise auch gegenständigen 0 . schraubig gestellten, bald ungetheilten, bald haarfein-fiedertheiligen B., ohne Nebenb. Bt. unscheinbar, zwittrig 0. 1 häusig. K. entweder 4 blättrig 0. nur einen schmalen Saum bildend. Krb. 4, oft fehlend. Stb. 1, (2), 4, (6) 0. 8. Frkn. unterständig, 1- o. 4 fächerig, mit einer Samenknospe in jedem Fache. Gr. o. N. 1 0. 4 . Fr. nicht aufspringend, entweder 1 samig 0 . in $(2-) 4$ 1 samige Theilfr. zerfallend. S. mit Nährgewebe. 


\section{Gattungen.}

B. haarfein-fiedertheilig; Bt. meist 1 laäusig, die oberen männlich; Kb. u. Krb. 4, letztere manchmal fehlend; Stb. meist 8; Frkn. 4 fächerig; N. 4 ; Fr. in 2-4 Theilfr. zerfallend. Myriophyllum. I. B. ungetheilt; Bt. zwittrig; K. kaum bemerkbar; Krb. fehlen; Stb. 1; Frkn. 1 fächerig; Gr. 1; Fr. 1 samig . . . . . . . . . . . . .

\section{Arten.}

\section{MYRIOPHYLIUM. $I$. Tausendblatt.}

Deckb. 2-3mal so lang als die Bt., kammförmigfiederspaltig; Btquirle blattwinkelständig o. Aehren bildend. Verbr. verticillatum. L. Quirlblütiges T.

1 Die oberen Deckb. kürzer o. höchstens so lang als die Bt., die unteren fiederspaltig o. eingeschnitten, die oberen ganzrandig; Btquirle eine oben nackte, unterbrochene Aehre bildend...............

Alle Bt. in Quirlen; Btstand aufrecht, verlängert. Verbr...................

2 Die oberen Bt. schraubig gestellt; Btstand armblütig, anfangs überhängend. $B$.

alternifforum. $D C$. Abwechselndblütiges T.

\section{HIPPURIS. L. Tannenwerlel.}

Stg. röhrig, gegliedert, kahl; B. lineal, ganzrandig. Verbr. .............. vulgaris. I. Gemeiner T.

\section{Familie. Araliaceae. Epheugewächse.}

Kletternde Sträucher mit ungetheilten o. gelappten, schraubig gestellten B., ohne Nebenb. Bt. zwittrig, regelmäßig. Kb. 5, sebr klein, zahnförmig. Krb. u. Stb. 5. Frkn. unterständig, 5 fächerig, mit 5 Samenknospen. Gr. 1, kurz. Fr. eine meist 5 samige Beere. S. mit zerklüftetem Nährgewebe.

\section{Gattung.}

Bt. grünlich-gelb, in Dolden; Beeren schwarz.

Hedera. I.

Art.

\section{HEUERA. $L$. Epheu.}

B. lederig, kahl, winkelig-5 lappig, an den blühenden Aesten jedoch eiförmig, zugespitzt, ohne Lappen; Dolden flaumig. Verbr. ...Helix. L. Gemeiner E. 


\section{IXXIX. Familie. Umbelliferae. Doldengewächse.}

Kräuter o. Stauden, selten Halbsträucher mit verschiedenartig getheilten, seltener nur gelappten 0 . ganz ungetheilten, schraubig gestellten (selten gegenständigen) B., meist ohne Nebenb., aber meist mit stark entwickelter Bscheide. Bt. klein, gewöhnlich zwittrig (seltener vielehig1 häusig 0 . 2 häusig), regelmäßig 0 . (namentlich die äu@eren des Btstandes) unregelmäl(sig, in zusammengesetzten, seltener einfachen u. dann oft köpfchenförmigen Dolden. Tragb. der Aeste der zusammengesetzten Dolde („Hülle“), sowie jene der einzelnen Btstiele ("Hüllchen") vorhanden o. fehlend. K. 5 blättrig, meist sehr klein u. einen 5 zähnigen Rand am oberen Ende des Frkn. darstellend, oft ohne deutliche Abgliederung der $5 \mathrm{~Kb}$. o. überhaupt ganz unmerklich. Ǩrb. 5, oft ungleich, häufig ausgerandet 0. 2 lappig. Stb. 5. Frkn. unterständig, 2 fächerig (sehr selten 1 fächerig), mit einer Samenknospe in jedem Fache. Gr. 2, einer den Frkn. bedeckenden Scheibe ( Griffelpolster" ${ }^{*}$ ) entspringend. Fr. meist 2 fächerig $u$. gewöhnlich zuletzt in 21 samige Theilfr. zerfallend, welche an einem gemeinsamen fädlichen "Frhalter" hängen. S. mit der Frwand mehr o. weniger verwachsen, mit reichlichem Nährgewebe.

\section{Gattungen.}

(B. ungetheilt u. ganzrandig; Bt. gelb o. röthlich1 gelb; Theilfr. 5 rippig..... Bupleurum. XXXIX.

B. verschiedenartig getheilt, gelappt o. mindestens

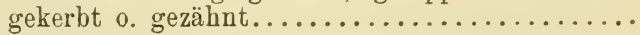

Bt. in einfachen, oft köpfchenförmigen Dolden, die oft zu unregelmäßigen Btständen vereinigt sind; B. ungetheilt 0 . handförmig getheilt, seltener

2 fiederförmig getheilt, dann aber dornig ......... Bt. in regelmäligen zusammengesetzten Dolden (selten in einfachen Dolden, dann aber die B. 2- bis 4 fach fiedertheilig $u$. nicht dornig)............

$\left\{\begin{array}{c}\text { B. schildförmig-kreisförmig; Dolde kopfig, meist 5- } \\ \text { blütig; wasserliebende, kriechende Pfl. } \\ \text { Hydrocotyle. I. }\end{array}\right.$ B. nicht schildförmig ......................

$4\{$ Bt. gelb; Dolden mit großen Hüllb. Hacquetia. III. Bt. anders gefärbt..................... 5

Dornige Pfl.; Bt. in rundlichen o. ovalen Küpfchen; $B$. fiederförmig getheilt.......... Eryngium. V. 5 Wehrlose Stauden; Bt. in unregelmäGig zusammengesetzten Dolden; B. handförmig gelappt o. ge-

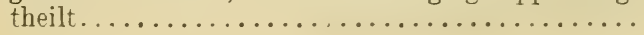


Döldchen mit großer, weißlicher o. röthlicher Hülle; Fr. ohne Weichstacheln, aber mit gezackten Rippen.

Astrantia. IV.

Döldchen mit kleiner, unauffälliger, grünlicher Hülle; Fr. hakig-weichstachelig......... Sanicula. II.

Theilfr. mit 5 Rippen 0 . undeutlich 0 . gar nicht

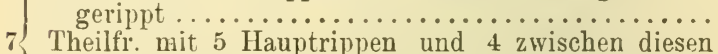
liegenden Nebenrippen, welche nur manchmal durch dichte Bestachelung der Theilfr. undeutlich werden

Fr. von der Seite her deutlich zusammengedrückt 0 . an den Seiten zusammengezogen und dann mehr

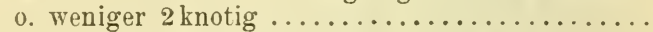

Fr. auf dem Querschnitte stielrund o. vom Rücken her zusammengedrückt .................

Bt. 2 häusig, die männlichen gelblich-weiß, die weib9 lichen weiß; Hülle fehlend ......Trinia. XXXV. Bt. zwittrig, seltener vielehig-1 häusig ........ 10

Theilfr. deutlich $(3-)$ rippig $\ldots \ldots \ldots \ldots \ldots \ldots \ldots 11$

10 Theilfr. undeutlich 5 rippig 0 rippenlos, oft geschnäbelt und dann der Schnabel oft gerippt........44

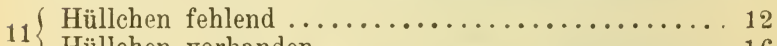

Hüllchen vorhanden $\ldots \ldots \ldots \ldots \ldots \ldots \ldots \ldots \ldots$

Bt. weiß, grünlichweiß, röthlich 0 . satt rosenroth.. 13

Bt. gelb o. grünlichgelb; Krb. lanzettlich o. elliptisch,

12 mit einwärts gebogener Spitze; Fr. kugelig-nierenförmig; die 2 Randrippen jeder Theilfr. verwischt.

Smyrnium. XXIII.

Krb. verkehrt-herzförmig-ausgerandet, mit einwärts gebogenem Endläppchen, weið ............. 14

13 Krb. nicht ausgerandet, sehr klein, rundlich mit eingerollter Spitze, grünlichweiß; Fr. rundlich, 2 knotig . ................

Untere B. doppelt-3 schnittig, mit breiten, eilänglichen Abschnitten; Theilfr. ohne Striemen zwi-

14 schen den Rippen..........Aegopodium. XXXI.

Untere B. fiederförmig getheilt; Theilfr. zwischen den Rippen mit 10 . mehreren Striemen ....... 15

Fr. länglich, mit je einer Strieme zwischen 2 Rippen;

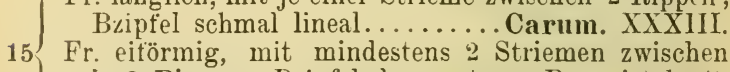
je 2 Rippen; Bzipfel der unteren B. meist breit. Pimpinella. XXXII.

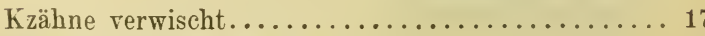

Kzähne deutlich entwickelt.............. 30 
( Rippen der Theilfr. wellig gekerbt; Krb. verkelırtherzförmig; 2 jähriges, stinkendes Kraut.

Conium. XXI.

Rippen der Theilfr. nicht gekerbt............. 18

Wenigstens der untere Theil des Stg. liegend 0. schwimmend, oft wurzelnd und kriechend; Dolden

18 scheinbar den B. gegenständig; kleine, wasserliebende Stauden...... Helosciadium. XXXVIII.

Stg. aufrecht, niemals kriechend $\ldots \ldots \ldots \ldots \ldots \ldots 19$

$19\{$ Hülle vorhanden, wenn auch oft nur 1-2 blättrig . 20

Hülle ganz fehlend ..................... 25

Doldenstrahlen wenige $(3-6$, meist 4$)$; $\mathrm{Krb}$. rundlich; Gr. sehr kurz; Fr. eiförmig, mit je einer keulenförmigen Strieme zwischen 2 Pippen.

Sison. XXX.

Doldenstrahlen mehr als 6 , nur ausnahmsweise weniger..............................

Bt. grünlich; Krb. rundlich, mit einwärts gebogenem Endläppchen; Fr. eiförmig, mit je einer strieme 21 zwischen 2 Rippen...... Petroselinum. XXXVI. Bt. weiß, röthlich o. tief rosenroth; Krb. verkehrtherzförmig 0.2 lappig.....................

Krb. ungleich-2 lappig, die äußeren am Rande der

22 Döldchen größer; Fr. eilänglich, mit je einer Strieme zwischen 2 Rippen..... A mmi. XXVIII. Krrb. verkehrt-herzförmig; Bt. regelmäßig ..........

Fr länglich; Bzipfel schmal, meist lineal ........ 24

23 Fr. eiförmig, mit mindestens 2 Striemen $z$ wischen je 2 Rippen; Zipfel der unteren B. meist breit.

Pimpinella. XXXII.

$24\left\{\begin{array}{l}\text { Fr. mit je einer Strieme zwischen } 2 \text { Rippen. } \\ \text { Carum. XXXıII. } \\ \text { Fr. mit } 3 \text { Striemen zwischen je } 2 \text { Rippen. } \\ \text { Bunium. XXXIV. }\end{array}\right.$

$25\left\{\begin{array}{l}\text { Bt. gelb o. grünlich } \ldots \ldots \ldots \ldots \ldots \ldots \ldots \ldots \ldots \ldots \ldots \ldots \ldots \ldots \\ \text { Bt. weiø, röthlich 0. tief rosenroth } \ldots \ldots \ldots \ldots \ldots\end{array}\right.$

Untere B. 2-3 fach-fiederschnittig, nur die obersten 3 zählig; Bt. grünlich; Fr. eiförmig, mit 10 gleichen, stumpfen Rippen..Petroselinum. XXXVI.

26 Untere B. 2-3 fach-3 zählig, obere 3 zählig o. ungetheilt; Bt. gelb o. grünlich-gelb; Fr. 2 knotig; Theilfr. fast kugelig, mit 3 geschärften und 2 undeutlichen Rippen ........ . Smyrnium. XXIII. 
Rippen der Theilfr. stark vortretend, spitz u. rauh gekielt, hohl; B. der Hüllchen lanzettlich, zugespitzt, gewimpert; Pfl. wohlriechend.

Myrrhis. VII.

Pippen der Theilfr. nicht hohl............ 28

$\int$ Fr. lineal, kohlschwarz, mit scharfen, fast geflügelten

Rippen; B. der Hüllcheı eilanzettlich, haarspitzig.

Freyera. XII.

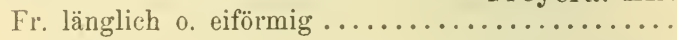

Fr. länglich, mit je einer Strieme zwischen 2 Rippen;

29 Bzipfel schmal, meist lineal... Carum. XXXIII.

Fr. eiförmig, mit mindestens 2 Striemen zwischen je 2 Rippen; Zipfel der unteren B. meist breit.

Pimpinella. XXXII.

Bt. weiø, selten grünlichweiß 0 . röthlich 0 . mit gelber Scheibe $\ldots \ldots \ldots \ldots \ldots \ldots \ldots \ldots \ldots \ldots$

Bt. gelb o. grünlichgelb; Krb. lanzettlich o. ellip-

30 tisch, mit einwärts gebogener Spitze; Fr. kugelignierenförmig, die 2 Randrippen jeder Theilfr. verwischt ................. Smyrnim. XXIII.

Kleine Pfl. mit einfach gefiederten B.; wenigstens der untere Theil des Stg. liegend 0. schwimmend, oft wurzelnd und kriechend; Dolden scheinbar den B. gegenständig ....... Helosciadium. XXXVIII. Stg. aufiecht, manchmal am Grunde schwimmend 0. wurzelnd, dann aber große, kräftige Pfl........

Hülle fehlend 0 . aus $1-3$ meist bald abfallenden $B$. gebildet

Hülle stets vorhanden und fast ausnahmslos aus

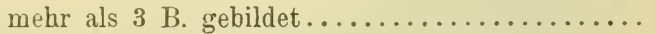

Grofe, wasserliebende Staude mit dickem, hohlem, innen gefächertem Wst.; Bzipfel lineal-lanzettlich o. lineal, meist gesägt; Fr. breiter als lang, rundlich, 2 knotig ..................... Kräuter trockener, sonniger Standorte mit spindliger Wz.; Zipfel der oberen B. lineal-fädlich; Fr. länglich 0. eiförmig............. Ptychotis. XXIX'.

Fr. kurz geschnäbelt, fast stielrund, von den am Ende verdickten und ausgehöhlten Döldchenstielen

34 eingeschlossen; B. starr, mit fast 3 kantigen, stechenden Zipfeln ..........Echinophora. VI.

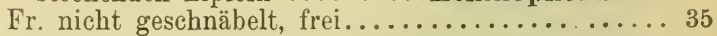

Wasserliebende Stauden mit einfach gefiederten B. (nur die im Wasser untergetauchten B. sind oft mehrfach getheilt)

Landpfl. mit mehrfach getheilten 0 . theilweise 3 zähligen $B$. 
Stg. kantig-gefurcht; Dolden endständig; Fr. länglich-oval; die 2 seitlichen Rippen am Rande der Theilfr. stehend .................. Sium. XXV. 36 sitg. fein gerillt; Dolden theils endständig, theils (scheinbar) den B. gegenständig; Fr. eiförmig; die 2 seitlichen Rippen vor dem Rande der Theilfr. stehend................... Berula. XXVI.

Krrb. verkehrt-eiförmig, länglich-lanzettlich, nicht ausgerandet

Krb. verkehrt-herzföımig 0 . ausgerandet ..........

Die 3 mittleren Ripuen der Theilfr. geschärft und häutig geflügelt, die 2 seitlichen weniger vortretend; Krb. lanzettlich, lang zugespitzt.

Iolopospernum. XVIII.

Alle 5 Rippen der Theilfr. gleich, aufgeblasen-geflügelt; Krb. verkehrt-eiförmig o. länglich, manchmal in ein Spitzchen vorgezogen.

Pleurospermum. XIX.

Rippen der Theilfr. geschärft, fast geflügelt; B. fein 39 getheilt, seegrün, glänzend ......Mladnikia. XX. Rippen der Theilfr. fädlich, wenig vortretend .... 40

$40\left\{\begin{array}{l}\text { Fr. länglich; Stg. stielrund, gerillt; Grundb. 3 zählig. } \\ \text { Frr. herzeiförmig-2 knotig; Stg. kantig-gefurcht; alle }\end{array}\right.$ B. mehrfach getheilt....Physospermum. XXII.

Fr. brillenförmig-2 knotig, mit kugeligen Theilfr.; stinkende Kräuter mit 2-8strahligen Dolden.

Bifora. XVI.

Fr. lineal, länglich o. eiförmig, oft geschnäbelt... 42

Fr. lang geschnäbelt, viel kürzer als ihr Schnabel, letzterer steifhaarig; einjährige Kräuter.

Scandix. XI.

Fr. kurz 0. gar nicht geschnäbelt ........... 43

Fr. mit 5 undeutlichen Rippen, nicht geschnäbelt.. 44 Fr. ganz ohne Rippen, kurz geschnäbelt, der Schnabel 5 rippig; Krb. meist nicht ausgerandet.

Anthriscus. X. $44\left\{\begin{array}{l}\text { Gr. fädlich; Krb. meist ausgerandet; Dolden min- } \\ \text { destens } 6 \text { strahlig } \ldots \ldots \ldots \ldots \text { Chaerophyllum. IX. }\end{array}\right.$ Gr. fast fehlend; Krb. meist nicht ausgerandet; Dolden 2-3 strahlig........ Physocaulos. VIII.

Fr. nicht zusammengedrückt, auf dem Querschnitte

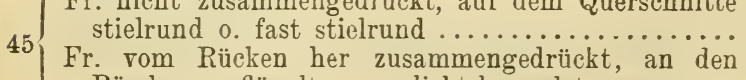
46 Rändern geflügelt 0 . verdickt-berandet 


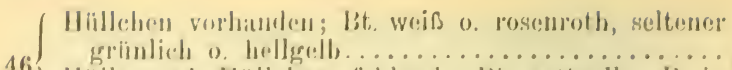

Hiille und Hiilleden fohlend; Bst. sattgelb; B3. in horstliche Kippel getheilt.... Foeniculum. XLIL.

f Krb. alliptisch, an beiden Enden spitz; Gebirgsptl.

47 mit fein getheilten L............. Meum. XLI.

Krh. anders geformt................ 48

48) Krallue dentlich entwickell............... 4!

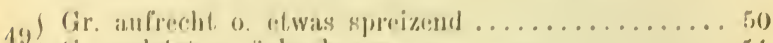

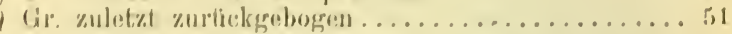

Fre kahl; 'Thrilfr. mit je vinel Strieme zwischen 2 Rippen; Pfl. lenrhter ()rto ...(Oensunthe. LIII.

50) Fre dicht lechatat; 'Theilfr. mit $1-3$ (meist 2) Striemen \%wischen je: 2 Rippen; fielsenpfl.

Atlituanta. XILI.

K\%iilıne 3eckig, ku\%, dicklich, bleibend; Hïlle foh-

51 lend 0. armblithrig............. Seseli. LI.

Kxiihne pfriemlich, verliangert, abfüllig; Hëlle meist; vielhliilfrig; Stgr. lantig-gefureht. . Libanotis. I.

Hille, 5- o, mehrblithrig ............. 5.3

5e llible fohlend o, ans $1-4$ meist, hinfialligen B. bestehend. . . . . . . . . . . . . . . . .

Moerstrandspll. mit, seegrinen, lleisehigen B.; Krb. rundlich o. queroval, eingerollt, nicht, ausgerandet.

b. nicht fleischig; Krb. Lermeiförmig o. verkehrt-

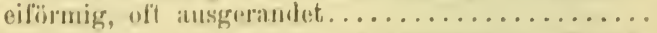

Kleine Alpenufl.; Dolden 12-20strahlig; 'T'beilfr. ohur dentlich sichtbaro striemen zwischen den Rippen............. Pachypleusum. XI,VI. Pfl. niedriger Standorta; Dolden 20 -40 strahlig; 'I'heilfr. mit jo 1 striene zwischen 2 Rippen.

Cuidium. XI,VIII.

Doldenstrahlen 4-10; Bt. blassgell o. grobulich ... 50;

55) Doldrustrahlun fiast immer mehr als 10 ; Bt. weib,

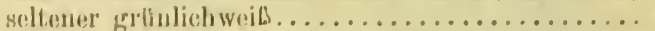

Hallehen:3-5blitlrig, abfiillig; Krb. spatelig-benatgelt, grinlich; Briplel groh-gesïgt.

56) Hublehen vielhlattrig; Krb. Im Gronde gestutat o. her\%formig, hassgelb; Baipleal sehr foin gesïgt.

Silaus. XI,IV

f Hallchen $(1-) 3$ bliithig, einseitig, meist. herabge-

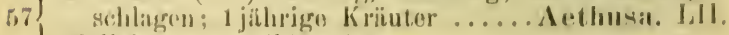

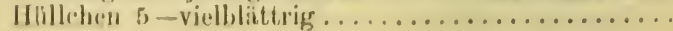


Die rambtändigen Rippen der 'Theilfr. doppelt so breit gellügelt als die iibrigen; kahle staude.

Alle 5 Rippen gleich o. fist gloieh, geschïrt o. etwas geflizgelt

'Theilfr. mit mehreren Striemen \%wischen je ¿ Rippen; Krb. am Grundo kur\% keilig-benigelt.

Theilfr. mit je eine Strime zwischen \& Rippen;

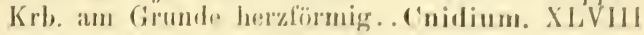

'Theilfr. unr durch eins schmale fiuge verbunden, die gefliggelten Randrippen derselben dahere dent. lich getrennt, so dass a Fligel ueben einandror

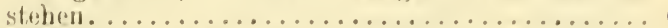

Theilfr. dicht aneinander liegend, die Randrippen daher zusammenstoßend, so dass die ganze $\mathrm{F} \cdot$ von einem geflïgelten o. knorpeligen verdickten Rands umgeben erscheint ............. lif;

61) Krb. lanzettlich o. clliptisch, zugespitat ........ 62

, Krb.verkahrt-heryformig, verkehrt-eiförmigo.rundlich 633

Kb. undentlich; Krb. lan\%ottlich; S. an die Frwand angowachsen; die Rijekenripuen der Jir. fidlich.

Angelica. I,VII

K. klein, 5rälıng; Krb. elliptisch; S. foei; Rolokenrippen der lir. erhaben, dicklich.

A rehangelica. IVI.

K. 5rïhnig, Zähne eiförmig; S. unr zwisehen den Rippen mit dor Frwand \%usammenhängend; Rippen fädlich; Krb. benagelt, rundlich - vorkehrt - herzförnig................ Ostericum. LVIII. Kb. undentlich; S. mit der firwand gan\% verwachsen;

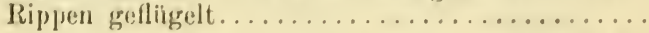

Bt. blassgelb; Krb. rundlich, nicht ausgerandet; hochwüchsige, kahle staude. . I Ievisticum. IIV. Bt. weib, oft etwas röthlich o. grinulieh; Krb. ausgerandet 0 . verkehrt-hermförmig ............

Stg. kantig-gefurcht; zwischen den Rückenrippen der 'Theilfr. je 1 Strieme ......... Selinmm. LIX. Stg. stielrund, gerillt; zwischen den Rïckenrippen der 'Theilfr. je $2-3$ striemen.

Conioselinnm. XI,VH

Bt. gelb o. grünlich

Bt. weib o. röthlich

$67\{$ Babschnitte borstlich-lineal $\ldots \ldots \ldots \ldots \ldots \ldots \ldots$

Babschnitte nicht lineal, verschieden gestaltet. 70) 
Krb. rundlich, eingerollt ............... 69 $68\left\{\begin{array}{l}\text { Krb. flach o. nur etwas einwärts gebogen (das End- } \\ \text { läppchen eingeschlagen); Hülle fehlend o. arm- }\end{array}\right.$ blättrig................Peucedanum. LXII.

( Hülle u. Hüllchen stets vorhanden; große Stande.

69 Ferulago. LX. IIïlle u. Hüllchen fehlen; 1 jähriges Kraut.

Anethum. LXIII.

Krrb. eingerollt ................... 71

70 Krb. flach 0 . nur etwas einwärts gebogen, das End-

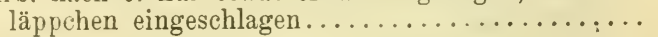

Hüllchen fehlend 0 , aus wenigen hinfälligen $B$. be-

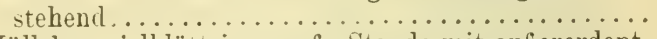

71 Hüllchen vielblättrig; große Staude mit außerordent72 lich großen, mehrfach fiederschnittigen, im Umrisse dreieckigen B............ Opopanax. LXIV.

Große, kahle Staude; alle 5 Rippen der Theilfr. ungefähr gleic’s weit von einander entfernt.

Tommasinia. LV.

72 Zweijährige Kräuter; B. wenigstens unterseits behaart; die 2 Randrippen der Theilfr. von den 3 rückenständigen Rippen abgerückt, alle sehr fein.

Pastinaca. LXV.

Alle 5 Rippen der 'Theilfr. ungefähr gleich weit von einander entfernt..........Peucedanum. LXII.

73 Die 2 Randrippen der Theilfr. von den 3 rückenständigen Kippen abgerückt, alle sehr fein.

Heracleum. LXVI.

Alle 5 Rippen der Theilfr. ungefähr gleich weit von

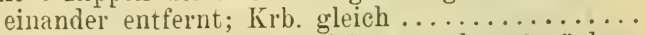

74 Die 2 Randrippen der Theilfr. von den 3 rückenständigen Rippen abgerückt, alle sehr fein; die Krb. am Rande der Döldchen meist größer .....

Kzähne verwischt; Grundb. 3zählig 0. doppelt3 zählig; Bscheiden groß, aufgeblasen.

$75)$ Imperatoria. LXI. K. deutlich 5 zähnig; B. ein- 0. mehrfach fiederschnittig o. mehrfach zusammengesetzt.

Peucedanum. LXII.

$76\left\{\begin{array}{l}\text { Frrand verdickt, runzelig-knotig. } \\ \text { Tordylium. LXVII. } \\ \text { Frrand abgeflacht .......... Heracleum. LXVI. }\end{array}\right.$

Fr. weder geflügelt noch bestachelt; Rippen fädlich

77 0. kielförmig hervortretend ............. 78

F'r. entweder geflügelt 0 . stachelig $\ldots \ldots \ldots \ldots \ldots .79$ 
Die 4 Nebenrippen der Theilfr. weniger hervortretend als die 5 Hauptrippen; große Staude mit 2-3 fach 3 zähligen $B$. und gro@en, rundlichen Blättchen ...................... Die 4 Nebenrippen der Theilfr. gekielt gerade, die 5 Hauptrippen schwächer, geschlängelt; 1 jähriges Kraut mit 1-3 fach fiederschnittigen $B$.

Coriandrum. XVII.

Fr. stachellos, Nebenrippen geflügelt, Hauptrippen fädlich, daher jede Theilfr. 4 flügelig; Stauden, selten Kräuter............Laserpitium. LXIX.

Fr. stets bestachelt; Kräuter.................

B. der Hülle fiedertheilig o. 3 spaltig mit schmalen, langen Zipfeln; B. der Hüllchen 2-3spaltig 0 . ungetheilt; Hauptrippen der Theilfr. fädlich, beborstet, Nebenrippen viel mehr vorragend, 1 reihig bestachelt ............... Daucus. LXXI.

Hülle fehlend 0 . aus ungetheilten $B$. bestehend.... 81

Die 3 rückenständigen Hauptrippen der Theilfr. sind gleich hoch wie die 4 Nebenrippen $u$. wie diese $2-3$ reihig bestachelt, die 2 Randrippen sind viel kürzer u. feiner bestachelt .... .Turgenia. XIII.

Die 3 rückständigen Hauptrippen treten viel weniger hervor 0 . sind viel schmälel als die 4 Neben-

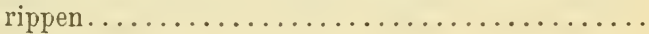

Die 4 Nebenrippen der Theilfr. stark hervortretend, viel höher als die Hauptrippen, $1-3$ reihig be-

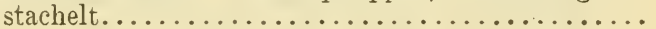

Die 4 Nebenrippen breit $u$. flach, so dicht bestachelt, dass sie kaum deutlich hervortreten $u$. die ganze Fr. dicht bestachelt erscheint.

Torilis. XV.

Hülle stets vorhanden, aus 2-j B. bestehend; Fr. vom Rücken her zusammengedrückt, mit schlanken, pfriemlichen Stacheln........ Orlaya. LXX.

Hülle fehlend 0 . aus 1-2 B. bestehend; Fr. etwas von der Seite zusamınengedrückt, ihre Stacheln mit kegeligem Grunde......... Caucalis. XIV.

\section{Arten.}

\section{HYDROCOTYLE. L. Wassernabel.}

B. doppelt-gekerbt, schildförmig, 3 nervig; Dolden kopfig, meist 5 blütig; Bt. weißlich, röthlich 0 . grünlich. Sch. B. T. $K r$.

vulgaris. $L$. Gemeiner W. 


\section{I1. SANICULA. L. Heilknecke.}

Grundb. handförmig-getheilt, Zipfel 3 spaltig, ungleich eingeschnitten; Stg. fast blattlos; Bt. weißlich o, etwas röthlich. Verbr.

Europaea. L. Europäische H.

\section{HACQUETIA. Neck. Schaftiolie.}

Grundb. gestielt, handförmig-getheilt; Lappen vorne 2-3 spaltig. Sch. M. Südst. K. Kr. J.

Epipactis. (Scop.) $D($ '. Grüne Sch.

\section{ASTRANTIA. $L$. Sterndolde.}

( Untere B. tief $(5-) 7-9$ theilig, fast gefingert, mit lineal-lanzettlichen, fast gestielten Abschnitten; Dolden und Hüllen klein, weiß, manchmal röthlich o. grünlich überlaufen. $A$. v. (O.?) Südt. minor. $L$. Kleine St.

Untere B. $3-5$ (sehr selten 7 theilig), mit mehr 0 .

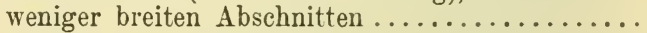

Untere B. meist 3 theilig, seltener 5 theilig; Dolden und Hüllen klein, weiß o. etwas grünlich, niemals röthlich. Südst. K. Kr.J.

Carniolica. Wulf. Krainer St.

Untere B. 5 theilig; Dolden und Hüllen ansehnlich, weißlich, grünlich 0 . röthlich bis lebhaft rosenroth

Kb. eiförmig, stumpf, undeutlich stachelspitzig; Mittelzipfel der unteren B. tiefer reichend als die anderen; Zacken der Rippen an der Fr. spitz. Vora. v. T. K. St. Kr. J.

Bararica. F. Schltz. Baierische St. $\mathrm{Kb}$. eilanzettlich, stachelspitzig begrannt; Babschnitte fast gleich; die unteren Zacken an den Rippen

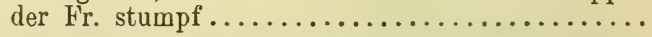

Hülle so lang 0 . wenig länger als die Dolde, weißlich, grünlich o. röthlich; Kb. wenig länger als die Krb. Verbr.......... major. L. Große St.

4 Hülle fast doppelt so lang als die Dolde, meist rosa; $\mathrm{Kb}$. länger zugespitzt, fast doppelt so lang als die Krb. O. S. St. K. Kr.

Carinthiaca. Hoppe. Kärntner St.

\section{ERYNGIUM. L. Donardistel.}

${ }_{1}$ B. doppelt-fiederspaltig o. 3 zählig-doppelt-fieder-

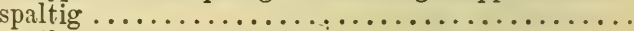
Grundb. ungetheilt, am Grunde herzförmig....... 
Btstände hell bläulich-grün; B. 3 zählig-doppeltfiederspaltig, netzig-aderig. Verbr. (fehlt $S$.)

campestre. $L$. Gemeine D.

Btstände blan; B. doppelt-fiederspaltig, nervig-aderig.

Sïdt. K. Kr. J. . amethystinum. L. Blaue D.

Hüllb. lineal-lanzettlich, entfernt dornig-gezähnt; Grundb. oval-herzförmig, stumpf, gekerbt-gesägt;

3 Btstände blau. $M . N$. Kr.J.

Hüllb. eiförmig 0 . fiederspaltig............... planum. $L$. Flachblättrige $D$. Hüllb. eiförmig, dornig-gezähnt; Grundb. herznierenförmig; Btstände blau, seltener weißlich. $J$.

maritimum. L. Meerstrands-D.

Hüllb. vielspaltig, borstig-gezähnt; Grundb. herzförmig, spitz; Btstände blau, seltener weißlich.

A. v. $T . K$. $K r . J . \ldots \ldots$ alpinum. $L$. Alpen-D.

Anmerkung. In Sïdt. wurde E. amethystinum $X$ campestre beobachtet.

\section{ECHINOPHORA. L. Stacheldolde.}

Staude; B. fiederschnittig, die unteren mit fiederspaltigen Fiedern; Hüllb. starr, stechend; Bt. weiß. $J . \ldots \ldots \ldots \ldots \ldots \ldots$ spinosa. L. Starre St.

\section{MYRRHIS. Scop. Süßdolde.}

Staude; B. 2-3 fach fiederschnittig, fein zottig; Hüllchenb. lanzettlich, zugespitzt; Bt. weiß; Fr. lineal-länglich, glänzend.
(B. MI. Sch.) St. Kr. J. K. S. T. (bes. Geb.) olorata. (L.) Scop. Wohlriechende S.

\section{PHYSOCAULOS. Tausch. Knotendolde.}

Einjähriges Kraut; Stg. unter den Gelenken aufgeblasen; B. 3 zählig-doppelt-fiederschnittig. J. nodosus. (L.) Tausch. Europäische Ḱ.

\section{CHAEROPHYLLUM. L. Kälberkropf.}

Blättchen ungetheilt, eiförmig-länglich, zugespitzt, gesägt; B. 3 fach zusammengesetzt; Stg. unter den Gelenken verdickt; Gr. spreizend; Bt. weiß. Verbr. (fehlt $O . K . J$.)

aromaticum. $L$. Gewürzhafter $\mathrm{K}$. Blättchen eingeschnitten 0 . fiederspaltig ......... 2 Stg. unter den Gelenken verdickt; Gr. zurückgekrümmt; Krb. kahl, weiß................. Stg. fast gleich dick; Gr. aufrecht 0 . abstehend; Krb. (wenigstens an dem eingeschlagenen Läppchen) wie die Hüllchen gewimpert, weib 0 . rosa.. 
Gr. länger als der Griffelpolster; Hüllchen gewimpert; Staude; B. 3 fach-fiederschnittig, Blättchen am Grunde fiederspaltig, an der lang vorgezogenen Spitze gesägt. Vcrbr. (fehlt Sch.)

aureum. L. Goldfrüchtiger $\mathrm{K}$.

Gr. so lang als der Griffelpolster; Stg. unten steif-

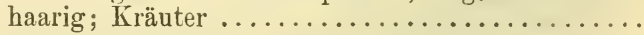

Stg. oben kurzhaarig; B. doppelt-fiederschnittig, Blättchen stumpf-lappig-fiederspaltig; Hüllchen gewimpert. Verbr. temulum. L. Betäubender K.

4 Stg. oben kahl; B. vielfach-zusammengesetzt; Blättchen tief-fiederspaltig; Zipfel lineal o. lineal-lanzettlich, spitz; Hüllchen kahl. Verbr. (fehlt J.)

bulbosum. L. Kerbelrübe.

Krb. ringsum gewimpert, nur an der Spitze kahl; Hüllchenb. eilanzettlich 0 . lanzettlich ..........

Krb. nur am eingeschlagenen Läppchen gewimpert, sonst kahl; Hüllchenb. sehr lang, fast lineal und größtentheils häutig. $A$. v. $T$.

elegaus. Gaud. Schöner K.

Frhalter bis gegen den Grund zu 2 theilig; B. doppeltfiederschnittig, Abschnitte im Umrisse länglich 0 . länglich-lanzettlich, fiederspaltig, mit gesägten Zipfeln. A. u. Vora... Villarsii. Koch. Alpen-K. Frhalter nur an der Spitze 2spaltig; B. doppelt3 schnittig, Abschnitte im Umrisse eiförmig o. länglich, lappig eingeschnitten, mit gesägten Zipfeln. Verbr........Cicutaria. Vill. Rauhhaariger K.

\section{ANTHRISCUS. Hoffm. Kerbelkraut.}

Stg. und meist auch die B. von sehr kurzem Flaume fast sammtig; B. 2-3 fach fiederschnittig; Fr. lineal-länglich; Staude. $K r . J$.

fumarioides. $S p r$. Erdrauchartiges K. Stg. kahl o. unten rauhhaarig, o. nur über den Ge-

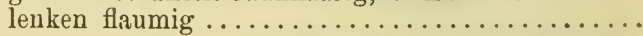

Einjährige Kräuter; Stg. gerillt; Dolden 2-6 strablig, theilweise scheinbar den B. gegenständig .......

2 Stauden 0. zweijährige Kräuter; Stg. gefurcht; Dolden 8-15 strahlig, am Stg. und an den Aesten endständig . . . . . . . . . . . . . . . . . .

Doldenstrahlen u. meist auch der Stg. über den Gelenken flaumig; Fr. lineal ............... Stg. sammt den Doldenstrahlen kahl; Gr. sebr kurz; N. fast sitzend ; Fr. eiförmig, mit kleinen, einwärts gekrümmten Stachelchen dicht besetzt.

Sch. M. B. O. N. K. Kr.

Seandix. (Scop.) Beck. Eselsherbel. 
$4\left\{\begin{array}{l}\text { Fr. kahl, glänzend. Cult. n. verw. } \\ \text { Cerefolium. (L.) Hoffm. Echtes K. } \\ \text { Fr. stachelborstig. B. M. N. O. }\end{array}\right.$ trichospermus. Schult. Wildes $\mathrm{K}$. Stg. unten rauhhaarig, oben kahl; Blattscheiden u. Hüllchen am Rande wollig-zottig. Terbr. $\iota . h f g$. silvester. (L.) Hoffm. Wiesen-h. 5 Stg. kahl o. gröstentheils kahl; Blattscheiden u. Hüllchen am Rande gewimpert. Geb. (fehlt .J.) nitidus. (Wahlbg.) Garcke. Alpen-K.

\section{SCANDIX. L. Nadelkerbel.}

B. der Hüllchen viel länger als breit, lıneal, lanzettlich o. länglich; die randständigen Bt. wenig 0 . gar nicht gröfer als die übrigen .............

1 B. der Hüllchen rauten-eiförmig, fast breiter als lang, breit randhäutig, abstehend o. zurückgebogen : die randständigen Bt. groß, nnregelmäßig. J.

\section{grandiflora. $L$. Grobblütiger N.}

Schnabel ungefähr doppelt so lang als die Fr., von der Seite zusammengedrückt, überall steifhaarig; B. der Hüllchen lanzettlich 0 . lineal, oft 2 - bis 3 spaltig. B. M. N. U. Südst. Kr. J. Südt.

Pecten Veneris. L. Venuskamm.

Schnabel ungefähr 4 mal so lang als die Fr., vom Rücken her zusammengedrückt, 2 reihig-steif haarig; B. der Hüllchen länglich, ungetheilt 0 . an $\mathrm{der}^{\circ}$ Spitze 2 zähnig. J....australis. L. Südlicher N.

\section{FREIERA. Rchb. Knollendolde.}

Knollen rundlich; B. doppelt-fiederschnittig, kahl; Dolden 8-10 strahlig; Krb. weiß. J. cynapioides. (Guss.) Griseb. Istrianische K.

\section{TURGFNIA. Hoffm. Klettendolde.}

Einjähriges Kraut; B. fiederschnittig, mit lanzettlichen, eingeschnitten-gesägten Abschnitten; Dolden $2-5$ strahlig; Bt. weiß o. rosenroth.

B. M. N. Sï̈t. J.

latifolia. (L.) Huffim. Breitblättrige $\mathrm{K}$.

\section{CAUCALIS. L. Haftdolde.}

Dolden 2-5 strahlig, scheinbar den B. gegenständig: Stg. kantig; Pfl. 1 jährig .................

1 Dolden 8-15 strahlig, endständig; B. fein zertheilt; 2 Stg. stielrund, fein gerillt; Pfl. 2 jährig; Stacheln der Theilfr. lang u. dünn. $B$. (eingeschleppt). orientalis. $L$. Orientalische $\mathrm{H}$. 
Fr. eilänglich; Stacheln der Theilfr. auf jeder Neben-

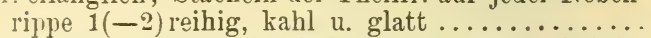
2 Fr. lineal-länglich; Stacheln der Theilfr. auf jeder Nebenrippe meist 3 reihig, körnig-rauh. J. (T.)

leptophylla. $L$. Schmalblättrige $\mathrm{H}$.

Stacheln der Theilfr. so lang o. länger als der Querdurchmesser der Theilfr., an der Spitze hakig.

Verbr. .........dancoides. $L$. Möhrenartige $H$.

3 Stacheln der Theilfr. viel kürzer als der Querdurchmesser der Theilfr., an der sehr feinen Spitze aufwärts gebogen 0 . fast gerade. $B . N$. St.

muricata. Bischoff. Kurzstachelige H.

\section{TORILIS. Adans. Borstendolde.}

Dolden geknäuelt, sitzend, scheinbar den B. gegenständig; die äußeren Fr. stachelig, widerhakig, die inneren körnig-rauh. Südt. $J$.

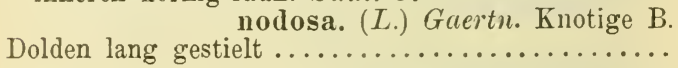

Stacheln der Fr. nicht widerhakig, einwärts gekrümmt; Hülle mehrblättrig. Terbr.

Anthriscus. (L.) Gimel. Wald-B.

Stacheln der Fr. widerhakig; Hülle 1 blättrig 0 .

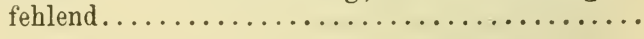

Krb. der Randbt. 2 mal so lang als der Frkn.; Fr. vielmal länger als der Griffelpolster; B. doppeltfiederschnittig. $N$.

neglecta. Spr. Vernachlässigte B. Krb. so lang o. kürzer als der Frkn.; obere B. fieder-

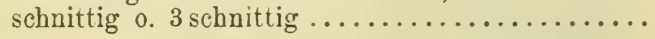


XVII. CORIANDRUM. L. Koriander.

Stg. stielrund, fein gerillt, kahl; Fr. röthlichbraun. Cult. u. verw..........sativum. L. Gebauter K.

XVIII. MOLOPOSPERIIUM. Koch. Striemendolde.

Staude; B. zusammengesetzt; Blättchen rhombischverlängert-lanzettlich, fiederspaltig; Bt. weiß; Fr. strohgelb. Südt. K. Kr.J.

Peloponnesiacum. (L.) Koch. Griechische St.

XIX. PLEUROSPERIIUII. Hoffm. Rippendolde. Pfl. kräftig, ausdauernd 0 . 2jährig; B. $1-2$ fach fiederschnittig 0.3 zählig-doppelt - fiederschnittig mit fiederspaltigen Abschnitten. Verbr. (fehlt J.)

Austriacum. (L.) Hoffm. Oesterreichische R.

XX. HLADNIKIA. Koch. Kerndolde.

Staude; Stg. stielrund, glatt und kahl; B. im Umrisse 3 eckig, 3 zählig-herablaufend-doppelt-fiederschnittig; Bt. weiß. Vora. v. Südt. Kr. J.

Golaka. (Hacq.) Rchb. Krainer K.

\section{CONIUY. L. Schierling.}

Stg. oft blutroth gefleckt; B. der Huillchen lanzettlich, kürzer als die Döldchen; Bt. weiß. Verbr.

maculatum. $L$. Gefleckter Sch.

XXII. PHYSOSPERMUM. Cusson. Blasendolde. Staude; Verästelungen des Btstieles spreizend; Zähne der Bzipfel stachelspitzig; B. der Hülle u. Hüllchen kurz. $J$.

verticillatum. (W.K.) Vis. Quirlästige B.

\section{SIIYRNIUM. $L$. Gelbdolde.}

Stgb. umfassend, herz-eiförmig, gekerbt; Stg, oberwärts kantig-geflügelt; Bt. gelb. $K r$. J.

perfoliatum. Mill. Durchwachsene G. Untere B. 3 fach-3 schnittig, die oberen 3 schnittig; Blättchen eiförmig; Hüllchen sehr kurz; Bt. grünlich. J.............. Olusatrum. L. Gespenst.

XXIV. CICUTA. $L$. Wasserschierling.

B. 3 fach-fiederschnittig; Bt. weiß, theils zwittrig, theils männlich. Verbr...virosa. L. Giftiger W.

XXV. SIUM. L. Merk.

Blättchen lanzettlich, gesägt, am Grunde ungleich; Bt. weiß. Verbr. (fehlt S. K.)

latifolium. L. Wasser-M. 
XXII. BFRULA. L. Berle.

Blättchen eilänglich, eingeschnitten - gesägt, am Grunde ungleich; Bt. weib. Vertr.

angustifolia. (I.) Koch. Schmalblättrige B.

xXVII. PRIONITIS. Adans. Sicheldolie.

Pfl. seegrün; Zipfel der B. lineal-lanzettlich, gleichförmig gesägt, mit stachelspitzigen Sägezähnen.

Verlur. (fehlt Sch. S. Kr.J.)

Falcaria. (L.) Dum. Gemeine S.

Pfl. grasgrün; Zipfel der unteren B. eiförmig, ungleich tief-gesägt, die der oberen länglich-keilig, eingeschnitten-gesägt. Vor $a$. v. $K r$. J.

pastinacifolia. (Rchb.) Fritsch. Pastinakblättrige $\mathrm{S}$.

\section{XXVII. АММI. L. Knorpelmöhre.}

Einjähriges Krant; untere B. 1-2 fach fiederschnittig; Blättchen lanzettlich, knorpelig-stachelspitzig-gesägt: B. der Hïlle meist 3 spaltig. (N.) $J$.

majus. $L$. Grobe $\mathrm{K}$.

\section{PTYCHOTIS. Koch. Haardolde.}

B. der Hüllchen borstlich, 3 derselben gröber; Bspindel geflügelt. Sï̈t.

saxifraga. $(L$.) Wollf. Bibernellblättrige $H$.

B. der Hüllchen meist 5 , davon 2 spatelig, haarspitzig, 3 lineal-pfriemlich; Bspindel ungeflügelt; Pfl. kleiner. $J$. $(K r$ ? $)$

ammoides. (Gouan.) Koch. Knorpelmöhren-

\section{SISON. L. Wiirzsilge.}

blättrige $\mathrm{H}$.

Zweijähriges Krant; Stg. sehr ästig; B. fiederschnittig. $K r . J . . .$. Amomum. L. Bibernellblättrige W.

\section{AEGOPODIUM. L. Geißfuß.}

Staude; Stg. gefurcht; Grundb. doppelt-3 schnittig.

Verbr. u. hfg.....Podagraria. I. Gemeiner G.

XXXII. PIMPINELLA. L. Bibernell.

$1\{$ Fr. kahl; Bt. weiß o. rosa; Stauden ........... 2

Fr. flaumig o. ranhhaarig; Bt. stets weiß; Kräuter. 4

Stg. kantig-gefurcht, beblättert; Gr. länger als der Frkn.; Fiederblättchen spitz. Verbr. $u$. hfg.

magna. L.*) Große B.

Stg. stielrund, gerillt, oberwärts fast nackt; Gr. während der Btzeit kürzer als der Frkn........

*) Umfasst mehrere Formen! P. rubra Hoppe ist eine ebhaft rosa blühende Gebirgsform. 
Stg. fein gerillt, wenigstens unten flaumig, selten ganz kahl; Fiedern der Grundb. in der Regel ungetheilt u. stumpf, aber auch manchmal fiederspaltig; Dolden reichstrahlig. V' $\epsilon r b r . u$. hfg.

saxifraga. $L .^{*}$ ) Gemeine B.

Stg. ungleich-, fast kantig-gerillt, ganz kahl ; Fiedern der Grundb. fast handförmig eingeschnitten, mit lanzettlichen, fein zugespitzten Zipfeln; Dolden 5-7 strahlig. Geb......alpestris. (Spr.) Alpen-B.

Fr. abstehend-rauhhaarig; alle B. 1(-2) fach fiederschnittig ; Doldenstrahlen behaart; Hüllchen fehlend.

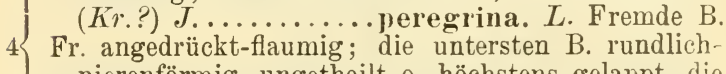
nierenförmig, ungetheilt 0 . höchstens gelappt, die oberen 1-3 fach fiederschnittig; Hüllchen armblättrig. Cult. ............... Anisum. L. Anis.

A n merkung. P. magna $\$ Saxifraga ist selten.

\section{CARUM. L. Kïmmel.}

Hülle u. Hüllehen fehlen; B. doppelt-fiederschnittig, Abschnitte fiederspaltig-vielspaltig; Stg. kantig; Wz. möhrenförmig. Verbr. $\iota$. hfg .

Carvi. L. Garten-K.

Hülle u. Hüllchen vorhanden; Stg. stielrund; Wst. fast kugelig, knollenförmig .................

Hülle u. Hüllchen reichblättrig; Theilfr. aneinander liegend, länglich; Dolden 12-24 strahlig.

(B. M. N.) Kr.

2 Bulbocastanum. (L.) Koch. Knolliger K. Früchtchen abstehend, lineal; Dolden 6-12 strahlig. $J$.

ferulaefolium. (Desf.) Boiss. Spreizender K.

\section{BUNIUM. $L$. Erdknollen.}

Dolde 6-12 strahlig; B. der Hüllchen schmaltrockenhäutig-berandet; Bzipfel 1 nervig, nicht fleischig. J. ........ divaricatum. Bert. Berg-E.

Dolde 4-6 strahlig; B. der Hüllchen breit-weibhautrandig; Frstiele dick, 2 schneidig; Bzipfel fleischig; nervenlos. (J.?)

alpinum. $W, K$. Alpen-E.

*) P. nigra Willd. ist eine graulich behaarte, kräftige Form dieser Art. 
XXXV. TRINIA. Hoffm. Faserschirm.

Hüllchen fehlend o. 1 blättrig; Stg. niedrig.

M. N. O. Südst. Kr. Südt.

glauca. (L.) Dum. Kleiner F.

Hüllchen 3-6 blättrig; Stg. höher. $M . N$. J.

Kitaibelii. $M$. B. Großer F.

XXXVI. PETROSELINUM. Hoffim. Petersilie. Kraut; B. glänzend, die unteren 2-3 fach fiederschnittig mit 3 spaltigen Blättchen, die obersten 3 schnittig.

Cult. u. verw. (Südt. J. wild?)

sativum. Hoffm. Gemeine $\mathrm{P}$.

XXXVII. APIUM. L. Sellerie.

Pfl. kahl; B. fiederschnittig, die oberen 3 schnittig, Abschnitte keilig, an der Spitze eingeschnittengesägt. N. T. J. (sonst cult. u. verw.)

graveolens. L. Gemeiner s.

XXXVII. HELOSCIADIUM. Koch. Sumpfschirm.

Bfiedern eilanzettlich, gleichförmig-stumpflich-gesägt;

Dolden reichstrahlig, fast sitzend. Sudt. (Kr.?)

nodiflorum. $(L$.) Koch. Knotenblütiger S. Bfiedern rundlich-eiförmig, ungleich-gezähnt-gesägt

o. gelappt; Dolden 3-6 strahlig, lang gestielt.

N. O. S. T. K. St.

repens. (Jacq.) Koch. Kriechender S.

\section{BUPLEURUM. L. Hasenohr.}

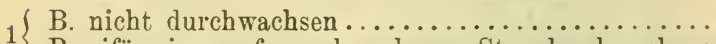

B. eiförmig, umfassend und vom Stg. durchwachsen 12

( B. mit mehreren Längsnerven, dazwischen manchmal

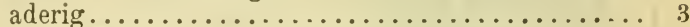

B. mit Mittelnerv, netzaderig; Stauden ........ 11

${ }_{3}$ Stauden $\ldots \ldots \ldots \ldots \ldots \ldots \ldots \ldots \ldots \ldots \ldots \ldots \ldots$

Einjährige Kräuter ................. 8

Stg. astlos, blattlos 0. oben 1 blättrig; Grundb. lineal; Stgb. lanzettlich; B. der Hüllchen 5-9, elliptisch, zugespitzt, länger als die Döldchen.

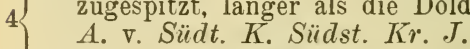

petraeum. $L$. Felsenbewohnendes $H$.

Stg. ästig, seltener astlos, mehrblättrig ..........

Obere Stgb. aus herz- o. eiförmigem Grunde verschmälert-zugespitzt; Grundb. lineal o. lineal-lanzettlich, oft sehr schmal; Hüllchen länger als die

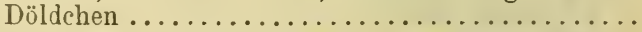
Obere Stgb. 0. alle B. lineal 0. lineal-lanzettlich... 
Grundb. lineal-lanzettlich o. lineal; Hülle 2- bis 6 blättrig; B. der Hüllchen verkehrt-eiförmig 0. elliptisch; Bt. dunkelgelb. A. v. S. T. $K r$.

ranunculoides. $L$. Hahnenfußblütiges $\mathrm{H}$. Grundb. schmal-lineal; Hülle 1(-3) blättrig; B. der Hüllchen eilanzettlich, klein; Bt. sehr klein, blassgelb. K.....Canalense. Wulf. Kanalthaler H.

Die oberen B. lanzettlich, nach beiden Enden zu verschmälert, die unteren elliptisch 0 . länglich, am Grunde in den Bstiel verlaufend; B. der Hüllchen lanzettlich, haarspitzig. Verbr. (fehlt $S . K$.)

falcatum. $L$. Sichelblättriges $\mathrm{S}$.

Die oberen B. lineal, die unteren schmal lineal-lanzettlich, grasartig; B. der Hüllchen lineal-pfriemlich, zugespitzt, ohne Haarspitze. $K r^{\circ}$.J.

gramineum. Vill. Grasartiges $\mathrm{H}$.

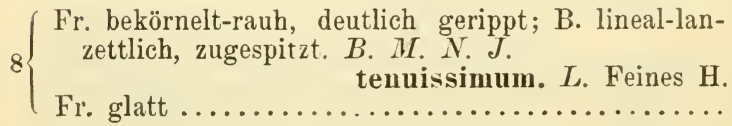

B. der Hüllchen kürzer als die Frdöldchen, lanzettlich-lineal; Frstiele um die Hälfte kürzer als die Fr.; B. 5-7nervig. $N$. $K r$. J.

junceum. $L$. Binsenstengliges $\mathrm{H}$. Hüllchen länger als die Frdöldchen; B. 3-5 nervig 10

B. der Hüllchen elliptisch 0 . lanzettlich, breit randhäutig, begrannt-haarspitzig; B. 3 nervig; Griffelpolster so breit als die Fr. Südt. Südst. Kr.J. aristatum. Bartl. Begranntes $\mathrm{H}$. Hüllchen lanzettlich, zugespitzt o. pfriemlich; B. 3bis 5 nervig; Griffelpolster viel schmäler als die Fr. M. N. J...........affine. Sadl. Verwandtes H.

Stg. beblättert, oft oben etwas ästig ; B. der Hüllchen frei, elliptisch; obere B. eiförmig o. eilänglich, am Grunde herzförrnig, umfassend.

Verbr. (fehlt T. K. Kr.J.)

longifolium. $L$. Langblättriges $\mathrm{H}$.

Stg. blattlos 0. oben 1-2 blättrig; B. der Hüllehen bis zur Mitte zusammengewachsen, verkehrt-eiförmig; Grundb. lineal-lanzettlich.

A. v. Sïdt. $K r$. stellatum. $L$. Sternblütiges $\mathrm{H}$. 
stg. vom Grunde an ästig; Dolden 2-3 strahlig; B. der Hüllchen immer abstehend; Fr. zwischen den Rippen körnig. $J$.

protractum. Lk. et Hoffgg. Ausgebreitetes $\mathrm{H}$.

Stg. oben ästig 0. einfach; Dolden 4-8 strahlig; B. der Hüllchen nach dem Verblühen aufgerichtet; Fr. zwischen den Rippen fein gerillt.

Verbr. (fehlt $S . K r$.)

rotundifolium. L. Rundblättriges $\mathrm{H}$.

XL. TROCHISCANTHES. Koch. Nagelblatt.

Schlanke Staude; die untersten B. sehr grob, 2- bis 3 fach dreizählig-fiederschnittig; Dolden zahlreich, rispig zusammengestellt. Sïdt. J.

nodiflorus. (All.) Koch. Knotenblütiges N.

XLI. MELM. Adans. Bärwurz.

Zipfel der fiedertheilig-vielspaltigen Babschnitte fast quirlig, haardünn, spitzig; Bt. weißlich.

Geb. (fehlt $M$. Sch.)

athamanticum. Jacq. Haarblättrige B.

Zipfel der fiedertheiligen Babschnitte lineal-lanzettlich oder lineal, zugespitzt, stachelspitzig, ungetheilt 0. 2-3 spaltig; Bt. meist lebhaft rosa, seltener weiß. Geb.

Mutellina. (L.) Gärtn. Alpen-B.

Xli. FOENICULUII. Adans. Fenchel.

Bzipfel lineal-borstlich, verlängert, schlaff; Dolden 10-25strahlig. Südt. J. (sonst cult. u. verw.)

vulgare. Mill. Echter F.

Zipfel der unteren B. pfriemlich, kurz stachelspitzig, starr; Dolden ungleich $4-8$ strahlig. $J$.

piperitum. $D C$. Scharfer $\mathrm{F}$.

\section{CRITHNIU. L. Meerfenchel.}

Stg. glatt, einfach, gelblich; B. 3 fach-3 schnittig; Blättchen länglich-lanzettlich, fleischig; Bt. grünlich-gelb. J.......maritimum. L. Gemeiner M.

\section{SILAUS. Bess. Wiesensilge.}

Staude; B. 3-4fach-fiederschnittig, Zipfel lineal, stachelspitzig; Hülle 1-2 blättrig o. fehlend.

Verbr. (fehlt K.)

selinoides. (Jacq.) Beck. Gemeine W.

XLV. LIGUSTICUM. L. Leckermaul.

Staude; Zipfel der mehrfach-fiederschnittigen B. lineal, stachelspitzig-zugespitzt; Hüllb. ungetheilt, $1-5$ o. fehlend. Sǜt. $K r . J$.

Seguieri. (L.f.) Koch. Seguier's L. 
Xlvi. PACHYPLEURUM. Mey. Zwergdolde.

B. 2-3 fach-fiederschnittig, Zipfel lineal; B. der Hülle und Hüllchen oft $2-3$ spaltig. $A$. (fehlt J.)

simplex. (L.) Rehb. Alpen-Z.

XlviI. ConioselinuM. Fisch. Schierlingssilge.

Stg. stielrund, gestreift; B. 2-3 fach-fiederschnittig; Blättchen unterwärts fiedertheilig, oberwärts eingeschnitten-gesägt. Sud.

Tataricum. Fisch. Tatarische s.

\section{CNIDIUI. Cuss. Bremindolde.}

Die oberen Bscheiden straff anliegend; B. der Hüllchen pfriemlich, kahl, so lang als die Döldchen;

1 Stg. gerillt; B. doppelt-fiederschnittig. B. M. N. venosum. (Hoffm.) Koch. Aderige B.

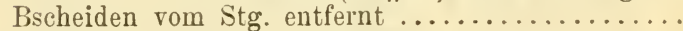

Einjähriges Kraut; B. der Hüllchen borstlich-rauh; Stg. kantig; B. doppelt-fiederschnittig; Zipfel der Blättchen kurz bespitzt. $K r . J$.

Monnieri. (L.) Cuss. Französische B.

2 Staude; B. der Hüllchen kahl; Stg. gerillt; B. 3 fachfiederschnittig; Zipfel der Blättchen stachelspitzig. (B.) $K r . J$.

apioides. (Lam.) Spr. Sellerieartige B.

\section{ATHA.MANT. L. Augenwurz.}

(Dolden 4-12 strahlig; Bzipfel-lineal-lanzettlich o. 1 lineal; Fr. rauhhaarig, Haare wagrecht abstehend. A.................. Cretensis. L. Alpen-A.

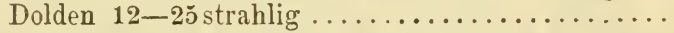

Stg. kahl o. fast kahl; Bzipfel sehr schmal, fädlichlineal; B. der Hüllchen 2-3, kürzer als die Btstiele; Fr. sammtig. $J$.

rupestris. (Scop.) Rchb. Felsen-A. Stg. reichlich behaart; Bzipfel lineal o. lineal-lanzettlich, nicht fädlich; B. der Hüllchen ungefähr

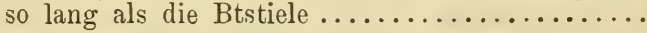

Stg. weich-wollig-zottig; Dolden zottig; Fr. von langen Haaren dicht seidig-zottig. Südt. $K$.

Vestina. Kern. Südtiroler A.

3 Stg. behaart; Dolden dicht flaumig; Fr. sammtig behaart. St. $K$. Kr. J.

Haynaldi. Borb. et Uechtr. Croatische A. 


\section{IABANOTIS. Cr. Heilwurz.}

Untere B. $2-3$ fach-fiederschnittig............

Untere B. fiederschnittig, Fiedern am Grunde fieder-

1 spaltig, mit grob gezähnten Abschnitten und eiförmigen, zugespitzten Zipfeln. $B$.

Sibirica. (L.) Koch. Sibirische H.

Fr. kur'zhaarig; untere B. 2-3 fach-fiederschnittig, mit gezähuten o. fiederspaltigen Abschnitten und breit lanzettlichen Zipfeln. Verbr.

montana. $\left.C r{ }^{*}\right)$ Gemeine $\mathrm{H}$.

Fr. scheinbar kahl (äußerst fein behaart); untere B. 3fach-fiederschnittig, mit fiederspaltigen Abschnitten u. lanzettlichen, stachelspitzigen Zipfeln. $K r$. .J. athamantoides. $D C$. Augenwurzartige $\mathrm{H}$.

\section{SESELI. L. BergfencheI.}

B. der Hüllchen fast bis zur Spitze mit einander verwachsen; B. 3 fach-fiederschnittig; Dolden 9bis 12 strahlig; Staude. B. M. Sch. N. O. Kr.

Hippomarathrum. L. Pferde-Dill.

B. der Hüllchen frei....................

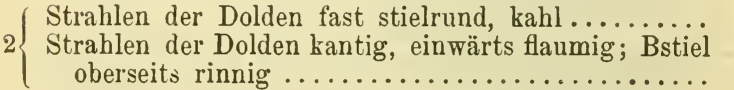

Dolden 3-6 strahlig; Hüllchen zur Btzeit so lang als die Btstiele. Sïdt. $K r$. J.

Dolden $10-25$ stahlig; Hull L. Hochwuchsiger B. elatum. $L$. Hochwächsiger B.

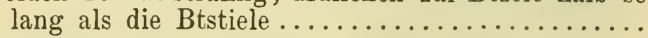

Bstiel stielrund o. von der Seite zusammengedrückt; Dolden (5-)10-15(-20) strahlig; Fr. kurz-kreiselförmig 0. oval; B. der Hüllchen pfriemlich .....

4 Bstiel oberseits rinnig; Dolden 15-25 strahlig; Fr: lineal-länglich, kahl; Hüllblättchen lanzettlich, zugespitzt. $M$. N. St. $K r$. Sü̈dt.

varium. Trev. Bunter $B$.

Fr. dicht mehlig bestäubt, mit 2-3 Striemen zwischen je 2 Rippen. $N$.

5 Austriacum. (Beck.) Wohlf. Oesterreichischer B. Fr. feinflaumig o. kahl, mit je einer Strieme zwischen 2 Rippen. Verbr. (fehlt Sch. S.) glaucum. L. Seegrüner B.

*) L. pubescens (Retz.) (DC.) ist eine niedrige, stark behaarte, L. praecox Kern. eine niedrige, kahle Pfl. 
Hüllchen zur Zeit der Bt. so lang als die Döldchen;

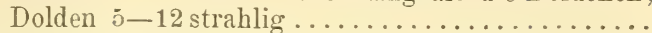
B. der Hüllchen zur Zeit der Bt. länger als die Döldchen, mit breitem häutigem Rande; Dolden 15-30 strahlig. Verbr.. annuum. L. Rossfenchel.

B. der Hüllchen breit häutig berandet; Hülle 1- bis 3 blättrig; Stg. ausgesperrt-ästig. Südt. J.

tortuosum. L. Gewundener B. B. der Hüllchen ohne 0 . mit sehr schmalem Hautrande

Stg. nur oben ästig; Hülle $1-3$ blättrig, selten fehlend; Hüllchenb. mit schmalem Hautrande; Fr. feinhaarig. $K$. J. .....montanum. $L$. Echter B. Stg. meist vom Grunde an ästig; Hülle fehlend; Hüllchenb. ohne Hautrand; reife Fr. kahl. J.

Tommasinii. Rchb. Istrianer B.

\section{AETHUSA. L. Gleisse.}

Stg. nicht immer bereift; Hüllchen länger als die Döldchen. Terbr.

Cynapium. L.*) Hundspetersilie. Stg. höher, stark bereift; Hüllchen so lang o. kürzer als die Döldchen. B. M. N. O. K. T.

cynapioides. $M . B$. Wald-G.

\section{OENANTHE. $L$. Rebendolde.}

Blättchen stielrund, an den Stgb. nebst den Bstielen röhrig-hohl; Stgb. kürzer als der Bstiel; Fr. kreiselförmig. B.? M.? N. Südst. Kr. J.

fistulosa. L. Tropfwurz.

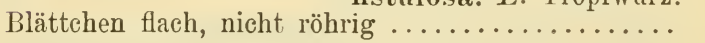

Btstiele an der Spitze ohne Schwielenring ........

2 Btstiele an der Spitze mit einem Schwielenring, der auch am Grunde der Fr. vorhanden ist........

Die Randbt. größer, strahlend; Stg. oben kantig; Wzfasern fleischig, walzlich 0 . kenlig. J.

Lachenalii. Gmel. Keulenwurzlige R.

3 Alle Bt. gleich; Stg. stielrund, gerillt; Wz. spindelförmig; die untergetauchten B. in haardünne Zipfel getheilt. Verbr.

aquatica. (L.) Lam. Wasserfenchel.

*) Umfasst mehrere Formen!

Fritseh, Excursionsflora. 
Wzfasern theils fädlich, theils walzlich 0 . spindeligkeulig; Hülle fehlend o. 1 blättrig; Hüllchenb.

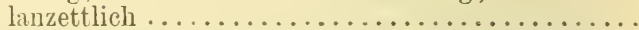

4 Wrfasern fädlich, am Ende in fast kugelige 0 röhrenförmige Knollen verdickt; Hülle meist 4- bis 6 blättrig; Hüllchenb. pfriemlich. $K r . J$. pimpinelloides. $L$. Bibernellartige $R$.

Randbt. etwas größer; Doldenstrahlen 5-8; Zipfel des Stgb, verlängert lineal. $N$.

media. Gris. Mittlere R.

5 Alle Bt. gleich; Doldenstrahlen 3-6; Zipfel der unteren Stgb. lanzettlich, die der oberen lineal.

1I. N. Südst. K. Kr. J.

silaifolia. $M$. B. Wiesensilgenblättrige $\mathrm{R}$.

IIV. LEVISTICUM. Koch. Liebstöckel.

B. doppelt fiederschnittig; Blättchen verkehrt-eirörmig o. keilförmig, eingeschnitten-gezähnt; Hülle u. Hüllchen vielblättrig. Cult. u. verw.

paludapifolium. (Lam.) Aschers. Gebräuchliches $\mathrm{L}$.

\section{TOMMASINIA. Bertol. Wirbeldolde.}

B. 3 fach-fiederschnittig; Blättchen eiförmig, spitz gesägt, oft 2-3 spaltig; Bscheiden groß, aufgeblasen. N. O. Südst. K. Kr. J. T.

verticillaris. (L.) Bertol. Quirlige W.

\section{ARCHANGELICA. Hoffm. Angstheilwurz.}

Hochwüchsiges, 2 jähriges Kraut; B. doppelt fiederschnittig; Blättchen eiförmig o. elliptisch, ungleichgesägt; Dolden mehlig-flaumig. $B .(M . S c h)$.$N . O$. sativa. (Mill.) Bess. Gebräuchliche A.

\section{IVII. ANGELICA. L. Angstwurz.}

Blättchen eiförmig 0 . elliptisch, nicht herablaufend. Verbr. $u$. hfg........silvestris. L. Gemeine A. Blättchen länglich 0 . lanzettlich, die obersten herablaufend; Pfl. sehr hochwüchsig. Verbr. (bes. Geb.) elatior. ( Wahlbg.) Berg-A.

\section{OSTERICUM. Hoffm. Mutterwurz.}

Stg. gefurcht; Hülle fehlend 0. 1 blättrig; B. der Hüllchen zahlreich, lanzettlich o. pfriemlich. $B . K$. palustre. Bess. Sumpf-M.

\section{SELINUM. L. Silge.}

Stg. kantig-gefurcht; Doldenstrahlen kahl. Terbr.

Carvifolia. L. Gemeine S. 


\section{FERULAGO. Koch. Birkwurz.}

Stg. gerillt; B. vielfach-zusammengesetzt; B. der Hüllchen lineal-länglich, zugespitzt; Gr. an der Fr. bogig-zurückgelegt; Bt. gelb. Sïdt. $K r$. J.

nodiflora. (L.) Koch. Istrianer B.

\section{IMPERATORIA. L. Meisterwurz.}

Staude; Blättchen breit eiförmig, doppelt gesägt, oft $2-3$ spaltig. Geb.

Ostruthimm. L. Gemeine II.

\section{PEUCEDANUM. L. Haarstrang.}

$1\{$ Hülle fehlend $0.1-3$ blättrig .............. 2

Hülle mindestens 4 blättrig .............. 5

( B. 3-5 mal-3 schnittig; Blättchen ungetheilt....... 3

2 B. fiederschnittig, Fiedern sitzend, die der unteren B. vielspaltig, Zipfel lineal, am Grunde kreuzständig 4

Bt. gelb; Frstiele 2-3 mal so lang als die Fr.; Blättchen lineal; Strahlen der Dolde kahl. N. St.

3 officinale. $L$. Gemeiner $H$. Bt. weiß; Frstiele so lang als die Fr.; Blättchen lineal-lanzettlich; Strahlen der Dolde innen flaumig-rauh. $K r$. J. Parisiense. $D C$. Pariser $\mathrm{H}$.

B. beiderseits glänzend; Strahlen der Dolde innen kurzhaarig; Kzähne undentlich; Bt. gelblich-wei@ o. grünlich. N. St. J. Südt.

Carvifolia. Vill. Kümmelblättriger $\mathrm{H}$.

B. glanzlos, etwas seegrün; Strahlen der Dolde kahl; K. 5 zähnig. Südt. Kr:J.

Schottii. Bess.*) Schott's H.

Flügelrand der $\mathrm{Fr}$. höchstens halb so breit als die

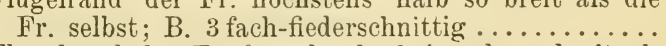
Flügelrand der Fr. fast durchscheinend, so breit als die Fr. selbst; B. 3 zählig-3 fach-fiederschnittig; Krb. breit-verkehrt-herzförmig, benagelt ...... 10

Hülle zurückgeschlagen; Bt. weiß o. röthlich ......

6 Hülle abstehend, 5-8 blättrig; Stg. kantig-gefurcht; Blättchen fiederspaltig, Zipfel stachelspitzig, am

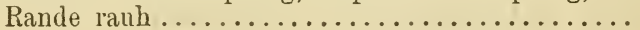

*) P. petraeum Noë (J.) hat mehrblättrige Hüllchen, das typische $P$. Schottii Bess. fehlende 0 . armblättrige Hüllchen. 
Zweijähriges Kraut; Stg. röhrig, gefurcht; Bzipfel lanzettlich o. lineal; Striemen der Berührungsfläche äu§erlich nicht sichtbar. Verbr.

palustre. (L.) Mnch. Sumpf-H.

Stauden; Stg. stielrund, fein gerillt, nicht röhrig; Striemen der Berührungsfäche 2, sehr dentlich

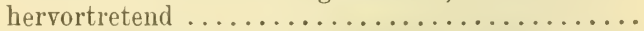

Blättchen seegrün, fast dornig-gesägt, die oberen zusammenfliefend; Striemen der Berührungsfläch gleichlaufend. Verbr.

Cervaria. (L.) Cuss. Hirschwurz.

8 Blättchen glänzend, eingeschnitten- 0. fast fiederspaltig-gezähnt, Zähne kurz-zugespitzt, stachelspitzig; Stiele der Blättchen zum Theile zurückgebrochen; Striemen der Berührungsfläche bogig. Verbr. . . . . Oreoselinum. (L.) Much. Berg-H.

- Bt. blassgelb; Strahlen der Dolde kahl; die herabgebogenen $\mathrm{Gr}$. der Fr. wenig länger als der Grpoister. B. M. N. O. St. K. Kr.

Alsaticum. L. Elsässischer $\mathrm{H}$. die herabgebogenen Gr. der Fr. fast halb so lang als die Fr. selbst. Südt. J.

Venetum. Koch. Venetianischer $\mathrm{H}$.

Blättchen fiederspaltig, Zipfel lanzettlich-lineal, zugespitzt. (B.) N. O. Südst. K. Kr.J.

10 Austriacum. (Jacq.) Koch. Oesterreichischer H. Blättchen vielspaltig, Zipfel schmal-lineal, zugespitzt. Sï̈t. K. Kr.J.

Rablense. (Wulf.) Koch. Kärntner H

\section{ANETHUM. $L$. Dill.}

Stg. stielrund, fein gerillt, bläulich bereift, kahl; Bt. sattgelb. Cult. u. verw.

graveolens. $L$. Gemeiner D.

\section{OPOPANAX. Koch. Gummivurz.}

Dolden zahlreich, oben meist quirlständig; Bt. honiggelb; liruchtrand schmal. $J$.

Chironium. (L.) Koch. Große G.

\section{PASTINACA. I. Pastinak.}

B. doppelt-fiederschnittig, Fiederchen elliptisch-lanzettlich, fiederspaltig gezähnt. $K r$.

Fleischmauni. Hladu. Fleischmann's P.

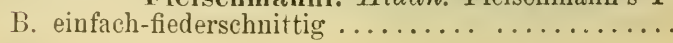


B. oberseits glänzend, unterseits flaumig, Abschnitte eiförmig 0 . länglich; Bt. goldgelb. Verbr.

sativa. $L$. Gemeiner $P$.

B. glanzlos, beiderseits flaumig, Abschnitte eiförmig, am Grunde fast herzförmig; Bt. grünlichgelb.

B. T. J.......... opaca. Bernh. Glanzloser P.

\section{HERACLEUM. I. Bärenklau.}

( B. entweder alle, o. doch die Grundb. ungetheilt, fast

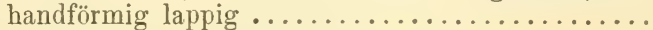

B. tief-fiederspaltig, fiederschnittig 0.3 schnittig ...

B. herzförmig, 3-7 lappig, nicht auffallend breit; Frkn. kurz-rauhhaarig 0. zottig; Fr. elliptisch, zu-

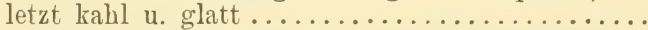

2 B. breiter als lang, rundlich, am Grunde herzförmig, 7-9lappig; Frkn. behaart; Fr. oval, warzig-rauh, sonst zuletzt kahl. Fora. v. Südt. K. J. (?)

palmatum. Baumg. Handlappige B.

B. unterseits weichhaarig und oft graulich, aber nicht filzig, 3-5 lappig, mit zugespitzten Lappen ; Frkn. kurz-rauhhaarig. $A$. u. Tora.

montanum. Schleich. Berg. B

B. unterseits weisfilzig, 5-7lappig, mit stumpfen Lappen; Frkn. zottig. Vora. u. Südt.

Pyrenaicum. Lam. Pyrenäische B.

B. fiederschnittig 0. 3 schnittig; Abschnitte der Grundb. eiförmig, die der Stgb. lanzettlich, zugespitzt; Striemen der Beriihrungsfläche fehlend o. sehr

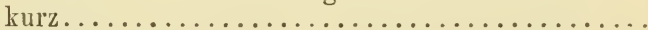

B. fiederschnittig o. tief-fiederspaltig, rauhhaarig;

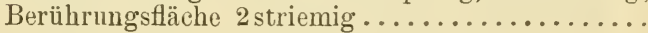
2

Bt. weiß o. etwas röthlich; Fr. zuletzt kahl.

A. u. Vora. (fehlt J.)

Austriacum. L. Oesterreichische B. Bt. rosenroth; Fr. steifhaarig. $A$. u. Vora. v. $K$. $K r$. siifolium. Rchb. Merkblättrige B.

$6\left\{\begin{array}{l}\text { Randbt. größer, strahlend; Frkn. daumig; Fr. oval. } \\ \text { Verbr. } u \text {. hfg. . Sphondylium. L.*) Gemeine B. } \\ \text { Bt. fast gleich; Frkn. kahl; Fr. rundlich. Verbr. (?) } \\ \text { Sibiricum. L.*) Sibirische B. }\end{array}\right.$

*) Beide Arten sind formenreich und noch nicht genügend geklärt. 


\section{TORDYLILM. L. Zirmet.}

Hülle so lang o. länger als die Doldenstrahlen; Hüllchen länger als die Döldchen; Krb. u. Gr. kahl. J........ officinale. L. Gebräuchlicher Z. Hülle kürzer als die Doldenstrahlen; Hüllchen höchstens so lang als die Döldchen..............

Dolden 3-8strahlig; Hüllchen kürzer als die Döldchen; Krb. u. Gr. kahl. J.

A pulum. L. Apulischer Z.

2 Dolden 5-15strahlig; Hüllehen so lang: als die Döldchen; Krb. außen behaart; Gr. kurzborstig. II. N. O. Südst. J. Südt.

maximum. I. Großer Z.

LXVIII. SILER. $C r$. Rosskïmmel.

Stg. stielrund, feingerillt; Dolden grob, reichblütig. II. N. St. Kr. K. T. trilobum. (L.) Cr. Gemeiner R.

\section{LASERPITIUM. L. Bergkïmmel.}

$1\left\{\begin{array}{l}\text { Stg. gefurcht } \ldots \ldots \ldots \ldots \ldots \ldots \ldots \ldots \ldots \ldots \ldots \ldots \ldots \\ \text { Stg. stielrund, gerillt } \ldots \ldots \ldots \ldots \ldots \ldots \ldots\end{array}\right.$

B. doppelt-fiederschnittig, Abschnitte fiederspaltig mit lanzettlichen, am Rande rauhen Zipfeln; B. der Hülle lanzettlich, breit randhäutig; Bt. weiß 0 . gelblich; Fr. auf den Hauptrippen zerstrent beborstet. Verbr. Prutenicum. L. Preußischer B.

B. 3 zählig-2-3 fach fiederschnittig, Abschnitte eiförmig, ungleich gesägt, unterseits dicht rauhhaarig ; B. der Hülle laubartig; Bt. weiß o. röthlich; Fr. kahl. Geb. v. Sch. M. Kr.

Archangelica. Wulf. Handblättriger B.

$3\{$ Dolden $20-30$ strahlig $\ldots \ldots \ldots \ldots \ldots \ldots \ldots \ldots$

$3\{$ Dolden $4-15$ strahlig $\ldots \ldots \ldots \ldots \ldots \ldots \ldots \ldots \ldots \ldots \ldots$

Bzipfel lanzettlich o. lineal, o. im Umrisse eiförmig

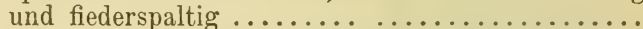
Blättchen groß und breit, herzeiförmig, grob gesägt; Bscheiden groß, aufgeblasen; Doldenstrahlen innen rauh. Verbr. (fehlt Sch.)

latifolium. $\left.L *^{*}\right)$ Breitblättriger $B$.

*) L. asperum Cr. unterscheidet sich durch st haarige Bstiele und Unterseite der Blättchen. 
Cntere B. 3 fach fiederschnittig, mit lanzettlichen, ganzrandigen 0. 2-3 spaltigen, kahlen Blättchen; B. der Hüllchen lanzettlich, pfriemlich, kurz; Fr. lineal-länglich. Vora.

siler. L. Schmalblättriger B.

Untere B. vielfach zusammengesetzt, mehr 0 . weniger kurzhaarig, mit ficderspaltigen Abschnitten u. linealen Zipfeln; B. der Hüllchen lanzettlich, breit randhäutig; Fr. oval. Vora. v. T. Kr .

Panax. Gouan. Rauhhaariger B.

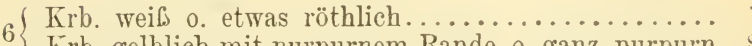
Krb. gelblich mit purpurnem Rande o. ganz purpurn s

B. doppelt fiederschnittig, Abschnitte fiederlappig 0 . geschärft-gesägt, unterseits steifhaarig; Fr. zuletzt gelb. Vora. v. Südt.

nitidum. Zanted. Glänzender B.

7 Untere B. 3 zählig-2-3 fach-fiederschnittig 0. doppelt 3 schnittig, mit länglichen, lanzettlichen 0 . linealen, ganzrandigen, kahlen Blättchen; Fr. oft purpurn. Vora. v. T. K. Südst. Kr. J.

peucedanoides. L. Haarstrangartiger $B$.

Doldenstrahlen imnen kurzhaarig-rauh; Hauptrippen

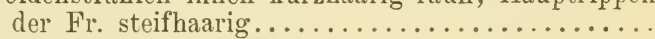

Doldenstrahlen kahl; Hauptrippen der Fr. kahl.

Vora. v. T. ......Gaudini. Mor. Gaudin's B.

Krb. gelblich mit purpurnem Rande; Blättchen herzeiförmig, 2-3 spaltig o. nur gekerbt-gesägt, die seitenständigen sitzend 0 . kaum gestielt. Kr. J.

marginatum. $W$. K. Berandeter $B$.

Krb. purpurn; Blättchen deutlich gestielt, länglich, 2-4 spaltig. $K r . \ldots$ Aruncus. (Rchb.) Rother B.

LXX. ORLAYA. Hoffm. Strahldolde.

Dolden 5-12strahlig; die strahlenden Krb. des Pandes vielmal länger als der Frkı.; Nebenrippen gleich. (B.) M. N. O. Sïdt. K. J.

grandiflora. (L.) Hoffm. Großblütige St.

Dolden 2-3 strahlig; die strahlenden Krb. des Randes so lang als der Frkn.; die 2 äuberen Nebenrippen doppelt so breit als die 2 mittle re J.... platycarpa. (I.) Koch. Breitfrüchtige St. 


\section{DAUCUS. I. Möhre.}

Grundb. im Umrisse länglich, die untersten Hauptabschnitte nicht 0 . nur wenig länger als die folgenden. Verbr. u. $h f g$. Carota. $L^{*}$ ) Gelbe Rübe. Grundb. im Umrisse dreieckig, die untersten Hauptabschnitte viel länger als die oberen; $B$. der Hülle u. Hüllchen schmal, mit langen, fast borstlichen Zipfeln. J.....maximus. Desf. Grobe MI.

LXX. Familie. Cornaceae. Hartriegelgewächse.

Holzgewächse mit ungetheilten, ganzrandigen, gegenständigen B., ohne Nebenb. Bt. meist zwittrig, regelmäCig, in doldenähnlichen Btständen. Kb. 4, sehr klein, einen tzähnigen Rand am oberen Ende des Frkn. darstellend. Krb. 4. Stb. 4. Frkn. unterständig, meist 2 fächerig, mit einer Samenknospe in jedem Fache. Gr. 1. Fr. eine 1- bis $\stackrel{2}{2}(-3)$ fächerige Steinfr: S. mit Nährgewebe.

\section{Gattung.}

Wuchs strauchig, selten baumartig; Steinfr. genabelt. Cornus. I.

Arten.

\section{CORNUS. L. Hartriegel.}

Bt. gelb, in Dolden, welche von einer 4 blättrigen Hülle umgeben sind, im ersten Frühjahre vor den B. erscheinend; Fr. blutroth, ellipsoidisch. Verbr.

mas. $L$. Kornelkirsche.

Bt. weiß o. etwas grünlich, in doldenähnlichen, hüllenlosen Btständen, im Frühsommer am Ende beblätterter Zweige erscheinend; Fr. kugelig ....

$2\left\{\begin{array}{l}\text { B. beiderseits grün; Fr. schwarz. Verbr. u. hfg. } \\ \text { sangninea. L. Rother H. } \\ \text { B. unterseits graugrün; Fr. weiß. Cult. } \\ \text { alba. L. Weißfrüchtiger H. }\end{array}\right.$

LXXI. Familie. Pirolaceae. Wintergrüngewächse.

Stauden mit ungetheilten, schraubig gestellten, aber oft zu Rosetten o. Scheinwirteln zusammengedrängten B., die manchmal nur durch kleine Schuppen vertreten sind. Nebenb. fehlen. Bt. zwittrig, regelmäßig. Kb. 4-5, oft am Grunde verwachsen. Krb. 4-5. Stb. 8-10, frei. Frkn. 1, oberständig, vollständig 0 . unvollständig 4-5 fächerig, mit

*) In J. wächst die var. major Vis. mit gelblichen Bt. und breiten Babschnitten; in $B$. wurde eine ganz kahle Form (var. glaber Opiz) beobachtet. 
zahlreichen Samenknospen in jedem Fache. Gr. 1. Fr. eine 4-5 klappige Kapsel. S. sehr klein u. zahlreich, von der Sschale locker umhüllt, mit öligem Nährgewebe u. sehr kleinem, ungegliedertem Keimling.

\section{Gattungen.}

B. immergrün...................

An Stelle der B. gelbliche o. bräunliche Schuppen; die ganze Pfl. bleich, mit blassgelblichen Bt.

Monotropa. III.

Bt. in einer Dolde (Doldentraube); Gr. sehr kurz und dick, mit schildförmiger N. Chimaphila. I.

2 Bt. in Trauben o. einzeln; Gr. verlängert, mit 5 zähniger $\mathrm{N}$. . . . . . . . . . . . Pirola. II.

\section{Arten.}

I. CHIMAPHILA. Pursh. Winterlieb.

B. keilig-lanzettlich, grob gesägt; Bt. weiß o. rosa B. II. Sch. N. O. St. K.

umbellata. (L.) Nutt. Doldiges W.

\section{PIROLA. L. Wintergriin.}

(Bt. einzein, nickend, weis; B. eiförmig o. rundlich1 spatelig. Verbr. ....uniflora. L. Einblütiges W.

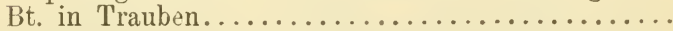

Trauben einseitswendig; B. eiförmig, spitz; Bt. grünlich-weiß. Verbr.

secunda. L. Einseitswendiges W.

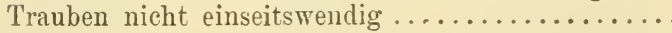

Stb. aufwärts-gekrümmt; Gr. abwärts geneigt, fast

S-förmig gebogen; Bt. weib o. grünlich........ Stb. gleichförmig-zusammenschlie£end; Gr. gerade;

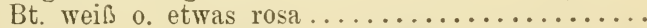

Kzipfel lanzettlich, zugespitzt, an der Spitze zurückgekrümmt, halb so lang als die Blkr. Verbr.

rotundifolia. $L$. Rundblättriges $\mathrm{W}$.

4 Kzipfel eiförmig, kurz zugespitzt, so breit als lang, 4 mal kürzer als die grünliche Blkr.

Verbr. (fehlt J.)

chlorantha. Su. Grünlichblühendes W.

Gr. etwas schief eingefügt, nach oben verdickt, so dass die N. sich wenig abhebt, aus der Blkr. etwas herausragend. Verbr. (fehlt $K r$. J.)

media. Sw. Mittleres IV.

Gr. senkrecht eingefügt, nach oben nicht verdickt, viel schmäler als die $\mathrm{N}$, in der Blkr. eingeschlossen. Verbr.........minor. I. Kleines IV. 


\section{MONOTROPA. $L$. Fichtenspargel.}

Die ganze Pfl. kahl; Kapsel kurz, fast rundlich. R N. O. St. S. T. hypophegea. Wallr. Kahler F. Bt. (namentlich innen), meist auch die Traubenspindel und die Deckb. kurzhaarig; Kapsel länglich. Verbr.

\section{multiflora. (Scop.) Fritsch. Behaarter F.}

\section{Familie. Ericaceae. Heidegewächse.}

Holzgewächse von meist niedrigem, strauchigem Wuchse, seltener größere Sträucher 0. Bäume. B. ungetheilt, bald schraubig gestellt, bald gegenständig o. quirlig, manchmal nadel- o. schuppenförmig, ohne Nebenb. Bt. zwittrig, regelmäßig, selten etwas unregelmäßig. Kb. 4-5, meist am Grunde mehr o. weniger verwachsen. Krb. 4-5, selten frei, meist mit walzlicher, glockiger o. krugförmiger Röhre. Stb. 5, 8 o. 10, dem Btboden eingefügt. Frkn. 1, ober- 0 . unterständig, 2-5fächerig, mit 1 , mehreren o. zahlreichen Samenknospen in jedem Fache. Gr. u. N. 1. Fr. eine Kapsel, Beere o. Steinfr. S. mit Nährgewebe.

\section{Gattungen.}

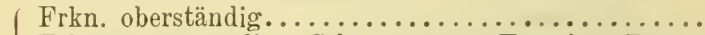

1 Frkn. unterständig; Stb. 8 o. 10; Fr. eine Beere; B. flach 0. am Rande umgerollt. Vaccinium. VIII. Krb. 5, frei; K. klein, 5 zähnig; Stb. 10; Fr. eine

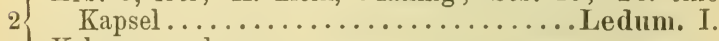

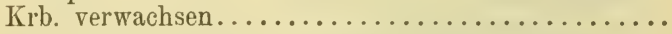
Kb. u. Krb. 4, letztere nicht abfällig, sondern all

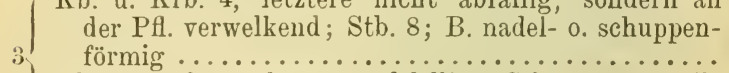
Kb. u. Krb. 5, letztere abfällig; Stb. 5 0. 10; B.

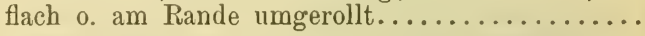

B. gegenständig; Kapseln wandspaltig, die Klappen von den Scheidewänden der Fächer sich ablösend.

Calluna. IX.

4 B. zu 3-4 quirlig; Kapseln fachspaltig, die Scheidewände in der Mitte der Klappen befestigt.

Erica. X.

$5\left\{\begin{array}{l}\text { Stb. 5; Blkr. glockig, } 5 \text { spaltig; Alpenpfl. } \\ \text { Loiseleuria. III. }\end{array}\right.$

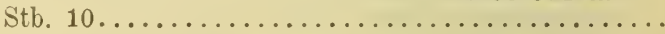

Blkr. trichterig o. radförmig; Fr. eine wandspaltige

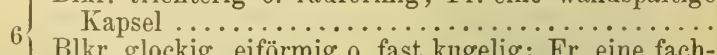
Blkr. glockig, eiförmig o. fast kugelig; Fr. eine fachspaltige Kapsel, eine Steinfr. 0. eine Beere..... 
Blkr. radförmig, ausgebreitet, regelmäßig; Bt. zu $1-3 \ldots \ldots \ldots \ldots$ Rhodothamuus. IV

7 Blkr. trichterig, wit walzlicher Röhre, etwas unregelmäßig; Bt. in Doldentrauben.

Rhododendron. II.

B. ausgesprochen 2 farbig, oberseits glänzend llunkelgrün, unterseits blaugrïn und matt; Fr. eine Kapsel................ Indromeda. V.

B. nicht ausgesprochen 2 farbig, wenn auch unterseits heller; Fr. eine Steinfr. o. Beere.........

Kleine, niederliegende Sträucher; Fr. eine żsteinige Steinfr............. Aretostaphylos. VII.

Kleiner Baum o. hoher aufrechter Strauch; Fr. eine vielsamige Bcere............. Arbutus. VI.

Arten.

I. LEDUM. L. Porst.

B. lineal, am Rande zurückgerollt, unterseits rostfarben filzig; Bt. weib, selten rosa.

B. M. Sch. N. O. St...ppalustre. L. Sumpf-P.

\section{RHODODENIRON. $L$. Alpenrose.}

B. am Rande kahl, unterseits zuletzt dicht rostrothschuppig. A. v. T. S. K. St. $\mathbf{L}$.

ferrugineum. $L$. Rostrothe $A$.

B. am Rande gewimpert, unterseits zerstreut driisiggetiipfelt. A. u. Vor $a$.

hirsutun. L. Rauhhaarige A.

Anmerkung. Der Bastart Rh. ferrugineum hirsutum ist nicht selten.

\section{LOISELEURIA. Desv. Gemsenheide.}

B. lederig, kurz gestielt, elliptisch-lanzettlich, am Rande zurückgerollt; Bt. rosa. A. (fehlt $K r$. J.)

procunbens. (L.) I)csi. Niederliegende G

\section{RHODOTHAMNUS. Rchb. Zwergalpenrose.}

B. elliptisch-lanzettlich, gesägt-gewimpert; Btstiele drüsig behaart; Bt. groo, hellrosa; A. schwarzpurpurn. A. u. Vora.

Chamaecistus. (L.) Rehb. Europäische Z.

\section{ANDROMEDA. L. Kienporst.}

B. lineal-lanzettlich 0 . länglich, am Rande umgerollt; Bt. hellrosa. Verbr. (fehlt $J$.)

polifolia. L. Poleiblättriger $\mathrm{K}$. 
VI. ARBUTUS. L. Erdbeerbaum.

B. verkehrt-eiförmig o. länglich-lanzettlich, gesägt. lederig, kahl; Bt. weiß, an der Spitze grün, im Winter erscheinend; Beeren groß, roth. $J$.

Unedo. $L$. Gemeiner E.

\section{ARCTOSTAPIILOS. Adans. Bärentraube.}

Bt. weiß, am Schlınde grün, seltener röthlich; B. ungleich-klein-gesägt, verkehrt-eiförmig, im Herbste abfallend; Beeren zuletzt blauschwarz (vorher roth). A. (fehlt J.) .........alpina. (L.) Spr. Alpen-B.

Bt. fleischfarben (o. weiß); B. ganzrandig, länglichverkehrt-eiförmig, immergrün; Beeren roth.

Verbr. (bes. Geb.; fehlt Sch. MI. J.)

Ura ursi. (L.) Spr. Gebräuchliche B.

\section{VACCINIUM. L. Heidelbeere.}

Blkr. radförmig, zurückgeschlagen ; Stämmchen kriechend; B. immergrün, eiförmig, spitz, unterseits aschgrau; Bt. purpurn; Beeren roth. Verbr.

Oxycoccos. L. Moosbeere.

Blkr. eiförmig, kugelig o. glockig ...............

B. immergrün, verkehrt-eiförmig, am Rande zurückgerollt, unterseits punktirt; Blkr. glockig; Beeren roth; Bt. weib o. röthlich. Verbr.

Vitis idaea. $L$. Preiselbeere.

B. abfällig; Blkr. eiförmig 0. kugelig; Beeren

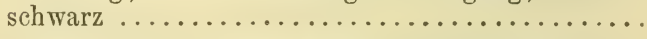

B. eiförmig, kleingesägt, kahl; Blkr. kugelig, blassgrün, fleischfarben überlaufen. Verbr. $u$. hfg.

Hyrtillus. $L$. Gemeine $H$.

B. verkehrt-eiförmig, ganzrandig, unterseits bläulichgrün, netzig-aderig; Blkr. eiförmig, weiß o. röthlich. Verbr. .......uliginosum. L. Moor-Heidelbeere.

\section{CALLUNA. Salisb. Besenheide.}

B. 3 kantig, kahl; Bt. lila, selten weiß, im Herbste erscheinend. Ver.br: u. hifg.

vulgaris. (L.) Salisb. Gemeine B.

\section{ERICA. L. Heidekraut.}

Bt. weiß; A. in der Blkr. eingeschlossen, am Grunde mit Anhängsel; Blkr. glockig. Sïdt. J.

arborea. $L$. Baumartiges $H$.

Bt. fleischfarben; A. ohne Anhängsel, aus der Blkr. heraustretend 
Blkr. krugförmig-röhrig; Kb. lanzettlich, länger als die halbe Blkr. Verbr. (fehlt Sch. M.)

carnea. L. Frühlings-H.

Blkr. glockenförmig; Kb. eiförmig, kürzer als die halbe Blkr. J. verticillata. Forsk. Quirliges $H$.

LXXIII. Familie. Primulaceae. Primelgewächse.

Stauden o. Kräuter mit ungetheilten, selten gelappten o. fiedertheiligen, verschieden gestellten B., ohne Nebenb Bt. zwittrig, regelmäßig. Kb. $4-7$ (meist 5), meist am Grunde verwachsen. Krb. 4-7 (meist 5), entweder nur am Grunde verwachsen 0 . eine verschieden gestaltete Röhre bildend. Stb. 4-7 (meist 5), ror den Krb. stehend, außerdem manchmal 5 zwischen den Krł. stehende Stb. durch Schüppchen angedeutet. Frkn. 1, oberständig, selten halb unterständig, 1 fächerig, mit zahlreichen, seltener wenigen, an einer Mittelsäule befestigten Samenknospen. Gr. 1, mit $1 \mathrm{~N}$ Fr. stets aufspringend. S. mit fleischigem Nähr'gewebe.

\section{Gattungen.}

( Blkr. fehlend; K. glockig, weiß o. rosa gefärbt.

Blkr. vorhanden .................... $2_{2}$

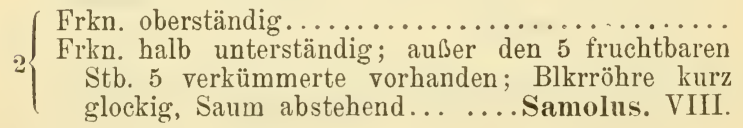

Stg. beblättert . .................. 4

3 Alle B. grundständig; Schaft grundständig, manchmal sehr verkürzt ..................... 10

${ }_{4}\left\{\begin{array}{l}\text { Kb., Krb. u. Stb. meist 7; Blkr. sternförmig. } \\ \text { Trientalis. XI. }\end{array}\right.$ Kb., Krb. u. fruchtbare Stb. $4-5$............

B. quirlig, kämmig-fiedertheilig, mit lineal-fädlichen $5\left\{\begin{array}{l}\text { Zipfeln; Bt. in endständigen Trauben; Blkr. stiel- } \\ 5\end{array}\right.$ tellerförmig................ Hottonia. VII.

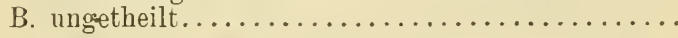

B. schraubig gestellt; Kb., Krb. u. Stb. 4 ; Blkrröhre fast kugelig-bauchig; Kapsel mit einem Deckel aufspringend............. Centunculus. XV. B. gegenständig o. quirlig; Kb., Krb. u. fruchtbare Stb. 5 ; Blkrröhre sehr kurz 0 . fast fehlend .... 7

Stauden mit gelben Bt................ 8

7 Einjährige Kräuter, selten zarte Stauden mit blauen, mennigrothen, rosenfarbenen 0 . weißen Bt..... 
Zwischen den Krb. 5 Schuppen (unfruchtbare Stb.): Bt. klein, in gedrungenen, blattachselständigen Trauben ................. Naumburgia. X. Zwischen den Krb. keine Schuppen; Bt. einzeln 0. in blattachselständigen, zu rispenartigen Btständen zusammengestellten Trugdolden. Lysimachia. IX

B. eiförmig o. fast rundlich; Bt. blau, mennigroth o. rosa (nur ausuahmsweise weiß); Kapsel mit einem Deckel aufspringend.....Anagallis. XIV.

B. lanzettlich; Bt. weiølich; Kapsel 5klappig aufspringend ............. Asterolinum. XII.

(Blkrzipfel über der kurz-glockigen Pöhre zurücl ge10 brochen, spitz; Kapsel 5 klappig. Cyclamen. XVI. Blkrsaum aufrecht- 0. ausgebreitet-abstehend...... 11

Stb. auf einem hervortretenden Ringe im Schlunde der Blkr. entspringend; Blkr. trichterförmig, Zipfel

11 spitz; Kapsel 2 klappig............ Cortusa. V. Stb. ohne Ring in der Blkrröhre eingefügt; Kapsel 5 klappig o. mit einem Deckel aufspringend ..... 12

Blkr. trichterförmig-glockig, 5spaltig, Zipfel vielspaltig; K. 5 theilig; Kapsel mit einem Deckel

12 aufspringend ............. Soldanella. VI. Blkr. stielteller- o. trichterförmig mit ungetheilten 0 . 2spaltigen 'Lipfeln; K. 5 spaltig 0. 5 zähnig; Kapsel 5 klappig................... 13

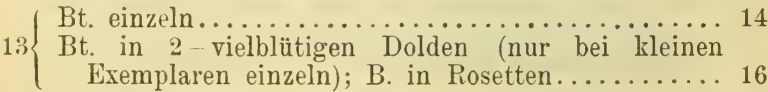
14

( Bt. gelb, sitzend; sehr kleine Alpenpfl. mit linealen 14 B. . . . . . . . . . . . Douglasia. II. Bt. entweder nicht gelb o. lang gestielt

Blkrröhre eiförmig, an der Spitze verengt, ungefähr so lang als der K.; Bt. sehr kurz gestielt, weiß o. rosa, oft mit gelben Deckklappen im Schlunde; B. lineal o. lamzettlich, dachig; Wuchs dicht rasig.

Blkrröhre walzlich, verlängert, am Schlunder. der Einfüguno'sstelle der Stb. meist erweitert; Bth. kürzer o. länger gestielt, verschieden gefärbt; B. niemals lineal 0 . lanzettlich..... Primula. I.

Blkrröhre eiföımig, an der Spitze verengt, ungefähr so lang als der K.; Bt. meist weif, klein.

16 Blkıröhre walzlich, verlängert, am Schlunde 0. an der Einfügungsstelle der Stb. meist erweitert; Bt. oft ansehnlich, nur ausnahmsweise weiß. 


\section{Arten.}

\section{PRIMULA. L. Schliisselblume.}

Die jüngeren $B$. rückwärts gerollt, mehr o. weniger runzelig; Deckklappen am Schlunde der Blkrröhre

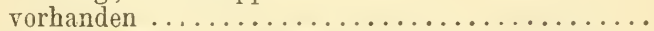

Die jüngeren B. nach oben zusammengerollt, die ausgebildeten flach, etwas fleischig, nicht runzelig; Schlund der Blkrröhre ohne Deckklappen .......

B. kahl, unterseits mehr o. weniger mit Mehl bestäubt, verkehrt-eiförmig-länglich, gekerbt; Deckklappen gefärbt; Bt. fleischroth ..............

B. unterseits kurzhaarig, sammtig o. filzig, nicht bestäubt; Deckklappen meist mit dem Rande des Saumes gleichfarbig; Bt. heller o. dunkler gelb..

Kzähne eiförmig; Blkrröhre $1^{1}{ }_{2}$ mal so lang als der K.; Dolde reichblütig. Verbr. (fehlt B. M. Sch.) farinosa. $L$. Bestäubte S.

Kzähne lanzettlich; Blkrröhre 3 mal so lang als der K.; Dolde $2-5$ blütig. $A$.. . T. S. St. K. Kr longiflora. All. Langblütige S.

Btstiele grundständig, lang behaart; Bt. bleichschwefelgelb mit dunkleren Flecken.

N. O. St. K. Kr.J. T.

acaulis. (L.) Stengellose $\mathrm{S}$.

Bt. in gestielten Dolden..................

Zipfel des Blkrsaumes concav, glockig; Bt. dottero. citrongelb, mit 5 orangegelben Flecken am Schlunde; K. weißlich o. gelblich, trichterförmigaufgeblasen, Zähne breit eiförmig, kurz-zugespitzt; B. eiförmig, fast herzförmig, wellig-gekerbt, unter-

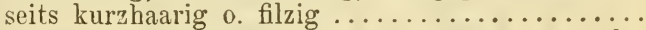
Zipfel des Blkrsaumes flach; K. wenigstens an den Rippen grün; B. länglich-verkehrt-eiförmig 0 . verkehrt-eiförmig, in den Bstiel verschmälert,

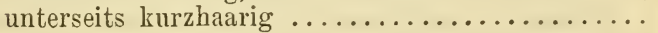

B. unterseits sammt Schaft u. Dolde sammtig. $\left.{ }^{*}\right)$ Verbr......... officinalis. ( $\left.I_{\text {. }}\right)$ Gebräuchliche S. 6 B. unterseits schneeweib-filzig, in den wenig gezähnten Bstiel herablaufend. $J$.

Columnae. Ten. Wohlriechende S.

*) Bei P. Pannonica Kern. sind dia B. unterseits graufilzig. 
B. eiförmig o. eilänglich, unterseits wenigstens in der Jugend etwas graugrün, rasch in den Bstiel zusammengezogen; Schaft meist viel länger als die B.; Kapsel den K. etwas überragend. Verbr.

elatior. $(L$.$) Hohe \mathrm{S}$.

B. länglich, unterseits grasgrün, in den Bstiel allmälig verschmälert; Schaft meist ungefähr von der Länge der B. Kapsel so lang als der K. Sïdt.

intricata. Gren. et Godr. Pyrenäische S.

Deckb. eiförmig, kürzer als die Btstiele; die längeren Btstiele $1_{1}^{1 / 2}-3 \mathrm{mal}$ so lang als der K.; Blkrzipfel verkehrt-her"zförmig, aber nicht bis auf $1 / 4 \mathrm{del}$

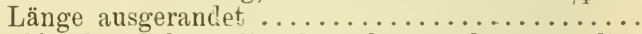

Deckb. länglich o. lineal, so lang o. länger, selten kürzer als die Btstiele; Bt. kurz-gestielt 0 . fast sitzend; Blkrzipfel 2spaltig, seltener nur ausge-

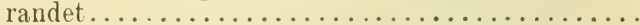

Schaft u. Btstiele von gegliederten, drüsentragenden Haaren kurz-zottig; B. beiderseits klebrig-flaumig 10

9 Schaft kahl, wenn auch oben sammt den Btstielen u. K. mehlig o. mit sehr kleinen sitzenden Drüsen besetzt

Blkr. violett, beim Aufblühen fast schwarz, ihre Röhre 3-4 mal so lang als der K., allmälig in den trichterigen Saum sich erweiternd; Kapsel länger als der K. $A$. v. $T$.

latifolia. Lap. Breitblättrige S.

Blkr. rosa, lila u. purpurn, ihre Röhre 2-3 mal so lang als der K., der Saum deutlich abgesetzt, zuletzt ziemlich flach ausgebreitet*) ......... 11

B. am Grunde meist allmählig verschmälert...... 12

B. am Grunde rasch in den Bstiel zusammengezogen,

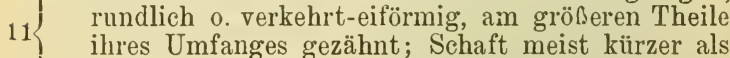
die B.; Kapsel im K. eingeschlossen. A. v. T. S. viscosa. Vill. Klebrige S.

B. kurz gestielt, vorne ziemlich gleichmäßig klein gezähnt o. ganzrandig; Kapsel so lang o. etwas

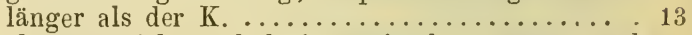

12 B. lang gestielt, verhältnissmäßig dünu, vorne grob и. ungleich gezähnt; Kapsel meist etwas kürzer als der K. St. (Herberstein).

commutata. Schott. Verwechselte S.

*) Die folgenden 4 Arten sind einander sehr ähnlich II. oft schwer $\mathrm{zu}$ unterscheiden; aber jede von ihnen bewohnt ein getrenntes Gebiet. 
b. r'undlich-verkehrt-eiförmig o. oval, manchmal ganzrandig; Drüsenhaare mit kleinem Köpfchen. A. v. St. K. Kr. ....villosa. Wulf. Zottige S.

13 B. länglich-keilig, seltener verkehrt-eiförmig, vorne stets gezähnt; Drüsenhare sehr kurz, mit verhältnissmälig großem Köpfchen; Pfl. kleiner. A. v. T........Oenensis. Thom. Innthaler S.

( B. kahl, knorpelrandig, glänzend hellgrün, ganz14 randig 0 . ausgeschweift; Bt. rosa o. lila. Südt. $K r$.

B. am Rande drüsig bewimpert; Bt. gelb....... 15

Bt. hellgelb, meist wohlriechend; wenigstens der K. meist auch die Btstiele $\mathrm{n}$. Bränder mit Mehlstaub bedeckt. A. «. Vor a. Auricula. L. Echte Aurikel.

15 Bt. dunkelgelb, geruchlos; Mellstaub nur auf der Blkr.; Drüsenhaare am Blattrande länger. Südt.

Balbisii. Lehm. Falsche Aurikel.

16 B. knorpelig beraudet, ganzrandig; Bt. rosa, lila 0.

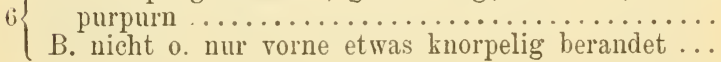

B. grasgrün, klebrig, durchscheinend punktirt, Knorpelrand breit; die meisten Deckb. kürzer als die Btstiele. A. v. Sï̈t.

17 spectabilis. Tratt. Ansehnliche S.

B. nicht punktirt, nicht 0 . kaum klebrig; die meisten Deckb. länger als die Btstiele ........... 18

B. blaugrün, sehr steif, mit breitem Knorpelrande; Krb. etwa bis $\mathrm{zu}{ }^{1 / 3} 2$ spaltig ............ 19

18 B. graugrün, weniger steif', mit schmalem Knorpelrande; Krb. etwa bis zur Mitte 2 spaltig. A. v. S. St. O. N.

Clusiana. Tausch. Clusius's.

Blattrand sehr fein drüsenhaarig*); Bt. zu 1-3; Kzipfel stumpf. $A$. v. $K$. $K r$.

19 Wulfeniana. Schott. Wulfen's S.

B. ganz kahl; Bt. zu 2-6; Kzipfel spitz. A. v. Sü̈lt....calyciua. Duby. Lombardische S.

B. u. K. dicht drüsenhaarig, klebrig; Bt. 1 --2, rosa o. lila; Pfl. sehr klein. A. v. Süidt.

20 Tiroliensis. Schott. Tiroler S. B. kahl o. am Rande gewimpert u. oberseits spärlich drüsenhaarig, oft klebrig ..............

*) Nur mit scharfer Loupe zu sehen! 
1). ganzrandig, elliptisch o. länglich, am Rande gewimpert u. oberseits spärlich drüsenhaarig, aber kaum klebrig; Bt. $1-3$, röthlich-lila. $A$. v. $T$. integrifolia. L. Ganzblättrige S.

B. vorne gesägt (nur ausnahmsweise ganzrandig), scheinbar ganz kahl, aber oft klebrig...........

Bt. 1-2, lebhaft rosa; B. nicht klebrig, mit 3 bis 9 großen, stachelspitzigen Sägezähnen.

Geb. (fehlt Sch. M.J.)..minima. L. Kleinste S.

22 Bt. 1-6, blauviolett; B. klebrig, mit 7-20 kleinen, manchmal undeutlichen, spitzen (aber nicht stachelspitzigen) Sägezähnen. A. v. T. S. K. St. Kr. glutinosa. Wrulf. Klebrige $\mathrm{S}$.

A nmerkung. Bastarte sind in der Gattung Primula verhältnissmäßig häufig. Im Gebiete wurden beobachtet: $\mathrm{P}$. acaulis $\times$ officinalis, acanlis $\times \mathrm{Co}_{0}$ lumnae, acaulis $X$ elatior, elatior $X$ officinalis, Columnae $X$ elatior, Auricula $X$ viscosa, integrifolia $X$ viscosa, minima $X$ viscosa, Auricula $X$ villosa, minima $X$ villosa, Auricula $X$ Oenensis, minima $X$ Oenensis, Auricula $\times$ Carniolica, Auricula $\times$ Clusiana, Auricula $\times$ Wulfeniana, minima $\times$ spectabilis, Clusiana $X$ minima, minima $X$ Wulfeniana, minima $X$ Tiroliensis, glutinosa $X$ minima. Einige dieser Bastarte sind übrigens zweifelhaft.

\section{DOUGLASTA. Lindl. Schlüsselspeik.}

B. spitz, am Rande u. unterseits flaumig; Frkn. mit 5 Samenknospen. A. v. Südt.

Vitaliana. (L.) Hook. Gelber S.

\section{ARETIA. $L$ Moosprimel.}

Alle B. dicht dachig, so dass die Stämmchen säulenförmig werden und fast geschlossene Rasen bilden B. sternhaarig - flaumig, nur an der Spitze der Stämmchen dichte Rosetten bildend, sonst ziemlich locker gestellt, die Rasen daher nicht geschlossen; Kzipfel spitz; Blkr. lebhaft rosa, selten weiß, mit gelben Deckklappen. A. v. T. S. O. St. K. alpina. (Lam.) Wrulf. Alpen-M.

B. von dicht stehenden Sternhaaren graufilzig, stumpf; Kzipfel stumpf; Blkr. weiß mit purpurner Röhre und ebensolchen Deckklappen. A. v. Sïdt. imbricata. (Lam.) Pax. Säulenförmige M. B. von einfachen 0 . gegabelten Haaren kurzhaarig; Kizipfel spitz; Deckklappen der Blkr. gelb ...... 
Haare der B. einfach, abwärts-gekehrt; Bt. weiß (manchmal etwas rosa überlaufen).

A. v. T. S. O. St. K.

Helvetica. (L.) Nym. Schweizer M.

Haare der B. wenigstens theilweise gegabelt; Bt. heller 0 dunkler rosa.......................

Blkr. klein, blassrosa, stieltellerförmig; Kzipfel länger als die Blkrröhre. A. v. Südt. K. St.

Hausmanni. (Leyb.) Nym. Tiroler MI. Blkr. ansehnlich, dunkelrosa, trichterig; Kzipfel so lang o. kürzer als die Blkrröhre. A. v. S. K. St.

Wulfeniana. Sieb. Steierische M.

A nmerkung. Zwischen A. alpina u. Helvetica kommt ein Bastart vor, außerdem zwischen Androsace obtusifolia u. Aretia alpina.

\section{ANDROSACE. L. Mannsschild.}

1 Alpenpfl. mit ausdauernden Stämmchen......... 2

Kräuter mit spindliger Wurzel............... 6

Schaft, Btstiele u. K. ganz kahl; B. lanzettlich o. lineal, kahl o. gewimpert; Btstiele verlängert; Bt. schneeweib, Schlundrand gelb. A. (fehlt $K r$. J.)

lactea. L. Milchweißer M.

Schaft, Btstiele u. K. zottig o. flaumig ............

Schaft u. Dolde zottig, Haare gegliedert; B. lanzett-

$3\left\{\begin{array}{c}\text { sch, ganzrandig, am Grunde verschmälert....... } \\ \text { lich } \\ \text { Schaft u. Dolde kurzhaarig, Haare sternförmig .... }\end{array}\right.$

B. ganz zottig; Rosetten fast kugelig; Bt. rosa 0. weis, mit gelbem o. purpurnem s'chlunde.

$4 \quad A$. v. St. $K$. $K r$. Südt. villosa. $L$. Zottiger M. B. am Rande zottig; Rosetten flach; Bt. weib, Schlund gelb. A. (fehlt $J$.)

Chamaejasme. Host. Haariger M.

B. lanzettlich, am Rande flaumig; Btstiele länger als die Deckb.; Bt. weiß o. röthlich mit gelblicher Röhre. $A$. (fehlt $O . J$.)

obtusifolia. All. Stumpfblättriger M.

B. lineal, gegen die Spitze verschmälert, unterseits gekielt, an der Spitze zurückgekrïmmt, kurz gewimpert; Bt. fleischroth. A. v. Südt.

carnea. $L$. Fleischrother M. 
Deckklappen den Schlund nicht verengend; Schaft u. Dolde behaart, Haare gegliedert; $K$. länger als die Blkr.; Bt. weiß o. röthlich, Deckklappen gelb. II. N. (Südt. ?) . . maxima. T. Mannsharnisch. Decklilappen den Schlund verengend; Schaft u. Dolde flaumig, Haare kurz, fein-sternförmig; B. lanzettlich, gezähnt; Bt. milchweiß mit gelben Deck-

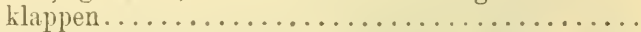

K. länger als die Blkr., flaumig; B. am Pande flaumig. B. M. (Sch.) N. Sü̈lst.

elongata. L. Verlängerter M.

${ }^{7}$ K. kürzer als die Blkr., kahl; B. ganz flaumig 0. ziemlich kahl. B. (M.?) N.T. septentrionalis. L. Nordischer M.

A n merkung. Zwischen A. lactea und A. obtusifolia kommt ein Bastart vor. (Vgl. auch unter Aretia.)

\section{CORTUSA. L. Heilglöckchen.}

Staude; B. lang gestielt, rundlich-nierenförmig, eckiggelappt; Bt. hellpurpurn. Fora. (fehit $K r$. J.)

Natthioli. L. Europäisches H.

\section{SOLDANELLA. L. Alpenglöckchen.}

(Bt. einzeln (selten 2); Gr. kürzer als die Blkr....

1 Bt. hellviolett, in armblütigen Dolden (nur ausnahmsweise einzeln); Gr. so lang o. länger als die Blkr.

B. herz-nierenförmig, etwas ausgeschweift; Btstiele fein-drüsig-rauh; Bt. kupferroth o. hellviolett.

๑ A. (fehlt J.).... pusilla. Baumg. Niedriges A. 2 B. kreisrund; Btstiele fein-drüsig-flaumig; Bt. helllila, inwendig purpurn-gestreift. $A$.

milim . Hoppe. Kleinstes A.

B. rundlich, entfernt-seicht-gekerbt; Stg. u. Btstiele kahl, nur die Bstiele spärlich drüsig. $A$. v. $K r$.

pirolaefolia. Schott et Kotschy. Wintergrünblättriges $\mathrm{A}$.

B. rundlich-nierenförmig, ganzrandig, ausgeschweift, o. entfernt-gekerbt; Btstiele von sitzenden Drüsen

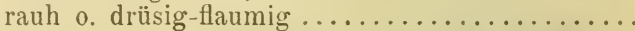

Stg. niedrig, meist $2-3$ blütig, wie die Btstiele von sitzenden Drüisen etwas rauh; B. ganzrandig 0 . etwas ausgeschweift. A. alpina. $L$. Gemeines A.

Stg. höher, meist mehrblütig, wie die Btstiele drüsig. flaumig; B. entfernt-gekerbt.

Verbr. (fehlt Sch. $K r . J$.)

montana. Willd. Großes A. 
Anmerkung. Von Bastarten wurden im Gebiete $\mathrm{S}$. alpina $\times$ pusilla und $\mathrm{S}$. alpina $\times$ minima beobachtet.

VII. HOTTONIA. L. Wasserfeder. Ausdauernde Wasserpfl.; Bt. blassrosa. B. II. Sch. N. O. Südst. Kr. Südt. palustris. L. Europäische $W$.

\section{SAMOLUS. L. Pungen.}

Staude; B. verkehrt-eiförmig o. länglich, stumpf; Trauben zuletzt verlängert; Bt. weic; Kapsel fast kugelig. B. MI. N. Südt. J.

Valerandi. L. Gemeine P.

\section{LISIMACHA. L. Weidenkraut.}

Stb. bis zur Mitte zusammengewachsen, den Frkn. bedeckend; Stg. aufrecht; B. lanzettlich 0 . eiförmig, kurz gestielt, oft quirlig:; Btstände rispen-

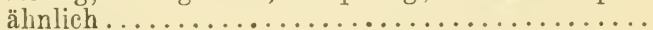
Stb. frei, den Frkn. nicht bedeckend; Stg. liegend;

B. gegenständig; Bt. einzeln, blattachselständig. .

Kzipfel roth gesäumt; Blkrzipfel am Rande kahl, eiförmig; B. unterseits etwas zottig. Verbr.

vulgaris. L. Gemeines W.

2 Kzipfel ohne rothen Saum; Blkrzipfel drüsig-gewimpert; B. flaumig, unterseits meist schwarzpunktirt. Verbr. (fehlt Sch.)

punctata. L. Punktirtes IV.

B. herzförmig-r'undlich; Kzipfel herzförmig; Stg. kriechend; Bt. ansehnlich. Verbr.

Nummularia. L. Kriechendes W.

B. eiförmig, spitz; Kzipfel lineal-pfriemlich; Bt. klein. Verbr. (fehlt J.) . nemorum. L. Hain-W.

X. NACHBURGIA. MInch. Straußweidenkraut.

B. gegenständig o. quirlig, verlängert-lanzettlich; Bt. oft roth punktirt. Verbr. (fehlt $K r$. J.)

thyrsiflora. (L.) Rchb. Gemeines St.

\section{TRIENTALIS. L. Siebenstern.}

Zarte Staude; B. eilanzettlich, ganzrandig, an der Spitze des Stg. fast quirlig zusammengedrängt; Bt. weiß. B. M. Sch. N. O. K. T.

Europaea. L. Europäischer S.

XII. ASTEROLINUM. Lk. et Hffgg. Sternlein. Stg. niedrig 0. zart; B. kahl, zugespitzt; Bt. blattachselständig; S. quer-runzelig. $J$. stellatum. (I.) L7. et Hffgg. Europäischer St. 


\section{GLALX. I. Milchkraut.}

Kleine Staude; Stg. meist niedergestreckt, ästig; B. gegenständig, lanzettlich, fleischig; Bt. blattachselständig. B. M. N. maritima. I. Meerstrands-M.

XIV. INAGALIIS. L. Gauchheil.

(Zarte Staude; B. gestielt, rundlich-eiförmig; Bt. rosa,

1 dunkler geadert. T. S. J. tenella. L. Zartes G. Einjährige Kräuter; B. sitzend, eiförmig .........

Bt. meist mennigroth; Blkrzipfel verkehrt-eiförmig, fein drüsig gewimpert. Verbr.

arvensis. $L$. Acker-G.

Bt. fast ımmer blau; Blkrzipfel oval, fast drüsenlos. Verbr. (fehlt S.)...coerulea. Schreb. Blaues G.

Anmerkung. Der Bastart A. arvensis $X$ coerulea ist selten.

\section{CENTUNCULUS, L. Kleinling.}

Sehr kleines, 1 jähriges Krraut; B. eiförmig; Bt. in den Blattachseln sitzend, weiß o. röthlich, kaum bemerkbar. Terlt......minimus. L. Wiesen-K.

\section{CICLAMEN. L. Eribrod.}

(B. ausgeschweift 0 . kleingekerbt, Kerben nicht stachelspitzig; Bt. rosa. Verbr. (fehlt Sch.)

Europaeum. L. Gemeines E.

B. eckig - ausgeschweift, mit kurz - stachelspitżigen Ecken; Bt. purpurn. J.

repandum. Sibth Ausgeschweiftes E.

\section{IXXIV. Familie. Plumbagineae. Bleiwurzgewächse.}

Stauden o. Halbsträucher mit, ungetheilten, schraubig gestellten, meist zu Rosetten zusammengestellten B., ohne Nebenb. Bt. zwittrig, regelmähig. K. gefaltet, 5 zähnig, oft oben trockenhäutig, nicht abfällig. Krb. 5, bald frei 0 . fast frei, bald ziemlich hoch hinauf verwachsen. Stb. 5, vor den Krb. stehend. Frkn. 1, oberständig, 1 fächerig, mit einer grundständigen Samenknospe. Gr. 0. N. 5. Fr. trocken, bald geschlossen bleibend, bald in verschiedener Weise aufspringend. S. mit mehligem Nährgewebe.

\section{Gattungen.}

Stg. beblättert; K. krautig; Blkr. trichterig, mit 5lappigem Saume; Gr. 1; N. 5, fädlich.

\section{Plumbago. I.}

B. grundständig, Rosetten bildend; K. wenigstens oben trockenhäutig; Krb. frei o. nur am Grunde

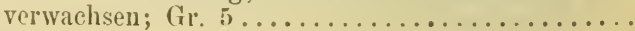


Schaft unverzweigt; Btstand kopfig, unter demselben eine röhrige Hülle; Bt. rosenroth (selten weiß).

Schaft verzweigt, der Btstand daher rispenartig, aus einseitswendigen Aehren bestehend; Bt. violett.

statice. III.

Arten.

\section{PLUMBAGO. I. Bleiwur.}

Stgb. lanzettlieh, umfassend, am Rande rauh; $K$. drüsenborstig; Bt. hellviolett. $J$.

Europaca. L. Europäische B.

\section{ARMERIA. Willd. Grasnelke.}

B. 1 nervig, lineal, spitzlich, am Rande gewimpert; Btstiele so lang als die Kröhre; Krb. ganzrandig, gekerbt 0 . schwach-ausgerandet.

T. M. Sch. N. St. (J.?)

elongata. (Hoffm.) Koch. Gemeine G.

B. fast 3 nervig, lanzettlich-lineal o. lineal, kahl; Btstiele halb so lang als die Krölıe; Krb. ansgerandet. A... alpina. (Hoppe.) Willd. Alpen-G.

\section{STA'TICE. I. Sandnelke.}

1 Schaft u. B. filzig, flaumig o. zerstreut kurzhaarig, ersterer vom Grunde an sehr ästig............ Schaft 1 . B. kahl, ersterer erst über der Mitte ästig 3 Schaft in der Regel fast rechtwinkelig hin- und hergebogen, sammt den B. filzig kurzhaarig; Kzähno ¿ spitz. J.......... cancellata. Bernh. Gegitterte S. Schaft nicht winkelig gebogen, sammt den B. zerstreut kurzhaarig; Kzähne stumpflich. $J$.

cordata. L. Flammige S.

B. mit 3-5 Längsnerven, länglich-spatelig; Aelren locker; Kzähne länglich, stumpf. $J$.

eonfusa. Gren. et Godr. Verwechselte s.

3 B. mit einem Mittelnerv und fiederig gestellten Seitennerven; Aehren dichtblütig; Kzähne eiförınig, spitz. J. ............... Limonium. L.*) Meer-S.

LXXV. Familie. Oleaceae. Oelbaumgewächse.

Holzgewächse mit ungetheilten o. gefiederten, meist gegenständigen, seltener schraubig gestellten B., ohne Nebenb. Bt. regelmäßig, zwittrig o. vielehig-2 häusig. $\mathrm{Kb}$. 3-8 (am häufigsten 4), am Grunde mehr 0. weniger ver-

*) S. serotina Rchb. ist durch mehr abstehende, oft zurückgekrïmmte Aeste ausgezeichnet. 
wachsen, manchmal fehlend. Krb. 3-8 (meist 4), oft zu einer kürzeren 0 . längeren Röhre verwachsen, manchmal fehlend. Stb. 2 (ausnahmsweise auch 3-4). Frkn. 1, oberständig, 2 fächerig, mit $1-3$ (meist 2) Samenknospen in jedem Fache. Gr. 1, meist kurz, oft mit 2 lappiger N. Fr. verschieden ausgebildet. S. mit o. ohne Nährgewebe.

\section{Gattungen.}

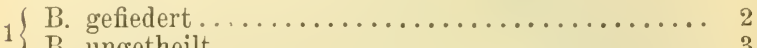

$1\{$ B. ungetheilt $\ldots \ldots \ldots \ldots \ldots \ldots \ldots \ldots \ldots \ldots \ldots \ldots$

(Blkr. stieltellerförmig, mit verlängerter Röhre u.

${ }_{2}$ 5-8 Zipfeln; Bt. zwittrig; Fr. eine trockene Beere.

Jasminum. VI

Bikr. bis zum Grunde 3-4 theilig, oft fehlend; Bt. vielehig, 2 häusig; Flïgelfrucht..... Fraxinus. I.

${ }_{3}$ B. schraubig gestellt; Bt. weiß o. grünlich; Steinfr.

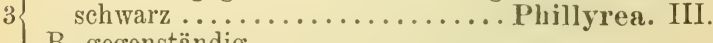

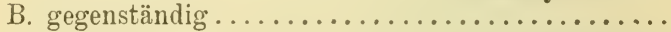

(B. immergrün, unterseits mehlig-schülferig; Steinfr. 4\{

B. sommergrïn, kahl; Kapsel o. Beere......... Olea. IV.

B. her'zförmig; Bt. lila, seltener weiß; Kapsel 52 klappig.................... Syringa. II. B. länglich-lanzettlich; Bt. weiß; Beere schwarz.

Ligustrum. V.

\section{Arten.}

\section{FRAXINUS. $L$. Esche.}

K. u. Blkr. fehlen; Bt. bräunlich; Blättchen 7-13, fast sitzend. Verbr......excelsior. L. Hohe E. K. u. Blkr. vorhanden; Bt. gelblich-weiß; Blättchen 7-9, deutlich gestielt. Süidt. K. Südst. $K r^{\circ}$. J. Ornus. L. Manna-E.

\section{STRINGA. L. Flieder.}

B. zugespitzt; Bt. in pyramidenförmigen Sträußen; S. geflügelt. Cult. u. verv.

vulgaris. $L$. Gemeiner F.

\section{PHILITREA. L. Steinlinde.}

B. eilanzettlich 0 . länglich, ganzrandig 0 . häufiger gesägt; Steinfr. erbsengroß. Sïdt. J.

latifolia. L. Breitblättrige St.

\section{OLEA. L. Oelbaum.}

B. lanzettlich, ganzrandig; Bt. in blattwinkelständigen Trauben o. Rispen, weiß.

Cult. u. verw. (Sü̈t. J.)

Europaea. I. Europäischer 0 . 


\section{IIGUSTRUM. L. Rainweide.}

Strauch; Rispe endständig, gedrungen; Bt. weiß.

Verbr.............. vilgare. L. Gemeine R.

\section{JASMINUM. L. Jasmin.}

Blättchen lanzettlich, zugespitzt, kahl; Bt. weiß, wohlriechend. Cult. u. verw. (Sü̈lt. J.)

officinale. $L$. Echter J.

\section{Familie. Gentianaceae. Enziangewächse.}

Kräuter o. Stauden mit ungetheilten (selten 3 zähligen) u. ganzrandigen, meist gegenständigen, seltener schraubig gestellten B., ohne Nebenb. Bt. zwittrig, regelmäßig. Kb. 4-10 (meist 4-5), in der Regel mehr 0 . weniger mit einander verwachsen. Krb. so viele als Kb., stets wenigstens am Grunde verwachsen, oft eine verlängerte Röhre bildend. Stb. so viele als Krb., zwischen den Krb. in der Blkrröhre eingefügt. Frkn. 1, oberständig, 1 fächerig 0 . unvollkommen 2 fächerig, eine unbestimmte (meist große) Zahl von Samenknospen enthaltend. Gr. 0. N. 2, oft vollständig verwachsen Fr. eine 2 klappig aufspringende Kapsel, seltener unregelmäßig o. gar nicht sich öffnelld, stets mehrsamig. S. mit reichlichem Nährgewebe.

\section{Gattungen.}

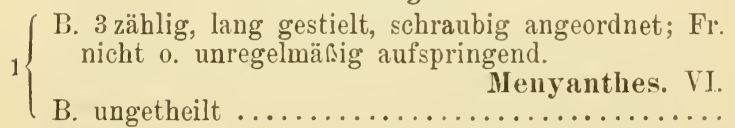

(B. schraubig gestellt, lang gestielt, herzförmig-kreis2 rund, schwimmend; Fr. nicht 0 . unregelmäßig aufspringend. ............... Limnanthemum. VII. B. meist gegenständig; Fr. 2 klappig aufspringend . Blkr. trichterförmig, glockig, keulig-walzlich o. stieltellerförmig, mit mehr 0 . weniger verlängerter Röhre (selten radförmig, mit kurzer Röhre, dann

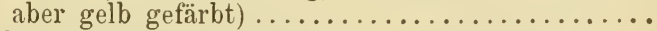
Blkr. radförmig, tief 5 spaltig, mit sehr kurzer Röhre und 2 gefransten Schuppen o. Honiggruben am Grunde jedes Zipfels; Bt. blassblau o. trübviolett (selten weiß o. gelblichgrün) ....... Sweertia. V. Kb., Krb. 11. Stb. $4-5 \ldots \ldots \ldots \ldots \ldots \ldots \ldots \ldots \ldots$. 5

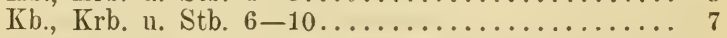

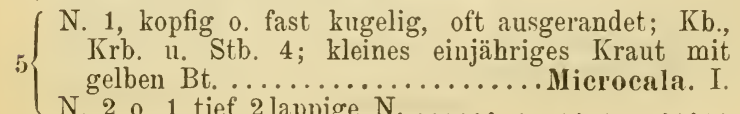
N. 2 o. 1 tief 2 lappige $\mathrm{N}$. 
A. nach dem Verblühen schraubig-zusammengedreht; Bt. rosa, seltener gelb, ausnahmsweise auch weib; Kräuter .................Erythraea. II. A. nach dem Verblühen nicht gedreht; Bt. verschieden gefärbt, am häufigsten blau; Kräuter 0 . Stauden.....................

Einjährige Kräuter mit gelben Bt.; Blkrröhre kurz; Pfl. blangrau bereift ......... Blackstonia. III. Kräftige Stauden; Blkrröhre verlängert; Pfl. nicht bereift ................ (ientiana. IV.

\section{Arten.}

I. MICROCALA. Lk. et Hffgg. Bitterblatt.

B. lanzettlich; Btstiele verlängert. . .

filiformis. (L.) $L \hbar$. Fädliches B.

\section{ERYTHRAEA. L. C. Rich. Tausendgulden- kraut.}

( Bt. gelb; N. fädlich, länger als der Gr.; B. eiförmig. J..........maritima. (Willd.) Pers. Gelbes 'T'. Bt. rosa, seltener blassröthlich 0 . weiß; N. rundlich,

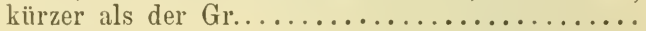

Die seitenständigen Bt. in verlängerten Scheinähren; Stg. ästig; B. länglich; Krzipfel lanzettlich. $J$.

spicata. (L.) Pers. Aehriges T. Bt. in Ebensträuœen 0. rispenförmigen Trugdolden. B. oval-länglich, meist 5 nervig, wie der Stg. kahl. B. lineal o. lineal-länglich, meist 3 nervig, am Rande fein gewimpert; Stg. fein flaumig o. doch rauh, selten kahl ; Trugdolden gebüschelt, zuletzt lockerrispig. $B . M I$. N. St.

uliginosa. ( $W . K$.$) (Wittr.) Sumpf-T'.$

Kzipfel zur Zeit des Aufblühens so lang als die Röhre der Blkr.; Kapsel so lang o. etwas kürzer als der K.; Trugdolden gebüschelt, mit kurz gestielten Bt. $J$.

tenuiflora. Lk. et Hoffgg. Schmalblütiges T. Kzipfel stets kürzer als die Blkrröhre; Kapsel länger

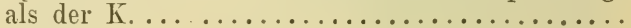

Bt. kurz gestielt, in gebüschelten Trugdolden (Ebensträußen); Stg. meist erst oben ästig. Verbr.

Centaurium. (L.) Pers. Echtes T.

Bt. lang gestielt, in sehr lockeren rispenförmigen 'Trugdolden; Stg. oft schon am Grunde verästelt; Iit. kleiner. Verbr.

pulchella. (Sw.) $F r$. Kleines T. 


\section{BLACKSTONIA. Huds. Bitterling.}

Stgb. 3 eckig-eiförmig, mit ibrer ganzen Breite paarweise verwachsen; Kzipfel 1 nervig, kürzer als die Blkr. J.

perfoliata. (L.) Huds. Durchwachsener B. Stgb. eiförmig 0 . eiförmig-lanzettlich, am abgerundeten Grunde verwachsen; Kzipfel schwach3 nervig, so lang als die Blkr. N. St. J. Südt. serotina. (Koch.) Beck. Spätblühender B.

\section{GENTIANA. L. Enzian.}

Blkrzipfel gesägt, an den Seitenrändern eingeschnittengefranst, Schlund nackt; Bt. endständig, einzeln, blau, gegen den Herbst erscheinend; B. lineallanzettlich; Stg. hin- u. hergebogen, kantig.

Verbr................ ciliata. L. Gefranster E. Blkrzipfel nicht gefranst, aber oft am Grunde bärtig

Schlund der Blkr. inwendig nackt, Blkrröhre zwischen den Zipfeln mit einer gestutzten 0 . in einen

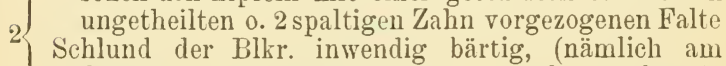
Grunde jedes Zipfels liegen 1-2 fein gefranste

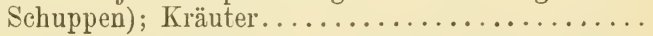

Blkr. keulig-glockig o. stieltellerförmig, die Zipfel stets kürzer als die Röhre................ Blkr. radförmig, 5 theilig, gelb, die Zipfel viel länger als die Röhre, schmal-lanzettlich; K. halbirt, d. h. der Länge nach geschlitzt; große Staude. A. v. T. $K$. $K r . \ldots \ldots \ldots \ldots$ Intea. L**) Gelber E.

Blkr. keulig - glockig, mit ziemlich kurzen, nicht

4 auffallend abgesetzten Zipfeln; Stauden ..........

Blkr. stieltellerförmig, mit walzlicher Röhre und abstehenden Zipfeln................. 14

(Blkrzipfel 4, nur bei einzelnen Bt. 5 ; Bt. blau, 5 außen etwas grünlich; B. lanzettlich, 3 nervig, am Grunde scheidig. Verbr. ..cruciata. L. Kreuz-E. Blkrzipfel 5 o. mehr................... 6

Bt. gelb o. purpurn, quirlig o. kopfig angeordnet;

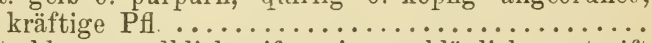

6 Bt. blau 0. gelblichweiळ u. innen bläulich gestreift (selten weiß), einzeln $0 . \mathrm{zu} 2-3$ gebüschelt, oft ährenartig zusammengestellt .............

*) Die typische G. lutea L. wächst nur in $T$. Die Pflanze der übrigen Länder hat verwachsene A. und ist G. symphyandra Murbeck. 
K. halbirt, d. h. ler Länge nach geschlitzt; Blkr.

7 außen hellpurpurn, innen gelb. A. v. T.

$7\{$ purpurea. L. Purpurner E.

K. glockig, ziemlich gleichmäßig $5-8$ spaltig..... \&

Kzähne zurückgekrümmt; Blkr. trübpurpurn, schwarz punktirt, Röhre bleichgelb. A. u. Böhmerwald.

Pamonica. Scop. Ungarischer E.

Kzähne aufrecht; Blkr. hellgelb mit schwarz-purpurnen Punkten. Geb. v. Sch. M. St. Kr. K. T. S.

punctata. L. Punktirter E.

N N. halbkreisförmig, gezähnelt; Grundb. rosettig;

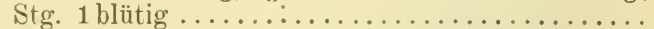

$\mathrm{N}$. länglich 0. lineal; Stg. 1-mehrblütig ........ 1

Kzähne aus breiterem Grunde verschmälert-lanzettlich, an die Blkrröhre angedrïckt; Grundb. lanzettlich o. elliptisch. A. u. Vora.

Kzähne aus verschmälertem Grunde eiförmig-lanzettlich, abstehend; Grundb. elliptisch 0. oval.

A. v. T. S. O. St. K. acaulis. L. Stengelloser E.

B. aus eiförmigem Grunde lanzettlich, zugespitzt, sitzend, 5 nervig; Stg. vielblütig: Blkr. azurblau, innen dunkel punktirt, selten weis. Verbr.

asclepiadea. L. Schwalbenwurzartiger E.

B. lineal-lanzettlich, die unteren scheidig ....... 12

B. kurz-scheidig, die untersten klein, schuppenförmig ; N. lineal, verlängert; Stg. 1-vielblütig; Blkr. azurblau, innen mit 5 grünpunktirten Streifen. Verbr........Pueumonanthe. $I$. Lungenblume. Grundb. und untere Stgb. mit oberwärts erweiterten Scheiden, gehäuft; N. länglich; Stg. 1-2 blütig .

A. zusammengewachsen; Gr. halb so lang als der Frkn.; Blkr. hellblau. A. v. $K$. $K r$.

Fröhlichii. Hladn. Fröhlich's E.

13 A. frei; Gr. vielmal kürzer als der Frkn.; Blkr. gelblichweiß, punktirt, innen mit 5 bläulichen Streifen. A. v. St.

frigida. Häntie. Kälteliebender E.

(Ausdauernde Pfl. mit unfruchtbaren Bbüscheln neben 14 dem blühenden Stg., letzterer stets 1 blütig, niedrig Einjährige Pfl. ohne unfruchtbare Bbüschel; Stg. meist ästig und mehrblütig ..............

Gr. tief-2 spaltig; B. verkehrt-eiförmig, in den 15 knrzen Bstiel zusammengezogen, die unteren 0. alle gedrungen. A. Bavarica. $L$. Baierischer E.

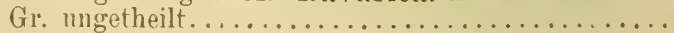


(B. am Grunde kaum schmäler, lineal, die unteren 16 gedrungen. A. ....... pumila. Jacq. Zwerg-E. B. am Grunde verschmälert, nicht lineal....... 17

B. sämmtlich dachig, lanzettlich-elliptisch, spitz, am Rande rauh, die untersten nicht grölser als die

17 übrigen. A. v. T. K. St. Kr r. J.

imbricata. Froel. Dachigblättriger E. Grundb. rosettig, größer als die übrigen ........ 1s

B. rundlich-eiförmig, kurz zugespitzt, in den kurzen Bstiel zusammengezogen; Kanten des K. nicht geflügelt. A. v. T. S. O. St. K.

brachyphylla. Vill. Kurzblättriger E.

B. elliptisch 0 . lanzettlich, spitz; Kanten des K. ge-

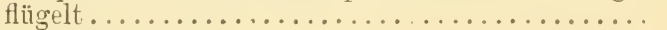

B. elliptisch; Kanten des K. schmal-geflügelt. *) Verbr. ............ verna. L. Frühlings-E.

19 B. lanzettlich, schmal; Flügel der Kanten des K. in der Mitte sehr breit. $K r$. J.

Tergestina. Beck. Triestiner E.

Stg. liegend 0. aufstrebend; untere B. verkehrt-eiförmig, ziegeldachig; Gr. 2 theilig, zurückgerollt. A. v. T. S. St. K.

prostrata. Hänke. Liegender E.

Stg. aufrecht; untere B. rosettig, eiförmig 0. länglich 21

K. anfgeblasen, geflügelt-kantig, oval ; Gr. verlängert; Bt. mittelgroß. A. u. Vora.

utriculosa. L. Bauchiger E.

K. walzlich, kielig-kantig; Gr. ziemlich kurz; Bt. klein. A.............nivalis. $L$. Schnee-E.

Stg. am Grunde und oben o. nur oben verzweigt; K. röhrig, 4-5 zähnig, der Blkr. anliegend; am Grunde jedes Zipfels der Blkr. eine breite lang gefranste Schuppe; Bt. meist lila ............

Kleine Alpenpfl., deren Stg. nur am Grunde verzweigt ist; K. glockig, tief $4-5$ theilig, der Blkr. nicht anliegend; am Grunde jedes Zipfels der Blkr. 2 kleine gefranste Schuppen.......... 41

$23\{$ Zipfel des K. u. der Blkr. $4 \ldots \ldots \ldots \ldots \ldots \ldots \ldots 24$

23 Zipfel des K. u. der Blkr. 5............. 25

*) Bei G. aestiva (Schm.) Schult. sind die Kflügel in del Mitte verbreitert. 
Pfl, einjährig; Grundb. eilanzettlich, gegen den Grund zu am breitesten, zur Btzeit (Herbst) noch alle frisch. B.....Baltica. Murb. Baltischer E.

24 Pfl. 2 jährig; Grundb. spatelförmig, gegen die Spitze zu am breitesten, unter ihnen vertrocknete Reste der vorjährigen B. Verbr. (fehlt $N$. O.)

campestris. L. Feld-E.

( Frkn. u. Fr. sitzend; Bt. klein, röthlich-lila (selten

25 gelblichweiß) $\ldots \ldots \ldots \ldots \ldots \ldots \ldots \ldots \ldots \ldots$

Frkn. u. Fr. kürzer 0 . länger gestielt.......... 28

${ }_{26}$ Pfl. 1 jährig, klein und zart; Grundb. lanzettlich. $B$.

Pfl. 2 jährig; Gruntb. uliginosa. Willd. Sumpf-E.

Stgglieder 3-5, das zweite 0 . dritte viel länger als die übrigen; mittlere Stgb. stumpf; blüht im Frühsommer. B...lingulata. $A g$. Spatelblättriger E.

27 Stgglieder 5-12, die untersten 3 an Länge wenig ungleich, die oberen oft viel länger; mittlere Stgb. spitz; blüht im Spätsommer u. Herbst. B. $M$.

Amerella. L. Bitterer E.

B. aus breiterem Grunde lanzettlich o. eilanzettlich, spitz; Stg. meist schon unten verzweigt; im Herbste

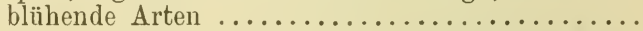

Untere B. länglich, stumpf, nur die obersten spitz; Stg. erst oben o. gar nicht verzweigt; im Sommer blühende Arten.........................

$29\{$ Kzipfel am Rande gewimpert 0. fein flammig......30

Kzipfel ganz kahl ........................ 32

Kzipfel nur am Rande (sehr fein) steif gewimpert und daselbst zurückgerollt; Pfl. meist niedrig und reichlich verzweigt, auf Alpen auch unverzweigt; Bt. mittelgroß. T. S. K. Südst. $K r$.

calycina. (Koch.) Kelch-E.

Kzipfel am Rande und am Mittelnerven fein tlaumig, flach 0. mit etwas umgerollten Rändern ....... 31

Nittlere Stgb. lanzettlich, mindestens 4 mal so lang als breit; Bt. mittelgroß; Frkn. sehr kurz gestielt. Sült. K. J. ......pilosa. Wettst. Behaarter E. Mittlere Stgb. 3 eckig-eiförmig. höchstens 3 mal so lang als breit; Bt. groß; Frkn. ziemlich lang gestielt. B. N. U. St. S. K. T.

Sturmiana. Kern. Sturm's E. 
Kzipfel durch abgerundete Buchten von einander getrennt ........................... $3: 3$

Kzipfel durch spitze (selten etwas stumpfliche) Buchten von einander getrennt .............. 34

Stg. niedrig, Aeste ungefähr gleich hoch, der Btstand daher nahezu ebensträußig; Bt. sehr groß; Kzipfel entschieden länger als die Kröhre.

B. M. N. O. St. Kr.

Austriaca. Kern. Oesterreichischer E.

Stg. schlank, mit ziemlich kurzen, ungleich hohen Aesten, der Btstand daher rispenartig; Bt. mittelgrof; Kzipfel kaum länger als die Kröhre.

Sch. MI. B. N. Carpatica. Wettst. Karpathen-E.

$34\left\{\begin{array}{l}\text { Blkr. röhrig-glockig; Btstand ebensträußig .......... } \\ \text { Blkr. röhrig-trichterig; Btstand durch ungleich hohe }\end{array}\right.$ 35 A este rispenartig $\ldots \ldots \ldots \ldots \ldots \ldots \ldots \ldots \ldots \ldots \ldots$

Stg. aufrecht, nicht unmittelbar ïber dem Boden verzweigt; Bt. groß, lebhaft lila, selten weißlich. N. St. S. K....Stiriaca. Wettst. Steierischer E. 35 Stg. gleich über den Boden in dichtblütige Aeste aufgelöst, stets niedrig; Bt. ziemlich klein, weißlich 0. hellilia. A. v. Südt

Murbeckii. W'ettst. Murbeck's E.

Kanten der Kröhre etwas geflügelt; Kzipfel meist am Rande umgerollt; $\mathbf{B}$. meist kürzer als die Stgglieder. $M$. B. T.

Wettsteinii. Murb. Wettstein's E. Kanten der Kröhre nicht geflügelt; Kzipfel meist flach; B. länger als die Stgglieder. A. v. T.

Rhaetica. Kern. Rhätischer E.

37 Kzipfel am Rande gewimpert o. fein flaumig ...... 38

Kzipfel ganz kahl ........................ 39 $38\left\{\begin{array}{l}\text { Kzipfel nur am Rande fein gewimpert. T. S. K. Kr. } \\ \text { antecedens. Wettst. Vorausblühender } \mathrm{E} . \\ \text { Kzipfel am Rande und am Mittelnerven fein flaumig. }\end{array}\right.$ Kzipfel am Rande und am Mittelnerven fein flaumig. T. S. O. St. K. .... Norica. Kern. Norischer E.

Kzipfel durch abgerundete Buchten von einander getrennt......................... 40

$39)$ Kzipfel durch spitze Buchten von einander getrennt. T. S. St. $K r$.

obtusifolia. (Schmidt.) Willd. Stumpfblättriger E.

Kzipfel entschieden länger als die Kröhre. $A$. v. $N$.

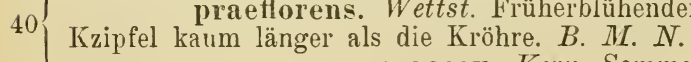
praecox. Kern. Sommer-E. 
B. elliptisch-länglich, spitzlich; Kzipfel 4, eilanzettlich ; Blkrzipfel 4, eilanzettlich, ziemlich lang zugespitzt.

$41 \quad A . \nabla . T . S . K .(K r$ ? $)$ tenella. Rottb. Zarter E. B. verkehrt-ciförmig, abgerundet-stumpf; Kzipfel 5, eiförmig; Blkrzipfel 5, eiförmig, kurz zugespitzt. A. v. T. S. K...... nana. Wulf. Kleinster E.

Anmerkung. Bastarte wurden im Gebiete zwischen $G$. lutea und $G$. Pannonica, G. lutea und G. punctata, G. acaulis und G. vulgaris, ferner zwischen G. campestris und G. Wettsteinii beobachtet. - Viele der Arten mit bärtigem Schlund der Blkr. sind durch Zwischenformen miteinander verbunden.

\section{SIVEERTIA. $L$. Tarant.}

Staude; Bt. trübviolett (selten gelblichgrün), in traubenförmig zusammengestellten Trugdolden; am Grunde jedes Zipfels der Blkr. 2 am Rande gefranste Ḧoniggruben. Verbr. (fehlt J.) perennis. L. Ausdauernder T. Kleines, 1 jähriges Kraut; Bt. blassblau (selten weiß), einzeln, lang gestielt; am Grunde jedes Zipfels der Blkr. 2 gefranste Schuppen. A. v. T. S. K.

Carinthiaca. Wulf. Alpen-T.

\section{MENYANTHES. L. Fieberklee.}

Wasserliebende Stande; Bt. in lang gestielten Trauben; Blkr. blassrosa, innen lang gebärtet. Verbr.

trifoliata. L. Dreiblättriger F.

\section{LIMNANTHEMUM. Gmel. Sumpfblume.}

Ausdauernde Wasserpfl. ; Bt. groß, gelb, schwimmend. B. M. Sch. N. St. T.

nymphoides. (L.) Hoffgg. et Lk. Seerosenartige S.

\section{IXXVII. Familie. Apocyneae. Hundsgiftgewächso.}

Stauden 0. Holzgewächse mit ungetheilten, ganzrandigen, gegenständigen o. wirteligen B., ohne Nebenb. Bt. zwittrig, regelmäßig. Kb. 5. Krb. 5, am Grunde in eine glockige, trichterige 0 . walzliche Röhre verwachsen, in der Knospenlage gedreht. Stb. 5, in der Blkrröhre befestigt. Frkn. 2, oberständig, 1 fächerig, oft theilweise verwachsen, mit mehreren 0. zahlreichen Samenknospen. Gr. 1-2; N. 1. Fr. aufspringend, mehrsamig. S. meist mit Nährgewebe. 


\section{Gattungen.}

B. wirtelig (meist zu 3); Holzgewächse mit großen, lebhaft rosa gefärbten (selten weiøen) Bt.; Blkı. trichterig, am Schlunde mit geschlitzten Schuppen besetzt....................... B. gegenständig; Stauden 0. Halbsträucher........

(Bt. einzeln, ansehulich, meist blan; Bllir. stielteller2 förmig; S. ohne Haarschopf ......... Vinca. I. Bt. klein, rosa, in rispenartigen Btständen; Blkr. glockig; S. mit Haalschopf ......Apocynum. II.

Arten.

\section{VINCA. L. Singriin.}

Stg. halbstrauchig, ausdauernd; blühende Aeste auf-

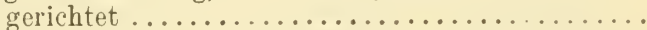

1 Stg. krautig, sammt den blühenden Aesten liegend; B. fein gewimpert, die unteren eiförmig, die oberen lanzettlich. N.......herbacea. $L$. Krantiges S.

Kb. und Zipfel der Blkr. kahl; B. länglich-lanzettlich. Verbr. ...........minor. L. Kleines s. Kb. und Zipfel der Blkr. gewimpert; untere B. her\%eiförmig, breit, obere eilanzettlich; Bt. gröber. Südt. Kr.J. (meist nur verv.)

major. $L$. Großes S

\section{APOCYNUII. L. Hundsgift.}

B. länglich-lanzettlich, kahl, stachelspitzig, am Rande gezähnelt-rauh. J.. Venetum. $L$. Venetianisches H.

\section{NERIUM, $L$. Oleander.}

B. Ianzettlich, lederig; Bt. in Trugdold’n. Sïdt. (sonst cult.)...Oleander. $L$. Gemeiner 0.

\section{Familie. Asclepiadeae. Seidenpflanzen.}

Stauden mit ungetheilten, gegenständigen B., ohne Nebenb. Bt. zwittrig, regelmäßig. Kb. 5. Krb. 5, am Grunde verwachsen, in der Knospenlage gedreht o. klappig, mit Nebenkrone. Stb. 5, zu einer die Frkn. umgebenden Röhre verwachsen. Frkn. 2, oberständig, 1 fächerig, mit zahlreichın Samenknospen. Gr. 2, oben verwachsen, mit gemeinsamer, 5 kantiger N. Fr. aufspringend, vielsamig. S. mit langem Haarschopf, mit Nährgewebe. 


\section{Gattungen.}

Nebenkrone aus 5 kappenförmigen Zipfeln bestehend, aus deren Höhlung ein hornartiges Anhängsel

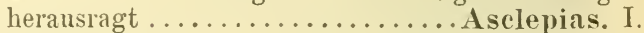

Nebenkrone einfach 5 lappig o. doppelt u. dann aus 10 Lappen bestehend, Lappen nicht kappenförmig, ohne hornartige Anhängsel.....Cynanchum. II.

\section{Arten.}

\section{ASCLEPIAS. $L$. Seidenpfianze.}

Pfl. groß u. kräftig; B. elliptisch, unterseits weichhaarig; Dolden blattachselständig; Bt. fleischfarben. Cult. u. vervv. (selten).

Syriaca. L. Echte S.

\section{CYNANCHUM. $R$. $B r$. Schwalbenwurz.}

Nebenkrone doppelt, mit 5 äußeren u. 5 inneren Lappen; Bt. blassrosa; Stg. windend; B. tiefherzförmig, zugespitzt. $J$.

acutum. $L$. Hundswürger.

Nebenkrone einfach, 5lappig; Bt. weiß, gelblich,

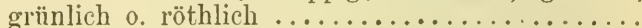

Bt. gelblich 0. röthlich, stinkend, beim Trocknen

rasch braun werdend; Stg. schlank, oft oben windend. J. ......... fuscatum. Rchb. Braune Sch.

Bt. weiß, außen gelblich, am Grunde grünlich.....

Lappen der Nebenkrone ohne Zwischenhaut, aufrecht, aneinanderschließend. $J$.

contiguum. Koch. Geschlossene Sch.

Lappen der Nebenkrone durch eine durchsichtige Zwischenhaut verbunden

Mittlere B. herz-eiförmig; Blkrzipfel eiförmig.

Verbr. Vincetoxicum. (L.) R. Br. Gemeine Sch. Mittlere B. aus herzförmigem Grunde länglichlanzettlich; Blkrzipfel länglich, am Rande zurückgebogen. Verbr.(?)

Iaxım. Bartl. Lockerblütige Sch.

LXXIX. Familie. Convolvulaceae. Windengewächse.

Kräuter 0. Stauden. Stg. oft windend. B. schraubig gestellt, meist ungetheilt, oft ganz verkümmert 0 . fehlend. Bt. zwittrig, regelmäßig. Kb. 5, selten 4, oft am Grunde verwachsen. Krb. (4-)5, entweder nur im unteren Theile 0. der ganzen Länge nach verwachsen $u$. dann nur durch 5 Lappen 0. Ecken, sowie durch Falten in der Blkrröhre angedeutet. Stb. (4-)5, der Blkrröhre eingefügt. Frkn. 1, oberständig, 1-2 fächerig, meist 4 Samenknospen enthaltend. Gr. 1-2; N. 1-2. Fr. in verschiedener Weise aufspringend, 2-4 samig. S. mit Nährgewebe; Keimling oft ohne Keimb. 


\section{Gattungen.}

(B. normal entwickelt; Blkr. groß, trichterig-glockig, 5 lappig-eckig, 5 faltig, ohne Schuppen im Innern der Röhre

B. fehlend 0. an ihrer Stelle sehr kleine Schüppchen; Blkr. klein, 4-5 spaltig, innen mit Schuppen unter den Stb......................

K. von 2 groben Vorb. eingeschlossen; Frkn. 1 fächerig o. unvollkommen 2 fächerig; Nlappen groß, flach. Calystegia. II. K. nicht von Vorb. umgeben; Frkn. 2 fächerig; Nlappen fädlich o. keulig...... Couvolvulus. I.

\section{Arten.}

\section{CONTOLVULUS. L. Winde.}

Stg. nicht windend, rauhhaarig; B. lineal-lanzettlich, $1\left\{\begin{array}{r}\text { spitz; Bt. rosa, auben behaart. N. Kr.J. Südt. } \\ \text { Cantabricus. L. Cantabrische W. }\end{array}\right.$ Stg. windend; B. herz- o. pfeilförmig ........... Stg. wenig behaart o. fast kahl; B. pfeilförmig; Bt. rosa 0 . weib. Verbr. $u$. $h f g$. arvensis. $L$. Acker-W. Stg. silberig-seidig; untere B. herzförmig, obere fußförmig gespalten. $J$. tenuissimus. Sibth. et Sm. Seidige W.

\section{CALYSTEGIA. $R$. $B r$. Zaunwinde.}

Stg. sehr verlängert, windend; B. pfeilförmig; Vorb. herzförmig; Bt. sehr groß, weiß (höchst selten rosa). Verbr. sepium. (L.) $R . B r^{*}$ ) Gemeine Z. Stg. niederliegend; B. nierenförmig, dicklich; Vorb. eiförmig, stumpf; Bt. blassrosa. 'T.

Soldanella. (L.) R. Br. Meerstrandswinde.

\section{CUSCUTA. L. Flachsseide.}

( Gr. 1, mit kopfiger N.; Bt. einzeln 0. zu 2-3, zu lockeren Aehren o. Trauben zusammengestellt; Röhre der Blkr. walzlich, später eiförmig, doppelt so lang als die Zipfel; meist auf Holzgewächsen, besonders Weiden. $M$. $N$.

lupuliformis. Krock. Hopfenseide.

Gr. u. N. 2

*) C. silvatica (W. K.) Choisy, durch sehr großse Bt. u. aufgeblasene Vorb. ausgezeichnet, soll in $K r$. u. J. vorkommen. 
Bt. deutlich gestielt, in ziemlich lockeren Trauben, wohlriechend; N. kopfig; auf Luzernerklee.

Lingeschleppt (selten).

suaveolens. Sér. Wohlriechende F.

Bt. sitzend o. kurz gestielt, in dichten Knäueln; N. fädlich

Stg. unverzweigt; Blkrröhre fast kugelig, doppelt so lang als die Zipfel; auf Lein. Verbr.

Epilinmm. Weihe. Echte F.

Stg. ästig; Blkrröhre so lang o. kürzer als die Zipfel

Gr. so lang o. kürzer als der Frkn.; Schuppen der Blkrröhre angedrückt, aufrecht. Verbr.

Europaea. L. Europäische F.

Gr. länger als der Frkn.; Schuppen der Blkrröhre meist zusammenneigend ..................

( Blkrröhre kurzglockig, kürzer als die Zipfel; Bt.

5 weiß. Südt. J............alba. Presl. Weiße F. Blkrröhre walzlich, so lang als die Zipfel....... 6

Bt. sitzend 0 . sehr kurz gestielt ............. 7

Btstiele ungefähr so lang als der K.; Bt. verhältnissmäßig groß, in reichblütigen Knäueln; auf Klee. Verbr............Trifolii. Bab. Kleeseide.

Bt. meist rosa; Blkr. den K. überragend. Verbr.

Epithymum. Murr. Quendelseide.

7 Bt. weiß, in sehr kleinen, aber vielblütigen Knäueln; K. u. Blkr. ziemlich gleich lang. J.

Palaestina. Boiss. Palästinische F.

LXXX. Familie. Polemoniaceae. Sperrkrautgewächse.

Stauden o. Kräuter mit ungetheilten o. fiederschnittigen, schraubig gestellten B., ohne Nebenb. Bt. zwittrig, regelmäßig o. etwas unregelmäßig. K. glockig, 5 spaltig. Blkr. glockig-radförmig o. stieltellerförmig, mit 5 Zipfeln. Sttb. 5, der Blkrröhre eingefügt. Frkn. 1, oberständig, 3fächerig, mit einer 0. häufiger mehreren Samenknospen in jedem Fache. Gr. 1; N. 3. Fr. eine 3 klappige, mehrsamige Kapsel. S. mit Nährgewebe.

\section{Gattungen.}

Einjähriges Kraut; B. ungetheilt 0 . höchstens eingeschnitten-gesägt; Blkr. stieltellerförmig, gelblich 0 . fleischroth................. ('ollomia. I. Staude; B. fiederschnittig; Blkr. glockig-radförmig, blau 0 . weiß............... Polemoninm. II. 
Arten.

I. COLLOMIA. Nutt. Kollomie.

B. länglich-lanzettlich 0 . eilanzettlich, am Rande rauh. B. (verv.)

grandiflora. Dougl. Großblütige K.

\section{POLEMONIUM. $L$. Sperrkraut.}

Stg. oben drüsig-flaumig; Bfiedern eilanzettlich, zugespitzt. Verbr. (oft nur cult. u. verw.)

coeruleum, L. Blaues s.

Anmerkung. Verschiedene Arten der Gattung Phlox (durch gegenständige 0 . wirtelige B. ausgezeichnet) werden oft cultivirt, und kommen manchmal halb verwildert vor.

LXXXI. Familie. Borragineae. Boretschgewächse.

Kräuter o. Stauden, selten Halbsträucher mit ungetheilten und sehr oft auch ganzrandigen, schraubig gestellten (selten theilweise gegenständigen) B., ohne Nebenb. Bt. zwittrig, regelmäßig, seltener etwas unregelmäßig. Kb. 5 , meist mehr 0 . weniger verwachsen. Blkr. verwachsenblättrig, 5spaltig 0. 5zähnig (im Schlunde oft mit Deckklappen). Stb. 5, der Blkrröhre eingefügt. Frkn. oberständig, entweder einer und dann vierfächerig mit einer Samenknospe in jedem Fache, oder 4 einfächerige Frkn. mit je einer Samenknospe. Gr. 1; N. 1-2. Fr. nicht aufspringend, sondern in (2 bis) 4 Theilfr. zerfallend. S. meist mit spärlichem Nährgewebe.

\section{Gattungen.}

Die ganze Pfl. kahl (höchstens die B. warzig und

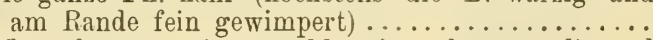
$\mathrm{Pfl}$. mehr 0. weniger rauhhaarig, seltener anliegend

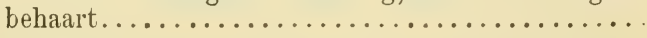

Blkr. walzlich-glockig, 5 zähnig, ohne Deckklappen, gelb, oft violett 0 . braun gefleckt. Cerinthe. XVII.

2 Blkr. stieltellerförmig, 5 spaltig, mit Deckklappen, meist himmelblau mit gelben Deckklappen, selten weiß 0 . hellrosa...............Myosotis. XIII.

Frkn. 1 mit dem Gr. an der Spitze, bei der Reife in 4 Theilfr. sich spaltend; Blkr. trichterig mit faltigem Saume; Deckklappen fehlen.

Heliotropium. I.

Frkn. 4, oft am Grunde verwachsen, mit dem Gr. in der Mitte .................... 4

Blkr. regelmäßig .................. 5

4 Blkr. etwas unregelmäßig, trichterig o. glockig, mit

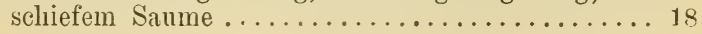


K. mit 2 kleinen Zähnchen zwischen je 2 Zipfeln, zur Zeit der Frreife vergrößert und flachgedrückt.

K. ohne Zähnchen zwischen den Zipfeln, zur Zeit der Frreife nicht flachgedrückt .............

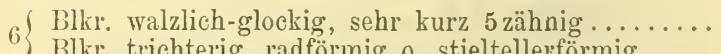

Blkr. trichterig, radförmig 0 . stieltellerförmig .....

Blkr. ohne Deckklappen; Theilfr. am Grunde flach, ohne Ring; Stauden o. Kräuter ..Onosma. XVI. Blkr. mit pfriemlichen, zusammenneigenden Deck-

7 klappen; Theilfr. am Grunde ausgehöhlt und mit einem gedunsenen Ringe umgeben; Stauden.

Symphytum. VII.

$8\{$ Theilfr. mit hakigen Weichstacheln besetzt; Kräuter 9

Theilfr. ohne hakige Weichstacheln .......... 10

Theilfr. pyramidenförmig-3 kantig; Bt. sehr klein, himmelblau ..................... Theilfr. eiförmig, flachgedrückt; Bt. mittelgroß, trübblutroth o. hellblau mit blutrothen Deckklappen.

Cynoglossum. III.

Theilfr. mit dem Rücken an den Gr. angewachsen, 10 napfförmig ausgehöhlt; Blkr. blau mit weißen o. Theilfr. nicht an den $\mathrm{Gr}$. angewachsen ..........

Theilfr. am Grunde mit einem gedunsenen, gerieften Ringe umgeben und innerhalb des Ringes ausgehöhlt ....................... 12 Theilfr. am Grunde nicht ausgehöhlt......... 14

Blkr. radförmig; Deckklappen ausgerandet; Stf. 2 spaltig, der innere Schenkel die A. tragend.

Blkr. trichterig; Deckklappen nicht ausgerandet 0 . fehlend ......................... 13

(Schlund der Blkr. offen, bärtig, kaum verengert; 13 Bt. tief purpurbraun ............ Nonnea. XI. Schlund der Blkr. durch stumpfe kapuzenförmige Deckklappen geschlossen .........Anchusa. IX.

${ }_{14}$ K. prismatisch-5 kantig, 5 zähnig; Schlund der Blkr. 14 ohwe Deckklappen, gebärtet...Pulmonaria. XII. K. röhrig, nicht 5 kantis $\ldots \ldots \ldots \ldots \ldots \ldots \ldots \ldots$ 15 
Alle o. doch die oberen Btstiele ohne Tragb.; Blkr. stieltellerförmig 0. trichterig, Röhre kurz, Schlund durch kahle, meist gelb gefärbte Deckklappen fast ganz verschlossen; Btfarbe himmelblau, selten rosa

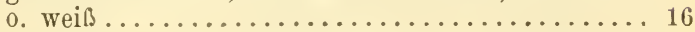

Am Grunde jedes Btstieles ein Tragb. ; Blkr. trichterig, der Schlund mit behaarten Falten o. Deckklappen, aber nicht verschlossen.................

Theilfr. unberandet, vorne convex, hinten stumpfgekielt; N. einfach kopfig; Deckklappen einfach, kurz .................. Iyosotis. XIII.

Theilfr. 3 kantig, vorne flach und mit vorspringendem Rande umgeben; N. 4 knotig; Deckklappen 2lippig; kleine dichtrasige Alpenfl. ......Eritrichium. V.

Stb. aus der Blkr. herausragend; Halbstrauch.

Stb. in der Blkrröhre eingeschlossen; Stauden oder Kräuter.............. Lithospermum. XV.

Blkr. ohne Deckklappen; Theilfr. am Grunde nicht ausgehöhlt ............... Echium. XVIII.

Blkr. mit behaarten Deckklappen; Theilfr. am Grunde ausgehöhlt und von einem gedunsenen Ringe umgeben .................................

\section{Arten.}

\section{HELIOTROPIUM. $L$. Wodanskraut.}

Einjährig; B. eiförmig, ganzrandig. filzig-rauh; Fr.kelche sternförmig-abstehend; Bt. weiß 0 . hellviolett. M. N. Kr.J. T.

Europaeum. L. Europäisches W.

\section{OMPHALODES. Inuch. Nabelnuss.}

Kraut; Bt. blattachselständig, klein, himmelblau mit gelben Deckklappen. B. M. N. O. S. K. St.

scorpioides. (Hnke.) Schrt. Kleinblütige N.

Zarte Staude; Bt. ohne Tragb., ansehnlich, azarblau mit weißen Deckklappen.

Südst. K. Kr. (sonst. cult. u. verw.)

verna. Mnch. Frühlings-N.

\section{CYNOGLOSSUM. L. Hundszunge.}

B. zerstreut-behaart, oberseits fast kahl, glänzend, unterseits etwas rauh; Bt. trübblutroth. N. Südst. J... Germanicum. Jacq. Deutsche H. B. graulich-feinfilzig, die oberen aus fast herzförmigem, halbumfassendem Grunde lanzettlich........... 
Untere B. elliptisch; Bt. trübblutroth (selten weiß), mit purpurnen Deckklappen. Verbr.

officinale. $L$. Gemeine $H$.

Untere B. länglich; Bt. hellblau mit purpurnen Adern, Deckklappen blutroth. Südt. J.

pictum. Ait. Geäderte H.

\section{LAPPULA. Gilib. Igelsame.}

Frstiele aufrecht; Theilfr. am Rande mit 2 Stachelreihen; B. anliegend behaart. Verbr.

echinata. Gilib. Gemeiner J.

Frstiele zurückgebogen; Theilfr. am Rande mit einer Stachelreihe; Behaarung der B. mehr abstehend. Verbr. (fehlt $K r . J$.

deflexa. (Wahlbg.) Garcke. Herabgebogener J.

\section{ERITRICHIUM. Schrad. Himmelsherold.}

B. länglich-lanzettlich, zottig; Btstände $3-6$ blütig, meist dicht über den B.; Bt. lebhaft blau.

A. v. T. S. K. St. $K r$. I.

Terglonense. (Hacqu.) Kern. Alpen-H.

\section{ASPERUGO. L. Scharfkraut.}

Einjähriges Kraut; Stg. kantig, sehr rauh; Bt. blattachselständig, klein, blauviolett. Verbr:

procumbens. $L$. Gemeines Sch.

\section{SYMPHYTUM. $L$. Beinwurz.}

Wz. spindelförmig, ästig; obere B. herablaufend; Bt. violett, rosa 0. weis. Verbr. $u . h f g$.

officinale. L. Gemeine B.

Wst. knollentragend, o. schief, fleischig und stellenweise verdickt; obere B. halb- 0 . kaum herablaufend Wst. knollentragend, mit Ausläufern; Blkr. fast walzlich, 5spaltig, Zipfel aufrecht; Bt. weißlich mit hellgelbem Saume. $J$.

bulbosum. Schimp. Kriechende B.

Wst. schief, fleischig, stellenweise knotig verdickt; Blkı. trichterförmig-röhrig, 5 zähnig, mit zurückgekrümmten Zähnen; Bt. blassgelb. Terbr.

tuberosum. L. Knollige B.

Anmerkung. Der Bastart S. officinale $X$ tuberosum ist selten.

\section{BORRAGO. L. Boretsch.}

Einjährig; die unteren B. elliptisch, stumpf, nach dem Grunde verschmälert; Blkrzipfel eiförmig, zugespitzt; Bt. blau. Cult. u. verw.

officinalis. $L$. Gemeiner B 


\section{ANChUSA. L. Ochsenzmnge.}

Deckklappen länglich, pinselförmig-behaart; Deckb. lineal-lanzettlich; B. glänzend; Bt. groß, azurblau; Deckklappen weiß. (N.) J. Südt.

Italica. Retz. Italienische 0 .

Deckklappen eiförmig, sammtig; Deckb. eilanzettlich

K. fast bis zum Grunde getheilt, seine Zipfel zur Btzeit gegen die Spitze verbreitert; Blkrröhre sehr kurz. N........Barrelieri. Vitm. Barrelier's B.

K. 5spaltig, seine Zipfel gegen die Spitze verschmälert; Blkrröhre walzlich, verlängert.

Verbr............ officinalis. L.*) Gemeine 0 .

\section{LYCOPSIS. $L$. Wolfsauge.}

Blkrröhre in der Mitte gekrümmt; Stg. aufrecht; Tr. beblättert; Bt. himmelblau. Verbr.

arrensis. L. Gemeines W.

Blkrröhre fast gerade; Stg. aufstrebend; Trauben oberwärts nackt; Saum der Blkr. azurblau mit 5 weißen Linien. J. variegata. $L$. Geschecktes W.

\section{NONNEA. Med. Runzelnüsschen.}

B. lanzettlich, ganzrandig, angedrückt-haarig; Saum der Blkr. so lang als die Röhre; Bt. purpurbraun, fast schwarz (sehr selten gelblichweiß).

Sch. MI. B. N. O. St.

pulla. (L.) DC. Schwarzbraunes R.

\section{PULMONARIA. L. Lungenkrảnt.**)}

B. der neben dem blühenden Stg. sich entwickelnden Bbüschel lanzettlich, gegen den Grund sehr allmälig verschmälert, oberseits von dicht stehenden Borsten rauh, drüsenlos; Bt. azurblan, beim Aufblühen röthlich $\ldots \ldots \ldots \ldots \ldots \ldots \ldots \ldots \ldots .2$

B. der neben dem blühenden Stg. sich entwickelnden Bbüschel am Grunde rasch in den Bstiel zusammengezogen, seltener verschmälert, dann aber nebst den Borsten mehr o. weniger reichlich drüsenhaarig ..........................

*) Umfasst mehrere Formen!

**) Zur Bestimmung sind die oft erst nach dem $\mathrm{Ab}$ blühen sich entwickelnden B. der seitlichen Bbüschel erforderlich. 
B. weißlich gefleckt, die der seitlichen Bbüschel sehr lang; Stg. oben beborstet u. mit langen, dic Borsten überragenden Drüsenhaaren reichlich besetzt. St. ............Kerneri. W'ettst. Kerner's L.

2 B. ungefleckt, auffallend schmal; Stg. oben von Borsten sehr rauh, dazwischen mit einzelnen, die Borsten nicht überragenden Drüsenhaaren besetzt. Verbr. (fehlt $S . K$.) angustifolia. L. Schmalblättriges L.

B. der seitlichen Bbüschel lang gestielt, herzeiförmig 0 . eilanzettlich, plötzlich in den Bstiel zusammengezogen, oberseits von dicht stehenden Borsten rauh, fast drüsenlos; Stg. oben von zahlreichen Borsten rauh u. drüsenhaarig; Bt. anfangs

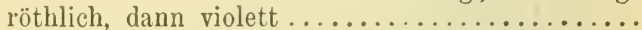

13. del' seitlichen Bbüschel oberseits beborstet u. reichlich drüsenhaarig, kaum rauh; Stg. oben wenig borstig, aber sehr reichlich drüsenhaarig, daher nicht rauh, sondern klebrig ...........

B. weißlich gefleckt, selten ungefleckt; Bspreiten der seitlichen Bbüschel ungefähr so lang als ihre Bstiele. Verbr. u. hfg.

officinalis. L. Gebräuchliches L.

B ungefleckt, selten undeutlich gefleckt; Bspreiten der seitlichen Bbüschel viel kürzer als ihre Bstiele; Behaarung dichter u. weniger steif. Sch. $M$. $N$. obscura. Dum. Dunkles L.

Oberseite der B. mit langen Borsten u. Drüsenhaaren besetzt, außerdem aber dicht von äußerst kurzen Haaren bekleidet $u$. daher fast sammtig weich; Stg. oben kurz drüsenhaarig; Bt. zuerst röthlich, dann violett. Sü̈t.

Vallarsae. Kern. Südtiroler L. Oberseite der B. reichlich borstig u. drüsenhaarig, aber ohne sammtige Behaarung.............

B. meist weißlich gefleckt; Bspreiten der seitlicnen Bbüschel viel länger als ihre Bstiele; Stg. oben mit sehr langen Drüsenhaaren dicht besetzt; $\mathrm{Bt}$. azurblau, beim Aufblühen röthlich. St. K. Kr.J.

Stiriaca. Kern. Steierisches L.

Bt. stets ungefleckt; Bspreiten der seitlichen Bbüschel wenig 0. gar nicht kürzer als ihre Bstiele; Bt. zuerst röthlich, dann violett 0 . blauviolett ...... 
B. grasgrün; obere Stg. halb unfassend u. etwas herablaufend; K. drüsig-klebrig II. von Borsten etwas rauh; A. schwarzviolett. 'T. $S$.

montana. Lej. Berg-L.

B. von dichter Behaarung graugrün; obere Stgb. halb umfassend, nicht herablaufend; K. dicht drüsig u. klebrig, aber nicht rauh; A. gelblich. M. N. St. mollissima. Keru. Weichbaariges L.

A n merkung. Von Bastarten wurden im Gebiete beobachtet: $\mathrm{P}$. angustifolia $X$ officinalis, angustifolia $X$ obscura und officinalis $X$ Stiriaca.

XII. MYOSOTIS. L. Vergissmeinnicht.

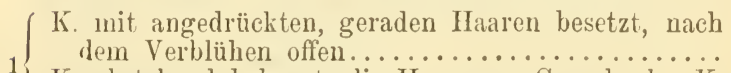
K. abstehend behaart, die Haare am Grunde des K. weit abstehend und hakig-zurückgekrümmt.....

Staude mit schiefem, kriechendem Wst.; Stg. kantig; Stgb. länglich-lanzettlich, ziemlich spitz; Btstiele ohne Tragb. Verbr. u. hfy.

palustris. $\left.(L .)^{*}\right)$ Sumpf-V.

Kraut mit faseriger, absteigender $\mathrm{Wz}_{\mathrm{z}}$; Stg. stielrund; Stgb. lineal-länglich, stumpf; die untersten Btstiele mit Tragb. Verbr.

caespitosa. Schultz. Rasiges V.

$3\{$ Frstiele kürzer als der K.; Kräuter .......... 4

$3\left\{\begin{array}{c}\text { Frstiele so lang } 0 \text {. länger als der } \mathrm{K} \ldots \ldots \ldots \ldots \ldots \ldots \\ 5\end{array}\right.$

Blkrröhre im K. eingeschlossen; die untersten Bt. meist mit 'Tragb.; Bt. sehr klein, himmelblau. Verbr..................

4 Blkrröhre aus dem K. herausragend; alle Bt. ohne Tragb.; Bt. anfangs gelb o. röthlich, dann himmelblau, zuletzt violett. Vcrbr. (fehlt $S . T . K . K r$.) versicolor. (Pers.) Buntes V.

Die unteren Bt. stets mit 'Tragb.; Btstand sehr locker; Bt. selı klein, himmelblau; einjälıriges Kraut. Verbr. (fehlt $O . T$. J.)

sparsiflora. Milian. Zerstreutblütiges $\mathrm{V}$.

Alle Bt. ohne Tragb.

*) M. strigulosa Rehb. ist durch anliegende (nicht abstehende) Behaarung des Stg., M. laxiflora Rchb. durch grobe Bt. und lange Frstiele, M. Rehsteineri Wartm. durch niedrigen, rasigen Wuchs und armblütigen Btstand ausgezeichnet. 
A. länger als die Deckklappen, aus der Blkrröhre herausragend, diese zuletzt doppelt so lang als der K.; Bt. anfangs gelb, dann röthlich, zuletzt

6 blau. Vora. v. N.St. S.

A. kürzer als die Deckklappen, in der Blkrröhre

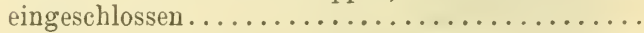

Frkelch offen; Frstiele wagrecht-abstehend, so lang als der K.; einjähriges Kraut. Verbr.

hispida. Schldl. Steifhaariges V.

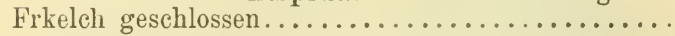

Saum der Blkr. ganz flach; B. grün; Frstiele so lang 0 . wenig länger als der $\mathrm{K} \ldots \ldots \ldots \ldots \ldots \ldots$ Saum der Blkr. concav; B. graulich; Frstiele doppelt so lang als der K. Verbr. u. $h$ fg.

arvensis. (L.) Acker-V.

Stg. verlängert, ästig, weich behaart; Frstände sehr verlängert und locker: Stiel der unteren B. meist kürzer als die Bspreite; K. grünlich. Verbr.

silvatica. Hoffm. Wald-V.

Stg. niedrig, steif-behaart; Frstände kurz; Stiel der unteren B. meist länger als die Bspreite; K. von dichter Behaarung graulich................ 10

Untere Stgb. verkehrt-eiförmig o. länglich, obere eilänglich 0. länglich; Btstand gedrungen.

Geb. (fehlt Sch. MI.) alpestris. Schm. Alpen-V.

10 Untere Stgb. länglich, obere fast lineal, auffallend schmal; Btstand mehr locker; K. größer, tiefer getheilt. $N$. u. A. v. $K r$. J.

suaveolens. W. K. Wohlriechendes V.

\section{MOLTKIA. Lehm. Moltkie.}

B. lineal, arn Rande umgerollt; Bt. blau; Fr. glatt. Vora. v. Sü̈dt.

graminifolia. (Tiv.) Nym. Grasblättrige M.

\section{LithospermuM. $L$. Steinsame.}

(Bt. gelb; einjähriges Kraut mit spatelig-lanzett-

Bt. nicht gelb. Apulum. Vahl. Apulischer St.

Bt. zuerst purpurn, dann azurblau, ansehnlich; Staude mit lanzettlichen B.; Fr. glatt, glänzend.

2 Verbr. (fehlt Sch. O. S. K.)

purpureo-coeruleum. $L$. Blauer St.

Bt. weiß o. grïnlichweiß (selten hellblau) ......... 
Einjähriges Kraut; Frstand sehr locker; Fr. runzeligrauh, bräunlich. Verbr. ... arvense. L. Acker-St.

3 Staude; Frstand ziemlich gedrungen; Fr. glatt, glänzend weiß. Verbr.

officinale. $L$. Gebräuchlicher St.

\section{ONOSMA. L. Lotwurz.}

Die unteren B. mit steifen Borsten besetzt, welche auf sternförmig behaarten Knötchen aufsitzen;

Stg. nur oben 0 . gar nicht verzweigt...........

Die unteren B. mit steifen Borsten besetzt, welche auf kahlen (seltener kurzborstigen) Knötchen aufsitzen; Stg. oft sehr ästig.................

Staude; Blkr. außen flaumig; A. etwas länger als die Stf.*); Frkn. fast sitzend. Südt. $K r$. J.

2 echioides. L. Natterkopfartige L. Halbstrauch; Blkr. kahl; A. etwas kürzer als die Stf. $\left.{ }^{*}\right)$; Frkn. dreimal so lang als sein Stiel.

$J$. (Lussin). stellulatum. W. K. Sternhaarige L.

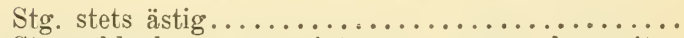

Stg. schlank, unverzweigt 0 . nur ganz oben mit 1 bis 2 kurzen Aesten; Bt. sehr groß, außen kurzborstig. N. Austriacum. Beck. Oesterreichische L. Bt. zuerst wei $\AA$, dann bald blassgelb; Stg. schon im unteren Theile ästig, ohne seitliche Bbüschel; A. am Rande glatt. M. N.

Visianii. Clem. Visiani's L.

Bt. schon beim Aufblühen blassgelb; Stg. erst oberhalb der Mitte ästig, oft von Bbüscheln umgeben; A. am Rande fein gesägt.................

A. dreimal so lang und ebenso breit als die Stf.*); Frkn. dreimal so lang als sein Stiel. $J$.

lingulatum. (Freyn.) Zungenblättrige L.

A. wenig länger und etwas schmäler als die Stf.*); Frkn. fast sitzend. M. N. Südt.

arenarium. $W . K$. Sand-L.

Anmerkung. In Südt. wurde O. arenarium $X$ echioides beobachtet.

\section{CERINTHE. $L$. Wachsblume.}

A. wenig länger als die Stf.; Blkr. ansehnlich, blassgelb und violett, seltener einfärbig blassgelb; B. 1 warzig und am Rande fein gewimpert. $K r . J$. major. L. Große W.

A. 4 mal länger als die Stf.; B. ganz kahl und glatt 2

*) Der an die Blkrröhre angewachsene Theil der Stf. ist nicht mitgerechnet. 
Blkrzipfel aufrecht, pfriemlich, wenig kür'zer als die Röhre; Bt. meist einfärbig citronengelb. Verbr. 2 Blkrzipfel sehr kurz, eiförmig, an der. Spitze zurückgekrümmt; Bt. meist mit 5 purpurnen Flecken. Vora. v. T. Sïdst. $K r$... alpina. Kit. Alpen-W.

\section{ECHIUM. L. Natterkopf.}

Die unteren Btstände gegabelt 0. 3 spaltig; Gr. an der Spitze 2 spaltig; B. lanzettlich; Bt. weis 0 . blassröthlich. $N$. Südt. $K r$. J.

altissimum. Jacq. Hoher N.

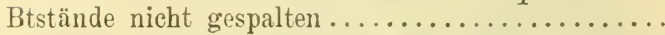

Die oberen B. aus herzförmig-stengelumfassendem Grunde verschmälert, die unteren länglich-lanzettlich; Bt. groh, blauviolett. $J$.

plantagineum. L. Wegerichblättriger $\mathrm{N}$.

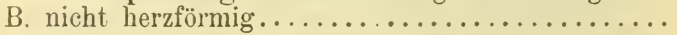

Blkrröhre kürzer als der K.; Gr. 2 spaltig; Stb. abwärts-geneigt, an dem Saume der Blkr. anliegend;

3 Bt. meist blau, seltener rosa 0 . weiß.

Verbr. $u$. $h f y . . . \ldots \ldots$ vulgare. L. Gemeiner N. Blkrröhre länger als der $\mathrm{K} . . . \ldots \ldots \ldots \ldots \ldots$

( Bt. blutroth (selten weiß); Gr. ungetheilt; B. lineal4 lanzettlich. $M . N . K r$. rubrum. Jacq. Rother N. Bt. blau; Gr. an der Spitze 2 spaltig ............

Stg. von dichten kurzen Flaumhaaren graulich und auferdem beborstet; Blkrröhre fast 3 mal so lang als der K.; Bt. mit 5 violetten, heller berandeten Streifen. J.... pustulatum. Sibth. Borstiger N. Stg. abstehend bor'stig; Blkrröhre wenig länger als der K.; Bt. am Grunde weiß. $J$.

parviflorum. Mnch. Kleinblütiger $\mathrm{N}$.

LXXXII. Familie. Verbenaceae. Eisenkrautgewächse.

Stauden 0. Sträucher mit gegenständigen, getheilten o. gelappten B., ohne Nebenb. Bt. zwittrig, etwas unregelmäßig. Kb. 5, stets verwachsen. Blkr. mit walzlich-trichteriger Röhre und schiefem, 5 lappigem, etwas 2 lippigem Saume. Stb. 4, 2 mächtig, der Blkrröhre eingefügt. Frkn. 1, oberständig, 4 fächerig, mit einer Samenknospe in jedem Fache. Gr. 1, oben 2 spaltig 0 . mit 2 lappiger $\mathrm{N}$. Steinfr. mit vierfächerigem, viersamigem Steinkern 0 . in 4 Theilfr. sich spaltend. S. ohne o. mit spärlichem Nährgewebe. 


\section{Gattungen.}

Staude; B. 3 spaltig o. fiederlappig; Fr. in 4 Theilfr. sich spaltend .................. Verbena. I.

Holzgewächse; B. gefingert 5-7 zählig; Fr. mit 4 fächerigem Steinkern.............. Vitex. II.

\section{Arten.}

\section{VERBENA. L. Eisenkraut.}

Bt. klein, blasslila, in schmalen, zuletzt sehr verlängerten Aehren. Verbr.

officinalis. L. Gemeines E.

\section{VITEX. L. Mulle.}

Blättchen lanzettlich, ganzrandig, unterseits filzig; Bt. violett. $J$.......Agnus castus. $L$. Schaf-M.

\section{Familie. Labiatae. Lippenblütler.}

Kräuter, Stauden 0. Halbsträucher, selten Sträucher mit gegenständigen, ungetheilten, seltener getheilten B., ohne Nebenb. Bt. zwittrig 0. vielehig-2 häusig, unregelmä..ig, seltener fast regelmäßig. Kb. 5, stets verwachsen; manchmal treten $\mathrm{z}$ wischen die $\mathbf{5}$ freien Zipfel der $\mathrm{Kb}$. andere Zipfel, wodurch der K. dann mehrzähnig wird. Blkr. mit walzlicher o. häufiger trichterig erweiterter Röhre und ursprünglich 5 spaltigem, aber in der Regel ausgesprochen 2 lippigem, seltener durch Verkümmerung der Oberlippe 1 lippigem 0 . durch Verwachsen der beiden oberen Zipfel fast regelmäßig 4 spaltigem Saume. Stb. 4, 2 mächtig, seltener 2, der Blkrröhre eingefügt. Frkn. 4, oberständig, 1 fächerig, mit 1 Samenkospe (oder 1 4lappiger, 4 fächeriger Frkn. mit 4 Samenknospen). Gr. 1 , oben meist 2 spaltig. Fr. in 4 Theilfr. zerfallend 0.4 von Anfang an getrennte Theilfr. S. ohne o. mit sehr spärlichem Nährgewebe.

\section{Gattungen.}

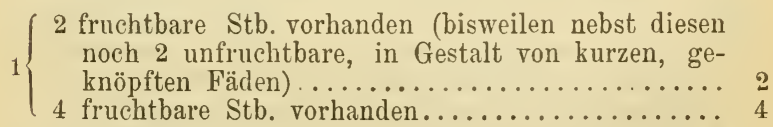

$2\left\{\begin{array}{c}\text { Blkr. trichterförmig, fast regelmäßig } 4 \text { spaltig, der } \\ \text { obere Zipfel ausgerandet; K. } 5 \text { zähnig. }\end{array}\right.$

Blkr. unregelmäळig, rachenförmig; K. 2 lippig.... 3 
Oberlippe der Blkr. 2 spaltig, flach, aufrecht, Unterlippe 3 theilig, Lippen fast gleichlang; B. lineal, am Rande umgerollt .........Rosmarinus. III. (Oberlippe der Blkr. ganzrandig o. ausgerandet, gerade, sichelförmig 0 . helmförmig, Unterlippe 3 spaltig, kürzer als die Oberlippe ..............

A. nierenförmig, 1 fächerig, mit einer halbkreisförmigen Ritze aufspringend und dann ein flaches, kleisrundes Tellerchen darstellend; B. lineal 0. lanzettlich, am Rande umgerollt; Btquirle in unterbrochenen Aehren.......... Lavandula. VI.

A. anders gestaltet und anders aufspringend ......

$\mathrm{Blkr}$. trichterig, fast regelmäßig 4 spaltig, der obere Zipfel oft ausgerandet..........Mentha. XXIX. Blkr. ausgesprochen 2 lippig o. durch Verkümmerung

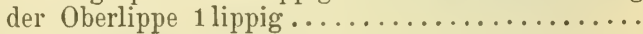

Blkr. 1 lippig, die Oberlippe fehlend o. äußerst kurz; K. 5 zähnig

Blkr. 2 lippig

0. 5 spaltig . .

Oberlippe der Blkr. aus 2 kleinen, kurzen Läppchen bestehend, Unterlippe 3 spaltig ........Ajuga. I.

Oberlippe der Kr. fehlend, an ihrer Stelle eine Spalte; Unterlippe 5 spaltig........... Teucrium. II.

Stb. nicht gleichlaufend, entweder oberwärts auseinander weichend, o. unter der Oberlippe der

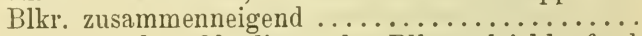

Stb. unter der Oberlippe der Blkr. gleichlaufend, dicht nebeneinander gestellt (nur nach dem Verblïhen bisweilen auswärts gebogen) ......... 16

K. 5 zähnig 0 . halbirt und auf einer Seite fast bis

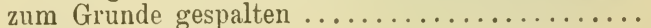

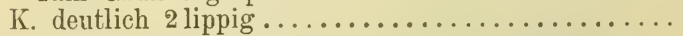

Stl, unter der Oberlippe zusammenneigend; K. röhrig-glockig 0 . walzlich-röhrig.

\section{Satureja. XXIII.}

Stb. oberwärts auseinander tretend ........... 11

K. 15 nervig; Oberlippe der Blkr. 2 spaltig; Stb. am Grunde aufsteigend, dann auseinander tretend.

Hyssopus. XXIV.

K. 10-13 nervig; Oberlippe der Blkr. ausgerandet; Stb. vom Grunde an auseinander tretend .......

K. halbirt, auf einer Seite fast bis zum Grunde gespalten; B. elliptisch, graufilzig; Bt. weiß.

K. gleichmäßig 5 zähnig; Stauden mit eiförmigen, grünen B.; Bt. hellyurpurn, seltener weiß. 
Blkr. innen unterhalb der Einfügung der Stb. mit einem Haarringe; Oberlippe gerade, 2 spaltig.

Horminum. XXI.

Blkr. innen ohne Haarring ................. 14

Stb. oberwärts auseinander tretend; Oberlippe der 14 Blkr. gerade, ausgerandet ..... Thymus. XXVII. Stb. unter der Oberlippe der Blkr. zusammenneigend 15

Blkrröhre unterhalb der Mitte aufsteigend-zurückgebogen; Oberlippe etwas gewölbt, mit flachem 15 Rande..................... Melissa. XXII. Blkrröhre gerade 0 . wenig gebogen; Oberlippe flach.

Satureja. XXIII.

$16\{$ Oberlippe der Blkr. flach u. gerade........... 17

Oberlippe der Blkr. gewölbt................. 21

Stb. u. Gr. in der Blkrröhre verborgen ......... 18

17 Stb. u. Gr. hervortretend, unter der Oberlippe gleichlaufend ............................

Einjährige, zottige Kräuter; Theilfr. abgerundetstumpf; K. 2 lippig............. Sideritis. VIII. Filzige Stauden; Theilfr. an der Spitze mit einer 3 eckigen Fläche abgeschnitten; K. 5-10 zähnig.

Marrubium. VII.

A. paarweise in ein Kreuz gestellt..............

19 A. gleichlaufend, nicht kreuzständig; Unterlippe der Blkr. mit abgerundetem, ausgehöhltem Mittelzipfel.

Nepeta. IX.

Die 2 oberen Stb. länger; K. röhrig, 5 zähnig; B. herz- o. nierenförmig; Bt. meist klein u. violett.

Glechoma. X.

Die 2 unteren Stb. länger; K. weit glockig, lappig2 lippig; B. eiförmig 0. herz-eiförmig; Bt. ansehnlich, weiß, purpurn 0. gescheckt..Melittis. XIII.

$21\{$ Röhre der Blkr. innen ohne Haarleiste...$\ldots \ldots$.

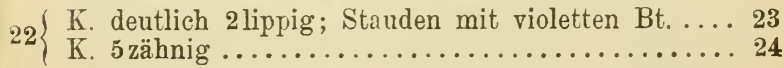

Oberlippe des K. aus einem großen Zahne, Unterlippe aus 4 viel kleineren Zähnen gebildet; die $\mathbf{2}$ oberen Stb. länger. ....... Dracocephalum. XI.

23 Oberlippe des $K$. auf dem Rücken mit einer aufgerichteten hohlen Schuppe, wie die Unterlippe ungetheilt; die 2 unteren Stb. länger:

Scutellaria. V. 
Die seitlichen Zipfel der Unterlippe der Blkr. klein, zahnförmig 0 . fehlend, der mittlere verkehrt-herz-

24 förmig............................. XVI

Die seitlichen Zipfel der Unterlippe der Blkr. deut-

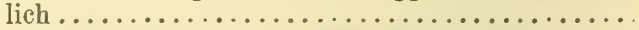

Zipfel der 3 spaltigen Unterlippe der Blkr. fast 4 eckig, der mittlere länger, meist breiter $u$. am Grunde mit 2 hohlen, kegelförmigen Zähnchen besetzt.

Galeopsis. XV.

Zipfel der Unterlippe der Blkr. anders gestaltet, der mittlere ohne hohle Zähnchen ...............

Großes Kraut; Scheinquirle zu langen, sehr lockeren, beblätterten Aehren zusammengestellt; Theilfr. an der Spitze mit einer 3 eckigen Fläche abgeschnitten.

Leonurus. XVII.

Stauden; obere Scheinquirle zu gedrungenen, oft fast kopfigen Aehren zusammengestellt; Theilfr. abgerundet-stumpf.................Stachys. XIX.

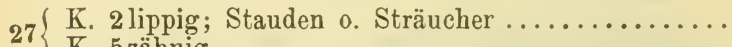

Strauch; Scheinquirle 2 blütig; K. zur Zeit der Frreife offen .................

28 Kleine Stauden; Scheinquirle mehrblütig, dicht aneinander gedrängt; $\mathbf{K}$. zur Zeit der Frreife geschlossen..........................

Der hintere Griffelast kürzer als der vordere; die 2 oberen Stb. am Grunde mit Anhängsel; Theilfr. mit einer 3 eckigen Fläche abgeschnitten.

Phlomis. XIV.

Griffeläste ungefähr gleich lang; Stb. ohne Anhängsel 30 Unterlippe der Blkr. entweder obne o. mit sehr kleinen, zahnförmigen Seitenzipfeln o. 3 spaltig

30 mit spitzen Zipfeln. ...........Lamium. XVI. Unterlippe der Blkr. 3 spaltig mit stumpfem 0 . ausgerandetem Mittelzipfel

Unterlippe der Blkr. zusammengerollt, einen lanzettlich-pfriemlichen Zapfen bildend; große Staude

31 mit $3-7$ spaltigen B. .........Leonurus. XVII. Unterlippe der Blkr. nicht zusammengerollt; B. ungetheilt

Stb. nach dem Verblühen gerade; Mittelzipfel der Unterlippe der Blkr. verkehrt-herzförmig.

Ballota. XVIII.

32 Die unteren Stb. nach dem Verblühen zusammengedreht und auswärts zurückgebogen; Mittelzipfel der Unterlippe der Blkr. verkehrt-eiförmig o. verkehrt-herzförmig.............. Stachys. XIX. 
Arten.

1. AJUGA. L. Günsel.

Bt. blau, ausnahmsweise auch rosa 0 . weiß, in 6bis 12 blütigen Scheinquirlen; B. ungetheilt, länglich o. verkehrt-eiförmig; kleine Stauden .......

1 Bt. gelb, in 2 blütigen Scheinquirlen; B. 3 spaltig, mit linealen Zipfeln; einjähriges Kraut.

Verbr. (fehlt Sch. S. K.)

Chamaepitys. (L.) Schreb. Acker-G.

Wst. kriechende, beblätterte Ausläufer treibend; Stg. 2 reihig behaart 0 . fast kahl. Verbr. $u$. $h f g$.

reptans. $L$. Kriechender G.

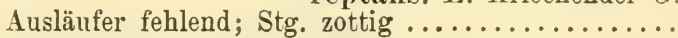

Die unteren Deckb. meist 3 lappig, die oberen kürzer als die Scheinquirle; Pfl. ziemlich schlank; Bt. verhältnissmäßig groß, meist dunkel azurblau, beim Trocknen nicht verbleichend. Verbr.

Genevensis. L. Berg-G.

Alle Deckb. etwa doppelt so lang als die Scheinquirle; Pfl. niedrig und gedrungen, fast pyramidenförmig; Bt. kleiner, heller blau, beim Trocknen verbleichend. Verbr. (fehlt Sch. M. J.)

pyramidalis. $L$. Gulden-G.

Anmerkung. Die 3 blaublühenden Arten bilden untereinander Bastarte.

\section{TEUCRIUM. L. Gamander.}

K. 2 lippig, obere Lippe eiförmig, ungetheilt, untere 4 zähnig; B. eiförmig 0 . länglich mit herzförmigem Grunde, runzelig, flaumig; Bt. blass grünlichgelb, in verlängerten, einseitswendigen Scheinähren. T. S. O. Südst. Kr.

Scorodonia. L. Salbeiblättriger $G$.

K. 5 zähnig; Bt. in Scheinquirlen 0. Köpfchen.....

Bt. in 2-6 blütigen Scheinquirlen, diese blattachselständig, von einander entfernt, 0 . in eine end-

2 ständige Scheintraube zusammengestellt........ Scheinquirle in ein endständiges Köpfchen zusammen-

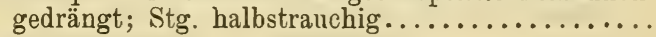

Scheinquirle blattwinkelständig, entfernt; Deckb. den Stgb. gleichgestaltet; Bt. hellpurpurn .........

3 Die meist 6 blütigen Scheinquirle in eine endständige Tr. zusammengestellt; wenigstens die oberen Deckb. von den Stgb. verschieden ............. 
Einjähriges Kraut; B. doppelt-fiederspaltig-geschlitzt; Scheinquirle $2-6$ blütig; Stg. klebrig-flaumig.

4 Verbr. (fehlt Sch.) .... Botrys. L. Trauben-G.

B. gekerbt-gesägt, nicht fiederspaltig, sitzend; Quirle meist 4 blütig; Stg. wollig-zottig ............

Untere B. länglich, am Grunde abgerundet, die oberen lanzettlich. Verbr. (fehlt Sch. S.)

Scordium. L. Knoblauch-G.

B. eiförmig, die unteren am Grunde fast herzförmig. J. $K r$...scordioides. Schreb. Starkriechender G.

Halbstrauchig; B. keilig-eiförmig, eingeschnittengekerbt; Stg. liegend, Aeste aufstrebend; Bt. purpurn. Verbr. (fehlt Sch.)

Chamaedrys. L. Gemeiner G.

Strauchig; B. fast 3 eckig-eiförmig, stumpf-gekerbt, am Grunde fast abgeschnitten; Bt. gelb. J.

flavum. I. Gelber G.

Köpfehen rundlich 0. oval, gestielt; Stg. aufstrebend, filzig 0. haarig; B. keilig-länglich o. lineal, gekerbt, ganz filzig, am Rande umgerollt. $J$.

Polium. L. Polei-G.

7) Köpfchen ebensträußig; Stg. niedergestreckt; B. lineal-lanzettlich, ganzrandig, unterseits 0 . beiderseits grau. Verbr. (fehlt $B$. Sch.)

montanum. L. Berg-G.

\section{HI. ROSMARINUS. L. Rosmarin.}

Strauch; B. sitzend, lederig, am Rande zurückgerollt; Bt. blassblau. (S̈̈idt.) $J$.

officinalis. L. Echter R.

\section{PRASIUM. L. Klippenziest.}

B. eiförmig, gekerbt-gesägt; Bt. weiß, mit purpurn punktirter Unterlippe. .J. ..majus. $L$. Großer $\mathrm{K}$.

\section{SCUTELLARIA. L. Helmkraut.}

B. aus herzförmigem Grunde länglich-lanzettlich, entfernt gekerbt-gesägt; K. kahl o. etwas flaumig. Verbr. .......... galericulata. $L$. Gemeines H.

B. länglich-lanzettlich, am Grunde beiderseits 1- bis 2 zähnig u. daher fast spießförmig; $K$. drüsigflaumig. B. M. Sch. N. O. St. K. Kr.

hastifolia. $L$. Spießblättriges $\mathrm{H}$.

\section{LA VANDULA. L. Lavendel.}

Halbstrauch; Deckb. rauten-eiförmig, zugespitzt; Bt. violettblau. Südt. J. (N. verw.)

Spica. L. Echter L. 


\section{MARRUBIUMI. $L$. Andorn.}

Kzähne 10, samrnt den Deckb. zottig, von der Mitte an kahl, an der Spitze hakig-zurückgekrümmt; B. eiförmig, filzig, runzelig. Verbr. (fehlt S.)

vulgare. $L$. Gemeiner A.

Kzähne 5, gerade o. wenig gebogen, bis zur Spitze filzig ................................

Pfl. dicht weißfilzig; untere B. breit-eiförmig, obere oval; Scheinquirle reichblütig, fast kugelig. $J$.

candidissimum. $L$. Weisfilziger A.

2 Pfl. graufilzig; untere B. eiförmig, obere länglichlanzettlich; Scheinquirle 6- bis mehrblütig, ziemlich flach. $M . N . K r . J$.

peregrinum. L. Fremder A.

Anmerkung. Zwischen M. peregrinum und M. vulgare kommt ein Bastart vor.

VIII. SIDERITIS. $L$. Gliedkraut.

K. länger als die Blkr., mit 3 spaltiger Oberlippe; Bt. citronengelb, am Rande $u$. an den Lippen meist braun. $M . N$. O....montana. L. Berg-G. $\mathrm{K}$. kürzer als die Blkr., mit eiförmiger, ungetheilter Oberlippe u. 4 zähniger Unterlippe; Bt. weiß, mit rosenrother Oberlippe. $J$.

Romana. L. Römisches G.

\section{NEPETA. $L$. Katzenminze.}

B. beiderseits grasgrün $u$. fast $\mathrm{kahl}$, sitzend 0 . sehr kurz gestielt; Bt. lila 0 . weiß, meist mit purpurn punktirter Unterlippe .....................

1 B. unterseits graufilzig, gestielt; Bt. klein, weiß 0. etwas röthlich mit purpurn punktirter Unterlippe. Verbr. (oft nur verw.) . Cataria. L. Gemeine K. Aeste abstehend; Btstände locker. Südt. $K . K r$. J. violacea. $L$. Violette $K$.

2 Aeste aufgerichtet; Btstände dicht; Pfl. in allen Theilen größer u. kräftiger. B. M. N. St. K. Kr. Pannonica. L. Ungarische $K$.

\section{GLECHOMA. L. Gundelrebe.}

Kzähne 3 eckig-eiförmig, begrannt-zugespitzt, viel kürzer als die Kröhre; Blkrröhre gleich über dem Grunde trichterig erweitert. Verbr. $u$. $h f g$.

hederacea. $\left.L .{ }^{*}\right)$ Gemeine $G$.

Kzähne lanzettlich, allmälig lang begrannt-zugespitzt, die oberen kaum kürzer als die Kröhre; Blkrröhre verlängert; Pfl. höher, kräftiger u. mehr behaart. M. N. O. St. Kr.

hirsuta. $W . K$. Rauhhaarige G.

*) Umfasst mehrere Formen! 


\section{DRACOCEPHALUM. L. Drachenkopf.}

B. lineal-lanzettlich, ungetheilt, ganzrandig. $J$.

Ruyschiana. L. Schwedischer D.

B. fiederig- $5-7$ theilig mit linealen, stumpfen Zipfeln, die oberen 3 theilig 0 . ungetheilt. $B . N$. T.

Austriacum. L. Oesterreichischer D.

Anmerkung. In $B$. u. $M$. wurde das einjährige D. Moldavica L., in $N$. D. thymiflorum verwildert gefunden.

\section{BRUNELLA. L. Brunelle.}

Stb. alle wehrlos, die längeren an der Spitze mit einem kleinen Höcker; Zähne der Oberlippe des K. breit-eiförmig, die der Unterlippe lanzettlich, gewimpert; Bt. meist violett, groß. Verbr. grandiflora. (L.) Grobblütige B.

Die längeren Stb. an der Spitze mit einem dornförmigen Zahne versehen .................

B. ungetheilt; Zähne der Oberlippe des K. sehr kurz, abgeschnitten, die der Unterlippe eiförmig-lanzettlich, schwach-gewimpert; Bt. meist violett.

Verbr. $u$. $h f g$........vulgaris. L. Gemeine B.

B. meist fiederspaltig; Zähne der Oberlippe des K. breit-eiförmig, zugespitzt-begrannt, die der Unterlippe lanzettlich-pfriemlich, kammförmig-gewimpert; Bt. meist gelblichweiß. Verbr. (fehlt Sch. S.)

laciniata. $L$. Weiße $B$.

Anmerkung. Die 3 Arten bilden untereinander Bastarté.

\section{MELITTIS. $L$. Inmenblatt.}

Staude; Stg. rauhhaarig; Scheinquirle $2-6$ blütig. Verbr. (fehlt $S$.)

Melissophyllum. L. Melissenblättriges I.

\section{PHLOMIS. L. Brandkraut.}

Hohe Staude; Grundb. eiförmig, am Grunde tief herzförmig, gekerbt; Bt. rosa. $M . N$.

tuberosa. $L$. Knolliges B.

\section{GALEOPSIS. $L$. Hanfnessel.}

Der Stg. unter den Gelenken nicht verdickt, voll ab-

wärts angedrückten, weichen Haaren flaumig .... 2

Der Stg. unter den Gelenken verdickt ......... 4 
( B. lineal-lanzettlich, länglich-lanzettlich 0 . eilänglich; Bt. purpurn (selten weiß), mit einem gelblich-weißen, purpurn gefleckten Hofe auf der

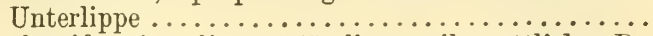
2 Stgb. eiförmig, die astständigen eilanzettlich; Bt. gelblichweiß, mit einem schwefelgelben Hofe auf der Unterlippe; B. seidenhaarig.

B. S. T. K. Sïdst. $K r$.

dubia. Leers. Gelblichweiße H.

B. eilänglich 0 . länglich-lanzettlich, rasch in den Bstiel zusammengezogen, grob-gesägt; Kzähne wenig ungleich, flach. Verbr.

Ladanum. L. Acker-H.

B. lanzettlich o. lineal-lanzettlich, nach dem Grunde verschmälert, ganzrandig 0 . mit wenigen Sägezähnen; Kzähne ungleich, rinnig. Verlr.

angustifolia. Ehrh.*) Schmalblättrige $\mathrm{H}$.

$4\{$ Blkrröhre so lang als der K. o. kürzer ........ 5

Blkrröhre länger als der K. ............ 6

Mittelzipfel der Unterlippe der Blkr. abgerundet 0. stumpflich; Bt. hellpurpurn o. weiß, mit einem schwefelgelben, purpurn gescheckten Hofe auf der Unterlippe; Stg. borstig und drüsenhaarig.

5 Verbr. u. hfg........Tetrahit. L. ${ }^{* *}$ ) Große H. Mittelzipfel der Unterlippe ausgerandet; Bt. klein, rosenroth, Mittelzipfel dunkel-purpurn o. violett mit weiblichem Rande, am Grunde mit 2 gelben Flecken; Stg. drüsenlos. Verbr.

bifida. В̈̈ии. Ausgerandete $\mathrm{H}$.

Stg. steifhaarig; Blkr. von schwefelgelber Grund-

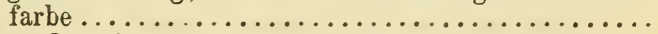
Stg. flaumig, unter den Gelenken steifharig; Bt. purpurn, Unterlippe heller, purpurn gefleckt, Röhre weißlich, oberwärts bräunlichgelb (selten die Bt. von weißer Grundfarbe). Verbr.

pubescens. Bess. Flaumige H.

Mittelzipfel der Unterlippe ganz violett, weißlich berandet. Verbr. u. $h f g$. speciosa. Mill. Bunte H.

7 Mittelzipfel der Unterlippe mit violetter Zeichnung; Behaarung weicher; Bt. kleiner. T. $K$.

Murriana. Borb. et Wettst. Murr's H.

*) G. canescens Schult. ist durch dichte grauliche, fast filzige Behaarung ausgezeichnet.

**) Umfasst mehrere Formen! 
Anmerkung. Ton Bastarten wurden im Gebiete beobachtet: G. speciosa $\times$ Tetrahit, pubescens $X$ Tetrahit, bifida $X$ speciosa und pubescens $X$ speciosa.

\section{LAMIUM. L. Taubnessel.}

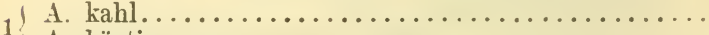

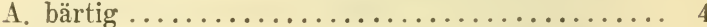

(Bt. groß, trübpurpurn, mit weißlicher Blkrröhre; J. 2 breit-eiförmig, zugespitzt, doppelt tief-gesägt.

Südt. K. Südst. Kr. .J. Or rala. L. Großblütige 'T' Bt. mittelgroß, gelb, oft bräunlich gezeichnet......

B. eiförmig, die oberen wenig 0 . gar nicht über die Scheinquirle hinausragend; Bt. blassgelb.

B. M. Sch. (N.?)

vulgare. (Pers.) Fritsch. Blasse Goldnessel.

3 B. schmäler, die oberen lanzettlich, lang zugespitzt und weit über die Scheinquirle hinausragend; Bt. hellgoldgelb, bräunlich gezeichnet. Verbr.

luteum. (Huds.) Krock. Echte Goldnessel.

Einjährige Kräuter mit kleinen Bt.; Blkrröhre ge-

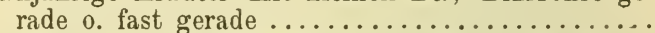
Stauden mit ansehnlichen Bt.; Blkrröhre gekrümmt, über dem Grunde bauchig erweitert ..........

B. rundlich-nierenförmig, stumpf, die oberen umfassend, lappig-gekerbt; Kröhre rauhhaarig; Blkrröhre innen ohne Haarleiste. Verbr.

amplexicaule. $L$. Acker-T:

B. herzeiförmig, gestielt, die oberen spitz, gekerbt; Kröhre kahl, nur die Kzähne behaart; Blkrröhre innen über dem Grunde mit einer Haarleiste.

Verbr. $u$. hfg....... purpureum. L. Kleine 'T'.

Bt. hellpurpurn, seltener blassrosa o. weiß; Haarleiste im Inneren der Blkrröhre quer gestellt; Pollen dunkelgelb. Verbr. u. $h f g$.

maculatum. $L$. Gefleckte T.

Bt. gelblichweiß; Haarleiste im Inneren der Blkrröhre schief gestellt; Pollen blassgelb. Verbr.

album. $L$. Weiße T'.

Anmerkung. Bastarte sind in der Gattung Lamium selten. Im Gebiete wurden L. amplexicaule $X$ purpureum und L. album $X$ maculatum beobachtet. 


\section{LEONURUS. L. Löwenschwanz.}

Die unteren B. handförmig-5 spaltig, eingeschnittengezähnt, die oberen 3 lappig, am Grunde keilig, oft mit ganzrandigen Lappen; Bt. rosa, mit punktirter Unterlippe; die 2 unteren Stb. nach dem Verblühen auswärts gebogen. Verbr.

Cardiaca. $L$. Gemeiner L.

B. ungetheilt, länglich, grob gesägt; Bt. rosa; die 2 unteren Stb. nach dem Verblühen nicht auswärts gebogen. Verbr. (fehlt $S . T$. $K r$.)

Marrubiastrum. L. Katzenschwanz.

\section{BALLOTA. L. Stinkandorn.}

K. 10 zähnig; B. herzeiförmig, spitz; Pfl. filzig1 zottig. J.........acuta. (Mnch.) Briq. Felsen-St. K. 5 zähnig . . . . . . . . . . . . . . . . Kzähne eiförmig 0 . dreieckig, begrannt-zugespitzt; $B$. meist länger als breit. Verbr.

Kzähue abgerundet-eiförmig, plötzlich in eine kurze Stachelspitze verschmälert; B. ungefähr so lang als breit. N. O. St. T. J... alba. L. Weißer St.

\section{STACHYS. L. Ziest.}

Blkrröhre innen mit einer Haarleiste; die 2 unteren Stb. nach dem Verblühen auswärts gebogen.....

Blkrröhre innen ohne Haarleiste; die 2 unteren Stb. nach dem Verblühen nicht auswärts gebogen.... 12

(Scheinquirle vielblütig; Vorb. so lang 0 . wenig

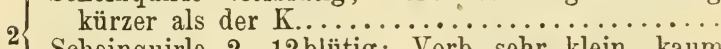

Scheinquirle 2-12blütig; Vorb. sehr klein, kaum

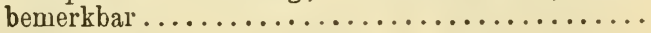

Stg. rauhhaarig, oben drüsig; B. gestielt, ei-herzförmig, spitz, gesägt; Bt. röthlich, seltener gelblich. Verbr. .............. alpina. L. Alpen-Z. Stg. wollig o. filzig, nie drüsig; die oberen B.

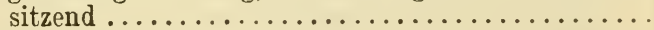

Stg. dicht-wollig-zottig; B. eiförmig-herzförmig, gekerbt, wollig-filzig, die oberen lanzettlich. Verbr. Germanica. L. Deutscher Z.

4 Stg. wollig-filzig; B. länglich, am Grunde abgerundet 0 . etwas herzförmig, kleingekerbt, filzig, die oberen fast 3 eckig-eiförmig. $K r$. J.

Italica. Mill. Italienischer Z.

Bt. gelblich-weiß 
Einjähriges Kraut; B. ei-herzförmig, stumpf, gekerbt, die obersten sitzend, eiförmig-länglich, begrannt; K. fast so lang als die Blkr.; Stg. steifhaarig; Bt. hellpurpurn o. rosa.

B. M. Sch. N. T. Südst. $K r$.

arvensis. $L$. Acker-Z.

Stauden; B. spitz o. zugespitzt; Blkr. doppelt so lang

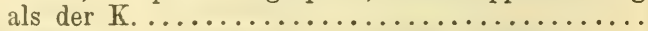

Stg. rauhhaarig, oberwärts ästig und drüsenhaarig; B. gestielt, breit-ei-herzförmig, gesägt, rauhhaarig; Bt. braun-purpurn, Unterlippe mit weißen, geschlängelten Streifen. Verbr. silvatica. L. Wald-Z. Stg. steifhaarig, Haare abwärts gebogen; B. aus herzförmigem Grunde lanzettlich, spitz, gekerbtgesägt, flaumig, die unteren kurz gestielt, die oberen halbumfassend; Bt. hellpurpurn. Verbr.

palustris. $L$. Sumpf-Z.

B. kahl, gestielt, gekerbt-gesägt, die unteren ovallänglich, die obersten lanzettlich, kurz-stachelspitzig; Scheinquirle 2-6 blütig; 1 jähriges Kraut. Verbr. . ............. anmua. L. Jähriger Z.

B. behaart 0. filzig-zottig; Quirle 6-10 blütig.....

$9 \begin{aligned} & \text { B. sammt dem oberen Theile des Stg. und den } K \text {. } \\ & \text { filzig-zottig, gestielt, oval-länglich, gekerbt, stumpf. }\end{aligned}$

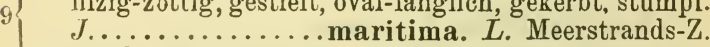

B. rauhhaarig 0 . zerstreut-behaart .......... 10

Einjähriges Kraut; B. eiförmig, stumpf, die unteren am Grunde herzförmig; K. weit glockig, mit breit eiförmigen, stachelspitzigen Zähnen. $J$.

10 spinulosa. Sibth. et Sm. Stacheliger Z.

Stauden; B. lanzettlich o. länglich, die obersten eiförmig, zugespitzt; K. röhrig-glockig, mit zuge-

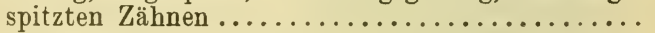

K. rauhhaarig; B. gekerbt, die obersten begrannt, ganzrandig; Stg. aufrecht 0 . aufstrebend. Verbr. recta. $L$. Gemeines Beschreikraut.

11 K. kurzhaarig; B. entfernt-gekerbt o. ganzrandig, die astständigen lineal, die obersten stachelspitzig; Stg. ausgebreitet 0 . aufstrebend. $K r$. J.

subcrenata. Vis. Dalmatinisches Beschreikraut.

Blkr. purpurn (sehr selten weiß), ihre Röhre aus

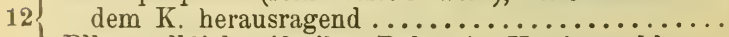
13

Blkr. gelblichweiß, ihre Röhre im K. eingeschlossen 15

K. glockig-röhrig, scheinbar aderlos; Stb. kürzer als die halbe Oberlippe der Blkr.............. 14

13 K. verlängert röhrig, netzig-aderig; Stb. fast so lang als die Oberlippe der Blkr. Vora. v. Südt. $K$. $K r$. densiflora. Benth. Dichtblütiger Z. 
Scheinähre dichtblütig, unten oft unterbrochen; obere B. verlängert-eilanzettlich; blüht im Frühsommer. Verbr.

officinalis. (L.) Trev.*) Gemeine Flohblume. 14 Scheinähre schlank, lockerblütig, meist unterbrochen; obere B. lineal-lanzettlich; Grundb. sehr lang gestielt; blüht im Spätsommer. $J$.

serotina. (Host.) Fritsch. Spätblühende Flohblume.

Scheinähre kurz und dick, dichtblütig; K. netzigaderig; Oberlippe der Blkr. stumpf. Vora. v. Siidt. Alopecurus. (L.) Benth. Fuchsschwanz-Z. 15 Scheinähre walzlich, lockerblütig; K. nervig-berippt, nicht netzaderig; Oberlippe der Blkr. 2 lappig. A. и. Vora.

Jacquini. (Gren. et Godr.) (Briq.) Jacquin's Z.

A nmerkung. Bastarte kommen zwischen S. alpina u. S. Germanica, ferner zwischen S. palustris u. S. silvatica vor.

\section{SALVIA, L. Salbei.}

Stb. weit aus der Blkr. herausragend; Bt. gelblichweiß; Staude mit gelappten 0 . fast fiederspaltigen B.; Btstand zottig u. drüsig. (M.) N. St.

Austriaca. Jacq. Oesterreichischer S. Stb. so lang 0. kürzer als die Blkr., dieselbe nicht

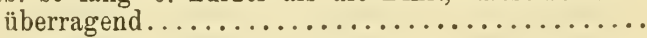

Scheinquirle höchstens 12 blütig; Gr. aus der Oberlippe hervortretend $\ldots \ldots \ldots \ldots \ldots \ldots \ldots \ldots$ Scheinquirle reichblütig, fast kugelig; Gr. auf die Unterljppe herabgebogen; Bt. klein, hellviolett (selten weiß); Staude mit 3 eckig-herzförmigen B. Verbr...........verticillata. L. Quirlblütiger S.

B. herz-spießförmig, grob-gesägt, die oberen lang zugespitzt; Stg. oben drüsig-klebrig; Bt. groß, schwefelgelb, braun punktirt. Verbr.

glutinosa. $L$. Klebriger $\mathrm{S}$.

B. nicht spießförmig; Bt. niemals gelb ...........

Halbstrauch; B. eilanzettlich o. lanzettlich, runzelig, die jüngeren graufilzig; Blkr. violett (selten rosa 0 . weiB), mit einer Haarleiste in der Röhre.

.J. (Südt.)............. officinalis. L. Echter S. Stauden 0. Kräuter; Blkrröhre ohne Haarleiste ....

*) Umfasst mehrere Formen, die noch der Klärung bedürfen. 
( Zweijährige Kräuter; Oberlippe des K. flach, mit 3

5 geraden, lang begrannten Zähnen .............

Stauden; Oberlippe des K. concav, 3 furchig, mit 2 bis 3 zusammenneigenden, kleinen, spitzen Zähnen

B. nebst den K. weiß-wollig, eiförmig, fast herzförmig, gekerbt, buchtig o. lappig; Deckb. meist ungefärbt; Bt. weiß. (M.) $N$.

Aethiopis. L. Ungarischer S.

B. fast filzig, doppelt gekerbt, die unteren herzförmig; Deckb. rosenroth o. violett; Bt. hellbläulich mit gelblicher Unterlippe.

Sïdt. Südst. $K r$. J....Sclarea. $L$. Scharlach-S.

Oberlippe des K. abgerundet, sehr klein-3 zähnig, weiß behaart; Deckb. rundlich-eiförmig, zuletzt herabgebogen; B. länglich, lappig-gezähnt o. fieder-

7 spaltig; Bt. hellblau. $J$.

clandestina. $L$. Orientalischer S

Oberlippe des K. kurz-3 zähnig, nicht abgerundet;

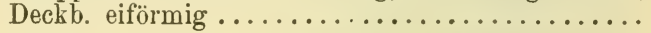

Deckb. krautig, grün; Stg. oben sammt den Deckb.,

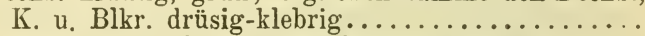

Die oberen Deckb. purpurn überlaufen; Stg., Deckb., K. u. Unterseite der B. feinflaumig.

Verbr. (fehlt Sch. S. T. J.) nemorosa. L. Hain-S.

Oberlippe des K. 3 zähnig; Unterlippe der Blkr. mit aufgebogenen Seitenzipfeln. Verbr. $u$. $h \mathrm{fg}$.

9) $\begin{aligned} & \text { pratensis. L. Wiesen-S. } \\ & \text { Oberlippe des K. } 2 \text { zähnig; Unterlippe der Blkr. mit }\end{aligned}$ abstehenden Seitenzipfeln; Bt. kleiner; Behaarung schwächer. J.....Bertolonii. Vis. Bertoloni's S.

Anmerkung. Zwischen S. nemorosa $u$. S. pratensis kommt ein Bastart vor.

\section{HORHINUM. L. Drachenmaul.}

Staude; B. alle grundständig, länglich, stumpf, gekerbt; Bt. violett. A. u. Vora. v. S. T. K. St. Kr. Pyrenaicum. L. Pyrenäisches D.

\section{MELISSA. $L$. Herzkraut.}

Staude; B. eiförmig, gekerbt-gesägt, die unteren fast herzförmig; Scheinquirle halbirt, einseitswendig; Bt. weib o. etwas rosa.

Südt. Südst. $K r$. J. (sonst cult. u. verw.)

officinalis. $L$. Gebräuchliches H. 
XXIII. SATUREJA. L. Bergminze.

Scheinquirle dichtblütig, am Grunde von borstenförmigen Vorb., die die Länge des K. erreichen, umgeben; Bt. purpurn (sehr selten weiß) .......

Scheinquirle ohne 0 . mit sehr kurzen, unauffälligen Vorb.

B. klein, eiförmig, länglich o. lineal, am Rande umgerollt; K. 5 zähnig, kaum 2 lippig; Bt. sehr klein. . ............Juliana. L. Julianische B.

B. ziemlich groß, eiförmig 0 . eilänglich, entferntgesägt, flach; K. deutlich 2 lippig. Verbr. u. lify. vulgaris. (L.) Fritsch. Wirbeldost.

B. schmal, lanzettlich o. lineal-lanzettlich; $\mathrm{K}$. 5zähnig, undeutlich 0 . gar nicht 2 lippig.......

B. elliptisch, eiförmig 0 . rundlich; K. meist ausge-

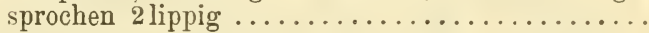

Einjähriges Kraut; B. lineal-lanzettlich; Bt. lila. Südt. $K r$. (sonst cult. u. verw.)

hortensis. $L$. Pfefferkraut.

Halbsträucher; B. lanzettlich, die oberen stachel-

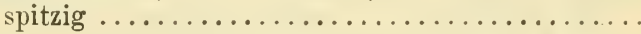

Stg. 4 kantig, kahl; B. unterseits spärlich-drüsigpunktirt; Bt. violett, Schlund dunkler gefleckt. $K r . J \ldots \ldots \ldots \ldots$ subspicata. Tis. Zwergige B. Stg. fast stielrund, flaumig; B. beiderseits drüsig-punktirt; Bt. weiß, Oberlippe rosenroth, Unterlippe pnrpurn punktirt, selten lila mit violetten Punkten

Zipfel der Unterlippe der Blkr. fast gleich, länglich, stumpf; Oberlippe tief ausgerandet; Btstand gedrungen; Bt. meist von weißer Grundfarbe.

Südt. $K$. $K r$. J........montana. L. Karst-B.

6 Die seitlichen Zipfel der Unterlippe der Blkr. gestutzt, der mittlere doppelt so breit, rundlich, ungetheilt, am Rande wellig; Btstand lockerer; Bt. größer, meist helllila. $K . K r . J$.

variegata. Host. Bunte $B$.

Scheinquirle meist 6 blütig, jede $\mathrm{Bt}$. gestielt, von den anderen getrennt, ohne gemeinsamen Stiel ..

Scheinquirle in 2 lockere, gestielte, trugdoldige Btstände aufgelöst, meist mehr als 6 blütig......

Pfl. 1-mehrjährig; Bt. klein, lila o. blassviolett; Frkelche an der Spitze zusammengezogen, durch die aneinander gedrängten Zähne geschlossen.

Verbr.......A Acinos. (L.) Scheele. Steinquendel.

Pfl. ausdauernd; Bt. ziemlich grol, lebhaft violett (selten weiß); Frkelche offen, mit aufrecht-abstehenden Zähnen. Verbr. (fehlt $B$. $M$. Sch.)

alpina. (L.) Scheele. Alpenquendel. 
Kschlund nackt; B. elliptisch, stumpf, schwach-gesägt, kahl; Bt. weiß, Oberlippe hellviolett, Unterlippe violett punktirt. $T . K . K r . J$.

rupestris. Wulf. Felsenliebende B.

Kschlund mit einem (oft schwachen) Haarringe; $B$. eiförmig 0 . fast rundlich, mehr 0 . weniger be-

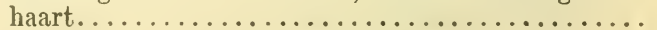

B. spitz, tief- u. spitz-gesägt; Tr. $3-5$ blütig; Theilfr. schwarz, rundlich-oval; Bt. groß, purpurn. Südt. K. Südst. Kr. J.

grandiflora. (L.) Scheele. Großblütige B. B. stumpf, angedrückt-gesägt 0 . fast ganzrandig;

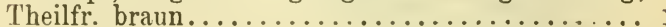

(Bt. purpurviolett, in oft nur 3-5blïtigen Trugdolden; B. stets deutlich gesägt............ 12

Bt. bläulich, lila 0 . weißlich, meist klein, in meist reichblütigen Trugdolden; $B$. oft fast ganzrandig

B. grob gesägt; Hauptäste der 'Trugdolden viel kürzer als die Deckb.; die unteren Kzähne so lang als die Kröhre. O. S. T. K. St. Kr. J.

Calamintha. (L.) Scheele. Echte B.

B. feiner gesägt; Hauptäste der Trugdolden kaum kürzer als die Deckb.; die unteren Kzähne kürzer als die Kröhre. $J$.

menthaefolia. (Host.) Fritsch. Minzenblättrige B.

B. deutlich und ziemlich grob gesägt; Btstand sehr locker. Verbr: (fehlt B. M. Sch.)

13 nepetoides. (Jord.) (Briq.) Kleinblütige B. B. klein, kurz und breit, dicht flaumig, meist fast ganzrandig; Btstand ziemlich dicht; Bt. kleiner. Sïdt. J........Nepeta. (L.) (Briq.) Katzen-B.

Anmerkung. Zwischen S. Acinos und S. alpina wurde ein Bastart beobachtet.

\section{HYSSOPUS. $L$. Ysop.}

Halbstrauch; B. lanzettlich, ganzrandig; Btstand einseitswendig.

B. M. N. Sï̈st. Kr. J. Südt. (meist verw.) officinalis. L. Gebräuchlicher $\mathrm{Y}$.

XXV. MAJORANA. Mnch. Majoran.

Kraut o. Staude; Deckb. gefurcht, dicht dachig, graufilzig und drïsig. Cult.

hortensis. Much. Garten-M. 


\section{ORIGANUM. L. Dost.}

Vorb. an der inneren und äußeren Seite drüsig-punktirt, Drüsen feuerfarben, hervortretend. $J$.

hirtum. $L k$. Kurzhaariger D.

Vorb. an der inneren Seite drüsenlos. Terbr.

vulgare. $L$. Gemeiner D.

\section{THYMUS. $L$. Quendel.}

(B. am Rande zurückgerollt, sitzend, lineal o. länglich-eiförmig, spitz, unterseits filzig, in den Blatt-

1 achseln büschelig, die obersten lanzettlich, stumpf $K r$. J. (sonst cult.).....vulgaris. $L$. Thymian. B. am Rande flach, stumpf, in einen kurzen Stiel zusammengezogen ......................

Blühende Stg. vierkantig, zweireihig o. nur an den

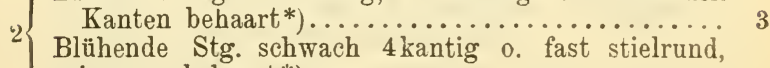
ringsum behaart*).....................

Behaarung des Stg. kurz; B. meist kahl, nur am Grunde gewimpert, seltener oberseits behaart.... Behaarung des Stg. lang, wollig, abstehend; B. beiderseits dicht behaart......................

Btstand ährenförmig, oft unterbrochen; Stg. aufsteigend 0 . fast aufrecht; B. meist eiförmig. Verbr.

ovatus. Mill. Eiblättriger Q.

Btstand kopfig, dicht; Stg. liegend, fast kriechend $\left.{ }^{*}\right)$; B. klein, elliptisch 0 . lanzettlich. Verbr.

Chamaedrys. Fr. Gamander-Q.

Btstand ährenförmig, locker, oft unterbrochen; die oberen Kzähne etwa so lang als der dritte Theil der Kröhre. T. $K$.

polytrichus. Kern. Langhaariger Q.

Btstand kopfig, zuletzt kurz ährenförmig; die oberen Kzähne viel kürzer als der dritte Theil der Kröhre; Stg. mehr halbstrauchig. $K$. $K r$.

Carniolicus. Borb. Krainer Q.

B. nur am Grunde gewimpert, sonst kahl o. seltener auf den Flächen mit spärlichen Haaren besetzt..

B. beiderseits dicht behaart.................. 9

*) Bei Alpenformen des Th. praecox Opiz ist der Stg. oft nur an den Kanten behaart. Bei Th. polytrichus Kern. ist der Stg. manchmal ringsum behaart, aber doch an 2 Seiten auffallend stärker. überall ein.

**) Bei Th. longicanlis Presl (J.) wurzeln die Stg. 
Stg. am Boden liegend, nach aufwärts blühende deste entsendend und an der Spitze fortwachsend; B. eiförmig, rundlich o. spatelförmig, seltener elliptisch, mit unterseits vorspringenden Nerven und mehr o. weniger verdicktem Rande. Verbr.

praecox. Opiz. Frühblühender Q.

Stg. liegend 0. aufsteigend, mit einem Btstand endigend; B. elliptisch, lanzettlich o. lineal, mit gegen den Rand hin sich verlierenden Nerven und nicht verdicktem Rande .................

Stg. liegend, kurz flaumig, meist verlängert, mit kurzen, reihenweise angeordneten blühenden Aesten; B. klein, meist lineal o. lineal-länglich. B. $M$. $\mathcal{~}$.

angustifolius. Pers. Schmalblättriger Q.

Stg. meist aufsteigend, verhältnissmäßig hoch und kräftig, oben langhaarig; B. nicht auffallend klein, länglich o. elliptisch. B. M. N. T.

Marschallianus. Willd. Großer Q.

Untere Kzähne verlängert, zuletzt fast stechend, meist gelblich; Btstand dick; B. verhältnissmäßig grob, eilanzettlich o. lanzettlich; Stg. kräftig, aufrecht, verhältnissmäßig hoch. Sü̈lt. $K r$.

Pannonicus. All. Ungarischer Q.

Kzähne nicht stechend; Btstand kopfig .......... 10

B. eiförmig o. rundlich spatelig, mit unterseits vorspringenden Nerven und verdicktem Rande. $N$.

Badensis. H. Braun. Badener Q.

B. elliptisch o. länglich-lanzettlich, mit gegen den Rand sich verlierenden Nerven und nicht verdicktem Rande. B. M. N. K. T.

lanuginosus. Mill. Zottiger $Q$.

Anmerkung. Die meisten Arten dieser Gattung sind veränderlich und durch Mittelformen und Bastarte mit einander verbunden. Die zahlreichen als eigene Arten beschriebenen Formen untergeordneten Ranges konnten hier keine Berücksichtigung finden.

\section{LYCOPUS. $L$. Wolfsfuß.}

B. tief fiederspaltig, die unteren im Umrisse breiteiförmig, die oberen lanzettlich; an Stelle der $\mathbf{2}$ oberen Stb. kupfige Staminodien; Bt. weiß, sehr klein. B. M. N. Südst. $K r$. J.

exaltatus. $L$. $f$. Hoher W.

B. ungetheilt, aber grob eingeschnitten-gesägt, nur die unteren gegen den Grund zu oft fiederspaltig; an Stelle der 2 oberen Stb. sehr kleine, fädliche Staminodien; Bt. weiß; roth punktirt.......... 
(Stg. flaumig o. fast kahl; B. länglich o. lanzettlich.

2 Verbr............... Stg. wollig; B. eiförmig o. fast rundlich. $T K$.

mollis. Kern. Weichhaariger W.

XXIX. MENTHA. L. Minze.

Scheinquirle zu endständigen, walzlichen Aehren zu-

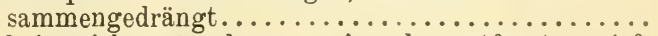

Scheinquirle entweder von einander entfernt 0 . (oft nur die oberen) zu einem rundlichen o. ovalen Köpfchen zusammengedrängt...............

B. beiderseits 0 . doch unterseits behaart; K. meist dicht flaumig 0. zottig ....................

B. kahl o. nur an den Nerven der Unterseite etwas flaumig; K. kahl o. spärlich behaart...........

B. sitzend, breit eiförmig 0 . fast rundlich, stumpf, gekerbt-gesägt, unterseits filzig, runzelig; Deckb. lanzettlich, zottig; K. zottig, mit kurzen, lanzettlich-pfriemlichen Zähnen.

Südt. Kr.J. (sonst cult. u. verw.)

rotundifolia. $L$. Rundblättrige $\mathrm{M}$.

B. spitz o. zugespitzt, mehr 0 . weniger scharf gesägt, nicht runzelig ......................

B. eiförmig o. länglich-eiförmig, nicht lang zugespitzt, unterseits filzig. (Verbr .?)

Niliaca. Juss.*) Breitblättrige M.

B. lanzettlich, länglich-lanzettlich o. eilanzettlich, in letzterem Falle lang zugespitzt..............

B. oberseits von dichter Behaarung grau o. weißlich, unterseits weißfilzig; untere Deckb. lanzettlich; K. weisfilzig, mit lineal-pfriemlichen Zähnen.

B. M. N. K. Kr. J.

mollissima. Borkh. Weichhaarige M.

5 B. oberseits zwar behaart, aber grün, unterseits mehr o. weniger dicht filzig; Deckb. lineal-lanzettlich o. lineal; K. mehr 0 . weniger dicht behaart, mit dreieckig - pfriemlichen o. lineal - pfriemlichen Zähnen. Verbr. $u$. $h f g$.

longifolia. ( $L$.) Langblättrige M.

*) Umfasst eine Reihe von Formen, welche M. rotundifolia mit M. longifolia verbinden. 
B. sitzend, nur die untersten oft kurz gestielt; Aehren schlank, lineal-walzlich; K. nicht deutlich gefurcht. Südt. $K r$. (sonst cult. u. verw.)

viridis. $L$. Grüne $M$.

B. deutlich gestielt; Aehren länglich-walzlich, dick, oft fast kopfförmig; K. gefurcht. Cult. u. verw.

piperita. $L$. Pfeffer-M.

Alle o. nur die oberen Scheinquirle zu einem endständigen, rundlichen 0 . ovalen Köpfchen zusammengedrängt; $K$. röhrig, gefurcht, mit dreieckig-pfriemlichen, zugespitzten Zähnen; B. gestielt, eiförmig 0. eilänglich, gesägt. Verbr. u. h†q. aquatica. $L$. Wasser-M.

Scheinquirle von einander entfernt, blattachselständig

K. 5 zähnig, nicht zweilippig, ohne Haarkranz.....

K. röhrig, etwas 2lippig, durch einen Haarkranz geschlossen; Scheinquirle kugelig; B. gestielt, elliptisch 0. länglich, schwach gesägt, die oberen deckblattartig verkleinert. Verbr. (fehlt $S_{\text {.) }}$

Pulegium. L. Polei-M.

Pfl. intensiv nach Citronen o. bergamottenartig riechend; Blkr. innen kahl................ 10

Pfl. olne Citronen- o. Bergamottengeruch; Blkr.

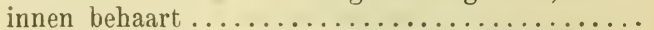

B. wenig behaart, oberseits oft fast kahl; K. am

$10\left\{\begin{array}{l}\text { Grunde kahl, mit gewimperten Zähnen.......... } \\ \text { Wenigstens die oberen B. beiderseits dicht behaart; }\end{array}\right.$

K. meist langzottig, nur am Grunde oft kahl.... 12

B. grob und scharf gesägt, oberseits nahezu kahl; Stg. meist roth überlaufen. Verbr. (?)

11 B. mit kleinen, oft stumpflichen Sägezähnen, Re M. seits zerstreut behaart. $B . M . N$.

grata. Host. Wohlriechende II.

Btstiele kahl o. fast kahl; B. elliptisch o. eiförmig 13

Btstiele behaart; Deckb. u. K. dicht behaart; Stg.

12 dicht zottig; B. unterseits filzig, oberseits dicht behaart, lanzettlich 0 . eilanzettlich. $K r$.

Dalmatica. Tausch. Dalmatiner II.

B. meist elliptisch, deutlich, die unteren ziemlich lang gestielt, nur die oberen dicht behaart, die obersten deckblattartig; K. am Grunde kahl. II. N............ gentilis. L. Heidnische II.

B. breit eiförmig, sehr kurz gestielt 0 . fast sitzend, dicht behaart, die obersten wenig verkleinert; $K$. dicht langhaarig. $K$.

Carinthiaca. Host. Kärntner M. 
K. röhrig-trichterig, mit dreieckig-pfriemlichen, spitzen Zähnen; sitg. oben dicht flaumig; B. eiförmig, beiderseits anliegend behaart; Theilfr. oft fein warzig. Verbr. (?)

verticillata. $L .^{*}$ ) Wirtelblütige $M$. K. kurz, glockig, mit kurz dreieckigen Zähnen; Theilfr. stets glatt.................. 15

B. am Grunde verschmälert, oft keilig......... 16

B. am Grunde breit zugerundet o. etwas herzförmig, nur die oberen manchmal verschmälert ........ 17

Untere Bstiele viel länger als die zugehörigen Scheinquirle; B. länglich-lanzettlich, wenig behaart 0 . kahl. B. M. N. K.

parietariaefolia. Becker. Glaskrautblättrige M. Bstiele so lang o. kürzer, selten etwas länger als die zugehörigen Schein quirle; B. meist elliptisch, mehr o. weniger behaart, seltener fast kahl. Verbr. (?) Austriaca. Jacq. Oesterreichische M. B. oft glänzend, spärlich behaart o. fast kahl; Btstiele kahl o. spärlich behaart. Verbr. (?)

palustris. Mnch. Sumpf-Mr. B. beiderseits anliegend behaart; Btstiele in der Regel dicht anliegend behaart. Verbr. $u$. $h f g$.

arvensis. L. Acker-M.

Anmerkung. Die Mehrzahl der hier aufgeführten Arten ist sehr formenreich und durch Mittelformen verbunden. Bastarte sind nicht selten; mit sicherheit sind insbesondere solche der M. aquatica mit M. mollissima, longifolia und arvensis bekannt. Auch unter den oben als Arten aufgeführten Minzen sind einige wahrscheinlich hybriden Ursprungs; da dieselben aber häufig ohne ihre muthmaßlichen Stammarten vorkommen, wurden sie in die Tabelle aufgenommen. - Die „Krauseminzen“ der Gärten sind irausblättrige Formen verschiedener Mentha-Arten.

LXXXIV. Familie. Solanaceae. Nachtschattengewächse.

Kräuter, Stauden 0. Sträucher mit ungetheilten, seltener fiederschnittigen, in der Regel schraubig gestellten B., ohne Nebenb. Bt. zwittrig, regelmäßig o. etwas unregelmäळig. Kił. 5, am Grunde mehr 0. weniger verwachsen. Blkr. verwachsenblättrig, mit 5 Zipfeln. Stb. 5, oft von ungleicher Länge. Frkn. 1, oberständig, 2 fächerig (durch Einschaltung

*) Umfasst eine Reihe von Formen, die sich zwischen M. aquatica und M. arvensis einschieben. 
falscher Scheidewände manchmal mehrfächerig), mit zahlreichen Samenknospen. Gr. 1; N. 1, kopfig 0. 2 lappig. Fr. eine Kapsel o. häufiger eine Beere, meist reichsamig. S. mit Nährgewebe.

\section{Gattungen.}

Blkr. glockig 0. röhrig-glockig, mit kurzen, wenig 0.

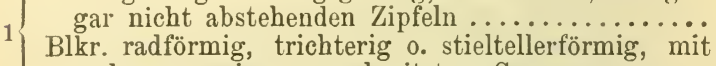
mehr 0 . weniger ausgebreitetem Saume........

K. tief $\mathbf{5}$ spaltig; Zipfel der Blkr. deutlich, etwas zurückgebogen; Fr. eine Beere..... Atropa. III. 2 K. glockig, kurz 5 zähnig; Blkr. fast gerade abgeschnitten, mit undeutlichen Zipfeln; Fr. eine mittels Deckels aufspringende Kapsel. Scopolia. IV.

Blkr. radförmig, mit sehr kurzer Röhre; Bt. in dolden- o. traubenähnlichen Btständen; A. zusammenneigend, an der Spitze mit Löchern aufspringend ...................... Blkr. trichterig o. stieltellerförmig, seltener fast radförmig (dann aber die Bt. einzeln in den Blattachseln); A. nicht zusammenneigend..........

Sträucher; B. länglich 0 . lanzettlich, ganzrandig; Blkr. mit verlängerter Röhre; Beeren ellipsoidisch, scharlachroth, nur am Grunde vom K. umgeben.

Lycium. II.

Kräuter o. Stauden; Fr. entweder eine Kapsel 0. eine vom vergrößerten, aufgeblasenen Kelche ganz

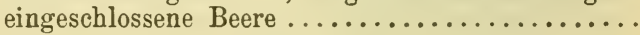

Bt. einzeln in den Blattachseln o. endständig, wenn auch oft einander genähert.............. Bt. in endständigen, rispenartigen Btständen; große Kräuter mit ganzrandigen 0 . fast ganzrandigen B.; Blkr. mit verlängerter Röhre und faltigem Saume; Kapsel 2-4 klappig........... Nicotiana. IX.

Blkr. groß, mit verlängerter Röhre und faltigem Saume mit spitzen Zipfeln; K. röhrig, 5zähnig, über dem Grunde abspringend; Frkn. 4 fächerig; Kapsel 4 klappig, stachelig ....... Datura. VIII.

Blkr. mit trichterig erweiterter, oft kurzer Röhre, Saum nicht faltig; Fr. eine Beere o. eine mittels Deckels aufspringende Kapsel, stets von dem vergrößerten $\mathrm{K}$. eingeschlossen ................

Pfl. drüsig-klebrig; K. krugförmig, 5 zähnig; Blkr. trichterig; Fr. eine Kapsel ....Hyoscyamus. V. Pfl. kahl o. behaart, nicht klebrig; Fr. eine Beere . 
(Einjähriges, kahles Kraut; Blkr. blau; Frkn. 3- bis

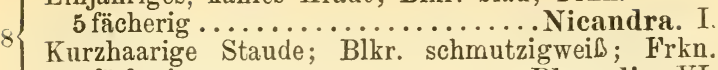
2 fächerig ................... Physalis. VI.

\section{Arten.}

I. NICANDRA. Adans. Giftbeere.

B. eiförmig 0 . elliptisch, buchtig-fiederlappig 0 . grob gezähnt. Cult. u. vervo.

physaloides. (L.) Gärtu. Judenkirschenartige G.

\section{LYCIUM. L. Bocksdorn.}

Zweige ruthenförmig, überhängend, oft bedornt; Blkr. rothviolett, mit trichteriger Röhre, welche ungefähr so lang ist als die Zipfel; Stb. über dem Grunde mit einem Haarbüschel. Cult. u. verw.

vulgare. Dun. Gemeiner B.

'Zweige paarig, zum Theile dornig; Blkr. hellviolett mit weißen Adern, mit walzlicher Röhre, welche ungefähr doppelt so lang ist als die Zipfel; Stb. kahl. J. .......Europaeum. L. Europäischer B.

\section{ATROPA. L. Tollkirsche.}

Große Staude; B. eiförmig o. elliptisch, ganzrandig; Bt. schmutzig violettbraun; Beere glänzend schwarz. Verbr. ........... Belladonna. Gemeine T.

\section{SCOPOLIA. Jacq. Tollkraut.}

Blkr. röhrig-glockig, außen glänzend braun, innen matt olivengrün. Südst. $K r$.

Carniolica. Jacq. Krainer T. Blkr. verkehrt-eiförmig-glockig, beiderseits grün.

Südst. $K r$...Hladnikiana. Freyer. Hladnik's T.

\section{HYOSCY AMUS. $L$. Bilsenkraut.}

B. eilänglich, buchtig-fiederspaltig, die unteren gestielt, die oberen halbumfassend-sitzend; Bt. schmutzig-hellgelb, meist mit violettem Adernetze und Schlunde. Verbr. ...niger. L. Schwarzes B.

B. rundlich-eiförmig, buchtig, stumpf gelappt, alle gestielt; Bt. kleiner, hellgelb mit violettem Schlunde ohne Adernetz. J. .......... albus. L. Weißes B.

\section{PHYSALIS. $L$. Judenkirsche.}

B. gestielt, spitz, meist ganzrandig; Beere sammt dem aufgeblasenen Frkelch mennigroth. Verbr.

Alkekengi. L. Gemeine J.

\section{SOLANUM. $L$. Nachtschatten.}

1) B. unterbrochen fiederspaltig ............. 2

\{ B. ungetheilt, höchstens gelappt ........... 3 
Knollentragende Staude; Stg. angedrückt-behaart, nicht klebrig; Bfiedern ganzrandig; Bt. blasslila o. weiß; Fr. grün. Cult. tuberosum. L. Kartoffel.

2 Großes Kraut; Stg. klebrig-behaart; Bfiedern grob eingeschnitten-gezähnt; Bt. hellgelb; Fr. groß, meist roth. Cult. u. verw.

Lycopersicum. L. Paradiesapfel.

Halbstrauch; B. herzeiförmig 0. eilänglich, die oberen oft spießförmig; Bt. violett; Beeren ellipsoidisch, scharlachroth. Verbr.

Dulcamara. $L . *)$ Bittersüßer N. Einjährige Kräuter; Bt. meist weiß, selten blass-

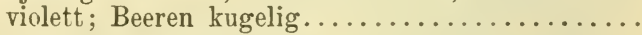

B. u. Stg. fast kahl; B. eirautenförmig, ausgeschweiftgezähnt; Beeren wachsgelb.

B. M. N. O. St. K. Südt. J.

humile. Bernh. Niedriger N.

B. u. Stg. zottig o. flaumig; B. buchtig gezähnt ..

Beeren schwarz, selten grünlich; B. eiförmig, fast deltaförmig. nebst dem Stg. flaumig, Haare einwärts-gekrümmt, aufrecht; Astkanten hervortretend. Verbr........nigrum. L. Schwarzer N.

Beeren roth 0. gelb; B. u. Stg. zottig ............

Beeren mennigroth; B. eiförınig, fast deltaförmig, sammt dem Stg. abstehend-zottig; Astkanten hervortretend. B. M. N. O. St. K. Südt. J.

alatum. Mnch. Mennigrother $\mathrm{N}$.

Beeren gelb; B. eiförmig, sammt den Stg. fast filzigzottig; Kanten der Aeste unmerklich.

B. N. Kr. J. Südt. villosum. Lam. Zottiger N.

\section{DATURA. I. Stechapfel.}

Bt. weiß; Stg. u. B. grün. Verbr.

Stramonium. L. Gemeiner St. Bt. hellblau; Stg., Bstiel, Bnerven u. K. violett überlaufen. Cult. u. verw.

Tatula. L. Hellblauer St.

\section{NICOTIANA. $L$. Tabak.}

Die unteren B. gestielt, eiförmig, ganzrandig; Blkrsaum mit rundlich-stumpfen Lappen; Bt. gelblich-

1 grün. Cult. u. verw....... rustica. L. Bauern-T. Die unteren B. herablaufend; Blkrsaum mit zuge-

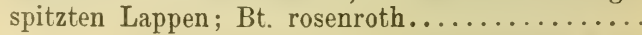

*) In Südt. kommt das durch filzige Stg. u. B. ausgezeichnete S. litorale Raab vor. 
( B. länglich-lanzettlich, die unteren verschmälertherablaufend; Blkrzipfel lang zugespitzt. Cult.

Tabacum. $L$. Virginischer T.

B. eiförmig-lanzettlich, die unteren aus geöhrltem Grunde herablaufend; Blkrzipfel kurz zugespitzt. Cult........ latissima. Mill. Großblättriger 'T.

LXXXV. Familie. Scrophulariaceae. Braunwurz: gewächse.

Kräuter 0. Stauden, seltener Halbsträucher. B. am häufigsten gegenständig, aber auch oft schraubig gestellt, bald ungetheilt, bald verschiedenartig getheilt. Nebenb. fehlen. Bt. zwittrig, niemals ganz regelmäßig. Kb. 4-5, am Grunde stets verwachsen. Blkr. stets verwachsenblättrig, mit 4-5 manchmal undeutlich ausgesprochenen Zipfeln, von sehr verschiedener Gestalt (radförmig, fast kugelig, stieltellerförmig, 2 lippig und dabei oft maskirt 0 . gespornt u. s. w.). Stb. am häufigsten 4 (2 längere und 2 kürzere), seltener 2 o. 5 (auch im letzten Falle meist ungleich lang). Frkn. 1, oberständig, 2 fächerig, mit zahlreichen, seitener wenigen Samenknospen. Gr. 1, manchmal '2 spaltig 0. häufiger mit 2 lappiger $\mathrm{N}$. Fr. eine in verschiedener Weise aufspringende, gewöhnlich mehrsamige Kapsel. S. mit Nährgewebe.

\section{Gattungen.}

Fruchtbare Stb. 5, ungleich lang; Blkr. radförmig,

1 mit 5 ungleichen Zipfeln....... Verbascum. I.

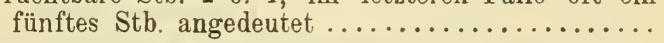

(Fruchtbare Stb. 2, außerdem manchmal noch 2 un-

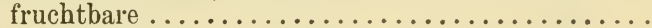

Fruchtbare Stb. 4, 2 mächtig ............ 5

Stf. 4, aber 2 mit verkümmerten A.; Blkr. 2 lippig, mit 4 seitiger Röhre; N. 2 spaltig. . Gratiola. IX' Stb. überhaupt nur 2 ; Blkr. radförmig 0. 2 lippig

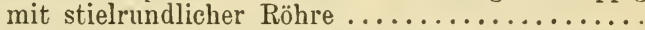

Staude mit grundständiger Brosette und blattlosem Schafte; Blkr. 2 lippig; Stf. im obersten Theile der verlängerten Blkrröhre eingefügt; A. nierenförmig ................. Vulfenia. XIII. Stauden mit gegenständigen, manchmal am Grunde des Stg. rosettenartig gedrängten B., o. Kräuter; Blkr. radförmig mit sehr kurzer 0. 2 lippig mit verlängerter Röhre, in letzterem Falle die Stf. tief unten eingefügt; A. herz-eiförmig o. länglich-eiförmig . .............. Veronica. XII. 
Afächer am Grunde stumpf .............. 6

5 Afächer am Grunde in eine Spitze auslaufend; Blkr. 6 mit helmartiger Oberlippe............... 16

Blkr. maskirt (d. h. ihr Schlund durch eine Einstülpung der Unterlippe verschlossen 0 . fast ver-

6 schlossen) und am Grunde gespornt 0 . ausgesackt Blkr. mit offenem Schlunde, ohne Sporn o. Aussackung am Grunde.................. 11

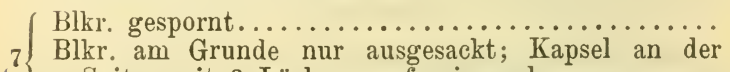
Spitze mit 3 Löchern aufspringend.

Antirrhinum. V.

B. handnervig, herzförmig-rundlich, meist 5 lappig; Bt. einzeln in den Blattachseln, helllila; Kapsel

8 an der Spitze mit 2 Löchern aufspringend.

Cymbalaria. II.

B. breit, rundlich-eiförmig o. spießförmig, zottig behaart; Bt. blattachselständig; Kapsel mit Deckeln aufspringend ...................

B. schmal, lanzettlich 0 . lineal, 0 . breiter, dann aber kahl; Kapsel mit Klappen 0. Löchern aufspringend 10

Schlund der Blkr. ganz geschlossen, ihre Oberlippe aufgebogen 0. zurückgeschlagen; Bt. in Aehren, Trauben 0 . Rispen .............. Linaria. IV.

10 Schlund der Blkr. nicht vollständig geschlossen, ihre Oberlippe gerade vorgestreckt; Bt. blattachselständig, aber zu lockeren Trauben zusammengestellt.

Chaenorrhinum. VI.

Blkr. 5 spaltig, präsentirtellerförmig o. fast radförmig, Saum flach o. trichterförmig, Zipfel gleich 0. un-

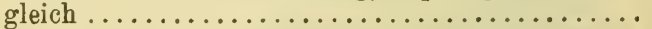

Blkr. 2 lippig 0. fast kugelig, o. glockig, 0. röhrigglockig mit schiefem, 3-5 spaltigem Saume.... 13

Wasserpfl.; B. grundständig, ganzrandig; Btstiele grundständig; K. 5 spaltig; Blkr. fast radförmig.

12 Limosella. X.

Alpenpfl.; B. vorne gekerbt; Bt. in Doldentrauben; K. bis zum Grunde 5 theilig; Blkr. präsentirtellerförmig.................... Erinus. XV.

Blkr. fast kugelig, mit 5 kleinen Zipfeln; Btstände

13 trugdoldig zusammengesetzt. Scrophularia. VII. Blkr. glockig, röhrig-glockig 0. 2 lippig; Btstände nicht trugdoldig..................... 14

Blkr. glockig, o. glockig-röhrig, mit schiefem Saume, 14 der obere Zipfel ausgerandet .... Digitalis. XIV. Blkr. 2lippig....................... 
Bt. weißlich; Oberlippe der Blkr. ausgerandet, Unterlippe 3 spaltig, der mittlere Zipfel größer; Blkr. kürzer als der 5 theilige K.; N. stumpf, 2 lappig.

Lindernia. XI.

Bt. gelb; Oberlippe der Blkr. 2 lappig, Unterlippe 3 spaltig, an der Basis oft 2 höckerig, Lappen fast gleich; Blkr. viel länger als der 5 zähnige K.; $\mathrm{N}$. aus 2 Plättchen gebildet.....Mimulus. VIII.

B. fiederspaltig 0. doppelt-fiederspaltig; Oberlippe der Blkr. zusammengedrückt, oft ausgerandet; $K$. röhrig 0 . aufgeblasen ...... Pedicularis. XXIV.

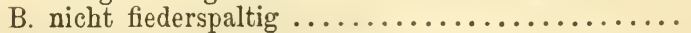

Saftige, fettglänzende Staude; Bt. gelb, Unterlippe blutroth-punktirt; Wst. dachig-schuppig.

Tozzia. XVII.

Anders beschaffene Pfl.

K. aufgeblasen, 4 zähnig; Bt. gelb mit weißlicher Röhre; Oberlippe 2 zähnig.

Alectorolophus. XXIII.

K. nicht aufgeblasen, röhrig 0 . glockig .........

Frknfächer mit 1-2 Samenknospen; K. röhrig; Oberlippe der Blkr. am Rande zurückgeschlagen, Unterlippe mit 3 Furchen ...Melampyrum. XVI.

Frknfächer mit zahlreichen Samenknospen ........

Oberlippe der Blkr. am Rande zurückgeschlagen; Bt. weiß mit violetter und gelber Zeichnung, 0. eine der letzteren Farben vorherrschend.

Euphrasia. XVIII.

Oberlippe der Blkr. mit geradem Rande; Bt. nicht

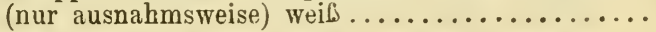

Bt. gelb; Blkrröhre kurz; A. anfangs zurückge21 schlagen, später vorgestreckt ...Orthantha. XX. Bt. fleischroth, purpurn 0. violett (selten weiß); Blkr-

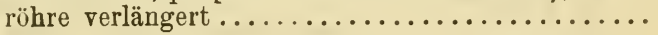

Ausdauernde Gebirgspfl. mit trübvioletten Bt.; S. nicht zahlreich, groß, flügelrandig.

Bartschia. XXII.

Einjährige Kräuter mit fleischrothen o. purpurnen

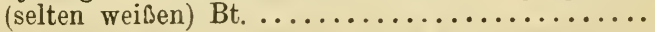

Obere B. handförmig eingeschnitten, untere gekerbt, alle eiförmig; Kapsel lanzettlich; S. zahlreich, glatt.......................

B. lanzettlich o. lineal-lanzettlich, entfernt-gesägt, nicht eingeschnitten; Kapsel eiförmig; S. nicht zahlreich, gefurcht........... Odontites. XXI. 


\section{Arten.}

I. VERBASCUM. $L$. Königskerze.

Bt. violett o. gelb, in einfachen o. zu Rispen zu-

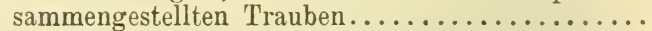

Bt. gelb (selten weiß), gebüschelt o. theilweise einzeln, die Büschel zu Trauben, Aehren o. Rispen

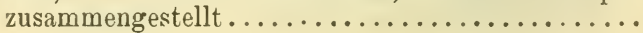

Bt. dunkelviolett; Btstiele viel länger als ihre Tragb.; A. nicht herablaufend; B. unterseits flaumig. B. M. N. St. K. Kr. J. Südt.

phoeniceum. L. Violette K.

Bt. gelb; Btstiele höchstens doppelt so lang als ihre Tragb.; die 2 längeren Stb. mit etwas herablaufenden A.; B. kahl. Verbr.

Blattaria. $L$. Traubige $\mathrm{K}$.

$3\{$ Alle o. nur die 3 kürzeren Stf. weißwollig ........

Stf. mit purpurvioletten Wollhaaren ............ 10

Die 2 längeren Stb. mit herablaufenden A.; B.

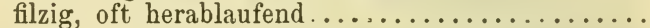

Alle A. gleich, nicht herablaufend; B. nicht herab-

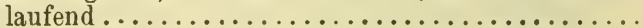

Die 2 längeren Stf. ungefähr 4 mal so lang als ihre

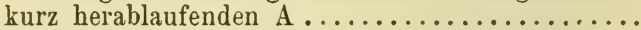
Die 2 längeren Stf. höchstens doppelt so lang als

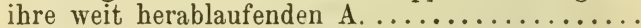

B. dicht filzig, in der Regel weit herablaufend, seltener wenig 0 . gar nicht herablaufend; Blkr. trichterig-radförmig; die \& längeren Stf. kahl o. fast kahl. Verbr....Thapsus. L. Kleinblütige K.

B. nur kurz herablaufend, oberseits dünnfilzig, unterseits mit vortretenden Nerven; Blkr. radförmig; die 2 längeren Stf. nur an der Spitze kahl. Südt. montanum. Schrad. Berg-K. $7\left\{\begin{array}{l}\text { Jedes B. bis zum nächsten herablaufend. Verbr. } \\ \text { thapsiforme. Schrad. Groiblütige K. } \\ \text { B. nur kur'z o. gar nicht herablaufend. Verbr. }\end{array}\right.$

phlomoides. L. Gemeine K.

B. oberseits fast kahl, unterseits staubig-filzig, graulich, die unteren elliptisch-länglich; die unteren Stgb. kurz gestielt, die oberen sitzend, eiförmig, zugespitzt; Btstand pyramidenförmig-rispig, mit scharfkantigen Aesten. Verbr.

Lychnitis. L. Heidenfackel.

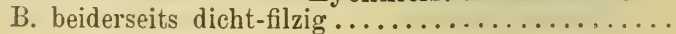


Filz der B. bleibend; B. ganzrandig, wellig, die unteren länglich, spitz; die Stgb. geöhrlt-herzförmig, sitzend; Aeste kantig. $M I$. $N$. (O.) $K r$.

speciosum. Schrad. Ansehnliche K.

9 Filz der B. abfällig, weiß, flockig; Grundb. länglichelliptisch, gestielt, die übrigen sitzend, unmerklichgekerbt, die oberen lang zugespitzt, halbumfassend; Aeste stielrund. $T$.

pulverulentum. Vill. Flockige K.

Stgb. halbumfassend und meist etwas herablaufend; Grundb. buchtig-gelappt; Btstiele kürzer als der

$10 \mathrm{~K}$.; Btstand ästig. J. sinuatum. L. Buchtige K. $\mathrm{Stgb}$. nicht herablaufend; Btstiele mindestens so

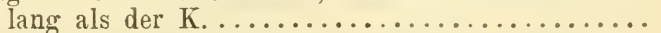

Stg. u. Aeste fast stielrund; Btstiele so lang 0. wenig länger als der K.; B. oberseits fast kahl, unterseits dünn-filzig; Btstand rispig-ästig ......

Stg. oben kantig; Btstiele ungefähr doppelt so lang als der K.; Btstand häufig unverzweigt 0 . am Grunde mit kurzen Aesten .................

Die unteren B. am Grunde eingeschnitten und dadurch fast leierförmig. $J$.

Chaixi. Vill. Leierblättrige $\mathbf{k}$.

B. nicht eingeschnitten, die unteren eilänglich, in den Bstiel zusammengezogen o. seicht-herzförmig, die oberen sitzend, am Grunde fast herzförmig. Verbr. (fehlt Sch.)

Austriacum. Schott. Oesterreichische K.

Die unteren und mittleren B. fast buchtig doppeltgekerbt, länglich, unterseits dicht wollig-filzig, gestielt, die oberen eilänglich, spitz gekerbt.

B. M. St. K. Kr. J. T.

lanatum. Schrad. Wollige $\mathrm{K}$.

Die unteren und mittleren $B$. einfach gekerbt, eilänglich, am Grunde herzförmig, unterseits dünnfilzig, lang gestielt, die oberen kurz gestielt 0 . sitzend. Verbr. ........nigrum. L. Schwarze $K$.

Anmerkung. Die Verbascum - Arten neigen sehr zur Bildung von Bastarten. Im Gebiete wurden beobachtet: V. Blattaria $\times$ phoeniceum, phoeniceum $\times$ Thapsus, Austriacum $\times$ phoeniceum, nigrum $\times$ phoeniceum, Blattaria $X$ thapsiforme, Blattaria $\times$ phlomoides, Blattaria $X$ sinuatum, Blattaria $X \mathrm{ni}-$ grum, thapsiforme $\times$ Thapsus, phlomoides $\times$ Thapsus, Lychnitis $X$ Thapsus, Austriacum $X$ Thapsus, nigrum $X$ Thapsus, phlomoides $X$ thapsiforme, Lychnitis $X$ thapsiforme, Austriacum $X$ thapsiforme, nigrum $X$ thapsiforme, Lychnitis $X$ phlomoides, phlomoides $X$ 
speciosum, Austriacum $\times$ phlomoides, nigrum $\times$ phlomoides, Lychnitis $X$ speciosum, Lychnitis $\times$ pulverulentum, Austriacum $\times$ Lychnitis, Lychnitis $X$ nigrum, Austriacum $\times$ speciosum, pulverulentum $\times$ sinuatum, Chaixi $\times$ pulverulentum, nigrum $\times$ pulverulentum, Chaixi $X$ sinuatum, Austriacum $X$ nigrum.

\section{CYMBALARIA. Baumg. Zimbelkraut.}

Zarte, auf Mauern o. Felsen kriechende Staude; B. kahl; Blkr. am Gaumen mit 2 gelben Höckern. Verbr. (meist verw.)

muralis. Baumg. Gemeines Z.

\section{KICKXIA. Dum. Tännelkraut.}

B. rundlich-eiförmig, am Grunde abgerundet o. etwas herzförmig; Btstiele zottig; Sporn gekrümmt; Oberlippe außen gelblich, innen schwarzviolett, Unterlippe hellgelb. Verbr. (fehlt $K$.)

spuria. (L.) Dum. Unechtes T. Die mittleren u. oberen B. am Grunde spießförmig Stg. u. Bstiele dicht zottig, nur die Btstiele oft kahl $\mathrm{P}$. zerstreut behaart; B. lanzettlich-spießförmig; $\mathrm{Kb}$. lanzettlich, zugespitzt, am Rande trockenhäutig; Bt. klein, bläulich, mit purpurnem Gaumen. J....... cirrhosa. (L.) Fritsch. Gewimpertes T. Btstiele dicht zottig; B. eiförmig-spießförmig; $\mathrm{Kb}$. lanzettlich; Oberlippe außen gelblich, innen violettbraun, Unterlippe lebhaft gelb. $J$.

lasiopoda. (Vis.) Fritsch. Behaartstieliges T. Btstiele kahl 0 . höchstens zerstreut behaart....... Sporn gerade; Bt. klein, weißlich, mit schwefelgelber Unterlippe und innen violetter Oberlippe.

Verbr. (fehlt $S . K$.) Elatine. (L.) Dum. Echtes T. Sporn aufwärts gekrümmt; Bt. ansehnlich, gelblich o. bläulich, mit innen azurblauer Oberlippe. J. commutata. (Bernh.) Fritsch. Verwechseltes T.

\section{LINARIA. Adans. Leinkraut.}

Bt. von violetter 0 . weißer Grundfarbe, manchmal mit blassgelbem 0 . orangefarbenem Gaumen ..... Bt. gelb o. weißlichgelb, der Gaumen meist dunkler gelb, nur der Sporn manchmal violett.........

$\mathrm{Kb}$. stumpf, nebst den Btstielen drüsig-behaart; Tr. gestielt, kopfig, später verlängert; B. lineal; Bt. hellblau mit dunkleren Streifen, Gaumen weißlich

2 mit violettem Netze. Sch. M. B. N.

arvensis. (L.) Desf. Feld-L. Kb. spitz o. zugespitzt, nebst den Btstielen ganz

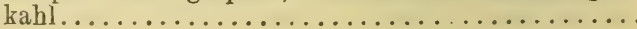


Bt. blauviolett mit orangefarbenem Gaumen; Kb. lanzettlich, kürzer als die verkehrt-eiförmige Kapsel; S. geflügelt. A. u. Vora.

alpina. (L.) Mill. Alpen-L.

Bt. violett 0 . wei $\delta$, mit weißlichem 0 . blassgelbem Gaumen; Kb. doppelt so lang als die Kapsel....

Tr. kopfig, später verlängert; Bt. hellblauviolett mit dunkleren Adern, der Gaumen weiß, violett gestreift; S. flachgedrückt, kammförmig-gewimpert. J.

Pelisseriana. (L.) Mill. Langsporniges L.

4 Tr. locker, verlängert; Bt. wei $\delta$, oft hellblauviolett gestreift, mit blassgelbem Gaumen; S. dreikantig, grubig-runzelig. $J$.

Chalepensis. (L.) Mill. Aleppisches L.

Wenigstens die unteren B. zu 3 quirlig, breit-ovallänglich; Bt. dicht-ährig, weißlichgelb mit dottergelbem Gaumen und violettem Sporn. $J$.

triphylla. (L.) Milll. Dreiblättriges L.

Alle B. schraubig gestellt; Sporn hellgelb o. weißlich ................................

Frspindel und Btstiele drüsig-flaumig; B. lineal-lanzettlich 0 . lineal, 3 nervig, meist aneinander gedrängt; Bt. hellgelb mit dunklerer Unterlippe und orangefarbenem Gaumen. Verbr.

vulgaris. Mill. Gemeines L.

Pfl. ganz kahl; Stg. meist locker beblättert.......

B. eilanzettlich o. länglich-lanzettlich, die obersten schmäler; Bt. gelb, mit etwas dunklerem Gaumen; $\mathrm{Kb}$. länger als die Kapsel; S. 3 kantig, punktirt. M. N. Sïdst.

genistifolia. (L.) Mill. Ginsterblättriges L.

B. lineal - lanzettlich; Bt. hellgelb, mit orangefarbenem Gaumen; Kb. kürzer als die Kapsel; S. flachgedrückt, geflügelt. Südt. Südst.

Italica. Trev. Italienisches L.

\section{ANTIRRHINUM. L. Löwenmaul.}

Kb. eiförmig, stumpf, viel kürzer als die Blkr.; Bt. purpurn 0. weiß, mit 2 gelben Flecken am Gaumen. Verbr. (meist nur verw.)...majus. L. Großes L. $\mathrm{Kb}$. lanzettlich, meist länger als die Blkr.; Bt. rosenroth, dunkler gestreift, mit purpurn geadertem Gaumen (selten weiß). Verbr. (feblt $S$.)

Orontium. $L$. Orant-L. 


\section{CHAENORRHINUM. Rehl. Orant.}

Btstiele $3 \mathrm{mal}$ so lang als der K.; Zipfel der Oberlippe spreizend; Bt. bleichviolett, mit gelblichweißem Gaumen. Terbr.

minus. (L.) Lge. Kleiner 0.

Btstiele so lang als der K.; Zipfel der Oberlippe vorgestreckt; Bt. lebhafter violett. I.

litorale. (Bernh.) Fritsch. Meerstands-0.

\section{SCROPHULARIA. I. Braunwurz.}

Trugdolden blattwinkelständig; Kzipfel ohne häutigen

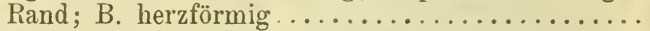

1 Bt. in einer endständigen, länglichen, aus trugdoldigen Aesten zusammengesetzten Rispe; Kzipfel häutig-

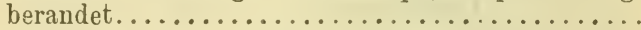

B. flaumig; Stg. u. Bstiele zottig; Bt. grünlichgelb. Sch. M. B. T. K. St. Kr. J.

verualis. $L$. Frühlings-B.

B. kahl, glänzend; Bt. dunkelblutroth. $J$.

peregrina. $L$. Fremde $B$.

An Stelle des 5. Stb. (unter der Oberlippe) ein rundliches, nierenförmiges o. querlängliches Schüppchen

Schüppchen an Stelle des 5. Stb. schmal, lanzettlich und spitzig, o. auch fehlend; B. kahl, fieder-

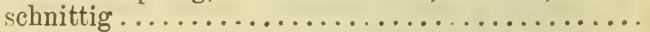

B. beiderseits flaumig, doppelt-gekerbt; Stg. u. Btstiele zottig; Bt. trüb-olivengrün und auf dem

$4\left\{\begin{array}{l}\text { Pücken braun o. ganz grün. } \\ \text { Sch. MI. Sï̀st. K. Kr.J. }\end{array}\right.$

Scopolii. Hoppe. Scopoli's B.

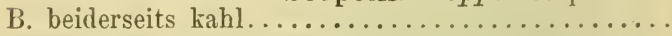

Stg. geschärft-4 kantig; B. länglich-eiförmig 0 . fast herzförmig, doppelt-gesägt; Kzipfel sehr schmalliäutig-berandet; Bt. trüb-olivengrün, auf dem Rücken braun o. ganz grün. Verbr. u. $h f g$.

nodosa. $L$. Gemeine $B$.

Stg. nebst den Bstielen breit-geflügelt; Kzipfel breit-

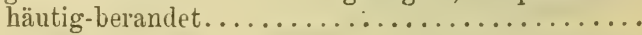

B. sämmtlich scharf-gesägt; Schüppchen verkehrtherzförmig-2 lappig, Lappen auseinander stehend; Bt. auf dem Rücken purpurbraun. Terbr.

alata. Gilib. Geflügelte B.

6 Die untersten B. gekerbt; Schüppchen quer-länglich, 3 mal breiter als lang, vorne seicht-ausgerandet; B. eiförmig 0 . eiförmig-länglich, stumpflich, die mittleren und oberen spitzlich und gesägt; Bt. rothbraun, am Grunde grünlich. B. M. O. S. T. 
Die Oberlippe der Blkr. 3 mal kürzer als die Röhre; Rispe drüsig, Drüsen sitzend; Bt. violettroth, die seitlichen Zipfel weiß, der unterste weiß-berandet. Südt. K. St. Kr. J. (N.)

canina. $I$. Gemeine Hundsraute.

Die Oberlippe der Blkr. etwas länger als die halbe Röhre; Rispe drüsenhaarig; Bt. violett, weiß berandet. $A$. u. Vora. v. Südt. K. Südst. Kr. J.

Hoppii. Koch. Alpen-Hundsraute.

\section{V'III. MIIULUS. $L$. Gauklerblume.}

Stg. kahl oder etwas drüsenhaarig; obere B. sitzend, untere lang gestielt; Kzähne eiförmig; Bt. ansehnlich. B. S. K. (ierw.; sonst cult.)

luteus. L. Gelbe G. Stg. drüsig-zottig; alle B. kurz gestielt; Kzähne lanzettlich; Bt. klein. B. (verv.; sonst cult.)

moschatus. Dougl. Moschuskraut.

\section{GRATIOLA. L. Gnadenkraut.}

Staude; B. sitzend, lanzettlich, klein gesägt; Bt. blattachselständig, weic o. etwas geröthet, mit unten gelblicher Röhre. Verbr. (fehlt S.)

officinalis. L. Gemeines G.

\section{LIMOSELLA. L. Sumpfglöckchen.}

B. lanzettlich-spatelig, etwas fleischig; Bt. weißlich o. lila, sehr klein. Verbr. (fehlt $K$. J.)

aquatica. $L$. Gemeines $S$.

\section{LINDERNIA. $L$. Büichsenkraut.}

Einjähriges Kraut; B. länglich-eiförmig, ganzrandig, 3 nervig, sitzend. B. M. Sclt. N. St. K. Kr.

pyxidaria. All. Europäisches B.

\section{VERONICA. L. Ehrenpreis.}

Bt. in blattachselständigen Trauben; Stauden ..... Bt. einzeln in den Blattachseln 0 . in endständigen

1 Aehren 0. Trauben; in letzterem Falle oft noch mehrere seitenständige Trauben unter der endständigen............................ 15

$2\{$ K. 4 theilig $\ldots \ldots \ldots \ldots \ldots \ldots \ldots \ldots \ldots \ldots \ldots$

K. 5theilig, der oberste Zipfel klein........... 12

(B. lanzettlich-lineal, sitzend, spitz, entfernt-rückwärts-gezähnelt; Kapsel zusammengedrückt, ausgerandet-2 lappig, quer-breiter; Bt. weiß o. rosa, manchmal blaugestreift. Verbr.

scutellata. L. Schildfrüchtiger E.

B. lanzettlich-länglich, eiförmig 0 . verkehrt-eiförmig, gesägt, gekerbt 0 . ganzrandig. 
'Trauben meist einzeln, 2-4blütig, auf langem, schaftförmigem Stiele; Stg. sehr kurz; B. fast rosettig 4 gehäuft, kurz gestielt, verkehrt-eiförmig-elliptisch. A. ............... aphylla. L. Blattloser E.

Trauben mehrere 0 . eine reichblütige...........

5 Stg. u. B. ganz kahl (nur der Btstand manchmal

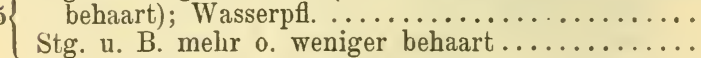

(B. sitzend, halbumfassend, spitz, lanzettlich 0 . eiförmig; Bt. blassblau, blassrosa o. weißlich....

6 B. gestielt, stumpf, elliptisch o. länglich; Kapsel rundlich, gedunsen; Bt. sattblau, dunkler geadert, selten rosa. Verbr. $u$. $h \mathrm{fg}$.

Beccabunga. L. Quellen-E.

Stg. dünn, nicht hohl; Bt. weißlich o. bläulich; Kapsel länglich-elliptisch, fast doppelt so lang als breit. M. N.J.

anagalloides. Guss. Schlamm-E.

Stg. dick, hohl; Bt. blassblau 0. rosa; Kapsel rundlich-elliptisch 0 . fast kreisrund ...............

Bt. blassblau mit dunkleren Adern; Frstiele aufrecht abstehend; Kapsel fast kreisrund. Verbr.

$8\left\{\begin{array}{l}\text { Anagallis. L. Gemeiner Wasser-E. } \\ \text { Bt. blassrosa o. weißlich; Frstiele fast wagrecht }\end{array}\right.$ abstehend; Kapsel rundlich-elliptisch. B. M. $N$. aquatica. Bernh. Bleicher Wasser-E.

Stg. 2 zeilig-behaart 0 . behaart $u$. überdies noch mit 2 dichten Haarleisten; B. eiförmig, eingeschnittengekerbt-gesägt; Kapsel 3 eckig-verkehrt-herzförmig, gewimpert; Bt. blau, selten rosa 0 . weiß.

Verbr. $u$. lifg.

Chamaedrys. $L .^{*}$ ) Gamanderartiger E.

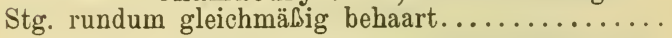

B. sitzend, eiförmig, gekerbt-gesägt, die oberen langzugespitzt; Kapsel fast kreisrund, quer-breiter; Bt. blassrosa, mit dunkleren Streifen, selten hellblau. Verbr. (fehlt B. M. Sch.)

latifolia. $L$. Nesselblättriger E.

B. gestielt; Stg. am Grunde kriechend.......... 11

B. lang gestielt, eiförmig, eingeschnitten-gekerbtgesägt; Kapsel rundlich, quer-breiter; Bt. weißlich, mit purpurblauen Streifen. Verbr. (fehlt J.) montana. L. Berg-E.

B. kurz gestielt, verkehrt-elliptisch o. länglich, gesägt; Kapsel 3 eckig-verkehrt-herzförmig; Bt. lila o. blassblau. Verbr.... officinalis. L. Grundheil.

*) Umfasst mehrere Formen! 
Die unfruchtbaren Stg. niedergestreckt, die blühenden aufstrebend; B. kur'z gestielt, lineal-lanzettlich, gekerbt-gesägt, am Grunde etwas eingeschnitten 0. ganzrandig; Bt. blassblau, selten weiß o. fleischfarben. Sch. MT. B. O. N. St. K. T.

prostrata. $L$. Niedergestreckter E. Stg. sämmtlich aufrecht 0 . aus bogigem Grunde

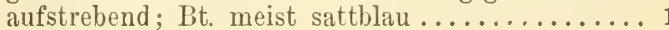

B. fiederspaltig-zerschlitzt. Südst. $K r$. J.

3 multifida. L. Schlitzblättriger E.

B. gesägt 0. gekerbt, nicht fiederspaltig ........

B. eiförmig 0. eilänglich, am Grunde fast herzförmig, sitzend. Verbr........Tencrinm. L. Großer E.

14 B. lanzettlich o. lineal, am Grunde verschmälert, sitzend 0 . kurz gestielt. $B$. M. N. O. St. K.

Austriaca. L. Oesterreichischer E.

Blkrröhre walzlich, länger als ihr Querdurchmesser, Saum mehr o. minder deutlich 2 lippig; Trauben endständig, oft mit mehreren seitenständigen Nebentrauben; Stauden ............... 16

Blkrröhre sehr kurz, die Blkr. daher radförmig 0 .

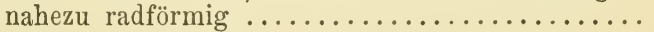

Bt. gelb; Oberlippe der Blkr. 2spaltig, Unterlippe 3 theilig; Stb. kürzer als die Blkr.

$16 \quad$ A. v. T. K. Südst. Kr.J.

lutea. (Scop.) Wettst. Gelber E. Bt. blau, violett, rosa o. weiß; Oberlippe der Blkr.

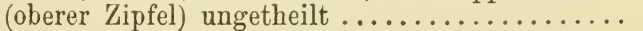

Zipfel der Blkr. ungefähr so lang als die Röhre; Stb. aus der Blkr. herausragend; Kapsel geschnäbelt-zıgespitzt. A. v. T. K. Kr. Sü̈lst.

Bonarota. L. Mänderle. Zipfel der Blkr. viel länger als die Röhre; Kapsel

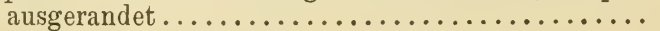

Tr. ziemlich locker, drüsenhaarig, meist mehrere; Btstiele länger als ihre Tragb.; B. gegenständig 0 . zu 3-4 wirtelig, länglich-lanzettlich 0 . lanzettlich, spitz, einfach 0 . doppelt gesägt. $B$.

spuria. $I$. Unechter E. Tr. dichtblütig, ährenförmig; Btstiele kürzer als ihre Tragb. 
B. gegenständig o. häufiger zu $3-4$ wirtelig, aus eiförmigem 0. herzförmigem Grunde lanzettlich, zugespitzt, bis zur Spitze scharf doppelt gesägt. Sch. M. B. N. Südst. Kr. (sonst cult. u. verw.)

longifolia. $L{ }^{*}$ ) Langblättriger $\mathrm{E}$.

B. stets gegenständig, meist gekerbt-gesägt, an der Spitze u. am Grunde gewöhnlich ganzrandig....

Zipfel der Blkr. beim Aufblühen vorgestreckt, zusammengelegt, nicht gewunden, an der Spitze öfters zurückgerollt, später flach; Bt. blau (selten weiß); B. meist glanzlos u. behaart.

Verbr. (fehlt $S$.) ....spicata. L.**) Aehriger E.

Zipfel der Blkr. schmal, beim Aufblühen vorgestreckt, der obere größer, zusammengelegt, die 3 anderen gewunden und meist auch an der Spitze zurückgerollt; Bt. blassblau, selten rosa, getrocknet gelblich; B. dicklich, glänzend, wenig behaart; Stg. höher. $N$. St. K. Südt.

orchidea. $\mathrm{C} r$. Knabenkrautartiger E.

Stgb. nach oben allmälig in kleine Deckb. übergehend, in deren Achseln die Bt. sitzen, welche zu (meist lockeren) Trauben o. Doldentrauben zusammengestellt sind; Btstiele stets aufrecht 0 . abstehend

Stgb. nach oben wenig verkleinert, in ihren Achseln die Bt.; Btstiele nach dem Verblühen zurückgebogen; 1 jährige Kräuter ...............

Die mittleren u. oberen B. fiederspaltig 0 . hand22 förmig getheilt, die unteren eiförmig, ungetheilt.

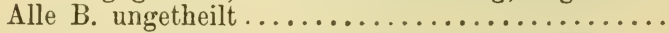

Die oberen Stgb. handförmig getheilt; Tragb. der Bt. dreitheilig; Frstiele länger als die Kapsel; Bt. dunkelblau. Verbr. .triphylla. L. Dreiblättriger E. Die oberen Stgb. fiederspaltig; Tragb. der oberen Bt. ungetheilt, lineal-lanzettlich; Frstiele so lang o. kürzer als die Kapsel ..................24

Gr. die Ausrandung der Kapsel kaum überragend; Bt. klein, himmelblau. Verbr. (fehlt $K r$. J.)

verna. $L$. Frühlings-E. Gr. die Ausrandung der Kapsel weit überragend; Bt. etwas größer, lebhaft blau; Pfl. kräftiger. B. M. N. K. T. .....Dillenii. Cr. Dillenius' E.

*) Umfasst mehrere Formen!

**) Umfasst mehrere Formen, die sich manchmal der $\mathrm{V}$. orchidea $\mathrm{Cr}$. nähern. 
Kapsel wenig o. kaum ausgerandet; Bt. in arm-

25 blütigen Doldentrauben; ausdauernde Alpenpfl... 26

Kapsel tief ausgerandet o. verkehıt-herzförmig; Stg.

u. Aeste reichblütig, locker-traubig o. traubig-ährig

Btstand rauhhaarig o. drüsig-zottig; Kapsel verkehrtciförmig, ausgerandet ..................

Btstand drüsig-flaumig, o. von gekräuselten drüsenlosen Haaren flaumig; Kapsel oval o. eiförmig; B. gekerbt 0 . ganzrandig, die untersten kleiner; halbstrauchige Pfi.

B. verkehrt-eiförmig, stumpf, meist etwas gekerbt, die unteren gröler, fast rosettig; 'Tr. drüsig-zottig; Bt. schmutzigblau. Sud.; A. v. S. T. K. St. Kr.

bellidioides. I. Ma@liebartiger E.

B. elliptisch, ganzrandig o. gekerbt, die untersten kleiner, rundlich; Tr. von abstehenden, drüsenlosen Haaren raulhhaarig; Bt. blauviolett.

Geb. v. B. N. O. S. T. K. St. alpina. L. Alpen-E.

Btstiele drüsig-flaumig; Kapsel oval, seicht ausgerandet; B. länglich, stumpf; Bt. fleischfarben mit rosenrothen Adorn. A. v. T. K. Kr. St.

fruticulosa. L. Strauchiger E.

Btstiele von gekräuselten, drüsenlosen Haaren flaumig; Kapsel eiförmig, oberwärts verschmälert, kaum ausgerandet; B. länglich o. elliptisch; Bt. azurblau, am Schlunde mit purpurnem Ringe. $A$.

fruticaus. Jacq. Felsen-E.

B. alle in den Bstiel keilförmig verschmälert, die unteren verkehrt-eiförmig-länglich, schwach gekerbt, die oberen lineal-länglich, ganzrandig; Bt. weiß o. bläulich. B. T. (eingeschleppt).

peregrina. $L$. Fremder $\mathrm{E}$.

B. in den Bstiel nicht keilförmig verschmälert.... 30

Btstiele abstehend, doppelt so lang als der K.; Kapsel quer-breiter, halb-2 spaltig, Lappen kreisrund; B. eiförmig; Bt. blau. St. K. J.

acinifolia. $L$. Thymianblättriger E.

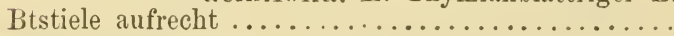

\section{8}


B iforaig. inst herzformig. gesiagt-geterbt

Wenigstos die unteren B. horformig-rundich und As: slapriz. a fast halbsreisrund und lappiz-ge-

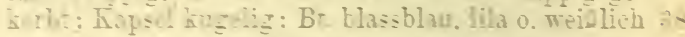

Kuyseln netzig-geadert. rerkehrt-nierenformig 0. zweihorniz. quer-breiter mit auseinan ler fabreden Lauren und stompfer Bucht: ebere Btstiele 4 - bis smal langer als die Kapsel: Bi. ziemlich arod . . Kaystn aderlos. mit spirzer buzht: B: klein .... Lappen der hapsel sitz, dis Kaysel deher abürniz: der bere Ziptel der Blisr. wnid die cbere Hallfe der 2 s-itliben Zipfel satt blau, der ubrige Theil der Bltr. weis. = (eingestheppt.

ceratocarpa. C. A. Mev. Hernfrōetiger E.

Lanpen de: Kiyst stumyt. die Kaysel daher rerGehrt-nerentiormig: Bisr. himmelblau. der untere Ziviel oft weis. ierlor

Tournefortii. Gael. Persischer E.

Haar ler hapsel groknuselt. Lamen am Pande zusammngedrukt-gek êt, 3-5 samig.

B .I. (.. I. ........ paca. Fi. Glanzloser E. Hare dar hay sal abstehend: Lavien gednnsen. mit ludeulichem hielrande

B. Geitliehzrün o. direngrün: Karsel zerstreutdrusig-behart: Blkr. milihmeis. blau gestreift. der ibere Iappen meist hellblan. Tertur. "? agrestis. I. diker-E.

B. dunistgrūn: Kaysel dicht-Haumig: Blàr. blau. skter weil Terbir. wh itg polita. Fr. Glatter E Kzipiel herftrmig: B herzformig-rundich. gekerbt. iast 5 lavtiz: Br. Gian. lila o weiolich........ 398

Kzivfi eliftisch: untere 5 . fist halb-breisrund. eimas berztormiz. lamig. j-akerbig: Bi. blãulichweis $h r . J$.

Crmbalaria. Bod. Zimbelknutartiger E.

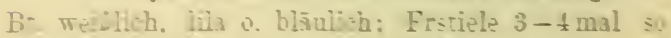
lang als der $\mathrm{K}$ : B. metst 5-9 lappig

Ter? r. un Afy hederifolia. L. Epheublätriser E. Bi. blau. Frstiele hjohstens doppels so lang a!s der $\mathrm{K}: \mathrm{B}$ Gein. meisi 3lawig. $\bar{B}$ M. .

triloba. Ugia. Ireilappiger $E$. Anmertung Der Bastart $\Gamma$. Bonaruta $\lambda$ latsa murde wiejerholt bsobschtet.

XIII. WTLFEIIA. Ja:q. Kühtritt.

B lānglich. spatelig. gesagt: Br. viclottblau. Schlun h weiblith it r. $h$.

Tarinthiaca. Jucq. Käutner $K$. 


\section{DIGITALIS. L Fingerhut.}

(Blkr. röhrig o. glockig, der mittlere Zipfel der Unter-

1 lippe viel kürzer als die Röhre............... Blkr. kurz-glockig, der mittlere Zipfel der Unterlippe fast so lang als die Röhre...................

Bt. purpurn, selten weiß, innen weiß und purpurn gezeichnet; Kzipfel rundlich-eiförmig, sich deckend; Ḱapsel kürzer als der K.

2 Sch. B. N. (theilweise verw.)

purpurea. L. Rother F.

Bt. hellgelb; Kzipfel lanzettlich, sich nicht deckend; Kapsel länger als der K..................

Stg. behaart, oben drüsig-flaumig; Blkr. grof, blassgelb, innen hellbraun gezeichnet, mit stumpfer, ausgerandeter o. etwas gezähnelter Oberlippe.

Terbr......... ambigua. MIurr. Großblütiger F. Stg. kahl o. nur an der Spitze etwas drüsig-flaumig; Blkr. klein, einfärbig, citronengelb, mit 2 zähniger Oberlippe. (B.) N. T...... . Intea. L. Gelber F.

K. wollig, mit spitzen Zipfeln; Deckb. länger als der K.; Blkr. weiblich, braunroth-geadert. N. (verw.)

lanata. Ehrh. Wolliger F.

K. kahl o. drüsig-flaumig; Blkr. von ockergelber Grundfarbe ...........................

Kzipfel lanzettlich, zugespitzt, am Rande drüsigflaumig; Blkr. braun gezeichnet, Unterlippe weiß, blassgrün geadert. Sï̀lst. $K r$.

laevigata. $I . K$. Glatter F.

Kizipfel länglich-eiförmig, abgerundet-stumpf; Blkr. innen rostfarben und braunpurpurn gezeichnet. Kr. J......... ferruginea. $L$. Rostfarbener $F$.

XV. ERINUS. $L$. Leberbalsam.

B. spatelig; Btstand nach dem Verblühen traubig; Bt. violett. A. $\nabla . T$. ...... alpinus. $L$. Alpen-L.

\section{XTI. MELAMPYRU.I. L. Wachtelweizen.}

Aehren dicht-dachziegelig, 4 kantig; Deckb. eiförmig, zurückgekrümmt, kämmig gezälınt; Bt. weißlich1 gelb o. purpurn, Unterlippe innen dottergelb. levbr. ....... cristatum. $\left.L .^{*}\right)$ Kammähriger W. Aehren nicht 4 lantig...................... 2

*) Die Deckb. sind jurpurn, bei der var. pallidum Tausch bleichgrünlich. 
(Aehren kegelförmig; Deckb. eiförmig, lanzettlich-

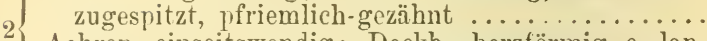
Aehren einseitswendig; Deckb. herzförmig o. lan-

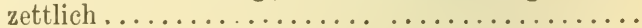

Bt. karminroth, in der Mitte mit einem weiben Ringe und einem gelben Flecke auf der Unterlippe; K. flaumig-rauh, fast so lang als die Blkrrölire; Deckb. purpurn. I erbr.

arvense. $L$. Acker-W.

Bt. gelb; K. ı auhhaarig, $3 \mathrm{mal}$ hïirzer als die Blkrröhre; Deckb. gelblichgrün, selten röthlich.

N. J. (sonst verschleppt.)

barbatum. $W . K$. Bärtiger W.

(Die oberen Deckb. mehr 0 . weniger blauviolett überlaufen*) ...

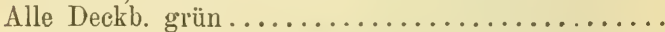

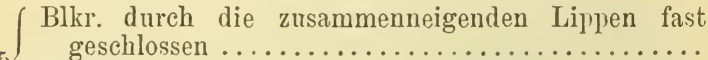

Schlund der Blkr. weit offen, Unterlippe herabge-

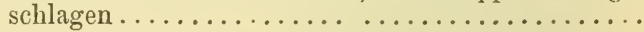

B. eilanzettlich o. länglich-lanzettlich, am Grunde abgerundet o. rasch zusammengezogen; obere Deckb. am Grunde spießförmig geöhrlt, grannig-gezähnt

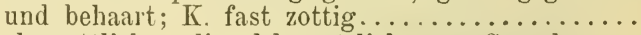

B. lanzettlich o. lineal-lanzettlich, am Grunde verschmälert; obere Deckb. am Grunde spärlich behaart, weniger gezähnt; K. spärlich behaart. $N$.

subalpinum. (Jur.) Voralpen-W.

Stg. meist ästig; B. eilanzettlich, breit, lang zugespitzt; Kzäbne zugespitzt. Verbr.

nemorosum. $L$. Blaner W.

Stg. meist einfach; B. länglich-lanzettlich, kïrzer und schmäler; Kzähne spitz; Aehren sehr dicht. M. N. . . Moravicum. H. Br. Mährischer W.

Obere Deckb. auffallend breiter als dis unteren, fast kahl, am Grunde scharf gezähnt, kurz zugespitzt, wenig länger als breit; Bt. ansehnlich; B. lanzettlich 0 . lineal-lanzettlich. $N$. St.

grandiflorum. Kern. Großblütiger W.

Obere Deckb. wenig breiter als die unteren, am Grunde behaart, weniger gezähnt, lang zugespitzt, viel länger als breit; Bt. klein; B. lineal-lanzettlich o. lineal, stets sehr schmal und lang zugespitzt. $N$. St. angustissimum. Beck. Schmalblättriger W.

*) Ausnahmsweise sind die Deckb. an Schattenformen fast ganz grün, dagegen bei M. fallax (Čelak.) manchmal die obersten etwas blau ïberlaufen. 
K. mindestens $1 / 3$ so lang als die Blkr., mit ab-

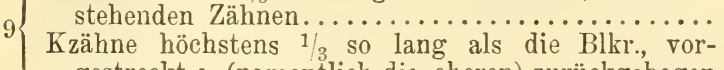
gestreckt 0 . (namentlich die oberen) zurückgebogen 11

K. spärlich behaart, kürzer als die halbe Blkr.; Deckb. am Grunde etwas behaart; Bt. mittelgrod.

$10\{$ B. M.........fallax. (Čelak.) Böhmischer W. K. kahl, so lang als die halbe Blkr.; Deckb. kahl; Bt. klein. Verbr. ....silvaticum. L.*) Wald-W.

B. eilanzettlich o. lanzettlich; obere Deckb. handförmig 5-7spaltig; Röhre der Blkr. meist weiß, seltener gelb, noch seltener purpurn überlaufen; A. gelb. Verbr. $u$. $h f g$.

commutatum. Tausch. Gemeiner W.

B. lineal-lanzettlich 0 . lineal; obere Deckb. am Grunde mit einigen Zähnen o. ganzrandig; Blkr. meist ganz gelb, seltener mit weißlicher Pöhre; A. rothbraun. Verbr. (?) ......pratense. L. Wiesen-W.

\section{TOZZIA. L. Alpenrachen.}

Stg. 4 kantig; B. sitzend, eiförmig, spärlich gekerbtgesägt. Geb. v. Sch. N. O. S. T. K. St.

alpina. L. Echter A.

\section{EUPHrasia. L. Augentrost.}

$\int$ Deckb. mindestens am Grunde ihres Randes drüsig

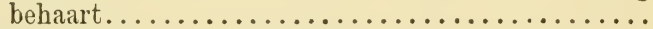

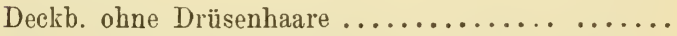

Blkr. verhältnissmäßig groß, während des Blühens sich verlängernd, ihre Röhre zuletzt ziemlich weit aus dem K. herausragend; Gr. beim Verblühen

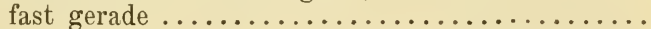

Blkr. klein o. mittelgro@, während des Blühens sich nicht verlängernd, ihre Röhre wenig o. gar nicht aus dem $K$. herausragend; Gr. stets herabgebogen

Stg. fast immer schon im unteren Theile verzweigt; obere B. spitz, einander genähert, spitz gezähnt; Deckb. meist dicht drüsig; blüht im Hochsommer und Herbst. Verbr. u. hfg.

Rostkoviana. Hayne. Gemeiner A.

Stg. unverzweigt 0 . im oberen Theile mit kurzen Aesten; B. stumpf, von einander entfernt, stumpflich gezähnt; Deckb. meist nur spärlich drüsig; blüht zu Anfang des Sommers. B. N.St. K. S. T. montana. Jord. Berg-A.

*) Die Bt. sind meist gelb, bei M. saxosum Baumg. weißlich mit purpurner Zeichnung. 
Deckb. von langen, dicht stehenden Drüsenhaaren zottig; Bt. weiß, violett gestrichelt. $A$. v. Sïdt. hirtella. Jord. Zottiger A.

Deckb. mit zertreuten, kurzen Drüsenhaaren; Bt. gelb o. violett, 0 . weis mit violetter Oberlippe...

Blkr. mittelgroß, violett; größere, meist verzweigte Pfl. T. S. K. St.

brevipila. Burn. et Gremli. Kurzhaariger A.

Blkr. klein, gelb o. weiß mit violetter Oberlippe; kleine, oft unverzweigte AIpenpfl. A. v. T. S. $K$. drosocalyx. Freyn. Drüsiger A.

B. eiförmig 0 . länglich-eiförmig, höchstens doppelt so lang als breit; reife Kapseln behaart 0 . wenigstens am Rande mit aufrecht stehenden Borsten

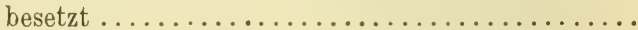

B. lanzettlich o. lineal, mindestens doppelt so lang als breit; reife Kapseln kahl o. höchstens am oberen Rande mit vereinzelten einwärts gekrümmten

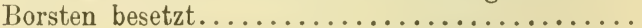

Blkr. verhältnissmäßig groß, während des Blühens sich verlängernd, ihre Röhre zuletzt ziemlich weit aus dem K. herausragend; Gr. beim Verblühen

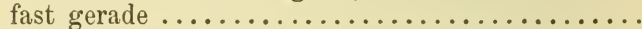

Blkr. klein 0. mittelgroß, während des Blühens sich nicht verlängernd, ihre Röhre wenig 0 . gar nicht aus dem K. herausragend; Gr. stets herabgebogen

Deckb. mit langen, fein zugespitzten, gekrümmten Zähnen; Blkr. blauviolett 0 . weißlich mit gelbgefleckter Unterlippe. A. v. Südt.

alpina. Lam. Alpen-A.

Zähne der Deckb. nicht in lange, gekrümmte Spitzen

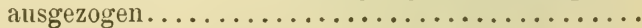

Größere, meist reichlich verzweigte Pfl.; B. spitz, die oberen mit spitzen Zähnen; Deckb. gegen den Grund allmälig verschmälert, mit grannigen Zähnen. N. O. 'T. K. Kr. J.

Kerneri. Wettst. Scharfzähniger A. Kleinere, oft unverzweigte Gebirgspfl.; Zähne der Deckb. nicht grannig verlängert........... 10

B. stumpf, mit stumpflichen Zähnen; Deckb. breit eiförmig, am Grunde rasch zusammengezogen.

Verbr. (bes. Geb.; fehlt J.)

picta. Wimm. Bunter A.

B. spitz, die oberen mit spitzen Zähnen; Deckb. eiförmig, am Grunde verschmälert. A. v. T. K. S. St.

versicolor. Kern. Farbenwechselnder A. 
B. kahl........................... 12

11 B. werigstens am Pande und an den Nerven kurz

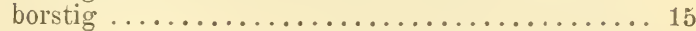

Deckb. scharf, oft grannig gezähnt; Stg. nicht auffallend dünn ...........................

12 Deckb. stumpflich gezähnt, aufgerichtet, glänzend; Stg. sehr dünn, fast fädlich, wenig o. gar nicht verzweigt; $B$. sehr klein. $B$. $M I$. N.

gracilis. Fr. Schlanker A.

Kleine, oft unverzweigte Alpenptl.; Deckb. dicht dachig gestellt; Aehre stets kurz. $A$. V. T.

pumila. Kern. Niedriger A.

Größere, meist reichlich verzweigte Pfl.; Aehre nach dem Verblühen verlängert................. 14

Deckb. den Bt. anliegend; Bt. mittelgroß; Bzälne begrannt. Verbr......... stricta. Host. Steifer A.

14 Deckb. abstehend o. zurückgekrümmt; Bt. sehr klein; Bzähne kaum begraunt. $B$.

nemorosa. Pers. Hain-A.

${ }_{15}\{$ B. stumpf.............................. 16

Wenigstens die oberen B. spitz .............. 18

Reife Kapsel länger als der K.; Alpenpft. ........ 17

16 Reife Kapsel so lang o. kürzer als der K.; Bt. violett, sehr klein. B. ...coerulea. Tausch. Violetter A.

Bt. sehr klein, bald gelb, bald weiß, bald ganz 0 . theilweise violett; Zipfel der Oberlippe nicht ausgerandet, auseinanderfahrend. A. (fehlt $K r . J$.)

minima. Jacq. Kleinster A.

Bt. mittelgroß, niemals gelb; Zipfel der Oberlippe breiter, ausgerandet, zusammenneigend.

A. v. T. K. S. O. pulchella. Kern. Hübscher A.

Obere B. 4-7zähnig; Stg. nicht auffallend dünn.. 19

18 Obere B. 3-5 zähnig; Stg. unverzweigt 0. wenig verzweigt, dünn und schlank; Bt. sehr klein.

Vora. v. J. Liburnica. Wettst. Liburnischer A.

Stg. meist reichlich verzweigt; Zähne der oberen B. u. Deckb. spitz, aber nicht begrannt; Bt. sehr
klein. $B . \ldots \ldots \ldots$ curta. $F r$. Kurzstengliger A.

$19\left\{\begin{array}{c}\text { klein. B.......... curta. Fr. Kurzstengliger A. } \\ \text { Stg. meist wenig verzweigt o. unverzweigt; Zähne }\end{array}\right.$ der oberen B. u. Deckb. begrannt; Bt. mittelgroß. N........... Tatarica. Fisch. Tatarischer A.

B. lanzettlich o. lineal-lanzettlich; Blkr. klein 0. mittelgroß .......................... 21

20 B. lineal, beiderseits $1-2$ zähnig, selten zahnlos; Blkr. vor dem Verblühen verlängert, verhältnissmäßig groß 
Obere B. u. Deckb. lanzettlich, mit kurzem Endzahn; Bt. meist weib mit violetter Oberlippe.........22

21 Obere B. u. Deckb. lineal-lanzettlich, beiderseits 3bis 4 zähnig, mit verlängertem Endzahn; Bt. blauviolett. $K r$. J....Illyrica. Wettst. Illyrischer A.

B. meist stumpf u. stumpfzähnig; Deckb. eiförmig, beiderseits mit $2-4$ begrannten Zähnen. A. v. Südt.......P.Portae. Wettst. Südtiroler A. Die oberen B. spitz, mit begrannten Zähnen; Deckb. lanzettlich 0 . eilanzettlich, selten eiförmig...... 23

Obere B. 2-5 mal länger als breit, jederseits 2- bis 3 zähnig; Deckb. beiderseits $2-5$ zähnig; Bt. sehr klein. A. u. Vora.

Salisburgensis. Funk. Salzburger A.

Obere B. 5- 8 mal länger als breit, jederseits 2 zähnig; Deckb. beiderseits $2-3$ zähnig; Bt. mittelgroß.

N. St........ Stiriaca. Wettst. Steierischer A.

B. u. Deckb. beiderseits gegen die Spitze mit einem kurzen Zahne, manchmal zahnlos; Kzipfel nicht grannig zugespitzt. Südt.

tricuspidata. L. Dreizähniger A.

B. beiderseits mit 1-2 großen, dreieckigen Zähnen; Deckb. meist beiderseits 2 zähnig; Kzipfel grannig zugespitzt. St. K. $K r$. J.

cuspidata. Host. Spitzblättriger A.

Anmerkung. Von Bastarten wurden im Gebiete bisher beobachtet: E. Kerneri $\times$ Rostkoviana, picta $\times$ Rostkoviana, Rostkoviana $X$ versicolor, Rostkoviana $X$ stricta, hirtella $X$ minima, Kerneri $X$ tricuspidata, minima $X$ versicolor, nemorosa $X$ stricta, minima $\times$ pulchella, minima $X$ Salisburgensis. Es kommen aber sicher noch andere Bastarte vor.

xix. PARENTUCELIIA. Viv. Echsenfuß.

Bt. fast kopfig gehäuft, purpurn; B. drüsenhaarig. J........ latifolia. (L.) Car. Breitblättriger L.

XX. ORTHANTHA. Kern. Gelber Augentrost. Einjähriges Kraut; Blkr. bärtig gewimpert.

Verbr. (fehlt Sch. S.)

lutea. (L.) Kern. Gemeiner g. A.

\section{ODONTITES. Gilib. Zahntrost.}

B. aus breiterem Grunde verschmälert, lanzettlich o. lineal-lanzettlich; Deckb. so lang o. länger als

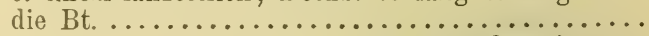

1 B. lanzettlich, zugespitzt, nach dem Grunde verschmälert; Deckb. kürzer als die Bt.; A. am Grunde gebärtet. $B . M . N$.

serotina. (Iam.) Rchb. Spätblïhender Z. 
Deckb. länger als die Bt.; A. am Grunde schwach gebärtet; Kapsel fast gestutzt Verbr.

Deckb. so lang als die Bt.; A. kahl; Kapsel stumpflich; Pfl. größer und sehr ästig. Südt. J.

Kocliii. Schltz. Istrianer Z.

XXI. BARTSCHIA. L. Alpenhelm.

B. gegenständig, eiförmig, fast umfassend, stumpfgesägt. Geb............alpina. L. Gemeiner A.

XXIII. ALECTOROLOPHUS. All. Klappertopf.

${ }_{1}$ Zähne der Oberlippe rundlich, kurz, nicht länger als

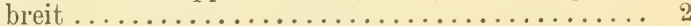

Zähne der Oberlippe doppelt so lang als breit.... 3

Stg. unverzweigt o. mit wenigen Aesten, welche in der Nähe des Btstandes entspringen $u$. oft selbst Bt. tragen; blüht im Frühsommer. Verbr. $u$. hfg. minor. (Ehrh.) Wimm. et Grab. Kleiner K.

Stg. stets verzweigt; zwischen den obersten Aesten

ı. dem mittleren Btstande stehen mindestens

2 Bpaare; blïht im Spätsommer. T. S. St. stenophyllus. (Schur.) Sterneck. Aestiger K.

$\int$ Unterlippe der Blkr. aufrecht, den Schlund verschliebsend .........................

Unterlippe der Blkr. abstehend, der Schlund daher geöffnet..$\ldots \ldots \ldots \ldots \ldots \ldots \ldots \ldots \ldots$.

$4\{$ K. kahl o. fast kahl, nur am Rande dentlich behaart

K. auf der Fläche behaart..................

Stg. unverzweigt 0 . mit wenigen Aesten, welche in der Nähe des Btstandes entspringen 11 . oft selbst Bt. tragen ; blüht im Frühsommer.

B. M. Sch. N. O. S.

major. (Ehrh.) Rchb. Grober K.

Stg. stets verzweigt; $z$ wischen den obersten Aesten u. dem mittleren Btstande stehen mindestens 2 Bpaare; blüht im Spätsommer. B. MI. Sch. N.

serotinus. (Schönh.) Bcck. Spätlıïhender K.

K. mit längeren weißlichen Wollhaaren bekleidet.. 7

6 K. mit kurzen Härchen besetzt; Stg. verzweigt, ziemlich dicht behaart; Bt. groß. $K r$. J.

Freynii. (Kern.) Sterneck. Freyn's K. 
B. länglich 0 . lineal-länglich, mit unverzweigten Seitennerven; Stg. nicht immer verzweigt; zwischen den obersten Aesten u. dem mittleren Btstande steht höchstens 1 Bpaar. Verbr.

hirsutus. All. Rauhhaariger K.

B. elliptisch, wenigstens einige der Seitennerven verzweigt; Stg. stets verzweigt; zwischen den obersten Aesten u. dem mittleren Btstande stehen stets mehrere Bpaare. $T$.

ellipticus. Hausskn. Breitblättriger K.

Stg. unverzweigt 0 . mit einigen dem Btstande genäherten Aesten......................

Stg. reichlich verzweigt, mit mehreren Bpaaren zwischen den obersten Aesten u. dem mittleren Btstande; Deckb. mit langbegrannten Zähnen; K. klein. A. u. Vora.

angustifolius. (Gmel.) Heynh. Schmalblättriger K.

Wenigstens die oberen Deckb. mit langbegrannten Zähnen; K. meist ohne dunkle Flecken. A. u. Vora. lanceolatus. (Neilr.) Sterneck. Lanzettblättriger $\mathrm{K}$.

Zähne der Deckb. nicht begranut; K. meist dunkel gefleckt. Sud.

pulcher. (Schumm.) Wimm. Schöner K.

A nmerkung. In $S$. wurde A. hirsutus $X$ major beobachtet.

\section{PEDICULARIS. L. Läusekraut.}

Blkrröhre in einen glockigen, durch die zusammenneigenden Lippen geschlossenen Schlund erweitert; Babschnitte eilänglich, stumpf, doppelt gekerbt; grobe Staude; Bt. schwefelgelb, mit blutrothem Rande der Unterlippe. S. St.

Sceptrum Carolinum. L. Karlsscepter. Blkrröhre nicht glockig erweitert .............

Oberlippe der Blkr. vorne geschnäbelt, Schnabel an

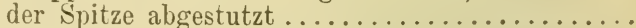

2 Oberlippe nicht geschnähelt, gerade 0 . sichelförmiggekrümmt, an dem meist nicht breiten Ende helmartig, stumpf $\ldots \ldots \ldots \ldots \ldots \ldots \ldots \ldots$. 
(Bt. gelb; K. bis zur Mitte 5 spaltig, mit gezähnten Zipfeln; B. tief doppelt-fiederspaltig, Fiederchen

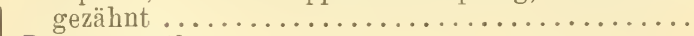
Bt. rosenroth 0. purpurn ................ 6

Stg. u. Bstiele dicht zottig; Kzipfel innen kahl; Traube kurz. A. v. T. S. K. $K r$.

tuberosa. $L$. Knolliges $\mathrm{L}$.

5 Stg. höher, 2-3 zeilig behaart, sonst kahl; Kzipfel innen flaumig; Traube verlängert.

A. v. Sï̈lt. K. $K r$. J.

elongata. Kern. Verlängertes L.

Oberlippe der Blkr. plötzlich in einen verlängerten, linealen, an der Spitze abgeschnittenen u. ausgerandeten Schnabel verschmälert ............

Oberlippe allmälig in einen kurz-kegelförmigen, an der Spitze abgeschnittenen Schnabel verschmälert; die längeren Stf. über der Mitte bärtig........

Stg. verlängert, reichblättrig; Kzipfel ganzrandig, gerade, die längeren so lang als die Blkrröhre; Btstand locker. A. (fehlt J.)

incarnata. Jacq. Fleischrothes L.

Stg. niedrig, armblättrig o. blattlos; Kzipfel gekerbt, an der Spitze zurückgekrümmt, 3 mal kürzer als die Blkrröhre

Unterlippe der Blkr. am Rande dicht gewimpert; K. länglich-glockig, kahl o. am Rande u. auf den Nerven flaumig; die 2 längeren Stf. am Grunde 11. an der Spitze spärlich behaart, seltener kahl. $A$. rostrata. L. Geschnäbeltes L. Unterlippe der Blkr. kahl; K. gleichmäßig zottig 0 . flaumig, selten kahl

K. wollig-zottig; die 2 längeren Stf. über der Mitte gewimpert; Bfiedern eiförmig, buchtig, fiederspaltig 0. grob gezähnt. A. v. T. S. O. St. K.

asplenifolia. Flörtie. Streifenfarnblättriges L.

K. Alaumig, selten kahl; die längeren Stf. an der Spitze dicht bärtig; Bfiedern länglich, doppelt eingeschnitten gezähnt. A. v. T. S. K. $K r$.

caespitosa. Sieb. Rasiges L.

K. röhrig-glockig, kahl, am Rande u. auf den Nerven flaumig, Zipfel zurückgekrümmt, kürzer als die Kröhre. A. v. N. St. S. K.

geminata. Portschlg. Zweiblütiges L.

K. glockig, bis über die Mitte 5 spaltig, dicht flanmig, Zipfel fiederspaltig o. gezähnt, gerade; die oberen Deckb. 3 spaltig. A. v. Südt.

gyroflexa. Vill. Büscheliges T, 
11 Bt. fleischroth o. rosa, nur ausnahmsweise weiß ... 12

Bt. citronengelb o. gelblichweiß............ 14

Schnabelzähne klein, pfriemlich; K. 2 lappig, Lappen kraus; Stg. aufrecht, vom Grunde an ästig. Verbr.

palustris. $L$. Sumpf-L. Schnabelzähne 3 eckig-pfriemlich; K. 5 zähnig 0 . 5 spaltig . . . . . . . . . . . . . .

Hauptstg. aufrecht u. vom Grunde an blütentragend, Nebenstg. hingestreckt; Oberlippe der Blkr. etwas sichelförmig; K. 5 zähnig, Zähne oberwärts gezähnt. B. MI. Sch. N. O. St.....silvatica. L. Wald-L. Stg. einfach; Oberlippe deutlich sichelförmig; K. 5 spaltig mit zottigen Kanten, Zähne klein-gesägt. B. (Riesengebirge). Sudetica. Willd. Sudeten-L. Kzähne sehr kurz, eiförmig, stumpf, breiter als lang; $\mathrm{K}$. an den Kanten flaumig; Bzipfel stachelspitziggesägt. A. v. Südt. comosa. L. Schopfblütiges L.

14 Kzähne lanzettlich, spitz, 2-3 mal länger als breit; K. eiförmig, von längeren Haaren wollig. Vora. v. J.

Friderici Augusti. Tomm. Friedrich August's L. Btstiele grundständig; Oberlippe sichelförmig, abgerundet-stumpf, am Rande zottig; Bt. röthlichweiß.

$15 \quad K r . J$. Südt. .... acaulis. Scop. Stengelloses L. Bt. in Aehren 0. Trauben; Oberlippe gerade 0. fast

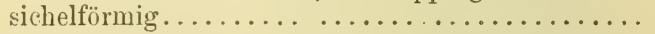

Stgb., Deckb. u. Bt. quirlig o. erstere gegenständig; $\mathrm{K}$. aufgeblasen, rauhbaarig; Bt. purpurn. $A$.

verticillata. $L$. Quirliges L.

B., Deck. u. Bt. schraubig gestell ..............

Oberlippe der Blkr. rauhhaarig; K. glockig, ungetheilt, auf den Kanten zottig, 5 zähnig, Zähne viel kürzer als die Röhre; Stf. an der Spitze dicht bärtig; Bt. schwefelgelb. A. u. Vora.

foliosa. L. Beblättertes $\mathrm{L}$.

Oberlippe kahl o. nur sehr wenig behaart........ 18

K. halb-2 spaltig, vorne zottig, 3-5zähnig, Zähne sehr kurz, 3 eckig; die längeren Stf. an der Spitze dicht-bärtig; Bt. schwefelgelb.

Vora. v. Sïdt. $K r$. J.

Summana. Spr. Veroneser L.

K. 5 zähnig 0 . fast bis zur Hälfte 5 spaltig....... 19

K. glockig, kahl, Zähne ungleich, lanzettlich, spitz; B. tief-fiederspaltig, Fiedern lanzettlich, fiederspaltig-gezähnt; Bt. rostbraun-purpurn. $A$.

recutita. $L$. Gestutztes L.

K. röhrig-glockig, wollig o. zottig; Oberlippe der

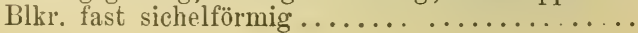


Bt. rosenroth; Kzähne gleich, lanzettlich-pfriemlich, spitz; untere Deckb. fiederspaltig-gezähnt; Bfiedern schmal-lanzettlich, spitz-gesägt. $A$.

rosea. Wulf. Rosenrothes L.

20 Bt. citronengelb, meist mit einem rothen o. dunkelpurpurnen Flecke; Kzähne ungleich, lanzettlich, an der Spitze zurückgekrümmt; untere Deckb. fiederspaltig-gekerbt; Bfiedern oval.

A. v. T. K. St........Oederi. Vahl. Buntes L.

Anmerkung. Von Bastarten sind im Gebiete gefunden worden: $P$. incarnata $X$ tuberosa, rostrata $X$ tuberosa, gyroflexa $X$ tuberosa, recutita $X$ tuberosa, elongata $X$ gyroflexa, incarnata $X$ recutita, rosea $X$ rostrata.

LXXXVI. Familie. Utriculariaceae. Wasserschlauchgewächse.

Zarte, ausdauernde Gewächse, theils an feuchten Orten, theils direct im Wasser lebend. B. entweder ungetheilt und Rosetten bildend, 0 . in haarförmige Zipfel fiederig zerschlitzt und dann im Wasser untergetaucht. Bt. zwittrig, unregelmäßig, einzeln 0. in lockeren Trauben am Ende ganz blattloser 0. nur beschuppter Schäfte. K. 2 blättrig 0.5 theilig. Blkr. verwachsenblättrig, 2 lippig, gespornt. Stb. 2, am Grunde der Blkr. eingefügt. Frkn. 1, oberständig, 1 fächerig, mit zahlreichen Samenknospen. Gr. sehr kurz, mit ungleich 2 lappiger N. Fr. eime Kapsel. S. ohne Nährgewebe.

\section{Gattungen.}

Pflanzen feuchter Orte; B. in grundständigen Rosetten, ungetheilt; Bt. einzeln; K. 5 theilig.

Pinguicula. I.

Wasserpfl.; B. im Wasser untergetaucht, in haarförmige Zipfel getheilt und Schläuche tragend; Bt. in lockeren, meist armblïtigen Trauben; $K$. 2 blättrig . .............. Utricularia. II.

\section{Arten.}

I. PINGUICULA. L. Fettkraut.

Sporn kegelförmig; Kapsel zugespitzt; Bt. weiß mit 1-2 citronengelben Flecken.

Verbr. (bes. A.; fehlt B. MI. Sch.)

alpina. $L$. Alpen-F.

Sporn pfriemlich; Kapsel eiförmig; Bt. violett, oft mit 2 weißen Flecken o. Linien. Verbr.

vulgaris. L.*) Gemeines $\mathrm{F}$.

*) Umfasst mehrere Formen! 


\section{UTRICULARIA. I. Wasserschauch.}

B. zweizeilig gestellt, theils wiederholt getheilt mit linealen, wimperig-gezähnelten Zipfeln, aber meist ohne Schläuche, theils wenig getheilt und einigge Schläuche tragend; Frstiele aufrecht 0 . abstehend

B. zwar zweizeilig gestellt, aber nach allen Seiten abstehend, alle wiederholt getheilt mit linealen 0 . haarförmigen Zipfeln und meist auch Schläuche tragend; Frstiele zuletzt zurückgebogen.........

Sporn fast so lang als die Unterlippe der Blkr., ziemlich gleich dünn; Blkr. schwefelgelb, an der Oberlippe und am Gaumen purpurn gestreift. Verbr. (fehlt J.)

intermedia. Hayne. Mittlerer W.

Sporn viel kürzer als die Unterlippe der Blkr., kegelförmig verschmälert; Blkr. blass citronengelb, nur am Gaumen bräunlich gestreift; Pfl. zarter. $B$. ochrolenca. Hartm. Blassgelber W.

Bripfel entfernt-borstig-gewimpert; Traube 4- bis 10 blütig; Blkr. citronen- o. dottergelb, am Gaumen orange gestreift, mit nicht 0 . kaum ausgerandeter

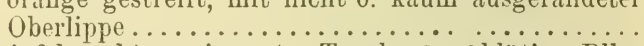

Bzipfel nicht gewimlert; Tranbe 2-6 blütig; Blkr. blassgelb, am Gaumen röthlich gestreift, mit deut-

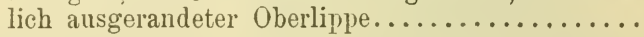

Btstiele 2-3 mal so lang als ihre Tragb.; Oberlippe der Blkr. kaum länger als der 2 lappige Gaumen, Unterlippe mit zurückgeschlagenen Rändern, kürzer als der Gaumen; Blkr. dottergelb. Verbr.

vuigaris. $L$. Gemeiner W.

Btstiele 3-5 mal so lang als ihre Tragb.; Oberlippe der Blkr. viel länger als der kurze, abgerundete Gaumen, Unterlippe fast flach, länger als der Gaumen; Blkr. citronengelb; Pfl. zarter. $B$.

neglecta. Lehm. Uebersehener W.

Kb. zugespitzt; Sporn sehr kurz, kegelförmig; Unterlippe der Blkr. eiförmig, mit zurückgeschlagenen

$5\left\{\begin{array}{l}\text { Rändern. Verbr.......... minor. } L \text {. Kleiner W. } \\ \text { Kb. kurz stachelspitzig; Unterlippe kreisrund, flach; }\end{array}\right.$ Pfl. weniger zart. T. $K$. $K r$.

Bremii. Heer. Brem's W.

\section{Familie. Orobanchaceae. Sommerwurz-} gewächse.

Ein- bis mehrjährige, nicht grüne Schmarotzerpflanzen, welche den $\mathrm{Wz}$. anderer Pfl. aufsitzen und an Stelle der B. schraubig gestellte Schuppen tragen. Bt. in endständigen 
Aehren o. Trauben, zwittrig, unregelmäßig. K. entweder 2blättrig mit ungetheilten 0 . 2 spaltigen, oft an einer Seite mit einander verwachsenen Kb., oder 4-5 spaltig. Blkr. verwachsenblättrig, rachenförmig-2lippig; Oberlippe ungetheilt 0. 2 lappig, Unterlippe 3 zähnig 0. 3 spaltig. Stb. 4, zweimächtig, der Blkrröhre eingefügt. Frkn. 1, oberständig, 1 fächerig, mit zahreichen Samenknospen. Gr. 1; N. oft 2bis 4 lappig. Fr. mehr o. weniger deutlich $2 \mathrm{klappig}$ aufspringend. S. mit Nährgewebe; Keimling sehr klein, ohne Keimb.

\section{Gattungen.}

Wst. weiblich, verzweigt, dicht mit fleischigen Schuppen besetzt, auf Wurzeln von Holzgewächsen aufsitzend; Stg. niedrig, anfangs nickend, blassrosa 0 . fast weiß; Btstand einseitswendig; $K$. 4 spaltig; Blkr. vor der Frreife ganz abfallend.

Lathraea. II. Stg. am Grunde (unter der Erde) knollig verdickt, mit dieser Verdickung auf Wurzeln von Kräutern o. Stauden, seltener von Holzpflanzen aufsitzend; Stg. stets aufrecht; Btstand allseitswendig; K bald 2 blättrig, bald 4-5 spaltig; Blkr. vor der Frreife über dem Grunde abspringend.

Orobanche. I.

\section{Arten.}

\section{OROBANCHE. $L$. Sommerwurz.}

(Jede Bt. von einem Deckb. u. 2 Vorb. gestützt; K. ringsum geschlossen, 4-5 spaltig; Blkr. mehr 0 . weniger blau 0 . lila überlaufen...............

1 Jede Bt. nur von einem Deckb. gestützt; Vorb. fehlen; K. 2 blättrig, die beiden Kb. manchmal vorne mit einander verwachsen, ungetheilt 0. 2-

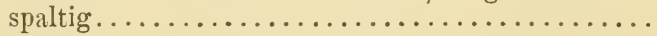

$2\{$ Stg. ästig (nur ausnahmweise unverzweigt) .......

Stg. unverzweigt (nur ausnahmsweise ästig) .......

Kzipfel eiförmig - dreieckig, pfriemlich - zugespitzt, kürzer als die Kröhre; Blkrröhre nahezu gerade;

3 Bt. klein, blau o. lila überlaufen; wächst am häufigsten auf Hanf. Verbr. ramosa. L. Aestige S. Kzipfel pfriemlich 0. lanzettlich-pfriemlich, so lang als die Kröhre; Blkrröhre vorwärts gebogen.....

Zipfel der Blkr. spitz; Bt. klein, in kurzen, lockeren Trauben, blauviolett. J...nana. Nö̈. Niedrige S.

4 Zipfel der Blkr. abgerundet; Bt. groß, in dichten, meist reichblütigen Trauben, bläulich-lila. $J$.

Muteli. Schltz. Mutel's S. 
A. kall, seltener am Grunde etwas behaart .......

A. gegen den Grund zu wollig-zottig; Blkr. blanviolett, mit trichterig erweiterter Röhre und abgerundeten Zipfeln der Unterlippe; wächst auf $A r$ temisia campestris. B. M. N. St. K. S. T.

arenaria. Borki. Sand-S.

Kzähne und meist auch der obere Theil des Stg. weißwollig; Blkr. groß, lebhaft blauviolett; Stg. sehr spärlich beschuppt; wächst auf Achillea- u. Artemisia-Arten. Verbr. (fehlt Sch.)

purpurea. Jacq.*) Blaue S.

Pfl. nirgends weißwollig; Blkr. ziemlich klein, hell lila; Stg. niedriger, reichlich beschuppt; wäcbst auf Artemisia-Arten. $N$.

caesia. Richb. Weißwollige s.

Bt. blauviolett; N. weißlich; Blkrröhre am Grunde bauchig-erweitert, dann eingeschnürt und gegen den Saum wieder erweitert; Stb. in der Mitte der

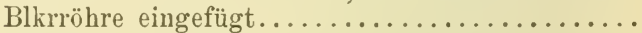

Bt. nicht blauviolett; N. gelb, purpurn, rothbraun o. violett; Blkrröhre nach oben hin erweitert, in der Mitte nicht eingeschnürt; Stb. meist unter der

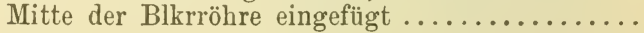

K., Deckb. und der obere Theil des Stg. spinnwebig weißwollig; Blkr. weiß behaart; wächst auf Artemisia campestris. B. M. N. O.

8 coerulescens. Steph. Bläuliche S. Pfl. ohne weiße Wollhaare; Blkr. ziemlich kahl; Bt. kleiner; wächst auf Artemisia-Arten. $J$.

cernua. Löfl. Spanische S.

$9\left\{\begin{array}{c}\text { N. gelb**), manchmal init purpurbraunem Rande } \\ \text { umzogen o. beim Abblühen sich bräunend ...... }\end{array}\right.$

$\mathrm{N}$. purpurn, rothbraun 0 . violett $\left.{ }^{*}\right)$........... 19

Blkr. außen gelb und gegen den Saum zu purpurn überlaufen, innen glänzend trüb-blutroth (sehr selten ganz gelb); N. gelb mit purpurbraunem Rande; wächst auf Leguminosen und riecht meist nach Nelken. Verbr. (fehlt Sch.)

gracilis. Sm. Blutrothe S.

Blkr. innen nicht glänzend trüb-blutroth........ 11

*) O. Bohemica Čelak. (B.) ist kräftiger, sehr reichund dichtblütig und hat gezähnelte Kzipfel.

**) Das Merkmal der Narbenfarbe ist insoferne nicht ganz constant, als man bei Arten, deren $\mathrm{N}$. gewöhnlich ilunkel gefärbt sind, vereinzelt auch Exemplare mit gelblichen $\mathrm{N}$. antrifft. 
Stf. am Grunde mehr o. weniger dicht behaart.... 12 Stf. am Grunde kabl, nur oben drüsig behaart; N. gelb mit purpurbraunem Rande; Blkr. drüsig behaart; wächst auf Leguminosen und riecht unangenehm. Südt.

Rapum Genistae. Thuill. Ginster-S.

Blkrröhre schlank, vor dem Saume etwas eingeschnürt, gegen den Grund zu am weitesten, auben weißlich mit röthlichen Adern, oben blassviolett überlaufen; wächst auf Epheu. Südt. J.

Hederae. Duby. Epheu-S.

Blkrröhre gegen den Saum zu erweitert, meist oberhalb der Mitte am breitesten ..............

Blkrröhre auf dem Rücken gerade, erst gegen den Saum zu vorwärts gekrümmt, außen meist röthlichgelb; Pfl. geruchlos; wächst auf Leguminosen. Terbr. (fehlt Sch.) .....lutea. Baumg. Gelbe S. Blkrröhre auf dem Rücken vom Grunde bis zum Saum ziemlich gleichmäßig gekrümmt........ 14

Aehre reich- $u$. dichtblütig, nur die untersten Bt. manchmal locker gestellt; Stg. stets reichlich be-

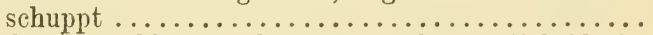
Aehre reichblütig, aber nur anfangs dichtblütig, später verlängert u. lockerblütig; Stg. nur unten

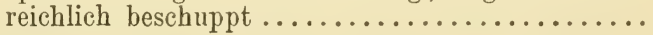

Blkrröhre oberhalb der Einfügungsstelle der Stb. allmälig erweitert, außen anfangs rosenroth, später mehr gelblich; Oberlippe der Blkr. undeutlich 0. gar nicht ausgerandet; Kzipfel undeutlich nervig; wächst auf Centaurea- u. Echinops-Arten. $V e r b r$. (fehlt $T$. $K r$.) . .... major. $L$. Große S. Blkrröhre oberhalb der Einfügungsstelle der Stb. bauchig-aufgeblasen, außen violettbraun o. gelblich; Oberlippe der Blkr. tief ausgerandet; Kzipfel deutlich längsnervig .

Stg. sehr kräftig, am Grunde keulig verdickt; Stf. unten dicht behaart, oben zerstreut drüsenhaarig; wächst auf Laserpitium Siler. $N$.

Laserpitii Sileris. Reut. Bergkümmel-S. Pfl. in allen Theilen schwächer u. kleiner; Stf. unten behaart, oben fast kahl o. sehr spärlich drüsenhaarig; wächst auf Peucedanum- u. LibanotisArten. B. M. N. Alsatica. Kirschl. Hirsehwurz-S. 
Oberlippe der Blkr. tief ausgerandet, mit am Rande fast kahlen, zuletzt zurückgeschlagenen Zipfeln; Blkr. klein, gelblich, gegen den Saum zu schwach röthlich; Stf. oben drüsenhaarig; wächst auf Petasites-, Tussilago- u. Adenostyles-Arten.

N. O. S. St. J. T. ...flava. Mart. Pestwurz-S. Oberlippe der Blkr. mit am Rande drüsenhaarigen, vorgestreckten 0. abstehenden Zipfeln; Stf. oben fast kahl o. sehr spärlich drüsenhaarig

Oberlippe der Blkr. schwach o. gar nicht ausgerandet, zuletzt abstehend; Gr. reichlich drüseuhaarig; wächst auf Salria-Arten. Vora. (fehlt J.)

Salviae. Schltz. Salbei-S. Oberlippe der Blkr. tief ausgerandet, gerade vorgestreckt; Gr. kahl o. sehr spärlich drüsenhaarig; wächst auf Berberis u. auf Rubus-Arten. T. S.

Incorum. $A$. $B r$. Hain-S.

Der obere Theil der Blkr. mit dunkilen, purpurnen o. violetten, oft auf Knötchen aufsitzenden Drüsenhaaren besetzt $u$. daher wie punktirt .......... Blkr. mehr o. weniger reichlich mit hellen Drüsenhaaren bekleidet, daher nicht punktirt erscheinend

Stg. am Grunde wenig o. gar nicht verdickt; Kzipfel deutlich 1-3 nervig; Blkr. rosenroth 0. etwas gelblich, mit wenig ausgerandeter Oberlippe; Stf. oben reichlich drüsenhaarig, ebenso der Gr.; wächst auf Labiaten. Verbr. (fehlt Sch.)

alba. Steph. Helle S.

20 Stg. am Grunde verdickt; Kzipfel undeutlich nervig; Blkr. gelblich u. violett überlaufen, mit tief ausgerandeter Oberlippe; Stf. oben sehr spärlich drüsenhaarig, ebenso der Gr.; wächst auf distelartigen Compositen, ferner auf Scabiosa- $\mathrm{u}$. Knautia-Arten. B. M. N. O. St. K. S. 'T'

reticulata. Wallr. Distel-S.

Blkr. grof, etwa doppelt so lang als der K. (o. noch länger), von gelblicher 0 . bräunlicher Grund-

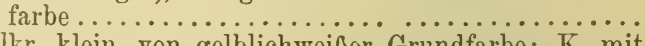

Blkr. klein, von gelblichweißer Grundfarbe; K. mit seinen langen, pfriemlich-zugespitzten Zipfeln stets

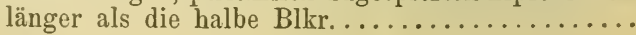


Blkr. am Rï̈cken sanft gekrümmt, bräunlichgelb 0 . röthlich, mit gerade vorgestreckter (erst zuletzt abstehender) Oberlippe; Stf. fast am Grunde der Blkrröhre eingefügt; $\mathrm{N}$. karminroth; wächst anf Rubiaceen. Verbr.

caryophyllacea. Sm. Labkraut-S.

Blkr. am Rücken gerade, erst oben vorwärts gebogen, violettbraun, mit abstehender Oberlippe; Stf. über dem Grunde der Blkrröhre eingefügt; N. braunpurpurn; wächst auf Teucrium-Arten.

N. O. S. St. K. T.

Tencrii. Holandre. Gamander-S.

Schlund der Blkr. weit geöffnet, Oberlippe zurück-

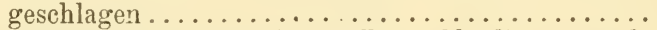

Schlund der Blkr. wenig geöffnet, Oberlippe gerade vorgestreckt; Blkr. klein, gelblichweis mit lilafarbenen Adern; Stf. spärlich behaart, oben oft kahl; wächst am häufigsten auf Klee.

Verbr. (fehlt Sch.) ....minor. Sutton. Kleine S.

Deckb. die Blkr. überragend; Kb. meist bis gegen den Grund zu 2 spaltig; Stf. oben zerstreut drüsenhaarig; wächst auf Artemisia campestris.

B. M. М. O. K. T...loricata. Rchb. Beifuß-S. Deckb. die Blkr. nicht überragend; Kb. höchstens bis über die Mitte 2 spaltig; Stf. oben meist kahl; wächst anf Compositen u. Umbelliferen.

B. N. O. Sülst. J. Picridis. Schltz. Bitterkraut-S.

\section{LATHRAEA. $L$. Schuppenwurz.}

Stg. unten kahl, oben drüsig-flaumig; Bt. nickend, blassrosa 0 . fast weiß. Verbr.

Squamaria. L. Gemeine Sch.

\section{Familie. Globulariaceae. Kugelblumen- gewächse.}

Stauden o. kleine Halbsträucher. B. schraubig gestellt, ungetheilt, ohne Nebenb. Bt. zwittrig, dentlich unregelmäßig. K. うspaltig. Blkr. verwachsenblättrig, 2 lippig, mit 5 schmalen Zipfeln, von denen 2 kürzere (manchmal verkümmerte) die Oberlippe, 3 längere die Unterlippe bilden. Stb. 4, 2 mächtig, der Blkrröhre eingefügt. Frkn. 1, oberständig, 1 fächerig, mit einer einzigen Samenknospe. Gr. 1; N. 2 spaltig. Fr. nicht aufspringend, von dem bleibenden $\mathrm{K}$. eingeschlossen. S. mit Nährgewebe. 


\section{Gattung.}

Bt. klein, blau o. hellviolett (ausnahmsweise auch weiß), zu endständigen Köpfchen zusammengestellt.

Globularia. I.

\section{Arten.}

\section{GLOBULARIA. L. Kugelblume.}

Staude mit beblättertem Stg.; Grundb. spatelig, meist ausgerandet 0 . vorne 3 zähnig; Stgb. zahlreich, lanzettlich. Verbr. (fehlt Sch. S.)

Willkommii. Nym. Gemeine K.

Stg. nur mit einigen Schuppen bekleidet 0 . ganz

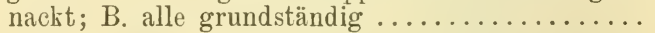

Stande mit Wst.; Grundb. groß, länglich-keilig, an der Spitze meist abgerundet; Stgschuppen nicht gewimpert, manchmal fehlend; Oberlippe der Blkr. verkümmert. $A$. (fehlt $J$.) nuclicaulis. $L$. Nacktstenglige K. Kleine Halbsträucher mit niederliegenden Stämmchen; Grundb. klein; Stgschuppen gewimpert; Oberlippe der Blkr. deutlich entwickelt ........

B. keilig-verkehrt-eiförmig, an der Spitze ausgerandet o. 3 zähnig; äußere Deckb. des Köpfchens gegen den Grund zu am breitesten, lang zugespitzt.

A. u. Vora. ....cordifolia. L. Herzblättrige K.

B. spatelförmig, kurz zugespitzt, seltener abgerundet; äußere Deckb. des Köpfchens breiter, kurz zugespitzt, gegen den Grund zu stark verschmälert. A. v. Sü̈st. K. Kr. J.

bellidifolia. Ten. Maßliebblättrige $\mathrm{K}$.

\section{Familie. Acanthaceae. Acanthusgewächse.}

Ansehnliche Stauden mit großen, fiederförmig getheilten, gröbtentheils grundständigen, zum Theile aber auch am Stg. gegenständigen B., ohne Nebenb. Bt. zwittrig, unregelmäßig, in steifen, dicken, endständigen Aehren. K. ursprünglich aus $5 \mathrm{~Kb}$. bestebend, aber durch Verwachsung der 2 unteren Kb. 4 theilig; der obere Kzipfel sehr grob, helmartig, die 2 seitlichen am kleinsten. Blkr. mit kurzer Röhre und großer 3 lappiger Unterlippe; Oberlippe fehlend. Stb. 4, etwas ungleich, mit dicken, steifen Stf. und paarweise zusammenneigenden A. Frkn. 1, oberständig, 2 fächerig, mit 2 Samenknospen in jedem Fache. Gr. verlängert, mit 2 spaltiger $\mathrm{N}$. Fr. eine 2 klappig aufspringende, 3-4 samige Kapsel. S. ohne Nährgewebe. 


\section{Gattung.}

Bt. von starren, stachelig-gezähnten Deckb. gestützt; Blkr. wei@ o. etwas röthlich ...... dcanthus. I.

\section{Arten.}

\section{ACANTHUS. $L$. Acanthus.}

Bfiedern im Umrisse breit eiförmig, gestielt, eingeschnitten-gezähnt; seitliche Kzipfel rundlich-verkehrt-eiförmig, sehr stumpf, kahl. $J$.

longifolius. Host. Langblättriger A. Bfiedern in Umrisse länglich, die meisten am Grunde zusammenfließend, buchtig - gezähnt; seitliche Kzipfel eiförmig, spitz, am Rande flaumig; Bt. etwas größer. J. $K r$. mollis. $L$. Weichblättriger A.

\section{Familie. Plantagineae. Wegerichgewächse.}

Kräuter, Stauden o. Halbsträucher. B. ungetheilt, selten fiederspaltig, sehr häufig in grundständigen Rosetten, manchmal aber auch am Stg. gegenständig. Nebenb. fehlen. Bt. zwittrig, seltener 1 häusig, regelmäßig. K. $(3-) 4$ theilig, bei weiblichen Bt. meist 3 blättrig. Blkr. trockenhäutig, verwachsenblättrig, mit 4 (bei weiblichen Bt. undeutlichen) Zipfeln. Stb. 4, gleichlang. Frkn. 1, oberständig, 2-4 fächerig, mit 1 o. mehreren Samenknospen. Gr. 1, verlängert, ungetheilt. Fr. meist ringsum aufspringend und dann gewöhnlich 2- o. mehrsamig, seltenel 1 samig und nicht aufspringend. S. mit Nährgewebe.

\section{Gattungen.}

(Bt. zwittrig, in (oft köpfchenförmigen) Aehren; Fr. aufspringend, 2- bis mehrsamig....Plantago. I. Bt. 1 häusig, die männlichen einzeln an langen Stielen, die weiblichen zu 2-3 am Grunde dieser Stiele sitzend; Fr. 1 samig, nicht aufspringend.

Litorella. II.

\section{Arten.}

\section{PLANTAGO. L. Wegerich.}

Stg. beblättert, oft ästig; B. lineal, ganzrandig,

1 gegenständig; Aehrenstiele blattachselständig.... Alle B. grundständig, rosettig; Aehren an der Spitze

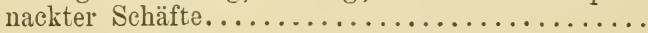

Einjährige Kräuter; Kzipfel lanzettlich 0 . die 2

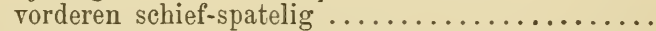

Halbstrauch; die vorderen Kzipfel breit-eiförmig, stumpf, stachelspitzig, die hinteren schmäler, gekielt, am Kiele gewimpert; die oberen Deckb. stachelspitzig. $N$. (Baden.)

Cyuops. L. Strauchiger W. 
Alle Kzipfel gleich, lanzettlich, allmälig zugespitzt; Deckb. aus eiförmigem Grunde pfriemlich zugespitzt. J.........Psyllium. L. Flohsamen-W.

3 Die 2 vorderen Kzipfel schief-spatelig, stumpf, die 2 hinteren lanzettlich; die untersten Deckb. rundlich-eiförmig, die oberen spatelig.

B. M. N. O. St. Kr. J. Südt.

arenaria. W. $K$. Sand-W.

4 Blkrröhre kahl .................... 5

Blkrröhre flaumig o. flaumig-zottig........... 14

$5\{$ B. eiförmig o. elliptisch, 5-9 nervig......... 6

B. lanzettlich 0 . lineal ................. 8

B. beiderseits kurzhaarig, elliptisch, $7-9$ nervig, in den kurzen, breiten Bstiel zusammengezogen; Schaft stielrund, seicht-gerillt; Deckb. kahl, am Rande häutig; Stf. verlängert, hellviolett.

Verbr. $u$. $h \mathrm{fg}$. .........media. L. Mittlerer W.

B. kahl o. zerstreut-flaumig, gestielt; Aehre linealwalzlich, verlängert; Deckb. eiförmig, gekielt....

Schaft aufstrebend, schwach-gerieft; Kapsel meist ssamig. Verbr. $u$. lifg...major. L. Gemeiner W.

7 Schaft aufrecht, tief-gerieft, 2-3 mal so lang als die B.; Kapsel 4 samig. $J$.

Cornuti. Gouan. Cornuti's IV.

B. lineal, einnervig 0 . undeutlich 3 nervig, gegen den Grund zu kaum verschmälert, kurzhaarig; Aehre locker; Pfl. einjährig. N. (Marchfeld.)

tenuiflora. W. K. Schmalähriger W.

B. lanzettlich, seltener lineal-lanzettlich, nach beiden Enden zu verschmälert, $3-7$ nervig...........

Deckb. krautig, häutig-berandet; B. 3 nervig, lineallanzettlich 0. lanzettlich, rauhhaarig; Schaft stielrund, von abstehenden Haaren zottig; Pfl. einjährig. J...........Bellardi. All. Haariger W.

Deckb. trockenhäutig; B. 3--7 nervig, lanzettlich, oft etwas gezähnelt................. 10

(Deckb. kahl 0. in der Mitte zerstreut-behaart, ei-

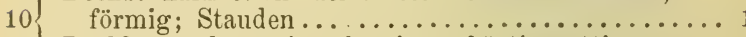

Deckb. an der Spitze bärtig o. bärtig-zottig....... 13

Schaft stielrund, seicht-gerieft; B. angedrückt-behaart, fast seidig; Deckb. in der Mitte zerstreutbehaart. Südt. K. $K r$. J.

argentea. Chaix. Silberhaariger W. Schaft kantig, gefurcht; B. kahl o. behaart; Deckb.

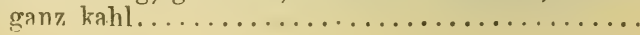


Schaft vielfurchig; die seitlichen Kzipfel gekielt, an der Spitze abgerundet-stumpf, am Rande gewimpert; B. 5--7 nervig. II. N. O. St. K. Kr. J. Südt.

altissima. $L$. Höchster W.

Schaft 5 furchig; die seitlichen Kzipfel kahnförmig, stumpf-zugespitzt, mit kahlem Rande; B. 3- bis 5 nervig. Verbr. $u$. $h f g$.

lanceolata. L.*) Spitzwegerich.

Pfl. einjährig; Schaft gefurcht; Deckb. eiförmig-lanzettlich, zugespitzt; die seitlichen Kzipfel gekielt. J.............Lagopus. L. Zottiger W.

13 Staude; Schaft stielrund; Deckb. breit-verkehrt-eiförmig, sehr stumpf, kurz-stachelspitzig; Kzipfel nicht gekielt. Geb. v. M. O. S. T. K. St. Kr.

montana. Lam. Berg-W.

Einjähriges Kraut; B. meist fiederspaltig: die seitlichen Kzipfel auf dem Rücken geflügelt; Frkn. 3-4 tächerig. J.

Coronopus. $L$. Schlitzblättriger W.

Stauden; B. meist ungetheilt; Kzipfel auf dem Rücken gekielt, aber nicht geflügelt; Frkn. 2 fächerig 15

Deckb. aus eiförmigem Grunde pfrieml.-verschmälert, länger als der K.; B. lineal, halb-stielrund-3 kantig, am Rande fein-borstig-gewimpert; Aehre walzlich,

15 lineal-verlängert. $J . K r$. K. Südt.

carinata. Schrad. Gekielter W.

Deckb. eiförmig, spitzlich, so lang o. kürzer als der K.; B. 3 nervig.................... 16

Seitennerven vom Blattrande und dem Mittelnerven ungleich-entfernt; Aehre länglich-walzlich.

16 A. v. T. S.............. alpina. L. Alpen-W. Seitennerven vom Blattrande und dem Mittelnervel gleichweit-entfernt; Aehre lineal, verlängert..... 17

Deckb. so lang als der K.; der häutige Theil del vorderen Kzipfel so breit als der krautige....... 18

Deckb. kürzer als der K.; der häutige Theil der vorderen Kzipfel viel schmäler als der krautige; B. am Rande kahl. $J$.

crassifolia. Forst: Dickblättriger W.

B. lineal o. lineal-lanzettlich, ganzrandig o. entfernt gezähnt, fleischig, rinnig (zuletzt oft flach werdend), am Rande kahl. Verbr. (fehlt Sch. S. K. St.) maritima. L.*) Meerstrands-W.

B. lineal, meist ganzrandig, lederig, flach, am Rande fein borstlich-gewimpert. $T$.

serpentina. Vill. Schlangen-W.

*) Umfasst mehrere Formen! 


\section{LITORELLA. Bergius. Strandling.}

B. fleischig, stielrund, pfriemlich, am Grunde scheidig; Pfl. niedrig; Bt. weißlich. B. N. K. T. uniflora. (L.) Aschers. Einblütiger St.

XCI. Familie. Rubiaceae. Krappgewächse.

Kräuter 0. Stauden mit ungetheilten, wirteligen*) B. Bt. zwittrig, seltener vielehig 0 . 1 häusig, regelmäßig. $K b$. 3-6, sehr oft undeutlich 0. ganz unentwickelt. Blkr. radförmig, trichterig 0 . glockig, 3-6 spaltig (am häufigsten 4 spaltig). Stb. der Blkrröhre eingefügt, so viele als Blkr.zipfel. Frkn. unterständig, oft 2 knotig, 2 fächerig, mit einer Samenknospe in jedem Fache. Gr. 2, oft am Grunde verwachsen; N. kopfig o. keulenförmig. Fr. meist 2 knotig und in 2 Theilfr. zerfallend, selten beerenartig. S. mit Nährgewebe.

\section{Gattungen.}

(Blkr. trichterförmig o. glockig, mit deutlich ent-

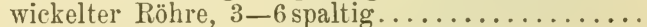
Blkr. radförmig, mit sehr kurzer Röhre......... 4

Kb. 4-6, deutlich entwickelt; Blkr. trichterförmig.

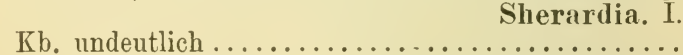

Btstand trugdoldig o. rispenartig; Blkr. mit abstehenden, selten einwärts gekrümmten Zipfeln.

Asperula. III.

3 Btstand dicht, ährenförmig, 2--4 zeilig; Blkr. gelb, mit einwärts gekrümmtem Anhängsel.

Crucianella. II.

Krand unregelmäßig 6-8zähnig; Bt. zu 3 verbunden, die mittlere zwittrig, mit 4 spaltiger Blkr., die seitlichen männlich, mit 3 spaltiger Blkr.; Fr. 3 hörnig, aus den 3 verwachsenen Frkn. gebildet.

Vaillantia. V.

Krand zahnlos; Bt. frei; Fr. 2 knotig, Früchtchen

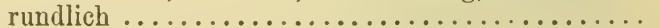

$5\left\{\begin{array}{l}\text { Fr. trocken; Blkr. 4 spaltig, selten } 3 \text { spaltig. } \\ \text { Galium. IV. } \\ \text { Fr. beerenartig, saftig; Blkr. meist } 5 \text { spaltig. } \\ \text { Rubia. VI. }\end{array}\right.$

*) Eigentlich sind die B. gegenständig und zwischen ihnen stehen 2 o. mehrere den B. gleichende Nebenb. 


\section{Arten.}

\section{SHERARDIA. L. Ackerröthe.}

Kraut mit aufstrebendem, ästigem, 4 kantigem Stg.; untere B. zu 4 wirtelig, verkehrt-eiförmig, obere zu 5-6 wirtelig, länglich o. lanzettlich, fein-stachelig-sägezähnig; Bt. lila. Verbr.

arvensis. $L$. Gemeine $\mathrm{A}$.

\section{CRUCIANELLA. L. Krenzblatt.}

Einjähriges Kraut; B. blaugrün, zu 4-6 wirtelig, die unteren verkehrt-eilänglich, die oberen lineallanzettlich. J.......latifolia. L. Dalmatiner K.

\section{ASPERULA. $L$. IValdmeister.}

Bikr. gelb, mit 5 einwärts gekrümmten Zipfeln; Bt. in end- und achselständigen, fast rispig zusammengestellten Büscheln; Deckb. am Rande zottig; B. schmal lanzettlich, zu $6-12$ wirtelig. $K r$. (?)

molluginoides. (ML. B.) Rchb. Gelber W. Blkr. weiß, rosa o. blau (seltener innen etwas gelb-

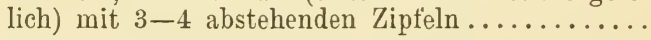

Einjähriges Kraut mit blauen Bt. in endständigen, von Hüllb. umgebenen Büscheln; untere B. verkehrt-eiförmig, zu 4, obere lineal-lanzettlich, zu 6-8 wirtelig. Verbr..... arvensis. L. Acker-W. Stauden mit weiळen 0 . etwas gerötheten, selten

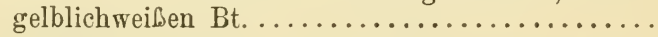

Stg. nebst dem Rande und Kiele der B. rückwärtsklein-stachelig-rauh; B. meist zu 8; Bt. weiß. (B.) $M$. Sch. $N$.

Aparine. $M$. B. Klebkrautartiger W.

Stg. stachellos..................... 4

$4\{$ B. elliptisch o. lanzettlich; Bt. weiß......... 5

Wenigstens die oberen B. schmal lineal........... 7

B. zu 4 wirtelig, breit elliptisch o. eilanzettlich;

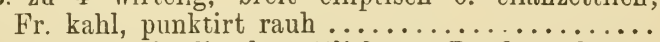

$5\{$ B. zu 6-8 wirtelig, lanzettlich, am Rande und Kiele rauh; Fr. mit hakigen Borsten besetzt. Verbr. odorata. L. Echtei W.

B. breit elliptisch, 1 nervig, stumpf, am Rande schärflich, sonst kahl; Btstand trugdoldig, ohne Hülle. J........... laevigata. L. Kahler W.

B. eilanzettlich, 3 nervig, zugespitzt, am Rande gewimpert; Btstand büschelig, von Hüllb. umgeben. T. S'̈̈dst. $K r . J$. . Taurina, $L$. Italienischer W. 
B. zu 8-10 wirtelig, unterseits seegrün, am Rande umgerollt und rauh; Stg. stielrund; Blkr. weiß, 4 spaltig, ihre Röhre kürzer als der Saum; Fr. glatt. B. M. Sch. N. O. St. K.

galioides. M. B. Labkrautartiger W.

B. zu 4-6 wirtelig 0. z. Th. gegenständig; Röhre der Blkr. so lang 0. länger als der Saum .......

Die meisten Blkr. 3 spaltig, weif, kahl; Deckb. eiförmig 0. oval; Fr. glatt und kahl. B. M. N. O. K. Kr.J.

tinctoria. I. Färbender W.

Die meisten Blkr. 4 spaltig, weiß, rosa o. gelblich; Deckb. lanzettlich 0 . fast lineal; Fr. oft rauh 0 .

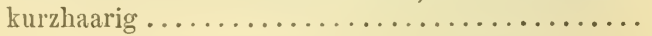

$9\{$ Röhre der Blkr. viel länger als der Saum....... 10

9 Röhre der Blkr. ungefähr so lang als der Saum ... 12

Blkr. außen behaart, lebhaft rosa, meist auch Stg., B. u. Fr. graulich behaart; Btstand schmal, mit kurzen Aestchen. J.

canescens. Tis. Graulicher IV.

Blkr. kahl o. nur etwas rauh; überhaupt die ganze Pfl. kahl o. fast kahl; Btstand breit rispig, mit ver-

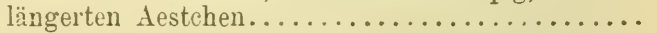

Aeste des Btstandes aufrecht abstehend; Blkr. weib, außen etwas röthlich, mit sehr spitzen Zipfeln.

Südt. K. Südst. Kr. J. (?)*)

longiflora. $W . K$. Langblütiger W. Aeste des Btstandes sparrig abstehend; Blkr. innen gelblichweib, außen röthlich, mit stumpflichen, kürzeren Zipfeln. Südt. K. Südst. Kr.J. (?)*)

aristata. L. f. Begrannter W.

Stg. mehr o. weniger verlängert, meist reichblütig; zur Btzeit meist nur schmal lineale B. vorhanden, welche gewöhnlich lïrzer sind als die Stgglieder; Blkr. hellrosa 0. weiß, außen meist rauhkörnig; Fr. deutlich bekörnelt. Verbr.

cynanchica. L. Kleiner W.

Stg. niedrig, starr, dicht rasig, sparrig-ästig; untere Stgb. verkehrt-eiförmig, zurückgekrümmt, obere schmal lineal, so lang o. länger als die Stgglieder; Blkr. meist außen lebhaft rosa, glatt; Fr. undeutlich bekörnelt. $A$. v. N. O. St.

Neilreichii. Beck: Alpen-IV.

*) Die Verbreitung dieser beiden Arten ist noch genaner festzustellen. 
IV. GALIUM. L. Labkrant.

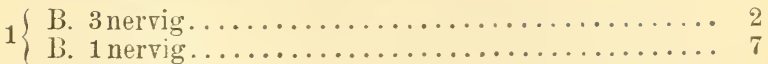

Bt. gelb o. grünlich, einhäusig-vielehig, die endständigen Bt. an den Verästelungen zwittrig und

2 fruchtbar, die seitenständigen männlich; Btstiele nach dem Verblühen zurückgekrümmt .......... Bt. weiß, zwittrig; Btstiele nach dem Verblühen gerade; Stauden .......................

(Btstiele mit Deckb., meist steifhaarig; Stg. rauh3 haarig; schlaffe Staude. Verbr. u. lifg.

Cruciata. (I.) Scop. Kreuz-L.

Btstiele deckblattlos ..................... 4

Btstiele kahl; Stg. glatt, kahl o. unten kurzhaarig; schlaffe Staude. Verbr. (fehlt $O$.)

vernum. Scop. Frühlings-L.

4 Btstiele zottig; Stg. rückwärts-stachelig, oft außerdem rauhhaarig; sehr zartes, einjähriges Kraut.

N. Sïdt. J.

Pedemontanum. All. Piemontesisches L.

B. kurz-stachelspitzig, oval 0. rundlich, am Rande borstlich-rauh; Stg. schlaff; Fr. hakig-steifhaarig. Verbr. (fehlt J.)

rotundifolium. $L$. Rundblättriges $L$.

B. stumpf, ohne Stachelspitze; Stg. steif........ 6

Stg. aufrecht, steif, 4 kantig; B. lanzettlich, gegen die Spitze lang verschmälert; Theilfr. steifhaarig o. kahl.*) Verbr......boreale. L. Nordisches L.

6 Stg. ausgebreitet-aufstrebend; B. oval 0. länglichlanzettlich, am Grunde zusammengezogen; Pfl. in allen Theilen größer; Theilfr. kahl. $B$. N. $K r$. rubioides. $L$. Krappartiges L.

$7\left\{\begin{array}{c}\text { B. ganz stumpf, olne Stachelspitze, lineal-länglich, } \\ \text { nach vorne breiter, zu } 4 \text {, seltener zu } 6 \text { wirtelig, } \\ \text { am Rande rückwärts-stachelig-scharf; Bt. weiß } \ldots \\ \text { B. stachelspitzig o. mit kurzer Kuorpelspitze...... }\end{array}\right.$
$8\left\{\begin{array}{c}\text { Bt. zu } 1-3 \text { in den Blattachseln; Frstiele zurückge- } \\ \text { krümmt. St. (Judenburg.) } \\ \text { trifidum. L. Dreispaltiges L. }\end{array}\right.$ Bt. zu Rispen zusammengestellt; Frstiele gerade...

*) Die kahlfrüchtige Form ist G. hyssopifolium Hoffm. 
Btstand locker; Btstiele länger als der Durchmesser der Bt.; Frstiele lang, wagrecht abstehend.

Verbr. $u$. $h f g . . . . . . .$. palustre. $L$. Sumpf-L.

9 Btstand ziemlich gedrängt; Btstiele so lang als der Durchmesser der Bt.; Frstiele nicht länger als der Durchmesser der Fr., gerade vorgestreckt. J.

constrictum. Chaub. Gedrängtblütiges L.

${ }_{10}$ Stg. durch kleine, abwärts gerichtete Stachelchen

rauh und dadurch leicht hängen bleibend*) .....

Stg. kahl o. behaart, aber nicht stachelig-rauh .... 16

Frstiele herabgekrümmt; Bt. weißlich; B. meist zu 8 wirtelig, lineal-lanzettlich; einjähriges Kraut.

11 B. M. Sch. N. O. (St. S. T.) J.

tricorue. With. Dreihörniges L.

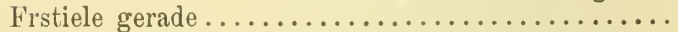

B. am Rande durch vorwärts gerichtete Stachelchen lauh, zu 5-7 wirtelig; Bt. grünlichgelb, außen

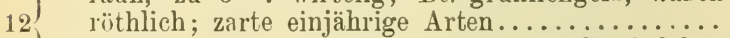

B. am Rande durch rückwärts gerichtete Stachelchen rauh, zu 6-9 wirtelig; Bt. weiß o. etwas grünlich 14

Aeste des Btstandes ungefähr gleich lang, die Rispe daher von eylindrischem Umrisse; B. zu 6-7 wirtelig, zuletzt zurückgeschlagen; Frstiele länger als die Fr. (N.) St. J. Sïdt.

Parisiense. L. Pariser L.

Die oberen Aeste des Btstandes länger, die Rispe daher breit verkehrt-eiförmig; B. zu 5-6 wirtelig, nie zurückgeschlagen; Frstiele so lang als die Fr. J. ........... divaricatum. Lam. Sparriges L.

Einjährige Kräuter; Btstände in den Blattachseln, keine Pispe bildend; Bt. weißlich, sehr klein.... 15

14 Zarte Staude; Btstand rispig; Bt. reinweih; Fr. kahl, fein bekörnelt. Verbr.

uliginosum. L. Schlamm-L.

Stg. kräftig, oft hoch kletternd, an den Knoten steifhaarig; B. keilig-länglich, seltener fast lineal; Theilfr. grof, kugelig, dicht hakenborstig. Verbr. u. $h \mathrm{fg}$. ....Aparine. $L$. Klimmendes L. Stg. dünn, meist liegend, an den Knoten kahl 0 . etwas steifhaarig; B. kleiner, keilig-lineal-länglich ; Theilfr. klein, halbkugelig, kahl 0 . hakenborstig**). Verbr............... spurium. $L$. Unechtes L.

*) G. spurium L. kommt sehr selten auch ohne Stachelchen am Stg. vor:

**) Die Form mit hakenborstigen Fr. ist G. Vaillantii D C. 
Zartes 1jähriges Kraut; die unteren B. zu 6, die oberen zu 4 wirtelig, lanzettlich; Bt. grünlichgelb, zu 1-3 in den Bachseln; Frstiele herabgekrümmt.

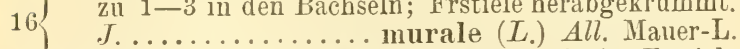
Stauden; B.zu 6-12 wirtelig; Btstand rispig; Frstiele

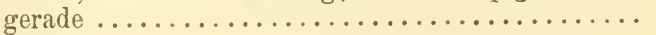

( Stg. stielrund, 4rippig, aufrecht; Blkrzipfel kurz-

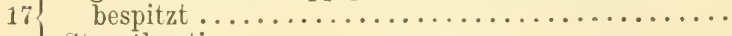

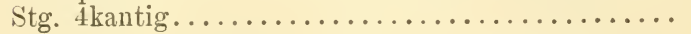

B. länglich-lanzettlich, zu 6 --10 wirtelig; Rispe weitschweifig; Btstiele vor dem Aufblühen nickend; Bt. weis. Verbr. $u$. $h f g$. silvaticum. L. Wald-L. B. lineal; Bt. gelb o. roth, selten weißlich........

Bt. gelb, selten weißlich; Frstiele fast wagrechtabstehend; Stg. flaumig-scharf; B. unterseits sammtig-flaumig. Verbr. $u$. hfg.

verum. $L$.*) Gelbes L.

Bt. blutroth; Frstiele haarfein, nickend, fast traubig angeordnet; Stg. flaumig; B. sehr schmal.

Sïdt. K. Kr. J.. purpureum. L. Purpurnes L.

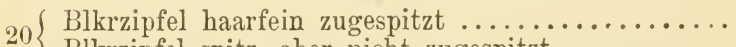

Blkrzipfel spitz, aber nicht zugespitzt.........28

Fr. bekörnelt; B. lineal oder lanzettlich, zu 6-8 wirtelig; Stg. schlaff, niedergestreckt; Rispe ausgebreitet, spreizend; Btstiele haarfein; Bt. blutroth, zuletzt gelblich, seltener von Anfang an weißlich.**) T. $K \ldots \ldots \ldots \ldots \ldots \ldots$ rubrum. $L$. Rothes L. Fr. nicht bekörnelt, glatt oder etwas runzelig; Bt. weiß 0 . etwas gelblich, höchst selten rosa über-

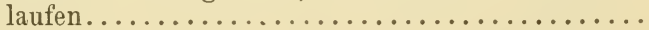

B. lanzettlich, von der Mitte an beiderseits verschmälert, meist zu 8 wirtelig; Rispe weitschweifig, die unteren Aeste derselben sehr verlängert $u$. erst im oberen Theile Bt. tragend; Btstiele Laarfein; Fr. ganz glatt ........................

B. meist über der Mitte am breitesten o. lineal; meist schon nahe dem Grunde Bt. tragenden

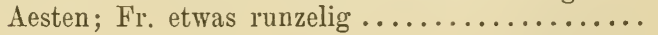

*) G. praecox (Lang) ist eine früher blühende Wiesenform mit verlängerter, lockerer Rispe.

**) Die weißlich blühende Form ist G. obliquum Vill. 
Stg. überall scharf 4 kantig; B. schmal lanzettlich, unterseits bläulichgrün; Fr. nicht bereift.

$23 S . T . K . S t . K r . J$. aristatum. L. Begranntes L. Stg. unten fast rundlich; B. meist breiter, graugriin; Fr. blänlich bereift. B. $M$. Sch. $K$.

Schultesii. Vest. Schultes' L.

B. lineal o. lanzettlich-lineal, mit breitem Mitteluerv, an Pande meist umgerollt, unterseits blasser 0 .

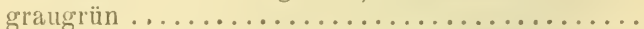

$\mathrm{B}$ länglich-verkehrt-eiförmig, seltener lanzettlich, mit schmalem Nittelnerv, beiderseits grün......

B. oberseits glänzend, unterseits blasser; Rispenäste steif, aufgerichtet; Btstiele kurz.

$25 \quad N . O . S t . K r \cdot J . T$. lucidum. All. Glänzendes L. B. unterseits wie der Stg. graugrün; Rispenäste aufrecht abstehend; Btstiele schlank. Südt.

cinereum. All. Graugrünes L.

B. länglich-verkehrt-eiförmig, vor der Spitze meist

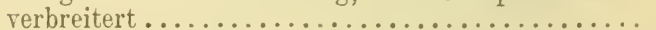

B. lanzettlich, vor der Spitze wenig o. gar nicht 27 verbreitert; Rispenäste kurz, aufgerichtet, lockerblütig; Btstiele meist verlängert. Verbr.

erectum. Huds. Aufgerichtetes L.

B. ziemlich derb, oft etwas glänzend, ohne deutliche Seitennerven; Btstand dichtblütig. Verbr. $u$. hfo.

Mollugo. L.*) Gemeines L.

27 B. dünn, matt, im getrockneten Zustande mit deutlichen Seitennerven, auffallend kurz; Stg. oft sehr verlängert, nicht selten klimmend; Btstand sehr ausgebreitet. Verbr.... elatum. Thuill. Hohes L.

B. dicklich, fast nervenlos, mit sehr kurzer Knorpelspitze; Aeste des Btstandes kurz, 1-3 blütig, traubig angeordnet 0 . fast ebensträußig; Bt. gelb-

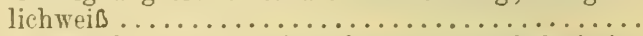

B. deutlich 1 nervig, fast begrannt-stachelspitzig; Btstand durch Verlängerung der unteren Aeste ebensträußig-rispig . . . . . . . . . . . . . .

Frstiele herabgekrümmt; B. flach, verkehrt-eiförmig o. spatelig, glanzlos; Btstand kurz, fast doldenartig; Fr. glatt; Wuchs rasig. A. v. T. S. O.

Helveticum. Weig. Schweizer L.

Frstiele gerade; Fr. fein gekörnelt; B. oberseits gedunsen, meist glänzend; Btstand traubig verlängert

*) Die Form mit behaartem Stg. ist G. pubescens 
B. meist zu 6 wirtelig, die der unfruchtbaren Stg. verkehrt-eiförmig, oberseits gekörnelt u. wenig glänzend, die der blühenden Stg. lineal-lanzettlich; Pf. getrocknet gelblich. Tora. v. Südt.

marcaritaceum. Kern. Perlschnur-I.

B. meist zu 8 wirtelig, alle rerkehrt-lanzettlich, oberseits glatt $u$. stark glänzend; Pfl. getrocknet leicht schwarz werdend. $A$. (fehlt S.)

Baldense. Spr. Südtiroler L.

Fr. dicht mit feinen, spitzen Warzen besetzt; B. meist zu 6 wirtelig, die der unfruchtbaren Stg. verkehrt-eiförmig, die der blühenden Stg. verkehrtlanzettlich; Bt. verhältnissmāßig grod. $B$.

Hercrnicum. Teig. Hercynisches L.

Fr. undeutlich gekörnelt; B. meist zu 8 wirtelig, an allen stg. ungefähr ron derselben Gestait; Bt.

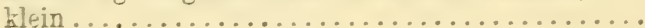

Stg. unten kurzhaarig, oben kahl o. fast kahl; $\mathrm{B}$. am Pande ron feinen Stachelchen rauh, lineallanzettlich 0. lineal: Btstand rispenartig u. meist locker. Vertr......asperum. Schreb. Pauhes L. Stg. ganz kabl*); L. am Pande glatt......... 33

B. lineal o. schmal-rerkehrt-lanzettlich; Btstand rispenartig, meist locker: Bt. weib; Wuchs locker, kaum rasig. Verbr.

Austriacum. Jacq. Oesterreichisches L.

B. rerkehrt-lanzettlich, meist 2 jedes Wirtels breiter; Btstand kurz, fast ebensträufig; Bt. meist gelblich; Wuchs ziemlich dicht-rasig. Geb.**,

anisophyllum. Vill. Ungleichblättriges L.

Anmerkung. G. Mollugo $\times$ rerum ist nicht selten; seltener sind $\mathrm{G}$. silvaticum $X$ verum und G. lucidum X rerum. Einige Arten der Gattung sind sehr reränderlich and mit anderen Arten durch $\mathrm{Z}$ wischenformen verbunden; so G. Mollugo mit $G$ erectum D. G. elatum, ferner S. Austriacum mit $G$. asperum u. G. anisophyllum.

\section{VAILLANTIA. L. Schuttkraut.}

Einjāhriges, kables Kraut; B. rundlich-eiförmig, zu 4 wirtelig; Bt. grünlichgelt. J.

muralis. I. Mauer-Sch.

*) Fine sehr seltene Form des G. anisophyllum Vill. hat unten kurzhaarigen Stg.

**) Die in den Sudeten wachsende Form ist G. Sudeticum Tausch. 


\section{RUBIA. $L$. Krapp.}

B. lanzettlich, netzig-aderig, etwas gestielt; Stg. im Herbste absterbend. Cult. u. verw.

tinctorum. L. Echter K.

B. lanzettlich o. elliptisch, ohne Seitenadern, sitzend; Stg. überwinternd. J. peregrina. $L$. Wilder $\mathrm{K}$.

XCII. Familie. Caprifoliaceae. Geißblattgewächse.

Sträucher, selten Bäume o. Stauden mit gegenständigen, ungetheilten, gelappten 0 . fiederschnittigen B., meist ohne Nebenb. Bt. zwittrig, regelmäßig o. unregelmäßig. Kb. klein, meist 5. Blkr. radförmig, trichterig-glockig o. 2 lippig, meist mit 5 Zipfeln. Stb. 5, selten 4, der Blkrröhre eingefügt. Frkn. unterständig, 1-5 fächerig, bald eine, bald mehrere Samenknospen enthaltend. Gr. 0. N. 1-5. Fr. eine Beere o. Steinfr., selten eine lederige Schließfr., niemals aufspringend. S. mit Nährgewebe.

\section{Gattungen.}

B. fiederschnittig; Btstände schirmförmig o. straub1 förmig, reichblütig; Blkr. radförmig; Stb. 5; N. Sambucus. I.

B. ungetheilt, höchstens gelappt ............ 2

Btstände zusammengesetzt, schirmförmig, reichblütig;

2 Blkr. radförmig; Stb. 5; N. meist 3, sitzend; Bt. zu 2 beisammen 0 . in Büscheln; Blkr. 2 lippig o. trichterig-glockig; Gr. verlängert, mit $1 \mathrm{~N} .$. .

Aufrechte o. kletternde Sträucher; Blkr. unregelmäßig, 2 lippig; Stb. 5; Fr. eine mehrsamige Beere.

3 Lonicera. IV.

Niederliegendes Sträuchlein; Blkr. fast regelmäßig, trichterig-glockig; Stb. 4, zweimächtig; Fr. 1 samig, lederig. ...................

\section{Arten.}

\section{SAMBUCUS. L. Hollunder.}

Bt. grünlichgelb, in eiförmigen Sträußen, im Frühling erscheinend; Mark der Aeste rothgelb; Fr. roth. Verbr. ........ racemosa. L. Trauben-H. Bt. weiß, in schirmförmigen Btständen, im Sommer erscheinend; Mark weiß; Fr. schwarz.......... 
(Strauch, seltener Baum; Nebenb. gewöhnlich fehlend o. doch verkümmert; Btstand こstrahlig; $\mathrm{A}$. gelb. Verbr. u. hfg. (auch cult.)

nigra. L. Schwarzer H.

Hohe Staude; Nebenb. eiförmig, gesägt; Btstand 3 strahlig; A. purpurn. Verbr.

Ebulus. L. Zwerg-H.

\section{VIBURNUM. $L$. Schneeball.}

B. ganzrandig, eiförmig-länglich, immergrün; Fr.

1 trocken. J. .........Tinus. Immergrüner Sch.

B. gezähnt, gesägt 0 . gelappt; Fr. beerenartig....

B. eiförmig 0. oval, am Grunde etwas herzförmig, kleingesägt, unterseits sternflaumig o. filzig; alle Bt. gleich und fruchtbar; Fr. zuletzt schwarz.

Verbr. u. hfg. (fehlt Sch.)

Lantana. $L$. Wolliger Sch.

B. 3-5 lappig, mit gezähnten Lappen, unterseits flaumig; Randbt. viel größer als die übrigen, unfruchtbar*); Fr. roth. Verbr. u. hffg.

Opulus. L. Gemeiner Sch.

\section{LINNAEA. Gronov. Erdkrönchen.}

Zweige fadenförmig, kriechend; $B$. rundlich-eiförmig; Bt. wei $\mathcal{B}$ mit röthlichen Streifen o. hellrosa.

Geb. v. B. S. T. K. borealis. L. Nordisches E.

\section{LONICERA. L. Heckenkirsche.}

(Kletternde Sträucher; Bt. in Büscheln, gelblichweiß

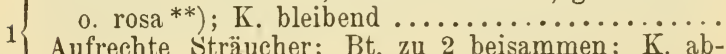
Aufrechte sträucher; Bt. zu 2 beisammen; K. abfällig..............................

Endständige Btbüschel dem obersten, verwachsenen Bpaar aufsitzend ....................... Endständige Btbüschel von dem obersten Bpaar entfernt ...

(B. abfällig; Gr. kahl. Verbr. (oft nur cult. u. verw.)

3 B. immergrün; Gr. rauhhaarig. J.

implexa. Ait. Verflochtenes Geißblatt.

*) Bei dem cultivirten "gefüllten" Schneeball sind alle Bt. vergrößert und unfruchtbar. rothe Bt.

**) Die oft cultivirte L. sempervirens L. hat scharlach- 
Obere B. paarweise zusammengewachsen.

$J$. (sonst cult.)

Alle B. getrennt. $T$. $K r$. J. (sonst cult.) Periclymenum. L. Wildes Geißblatt.

5 Die 2 Frkn. am Grunde verwachsen, oben frei.... 6

5 Die 2 Frkn. fast durchaus in 1 einzigen verwachsen 8

Gemeinsamer Btstiel flaumig, so lang als die Bt.; B. oval, flaumig; Bt. gelblich o. röthlich-weiß;

6 Beeren roth. Verbr. $u$. hifg.

Xylosteum. L. Gemeine H.

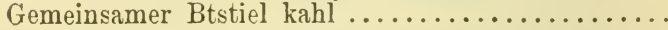

B. länglich, spitz; gemeinsamer Btstiel viel länger als die Bt.; Bt. weib o. rüthlich; Beeren schwarz.

7 Geb. (fehlt J.) ......... nigra. L. Schwarze H. länger als die Bt.; Bt. weiß o. rosa; Beeren roth. Cult. u. verw...... Tatarica. L. Tatarische H.

Gemeinsamer Btstiel kürzer als die Bt.; B. länglichelliptisch; Bt. gelblich-weiß; Beeren schwarz, bläulich bereift. Vora. (fehlt $N$. J.)

caerulea. $L$. Blaue $\mathrm{H}$. Gemeinsamer Btstiel länger als die Bt.; B. elliptisch, zugespitzt; Bt. trübpurpurn. Vora.

alpigena. $L$. Alpen-H.

Anmerkung. Sehr häufig cultivirte Ziersträucher sind die Schneebeere (Symphoricarpus racemosus Michx.) mit glockigen, röthlich-weißen Bt. und weißen Beeren, ferner die Weigelie (Diervilla florida (Bge.) S. Z.) mit rosenrothen, trichterigen Bt. und 2 klappigen Kapselfr.

XCIII. Familie. Adoxaceae, Bisamkrautgewächse.

Zarte Stauden mit beschupptem Wst. und theils grundständigen, theils am Stg. gegenständigen, $1-2$ fach- 3 schnittigen B. Nebenb. fehlen. Bt. zwittrig, regelmäßig. Kb. 2 bis 3 , am Grunde verwachsen. Blkr. radförmig, 4-5 spaltig. Stb. 8-10 (eigentlich 4-5 gespaltene Stb.), der Blkrröhre eingefügt. Frkn. halb unterständig, 3-5 fächerig, mit einer Samenknospe in jedem Fache. Gr. 3-5. Steinfr. mit 3 bis 5 Steinkernen. S. mit Nährgewebe. 


\section{Art.}

I. ADOXA. L. Bisamkraut.

Bt. zu 5-7 an der Spitze des Stg., unscheinbar, grünlich. Verbr. Moschatellina. L. Gemeines B.

XCIV. Familie. Valerianaceae. Baldriangewächse.

Stauden 0 . Kräuter mit gegenständigen, ungetheilten o. getheilten B., ohne Nebenb. Bt. zwittrig 0. 2 hāusig, vielehig, meist etwas unregelmäßig. K. zur Zeit des Blühens sehr klein, aus 1-6 Zähnen gebildet o. ganz unmerklich, zur Zeit der Frreife meist vergrößert und oft eine Haarkrone auf der Fr. bildend. Blkr. trichterig - röhrig, am Grunde oft mit einem Höcker 0. Sporn, ihr Saum meist 5 spaltig. Stb. 1-3, der Blkrröhre eingefügt. Frkn. unterständig, $1-3$ fächerig, aber stets nur eine Samenknospe enthaltend. Gr. 1; N. 1-3. Fr. niemals aufspringend. S. ohne Nährgewebe.

\section{Gattungen.}

(Blkr. am Grunde gespornt; Stb. 1; Fr. mit Haar1 krone $\ldots \ldots \ldots \ldots \ldots \ldots$. Centranthus. III. Blkr. am Grunde nicht gespornt, höchstens etwas

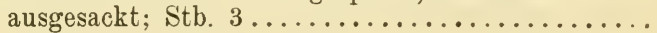

Stauden mit ungetheilten 0. getheilten B.; Stg. nicht gabelig verzweigt; Ksaum zur Btzeit eingerollt, an der Fr. eine Haarkrone bildend. Valeriana. II.

2 Einjährige Kräuter mit ungetheilten B.; Stg. gabelig verzweigt; $K$. mehr 0 . weniger deutlich 1-6zähnig, bleibend; Fr. ohne Haarkrone.

Valerianella. I.

Arten.

I. VALERIANELLA. Poll. Feldsalat.

(Ksaum becherförmig, häutig, innen ganz kahl, mit 6 begrannten Zähnen, bis über die Hälfte 6 spaltig, Zipfel an der Spitze hakig; Fr. zottig, eiförmig,

1 vorne 1 furchig. Südt. $J$.

coronata. (L.) DC. Bekrönter F. Ksaum 1-3 zähnig, o. klein-gezähnelt, o. schief-abgeschnitten und ungleich-gezähnt ............

K. mit 3 kegelförmig-pfriemlichen, zurückgekrümmten Zähnen; Fr. länglich, fast 3 seitig, 3 furchig. $K r$. J. ... echinata. (L.) DC. Igelstacheliger $\mathrm{F}$. Ksaum undeutlich-gezähnt o. schief abgeschnitten . 
Fr. zusammengedrückt 0 . fast 4 seitig; Ksaum undeutlich $1-3$ zähnig; Frühlingspfl. ...........

3 Fr. fast kugelig-eiförmig, o. vorne flach und binten gewölbt; Ksaum schief-gezähnelt, der hintere Zahn

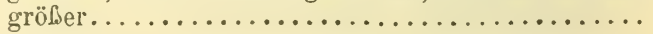

Fr. eiförmig-rundlich, beiderseits ziemlich flach, am Rande mit einer Furche, an den Seiten 2rippig; Ksaum undeutlich, 3 zähnig. Verbr. u. hfg.

olitoria. (L.) Poll. Gemeiner F.

4 Fr. länglich, fast 4 seitig, auf der hinteren Fläche tief-rinnig, auf der vorderen flach, in der Mitte und an den Seiten fein-1 rippig; Ksaum undeutlich-1 zähnig. $B . M . N$. O. St.

carinata. Lois. Gekielter F.

Fr. fast kugelig-eiförmig, fein-5 rippig, vorne 1 furchig ; Ksaum $1 / 3$ so breit als die Fr., klein-gezähnelt; blüht im Sommer. Verbr.

rimosa. Bast. Gefurchter F.

Fr. hinten gewölbt und fein-3 rippig, vorne flach, mit einer zwischen die erhabenen Ränder einge-

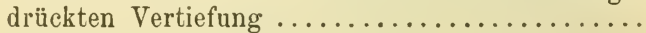

Ksaum von der Breite der Fr., glockig; Btstiele dicht-gedrängt; blüht im Frühling. $J$.

eriocarpa. Desv. Haarfrüchtiger F.

Ksaum halb so breit als die Fr.; Btstiele spreizend; blüht im Sommer. Verbr. (fehlt $K$.)

dentata. (I.) Poll. Gezähnter F.

\section{VALERIANA. $L$. Baldrian.}

$\int$ B. alle, o. nur die oberen Stgb. fiederschnittig 0. leierförmig-fiedertheilig ..................

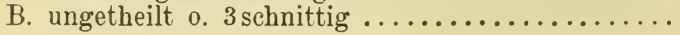

Alle B. fiederschnittig; Stg. gefurcht, hoch und

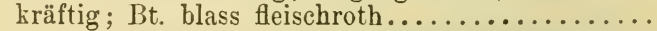

2 Grundb. eiförmig o. elliptisch, gestielt, die mittleren Stgb. leierförmig - fiedertheilig, die oberen fast fiederschnittig, mit linealen Zipfeln...........

Wst. vielstengelig, ohne Ausläufer; B. 7-10 paarig-

3 fiederschnittig. Verbr. exaltata. Mik. Hoher B. Wst. 1 stengelig, Ausläufer treibend .......... 4

B. 7-10 paarig-fiedersclınittig, Abschnitte lanzettlich o. eilanzettlich, gezähnt; Ausläufer unterirdisch, kurz. Verbr. $u$. hfg. officinalis. L. Gemeiner B.

4 B. 4-5 paarig-fiederschnittig, Abschnitte gezähntgesägt, an den Grundb. breit-eiförmig; Ausläufer oberirdisch, verlängert. Verbr. (bes. Geb.)

sambucifolia. Mik. Hollunderblättriger B. 
Fr. kahl; Wst. Ausläufer treibend; B. der unfruchtbaren Bbüschel eiförmig, lang gestielt. Verbr.

dioica. $L$. Kleiner B.

Fr. mit 2 seidenhaarigen Linien; Wst. knollenförmig, ohne Ausläufer; Grundb. elliptisch-länglich.

$K r$. J..............tuberosa. L. Knolliger B.

B. gezähnt, die der unfruchtbaren Büschel herzförmig, lang-gestielt; Stgb. meist 3 schnittig.

6 Verbr. (fehlt B.) tripteris. L. Dreischnittiger B. Grundb. ganzrandig o. sehwach gezähnt, sammt den Stgb. ungetheilt........................

( Bt. fleischroth 0. weiß; Btstand kopfig o. ebensträufig

7 o. die unteren Aeste entfernt ................

Bt. gelblich; Btstand traubenartig verlängert..... 12

Wst. Ausläufer treibend; B. eiförmig, die unteren 8 ganzrandig, die oberen oft gezähnt. Sch. MI. N.

simplicifolia. (Rchl.) Einfachblättriger B.

Wst. ohne Ausläufer ........................

Btstand kopfig, dichtblïtig, von B. umhüllt; niedrige Alpenpfl.............................

Btstand nicht umhüllt, ebensträußig o. die unteren

Aeste entfernt.........................

B. spatelig, gestielt, gewimpert, die obersten sitzend, lanzettlich. A. v. T. S. K. St.

supina. $L$. Niedriger $B$.

Grundb. verkehrt-eiförmig, kahl, in den Bstiel verschmälert; Stgb. wenige, lineal. A. v. T.

saliunca. All. Weidenblättriger B.

Grundb. eiförmig 0. fast rundlich; Stgh. 6 o. mehr, eiförmig 0. eilanzettlich; Btstand ebensträußig; Bt. blassrosa 0. weiß. Verbr. (fehlt $B$. MI.)

montana. $L$. Berg-B.

11 Grundb. länglich-spatelig; Stgb. (die Tragb. der Btstandäste nicht mitgerechnet) 20 . fehlend, lineallanzettlich; die unteren Aeste des Btstandes entfernt; Bt. weis; Pfl. viel zarter und kleiner. $A$. u. Vora............ saxatilis. L. Felsen-B.

Alle B. ganzrandig; Grundb. länglich-lanzettlich, Stgb, lineal, meist 2. A. v. T. S. O. St. K. Kr. Stgb. eiförmig, eingeschnitten-gezähnt. $A$. (fehlt $S$.) elongata. Jacq. Verlängerter B.

Anmerkung. Zwischen V. montana und V. tripteris, ferner zwischen V. elongata und V. saxatilis kommen Bastarte vor. 


\section{CENTRANTHUS. DC. Spornblume.}

Staude mit eiförmigen o. lanzettlichen B.; Sporn doppelt so lang als der Frkn.; Bt. hellpurpurn. Sïdt. J............ruber. (L.) DC. Rothe Sp.

\section{Familie. Dipsaceae. Kardengewächse.}

Stauden o. Kräuter mit gegenständigen, ungetheilten o. getheilten B., ohne Nebenb. Bt. zwittrig, meist etwas unregelmäßig, zu Köpfchen zusammengedrängt, welche von Hüllb. umgeben sind; außerdem meist unter jeder Bt. ein Tragb. (Spreub.). K. verschieden ausgebildet, oft aus Borsten bestehend; außerdem ein verschieden gestalteter Außenk. vorhanden. Blkr. trichterig-röhrig, mit 4-5 spaltigem Saume. Stb. 4, frei. Frkn. unterständig, 1 fächerig, mit einer Samenknospe. Gr. 1; N. oft 2 lappig. Fr. nicht aufspringend, rom K. gekrönt. S. mit Nährgewebe.

\section{Gattungen.}

Hülle des Köpfchens dicht-dachig, halbkugelig; Außenk. 8zähnig o. mit trockenhäutigem viel-

1 zähnigem Saume; K. beckenförmig, oft gezähnt.

Hülle sternförmig-ausgebreitet, Hüllb. 1- 0. mehr-

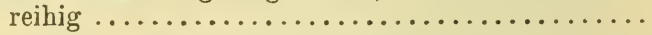

Stg. u. Köpfchenstiele stachelig; Frboden kegelförmig; Spreub. stachelig 0. langborstig gewimpert.

$2\{$ Dipsacus. II.

Stg. u. Köpfchenstiele ohne Stacheln; Frboden flach

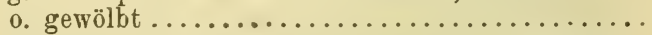

Frboden rauhhaarig, ohne Spreub.; K. 5-16 zähnig ; $3\left\{\begin{array}{l}\text { Zähne aus breitem Grunde pfriemlich; Außenk. } \\ \text { klein-gezähnt }\end{array}\right.$

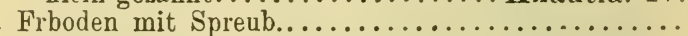

Blkr. 4 spaltig; Außenk. 8 furchig mit 4 lappigem krautigem Saume; K. schüsselförmig, 5 borstig 0 . ganzrandig; Randbt. nicht strahlend; Stauden mit

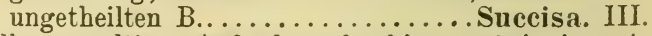

Blkr. 5spaltig; Außenk. Sfurchig o. 8 rippig mit radförmigem 0 . glockigem, trockenhäutigem, durchsichtigem Saume; K. 5-10 borstig 0. ganzrandig;

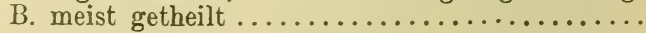

Kborsten 5, selten unentwickelt; Stauden 0. 2 jährige Kräuter........................ Vibiosa. VI. Kborsten 10, federig-grannig; 1 jähriges Kraut. 


\section{Arten.}

\section{CEPHALARIA. Schrad. Schuppenkopf.}

Außenk. trockenhäutig, vielzähnig; Hüllb. eiförmig, die äußeren abgerundet-stumpf; Blkr. weiß, gleich groo; Staude mit fiederspaltigen B. $K r$. J.

leucantha. (L.) Schrad. Weißblühender Sch. Außenk. mit 8 pfriemlichen Zähnen; Hüllb. eilanzettlich, grannig:bespitzt; Blkr. gelblich o. lila, die randständigen größer; Kraut mit fiederspaltigen B. $\Lambda$. lir. J.

Transsilvanica. (L.) Schrad. Sieben-

bürgischer Sch.

\section{DIPSACLS. L. Karde.}

B. gestielt, an der Spitze des Bstiels geöhrlt; Hüllb. abwärts-gerichtet; Spreub. borstig-bewimpert, gerade; Blkr. gelblichweib. Verbr. (fehlt Sch.)

pilosus. L. Behaarte $\mathrm{K}$. Stgb. sitzend, paarweise breit verwachsen; Blkr. lila,

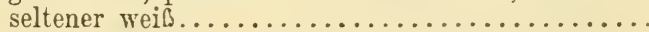

Spreub. steif, zurückgekrümmt, so lang als die Blkr.; Hüllb. wagrecht-abstehend; B. eingeschnittengekerbt. Cult. u. verw...sativus. (L.) Weber-K. Spreub. biegsam, gerade, länger als die Blkr.; Hüllb.

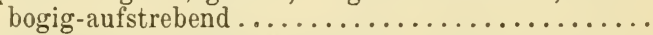

B. am Rande kahl o. zerstreut-stachelig, gekerbtgesägt; Hüllb. lineal-pfriemlich. Verbr.

fullonum. $L$. Wilde $\mathrm{K}$.

B. borstig-gewimpert, die unteren lappig-gekerbt, die übrigen fiederspaltig; Hüllb. lanzettlich-pfriemlich. Verbr. (fehlt T.S.)

\section{laciniatus. $L$. Schlitzblättrige $\mathrm{K}$.}

\section{SUCCISA. Neck. Teufelsabbiss.}

Außenk. rauhhaarig, 4 spaltig mit stachelspitzigen Zipfeln; K. 5 borstig; Bt. röthlichlila o. blaulila, selten weib. Verbr. $u$. $h f g$.

pratensis. Mnch. Gemeiner 'T'.

Außenk. kahl, mit 4 kurzen, stumpfen Lappen; K. ganzrandig, ohne Borsten; Bt. hellblaulila, selten gelblich. $\Lambda$. O. St. K. Kr.J. Südt.

inflexa. (Kluk.) Beck. Südlicher T.

\section{KNAUTIA. $L$. Witwenblume.}

Einjähriges Kraut; B. ungetheilt o. leierförmig-fiederspaltig; K. 4 mal kürzer als die F'r., meist 16 zähnig.

$J$. $K \ldots$... integrifolia. (L.) Bert. Einjährige W.

Der innere $K$. halb so lang als die Fr., meist

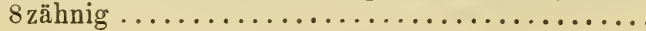


Bt. lila, rothviolett 0 . bläulichlila, sehr selten weiß

Bt. gelblichweiß; B. derb, bald alle ungetheilt, bald

2 einige fiederspaltig; Stg. rauhhaarig 0. unten nur flaumig. B. M. Sch. N.

Carpatica. (Fisch.) Heuff. Karpathen-W.

Stg. u. B. rauhhaarig, borstig o. flaumig, nur aus-

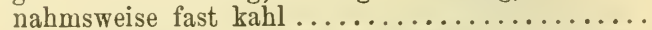

Stg. unten kahl o. fast kahl; ausgebildete B. kaum

3 behaart, verlängert-lanzettlich, ganzrandig 0. etwas gezähnelt; Bt. röthlichviolett.

Vora. v. O. S. T. K. St. Kr. J.

longifolia. (W. K.) Koch. Langblättrige W.

B. ungetheilt, sehr selten einige fiederspaltig; Stg. meist bis zur Mitte 0 . noch höher hinauf ziemlich

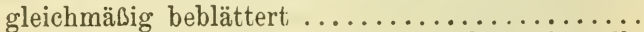

Die meisten B. fiederspaltig, seltener alle 0 . fast alle ungetheilt; Stg. nur am Grunde dicht (oft rosettig) beblättert, weiter oben mit entfernten, meist

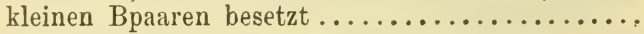

B. breit elliptisch 0 . eiförmig*), oft nur wenig länger als breit, kurz zugespitzt, meist gekerbt-gesägt, dünn u. weich, flaumig-rauh; Btköpfchen mittelgroß. B. M. N. St. K. Kr.

drymeia. Heuff. Ungarische W.

B. eilanzettlich, länglich-lanzettlich 0 . verlängert lanzettlich*), stets viel länger als breit, oft ganzrandig, ziemlich derb; Btköpfchen groß........

B. groß u. breit, eilanzettlich 0 . länglich-lanzettlich, oft gekerbt-gesägt, zerstreut steifhaarig, flaumigrauh o. fast kahl; Stg. namentlich unten dicht mit steifen, abwärts gerichteten Borsten bekleidet, seltener nahezu kahl. Verbr. (fehlt Sch.)

dipsacifolia. (Host.) Schltz. Kardenblättrige W.

B. schmal, verlängert-lanzettlich, meist ganzrandig, dicht angedrückt behaart und dadurch fast seidig schimmernd; Stg. u. Hüllb. zottig. A. v. Südt.

magnifica. Boiss, et Orph. Prächtige W.

Hüllb. dicht zottig; B. dicht anliegend behaart und dadurch schimmernd, nicht selten alle ungetheilt;

7 Bt. lebhaft rothviolett (fast pfirsichblütenfarbig). Vora. v. Südt.....persicina. Kern. Rothe W. Hüllb. mehr 0 . weniger borstig, aber nicht dicht zottig; B. mehr o. weniger behaart, selten kahl .

*) K. intermedia Pernh. et Wettst. hält die Mitte $z$ wischen $K$. drymeia und $K$. dipsacifolia. 
Stg. unten u. Bstiele zottig; Stgb. sehr klein und entfernt; fast alle B. eine grundständige Rosette bildend; Bt. rothviolett. J.

Illyrica. Beck.*) Illyrische W.

Stg. unten u. Bstiele steifborstig; Stgb. nicht auffallend klein; Bt. bläulichlila. Verbr. u. hfg.

arvensis. (L.) C'oult. ${ }^{* *}$ ) Gemeine W.

Anmerkung. Mehrere Arten sind veränderlich und durch Zwischenformen, die zum Theile wohl Bastarte sein dürften, verbunden.

\section{CAllistemia. $M$. $K$. Federkopf.}

Pfl. zottig; die meisten B. leierförmig; Bt. lila, die mittleren weißlich. $J$.

Sibthorpianum. (Sm.) (Boiss.) Dalmatinischer F.

\section{SCABIOSA. L. Grindkraut.}

Außenk. mit 8 tief-eingeschnittenen Furchen und 8 Rippen ............................

Außenk. zottig, unterwärts stielrund o. schwach-gerieft, oberwärts in 8 säulenförmige Zähne gespalten, welche durch eine einwärts gefaltete Haut verbunden sind .......................

B. der unfruchtbaren Büschel gekerbt, dabei ungetheilt 0 . leierförmig.......................

2 B. der unfruchtbaren Büschel ganzrandig, ungetheilt; Zipfel der fiederspaltigen Stgb. lineal, ganzrandig; Bt. blauviolett 0. lila .....................

Stgb. bis auf die Mittelrippe 2-3 fach-fiedertheilig; Kborsten so lang 0 . fast doppelt so lang als der Saum des Außienk. o. fehlend; Bt. blauviolett.

3 N. O. St. Kr.J.K. T' agrestis. W. K. Acker-G. Stgb. 1-2 fach-tiederspaltig, Zipfel der oberen $B$. ganzrandig 0 . gezähnt; Kborsten $3-4$ mal so lang als der Saum des Aubenk..................

Stgb. leierförmig, der Endlappen sehr groß, eiförmig, spitz, gesägt (oft fehlen die Seitenlappen gänzlich), die obersten B. fiederspaltig mit lanzettlichen, eingeschnittenen Zipfeln; Stgglieder 6-8, verlängert; Bt. blauviolett. Südst. $K r$. J.

Hladnikiana. Host. Hladnik's G. Höchstens die unteren Stgb. leierförmig, die übrigen $o$. alle fiederspaltig mit linealen o. lanzettlichlinealen Zipfeln ........................

*) K. rigidiuscula (Koch) $(K . K r$.) ist eine kahle, der K. Illyrica ähnliche Pfl.

**) Bei K. campestris (Andrz.) (Koch) sind die Randbt. nicht größer als die übrigen. 
Kborsten innen mit einem kielartigen Nerv; die unteren Stgb. ungetheilt o. am Grunde fiederspaltig, die oberen fiederspaltig, alle kahl 0 . fast kahl; Bt. röthlich-lila. Geb.

lucida. Vill. Glattblättriges G.

Kborsten meist nervenlos; Stgb. mehr o. weniger behaart, seltener kahl...................

Bt. blassgelb; Stg. unten flaumig, oft grau; Frköpfchen eiförmig. Verbr. (fehlt $S$.)

ochroleuca. L. Gelbes G.

Bt. blauviolett 0. röthlich-lila; Stg. unten oft kahl; Frköpfchen kugelig ....................

Stgb. bis auf die Mittelrippe doppelt-fiedertheilig, die unteren flaumig, die oberen $\mathrm{kahl} 0$. fast $\mathrm{kahl}$; Stg. mit langen spreizenden Aesten. $T$.

Gramuntia. L. Französisches G.

Die unteren Stgb. leierförmig, meist behaart, die oberen fiederspaltig, meist kahl o. fast kahl; Stg. unverzweigt 0. ästig. Verbr. (fehlt Sch.)

Columbaria. L. Gemeines G.

Saum des Außenk. bis zur Mitte 4 lappig, Lappen zugespitzt; unterste $B$. verkehrt-eiförmig-keilig;

8 Stgb. mit großem Endzipfel. $K r$.

silenifolia. $W . K$. Leimkrautblättriges G.

Saum des Außenk. ungespalten; Bt. blauviolett....

B. der unfruchtbaren Büschel u. untere Stgb. länglich o. lanzettlich; Kborsten wenig länger als der Saum des Außenk. B. M. N. O. Südst. $K r$. canescens. $W . K$. Grauliches G.

B. der unfruchtbaren Büschel u. untere Stgb. spatelig-keilförmig; Kborsten 4 mal so lang als der Saum des Aubenk. Südt.

Vestina. Facch. Tiroler G.

B. lineal o. lanzettlich-lineal, ganzrandig, silberigseidenhaarig; Außenk. ganz zottig; Bt. violettblau. Südt. K. Kr. J.

graminifolia. L. Grasblättriges G.

10 Grundb. lineal-länglich, gezähnt, die unteren Stgb. fiedertheilig mit linealen Zipfeln, die oberen Stgb. fast ungetheilt, lineal; Außenk. an der Spitze kahl; Bt. gelblich-weiß 0 . bläulich. $J$.

Wulfenii. (R. Sch.) Kern. Istrianer G.

Anmerkung. S. ochroleuca bildet mit $\mathrm{S}$. lucida, wahrscheinlich auch mit $\mathrm{S}$. agrestis $\mathrm{u}$. S. Columbaria, Bastarte. Die 3 letztgenannten Arten bastartiren wahrscheinlich auch unter einander. 


\section{Familie. Cucurbitaceae. Kürbisgewächse.}

Kräuter o. Stauden mit liegendem o. mittels Wickelranken kletterndem Stg. B. schraubig gestellt, handnervig, meist gelappt o. eckig. Nebenb. fehlen. Bt. einhäusig, selten zweihäusig, regelmäßig. $\mathrm{Kb}$. $\mathrm{u}$. Krb. 5 , mehr 0 . weniger weit hinauf mit einander verwachsen. Stb. 5, manchmal alle verwachsen, häufiger 1 frei, die anderen paarweise verwachsen. Frkn. unterständig, 3(-5) fächerig, mit zahlreichen Samenknospen. Gr. säulenförmig, mit $3(-5)$ oft gelappten o. gefransten N. Fr. beerenartig, oft sehr grof. S. ohne Nährgewebe.

\section{Gattungen.}

(Alle Stf. zu einer Säule verwachsen; 1 jähriges Kraut

1 mit 1 häusigen Bt................. Sicyos. VI.

Stb. 3 freie 0 . theilweise verwachsene Bündel bildend 2

( Pfl. rankenlos; B. länglich-herzförmig, grob gekerbt;

2 Bt. 1 häusig. ................. Ecballium. II.

Wickelranken stets vorhanden ............... 3

$3\{$ Wickelranken einfach $\ldots \ldots \ldots \ldots \ldots \ldots \ldots \ldots \ldots, 4$

Wickelranken 2- bis mehrspaltig.............. 5

Kletternde Stauden; Stg. rauh; Bt. grünlich-weiß;

Beeren klein, kugelig ............. Bryonia. I.

4 Einjährige Kräuter; Stg. steifhaarig; Bt. gelb; Fr. grofs, länglich (Gurke) 0. rundlich (Melone).

Cucumis. III.

Blkr. radförmig, fast freiblättrig; Fr. verlängert, meist keulenförmig 0 . flaschenförmig (Flaschenkürbis) $\ldots \ldots \ldots \ldots \ldots \ldots \ldots$ Lagenaria. IV.

Blkr. trichterig-glockig, verwachsenblättrig; Fr. meist rundlich (Kürbis) ............... Cucurbita. V.

\section{Arten.}

\section{BRYONIA. L. Zannrübe.}

Beeren schwarz; N. kahl; K. der weiblichen Bt. so lang als die Blkr.; Bt. 1 häusig. Verbr. (fehlt $O$. J.)

alba. $L$. Schwarzfrüchtige $Z$.

Beeren roth; N. haarig; $K$. der weiblichen Bt. halb so lang als die Blkr.; Bt. 2 häusig.

M. N. O. Südst. Kr. K. T.

dioica. Jacq. Rothfrüchtige Z.

\section{ECBALLIUM. Rich. Spritzgurke.}

Stg. fast stachelig-steifhaarig; Bt. gelb; Fr. eiförmig, steifhaarig. J. Elaterium. (L.) Rich. Gemeine S. 


\section{CUCUMIS. L. Gurke.}

(Ecken der B. spitz; Fr. länglich, knötig. Cult.

sativus. L. Gemeine G.

Ecken der B. abgerundet; Fr. kugelig o. oval, glatt o. netzig. Cult..............Melo. L. Melone.

1V. LAGENARIA. Sér. Flaschenkürbis.

B. herzförmig, abgerundet-stumpf, gezähnt; Bt. weiß; Fr. glatt. Cult...... vulgaris. Sér. Gemeiner F.

\section{CUCURBITA. L. Kürbis.}

(Blappen spitz; Btstiele stumpfkantig. Cult. u. verw.

Pepo. L. Gemeiner K.

Blappen abgerundet; Btstiele stielrund; Bt. u. Fr. größer. Cult. ........maxima. Duch. Riesen-K.

\section{SICYOS. L. Stichling.}

B. herzförmig, 5 eckig; Bt. grünlich; Fr. eiförmig, spitz. Cult. u. verw. angulatus. L. Gemeiner St.

\section{Familie. Campanulaceae. Glockenblumen- gewächse.}

Stauden o. Kräuter mit ungetheilten, schraubig gestellten B., ohne Nebenb. Bt. zwittrig, regelmäßig, seltener etwas unregelmäßig. Kb. 5. Krb. 5, entweder nur am Grunde oder häufiger fast vollständig verwachsen. Stb. 5, dem Btboden eingefügt, mit den Zipfeln der Blkr. abwechselnd. Frkn. unterständig, 2-5(-10)fächerig, mit zahlreichen Samenknospen. Gr. 1; N. so viele als Frknfächer. Fr. eine vielsamige Kapsel. S. mit Nährgewebe.

\section{Gattungen.}

( Blkr. mit linealen Zipfeln, die beim Aufblühen ver-

1 wachsen sind und sich später vom Grunde nach der Spitze trennen..................... 2

Blkr. glockig o. radförmig, mit kurzen breiten Zipfeln 3 Zweijähriges Kraut; Stf. pfriemlich; A. zusammenhängend; Kapsel an der Spitze mit einem Loche a ufspringend................Jasione. VI.

Stauden; Stf. am Grunde breit-3eckig; A. frei; Kapsel mit seitlichen Löchern aufspringend.

Phyteuma. IV.

Blkr. radförmig mit flachem Saume; Kapsel lineallänglich, prismatisch; 1 jährige Kräuter mit violetten Bt............... Specularia. III. Blkr. glockig; Kapsel eiförmig o. kreiselförmig; Stauden, seltener Kräuter................ 
Kapsel innerhalb des K. unregelmäßig aufspringend, Klappenstücke abfallend; niedrige Stauden; Bt-

4 köpfchen von Hüllb. umgeben. Hedraeanthus. V. Kapsel am Grunde oder gegen die Spitze zu mit seitlichen Löchern aufspringend..............

(Gr. am Grunde von einem röhrig-becherförmigen 5 Discusringe umgeben..........Adenophora. II. Gr. am Grunde ohne umgebenden Ring.

Campanula. I.

\section{Arten.}

\section{CAMPANULA. L. Glockenblume.}

(Buchten zwischen den Kzipfeln ohne Anhängsel... Buchten zwischen den Kzipfeln mit herabgebogenen Anhängseln versehen, welche die Kröhre mehr 0 . weniger bedecken; Bt. nickend...............

Bt. gestielt, einzeln 0. in Trauben oder Rispen, blau, zusammengestellt .......................

Blkr. mit dicht-bärtigen Zipfeln, länglich-glockig; B. ganzrandig, die unteren eiförmig, gestielt, die mittleren Stgb. spatelig, die oberen lineal.

A. v. K. Südst. Kr. J. Zoysii. Wulf. Nickende G. Blkrzipfel nicht bärtig....................

Stg. steif-aufrecht, sehr ästig, Aeste ruthenförmig, aufrecht; B. ganz kahl, gesägt, eiförmig, die oberen

4 lanzettlich, die der unfruchtbaren Büschel herzförmig und lang gestielt. $K r$. $J$.

pyramidalis. $L$. Aronsruthe. Stg. u. B. von anderer Beschaffenheit ............

Stgb. sämmtlich, o. wenigstens die oberen lineal u. 5 ganzrandig; Kb. lineal-borstlich 0 . pfriemlich.... 6 Stgb. elliptisch, eiförmig, herzförmig, länglich 0 . lineal-lanzettlich, dann aber gekerbt 0 . gesägt...

Kzipfel lineal-borstlich, so lang als die Blkr., zurückgebogen; Stg. 1 blütig; B. der nicht blühenden 6 Büschel eiförmig o. herzförmig, gestielt. A. v. Südt. K. St. Kr. J.

linifolia. Scop. Leinblättrige G. Kzipfel pfriemlich, kürzer als die Blkr........... 
Grundb. verkehrt-eiförmig, in einen ziemlich breiten Bstiel von der Länge des B. herablaufend; die unteren Stgb. lineal-lanzettlich; Stg. mehrblütig; Blkr. länglich-glockig, unter den Zipfeln etwas verengt. Vora. (fehlt $S$.)

caespitosa. Scop. Rasige G.

B. der nicht blühenden Büschel eiförmig, herzförmig o. nierenförmig, lang gestielt (stets kürzer als ihr

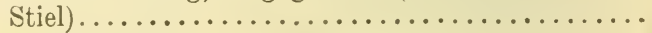

Blkr. blass-violettblau, bauchig-glockig o. fast walzlich, verhältnissmäßig klein; Kb. kaum länger als der Frkn.; Stg. niedrig, rasig, traubig 2-6 blütig (selten 1 blütig); B. der unfruchtbaren Büschel gesägt; untere Stgb. elliptisch. A. u. Vora.

pusilla. Hnke. Niedrige G.

Blkr. meist dunkel-violettblau, trichterig-weit-glockig; Kb. meist länger als der Frkn.; Stg. locker o. gar nicht rasig, oft rispig vielblütig *)...........

Untere Stgb. schmal lanzettlich, dentlich gestielt, die oberen oft am Grunde borstlich zusammen-

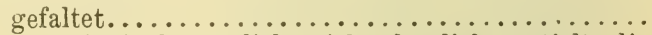

Untere Stgb. lanzettlich, nicht deutlich gestielt, die oberen am Grunde nicht borstlich zusammen-

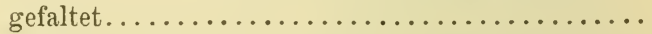

Btstiele u. Aeste des Btstandes aufgerichtet; $\mathrm{Kb}$. meist aufrecht abstehend 0 . an die Blkr. angedrückt, selten zurïckgeschlagen, oft länger als die halbe Blkr. Verbr. u. hfg.

rotundifolia. $I$. Rundblättrige $G$.

Btstiele u. Aeste des Btstandes hin- u. hergebogen, abstehend (der ganze Btstand dadurch schlaff und locker); Kb. wagrecht abstehend 0. zurückgekrümmt, meist kürzer als die halbe Blkr.

Vora. v. N.**) praesignis. Beck. Auffallende G.

Stg. armblütig (oft 1 blütig); Stgb. ganzrandig; $\mathrm{Kb}$. meist länger als die halbe Blkr.; Bt. groß, gesättigt-violettblau. Geb.

Schenchzeri. Vill. Scheuchzer's G.

Stg. traubig o. rispig-mehrblütig; die unteren Stgb. fein gesägt; $\mathrm{Kb}$. meist etwas kürzer als die halbe Blkr.; Bt. ziemlich klein, violettblau.

Vora. v. N.**)

pseudolanceolata. Pant. Lanzettblättrige G.

*) Die Arten dieser Gruppe bedürfen noch genauerer Untersuchungen!

**) Wohl weiter verbreitet! 
Stg. 1-2 blütig (selten 3- 0. 4 blütig); niedrige

(Blkr. bis über die Mitte in 5 Zipfel gespalten, dunkel-violettblau; Gr. mindestens so lang als die Blkr.; B. verkehrt-eiförmig. A. V. T.

cenisia. L. Französische G.

Blkr. nicht ïber $1 / 3$ ihrer Länge gespalten ........

Bt. aufrecht; $\mathrm{Kb}$. lanzettlich, 4 mal kürzer als die Blkr.; B. einfach-gesägt, die der unfruchtbaren

14 Büschel herzförmig, lang gestielt, die Stgb. eiförmig. Südt....Morettiana. Rchb. Moretti's G.

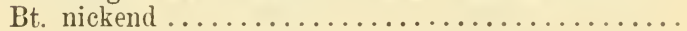

B. elliptisch, gekerbt, gestielt, $3 \mathrm{mal}$ so lang als der Bstiel, die unteren stumpf, die oberen spitz; Ǩb. pfriemlich. A. (fehlt $T$.)

pulla. L. Dunkelblaue G.

B. länglich-verkehrt-eiförmig, entfernt-gekerbt, die unteren spatelig; Kb. breit-eiförmig, zugespitzt. Südt. ............Raineri. Perp. Rainer's G.

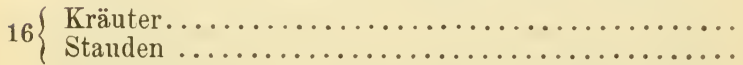

Blkr. sehr klein, röhrig-glockig, außen am Grunde kurzhaarig; Bt. fast sitzend; Stg. oberwärts meist gabelspaltig; untere B. verkehrt-eiförmig-länglich, in einen kurzen Bstiel verschmälert, die obersten beiderseits 1-2 zähnig. $J$.

Erinus. L. Gabelspaltige G. Blki. ansehnlich; Stg. nicht gabelspaltig, sondern traubig 0 . rispig verzweigt ................

Wz. dünn, spindlig-ästig; Btstand sehr locker-rispig; Bt. lila (selten weiß). Verbr. $u$. $h f g$.

patula. $L$. Wiesen-G.

$18 \mathrm{Wz}$. dick, fleischig, fast rübenförmig; Bt. in einer verlängerten, oft verzweigten, reichbliitigen Traube ; Bt. hellblauviolett. $M$. $I . K r$. J.

Rapunculıs. I. Rapunzel-G.

Stg. niedrig, oft liegend, oft hin- u. hergebogen, meist dünn und schwach, rasig .............. Stg. hochwüchsig, meist kräftig, niemals rasig ..... 
Stg. aufrecht, hin- u. hergebogen; B. sitzend, länglich, entfernt gesägt, die unteren stumpf, die oberen lang zugespitzt; Kb. pfriemlich, 4 mal kürzer als die glockige Blkr. $J$.

20 Tommasiniana. Reut. Tommasini's G. Stg. niederliegend; B. gestielt, ungleich-gesägt, stumpf o. spitz; Kb. lineal-lanzettlich, fast halb so lang als die weit geöffnete Blkr. .J.

Istriaca. Fecr. Istrianer $\mathrm{G}$.

Stgb. lineal-lanzettlich o. lineal, entferut-klein-gesägt; Bt. groß, bauchig-glockig, hellviolettblau, in meist armblütigen, selten verzweigten Trauben; Fr. aufrecht, gegen die Spitze zu aufspringend.

Verbr. u. htg......persicifolia. L. Waldzimbel. Stgb. am Grunde breit, herzförmig o. abgerundet; Fr. ïberhängend, am Grunde aufspringend......

B. unterseits locker-graufilzig, gekerbt-gesägt, die unteren herzförmig und lang gestielt, die oberen eiförmig, zugespitzt 0 . sitzend; Stg. stielrund, flaumig-filzig. $B, M . N . K r . J$. Sïdt.

Bononiensis. L. Bologneser G.

B. kahl o. behaart, aber nicht filzig; Stg. mehr 0 . weniger kantig, kahl 0 . behaart..............

Stg. stumpfkantig, sammt den B. kurzhaarig o. kahl 24 Stg. scharfkantig, sammt den B. steifhaarig; untere B. herzförmig, lang gestielt, obere länglich, sitzend; Bt. groß, blauviolett o. weißlich. Verbr. $u$. $h f g$.

Trachelium. L. Nesselblättrige G.

Wz. kriechend; Btstand verlängert, einseitswendig, nur unten durchblättert, oben nur mit kleinen Tragb.; Stg. u. B. kahl o. kurzhaarig-rauh. Verbr. u. hfg.

rapunculoides. $L$. Rapunzelartige $G$. W\%. nicht kriechend; Btstand durchblättert; Stg. u. B. kurz weichhaarig; Bt. sehr groß. Verbr.

latifolia. $L$. Breitblättrige $\mathrm{G}$.

25 Bt. in eine Aehre zusammengestellt ........... 26 Bt. in end- und seitenständigen Büscheln 0. Köpfchen 27

Bt. gelblich-weiß; Aehre eiförmig-länglich, dicht; B. lineal-länglich. $A$. (fehlt $O$. J.)

thyrsoidea. $L$. Straußblütige $G$.

Bt. blauviolett ; Aehre verlängert, unterbrochen; B. länglich-lanzettlich, die oberen umfassend. A. v. T. K. Südst. Kr. J. spicata. L. Aehrige G. 
Bt. gelblichweiß, in endständigen, von langen Hüllb. umgebenen Köpfchen; B. breit-lanzettlich, scharf gezähnt, unterseits graufilzig. Südt. Bt. blauviolett, selten weiß; B. fein gekerbt 0 . fast ganzrandig.......................... 28

Pfl. steifhaarig; B. lanzettlich, in den Bstiel verschmälert, die oberen lanzettlich-lineal, umfassend. Verbr. (fehlt O. S. K.)

Cervicaria. L. Natterkopfblättrige G.

Pfl. kurzhaarig, flaumig o. kahl; Grundb. herz-eiförmig 0. eiförmig-lanzettlich; die oberen Stb. mit herzförmigem Grunde umfassend. Verbr. u. hf'y. glomerata. $\left.L .{ }^{*}\right)$ Gekinäuelte $(*$.

Anhängsel der Kbuchten sehr kurz; Stg. oberwärts sammt den Brändern, K. u. Btsticlen wollig-zottig;

29 B. lineal, fast ganzrandig. $A$. (fehlt $K r$. J.) alpina. Jacq. Alpen-G.

Anhängsel der Kbuchten fast so lang als die Kröhre 30 Niedrige Staude; Blkr. an der Spitze innen dichtbärtig; B. länglich-lanzettlich, fast ganzrandig.

30 Geb.................. barbata. L. Bärtige G. Zweijähriges Kraut; Blkr. an der Spitze kahl; B. lanzettlich, wellig, die oberen halbumfassend.

1I. N. Südst. J. Südt. Sibirica. L. Sibirische G.

A n merkung. In 'T'. soll ein Bastart zwischen C. barbata u. Phyteuma hemisphaericum gefunden worden sein.

\section{ADENOPHORA. Fisch. Becherglocke.}

Staude; Stg. aufrecht; B. länglich, grob spitz-gesägt; Kb. drüsig gesägt; Gr. aus der Blkr. hervorragend; Bt. blassblau. B. N. J. Südt.

lilifolia. (L.) Bess. Wohlriechende B.

\section{SPECULARIA. Heister. Frauenspiegel.}

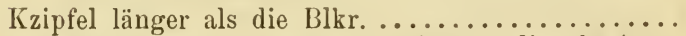

1 Kzipfel so lang als die Blkr. o. kürzer, lineal; Aeste spreizend. Verbr. (fehlt Sch.)

Spleculum. (L.) D C. Venusspiegel.

Kzipfel lanzettlich, am Grunde und an der Spitze verschmälert. $J$. $K$. Südt.

hybrida. ( $L$. .) DC. Bastart-F. Kzipfel lanzettlich-lineal, lang-verschmälert, bogigzurückgekrümmt. $J$. (?)

falcata. $D C$. Sichelförmiger $\mathrm{F}$.

*) Umfasst mehrere Formen! 


\section{PHYTEUMA. L. Rapunzel.}

(Bt. sitzend, in eine Aehre o. in ein von Hüllb. um-

1 gebenes Köpfchen dicht zusammengedrängt .....

Bt. kurz gestielt, doldig 0 . traubig-rispig ange-

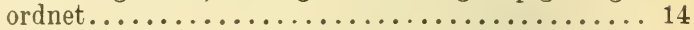

Bt. violett 0 . blau (selten weiß), in einem kugeligen

2 o. zuletzt ovalen Köpfchen .................

Bt. in einer eiförmigen 0 . länglichen, zuletzt walzlich verlängerten Aehre .................

Die äußeren Hüllb. lineal, ganzrandig, meist länger als das vielblütige Köpfchen.

3 Vora. v. Sïdt. K. St. Kr. J.

Scheuchzeri. All. Scheuchzer's R.

Die äu@eren Hüllb. am Grunde eitörmig elweitert .

Hüllb. eiförmig 0 . fast rundlich, stumpf o. spitzlich, zottig gewimpert, kürzer als das Köpfchen...... Hüllb. lanzettlich-verschmälert 0 . zugespitzt; Köpf-

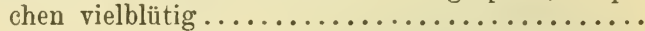

B. verkehrt-eiförmig 0 . verkehrt-eilanzettlich ; Hüllb. fast rundlich, stumpf; Köpfchen meist 5-7 blütig. A. v. T. S. K. St. Kr.J.

pauciflorum. L. Armblütige R.

B. lineal-keilig o. fast löffelförmig; Hüllb. eiförmig, spitzlich; Köpfchen meist $9-12$ blütig.

A. v. S. St. K. confusum. Kern. Verwechselte R.

B. der unfruchtbaren Büschel u. untere Stgb. lang gestielt, herzförmig, eiförmig o. eilanzettlich;

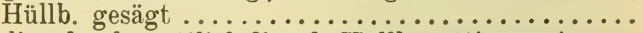

B. lineal o. lanzettlich-lineal; Hüllb. zottig-gewimpert

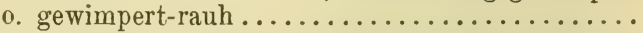

B. gekerbt, die oberen Stgb. sitzend, aus rauteneiförmigem Grunde verschmälert; äußere Hüllb. eiförmig, zugespitzt, geschärft-gesägt. A. v. Südt. K. S. O. St. Kr. J.

Sieberi. Spr. Sieber's R. B. gekerbt-gesägt, die oberen Stgb. lineal 0 . lanzettlich; äußere Hüllb. lanzettlich 0 . eilanzettlich, etwas

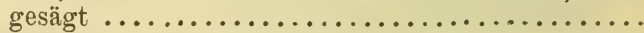

Untere Stgb. meist kürzer o. nur so lang als ihr Stiel; die obersten Stgb. u. die äu£eren Hüllb. lanzettlich, rinnig u. zurückgebogen. Verbr.

orbiculare. $L$. Rundköpfige $R$.

8 Untere Stgb. länger als ihr Stiel; die obersten Stgb. u. die äußeren Hüllb. eilanzettlich, flach u. gerade aufgerichtet; Pfl. meist kleiner. A. v. N. O. St. S. T.

Austriacum. Beck. Oesterreichische R. 
B. ganzrandig 0. an der Spitze etwas gekerbt; Hüllb. ganzrandig, zottig-gewimpert, halb so lang als das Köpfchen. $A$. v. T. S. O. St. K. Kr.

hemisphaericum. $L$. Teufalskrallen.

Die oberen B. entfernt-gezähnelt; Hüllb. am Grunde geschärft-gezähnt, am Rande gewimpert-rauh, fast so lang als das Köpfchen. $A$. v. $T$. S. K.

humile. Schl. Niedrige R.

Bt. grünlichweiß, selten blassblau; Aehre länglich, zuletzt walzlich; B. doppelt-gekerbt-gesägt, die unteren gestielt, herz-eiförmig, die oberen lanzettlich 0 . lineal. Verbr. $u$. $h \mathrm{fg}$.

spicatum. $L$. Aehrige $R$.

Bt. violett 0. blau ........................

Aehre verkehrt-eiförmig-länglich; B. grob doppeltgesägt, die unteren gestielt, eiförmig, die obersten lanzettlich; Bt. schwarz-violett, selten weis.

11 Vora. v. T. K. St. Kr. J.

Halleri. All. Haller's R. Aehre länglich 0 . oval, zuletzt walzlich; B. einfach gekerbt-gesägt, die obersten lanzettlich 0 . lineal

Aehre anfangs oval, zuletzt walzlich; B. entferntgekerbt-klein-gesägt, Grundb. u. untere Stgb. herzförmig o. eiförmig-lanzettlich o. fast lineal, gestielt, die obersten sitzend; Bt. hellblau-violett .. 13

12 Aehre schon anfangs länglich; B. gekerbt-gesägt, die unteren gestielt, eiförmig mit herzförmigem Grunde, die obersten lineal o. lanzettlich; Bt. dunkelviolett. B. N. O. (St. K.?)

nigrum. Schm. Schwarzviolette R.

Grundb. kahl o. am Rande gewimpert, lineal o. lineal-lanzettlich, meist allmälig in den Stiel verschmälert; N. meist 2. Südt. K. St. Kr.

Michelii. All. Micheli's R.

Grundb. meist behaart, herzförmig-lanzettlich 0 . lanzettlich; N. meist 3. T. S. K. St. Kr.

betonicifolium. Vill. Zehrkrautblättrige $R$.

Bt. groß, in einer endständigen Dolde, azurblau, an der Spitze schwarz-violett (selten weiß); Grundb. nierenförmig, gezähnt. Südt. $K$. Kr.J.

comosum. $L$. Schopfige $R$.

Bt. einzeln, zerstreut, traubig-rispig, bläulich; die unteren B. eiförmig, gekerbt-gesägt. Südst.

canescens. $W$. $K$. Grauliche $R$. 
Anmerkung. Von Bastarten wurden im Gebiete beobachtet: $\mathrm{Ph}$. Halleri $\times$ orbiculare, Halleri $X$ spicatum, nigrum $\times$ spicatum, betonicifolium $\times$ spicatum, betonicifolium $\times$ Halleri.

\section{HEDRAEA NTHUS. $D C$. Krugglocke.}

B. am Rande borstig-bewimpert; Hüllb. aus breitherzförmigem Grunde plötzlich in eine verlängerte Spitze zusammengezogen; Kzipfel fast 3 mal so lang als die Kröhre. J.

tenuifolius. ( $W . K$.) $D C$. Schmalblättrige K. B. nur am Grunde bewimpert; Hüllb. aus breitem Grunde allmälig verschmälert; Kzipfel wenig länger als die Kröhre. $A$. v. $K r$.

Croaticus. Kern. Kroatische K.

\section{JASIONE. L. Saudglöckchen.}

Stg. unten steifhaarig, oben meist kahl; B. lineallanzettlich; Bt. violettblau (sehr seiten weio), in endständigen Köpfchen. Verbr. (fehlt .J.)

montana. $L$. Gemeines $\mathrm{S}$.

\section{Familie. Compositae. Korbblütler.}

Kräuter o. Stauden, seltener Halbsträucher mit verschieden gestalteten, schraubig gestellten, seltener gegenständigen B. Nebenb. fehlen; jedoch finden sich manchmal Oehrchen an ihrer Stelle. Bt. in Köpfchen, welche von einer Hülle meist zahlreicher, schuppenförmiger B. (Hüllb.) umgeben sind, dicht zusammengedrängt, bald alle regelmälisg, bald nur die mittleren regelmäßig, bald alle unregelmäßig, hiebei zwittrig, vielehig, 1- o. 2 häusig. Tragb. der einzelnen Bt. (Spreub.) bald vorhanden, bald fehlend. K. (Pappus) verschieden ausgebildet, aus Haaren, Borsten o. Schüppchen gebildet, 0 . aus einem kurzen häutigen Rande bestehend, 0. ganz verkümmert. Blkr. verwachsenblättrig, bei den regelmäßigen Bt. röhrig, trichterig 0 . glockig, mit (4-)5 spaltigem Saume, bei den unregelmäßigen Bt. gewöhnlich mit schmaler Röhre $u$. einseitig verlängertem, zungenförmigem Saume. Stb. (4-)5, der Blkrröhre eingefügt; A. zu einer Röhre verwachsen, aus welcher der Gr. herausragt. Frkn. unterständig, 1 fächerig, mit 1 Samenknospe. Gr. 1, bei fruchtbaren Bt. oben in 2 schenkel gespalten, welche die $\mathrm{N}$. tragen, bei unfruchtbaren Bt. oft ungetheilt 0 . verkümmert. Fr. eine 1 samige, oft von dem stehen bleibenden Pappus gekrönte Schließfr. S. ohne Nährgewebe. 


\section{Gattungen.}

Köpfchen eingeschlechtlich, die männlichen mehrblütig, die weiblichen 1-2 blütig, mit verwachsenblättriger Hülle; weibliche Bt. ohne Blkr.; 1 jährige Kräuter ................. I anthium. XX.

1 Köpfchen in der Regel Zwitterbt. (oft neben eingeschlechtlichen) enthaltend; kommen rein weibliche Köpfchen vor, so sind dieselben mehrblütig; Blkr.

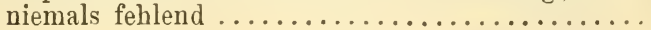

Alle Bt. unregelmäbig, zungenförmig ........... Alle Bt. o. die mittleren Bt. regelmäßig, röhrig mit 4-5 spaltigem Saume; die Randbt. oft zungell-

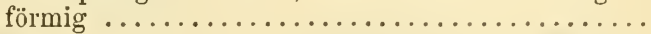

Pappus fehlend, o. nur aus einem kurzen häutigen

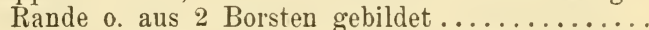

3 Pappus (wenigstens der mittleren Bt.) haarig, federig o. aus mehreren kurzen, lanzettlichen Blättchen gebildet $\ldots \ldots \ldots \ldots \ldots \ldots \ldots \ldots \ldots \ldots \ldots \ldots \ldots \ldots \ldots \ldots \ldots$

Spreub. vorhanden, an die Fr. angewachsen; Pappus aus 2 Borsten bestehend; B. starr, buchtig, dornig.

Scolymus. LVI.

Spreub. fehlend; Pappus fehlend o. nur einen schwachen Rand o. ein sehr kurzes 5 seitiges Kirönchen darstellend; $\mathrm{B}$. weich, nicht dornig .......

$5\{$ Schaft blattlos, $1-3 \mathrm{köpfig} \ldots \ldots \ldots \ldots \ldots \ldots \ldots$

Hülle zur Frzeit kugelig-zusammenschlie®end, wulstig-gekerbt; Fr. 10 riefig; Pappus ein kurzes 5 kantiges Krönchen; Schaft oben keulig verdickt; B. nur gezähnt............ Arnoseris. LXI. Hülle zur Frzeit unverändert; Fr. 5 riefig; Pappus nur 1 schwacher Rand; B. schrotsägeförmig.

Aposeris. LIX.

Frhïlle weit-abstehend; Fr. gebogen, ohne Pappus, die randständigen von den sichelförmigen Hüllb. eingewickelt, sternförmig-abstehend.

Rhagadiolus. LXIII.

Frhülle aufrecht; Fr. 20 riefig; Pappus ein schwacher Rand............................. LVIII.

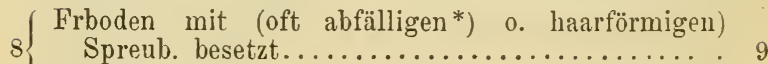

Frboden nackt 0 . fein-wimperig, o. etwas wabig ... 10

*) Man untersuche deshalb mehrere Btköpfchen. 
Pappus federig; Fr.geschnäbelt o. schnabellos; Hülle dachig................Hypochoeris. LXV. Pappus haarförmig, einfach, an den randständigen F'r. abfällig, diese einwärts 3 kantig u. 3 flügelig. Pterotheca. LXXI.

$\int$ Pappus wenigstens an den mittleren Bt. aus Schüpp10 chen bestehend, bisweilen gemengt mit kürzeren Borsten ........................11

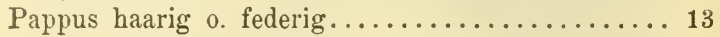

Pappus aller Bt. aus kurzen Schüppchen gebildet; Hülle doppelt; Bt. blau, selten weiß o. röthlich.

Cichorium. LVII.

Pappus der randständigen Bt. kurz-borstig, kronenförmig, der mittleren aus $3-5$ lanzettlichen Schüppchen u. kurzen Borsten gebildet; Bt. gelb 12

Alle Fr. ziemlich stielrund; Stg. beblättert.

Hedypnois. LXIV.

12 Fr. des Randes und des Mittelfeldes fast stielrund, die dazwischen liegenden geflügelt-zusammengedrückt; alle B. grundständig; Schaft oben keuligverdickt................... Hyoseris. LX.

$13\{$ Pappus aus federigen Haaren gebildet ......... 14

Pappus aus einfachen Haaren bestehend ......... 18

f Hïlle aus 8-12 einreihigen, am Grunde verwach14 senen Blättchen gebildet; Fr. geschnäbelt...... 15

Hülle dachig 0 . doppelt ................. 16

Strahlen des Pappus mit freien Federchen; Schnabel voll der Fr. abgegliedert, unten aufgeblasen und innen mit einer Querwand; Hülle flaumig o. steif-

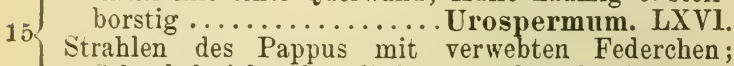
Schnabel nicht abgegliedert, am Grunde nicht aufgeblasen; Hülle kahl o. etwas filzig.

Tragopogon. LXIX.

16 Federchen des Pappus verwebt; am Grunde der Fr. 16 eine Schwiele............ Scorzonera. LXX.

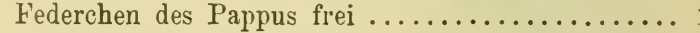

$17\left\{\begin{array}{l}\text { Alle B. grundständig*); Pappus stehen bleibend. } \\ \text { Leontodon. LXVII. }\end{array}\right.$

17 Stg. beblättert; Pappus in der Regel leicht abfällig. Picris. LXVIII.

*) Wenn der Schaft ästig ist, sind die Aeste oft von B. gestützt. 
( Fr. in einen stielartigen 0 . fädlichen Schnabel verlängert, daher der Pappus gestielt .............

Fr. schnabellos, höchstens nach oben verschmälert;

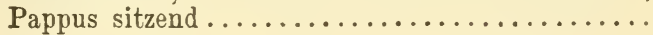

Schnabel der Fr. am Grunde mit Schuppen o. einem

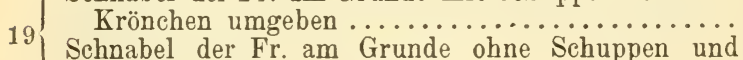
20

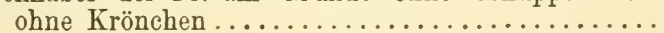

Bt. 2 reihig, 7-12 in einem Köpfchen; Hülle meist

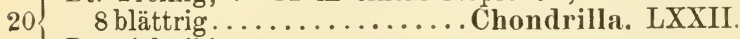

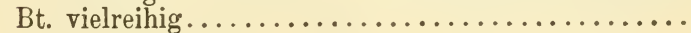

Fr. an der Spitze mit einem feingekerbten Krönchen; Strahlen des Pappus 1 reihig; Stg. blattarm, nicht röhrig, oben sammt der Hülle schwärzlich-zottig.

Willemetia. LXXIII.

Fr. an der Spitze schuppig-weichstachelig o. feinknötig; Strahlen des Pappus mehrreihig; alle B. grundständig; Schaft röhrig.

Taraxacum. LXXIV.

Fr. flach-gedrückt, Schnabel fädlich; Hülle dachig; Bt. 2-3 reihig; Pappus am Grunde mit einem 22 mehr 0 . weniger vorspringenden, oft gewimperten 22 Rande umzogen ........... Lactuca. LXXVII. Fr. stielrund; Hülle doppelt; Bt. vielreihig.

Crepis. LXXIX.

Fr. des Randes am Rücken sehr höckerig und von 23 den verdickten Hüllb. dicht umschlossen, die mittleren stielrundlich ..........Zazyntha. LXII.

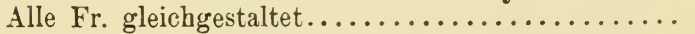

Fr. stark zusammengedrückt; Bt. vielreihig; Stgb.

24 am Grunde herz- 0 . pfeilförmig ..............

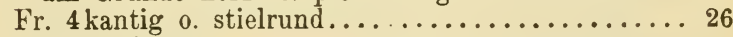

Pappus steif, zerbrechlich, am Grunde mit einem Borstenkrönchen; Bt. blauviolett.

Mulgedium. LXXV.

Pappus weich, biegsam, ohne Krönchen am Grunde; Bt. gelb ................... Sonchus. LXXVI.

Fr. 4 kantig, 4 furchig, die 4 Riefen stark gekerbt; 26 obere B. umfassend ..... Reichardia. LXXVIII.

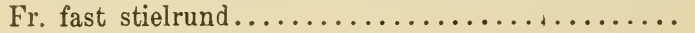

(Köpfchen 5 blütig; Bt. 1 reihig, purpurn; Hülle meist 278 blättrig .............. Prenanthes. LXXX. Köpfchen vielblütig; Bt. mehrreihig ........... 
Fr. durchaus gleichbreit, an der spitze mit einem kurzen, dünnen, gekerbten, den Grund des Pappus umgebenden Rande, 10 riefig, stielrund 0 . fast prismatisch, ganz schnabellos; Hülle dachig; Pappus zerbrechlich, meist gelblich. Hieracium. LXXXI. Fr. an der Spitze schmäler, manchmal geschnäbelt; Hülle doppelt o. etwas dachig; Pappus meist biegsam und rein weiß, seltener gelblich und zerbrechlich. Crepis. LXXIX.

Alle Bt. röhrig (die Randbt. oft größer, bisweilen

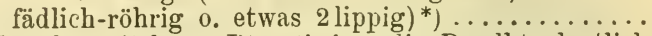
Nur die mittleren Bt. röhrig; die Randbt. deutlich zungenförmig*), wenn auch manchmal sehr schmal

Jede Bt. mit einer besonderen Hülle, alle in ein kugeliges Köpfchen zusammengestellt; Pappus ein häutiges, kurzgefranstes Krönchen; Bt. sämmtlich zwittrig; ansehnliche dornige $\mathrm{Pfl}$. mit blauen 0 . weißlichen Bt.............. Echinops. XL. Die einzelnen Bt. haben außer dem Pappus keine besondere Hülle ....................

Wenigstens die mittleren Bt. mit borstenförmigem, schuppigem, haarförmigem 0 . federigem Pappus. Pappus fehlend o. nur ein kurzes Krönchen o. Scheibchen auf der Spitze der Fr. darstellend......... 60

Frboden mit Spreub. besetzt, borstig o. durch stumpf32 abgestutzte Schuppen tief-bienenzellig-grubig .... Frboden nackt .......................... 48

Pappus aus 2-5 bleibenden scharfen Grannen 0. aus $5-10$ Schüppchen bestehend............ 34

Pappus haarig, borstig 0 . federig............ 35

Hüllb. krautig, 2 reihig, die äußeren abstehend; Pappus aus 2-5 rückwärts-stachligen Grannen bestehend ....................

34 Hüllb. trockenhäutig, dachig, vielreihig, die inneren gefärbt und strahlend; Randbt. 2lippig; Pappus aus 5-10 Schüppchen bestehend.

Xeranthemum. XLI.

Strahlen des Pappus ästig, 1 reihig, in Büschel o. in

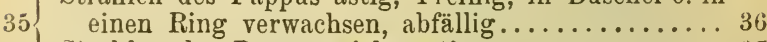

Strahlen des Pappus nicht ästig .............. 37

*) Man halte die oft blumenkronartig gefärbten inneren Hüllb. von Xeranthemum und Carlina nicht für zungenförınige Randbt.! 
Aeste der Pappusstrahlen federig; innere Hüllb. trockenhäutig, strahlend; Spreub. an der Spitze 36 gespalten .................. Carlina. XLII. Aeste der Pappusstrahlen einfach, fiederig-gestellt; Spreub. tief-gespalten ....... Staehelina. XLIV.

Strahlen des Pappus haarig o. borstig, bisweilen ge-

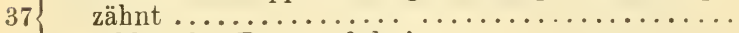

Strahlen des Pappus federig .................

Pappus am Grunde in einen Ring verwachsen und mit diesem abfällig, o. einem an der Fr. befind-

38 lichen Knopf aufgewachsen und sammt diesen abfällig ........................... 39

Pappus am Grunde nicht in einen Ring verwachsen 43

Frboden durch abgestutzte Schuppen tief-bienell39 zellig-grubig; ästige Disteln.... Onopordon. LI. Frboden mit Spreub. 0. Borsten besetzt ..........

Pappus an einen die Fr. krönenden Knopf aufgewachsen; Fr. 4 kantig; Bt. purpurn; B. unterseits 40 filzig; Pfl. unbewehrt ..........Jurinea. XLVI. Pappus am Grunde in einen Ring verwachsen; Disteln .............................

${ }_{41}\{$ Stf. frei.................... Carduus. XLVII.

Stf. wenigstens am Grunde in eine Röhre verwachsen 42

Strahlen des Pappus gezähnt; Hüllb. stark-dornig; B. umfassend, weiøgefleckt, kahl. Silybum. XLIX. Strahlen des Pappus glatt o. sehr kurz gezähnt; Hüllb. in ein gerades Dörnchen endigend; B. herablaufend, unterseits wollig....Tyrimnus. L.

Pappus aus hinfälligen, kurzen Borsten gebildet; Hüllb. mit einem sehr spitzigen Haken endigend; untere B. gestielt, herzförmig; Bt. purpurn.

Arctium. XLIII.

Pappus nicht abfällig; Hüllb. nicht hakenförmig. . 44

B. dornig; Köpfchen von dornigen B. umgeben; Fr.

4 kantig; Bt. gelb............. Carthamus. LV. B. nicht dornig, höchstens stachelspitzig - gesägt; Köpfehen nicht von B. umgeben; F'r. zusammengedrückt 0 . stielrund, seltener 4 kantig..........

Fr. stielrund o. am Grunde zusammengedrückt; Pappus schwärzlich, innerhalb desselben ein gekerbter Ring; Hüllb. lanzettlich, zugespitzt, ganzrandig, ohne

45 Anhängsel; 1 jährige Kräuter mit fein fiedertheiligen B. und Heischrothen Bt. .... Crupina. LII. Fr. zusammengedrückt $0.4 \mathrm{kantig}$; innerhalb des Pappus kein gekerbter Ring................ 
Hüllb. an der Spitze fransig-gespalten, o. mit einem Anhängsel 0. mit einem (oft getheilten) Dorn endigend; Randbt. meist auffallend gröber als die übrigen und trichterig erweitert. Centaurea. LIV. Hüllb. ohne Anhängsel, höchstens an der Spitze in 1 feinen, ungetheilten Dorn auslaufend; Randbt. ebenso gestaltet wie die übrigen. Serratula. LIII.

Pappus bleibend, nicht abfällig, die äußeren Strahlen kurz, borstig, gezähnelt; unbewehrte Pfl. mit

47 purpurnen o. violetten Bt. .... Saussurea. XLV. Strahlen des Pappus in einen Ring verwachsen $u$. später mit diesem abfallend; Disteln.

Cirsium. XLVIII.

Hülle 1 reihig, mit gleichlangen $B$,, bisweilen mit

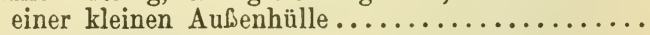

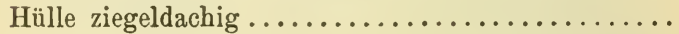

Schaft grundständig, beschuppt; die randständigen

49 Bt. fädlich; B. herz- o. nierenförmig ........... 50

Stg. beblättert .................... 51

Schaft $1-3$ köpfig; randständige Bt. weiblich, 1 reihig, die mittleren zwittrig..... Homogyne. XXXIII. Köpfchen zahlreich, einen Ebenstrauß o. eiförmigen 50 Strauß bildend; Bt. vielehig-2 häusig, die weiblichen Bt. randständig, in den weiblichen Köpfchen vielreihig, in den männlichen 1 reihig, ZwitterBt. der Mitte unfruchtbar... Petasites. XXXII.

Schenkel des Gr. durchaus flaumig; Bt. purpurn; 51 B. nieren-herzförmig..........Adenostyles. II. Schenkel des Gr. kahl, nur die Narbe flaumig; Bt.

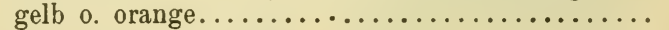

Randbt. fädlich, mehreihig, weiblich, die mittleren

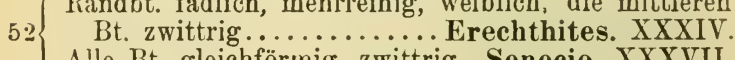
Alle Bt. gleichförmig, zwittrig.. Senecio. XXXVII.

Schenkel des Gr. durchaus flaumig; B. gegenständig, meist $3-5$ theilig; Bt. fleischfarben 0 . röthlich.

Eupatorium. I.

Schenkel des Gr. nur oben an der Aussenseite flaumig;

B. schraubig gestellt................. 54

Narbenspitzen fast herz-eiförmig, zusammenneigend; 54 Bt. gelb, alle zwittrig; B. lineal, kahl. Aster. V. geschwänzt......

Randbt. röhrig, 3 zähnig; Hüllb. krautig, die inner55 sten an der Spitze gefärbt; Bt. gelb. Inula. XIV. Randbt. fädlich, an der Spitze gezähnelt......... 
Hülle 5 kantig; Hüllb. krantig mit trockenhäutigem Rande; Bt. des Randes weiblich, zwischen die Hüllb. gestellt, die mittleren zwittrig, 4 zähnig.

Hïlilago. IX. Hülle halbkugelig o. stielrund; Hüllb. völlig trocken häutig, verschieden gefärbt; mittlere Bt. 5 zähnig 57

Pfl. 2 häusig; Bt. der männlichen Pfl. röhrig, 5-zähnig, mit verkümmerten Frkn.; Bt. der weiblichen Pfl. fädlich, ohne Stb. ............ Antennaria. X. Randbt. jedes Köpfchens weiblich, die mittleren zwittrig o. männlich, seltener einzelne Köpfchen einge-

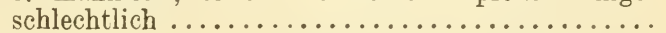

Weibliche Randbt. 1 reihig; Hüllb. gelb, an der 58 Spitze oft orange ..........Helichrysum. XIII. Weibliche Randbt. mehrreihig; Köpfchen bisweilen

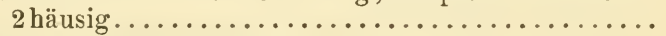

Mittlere Bt. des Köpfchens unfruchtbar, mit meist ungetheiltem Gr.; Köpfchen zu einem von sternförmig abstehenden, weif wolligen $B$. umgebenen Ebenstrauß zusammengestellt; Stg. unverzweigt.

Leontopodium. XI.

Mittlere Bt. des Köpfchens alle o. doch die meisten fruchtbar, mit 2 spaltigem Gr.; Köpfchen nicht von sternförmig abstehenden $B$. umgeben.

Gnaphalium. XII.

Frboden spreublättrig (wenigstens zwischen den rand-

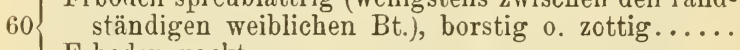

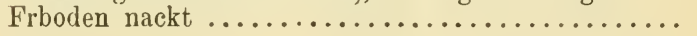

Frboden zottig; Fr. mit einer kleinen Scheibe an

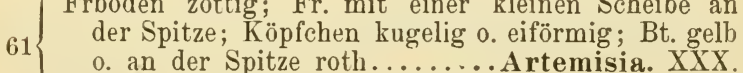

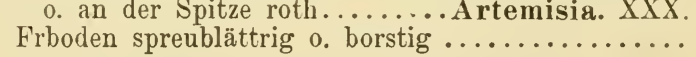

$62\left\{\begin{array}{l}\text { Randbt. größer, strahlend, unfruchtbar. } \\ \text { Centaurea. LIV. }\end{array}\right.$

Bt. gleichgebildet .................. 63

Hüllb. 1-2reihig; kleine graufilzige Pfl. mit verkehrt-eiförmigen B., welche um die doldig-ge-

63 häuften Btköpfe einen Rosettenstrahl bilden.

Evax. VIII.

Hüllb. ziegeldachig ................... 64

( Hülle halbkugelig; Blkrröhre beiderseits flügelrandig;

64 B. 4 reihig-gezähnt; Bt. gelb.. Santolina. XXV. Hülle kugelig; Fr. 4 rippig; B. klein dornig gezähnt; Bt. safranfarben ....... Carthamus. LV. 
(Hüllb. 1 reihig, 5-9, die Fr. einhüllend; niedrige, filzig-wollige $\mathrm{Pfl}$. mit lanzettlichen $\mathrm{B}$.

Hüllb. ziegeldachig ................. Micropus. VII.

Fr. geschnäbelt; A. geschwänzt; B. gestielt, oval 0 . 66 länglich; Bt. gelb .......... Carpesium. XVI. Fr. schnabellos, an der Spitze mit einem Scheibchen; Randbt. oft fädlich; A. nicht geschwänzt ......

Hülle kugelig o. eiförmig; Scheibchen der Fr. schmäler als diese; Köpfchen in Trauben o. Aehren.

Artemisia. XXX.

Hülle halbkugelig; Scheibchen der Fr. so breit als diese; Köpfchen in Ebensträußen; Bt. gelb.

Chrysanthemum. XXIX.

68 Frboden spreublättrig............... 69

Frboden nackt 0 . bisweilen zottig-behaart........ it

Pappus fehlend, statt dessen oft nur ein etwas hervorragender Rand; Blkrröhre beiderseits flügel-

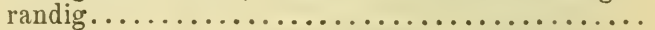

Pappus aus Schuppen 0 . Borsten bestehend, bisweilen kurz, häutig und kronenartig ..........

Fr. stark zusammengedrückt; Zungenbt. breit, meist rundlich, höchstens 10; Hülle eiförmig 0. länglich ; Köpfchen ebensträußig, selten einzeln; Stauden.

Achillea. XXVII.

Fr. wenig 0. gar nicht zusammengedrückt; Zungenbt. länglich, meist zahlreich; Hülle halbkugelig 0 . flach; Kräuter o. Stauden.....Anthemis. XXVI.

Hüllb. 1 reihig o. 2 reihig und die äußere Reihe ab-

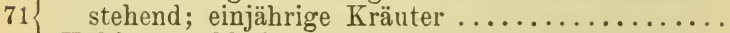
Hüllb. ziegeldachig $\ldots \ldots \ldots \ldots \ldots \ldots \ldots \ldots$;

Hüllb. 2 reihig, die äußeren abstehend; Pappus aus 2-4 rückwärts-scharfen Grannen bestehend.

Bidens. XXIII.

72 Hüllb. 1 reihig, 5-6; Strahlbt. meist 5; Pappus aus federig-gefransten Schuppen bestehend.

Galinsoga. XXIV.

A. nicht geschwänzt; Strahlbt. unfruchtbar; Bt.

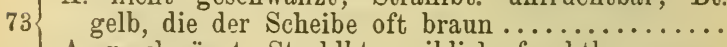
74

A. geschwänzt; Strahlbt. weiblich, fruchtbar ..... 75

Pappus aus 2-4 freien Schüppchen bestehend; B. ungetheilt, meist herzeiförmig. Heliantlıus. XXII.

74 Pappus aus einem kleinen, 4 zähnigen Krönchen bestehend; B. fiedertheilig o. 3 theilig. 
Zungenförmige Randbt. 2reihig; Fr. des Randes 75 flach, 2 flügelig; Hülle dornig; Pfl. wollig-zottig. Zungenförmige Randbt. 1 reihig; Fr. des Randes 3 seitig 0 . stielrund .....................

Stauden; Hüllb. kürzer als die Strahlbt., letztere nicht geöhrlt; Pappus aus einem zerschlitzten Krönchen bestehend..... Buphthalmum. XVIII.

76 Einjähriges Kraut; Hüllb. länger als die Strahlbt., letztere am Grunde 200 hrig; Pappus aus zahlreichen freien Schüppchen bestehend.

Odontospermum. XIX.

Pappus fehlend, an der Spitze der Fr. höchstens ein etwas hervortretender Rand ..................

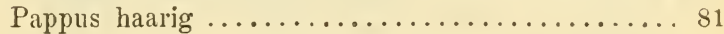

78 Hüllb. 2 reihig, gleichlang ................. 79

78 Hüllb. ziegeldachig $\ldots \ldots \ldots \ldots \ldots \ldots \ldots \ldots \ldots, 80$

Die mittleren Bt. unfruchtbar; A. geschwänzt; 79 Strahlbt. gelb; Kräuter.....Calendula. XXXIX. Die mittleren Bt. fruchtbar; A. nicht geschwänzt; Strahlbt. weiø o. röthlich ........... Bellis. IV.

Einjährige Kräuter; B. in schmal-lineale o. fädliche Zipfel getheilt; Hüllb. wenigreihig, ziemlich gleichlang; Strahlbt. weib o. fehlend.

80 Stauden, selten Kränter Matricaria. XXVIII. gelb); Bzipfel niemals fädlich; Hüllb. vielreihig; von sehr ungleicher Länge.

Chrysanthemum. XXIX

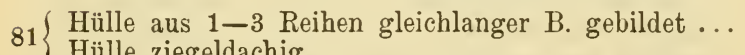
Hülle ziegeldachig........................ 89

82 (Hüllb. 1 reihig *), oft mit Außenhülle.......... 83

Hüllb. 2-3 reihig *) .................... 86

Stg. beblättert ...................... 84

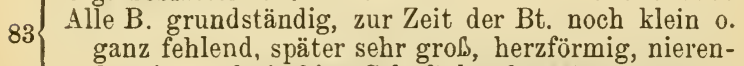
82 (n) 4 förmig o. dreieckig; Schaft beschuppt .........

Hüllb. sich gegenseitig mit den Rändern nicht 0 . nur etwas deckend, deutlich 1 reihig; Grschenkel nur an der Spitze flaumig... Senecio. XXXVII.

84 Einige Hüllb. mit breitem Hautrande, welcher von den daneben befindlichen Hüllb. bedeckt wird, daher die Hüllb. scheinbar 2 reihig; Grschenkel bis zum Grunde flaumig.......Ligularia. XXXVIII.

*) Vgl Ligularia! 
Schaft 1 köpfig; Bt. gelb; Strahlbt. mehrreihig, die mittleren Bt. zwittrig, fruchtbar.

Tussilago. XXXI.

85 Schaft mehrköpfig; Bt. weiß, grünlich 0. röthlich; Strahlbt. der weiblichen Köpfchen vielreihig, die der zwittrigen Köpfchen 1 reihig; die mittleren Bt. zwittrig, aber unfruchtbar. Petasites. XXXII.

Strahlbt. 2 reihig, weiß, mit kurz-borstigem Pappus; die mittleren Fr. mit doppelreihigem Pappus, die

86 äußere Reihe aus kurzen Borsten, die innere aus längeren Haaren bestehend........ Erigeron. VI. Strahlbt. 1 reihig; Pappus aller Fr. gleichförmig...

Schenkel des Gr. lanzettlich-verschmälert, spitz;

87 Schaft 1 köpfig; Strahlbt. weiß...... Aster. V. Schenkel des Gr. kopfig-abgeschnitten o. oben verdickt mit kegelförmiger Spitze; Strahlbt. gelb ..

Hülle walzlich; N. oben verdickt, mit kegelförmiger Spitze; Randbt. mit verkümmerten Stb.; Stgb. 88 gegenständig; Grundb. 5 nervig...Arnica. XXXV. Hülle flach 0 . halbkugelig; N. kopfig-abgeschnitten; Stgb. schraubig gestellt, oit umfassend.

Doronicum. XXXVI.

Rand- u. Scheibenbt. gleichfarbig-gelb......... 90

89 Randbt. anders gefärbt als die Bt. der Scheibe, näm-

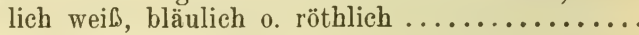

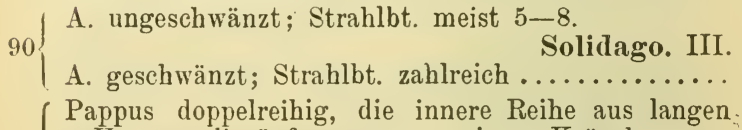

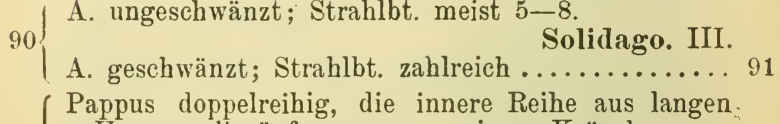

91 Haaren, die äußere aus zu einem Krönchen verwachsenen Schüppchen bestehend. Pulicaria. XV. Pappus gleichförmig.............. Inula. XIV. $92\left\{\begin{array}{l}\text { Strahlbt. mehrreihig, schmal, die der inneren Reihen } \\ \text { oft fädlich..................... Erigeron. VI. } \\ \text { Strahlbt. 1 reihig, lineal, meist ziemlich breit. }\end{array}\right.$ Aster. V.

Arten.

\section{EUPATORIUM. $L$. Wasserdost.}

Große Staude; Bzipfel lanzettlich, gesägt. Verbr.

cannabinum. $L$. Gemeiner $W$.

\section{ADENOSTYLES. Cass. Alpendost.}

B. fast gleichmäßig gezähnt, unterseits blassgrün, an den Adern flaumig; Stgb. ohne Oehrchen.

1 A. u. Vora......glabra. (Vill.) $D C$. Grüner A. B. unterseits wollig-filzig $u$. daher graulich 0 . fast

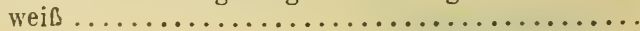


B. fast gleichmäßig gezähnt, etwas lederig; Stgb. ohne Oehrchen. A. V. T.

crassifolia. Kern. Dickblättriger A.

B. ungleich grob-doppelt-gezähnt, weich; die oberen Stgb. am Grunde mit 2 rundlichen Oehrchen. Geb.

Alliariae. (Gouan.) Kern. Weisfilziger A.

Anmerkung. Zwischen A. Alliariae und A. glabra kommt ein Bastart vor:

\section{SOLIDAGO. L. Goldruthe.}

Köpfchen in einfacher o. mit wenigen kurzen Aesten versehener Traube. Geb.

alpestris. $\left.W . K *^{*}\right)$ Alpen-G.

Köpfchen kleiner, rispenartig zusammengestellt; Stg. höher und ästiger. Verbr. $u$. hfg.

Virga aurea. $L . *$ ) Gemeine G.

A n m e r k u g. Mehrere nordamerikanische Solidago-Arten, welche durch kleine, sehr zahlreiche Köpfchen und hohen Wuchs ausgezeichnet sind, werden in Gärten oft cultivirt und verwildern nicht selten. Die bekannteste dieser Arten ist S. Canadensis L.

\section{BELLIS. L. Gänseblümchen.}

Einjähriges Kraut; B. aderig, nicht 3 nervig; blüht

1 im Frühling. J....... annua. L. Einjähriges, G. Stauden; B. mehr 0 . weniger deutlich 3 nervig .... 2 B. spatelig - verkehrt - eiförmig, schwach 3 nervig; Hüllb. sehr stumpf; blüht vorzugsweise im Frühling Verbr. $u . h f g . .$. perennis. L. Gemeines G.

2 B. länglich, allmälig in den Bstiel verschmälert, deutlich 3 nervig; Hüllb. spitzlich; Pfl. kräftiger; blüht vorzugsweise im Herbst. $J$.

silvestris. Cyr. Wald-G.

\section{ASTER. L. Sternblume.}

Alle B. grundständig, rosettig; Schaft 1 köpfig;

1 Zungenbt. weiß, seltener röthlich. A. u. Vora.

Bellidliastrum. (L.) Scop. Sternlieb.

Stg. beblättert $\ldots \ldots \ldots \ldots \ldots \ldots \ldots \ldots \ldots \ldots \ldots \ldots \ldots$

Zungenbt. fehlend; Scheibenbt. goldgelb; B. schinal lineal, sehr zahlreich. B. M. N. Südst. J. Süidt.

2 Linosyris. (L.) Bernh. Goldschopt. Zungenbt. violett, lila 0 . weißlich, nur ausnahmsweise fehlend; $\mathbf{B}$. niemals schmal lineal ........

*) Beide Arten umfassen mehrere Formen und sind noch nicht genïgend geklärt.

Fritsch, Excursionsflora. 
Stg. meist niedrig, 1 köpfig; Köpfchen ansehnlich; 3 Hüllb. lanzettlich, locker gestellt. Geb.

alpinus. $L .^{*}$ ) Alpen-St. Stg. mehrköpfig (nur ausnahmsweise 1 köpfig) .....

Zungenbt. lila, unfruchtbar, leer; grauflaumige Staude

4 mit 3 nervigen, punktirten B.; Stg. vielköpfig.

4 (II.) $N . \ldots \ldots \ldots \ldots \ldots$ cauts. $W^{\leftarrow} K$. Graue St.

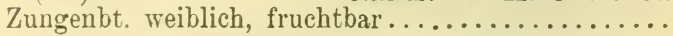

Stg. kurzhaarig-rauh; untere B. elliptisch, gestielt, die oberen länglich-lanzettlich, sitzend, kurzhaarigrauh; Köpfchen groß, oft nur wenige; Hüllschuppen

5 abgerundet-stumpf, abstehend; Zungenbt. hellviolett. Verbr..........Amellus. L. Berg-St. Stg. kahl o. mehrreihig fein behaart; B. kahl 0. rauh; Zungenbt. blassviolett ...............

Stg. ganz kahl; B. 1-3 nervig, etwas fleischig; der trockenhäutige Rand der Hüllb. röthlich.

II. N. St. Kr. J. . . . Tripolium. L. Strand-St. Stg. oben mehrreihig fein behaart; B. 1 nervig mit netzig verzweigten Seitennerven; der trockenhäutige Rand der Hüllb. weißlich.

(B. M.) N. O. Südst. K.

salicifolius. Scholl. Weidenblättrige St.

A nmerkung. Mehrere nordamerikanische, mit A. salicifolius verwandte Arten werden cultivirt und verwildern nicht selten. - Callistephus Chinensis (L.) Nees ist die eigentliche Garten-Aster, welche ab und zu vereinzelt auf Schutt etc. verwildert.

\section{ERIGERON, L. Berufkraut.}

Pappus der Scheibenbt. 1 reihig, haarförmig....... Pappus der Scheibenbt. 2 reihig, die äufere Reihe aus zahlreichen kurzen Borsten, die innere aus wenigen langen Haaren gebildet; Stg. vielköpfig; untere B. grob gesägt, obere meist ganzrandig; Strahlbt. weiß o. etwas bläulich.

Verbr. (eingebürgert.) (fehlt $B$. M. Sch.)

anmuus. (L.) Pers. Weiles B.

Strahlbt. aufrecht, so lang 0 . wenig länger als die Scheibenbt.; B. lineal-lanzettlich, die unteren in

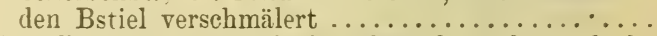

Strablbt. abstehend, oft fast doppelt so lang als die

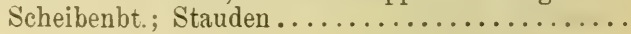


Pfl. 1jährig; Rispe länglich, sehr reichblütig, Aeste u. Aestchen traubig; B. kurzhaarig, lineal-lanzettlich, borstig-gewimpert; Strahlbt. schmutzig-weiß, selten etwas röthlich. Verbr. $u$. $h f g$. (eingebürgert.)

Canadensis. L. Kanadisches B.

Pfl. 2jährig o. ausdauernd; Stg. traubig 0. ebensträußig, verzweigt, mit 1-mehrköpfigen Aesten;

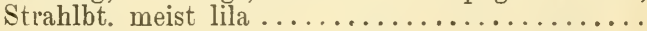

B. rauhhaarig. Verbr....... acer. L. Scharfes B.

4 B. kahl, am Rande gewimpert.

4 Verbr. (fehlt Sch. M.)

Droebachiensis. Müll. Kahles B.

B. sammt den Aesten und der Hülle drüsig-flaumig; Stg. 2-3 köpfig o. fast rispig verzweigt; B. länglich-lanzettlich; Strahlbt. purpurn. A. v. S. T. K.

Atticus. Vill. Drüsiges $\mathrm{B}$.

B. kahl o. rauhhaarig; Stg. 1-wenigköpfig; die

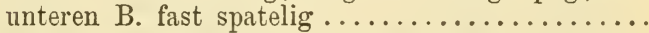

Die inneren weiblichen Bt. röhrig-fädlich und zahlreich; Hülle rauhhaarig 0. wollig-zottig; Strahlbt.

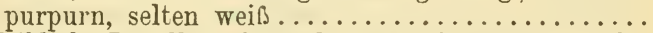

Weibliche Bt. alle o. fast alle zungenförmig; Strahlbt.

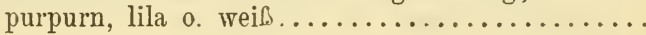

Untere B. etwas fleischig, nur am Rande flaumhaarig; Stg. stets 1 köpfig; Hülle dicht wollig - zottig; Strahlbt. wenig länger als die Scheibenbt.

7 A. v. T. K. neglectus. Kern. Vernachlässigtes B. B. nicht fleischig, rauhhaarig; Stg. $1-5$ köpfig; Hülle rauhhaarig; Strahlbt. fast doppelt so lang als die Scheibenbt. A......alpinus. $L$. Alpen-B.

Hülle flaumig-kurzhaarig; B. kahl u. kurzhaarig-gewimpert 0. kurzhaarig; Stg. 1-5 köpfig; Strahlbt. meist purpurn. $A$.

8 glabratus. Hoppe et Hornsch. Kahles B. Hülle dicht-wollig-zottig; B. rauhhaarig, die unteren fast kahl; Stg. stets $1 \mathrm{köpfig,} \mathrm{niedrig;} \mathrm{Strahlbt.}$ lila 0 . weißlich. $A$. (fehlt J.)

uniflorus. L. Einköpfiges B.

\section{MICROPUS. L. Falzblume.}

Einjähriges Kraut; Hülle wollig, die fast unmerklichen Bt. verdeckend. N. J. Südt.

erectus. L. Aufrechte F.

\section{EVAX. Gärtn. Filzkraut.}

Einjähriges Kraut; Bt. schmutzig-weiß. $J$.

pygmaea. (L.) Pers. Zwerg-F. 


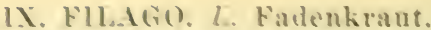

1 Hallb. hasspitsis. mu die immersten stumptlich .

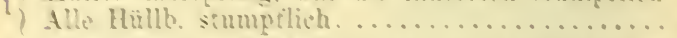

b. lanzettich: Kiptihen zu :(0-50 beisammen: Hulle stumpt 3 kimetip Verir.

Germanica. I. Deutsches F

$\Rightarrow$ B. spatelformig: Kiptihen zu $12-17$ heisammen: Hulle durch starke Faltmus der Hallb. schart 5ripeiz. I. spatulata. fresb. Spatelblateriges b'

Aeste tranbig anserordnet antiere Hällb. dichtwollig. erst zuletat die spitze kahl werdend. lerbr.

arvensis. L. Acker-by

deste erugdoldig angeordnet: änbere Hällb. an der

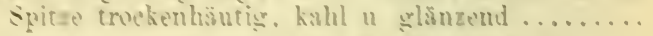

b. lineal-lamerttlieh, die die hïptiheuknimel mugebenden die letateren nieht ïbertistend, ansedrijekt: Pth. Wollis-tilzig. Verbr. . montana. L. Berg-k.

13. ptriemlich-lineal, die die kifptihenknamel umste. benden über letztere hinusrasemd: P’t. tast sebilizangedrükt-behaart. (li, ML), .

Galliea. 1.. Franzisisches $\mathrm{k}$

Anmerkung. Zwishen $\mathrm{k}$. arrensis und $k$. Germanies kemmt cin hastart ror.

\section{INTFXIARIA. Gürto. Katzenptötchen.}

Ausläufer treibend: cirumdb. obersects zuletzt kahl. unterseits weibtilzig: Hüllb. rosia o, weils.

berbr. uf hig. diviea. (1.) (iörth. (iemeines k Anslänter fehlen: B. beiderseits wollig: Hüllb. olirenbraun. - l. (fehlt $\mathbf{N}$ )

Carpatica. (Hohiby.) liluft et l'inus.

Karpathen-k

Anmerkung. Auaphalis mararitacea (L.) Benth et Hook.. dureh rerlägrert lanzettliehe, unterseits weibtilzige B. uni weilie Hüllb. ansarezeichnet. wird in bamerngirten enteire und verwildert bisweileu.

\section{I.EONTOPODILM. $R$. Br. Elelweiß.}

Niedrige Stande: ster. u. B. wollig-filzig; Bt. griünlich-gelb. A. ........ alpinum. C'ass. Alpen-E.

\section{G. APHALIUM, L. Ruhrkraut.}

(Einjähriģ hränter: Brköpfehen in Knämeln ......

1 Stauden: Btköptehen in Cehren, Trauben, Rispen o. eimzeln; Stg. unverzweigt. nur der Btstand oft ästig 


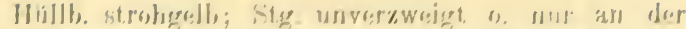

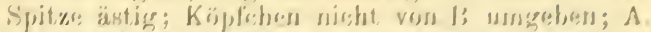

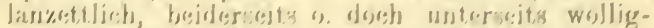

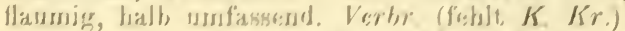

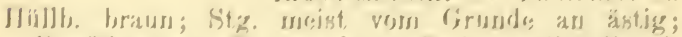

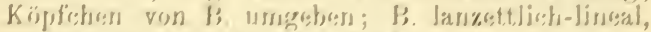
grauwollige, seltconer taithl. Vertor

ndiginosum. I. Sechlamans-R.

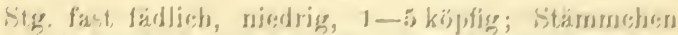

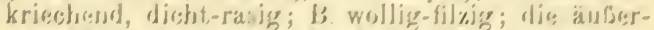

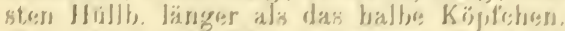

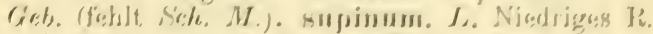

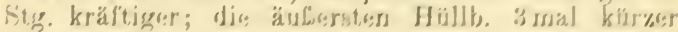

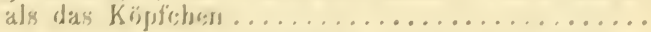

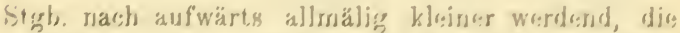

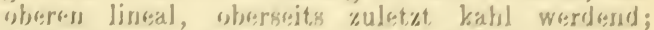

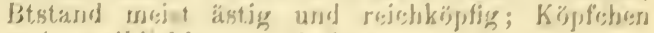
uresist gealblichtoraun. Verber.

cilvaticum. I, Wald-K.

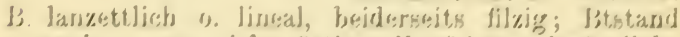

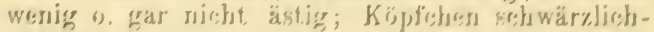

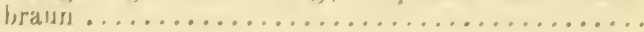

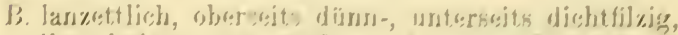

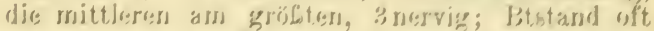
bot, was vor\%weigt. (ieb).

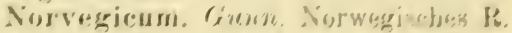

B. lineal-lanzettloch o. Jineal, bejderneito dichtefilzign, alle 1 nervig used ziessilich gleich gros; Sitstard

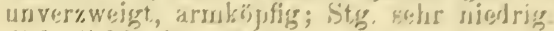

fieb. (ferbit Sick. H.)

Hopjeanum. Ko, Alpen-Ko.

\section{XIJ. HFLICHJYSI:M. Gartn. Strobblume.}

Staude; frundb. verkehert-eilanzettlichs; oberes Stetgh. lineal-lanzcttlich. Scch. M. S. N. Kr.

arenarium. (J,) J): Sard-St.

Halbstrauch ; b. lineal, an liand go zuruekegcorol]t.

$K r$.J...Italicum. (Jisth.) (juss. Jtalienischss St.

\section{XJV. INIJA. J. Alant.}

Inrere Hillh, an der Épitze verbrejtert, linealspatclig; Stoph, herz-6iformig, zugespitzt, unglejch gevährit-gesagt, unterseits filzig, ursfassend; hohe Staude; Konfohen setsr grocs. Cult. u. cerw.

Hejenium. L. Eehter A. 


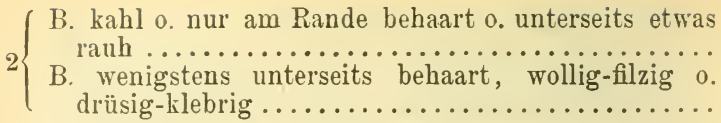

(B. lineal, fleischig, an der Spitze oft 3 spaltig; 3 Köpfchenstiele nach oben keulig verdickt; Fr. behaart. J. ........crithmoiles. $L$. Meerstrands-A. B. nicht fleischig, niemals 3 spaltig; Fr. kahl......

B. lineal-lanzettlich o. lineal, längsnervig, am Grunde verschmälert, am Rande oft etwas wollig-behaart. M. N. O. Sïdst. K. Kr. J. Südt.

ensifolia. $L$. Schwertblättriger A.

B. eilanzettlich, oval o. länglich-lanzettlich, netzigaderig, am Grunde oft herzförmig, am Rande oft rauh, aber niemals wollhaarig ..............

Obere Stgb. herzförmig-umfassend; Stg. meist armköpfig. Verbr........... salicina. $L$. Weiden-A.

5 Stgb. mit abgerundetem Grunde sitzend; Stg. dicht beblättert, oft vielköpfig. $K r$. J. Südt.

spiraeifolia. L. Spierstrauch-A.

$6\left\{\begin{array}{c}\text { Pfl. rauhhaarig, wollig } 0 . \text { filzig, aber nicht drüsig- } \\ \text { klebrig } \ldots \ldots \ldots \ldots \ldots \ldots \ldots \ldots \ldots \ldots \ldots \ldots \ldots \ldots \ldots \ldots \ldots \ldots \ldots \ldots\end{array}\right.$

Pfl. drüsig-klebrig .................. 12

Randbt. deutlich zungenförmig............ 8

Randbt. fädlich-röhrig, die Scheibenbt. nicht über-

7 ragend; Stg. rispig-ästig; B. elliptisch o. lanzettlich,

oberseits flaumig, unterseits dünn filzig, die unteren gestielt. Verbr.

vulgaris. (Lam.) Trevis. Dürrwurz.

B. oberseits ziemlich kahl, unterseits wollig-flaumig 9

8 B. beiderseits rauhhaarig, seidenhaarig-wollig 0. weißfilzig .

Zungenbt. wenig länger als die Scheibenbt.; Frkn. u. Fr. kahl; Köpfchen klein, zahlreich.

$9 \quad B . M . N . K r$. . . Germanica. L. Deutscher A. Zungenbl. viel länger als die Scheibenbt.; Frkn. u. Fr. kurzhaarig; Köpfehen groß. Verbr. (fehlt S.)

Britannica, L. Wiesen-A.

B. dunkelgrün, steif, beiderseits rauhhaarig, an Grunde verschmälert; Köpfchen groß; Frkn.u. Fr. kahl. Verbr. (fehlt $S$.)

hirta. L. Rauhhaariger A.

B. beiderseits seidenhaarig-wollig und graugrün 0 . weißfilzig; Frkn. u. Fr. kurzhaarig . 
Pfl. dicht weißfilzig; Stgb. gestielt, eiförmig o. lanzettlich. J. ... candida. (L.) Cass. Schneeweifer A. Pfl. seidenhaarig-wollig, graugrün; Stgb. länglich 0 . lanzettlich, die oberen mit herzförmigem Grunde Grunde sitzend. MI. N. Südst. K.

Oculus Christi. L. Christusange.

B. lanzettlich, entfernt-gesägt, die oberen am Grunde fast herzförmig; Zungenbt. verlängert. $J$.

viscosa. (L.) Ait. Klebriger A.

B. fast lineal, nahezu ganzrandig, am Grunde verschmälert; Zungenbt. sehr kurz. $J$.

graveolens. (I.) Desf. Stinkender A.

Anmerkung. Von Bastarten wurden im Gebiete beobachtet: J. ensifolia $X$ salicina, ensifolia $X$ Germanica, ensifolia $\times$ hirta, hirta $X$ salicina, hirta $X$ spiraeifolia und Oculus Christi $X$ vulgaris.

\section{PULICARIA. Gärtn. Flohkraut.}

Kraut mit spindliger, ästiger Wz.; B. am Grunde nicht herzförmig; Zungenbt. kaum länger als die Scheibenbt. Verbr. (fehlt S.) vulgaris. Gärtn. Gemeines F.
Stauden mit kriechendem Wst; Stgb. mit tief-herzförmigem Grunde umfassend; Zungenbt. viel länger als die Scheibenbt.......................

Stg. erst oben ästig, Aeste schief aufrecht, wollig, 2-mehrköpfig. Verbr. (fehlt B. Sch.)

dysenterica. (L.) Gürtn. Ruhrwurz. Stg. vom Grunde an ästig, Aeste wagrecht abstehend, kurzhaarig, 1-2(-4) köpfig; Köpfchen kleiner. J. uliginosa. Stev. Sumpf-Ruhrwurz.

\section{CARPESIUM. $L$. Kragenblune.}

Köpfchen einzeln, endständig, überhängend, mit einer Hülle von Laubb. umgeben. $N$. O. St. Kr. J. Sïdt. cernuum. $L$. Ueberhängende $\hbar$. Köpfechen blattachselständig, fast traubig angeordnet, olne Laubbhülle. $J$.

abrotanoides. $L$. Stabwurzartige $K$.

XVII. PALlenis. C'ass. Goldange.

Einjähriges Kraut mit gelben Bt. $J$.

spinosa. (L.) Cass. Dorniges G. 


\section{BUPHTHAIMUM. L. Ochsenange.}

Köpfchen groß, an langen Stielen ebensträußig zusammengestellt; alle Fr. stielrund; B. sehr grob, herzförmig, doppelt gesägt, die unteren gestielt.

Südst. Kr.J....speciosum. Schreb. Großes 0. Köpfchen einzeln, endständig; die randständigen Fr.

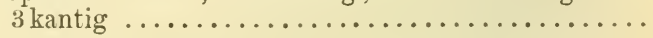

B. herzförmig, umfassend, kahl, spitz-gezähnt; Fr. an der Spitze flaumig. Siidt.

speciosissimum. Avd. Prächtiges R.

2 B. länglich-lanzettlich, flaumig, etwas gezähnelt, die unteren in den Bstiel verschmälert; Fr. kahl.

Verbr. (fehlt B. Sch.)

salicifolium. L.*) Gemeines 0 .

\section{ODONTOSPERMUM. Neck. Sternauge.}

B. länglich-lanzettlich, stumpf; Bt. gelb; Fr. seidenhaarig. J... aquaticum. (L.) Neck. Gemeines St.

\section{XX. ХANTHIUM. L. Spitzklette.}

Am Grunde der Bstiele stehen gelbe, meist 3 theilige Stacheln; B. unterseits graufilzig.

Verbr. (fehlt S. K.) ..spinosum. L. Dornige S. Stg. u. B. wehrlos; B. nicht filzig ............

B. am Grunde herzförmig; Frköpfchen eiförmig, mit geraden Schnäbeln, zwischen den Dornen weichhaarig. Verbr. (fehlt $S$.)

strumarium. L. Gemeine S.

B. am Grunde gestutzt 0. keilig; Frköpfchen groß, länglich-eiförınig, mit hakigen Schnäbeln, zwischen

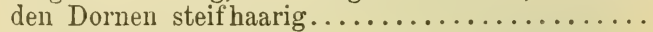

Dornen der Frköpfrhen kräftig, stark hakig; Schnäbel zusammenneigend. $K$. N. (eingeschleppt).

macrocarpum. $\left.D C .^{* *}\right)$ Großfrüchtige $\mathrm{S}$.

Dornen der Frköpfchen schwächer, sehr dicht stehend, nur an der Spitze hakig; Schnäbel abstehend.

(B. O.) J. Italicum. Moretti.**) Italienische S.

\section{RUDBECKIA. L' Rudbeckie.}

Hochwüchsige Staude; Köpfchen lang gestielt.

Cult. u. verv. . laciniata. L. Schlitzblättrige R.

*) Umfasst mehrere Formen!

**) Die Standorte dieser beiden Arten bedürfen noch kritischer Sichtung. 


\section{HELIANTHUS. L. Sommenblume.}

Knollen tragende Staude; obere B. länglich-eiförmig 0. lanzettlich, zugespitzt; blüht im Spätherbst.

Cult. u. icrv.........tuberosus. L. Erdbirne. Einjähriges, hochwüchsiges Kraut; alle B. herzförmig; Köpfchen bei normaler Entwicklung sehr groß, nickend. Cult. u. verv.

\section{BIDENS. L. Zweizahn.}

amnuus. L. Große S.

B. doppelt-fiederschnittig; Fr. lineal, glattrandig, doppelt so lang als die Hülle. Südt. $K$. bipinnata. L. Fiederblättriger Z.
B. ungetheilt 0. $3-5$ theilig; Fr. am Rande stachelig, so lang als die inneren Hüllb.

B. 3-5 theilig, Zipfel lanzettlich, gesägt; Strahlbt.

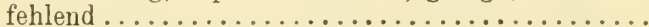

2 B. lanzettlich, gesägt, am Grunde etwas zusammengewachsen; Strahlbt. oft vorhanden; Fr. fast keilförmig. Verlr. .........cernua. L. Nickender Z.

Zähne des Blattrandes gerade o. wenig gekrümmt; Köpfchen so hoch als breit, mit 5-8 laubigen Hüllb.; Spreub. breit lineal. Verbr.

tripartita. L. Dreitheiliger Z.

Zähne des Blattrandes gekrümmt; Köpfchen breiter als hoch, mit 10 o. mehr laubigen Hüllb.; Spreub. schmal lineal. B. radiata. Thuill. Strahlender Z.

XXIV. GALINSOGA. $R$. P. Gängelkraut.

B. gegenständig, eiförmig; Strahlbt. weiø, Scheibenbt. gelb. Eingeschleppt.

parviflora. Cavan. Kleinblütiges G.

\section{XXT. SANTOLINA. L. Heiligenkraut.}

Stark riechender, filziger Halbstrauch; B. 4 reihiggezähnt. Südst. J.

Chamaecyparissus. $L$. Cypressenkraut.

\section{ANTHEIIS. L. Hundskamille.}

Strahlbt. gelb, viel kürzer als der Durchmesser der Scheibe (selten fehlend); Staude; Bfiedern kämmigfiederspaltig, mit gesägten Fiederchen.

1 Verbr. (fehlt S.)....tinctoria. L. Färberkamille. Strahlbt. weiB, oft so lang als der Durchmesser der

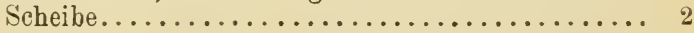

${ }_{2}\left\{\right.$ Spreub. zerfetzt-gezähnt; Stauden $\left.{ }^{*}\right) \ldots \ldots \ldots \ldots \ldots .3$

$2\{$ Spreub. ganzrandig, manchmal borstlich; Kräuter . 4

*) Sind die Scheibenbt. nicht gelb, sondern schmutzigweib, so vgl. man Achillea oxyloba. 
Babschnitte ungleich, theils lineal-spatelig, theils verkürzt und abgerundet; Hüllb. mit breitem schwarzem Rande. A. v. St.

Carpatica. W. K. Karpathen-H.

Babschnitte lineal-lanzettlich 0 . spatelig; Hüllb. mit häutigem, oft gebräuntem Rande; Köpfchen viel kleiner. B............montana. L. Berg-H.

Spreub. lineal-borstlich; Frboden verlängert-kegelförmig; Fr. fast stielrund, mit einem gekerbten 4 Rande endigend. Verbr. Cotula. L. Stinkende H. Spreub. lanzettlich, länglich-verkehrt-eiförmig 0 . keilförmig, in eine Stachelspitze endigend.......

Frboden gewölbt 0 . halbkugelig; Fr. zusammengedrückt-4eckig, 2 schneidig, mit einem scharfen

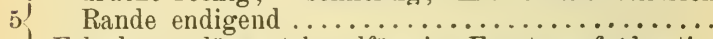
Frboden verlängert-kegelförmig; Fr. stumpf-4 kantig, gleichförmig-gefurcht; B. doppelt-fiedertheilig ...

Bfiederchen ganzrandig, kammförmig-gestellt; B. wollig-flaumig; Fr. beiderseits 3 streifig.

6 B.M. N. O. St. J.

Austriaca. Jacq. Oesterreichische $\mathrm{H}$.

Bfiederchen gezähnt 0 . gespalten ...............

Spreub. verkehrt-eiförmig, plötzlich in eine starre Stachelspitze zusammengezogen, welche länger ist als die Bt.; Bfiederchen gezähnt; Fr. schmal-geflügelt, beiderseits 10 streifig. $J$.

altissima. L. Höchste $\mathrm{H}$. Spreub. länglich, mit einer starren Stachelspitze, welche kürzer ist als die Bt; Bfiederchen 3 spaltig o. fiederig-5 spaltig; Fr. ungeflügelt, beiderseits 5 streifig. J......brachycentros. Gay. Große H.

Spreub. verkehrt-eiförmig-länglich o. keilförmig, an der Spitze gezähnelt und starr-stachelspitzig; die äußeren Fr. meist mit einem halbirten, schief-abgestutzten Krönchen; die ganze Pfl. flaumig-zottig. B. M. N. (K.) J.

8) Ruthenica. MI. B. Ruthenische H.

Spreub. spitz und in eine starre Stachelspitze zugespitzt; die äußeren Fr. mit einem gedunsenen, taltig-runzeligen Ringe; die ganze Pfl. wolligflaumig. Verbr. u. hfy.

arvensis. L.*) Feld-Kamille.

*) A. incrassata Lois. (J.) ist durch oberwärts verdickte Köpfchenstiele ausgezeichnet. 


\section{ACHILLEA. L. Schafgarbe.}

Strahlbt. 6-12 (am häufigsten 10), so lang 0. länger als die Hülle, weiß; Stg. 1 -vielköpfig......... Strahlbt. $(4-) 5$, nicht länger als die halbe Hülle, weif, rosa 0. gelb; Stg. reichköpfig ..........

B. ungetheilt, lanzettlich-lineal, bis zur Mitte kleinu. dicht-, über der Mitte tiefer-u. entfernter2 gesägt, kahl. Verbr. (oft nur verw.; fehlt $S . K r$.J.)

Ptarmica. L. Deutscher Bertram.

B. fiederspaltig 0 . fiederschnittig .............

B. fiederspaltig, im Umrisse länglich-keilig, Zipfel länglich, stumpf, ganzrandig 0. 2-3 zähnig; Stg. sammt den B. weißgrau-seidig, sehr selten kahl. $A$.

Clavenae. $L$. Weißer Speik.

B. fiederschnittig, nicht seidig behaart .........

B. wollig-zottig, im Umrisse schmal-lanzettlich; Fiedern der Grundb. 2 theilig, der vordere Zipfel 3 spaltig, der hintere 2 spaltig; Ebensträuße fast kugelig. A. v. T. K..... nana. $L$. Zwerg-Sch.

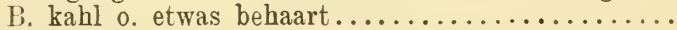

Ebensträuße zusammengesetzt; B. im Umrisse breiteiförmig, Fiedern ziemlich breit-lanzettlich, zugespitzt, eingeschnitten-doppelt-gesägt.

5 Vora. v. T. K.

macrophylla. $L$. Großblättrige Sch. Köpfchen in meist einfachen Ebensträußen o. einzeln; B. im Umrisse länglich ................

Stg. meist einköpfig; B. fiederschnittig, Fiedern lineal, meist ungetheilt; Köpfchen groß; Strahlbt. stets mehr als 10 . A. v. T. S. K. St.

oxyloba. ( $D C$.) Schltz. Spitzblättrige Sch.

Stg. fast immer mehrköpfig; Strahlbt. meist un-

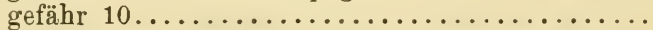

B. kammförmig-fiederschnittig, Fiedern lanzettlichlineal, ungetheilt $0.1 \mathrm{zähnig,} \mathrm{nur} \mathrm{an} \mathrm{den} \mathrm{unteren}$ B. 2-3 zähnig. A. v. T. S. K. St.

moschata. Wulf. Bisam-Sch.

B. einfach- o. doppelt-fiederschnittig, die Fiedern

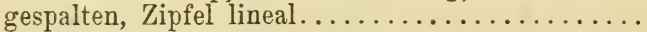

B. einfach-fiederschnittig, Fiedern $2-3$ spaltig 0. fiederig-5 spaltig, Zipfel lineal, spitz, stachelspitzig, an den gröberen Fiedern zu 3-5. $A$.

atrata. $L$. Schwarze Sch.

B. doppelt-fiederschnittig, Fiederchen $2-3$ spaltig 0 . fiederig $5-6$ spaltig, Zipfel schmal, lineal, spitz, an den größeren Fiedern zu 12-15. A. (verbr.?)

Clusiana. Tausch. Clusius' Sch. 
Bt. goldgelb; B. sehr zottig, fiederschnittig, Fiedern der unteren $B$. fingerig-3 theilig, der mittleren 2bis 3 spaltig, der obersten ungetheilt. Südt. $K r$.

tomentosa. L. Filzige Sch.

Scheibenbt. weißlich, Strahlbt. weiø, purpurn, rosa 0. gelblich; B. doppelt-fiederspaltig, wollig-zottig 0 .

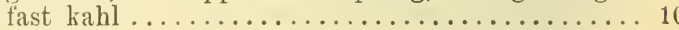

S Strahlbt. 3-4 mal kürzer als die Hülle, meist zu10 rückgebogen, blassgelb o. weiß; B. im Umrisse oval o. länglich-oval ................. 11

Strahlbt. ungefähr halb so lang als die Hülle.... 12

Bspindel schmal, von der Spitze bis zur Mitte des B. gezähnt, Zähne lineal; Fiederchen fiederspaltiggezähnt, die größeren 5-7 zähnig. B. M. N. St. K. Kr.J. Sïdt.

nobilis. $\left.L{ }^{*}\right)$ Edle Sch. Bspindel nicht gezähnt; Fiederchen lineal, ganzrandig 0.1 zähnig. $J$.

virescens. (Fenzl.) Grüne Sch.

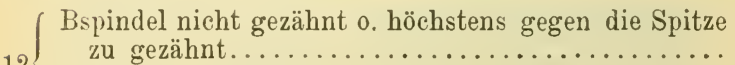

12 Bspindel (wenigstens an den unteren B.) geflügelt

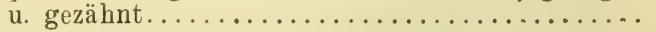

B. oberseits punktirt, die oberen mit breit geflügelter Bspindel; Bzipfel knorpelig verdickt, mit fast

13 stechender Spitze; Strahlbt. meist dunkelrosa. B. M. N. O.S.

asplenifolia. Vent. Milzfarnblättrige Sch.

B. nicht punktirt, mit schmal geflügelter Bspindel. 14

Bzipfel borstlich, fein zugespitzt, büschelig aneinandergedrängt; Stg. u. B. seidig-wollig; Strahlbt.

14 weiß o. etwas gelblich. B. M. Sch. N. St. K.

setacea. W. K. Borstlichblättrige Sch.

Bzipfel lanzettlich 0 . fast lineal, nicht borstlich ... 15

Stg. u. B. wollig-zottig, letztere im Umrisse fast lineal, mit schmalen, aneinander gedrängten Zipfeln; Strahlbt. weiß o. etwas gelblich.

$15\left\{\begin{array}{l}\text { Zipfeln; Strahlbt. weiß o. etwas } \\ \text { B. M. N. O. St. K. Kr. Südt. }\end{array}\right.$

Pannonica. Scheele. Ungarische Sch.

Stg. u. B. zerstreut wollig 0 . nahezu kahl....... 16

*) Die hier vorherrschende A. Neilreichii Kern. hat blassgelbe $\mathrm{Bt}$. 
B. im Umrisse lineal-lanzettlich, steif, mit gedrängten Zipfeln; Endzipfel kurz, eilänglich; Strahlbt. weiß o. etwas gelblich. Verbr. $u$. $h f g$.

collina. Becker. Hügel-Sch.

B. im Umrisse länglich-lanzettlich, oft schlaff, fein getheilt; Endzipfel verlängert, lineal-lanzettlich; Strahlbt. heller 0. dunkler rosa 0. auch weiß, aber

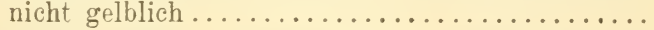

(IIüllb. schınal braun berandet. Verbr. $\iota$. hfg.

17 Millefolium. $L$. Gemeine Sch. Hüllb. breit schwarzbraun berandet; B. sehr fein getheilt. Geb...... Sudetica. Opiz. Sudeten-Sch.

Bspindel schmal geflügelt; Bzipfel schmal, lanzettlich 0. fast lineal; Strahlbt. weis o. hellrosa. $N$.

stricta. Schl. Steife Sch.

Bspindel breit geflügelt; Bzipfel breit, untereinander verbunden .........................

Strahlbt. weif o. blassrosa; Bspindel der ganzen Länge nach reichlich gezähnt. $T$. $K$. $K r$.

distans. W. K. Gezähntblättrige Sch.

19 Strahlbt. purpurn; Bspindel nur am Grunde der einzelnen Fiedern mit 2 o. mehr Zähnen beiderseits. O. S. Südst. Kr. (?)

tanacetifolia. All. Rainfarnblättrige Sch.

Anmerkung. Von Bastarten wurden im Gebiete beobachtet: A. Clavenae $\times$ macrophylla, Clavenae $X$ oxyloba, Clavenae $X$ moschata, atrata $X$ Clavenae, Clavenae $\times$ Clusiana, moschata $X$ nana, atrata $X$ macrophylla, atrata $X$ moschata.

\section{MATRICARIA. $L$. Kamille.}

(Strahlbt. weiß, sehr selten fehlend; Scheibenbt. mit

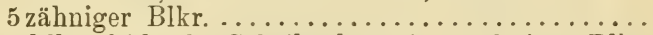
Strahlbt. fehlend; Scheibenbt. mit 4 zähniger Blkr. Eingeschlepist... discoidea. $D C$. Strahllose K.

(Frboden kegelförmig, hohl; Fr. an der Innenseite 4-5 rippig; Köpfchen klein. Verbr.

Chamomilla. L. Echte K.

Frboden halbkugelig, ausgefüllt; Fr. an der Innenseite 3 kantig; Köpfthen größer. Verbr.

inorlora. L. Geruchlose K. 
XXIX. CHRYSANTHEIUM. $L$. Wucherblume.

Einjähriges Kraut mit goldgelben Strahlbt.; B. kahl, gezähnt, vorne verbreitert und oft 3 spaltig.

$J$. (sonst eingeschleppt).

segetum. L.*) Gelbe W.

Stauden; Strahlbt. weiø (sehr selten gelb) o. fehlend

Stg. $1 \mathrm{köpfig} 0$. in verlängerte 1 köpfige Aeste ge-

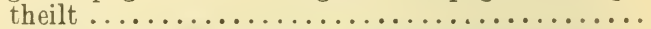
Stg. ebensträußig-vielköpfig; B. fiederschnittig.....

Die meisten B. grundständig, kämmig-fiederspaltig, Zipfel genähert, ganzrandig; obere Stgb. lineal, ganzrandig; Stg. niedrig. $A$. (fehlt $N . J$.)

alpinum. $L$. Alpen-W.

B. ungetheilt, aber meist gekerbt, gesägt 0 . einge-

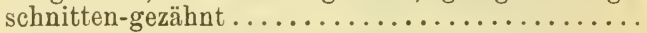

Alle Fr. ohne Krönchen (höchstens einige der randständigen ein Krönchen tragend); untere B. lang gestielt, verkehrt-eiförmig-spatelig, gekerbt 0 . fast gelappt, die oberen sitzend. Verbr. $u$. hfg.

Leucanthemum. $L{ }^{* *}$ ) Gemeine W.

Alle 0 . doch die randständigen Fr. mit einem ge-

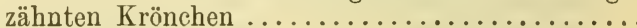

Untere B.verkehrt-eiförmig-keilförmig, eingeschnitten5-7 zähnig; Stgb. eingeschnitten-gesägt, mit lanzettlich-pfriemlichen Zähnen; Hüllb. breit schwarz berandet. $A$. atratum. Jacq. Schwarzrandige W.

Untere B. länglich, gekerbt, die mittleren und oberen gesägt, Sägezähne am Grunde der B. schmäler u.

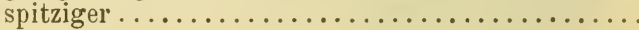

Die untersten B. verkehrt-eiförmig, plötzlich in den Bstiel zusammengezogen; Stgb. lanzettlich, entfernt gesägt; Stg. niedrig; Köpfchen groß; Hüllb. mit breitem schwarzbraunem Rande.

A. u. Vora. v. T. K. St. Kr. J.

adustum. (Koch.) Niedrige W.

Die untersten B. länglich, seltener verkehrt-eiförmig, allmälig in den Bstiel verschmälert; Hüllb. mit hellem Hautrande und vor demselben mit brauner Linie ..............................

*) In B. u. $N$. wurde das ähnliche $\mathrm{Chr}$. coronarium L. (mit fiedertheiligen B.) verw. beobachtet. **) Umfasst mehrere Formen! 
( Untere B. verkehrt-eiförmig o. länglich, spärlich gezähnt, obere lineal-lanzettlich 0 . lineal, oft fast

7 ganzrandig. J.........montanum. $L$. Berg-W. Untere B. länglich, obere lanzettlich, alle fast gleich-

mäGig gesägt; Stg. höher. Vora. v. Südt.
heterophyllum. Willd. Verschiedenblättrige W.

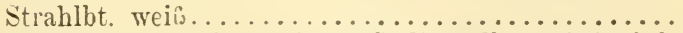

Strahlbt. fehlend, an ihrer Stelle gelbe, röhrig-fäd-

8 liche, weibliche Bt.; B. doppelt fiederspaltig, mit gesägten Zipfeln. Terbr.

vulgare. (L.) Bernh.*) Rainfarm.

Bfiedern stumpf, elliptisch-länglich, fiederspaltig, die obersten zusammenfließend, mit etwas gezähnten,

9 kurz bespitzten Zipfeln. Verbr. (meist nur verw.)

Parthenium. (I.) Pers. Mutterkraut.

Bfiedern spitz, mit spitz gezähnten 0 . gesägten Zipfeln

Fiedern der unteren B. fiederspaltig, Zipfel mit stachelspitzigen Sägezähnen; Zunge der Strahlbt. lineal-länglich, meist länger als die Hülle.

Verbr. (fehlt Sch. S.)

corymbosum. L. Ebensträubige W.

10 Bspindel durch Herablaufen der Bfiedern breit geflügelt; Bfiedern breit-lanzettlich, $2-3$ fach eingeschnitten-gezähnt; Zunge der Strahlbt. rundlichverkehrt-eiförmig, etwa halb so lang als die Hüile. $K r$. J.

macrophyllum. W. $K$. Großblättrige W.

\section{ARTEmisia. L. Beifuß.}

(Randbt. weiblich; Scheibenbt. zwittrig, dabei frucht-

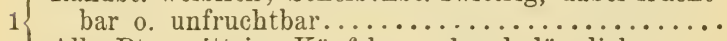
Alle Bt. zwittrig; Köpfchen schmal, länglich ....... 15

2 Frboden zottig 0. doch behaart; Stauden.........

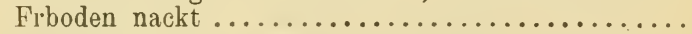

Untere B. 2- o. 3 fach-fiederspaltig o. doppelt-fiederschnittig; äu@ere Hüllb. lineal; Btköpfchen kugelig,

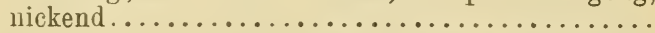

Untere B. 3 theilig-vielspaltig, obere fiederspaltig, alle grau-seidenhaarig; äußere Hüllb. länglich 0 .

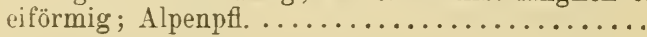
3 7

*) In $N$. wurde auch C. Balsamita L. (mit fast ungetheilten B.) verw. gefunden. 
(Untere B. 3 fach o. doppelt-fiederspaltig, die oberen 1 fach - fiederspaltig, Zipfel lanzettlich, stumpf; Bstiel ohne Oehrchen; Frboden rauhhaarig. Verbr.

Absinthium. L. Wermuth.

Untere B. doppelt-fiederschnittig, im Umrisse rundlich-eiförmig, Zipfel schmal-lineal; alle B. gestielt, Bstiel am Grunde geöhrlt; Frboden kraushaarig .

Pfl. grün o. dünn graufilzig. Südst. $K r$. J. Südt.

$\int$ camphorata. Vill. *) Kampfer-B.

5 B. u. Köpfchen dicht weisfilzig; Pfl. kleiner und gedrungener. $J$.

Biasolettiana. Vis. Biasoletti's B.

Untere B. gestielt, die oberen sitzend, fiederspaltig; Köpfchen gestielt, nickend, fast kugelig, ungefähr 24 blüitig. A. v. T.

niticla. Bert. Glänzende Edelraute.

Alle B. gestielt, die oberen fast fingerig-fiederspaltig; Köpfchen aufrecht, rundlich-kreiselförmig, traubigährig, ungefälı 15 blütig. A. v. T. S. K. St.

laxa. (Lam.) Fritsch. Echte Edelraute.

B. am Grunde des Bstieles ohne Oehrchen.......

7 Die unteren Stgb. am Grunde geöhrlt 0 . daselbst

fiederspaltig-gezälınt ..................

Untere B. fingerig-vielspaltig, obere fiederspaltig, im Umrisse länglich, grauseidig; Köpfchen aufrecht, traubig-ährig; Hüllblättchen filzig. A. v. T. S. K. St.

Genipi. Web. Schwarze Edelraute.

Untere B. gestielt, doppelt-fiederspaltig, Fiederchen gezähnt, Zähne u. Zipfelchen lanzettlich, stachelspitzig; die obersten B. ungetheilt, ganzrandig;

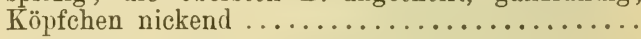

Köpfchen groß, in einfacher Traube; Hüllb. geschwärzt; Stg. oben wollig; Bt. wollig-zottig.

A. v. J. (Moresch.) . atrata. Lam. Schwarzer B. Köpfchen klein, rispig (selten einfach traubig) angeordnet; Hüllb. hellbräunlich; Stg. nur etwas flaumig. $N$. Iaciniata. Willd. Schlitzblättriger B.

Köpfchen grauhaarig 0 . filzig ............. 11

10 Köpfchen kahl; untere B. $2-3$ fach-, obere einfach-

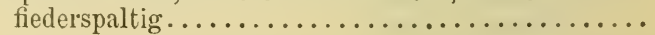

*) Die Pfl. unseres Gebietes gehört größtentheils zu A. incanescens Jord. 
Köpfchen länglich o. eiförmig, fast sitzend, filzig ; B. fiederspaltig, unterseits weiळfilzig, Fiedern lanzettlich, zugespitzt, eingeschnitten-gesägt 0 . ganz-

11 randig. Verbr. .......vulgaris. L. Gemeiner B. Köpfchen fast kugelig o. rundlich-eiförmig; untere B. doppelt-fiedertheilig, Fiedern oft vielspaltig,

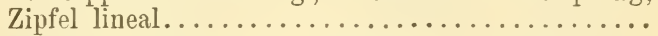

Köpfchen grauhaarig, fast kugelig; B. doppelt-fiedertheilig, oberseits kahl o. grau, unterseits filzig; Hüllb. verkehrt-eiförınig, die äußeren lanzettlich. B. M. N. O. St. K. Pontica. L. Pontischer B.

12 Köpfchen rauhhaarig-filzig, rundlich-eiförmig; $B$. doppelt - fiedertheilig - vielspaltig, graufilzig, die oberen fast fingerig-getheilt; Hüllb. länglich, die äußeren lineal. B. M. N. St. Kr.

Austriaca. Jacq. Oesterreichischer B.

Einjähriges Kraut; Stg. einzeln, aufrecht; Köpfchen rundlich-eiförmig; B. im Umrisse eiförmig, Zipfel lineal, die der unteren B. fast lanzettlich.

13 B. MI. N. O. St. . scoparia. W. K.*) Besen-B. Stauden; unfruchtbare Stg. rasig, die blühenden aufstrebend; B. seidenhaarig-grau o. kahl, Zipfel stachelspitzig...................... 14

Köpfchen eiförmig; innerste Hüllb. eilänglich, die äu@eren eiförmig und kürzer; Stg. rispig-ästig. Verbr. ............... Köpfchen kugelig; Hüllb. eiförmig; blühende Stg. oft unverzweigt; Köpfchen traubig angeordnet.

A. v. T. S. K. borealis. Pall.**) Nordischer B.

B. 2-3 fach fiederschnittig, Zipfel lineal, stumpf. $N$.

Santonicum. L. Geheiligter B.

B. ungetheilt, lanzettlich, nur an den unfruchtbaren Stg. eingeschnitten 0 . fiederspaltig. $J$.

coevulescens. $L$. Bläulicher B.

A nmerkung. A. Dracunculus L. und A. Abrotanum L., erstere durch ungetheilte, kahle B., letztere durch fast strauchigen Wuchs ausgezeichnet, werden nicht selten cultivirt.

\section{TUSSILAGO. L. Huflattich.}

B. herzförmig-rundlich, eckig, gezähnt, unterseits filzig; blüht im ersten Frühling vor Entwicklung der B. Verbr. $u$. $h f g$. Farfara. L. Gemeiner H.

*) A. annua L. (durch starken Geruch ausgezeichnet), wurde in $N$. eingeschleppt gefunden.

**) A. alpina (DC.) (Vora. v. T. S. K.) hält die Mitte $\mathrm{zwischen} \mathrm{A}$. campestris und $\mathrm{A}$. borealis. 


\section{PETASITES. Gürtn. Pestwurz.*)}

Grschenkel der Zwitterbt. kurz, eiförmig; B. herzförmig, unterseits wollig-grau, zuletzt fast kahl, Lappen am Grunde ruudlich; Btstand länglich 0. eiförmig; Bt. röthlich, die weiblichen bleicher.

Verbr. .hybridus. (L.) G. M. Sch. Gemeine P. Grschenkel der Zwitterbt. verlängert, lanzettlich,

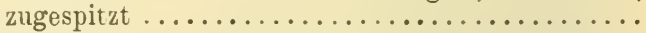

Stgschuppen blassgrün o. gelblichgrün; Hüllb. grünlich, mit weißlichem Rande; Bt. weiß o. gelblichwei@, seltener etwas röthlich; B. zuletzt lockerfilzig 0 . nahezu $\mathrm{kahl} . \ldots \ldots \ldots \ldots \ldots \ldots \ldots \ldots$

Stgschuppen roth überlaufen; Hüllb. grünlich, mit rosenrothem Rande; B. 3 eckig-herzförmig, unterseits mit bleibendem schneeweifem Filze bedeckt. Vora. ...niveus. (Vill.) Baumg. Schneeweiße P.

Bt. weis o. gelblichweiß, niemals röthlich; A. gelb Bt. weiß o. blassröthlich; A. purpurn; B. nierenförmig, mit tiefem Ausschnitte am Grunde. $K r$. Deschınanni. Keru. Krainer P.

Btstand halbkugelig o. nur wenig gewölbt, dichtblütig; ausgebildete B. herzförmig-rundlich, winkelig und stachelspitzig-gezähnt, unterseits mit lockerem Filze bekleidet. Verbr.

albus. (L.) Gürtn. Weiße P.

Btstand eilänglich 0 . eiförmig, ziemlich lockerblütig; a usgebildete B. dreieckig-herzförmig, gezähnt (aber kaum winkelig), unterseits fast kahl. $B$. (Sud.)

Kablikianus. Tausch. Sudeten-P.

Anmerkung. Von Bastarten wurden im Gebiete beobachtet: $\mathrm{P}$. albus $X$ hybridus, hybridus $X$ Kablikianus und albus $X$ niveus.

\section{HONOGYNE. Cass. Brandlattich.}

(B. gelappt, die mittleren Lappen 3 zähnig.

1 Vora. v. Südst. K. Kr. J.

silvestris. (Scop.) Cass. Wilder B.

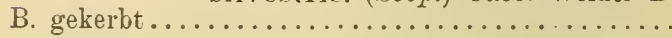

B. gezähnt-gekerbt, unterseits an den Nerven flaumig.

2 Verbr. (bes. Geb.)...alpina. (L.) Cass. Echter 13. B. geschweift-gekerbt, unterseits dicht-filzig. $A$.

discolor. (Jacq.) Cass. Verschiedenfarbiger B.

*) Man beachte beim Bestimmen, dass es von jeder Art eine zwittrig blühende und eine weibliche Form gibt, die einander ziemlich unähnlich sind. 
XXXI. ERECHTHITES. Raf. Falsches Kreuzkraut.

Einjähriges Kraut; B. elliptisch o. länglich-lanzettlich, scharf gezähnt; Bt. blassgelb. Eingeschleppt. hieracifolia. (L.) Raf. Amerikanisches f. K.

\section{ARNICA. L. Wohlverleih.}

Staude; Grundb. länglich-verkehrt-eiförmig, 5 nervig, fast ganzrandig; Bt. goldgelb. Verbr. (bes. A.)

montana. L. Berg-W.

\section{DORONICUII. L. Gemswurz.}

Randbt. ohne Pappus; Stg. nicht selten mehrköpfig 1 Alle Bt. mit haarigem Pappus; Stg. fast immer 1 köpfig............................

Grundb. fehlend, die untersten Stgb. klein, die folgenden größer, genähert, herzförmig, zugespitzt, gezähnelt, geöhrlt-gestielt, die oberen länglich, umfassend, die obersten lanzettlich. Verbr. (bes. Geb.)

Austriacum. Jacq. Oesterreichische G. Grundb. lang gestielt, tief-herzförmig.............

Unterirdische Ausläufer schlank, an der Spitze verdickt $u$. wieder B. tragend; Stg. weichbaarig 0. zottig; untere Stgb. eiförmig, gezähnelt, die mittleren geöhrlt-gestielt, die oberen umfassend; Frboden zottig. A. v. T. K. St. Kr.

Matthioli. Tausch. Ausläufertreibende G. Cnterirdische Ausläufer fehlen; Grundb. grob-gezähnt; Stgb. mit tief-herzförmigem Grunde umfassend; Frboden kurzhaarig. A. v. T. S. K. St. Columnae. Ten. Herzblättrige G.

Untere B. eiförmig o. oval, am Grunde manchmal herzförmig, grob buchtig gezähnt, obere eilänglich o. eilanzettlich, am Grunde abgerundet, halbumfassend, alle mit Gliederhaaren u. kürzeren Drüsenhaaren bekleidet. $A$.

Halleri. Tausch. Haller's G.

Untere B. länglich, in den Bstiel verschmälert, ausgeschweift-gezähnt 0 . fast ganzrandig, obere mehr lanzettlich, am Grunde verschmälert, seltener abgerundet, mit o. ohne Drüsenhaare, stets mit Gliederhaaren .......................... 
B. dicklich, ziemlich steif, auf den Flächen nahezu kahl, am Rande mit Gliederhaaren u. kürzeren Drüsenhaaren bekleidet; Stg. meist niedrig, nur oben hohl. A. v. T. S. $K$.

B. weich, auf den Flächen mehr 0 . weniger behaart, am Rande mit Gliederhaaren u. kürzeren, gekräuselten (nicht drüsigen) Haaren bekleidet; Stg. hohl. A...... Clusii. (All.) Tausch. Clusius' G.

\section{SENECIO. L. Kreuzkraut.}

Am Grunde der Hülle finden sich keine Schuppen . Am Grunde der Hülle finden sich Schuppen, welche manchmal eine deutliche Außenhülle bilden, manchmal aber auch zum Theile auf die Köpfchenstiele herabgerückt 0 . nur in sehr geringer Zahl vor-

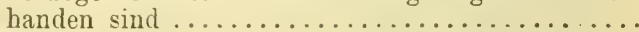

Kraut mit zottigem, ästigem Stg.; B. lanzettlich, halbumfassend, die unteren buchtig gezähnt; Bt. blassgelb. B. M. Sch..paluster. (L.) D C. Moor-K. Stauden mit kahlem o. spinnwebig-wolligem Stg... Die unteren B. am Grunde herzförmig, gezähnt, die oberen in einen breit geflügelten, oft gezähnten Bstiel zusammengezogen. Verbr. (bes. Geb.)

crispatus. $D C^{*}$ ) Krausblättriges K.

Die unteren B. entweder allmälig in den Bstiel verschmälert o. plötzlich in denselben zusaminengezogen, aber nicht herzförmig .............

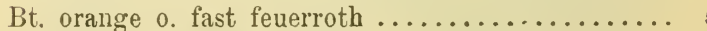

Bt. heller 0 . dunkler gelb ............... 6

B. spärlich-wollig, zuletzt fast kahl, die untersteu eiförmig, die obersten lineal, entfernt; Bt. orange. Geb. (fehlt Sch. O. J.)

aurantiacus. (Hoppe.) DC. Orangefarbiges $\mathrm{K}$

5 B. dicht wollig und außerdem kurzhaarig-rauh, dicklich, die unteren länglich-eiförmig, die oberen lanzettlich; Bt. fast feuerroth, in wenigen großen Köpfchen. A. v. K. St.

capitatus. (Wallbg.) Steud. Kopfiges K.

B. unterseits dicht weiß-wollig, oberseits etwas flockig und spärlich kurzhaarig, die unteren eiförmig, die oberen länglich; Frkn. kurzhaarig.

$6\left\{\begin{array}{l}\text { T. (K. Südst. Kr. O.?) } \\ \text {. }\end{array}\right.$

spatulifolius. (Gmel.) DC. Spatelblättriges K. B. mehr 0 . weniger spinnwebig-wollig, aber nicht

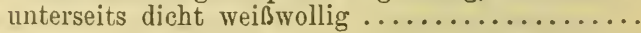

*) S. croceus (Tratt.) DC. (Geb.) ist durch orangefarbene Bt. u. purpurn überlaufene Hüllb. ausgezeichnet. 
Grundb. eiförmig 0 . elliptisch, meist rasch in den Bstiel zusammengezogen; Frkn. oft kurzhaarig... 7) Grundb. längticìn, ausgeschweift-gezähnelt, sehr allmälig in den Bstiel verschmälert; obere B. keiliglanzettlich; Frkn. kahl. O. S. T. K. St. Kr.

pratensis. (Hoppe.) DC. Wiesen-K.

Stg. u. B. dicht kurzhaarig-rauh und auberdem spinnwebig wollig; die meisten B. ausgeschweiftgezähnt; Frkn. kahl o. flaumig. Tora.

alpester. (Hoppe.) D C.*) Voralpen-K.

Stg. u. B. spinnwebig-wollig, sonst fast kahl; die meisten B. ganzrandig; Frkn. kurzhaarig.

Verbr. (fehlt Sch. S.)

campester. (Retz.) DC. Feld-K.

Wenigstens die unteren B. herzförmig, gestielt; kräf-

tige Stauden; Fr. kahl................ 10

B. niemals herzförmig $\ldots \ldots \ldots$. .......... 11

B. herzeiförmig, länger als breit, die oberen mit schmalem, ganzrandigem Bstiel und kurzen, kaum umfassenden Oehrchen an dessen Grunde. $A$.

alpinus. (L.) Scop. Alpen-K.

10 B. herzförmig-rundlich, so lang als treit, die oberen nit breit geflügeltem Bstiel und umfassenden Oehrchen an dessen Grunde 0 . auch mit halbumfassendem, oft fiederspaltigem Grunde sitzend. Geb. subalpinus. Koch. Voralpen-K.

B. fiederspaltig, leierförmig o. doch eingeschnitten11 gekerbt, nur die unteren manchmal ungetheilt...

Alle B. ungetheilt, dabei gesägt, gezähnt o. ganzrandig.

Strahlbt. fehlend o. zurückgerollt; B. fiederspaltig, mit gezähnten 0 . fast fiederspaltigen Zipfeln; 1 jäh-

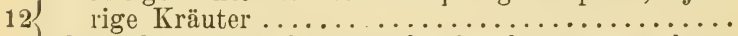

Strahlbt. zungenförmig, abstehend, nur ausnahms-

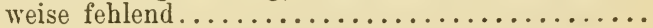

Strahlbt. fehlend; alle Bt. röhrig; Schuppen der Außenhülle meist 10, mit schwarzer Spitze, viel kürzer als die Hülle; obere B. mit geöhrltem Grunde umfassend. Verbr. $u$. hifg.

vulgaris. $L$. Grimmkraut. Strahlbt. zurückgerollt (sehr selten fehlend) .......

*) S. brachychaetus DC. unterscheidet sich durch schmälere untere B., S. Ovirensis (Koch) DC. durch dichtwollige $B$. 
B. u. Hülle drüsenhaarig-klebrig; Außenhülle locker, halb so lang als die Hülle; Fr. kahl. Verbr.

viscosus. $L$. Klebriges $K$.

14 B spinnwebig-flaumig; Außenhülle angedrückt, sehr kurz; Fr. grauflaumig. Verbr.

silvaticus. $L$. Wald-K.

B. beiderseits grau- o. weißfilzig o. seidig; Bstiel am 15 Grunde ohne Oehrchen.................. 16

B. kiahl, zottig o. flockig-wollig ........... 18

Stg. 1 köpfig; B. schneeweiß-filzig, die unteren eiförmig, eingeschnitten-gekerbt, die oberen lineal, 16 ganzrandig. $A$. v. Südt.

uniflor'us. All. Einblütiges K.

Köpfchen ebensträußig; B. fiederspaltig o. leierförmig

B. von angedrücktem, fast seidenhaarigem Filze grau, zuletzt kahl werdend; Grundb. u. untere Stgb. eingeschnitten-gekerbt o. fiederspaltig, mit ganzrandigen 0 . gekerbten Zipfeln. $A$. (fehlt $N . J$.)

Carniolicus. Willd. Krainer $\mathrm{K}$.

B. von wolligem Filze schneeweiß; Grundb. und untere Stgb. eiförmig, fiederspaltig, Zipfel 2-3fach eingeschnitten gekerbt. $A$. v. $T$. $K$.

incanus. $L$. Graues $\mathrm{K}$.

$\int \begin{aligned} & \text { Bspindel gezähnt; B. leierförmig o. fiederspaltig, ge- } \\ & \text { öhrlt-umfassend; Fr. grau-flaumig............. }\end{aligned}$

$18\left\{\begin{array}{l}\text { öhrlt-umfassend; Fr. grau-flaumig...................... } \\ \text { Bspindel ganzrandig; B. fiedertheilig, Zipfel lineal, }\end{array}\right.$

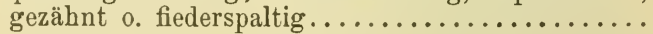

Bzipfel lineal; Au@enhülle meist 1 blättrig. $K r . J .(?)$ squalidus. $L$. Schmutziges $\mathrm{K}$. Bzipfel länglich o. eiförmig, stumpf; Außenhülle 6-

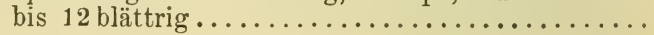

B. beiderseits von abstehenden Haaren zottig, länglich, fiederspaltig-buchtig, Lappen eiförmig, stumpf, am Rande kraus und gezähnt. Sch. $M$. $K r$.

vernalis. $W . K$. Frühlings-K.

B. kahl o. etwas wollig, die unteren leierförmig, die mittleren fiederspaltig, Lappen länglich, stumpf. Verbr. (fehlt B. Sch.)

rupestris. $W . K$. Felsen-K.

B. fiedertheilig 0 . doppelt-fiedertheilig mit linealen $21\left\{\begin{array}{l}\text { Zipfeln; Außenhülle halb so lang als die Hülle.. } \\ \text { B. zum Theile o. sämmtlich leierförmig; Außen- }\end{array}\right.$ 22 hülle sehr kurz ....................... 
Ebenstrauß vielköpfig; Fr. kurzhaarig-rauh; B. fiedertheilig, die unteren gestielt, die oberen sitzend, Zipfel gezähnt o. fiederspaltig. Terbr.

erucifolius. $L$. Raukenblättriges $\mathrm{K}$.

Ebenstraub 3-6 köpfig; Fr. kahl; B. kahl, die unteren doppelt-fiedertheilig mit ganzrandigen 0 . höchstens 1 zähnigen Zipfeln. $A$.

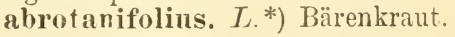

Die mittleren Fr. kurz-haarig; untere B. leierförmig, die übrigen Stgb. fiedertheilig, Abschnitte gezähnt 0 . fast fiederspaltig, vorne 2 spaltig, mit auseinanderfahrenden Zipfeln. Spindel ganzrandig.

Verbr. u. $h f g . . . . .$. Jacobaea. I. Jacobskraut. Alle Fr. kahl o. die mittleren undeutlich-flaumig..

B. leierförmig, Abschnitte der mittleren Stgb. gezähnt, meist zu 5 , die seitenständigen weit abstehend, verkehrt-eiförmig-länglich, der Endlappen an den unteren B. sehr grols, herz-eiförmig, an den oberen B. keilig. Verbr. (fehlt S.)

erraticus. Bert. Spreizendes K.

Grundb. u. untere Stgb. länglich-eiförmig, ungetheilt 0 . leierförmig, die mittleren Stgb. am Grunde eingeschnitten 0 . leierförmig, die seitlichen $\mathrm{Ab}$ schnitte länglich 0 . lineal, schief vortretend, der Endlappen eiförmig-länglich, gezähnt o. gelappt. Verbr. (?) ........ aquaticus. Huds. Wasser-K.

Strahlbt. 5-8 o. fehlend; Köpfchen zahlreich, eben-

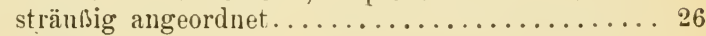

Strahlbt. $10-20 \ldots \ldots \ldots \ldots \ldots \ldots \ldots \ldots \ldots \ldots \ldots \ldots \ldots \ldots \ldots$

Strahlbt. fehlend; B. elliptisch-lanzettlich, gezähntgesägt, Spitzchen der Sägezähne gerade; Deckb. lineal; Außenhülle so lang als die Hülle; Bt. gelblichweiß. Vora. v. S. St. K. J. Sïdt.

Cacaliaster. Lam. Pestwurzartiges K.

Strahlbt. gelb, nur ausnahmsweise fehlend ........

Stg. bis zum Btstande reichlich beblättert; B. gras$27 \begin{aligned} & \text { grün, die oberen wenig kleiner, von den Deckb. } \\ & \text { des Btstandes ganz verschieden } \ldots \ldots \ldots \ldots \ldots \ldots .\end{aligned}$

Stg. oben armblättrig; B. bläulichgrün, die oberen viel kleiner und allmälig in Deckb. übergehend . 30

*) S. Tiroliensis Kern. hat oben verdickte Köpfchenstiele und kurze, orangefarbige Strahlbt. 
Wst. holzig, ziemlich kurz, nicht kriechend; Strahlbt. meist 5, selten mehr; Sägezähne der B. mit geradem

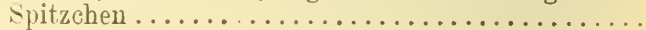

Wst. fleischig, kriechend; Strahlbt. 7-8; B. länglich-lanzettlich, am Grunde keilig; Spitzchen der sägezähne vorwärtsgekrümmt.

B. M. Sch. N. O. Sïdst. Kr. (K. T.?)

fluviatilis. Wallr. Fluss-K.

B. unterseits kraus behaart, die unteren eiförmig 0 . elliptisch, die oberen länglich, sitzend; Fr. behaart. Verbr. ............ nemorensis. $L$. Hain-K.

B. beiderseits kahl, seltener unterseits etwas flaumig, alle lanzettlich o. länglich-lanzettlich; Fr. meist kahl. Verbr. u. $h f g$.

Sarracenicus. L. Schmalblättriges K.

Stg. u. B. kahl o. nahezu kahl; Strahlbt. meist 5.

I. N. K............Doria. L. Hohes K. Stg. wollig-kraushaarig; B. unterseits kurzhaarigrauh; Strahlbt. meist 8. N.

umbrosus. W. K. Schatten-K.

Wst. kriechend; Stg. hochwüchsig, meist reichköpfig; B. lineal-lanzettlich, scharf gesägt, unterseits oft wollig o. filzig; Außenhülle halb so lang als die Hülle. Verbr. (fehlt Sch.)

paludosus. $L$. Sumpf-K. Wst. nicht kriechend; Stg. ziemlich niedrig, meist $1-3 \mathrm{köpfig;} \mathrm{die} \mathrm{unteren} \mathrm{B.} \mathrm{eiförmig} \mathrm{o.} \mathrm{spatelig,}$ gezähnelt; Au@enhülle so lang als die Hülle ....

B. lederig, kurzhaarig, bisweilen etwas wollig; Stg. 1-mehrköpfig; Bt. goldgelb o. orange.

A. (fehlt St.) ......Doronicum. L. Gebirgs-K.

B. krautig-weich, kahl o. wollig; Hülle dichtwollig; Stg. 1 köpfig; Bt. citronengelb. $K r$. J.

lanatus. Scop. Wolliges K.

Anmerkung. Von Bastarten wurden im Gebiete beobachtet: $\mathrm{S}$. alpinus $X$ erucifolius, alpinus $X$ Jacobaea, vernalis $X$ vulgaris, silvaticus $X$ viscosus und rupestris $X$ silvaticus.

\section{LIGULARIA. Cass. Goldkolbe.}

Hohe Staude; B. fast pfeilförmig-herzförmig, gezähnt; Köpfehen in endständiger Traube; Bt. gelb. B....... Sibirica. (L.) C'ass. Sibirische G. 
XXXIX. CALENDLIA. L. Ringelblume.

B. länglich-lanzettlich, etwas gezähnelt, die oberen mit abgerundetem Grunde halbumfassend; Bt. hellgelb; Fr. am Rücken weichstachelig, die äußersten u. innersten lineal (letztere eingerollt), einige mittlere kahnförmig. Südt. $J$.

arvensis. $L$. Wilde $\mathrm{P}$.

B. länglich-verkehrt-eiförmig, entfernt gezähnelt 0 . fast ganzrandig, alle gegen den Grund verschmälert; Bt. goldgelb; Fr. am Rücken stachelig, die meisten kahnförmig. Cult. u. verw.

officinalis. L. Echte R.

\section{ECHINOPS. L. Kugeldistel.}

Aeubere Hüllb. auf dem Rücken drüsig-behaart; B. oberseits von etwas klebrigen Haaren flaumig, unterseits wollig-filzig; Bt. weiblich; A. bleigrau. T. $M . S c h . N .(K r . ?) T$.

splıaerocephalus. $L$. Rundköpfige $\mathrm{K}$.

Hüllb. auf dem Rücken kahl ...............

B. oberseits kahl o. flaumig, unterseits schneeweiß-

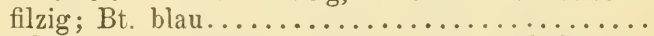

B. oberseits mit dornigen Börstchen spärlich besetzt, unterseits grau-filzig, tief-fiederspaltig; Bt. weißlich. Südst. $K r$. J.

commutatus. Jur. Verwechselte K.

B. doppelt-fiederspaltig; Pappus bis über die Mitte in lineale Zipfel gespalten. $N$. $K r$. J.

Ritro. L. Blaue K.

B. fiederspaltig 0 . die oberen nur ausgeschweiftgezähnt; Pappus an der Spitze in kurze Zipfel getheilt. J....... Banaticus. Roch. Banater K.

\section{XeRANTHEMUM. L. Spreublume.}

Hülle halbkugelig; Hüllb. kahl, stachelspitzig, die iuneren doppelt so lang als die Scheibe.

B. M. N. J........ annuum. L. Jährige St. Hülle walzlich; die äu@eren Hüllb. grannenlos, auf der Mitte filzig. $J . K r$.

cylindraceum. Sibth. et Sm. Walzliche St.

\section{CARIINA. I. Eberwurz.}

Stg. 1 köpfig, meist sehr verkürzt; strahlende Hüllb. meist weiß; B. sämmtlich 0 . nur die äußeren tief-

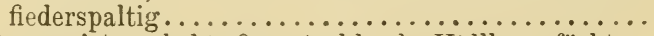
Stg. meist mehrköpfig; strahlende Hüllb. gefärbt 0.

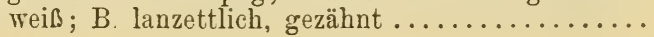


B. unterseits grau-wollig, die äußeren fiederspaltig, die innersten ungetheilt; Köpfchen grundständig.

$2 J . K r$.. acanthifolia. All. Krebsdistelblättrige E. B. kahl o. unterseits etwas spinnwebig-wollig, alle

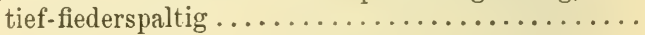

Köpfchen meist grundständig*); die strahlenden Hüllb. bis über die Mitte lineal, an der Spitze lanzettlich. Verbr...... acaulis. L. Wetterdistel. 3 Stg. stets entwickelt; die strahlenden Hüllb. lanzettlich, unterhalb der Mitte verschmälert. $K . K r . J$. simplex. $W . K$. Einfache E.

Strahlende Hüllb. kahl, oberseits gelb o. purpurn.. Strahlende Hüllb. bis zur Mitte gewimpert, oberseits blassgelb

o. weib.

Strahlende Hüllb. oberseits gelb; Stg. fast ebensträußig-mehrköpfig. $J$.

corymbosa. L. Ebensträulige E.

Strahlende Hüllb. oberseits purpurn; Stg. meist 3 köpfig; B. filzig-wollig. $J$.

lanata. $L$. Wollige $\mathrm{E}$.

B. länglich-lanzettlich, buchtig-gezähnt, die obersten kül'zer als die Köpfchen; Stg. meist mehrköpfig. Verbr. $u$. $h f g . . . . .$. vulgaris. L. Gemeine E. B. lanzettlich, entfernt-gezähnt, nicht buchtig, die obersten länger als die Köpfchen; Stg. armköpfig. Sch. B. N.S.T. .longifolia. Rchb. Langblättrige E.

\section{ARCTIUM. $L$. Klette.}

Hülle spinnwebig-weiß-wollig; die inneren Hüllb. meist purpurn mit gerader Stachelspitze, die äußeren widerhakig; Köpfchen fast ebensträußig angeordnet. Verbr. tomentosum. Mill. Wollige $\mathrm{K}$. Hülle nur spärlich spinnwebig-haarig 0 . ganz kahl

Köpfchen groß, fast ebensträußig angeordnet; Hülle ohne Spinnwebhaare; alle Hüllb. an der Spitze widerhakig; Spreub. halb so lang als die innersten Hüllb. Verbr.......... Lappa. L. Gemeine K. Köpfchen traubig angeordnet; Spreub. wenig kürzer als die innersten Hüllb.................

*) Dic Form mit entwickeltem Stg. ist C. alpina Jacq. 
Köpfchen verhältnissmäßig klein, meist voneinander entfernt; Hüllb. meist spinnwebig-haarig, die innersten lineal. Verbr.

minus. Bernh. Kleinköpfige K.

Köpfchen sehr groß, die oberen dicht gedrängt; Hüllb. fast ohne Spinnwebhaare, die innersten lanzettlich; Aeste verlängert, oft herabgebogen. B. N........... nemorosum. Lej. Hain-K.

An merkung. Zwischen A. Lappa u. A. tomentosum, sowie wahrscheinlich auch zwischen den anderen Arten kommen Bastarte vor.

\section{STAEHELINA. L. Strauchscharte.}

Halbstrauch; B. lineal, entfernt-gezähnelt, oberseits graulich, unterseits weiß-filzig; Bt. purpurn. $J$.

dubia. $L$. Zweifelhafte St.

\section{SAUSSUREA. $D C$. Alpenscharte.}

Stg. 1 köpfig; B. lineal-lanzettlich o. lineal, oberseits zerstreut-, unterseits dicht-rauhhaarig. $A$.

pygmaea. (Jacq.) Spr. Zwergige A. Köpfchen ebensträußig; Grundb. eiförmig-lanzettlich, gestielt; die obersten Stgb. sitzend ...........

B. unterseits spinnwebig-wollig; Grundb. mit abgerundetem Grunde. A. v. T. S. K. Kr. St.

alpina. ( $L.) D C .^{*}$ ) Echte A.

2 B. unterseits schneeweib-filzig; Grundb. mit herzförmigem, seltener abgestutztem Grunde. A. (fehlt O. S.)

lapathifolia. (L.) Beck. Zweifarbige A.

\section{JURINEA. Cass. Silberscharte.}

Hüllb. spinnwebig-wollig, die äußeren zurückgebogen; Fr. schuppig-querrunzelig; Stg. oben nackt, meist 1 köpfig; B. ungetbeilt 0 . fiederspaltig.

II. N. Südst. Irr. J. mollis. (L.) Rchb. Weiche S. Hüllb. graufilzig, aufrecht; Fr. glatt, nur etwas grubig; Stg. meist ästig, Aeste 1 köpfig; B. meist fiederspaltig, $B$.

cyanoides. (L.) Rchb. Kornblumenartige S.

*) S. macrophylla Saut. (T. S. K.) ist durch breite B. u. breitere Hüllb., S. depressa Gren. $(K$.) durch verkürzten, armköpfigen Stg. ausgezeichnet. 


\section{XlVII. CARUUUS. L. Distel.}

Köpfchen länglich, fast walzlich; B. oberseits etwas zottig: unterseits wollig-filzig 0 . weißlich-wollig,

1 buchtig u. fiederspaltig, Lappen eiförmig, eckig, gezähnt, dornig. $J$.

Köpfchen pycnocephalus. Jacq. ) Dichthöpfige D.

Die mittleren Hüllb. über dem eiförmigen o. ovalen Grunde zusammengezogen, oberhalb der Einschnürung lanzettlich, in einen Dorn zngespitzt, abstehend 0 . herabgeknickt; B. tief-fiederspaltig, Abschnitte eiförmig, fast handförmig 3spaltig; Köpfchen groß, rundlich, einzeln 0 . paarig...... Hüllb. lineal 0. lanzettlich, nicht herabgeknickt...

Köpfchen nickend, einzeln; mittlere Hüllb. allmälig lang zugespitzt. Terbr. nutans. L. Nickende D. Köpfchen aufrecht, einzeln o. paarig, u. dann das eine sitzend $u$. wagrecht; mittlere Hüllb. plötzlich zugespitzt. O. S. T. K. St.

platylepis. Saut. Breitschuppige D.

Stg. 1 köpfig o. häufiger in mehrere verlängerte, ineist oben nackte, fast immer 1 köpfige Aeste getheilt Stg. stets ästig u. mehrköpfig; Köpfchen gehäuft 0 . zu 2-3 beisammen, seltener einzeln, auf dornig geflügelten, nur ganz oben oft nackten Stielen...

Die Abschnitte der tief-fiederspaltigen B. eiförmig, 3 spaltig und gelappt, Lappen dornig-gewimpert, mit einem starken Dorn endigend; Aeste ruthen-
förmig, ziemlich weit hinauf mit immer kleiner werdenden $B$. besetzt und dornig-geflügelt ...... Die Bfiedern lanzettlich, vorne 2-3 lappig, o. die B. überhaupt nicht fiederspaltig; Köpfchen auf langen,

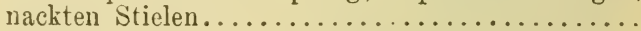

Die inneren Hüllb. hakig zurückgekrümmt; B. oberseits zerstreut behaart, unterseits spinnwebig-wollig 0 . fast kahl. $N$. $K r$. hamulosus. Ehrh. Hakige D. Hüllb. angedrückt 0 . abstehend; B. unterseits 0 . beiderseits wollig-filzig, seltener fast kahl. Südst. Kr. J. . ...... collinus. W. K. Hügel-D.

*) C. acicularis Bert., welcher in $J$. gefunden wurde, unterscheidet sich durch einzeln stehende Köpfchen und durch aufrechte, lang verschmälerte Hüllb. 
B. fiederspaltig 0 . fiederlappig, unterseits spinnwebigwollig, zuletzt kahl, herablaufend ...........

B. lanzettlich o. länglich, kahl 0 . unterseits auf den Adern behaart, gezähnt, gesägt, gelappt 0 . bis zur Mitte fiederspaltig, die untersten und die obersten

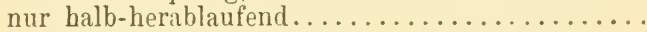

B. fiederlappig o. seicht fiederspaltig, mit eiförmigen, 2spaltigen Abschnitten, unterseits anfangs dicht wollig. Vora. v. $K r$.

alpestris. $W . K$. Voralpen-D.

8. B. tief-fiederspaltig, mit verlängerten Endlappen und lanzettlichen, am oberen Rande 2-3lappigen $\mathrm{Ab}$ schnitten, unterseits nur etwas wollig.

Vora. v. Südt. K. St. $K r . J$.

Carduelis. (L.) W. K. Kletten-D.

B. beiderseits grasgrün; mittlere Hüllb. aus eiförmigem Grunde lineal-lanzettlich, vielmal länger als breit, mit langer, linealer, krautig weicher, dunkelgrüner Spitze. A. u. Vora.

viridis. Ker». Grünblättrige G.

B. beiderseits 0 . doch unterseits seegrün; mittlere Hüllb. mit steifer, oft kurzer, blassgrüner Spitze

Mittlere Hüllb. höchstens 4 mal so lang als breit, eilanzettlich, nur mit der Spitze etwas abstehend; Fr. $2^{1 / 2}$ mal so lang als breit, verkehrt-eifürmig, zusammengedrückt. $N$. St.

glaucus. Baung. Seegrüne D.

Mittlere Hüllb. mindestens 6 mal so lang als breit, aus eiförmigem Grunde lineal-lanzettlich, über der Mitte auswärts gebogen; Fr. 3-4 mal so lang als breit, länglich-walzlich, wenig zusammengedrückt

Hülle eiförmig: die unteren Hüllb. allmälig verschmälert, die obersten mit dünner, verbogener, nicht dorniger Spitze; Fr. 3 mal so lang als breit; Flügel des Stg. nur unter den B. breit, dann rasch verschmälert, flach, feinstachelig-gewimpert.

A. u. Vora............ defloratus. $L$. Alpen-D.

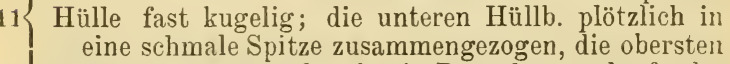
mit starrer, gerader, in ein Dörnchen auslaufender Spitze; Fr. 4 mal so lang als breit; Flügel des Stg. breit, gelappt, kraus verbogen und kräftig bestachelt. Vora. v. T. K.

Rhaeticus. $(D C$.) Rhaetische D. 
Pfl. ausdauernd; B. breit, unterseits dünn grauwollig 0 . zuletzt fast $\mathrm{kahl}$, die unteren fiederspaltig o. fiederlappig, die oberen ungetheilt, eitörmig, eilanzettlich 0 . elliptisch, am Grunde meist abgerundet; Köpfchen an der Spitze des Stg. und der Aeste gehäuft; Hüllb. zurückgekrümmt. $V e r b r$. (bes. Geb.) (fehlt .J.)

Personata. (L.) Jacq. Maskirte D. Pfl. 2jährig; die meisten B. fiederspaltig o. fiederlappig, seltener alle 0 . die oberen ungetheilt; Köpfehen zu 2-3 o. einzeln, doldentraubig 0 .

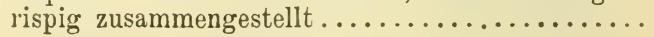

Stg. steif und zähe; B. steif, meist alle fiederspaltig, unterseits zerstreut wollharig o. kahl, Zipfel dornig gewimpert und mit einem stechenden Dorn endigend; Köpfchen meist einzeln. Verbr.

acanthoides. $L$. Weg-D. Stg. zerbrechlich; B. weich, dornig-gewimpert; Köpf-

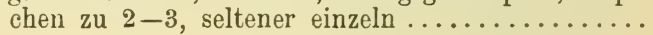

B. oberseits dunkelgrün, unterseits graufilzig 0 . doch wollig, die oberen gegen den Grund verschmälert; Hüllb. mehr o. weniger spinnwebhaarig. Verbr.

crispus. $L$. Krause D.

B. hellgrün, unterseits dünn 0 . gar nicht filzig, die oberen halbumfassend; Hüllb. kahl. Vora. v. T. agrestis. Kern. Feld-D.

Anmerkung. Die Carduus-Arten neigen sehr zur Bildung von Bastarten. Im Gebiete wurden beobachtet: C. glaucus $X$ nutans, defloratus $X$ nutans, acanthoides $X$ nutans, crispus $X$ nutans, acanthoides $X$ hamulosus, crispus $X$ viridis, acanthoides $X$ glaucus, defloratus $\times$ Personata, acanthoides $\times$ defloratus, crispus $X$ defloratus, Personata $X$ Rhaeticus, crispus $X$ Personata, acanthoides $X$ crispus.

\section{CIRSIUM. Adans. Kratzdistel.}

1 Bt. gelb o. gelblich-weiß, sehr selten purpurn .... 2

Bt. purpurn 0. röthlich-lila, selten weiß........ 5

Stg. oberwärts nebst den Köpfchenstielen u. Deckb. rostfarbig-zottig; die unteren B. gestielt, eiförmig, die oberen mit herzförmigem Grunde umfassend. Vora. (fehlt $S$. J.)

Carniolicumı. Scop. Krainer K. Stg., Köpfchenstiele u. Deckb. nicht rostfarbig-zottig 
Köpfchenstiele nickend; Hüllb. gekielt, auf dem Kiele klebrig; B. zerstreut-flaumig, umfassend, tief-fiederspaltig. Vora. (fehlt S.)

Erisithales. (L.) Scop. Klebrige K.

Köpfchenstiele aufrecht; B. kahl o. zerstreut-behaart;

Deckb. bleich-gelblichgrün .................

Deckb. fiederspaltig-zerschlitzt, dornig; B. länglich o. lanzettlich, die unteren in den Bstiel verschmälert, die oberen umfassend, alle fiederspaltig-gelappt, Lappen eiförmig, 3spaltig; Stg. dicht beblättert, an der Spitze zottig. $A$.

spinosissinum. (L.) Scop. Stachligste h. Die äußeren Deckb. nicht zerschlitzt, eiförmig; B. umfassend, die unteren gewöhnlich fiederspaltig, Abschnitte lanzettlich, zugespitzt, gezähnt, die oberen ungetheilt, gezähnt. Verbr. u. $h f g$.

oleraceum. (L.) Scop. Kohldistel.

Innere Hüllb. mit einem fiedertheiligen Dorn endigend; Stg. breit geflügelt, wie die B. graufilzig; Köpfehen gehäuft. $J$.

Acarra. (L.) DC. Sperrdistel. Hüllb. ohne fiedertheilige Dornen ............. 6

6 B. oberseits dornig-steifhaarig; Köpfehen groß..... 7

B. oberseits kahl 0 . weichhaarig.............. 8

B. herablaufend, buchtig-fiederspaltig, unterseits etwas spinnwebig 0 . weiß-wollig; Köpfchen eiförmig. Verbr.

lanceolatum. (L.) Scop. Lanzettblättrige K.

7 B. nicht herablaufend, umfassend, tief-buchtig-fiedertheilig, unterseits filzig; Köpfchen kugelig; Hülle weiळ wollig. Verbr.

eriophorum. (L.) Scop. Wollköpfige K.

8) Wenigstens die unteren B. länger o. kürzer herab-

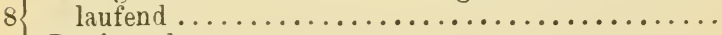

B. sitzend $\ldots \ldots \ldots \ldots \ldots \ldots \ldots \ldots \ldots \ldots \ldots, 12$

Innere Hüllb. an der Spitze eilanzettlich verbreitert; Wzfasern knollig verdickt, länglich 0 . spindelförmig. Verbr: (fehlt S. T.)

canum. (L.) M. B. Graue K. Innere Hüllb. gegen die Spitze verschmälert ...... 10

Stg. vom Grunde bis zur Spitze lappig- o. gekraustgeflügelt; Köpfchen traubig-geknäuelt; Hüllb. in

10 einen sehr kurzen Dorn auslaufend. Verbr. $u$. hfg.

palustre. (I.) Scop. Sumpf-K.

Stg. oben fast blattlos und daselbst nicht geflügelt 11 
Stg. unten von den ganz herablaufenden ungetheilten

B. lappig- o. gekraust-geflügelt, weichdornig; obere B. fiederspaltig mit meist ganzrandiger vorgezogener Spitze; Hüllb. in einen abstehenden strohgelben Dorn zugespitzt; Bt. lila o. weißlich. $N$.

St orachycephalum. Juratzk. Kurzkopfige K. Stg. unten von den kurz herablaufenden B. schwach und ganzrandig geflügelt, kaum dornig; alle B. ungetheilt; Hüllb. nicht dornig; Bt. purpurn.

Terbr. (fehlt Scl. S.)

Pamnonicum. (I. f.) Gaud. Ungarische K.

Saum der Blkr. fast bis zum Grunde gespalten, viel kürzer als die Röhre; Bt. röthlich-lila, sehr selten weiß; Köpfchen zahlreich, klein, rispig - ebensträußig; Wst. kriechend. Verbr. u. hfg.

arvense. Scop. Feld-K.

Sanm der Blkr. etwa bis zur Mitte gespalten, wenig kürzer, ebenso lang o. länger als die Röhre; Wst.

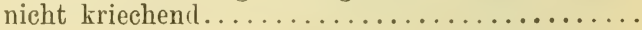

Hüllb. an der Spitze abstehend o. zurückgebogen .. 14

13 Hüllb. angedrüickt, oft stumpf und plötzlich in einen

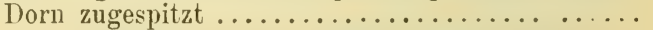

Alle B. ungetheilt, gezähnt o. gelappt, unterseits spinnwebig-wollig; Grundb. gestielt, untere Stgb. mit dem geflïgelten und geöhrlten Bstiele umfassend, obere mit herzförmigem Grunde sitzend. Fora. v. St. K. Kr. pauciflorum. Spr. Grobe K. Wenigstens die unteren $\mathrm{B}$. tief fiederspaltig, beiderseits grün; Sig. hoch hinauf gleichmäßig beblättert. Tora. v. Südt.

montanum. ( $W . K$.) Spr. Berg-K.

Stg. sehr verkürzt 0 . doch niedrig, dicht beblättert, $1(-4)$ köpfig; B. kahl, lanzettlich, buchtig-fiederspaltig, Abschnitte eiförmig, eckig, fast 3 spaltig. B. S. T. K. Kr. J.

acaule. (L.) All. Stengellose K. Stg. hochwüchsig; B. oberseits zerstreut flaumig 0 . behaart, 0 . unterseits wollig 0 . filzig ........ 16

B. ober'seits kahl, unterseits weißfilzig, bald ungetheilt, bald fiederspaltig; Stg. 1 köpfig 0 . mit 2 bis 3 einköpfigen Aesten. Verbr. (bes. Geb.)

heterophyllnm. All. Verschiedenblättrige K. B. zerstreut-flaumig 0 . unterseits spinnwebig- wollig,

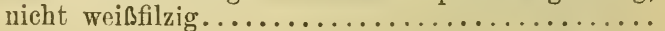


Wzfasern nicht verdickt; B. zerstrent-flaumig, beiderseits grün, umfassend, fiederspaltig, untere Stgb. in den geflügelten, am Grunde verbreiterten Bstiel zusammengezogen; Deckb. lineal, ganzrandig.

Terbr............ rivulare. (Jacq.) Ll. Bach-K.

Wzfasern verdickt, nach beiden Enden verschmälert; B. oberseits zerstreut-behart, unterseits spinnwebig-wollig, tief-fiederspaltig, die unteren gestielt, Abschnitte gezähnt, klein-gelappt und 2bis 3 spaltig; Stg. $1-3$ köpfig. B. Südt. Kr.J. bulbosum. (Lam.) $D C$. Knollige K.

Anmerkung. Bastarte sind in der Gattung Cirsium verhältnissmäळig häufig. Im Gebiete wurden beobachtet (einige davon etwas zweifelhaft): C. Carniolicum $\times$ Erisithales, Erisithales $X$ spinosissimum, Erisithales $X$ oleraceum, Erisithales $X$ palustre. Erisithales $\times$ Pannonicum, arvense $\times$ Erisithales, Erisithales $\times$ pauciflorum, Erisithales $X$ montanum, acaule $X$ Erisithales, Erisithales $X$ heterophyllum, Erisithales $X$ rivulare, oleraceum $X$ spinosissimum, palustre $X$ spinosissimum, montanum $X$ spinosissimum, acaule $X$ spinosissimum, heterophyllum $X$ spinosissimum, canum $X$ oleraceum, oleraceum $X$ palustre, oleraceum $\times$ Pannonicum, arvense $X$ oleraceum, oleraceum $X$ pauciflorum, acaule $X$ oleraceum, heterophyllum $X$ oleraceum, oleraceum $X$ rivulare, eriophorum $X$ lanceolatum, lanceolatunı $X$ palustre, lanceolatum $\times$ Pannonicum, acaule $X$ lanceolatum, canum $X$ palustre, canum $\times$ Pannonicum, acaule $X$ canum, canum $X$ rivulare, canum $X$ dissectum, palustre $\times$ Pannonicum, arveuse $\times$ palustre, palustre $X$ pauciflorum, heterophyllum $X$ palustre, palustre $X$ rivulare, dissectum $X$ palustre, acaule $X$ Pannonicum, Pannonicum $X$ rivulare, heterophyllum $X$ pauciflorum, pauciflorum $X$ rivulare, acaule $X$ montanum, heterophyllum $X$ montanum, acaule $X$ hetephyllum, acaule $X$ dissectum. - Auch Tripelbastarte bommen vor, wie z. B.: C. Erisithales $X$ oleraceum $X$ spinosissimum $(T$.), C. Erisithales $X$ heterophyllum $X$ spinosissimum $(T$.$) , C. Erisithales X$ oleraceum $X$ pauciflorum $(S t$.) und C. Erisithales $X$ oleraceum $X$ rivulare $(\boldsymbol{N}$.$) .$

\section{SILYBUM. Gärtn. Mariendistel.}

Zweijähriges, dorniges Kraut; Köpfchen einzeln; Hüllb. zurückgebrochen; Bt. purpurn.

J. (sonst cult. u. verw.)

Marianum. (L.) Gärrtu. Gemeine M. 
L. TYRIMNUS. Cass. Weißdistel.

Zweijähriges, dorniges Kraut; Köpfchen lang gestielt; Bt. purpurn, selten weif. J.

leucographus. (L.) Cass. Gefleckte W.

\section{ONOPORDON. L. Eselsdistel.}

B. elliptisch-länglich, buchtig-gelappt, spinnwebigwollig; Hüllb, aus eiförmigem Grunde linealpfriemlich, die unteren weit abstehend.

Verbr. (fehlt S.)....Acanthium. L. Gemeine E.

B lanzettlich, tief-fiederspaltig, weirfilzig; Hüllb. eilanzettlich, die unteren bogig herabgekrümmt. $J$.

Illyricum. $L$. Illyrische E.

\section{CRUPINA. Cass. Schliipfsame.}

(B. kurzhaarig-lauh, nicht wollig; Fr. sticlrund. J.

B. unterseits weißwollig; Fr. am Grunde zusammen-
gedrückt. J. Crupinastrum. Tis. Dalmatiner Sch.

\section{SERRATULA. $L$. Scharte.}

Stg. $1 \mathrm{köpfig} 0$. in mehrere verlängerte $1 \mathrm{kö \jmath fige}$ Aeste getheilt, wenigstens unten flaumig; Hiille kugelig-eiförmig; Köpfehen groß .............

1 Stg. rispig-ästig 0. doldentraubig-mehrköpfig, kahl; Hülle länglich-walzlich; Köpfchen klein; B. greschärft-gesägt, ungetheilt 0 . fiederspaltig. Ver.hr.

tinctoria. $L .^{*}$ ) Färber-Sch.

Stg. nur unten flaumig und beblättert, oben nackt 0 . kahl, stets unverzweigt und 1 köpfig; untere B. meist ungetheilt, obere fiederspaltig. M. N.J. lycopifolia. (Vill.) Wettst. Wolfsfußblättrige sch. Stg. bis zur Spitze flaumig-rauh und beblättert, gewöhnlich ästig; B. kämmig-fiederspaltig, nur die obersten ungetheilt. $J$.

radiata. ( $W . K$.) $M$. B. Strahlige Sch.

\section{CENTAUREA. L. Flockenblume.}

Hüllb. ungefranst, an der Spitze in einen handförmig- 0 . fiederförmig-getheilten Dorn auslaufend;

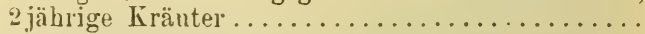
Hüllb. mit einem trockenhäntigen, oft gefransten Anhängsel o. mit einem einfachen Dorn endigend

*) S. Vulpii Fisch. Oost. (A. จ. $K . J$.) ist niedriger und hat größere, dickere Köpfehen. 
Bt. citronengelb; Hülle wollig; Stgb. graulich, lineallanzettlich, herablaufend, ganzrandig; Grundb. leierförmig. (B. M. Sch. N. O.) Sü̈dst. J.

solstitialis. $L$. Sommer-F.

Bt. purpurn; Hülle kahl; B. tief-fiederspaltig, mit linealen, gezähnten Zipfeln; Stg. sehr ästig, behaart. (B. O.) N. J. Sïdt.

Calcitrapa. I. Sterndistel.

Das Anhängsel der Hüllb. ganzrandig o. unregelmäßig-zer'schlitzt, an den äußeren u. mittleren Hüllb. oft fransig-gewimpert, die endständigen Wimpern nicht dicker u. nicht starrer als die übrigen; Stauden ..................... Das Anhängsel der Hüllb. 0. die Spitze fransiggesägt 0 . gespalten, die Endfranse breiter u. stärker, obschon nicht selten kürzer, oft dornig .

Bt. gelb; B. groß, fiederschnittig; Köpfehen grof; Pappus doppelt, der innere kürzer. $J$.

alpina. L. Alpen-F.

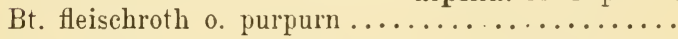

B. 1-2 fach fiedertheilig, mit linealen Zipfeln, höchstens die oberen ungetheilt; Anhängsel der Hüllb. durchscheinend, eiförmig, aufgeblasen-concav. $K r . J . \ldots \ldots \ldots \ldots \ldots \ldots$ alba. $L$. Weibe F. B. alle ungetheilt 0 . die unteren leierförmig bis

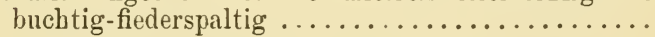

6 Pappus fehlend 0 . nur durch einige sehr kurze

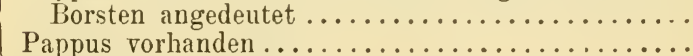
Anhängsel der Hüllb. ungetheilt, höchstens etwas gezähnelt, nur die untersten manchmal gefranst. Die Anhängsel aller 0 . doch der mittleren Hüllb. regelnäßig kämmig- 0 . fiederig-gefranst .......

Anhängsel der mittleren Hüllb. mit breitem, durchscheinenden Rande; Hülle dahel we:ßlich; Stg. u. B. spinnwebig-wollig. N. T.

Gaudini. Boiss. et Reut. Gaudin's F. Anhängsel der Hüllb. ohne durchscheinenden Rand (höchstens die untersten mit einem solchen); Hülle

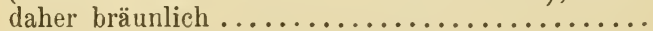

B. grün, elliptisch 0. lanzettlich; Aeste kurz, ziemlich aufrecht. Verbr. $u$. $l f g$. Jacea. L. Gemeine F. B. spinnwebig-wollig u. daher graugrün, lanzettlich o. lineal-lanzettlich; Aeste verlängert, schlank, mehr 0 . weniger abstehend. (B. M. O.?) N. Kr. J. T.

angustifolia. Schrk. Schmalblättrige F. 
Anhängsel der Hüllb. klein, von einander entfernt, die Nägel der Hüllb. nicht verdeckend, die Hülle daher grünlich $u$. schwarz gefleckt erscheinend.. 11

Anhängsel der Hüllb. die Nägel der Hüllb. fast vollkommen verdeckend, die Hülle daher braun 0 . schwärzlich. Verbr. decipiens. Thuill.*) Wiesen-F.

B. meist ungetheilt, dic oberen lanzettlich; Köpfehen ziemlich klein, kugelig-oval; alle Hüllb. mit kïmmig-gefransten Anhängseln (die obersten ausgenommen). Terbr. (fehlt $O . S$.)

nigrescens. Willd. Schwärzliche F.

B. größer u. breiter, oft fiederlappig; Köpfchen größer, oval; nur die mittleren Hüllb. mit kämmiggefransten Anhängseln. Südt.

transalpina. Schl. Südliche F.

B. unterseits weißlich-filzig, oft leierförmig; Köpfchen sehr groß, mit lederig-häutigen Hüllb.; Pappus so lang als die Fr.; Stg. sehr hoch, 1 köpfig. Tora. v. T. $K r$.

heleniifolia. (Gren. et Godr.) (Arcang.) Alantblättrige $\mathrm{F}$.

B. beiderseits grün; Anhängsel der Hüllb. lanzettlich o. pfriemlich, lang-fiederig-gefranst.......... 13

Anhängsel der Hüllb. lanzettlich, aufrecht, Fransen worstlich, doppelt so lang als die Breite des Mittelfeldes; Fr. 6 mal länger als der Pappus ; B. lanzettlich, die unteren gezähnt 0 . fast buchtig; strahlende Randbt. meist fehlend. $B$. (K.?)

nigra. L. Schwarze F. Anhängsel der Hüllb. aus lanzettlichem Grunde langpfriemlich, zurückgekrümmt; strahlende Randbt.

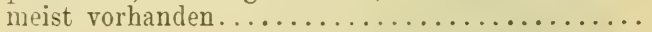

Stg. u. B. kalıl o. etwas spinnwebig-behaart; B. schmal u. lang; Hülle länglich, von den Anhängseln nicht vollkommen bedeckt.

Vora. v. Südt..... cirrhata. Rchb. Gefranste F. Stg. u. B. kurzhaarig-raub, oft außerdem etwas spinnwebig; Hïlle eiförmig 0 . fast kugelig......

Fr. 3-5 mal länger als der Pappus; B. grasgrün; Hüllen ohne Spinnwebhaare .............. 16 15 Fr. 6-8 mal länger als der Pappus; $B$. graugrün; Hüllen anfangs spinnwebig-behaart, von den hellbraunen Anhängseln nicht vollkommen bedeckt. H. N....stenolepis. Kern. Schmalschuppige F.

*) C. pratensis Thuill. ist durch verlängerte, oft zurückgekrümmte Anhängsel der Hüllb. ausgezeichnet. 
B. am Grunde abgestutzt 0 . fast geöhrlt; Stg. ziemlich niedrig, 1 köpfig; Köpfchen grob; Anhängsel hellbraun. A. v. Süidt. K. Kr?

plumosa. Lam. Federige F.

B. gegen den Grund verschinälert; Stg. oft ästig;

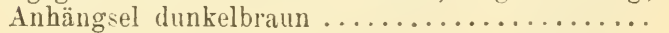

Anhängsel der 3 inneren Reihen der Hüllb. über die äußeren hinausragend; B. länglich-elliptisch o. lanzettlich, gesägt-gezähnt. $B$.

Phrygia. L. Phrygische F. Anhängsel der innersten Reihe von den Fransen del vorhergehenden Reihe bedeckt; B. länglich-elliptisch 0. eiförmig, gezähnelt. Terbr.

pseudophrygia. C. A. Mey. Perücken-F.

B. ungetheilt 0 . buchtig gelappt, die mittleren u. oberen am Stg. herablaufend; Bt. blau o. violett

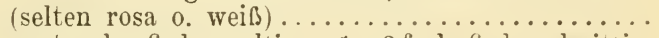

B. entweder fiederspaltig o. 1-3 fach fiederschnittig, o. ungetheilt, aber nicht herablaufend ........

Fransen der Hüllb. ungefähr so lang als die Breite des schwarzen Randes; B. ganzrandig o. gezähnelt. grün. Verbr. (fehlt $M$.) ...montana. L. Berg-F.

19 Fransen der Hüllb. beinahe doppelt so lang als die Breite des braunen Randes, fast knorpelig; $B$. ungetheilt 0 . buchtig-gelappt, graugrïn 0 . weibgrau. Verbr. (fehlt Sch. S.)

axillaris. Willd. Seitenblütige F.

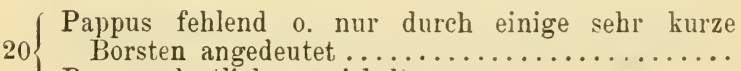
Pappus deutlich entwickelt.........................

Anhängsel der Hüllb. in einen Dorn endigend..... 22

21 Anhängsel der Hüllb. zwar zugespitzt, aber nicht

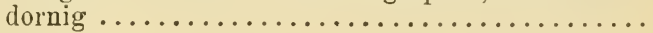

Köpfchen mittelgroß, eiförmig; Anhängsel der Hüllb. braun; Bt. fleischroth; Grundb. 2-3 fach fiedertheilig; Stgb. einfach fiedertheilig, mit linealen Abschnitten; Pfl. sehr rauh. J.

spinoso-ciliata. Bernh. Dornschuppige F. Köpfchen sehr klein; Hüllb. blass; Bt. weiSlich; Grundb. doppelt fiedertheilig; Stgb. fiedertheilig o. fiederlappig, die obersten oft ungetheilt. $(J$. diffusa. Lam. Ausgebreitete F. 
Babschnitte schmal-lineal-lanzettlich, bespitzt; Anhängsel der Hüllb. lang kämmig-gewimpert, Wimpern sich gegenseitig deckend. J. (Südst.?)

Babschnitte länglich o. verkehrt-eilanzettlich; Anhängsel der Hiillb. sehr kurz kämmig-gewimpert, Wimpern sich gegenseitig nicht deckend. $J$.

Tommasinii. Kern. Tommasini's F.

24 Hüllb. erhaben 5nervig*) . . . . . . . . . . 25

Hiillb. undeutlich 0 . gar nicht längsnervig........

Anhängsel der Hüllb. mit einem 3 eckigen, schwarzen Flecke; B. rauh, etwas wollig, Zipfel lineal; Stg. uberwärts rispig-ebensträußig; Bt. lila o. hell25 jurpurn. Verbr. (fehlt S.)

Rhenana. Bjor. Rheinländische F. Anhängsel der Hülle obne 3 eckigen schwarzen Fleck; Stg. vom Grunde an ästig ...............

Stg. steif aufgerichtet; untere B. mit $5-7$ verkehrteilanzettlichen Abschnitten; Anhängsel der Hüllb blassgelb. $K r$. J. Kartschiana. Scop. Istrianer F. 26 Stg. aufsteigend, meist hin- und hergebogen; untere T. mit 9-15 linealen Abschnitten; Anhängsel der Hüllb. braun $J$.

Dalmatica. Kern. Dalmatinische F.

Kraut mit blauen, selten violetten, rosenrothen 0. weißen Bt.; B. lineal-lanzettlich o. lineal, die untersten oft fiedertheilig. Ver.br. $u$. $h f g$.

Cyanus. $L$. Kornblume. Stauden mit hellpurpurnen 0 . gelben (selten weißen) Bt.

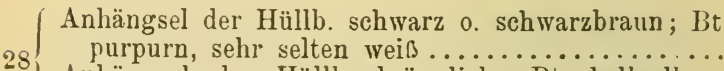
Anhängsel der Hüllb. bräunlich; Bt. hellgelb 0 . röthlichgelb, seltener furpurn ..............

*) In diese Abtheilung gehört auch C. punctata Vis., welche deu Wuchs der C. Rhenana Bor., aber keine schwarzen Flecken auf den Anhängseln der Hüllb. hat. Diese Art soll auf der Insel Lussin vorkommen. 
Anhängsel die Nägel der Hüllb. nicht verdeckend, so dass die Hülle grünlich und schwärzlich gescheckt erscheint; Fransen so lang o. kürzer als der Querdurchmesser des Anhängsels; Stg. meist ästig und mehrköpfig. Verbr. u. hlfg.

Scabiosa. $L{ }^{*}$ ) Grindkraut-F.

Anhängsel die Nägel der Hüllb. fast vollständig verdeckend, die Hülle daher fast ganz schwarz; Fransen länger als der Querdurchmesser des Anhängsels; Stg. meist niedrig und am häufigsten 1 köpfig; Köpfchen sehr groß. A v. N. O. T.

alpestris. Hgtsch. et Heer. Voralpen-F.

B. im ausgewachsenen Zustande ganz kahl; Allhängsel der Hüllb. dreieckig; Bt. gelb, röthlichgelb o. purpurn; Pappus so lang als die Fr.

Südt. K. Kr $r$. J.

dichroantha. Kern. Zweifarbige F. B. am Rande rauh, unterseits oft wollig-flockig; Anhängsel der Hüllb. länglich-eiförmig; Bt. stets gelb ; Pappus viel kürzer als die Fr. Kir. $J$.

rupestris. L. Felsen-F.

Anmerkung. Von Bastarten wurden im Gebiete beobachtet: C. Jacea $X$ nigrescens, Jacea $X$ stenolepis, Jacea $\times$ Rhenana u. Rhenana $\times$ Scabiosa.

\section{CARThajus. L. Saflor.}

Pappus fehlend; Stg. u. B. kahl, letztere ungetheilt, dornig-gezähnt-gesägt. Cult .

tinctorius. $L$. Echter S.

Pappus schuppenförmig, nur an den Randbt. fehlend; Stg. spinnwebig-wollig; B. buchtig-dornig-gezähnt o. fiederspaltig. (N.) Südt. $K r$. J.

lanatus. $L$. Wolliger $\mathrm{S}$.

Anmerkung. Das Benediktenkraut (Cnicus Benedictus L.), durch drüsige Behaarung des Stg. und fiedertheilige Enddornen der Hüllb. ausgezeichnet, wird öfters cultivirt und verwildert bisweilen.

\section{LYI. SCOLYMUS. L. Golddistel.}

B. herablaufend; Hüllb. zugespitzt; Bt. gelb. J.

Hispanicus. $L$. Spanische G.

*) C. Badensis T'ratt. hat kahle, glänzende, meist fein getheilte B. 


\section{CICHORIUM. L. Wegwart.}

Grundb. meist schrotsägeförmig, seltener ungetheilt; obere Stgb. eilanzettlich; Fr. 8 -10 mal so lang als der Pappus. Verbr. u. hfg. Intybus. L. Cichorie. Grundb. länglich, gezähnt o. zerschlitzt; obere Stgb. breit herz-eiförmig; Fr. $4 \mathrm{mal}$ so lang als der Pappus. Cult. (J. rerw.) ... Endivia. L. Endivie.

LVIII. LAPSANA. L. Rainkohl.

Einjähriges Kraut; B. gezähnt, die unteren leierförmig; Köpfchen klein, rispig angeordnet; Bt. gelb. Verbr.......... communis. $L$. Gemeiner R.

LIX. APOSERIS. Neck. Stinkkohl.

Schaft 1 köpfig; B. schrotsägeförmig-fiederspaltig, Zipfel fast rautenförmig, der endständige 3 eckig, fast 3 lappig; Bt. gelb. Tora. (fehlt J.) foetida. (L.) Cass. Gelber St.

LX. HYOSERIS. L. Schweinssalat.

Einjähriges Kraut; B. schrotsägeförmig-fiederspaltig, Lappen eiförmig, gezähnt. $J$. scabra. L. Rauher S.

LXI. ARNOSERIS. Gürtu. Lämmersalat.

Einjähriges Kraut; Schaft 1-3köpfig; Köpfchenstiele oberwärts keulig-verdickt, röhrig; B. verkehrt-eiförmig-länglich, gezähnt; Bt. gelb.

B. MI. Sch. N. O. Sïdst.

minima. (L.) $L k$. Kleiner L.

\section{ZACYNTHA. Gürtn. Höckerlattich.}

Einjähriges Kraut; Grundb. schrotsägeförmig, leierförmig 0. ungetheilt; Stgb. lineal-pfeilförmig; Bt. gelb. J........verrucosa. Gärtu. Warziger $H$.

\section{RHAGADIOLUs. Juss. Sichelsalat.}

B. meist ungetheilt, gezähnt; Hüllb. gegen die Spitze zu borstig. $J$.

stellatus. (L.) Gärtu. Sternfrüchtiger S. Die unteren B. leierförmig; Hüllb. kahl. $J$. edulis. Gärtı. Essbarer S.

LXIV. HEDYPNOIS. Schreb. Röhrehenkrant. Einjähriges Kraut; Grundb. buchtig-gezähnt; Köpfchenstiele keulig verdickt; Hüllb. auf dem Rücken steifhaarig. $J$.

Cretica. (L.) Willd. Kretensisches R. 


\section{HYPOCHOERIS. L. Ferkelkrant.}

(Stg. kahl, blattlos, ästig; äußere Strahlen des Pappus

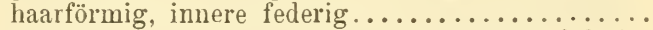

Stg. steifhaarig; alle strahlen des Pappus federig;

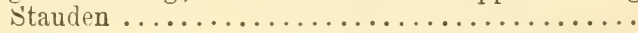

Einjähriges Kraut; Randbt. so lang als die Hülle; innere Strahlen des Pappus der Randfr. mit fleien Federchen. P M. Sch. N. O. St. J. glabra. $I$. Kahles F.

Staude; Pandbt. länger als die Hülle; innere Strahlen des Pappus der Randfr. dicht wollig-verwebt.

Verbr.......... radicata. L. Langwurzliges F.

Köpfchenstiele fast gleichdick; Stg. 1-3 köpfig, kurzsteifhaarig; B. braun-gefleckt o. ungefleckt. Terbr.

maculata. $L$. Geflecktes F.

Köpfchenstiele oben fast keulig verdickt; Stg. 1 köpfig, steif-rauhhaarig, am Grunde beblättert.........

Hüllb. am Rande gefranst-gezähnt; Köpfchen sehr grob. Geb. (fehlt N. O. J.)

uniflora. Vill. Einköpfiges F.

Hüllb. am Rande kahl; Köpfchen kleiner.

Vora. v. Südt. Facchiniana. Ambr. Südtiroler F.

I.XVI. UROSPERMUM. Scop. Schwefelsame.

Hülle weich-flaumig; Frschnabel vom Grunde an allmälig verschmälert. $J$.

Dalechampii. (L.) Desf. Weichhaariger S. Hülle borstig-steifhaarig; Frschnabel plötzlich in einen fadenförmigen Stiel zusammengezogen. J.

picroides. $(L$.$) Desf. Bitterkrautartiger S.$

\section{LEONTODON. L. Löwenzahn.}

Alle Fr. mit federigem Pappus ..............

Die randständigen Fr. ohne federigen Pappus, nur mit einem zerschlitzten Krönchen o. mit einigen Schüppchen an Stelle des Pappus ............ 11

Strahlen des Pappus alle gleichartig federig; Stg. oft ästig; B. fiederspaltig 0 . nur gezähnt; Köpfchenstiele oben verdickt; Gr. (wenigstens getrocknet) schwärzlich 0 . grünlich. Verbr. $u$. $h f g$.

autumnalis. $L * *$ ) Herbst-L.

Strahlen des Pappus ungleich, die inneren federig, die äußeren kürzer, oft baarförmig und rauh, seltener ebenfalls federig; Gr. gelb ............

*) I. pratensis Rchb. ist durch schwärzlich-zottige Hüllen ausgezeichnet. 
Hülle von langen schwarzen Haaren zottig-rauhhaarig; B. lanzettlich, in den Bstiel verschmälert, ganzrandig, gezähnt o. fiederspaltig; Schaft oben verdickt, kaum länger als die B. $A$. (fehlt .J.)

Taraxaci. (Vill.) Lois. Schwarzhaariger I.

Hülle kurzhaarig, filzig 0 . kahl ............. 4

B. kahl 0. zerstreut behaart ............. 5

4 B. mehr 0 . weniger dicht mit gegabelten 0 . verzweigten Haaren besetzt, of graufilzig.........

Köpfchenstiel mit mehreren Schuppen besetzt; Hüllb. kurz kraushaarig; B. seicht gezähnt 0 . ganzrandig, kahl o. mit zerstreuten einfachen Haaren; Bt. gelb, seltener orange. $A$. (fehlt J.)

Pyrenaicus. Gouan. Pyrenäischer L. Köpfchenstiel mit 1 - 2 Schuppen besetzt 0 . nackt; llüllb. kahl o. spärlich behaart; Bt. gelb .......

b. luchtig gezähnt, nur ausnahmsweise fiederspaltig. Verbr. u. lifg. .. Danubialis. Jacq. Gemeiner I.

6 B. tief fiedertheilig, init schmalen, oft linealen Abschnitten; Stg. weist niedrig. $A$.

hyoseroides. Welw. Schweinssalatblättriger $\mathrm{L}$.

B. buchtig gezähnt o. fiederspaltig .

B. ganzrandig 0. entfernt klein-gezähnelt; Stg., J).

7) 11. Hülle von dichter Behaarung grau o. graugrün; Wst. in eine senkrechte, spindelförmig-walzliche I'fahlwurzel verlängert..................

W:st. kurz, schief, abgestutzt; die äußeren Strahlen des Pappus haarförnig, scharf; Schaft iumer 1 köpfig. Verlur. u. hifg.

hispidus. L.*, Kurzhaariger $I$.

Wst. senkrecht, in eine verlängert spindelformige Pfahlwnrzel übergehend; alle Pappusstrablen federig; Schaft $1-3$ köpfig (meist $1 \mathrm{köpfig)} \mathrm{.......}$

Aeucere Hüllb. dicht kämmig-gewimpert; mittløre Fr. 4 mal länger als der Pappus. $K r$.

asper. (W. K.) Richt. Pauher L. Aen:Cere Hüllb, am Pande etwas angedrürckt flaumig. nicht gewimpert; mittlere Fr. vielmal länger als der Pappus; Köpfchen kleiner; Schaft niedriger, weniger dicht behaart. Sü̈t. $\delta$. $K r$.

crispus. Vill. Felsen-I.

*) Sind die B. tief fiederspaltig, so liegt eine stärker beharte Form des L. hyoseroides Welw. vor. 


\section{Sehaft immer 1 köpfig; Behaarung kurz-filzig. M. N. (). S. T. h. St. Kr .

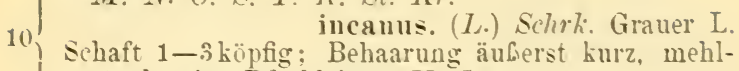 staubartig; PAl. kleiner. K. .I. \\ Berinii. (Bartl.) Roth. Bestäubter L.}

Wzfasern walzlich; die mittleren Fr. an der spitze in einen Schnabel rerschmälert.

I. (N.?) St. K. Kr.J.

Leysseri. (Wallr.) Bcck. Hundslattich. Wzfasern rübenförmig rerdicht: die mittleren Fr. ron der Mitte an in einen schnabel rerschmälert. $J$.

tuberosus. L. Knolliger L.

\section{IXVIII. PICRIS. I. Bitterkraut.}

Dir äußeren Hüllb. herz-eiförmig. zugespitzt, eine AnGenhülle bildend; die mittleren Fr. an der spitze abgerundet. mit einem harfeinen schmabel: stgb. lierzförmig-umfassend. (R.) N. (Südt.?) Süulst..J. echioides. $L$. Wurmlattich. Hüllb. dachig, die äußeren nicht herz-ciförmig; Fr.

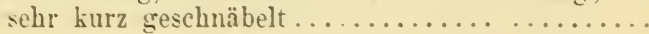

Aenßere Hüllb. am Rande borstig-gewimpert; Stgb. am Grunde herzförmigr. J.

2 hispidissima. (Bartl.) Koch. Borstigstes B. Hïllb. rerschiedenartig behaart o. beborstet, aber

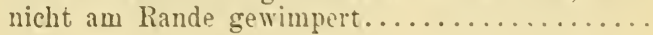

Köpfchenstiele und Hüllen mehr o. weniger dicht mit schuarzen, gröbtentheils eiufachen borsten

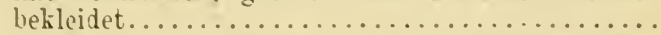
Kïpfchenstiele mit hellen, oft widerhakig-gegabelten Borsten besetzt, o. nur flamig o. mahezu kahl ..

Untere B. verlängent, gregen den Grund lang rerschmälert, dicht beborstet und dadurch sehr raun: änbere Hüllb. abstehend, lineal o. lanzettlich. imnen lang-schwarzzottig; stg. meist reichköpfig. Siüdt. ............ auriculata. Schltz. Rauhes l3.

B. ziemlich klein, zerstreut borstig, nur etwas rauh; änßere Hiillb. aufgerichtet, elliptisch o. cilanzettlich, innere schwarz-borstig; stg. oft armkïpfig. lora. r. N. St.

paleacea. lest. Breitschuppiges B. 
$\mathrm{PH}$. dicht beborstet und daher sehr rauh; untere B. buchtig gezähnt, vbere lineal 0 . schmal lanzettlich,

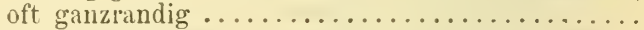
Pfl. spärlich beborstet, wenig rauh, lebhaft grün; B. klein gezähnelt 0 . nur die untersten buchtiggezähnt, die oberen länglich-eiförmig, alle verJältnissmäßig groß und breit; Köpfchen u. Früchte größer. T. S. (St.?)

crepoides. Saut. Pippauartiges B.

Köpfchen doldentraubig 0 . rispig gruppirt, die seitlichen gestielt. Verbr.

6 Köpfchen kleiner, an der Spitze des Stg. fast doldig gedrungen zusammengestellt, die seitlichen fast sitzend. .......... spinulosa. Bert. Dorniges B.

\section{TRAGOPOGON. L. Bocksbart.}

(Köpfchenstiele nach aufwärts allmälig verdickt,

1 keulenförmig, hohl; Hülle länger als die Randbt. Köpfchenstiele unter dem Köpfchen nur wenig 0. gar nicht verdickt; Bt. gelb ...............

Bt. bläulich-purpurn; Hülle 8 blättrig; Köpfehen oberseits ganz flach. $J$.

porrifolius. $L$. Lauchblättriger $\mathrm{B}$.

2 Bt. gelb; Hülle 8-12 blättrig; Köpfchen oberseits vertieft. Verbr. (fehlt Sch. S. K.)

major. Jacq. Grofer B.

Frschnabel $1^{1 / 2}$ mal so lang als die Fr.; Pfl. anfangs weibflockig. $K r$. J.

Tommasinii. Schltz. Krainer B. Frschnabel halb- o. eben so lang als die Fr.; Hüllb. über dem Grunde quereingedrückt............ Riandbt. so lang als die Hülle o. kürzer; randstänlige Fr. knötig-rauh, ungefähr so lang als ihr schnabel. Verbr.(?).... pratensis. L. Wiesen-B. 4 Randbt. meist länger als die Hülle; randständige Fr. schuppig-weich-stachelig, fast doppelt so lang als ihr Schnabel. Verbr. $u$. $h f g$.

orientalis. L. Gemeiner B.

An merkung. Zwischen T. major und T. orieutalis kommt ein Bastart vor.

\section{SCORZONERA. L. Schlangenwurz.}

( B. fiedertheilig, nur die untersten und obersten oft

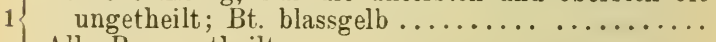

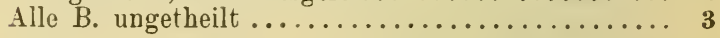

*) P. ruderalis Schm. ist durch dicht steifborstige Hüllb. ausgezeichnet. 
Staude mit unfruchtbaren Bbüscheln neben den blühenden Stg.; Stg. oben gefurcht; Randbt. ungefähr doppelt so lang als die Hülle. B. $M . N$. J. Jacquiniana. (Koch.) Celat: Gemeine S.

Zweijähriges Kraut ohne unfruchtbare Bbüschel; Stg. stielrund, feingerillt; Randbt. wenig o. gar nicht länger als die Hülle. B. M. N. O. Südst. J.

laciniata. $L$. Schlitzblättrige $\mathrm{S}$.

Bt. gelb . . . . . . . . . . . . . . . . . . .

Bt. rosenroth o. lila; B. lineal o. lineal-lanzettlich; die äußeren Hüillb. eilanzettlich; Wst. an der Spitze mit einem Faserschopf besetzt.............

B. kahl o. spinnwebig-wollig; Pappus gleichmäøig

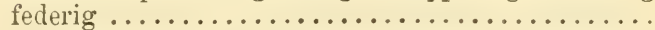

B. zerstreut-zottig, lineal, gekielt; die äußeren Strahlen des Pappus haarfein, scharf, die inneren am Grunde erweitert und daselbst innen federigzottig. (Südt.?) $K r$. J. villosa. Scop. Zottige S.

Stg. beblättert, 1-mehrköpfig, etwas wollig; die landständigen Fr. fein-weichstachelig; B. länglich o. lanzettlich, zugespitzt; Hülle halb so lang als die Randbt., kahl, die äußeren Hüllb. 3 eckig-eiförmig, die inneren eilanzettlich, alle spitz.

B. II. N. St. (K.) Kr.J.

Hispanica. $L$. Schwar'zwurz.

Stg. nackt 0 . mit $2-3$ linealen 0 . schuppenförmigen

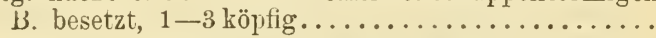

Stg. nackt, 1 köpfig; die äußeren Hïllb. eilanzettlich, an der Spitze verlängert-pfriemlich, oft so lang als die inneren; Fr. quer-faltig-knötig; B. lineal-lanzettlich o. lineal. A. v. $T . K . K r$.

aristata. Ram. Grannige Sch.

Stg. mit 2-3 schuppenförmigen o. linealen B. besetzt; Fr. glatt-gerieft ................

Wst. an der Spitze mit einem Faserschopf besetzt; Stg. meist 1 köpfig, mit 2-3 schuppenförmigen B., kahl; Hüllb. zugespitzt, an der Spitze selbst stumpf, die äuberen eiförmig; B. länglich-lanzettlich 0. lineal. $M . \Lambda$. O. St. J. Sïdt.

Austriaca. Willd. Oesterreichische Sch.

Wst. ohne Faserschopf; Stg. 1-3köpfig, mit 2 bis

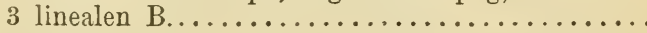

Stg. meist wollig; Hülle so lang als die Randbt., ihre äußeren B. eilanzettlich. Ver br. (fehlt $K$.)

humilis. $L$. Nattermilch.

Stg. kahl; Hülle so lang als die Randbt., ihre äufieren B. eiförmig. $B$. $M . N$.

parviflora. Jacq. Kleinblütige Sch. 
Riefen der Fr. glatt; Stg. 1 köpfig o. an der Spitze ästig. 2-4 köpfig; B. schmal lineal, rinnig.

B. M. N. O. St. Kr r. (S̈̈̈lt.?)

purpurea. L. Blassrothe Sch.

Riefen der Fr. oberwärts gezähnelt-raub; Stg. 1 köpfig o. am Grunde mit wenigen Aesten; B. lineal-lanzettlich, flach. Vorc v. Sü̈lt. $K$. Südst. $K r$.

rosea. $W . K$. Rosenrothe Sch.

\section{PTEROTHECA. Cass. Fliigellattich.}

Einjähriges Kraut; B. gezähnt o. leierförmig; Bt. gelb. J...bifida. Fisch. et Mey. Zweispaltiger F.

\section{CHONDRILLA. L. Knorpellattich.}

Grundb. schrotsägeförmig, obere Stgb. lineal o. lanzettlich; Aeste ruthenförmig; Köpfchen in ährenartigen Trauben; Fr. mit 5 lanzettlichen Zähnen endigend. Verbr. juncea. $L$. Ruthenförmiger K. Grundb. lanzettlich, gegen den Grund verschmälert, entfernt-gezähnelt; Stg. gabelspaltig, fast nackt; Köpfchen größer, doldentraubig angeordnet; Fr. mit einem gekerbten Krönchen endigend.

O. T. K. K $r$. J. prenanthoides. Vill. Alpen-K.

\section{WILLEMETIA. Neck. Kronlattich.}

Staude; Grundb. verkehrt-eilanzettlich, gezähnt, kabl; Bt. gelb. Verbr. (fehlt J.)

stipitata. (Jacq.) Cass. Gemeiner K.

\section{TARAXACUM. Wigg. Kuhblume.}

Der ungefärbte Theil des Schnabels der Fr. länger als diese mit dem gefärbten Theile des Schnabels

1 Der ungefärbte Theil des Schnabels kürzer 0 . höchstens so lang als die Fr. mit dem gefärbten Theile

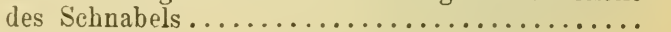

Acuœere Hüllb. abstehend o. zurückgeschlagen..... 3 Aeußere Hüllb. anliegend, breit eiförmig; Köpfchen 2 mittelgrof, mit hellgelben Bt., welche die Hülle wenig überragen; B. lineal-lanzettlich, gezähnt 0 . ganzrandig, selten schrotsägeförmig. Verbr.

paludosum. (Ścop.) Keru. Sumpf-K.

Pappus rein weiß; B. fist immer schrotsägeförmig. 4 Pappus röthlichweilj; äubere Hüllb. schmal lanzettlich, abstehend; Köpfchen klein, mit blassgelben Bt., welche die Hülle nicht viel überragen; B. balıl schrotsägeförmig, bald nur gezähnt 0 . ganzrandig. $B$. $I$. N..leptocephalum. Rchl. Kleinköpfige K. 
Aeußere Hüllb. abstehend, aber nicht herabgeschlagen; innere Hïllb. nur am Grunde mit Hautrand, an der Spitze meist einen Höcker o. ein Hörnchen tragend; Bt. hellgelb; Fr. meist braunroth; PA. in allen Theilen klein.

B. M. N. O. St. Kr. J. Südt.

corniculatum. (Kit.) D C. Gehörnte K. Aenßere Hüllb. oft zurückgeschlagen; innere Hüllb. mit Hautrand, ohne Höcker; reife Fr. meist graulich .............................

Aeußere Hüllb. lineal-lanzettlich o. länglich, bald zurïckgeschlagen. Verbr. u. hf

officinale. Wigg. Gemeine K. Aeůere Hüllb. eiförmig 0 . eilänglich, abstehend 0 . herabgebogen; Stg. niedriger: $A$.

alpinum. (Hoppe.) Koch. Alpen-K.

Stg. oben dicht weif-wollig; B. anfangs unterseits graufilzig; Fr. lineal-länglich, beiderseits verschmälert, an der Spitze feinknötig; blüht im Sommer u. Herbst. M. $N$. (O.) $K r$.

serotinum. (W. K.) I'oir. Spätblühende K. Stg. u. B. kahl o. doch nur wenig wollig........ 7

B. schrotsägeförmig ................... \&

B. lineal o. lineal-lanzettlich, ganzrandig o. entfernt gezähnelt; Fr. lineal-verkehrt-eiförmig. J.

tenuifolium. Hoppe. Schmalblättrige K.

Aeußere Hüllb. angedrückt 0 . etwas abstehend; Fr. fast glatt (nur mit spärlichen Knötchen u. Stachelchen unter der Spitze). A. v. T. $K$.

Pacheri. Schltz. Kärntner K. Spitze schuppig-weichstachelig 0 . höckerig. $B$. (Riesengebirge).

nigricans. (Kit.) Rchb. Schwärzliche K.

Anmerkung. Die Arten dieser Gattung sind zum Theile durch $Z$ wischenformen verbunden und bedürfen noch genaueren Studiums.

\section{MULGEDIUM. Cass. Milchlattich.}

Staude; Köpfchen traubig o. rispig angeordnet, ihre Stiele drüsig-behaart; B. leierfơrmig, Lappen gezähnt, der endständige sehr groß, spieß́łtörmig3 eckig. Geb...... alpinum. (L.) Less. Alpen-II. 


\section{IXXVI. SONCHUS. L. Gänsedistel.}

Hülle am Grunde schneeweiß-flockig; Fr. vielrippig; B. gestielt, fiedertheilig, Bstiele der mittleren

1) Stgb. am Grunde mit lang-zugespitzten Oehrchen; einjähriges Kraut. J... tenerrimus. $L$. Zarte G.

Hülle drüsenborstig, steifhaarig 0 . kahl, nicht weib-

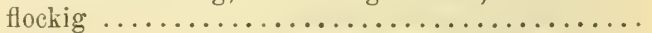

of Kräuter ; Fr. beiderseits 3 rippig ........... 3

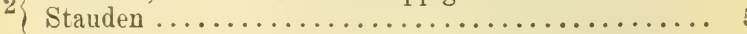

Fr. querrunzelig, am Rande fein gezähnt; obere Stgb. pfeilförmig-umfassend, mit zugespitzten Oehrchen, in der Gestalt veränderlich. Verbr. $u$. hfg.

laevis. (L.) Gemeine G.

Fr. ohne Querrunzeln; obere Stgb. herzförmig umfassend, mit abgerundeten Oehrchen ...........

Fr. am Rande kurz bewimpert; Stg. oben mit violetten Drüsenhaaren besetzt; $B$. leierförmigfiederspaltig, dornig-gezähnt. $J$.

4 glaucescens. Jord. Bläuliche G.

Fr. am Rande ohne Wimpern; Stg. kahl 0. oben drïsenborstig; B. ungetheilt, gelappt 0 . schrotsägeförmig, dornig-gezähnt. Verbr.

asper. $(L$.) Rauhe G.

Wst. kriechend; obere Stgb. am Grunde herzförmig, mit abgerundeten Oehrchen; Fr. braun ........

Wst. dick, nicht kriechend; Stg. hoch u. dick, hohl; obere Stgb. am Grunde pfeilförmig mit spitzen 0. zugespitzten Oehrchen; Fr. gelblich, mit starker Mittelrippe u. erhabenem Rande. (B.? $M$.?) $N$. (K.?) $K r$.

paIuster. $L$. Sumpf-G.

Stgb. verlängert-lanzettlich, ungetheilt 0 . etwas luchtig; Stg. armköpfig; Köpfchenstiele u. Hüllen kahl; äußere Hüllb. breit-eiförmig. $J$.

maritimus. L. Meerstrands-G.

6 Stgb. schrotsägeförmig, seltener nur buchtig 0 . ungetheilt; Stg. meist mehrköpfig; Köpfchenstiele it. Hüllen meist drüsenborstig*); äußere Hüllb. eilanzettlich. Verbr. u. hf'g.. arvensis. L. Acker-G.

\section{LACTUCA. L. Lattich.}

(Bt. lila; Fr. beiderseits 1 rippig; Staude mit kahlen, fiederspaltigen B. B. T. K. Sü̈dst. $K r$. J.

perennis. L. Ausdauernder L.

Bt. gelb; Fr. beiderseits mehrrippig...........

*) Die Form mit kahlen Hüllen u. Köpfchenstielen ist S. uliginosus M. B. 
${ }_{2}\left\{\begin{array}{l}\text { Köpfchen } 5 \text { blütig; B. herablaufend } 0 \text {, gestielt ...... } \\ \text { Köpfchen mehr als } 5 \text { blütig; B. sitzend, nicht herab- }\end{array}\right.$

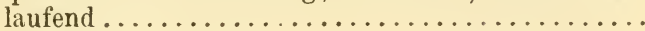

Stg. weißlich, beinartig fest; B. herablaufend, die unteren tief-fiederspaltig, mit linealen, ganzrandigen o. etwas gezähnten Zipfeln, die oberen lineal, ungetheilt; Frschnabel sch warz; wächst an steinigen, warmen Orten. B. M. $\Lambda$. Südst. $K r$. J. (T.?)

viminea. (L.) Presl. Ruthen-L.

Stg. grün 0. röthlich, krautig; B. gestielt, leierförmig-fiederspaltig, Zipfel eiförmig, winkelig-gezähnt; Köpfchen rispig; Frschnabel blass; wächst meist in Wäldern, auch auf Mauern.

Verbr. u. $h f g . . . . m$ muralis. (L.) Fres. Mauer-L.

Schnabel der Fr. schwarz, halb so lang als die Fr.; B. unterseits glatt; Stg. krautig, grün 0. röthlich Schnabel der Fr. weiß; B. meist am Kiele stachelig;

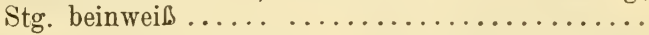

Grundb. und untere Stgb. schrotsägeförmig-leierförmig, gezähnt, die oberen fiederspaltig mit pfeilförmigem Grunde. B. M. $N$. $K r$.

quercina. L. Wald-L.

5 Grundb. in den Bstiel ver'schmälert, buchtig-gezähnt, Stgb. pfeilförmig, ungetheilt, gezähnelt, die unteren länglich mit verschmälertem Grunde, die oberen eiförmig-lanzettlich, zugespitzt. $M . N$. J.

sagittata. $W . K$. Pfeilblättriger $\mathrm{L}$.

B. ganzrandig, lineal, zugespitzt, die untersten schrotsägeförmig-fiederspaltig; Aeste ruthenförmig, traubig-ährig. B. M. N. Südt. $K v$. .J.

saligna. $L$. Weidenblättriger $\mathrm{L}$.

B. gezähnelt, länglich 0. oval, am Grunde pfeil-

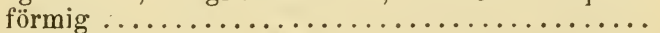

Rispe verbreitert, ebensträußig, flach; B. mit herzpfeilförmigem Grunde umfassend, gezähnelt, ungetheilt 0 . fiederspaltig. Cult. u. verw.

sativa. L. Kopfsalat.

Rispe pyramidenförmig o. mit abstehenden Aesten; B. oval-länglich, auf dem Kiele stachelig .......

B. senkrecht 0 . schief gestellt, spitz, fiederspaltigschrotsägeförmig, selten ungetheilt; Rispe pyramidenförmig, Aeste traubig; Fr. an der Spitze kurz-borstig. Verbr. (fehlt $S$.)

Seariola. $L$. Zaunlattich.

B. wagrecht gestellt, stumpf, ungetheilt o. buchtig, die oberen zugespitzt; Kispenäste abstehend; Fr. kahl. Südt. $K r$. J.......virosa. L. Giftlattich. 
LXXVII. REICHARDIA. Roth. Bitterlattich.

Einjähriges Krant; untere B. buchtig-fiederspaltig, obere länglich, fast ganzrandig; Köpfchenstiele an der spitze verdickt. $J$.

picroirles. (L.) Roth. Gemeiner B.

\section{CREPIS. L. Pippau.}

1 ) Bt. hellpurpurn, Heischfarben 0 . weiß..........

Bt. heller o. dunkler gelb o. orange bis feuerroth..

Fr. geschnäbelt; Bt. hellpurpurn; untere B. schrotsägeförmig 0 . fiederspaltig, obere ungetheilt; einjähriges Kraut. J. ........rubra. L. Rother P. 2 Fr. nicht geschnäbelt; Bt. Aleischfarben 0 . weib; alle B. grundständig, verkehrt-eilänglich, gezähnelt; Staude. Vora. v. T. K. Sü̈lst. Kr$r$.

incarnata. (Wulf.) Tausch. Fleischfarbener P.

$3\left\{\begin{array}{l}\text { Pappus reinweib, meist weich und biegsam........ } \\ \text { Pappus schmutzigweiß o. gelblich, mehr borsten- }\end{array}\right.$ förmig, oft zerbrechlich; Stauden ............

4) Stauden mit dunklem Wst............. 5

$4\left\{\right.$ Kränter mit spindliger, oft ästiger, bleicher $\mathrm{WV}_{\mathrm{z}} \ldots 17$

(Bt. orange o. feuerroth; alle B. grundständig; Schaft $5\{1(-3)$ köpfig, oben schwarz-rauhhaarig. $A$.

aurea. (L.) Cass. Feuerfarbener P. Bt. heller o. dunkler gelb .............. 6

Alle B. grundständig, ungetheilt; Schaft an der Spitze traubig- o. doldentraubig-ästig, mehrköpfig Stg. beblättert, seltener nackt, dann aber $1 \mathrm{köpfig}$ oder mit wenigen 1 köpfigen Aesten ...........

Köpfchen traubig-rispig angeordnet, oft zahlreich; $\mathrm{B}$. länglich-verkehrt-eiförmig, ganzrandig 0 . gezähnelt. Verzr.

praemorsa. (L.) Tausch. Abgebissener P. Köpfchen $3-7$, doldentraubig angeordnet; B. gezähnelt; Pfl. zarter. Vora. v. Sü̈lt.

Froelichiana. $D C$. Fröhlich's P.

Stg. entweder blattlos o. mit gestielten o. gegen den Grund verschmälerten, oft gespaltenen B. besetzt 9 Stg. stets beblättert; obere Stgb. mit abgerundetem, herzförmigem 0. pfeilförmigem Grunde sitzend, oft umfassend .........................

Bstiele leierförmig-gezähnt; alle B. gestielt, eiförmig o. herz-eiförmig; Stg. liegend, 1-0. armköpfig; Hülle grauflockig. A. v. T.....py gymaea. L. Zwerg-P. Bstiele nicht gezähnt, oft fehlend .......... 10 
Stg. an der Spitze rispig-ästig; B. 1-2 fach-fiedertheilig, mit schmalen, linealen Zipfeln; innere Hüllb. graufilzig. $K r$. J.

chondrilloides. Jacq. Fenchelblättriger $\mathrm{P}$.

Stg. meist 1 köpfig (seltener $2-3 \mathrm{köpfig);} \mathrm{B.} \mathrm{unge-}$ theilt 0. schrotsägeförmig .............. 11

Stg. blattlos 0. 1-3blättrig, unter dem Köpfchen nackt $\ldots \ldots \ldots \ldots \ldots \ldots \ldots \ldots \ldots \ldots \ldots \ldots \ldots \ldots \ldots \ldots \ldots$ Stg. niedrig, 1 köpfig, bis zum Köpfchen dicht be11 blättert, oben keulig verdickt; B. meist schrotsägeförmig; Köpfchen sehr groß, mit zottiger Hülle. A. (fehlt $K$. J.)

Terglonensis. (Hacq.) Kern. Terglou-P.

Wz. knollentragend; B. länglich-lanzettlich, gezähnt, kahl; Hülle drüsenhaarig. $J$.

bulbosa. (L.) Cass. Knolliger P.

$\mathrm{W}_{\mathrm{z}}$. ohne Knollen; Pf. der Alpen und Voralpen...

Wst. walzlich-spindelförmig; Stg. flaumig, oben graufilzig; B. flaunig, geschweift-gezähnt 0 . schrotsägeförmig; Hülle grauflaumig o. rauhhaarig.

Vora. (fehlt J.)

alpestris. (Jacq.) Tausch. Voralpen-P.

Wst. kurz, fast wagrecht; Stg. oben wie die Hülle dicht zottig; Grundb. kahl, ganzrandig 0. etwas gezähnt. A. จ. $T$.

jubata. Koch. Mähnentragender $\mathrm{P}$.

Obere Stg. am Grunde herzförmig- o. häufiger pfeil-

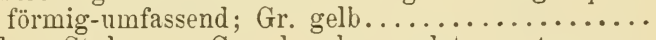

$14\{$ Obere Stgb. am Grunde abgerundet o. etwas geöhrlt-umfassend; Gr. wenigstens im getrockneten Zustande schwälzlichgrün ............. 16

B. länglich, gezähnt, kahl 0. drüsenlos behaart; Hülle rauhhaarig, drüsenlos, aus gleichlangen $\mathbf{B}$. bestehend. $A$. (fehlt $J$.)

blattarioides. (L.) Vill. Schabenkrautartiger P.

15 B. länglich-lanzettlich, drüsig-weichhaarig; .Hülle rauhhaarig und dicht drüsig, ihre äußeren $B$. kürzer als die inneren. Geb. (fehlt $N$.J.)

grandiflora. (All.) Tausch. Großköpfiger P.

Stg. u. B. kahl o. zerstreut behaart; untere B. so lang o. kürzer als ihr Stiel; Hülle flaumig, oft auch drüsig. Verbr. (fehlt $K$. $K r$. J.)

succisifolia. (All.) Tausch. Abbissblättriger $\mathrm{P}$.

Stg. u. B. steifhaarig-rauh; untere B. meist länger als ihr Stiel; Hülle zottig und drüsig.

Verbr. (fehlt $K . K r \cdot J$.

mollis. (Jacq.) (Koch.) Weichhaariger P. 
Hüllb. ganz kahl, die äußeren viel kürzer als die inneren, eiförmig, angedrückt; Köpfchen klein; Bt. citronengelb. $N$. O. S. Siidt. Kr.J.

pulchra. L. Schöner P. Alle 0. doch die inneren Hüllb. flaumig, drüsig, rauh-

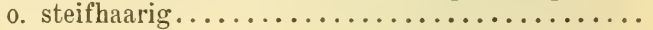

$18\{$ Alle 0 . doch die mittleren Fr. geschnäbelt ....... 19

Fr. schnabellos ....................... 23

Köpfchenstiele vor dem Aufblühen nickend; Gr. gelb 20

19 Köpfchenstiele stets aufgerichtet; Gr. oft schwärz-

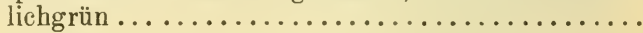

Stg. oben wie die Hüllb. borstig-steifbaarig, meist ohne Drüsen; untere B. meist schrotsägeförmig. B. M. N. O. St.

20 rhoeadifolia. $M$. B. Mohnblättriger $\mathrm{P}$. Stg. weichhaarig; Hüllb. drüsig-rauhhaarig; Fr. lang geschnäbelt. B. Südt. (St.?)

foetida. $L$. Stinkender P.

Hülle nach dem Verblühen von der Länge des Pappus; äußere Hüllb. lanzettlich, spitz, nebst dem Rande der Deckb., dem Rücken der inneren Hüllb. und den Köpfchenstielen fast dornig-steifhaarig. (B.) M. N. O. St. Kr. J. Südt.

setosa. Hall. $f$. Borstiger $\mathrm{P}$.

Hülle nach dem Verblühen von der halben Länge des Pappus; äußere Hülib. kahl, innere graı. flaumig und außerdem oft steifhaarig..........

Aeußere Hüllb. eilanzettlich, gegen die Spitze verschmälert, am Rande häutig; die Deckb. lineal, krautig, schmal-häutig-berandet. ( $N$.) T.J.

22 taraxacifolia. Thuill. Löwenzahnblättriger $\mathrm{P}$. Aeußere Hüllb. oval, concav, häutig; die Deckb. länglich, stumpf, häutig, mit schmalem krautigem Rückenstreifen. J......vesicaria. L. Blasiger P.

Stg. vom Grunde an ästig, Aestchen $2-3 \mathrm{köpfig,}$ vor der Btzeit überhängend; äußere Hüllb. angedrückt, lanzettlich, nebst den Deckb. am Rande kahl. J. $K r$...neglecta. $L$. Vernachlässigter P. Stg. oben doldentraubig verästelt, deste stets auf-

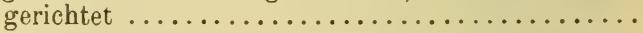

Die inneren Hüllb. an ihrer Innenfläche haarig, die äußeren abstehend .................... 25

Die inneren Hüllb. an ihrer Innenfläche kahl; Stgb. flach, die oberen am Grunde pfeilförmig ....... 
Stgb. flach, am Grunde geöhrlt-gezähnt; Hüllb. länglich-lineal, stumpflich; Gr. gelb. Verbr $u$. $h \mathrm{fg}$. biennis. $L$. Zweijähriger $\mathrm{P}$.

25 Stgb. lineal, am Grunde pfeilförmig, am Rande zurückgerollt; Hüllb. lanzettlich, verschmälert; Gr. (wenigstens getrocknet) schwärzlichgrün. Verbr...............tectorum. L. Dach-P.

Die äußeren Hüllb. abstehend, lanzettlich; Fr. an der Spitze verschmälert; Oehrchen der Stgb. zugespitzt $u$. abwärts gerichtet; Frboden kurzhaarig. (B. M. N. S. T.) Nicaeensis. Balb. Nicäischer P. Die äußeren Hüllb. angedrückt, lineal o. lineal-

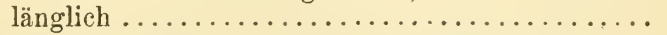

Köpfchen gro@; äu@ere Hüllb. lineal-länglich; Fr. an der Spitze verschmälert; Frboden fransig-borstig; Stg. steif, aufrecht, kantig gefurcht; B. dick, kurzrauhhaarig. $M$.

Pannonica. (Jacq.) C. Koch. Ungarischer P. Köpfchen klein; äußere Hüllb. schmal-lineal; Fr. an der Spitze kaum verschmälert; Frboden kahl; B. dünn, ziemlich kabl. Verbr..virens. L. Grüner P.

Stgb. fiederspaltig mit lineal-lanzettlichen Abschnitten, gestielt 0 . gegen den Grund verschmälert; Hülle locker-filzig $u$. außerdem oft schwarz-rauhhaarig. A......Jacquini. Tausch. Jacquin's P. Alle 0 . die oberen Stgb. ungetheilt, mit abgerundetem, herzförmigem o. spießförmigem Grunde

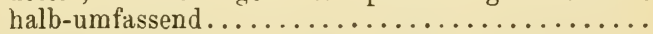

Stg. 1 köpfig, meist nur am Grunde beblättert; B. elliptisch-länglich, gezähnt; Köpfchenstiel oben stark verdickt u. hohl; Hülle zottig; Fr. 5 rippig. A. v. N. O. S. K. T.

montana. (L.) Tausch. Berg-P.

Stg. mindestens $2 \mathrm{köpfig,} \mathrm{reichlich} \mathrm{beblättert} \mathrm{.....} 30$

Gr. gelb; Fr. 20 rippig; Stg. steifhaarig-rauh. 2- bis 5 köpfig. Sch. (Gesenke).

Sibirica. $L$. Sibirischer P. Gr: (wenigstens getrocknet) schwärzlichgrün; Fr. 10 rippig; Stg. kahl, oft reichköpfig. Verbr.

paludosa. $L$. Sumpf-P.

Anmerkung. Zwischen C. Jacquini u. C. Terglouensis wurde ein Bastart beobachtet.

\section{PRENANTHES. L. Hasenlattich.}

Staude; B. am Grunde herzförmig-umfassend, kahl, unterseits seegrün: Köpfchen lilein, rispig angeordnet. Verbr. $u$. $h f g$. purpurea. $L$. Gemeiner H. 


\section{HIERACIUM. I. Habichtskraut.}

Strahlen des Pappus gleichlang, 1reihig; Wst. schief o. wagrecht, oft beblätterte Ausläufer treibend; Stg. schaftartig, oft gabelig, blattlos 0 . armblättrig, selten mehrblättrig; B. ganzrandig 0 .

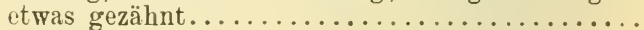

Strahlen des Pappus ungleich, fast 2 reihig, die äußeren kürzer; Ausläufer fehlen.............

Reife Fr. klein, schwarz, ihre Rippen oben in kurze Zähne auslaufend; Wst. meist kurz; Hüllb. in der Regel deutlich dachig angeordnet............ Reife Fr. braun, ihre Rippen oben in einen Ringwulst verschmelzend; Wst. verlängert, kriechend, ohne beblätterte Ausläufer; Hüllb. 2 reihig, die äußeren sehr kurz; Bt. hellgelb, getrocknet grün werdend; Stg. 1-3 köpfig; $\mathrm{B}$ lineal o. lineal-lanzettlich. Verbr. (fehlt B. M. Sch.)

staticifolium. Vill. Grasnelkenblättriges H.

Stg. schaftförmig und $1 \mathrm{köpfig,} \mathrm{o.} \mathrm{gabelspaltig} \mathrm{und}$ 2 köpfig, o. wiederholt gabelspaltig und jeder Ast

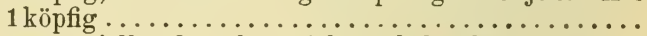
Stg. 2-vielköpfig, aber nicht gabelspaltig, nur ausnahmsweise 1 köpfig*); Köpfichen ebensträußig...

Stg. nackt, 1 köpfig; Hülle kurz-walzlich; B. etwas seegrün, verkehrt-eiförmig-länglich 0 . lanzettlich, unterseits meist grau- o. weiøfilzig; beblätterte Ausläufer stets vorhanden, aber oft sehr kurz; Köpfchen groß; Randbt. auwen oft roth gestreift Stg. meist 1 blättrig, 2 köpfig 0 . gabelspaltig 3 - bis

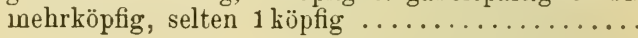

Hüllb. schmal und spitz; Ausläufer schlank, verlängert. Verbr. $u$. h $\mathrm{fg}$.

Pilosella. L.**) Gemeines Dukatenröschen. 5 Hüllb. breit, gerundet-stumpf 0 . bespitzt, hell berandet; Ausläufer kurz und dick; Pfl. kräftigel und oft auch höher. Verbr. (fehlt B. M. Sch.)

Hoppeanum. Schult. Großes Dukatenröschen.

*) H. Auricula L. ist oft 1 köpfig; häufig findet man aber dann verkümmerte Köpfchen unter dem blühenden.

**) H. Peleterianum Mérat (B. T.) unterscheidet sich durch langzottige Hüllen. 
Ausläufer sehr kurz 0. ganz fehlend*); Hülle zur Frzeit kugelig; B. kahl o. zerstreut borstig, unterseits mit fein sternförmigem Flaume besetzt, auf der Mittelrippe borstig; Pandbt. unterseits meist purpurn-streifig. A. v. T. S. K. St.

furcatum. Hoppe. Gabeliges $\mathrm{H}$.

Ausläufer liegend, verlängert, unfruchtbar oder Bt.

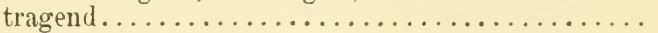

Randbt. unterseits purpurn-streifig; Hülle zur Frzeit niedergedrückt-kugelig; Grundb. verkehrt-eilänglich, blassgrün, oberseits zerstreut-zottig, nnterseits zerstreut-sternharig; Ausläufer oft Köpfchen tragend. $B . M$. Sch.

flagellare. Willd. Ausläuferblütiges $\mathrm{H}$.

Randbt. meist gleichfarbig; Hülle zur Frzeit eiförmigkegelförmig; Grundb. schmal-lanzettlich, beiderseits grün, oberseits kahl o. zerstreut-borstig; Ausläufer unfiuchtbar. Sucl.

Tatrense. Peter. Tatra-H.

Stg. niedrig, am Grunde bogig aufsteigend, an der Spitze $1-5$ köpfig; Bt. rein gelb**) .......... Stg. mehr o. weniger verlängert, meist vom Grunde an aufrecht, meist reichköpfig; Bt. gelb, orange 0 .

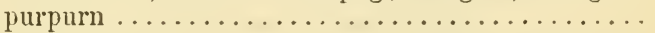

Ausläufer stets vorhanden, ihre oberen B. gröler als die unteren; $\mathrm{B}$. bläulich-grün, lanzettlich-spatelig, am Rande gewimpert, sonst meist kahl, nicht flockig, drüsenlos; Hülle flaumig und drüsig.

Verbr. u. hfg....... Auricula. L. Nausöhrchen. Ausläufer fehlend o. sehr kurz; B. grasgı ïn, wenigstens unterseits 0 . am Rande flockig; Hülle seiden-

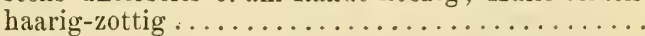

Hülle klein, von der Behaarung nicht verdeckt; $B$. unterseits 0 . doch am Rande flockig***), drüsenlos; Stg. meist blattlos 0. 1 blättrig. $A$. (fehlt $\lambda$. J.)

10 Hülle ziemlich grof, kugelig, von langen Seidenhaaren verdeckt; B. reichlich flockig, unterseits 0. aın Rande drüsig; Stg. oft mehrblättrig. A. v. T. S. K. St.

alpicola. Schl. Alpenbewohnendes H.

*) Vergl. auch H. alpicola Sch.

**) Vgl. auch H. floribundum W. Gr. (unter Nr. 17) u. H. Laggeri Schltz. (unter Nr. 19).

${ }^{* * *}$ ) H. Kochii (Gremli) (A. v. T.) hat beiderseits reichlich flockige $B$. 
(Bt. heller o. dunkler gelb, ohne Beimischung von

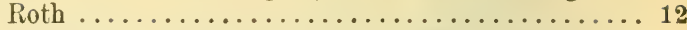

Bt. orange o. purpurn, o. die inneren gelb, die äußeren orange bis purpurn................

B. mehr o. weniger bläulich-grün, ziemlich steif, niemals grasgrün, am Rande 0 . überall borstigsteifhaarig, $u$. oft unterseits 0 . beiderseits stern-

12 haarig-flockig, seltener ganz kahl, niemals an der Spitze drüsig.................... 13

B. grasgrün o. gelblich-grün, weich, oft rauhhaarig, manchmal (namentlich die oberen) an der Spitze

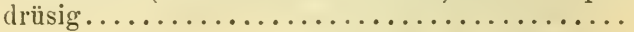

Stgr. 3-12 blättrig, am Grunde ohne Brosette; B. nach aufwärts an Gröbe allmälig abnehmend, lanzettlich, von sternförmigem Flaume weißfilzig 0 . loch grauflockig $u$. von starren, langen Borsten

13 beiderseits steif harrig; Köpfchenstiele weiß- 0. graufilzig; Ausläıfer fehlen.............. 14

Stg. nackt 0. nur am Grunde 3-5 blättrig; Köpfchenstiele oft flockig, aber nicht filzig; Ausläufer oft

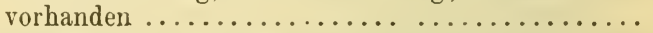

Köpfehen doldenförmig zusammengestellt; Stg. 5bis 12 blättrig; $\mathrm{Bt}$. dunkel goldgelb. B. M. N.

echioides. Lumu. Natterkopfartiges H. unten meist $3-6$ blättrig; Bt. hellgelb. B. M. N. setigerum. Tausch. Borstiges H.

Ausläufer fehlen..................... 16

15 Ausläufer verlängert, ihre oberen B. meist kleiner

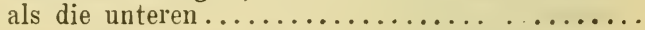

Stgb. mit verbreitertem Grunde sitzend, oft halbumfassend, lang gewimpert, sonst wie der Stg. nahezu kahl; stg. schon tief unten sparrig-veràstelt, sehr reichköpfig. $K r$.

16 Fussianum. Schur. Siebenbürgisches H. Stgb. mit verschmälertem 0 . doch nicht deutlich verbreitertem Grunde sitzend; Stg. erst oben rispigverästelt, kahl o. wenig behaart; Grundb. borstenhaarig. Verbr. u. hfg.

Florentinum. $A l l$. Florenzer $\mathrm{H}$.

Köpfchen 4-16, locker doldenrispig angeordnet, mittelgroß; Hülle schwärzlich, kugelig-eiförmig, zuletzt bauchig; Ausläufer oft blühend; Bt. goldgelb. B. M. Sih.

floribundum. W. $G r$. Reichblütiges $\mathrm{H}$.

Köpfchen meist zahlreich, klein; Hülle grünlich; Ausläufer nicht blïhend; Bt. hellgelb; Stg. höher. Vcrbr. (?) Bauhini. Bess. Ausläufertreibendes H. 
Ausläufer stets vorhanden, aber oft unterirdisch u. nur beschuppt; B. grasgriin, oberseits ohne Sternhaare; Stg. röhrig; Pfl. mehr o. weniger langborstig. Verbr. (fehit J.)

collinum. Gochnat. Hügel-H.

Ausläufer fehlend 0 . sehr kurz; B. gelblichgrün, beiderseits mehr 0. weniger sternhaarig-flockig; Stg. steifer, nicht röhrig; Pfl. meist dicht kurzhaarig

Köpfchen 3-10, mittelgrob, etwas bauchig; Stg. niedrig, meist nur $1 \mathrm{~B}$. tragend, oben reichlich drüsenhaarig; Grundb. lanzettlich o. etwas spatelig. A . $T$. ........ Laggeri. Schltz. Lagger's H.

Köpfchen klein, zahlreich; stg. höher, 1 - 4 blättrig, oben nur spärlich drüsenhaarig; Grundb. verkehrteilänglich o. länglich. Verbr. (fehlt $S$.)

cymosum. $\left.L .{ }^{*}\right)$ Trugdoldiges $H$.

Stg. aufrecht, ziemlich hoch, 8-30köpfig; Köpfchen mehr 0 . weniger deutlich doldig angeordnet; beblätterte Ausläufer fehlen. T. (O.?)

multiflorım. Schl. Vielblütiges H.

Stg. meist am Grunde bogig aufsteigend, 3-12köpfig; beblätterte Ausläufer oft vorhanden ..... 21

B weich, grasgrün 0 . nur etwas bläulich, länglichlanzettlich; Stg. hohl, oft ziemlich hoch; Bt. purpurn, nur ausnahmsweise orange. Geb.

aurantiacum. L. Feuerfarbenes $H$.

B. bläulich-grün, etwas steif, oft spatelförmig, weniger behaart; Stg. niedriger, nicht hohl; Bt. orange 0. purpurn. A. v. T. K. fuscum. Vill. Braunrothes $H$.

Grundb. der nicht blühenden Stämmchen überwinternd und im nächsten Jahre zur / eit des Aufblühens noch frisch, daher stets eine Grundb.Rosette 0 . doch einige Grundb. vorhanden $\left.{ }^{* *}\right)$.... 2:3

Grundb. fehlen giinzlich o. sind schon vor der Btzeit vertrocknet; die Pfl. setzt im Herbste Ḱnospen an, die im iolgenden Jahre einen Stg. o. kleine Bbüschel treiben, die noch vor dem Aufblühen verwelken 61

*) H. Sabinum Seb. et M. ist durch dicht zusammengedrängte Köpfchen u. längere Belıarung, $H$. Nestleri Vill. durch sehr locker angeordnete Köpfchen u. wenig o. dunkel behaarte Köpfchenstiele ausgezeichnet.

${ }^{* *}$ ) Jene Arten, die zur Btzeit meist nur wenige, manchmal schon theilweise vertrocknete Grundb. haben, sind zumeist in die erste Abtheilung aufgenommen; man wird aber in solchen Fällen gut thun, auch die zweite Abtheilung $\mathrm{zu}$ vergleichen. 
13. ohne Drüsenhaare; Blkr. an der Spitze meist $\left.\mathrm{kahl}^{*}\right) \ldots \ldots \ldots \ldots \ldots \ldots \ldots \ldots \ldots \ldots \ldots \ldots \ldots \ldots$

B. mehr o. weniger reichlich drüsenhaarig, selten fast drüsenlos, grün, kaum in's Bläuliche spielend; Trundb. in den Bstiel verschmälert; Blkr. oft an der Spitze behart 0 . gewimpert .............

Hüllb. dachig angenrdnet; B. meist am Grunde verschmälert, oft blaugrün, häufiger schmal als breit, nicht selten ganzrandig

Innere Hüllb. fast gleichlang, äubere dagegen viel kürzer; B. meist breit, oft grob gezähnt...... 37

25) Hülle walzlich, sternflaumig $0 . \mathrm{kahl}$; die ganze Pfl.

25 wenig 0 . gar nicht behaart ...............

Hülle kngelig, langzottig 0 . dnch reichlich behaart 31

Grundb. schmal, lineal o. lanzettlich, ganzrandig $26\left\{\begin{array}{l}\text { (selten entfernt gezähnelt), nicht deutlich gestielt } \\ \text { Grundb. lanzettlich o. länglich-spatelig, nicht selten }\end{array}\right.$ 27 gezälınt, fast immer deutlich gestielt ........ 28

Grundb. lineal-spatelig, zugespitzt; Stg. oft rom Grunde an ästig, locker-rispig; Aeste schlank, abstehend; Köpfchen klein; Hülle meist in den Köpfchenstiel vorgezogen; Fr. strohgelb.

N. O. St. $K r$. J. K. T.

porrifolium. $L$. Jauchblättriges $\mathrm{H}$.

Grundb. lanzettlich; Stg. nur oben mit meist kurzen Aeston; Köpfchen mittelgroß; Hülle gegen den Köpfchenstiel abgesetzt; Fr. dunkelbraun 0. schwärzlich. A. u. Vora. v. N. O. S. T. K. Krr.

bupleuroides. Gmel. Hasenohrblättriges H.

Grundb. lang gestielt, länglich-spatelig, wellig, fein gezähnelt, gegen den Grund zu mit sehr langen, welligen Haaren besetzt; Stgb. nach oben allmälig kleiner werdend. Fr. strohgelb. J. (Veglia?)

stupposum. Rchb. Langhaariges $\mathrm{H}$. Grundb. kurz o. undentlich gestielt, kahl, gewimpert o. stellenweise behaart; Fr. braun 0 . schwarz....

Stg. meist ziemlich niedrig, mit wenigen, nach oben rasch kleiner werdendeu, linealen $B$. besetzt $u$. daher fast nackt erscheinend; Grundb. schmal, meist lanzettlich, oft fast ganzrandig. kahl o. am Grunde gewimpert. Verlor. (fehlt $B$. M. Sch.)

glaucum. All. Blaugrünes $\mathrm{H}$.

Stg. hochwüchsig, meist reichlich beblättert; Grundb. stets gezähnt, gegen den Grund zu stets mehl 0.

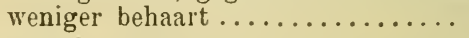

*) Vgl. anch die in der zweiten Gruppe stehenden Arten von Nr. 55-60. 
Stg. oft vom Grunde an ästig; Grundb. lanzettlich, sehr kurz gestielt; Hüllb. spitz o. stumpflich, dunkel. N. O. Sü̈tt. K. Kir. J.

six atile. Jacq. Felsen-H.

Stg. erst oben ästig; Grundb. länglich-lanzettlich, deutlich gestielt; Hüllb. stumpf, grünlich. $K$. $K r . J$. leioceplıalum. Burtl. Kahlköpfiges $H$.

Stg. beblättert, 1- o. mehrköpfig, oft zottig, aber niemals drüsig; Köpfchen groß; Hüllb. breit, die äußeren meist locker gestellt, spitz o. zuge-

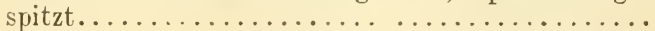

Stg. meist niedrig, blattlos und 1 köpfig, seltener mit

$1-3$ kleinen B. besetzt 0 . 2-3köpfig, oben meist sehr reichlich drüsenhaarig*); Köpfichen mittelgroß; Hüllb. schmal, anliegend, sehr spitz, vou oft graulichen Haaren bärtig-zottig.

A. v. N. O. St. K. S. T.

glanduliferum. Hoppe Drüsentragendes $\mathrm{H}$.

Aeußere Hüllb. blattartig, abstehend, elliptisch, länglich 0 . breit lanzettlich, innere fast lineal; Stgb. beiderseits oder doch unterseits langzottig, mit breitem Grunde sitzend 0 . halbumfassend.

Geb. (B.?) .......... villosum. L. Zottiges H. Aeußere Hüllb. nicht blattartig, lanzettlich o. lineal, nicht oder wenig breiter als die inneren, mehr 0. weniger aufgerichtet $\ldots \ldots \ldots \ldots \ldots \ldots \ldots \ldots$

B. beiderseits 0 . doch unterseits reichlich behaart.. 34

B. kahl o. gegen den Grund zu am Rande und am Mittelnerven gewimpert, blaugrün und steif, lineallanzettlich 0 . lanzettlich. $A$.

glabratum. Hoppe. Kahlblättriges $\mathrm{H}$.

B. beiderseits reichlich behaart, oft langzottig.... 35

34 B. oberseits kahl o. spärlich, unterseits reichlich be-

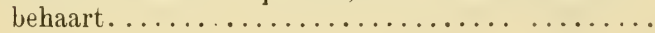

Grundb. spatelig-länglich o. lanzettlich, etwas wellig, fast ganzrandig, langzottig, ihr Stiel nicht deutlich abgesetzt 0 . fehlend; Köpfehen groß und dick, langzottig. $A$.

villosiceps. Näg. et Pet. Zottigköpfiges $\mathrm{H}$.

Grundb. elliptisch o. breit-lanzettlich, meist grob gezähnt, kürzer behaart, ihr Stiel gewöhnlich deutlich abgesetzt; Köpfchen kleiner u. schmäler, weniger zot.tig. $A$.

dentatum. Hoppe. Gezähntblättriges $\mathrm{H}$.

*) H. piliferum Hoppe unterscheidet sich durch langhaarigen, drüsenlosen o. fiast drüsenlosen Stg. 
Grundb. lineal-lanzettlich o. lanzettlich, ganzrandig o. entfernt gezähnelt; Stgb. 4-7. A.

36 scorzonerifolium. Vill. Schwarzwurzblättriges $H$. Grundb. lanzettlich o. elliptisch, mehr o. weniger (oft grob) gezähnt; Stgb. 2-5. A. v. T. K. N. subspeciosum. Näg. Prächtiges $\mathrm{H}$.

Stg. schaftartig, blattlos o. mit $1-3 \mathrm{~B}$. besetzt, von 37 denen nur das unterste ungefähr die Gıöße der

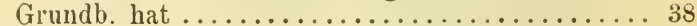

Stg. beblättert .................. 45

(Grundb. in den Bstiel mehr o. weniger rasch ver-

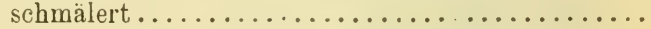
Grundb. am Grunde abgestutzt, herzförmig o. plötzlich in den Btstiel zusammengezogen..........

Grundb. beiderseits reichlich behaart o. zottig ....440

39 Grundb. oberseits wenig behaart 0 . kahl, nur am Rande und am Mittelnerven oft zottig behaart ..

Bstiele u. Grundb. dicht zottig, letztere oft fast ganzrandig; Köpfchen klein u. schmal, zahlreich; Köpfchenstiele $u$. Hüllen flaumig und reichlich drüsig. St.

pleiophyllum. Schur. Siebenbürgisches H.

Bstiele u. Grundb. weichhaarig, letztere meist eingeschnitten - gezähnt; Köpfichen ziemlich grols, wenige; Köptchenstiele u. Hüllen langhaarig und flaumig, meist ohne Drïsen. A. u. Vora.

incisum. Hol,pe. Schlitzblättriges $\mathrm{H}$.

Köpfchenstiele $u$. Hüllen mehr o. weniger reichlich drüsenhaarig, oft außerdem behaart 0 . Haunig-

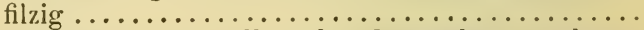

Köpf́chenstiele u. Hüllen ohne Drüsenhaare, seltener wit vereinzelten Drüsenhaaren ..............

Grundb. lanzettlich, lang zugespitzt und gegen den Grund sehr lang verschmälert und daselbst zottig gewimpert, seegrün, buchtig gezähnt; Gr. dunkel gefärbt. $N$. U. St. Kr. J. K. T.

Dollineri. F. Schltz. Oesterreichisches H.

42 Grundb. eilänglich o. elliptisch, stumptlich, ziemlich lasch in den verlängerten Bstiel verschmälert, hellgrasgrün, buchtig-gezähnt, am Grunde steifborstig ; Gr. gelb. Verbr. (fehlt $K r$. J.)

Schmidtii. Tausch. Schmidit's H. 
Grundb. kurz gestielt, meist elliptisch; Hüllen graufilzig und spärlich behaart. Verbr. (?)

caesium. $\mathrm{Fr}$. Blaugrünes $\mathrm{H}$.

43 Grundb. lang gestielt, länglich-lanzettlich; Hüllen schwärzlich, behaart und flaumig-flockig. A. v. N. K. T.

Trachselianum. Christener. Trachsel's H.

Köpfchenstiele u. Hüllen reichlich drüsenhaarig, flockig-filzig und oft außerdem noch behaart; Stg. reichköpfig. Verbr. $u$. hffg.

silvaticum. ( $L$ ) Wald-H.

Köpfchenstiele und Hüllen drüsenlos o. mit vereinzelten Drüsenhaaren, flockig-flaumig und behaart; Stg. armköpfig; Hüllb. lang zugespitzt. Verbr. (?) bifidum. Kit. Gegabeltes H.

B. grasgrün; Stg. reichköpfig; Köpfchen ziemlich klein, ihre Stiele u. Hüllen meist filzig u. reichlich drüsenhaarig. Verbr. vulgatum. $F r$. Gemeines $H$.

B. blaugrün; Köpfchen meist wenige, ziemlich groß, ihre Stiele u. Hüllen nur mit wenigen Drüsen u. Härchen besetzt, sonst kahl...............

Stg. glatt u. kahl; Stgb. am Grunde kaum verschmälert, halb umfassend, die oberen ganzrandig, ganz kahl, die unteren zerstreut behaart.

A. v. T. (Oetzthal).

Grisebachii. Kern. Grisebach's H.

Stg. unten zottig; Stgb gegen den Grund verschmälert, die unteren unterseits rauhhaarig, entfernt gezähnelt. Sch. M. (Gesenke).

Silesiacum. Krause. Schlesisches H.

Pfl. durch dicht-drüsige Behaarung klebrig; Stgb. oft halb umfassend; Hülle dicht drüsenhaarig, ohne

o. nur mit wenigen einlachen Haaren..........

Pfl. nicht klebrig, bald reichlich, bald nur sehr spärlich drüsenhaarig; Hülle meist behaart, oft zottig, aber niemals dicht drüsenhaarig ............

B. nur drüsig behaart, die oberen breit, halb umfassend; Pfl. kräftig, meist reichlich verzweigt; Köpfchen zahlreich, groß. N. U. St. S. K. T.

amplexicaule. $L$. Stengelumfassendes $H$. 48 Wenigstens an den unteren B. ein großer Theil der Haare drüsenlos; Pfl. kleiner, weniger ästig; Stgb. kleiner, kaum umfassend; Köpfchen wenige, mittelgrob. A. v. T. S. $K$.

pulmonarioides. Vill. Lungenkrautartiges $\mathrm{H}$. 
Hiillb. dachig angeordnet; Stgb. oft am Grunde verschmälert 0. kurz gestielt, seltener mit breitem Grunde sitzend 0. halbumfassend........... 50

Innere Hüllb. fast gleichlang, äußere viel kürzer; ohne Stgb. mit breitem Grunde sitzend, oft halb umfassend, sehr selten kurz gestielt......... 54

Blkr. an der Spitze gewimpert............ 51

Blkr. an der Spitze kahl; Stg. niedrig, aufstrebend, 50 beblättert, armköpfig; Grundb. gestielt, am Grunde tief gezähnt 0 . fast fiederspaltig, grasgrün.

N. O. St. Kr. K. S. T.

humile. Jacq. Niedriges $\mathrm{H}$.

Stgb. 1-8, länglich o. lanzettlich, gegen den Grund verschmälert 0 . kurz gestielt, o. ganz fehlend ... Stgb. 4-6, eiförmig, mit breitem Grunde sitzend. oft halb umfassend, niemals fehlend; Stg. 1 köpfig o. mit mehreren 1 köptigen Aesten; Hüllen zottig u. etwas drüsenhaarig. $B$. (Riesengebirge).

perlunculare. Tuusch. Langästiges $\mathrm{H}$.

Köpfchenstiele u. Hüllen reichlich langzottig, dazwischen oft auch kurz drüsenhaarig .......... Köpfchenstiele u. Hüllen reichlich mit längeren.

52 schwarzen Drüsenhaaren besetzt, außerdem wenigel 53 reichlich kurz-zottig; Stgb. 1-2, grob gezähnt. Geb. (verbr.?)

nigrescens. Willd. Schwärzliches $H$.

Pfl. meist niedrig; Stgb. $1-3$ o. fehlend, selten 4 bis $\left.8^{*}\right)$; B. zottig n. drïseuhaarig; Köpfchen mittelgroß; Blkr. am Ende langhaarig. Geb.

53 Pfl. höher, kräftig; Stgb. alpimum. L. Alpen-H. Köpfchen sehr grob, halbkugelig; Blkr. am Ende wenig behaart. Sud. (A.?)

eximium. Backi. Ausgezeichnetes $\mathrm{H}$.

Obere Stgb. mit breitem Grunde sitzend, oft halb

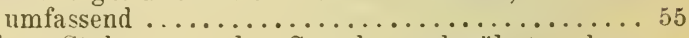

Obere Stgb. gegen den Grund verschmälert o. kurz gestielt, selten etwas $n$ mfassend............ 59

Köpfchen grob; reife Fr. schwärzlich o. dunkelbraun 56 Köpfchen mittelgroß; reife Fr. rothbraun 0 . hell55 braun; Stg. hin- u. hergebogen, fast kahl; Grundb. wenige, eiförmig o. eilänglich, stumpf; Hüllb. schwärzlich, drïsig behaart. Sud.

albinum. $F r$. Elbe-H.

*) Letzteres ist namentlich bei H. Fritzei F. Schltz. (Sud.) der Fall. 
56 ( . grasgrün, länglich-eiförmig o. länglich-lanzettlich 57

$56\{$ B. trübgrün o. dunkelgrün, lanzettlich......... 58

Hüllb. spärlich behaart u. drüsig, schwärzlich, die inneren breit hell berandet. Sud.

pallidifolium. Kuaf. Blassblättriges H.

Hüllb. kurz-zottig u. reichlich drüsig, schwärzlich, die inneren schmal hell berandet. Sud.

nigritum. Techtr. Geschwärztes H.

Köpfchenstiele meist bogig aufsteigend, flaumigfilzig u. zerstreut drüsenhaarig. Sud.

stygium. Lechtr. Täuschendes H.

Köpfchenstiele steif aufrecht, flaumig-filzig u. borstig, aber drüsenlos. Sud. Engleri. Uechtr. Engler's H.

Stg. meist 1 blättrig, seltener $2-3$ blättrig ...... 60 Stg. 3-5̃ blättrig: B. weich, etwas glänzend, buchtig gezähnt; Hüllb. dicht drüsenhaarig. A. v. T.S.K.

Bocconei. Gris. Boccone's H.

B. grob gezähnt, zerstreut zottig; Köpfchen meist 3, ziemlich groß; Köpfehenstiele u. Hüllen schwarzborstig u. drüsig. Sud.; A. v. S. K.

atratum. $F r$. Schwarzes $\mathrm{H}$.

B. fein gezähnelt, spärlich fein behaart; Köpfchen 3-7, kleiner; Köpfchenstiele u. Hüllen grauflaumig, reichlich drüsig. B. (Riesengebirge).

Wimmeri. Uechtr. Wimmer's H.

Wenigstens die mittleren Stgb. mit breitem, oft um-

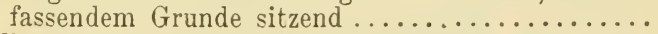

Alle Stgb. gegen den Grund verschmälert, die unteren

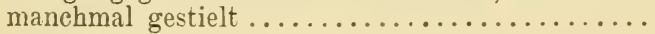

Köptchenstiele mehr o. weniger reichlich (selten spärlich) drüsenhaarig; Blkr. am Ende bewimpert, seltener kahl; Fr. oft hell gefärbt.............

Köpfchenstiele drüsenlos; Blkr. am Ende kahl*); Fr.

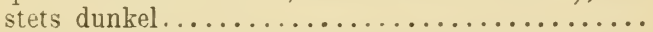

63 B. mehr 0. weniger reichlich drüsenhaarig, selten 63 fast drüsenlos .................... 64 B. olne Drüsenhaare.................. 67

64 Bt. blassgelb; Fr. blassbräunlich o. hellroth; Köpfchenstiele u. Hüllen dicht drüsenhaarig..........65 Bt. goldgelb; Fr. rothbraun 0. schwarzbraun**) ...66

*) Vgl. auch H. riphaeum (Nr. 66), H. valdepilosum und $\mathrm{H}$. inuloides ( $\mathrm{Nr}, 68)$.

**) Vgl. auch H. inuloides unter $\mathrm{Nr} .68$. 
Stg. ziemlich hochwüchsig, doldentraubig-mehrköpfig; B. unterseits netzaderig, die oberen umfassend, oft fast ganzrandig; Fr. blassbräunlich. A. v. T. ....ochroleucum. Schl. Blassgelbes H. Stg. niedrig, $1-5$ köpfig; B. unterseits nicht netzaderig, nur halb umfassend, buchtig-gezähnt; Fr. hellroth. A. จ. T. $K$.

picroides. I'ill. Bitterkrautartiges H.

Hüllb. reichlich drüsenhaarig u. zerstreut kurz-zottig; Stg. doldentraubig-ästig, mit beblätterten Aesten, selten unverzweigt; B. eilänglich 0 . eilanzettlich, gezähnt, am Grunde oft fast geigenförmig.

$B$. (Riesengebirge).

Bohemicum. $F r$. Böhmisches $\mathrm{H}$.
Hüllb. spärlich drïsig u. borstig, die inneren fast kahl; Stg. unverzweigt 0. doldentraubig-3 4 köpfis; B. länglich-lanzettlich 0 . eilanzettlich, klein-gezähnelt. $B$. (Riesengebirge).

riphaeum. Lechtr. Sudeten-H.

Köpfchenstiele u. Hüllen (namentlich erstere) nur spärlich drüsenhaarig . . ................. 68

Köpfchenstiele $u$. Hüllen stets reichlich drüsenhaarig 69

Stg., B. u. Hüllen rauhhaarig o. zottig; Blkr. am Ende meist gewimpert. $A$.

valdepilosum. Vill. Dichthaariges $H$.

Stg. mit Ausnahme des Grundes nahezu kahl; B. höchstens unterseits weichhaarig; Hüllen fast kahl; Blkr. am Ende kahl. Sucl. u. N.

inuloides. Tausch. Alantblättriges H.

Stg. u. B. größtentheils kahl; Köpfchen 2 -viele, locker gestellt; Fr. hellbraun. A. v. N.

orthophyllum. Beck. Aufrechtblättriges $\mathrm{H}$.

Stg. u. B. mehr o. weniger reichlich behaart..... 70

B. dünn, unterseits bläulichgrün u. auffallend netzaderig, am Grunde oft geigenförmig; Fr. gelblich. Geb. prenanthoides. Vill. Hasenlattichartiges $\mathrm{H}$.

B. etwas derb, unterseits hellgrün, undeutlich netzaderig, am Grunde kaum geigenförmig; Fr. braun. A. v. T. .......... strictum. Fr. Steifes H.

Obere Stgb. mit herzförmigem Grunde umfassend.. $\mathrm{Stgb}$. theils gestielt 0 . mit verschmälertem Grunde sitzend, theils mit breitem abgerundetem Grunde

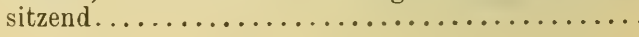


Alle Hüllb. angedrückt; Stg. unten langhaarig, oben kürzer behaart; B. meist rauhhaarig. Verbr.

Sabandum. L. Savoyer H.

Wenigstens die äu@eren Hüllb. zurückgebogen; Stg. steif, weniger behaart; B. kahl o. kurzborstig. $K r$. J.......latifolium. Spr. Breitblättriges H

Hüllen schwärzlich o. dunkelgrün; Köpfchenstiele meist beschuppt, oben verdickt; Köpfchen doldentraubig 0 . risjig angeordnet; obere $B$. lanzettlich, fast sitzend. Verbr. $u$. $h \mathrm{fg}$.

silvestre. Tausch. Herbst-H.

Hülle hellgrasgrün; Köpfchen traubig o. traubigrispig angeordnet; B. gezähnt, die unteren in den Bstiel ver'schmälert, die oberen eiförmig, zugespitzt, halb umfassend. $M$. N. St. K. J.

racemosum. $W . K$. Traubiges $H$.

B., Stg., Köpfchenstiele u. Hüllen dicht-drüsenhaarigklebrig; B. verlängert lanzettlich, ausgeschweift- 0 . buchtig-gezähnt; Stg. 1 köpfig o. ästig mit 1 köpfigen Aesten; Bt. blassgelb. A. v. T. S. K. St.

intybacenm. Wulf. Weißliches $\mathrm{H}$.

B. nicht drüsenhaarig; Stg. starr, blattreich.......

Alle Hüllb. anliegend, die inneren ziemlich spitz; Köpfchen rispig angeordnet; Stgb. nicht sehr

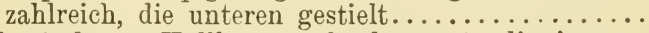

Die äußeren Hüllb. zurückgekrümmt, die inneren stumpf; Köpfehen alle o. doch die oberen doldig angeordnet*); Stgb. zahlreich, sitzend .........

B. meist mit wenigen großen Zähnen, die unteren in den Bstiel verschmälert, die oberen sitzend; Hüllb. schmutziggrün, am Rande blass; Gr. zuletzt bräunlich; Köpfchen meist zahlreich. B. M. Sch. N. O. S. T.

laevigatum. Willd. Glattes $\mathrm{H}$.

Mittlere u. obere B. mit breitem Grunde sitzend; Hüllb. schwärzlichgrün, die inneren heller; Gr. gelb; Köpfchen nicht viele, ebensträußig.

B. II. Sch. K. T. Gothicum. Fr. Gothisches H.

B. länglich-lanzettlich 0 . lineal-lanzettlich, mehr 0 . weniger buchtig gezähnt; Hülle schwärzlich.

Verbr. u. $h f g . . . . . u m b e l l a t u m . ~ L$. Doldiges $\mathrm{H}$.

B. schmal-lineal, ganzrandig o. klein-gezähnt, die oberen viel kleiner; Hülle dunkelgrün; Stg. dünner. Verbr. (?) gramineum. (Gaud.) Grasblättriges H.

*) Bei abgemäht Exemplaren sind die Köpfchen oft traubig angeordnet. 
A nme rk ung. Das Studium der Gattung Hieracium ist einerseits wegen der großen Veränderlichkeit der meisten Arten, andererseits wegen des sehr häufigen Vorkommens von Zwischenformen sehr schwierig. In die Bestimmungstabelle wurden nur die Hauptarten und solche Zwischenformen aufgenommen, welche gewiss keine Bastarte sind und mehr 0 . weniger verbreitet sind 0 . doch an ihren Standorten in Menge vorkommen. Von anderen Zwischenformen, welche zum größten Theile gewiss Bastarte sind, wurden im Gebiete gefunden; H. Hoppeanum $\times$ Pilosella, furcatum $\times$ Pilosella, Auricula $\times$ Pilosella, glaciale $\times$ Pilosella, echioides $\times$ Pilosella, Florentinum $\times$ Pilosella, floribundum $\times$ Pilosella, Banhini $\times$ Pilosella, collinum $\times$ Pilosella, cymosum $\times$ Pilosella,aurantiacum $\times$ Pilosella, furcatum $\times$ Hoppeanum, Auricula $\times$ Hoppeanum, glaciale $\times$ Hoppeanum, Florentinum $\times$ Hoppeanum, Auricula $\times$ furcatum, furcatum $\times$ glaciale, aurantiacum $\times$ furcatum, Auricula $\times$ glaciale, Auricula $\times$ echioides, Auricula $\times$ Florentinum, $\mathrm{Au}-$ ricula $X$ collinum, Auricula $X$ cymosum, aurantiacum $\times$ Auricula, cymosum $X$ glaciale, echioides $X$ Florentinum, Bauhini $>$ echioides, cymosum $\times$ echioides, collinum $\times$ Florentinum, cymosum $\times$ Florentinum, Bauhini $X$ collinum, Bauhini $X$ cymosum, aurantiacum $\times$ Bauhini, aurantiacum $\times$ cymosum; - ferner (z. Th. noch zweifelhaft) H. glancum $X$ porrifolium, porrifolium $\times$ Sabaudum, porrifolium $X$ umbellatum, bupleuroides $X$ glaucum, bupleuroides $X$ prenanthoides, bupleuroides $X$ Sabaudum, Sabaudum $X$ stupposum, glaucum $X$ villosum, glaucum $X$ silvaticum, glanduliferum $X$ villosum, glanduliferum $\times$ silvaticum, alpinum $\times$ glanduliferum, villosiceps $X$ villosum, silvaticum $X$ villosum, villosum $\times$ vulgatum, ochroleucum $X$ villosum, prenanthoides $X$ villosum, valdepilosum $X$ villosiceps, alpinum $X$ scorzonerifolium, caesium $X$ vulgatum, silvaticum $\times$ vulgatum, alpinum $\times$ silvaticum, prenanthoides $X$ silvaticum, pulmonarioides $X$ vulgatum, alpinum $X$ vulgatum, prenanthoides $X$ vulgatum, silvestre $X$ vulgatum, umbellatum $X$ vulgatum, alpinum $X$ prenanthoides, alpinum $X$ intybaceum, orthophyllum $X$ valdepilosum, prenanthoides $\times$ Sabaudum. - Das Vorkommen von Bastarten zwischen drei und selbst noch mehr Arten ist zweifellos; jedoch sind derartige Formen selten und meist kaum mit Sicherheit zu deuten. 


\section{Verzeichniss der gebränchlichsten Synonyme.}

Dieses Verzeichniss enthält die gebräuchlichsten, namentlich die von $\mathrm{Koch}$, Neilreich, Lorinser u. A. verwendeten und durch diese Handbücher eingebürgerten Pflanzennamen, welche in dem vorliegenden Buche aus wissenschaftlichen oder nomenclatorischen Gründen geändert wurden. Autorennamen wurden nur dort beigesetzt, wo dies mit Rïcksicht auf etwaige Verwechslungen oder aus anderen Gründen wünschenswerth erschien. Der erste Name ist der gebräuchliche, aber hier nicht angewendete, der hinter dem Zeichen = stehende der in diesem Buche verwendete. Der Gattungsname ist, wenn er derselbe ist, abgekürzt, sonst stets ausgeschrieben. Arabis brassicaeformis $=\mathrm{A}$. pauciflora bedeutet also: Die von älteren Autoren als Arabis brassicaeformis bezeichnete Pflanze findet sich in dieser Excursionsflora unter dem Namen Arabis pauciflora. Direct falsche Artnamen, welche aber vielfach gebraucht wurden, sind zwischen Anführungszeichen gesetzt. Hedraeanthus "Kitaibelii" $=\mathrm{H}$. Croaticus heist also: Der im Gebiete (Krain) fälschlich angegebene Hedraeanthus Kitaibelii ist nicht diese Art, sondern Hedraeanthus Croaticus. Alle Angaben beziehen sich nur auf das in diesem Buche behandelte Florengebiet; nicht die ganze Ononis "repens" des $K o c h$ ist Ononis foetens, wohl aber die in Oesterreich angegebene.

Abies excelsa $=$ Picea excelsa.

- Larix = Larix decidua.

- pectinata $=$ A. alba.

- Picea Mill. = Picea excelsa. Achillea "lanata $=\mathrm{A}$. Pannonica.

- rodorata $^{*}=\mathrm{A}$. virescens.

Aconitum Lycoctonum $=$ A. Vulparia.

- variegatum $=A$. rostratum.

Actaea spicata $=$ A. nigra.

Adenophora suaveolens $=A$. lilifolia.

Adenostyles albifrons $=\mathrm{A}$. Alliariae.

- alpina $=$ A. glabra. 
Adonis aestivalis $=\mathrm{A}$. phoenicea .

- autumnalis $=\mathrm{A}$. atrorubens.

Agrostis Spica venti = Apera Spica venti.

- stolonifera $=$ A. alba.

Aira caespitosa $=$ Deschampsia caespitosa .

- flexuosa = Deschampsia flexuosa.

Alchemilla glabra $=\mathrm{A}$. alpestris .

- montana $=$ A. hybrida .

- "pubescens" $=$ A. flabellata.

Allium acutangulum $=\mathrm{A}$. angulosum.

- fallax $=A$. senescens.

- montanum $=\mathrm{A}$. senescens.

- pallens = A. Coppoleri u. a. A.

- paniculatum $=\mathrm{A}$. tenuiflorum.

Allosorus crispus = Cryptogramme crispa.

Alsine Jacquini $=$ A. fasciculata.

- sedoides Froel. $=$ A. decandra.

Alyssum incanum $=$ Berteroa incana.

- $\operatorname{minimum}=\mathbf{A}$. desertorum.

- saxatile ${ }^{*}$ ) = A. Arduini.

Amarantus Blitum L. $=$ A. viridis.

-- Blitum Moq. = A. silvester.

- prostratus $=\mathrm{A}$. deflexus.

Amelanchier vulgaris $=\mathrm{A}$. ovalis.

Ampelopsis $=$ Parthenocissus.

Amygdalus communis $=$ Prunus communis.

- nana $=$ Prunus nana.

- Persica $=$ Prunus Persica.

Anchusa arvensis $=$ Lycopsis arvensis.

Andropogon Gryllus = Chrysopogon Gryllus.

Androsace glacialis = Aretia alpina.

- Hausmanni = Aretia Hausmanni.

- Helvetica = Aretia Helvetica.

- imbricata $=$ Aretia imbricata

- Wulfeniana = Aretia Wulfeniana.

Androsaemum officinale $=$ Hypericum Androsaemum.

Anemone pratensis z. Th. = Anemone nigricans.

- stellata $=$ A. hortensis.

Angelica montana $=\mathrm{A}$. elatior.

Anthemis alpina $=$ Achillea oxyloba.

- ${ }$ Cota = A. brachycentros.

- Neilreichii $=$ A. Ruthenica.

Anthriscus alpestris $=A$. nitidus.

- vulgaris $=\mathrm{A}$. Scandix.

- alpina = Achillea oxyloba.

*) Alyssum saxatile L. umfasst A. Orientale Ard. und A. Arduini Fritsch. Letzteres ist das A. saxatile aller neueren Autoren. 
Anthyllis "montana" $=$ A. Jacquini. Aquilegia atrata $=\mathrm{A}$. atroviolacea.

- Bauhini $=$ A. Einseleana.

- Haenkeana $=$ A. nigricans.

Arabis bellidifolia $=$ A. Jacquinii.

- brassicaeformis = A. pauciflora

- petraea $=$ A. hispida.

- Thaliana $=$ Stenophragma Thalianum.

Archangelica officinalis $=\mathrm{A}$. sativa. Arctostaphylos officinalis $=\mathrm{A}$. Uva ursi. Aretia Vitaliana $=$ Douglasia Vitaliana

Armeria vulgaris $=$ A. elongata. Aronia rotundifolia $=$ Amelanchier ovalis Aronicum Clusii $=$ Doronicum Clusii.

- glaciale $=$ Doronicum glaciale

- scorpioides $=$ Doronicum Halleri.

Artemisia "lanata" $=$ A. nitida.

- "maritima" = A. Santonicum.

- monogyna $=$ A. Santonicum.

- Mutellina $=$ A. laxa.

- 11ana $=\mathrm{A}$. borealis.

- spicata $=$ A. Genipi.

- tanacetifolia All. = A. atrata.

Arum Arisarum = Arisarum vulgare.

Asparagus officinalis $=A$. altilis.

Asphodelus Liburnicus = Asphodeline Liburnica.

- luteus = Asphodeline lutea.

- ramosus $=A$. microcarpus.

Aspidium ,aculeatum" $=\mathrm{A}$. lobatum u. a. A.

Filix femina $=$ Athyrium Felix femina.

Asplenium Filix femina = Athyrium Filix femina

- Serpentini $=$ A. cuneifolium.

Asteriscus aquaticus $=$ Odontospermum aquaticum.

Astragalus argenteus $=\mathrm{A}$. Muelleri.

- "Hypoglottis" = A. Danicus.

- "incurvus" $=$ A. Illyricus.

Astrantia "Carniolica“ $=$ A. Bavarica.

- "gracilis" $=$ A. Carniolica.

Athamanta Matthioli $=$ A. rupestris u. a. A.

Atragene alpina $=$ Clematis alpina.

Atriplex laciniatum $=\mathrm{A}$. Tataricum .

— "Tataricum" = A. oblongifolium.

Avena alpestris $=$ Trisetum alpestre.

- alpina $=$ Avenastrum alpinum.

- amethystina $=$ Avenastrum sesquitertium.

- argentea $=$ Trisetum argenteum.

- caespitosa $=$ Deschampsia caespitosa.

- capillaris = Aira capillaris.

- caryophyllea = Aira caryophyllea .

- distichophylla $=$ Trisetum distichophyllum. 
Avena flavescens $=$ Trisetum flavescens.

- hirsuta $=$ A. barbata.

- hybrida $=$ A. vilis .

- planiculmis = Avenastrum planiculme.

- praecox $=$ Aira praecox.

- pratensis = Avenastrum pratense.

- pseudoviolacea Kern. = Avenastrum psendoviolaceum.

- pubescens = Avenastrum pubescens.

- sempervirens $=$ Avenastrum Parlatorii.

- striata = Avenastrum filifolium.

- subspicata $=$ Trisetum spicatum.

- tenuis = Ventenata dubia.

- versicolor = Avenastrum versicolor.

Azalea procumbens = Loiseleuria procumbens.

Ballota rupestris $=$ B. acuta.

Batrachium siehe Ramunculus.

Bellidiastrum Michelii $=$ Aster Bellidiastrum.

Betonica "Alopecurus" = Stachys Jacquini u. Stachys Alopecurus.

- hirsnta $=$ Stachys densiflora.

- officinalis = Stachys officinalis.

- serotina $=$ Stachys serotina.

Betula ${ }_{n}$ alba ${ }^{*}=\mathrm{B}$. verrucosa.

- pubescens $=\mathrm{B}$. alba.

Biasolettia tuberosa = Freyera cynapioides.

Blitum capitatum = Chenopodium capitatum.

- virgatum = Chenopodium foliosum.

Bonjeania hirsuta $=$ Dorycnium hirsutum.

Botrychium matricariaefolium $=\mathrm{B}$. rimosum.

- rutaefolium $=$ B. Matricariae.

Brunella alba $=\mathrm{B}$. laciniata.

Bulliarda aquatica = Crassula aquatica.

Bunium Bulbocastanum = Carum Bulbocastanum.

- montanum $=\mathrm{B}$. divaricatum.

Bupleurum exaltatum $=\mathrm{B}$. gramineum.

- graminifolium $=$ B. petraeum.

Calamagrostis Halleriana $=\mathrm{C}$. villosa.

- litorea $=\mathrm{C}$. pseudophragmites.

- montana $=$ C. varia.

- silvatica $=\mathrm{C}$. arundinacea.

Calamintha Acinos = Satureja Acinos

- alpina $=$ Satureja alpina.

- Clinopodium = Satureja vulgaris.

- grandiflora = Satureja grandiflora

- menthaefolia Host = Satureja menthaefolia.

- officinalis = Satureja Calamintha.

- Nepeta $=$ Satureja Nepeta.

- nepetoides = Satureja nepetoides.

- silvatica $=$ Satureja Calamintha. 
Callitriche vernalis $=\mathrm{C}$. verna.

Camelina foetida $=\mathrm{C}$. dentata.

- sativa = C. glabrata und C. microcarpa.

Campanula Carnica $=\mathrm{C}$. linifolia.

- "Garganica" $=$ C. Istriaca.

Capsella Bursa pastoris = Bursa pastoris.

- pauciflora $=$ Hutchinsia pauciflora.

- procumbens $=$ Hutchinsia procumbens.

- rubella = Bursa rubella.

Cardamine thalictroides z. Th. = C. glauea

Carduus aretioides $=\mathrm{C}$. Carduelis.

Carex acuta $=C$. rufa.

- alpestris $=$ C. Halleriana.

- ampullacea $=$ C. rostrata.

- divulsa $=$ C. virens.

- glauca $=$ C. flacca.

- gynomane $=$ C. Linkii.

- longifolia $=$ C. umbrosa.

- maxima $=\mathrm{C}$. pendula.

- nigra All. = C. parviflora.

- paludosa $=$ C. acutiformis.

- Persoonii $=$ C. brunnescens.

- polyrrhiza $=$ C. umbrosa.

- praecox Jacq. = C. verna.

- Schreberi $=$ C. praecox.

- stellulata $=$ C. echinata.

- tenuis $=$ C. brachystachys.

- Vahlii = C. alpina.

- vulgaris = C. nigra u. a. A.

Carlina Nebrodensis = C. longifolia.

Carım divaricatum $=$ C. ferulaefolium.

Castanea vesea $=$ C. . vulgaris.

Centaurea „amara" z. Th. = C. angustifolia.

- Austriaca $=$ C. Phrygia.

- "Kotschyana" $=$ C. alpestris.

- maculosa $=$ C. Rhenana.

- nervosa $=$ C. plumosa.

- "paniculata" $=$ C. Rhenana.

- "Phrygia" = C. Pseudophrygia (u. C. stenolepis).

- "sordida" z. Th. = C. dichroantha.

- splendens $=$ C. alba.

- Vochinensis $=\mathrm{C}$. nigrescens.

Cephalanthera ensifolia $=\mathrm{C}$. longifolia.

- pallens $=$ C. alba.

Cerastium glomeratum $=\mathrm{C}$. viscosum.

- "grandiflorum" = C. filifolium.

- ovatum $=$ C. Carinthiacum.

- triviale $=$ C. vulgatum.

Ceratocephalus falcatus = Ranunculus falcatus.

- orthoceras = Ranunculus testiculatus. 
Cerinthe aspera $=$ C. major.

Chaerophyllum "hirsutum" $=\mathrm{Ch}$. Cicutaria.

Chaiturus Marrubiastrum $=$ Leonurus Marrubiastrum.

Chamaemelum inodorum = Matricaria inodora.

Cheiranthus Cheiri = Erysimum Cheiri.

Cherleria sedoides $=$ Alsine sedoides.

Chlora = Blackstonia.

Chrysanthemum coronopifolium $=\mathrm{C}$. atratum.

- inodorum = Matricaria inodora.

Cicendia filiformis = Microcala filiformis

- Cimicifuga foetida = Actaea Cimicifuga.

Cineraria siehe Senecio.

Cirsium tuberosum $=$ C. bulbosum.

Cistus "Creticus" $=$ C. incanus u. C. villosus.

Clinopodium vulgare $=$ Satureja vulgaris.

Cochlearia Armoracia $=$ Armoracia rusticana.

- brevicaulis $=$ Kernera alpina.

- saxatilis = Kernera saxatilis.

Comarum palustre $=$ Potentilla palustris

Conioselinum Fischeri $=$ C. Tataricum.

Convallaria latifolia $=$ Polygonatum latifolium .

- multiflora $=$ Polygonatum multiflorum.

- Polygonatum = Polygonatum officinale

- verticillata $=$ Polygonatum verticillatum.

Convolvulus sepium $=$ Calystegia sepium.

- Soldanella = Calystegia Soldanella.

Coronilla montana $=$ C. coronata .

Corydalis fabacea $=\mathrm{C}$. inter'media.

Corynephorus canescens $=$ Weingaertneria canescens.

Cotoneaster vulgaris $=\mathrm{C}$. integerrima.

Crassula Magnolii $=\mathrm{C}$. caespitosa.

Crepis hyoseridifolia $=$ C. Terglouensis.

- rigida $=\mathrm{C}$. Pannonica.

Crocus sativus $=$ C. officinalis.

Crucianella angustifolia $=\mathrm{C}$. latifolia

- molluginoides = Asperula molluginoides.

Crypsis alopecuroides $==$ Heleochloa alopecuroides

- schoenoides $=$ Heleochloa schoenoides.

Cuscuta monogyna $=\mathrm{C}$. lupuliformis.

- "planiflora" $=$ C. alba.

Cyperus Monti $=$ C. serotinus.

Cystopteris regia $=\mathrm{C}$. alpina.

Cytisus alpinus = Laburnum alpinum.

- argenteus = Argyrolobium argenteum.

- holopetalus = Genista holopetala.

- Laburnum = Laburnum vulgare.

- radiatus $=$ Genista radiata.

- sagittalis = Genista sagittalis. spinosus $=$ Calycotome infesta .

- "supinus" $=$ C. Ratisbonensis. 
Dactylis litoralis $=$ Aeluropus litoralis.

Danthonia decumbens $=$ Sieglingia decumbens .

Delphinium fissum $=\mathrm{D}$. hybridum.

Dianthus atrorubens z. Th. $=\left\{\begin{array}{l}\text { D. vaginatus. } \\ \text { D. Pontederae. }\end{array}\right.$

- prolifer $=$ Kohlrauschia prolifera.

- silvester $=\mathrm{D}$. inodorus.

- velutinus $=$ Kohlrauschia velutina.

Digitalis grandiflora $=\mathrm{D}$. ambigua.

Digitaria filiformis $=\mathrm{D}$. linearis.

Digraphis arundinacea $=$ Baldingera arundinacea.

Dipsacus fullonum Mill. $=\mathrm{D}$. sativus.

- silvester Huds. = D. fullonım.

Doronicum cordifolium $=\mathrm{D}$. Columnae.

- "Pardalianches" $=$ D. Matthioli.

Dorycnium pentaphyllum $=\mathrm{D}$. suffruticosum u. D. herbaceum.

Draba ciliata $=$ Arabis Scopoliana.

- frigida $=$ D. dubia.

- Johannis $=$ D. Carinthiaca.

- Wahlenbergii = D. Fladnitzensis u. D. laevigata.

- Zahlbruckneri = D. Hoppeana.

Drosera longifolia $=\mathrm{D}$. Anglica.

Echinospermum deflexum = Lappula deflexa.

- Lappula = Lappula echinata.

Echium "Italicum" = E. altissimum.

- ${ }_{n}$ violaceum $"=\mathrm{E}$. plantagineum.

Elyna spicata $=$ E. Bellardi.

Ephedra monostachya $=\mathrm{E}$. distachya.

Epilobium alpinum $=\mathrm{E}$. anagallidifolium.

- angustifolium = Chamaenerium angustifolium.

- Dodonaei $=$ Chamaenerium palustre.

- Fleischeri = Chamaenerium Fleischeri.

- origanifolium $=\mathrm{E}$. alsinefolium.

- "tetragonum" = E. adnatum u. a. A.

- "trigonum" $=\mathrm{E}$. alpestre.

Epipogium Gmelini = Epipogon aphyllus.

Equisetum ramosum $=\mathrm{E}$. ramosissimum.

- Telmateja = E. maximum.

- umbrosum $=\mathrm{E}$. pratense.

Eragrostis megastachya $=$ E. multiflora.

- poaeoides $=\mathrm{E}$. minor.

Erica "vagans" $=$ E. verticillata.

Erigeron Villarsii $=\mathrm{E}$. Atticus.

Eriophorum alpinum = Trichophorum alpinum.

- angustifolium = E. polystachyum.

Eritrichium nanum $=\mathrm{E}$. Terglouense.

Ervum Cassubicum = Vicia Cassubica.

- Ervilia = Vicia Ervilia.

- gracile $=$ Vicia gracilis. 
Ervum hirsutum $=$ Vicia hirsuta.

- Lens $=$ Lens esculenta.

- Lenticula $=$ Lens Lenticula.

- monanthum $=$ Vicia monantha.

- nigricans $=$ Lens nigricans.

- pisiforme $=$ Vicia pisiformis

- silvaticum $=$ Vicia silvatica .

- tetraspermum = Vicia tetrasperma.

Erysimum Austriacum = Conringia Austriaca.

- Cheiranthus $=\mathrm{E}$. silvestre.

- odoratum $=\mathrm{E}$. Pannonicum.

- orientale $=$ Conringia orientalis.

- strictum $=\mathrm{E}$. hieracifolium.

- virgatum $=$ E. durum.

Erythraea linariaefolia $=$ E. uliginosa.

Euclidium Syriacum $=$ Soria Syriaca .

Eufragia latifolia = Parentucellia latifolia.

Euphorbia „epithymoides" = E. polychroma.

- fragifera = E. epithymoides.

- pilosa $=\mathrm{E}$. villosa u. E. Austriaca.

- Preslii = E. nutans.

- "procera" $=$ E. villosa u. Austriaca.

Euphrasia lutea $=$ Ortbantha lutea.

- Odontites = Odontites rubra u. a. A.

- "officinalis" $=$ E. Rostkoviana u. a. A.

- serotina $=$ Odontites serotina (u. O. Kochii).

Evonymus Europaea $=$ E. vulgaris.

Facchinia lanceolata $=$ Alsine lanceolata

Falcaria latifolia $=$ Prionitis pastinacifolia.

- Rivini $=$ Prionitis Falcaria.

Farsetia clypeata = Fibigia clypeata.

- incana $=$ Berteroa incana.

Ferulago galbanifera $=\mathrm{F}$. nodiflora .

Festuca bromoides $=$ Vulpia bromoides.

- ciliata $=$ Vulpia ciliata.

- drymeia $=\mathrm{F}$. montana.

- Myurus = Vulpia Myurus.

- pilosa Hall. = Poa violacea.

- rigida $=$ Scleropoa rigida .

- Scheuchzeri = F. pulchella.

- "spadicea" $=\mathrm{F}$. aurea.

- uniglumis = Vulpia uniglumis.

Ficaria siehe Ranunculus.

Foeniculum officinale $=\mathrm{F}$. vulgare.

Fritillaria montana $=\mathrm{F}$. tenella.

Fumaria "agraria“ $=\mathrm{F}$. flabellata.

Gagea stenopetala $=\mathrm{G}$. pratensis.

Galasia villosa $=$ Scorzonera villosa. 
Galatella cana $=$ Aster canus.

Galeobdolon luteum = Lamium luteum u. Lamium vulgare.

Galeopsis ochroleuca $=$ G. dubia.

- versicolor $=G$. speciosa.

Galium debile $=\mathrm{G}$. constrictum.

- ${ }_{n}$ Helveticum ${ }^{4}=$ G. Baldense u. a. A.

- "pumilum" $=$ G. Austriacum u. a. A.

- "pusillum" = G. Austriacum u. a. A.

- "saxatile $=$ G. Hercynicum u. a. A.

- silvestre $=$ G. asperum u. a. A.

Gaya simplex $=$ Pachypleurum simplex.

Genista diffusa $=$ Cytisus diffusus.

- procumbens $=$ Cytisus Kitaibelii.

Gentiana „acaulis" $=\mathrm{G}$. vulgaris.

- excisa $=$ G. acaulis.

- "Germanica" $=$ G. Wettsteinii u. a. A.

Geranium aconitifolium $=\mathrm{G}$. rivulare.

Glaucium luteum $=\mathrm{G}$. Havum.

Globularia "vulgaris" = G. Willkommii.

Glyceria aquatica (L.) Presl = Catabrosa aquatica.

- distans $=$ Atropis distans.

- festucaeformis = Atropis festucaeformis.

- spectabilis $=$ G. aquatica.

Gnaphalium Carpaticum = Antennaria Carpatica.

- dioicum = Antennaria dioica.

- Leontopodium = Leontopodium alpinum.

Grammitis Ceterach $=$ Ceterach officinarum.

Halianthus peploides $=$ Alsine peploides.

Halimus portulacoides $=$ Atriplex portulacoides.

Hedraeanthus ${ }_{\text {nKitaibelii }}{ }=\mathrm{H}$. Croaticus.

Helianthemum Fumana $=$ Fumana procumbens.

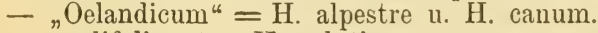

- "polifolium ${ }^{\prime}=\mathrm{H}$. velutinum.

- vulgare $=\mathrm{H}$. obscurmm u. a. A.

Helichrysum angustifolium $=\mathrm{H}$. Italicum.

Helminthia echioides $=$ Picris echioides.

Hepatica triloba $=$ Anemone Hepatica.

Heracleum „asperum" $=$ H. montanum.

Hesperis runcinata $=\mathrm{H}$. silvestris.

Heteropogon Allionii $=\mathrm{H}$. glaber.

Hieracium albidum $=\mathrm{H}$. intybaceum.

- angustifolium $=\mathrm{H}$. glaciale .

- boreale $=\mathrm{H}$. silvestre.

- Jacquini $=$ H. humile.

- murorum $=\mathrm{H}$. silvaticum u. a. A.

- pilosellaeforme $=\mathrm{H}$. Hoppeanum.

- praealtum $=\mathrm{H}$. Florentinum.

- pratense $=H$. collinum .

- sphaerocephalum $=\mathrm{H}$. furcatum. 
Hieracium „stoloniflorum“ z. Th. = H. flagellare.

- tridentatum $=\mathrm{H}$. laevigatum.

Hierochloa borealis $=\mathrm{H}$. odorata .

Honkenya peploides $=$ Alsine peploides.

Hordeum strictum $=\mathrm{H}$. bulbosum.

Hypericum tetrapterum $=\mathrm{H}$. acutum.

Imperata cylindrica $=\mathrm{I}$. arundinac ea.

Inula Conyza $=\mathrm{I}$. vulgaris.

- squarrosa $=$ I. spiraeifolia.

Iris Bohemica $=$ I. aphylla.

- Fieberi = I. aphylla.

- Hungarica $=$ I. aphylla.

Isnardia palustris = Ludwigia palustris.

Juncus conglomeratus $=J$. Leersii.

- Hostii $=$ J. monanthus.

- lampocarpus $=\mathrm{J}$. articulatus.

- supinus $=\mathrm{J}$. bulbosus.

Kentrophyllum lanatum = Carthamus lanatus. Knautia ,collina" $=\mathrm{K}$. Illyrica.

- hybrida $=\mathrm{K}$. integrifolia.

- Moravica $=\mathrm{K}$. Carpatica.

- "Pannonica" $=\mathrm{K}$. drymeia.

- silvatica $=\mathrm{K}$. dipsacifolia u. K. drymeia. Kobresia caricina $=\bar{K}$. bipartita.

Lactuca stricta $=\mathrm{L}$. quercina.

Lagoseris bifida $=$ Pterotheca bifida.

Lappa major $=$ Arctium Lappa.

- minor $=$ Arctium minus.

- nemorosa $=$ Arctium nemorosum.

- officinalis $=$ Arctium Lappa.

- tomentosa $=$ Arctium tomentosum.

Laserpitium hirsutum =: L. Panax.

Lathyrus auriculatus $=\mathrm{L}$. Clymenum.

- ensifolius $=$ L. membranaceus.

- latifolius $=\mathrm{L}$. megalanthus.

- Lens $=$ Lens esculenta.

- Lenticula $=$ Lens Lenticula.

Lavandula vera $=\mathrm{L}$. Spica.

Lemna polyrrhiza $=$ Spirodela polyrrhiza.

Leontodon hastilis $=\mathrm{L}$. Danubialis.

- saxatilis $=\mathrm{L}$. crispus.

Lepigonum inarginatum = Spergularia media .

- marinum = Spergularia marina.

- rubrum = Spergularia campestris.

Lepturus cylindricus $=$ Monerma cylindrica.

Levisticum officinale $=\mathrm{L}$. paludapifolium.

Limodorum abortivum $=$ Centrosis abortiva. 
Linaria cirrhosa $=$ Kickxia cirrhosa

- commutata Bernh. = Kickxia commutata.

- Cymbalaria = Cymbalaria muralis.

- Elatine = Kickxia Elatine.

- lasiopoda = Kickxia lasiopoda.

- litoralis = Chaenorrhinum litorale.

- minor $=$ Chaenorrhinum minus.

- spuria $=$ Kickxia spuria.

Linosyris rulgaris $=$ Aster Linosyris

Lithospermum graminifolium = Moltkia graminifolia.

Litorella juncea $=\mathrm{L}$. uniflora.

Lolium linicola $=\mathrm{L}$. remotum.

Lomatogonium Carinthiaeum $=$ Sweertia Carinthiaca.

Luzula albida $=\mathrm{L}$. angustifolia.

- maxima $=\mathrm{L}$. silvatica.

Lychnis alpina $=$ Viscaria alpina.

- diurna $=$ Melandryum rubrum.

- vespertina $=$ Melandryum album.

- Viscaria $=$ Viscaria viscosa

Lycium barbarum $=$ L. vulgare.

Lysimachia Linum stellatum $=$ Asterolinum stellatum.

- thyrsiflora $=$ Naumburgia thyrsiflora.

Malabaila Hacquetii = Hladnikia Golaka.

Malachium aquaticum $=$ Stellaria aquatica.

Malaxis monophyllos = Microstylis monophylla.

Malcolmia Africana $=$ Wilckia Africana.

Malva borealis $=$ M. pusilla.

- ,rotundifolia" = M. neglecta.

Medicago apiculata $=$ M. hispida.

- circinata $=$ Circinus circinatus.

- denticulata $=$ M. hispida.

- Gerardi $=$ M. rigidula.

- maculata $=$ M. Arabica.

Melampyrum "pratense“ $=$ M. commutatum (u. M. pratense).

Melandryum pratense $=$ I. album.

- silvestre $=$ M. rubrum.

Melilotus coeruleus = Trigonella coerulea.

- gracilis $=$ M. Neapolitanus.

- macrorrhizus $=$ M. altissimus.

Mentha nemorosa $=$ M. Niliaca.

- sativa z. Th. $=$ M. verticillata.

- silvestris $=$ M. longifolia u. M. mollissima.

Micromeria Juliana = Satureja Juliana.

Milium multiflorum $=$ Oryzopsis miliacea.

- paradoxum $=$ Oryzopsis virescens.

Moehringia glauca Leyb. = M. glaucovirens.

- polygonoides $=\mathbf{M}$. ciliata.

- Ponae = M. Bavarica .

Molinia serotina $=$ Diplachne serotina 
Molopospermum cicutarium $=$ M. Peloponnesiacum.

Monotropa Hypopitys = M. multiflora u. M. hypophegea.

Myosotis intermedia $=$ M. arvensis.

Myrtus "communis" $=$ M. Italica.

Najas major $=\mathrm{N}$. marina.

Nasturtium siehe Roripa.

Nasturtium officinale $=$ Cardamine Nasturtium.

Nepeta nuda $=$ N. Pannonica u. N. violacea.

Nigritella angustifolia $=N$. nigra.

Obione portulacoides $=$ Atriplex portulacoides.

Oenanthe Phellandrium $=0$. aquatica.

Onobrychis sativa $=0$. viciaefolia.

Ononis Columnae $=0$. subocculta.

- ${ }_{\text {"repens }}{ }^{*}=0$. foetens.

Onosma "echioides" $=0$. Visianii.

- "stellulatum" $=0$. echioides (u. O. stellulatum).

Ophrys muscifera $=0$. myodes.

Orchis fusca $=0$. purpurea.

- Traunsteineri $=0$. angustifolia.

- variegata $=0$. tridentata.

Origanum Majorana = Majorana hortensis.

Ornithogalum chloranthum $=0$. Boucheamum.

- "Narbonense" $=0$. pyramidale (u. O. Narbonense).

- ${ }_{n}$ Pyrenaicum" $=0$. sphaerocarpum.

- sulfureum $=0$. Pyrenaicum.

Orobanche coerulea $=0$. purpurea.

- cruenta $=0$. gracilis.

- "elatior" $=0$. lutea.

- Epithymum $=0$. alba.

- fragrans $=0$. major.

- Galii $=0$. caryophyllacea .

- platystigma $=0$. reticulata.

- rubens $=0$. lutea.

- Scabiosae $=0$. reticulata .

Orobus albus $=$ Lathyrus Pannonicus.

- Iuteus $=$ Lathyrus occidentalis (u. L. laevigatus).

- niger = Lathyrus niger.

- Pannonicus = Lathyrus Pannonicus.

- tuberosus $=$ Lathyrus montanus.

- variegatus = Lathyrus variegatus.

- vernus = Lathyrus vernus.

Oxytropis "cyanea" $=0$. neglecta.

- "sordida" $=0$. Tiroliensis.

Paederota Ageria $=$ Veronica lutea.

- Bonarota $=$ Veronica Bonarota.

Paliurus aculeatus $=P$. australis. 
Panicum ciliare $=$ Digitaria ciliaris.

- Crus galli = Echinochloa Crus galli.

- glabrum $=$ Digitaria linearis.

- sanguinale = Digitaria sanguinalis.

- undulatifolium = Oplismenus undulatifolius.

Parietaria diffusa $=\mathrm{P}$. ramiflora.

- erecta $=$ P. officinalis.

Paronychia "capitata“ $=$ P. Kapela.

Passerina annua = Thymelaea Passerina.

- hirsuta $=$ Thymelaea hirsuta.

Pedicularis fasciculata $=$ P. gyroflexa.

- Hacquetii $=$ P. Summana.

- Jacquini $=$ P. rostrata.

- Portenschlagii $=$ P. geminata.

- "rostrata“ $=$ P. caespitosa.

- versicolor $=$ P. Oederi.

Persica vulgaris $=$ Prunus Persica.

Petasites officinalis $=\mathrm{P}$. hybridus.

Peucedanum Chabraei $=$ P. Carvifolia

- Ostruthium $=$ Imperatoria Ostruthium.

- verticillare $=$ Tommasinia verticillaris.

Phaca alpina $=$ Astragalus penduliflorus.

- astragalina $=$ Astragalus alpinus.

- australis = Astragalus australis.

- frigida $=$ Astragalus frigidus.

Phalaris arundinacea $=$ Baldingera arundinacea .

Phillyrea "media ${ }^{*}=$ P. latifolia.

Phleum Boehmeri $=$ P. phalaroides.

- tenue $=$ P. bulbosum.

Picnomon Acarna $=$ Cirsium Acarna.

Picridium vulgare $=$ Reichardia picroides.

Pinus Abies L. = Picea excelsa.

- "Laricio" $=$ P. nigra.

- Larix = Larix decidua.

- Mughus $=$ P. montana.

- Picea L. = Abies alba.

- Pumilio $=$ P. montana.

Piptatherum multiflorum $=$ Oryzopsis miliacea

- paradoxum $=$ Oryzopsis virescens.

Pirola umbellata $=$ Chimaphila umbellata.

Pirus communis $=$ P. Piraster u. a. A.

Plantago pilosa $=$ P. Bellardi.

- "recurvata $=$ P. crassifolia.

- "serpentina" $=\mathrm{P}$. carinata.

- Victorialis $=$ P. argentea.

Platanthera chlorantha $=$ P. montana.

Pleurogyne Carinthiaca $=$ Sweertia Carinthiaca

Poa "concinna" $==$ P. Carniolica.

- dura = Sclerochloa dura.

- fertilis $=\mathrm{P}$. palustris. 
Poa loliacea $=$ Catapodium loliaceum.

- Sudetica $=$ P. Chaixii (u. P. hybrida).

Podospermum Jacquinianum = Scorzonera Jacquiniana.

- laciniatum = Scorzonera laciniata.

Polygala alpestris $=$ P. microcarpa.

- Chamaebuxus = Chamaebuxus alpestris.

- depressa $=$ P. serpyllacea.

Polygonum Fagopyrum = Fagopyrum sagittatum.

- Tataricum = Fagopyrum Tataricum.

Polypodium alpestre = Athyrium alpestre.

- calcareum $=$ Phegopteris Robertiana.

- Dryopteris = Phegopteris Dryopteris.

- Phegopteris $=$ Phegopteris polypodioides .

Polystichum siehe Aspidium.

Potamogeton Hornemanni $=$ P. coloratus.

- rufescens $=\mathrm{P}$. alpinus.

Potentilla "cinerea ${ }^{*}=\mathrm{P}$. arenaria .

- Fragariastrum $=$ P. sterilis.

- hirta $=$ P. pedata.

- "inclinata ${ }^{\prime}=\mathrm{P}$. canescens.

- maculata $=\mathrm{P}$. Crantzii.

- "opaca" $=$ P. rubens (u. P. viridis).

- Salisburgensis $=$ P. Crantzii.

- Tormentilla $=$ P. erecta.

- "verna $=$ P. viridis u. a. A.

- ${ }_{n \text { villosa }}$ = P. Crantzii.

Poterium polygamum = Sanguisorba polygama.

- Sanguisorba = Sanguisorba minor.

Primula suaveolens $=$ P. Columnae.

Prunus Chamaecerasus $=\mathrm{P}$. pumila.

Psamma arenaria $=$ Ammophila arenaria.

Psilurus nardoides $=P$. aristatus.

Pteris aquilina $=$ Pteridium aquilinum.

Pterotheca "Nemausensis" $=\mathrm{P}$. bifida.

Ptychotis heterophylla $=$ P. saxifraga.

Pulicaria viscosa = Inula viscosa.

Pulmonaria mollis $=$ P. montana $u$. P. mollissima.

Pyrethrum siehe Chrysanthemum.

Quercus pedunculata $=Q$. Robur.

- pubescens $=Q$. lanuginosa.

Ranunculus anemonoides $=$ Callianthemum anemonoides.

- "parviflorus" $=\mathrm{R}$. Chius u. R. parviflorus.

- Philonotis $=R$. Sardous.

- rutaefolius = Callianthemum rutaefolium.

Rhamnus "alpina" $=$ R. Carniolica.

- infectoria $=\mathrm{R}$. intermedia.

Rhaponticum heleniifolium = Centaurea heleniifolia . 
Rhinanthus Alectorolophus $=$ Alectorolophus hirsutus.

- alpinus" = Alectorolophus lanceolatus u. a. A.

- angustifolius $=$ Alectorolophus angustifolius.

- Crista galli $=$ Alectorolophus minor u. a. A.

- hirsutus = Alectorolophus hirsutus.

- major $=$ Alectorolophus major.

- minor $=$ Alectorolophus minor.

- serotinus $=$ Alectorolophus serotinus.

Rhodiola rosea $=$ Sedum roseum.

Rhododendron Chamaecistus = Rhodothamnus Chamaecistus.

Rhus Cotinus = Cotinus Coggygria.

Roripa rusticana $=$ Armoracia rusticana

Rosa alpina $=R$. pendulina.

- Austriaca $=$ R. Gallica.

- "gentilis" $=\mathrm{R}$. rubella.

- glandulosa ${ }^{*}=\mathrm{R}$. montana.

- pimpinellifolia $=$ R. spinosissima

- rubrifolia $=R$. ferruginea.

- sepium $=R$. agrestis.

- silvestris $=R$. arvensis.

- "systyla" $=\mathrm{R}$. stylosa.

Rubus amoenus $=R$. ulmifolius.

- candicans $=R$. montanus.

- discolor $\mathrm{z}$. Th. $=$ R. macrostemon.

- fruticosus z. Th. $=$ R. plicatus.

- montanus Wirtg. = R. senticosus.

- rusticanus $=\mathrm{R}$. ulmifolius.

- suberectus $=R$. Nessensis.

- vestitus $=R$. leucostachys.

Rumex nemorosus $=R$. sanguineus.

- palustris $=\mathrm{R}$. limosus.

- ,pratensis“ z. Th. $=$ R. biformis.

Sagina saxatilis $=$ S. Linnaei.

- stricta $=$ S. maritima.

Salix amygdalina $=\mathrm{S}$. triandra.

- repens $=$ S. rosmarinifolia.

Salvia silvestris" $=\mathrm{S}$. nemorosa.

Saponaria Vaccaria = Vaccaria parviflora u. V. grandiflora.

Sarothamnus scoparius = Cytisus scoparius.

Satureja pygmaea $=$ S. subspicata.

Saussurea discolor $=\mathrm{S}$. lapathifolia.

Saxifraga controversa $=\mathrm{S}$. adscendens.

- crustata $=\mathrm{S}$. incrustata.

- elatior $=$ S. Hostii.

- muscoides Wulf. = S. moschata.

- sponhemica $=$ S. quinquefida.

- stenopetala $=\mathrm{S}$. aphylla.

Scabiosa suaveolens $=\mathrm{S}$. canescens.

- Succisa = Succisa pratensis.

Fritsch, Excursionsflora. 
Scabiosa "Ucranica" $=\mathrm{S}$. Wulfenii.

Schoberia fruticosa $=$ Suaeda fruticosa.

- maritima $=$ Suaeda maritima.

Schoenus mucronatus $=$ Cyperus capitatus.

Scirpus caespitosus = Trichophorum caespitosum.

- compressus $=$ Blysmus compressus.

- Duvalii $=$ Schoenoplectus carinatus.

- fluitans = Isolepis fluitans.

- Holoschoenus $=$ Holoschoenus vulgaris.

- lacustris = Schoenoplectus lacustris.

- litoralis = Schoenoplectus litoralis.

- Michelianus = Dichostylis Micheliana

- mucronatus $=$ Schoenoplectus mueronatus.

- parvulus $=$ Heleocharis parvula

- pauciflorus $=$ Heleocharis pauciflora .

- Rothii $=$ Schoenoplectus pungens.

- setaceus $=$ Isolepis setacea

- supinus $=$ Schoenoplectus supinus.

- Tabernaemontani = Schoenoplectus Tabernaemontani.

- triqueter = Schoenoplectus triqueter.

Scopolina atropoides = Scopolia Carniolica.

Scrophularia aquatica $=$ S. alata $u$. s. Neesii.

- Ehrharti = S. alata.

Sedum anopetalum $=\mathrm{S}$. ochroleucum.

- repens $=\mathrm{S}$. alpestre.

- sexangulare $=\mathrm{S}$. Boloniense.

- Telephium $=\mathrm{S}$. maximum u. a $\mathrm{A}$.

Selaginella spinulosa $=\mathrm{S}$. selaginoides.

Senebiera Coronopus $=$ Coronopus procumbens .

Senecio cordatus $=\mathrm{S}$. alpinus.

- Fuchsii = S. sarracenicus.

- "Nebrodensis" $=\mathrm{S}$. rupestris.

- "Sarracenicus" $=\mathrm{S}$. fluviatilis.

Serratula heleniifolia $=$ Centaurea heleniifolia.

- heterophylla $=\mathrm{S}$. lycopifolia.

- "Rhaponticum" = Centaurea heleniifolia.

Seseli coloratum $=\mathrm{S}$. annuum.

- Gouani = S. elatum.

Sesleria coerulea $=\mathrm{S}$. varia $\mathrm{u}$. S. coerulea.

- disticha $=$ Oreochloa disticha.

- elongata $=\mathrm{S}$. autumnalis.

- microcephala $=\mathrm{S}$. ovata.

Silaus pratensis $=\mathrm{S}$. selinoides.

Silene alpestris = Heliosperma alpestre.

- Elisabethae $=$ Melandryum Elisabethae.

- eriophylla $=$ Heliosperma eriophorum.

- inflata $=\mathrm{S}$. venosa.

- noctiflora $=$ Melandryum noctiflorum.

- Pumilio = Saponaria Pumilio.

- quadrifida $=$ Heliosperma quadrifidum. 
Silene viscosa - Melandryum viscosum.

Sinapis nigra $=$ Brassica nigra.

Sisymbrium Alliaria $=$ Alliaria officinalis.

- Columnae $=\mathrm{S}$. orientale.

- Pannonicum = S. Sinapistrum.

- Thalianum = Stenophragma Thalianum.

Solanum miniatum $=\mathrm{S}$. alatum.

Sonchus oleraceus $=\mathrm{S}$. laevis.

Sorbus Scandica $=$ S. Suecica.

Soyeria hyoseridifolia $=$ Crepis Terglouensis .

- montana $=$ Crepis montana.

Sparganium natans $=\mathrm{S}$. minimum u. а. A.

- ramosum $=\mathrm{S}$. erectum u. a. A.

Spergularia marginata $=\mathrm{S}$. media .

- rubra $=\mathrm{S}$. campestris.

- salina $=\mathrm{S}$. marina.

Spinacia inermis $=\mathrm{S}$. glabra .

Spiraea Aruncus = Aruncus silvester.

- Filipendula $=$ Filipendula hexapetala.

- Ulmaria = Filipendula Ulmaria.

Spiranthes autumnalis $=$ S. spiralis.

Statice alpina $=$ Armeria alpina.

- elongata $=$ Armeria elongata

- globulariaefolia $=\mathrm{S}$. confusa.

Stellaria cerastoides $=$ Cerastium trigynum.

- glauca $=$ S. palustris.

- viscida $=$ Cerastium anomalum.

Stenactis annua $=$ Erigeron annuus.

- bellidiflora $=$ Erigeron annuus.

Struthiopteris Germanica = Onoclea Struthiopteris.

Succisa australis $=\mathrm{S}$. inflexa.

Tanacetum vulgare = Chrysanthemum vulgare.

Taraxacum palustre $=\mathrm{T}$. paludosum.

Telekia speciosa $=$ Buphthalmum speciosum.

Tetragonolobus siliquosus = Lotus siliquosus.

Thalictrum angustifolium $=\mathrm{Th}$. lucidum.

- collinum $=\mathrm{Th}$. flexuosum.

- Jacquinianum $=\mathrm{Th}$. flexuosum.

- silvaticum $=\mathrm{Th}$. saxatile.

Thesium Linophyllum $=$ T. intermedium (u. T. montanum).

Thlaspi campestre $=$ Lepidium campestre.

Thrincia hirta $=$ Leontodon Leysseri.

- tuberosa $=$ Leontodon tuberosus.

Thymus humifusus $=$ Th. praecox.

- "Serpyllum" = Th. Chamaedrys u. a. A. Thysselinum palustre $=$ Peucedanum palustre.

Tilia grandifolia = T. platyphylla.

- parvifolia $=\mathrm{T}$. cordata.

Tofieldia borealis $=\mathrm{T}$. palustris. 
Torilis Helvetica $=\mathrm{T}$. arvensis.

Tragopogon "floccosus" $=$ T. Tommasinii.

Trichonema Bulbocodium = Romulea Bulbocodium.

I'rifolium agrarium $=\mathrm{T}$. aureum.

- caespitosum $=\mathrm{T}$. Thalii.

- "filiforme ${ }^{u}=\mathrm{T}$. minus.

- micranthum $=\mathrm{T}$. filiforme.

- procumbens $=\mathrm{T}$. campestre.

Trinia vulgaris $=\mathrm{T}$. glauca.

Triodia decumbens $=$ Sieglingia decumbens.

Triticum acutum = Agropyrum acutum.

- biflorum = Agropyrum biflorum .

- caninum $=$ Agropyrum caninum.

- cristatum $=$ Agropyrum cristatum.

- glaucum = Agropyrum glaucum .

- junceum $=$ Agropyrum junceum.

- pungens $=$ Agropyrum pungens.

- repens $=$ Agropyrum repens.

- villosum = Haynaldia villosa

Trixago latifolia $=$ Parentucellia latifolia.

Turritis glabra $=$ Arabis glabra .

Ulmus campestris $=\mathrm{U}$. glabra und $\mathrm{U}$. montana - effusa $=U$. pedunculata.

Umbilicus horizontalis = Cotyledon horizontalis. Urtica radicans $=\mathrm{U}$. Kioviensis.

Valerianella Auricula $=$ V. rimosa.

- Morisonii $==\mathrm{V}$. dentata.

Verbascum floccosum $=\mathrm{V}$. pulverulentum.

- , orientale $^{*}=\mathrm{V}$. Austriacum u. V. Chaixi.

Veronica ,agrestis" $=\mathrm{V}$. polita u. a. A.

- Austriaca z. T'h. $=\mathrm{V}$. multifida.

- Buxbaumii $=$ V. Tournefortii.

- dentata $=$ V. Austriaca.

- "latifolia" $=\mathrm{V}$. Teucrium.

- saxatilis $=\mathrm{V}$. fruticans.

- urticifolia $=\mathrm{V}$. latifolia.

Vesicaria sinuata $=$ Alyssum sinuatum.

Vicia angustifolia $=V$. nigra.

Vincetoxicum officinale = Cynanchum Vincetoxicum.

Viola arenaria $=\mathrm{V}$. rupestris.

- ${ }_{\text {"persicifolia }}{ }=\mathrm{V}$. stagnina u. a. A.

Viscum Oxycedri $=$ Arceuthobium Oxycedri.

Waldsteinia trifolia $=W$. ternata.

Willemetia apargioides $=\mathrm{W}$. stipitata.

Woodsia hyperborea $=\mathrm{IV}$. alpina. 


\section{Register}

der deutschen Pflanzennamen.

\begin{tabular}{|c|c|c|}
\hline Seite & Seite & Seite \\
\hline canthus ... & Arongewächse & Bergminze \\
\hline Acanthusge- & Aronsruthe.....543 & Berle ........ \\
\hline wächse ... & Aronsstab.. & Bertram, deut- \\
\hline Ackerkohl... & Augentrost. & scher .......571 \\
\hline Ackerkresse . & Augentrost, & Berufkraut \\
\hline Ackernüsschen & gelber ... & Beschreikraut \\
\hline Ackerröthe ... & Algenwurz. & Besengras.. \\
\hline Adlerfarn ... & Aurikel .... & Besenheide. \\
\hline Aehrenhafer. . . 54 & Azarole ..... & Besenstrauch \\
\hline Aehrensch wingel 68 & & Bibernell.... \\
\hline Affodill .......107 & & Bilsenkraut. \\
\hline Agare ..... & Backenklee & Bingelkraut \\
\hline Ahorn .........368 & Barbarakraut & Birke........ \\
\hline Ahorngewächse .367 & Bärenfuß..... & Birkengewächs \\
\hline Akelei .. . . . & Bärenklau. & Birkwurz.... \\
\hline Alant......... & Bärenkraut. & Birnbaum \\
\hline Allermannshar- & Bärentraube & Birtze ..... \\
\hline nich & Bärlapp.... & Bisamkraut.... \\
\hline Alpendost .... & Bärlappe. & Bisamkrautge- \\
\hline englöckchen & Bärwurz . & \\
\hline Alpengras ..... & Baldrian & Bitterblatt . \\
\hline Alpenhelm ... & & Bitterkraut. \\
\hline nquendel & wächse .... & Bitterlattich \\
\hline enrachen. & Bandgras ..... & Bitterling ... \\
\hline 219 & Bartgras . . & Blasendolde . \\
\hline & Bauernsenf. & Blasenfarn . \\
\hline Alpenscharte . & Baumhasel . & Blasenschötchen.254 \\
\hline 173 & Becherglocke & Blasenstrauch....332 \\
\hline & & .220 \\
\hline .469 & Beilwicke & Blaustern .. \\
\hline ggstheilwurz ..418 & Beinwurz .... & Bleiwurz... \\
\hline gstwurz ... & Benediktenkraut 599 & Bleiwurzge- \\
\hline 41 & Bergfenchel ... & wächse... \\
\hline & Bergffachs.. & Blumensimse \\
\hline cosenbaum . 306 & Berghähnlein & Blutheil..... \\
\hline Aremonie ......298 & Bergkümmel....422 & Blutströpfchen ..226 \\
\hline
\end{tabular}


Seite

Blutwurz...... . 292

Bocksbart . . . . .604

Bocksdorn.....485

Bohne ........347

Boretsch ......456

Boretschge-

Borstendolde ...4408

Borstengras ... 45

Borstenhirse... . 45

Borstenschwanz . 72

Brachsenkraut.. 17

Brachsenkräuter 17

Brandkraut.....470

Brandlattich....578

Braunwurz .....494

Braunwurzge-

wächse......487

Breitschötchen ..254

Brenndolde....445

Brennessel .....168

Brennkraut.....219

Brillenschötchen 237

Brombeere ....278

Bruchkraut....208

Brunelle .....470

Brunnenkresse . .245

Buche .........164

Buchenfarn

Buchengewächse 163

Buchsbaum.....365

Buchsbaumge-

wächse......365

Buchweizen ....177

Büchsenkraut...495

Burgunderrübe .179

Burzeldorn .....354

Burzelkohl .....186

Burzelkohlge-

wächse.....186

Bürstengras .... 48

Calepine .....241

Christophskraut.215

Christusauge ...567

Cichorie......600

Cistrose......378

Cistrosenge-

wächse.....378
Seite

Cypergras ..... 78

Cypresse ...... 21

Cypressenkraut .569

Elfengras

Seite

277

Endivie.......600

Engelsüß...... 5

Enzian........ 443

Dickblatt ....2 263 Enziangewächse.441

Dickblattge- Epheu ........394 wächse......25̌7 Epheugewächse .394 Dill .........420 Erbse .........346

Dingel ........133 Erdbeerbaum ...428

Distel .......588 Erdbeere .......291

Doldengewächse.395 Erdbeerspinat...181

Donardistel....404 Erdbirne......569

Doppelblattge-

wächse ......354

Doppelgriffel ... 80

Doppelrauke... . 241

Dorngras ..... 46

Dornklee......316

Dost .......479

Dotterblume ...212

Drachenkopf ...470

Drachenmaul ...476

Drachenwurz . . 97

Drehähre .....133

Drehling......134

Dreizack ...... 31

Dreizackge-

wächse ..... 30

Dreizahn...... 56

Dukatenröschen.614

Dürrwurz .....566

Eberesche .....276

Eberwurz ......585

Echsenfuß.....506

Edelraute .....576

Edelweiß......564

Ehrenpreis ....445

Eibe.........2 21

Eibisch ........373

Eiche.........164

Eichenfarn .... 8

Einbeere ......117

Eisenhut .....216

Eisenkraut ....463

Eisenkrautge-

wächse ....462
Erdbrod........438

Erdknollen .....411

Erdkrönchen . . . .531

Erdmandel .... 79

Erdrauch.......230

Erdzwiebel ....t49

Erle ..........163

Esche........440

Eselsdistel.....594

Eselskerbel .... 406

Esparsette.....337

Essigbaum ....366

Fackeldistelge-

wächse......385

Fadenkraut.....56t

Fadennarbe ...121

Fahnenhafer ... 52

Faltenlilie ....113

Falzblume ....563

Färberkamille . .569

Farnkräuter .... 2

Faserschirm ....412

Faulbaum.....371

Federkopf ..... . 539

Feigenbaum ....167

Feigendistel . ...385

Feigwurz .....222

Feldkamille ...5570

Feldsalat .....533

Felsenbeere ...2.278

Felsenbirne. . . .277

Felsennelke ...196

Fenchel .......414

Ferkelkraut ...6601 
Seite

Fetthenne.....258

Fettkraut .....5 511

Feuerröschen ...226

Fibigie .......254

Fichte ....... 20

Fichtenspargel . .426

Fieberklee ....448

Filzkraut......563

Fingergras .... 44

Fingerhut .....501

Fingerkraut ....291

Flachsseide....451

Flaschenkürbis. .542

Flattergras .... . 46

Flieder........440

Flockenblume...594

Flohkraut .....567

Fluhblume ....475

Flügellattich . .6606

Flughafer ..... 52

Föhre ........20

Fransenbinse ...88 83

Frauenfarn ..... 6

Frauenmantel ..297

Frauenschuh...126

Frauenspiegel ...547

Friggagras .....132

Froschbiss..... 33

Froschbissge-

wächse...... 32

Froschlöffel.... . 31

Froschlöffelge-

wächse...... 31

Fuchsschwanz 48,184

Fuchsschwanzge-

wächse......184

Fuchsschwingel . 68

Futterhafer.... 52

Gamander.....4467

Gängelkraut ....569

Gänseblümchen . 561

Gänsedistel....608

Gänsefu@ ......179

Gänsefulige-

wächse......178

Gänsekresse ... 249

Gartenaster ....56?
Seite

Seite

Gauchheil .....4438

Gauklerblume...495

Geißbart . ...275

Geibblatt......531

Geißblattge-

wächse... . . .530

Geißfub .....4410

Geißklee ......316

Geibraute ......332

Gelbdolde .....4409

Gelbling . . . . 296

Gelbstern .....108

Gemsenheide ...427

Gemskresse. . . .246

Gemswurz . . . . .579

Gemüsekohl . . . 242

Germer ........107

Gerste ....... 75

Gespenst ......409

Gewitterblume ..118

Giftbeere......485

Giftheil ......216

Giftlattich ....609

Gilbraute ......355

Ginstel .......314

Glanzbinse .... 80

Glanzgras ......45

Glaskrant ..... 168

Glasschmalz . . . 183

Glatthafer..... 5t

Gleisse ........417

Gliedermelde ...183

Gliedkraut .... .469

Glimmerstein-

brech ......271

Glockenblume . . 543

Glockenblumen-

gewächse... . 542

Gnadenkraut....495

Gnetaceen ..... 22

Goldauge.......567

Goldbart ..... 44

Golddistel . . . . . 5999

Goldhafer ..... 51

Goldkolbe ......584

Goldlack ......251

Goldnessel.....472

Goldregen ......316

Goldruthe .....561
Goldschopf . . . . 56 561

Grabenbinse .... 81

Granatapfelbaum 389

Granatapfelge-

wächse......388

Gräser, echte... 33

Graslilie ......107

Grasnelke .....449

Grasschwertel. . . 122

Grauklesse . . . 2254

Graumändl . . . . 226

Grimmkraut ....581

Grimwurz . . . . .230

Grindkraut . . .539

Grundheil.....496

Gummiwur' . . . 420

Gundelrebe.....469

Günsel.......467

Gurke .......542

Guter Heinrich . 180

Gypskraut..... 195

Haarbinse .... . 79

Haardolde. . . . .4410

Haarfarn..... 5

Haargras..... 76

Haarstrang . . . . 44 49

Habichtskraut . .614

Hafer ........ . 52

Haftdolde . ....407

Hahnenfub . . . .220

Hahnenfußge-

wächse.....2210

Haideröschen . . . 380

Hainbuche ....162

Hainsimse. . . . . 102

Hanf .........167

Hanfnessel ....470

Harnstrauch . . . 170

Hartheuge-

wächse .....375

Hartgras ..... 59

Hartriegel.....424

Hartriegelge-

wächse......424

Haselstrauch ...162

Haselwurz..... 172
Grannenhirse ... 46 
Hasenlattich. . . .613

Hasenohr . . . . .412

Hauhechel ....317

Hauswurz . . . . . 260

Haynaldie.... . 73

Heckenkirsche . .531

Hederich .......251

Heidegewächse . . 426

Heidekraut . . . . .428

Heidelbeere. . . . 4428

Heidenfackel. . . .490

Heilglöckchen. . .436

Heiligenkraut. . . 569

Heilknecke . . . . 404

Heilwurz . . . . . .416

Heinrich, guter .180

Helmkraut ....448

Herminie. . . . . . 131

Herzklee . . . . . .331

Herzkraut . . . . .476

Heusenkraut. . .390

Hexenkraut. . . . . 393

Himbeere . . . . 278

Himmelsherold .456

Hirschhaar .... . 71

Hirschsprung . . . 208

Hirschwurz . . . 420

Hirschzunge .... 6

Hirse . . . . . . . 44

Hirtentäschel . . 247

Hochmuth. . . . 198

Höckerlattich . . .600

Hohldotter . . . . 241

Hohlsame ....408

Hohlwurz ... . .230

Hohlzunge .....131

Hollunder . . . . . .530

Holzapfel ....276

Holzbirne ....276

Honiggras . . . . . 50

Hopfen .......167

Hopfenbuche ...162

Hopfenklee . . . . .319

Hopfenseide . . .451

Hornblatt . . . . 2210

Hornblattge-

wächse......209

Hornklee........318

Hornköpfehen ..223
Hornkraut. . . . . 200

Hornmelde . . . . 18:3

Hornmohn ....229

Hühnerdarm....199

Hufeisenklee. . . . 337

Huflattich. . . . .577

Hülsenfrüchtler . 307

Hundsgift . . . . 449

Hundsgiftge-

wächse......448

Hundskamille. . .569

Hundskohl ..... 185

Hundskohlge-

wächse......185

Hundslattich ...603

Hundspetersilie .417

Hundsrante. . . . 495

Hundswürger . . .450

Hundswurz . . . . 131

Hundszahn .... 54

Hundszunge . . . 455

Hungerblümchen'247

Hypocist ......172

Jägerkraut . . . .213

Jacobskraut ....583

Jasmin........41

Ibisch ........375

Igelgras....... 54

Igelkolben..... 26

Igelkolbenge-

wächse... .. 26

Igelsame ..... . . .456

Immenblatt ...470

Johannisbeere. . .271

Johannisbrot-

baum ........314

Johanniskiaut . . 375

Judasbalım . . . . 313

Judendorrı. . . . . 370

Judenkirsche ...485

Jungfer im

Grünen .....2214

Junkerlilie ....108

Kälberkrojıf . . ..405

Kialkfarn..
Kalmus ....... 97

Kamille.......573

Kammgras .... 59

Kampherkraut ..183

Kappernge-

wächse ....25 25

Kappernstrauch . 256

Karde ........537

Kardengewächse 536

Karfiol ......242

Karlsscepter ...508

Kartoffel ......486

Kastanienbaum .164

Käsepappel ....374

Katzenminze ...469

Katzenpfötchen . 564

Katzenschwanz .473

Kelchgras .... 54

Kerbelkiraut ....406

Kerbelrübe ... .406

Kermesbeere....185

Kermesgewächse 185

Kerndolde..... 409

Keulengras .... 51

Kichererbse ....338

Kienporst .....427

Kirschbaum . . . .307

Klappertopt . . . .507

Klee..........322

Kleeseide .... . 452

Kleingriffel.....134

Kleinling. . . . . 448

Klette ........586

Klettendolde...4407

Klettengras. . . . 44

Klippenziest . . . .468

Knabenkraut....127

Knabenkiautge-

wächse .....123

Knackbusch ...2275

Knäuel.......208

Knäuelgras . . . . 58

Knoblauch ....112

Knollendolde . .407

Knollenlilie... . .121

Knopfyras..... 83

Knopfnelke. . .196

Knorpelblume ..208

Knorpelkraut . 179 
Knorpellattich . .606

Knorpelmöhre . .410

Knotenblume ...118

Knotendolde....405

Knotenfuß......117

Knöterich ..... 176

Knöterichge-

wächse.... 172

Kohl.

242

Kohldistel.

591

Kohlröschen ....131

Kohlrübe......242

Kollomie ......453

Königskerze ...4490

Kopfsalat . . . . . 609

Kopfstendel ....132

Korallenwurz . . . 134

Korbblütler..... .550

Koriander . . . .4409

Kornblume . . . . .598

Kornelkirsche...424

Kornrade. . . . . . 190

Krähenfuß ... 237

Kragenblume . ..567

Krapp ...... 530

Krappgewächse .522

Kratzdistel . . . 5 590

Kren .........244

Kresse ... . ...236

Kreuzblatt ....5.523

Kr reuzblütler. . . .231

Kreuzblume ...356

Kreuzblumenge-

wächse.....355

Kreuzdorn . . . . . 370

Kreuzdornge-

wächse . . . . 369

Kreuzkraut. . . 580

Kreuzkraut,

falsches .... 579

Kriechenbaum . . 306

Kronenkraut....195

Kronlattich. . ..6606

Kronwicke ...336

Krugglocke ...550

Krummstab . . . 998

Küchenschelle ..218

Kugelblume ... 518
Kugelblumenge-

wächse ....517

Kugeldistel . ...585

Kugelschötchen .239

Kuhblume.... 606

Kuhkraut . ...196

Kühtritt ....5500

Kümmel ..... 411

Kürbis.......542

Kürbisgewächse . 541

Labkraut . . . . .525

Laichkraut ..... 27

Laichkrautge-

wächse ....

Lamarckie..... 59

Iambertveilchen 255

Lämmersalat. . .600

Lappenblume . . .254

Lärche... . . . 20 20

Lattich . . . .6608

Läusekraut . . . . 508

Lauch ........109

Lauchkraut. . . . 2 40

Lavendel . .....4468

Leberbalsam .... 501

Leberblümchen . 218

Leckermaul. . . 414

Legföhre ..... 20

Leimkraut .....191

Lein ...... 352

Leindotter ... . .247

Leingewächse . 351

Leinkraut . . . .492

Lerchensporn ...229

Lichtnelke .....193

Liebesgras .... 56

Liebstöckel .... 418

Lieschgras .... 47

Lilie ........112

Liliengewächse. 104

Linde.... . . . 372

Lindengewächse.372

Linse . . . .343

Lippenblütler . . . 463

Löffelkraut . . . . 239

Lolch

71

Lolchschwingel . 68
Lorbeerbaum . . 228

Lorbeergewächse 227

Lotwurz . . . . .461

Löwenmaul. . . 493

Löwenschwanz . 473

Löwenzahn . . . . 601

Lungenblume . . .444

Lungenkraut . 457

Luzernerklee . . 319

Mädesïß ......297

Maiglöckchen ...11?

Majoran .... 478

Mais .... . 43

Malvengewächse 372

Mandelbaum... . 306

Mänderle......4.97

Mangold ......179

Mannsharnisch . 436

Mannsschild ... . 4.35

Mariendistel ....593

Mariengras . ... 46

Marienröschen ...194

Marsilie....... 13

Mastixbauın . ..365

Mastkraut ....202

Mauerpfeffer. . . . 260

Mauerraute....208

Maulbeerbaum . . 167

Maulbeerge-

wächse .....166

Mäusedorn . . . 116

Mäuseschwanz . 220

Mausöhrchen ...615

Meerfaden...... 29

Meerfenchel ...44t4

Meerkohl. . . . . .243

Meersenf . . . . 24 241

Meerstrandsbinse 81

Meerträubchen 22

Meerviole ..... 254

Mehlbeerbaum . 277

Meisterwurz ....419

Melde .........181

Melone .......542

Merk .........409

Miere.........203

Milchkraut....438 
Seite

Milchlattich .. .607

Milchstern .....114

Milzfarn ...... 7

Milzkraut .....271

Minze ......481

Mispel.......278

Mistel .......169

Mistelgewächse . 169

Möhre.......424

Mohn........229

Mohngewächse..228

Mohrenhirse... 4 43

Molinie ....... 56

Moltebeere ....278

Moltkie.......460

Mondraute .... 11

Mondviole... . . .246

Moorföhre..... 20 20

Moosbeere.....428

Moosfarn ..... 17

Moosfarne..... 17

Moosmiere . ..2206

Moosprimel ....43t

Moschuskraut...495

Mülle........ . 463

Muschelblüm-

chen.......215

Mutterkraut...575

Mutterwurz ....418

Myrte ........389

Myrtengewächse 389

Myrtenkraut....358

Nabelkraut.....263

Nabelmiere....206

Nabelnuss......455

Nachtkerze .....392

Nachtkerzenge-

wächse......389

Nachschatten ...485

Nachtschattenge-

wächse......483

Nachtviole . . . .255

Nacktfarn..... 5 5

Nacktriet ...... 83

Nadelhölzer ... . 19

Nadelkerbel ...4407

Nagelblatt ....4414
Seite

Seite

Nagelkraut....208

Najade....... 30

Najadenge-

wächse...... 30

Nareisse ......118

Nareissenge-

wächse......117

Natternknob-

lauch ..... .112

Natterkopf . . . 46.

Nattermilch . . .605

Natterwurz. . . .176

Natterzunge.... 11

Natterzungen ... 11

Nelke... ..... 196

Nelkengewächse 186

Nelkenhafer ... . 51

Nelkenwurz . . . 296

Neptunsgras ... . 30

Nesselgewächse . 168

Nestwurz . . . . 134

Nießwurz . . . . . 213

Nissengras .... 49

Nixenblume ... . 209

Nussbaum.....15t

Ochsenauge . . .568

Ochsenzunge ...457

Odermennig ...2298

Oelbaum ......440

Oelbaumge-

wächse......4 439

Oelweide.......387

Oelweidenge-

wächse......387

Oleander .......449

Orant........4494

Osterblume ... .218

Osterluzei ..... 172

Osterluzeige-

wächse......171

Otterwurz.....176

Papiermaulbeerbaum.......167

Pappel........155
Pappelrose .... 374

Paradiesapfel . . .486

Pastinak ....4420

Pechnelke ....190

Pelzfarn ...... 5

Perlgras ...... 57

Perückenbaum ..366

Pestwurz .....578

Petersilie .....412

Pfahlrohr..... 55

Pfefferkraut ....477

Pfeifenstrauch . .271

Pfeilkraut ..... 31

Pfennigklee ....330

Pferde-Dill. . . . .416

Pfingstrose ....212

Pfirsichbaum ...307

Pflaume ......306

Pfriemen ......314

Pfriemengras ... 46

Pfriemen-

schwanz .... 72

Pillenfarn..... 13

Pimpernuss . ...367

Pimpernuss-

gewächse . . . .367

Pippau ......6610

Pistazie.......365

Pistazien-

gewächse ....365

Platane.......271

Platterbse......343

Porre .........110

Porst.........427

Porstbirtze....378

Preiselbeere . . .428

Primelgewächse . 429

Pungen.......437

Punktfarn .... 7

Quecke ......7 72

Quellgras .....5 57

Quellkraut ....186

Quellriet.......81

Quendel ......479

Quendelseide ...452

Quitte.......275 
Seite

Rafflesien-

gewächse ...172

Ragwurz ......126

Rainfarn ......575

Rainkohl.....600

Rainweide.....444

Rapsdotter ....243

Rapunzel .....5 48

Rauhgras ..... 46

Rauhhafer .... 52

Pauke ........240

Rauschbeere...364

Rauschbeer-

gewächse ....364

Raute ........355

Rautengewächse 354

Rebendolde....447

Rebengewächse .371

Rebenrohr .... 55

Reiherschnabel .350

Reineclaude ...306

Reisquecke.....45

Reitgras ...... 49

Rempe.......242

Repskohl......242

Rettig .......242

Riedgräser .....76

Riemenmistel...169

Riemenzunge ...131

Ringelblume....585

Rippendolde...4409

Rippenfaru .... 5 5

Rispenfarn .... 11

Rispenfarne .... 10

Rispengras .... 5. 59

Rittersporn....215

Pobinie.......332

Roggen .......73

Rohrkolben..... 25

Rohrkolbenge-

wächse. .

25

Röhrchenkraut..600

Rollfarn ..... 5

Rose .. ......299

Rosengewächse. . 272

Posenwurz . . . . 258

Posmarin .....468

Rossfenchel ...417

Rosskastanie ...369
Seite

Rosskastaniengewächse ....368

Rosskümmel. ..422

Rübe, gelbe ...424

Rübe, rothe ...179

Rübe, weiße ...242

Rübenkohl . . . . 242

Ruchgras . . . 46

Rudbeckie... . .568

Ruhrkraut .... 564

Pizhrwurz . . ...567

Ruke ........241

Runkelrübe.....179

Punzelnüsschen 457

Sadebaum ..... 21

Saflor.........599

Safran ........ 120

Salbei .......47j

Salvinie...... 13

Salzkraut ....184

Salzmelde ......183

Salzmiere ....207

Salzschwaden ... 62

Sammtpappel ...373

Sammtgras .... 50

Sanddorn .... . 387

Sandelgewächse .170

Sandglöckchen . .550

Sandkraut. . . 205

Sandnelke . . .4439

Sandrohr ..... 50

Saubohne . . . 340

Sauerdorn ... . .227

Sauerdornge-

wächse. .

227

Sauerklee .... 351

Saurkleege-

wächse .... 351

Säuerling .... 176

Schachblume . . 113

Schachtelhalm . . 14

Schachtelhalme . 13

Schafgarbe ....575

Schaftdolde.... 401

Schalotte..... 109

Scharfkraut ...456

Scharte.......594
Seite

Schattenblume..116

Schaumkraut ...244

Scheibenkraut . 240

Scheidengras ... 48

Schierling .....409

Schierlingssilge . 415

Schildfarn..... 8

Schildkraut. ... . 254

Schilfrohr..... 55

Schillergras .... 56

Schlangenwurz .604

Schlehdorn .. . 306

Schlüpfsame... . 594

Schlüsselblume .431

Schlüsselspeik . .434

Schmalbirne... .276

Schmeerwurz . ..119

Schmiele .... 51

Schmielenhafer . 52

Schnabelbinse .. 83

Schnabel-

schötchen ...254

Schneckenklee ..318

Schneeball.....531

Schneebeere ...552

Schneebirne ... 276

Schneeglöckchen 118

Schneerose ...2 213

Schneide ..... . 83

Schnittlauch. . 110

Schöllkraut. . . .228

Scho@wurz ....113

Schopfgras .... 44

Schotenklee.....330

Schuppenkopf...537

Schuppenriet ... 83

Schuppen-

schwanz... . 72

Schuppenwurz . .517

Schuttkraut ... 529

Schwalbenwurz . 450

Schwarzföhre ... 20

Schwarzkümmel .214

Schwarzwurz . . 605

Schwefelsame. . 601

Schweinssalat. . 600

Schwertelge-

wächse ... . 119

Schwertlilie.. . 121 
Seite

Schwertwurz . .130

Schwimmfarne. . 12

Schwingel .

62

Scorpionswicke. . 336

Seegras ....... 30

Seerose

Seerosenge-

wächse . . . . . 209

Segge ....... 84

Seidelbast . . . . 386

Seidelbastge-

wächse......385

Seidenpflanze ...450

Seidenpflanzen . .449

Seifenkraut . . . 199

Sellerie ......44 412

Senf....... 241

Senf, schwarzer 242

Serradella . . . 3:36

Sicheldolde. ...410

Sichelsalat ...6600

Siebenstern ...4437

Siegmarsw ur' $\quad .123$

Siegwurz . . . . . 123

Silbergras ..... 43

Silberhafer .... 51

Silberklee ......314

Silberscharte .. 587

Silberwurz ....297

Silge......4418

Simse ........ 99

Simsengewächse 99

Singrün ....4449

Sockenblume ...227

Sommerwurz ... .513

Sommerwurzge-

wächse..... 512

Sounenblume . . .569

Sonnenröschen . . 379

Sonnenthau ...257

Sonnenthauge-

wächse ....257

Spargel .......116

Spark....... 207

Spechtwurz.... . 355

Speierling. . . . .276

Speik........535

Speik, weißer . 571

Spelz ....... sperrdistel ...

Sperrkraut

Sperrkrautge-

wächse

Spierstrauch.

Spinat

Spindelbaum

Spindelbaumgewächse

Spitzkiel

Spitzklette.

Seite

Seite

Spitzwegerich 521

Spornblume ...556

Spreublume . . . 585

Springkrant

Springkrautge-

wächse

369

Springwurz . . . 361

Spritzgurke . . 541

Spurre.......202

Stachelbeere . . 271

Stacheldolde ...405

Stachelgras..... 44

Starrgras ... . 6 68

Stechapfel. ....486

Stechdorn ... . 370

Stechpalme ...366

Stechpalmenge-

wächse

Stechwinde

Stechwinde ....117

Steckrübe ...242

Steifhalm .. . 56

Steinbrech .... 265

Steinbrechge-

wächse.

264

Steinklee ... 321

Steinkraut . ..252

Steinlinde ... . 4440

Steinmispel ...275

Steinquendel ...477

Steinröslein . . . 3866

Steinsame ....460

Steinschmückel 238

Steintäschel . . . 238

Steinweichsel . . .307

Stendelwurz ... 132

Sternauge .....568

Stern blume. . . . 561

Sterudistel .... . 595
Sterndolde ....404

Sternlein......4437

Sternlieb . . . . . .561

Sternmiere . . . 199

Stichling. . . . . 5 5 42

Stinkandorn ...473

Stinkkohl . . . . 600

Storchschnabel .348

Storchschnabel-

gewächse.....347

Strahldolde. . . . 423

Strahlensame . . 194

Strandgras .... 58

Strandkraut . . 183

Strandling . . . .522

Strauchpappel ..373

Strauchscharte . .587

Straubfarn ..... 10

Straubweiden-

kraut ... ..4437

Streifenfarn .... 6

Striemendolde . .409

Strohblume.... 565

Studentenrös-

chen ......27

Sumach ... . . . 366

Sumpfblume .. 448

Sumpffarne.... 13

Siunjfglöckchen 495

Sumpfgras... . 47

Sumpflresse . . . . 243

sumpfquendel . .3\$s

sumpfriet .... s.

Sumpt'schirm . . 412

Sumpfistendel . 132

Süßdolde .... . . 405

Süßgras ...... 61

Süßholz . . . . . 336

Süßklee ..... 337

Tabak .......486

Taglilie....... 108

Tamarisken-

gewächse ...377

Tanggras ..... 30

Tanne .......2 21

Tännel .......377

Tännelgewächse 377

Tännelkraut ...492

Tannenwedel . . .394 
Seite

Tarant........448

Täschelkraut . . .238

Taubenkl'opf

195,230

T'aubnessel ....472

Tausendblatt ...394

Tausendblatt-

gewächse . . . 393

Tausendgulden-

kiraut .......442

Teesdalie .....236

Teichbinse ....8 80

Teichfaden ..... 30

Teichlinse..... 98

Terpentinbaum .365

Teufelsabbiss . . .537

Teufelsauge ...226

Teufelskrallen . 549

Thurmkraut . . .249

Thymian ... . 479

Tollkirsche ... .485

Tollkraut .....485

Tragant ......332

Traubenhya-

cinthe

$\ldots 115$

Traubenkirsche .307

Trauerweide . . . 156

Trespe ......6.68

Trichterlilie... 108

Trollblume... . .213

Tropfwurz ...417

Tulpe ........113

Tüpfelfarn ..... 5

Türkenbundlilie 112

Ulme . . . . . . 166

Ulmengewächse 165

Unholdenkraut. 392

Vallisnerie .... 33

Veilchen ..... 380 Veilchengewächse

Venushaar ..... 5

Venuskamm ....407

Venusspiegel ...5 547

Venuswagen . . .217
Seite

Vergissmein-

nicht ......459

Vogelbeerbaum . 276

Vogelhirse . ...45

Vogelkopf.....386

Wachholder

Wachholdermistel

21

169

Wachsblume . 461

Wachtelweizen . .501

Waid ... . .241

Walch ... 74

Waldmeister....523

Waldrebe .....219

Waldsteinie ...296

Waldzimbel ...546

Wallnubge-

wächse......154

Wanzenkraut ...215

Wanzensame....18:3

Wasserdarm ....199

Wasserdost ....560

Wasserfeder ....437

Wasserfenchel ..417

Wasserhade ....

Wasserkresse ...244

Wasserlinse ....99

Wasserlinsenge-

wächse...... 98

Wassernabel...4403

Wassernuss.....393

Wassernussge-

wächse.......393

Wasserpest.... 33

Wasserpfeffer ...177

Wasserscheere . 33

Wasserschierling 409

Wasserschlauch .512

Wasserschlauch-

gewächse.....511

Wasserstern ... 364

Wassersternge-

wächse......36:

Wasserviole ... 3.2

Wasserviolen ... 32

WVau.........256

Waugewächse...256
Seite

Wegerich......519

Wegerichge-

wächse......519

Wegwart .... .600

Weichselbaum ..307

IVeichstendel ...13t

Weide ........155

Weidengewächse 154

Weidenkraut... $4: 37$

Weidenröschen..390

Weiderich .....388

Weiderichge-

wächse......387

Weigelie..... . 532

Weinlauch.....109

Wein, wilder ...371

Weinstock.....371

Weifdistel .... 594

Weißdorn .....278

Weißmiere ... .202

Weißtanne ....2 21

Weißwurz .....117

Weizen ...... 74

Wermuth .....576

Wetterdistel ....556

Wicke ........338

Widerbart......133

Wiesenhafer.... 53

Wiesenknopf ...299

Wiesenraute ... 225

Wiesensilge... 4 414

Winde.......451

Windengewächse 450

Windfahme ..... 50

Windhalm..... 48

Windröschen ...217

Wintergrün . ..425

Wintergrünge-

wächse .....424

Winterlieb ....425

Winterling ....2214

Winterzwiebel ..110

Wirbeldolde ...418

Wirbeldost ....477

Witwenblume...5:37

Wodanskiraut ...455

Wohlverleih ..579

Wolfsauge ...457

Wolfsbohne ... 314 


\begin{tabular}{|c|c|c|}
\hline Seite & Seite & Seite \\
\hline Woltsfuß & Zackenschötchen 255 & Zuckerhirse \\
\hline Wolfsmilch.....358 & Zahntrost .....506 & Zuckerrübe .. \\
\hline Wolfsmilchge- & Zahnwurz .....245 & Zürgelbaum. \\
\hline wächse.......357 & Zartriet...... & Zweiblatt ... \\
\hline Wollgras..... 79 & Zaunlattich....6609 & Zweizahn . . \\
\hline Wollrohr...... 43 & Zaunlilie ......108 & Zwenke.. \\
\hline Woodsie ...... 10 & Zaunrebe..... & Zwergalpenrose .427 \\
\hline Wucherblume...574 & Zaunrübe .. & gbuchsbaum 356 \\
\hline Wundklee . . . . . 329 & Zaunwinde ....451 & dolde....4415 \\
\hline Wurmfarn .... 9 & Zeitlose.......107 & .352 \\
\hline Wurmlattich ...603 & Zierspark .....207 & andel. \\
\hline \multirow[t]{3}{*}{ Würzsilge .....4410 } & Ziest ........473 & Zwergstendel. \\
\hline & Zimbelkraut. & fweichsel ..307 \\
\hline & Zinukraut...... 14 & Zwetschkenbaum 306 \\
\hline Yam & Zirbelkiefer... & Zwiebel. \\
\hline & Zirmet....... & Zwiebelstendel ...134 \\
\hline Ysop ... & Zittergras..... 58 & \\
\hline
\end{tabular}




\section{Register}

der lateinischen Familien- und Gattungsnamen.

Die an Stelle der Seitenzahl mit * bezeichneten Gattungsnamen sind im Verzeichniss der gebräuchlichsten Synonyme (Seite 627) zu suchen.

Seite

Abies........21 21

Abutilon ......373

Acanthaceae. ..518

Acanthus .....519

Acer ..........368

Acerineae .....367

Achillea . ....571

Aconitum ....216

Acorus ....... 97

Actaea......2.215

Adenophora ... .547

Adenostyles ... 560

Adiantum ..... 5

Adonis.......226

Adoxa ........533

Adoxaceae.....5532

Aegilops ..... . 74

Aegopodium ...410

Aeluropus......58 58

Aesculus .....369

Aethionema ... 238

Aethusa ......417

Agave ........ 119

Agrimonia ....298

Agropyrum ..... 72

Agrostemma ...190

Agrostis ......48

Aira......... 51

Ajuga .......467

Alchemilla ....297

Aldrovanda.... . 257

Alectorolophus 507

Alisma
Seite

Alismaceae ... . 31

Alliaria .....240

Allium ........109

Allosorus.......*

Alnus ........163

Alopecurus .... 48

Alsine ......203

Althaea ........373

Alyssum ......252

Amarantaceae ..184

Amarantus .....184

Amaryllideae ...117

Amelanchier...277

Ammi .......4410

Ammophila.... 50

Ampelideae.....371

Ampelodesmos . . 55

Ampelopsis.....*

Amygdalus .....**

Anacamptis ...131

Anacardiaceae ..365

Anagallis .....438

Anchusa ......457

Andrachne ....358

Andromeda .....427

Andropogon ....44 43

Androsace.....4.455

Androsaemum ...*

Anemone.....217

Anethum.....420

Angelica ......418

Antennaria ....564

Anthemis .....569
Seite

Anthericum ....108

Anthoxanthum . . 46

Anthriscus ....406

Anthyllis..... . 329

Antirrhinum....493

Apera........ 50

Apium ........4412

Apocyneae.....448

Apocynum......449

Aposeris ....6.600

Aquifoliaceae ...366

Aquilegia . . . .2.215

Arabis ... . . . .249

Araceae ...... . 97

Araliaceae ......394

Arbutus.......428

Arceuthobium...169

Archangelica ...418

Arctium.......586

Arctostaphylos . .428

Aremonia ....2298

Arenaria ......205

Aretia .........434

Argyrolobium . . . 314

Arisarum...... 98

Aristolochia ... 172

Aristolochiaceae.171

Armeria... . . . . 439

Armoracia.... . 244

Arnica....... 579

Arnoseris . . . . .600

Aronia .........*

Aronicum ......* 
Arrhenatherum . 54

Artemisia ......575

Arthrocnemum . . 18:3

Arum

98

Aruncus . . . . . 275

Arundo . . . . . . 52

Asarum.......172

Asclepiadeae ...449

Asclepias ...4450

Asparagus ... .116

Asperugo . . . . 456

Asperula . . . . 523

Asphodeline ....108

Asphodelus.....107

Aspidium ..... 8

Asplenium .... 6

Aster . .....561

Asteriscus .....*

Asterolinum. . . 437

Astragalus ...332

Astrantia .....404

Athamanta ....415

Athyrium ..... 6

Atragene. . . . . * *

Atriplex ...... 181

Atropa .......455

Atropis ......6 62

Avena ....... 52

Avenastrum ... 53

Azalea........

Baldingera .... 46

Ballota .......473

Balsamineae. ...369

Barbarea......243

Bartschia .....507

Batrachium ....**

Bellidiastrum... *

Bellis .... . .561

Berberideae ...227

Berberis ......227

Berteroa ..... 254

Berula........410

Beta ........17y

Betonica ..... . *

Betula .......162

Betulaceae ....161

Biasolettia .
Bidens. . . . . . .569

Bifora .......4408

Biscutella .....237

Blackstonia ....443

Blechnum ..... 5

Blitum .......**

Blysmus ...... 81

Bonaveria.....330

Bonjeania......*

Borragineae ...453

Borrago ......456

Botrychinm .... 11

Brachypodium .. 70

Brassica .....2242

Braya .......254

Briza ........ 58

Bromus......6 68

Broussonetia ...167

Brunella......470

Bryonia......5541

Bulliarda ......*

Bunias ......255

Bunium .....4.411

Buphthalmum ..568

Bupleurum .....412

Bursa .......247

Butomaceae ... 32

Butomus ...... 32

Buxaceae....... 365

Buxus ....... 365

Cactere........385

Cakile ..... ..241

Calamagrostis .. 49

Calamintha ....

Calendula......585

Calepina . ...2.241

Calli ....... . 97

Callianthemum .213

Callistemma . . . .539

Callitriche .....364

Callitrichil eae ..363

Calluna ........428

Caltha.......212

Calycotome ...316

Calystegia.... .451

Camelina .....247

Campanula....543
Campanulaceae .542

Camphorosma ..183

Cannabis.......167

Capparideae ...255

Capparis .....256

Caprifoliaceae ..530

Capsella .......* *

Cardamine . . . . 244

Carduus . . . . .588

Carex......... 84

Carlina .......585

Carpesium ....567

Carpinus......162

Carthamus . . . . 599

Carum........411

Caryophyllaceae 186

Castanea.......164

Catabrosa ..... 57

Catapodium .... 68

Caucalis ......407

Celastraceae... 366

Celtis .......166

Centaurea. . . .594

Centranthus . . . .536

Centrosis . . . . 133

Centunculus....438

Cephalanthera ..132

Cephalaria ....537

Cerastium ....200

Ceratocephalus . *

Ceratonia ......314

Ceratophylleae. . 209

Ceratophyllum . .210

Cercis ........313

Cerinthe .....461

Ceterach ...... 7

Chaenorrhinum .494

Chaerophyllum .405

Chaiturus ...... *

Chamaebuxus. ..356

Chamaemelum .. *

Chamaeorchis ..131

Chamaenerium .392

Cheiranthus ....**

Chelidonium ...228

('henopodiaceae .178

Chenopodium...179

Cherleria

*

Chimaphila ...4.25 
Seite Seite

Seite

Chlora.......* Cotoneaster ...275

Chondrilla ....606

Chrysanthemum 574

Cotyledon . . . . .263

Chrysopogon ... 44

Chrysosplenium.271

Cicendia .......

Cicer .. ......338

Cichorium . ...660

Cicuta.......409

Cimicifuga .....*

Cineraria .......*

Circaea .......393

Circinus .......330

Cirsium.......590

Cistineae......378

Cistus ........378

Cladium ...... 83

Clematis......219

Clinopodium ...**

Clypeola.....254

Cnidium ......415

Cochlearia ... . 239

Coeloglossum...131

Colchicum .....107

Coleanthus .... 48

Collomia ......453

Colutea.......332

Comarum ...... *

Compositae.....550

Coniferae ..... 19

Conioselinum...415

Conium......409

Conringia.....255

Convallaria.....117

Convolvulaceae .450

Convolvulus ....451

Coralliorrhiza .. 134

Coriandrum ...4409

Corispermum ...183

Cornaceae.....424

Cornus .......424

Coronilla .....336

Coronopus ....237

Corrigiola.....208

Cortusa.......436

Corydalis . . . . 229

Corylus........162

Corynephorus . . *

Cotinus .......366

Crambe.......243

Crassula .....2.263

Crassulaceae...257

Crataegus . . ..278

Crepis.......610

Crithmum .....414

Crocus.... ..120

Crucianella.....523

Cruciferae.....231

Crupina ......594

Crypsis ...... 46

Cryptogramme. . 5

Cucubalus......195

Cucumis ......542

Cucurbita .....5 542

Cucurbitaceae ..5 5

Cupressus..... 21

Cuscuta......451

Cyclamen .....438

Cydonia .....275

Cymbalaria....492

Cymodocea ..... 30

Cynanchum ....450

Cynodon ......5 54

Cynoglossum ...455

Cynosurus .... 59

Cyperaceae.... 76

Cyperus ......78 78

Cypripedilum...126

Cystopteris..... 9

Cytinus ........172

Cytisus ......316

Dactylis ..... 58

Danthonia .... 54

Daphrie.......386

Datura ......486

Daucus .......424

Delphinium ...215

Dentaria......245

Deschampsia ... 51

Dianthus .....196

Dichostylis .... 80

Dictamnus ..... 355

Diervilla ......532

Digitalis .....501

Ecballium.....541

Echinaria ..... 54

Echinochloa .... 44

Echinophora ...405

Echinops......585

Echinospermum. *

Echium..... . 4462

Elaeagnaceae ...387

Elaeagnus......387

Elatine .......377

Elatineae .....377

Elodea........ 33

Elymus ...... 76

Elyna ....... 83

Empetraceae ...364

Empetrum .....364

Ephedra ...... 22

Epilobium ....390

Epimedium ...227

Epipactis .....132

Epipogon ......133

Equisetaceae ... 13

Equisetum ..... 14

Eragrostis ....5 56

Eranthis .....2214

Erechthites ...579

Erianthus.... . 43

Erica........428

Ericaceae .....426

Erigeron.... .562

Erinus.......501

Fritsch, Excursionsflora. 
Eriophorum ... 79

Eritrichium ...456

Erodium .......350

Eruca........ 241

Erucastrum.....242

Ervum .........*

Eryngium .....404

Erysimum .....251

Erythraea .....4442

Erythronium....113

Euclidium ......*

Eufragia ........*

Eupatorium ...5560

Euphorbia......358

Euphorbiaceae ..357

Euphrasia .....503

Eurotia ........181

Evax.........563

Evonymus ....367

Facchinia ......*

Fagaceae......163

Fagopyrum .....177

Fagus ........164

Falcaria.

*

Farsetia *

Ferulago......4419

Festuca

Fibigia ......254

Ficaria ........*

Ficus ........167

Filago .......564

Filipendula....297

Fimbristylis ....83 83

Foeniculum....4414

Fragaria .....2291

Fraxinus ......440

Freyera .......407

Fritillaria ......113

Fumana.......380

Fumaria .....2230

Gagea ........10s

Galanthus......118

Galasia .......**

Galatella .......**

Galega.........332
Galeobdolon ....**

Galeopsis......470

Galinsoga ... . .569

Galium .......525

Gastridium .... 49

Gaudinia ...... 54

Gaya

Genista .......314

Gentiana ......443

Gentianaceae ...441

Geraniaceae ....347

Geranium . . . . 348

Geum........296

Gladiolus . . . . . . 12:3

Glaucium ....2.229

Glaux.......448

Glechoma .....469

Globularia.....518

Globulariaceae ..517

Glycyrrhiza....336

Glyceria....... 61

Gnaphalium ....564

Gnetaceae..... 22

Goodyera.......134

Gramineae..... 33

Grammitis......*

Gratiola.......495

Guttiferae.....375

Gymnadenia ....132

Gymnogramme.. 5

Gypsophila .....195

Hacquetia .....404

Halianthus ..... *

Halimus........ *

Halorrhageae . . .393

Haynaldia ... . . 73

Hedera.........394

Hedraeanthus. . .550

Hedypnois. . . . .660

Hedysarum . . . . . 337

Heleocharis .... 82

Heleochloa .... 47

Helianthemum . . 379

Helianthus ... . .569

Helichrysum... 565

Heliosperma . . . . 194

Heliotropium ...455
Helleborus.....213

Helminthia ..... .*

Helosciadium . . .412

Hemerocallis . . . 108

Hepatica ......

Heracleum. . . . .421

Herminium. . . . 131

Hermodactylus . . 121

Herniaria......208

Hesperis . . . . 255

Heteropogon... 44

Hibiscus .....375

Hieracium . . . . .6614

Hierochloa .... 46

Himantoglossum 131

Hippocastaneae .368

Hippocrepis ....337

Hippophaё......387

Hippuris . . . . . 394

Hladnikia . . . . 409

Holcus ........ 50

Holoschoenus ... 80

Holosteum . . . . 202

Homogyne . . ..578

Honkenya ......**

Hordeum.... . . 75

Horminum . . . 4476

Hottonia .....447

Humulus . . . . . . 167

Hutchinsia ....246

Hydrocaryaceae .393

Hrdrocharideae . 32

Hydrocharis ... . 33

Hydrocotyle . . . 403

Hyoscyamus ... . 485

Hyoseris .....6600

Hypericum . . . . 375

Hypochoeris . . .6601

Hyssopus......478

Jasione .......550

Jasminum. . . . .441

Iberis........238

Ilex .........366

Illecebrum . . . 2208

Impatiens . . . . . 369

Imperata ...... 43

Imperatoria . . 4419 
Inula . . . . . . . . 65

Irideae. . . . . .119

Iris . . . . . . . 121

Isatis . . . . . . 241

Isnardia

Isoëtaceae

Isoëtes . .

17

Isolepis .

80

Isopyrum

215

Juglandaceae . . .154

Juglans . . . . . . . 154

Juncaceae . . . . 99

Juncagineae . . . 30

Juncus. . . . . . 99

Juniperus ..... 21

Jurinea ....... รs

Kentrophyllum .

Kernera....... .239

Kickxia .......492

Knautia......537

Kobresia ...... 83

Kochia ........183

Kueleria ...... 56

Kohlrauschia ...196

Labiatae . . . . . 463

Laburnum... . . 316

Lactuca . . . . . .668

Lagenaria . . . . . 5 542

Lagoseris ......**

Lagurus ...... 50

Lamarckia .... 5 59

Lamium ......472

Lappa ........**

Lappula . . . . .456

Lapsana .....600

Larix ........ 20

Laserpitium . . . . 422

Lasiagrostis . . . 46

Lathraea ... . . . 517

Lathyrus... . . 343

Lauraceae .... . 227

Laurus..... . . 228

Lavandula.....468

Lavatera . . . . . . 373

Ledum.......427
Leersia

Leguminosae . . .307

Lenna........ . 98

Lemnaceae .... 98

Lens

343

Leontodon ....601

Leontopodium . .564

Leonurus .....473

Lepidium ....2.236

Lepigonum .... * *

Lepturus .... 72

Leucojum ......118

Levisticum ....4418

Libanotis . . .44 416

Ligularia ....554

Ligusticum . . . . 44t

Ligustrum . . . 441

Liliaceae . .... 104

Lilium . . . . . 112

Limnanthemum 448

Limodorum .... *

Linosella . . . . . 495

Linaria ..... . .492

Lindernia . . . . .495

Lineae........351

Linnaea.......531

Linosyris.......**

Linum . . . . . . . 352

Listera .......133

Lithospermum . 460

Litorella .....522

Lloydia ..... . . 113

Lobularia .....254

Loiseleuria . . . .427

Lolium ...... 71

Lomatogonium. .

Lonicera . . . . . .531

Loranthaceae . . 169

Loranthus. . . . . 169

Lotus. . . . . . . 330

Ludwigia. . . . . 390

Lunaria......246

Lupinus. . . . . . .314

Luzula .......102

Lychnis . . . . . 193

Lycium .......485

Lycopodiaceae . 15

Lycopodium .... 15

Lycopsis . . . . .457
Lycopus. . . . . .480

Lysimachia. . . . .437

Lythraceae . . . . . 387

Lythrum ......388

Majanthemum ..116

Majorana.....478

Malabaila ......**

Malachium .....*

Malaxis .......13t

Malcolmia ......**

Malva ........ 374

Malvaceae......372

Marrubium .....469

Marsilia ...... 13

Marsiliaceae.... 13

Matricaria.....553

Matthiola .....255

Medicago .....318

Melampyrum ...501

Melandryum .... 194

Melica....... 57

Melilotus......321

Melissa ......476

Melittis .....470

Mentha .......481

Menyanthes ...448

Mercurialis .....358

Mespilus .....278

Meum .... ...414

Microcala . . . . 4442

Micromeria.....**

Micropus......563

Microstylis . . . . 134

Milium ...... 46

Mimulus ......495

Moehringia....206

Moenchia ....202

Molinia ....... 56

Molopospermum 409

Moltkia......460

Monerma .... 72

Monotropa ...426

Montia .......186

Moraceae ....166

Morus .......167

Mulgedium....607

Muscari.... . 115 
Myagrum .... . 241

Myosotis ......459

Myosurus .....220

Myricaria .....378

Myriophyllum ..394

Myrrhis

Myrtaceae ... . . . 389

Myrtus

Najadeae...... 30

Najas ...... . 30

Nareissus ....118

Nardus ..... . 71

Nardurus . . . . . 68

Nasturtium ... *

Naumburgia ...437

Neottia ......134

Nepeta...... . 469

Nerium .......449

Neslia ........247

Nicandra ....4485

Nicotiana .... . 486

Nigella ......2.214

Nigritella . ...131

Nonnea .......457

Notholaena .... . 5

Nuphar . . . . . . 209

Nymphaea. . . . 209

Nymphaeaceae . 209

Obione.........*

Odontites ....5506

Odontospermum .568

Oenanthe.....447

Oenothera ... . . 392

Oenothereae . . . 3839

Olea ... . . . . . . 4440

Oleaceae.......4439

Omphalodes . . .455

Onobrychis .....337

Onoclea ....... 10

Ononis........317

Onopordon ....594

Onosma.......461

Ophioglossaceae. 11

Ophioglossum

Ophrys........126

Oplismenus . ...45

Opopanax .

420
Opuntia.......385

Orchideae .....123

Orchis ........127

Oreochloa .... 55

Origanum .... 479

Orlaya ...... 423

Ornithogalum ..114

Ornithopus ....336

Orobanchaceae . 512

Orobanche.....513

Orobus .

Orthantha...5 506

Oryzopsis .....44 46

Osinunda ...... 11

Osmundaceae ... 10

Ostericum .....418

Ostrya ...... .162

Osyris ....... 170

Oxalideae.......351

Oxalis.........351

Oxyria .......176

Oxytropis ... . .335

Pachypleurum ..415

Paederota......*

Paeonia.... ..212

Paliurus ......370

Pallenis ......567

Panicum..... . 44

Papaver ....229

Papaveraceae . . 2.28

Paradisia ....108

Parentucellia . 506

Parietaria ....168

Paris .........117

Parnassia ....2271

Paronychia... 208

Parthenocissus .371

Passerina ......**

Pastinaca ....4.420

Pedicularis... 508

Peltaria......2.240

Peplis ..... ...388

Persica ........*

Petasites ......578

Petrocallis ...2238

Petroselinum . . .412

Peucedallum. . . 419
Phalaris ..... 45

Phaseolus .... .347

Phegopteris ... 7

Philadelphus ...271

Phillyrea......440

Phleum ...... 47

Phlomis .. . . 470

Phlox ......453

Phragmites... . 55

Physalis ..... 485

Physocarpus... 275

Physocaulos ... 405

Physospermum 409

Phyteuma .... 548

Phytolacca .... 185

Phytolaccaceae .185

Picea ....... 20

Picnomon ..... *

Picridium .......*

Picris . . ..6603

Pilularia . .... 13

Pimpinella ....410

Pinguicula ....511

Pinus ....... 20

Piptatherum ... *

Pirola ......425

Pirolaceae.... .424

Pirus ........ 275

Pistacia.......365

Pisum ..... . . 346

Plantagineae . . 519

Plantago..... . 519

Platanaceae ... 271

Platanthera ... 132

Platanus .....271

Pleurogyne.....* *

Pleurospermum . 409

Plumbagineae . .438

Plumbago . . . 439

Poa ......... 59

Podospermum .. *

Polemoniaceae . .452

Polemonium....453

Polycarpon....208

Polycnemuin ...179

Polygala.......356

Polygalaceae ...355

Polygonatum ...117

Polygoneae....172 
Seite

Polygonum.....176

Polypodiaceae .. 2

Polypodium .... 5

Polypogon .....4 48

Polystichum....

Populus ......157

Portulaca .....186

Portulacaceae...186

Posidonia..... 30

Potamogeton ... 27

Potamogetoneae 27

Potentilla .....2921

Poterium

Prenanthes....6613

Prasium ......468

Primula .....4431

Primulaceae . ..429

Prionitis . . . . . 4410

Prunus .......306

Psamma

Psilurus

72

Psoralea.......331

Pteridium..... 5

Pteris

Pterotheca . . ..606

Ptychotis . . . . .410

Pulegium.

Pulicaria......567

Pulmonaria ...457

Punica ........389

Punicaceae. ...388

Pyrethrum .....**

Quercus ......164

Radiola

352

Rafflesiaceae....172

Ranunculaceae ..210

Ranunculus ...220

Raphanus .....242

Rapistrum ....243

Reichardia ....610

Reseda ......256

Resedaceae . . . .256

Rhagadiolus . . .6600

Rhamnaceae... .369

Phamnus .....370

Rhaponticum ...**

Rhinanthus
Seite

Rhodiola

Rhododendron ..427

Rhodothamnus .427

Rhus ......366

Rhynchospora .. 83

Ribes........271

Robinia........332

Romulea......121

Roripa.......243

Rosa ........299

Rosaceae.....272

Rosmarinus ...468

Rubia ......5530

Rubiaceae.....522

Rubus.......278

Rudbeckia ....568

Riumex .......173

Ruppia ...... 29

Ruscus ......116

Ruta .........355

Rutaceae......354

Sagina......202

Sagittaria ..... 31

Salicineae ......154

Salicornia..... 183

Salix ... . . . . 155

Salsola .......184

Salvia .......475

Salvinia ...... 13

Salviniaceae.... 12

Sambucus.....530

Samolus ......437

Sanguisorba . . . . 299

Sanicula ......4404

Santalaceae....170

Santolina ....569

Saponaria ..... 199

Sarothamnus ...**

Satureja .....477

Saussurea .....587

Saxifraga .....265

Saxifragaceae.. 264

Scabiosa ...... 539

Scandix......407

Scheuchzeria ... 31

Schoberia .......*

Schoenoplectus . so

Schoenus ..... 83
Seite

Scilla.........113

Scirpus ...... 81

Scleranthus ...208

Sclerochloa.... 59

Scleropoa ....6 68

Scolopendrium. . 6

Scolymus .....599

Scopolia ......485

Scorpiurus . . . . 336

Scorzonera ....604

Scrophularia ...494

Serophulariaceae 487

Scutellaria ....468

Secale ....... 73

Securigera .... .

Sedum.......258

Selaginella .... 17

Selaginellaceae . 17

Selinum .....4418

Sempervivum...260

Senebiera ......**

Senecio ......580

Serapias ......130

Serratula .....594

Seseli ........416

Sesleria...... 54

Setaria .......45

Sherardia .....523

Sibbaldia ....296

Sicyos ........542

Sideritis . . . . 469

Sieglingia .... . 56

Silaus .......414

Silene.........191

Siler..........422

Silybum...... . 593

Sinapis .....241

Sison ........4410

Sisymbrium ...240

Sisyrinchium ...122

Sium .........409

Smilax........117

Smyrnium ....409

Solanaceae ....448:

Solanum ......4485

Soldanella .....436

Solidago ..... 561

Sonchus......608

Sorbus .......276 


\begin{tabular}{|c|c|c|}
\hline & & \\
\hline$\ldots .254$ & Thelygonum .... 1S5̃ & rmum \\
\hline$\ldots .43$ & Thesium ....... 170 & \\
\hline ria $\ldots \ldots \ldots{ }^{*}$ & Thlaspi .......238 & U \\
\hline parganiaceae .. 26 & Thrincia ....... & \\
\hline parganium .... 26 & Thuja........ 2 & Utriculariaceae . \\
\hline na $\ldots \ldots$ & elaea .....386 & \\
\hline partium.........514 & $\begin{array}{l}\text { Thymelaeaceae } \quad .385 \\
\text { Thymus ........479 }\end{array}$ & \\
\hline bergula ......207 & Thysselinum.....** & \\
\hline laria.. . .207 & $\ldots \ldots \ldots 372$ & \\
\hline$\ldots \ldots 1$ & $\ldots \ldots 372$ & \\
\hline$\ldots \ldots 2$ & $\ldots \ldots 107$ & \\
\hline$\ldots 1$ & ia $\ldots 418$ & \\
\hline$\ldots \ldots$ : & .....4 & \\
\hline$\ldots \ldots 473$ & Torilis . ....... & \\
\hline$\ldots \ldots 58$ & $\ldots \ldots 5$ & \\
\hline . .36 & $n \ldots .6$ & \\
\hline ae.... & . . . . 44 & e. \\
\hline$\ldots .4$ & . . . . . 393 & \\
\hline$\ldots \ldots$ & $\ldots \ldots$ & \\
\hline$\ldots \ldots *$ & Tri & $\because \ldots$ \\
\hline na. . 2 & rum .. 79 & \\
\hline gia. . . .1 & $\ldots .437$ & $\ldots \ldots$ \\
\hline & .....322 & um. \\
\hline$\ldots$ & $\ldots \ldots 31$ & $V$ \\
\hline$\because \ldots 11$ & $\ldots \ldots 318$ & e $\ldots$ \\
\hline & $\ldots \ldots 412$ & . $\cdots$ \\
\hline$\ldots 13$ & & $a \ldots \ldots$ \\
\hline & Tri & \\
\hline & ..... & \\
\hline & ..... 51 & gipta......... \\
\hline & Trit & \\
\hline & & neria. \\
\hline & $\begin{array}{l}\text { thes. .414 } \\
\ldots . .213\end{array}$ & HerTa. \\
\hline & $\mathrm{Tu}$ & $1 \mathrm{a}$. \\
\hline ... & $\ldots \ldots 196$ & \\
\hline & $\ldots \ldots 407$ & \\
\hline 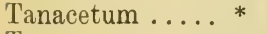 & $\mathrm{Tu}$ & \\
\hline 1 & & \\
\hline & & \\
\hline . .236 & Typ. & \\
\hline & Tyrimuus . . . . 594 & \\
\hline & & \\
\hline & & \\
\hline & & \\
\hline helygoneae....185 & Umbilicus......** & $\begin{array}{l}\text { Zostera ........ } \\
\text { Zygophylleae. }\end{array}$ \\
\hline & & \\
\hline
\end{tabular}




\section{Einige Verbesserungen und Nachträge.}

Zu Seite 8. Aspidium aculeatum u. A. Braunii wachsen auch in $\mathrm{Krain}$.

$\mathrm{Zu}$ Seite 16. Lycopodium Chamaecyparissus wächst ebenfalls in Krain.

Seite 23 soll es unter Nr. 1 heifen: Verschieden gestaltete $\mathrm{Pfl}$. mit stets deutlich entwickelten, wenn auch oft schuppenförmigen B.

Seite 25 soll es unter $\mathrm{Nr}$. 18 heißen: Wenigstens die zwittrigen u. männlichen Bt. nicht in Kolben; Frkn. sitzend.

$\mathrm{Zu}$ Seite 46. Oryzopsis virescens wächst anch in Sü dsteiermark.

Zu Seite 50. In Tirol wurden 3 Bastarte aus der Gattung Calamagrostis beobachtet: C. Epigeios $X$ pseudophragmites, pseudophragmites $X$ varia und Epigeios $\times$ varia.

Seite 72 soll es heiøen: Psilurus aristatus (L.) DuralJouve statt (L.) Lor. et Barr.

$\mathrm{Zu}$ Seite 83. Cladium Mariscus wächst auch in Steiermark.

Zu Seite 97. In Tirol wurde Carex Kerneri $\times$ sempervirens beobachtet.

$\mathrm{Zu}$ Seite 121. In $\mathrm{Kr}$ ain wurde angeblich ein Bastart zwischen Crocus albiflorus u. C. vernus gefunden.

Seite 131 soll es heißen: Serapias longipetala (Ten.) Pollini statt (L.) Poll.; ferner Coeloglossum statt Coeloglosum.

Seite 145 soll es unter Nr. 102 heißen: Blkr. meist unregelmäßig, rachig, o. 2lippig, s el t en er fast regelmäbig 4 spaltig.

Seite 147 gehört zu Nr. 113: "Holzgewächse" eine Fußnote: Vergl. a uch Lycium (Solanaceae).

Seite 148 soll es unter Nr. 123 heiben: B. gegenständig o. wirtelig.

Zu Seite 160. In Tirol wurden beobachtet: Salix reticulata $X$ retusa und $S$. arbuscula $X$ hastata.

$\mathrm{Zu}$ Seite 162. In Steiermark wurde ein Bastart zwischen Betula alba und $B$. verrucosa beobachtet. 
Zu Seite 181. Zwischen Chenopodium album und Ch. opulifolium wurde ein Bastart beobachtet.

Seite 18: unter $\mathrm{Nr} .2$ soll es statt "litoralis" litorale heißen.

Seite 183 soll es Arthrocnemum statt Athrocnemum heißen.

$\mathrm{Zu}$ Seite 238. Thlaspi alliaceum wächst auch in Steiermark.

Zu Seite 248. Draba nemorosa wächst ebenfalls in Steiermark.

Seite 254 soll es heißen: Wilckia Africana (L.) F. v. II uell. statt (L.) Hal.

Seite $36 j$ soll es unter Nr. 2 heiळen: Bthülle einfach, aus $3-5 \mathrm{~B}$. bestehend.

Seite 369 soll es in der Diagnose der Rhamnaceae heißen : Krb. 4-5, manchmal fehlend.

Seite 389 soll es unter Nr. 1 heißen: Stb. 2-4; Krb. 2 o. fehlend.

Seite 421 lautet die Verbreitungsangabe bei Heracleum Pyrenaicum richtig: Vora. von $S$ üdt., nicht Vora. u. Sü dt.

Seite 446 soll es (Gentiana) Amarella statt Amerella heißen.

Seite 463 soll es heißen: Vitex L. Mülle (nicht Mulle).

Zu Seite 580. Zwischen Doronicum Columnae und D. glaciale wurde ein Bastart beobachtet.

Seite $6: 26$ ist unter den Bastarten der Gattung Hieracium H. aurantiacum $\times$ Hoppeanum einzuschalten. 


QK 318 .F7

Fritsch, Karl/Excursionsflora fur Oester

|| || || || || || ||| || || || || || || || || || || || ||

| | | | | | | | | || || || || || || || || || || || || || || || || || || ||

35185001087244 
